\title{
Financial Statistics of Major Publicly Owned Electric Utilities 1991
}

\author{
March 1993
}

\author{
Energy Information Administration \\ Office of Coal, Nuclear, Electric \\ and Alternate Fuels \\ U.S. Department of Energy \\ Washington, DC 20585
}

\section{MASTER}

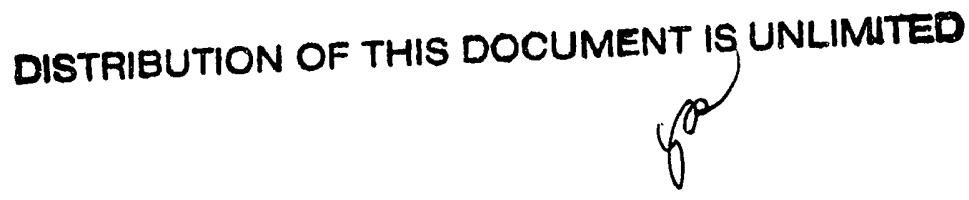

This report was prepared by the Energy Information Administration, the independent statistical and analytical agency within the Department of Energy. The information contained herein should not be construed as advocating or reflecting any policy position of the Department of Energy or any other organization. 


\section{Contacts}

The Financial Statistics of Major Publicly Owned Electric Utilities is prepared annually by the Survey Management Division; Office of Coal, Nuclear, Electric, and Alternate Fuels (CNEAF); Energy Information Administration (EIA); U. S. Department of Energy (DOE).

General information about data appearing in this document may be obtained from the National Energy Information Center (202/586-8800) or from Howard $L$. Walton (202/254-5500), Director of the Survey Man- agement Division, or Fred Mayes (202/254-5300), Chief of the Renewable and Financial Data Systems and Outreach Branch.

Questions and comments should be referred to Roger L. Sacquety (202/254-5440), Financial Systems Team Leader. Specific information about data contained in the Form EIA-412 may be obtained from Charlene Harris-Russell (202/254-5437) or Thomas Williams (202/254-5436). 


\section{Contents}

Introduction $\ldots \ldots \ldots \ldots \ldots \ldots \ldots \ldots \ldots \ldots \ldots \ldots \ldots \ldots \ldots \ldots \ldots \ldots \ldots \ldots$

Summary Statistics of Major Publicly Owned Electric Utilities $\ldots \ldots \ldots \ldots \ldots \ldots \ldots \ldots \ldots \ldots$

Detailed Statistics of Major Publicly Owned Electric Utilities $\ldots \ldots \ldots \ldots \ldots \ldots \ldots \ldots$

Summary Statistics of Federal Electric Utilities $\ldots \ldots \ldots \ldots \ldots \ldots \ldots \ldots \ldots \ldots \ldots \ldots$

Appendices

A. Summary Statistics of Rural Electric Cooperative Borrowers $\ldots \ldots \ldots \ldots \ldots \ldots \ldots \ldots$

B. Publicly Owned Electric Utility Respondents . . . . . . . . . . . . . . . . . . 377

C. Respondents by June 30 and December 31 Fiscal Years and by All Respondents, 1989-1991 . 389

D. Regulation of Publicly Owned Electric Utilities $\ldots \ldots \ldots \ldots \ldots \ldots \ldots \ldots \ldots \ldots \ldots$

E. Technical Notes $\ldots \ldots \ldots \ldots \ldots \ldots \ldots \ldots \ldots \ldots \ldots \ldots \ldots \ldots \ldots \ldots \ldots$

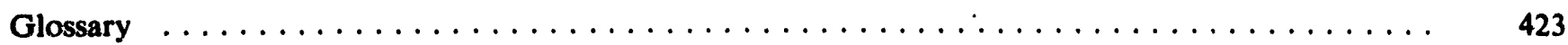


1. Selected Electric Utility Data by Ownership, $1991 \ldots \ldots \ldots \ldots \ldots \ldots$

2. Selected Data for Major Publicly Owned and Federal Electric Utilities Included in This Report Compared to All Publicly Owned and Federal Electric Utilities, 1991 . . . . . . . . .

3. Ten Largest Publicly Owned Generating Electric Utilities Ranked by Megawatthour Sales to Ultimate Consumers, $1991 \ldots \ldots \ldots \ldots \ldots \ldots \ldots \ldots \ldots \ldots \ldots \ldots$

4. Ten Largest Publicly Owned Generating Electric Utilities Ranked by Megawatthour Sales

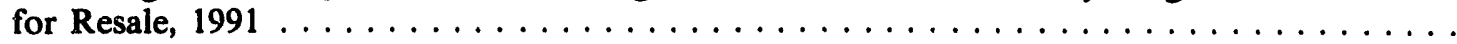

5. Ten Largest Publicly Owned Nongenerating Electric Utilities Ranked by Megawatthour

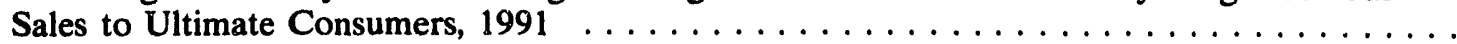

6. Ten Largest Publicly Owned Nongenerating Electric Utilities Ranked by Megawatthour Sales for Resale, $1991 \ldots \ldots \ldots \ldots \ldots \ldots \ldots \ldots \ldots \ldots \ldots \ldots$

7. Composite Statement of Income for Major Publicly Owned Electric Utilities by Generators and Nongenerators, $1989-1991 \ldots \ldots \ldots \ldots \ldots \ldots \ldots \ldots \ldots$

8. Composite Balance Sheet for Major Publicly Owned Electric Utilities by Generators and

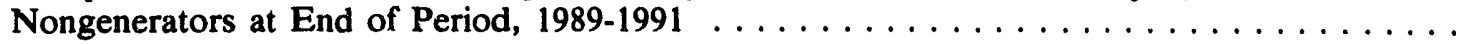

9. Composite Financial Indicators for Major Publicly Owned Electric Utilities by Generators

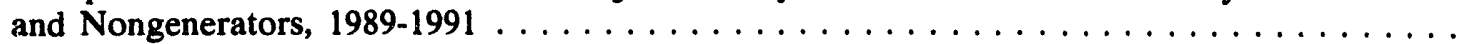

10. Electric Operation and Maintenance Expenses for Major Publicly Owned Electric Utilities by Generators and Nongenerators, $1989-1991 \ldots \ldots \ldots \ldots \ldots \ldots \ldots$

11. Electric Utility Plant for Major Publicly Owned Electric Utilities by Generators and Nongenerators at End of Period, $1989-1991 \ldots \ldots \ldots \ldots \ldots \ldots \ldots \ldots$

12. Number of Consumers, Sales, and Operating Revenue for Major Publicly Owned Electric Utilities by Generators and Nongenerators, $1989.1991 \ldots \ldots \ldots \ldots \ldots \ldots \ldots \ldots$

13. Electric Energy Account for Major Publicly Owned Electric Utilities by Generators and

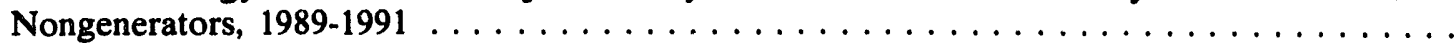

14. Ten Largest Generating Publicly Owned Electric Utilities Ranked by Megawatthour Sales

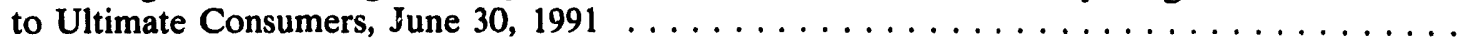

15. Ten Largest Generating Publicly Owned Electric Utilities Ranked by Megawatthour Sales

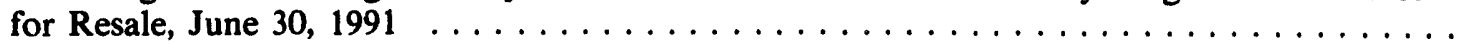

16. Ten Largest Generating Publicly Owned Electric Utilities Ranked by Megawatthour Sales to Ultimate Consumers, December $31,1991 \ldots \ldots \ldots \ldots \ldots \ldots \ldots \ldots \ldots$

17. Ten Largest Generating Publicly Owned Electric Utilities Ranked by Megawatthour Sales

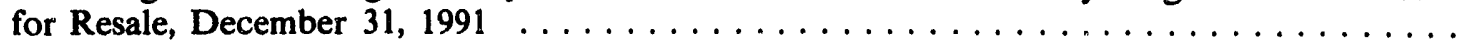

18. Composite Statement of Income for Major Publicly Owned Generating Electric Utilities,

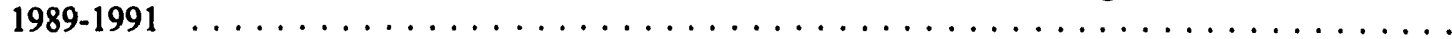

19. Composite Balance Sheet for Major Publicly Owned Generating Electric Utilities at End of

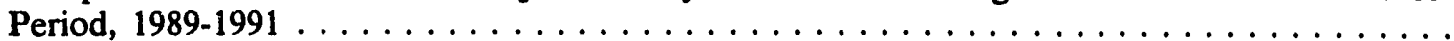

20. Composite Financial Indicators for Major Publicly Owned Generating Electric Utilities,

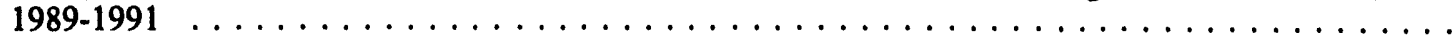

21. Electric Operation and Maintenance Expenses for Major Publicly Owned Electric Utilities,

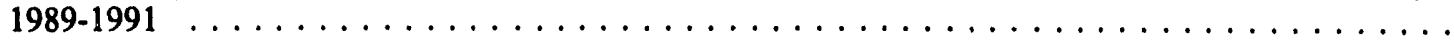

22. Electric Utility Plant for Major Publicly Owned Generating Electric Utilities at End of Period, 1989-1991

23. Number of Consumers, Sales, and Operating Revenues for Major Publicly Owned Generating Electric Utilities, 1989-1991 ...

24. Electric Energy Account for Major Publicly Owned Generating Electric Utilities, $1989-1991$

25. Ten Largest Publicly Owned Nongenerating Electric Utilities Ranked by Megawatthour Sales to Ultimate Consumers, June $30,1991 \ldots \ldots \ldots \ldots \ldots \ldots \ldots \ldots$

26. Ten Largest Publicly Owned Nongenerating Electric Utilities Ranked by Megawatthour Sales for Resale, June $30,1991 \ldots \ldots \ldots \ldots \ldots \ldots \ldots \ldots \ldots$

27. Ten Largest Publicly Owned Nongenerating Electric Utilities Ranked by Megawatthour Sales to Ultimate Consumers, December $31,1991 \ldots \ldots \ldots \ldots \ldots \ldots \ldots \ldots$

28. Ten Largest Publicly Owned Nongenerating Electric Utilities Ranked by Megawatthour

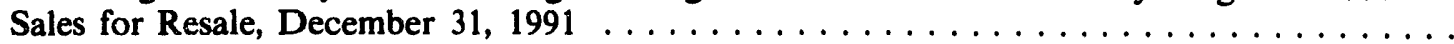

29. Composite Statement of Income for Major Publicly Owned Nongenerating Electric Utilities, 1989-1991

30. Composite Balance Sheet for Major Publicly Owned Nongenerating Electric Utilities at End

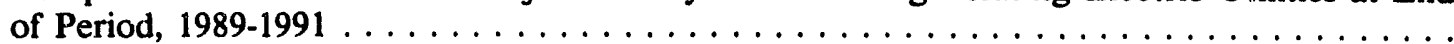


31. Composite Financial Indicators for Major Publicly Owned Nongenerating Electric Utilities,

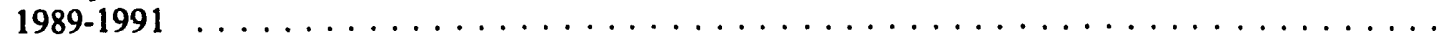

32. Electric Operation and Maintenance Expenses for Major Publicly Owned Nongenerating

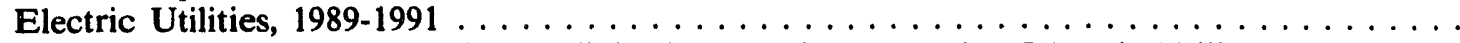

33. Electric Utility Plant for Major Publicly Owned Nongenerating Electric Utilities at End of

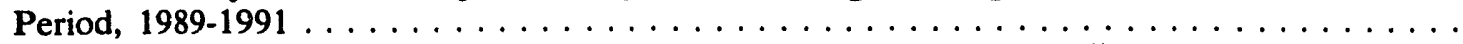

34. Number of Consumers, Sales, and Operating Revenue for Major Publicly Owned Nongenerating Electric Utilities, $1989-1991 \ldots \ldots \ldots \ldots \ldots \ldots \ldots \ldots \ldots \ldots \ldots$

35. Electric Energy Account for Major Publicly Owned Nongenerating Electric Utilities,

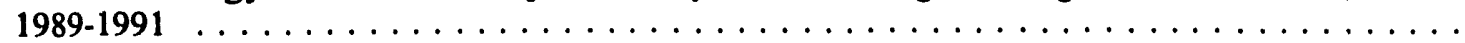

36. Statement of Income by Publicly Owned Electric Utility Within State, $1991 \ldots \ldots$. . . . . .

37. Balance Sheet by Major Publicly Owned Electric Utility Within State at End of Period,

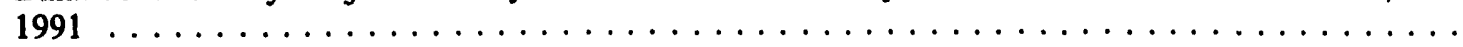

38. Electric Operation and Maintenance Expenses by Major Publicly Owned Electric Utility

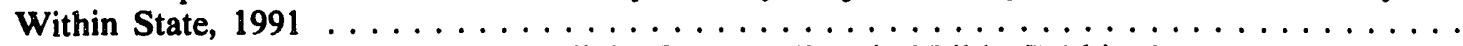

39. Electric Utility Plant by Major Publicly Owned Electric Utiltiy Within State at End of Pe-

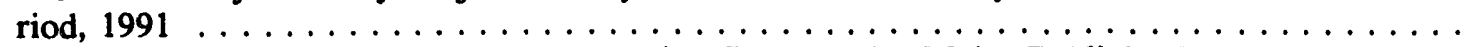

40. Number of Consumers, Sales, and Operating Revenue by Major Publicly Owned Electric

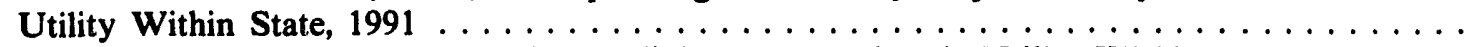

41. Electric Energy Account by Major Publicly Owned Electric Utility Within State, 1991 . . .

42. Statement of Income by Federal Electric Utility, $1991 \ldots \ldots \ldots \ldots \ldots \ldots \ldots \ldots \ldots$

43. Balance Sheet by Federal Electric Utility, $1991 \ldots \ldots \ldots \ldots \ldots \ldots \ldots \ldots \ldots$

44. Electric Operation and Maintenance Expenses by Federal Electric Utility, $1991 \ldots \ldots \ldots$

45. Electric Utility Plant by Federal Electric Utility, $1991 \ldots \ldots \ldots \ldots \ldots \ldots \ldots \ldots \ldots$

46. Number of Consumers, Sales, and Operating Revenue by Federal Electric Utility, 1991 . . .

47. Electric Energy Account by Federal Electric Utility, $1991 \ldots \ldots \ldots \ldots \ldots \ldots \ldots \ldots$

A1. Composite Statement of Income for the Cooperative Borrowers, 1988-1991 . . . . . . . .

A2. Composite Balance Sheet for the Cooperative Borrowers on December 31, 1988-1991 . . . .

A3. Electric Operation and Maintenance Expenses for the Cooperative Borrowers, 1988-1991 ...

A4. Number of Consumers, Sales, and Operating Revenue for the Cooperative Distributor Bor-

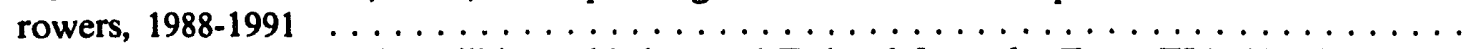

B1. Publicly Owned Electric Utilities Added to and Deleted from the Form EIA-412, 1989-1991

B2. Publicly Owned Electric Utilities That Submitted the Form EIA-412, $1991 \ldots \ldots \ldots \ldots \ldots$

C1. Ten Largest Publicly Owned Electric Utilities Ranked by Megawatthour Sales to Ultimate Consumers, June 30, $1991 \ldots \ldots \ldots \ldots \ldots \ldots \ldots \ldots \ldots \ldots \ldots \ldots$

C2. Ten Largest Publicly Owned Electric Utilities Ranked by Megawatthour Sales for Resale,

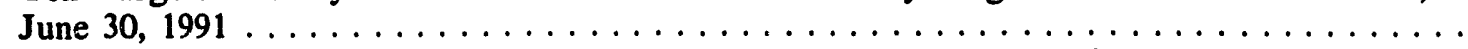

C3. Ten Largest Publicly Owned Electric Utilities Ranked by Megawatthour Sales to Ultimate

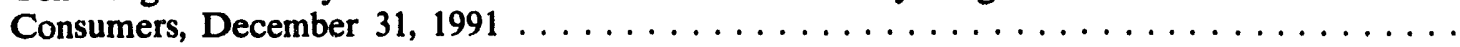

C4. Ten Largest Publicly Owned Electric Utilities Ranked by Megawatthour Sales for Resale,

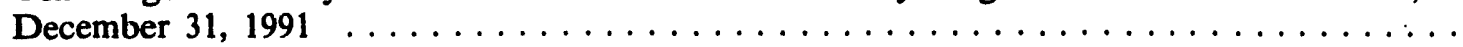

C5. Composite Statement of Income for Major Publicly Owned Electric Utilities, 1989-1991 . . .

C6. Composite Balance Sheet for Major Publicly Owned Electric Utilities at End of Period,

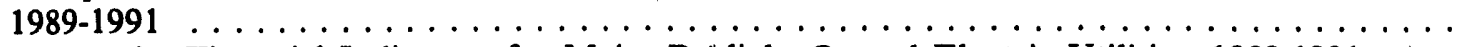

C7. Composite Financial Indicators for Major Publicly Owned Electric Utilities, 1989-1991 . . .

C8. Electric Operation and Maintenance Expenses for Major Publicly Owned Electric Utilities,

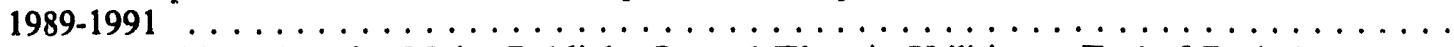

C9. Electric Utility Plant for Major Publicly Owned Electric Utilities at End of Period, 1989-1991 . . . . . . . . . . . . . . . . . . . . . . . . . . . . . .

C10. Number of Consumers, Sales, and Operating Revenue for Major Publicly Owned Electric

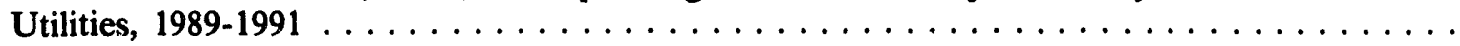

C11. Electric Energy Account for Major Publicly Owned Electric Utilities, 1989-1991 . . . . . .

C12. Ten Largest Publicly Owned Electric Utilities Ranked by Megawatthour Sales to Ultimate

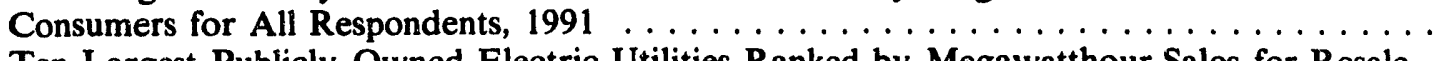

C13. Ten Largest Publicly Owned Electric Utilities Ranked by Megawatthour Sales for Resale for All Respondnets, $1991 \ldots \ldots \ldots \ldots \ldots \ldots \ldots \ldots \ldots \ldots \ldots \ldots \ldots \ldots$

C14. Twenty Largest Publicly Owned Electric Utilities Ranked by Electric Utility Revenues,

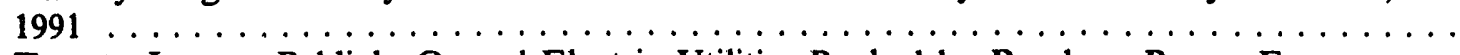

C15. Twenty Largest Publicly Owned Electric Utilities Ranked by Purchase Power Expenses,

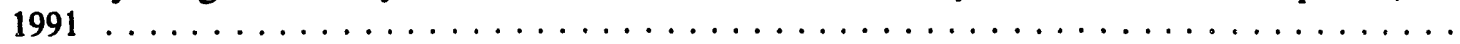

C16. Twenty Largest Publicly Owned Electric Utilities Ranked by Electric Utility Plant, 1991 .

C17. Twenty Largest Publicly Owned Electric Utilities Ranked by Construction Work in Progress, 1991 
C18. Composite Statement of Income for Major Publicly Owned Electric Utilities for All Respon-

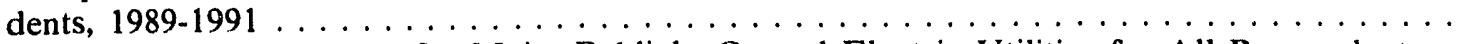

C19. Composite Balance Sheet for Major Publicly Owned Electric Utilities for All Respondents

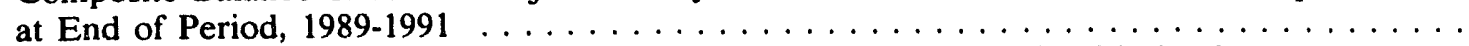

C20. Composite Financial Indicators for Major Publicly Owned Electric Utilities for All Respon-

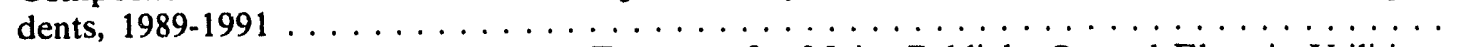

C21. Electric Operation and Maintenance Expenses for Major Publicly Owned Electric Utilities for All Respondents, $1989-1991 \ldots \ldots \ldots \ldots \ldots \ldots \ldots \ldots \ldots \ldots$

C22. Electric Utility Plant for Major Publicly Owned Electric Utilities for All Respondents at

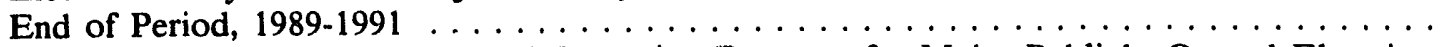

C23. Number of Consumers, Sales, and Operating Revenue for Major Publicly Owned Electric

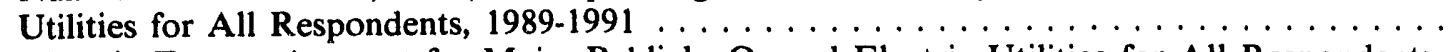

C24. Electric Energy Account for Major Publicly Owned Electric Utilities for All Respondents,

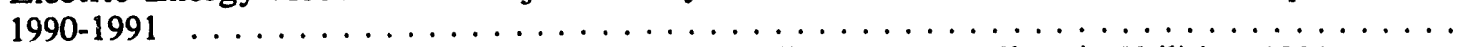

D1. State Agency Authority to Regulate Rate of Publicly Owned Electric Utilities, 1991 . . . .

\section{Illustrations}

B1. Principal Business Office of the Major Publicly Owned Electric Utilities, $1991 \ldots \ldots$ 


\section{Introduction}

The Financial Statistics of Major Publicly Owned Electric Utilities publication presents summary and detailed financial accounting data on the publicly owned electric utilities. The objective of the publication is to provide Federal and State governments, industry, and the general public with data that can be used for policymaking and decisionmaking purposes relating to publicly owned electric utility issues.

\section{Background}

The Financial Statistics of Major Publicly Owned Electric Utilities publication is prepared by the Survey Management Division; Office of Coal, Nuclear, Electric and Alternate Fuels; Energy Information Administration; U.S. Department of Energy. Historically, financial statistics for publicly owned electric utilities have been compiled and published annually since 1946 to satisfy the requirements for accurate, readily available data regarding the electric power industry. The format was designed to be used by a variety of private, electric power industry, and government users. The publication contents and format have evolved over the years to better serve the needs and requirements of the targeted audience.

As the result of the Federal Power Act of 1935, the Federal Power Commission (FPC), which was the predecessor to the Federal Energy Regulatory Commission (FERC), began collecting financial statistics for investor-owned electric utilities in 1938. In 1946, the FPC started collecting financial statistics on publicly owned electric utilities. The Energy Information Administration (EIA) took over the responsibility of gathering and publishing the financial statistics from the FERC upon EIA's establishment in October 1977. In 1982, the EIA combined the contents of two publications containing financial statistics of investorowned (private) and publicly owned electric utilities into a single volume, the Financial Statistics of Selected Electric Utilities. The 1989 edition reverted to the two separate publications, the Financial Statistics of Selected Investor-Owned Electric Utilities and the Financial Statistics of Selected Publicly Owned Electric Utilities. In 1991, the publication titles were changed to the Financial Statistics of Major Investor-Owned Electric Utilities and the Financial Statistics of Major Publicly Owned Eiectric Utilities.
The 1991 edition of the Financial Statistics of Major Publicly Owned Electric Utilities, includes 3 years of summary financial data in the composite tables. The composite tables provide various summaries for the following categories in the main body of the report:

- Generators and nongenerators

- Generators and nongenerators for fiscal years ending June 30 and December 31.

The composite tables present aggregates of income statement and balance sheet data, as well as ratios of financial indicators. Composite tables also display electric operation and maintenance expenses; electric utility plant; number of consumers, sales, and operating revenue; and electric energy account data.

The primary source of financial data is the Form EIA-412. Electric utilities file this survey on a fiscal year, rather than a calendar year basis, in conformance with their recordkeeping practices. In previous editions of this publication, data were aggregated by the two most commonly-reported fiscal years, June 30th and December 31 st. This omitted approximately 20 percent of the respondents who have different fiscal yearending data.

A review of published fiscal year aggregate data has indicated, however, that observed differences in financial indicators between the two groups may result from different characteristics of the electric utilities in the two groups, rather than the different time periods covered. In particular, several financial indicators show marked differences between generators and nongenerators. These types of electric utilities are not uniformly represented among the June 30 and December 31 fiscal years. Appendix $C$ contains composite tables for fiscal years of June 30 and December 31 as presented in the last three publications. In addition, composite tables for all respondents are presented. From these tables the reader can discern differences between fiscal year versus generator/nongenerator status.

The U.S. electric power industry is a combination of electric utilities (investor-owned, publicly owned, Federal, and cooperatives) and nonutility power producers. Investor-owned electric utilities account for over three-fourths of the sales and revenue in the industry. Historically, the investor-owned electric utilities serve the large consolidated markets and operate in all States 
except Nebraska. Hawaii is the only State in which all electricity is supplied by investor-owned electric utilities.

Publicly owned electric utilities are nonprofit operations that have been established to serve their communities and nearby consumers at cost. The publicly owned electric utilities in this publication include municipals, public power districts, State authorities, irrigation districts, and other State organizations. Publicly owned electric utilities are exempt from taxes and can obtain financing at lower rates than investor-owned electric utilities. The publicly owned electric utilities may be divided into generators and nongenerators. Generators are those electric utilities that own and operate generating capacity to supply some or all of their customer needs. However, most of these electric utilities supplement their demand by purchasing power. The nongenerators do not utilize any generating capacity and rely exclusively on purchasing power. Their primary function is to transmit and distribute electricity to their customers. Pure nongenerators comprise just over half in number of the major publicly owned electric utilities.

Federal electric utilities are also presented in this publication and include the five Federal power marketing administrations, the Tennessee Valley Authority, U.S. Army Corps of Engineers, and the U.S. Bureau of Indian Affairs. Electric power produced by Federal electric utilities is generated primarily by water resources. This power, which is not produced for profit, is primarily wholesaled to other electric utilities rather than being distributed to ultimate consumers. Publicly owned and cooperative electric utilities are given preference in the purchase of less expensive power produced by the Federal electric utilities.

The rural electric cooperatives, also known as cooperative borrowers, are owned by their members and operate in rural areas to provide electricity to their members. They were originally formed in rural areas where it was not viewed as economical for investor-owned electric utilities to provide service. Cooperative borrowers currently operate in 46 States. Data for the cooperative electric utilities are found in the Statistical Report, Rural Electric Borrowers published by the Rural Electrification Administration, the U.S. Department of Agriculture. Summary tables for the cooperative borrowers are provided in Appendix A.

\section{Data Users}

The Financial Statistics of Major Publicly Owned Electric Utilities publication provides information about the financial results from operations of publicly owned electric utilities for use by government, industry, electric utilities, financial organizations and educational institutions in energy planning. In the private sector, the readers of this publication are researchers and analysts associated with the financial markets, the policymaking and decisionmaking members of electric utility companies, and economic development organizations. Other organizations that may be interested in data presented in this publication include manufacturers of electric power equipment and marketing organizations. In the public sector, the readers of this publication include analysts, researchers, statisticians, and other professionals engaged in regulatory, policy, and program areas. These individuals are generally associated with the Congress, other legislative bodies, State public utility commissions, universities, and national strategic planning organizations.

\section{Coverage of Sources}

The Federal Power Commission (FPC) Form 1M, predecessor of the current Form EIA-412, was initiated as a voluntary financial survey in 1946 . The data collection responsibility for this survey was conveyed to the EIA in October 1977, when the FPC was consolidated into the U.S. Department of Energy. Since 1979, the FPC Form 1M has been superseded by the Economic Regulatory Administration (ERA) Form ERA-412, and more recently, the Form EIA-412.

Information for the publicly owned electric utilities has been compiled from the Form EIA-412, "Annual Report of Public Electric Utilities." Publicly owned electric utilities are required to submit the Form EIA-412 when the generation, transmission, or distribution of electricity results in one of the following:

- 120,000 megawatthours of sales to ultimate consumers

- 120,000 megawatthours of sales for resale.

These criteria are based on data reported on the Form EIA-861, "Annual Electric Utility Report," for the 2 previous years. This survey is submitted by all electric utilities in the United States, the U.S. territories, and Puerto Rico. Appendix B contains a list of the publicly owned electric utilities that submitted data for 1991 .

Many of the publicly owned electric utilities are selfregulated while some fall under the jurisdiction of State public utility commissions as shown in Appendix D. Because of the absence of required reporting to a specific regulatory body, the accounting practices and policies of publicly owned electric utilities vary considerably. Many use the FERC Uniform System of Accounts or variations of this and other accounting systems. The composite statistics provided in this publication must be viewed with an appropriate degree of caution.

The Form EIA-412 is used to collect detailed annual accounting, financial, and other operating characteristics of publicly owned electric utilities for publication in EIA reports. A total of 470 publicly owned electric utilities submitted the 1991 survey data to EIA. Although calender year reporting of data is preferred, 
electric utilities are given the option of reporting data on a fiscal year basis. This option is permitted in order to minimize respondent burden in preparing the data. When reporting by fiscal year, electric utilities must report operational data for a 12 -month period and show consistency in fiscal periods and accounting practices.

\section{Industry Profile}

In 1991, there was a total of 3,231 investor-owned, publicly owned, Federal, and cooperative electric utilities. Selected electric utility data for 1991 was compiled from the Form EIA-861 for the total universe of electric utilities. The publicly owned electric utilities represent 62.1 percent $(2,007)$ of the total number of electric utilities.

\section{Table 1. Selected Electric Utility Data by Ownership, 1991}

\begin{tabular}{|c|c|c|c|c|c|}
\hline \multirow[b]{2}{*}{ Item } & \multicolumn{5}{|c|}{ Type of Electric Utility } \\
\hline & Investor-Owned & Publicly Owned & Federal & Cooperative & Total' \\
\hline 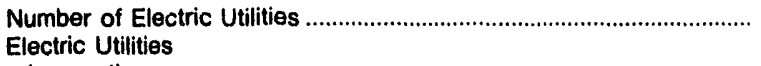 & 265 & 2,007 & 10 & 949 & 3,231 \\
\hline $\begin{array}{l}\text { (percont) } \\
\text { Revenues from Sales to Uitimate Consumers }\end{array}$ & 8.2 & 62.1 & * & 29.4 & 100.0 \\
\hline 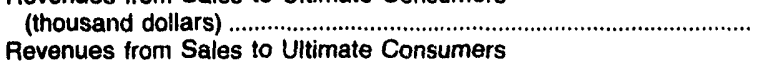 & $147,582,609$ & $23,151,761$ & $1,479,079$ & $14,147,154$ & $186,360,603$ \\
\hline $\begin{array}{l}\text { (percent) } \\
\text { Sales of Electricity to Uitimate Consumers }\end{array}$ & 79.2 & 12.4 & .8 & 7.6 & 100.0 \\
\hline $\begin{array}{l}\text { (thousand megawatthours) } \\
\text { Sales of Electricity to Uitimate Consumers }\end{array}$ & $2,110,528$ & 393,448 & 52,943 & 205,082 & $2,762,003$ \\
\hline $\begin{array}{l}\text { (percent) } \\
\text { Revenues from Sales for Resale }\end{array}$ & 76.4 & 14.3 & 1.9 & 7.4 & 100.0 \\
\hline $\begin{array}{l}\text { (thousand dollars) } \\
\text { Revenues from Sales for Resale }\end{array}$ & $17,459,163$ & $7,308,471$ & $6,341,529$ & $9,784,621$ & $40,893,784$ \\
\hline $\begin{array}{l}\text { (percent) } \\
\text { Sales of Electricity Available for Resale }\end{array}$ & 42.7 & 17.9 & 15.5 & 23.9 & 100.0 \\
\hline (percent) & 43.6 & 17.3 & 18.0 & 21.1 & 100.0 \\
\hline
\end{tabular}

Key facts concerning sales and revenues in 1991 (Table 1) are as follows:

- The 265 investor-owned electric utilities (8.2 percent of all electric utilities) accounted for 79.2 percent of all revenues from sales of electricity to ultimate consumers and 42.7 percent of all revenues from sales for resale.

- The 2,007 publicly owned electric utilities (62.1 percent of all electric utilities) accounted for 12.4 percent of all revenues from sales to ultimate con- sumers and 17.9 percent of all revenues from sales for resale.

- The 10 Federal electric utilities accounted for 0.8 percent of all revenues from sales to ultimate consumers and 15.5 percent of all revenues from sales for resale.

- The 949 cooperative borrowers $(29.4$ percent of all electric utilities) accounted for 7.6 percent of all revenues from sales to ultimate consumers and 23.9 percent of all revenues from sales for resale. 
In 1991 , the 470 publicly owned electric utilities in this publication (23.4 percent of all the publicly owned electric utilities) accounted for 86.6 percent of the revenues from sales to ultimate consumers and 98.8 percent of the revenues from sales for resale of all publicly owned electric utilities. The eight Federal electric utilities in this publication accounted for 100.0 percent of the revenues from sales to ultimate consumers and 100.0 percent of revenues from sales for resale of the Federal segment (Table 2).

Tables 3 through 41 contain summary and detailed data for the 470 publicly owned electric utilities. Tables 42 through 47 contain summary and detailed data for the 8 Federal electric utilities.

Appendix A tables contain 3 years of summary statistics on rural electric cooperative borrowers.

Appendix B contains a list of the publicly owned electric utility respondents. Table B1 lists the publicly owned electric utilities added and deleted for 1989 through 1991. Table B2 provides the name, State, and financial reporting date of the respondents.

Appendix $\mathrm{C}$ contains the publicly owned electric utilities for the fiscal year periods ending June 30 and December 31 and for all respondents. Tables $\mathrm{Cl}$ through C24 contain summary data for these electric utilities.

Appendix D contains the State agency that has regulation oversite over the publicly owned electric utilities.

Appendix E contains all Technical Notes for the publication. The key sections are Sources of Data, Quality of Data, Formulas and Calculations, and General Information.

The Glossary at the end of the publication defines common terms in the publication.

\section{Table 2. Selected Data for Major Publicly Owned and Federal Electric Utilities Included in This Report Compared to All Publicly Owned and Federal Electric Utilities, 1991}

\begin{tabular}{|c|c|c|}
\hline Item & Publicly Owned & Federal' \\
\hline $\begin{array}{l}\text { Number of Electric Utilities in This Report } \\
\text { Share of Electric Utilities Within Ownership Class }\end{array}$ & 470 & 8 \\
\hline $\begin{array}{l}\text { (percent) } \\
\text { Revenues from Sales to Ultimate Consumers }\end{array}$ & 23.4 & 80.0 \\
\hline (thousand dollars) & $20,045,984$ & $1,479,079$ \\
\hline $\begin{array}{l}\text { Share of Revenues from Sales to Ultimate Consumers } \\
\text { (percent) }\end{array}$ & 86.6 & 100.0 \\
\hline $\begin{array}{l}\text { Sales of Electricity to Ultimate Consumers } \\
\text { (thousand megawatthours) }\end{array}$ & 344,782 & 52,943 \\
\hline $\begin{array}{l}\text { Share of Sales of Electricity to Ultimate Consumers } \\
\text { (percent) }\end{array}$ & 87.6 & 100.0 \\
\hline $\begin{array}{l}\text { Revenues from Sales for Resale } \\
\text { (thousand dollars) }\end{array}$ & $7,221,545$ & $6,341,529$ \\
\hline $\begin{array}{l}\text { Share of Revenues from Sales for Resale } \\
\text { (percent) } \\
\text { Sales of Electricity Available for Resale }\end{array}$ & 98.8 & 100.0 \\
\hline (thousand megawatthours) & 190,797 & 200,666 \\
\hline $\begin{array}{l}\text { Share of Sales of Electricity Available for Resale } \\
\text { (percent) }\end{array}$ & 98.7 & 100.0 \\
\hline
\end{tabular}

- The Department of Interior-U.S. Bureau of Reclamation and the Department of State-International Water and Boundary Commission do not file the Form EIA-412; however, their energy is marketed and reported by the Bonneville Power Administration, the Southeastern Power Administration, the Southwestern Power Administration, and the Western Area Power Administration.

Source: Energy Information Administration, Form EIA-861, "Annual Electric Utility Report." Data are based on calendar year submissions. 


\section{Summary Statistics of Major Publicly Owned Electric Utilities}

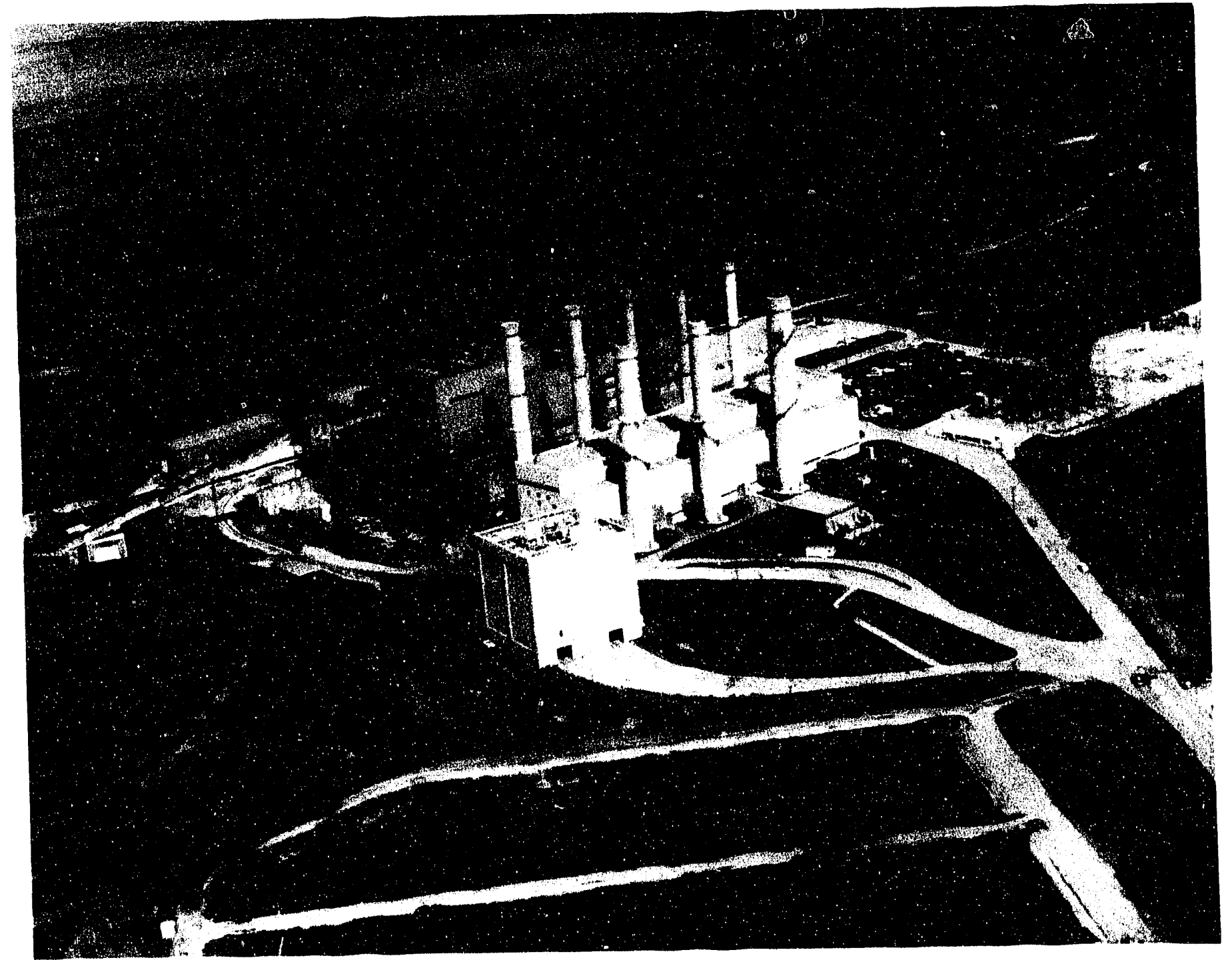

The North Omaha Station, a coal fired plant, is located near Omaha, Nebraska, and owned by the Omaha Public Power District. 


\section{Financial Performance for Generator Respondents}

Summary financial statistics are provided for major publicly owned generator electric utilities. These statistics include 218 electric utilities for 1991; 216 electric utilities for 1990; and 214 electric utilities for 1989. In 1990, new respondents were the City of Ketchikan (AK) and Rochelle Municipal Utilities (IL). In 1991, new respondents were the City of Benton (AR), the Hillsdale Board of Public Works (MI), the City of Kennett (MO), and the City of St. Marys( $(\mathrm{OH})$. Deleted 1991 respondents were the Kings River Conservation District (CA), the Merced Irrigation District (CA), and the Sebring Utilities Commission (FL). Ad ditionally, the Illinois Municipal Electric Agency (IL) and the Wisconsin Public Power Incorporated System (WI) were nongenerators that became generators, and the City of Marshfield (WI) was a generator that became a nongenerator in 1991.

Major publicly owned generator electric utilities require almost $\$ 4$ of investment to obtain $\$ 1$ in revenue. Electric operation and maintenance expenses averaged 65.4 percent of electric utility operating revenues during the years of 1989 through 1991. Interest on longterm debt as a percent of electric utility operating revenues averaged 22.7 over the same 3 years (Table 9).

\section{Income Statement}

In 1991, electric utility operating revenues were up 3.0 percent over 1990 levels, to $\$ 21,082.9$ million, compared with a 6.3 percent increast; in 1990. Total electric utility operating expenses increased 2.6 percent, to $\$ 16,886.9$ million, which in turn was a 4.7 percent increase over 1990 . Operation and maintenance expenses of $\$ 13,601.4$ million were up 1.5 percent over the prior year, represented 80.5 percent of total electric utility operating expenses.

With gains in revenue exceeding increased expenditures, total electric utility operating income increased 4.5 percent in 1991 , to $\$ 4,201.9$ million, up from $\$ 4,021.0$ million in 1990. Interest expenses were up only 2.4 percent despite a 3.6 percent increase in dett outstanding. Total net income rose 8.9 percent in 1991 over 1990 to 768.4 million (Table 7).

\section{Balance Sheet}

Total assets and other debits grew 3.9 percent in 1991 to $\$ 103,044.8$ million, compared with 4.3 percent in 1990. Other property and investments increased 9.7 percent to $\$ 17,332.6$ million, represented 39.7 percent of the increase in total assets and other debits between 1990 and 1991. Net electric utility plant increased $\$ 1,141.0$ million to $\$ 60,737.4$ million or 1.9 percent, accounted for 29.6 percent of the increase in total assets and other debits.

Total capitalization (investment and surplus plus longterm debt) increased $\$ 2,902.2$ million or 3.3 percent, to $\$ 91,093.6$ million in 1991. Over three-fourths of the increase was the result of adding $\$ 2,361.3$ million in long-term debt, making debt's share of total capitalization 75.6 percent in 1991 versus 75.4 percent in 1990 , and 75.0 percent in 1989. The ratio of long-term debt to total assets and other debits decreased marginally from 66.8 percent in 1991 to 67.1 percent in 1990 (Table 8).

\section{Sales of Electric Power}

In 1991, total sales to ultimate consumers grew 1.4 percent to 223.1 million megawatthours. However, total revenues from sales to ultimate consumers were up only 0.8 percent over the prior year, as average revenue per kilowatthour decreased almost 1.0 percent.

Sales for resale decreased in both megawatthour sales ( 0.7 percent) and average revenues $(0.1$ percent), producing revenues that were down 0.8 percent from 1990 (Table 12).

\section{Generation and Purchased Power}

Total net energy generated and received decreased 0.2 percent to 432.2 million megawatthours in 1991. The biggest change in the source of generation was in nuclear generation, which was up 13.8 percent over the prior year, and represented 19.3 percent of total generation. Steam generation was down 2.6 percent from 1990 and represented 55.1 percent of total net generation. Pumped storage hydroelectric power was down 20.1 percent while conventional hydroelectric power was down slightly ( 2.2 percent). Conventional hydroelectric power generation represented 24.6 percent of total generation for these electric utilitities, substantially more than the 13.0 percent contribution industrywide.

In 1991, total purchased power continued to play a major role in meeting the power requirements of these electric utilities, contributed 31.6 percent of the total net generated and received megawathours. Total purchased power from utilities and nonutilities in 1991 was 136.7 million megawatthours (Table 13). 
Table 3. Ten Largest Publicly Owned Generating Electric Utilities Ranked by Megawatthour Sales to Ultimate Consumers, 1991

\begin{tabular}{|c|c|c|c|}
\hline Publichy Owned Eloctric Utultise & State & Amount & Percent \\
\hline Los Angeles City of & $\mathrm{CA}$ & $21,803,360$ & 9.79 \\
\hline 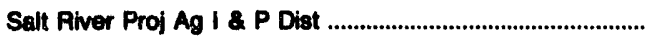 & $A Z$ & $14,591,895$ & 6.55 \\
\hline 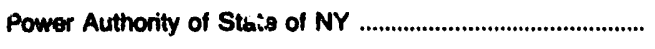 & NY & $13,326,360$ & 5.99 \\
\hline San Antonio City of & TX & $11,634,855$ & 5.23 \\
\hline Seattie City of & WA & $8,832,638$ & 3.97 \\
\hline 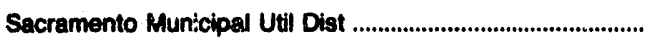 & CA & $8,421,441$ & 3.78 \\
\hline 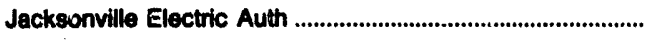 & FL & $7,751,649$ & 3.48 \\
\hline 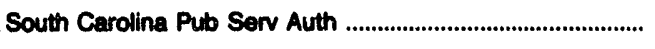 & SC & $7,508,723$ & 3.37 \\
\hline 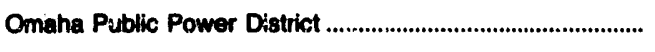 & NE & $6,705,518$ & 3.01 \\
\hline Alustin City of & $T X$ & $6,530,657$ & 2.93 \\
\hline 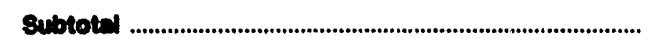 & & $107,107,166$ & 48.10 \\
\hline
\end{tabular}

Note: Percentage calculations are based on total Form EIA-412 respondents.

Source: Energy Information Admiristration, Form ElA-412, "Annual Report of Public Electric Uilities." Individual electric utilities report fiscal year data. Appendix B shows the fiscal year for each electric utility.

\section{Table 4. Ten Largest Publlcly Owned Generating Electric Utilities Ranked by Megawatthour Sales for Resale, 1991}

\begin{tabular}{|c|c|c|c|}
\hline Pubilicty Owred Elwetric Utumber & State & Anownt & Percent \\
\hline Power Authority of State of NY & NY & $22,905,668$ & 16.72 \\
\hline 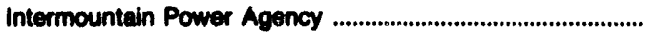 & UT & $10,750,184$ & 7.38 \\
\hline 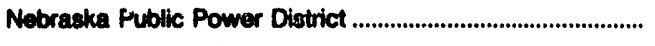 & NE & $10,550,435$ & 7.24 \\
\hline 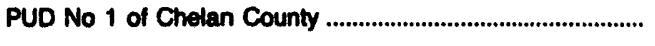 & WA & $10,354,969$ & 7.11 \\
\hline 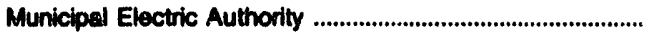 & GA & $9,312,381$ & 6.39 \\
\hline 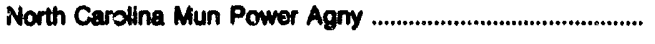 & NC & $8,022,722$ & 6.51 \\
\hline 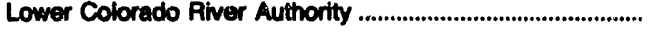 & TX & $7,822,764$ & 5.37 \\
\hline 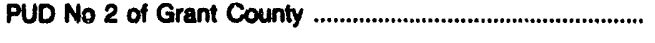 & WA & $7,326,020$ & 5.03 \\
\hline 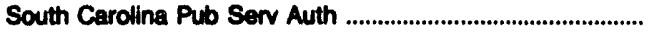 & SC & $6,088,552$ & 4.18 \\
\hline 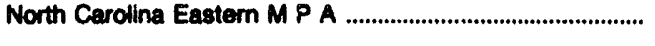 & NC & $5,862,319$ & 4.09 \\
\hline 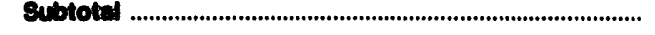 & & $75,136,652$ & 51.66 \\
\hline
\end{tabular}

Note: Percentage calculations are besed on total Form EIA-412 respondents. Source: Energy information Administration, Form EIA-412, "Annual Report of Public Electric Utillities." Individual electric utitities report fiscal year
data. Appendix B shows the fiscal year for each electric utility. 


\section{Financial Performance for Nongenerator Respondents}

Summary financial statistics are provided for major putlicly owned nongenerating electric utilities. These statistics include 252 electric utilities for 1991, 251 electric utilities for 1990, and 240 electric utilities for 1989. In 1990, new respondents were the Alabama Municipal Electric Authority (AL), the City of Geneva (IL), the City of Jefferson (WI), the City of Lawrenceville (GA), the McCook Public Power District (NE), the City of Oxford (MS), the City of Paris (TN), the City of Pierre (SD), the City of Plymouth (WI), the City of San Marcos(TX), and the City of Wapakoneta (OH). In 1991 new respondents were the City of Lebanon (MO), the City of Monett (MO), the Reedsburg Utility Commission (WI), and the Sturgeon Bay Combined Utilities (WI). Deleted 1991 respondents were the McCook Public Power District (NE) and the Village of Solvay (NY). Additionally, the City of Marshfield (WI) was a generator that became a nongenerator and the Illinois Municipal Electric Agency (IL) and the Wisconsin Public Power Incorporated System (WI) were nongenerators that became generators in 1991.

Major publicly owned nongenerator electric utilities require approximately $\$ 1$ of investment to obtain $\$ 1$ in revenue. Electric operation and maintenance expenses averaged 89.1 percent of electric utility operating revenues during the years 1989 through 1991. Interest on long-term debt as a percent of electric utility operating revenues averaged 1.6 over the same 3 years (Table 9).

\section{Income Statement}

In 1991, electric utility operating revenues were up 2.0 percent over 1990 levels, to $\$ 7,119.9$ million. This was a much smaller gain than the 6.5 percent experienced in 1990 over 1989 . Total electric utility operating expenses increased 1.8 percent, to $\$ 6,859.6$ million, compared with a 6.1 percent increase in 1990. Operation and maintenance expenses of $\$ 6,305.7$ million were up 1.4 percent over the prior year, represented 91.9 percent of total electric utility operating expenses.

Gains in revenue exceeded increased expenditures, and total electric utility operating income increased 9.8 percent in 1991, to \$263.5 million, up from $\$ 239.9$ mil- lion in 1990. Interest expense on long-term debt increased slightly in 1991 (1.9 percent). Total net income rose to $\$ 249.2$ million, up 1.6 percent from 1990 . However, 1991 net income was still 4.7 percent below the \$261.6 million recorded in 1989 (Table 7).

\section{Balance Sheet}

Total assets and other debits grew 5.7 percent in 1991 to $\$ 8,998.6$ million, compared with 6.3 percent in 1990 . Net electric utility plant increased $\$ 254.8$ million, to $\$ 4,662.4$ million or 5.8 percent, accounted for $\$ 2.5$ percent of the increase in total assets and other debits. Other property and investments increased 4.5 percent, to $\$ 1,849.6$ million, represented 16.2 percent of the increase in total assets and other debits between 1990 and 1991.

Total capitalization (investment and surplus plus longterm debt) increased $\$ 424.6$ million or 5.8 percent, to $\$ 7,767.4$ million in 1991. Almost half the increase was the result of adding $\$ 193.8$ million in long-term debt, raising debt's share of total capitalization to 32.7 percent in 1991 versus 32.0 percent in 1990, and 32.2 percent in 1989. The ratio of long-term debt to total assets and other debits increased marginally from 28.3 percent in 1991 to 27.6 percent in 1990 (Table 8).

\section{Sales of Electric Power}

In 1991, total sales to ultimate consumers grew 3.0 percent to 121.6 million megawatthours. However, total revenues from sales to ultimate consumers were up only 3.4 percent over the prior year, as average revenue per kilowatthour increased a more modest 0.4 percent.

Sales for resale decreased in both megawatthour sales (32.9 percent) and average revenues per kilowatthour (3.3 percent), combined to decrease revenues by 34.5 percent in 1991 (Table 12).

\section{Purchased Power}

In 1991, total purchased power of 134.3 million kilowatthours was essentially the same for 1990 . This followed a 5.7 percent increase over the 1989 level of 127.0 million kilowatthours (Table 13). 
Table 5. Ten Largest Publicly Owned Nongenerating Electric Utilities Ranked by Megawatthour Sales to Ultimate Consumers, 1991

\begin{tabular}{|c|c|c|c|}
\hline Publichy Owned Electric Utiltios & State & Amount & Percent \\
\hline Memphis City of & TN & $11,451,824$ & 9.47 \\
\hline 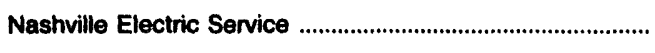 & TN & $9,74: 2,817$ & 8.06 \\
\hline Chattanooga City of & TN & $5,027,367$ & 4.16 \\
\hline 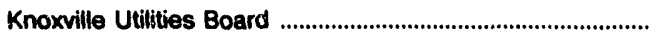 & TN & $4,359,615$ & 3.61 \\
\hline Huntsville City of & AL & $3,407,812$ & 2.82 \\
\hline 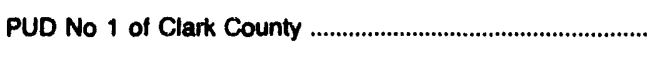 & WA & $3,122,251$ & 2.58 \\
\hline 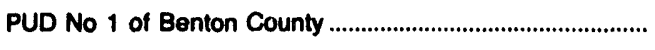 & WA & $1,383,117$ & 1.14 \\
\hline 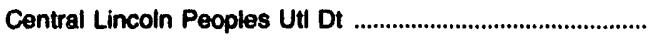 & OR & $1,367,872$ & 1.13 \\
\hline 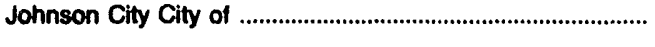 & TN & $1,324,422$ & 1.10 \\
\hline Decatur City of & AL & $1,296,729$ & 1.07 \\
\hline 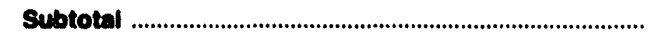 & & $42,483,826$ & 35.15 \\
\hline
\end{tabular}

Note: Percentage calculations are based on total Form ElA.412 respondents.

Source: Energy Information Administration, Form ElA-412, "Annual Report of Public Electric Utilities." Individual electric utilities report fiscal year data. Appendix $\mathbf{B}$ shows the fiscal year for each electric utility.

\section{Table 6. Ten Largest Publicly Owned Nongenerating Electric Utilities Ranked by Megawatthour Sales for Resale, 1991}

\begin{tabular}{|c|c|c|c|}
\hline Publlicty Owned Eloctric Uttilties & State & Amount & Percent \\
\hline 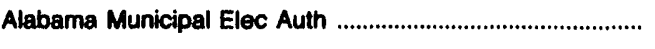 & AL & $2,179,091$ & 29.36 \\
\hline 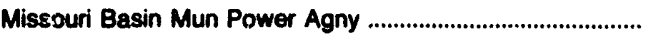 & SD & $1,873,259$ & 25.24 \\
\hline 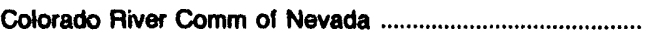 & NV & 915,290 & 12.33 \\
\hline Arizona Power Authority & $A Z$ & 833,232 & 11.23 \\
\hline 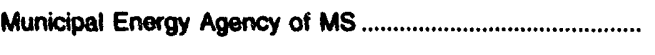 & MS & 776,246 & 10.46 \\
\hline 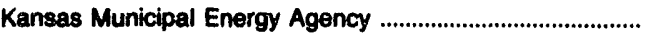 & KS & 394,759 & 5.32 \\
\hline 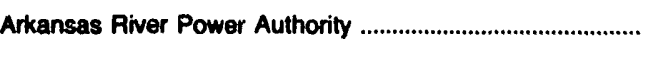 & co & 263,863 & 3.55 \\
\hline 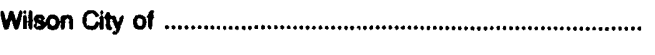 & NC & 59,098 & .80 \\
\hline 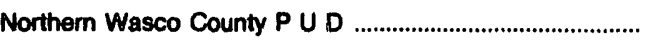 & OR & 23,070 & .31 \\
\hline Greenville Utilities Comm & NC & 22,000 & .30 \\
\hline Subtoted & & $7,339,914$ & 98.88 \\
\hline
\end{tabular}

Note: Percentage calculations are based on total Form EIA-412 respondents.

Source: Energy Information Administration, Form EIA-412, "Annual Report of Public Electric Utilities." Individual electric utilities repert fiscal year data. Appendix B shows the fiscal year for each electric utility. 
Table 7. Composite Statement of Income for Major Publicly Owned Electric Utilities by Generators and Nongenerators, 1989-1991 (Thousand Dollars)

\begin{tabular}{|c|c|c|c|c|c|c|}
\hline \multirow[b]{2}{*}{ Item } & 1991 & 1990 & 1989 & 1991 & 1990 & 1989 \\
\hline & \multicolumn{3}{|c|}{ Generator Utilities } & \multicolumn{3}{|c|}{ Nongenerator Utilities } \\
\hline Electric Utility Operating Revenues ............. & $21,082,870$ & $20,470,371$ & $19,261,832$ & $7,119,875$ & $6,978,752$ & $6,552,712$ \\
\hline 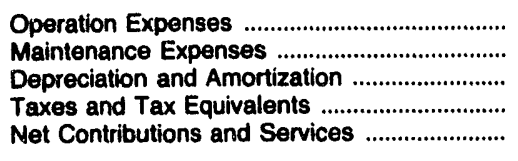 & $\begin{array}{r}12,155,075 \\
1,446,295 \\
2,300,532 \\
595,719 \\
389,300\end{array}$ & $\begin{array}{r}11,948,084 \\
1,455,786 \\
2,075,595 \\
550,042 \\
431,193\end{array}$ & $\begin{array}{r}11,310,048 \\
1,486,423 \\
2,051,058 \\
500,424 \\
373,165\end{array}$ & $\begin{array}{r}6,119,385 \\
186,267 \\
246,594 \\
138,491 \\
168,882\end{array}$ & $\begin{array}{r}6,030,028 \\
191,621 \\
231,197 \\
133,125 \\
154,956\end{array}$ & $\begin{array}{r}5,693,914 \\
182,509 \\
200,580 \\
124,160 \\
153,431\end{array}$ \\
\hline $\begin{array}{l}\text { Total Eloctric Utility Operating } \\
\text { Expenses }\end{array}$ & $16,886,921$ & $16,450,700$ & $15,721,118$ & $6,859,619$ & $6,740,926$ & $6,354,593$ \\
\hline $\begin{array}{l}\text { Net Electric Utility Operating Income ............... } \\
\text { Income from Electric Plant Leased }\end{array}$ & $4,195,949$ & $4,009,671$ & $3,540,714$ & 260,255 & 237,826 & 198,118 \\
\hline 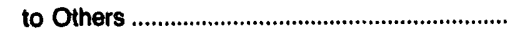 & 5,942 & 11,330 & 5,325 & 3,264 & 2,121 & 1,727 \\
\hline Total Electric Utility Operating Income. & $4,201,881$ & $4,021,001$ & $3,546,039$ & 263,520 & 239,948 & 199,845 \\
\hline 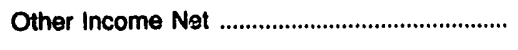 & $1,890,138$ & $1,735,107$ & $1,740,217$ & 147.117 & 154,240 & 169,518 \\
\hline $\begin{array}{l}\text { Other Electric Deductions } \\
\text { Allowance for Other Funds Used......................... }\end{array}$ & 123,345 & - & - & 13,949 & - & - \\
\hline 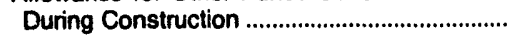 & 71,025 & 123,282 & 231,996 & 1,606 & -213 & -302 \\
\hline 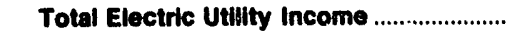 & $6,039,710$ & $5,879,390$ & $5,518,252$ & 398,294 & 393,975 & 369,062 \\
\hline 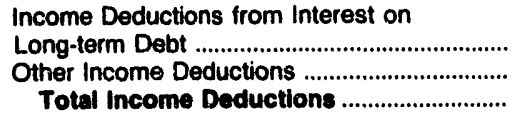 & $\begin{array}{r}4,775,003 \\
430,796 \\
5,205,799\end{array}$ & $\begin{array}{r}4,663,114 \\
401,822 \\
5,064,936\end{array}$ & $\begin{array}{r}4,337,962 \\
402,229 \\
4,740,190\end{array}$ & $\begin{array}{r}112,031 \\
27,775 \\
138,806\end{array}$ & $\begin{array}{r}109,972 \\
27,340 \\
137,311\end{array}$ & $\begin{array}{r}101,469 \\
20,934 \\
122,403\end{array}$ \\
\hline Income Before Extraordinary Items ...................... & 833,911 & 814,455 & 778,062 & 258,488 & 256,663 & 246,658 \\
\hline Extraordinary Income & 99,430 & 136,692 & 60,418 & 24,074 & 5,274 & 26,641 \\
\hline 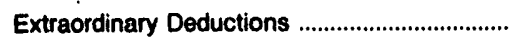 & 164,974 & 245,650 & 714,279 & 33,326 & 16,589 & 11,691 \\
\hline 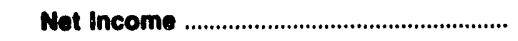 & 768,367 & 705,497 & 124,201 & 249,236 & 245,348 & 261,608 \\
\hline
\end{tabular}

- Data not available.

- Net income reflects $\$ 584$ million of extraordinary deduction associated with the abandonment of the Rancho Seco Nuclear Plant reported by the Sacramento Municipal Utility District.

Note: Totals may not equal sum of components because of independent rounding. Detailed data are provided in Table 38 . The number of publicly owned generating electric utilities for end of period is 218 for 1991,216 for 1990 , and 214 for 1989 . The number of publicly owned nongenerating electric utilities for end of period is 252 for 1991,251 for 1990 , and 240 for 1989 . Illinois Municipal Electric Agency (IL) and Wisconsin Public Power Incorporated System (WI) were nongenerators in 1989 and 1990, but became generators in 1991. The City of Marchfield (WI) was a generator in 1989 and 1990, but became a nongenerator in 1991.

Source: Energy Information Administration, Form ElA-412, "Annual Report of Public Electric Utilities." Individual electric utilities report fiscal year data. Appendix $B$ shows the fiscal year for each electric utility. 
Table 8. Composite Balance Sheet for Major Publicly Owned Electric Utilities by Generators and Nongenerators at End of Period, 1989-1991 (Thousand Dollars)

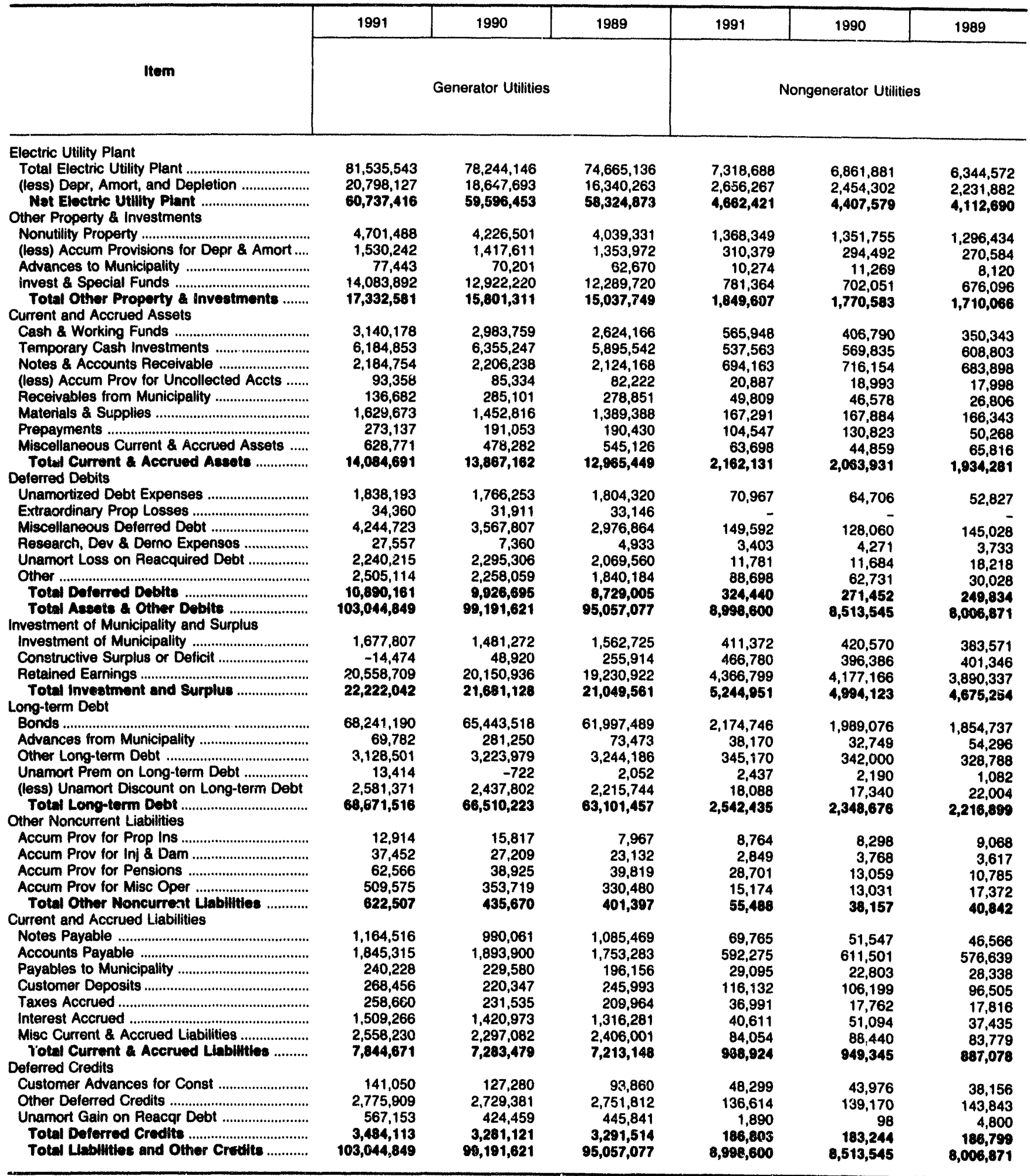

Note: Totals may not equal sum of components because of independent rounding. Detailed data are provided in Table 39 . The number of publicly owned generating electric utilities for end of period is 218 for 1991, 216 for 1990, and 214 for 1989 . The number of publicly owned nongenerating electric utilities for end of period is 252 for 1991, 251 for 1990, and 240 for 1989. Illinois Municipal Electric Agency (IL) and Wisconsin Public Power Incorporated System (WI) were nongenerators in 1989 and 1980, but became generators in 1991 . The City of Marchfield (WI) was a generator in 1989 and 1990 , but became a nongenerator in 1991.

Source: Energy Information Administration, Form ElA-412, "Annual Report of Public Electric Utilities." Individual electric utilities report fiscal year data. Appendix B shows the fiscal year for each electric utility. 
Table 9. Composite Financial Indicators for Major Publicly Owned Electric Utilities by Generators and Nongenerators, 1989-1991

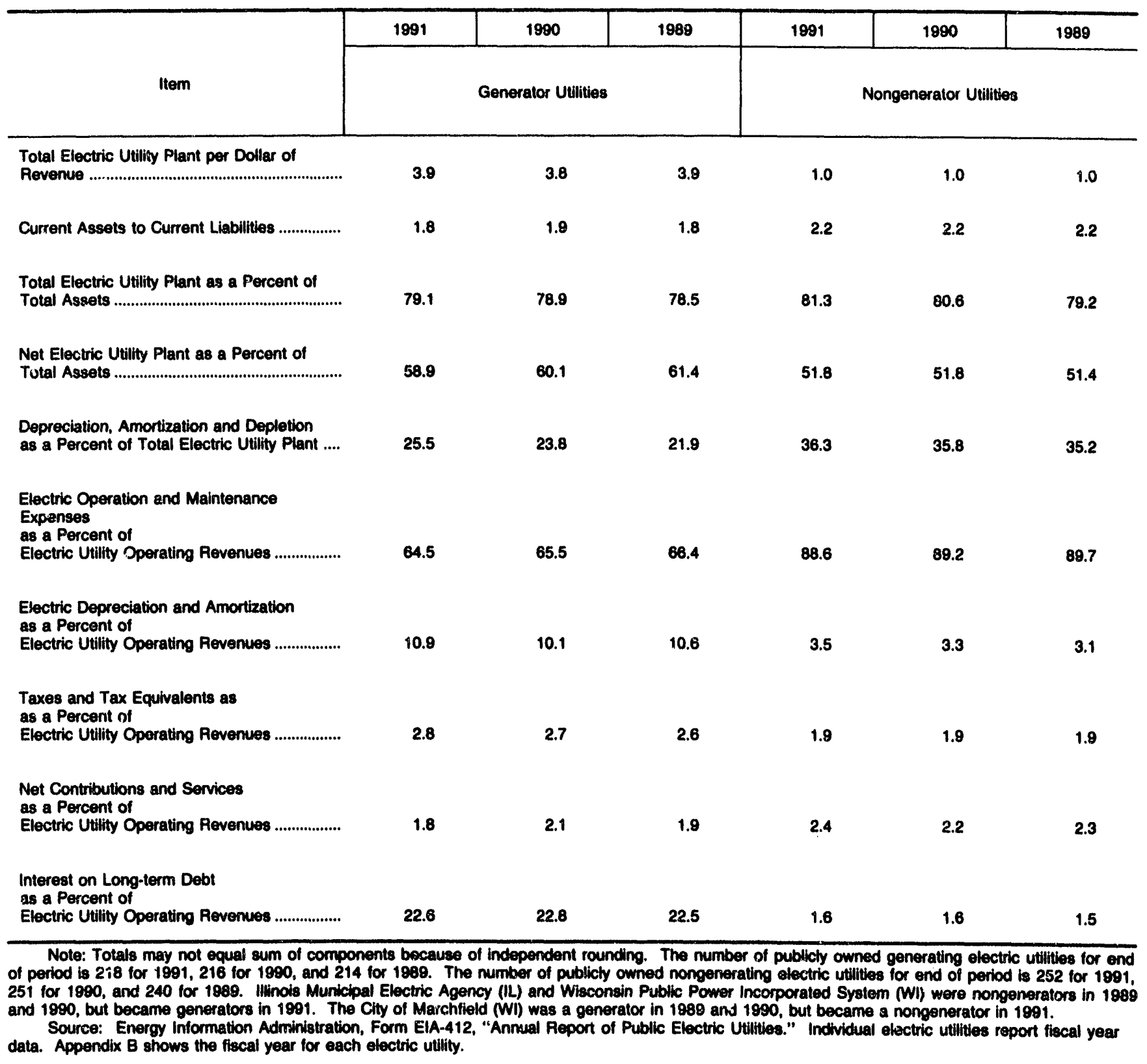


Table 10. Electric Operation and Maintenance Expenses for Major Publicly Owned Electric Utilities by Generators and Nongenerators, 1989-1991 (Thousand Dollars)

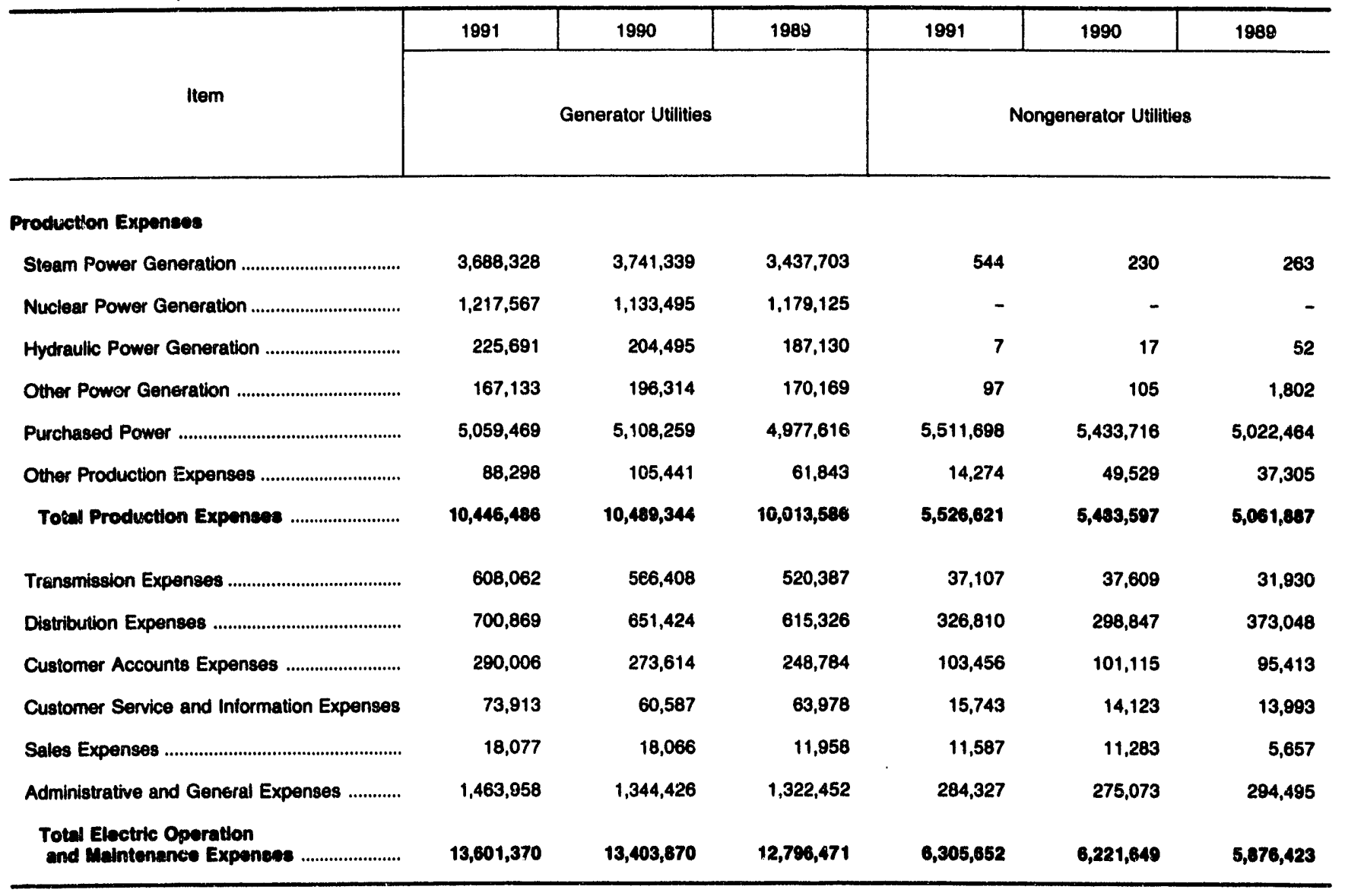

Note: Totals may not equal sum of components because of independent rounding. Detailed data are provided in Table 40 . The number of publicly owned generating electric utilities for end of period is 218 for 1991, 216 for 1990, and 214 for 1989 . The number of publicly owned nongenerating electric utillties for end of period is 252 for 1991, 251 for 1990 , and 240 for 1989. Illinois Municipal Electric Agency (IL) and Wisconsin Public Power Incorporated System (WI) were nongenerators in 1989 and 1990, but became generators in 1991 . The City of Marchtield (WI) was a generator in 1989 and 1990 , but became a nongenerator in 1991.

Source: Energy Information Administration, Form E.IA-412, "Annual Report of Public Electric Utilities." Individual electric utilities report fiscal year data. Appendix $B$ shows the fiscal year for each electric utility. 


\section{Table 11. Electric Utility Plant for Major Publicly Owned Electric Utilities by Generators and Nongenerators at End of Period, 1989-1991 (Thousand Dollars)}

\begin{tabular}{|c|c|c|c|c|c|c|}
\hline \multirow[b]{2}{*}{ Item } & 1991 & 1990 & 1989 & 1991 & 1990 & 1989 \\
\hline & \multicolumn{3}{|c|}{ Generator Utilities } & \multicolumn{3}{|c|}{ Nongenerator Utilities } \\
\hline \multicolumn{7}{|l|}{ Electric Plant in Service } \\
\hline Intangible Plant & 364,919 & 318,464 & 382,790 & 8,292 & 7,521 & 8,019 \\
\hline \multicolumn{7}{|l|}{ Production Plant } \\
\hline Steam & $22,488,350$ & $21,219,432$ & $19,120,267$ & 68,062 & 27,215 & 71,049 \\
\hline 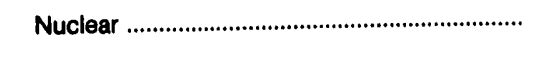 & $19,440,482$ & $18,992,687$ & $18,313,109$ & - & - & - \\
\hline 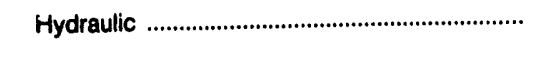 & $6,975,677$ & $6,837,541$ & $6,333,219$ & 15,334 & 15,334 & 14,956 \\
\hline Other & $1,557,135$ & $1,591,090$ & $1,470,073$ & 19,164 & 48,607 & 14,954 \\
\hline 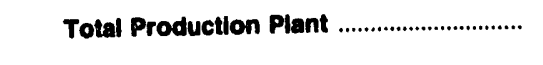 & $50,461,644$ & $48,640,749$ & $45,236,667$ & 102,560 & 91,156 & 100,959 \\
\hline 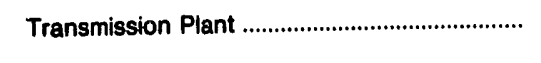 & $8,490,104$ & $7,847,445$ & $7,476,064$ & 589,808 & 501,168 & 460,099 \\
\hline 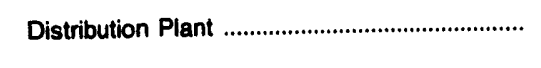 & $12,586,918$ & $11,675,396$ & $11,148,904$ & $5,192,372$ & $4,904,220$ & $4,537,394$ \\
\hline 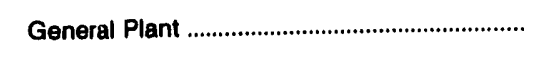 & $4,073,586$ & $3,790,484$ & $3,258,961$ & $1,147,474$ & $1,076,942$ & 968,309 \\
\hline 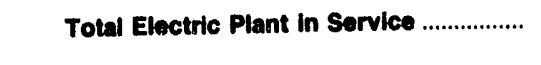 & $75,977,171$ & $72,272,538$ & $67,503,386$ & $7,040,506$ & $6,581,006$ & $6,074,779$ \\
\hline Electric Piant Leased to Others ....................... & 565,948 & 482,946 & 478,043 & 662 & 708 & 640 \\
\hline Construction Work in Progress - Electric ........ & $3,909,155$ & $3,938,231$ & $5,371,308$ & 210,030 & 212,939 & 188,487 \\
\hline Electric Plant Held for Future Use ................... & 626,776 & 819,007 & 743,806 & 13,860 & 11,391 & 10,638 \\
\hline Electric Plant Acquisition Adjustments ........... & 456,493 & 731,424 & 568,593 & 53,630 & 55,837 & 70,028 \\
\hline 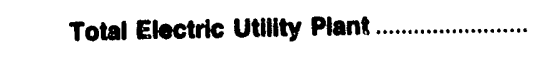 & $81,535,543$ & $78,244,146$ & $74,665,136$ & $7,318,688$ & $6,861,881$ & $6,344,572$ \\
\hline $\begin{array}{l}\text { Accumulated Provision for } \\
\text { Depreciation and Amortization ........................... }\end{array}$ & $20,798,127$ & $18,647,693$ & $16,340,263$ & $2,656,267$ & $2,454,302$ & $2,231,882$ \\
\hline Net Eloctric Utility Plant ................................ & $60,737,416$ & $59,596,453$ & $58,324,873$ & $4,662,421$ & $4,407,579$ & $4,112,690$ \\
\hline
\end{tabular}

Note: Totals may not equal sum of components because of independent rounding. Detailed data are provided in Table 41 . The number of publicly Note: Totals may not equal sum of components because of independent round and 214 for 1989 . The number of publicly owned nongenerating electric owned generating electric utilities for end of period is 218 for 1991,216 for 1989 . Illinois Municipal Electric Agency (IL) and Wisconsin Public Power Incorporated utilities for end of period is 252 for 1991,251 for 1990 , and 240 for 1989 . Illinois Municipal Electric Agency in 1989 and 1990, but became generators in 1991 . The City of Marchield (WI) was a generator in 1989 and 1990, but became a nongenerator in 1991.

Source: Energy Information Administration, Form EIA-412, "Annual Report of Public Electric Utilities." Individual electric utilities report fiscal year data. Appendix $B$ shows the fiscal year for each electric utility. 
Table 12. Number of Consumers, Sales, and Operating Revenue for Major Publicly Owned Electric Utilities by Generators and Nongenerators, 1989-1991

\begin{tabular}{|c|c|c|c|c|c|c|}
\hline \multirow{2}{*}{ Item } & 1991 & 1990 & 1989 & 1991 & 1990 & 1989 \\
\hline & \multicolumn{3}{|c|}{ Generator Utilities } & \multicolumn{3}{|c|}{ Nongenerator Utilities } \\
\hline \multicolumn{7}{|l|}{ Number of Consumers } \\
\hline 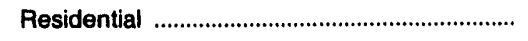 & $7,320,039$ & $7,155,754$ & $7,026,529$ & $3,624,017$ & $3,556,400$ & $3,454,713$ \\
\hline Commercial or Small & 894,604 & 893,611 & 929,909 & 503,917 & 493,348 & 451,951 \\
\hline Industrial or Large & 45,202 & 50,829 & 49,864 & 30,629 & 31,854 & 35,675 \\
\hline Other & 162,871 & 164,051 & 137,416 & 103,377 & 99,949 & 94,977 \\
\hline 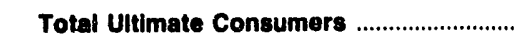 & $8,422,716$ & $8,264,245$ & $8,143,718$ & $4,261,940$ & $4,181,551$ & $4,037,316$ \\
\hline \multicolumn{7}{|l|}{ Sales for the Year (megawatthours) } \\
\hline 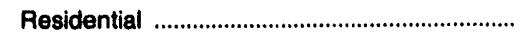 & $71,667,965$ & $70,078,774$ & $68,285,003$ & $46,808,977$ & $45,347,843$ & $44,021,341$ \\
\hline Commercial or Small & $65,283,723$ & $65,302,667$ & $62,908,557$ & $26,987,619$ & $25,768,440$ & $23,530,515$ \\
\hline Industrial or Large & $68,550,382$ & $67,376,604$ & $64,856,200$ & $44,693,894$ & $43,948,454$ & $42,770,643$ \\
\hline Other & $17,643,031$ & $17,378,120$ & $15,418,212$ & $3,146,985$ & $3,055,644$ & $2,987,772$ \\
\hline Total Sales to Uitimate Consumers ........... & $223,145,101$ & $220,136,165$ & $211,467,972$ & $121,637,475$ & $118,120,381$ & $113,310,271$ \\
\hline 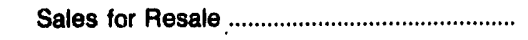 & $183,508,522$ & $184,836,059$ & $181,631,969$ & $7,288,781$ & $10,767,467$ & $8,041,747$ \\
\hline Total Sales ...................................................... & $406,653,623$ & $404,972,224$ & $393,099,941$ & $128,926,256$ & $128,887,848$ & $121,352,018$ \\
\hline \multicolumn{7}{|l|}{$\begin{array}{l}\text { Operating Revenues for the Year } \\
\text { (thousand dollars) }\end{array}$} \\
\hline 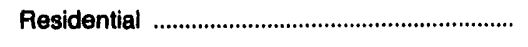 & $4,759,672$ & $4,673,479$ & $4,456,953$ & $2,752,710$ & $2,659,845$ & $2,557,348$ \\
\hline Commercial or Small & $4,244,293$ & $4,296,416$ & $4,015,774$ & $1,680,252$ & $1,596,862$ & $1,453,940$ \\
\hline Industrial or Large & $3,117,161$ & $3,014,459$ & $2,950,948$ & $2,188,095$ & $2,150,794$ & $2,093,283$ \\
\hline Other & $1,105,045$ & $1,142,976$ & $1,008,679$ & 198,756 & 190,987 & 183,398 \\
\hline $\begin{array}{l}\text { Total Revenues from Sales to } \\
\text { Ultimate Consumers }\end{array}$ & $13,226,171$ & $13,127,330$ & $12,432,354$ & $6,819,813$ & $6,598,488$ & $6,287,969$ \\
\hline Sales for Resale & $6,995,157$ & $7,051,730$ & $6,818,991$ & 226,388 & 345,818 & 256,140 \\
\hline $\begin{array}{l}\text { Total Revenues From Sales of } \\
\text { Electricity }\end{array}$ & $20,221,328$ & $20,179,060$ & $19,251,345$ & $7,046,201$ & $6,944,306$ & $6,544,109$ \\
\hline
\end{tabular}

Note: Totals may not equal sum of components because of independent rounding. Detailed data are provided in Table 42 . The number of publicly owned generating electric utilities for end of period is 218 for 1991, 216 for 1990, and 214 for 1989 . The number of publicly owned nongenerating electric utilities for end of period is 252 for 1991, 251 for 1990, and 240 for 1989. Illinois Municipal Electric Agency (IL) and Wisconsin Public Power Incorporated System (WI) were nongenerators in 1989 and 1990, but became generators in 1991. The City of Marchfield (WI) was a generator in 1989 and 1990, but became a nongenerator in 1991.

Source: Energy Information Administration, Form ElA-861, "Annual Electric Utility Report." Data are based on calendar year submissions. 
Table 13. Electric Energy Account for Major Publicly

Owned Electric Utilities by Generators

and Nongenerators, 1989-1991

(Megawatthours)

\begin{tabular}{|c|c|c|c|c|c|c|}
\hline \multirow{2}{*}{ Item } & 1991 & 1990 & 1989 & 1991 & 1990 & 1989 \\
\hline & \multicolumn{3}{|c|}{ Generator Utllities } & \multicolumn{3}{|c|}{ Nongenerator Utilities } \\
\hline 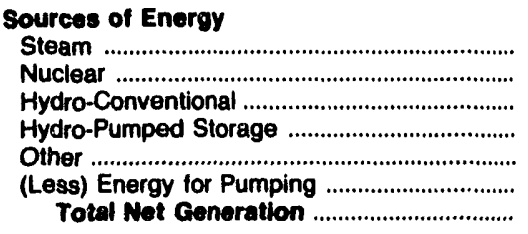 & $\begin{array}{r}164,401,739 \\
57,756,871 \\
73,348,633 \\
3,789,638 \\
3,137,344 \\
3,904,547 \\
298,529,686\end{array}$ & $\begin{array}{r}168,806,546 \\
50,740,159 \\
75,007,682 \\
4,741,854 \\
3,990,503 \\
3,551,799 \\
299,734,947\end{array}$ & $\begin{array}{r}177,940,856 \\
53,149,705 \\
68,743,015 \\
4,059,041 \\
2,371,953 \\
3,603,646 \\
302,660,924\end{array}$ & $\begin{array}{l}- \\
- \\
- \\
- \\
- \\
-\end{array}$ & $\begin{array}{l}- \\
- \\
- \\
- \\
-\end{array}$ & $\begin{array}{l}- \\
- \\
- \\
- \\
-\end{array}$ \\
\hline 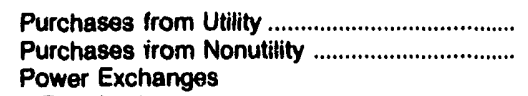 & $\begin{array}{r}135,721,748 \\
1,023,894\end{array}$ & $\begin{array}{r}134,078,420 \\
953,732\end{array}$ & $\begin{array}{r}117,464,109 \\
998,330\end{array}$ & $\begin{array}{r}133,942,064 \\
356,845\end{array}$ & $\begin{array}{r}134,171,017 \\
52,397\end{array}$ & $\begin{array}{r}126,967,286 \\
27,967\end{array}$ \\
\hline 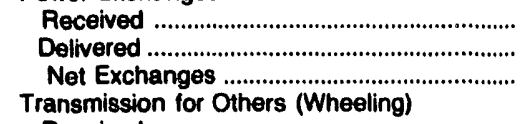 & $\begin{array}{l}19,499,318 \\
22,632,364 \\
-3,133,045\end{array}$ & $\begin{array}{l}35,396,785 \\
37,502,403 \\
-2,105,619\end{array}$ & $\begin{array}{r}20,982,909 \\
21,727,726 \\
-744,818\end{array}$ & $\begin{array}{r}289,014 \\
202,905 \\
86,109\end{array}$ & $\begin{array}{l}67,343 \\
22,994 \\
44,349\end{array}$ & $\begin{array}{r}274,661 \\
268,065 \\
6,595\end{array}$ \\
\hline 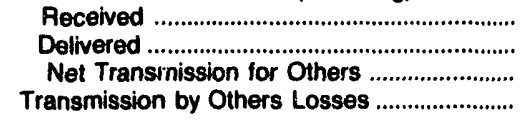 & $\begin{array}{r}27,653,990 \\
27,447,579 \\
206,410 \\
-162,245\end{array}$ & $\begin{array}{r}30,849,232 \\
30,575,781 \\
273,450 \\
-74,580\end{array}$ & $\begin{array}{r}30,245,487 \\
29,725,513 \\
519,974 \\
-\end{array}$ & $\begin{array}{r}7,164 \\
7,164 \\
-7,488\end{array}$ & $\begin{array}{r}8,071 \\
8,825 \\
-754 \\
-6,856\end{array}$ & $\begin{array}{r}14,484 \\
6,681 \\
7,803 \\
-\end{array}$ \\
\hline \multicolumn{6}{|l|}{ Total Net Energy Generated and } & $127,009,655$ \\
\hline 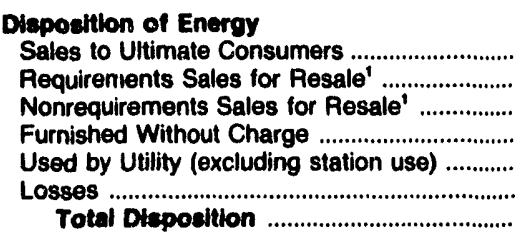 & $\begin{array}{r}222,657,472 \\
154,882,433 \\
30,076,686 \\
1,639,051 \\
7,627,773 \\
15,302,995 \\
432,186,432\end{array}$ & $\begin{array}{r}218,822,432 \\
150,992,085 \\
33,820,225 \\
1,732,209 \\
11,619,734 \\
15,873,662 \\
432,860,348\end{array}$ & $\begin{array}{r}211,222,453 \\
180,655,267 \\
- \\
1,746,258 \\
11,412,462 \\
15,862,067 \\
420,898,522\end{array}$ & $\begin{array}{r}120,874,508 \\
6,411,888 \\
1,010,926 \\
242,338 \\
237,494 \\
5,600,285 \\
134,377,529\end{array}$ & $\begin{array}{r}117,765,915 \\
9,460,262 \\
999,561 \\
225,282 \\
224,001 \\
5,585,110 \\
134,260,153\end{array}$ & $\begin{array}{r}113,029,611 \\
7,721,208 \\
- \\
260,310 \\
221,232 \\
5,777,292 \\
127,009,655\end{array}$ \\
\hline $\begin{array}{l}\text { The } 1989 \text { data were reported as Sales for } \\
\text { Note: Totals may not equal sum of comp } \\
\text { owned generating electric utilities for end of pe } \\
\text { utilities for end of period is } 252 \text { for } 1991,251 \\
\text { System (WI) were nongenerators in } 1989 \text { and } \\
\text { became a nongenerator in } 1991 \text {. Double counti } \\
\text { Purchases from utilities, net exchanges, and ne } \\
\text { mate consumers. } \\
\text { Source: Energy information Administratio } \\
\text { data. Appendix B shows the fiscal year for eac }\end{array}$ & $\begin{array}{l}\text { is } 218 \text { for } 1 \\
990 \text {, and } 26 \\
0 \text {, but becan } \\
\text { occurs in cor } \\
\text { heeling (exc }\end{array}$ & $\begin{array}{l}\text { dependent r } \\
216 \text { for } 1990 \\
1389 \text {. llino } \\
\text { nerators in } \\
\text { onts of both } \\
\text { r imports) a }\end{array}$ & $\begin{array}{l}\text { Requirements } \\
\text { ng. Detailed } \\
214 \text { for } 1989 \\
\text { nicipal Electric } \\
\text { The City of } \\
\text { es and dispos } \\
\text { luded in net } 9\end{array}$ & $\begin{array}{l}\text { es for Resale } \\
\text { are provided } \\
\text { e number of } \\
\text { uncy (IL) and } \\
\text { hfield (WI) w } \\
\text { of energy an } \\
\text { ation. Sales } \\
\text { es." Individu }\end{array}$ & $\begin{array}{l}\text { ble 43. The } \\
\text { ly owned no } \\
\text { onsin Public. } \\
\text { enerator in } \\
\text { neither pro } \\
\text { sale is inclu }\end{array}$ & $\begin{array}{l}\text { ber of publicly } \\
\text { erating electric } \\
\text { Incorporated } \\
\text { and } 1990, \text { but } \\
\text { a true total. } \\
\text { n sales to ulti- } \\
\text { t fiscal year }\end{array}$ \\
\hline
\end{tabular}


Table 14. Ten Largest Generating Publicly Owned Electric Utilities Ranked by Megawatthour Sales to Ultimate Consumers, June 30, 1991

\begin{tabular}{|c|c|c|}
\hline Publicly Owned Electric Uullities & State & Amount \\
\hline 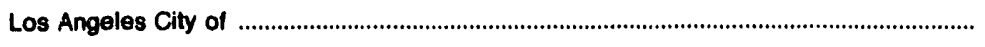 & CA & $21,803,360$ \\
\hline 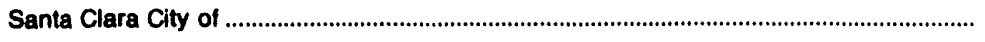 & CA & $2,262,202$ \\
\hline Anaheim City of & CA & $2,156,813$ \\
\hline Lansing City of . & Mi & $2,151,707$ \\
\hline Fayetteville Public Works Comm & NC & $1,547,965$ \\
\hline 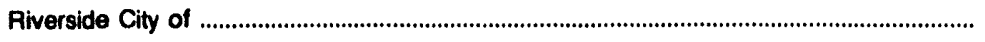 & CA & $1,495,000$ \\
\hline Pasadena City of & CA & $1,078,472$ \\
\hline Vernon City of & CA & $1,012,277$ \\
\hline Glendale City of & CA & 974,388 \\
\hline Burbank City of & CA & 962,211 \\
\hline
\end{tabular}

Source: Energy Information Administration, Form EIA-412, "Annual Report of Public Electric Utilities."

\section{Table 15. Ten Largest Generating Publicly Owned Electric Utilities Ranked by Megawatthour Sales for Resale, June 30, 1991}

\begin{tabular}{|c|c|c|}
\hline Publicly Owned Electric Uthlitios & State & Amount \\
\hline Intermountain Power Agency & UT & $10,750,184$ \\
\hline Lower Colorado River Authority & $\mathrm{TX}$ & $7,822,764$ \\
\hline Washington Pub Pwr Supply Sys & WA & $5,769,664$ \\
\hline 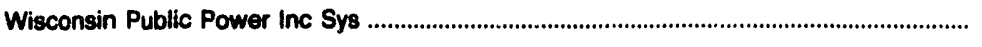 & WI & $3,164,342$ \\
\hline Southern California P P A & CA & $1,603,991$ \\
\hline 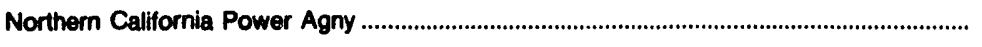 & CA & $1,571,529$ \\
\hline San Francisco City \& County of & CA & 927,224 \\
\hline 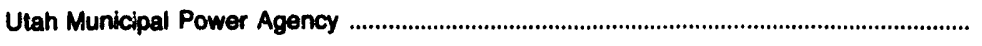 & UT & 771,802 \\
\hline 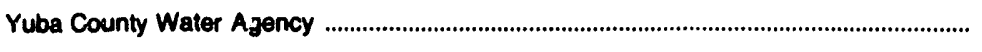 & CA & 694,481 \\
\hline 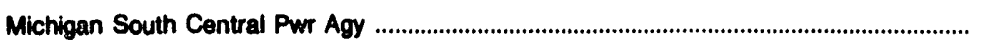 & MI & 404,878 \\
\hline
\end{tabular}

Source: Energy Information Administration, Form ElA-412, "Annual Report of Public Electric Uilities." 
Table 16. Ten Largest Generating Publicly Owned Electric Utilities Ranked by Megawatthour Sales to Ultimate Consumers, December 31, 1991

\begin{tabular}{|c|c|c|}
\hline Publicly Owned Electric Utilities & State & Amount \\
\hline Power Authority of State of NY & NY & $13,326,360$ \\
\hline Seattle City of & WA & $8,832,638$ \\
\hline 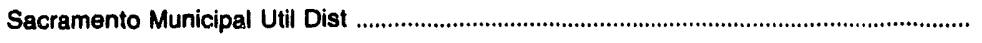 & CA & $8,421,441$ \\
\hline South Carolina Pub Serv Auth & sc & $7,508,723$ \\
\hline 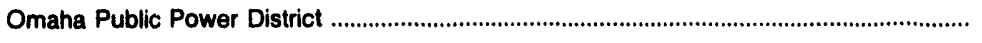 & NE & $6,705,518$ \\
\hline 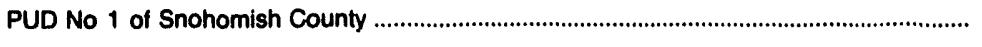 & WA & $5,631,998$ \\
\hline Tacoma City of & WA & $5,568,661$ \\
\hline 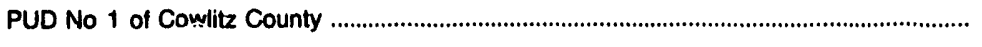 & WA & $4,217,152$ \\
\hline 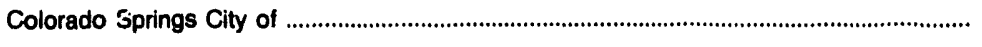 & $\mathrm{CO}$ & $2,899,022$ \\
\hline PUD No 2 of Grant County & WA & $2,577,017$ \\
\hline
\end{tabular}

Source: Energy Information Administration, Form ElA-412, "Annual Report of Public Electric Utilities."

\section{Table 17. Ten Largest Generating Publicly Owned Electric Utilities Ranked by Megawatthour Sales for Resale, December 31, 1991}

\begin{tabular}{|c|c|c|}
\hline Publicly Owned Electric Utilities & State & Amount \\
\hline Power Authority of State of NY & NY & $22,905,668$ \\
\hline Nebraska Public Power District & NE & $10,550,435$ \\
\hline PUD No 1 of Chelan County & WA & $10,354,989$ \\
\hline 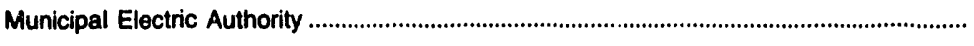 & GK & $9,312,381$ \\
\hline 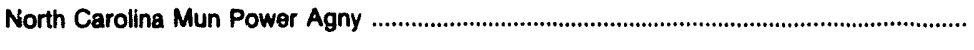 & NC & $8,022,722$ \\
\hline 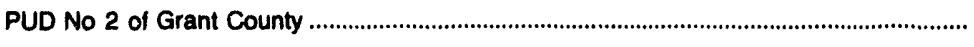 & WA & $7,326,020$ \\
\hline South Carolina Pub Serv Auth & SC & $6,088,552$ \\
\hline 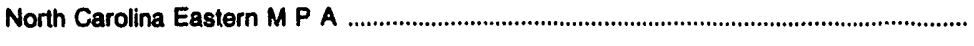 & NC & $5,962,319$ \\
\hline PUD No 1 of Douglas County & WA & $4,350,264$ \\
\hline Grand Piver Dam Authority & OK & $4,062,452$ \\
\hline
\end{tabular}

Source: Energy Information Administration, Form ElA-412, "Annual Report of Public Electric Utilities." 
Table 18. Composite Statement of Income for Major Publicly Owned Generating Electric Utilities, 1989-1991 (Thousand Dollars)

\begin{tabular}{|c|c|c|c|c|c|c|}
\hline \multirow[b]{2}{*}{ Item } & 1991 & 1990 & 1989 & 1991 & 1990 & 1889 \\
\hline & \multicolumn{3}{|c|}{$\begin{array}{c}\text { Generating Utilities with Financial Year } \\
\text { Ending on June } 30\end{array}$} & \multicolumn{3}{|c|}{$\begin{array}{l}\text { Generating Utilities with Financial Year } \\
\text { Ending on December } 31\end{array}$} \\
\hline Electric Utilty Operating Ksvenuses ........... & $5,503,003$ & $5,522,510$ & $5,580,005$ & $9,945,735$ & $9,563,608$ & $\therefore, 188,030$ \\
\hline 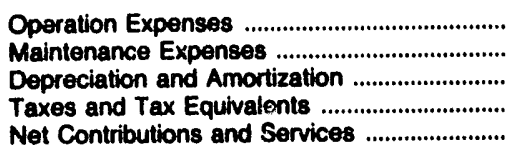 & $\begin{array}{r}3,389,558 \\
350,956 \\
623,168 \\
107,916 \\
66,809\end{array}$ & $\begin{array}{r}3, \Leftarrow 43,473 \\
404,302 \\
562,284 \\
101,236 \\
72,042\end{array}$ & $\begin{array}{r}3,167,210 \\
519,534 \\
641,313 \\
91,193 \\
91,112\end{array}$ & $\begin{array}{r}5,834,899 \\
691,105 \\
1,096,953 \\
237,006 \\
32,237\end{array}$ & $\begin{array}{r}5,860,117 \\
650,551 \\
964,558 \\
230,400 \\
34,621\end{array}$ & $\begin{array}{r}5,287,937 \\
610,525 \\
892,359 \\
212,213 \\
25,754\end{array}$ \\
\hline $\begin{array}{l}\text { Total Electric Utity Operating } \\
\text { Expenses }\end{array}$ & $4,583,407$ & $4,393,337$ & $4,510,362$ & $7,892,200$ & $7,740,246$ & $7,028,789$ \\
\hline $\begin{array}{l}\text { Net Electric Utility Operating Income .............. } \\
\text { Income from Electric Plant Lessed }\end{array}$ & $1,045,576$ & $1,139,173$ & $1,069,733$ & $2,053,535$ & $1,823,451$ & $1,459,241$ \\
\hline 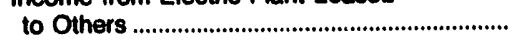 & 719 & 448 & 252 & 2,272 & 1,605 & 1,893 \\
\hline Total Electric Utilty Operating Income. & $1,048,205$ & $1,139,621$ & $1,069,985$ & $2,055,807$ & $1,825,057$ & $1,461,134$ \\
\hline 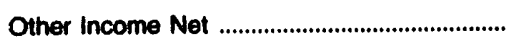 & 355,740 & 348,547 & 386,804 & 847,124 & 929,862 & $1,017,293$ \\
\hline $\begin{array}{l}\text { Other Electric Deductions ................................ } \\
\text { Allowance for Other Funds Used }\end{array}$ & 1,824 & - & - & 24,235 & - & - \\
\hline 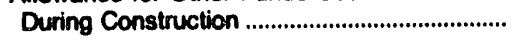 & 6,143 & 3,188 & 9,454 & 15,842 & 54,305 & 133,125 \\
\hline Totel Electric Utilty Income ........................ & $1,406,354$ & $1,491,356$ & $1,466,243$ & $2,924,538$ & $2,609,223$ & $2,611,552$ \\
\hline 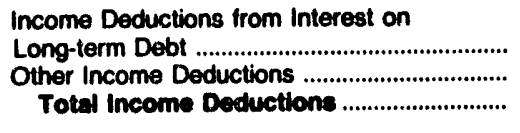 & $\begin{array}{r}1,182,775 \\
-87,632 \\
1,005,143\end{array}$ & $\begin{array}{r}1,172,787 \\
57,623 \\
1,230,400\end{array}$ & $\begin{array}{r}1,131,305 \\
-2,108 \\
1,129,186\end{array}$ & $\begin{array}{r}2,405,347 \\
119,052 \\
2,524,399\end{array}$ & $\begin{array}{r}2,299,233 \\
184,417 \\
2,493,649\end{array}$ & $\begin{array}{r}2,183,136 \\
202,297 \\
2,385,434\end{array}$ \\
\hline Income Before Extraordinary Items ................. & 311,212 & 260,947 & 337,046 & 470,139 & 325,574 & 226,119 \\
\hline 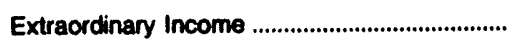 & 5,763 & 82,133 & 3,388 & 84,099 & 31,676 & 21,748 \\
\hline 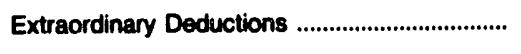 & 132,571 & 126,517 & 30,368 & 26,113 & 106,814 & 644,093 \\
\hline Not Income & 184,403 & 216,563 & 310,066 & 528,125 & 250,436 & ' $-396,227$ \\
\hline
\end{tabular}

- Data not available.

- Net income reflects $\$ 584$ million of extracrdinary deduction associated with the abandonment of the Rancho Seco Nuclear Plant reported by the Sacramento Municipal Utility District.

Note: Totals may not equal sum of components because of independent rounding. Detailed data are provided in Table 38 . The number of generating publicly owned electric utitities for end of period is 53 for June 30, 1991; 52 for June 30, 1990; and 50 for June 30, 1989 ; and is 110 for December 31, 1981; 110 for December 31, 1980; and 108 for December 31, 1989. The South Carolina Public Service Authority (SC) changed fiscal year from June 30 to December 31 in 1990. The Utah Associated Municipal Power System (UT) changed fiscal year from June 30 to March 31 in 1991 . The City of Marshfield (WI) was a generator in 1889 and 1890 , but became a nongenerator in 1981. The Wisconsin Public Power incorporated System (WI) was a nongenerator in 1989 and 1980, but became a generator in 1991.

Source: Energy Information Administration, Form EIA-412, "Annual Report of Public Electric Utilties." 
Table 19. Composite Balance Sheet for Major Publicly Owned Generating Electric Utilities at End of Period, 1989-1991 (Thousand Dollars)

\begin{tabular}{|c|c|c|c|c|c|c|}
\hline \multirow[b]{2}{*}{ Item } & 1991 & 1990 & 1989 & 1991 & 1990 & 1989 \\
\hline & \multicolumn{3}{|c|}{$\begin{array}{c}\text { Generating Utilities with Financial Year } \\
\text { Ending on June } 30\end{array}$} & \multicolumn{3}{|c|}{$\begin{array}{c}\text { Generating Utilities with Financial Year } \\
\text { Ending on December } 31\end{array}$} \\
\hline $\begin{array}{l}\text { Electric Utility Plant } \\
\text { Total Electric Utility Plant ..................................... } \\
\text { (less) Depr, Amort, and Depletion ................... } \\
\text { Nef Eloctric Utility Plant ................................. } \\
\text { Other Property \& Investments }\end{array}$ & $\begin{array}{r}21,287,167 \\
5,313,940 \\
15,973,226\end{array}$ & $\begin{array}{r}20,522,021 \\
4,722,915 \\
15,799,106\end{array}$ & $\begin{array}{r}22,055,492 \\
4,694,601 \\
17,360,891\end{array}$ & $\begin{array}{l}37,479,683 \\
10,075,535 \\
27,404,148\end{array}$ & $\begin{array}{r}35,754,753 \\
9,044,556 \\
26,710,198\end{array}$ & $\begin{array}{r}32,508,145 \\
7,623,800 \\
24,884,345\end{array}$ \\
\hline 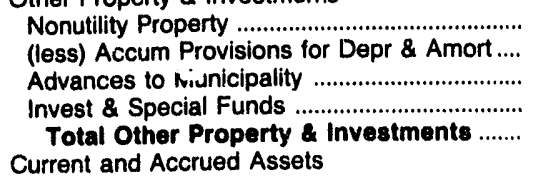 & $\begin{array}{r}4,083,541 \\
1,323,745 \\
2,351 \\
4,048,793 \\
6,810,940\end{array}$ & $\begin{array}{r}3,669,756 \\
1,212,730 \\
4,218 \\
4,151,242 \\
6,612,486\end{array}$ & $\begin{array}{r}3,436,470 \\
1,136,176 \\
1,304 \\
4,370,717 \\
6,672,314\end{array}$ & $\begin{array}{r}403,811 \\
163,570 \\
60,3,43 \\
6,462,983 \\
6,763,567\end{array}$ & $\begin{array}{r}371,810 \\
160,561 \\
58,539 \\
5,413,412 \\
5,683,199\end{array}$ & $\begin{array}{r}431,129 \\
179,516 \\
58,537 \\
5,158,118 \\
5,468,268\end{array}$ \\
\hline 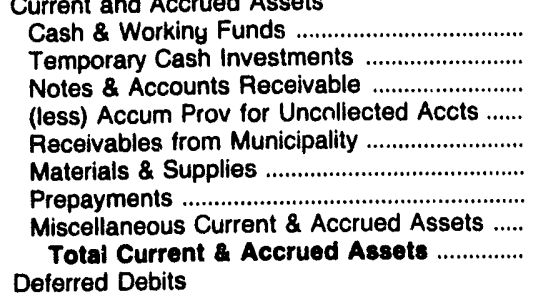 & $\begin{array}{r}963,777 \\
1,915,393 \\
644,203 \\
11,322 \\
22,760 \\
425,083 \\
79,627 \\
269,715 \\
4,309,236\end{array}$ & $\begin{array}{r}996,380 \\
2,022,896 \\
642,673 \\
9,364 \\
140,773 \\
364,691 \\
78,179 \\
132,754 \\
4,368,981\end{array}$ & $\begin{array}{r}1,111,134 \\
1,198,345 \\
662,590 \\
17,906 \\
139,351 \\
390,488 \\
76,338 \\
119,826 \\
3,680,165\end{array}$ & $\begin{array}{r}1,720,578 \\
3,545,993 \\
876,113 \\
19,880 \\
87,091 \\
700,104 \\
148,138 \\
250,407 \\
7,308,543\end{array}$ & $\begin{array}{r}1,574,605 \\
3,719,929 \\
879,808 \\
19,068 \\
86,677 \\
623,849 \\
74,488 \\
240,850 \\
7,181,141\end{array}$ & $\begin{array}{r}1,221,172 \\
4,042,960 \\
854,797 \\
16,539 \\
94,239 \\
534,578 \\
77,638 \\
254,643 \\
7,063,488\end{array}$ \\
\hline 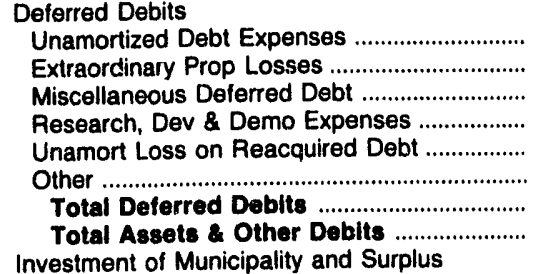 & $\begin{array}{r}951,622 \\
- \\
670,070 \\
593 \\
688,437 \\
1,040,713 \\
3,351,435 \\
30,444,837\end{array}$ & $\begin{array}{r}986,193 \\
- \\
600,264 \\
890 \\
686,685 \\
847,353 \\
3,121,386 \\
29,901,959\end{array}$ & $\begin{array}{r}1,011,799 \\
6,974 \\
498,286 \\
427 \\
820,463 \\
963,271 \\
3,401,220 \\
31,114,590\end{array}$ & $\begin{array}{r}736,895 \\
34,360 \\
2,918,934 \\
25,570 \\
892,093 \\
1,238,787 \\
5,846,637 \\
47,322,895\end{array}$ & $\begin{array}{r}643,102 \\
29,846 \\
2,354,751 \\
3,674 \\
953,142 \\
1,230,605 \\
5,215,120 \\
44,789,657\end{array}$ & $\begin{array}{r}650,285 \\
26,172 \\
1,935,337 \\
2,897 \\
747,919 \\
729,289 \\
4,091,899 \\
41,508,000\end{array}$ \\
\hline 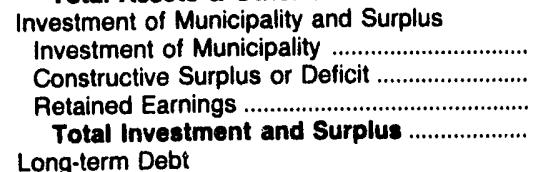 & $\begin{array}{r}1,171,715 \\
-251,794 \\
6,796,166 \\
7,716,086\end{array}$ & $\begin{array}{r}1,033,629 \\
-82,290 \\
6,482,752 \\
7,434,090\end{array}$ & $\begin{array}{r}1,025,960 \\
9,032 \\
6,468,155 \\
7,503,147\end{array}$ & $\begin{array}{r}308,846 \\
66,098 \\
7,426,859 \\
7,801,802\end{array}$ & $\begin{array}{r}256,885 \\
68,299 \\
7,288,802 \\
7,613,986\end{array}$ & $\begin{array}{r}343,767 \\
62,308 \\
6,390,869 \\
6,796,944\end{array}$ \\
\hline 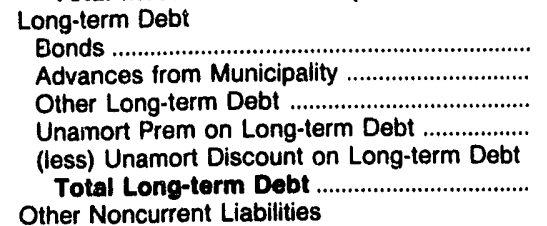 & $\begin{array}{r}18,835,964 \\
22,899 \\
571,718 \\
688 \\
986,782 \\
18,444,488\end{array}$ & $\begin{array}{r}18,600,918 \\
45,265 \\
476,646 \\
743 \\
944,583 \\
18,178,989\end{array}$ & $\begin{array}{r}19,241,142 \\
34,269 \\
517,995 \\
798 \\
912,420 \\
18,881,783\end{array}$ & $\begin{array}{r}33,165,999 \\
35,874 \\
1,847,314 \\
8,141 \\
984,342 \\
34,072,986\end{array}$ & $\begin{array}{r}30,950,035 \\
232,985 \\
2,083,314 \\
855 \\
917,760 \\
32,349,429\end{array}$ & $\begin{array}{r}29,105,207 \\
36,005 \\
2,166,948 \\
487 \\
879,102 \\
30,429,545\end{array}$ \\
\hline 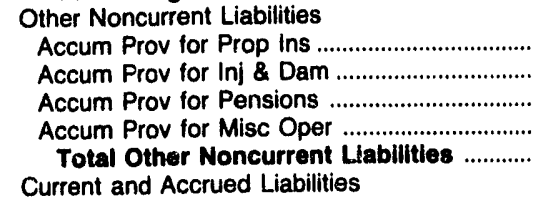 & $\begin{array}{r}454 \\
999 \\
12,321 \\
18,741 \\
32,515\end{array}$ & $\begin{array}{r}527 \\
594 \\
12,981 \\
19,261 \\
33,362\end{array}$ & $\begin{array}{r}1,496 \\
575 \\
12,463 \\
22,866 \\
37,400\end{array}$ & $\begin{array}{r}5,144 \\
24,882 \\
41,569 \\
343,136 \\
414,731\end{array}$ & $\begin{array}{r}7,976 \\
17,734 \\
18,029 \\
210,570 \\
254,309\end{array}$ & $\begin{array}{r}3,895 \\
14,083 \\
17,264 \\
263,487 \\
298,729\end{array}$ \\
\hline 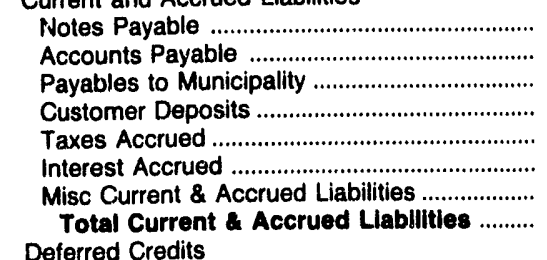 & $\begin{array}{r}100,631 \\
746,541 \\
149,637 \\
75,121 \\
21,522 \\
410,709 \\
1,827,133 \\
3,331,293\end{array}$ & $\begin{array}{r}117,925 \\
664,029 \\
139,883 \\
41,682 \\
14,220 \\
342,985 \\
1,824,711 \\
3,145,434\end{array}$ & $\begin{array}{r}183,392 \\
680,466 \\
124,922 \\
81,254 \\
17,277 \\
397,198 \\
1,914,085 \\
3,398,593\end{array}$ & $\begin{array}{r}761,201 \\
646,324 \\
46,715 \\
46,508 \\
90,009 \\
755,391 \\
506,597 \\
2,852,744\end{array}$ & $\begin{array}{r}709,310 \\
778,237 \\
35,375 \\
45,534 \\
88,738 \\
740,148 \\
357,230 \\
2,754,571\end{array}$ & $\begin{array}{r}452,701 \\
726,594 \\
37,210 \\
38,290 \\
75,552 \\
675,577 \\
321,843 \\
2,327,767\end{array}$ \\
\hline 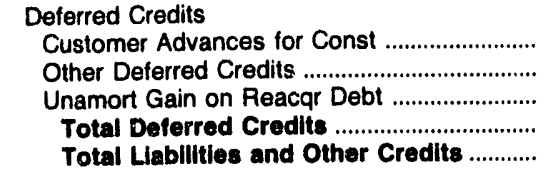 & $\begin{array}{r}51,082 \\
695,188 \\
174,185 \\
920,455 \\
30,444,837\end{array}$ & $\begin{array}{r}34,180 \\
928,499 \\
147,404 \\
1,110,083 \\
29,901,958\end{array}$ & $\begin{array}{r}30,886 \\
1,125,854 \\
136,926 \\
1,293,667 \\
31,114,590\end{array}$ & $\begin{array}{r}27,116 \\
1,914,443 \\
239,073 \\
2,180,632 \\
47,322,895\end{array}$ & $\begin{array}{r}30,138 \\
1,680,486 \\
106,738 \\
1,817,362 \\
44,789,657\end{array}$ & $\begin{array}{r}28,297 \\
1,513,951 \\
112,767 \\
1,655,015 \\
41,508,000\end{array}$ \\
\hline
\end{tabular}

Note: Totals may not equal sum of components because of independent rounding. Detailed data are provided on Table 39 . The number of generating publicly owned electric utilities for end of period is 53 for June 30, 1991; 52 for June 30, 1990; and 50 for June 30, 1989; and is 110 for December 31, 1991. 110 for December 31, 1990; and 108 for December 31, 1989. The South Carolina Public Service Authority (SC) changed fiscal year from June 30 to December 31 in 1990 . The Utah Associated Municipal Power System (UT) changed fiscal year from June 30 to March 31 in 1991. The City of Marshfield (WI) was a generator in 1989 and 1990 , but became a nongenerator in 1991 . The Wisconsin Public Power Incorporated System (WI) was a nongenerator in 1989 and 1990 , but became a generator in 1991.

Source: Energy Information Administration, Form ElA-412, "Annual Report of Public Electric Utilities." 


\section{Table 20. Composite Financiai Indicators for Major Publicly Owned Genersiting Electric Utilities, 1989-1991}

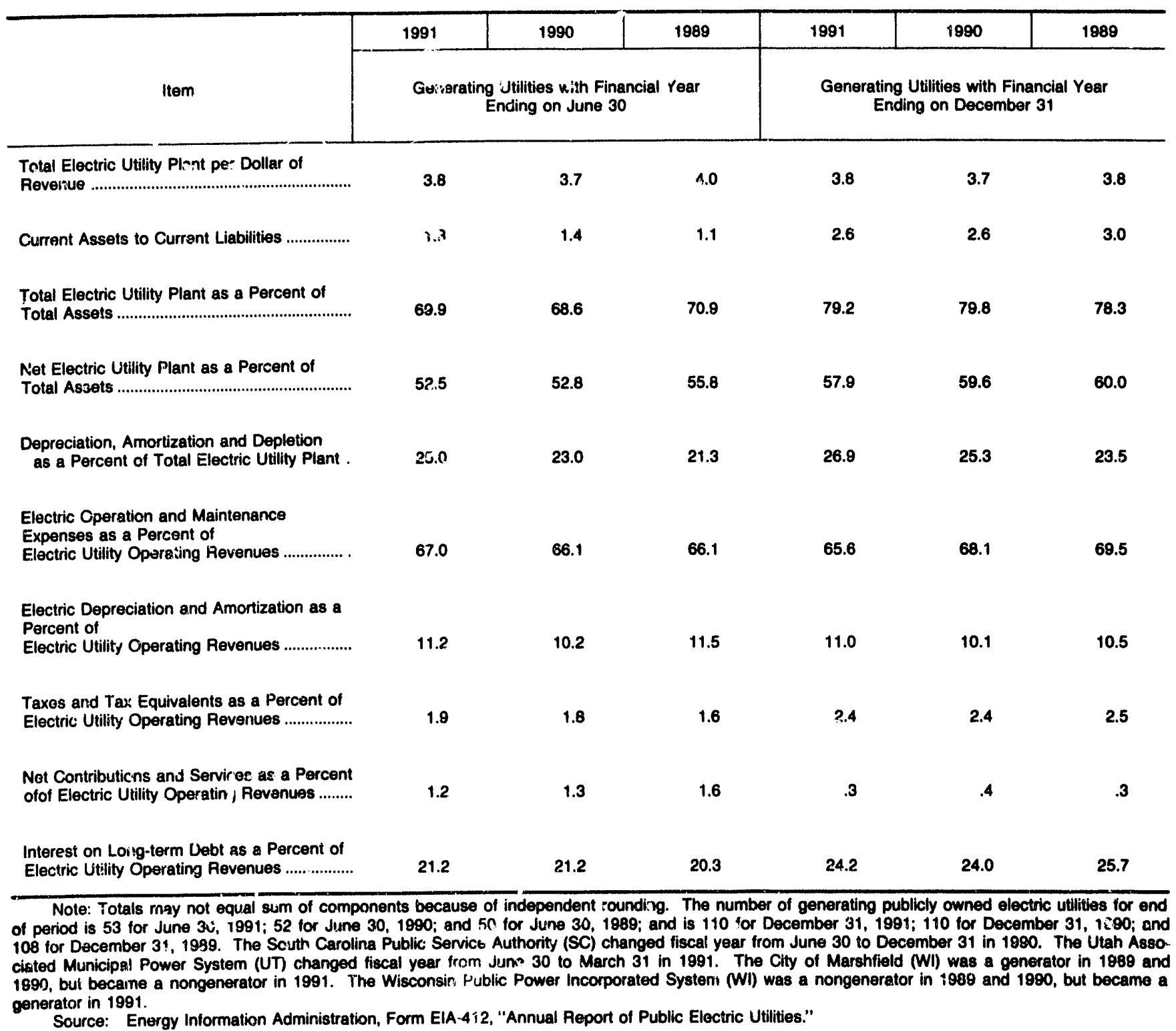


Table 21. Electric Operation and Maintenance Expenses for Major Publicly Owned Generating Electric Utilities, 1989-1991 (Thousand Dollars)

\begin{tabular}{|c|c|c|c|c|c|c|}
\hline \multirow[b]{2}{*}{ Ilem } & 1991 & 1980 & 1988 & 1891 & 1980 & 1989 \\
\hline & \multicolumn{3}{|c|}{$\begin{array}{c}\text { Generating Utilities with Financial Year } \\
\text { Ending on June } 30\end{array}$} & \multicolumn{3}{|c|}{$\begin{array}{c}\text { Generating Utilities with Financial Year } \\
\text { Ending on December } 31\end{array}$} \\
\hline \multicolumn{7}{|l|}{ Production Expensese } \\
\hline 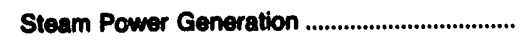 & 920,777 & 991,183 & $1,179,944$ & $1,300,701$ & $1,261,277$ & 927,117 \\
\hline Nuclear Power Generation ...................................... & 208,094 & 197,714 & 221,487 & 775,240 & 722,829 & 763,421 \\
\hline 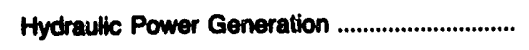 & 49,211 & 45,352 & 48,750 & 168,004 & 148,086 & 127,805 \\
\hline 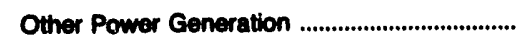 & 24,478 & 34,899 & 21,741 & 83,339 & 80,600 & 95,481 \\
\hline 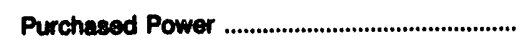 & $1,634,208$ & $1,542,275$ & $1,415,978$ & $2,569,367$ & $2,770,259$ & $2,567,040$ \\
\hline 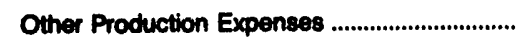 & 26,376 & 12,417 & 11,976 & 46,277 & 73,468 & 31,020 \\
\hline 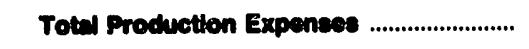 & $2,863,145$ & $2,823,830$ & $2,890,876$ & $4,949,920$ & $5,058,518$ & $4,611,805$ \\
\hline 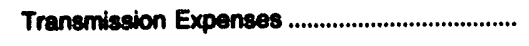 & 114,691 & 113,483 & 92,302 & 429,842 & 397,977 & 374,643 \\
\hline 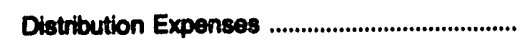 & 232,287 & 212,305 & 210,443 & 286,590 & 281,495 & 240,911 \\
\hline 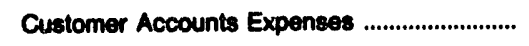 & 77,482 & 75,973 & 66,122 & 115,765 & 107,563 & 94,427 \\
\hline Customer Service and Information Expenses & 19,756 & 14,472 & 15,878 & 36,664 & 31,340 & 39,103 \\
\hline Sales Expenses & 3,126 & 4,155 & 3,703 & 7,617 & 7,067 & 5,445 \\
\hline Administrative and General Expenses ............ & 430,027 & 403,548 & 388,420 & 705,496 & 648,707 & 631,848 \\
\hline $\begin{array}{l}\text { Total Electric Operation } \\
\text { and Melintenance Expenses ........................ }\end{array}$ & $3,740,513$ & $3,647,775$ & $3,686,744$ & $6,528,004$ & $6,510,667$ & $5,808,463$ \\
\hline
\end{tabular}

Nole: Total may not equal sum of components because of independent rounding. Detailed data are provided in Tabie 40 . The number of generating publicty oumed electric utithies for end of period is 53 for June 30, 1991; 52 for June 30, 1980; and 50 for June 30, 1989 ; and is 110 for December 31, 1891; 110 for December 31, 1890; and 108 for December 31, 1989. The South Carolina Public Service Authority (SC) changed fiscal year from June 30 to December 31 in 1890. The Utati Associated Municipal Power System (UT) changed fiscal year from June 30 to March 31 in 1981. The City of Marshfield WI) was a generator in 1889 and 1980, but became a nongenerator in 1991. The Wisconsin Public Power Incorporated System (WI) was a nongenerator in 1889 and 1980, but became a generator in 1891.

Source: Energy Information Administration, Form EIA-412, "Annual Rep. wt of Public Electric Utilities." 
Table 22. Electric Utility Plant for Major Publicly Owned Generaiing Electric Utilities at End of Period, 1989-1991 (Thousand Dolliars)

\begin{tabular}{|c|c|c|c|c|c|c|}
\hline & 1991 & 1890 & 1989 & 1891 & 1890 & 1989 \\
\hline Item & \multicolumn{3}{|c|}{$\begin{array}{l}\text { Generating Utilities with Financial Year } \\
\text { Ending on June } 30\end{array}$} & \multicolumn{3}{|c|}{$\begin{array}{c}\text { Generating Utillties with Financial Year } \\
\text { Ending on December } 31\end{array}$} \\
\hline \multicolumn{7}{|l|}{ Eloctric Plant in Services } \\
\hline 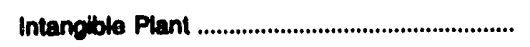 & 141,436 & 83,134 & 172,036 & 166,530 & 183,723 & 157,589 \\
\hline \multicolumn{7}{|l|}{ Production Plent } \\
\hline Steam & $5,648,534$ & $5,789,039$ & $6,485,865$ & $8,826,802$ & $7,885,718$ & $6,622,860$ \\
\hline Nuctear & $4,858,875$ & $4,857,227$ & $5,274,101$ & $9,484,275$ & $8,866,077$ & $8,028,487$ \\
\hline Hyoraulic ............................................................ & $1,784,146$ & 1.783 .520 & $1,457,555$ & $4,840,668$ & $4,799,518$ & $4,643,098$ \\
\hline Other & 248,642 & 217.512 & 236,807 & 898,234 & 921,650 & 804,293 \\
\hline 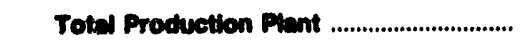 & $12,752,197$ & $12,667,200$ & $13,454,320$ & $24,167,090$ & $22,652,093$ & $20,008,738$ \\
\hline 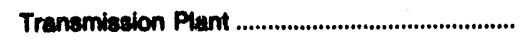 & $2,257,636$ & $2,211,441$ & $2,450,653$ & $4,332,303$ & $3,860,130$ & $3,314,733$ \\
\hline 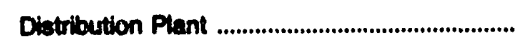 & $3,757,818$ & $3,443,680$ & $3,486,858$ & $4,808,645$ & $4,567,340$ & $4,153,899$ \\
\hline 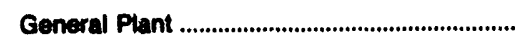 & $1,123,472$ & $1,037,843$ & $1,099,187$ & $1,928,771$ & $1,801,420$ & $1,491,094$ \\
\hline Total Eivetric Plant in Eervice ..................... & $20,032,050$ & $19,433,397$ & $20,083,004$ & $35,494,228$ & $33,076,578$ & $20,216,032$ \\
\hline 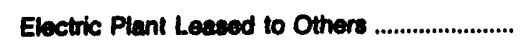 & 655 & 1,820 & 1 & 18,558 & 19,533 & 16,549 \\
\hline Conatruction Work in Progress - Electric ........ & $1,002,642$ & 840,847 & $1,366,413$ & $1,524,793$ & $1,984,117$ & $2,609,383$ \\
\hline Electric Plant Held for Future Use ........................ & 264,295 & 268,278 & 52,523 & 86,163 & 85,069 & 235,480 \\
\hline Electric Plant Acquisition Adyustments ............. & $-13,083$ & $-22,522$ & $-28,509$ & 345,841 & 580,458 & 430,670 \\
\hline 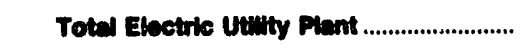 & $21,207,167$ & $20,522,021$ & $22,056,482$ & $37,470,643$ & $35,764,763$ & $38,508,145$ \\
\hline $\begin{array}{l}\text { Accumulated Providion for } \\
\text { Depreciation and Amortization ........................ }\end{array}$ & $5,313,940$ & $4,722,915$ & $4,694,601$ & $10,075,535$ & $8,044,556$ & $7,623,800$ \\
\hline Net Electric Uttily Plant ................................ & $15,073,226$ & $15,700,108$ & $17,300,091$ & $27,404,140$ & $23,710,198$ & $24,84,346$ \\
\hline
\end{tabular}

Note: Totals may not equal sum of components because of independent rounding. Detailed data are provided in Table 41 . The number of generating publlcty owned electric utilities for end of period bs 50 for June 30, 1991; 52 for June 30, 1890; and 50 for June 30, 1889; and is 110 for December 31, 1991; 110 for December 31, 1890; and 108 for December 31, 1989. The South Cerolina Public Senvice Authority (SC) changed fiecal year from June 30 to December 31 in 1980. The Utah Aasociated Municipal Power System (UT) changed fiscal year from June 30 to March 31 in 1991 . The City of Marshfield (WI) was a generator in 1989 and 1980, but became a nongenerator in 1991. The Wisconsin Publlc Power Incorporated System (WI) was a nongenerator in 1809 and 1890 , but became a generator in 1991.

Sxurce: Energy Information Administration, Form EIA-412, "Annual Report of Public Electric Utilities." 
Table 23. Number of Consumers, Sales, and Operating Revenue for Major Publicly Owned Generating Electric Utilities, 1989-1991

\begin{tabular}{|c|c|c|c|c|c|c|}
\hline \multirow[b]{2}{*}{ Item } & 1991 & 1990 & 1989 & 1991 & 1990 & 1989 \\
\hline & \multicolumn{3}{|c|}{$\begin{array}{l}\text { Generating Utilities with Financial Year } \\
\text { Ending on June } 30\end{array}$} & \multicolumn{3}{|c|}{$\begin{array}{c}\text { Generating Utilities with Financial Year } \\
\text { Ending on December } 31\end{array}$} \\
\hline \multicolumn{7}{|l|}{ Number of Consumers } \\
\hline 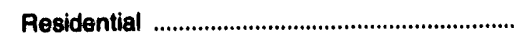 & $2,099,789$ & $2,004,831$ & $2,045,125$ & $2,764,821$ & $2,715,134$ & $2,582,601$ \\
\hline 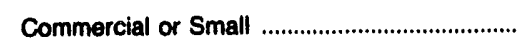 & 234,033 & 237,665 & 303,841 & 364,247 & 359,959 & 336,873 \\
\hline Industrial or Large & 20,265 & 23,732 & 24,026 & 17,030 & 18,626 & 16,447 \\
\hline Other & 20,055 & 24,462 & 19,326 & 38,909 & 35,493 & 30,932 \\
\hline 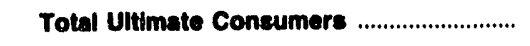 & $2,374,142$ & $2,290,690$ & $2,392,318$ & $3,185,007$ & $3,129,212$ & $2,866,053$ \\
\hline \multicolumn{7}{|l|}{ Sales for the Year (megawatthours) } \\
\hline 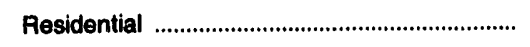 & $12,232,289$ & $12,283,575$ & $12,797,465$ & $30,255,280$ & $29,060,284$ & $27,672,270$ \\
\hline 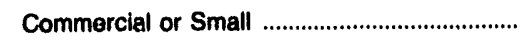 & $18,643,257$ & $19,535,853$ & $19,477,643$ & $22,393,283$ & $21,894,020$ & $20,215,328$ \\
\hline Industrial or Large & $12,451,053$ & $11,657,126$ & $17,450,359$ & $41,800,834$ & $41,714,889$ & $32,954,353$ \\
\hline 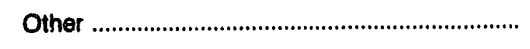 & $2,299,173$ & $2,234,449$ & $2,220,118$ & $11,674,348$ & $11,358,773$ & $11,080,275$ \\
\hline Total Sales to Ultimate Consumers .......... & $45,625,772$ & $45,711,003$ & $51,945,585$ & $106,123,745$ & 104,027,866 & $91,922,226$ \\
\hline Sales for Resale ................................................ & $33,831,354$ & $35,636,950$ & $40,700,200$ & $127,090,088$ & $128,453,278$ & $118,654,857$ \\
\hline Total Sales ........................................................ & $79,457,126$ & $81,347,953$ & $92,645,785$ & $233,213,833$ & $232,481,244$ & $210,577,083$ \\
\hline \multicolumn{7}{|l|}{$\begin{array}{l}\text { Cperating Revenues for the Year } \\
\text { (thousand dollars) }\end{array}$} \\
\hline 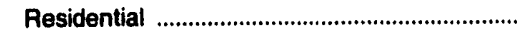 & $1,002,074$ & 998,394 & 993,414 & $1,662,361$ & $1,595,478$ & $1,476,648$ \\
\hline Commercial or Small & $1,469,595$ & $1,576,384$ & $1,478,254$ & $1,182,160$ & $1,136,745$ & $1,044,373$ \\
\hline Industrial or Large & 838,360 & 775,832 & 994,231 & $1,571,144$ & $1,550,851$ & $1,227,393$ \\
\hline Other & 145,979 & 162,520 & 149,472 & 739,838 & 745,745 & 711,863 \\
\hline $\begin{array}{l}\text { Total Rovenues from Sales to } \\
\text { Ultimate Consumers }\end{array}$ & $3,456,008$ & $3,513,130$ & $3,615,371$ & $5,155,503$ & $5,028,810$ & $4,460,277$ \\
\hline 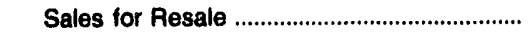 & $1,858,972$ & $1,945,902$ & $1,982,161$ & $4,317,957$ & $4,373,787$ & $4,008,169$ \\
\hline $\begin{array}{l}\text { Total Revenuses From Salos of } \\
\text { Eloctricity }\end{array}$ & $5,314,980$ & $5,459,032$ & $5,597,532$ & $8,473,460$ & $9,402,606$ & $8,468,446$ \\
\hline
\end{tabular}

Note: Totals may not equal sum of components because of independent rounding. Detailed data are provided in Table 42 . The number of generating publicly owned electric utilities for end of period is 53 for June 30, 1991; 52 for June 30, 1990; and 50 for June 30, 1989; and is 110 for December 31. 1991; 110 for December 31, 1990; and 108 for December 31, 1989. The City of Foley (AL) and the South Carolina Public Service Authority (SC) changed fiscal year trom June 30 to December 31 in 1990. The Utah Associated Municipal Power System (UT) changed fiscal year treiii June 30 to March 31 in 1991. The City of Marshfield (WI) was a generator in 1989 and 1990, but became a nongenerator in 1991. The Wisconsin Fublic Power Incorporated System (WI) was a nongenerator in 1989 and 1990, but became a generator in 1991.

Source: Energy Information Administration, Form EIA-861, "Annual Electric Utility Report." Data are based on calendar year submissions. 


\section{Table 24. Electric Energy Account for Major Publicly Owned Generating Electric Utilities, 1989-1991 (Megawatthours)}

\begin{tabular}{|c|c|c|c|c|c|c|}
\hline \multirow[b]{2}{*}{ Item } & 1991 & 1990 & 1989 & 1991 & 1990 & 1989 \\
\hline & \multicolumn{3}{|c|}{$\begin{array}{c}\text { Generating Utilities with Financial Year } \\
\text { Ending on June } 30\end{array}$} & \multicolumn{3}{|c|}{$\begin{array}{c}\text { Generating Utilities with Financial Year } \\
\text { Ending on December } 31\end{array}$} \\
\hline 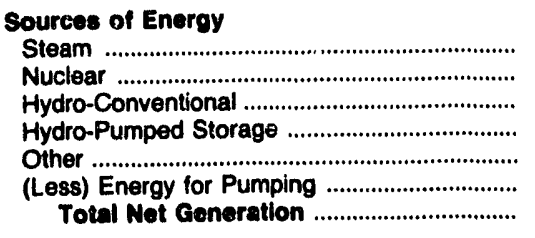 & $\begin{array}{r}35,805,972 \\
9,571,421 \\
5,277,435 \\
1,247,928 \\
777,690 \\
720,925 \\
51,959,522\end{array}$ & $\begin{array}{r}38,852,538 \\
8,156,114 \\
6,663,865 \\
1,158,727 \\
819,236 \\
494,296 \\
55,156,184\end{array}$ & $\begin{array}{r}56,925,918 \\
10,739,246 \\
7,572,745 \\
1,010,187 \\
609,282 \\
608,410 \\
76,248,968\end{array}$ & $\begin{array}{r}66,891,679 \\
36,462,063 \\
67,268,340 \\
2,364,088 \\
1,302,950 \\
2,942,457 \\
171,346,662\end{array}$ & $\begin{array}{r}68,121,001 \\
34,561,351 \\
67,433,345 \\
3,537,783 \\
1,316,570 \\
2,983,818 \\
171,986,234\end{array}$ & $\begin{array}{r}53,992,803 \\
36,125,796 \\
60,581,382 \\
3,048,854 \\
1,374,343 \\
2,995,236 \\
152,127,942\end{array}$ \\
\hline 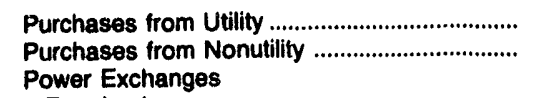 & $\begin{array}{r}36,465,229 \\
60,371\end{array}$ & $\begin{array}{r}33,376,728 \\
54,689\end{array}$ & $\begin{array}{r}23,484,457 \\
4,188\end{array}$ & $\begin{array}{r}76,660,807 \\
925,307\end{array}$ & $\begin{array}{r}78,428,609 \\
864,340\end{array}$ & $\begin{array}{r}73,986,902 \\
779,593\end{array}$ \\
\hline 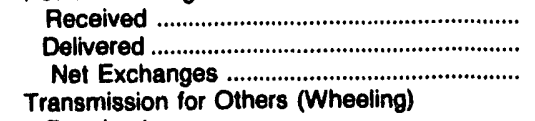 & $\begin{array}{r}1,748,125 \\
1,807,581 \\
-59,456\end{array}$ & $\begin{array}{r}18,533,919 \\
18,905,883 \\
-371,964\end{array}$ & $\begin{array}{r}2,518,889 \\
2,103,502 \\
415,387\end{array}$ & $\begin{array}{l}15,364,045 \\
18,418,514 \\
-3,054,468\end{array}$ & $\begin{array}{l}14,622,676 \\
16,409,072 \\
-1,786,397\end{array}$ & $\begin{array}{r}16,049,716 \\
16,700,782 \\
-651,067\end{array}$ \\
\hline 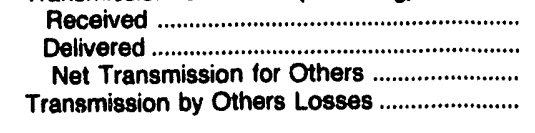 & $\begin{array}{r}17,569,869 \\
17,509,416 \\
60,453 \\
-130,869\end{array}$ & $\begin{array}{r}16,146,595 \\
16,005,354 \\
141,241 \\
-49,401\end{array}$ & $\begin{array}{r}22,123,228 \\
21,842,800 \\
280,428 \\
-\end{array}$ & $\begin{array}{r}6,457,352 \\
6,321,064 \\
136,287 \\
-12,108\end{array}$ & $\begin{array}{r}12,322,641 \\
12,203,547 \\
119,093 \\
-16,107\end{array}$ & $\begin{array}{r}5,160,664 \\
5,074,696 \\
85,968 \\
-\end{array}$ \\
\hline 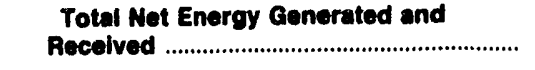 & $88,355,250$ & $88,307,477$ & $100,433,427$ & $246,002,489$ & $249,595,771$ & $226,329,339$ \\
\hline 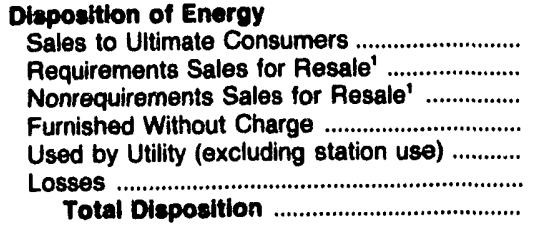 & $\begin{array}{r}45,847,782 \\
34,776,080 \\
759,838 \\
180,152 \\
2,590,094 \\
4,201,299 \\
88,355,250\end{array}$ & $\begin{array}{r}45,230,998 \\
34,269,664 \\
1,695,756 \\
65,996 \\
2,555,266 \\
4,489,797 \\
88,307,477\end{array}$ & $\begin{array}{r}51,859,155 \\
40,284,496 \\
- \\
170,627 \\
3,104,156 \\
5,014,997 \\
100,433,427\end{array}$ & $\begin{array}{r}106,253,382 \\
102,726,112 \\
24,241,019 \\
1,299,635 \\
4,793,554 \\
6,688,779 \\
246,002,489\end{array}$ & $\begin{array}{r}104,050,549 \\
101,969,005 \\
26,484,486 \\
1,474,860 \\
8,867,221 \\
6,749,649 \\
249,595,771\end{array}$ & $\begin{array}{r}91,842,235 \\
118,681,859 \\
- \\
1,385,340 \\
7,954,930 \\
6,454,962 \\
228,329,338\end{array}$ \\
\hline
\end{tabular}

1 The 1989 data were reported as Sales for Resale (one entry) which is shown as Requirements Sales for Resale.

Note: Totals may not equal sum of components because of indeperident rounding. Detailed data are provided in Table 43 . The number of generating publicly owned electric utilities for end of period is 53 for June 30, 1991; 52 for June 30, 1980; and 50 for June 30,1989 ; and is 110 for December 31 , 1991; 110 for December 31, 1990; and 108 for December 31, 1989. The South Carolina Public Service Authority (SC) changed fiscal year from June 30 to December 31 in 1990. The Utah Associated Municipal Power System (UT) changed fiscal year from June 30 to March 31 in 1991 . The City of Marshfield (WI) was a generator in 1989 and 1990, but became a nongenerator in 1991. The Wisconsin Public Power Incorporated System (WVI) was a nongenerator in 1889 and 1990, but became a generator in 1991.

Source: Energy Information Administration, Form EIA-412, "Annual Report of Public Electric Utilities." 
Table 25. Ten Largest Publicly Owned Nongenerating Electric Utilities Ranked by Megawatthour Sales to Ultimate Consumers, June 30, 1991

\begin{tabular}{|c|c|c|}
\hline Publicly Owned Electric Utilities & State & Amount \\
\hline 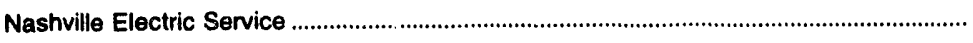 & TN & $9,742,817$ \\
\hline 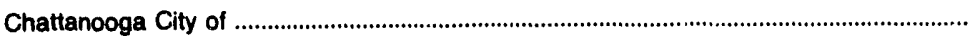 & TN & $5,027,367$ \\
\hline 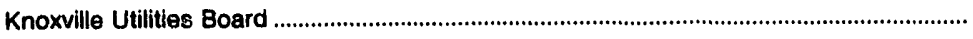 & TN & $4,359,615$ \\
\hline 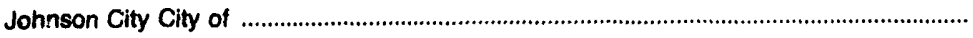 & TN & $1,324,422$ \\
\hline Decatur City of & $A L$ & $1,296,729$ \\
\hline Jackson City of & TN & $1,064,289$ \\
\hline Palo Alto City of & CA & $1,036,788$ \\
\hline 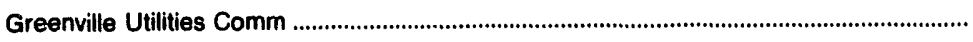 & NC & 969,000 \\
\hline Florence City of & AL & 912,568 \\
\hline Lenoir City City of & TN & 895,016 \\
\hline
\end{tabular}

Source: Energy Information Administration, Form EIA-412, "Annual Report of Public Electric Utilities."

\section{Table 26. Ten Largest Publicly-Owned Nongenerating Electric Utilities Ranked by Megawatthour Sales for Resale, June 30, 1991}

\begin{tabular}{|c|c|c|}
\hline Publicly Owned Elsctric Utilities & State & Amount \\
\hline Colorado River Comm of Nevada & NV & 915,290 \\
\hline Arizona Power Authority & AZ & 833,232 \\
\hline Wilson City of & NC & 59,098 \\
\hline 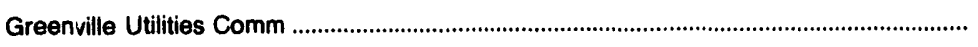 & NC & 22,000 \\
\hline Rocky Mount City of & NC & 15,845 \\
\hline Lodi City of & CA & 9,318 \\
\hline Groton City of & CT & 3,851 \\
\hline Mesa City of & $A Z$ & 1,551 \\
\hline
\end{tabular}

Source: Energy Information Administration, Form EIA-412, "Annual Report of Public Electric Utilities." 
Table 27. Ten Largest Publicly Owned Nongenerating Electric Utilities Ranked by Megawatthour Sales to Uitimate Consumers, December 31, 1991

\begin{tabular}{|c|c|c|}
\hline Puhllely Owned Electric Utulties & State & Amount \\
\hline 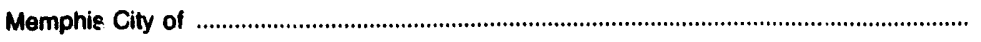 & TN & $11,451,824$ \\
\hline 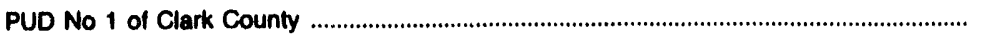 & WA & $3,122,251$ \\
\hline 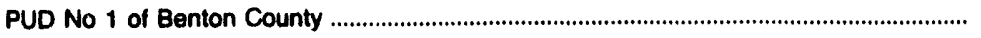 & WA & $1,383,117$ \\
\hline Central Lincoln Peoples UII Dt & OR & $1,367,872$ \\
\hline 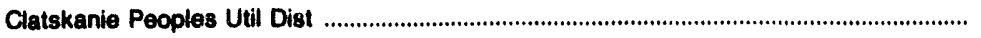 & OR & 881,202 \\
\hline Fort Collins City of & CO & 815,311 \\
\hline Springfield City of & OR & 765,185 \\
\hline Anderson City of & IN & 620,083 \\
\hline 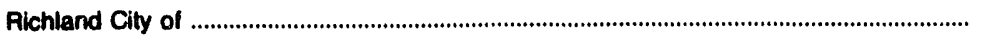 & WA & 596,113 \\
\hline PUD No 1 of Franklin County & WA & 585,237 \\
\hline
\end{tabular}

Source: Energy Information Administration, Form EIA-412, "Annual Report of Public Electric Utilities."

Table 28. Ten Largest Publicly Owned Nongenerating Electric Utilities Ranked by Megawatthour Sales for Resale, December 31, 1991

\begin{tabular}{|c|c|c|}
\hline Publlchy Ownad Elactrle Uturtias & State & Amount \\
\hline 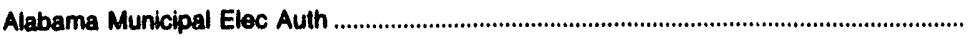 & AL & $2,178,091$ \\
\hline 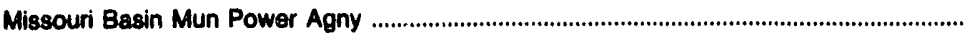 & SD & $1,873,259$ \\
\hline 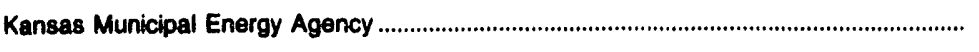 & KS & 394,759 \\
\hline 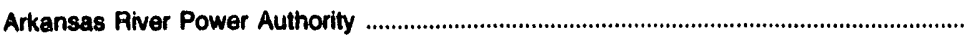 & co & 263,863 \\
\hline 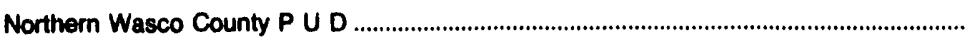 & OR & 23,076 \\
\hline 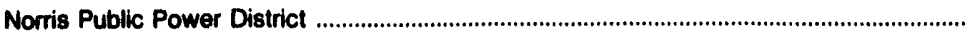 & NE & 14,301 \\
\hline 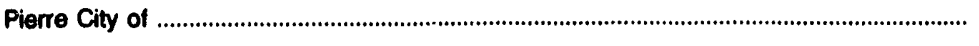 & SD & 9,438 \\
\hline 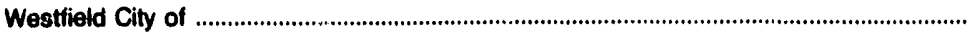 & MA & 7,322 \\
\hline Danvers Town of & MA & 6,392 \\
\hline 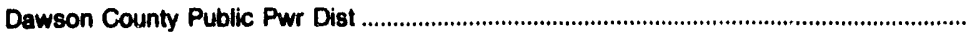 & NE & 5,692 \\
\hline
\end{tabular}

Source: Energy Information Administration, Form ElA-412, "Annual Report of Public Electric Utilities." 
Table 29. Composite Statement of Income for Major Publicly Owned Nongenerating Electric Utilities, 1989-1991 (Thousand Dollars)

\begin{tabular}{|c|c|c|c|c|c|c|}
\hline \multirow[b]{2}{*}{ Item } & 1991 & 1990 & 1389 & 1991 & 1990 & 1989 \\
\hline & \multicolumn{3}{|c|}{$\begin{array}{c}\text { Nongenerating Utilities with Financial Year } \\
\text { Ending on June } 30\end{array}$} & \multicolumn{3}{|c|}{$\begin{array}{c}\text { Nongenerating Utilities with Financial Year } \\
\text { Ending on December } 31\end{array}$} \\
\hline Electric Utilty Operating Revenues ............ & $4,167,470$ & $4,143,051$ & $4,002,283$ & $2,251,181$ & $2,128,674$ & $1,901,801$ \\
\hline 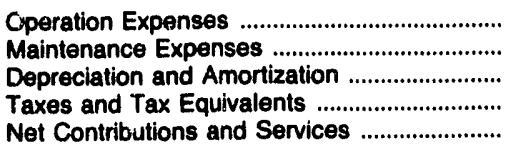 & $\begin{array}{r}3,646,906 \\
104,862 \\
121,975 \\
69,589 \\
106,005\end{array}$ & $\begin{array}{r}3,645,672 \\
111,773 \\
116,224 \\
64,919 \\
88,261\end{array}$ & $\begin{array}{r}3,514,644 \\
108,284 \\
107,743 \\
61,090 \\
103,436\end{array}$ & $\begin{array}{r}1,894,483 \\
63,243 \\
93,189 \\
54,151 \\
35,714\end{array}$ & $\begin{array}{r}1,794,945 \\
63,287 \\
89,010 \\
52,609 \\
35,693\end{array}$ & $\begin{array}{r}1,640,446 \\
59,486 \\
72,264 \\
49,263 \\
30,132\end{array}$ \\
\hline \multicolumn{6}{|l|}{ Total Electric Utility Operating } & $1,851,591$ \\
\hline $\begin{array}{l}\text { Net Electric Utility Operating Income .............. } \\
\text { Income from Electric Plant Leased }\end{array}$ & 118,134 & 116,201 & 107,086 & 110,401 & 93,131 & 50,210 \\
\hline 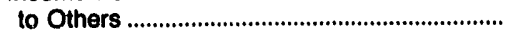 & 1,160 & 695 & 600 & 360 & 424 & 140 \\
\hline Total Electric Utility Operating Income. & 119,293 & 116,896 & 107,685 & 110,761 & 93,555 & 50,350 \\
\hline 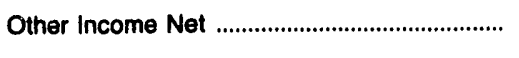 & 73,710 & 76,072 & 84,288 & 51,653 & 54,390 & 60,863 \\
\hline $\begin{array}{l}\text { Other Electric Deductions ................................ } \\
\text { Allowance for Other Funds Used }\end{array}$ & 8,220 & - & - & 4,873 & - & - \\
\hline 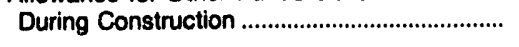 & 1,229 & 130 & 170 & 361 & 562 & 289 \\
\hline Total Electric Utility Income .......................... & 186,012 & 193,098 & 192,143 & 157,902 & 148,506 & 111,502 \\
\hline 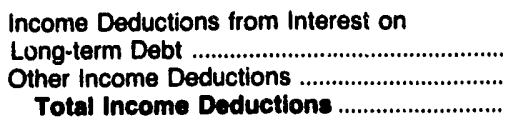 & $\begin{array}{l}43,191 \\
16,967 \\
60,157\end{array}$ & $\begin{array}{l}44,711 \\
14,892 \\
59,602\end{array}$ & $\begin{array}{l}45,145 \\
11,356 \\
56,500\end{array}$ & $\begin{array}{r}61,140 \\
4,724 \\
65,864\end{array}$ & $\begin{array}{r}57,925 \\
5,953 \\
63,878\end{array}$ & $\begin{array}{r}47,579 \\
3,970 \\
51,549\end{array}$ \\
\hline Income Before Extraordinany Items ................. & 125,855 & 133,496 & 135,643 & 92,038 & 84,628 & 59,953 \\
\hline 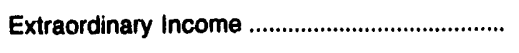 & 21,330 & 2,541 & 2,033 & 1,973 & 2,558 & 24,423 \\
\hline 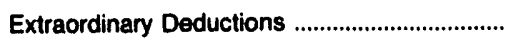 & 19,747 & 13,024 & 4,226 & 5,426 & 240 & 4,916 \\
\hline 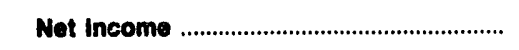 & 127,438 & 123,012 & 133,451 & 88,585 & 86,947 & 79,461 \\
\hline
\end{tabular}

- Data not available.

Note: Totals may not equal sum of components because of independent rounding. Detailed data are provided on Table 38 . The number of nongenerating publicly owned electric utilities for end of period is 135 for June 30, 1991; 136 for June 30, 1990; and 135 for June 30 , 1989 ; and is 86 for December 31, 1991; 84 for December 31, 1990; and 77 for December 31, 1989. The City of Foley (AL) changed fiscal year from June 30 to December 31 in 1990. The Wisconsin Public Power Incorporated System (WI) was a nongenerator in 1989 and 1990, but became a generator in 1991. The City of Marshfield (WI) was a generator in 1989 and 1990, but became a nongenerator in 1991.

Source: Energy Information Administration, Form EIA-412, "Annual Report of Public Electric Utilities." 
Table 30. Composite Balance Sheet for Major Publicly Owned Nongenerating Electric Utilities at End of Period, 1989-1991 (Thousand Dollars)

\begin{tabular}{|c|c|c|c|c|c|c|}
\hline \multirow[b]{2}{*}{ Item } & 1991 & 1990 & 1989 & 1991 & 1990 & 1989 \\
\hline & \multicolumn{3}{|c|}{$\begin{array}{l}\text { Nongenerating Utilities with Financial } \\
\text { Year Ending on June } 30\end{array}$} & \multicolumn{3}{|c|}{$\begin{array}{l}\text { Nongenerating Utilities with Financial } \\
\text { Year Ending on December } 31\end{array}$} \\
\hline \multicolumn{7}{|l|}{ Eloctric Utility Plant } \\
\hline $\begin{array}{l}\text { Total Electric Utility Plant .................................... } \\
\text { (less) Depr, Amort, and Depletion .................. } \\
\text { Net Electric Utility Plant ............................... } \\
\text { Other Property \& Investments }\end{array}$ & $\begin{array}{l}3,793,405 \\
1,356,953 \\
2,436,453\end{array}$ & $\begin{array}{l}3,563,010 \\
1,257,905 \\
2,305,105\end{array}$ & $\begin{array}{l}3,364,686 \\
1,175,271 \\
2,189,415\end{array}$ & $\begin{array}{l}2,852,226 \\
1,035,792 \\
1,816,434\end{array}$ & $\begin{array}{r}2,670,370 \\
960,118 \\
1,710,253\end{array}$ & $\begin{array}{r}2,432,306 \\
858,220 \\
1,574,086\end{array}$ \\
\hline 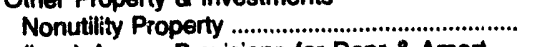 & $1,025,569$ & $1,057,341$ & $1,011,306$ & 198,098 & 159,993 & 159,012 \\
\hline $\begin{array}{l}\text { (less) Accum Provisions for Depr \& Amort.... } \\
\text { Advances to Municipality ........................................ }\end{array}$ & $\begin{array}{r}224,761 \\
9,821\end{array}$ & $\begin{array}{r}223,212 \\
9,969\end{array}$ & $\begin{array}{r}197,865 \\
6,018\end{array}$ & $\begin{array}{r}45,858 \\
99\end{array}$ & $\begin{array}{r}35,068 \\
525\end{array}$ & $\begin{array}{r}39.158 \\
788\end{array}$ \\
\hline $\begin{array}{l}\text { Invest \& Special Funds } \\
\text { Total Other Property \& Inveatments }\end{array}$ & $\begin{array}{r}342,179 \\
1,152,807\end{array}$ & $\begin{array}{r}326,036 \\
1,170,135\end{array}$ & $\begin{array}{r}339,994 \\
1,150,453\end{array}$ & $\begin{array}{l}370,683 \\
\mathbf{5 2 3 , 0 2 1}\end{array}$ & $\begin{array}{l}306,116 \\
438,566\end{array}$ & $\begin{array}{l}274,650 \\
395,293\end{array}$ \\
\hline \\
\hline & 288,307 & 187,788 & 138,658 & $183, r 98$ & 135,393 & 123,351 \\
\hline & $\begin{array}{l}317,896 \\
407,593\end{array}$ & $\begin{array}{l}401,063 \\
442,893\end{array}$ & $\begin{array}{l}429,668 \\
425,002\end{array}$ & $\begin{array}{l}179,622 \\
213,514\end{array}$ & $\begin{array}{l}136,255 \\
196,520\end{array}$ & $\begin{array}{l}157,305 \\
192,355\end{array}$ \\
\hline Notes \& Áccounts Recoivable & $\begin{array}{r}407,593 \\
10,519\end{array}$ & $\begin{array}{r}442,883 \\
8,962\end{array}$ & $\begin{array}{r}420,002 \\
9,480\end{array}$ & 7,590 & 6,807 & $\begin{array}{r}192,355 \\
6,626\end{array}$ \\
\hline & $\begin{array}{l}10,519 \\
23,858\end{array}$ & 23,445 & 18,932 & 22,330 & 19,191 & $\begin{array}{l}0,020 \\
5,743\end{array}$ \\
\hline & 82,498 & 83,405 & 86,000 & 67,872 & 67,040 & 62,867 \\
\hline & 20,390 & 44,432 & 38,564 & 83,368 & 85,744 & 10,138 \\
\hline Miscellaneous Current \& Accrued Assets ..... & 33,666 & 16,127 & $\begin{array}{r}30,200 \\
\end{array}$ & 27,160 & 24,173 & 33,421 \\
\hline $\begin{array}{l}\text { Total Current A Accrued Aseats .................. } \\
\text { Deferred Debits }\end{array}$ & $1,163,690$ & $1,190,190$ & $1,158,545$ & 768,834 & 657,510 & 578,555 \\
\hline \multicolumn{6}{|l|}{ Deferred Debits } & \\
\hline 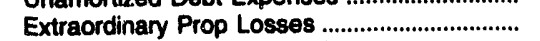 & & & - & 20,010 & 20,014 & $\begin{array}{r}15,817 \\
-\end{array}$ \\
\hline 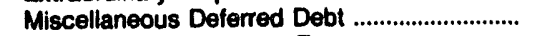 & 120,021 & 106,381 & 109,797 & 29,411 & 21,459 & 35,034 \\
\hline Research, Dev \& Demo Expenses ..................... & & & 331 & 3,403 & 4,271 & 3,403 \\
\hline Unamort Loss on Reacquired Debt ..................... & 10,351 & 10,750 & 10,079 & 1,430 & 934 & 8,139 \\
\hline Other & 40,659 & 13,598 & 10,199 & 46.401 & 48,228 & 19,132 \\
\hline 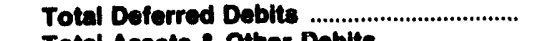 & 211,527 & 165,426 & $\begin{array}{r}163,442 \\
1670,955\end{array}$ & 106,520 & $\begin{array}{r}101,508 \\
200096\end{array}$ & 81,524 \\
\hline \multirow{2}{*}{\multicolumn{6}{|c|}{ 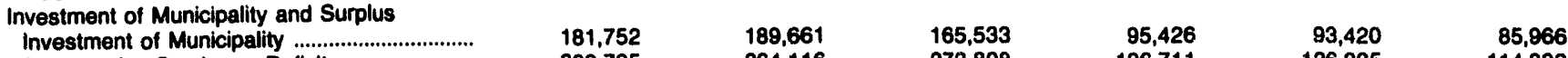 }} & $2,628,458$ \\
\hline & 181,752 & 189,661 & 165,533 & 95,426 & 93,420 & 85,866 \\
\hline 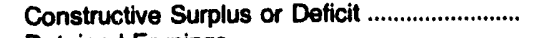 & 309,795 & 264,116 & 273,808 & $\begin{array}{r}136,711 \\
1\end{array}$ & 126,335 & 114,893 \\
\hline & $2,464,326$ & $2,400,616$ & $2,262,249$ & $1,512,670$ & $1,410,735$ & $1,305,678$ \\
\hline \\
\hline & $1,021,581$ & $1,014,631$ & $1,044,629$ & $1,011,891$ & 838,541 & 698,437 \\
\hline 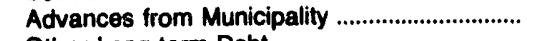 & 30,970 & 29,550 & 51,191 & $\mathbf{6 , 6 1 8}$ & 3,199 & 2,895 \\
\hline 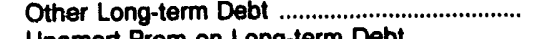 & $\begin{array}{r}275,430 \\
1,317\end{array}$ & 278,095 & $\begin{array}{r}258,253 \\
1,076\end{array}$ & $\begin{array}{r}51,982 \\
7\end{array}$ & $\begin{array}{r}47.784 \\
5\end{array}$ & 53,704 \\
\hline Unamort Prem on Long-term Debt ........... & $\begin{array}{r}1,317 \\
14,848\end{array}$ & $\begin{array}{r}994 \\
15,471\end{array}$ & $\begin{array}{r}1,076 \\
16,393\end{array}$ & $\begin{array}{r}7 \\
1,283\end{array}$ & $\begin{array}{r}5 \\
1,464\end{array}$ & $\begin{array}{r}5 \\
5.312\end{array}$ \\
\hline $\begin{array}{l}\text { (less) Unamort Discount on Long-term Debt } \\
\text { Total Long-term Debt }\end{array}$ & $1,314,349$ & $1,307,790$ & $1,338,756$ & $1,069,215$ & $\begin{array}{r}1,464 \\
888,064\end{array}$ & $\begin{array}{r}5,312 \\
749,730\end{array}$ \\
\hline \multicolumn{7}{|l|}{ Other Noncurrent Liabilities } \\
\hline 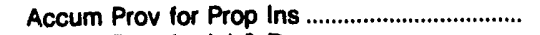 & 1,396 & 1,112 & 2,455 & 7,368 & 7,187 & 6,613 \\
\hline 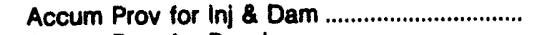 & 815 & 1,367 & 818 & 2,034 & 2,400 & 2,786 \\
\hline 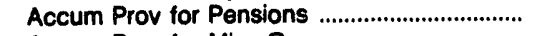 & 13,421 & 1,675 & 1,950 & 15,263 & 11,377 & 8,834 \\
\hline 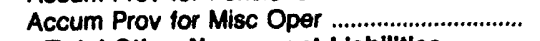 & 2,846 & 2,378 & 5,041 & 11,926 & 10,037 & 11,251 \\
\hline \multirow{2}{*}{\multicolumn{3}{|c|}{ Current and Accrued Liabilities }} & 10,264 & $\mathbf{3 6 , 5 9 0}$ & 31,001 & 29,484 \\
\hline & 23,134 & 27,149 & 22,272 & & 18,660 & 13,914 \\
\hline Accounts Payable & 358,975 & 359,439 & 335,341 & 192,092 & 192,249 & 188,613 \\
\hline 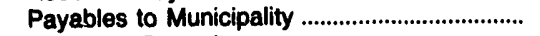 & 24,142 & 17,759 & 24,095 & 1,898 & 1,914 & 2,043 \\
\hline 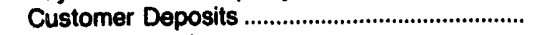 & 79,605 & 71,803 & 66,386 & 15,768 & 15,059 & 12,557 \\
\hline 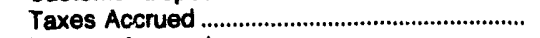 & 25,935 & 8,172 & 8,375 & 10,501 & 9,238 & 9,044 \\
\hline Interest Accrued & 27,387 & 38,542 & 26,363 & 10,514 & 9,736 & 8,719 \\
\hline 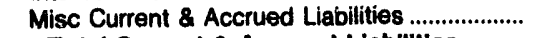 & 40,828 & 45,490 & 40,422 & 34,968 & 34,715 & 35,723 \\
\hline Total Current \& Accrued Llabilities .......... & 580,007 & 568,354 & 523,253 & 290,214 & 281,571 & 270,611 \\
\hline \multicolumn{7}{|l|}{ Deferred Credits } \\
\hline 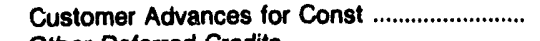 & 3,597 & 3,523 & 3,268 & 35,394 & 30,221 & 25,316 \\
\hline 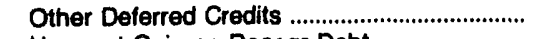 & 81,505 & 90,243 & 93,671 & 37,365 & 39,404 & 43,032 \\
\hline 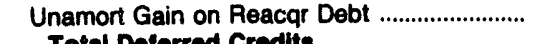 & 666 & & 52 & 1,224 & 85 & 4,748 \\
\hline 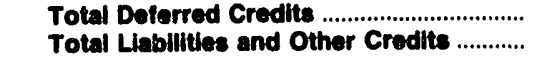 & $\begin{array}{r}95,769 \\
4,964,477\end{array}$ & $\begin{array}{r}93,778 \\
4,830,856\end{array}$ & $\begin{array}{r}86,992 \\
4,670,855\end{array}$ & $\begin{array}{r}73,992 \\
3,214,809\end{array}$ & $\begin{array}{r}69,710 \\
2,900,836\end{array}$ & $\begin{array}{r}73,096 \\
2,629,458\end{array}$ \\
\hline
\end{tabular}

Note: Totals may not equal sum of components because of independent rounding. Detailed data are provided on Table 39 . The number of nongenerating publicly owned electric utilities for end of period is 135 for June 30, 1991; 136 for June 30, 1990; and 135 for June 30, 1989; and is 86 for December 31, 1991; 84 for December 31, 1990; and 77 for December 31, 1989. The City of Foley (AL) changed fiscal year from June 30 to December 31 in 1990. The Wisconsin Public Power Incorporated System (WI) was a nongenerator in 1989 and 1990, but became a generator in 1991. The City of Marshfield (WI) was a generator in 1989 and 1990, but became a nongenerator in 1991.

Source: Energy Information Administration, Form EIA-412, "Annual Report of Public Electric Utilities." 
Table 31. Composite Financial Indicators for Major Publicly Owned Nongenerating Electric Utilities, 1989-1991

\begin{tabular}{|c|c|c|c|c|c|c|}
\hline & 1991 & 1990 & 1989 & 1991 & 1990 & 1989 \\
\hline Item & \multicolumn{3}{|c|}{$\begin{array}{l}\text { Nongenerating Utilities with Financial } \\
\text { Year Ending on June } 30\end{array}$} & \multicolumn{3}{|c|}{$\begin{array}{l}\text { Nongenerating Utilities with Financial } \\
\text { Year Ending on December } 31\end{array}$} \\
\hline $\begin{array}{l}\text { Total Electric Utility Plant per Dollar of } \\
\text { Revenue . }\end{array}$ & 0.9 & 0.9 & 0.8 & 1.3 & 1.3 & 1.3 \\
\hline Current Assets to Current Liabilities ..................... & 2.0 & 2.1 & 2.2 & 2.6 & 2.3 & 2.1 \\
\hline 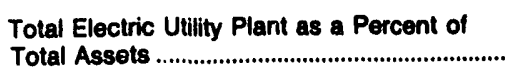 & 76.4 & 73.8 & 72.0 & 88.7 & 92.1 & 92.5 \\
\hline $\begin{array}{l}\text { Net Electric Utility Plant as a Percent of } \\
\text { Total Assets }\end{array}$ & 49.1 & 47.7 & 46.9 & 56.5 & 59.0 & 59.9 \\
\hline $\begin{array}{l}\text { Depreciation, Amortization and Depletion } \\
\text { as a Percent of Total Electric Utility Plant. }\end{array}$ & 35.8 & 35.3 & 34.9 & 36.3 & 36.0 & 35.3 \\
\hline $\begin{array}{l}\text { Electric Operation and Maintenance } \\
\text { Expenses as a Percent of } \\
\text { Electric Utility Operating Revenues ................ }\end{array}$ & 80.0 & 90.7 & 90.5 & 87.0 & 87.3 & 89.4 \\
\hline $\begin{array}{l}\text { Electric Depreciation and Amortization as a } \\
\text { Percent of } \\
\text { Electric Utility Operating Revenues ................. }\end{array}$ & 2.9 & 2.8 & 2.7 & 4.1 & 4.2 & 3.8 \\
\hline $\begin{array}{l}\text { Taxes and Tax Equivalents as a Percent of } \\
\text { Electric Utility Operating Revenues .................... }\end{array}$ & 1.7 & 1.6 & 1.5 & 2.4 & 2.5 & 2.6 \\
\hline $\begin{array}{l}\text { Net Contributions and Services as a Percent } \\
\text { ofof Electric Utility Operating Revenues ......... }\end{array}$ & 2.5 & 2.1 & 2.6 & 1.6 & 1.7 & 1.6 \\
\hline $\begin{array}{l}\text { Interest on Long-term Debt as a Percent of } \\
\text { Electric Utility Operating Revenues .................. }\end{array}$ & 1.0 & 1.1 & 1.1 & 2.7 & 2.7 & 2.5 \\
\hline
\end{tabular}


Table 32. Electric Operation and Maintenance Expenses for Major Publicly Owned Nongenerating Electric Utilities, 1989-1991 (Thousand Dollars)

\begin{tabular}{|c|c|c|c|c|c|c|}
\hline \multirow[b]{2}{*}{ Item } & 1991 & 1990 & 1989 & 1991 & 1990 & 1989 \\
\hline & \multicolumn{3}{|c|}{$\begin{array}{c}\text { Non-Generating Utilities with Financial } \\
\text { Year Ending on June } 30\end{array}$} & \multicolumn{3}{|c|}{$\begin{array}{c}\text { Non-Generating Utilities with Financial } \\
\text { Year Ending on December } 31\end{array}$} \\
\hline \multicolumn{7}{|l|}{ Production Expenses } \\
\hline Steam Power Generation ................................... & - & - & - & 544 & 230 & 263 \\
\hline 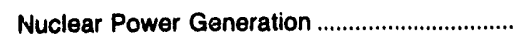 & - & - & - & - & - & - \\
\hline Hydraulic Power Generation ............................... & - & - & - & - & - & - \\
\hline Other Power Generation ................................... & - & - & 1,802 & 97 & 105 & - \\
\hline 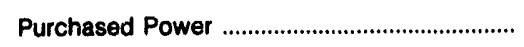 & $3,339,710$ & $3,352,355$ & $3,118,544$ & $1,648,190$ & $1,538,236$ & $1,414,003$ \\
\hline Other Production Expenses ............................ & 6,949 & 12,356 & 4,817 & 7,326 & 36,240 & 31,211 \\
\hline Total Production Expenses .......................... & $3,346,659$ & $3,364,711$ & $3,125,163$ & $1,656,156$ & $1,574,811$ & $1,445,478$ \\
\hline 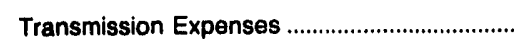 & 13,330 & 11,290 & 10,515 & 20,321 & 22,677 & 17,736 \\
\hline 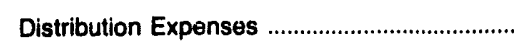 & 167,664 & 159,815 & 241,118 & 125,756 & 114,903 & 103,496 \\
\hline Customer Accounts Expenses .......................... & 60,355 & 59,192 & 55,808 & 37,058 & 36,105 & 33,759 \\
\hline Customer Service and Information Expenses & 9,006 & 8,043 & 8,011 & 5,280 & 4,879 & 4,695 \\
\hline Sales Expenses & 9,731 & 9,635 & 3,690 & 1,582 & 1,483 & 1,743 \\
\hline Administrative and General Expenses ........... & 145,023 & 144,759 & 178,624 & 111,572 & 103,374 & 93,025 \\
\hline $\begin{array}{l}\text { Total Electric Operation } \\
\text { and Maintenance Expenses }\end{array}$ & $3,751,767$ & $3,757,445$ & $3,622,929$ & $1,957,726$ & $1,858,231$ & $1,699,932$ \\
\hline
\end{tabular}

Note: Totals may not equal sum of components because of independent rounding. Detailed data are provided on Table 40 . The number of nongenerating publicly owned electric utilities for end of period is 135 for June 30, 1991; 136 for June 30, 1990; and 135 for June 30, 1989; and is 86 for December 31, 1991; 84 for December 31, 1990; and 77 for December 31, 1989. The City of Foley (AL) and changed fiscal year from June 30 to December 31 in 1990. The Wisconsin Public Power Incorporated System (WI) was a nongenerator in 1989 and 1990, but became generator in 1991. The City of Marshfield (WI) was a generator in 1989 and 1990, but became a nongenerator in 1991.

Source: Energy Information Administration, Form ElA-412, "Annual Report of Public Electric Utilities." 
Table 33. Electric Utility Plant for Major Publicly Owned Nongenerating Electric Utilities at End of Period, 1989-1991 (Thousand Dollars)

\begin{tabular}{|c|c|c|c|c|c|c|}
\hline \multirow[b]{2}{*}{ Item } & 1991 & 1990 & 1989 & 1991 & 1980 & 1989 \\
\hline & \multicolumn{3}{|c|}{$\begin{array}{l}\text { Nongenerating Utllities with Financial } \\
\text { Year Ending on June } 30\end{array}$} & \multicolumn{3}{|c|}{$\begin{array}{l}\text { Nongenerating Utilties with Financial } \\
\text { Year Ending on December } 31\end{array}$} \\
\hline \multicolumn{7}{|l|}{ Eloctric Plant in Earvice } \\
\hline 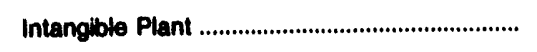 & 1 & 1 & 1 & 7,860 & 7,015 & 6,854 \\
\hline \multicolumn{7}{|l|}{ Production Plant } \\
\hline 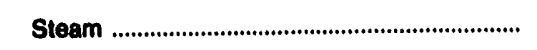 & 40,412 & 286 & 39,768 & 27,651 & 26,928 & 31,281 \\
\hline Nuclear & - & - & - & - & - & $\ddot{*}$ \\
\hline 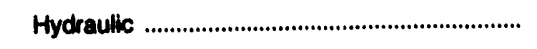 & - & - & - & 582 & 582 & 582 \\
\hline Other & 12,622 & 46,445 & 12,796 & 6,541 & 2,162 & 2,158 \\
\hline Totel Production Pient ................................. & 53,034 & 46,731 & 52,564 & 34,874 & 29,873 & 34,021 \\
\hline 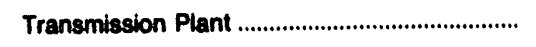 & 303,770 & 225,936 & 213,418 & 251,496 & 242,341 & 214,584 \\
\hline 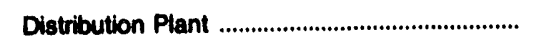 & $2,665,391$ & $2,534,520$ & $2,383,745$ & $2,060,843$ & $1,924,956$ & $1,753,797$ \\
\hline 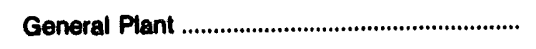 & 657,870 & 624,449 & 579,758 & 346,682 & 332,205 & 298,721 \\
\hline Totel Eloctric Plant in Eervice ................... & $3,680,067$ & $3,431,637$ & $3,230,487$ & $2,701,656$ & $2,536,190$ & $2,307,977$ \\
\hline Electric Plant Leased to Others ........................ & - & - & - & 662 & 708 & 640 \\
\hline Construction Work in Progress - Electric ........ & 91,741 & 107,001 & 88,806 & 103,286 & 88,870 & 75,729 \\
\hline Electric Plant Held for Future Use .................... & 3,207 & 1,195 & 592 & 10,653 & 10,197 & 10,046 \\
\hline Electric Plant Acquisition Adjustments ............ & 16,391 & 23,178 & 25.702 & 35,860 & 33,407 & 37,014 \\
\hline Totel Electric Utinty Plent ........................... & $3,793,405$ & $3,583,010$ & $3,384,686$ & $2,052,228$ & $2,670,370$ & $2,432,306$ \\
\hline 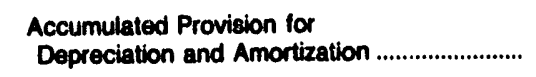 & $1,356,953$ & $1,257,905$ & $1,175,271$ & $1,035,792$ & 860,118 & 858,220 \\
\hline 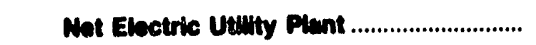 & $2,436,453$ & $2,305,105$ & $2,189,415$ & $1,816,434$ & $1,710,253$ & $1,574,098$ \\
\hline
\end{tabular}

Note: Totals may not equal sum of components because of independent rounding. Detailed data are provided on Table 41. The number of nongenerating publicly owned electric utilities for end of period is 135 for June 30, 1991; 136 for June 30, 1980; and 135 for June 30, 1889; and is 86 for December 31, 1991; 84 for December 31, 1990; and 77 for December 31, 1889. The City of Foley (AL) changed fiecal year from June 30 to December 31 in 1890. The Wisconsin Public Power incorporated System (WI) was a nongenerator in 1989 and 1980, but became a generator in 1991. The City of Marshtield (Wi) was a generator in 1889 and 1980, but became a nongererator in 1991.

Source: Energy Information Administration, Form ElA-412, "Annual Report of Public Electric Uitities." 
Table 34. Number of Consumers, Sales, and Operating Revenue for Major Publicly Owned Nongenerating Electric Utilities, 1989-1991

\begin{tabular}{|c|c|c|c|c|c|c|}
\hline \multirow[b]{2}{*}{ Item } & 1991 & 1990 & 1989 & 1991 & 1990 & 1909 \\
\hline & \multicolumn{3}{|c|}{$\begin{array}{c}\text { Nongenerating Utilities with Financial Year } \\
\text { Ending on June } 30\end{array}$} & \multicolumn{3}{|c|}{$\begin{array}{c}\text { Nongenerating Utilities with Financial Year } \\
\text { Ending on December } 31\end{array}$} \\
\hline \multicolumn{7}{|l|}{ Number of Consumers } \\
\hline 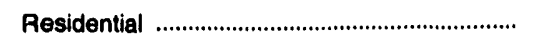 & $2,043,331$ & $2,014,320$ & $1,994,724$ & $1,215,874$ & $1,187,590$ & $1,131,699$ \\
\hline Commercial or Small & 304,983 & 299,578 & 274,668 & 146,187 & 143,435 & 131,239 \\
\hline Industrial or Large & 21,272 & 22,680 & 26,840 & 6,913 & 6,824 & 6,583 \\
\hline Other & 37,337 & 39,318 & 37,810 & 58,258 & 54,952 & 51,921 \\
\hline Total Uitimate Consumer .............................. & $2,406,923$ & $2,375,896$ & $2,334,042$ & $1,427,232$ & $1,392,801$ & $1,321,442$ \\
\hline \multicolumn{7}{|l|}{ Sales for the Year (megawatthours) } \\
\hline 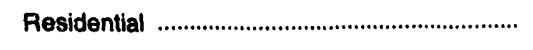 & $26,467,624$ & $25,874,718$ & $25,712,773$ & $15,659,505$ & $14,897,373$ & $14,093,218$ \\
\hline Commercial or Small & $12,926,802$ & $12,284,981$ & $10,997,593$ & $11,332,825$ & $10,868,836$ & $10,243,430$ \\
\hline Industrial or Large & $30,010,647$ & $29,889,490$ & $29,509,416$ & $11,090,867$ & $10,624,836$ & $10,064,758$ \\
\hline Other & $1,335,152$ & $1,319,707$ & $1,402,238$ & $1,432,510$ & $1,400,762$ & $1,312,076$ \\
\hline Total Sales to Uitimate Consumers ........... & $70,740,225$ & $69,368,896$ & $67,622,020$ & $39,515,707$ & $37,791,807$ & $35,713,482$ \\
\hline 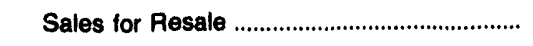 & $1,729,566$ & $4,488,088$ & $4,318,625$ & $4,786,485$ & $4,517,100$ & $2,070,272$ \\
\hline Total Sales ...................................................... & $72,469,791$ & $73,856,984$ & $71,940,645$ & $44,302,192$ & $42,308,907$ & $37,783,754$ \\
\hline \multicolumn{7}{|l|}{$\begin{array}{l}\text { Operating Revenues for the Year } \\
\text { (thousand dollars) }\end{array}$} \\
\hline 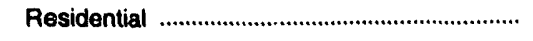 & $1,607,450$ & $1,569,090$ & $1,539,650$ & 859,173 & 814,217 & 761,718 \\
\hline Commercial or Small & 874,603 & 825,242 & 740,813 & 625,575 & 596,333 & 560,246 \\
\hline Industrial or Large & $1,539,511$ & $1,532,962$ & $1,509,668$ & 464,741 & 444,333 & 423,850 \\
\hline Other & 100,996 & 98,548 & 95,912 & 79,256 & 75,527 & 70,472 \\
\hline $\begin{array}{l}\text { Total Revenues from Sales to } \\
\text { Ultimate Consumars }\end{array}$ & $4,122,560$ & $4,025,842$ & $3,886,043$ & $2,028,745$ & $1,930,410$ & $1,816,286$ \\
\hline 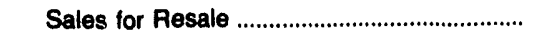 & 34,291 & 128,216 & 116,892 & 164,736 & 152,081 & 76,877 \\
\hline $\begin{array}{l}\text { Total Revenues From Sales of } \\
\text { Electricity }\end{array}$ & $4,156,851$ & $4,154,058$ & $4,002,935$ & $2,193,481$ & $2,082,491$ & $1,893,163$ \\
\hline
\end{tabular}

Note: Totals may not equal sum of components because of independent rounding. Detailed data are provided on Table 42 . The number of nongenerating publicly owned electric utilities for end of period is 135 for June 30, 1991; 136 for June 30, 1990; and 135 for June 30, 1989 ; and is 86 for December 31, 1991; 84 for December 31, 1990; and 77 for December 31, 1989. The City of Foley (AL) changed fiscal year from June 30 to December 31 in 1990. The Wisconsin Public Power Incorporated System (WI) was a nongenerator in 1989 and 1990, but became a generator in 1991. The City of Marshfield (WI) was a generator in 1989 and 1990, but became a nongenerator in 1991.

Source: Energy Information Administration, Form EIA-861, "Annual Electric Utility Report." Data are based on calendar year submissions. 


\section{Table 35. Electric Energy Account for Major Publicly Owned Nongenerating Electric Utilities, 1989-1991 \\ (Megawatthours)}

\begin{tabular}{|c|c|c|c|c|c|c|}
\hline \multirow[b]{2}{*}{ Item } & 1991 & 1990 & 1989 & 1991 & 1990 & 1989 \\
\hline & \multicolumn{3}{|c|}{$\begin{array}{l}\text { Nongenerating Utilities with Financial } \\
\text { Year Ending on June } 30\end{array}$} & \multicolumn{3}{|c|}{$\begin{array}{l}\text { Nongenerating Utilities with Financial } \\
\text { Year Ending on December } 31\end{array}$} \\
\hline \multicolumn{7}{|l|}{ Sources of Energy } \\
\hline & - & - & - & - & - & - \\
\hline & - & - & - & - & - & - \\
\hline 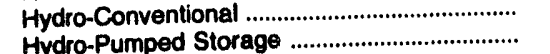 & - & - & - & - & - & - \\
\hline & - & - & - & - & - & - \\
\hline & - & - & - & - & - & - \\
\hline 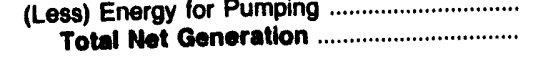 & - & - & - & - & - & - \\
\hline 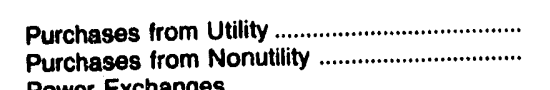 & $\begin{array}{r}75,437,318 \\
2,040\end{array}$ & $\begin{array}{r}76,601,551 \\
2,000\end{array}$ & $\begin{array}{r}74,896,969 \\
-\end{array}$ & $\begin{array}{r}45,754,785 \\
318,282\end{array}$ & $\begin{array}{r}44,246,921 \\
5,865\end{array}$ & $\begin{array}{r}39,792,406 \\
2,345\end{array}$ \\
\hline $\begin{array}{l}\text { Power Exchanges } \\
\text { Received }\end{array}$ & - & 17 & 30 & 289,014 & 67,326 & 274,542 \\
\hline 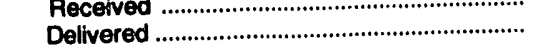 & - & $\overline{7}$ & - & 202,905 & 22,994 & 268,065 \\
\hline Net Exchanges ......................................... & - & 17 & 30 & 86,109 & 44,332 & 6,476 \\
\hline Transmission for Others (Wheeling) & - & - & - & 7,164 & 8,071 & 14,484 \\
\hline Received & - & - & - & 7,164 & 8,825 & 6,681 \\
\hline & - & - & - & - & -754 & 7,803 \\
\hline Transmission by Others Losses ........................ & - & - & - & - & - & - \\
\hline 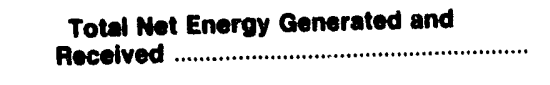 & $75,439,358$ & $76,603,568$ & $74,896,999$ & $46,159,176$ & $44,296,364$ & $39,809,034$ \\
\hline 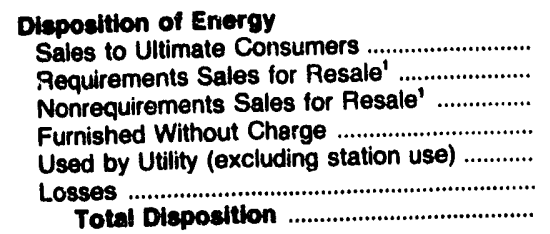 & $\begin{array}{r}70,032,792 \\
1,860,185 \\
- \\
67,296 \\
128,449 \\
3,350,648 \\
75,439,358\end{array}$ & $\begin{array}{r}69,035,099 \\
4,228,709 \\
- \\
44,395 \\
129,036 \\
3,166,319 \\
76,603,568\end{array}$ & $\begin{array}{r}67,340,630 \\
4,016,600 \\
- \\
87,31 \overline{8} \\
116,177 \\
3,336,278 \\
74,896,999\end{array}$ & $\begin{array}{r}39,512,479 \\
3,775,557 \\
1,010,926 \\
78,966 \\
54,114 \\
1,727,132 \\
46,159,176\end{array}$ & $\begin{array}{r}37,790,731 \\
3,517,537 \\
999,561 \\
86,114 \\
67,227 \\
1,835,182 \\
44,296,364\end{array}$ & $\begin{array}{r}35,735,573 \\
2,051,847 \\
- \\
83,438 \\
67,065 \\
1,871,106 \\
39,809,034\end{array}$ \\
\hline
\end{tabular}

1 The 1989 data were reported as Sales for Resale (one entry) which is shown as Requirements Sales for Resale.

Nete Tota may not equal sum of components of non-

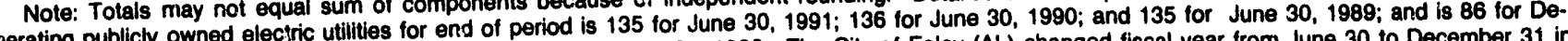
generating publicly owned electric utilities for end of period is 135 for June 30 . The City of Foley (AL) changed fiscal year from June 30 to December 31 in cember 31, 1991; 84 for December 31, 1990; and 77 for December 31, 1989. The City of Foley (AL) changed but became a generator in 1991. The City of 1990. The Wisconsin Public Power Incorporated System (WI) was a nongenerator in 19

Marshfield (WI) was a generator in 1989 and 1990, but became a nongeneralor in
Source: Energy Information Administration, Form ElA-412, "Annual Report of Public Electric Utilities." 


\section{Detailed Statistics of Major Publicly Owned Electric Utilities}

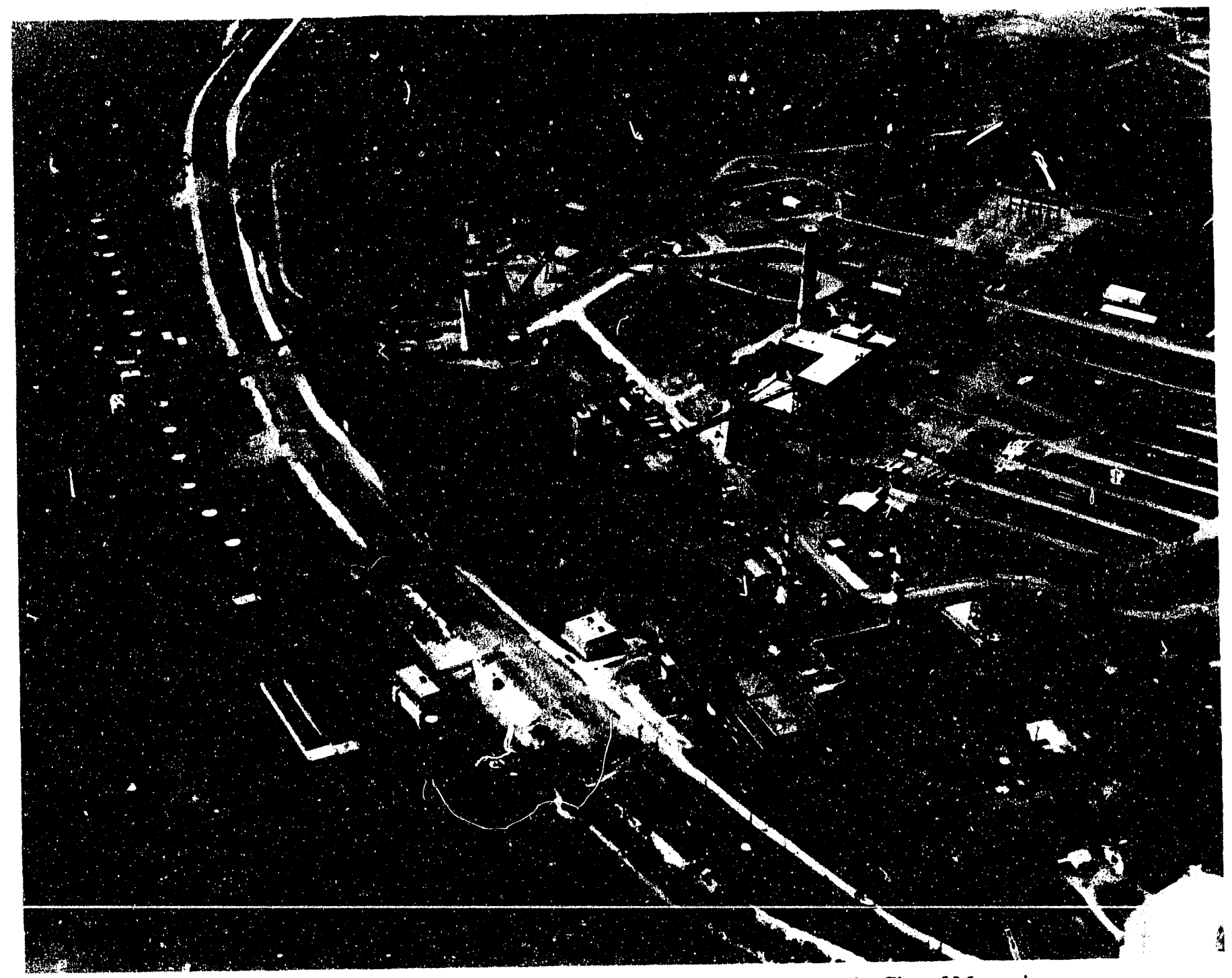

The Muscatine 'Plant, a coal fired plant, is located near Muscatire, lowa, and owned by the City of Muscatine. 


\section{Table 36. Statement of Income by Major Publicly Owned Electric Utility Within State, 1991}

(Thousand Dollars)

\begin{tabular}{|c|c|c|c|c|c|c|}
\hline Item & $\begin{array}{l}\text { Alabama } \\
\text { Alabama } \\
\text { Municipal } \\
\text { Elec Auth } \\
\text { December } 31\end{array}$ & $\begin{array}{l}\text { Alabama } \\
\text { Albertville } \\
\text { Municipai } \\
\text { Utils Bd } \\
\text { June } 30\end{array}$ & $\begin{array}{c}\text { Alabama } \\
\text { Andalusia } \\
\text { City of } \\
\text { September } 30\end{array}$ & $\begin{array}{c}\text { Alabama } \\
\text { Athens } \\
\text { City of } \\
\text { December } 31\end{array}$ & $\begin{array}{c}\text { Alabama } \\
\text { Bessemer } \\
\text { City of } \\
\text { June } 30\end{array}$ & $\begin{array}{c}\text { Alabama } \\
\text { Cullman } \\
\text { Power Board } \\
\text { June } 30\end{array}$ \\
\hline 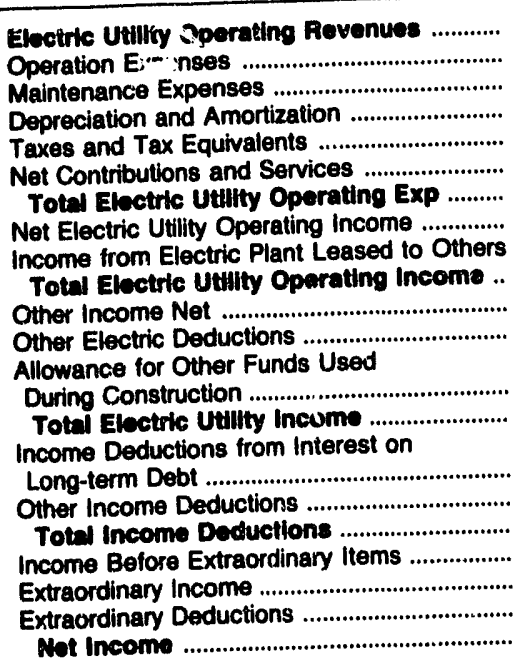 & $\begin{array}{r}89,840 \\
74,408 \\
0 \\
7,818 \\
640 \\
0 \\
82,868 \\
6,973 \\
0 \\
6,973 \\
3,668 \\
0 \\
0 \\
0 \\
i 0,641\end{array}$ & $\begin{array}{r}19,200 \\
17,180 \\
423 \\
474 \\
335 \\
4 \\
18,415 \\
786 \\
0 \\
786 \\
190 \\
0 \\
0 \\
0 \\
976\end{array}$ & $\begin{array}{r}11,387 \\
9,858 \\
295 \\
290 \\
0 \\
1,187 \\
11,631 \\
-264 \\
0 \\
-284 \\
148 \\
0 \\
0 \\
-116 \\
0 \\
0 \\
0 \\
-116 \\
0 \\
0 \\
-116\end{array}$ & $\begin{array}{r}34,755 \\
31,377 \\
838 \\
779 \\
658 \\
0 \\
33,651 \\
1,104 \\
0 \\
1,104 \\
548 \\
0 \\
\\
0 \\
1,652 \\
\\
996 \\
58 \\
1,055 \\
597 \\
50 \\
0 \\
647\end{array}$ & $\begin{array}{r}17,117 \\
14,916 \\
525 \\
545 \\
838 \\
0 \\
16,823 \\
293 \\
0 \\
283 \\
165 \\
2 \\
0 \\
457 \\
\\
168 \\
2 \\
170 \\
287 \\
0 \\
41 \\
246\end{array}$ & $\begin{array}{r}15,641 \\
14,980 \\
363 \\
289 \\
187 \\
0 \\
15,819 \\
-178 \\
0 \\
-178 \\
185 \\
1 \\
\\
0 \\
6 \\
\\
36 \\
0 \\
36 \\
-30 \\
0 \\
0 \\
-30\end{array}$ \\
\hline
\end{tabular}

\begin{tabular}{|c|c|c|c|c|c|c|}
\hline Item & $\begin{array}{l}\text { Alabama } \\
\text { Decatur } \\
\text { City of } \\
\text { June } 30\end{array}$ & $\begin{array}{l}\text { Alabama } \\
\text { Dothan } \\
\text { City of } \\
\text { September } 30\end{array}$ & $\begin{array}{l}\text { Alabama } \\
\text { Florence } \\
\text { City of } \\
\text { June } 30\end{array}$ & $\begin{array}{c}\text { Alabama } \\
\text { Foley } \\
\text { City of } \\
\text { (Riviera Utils) } \\
\text { December } 31\end{array}$ & $\begin{array}{c}\text { Alabama } \\
\text { Fort Payne } \\
\text { Improvement } \\
\text { Auth } \\
\text { June } 30\end{array}$ & $\begin{array}{l}\text { Alabama } \\
\text { Guntersville } \\
\text { Electric } \\
\text { Board } \\
\text { June } 30\end{array}$ \\
\hline 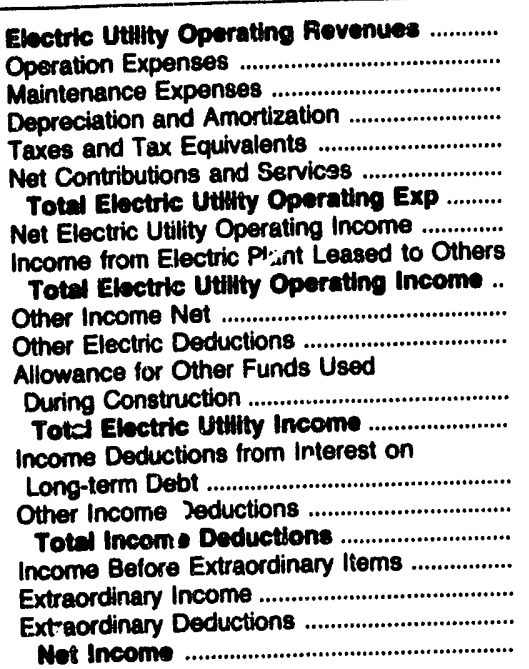 & $\begin{array}{r}59,342 \\
55,551 \\
691 \\
1,127 \\
904 \\
0 \\
58,273 \\
1,069 \\
0 \\
1,030 \\
587 \\
0 \\
0 \\
0 \\
1,656\end{array}$ & $\begin{array}{r}50,801 \\
39,116 \\
1,195 \\
1,445 \\
0 \\
0 \\
41,766 \\
9,044 \\
0 \\
9,044 \\
0 \\
0 \\
0 \\
0,044\end{array}$ & $\begin{array}{r}55,430 \\
48,519 \\
1,561 \\
1,943 \\
1,803 \\
0 \\
53,026 \\
1,604 \\
0 \\
1,604 \\
773 \\
125 \\
0 \\
0 \\
2,252\end{array}$ & $\begin{array}{r}29,532 \\
21,199 \\
586 \\
1,675 \\
649 \\
1,600 \\
25,708 \\
3,823 \\
0 \\
3,823 \\
549 \\
0 \\
0 \\
4,373 \\
864 \\
20 \\
884 \\
3,488 \\
0 \\
0 \\
3,488\end{array}$ & $\begin{array}{r}15,201 \\
13,627 \\
266 \\
333 \\
230 \\
97 \\
14,653 \\
648 \\
0 \\
648 \\
294 \\
0 \\
\\
0 \\
943 \\
\\
369 \\
31 \\
399 \\
543 \\
0 \\
0 \\
543\end{array}$ & $\begin{array}{r}11,072 \\
10,126 \\
261 \\
244 \\
177 \\
0 \\
10,808 \\
263 \\
0 \\
263 \\
33 \\
0 \\
0 \\
0 \\
296\end{array}$ \\
\hline
\end{tabular}

Note: Totals may not equal sum of components because oi incieperintent reiniding.

Soure. Elatic 
Table 36. Statement of Income by Major Publicly Owned Electric Utility Within State, 1991 (Continued) (Thousand Dollars)

\begin{tabular}{|c|c|c|c|c|c|c|}
\hline Item & $\begin{array}{l}\text { Alabarna } \\
\text { Huntsville } \\
\text { City of }\end{array}$ & $\begin{array}{l}\text { Alabama } \\
\text { Muscle } \\
\text { Shoals } \\
\text { City of } \\
\text { June } 30\end{array}$ & $\begin{array}{c}\text { Alabama } \\
\text { Opelika } \\
\text { City of } \\
\text { September } 30\end{array}$ & $\begin{array}{l}\text { Alabama } \\
\text { Scottsboro } \\
\text { City of } \\
\text { June } 30\end{array}$ & $\begin{array}{l}\text { Alabama } \\
\text { Sheffield } \\
\text { Utilities } \\
\text { June } 30\end{array}$ & $\begin{array}{c}\text { Alabama } \\
\text { Sylacauga } \\
\text { Utilities } \\
\text { Board }\end{array}$ \\
\hline 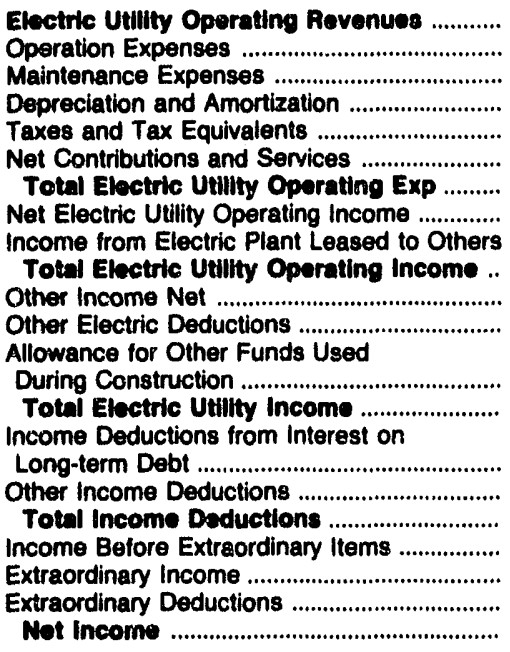 & $\begin{array}{r}181,540 \\
166,914 \\
2,452 \\
4,363 \\
4,390 \\
0 \\
178,119 \\
3,422 \\
0 \\
3,422 \\
6,086 \\
0 \\
0 \\
0 \\
9,508 \\
587 \\
410 \\
996 \\
8,511 \\
0 \\
0 \\
8,511\end{array}$ & $\begin{array}{r}10,689 \\
9,391 \\
221 \\
345 \\
333 \\
0 \\
10,290 \\
399 \\
0 \\
399 \\
76 \\
5 \\
0 \\
470\end{array}$ & $\begin{array}{r}17,330 \\
14,075 \\
722 \\
480 \\
0 \\
3,229 \\
18,505 \\
-1,175 \\
0 \\
-1,175 \\
403 \\
0 \\
0 \\
0 \\
-772 \\
\\
121 \\
0 \\
121 \\
-893 \\
0 \\
0 \\
-893\end{array}$ & $\begin{array}{r}16,015 \\
14,221 \\
514 \\
402 \\
223 \\
0 \\
15,381 \\
655 \\
0 \\
655 \\
83 \\
0 \\
0 \\
0 \\
737\end{array}$ & $\begin{array}{r}23,520 \\
20,626 \\
935 \\
931 \\
619 \\
0 \\
23,181 \\
409 \\
0 \\
400 \\
361 \\
17 \\
\\
0 \\
753\end{array}$ & $\begin{array}{r}10,178 \\
7,162 \\
185 \\
783 \\
0 \\
955 \\
9,005 \\
1,093 \\
0 \\
1,003 \\
0 \\
0 \\
0 \\
1,093\end{array}$ \\
\hline
\end{tabular}

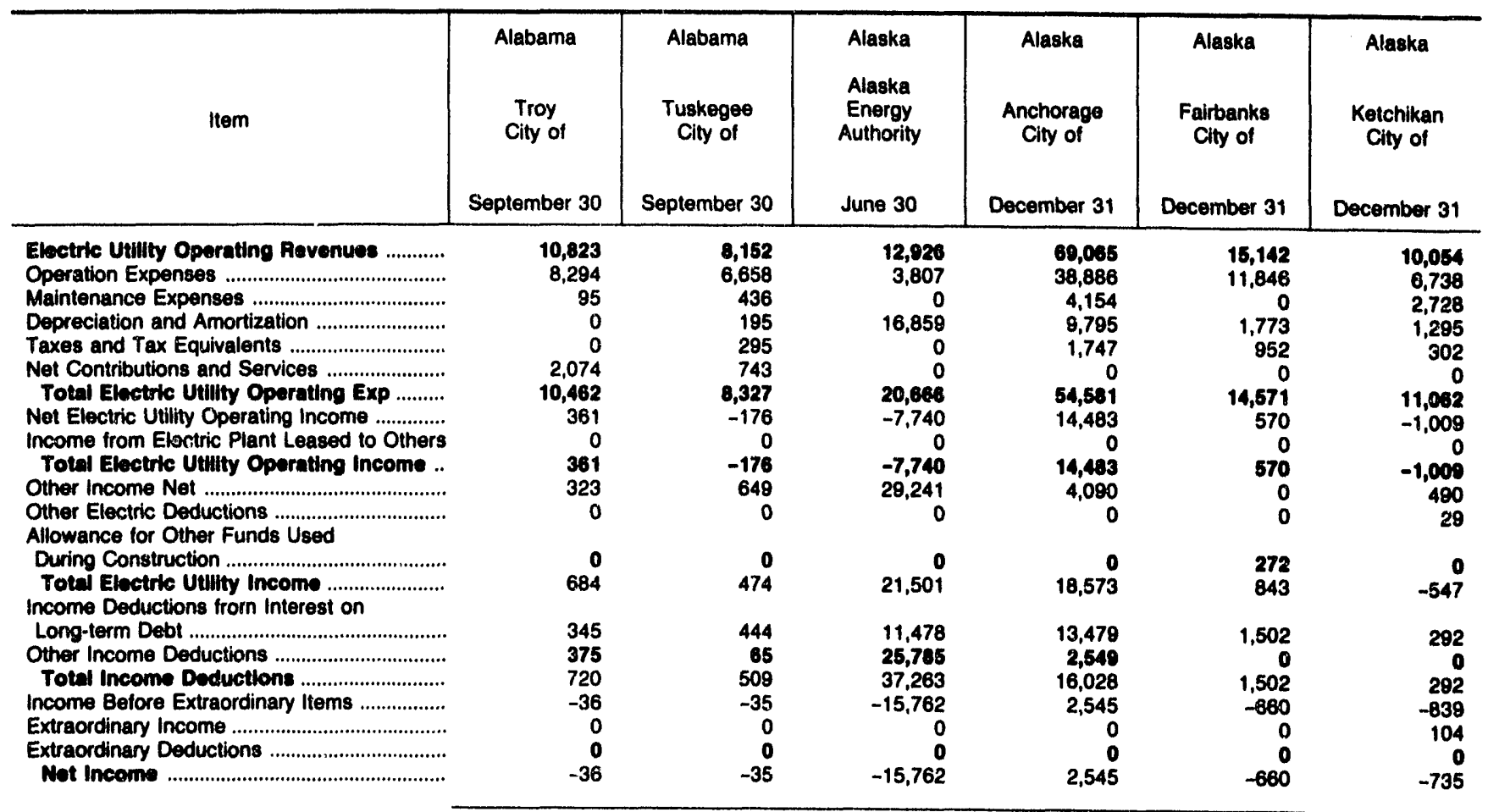

Note: Totals may not equal sum of components because of independent rounding.

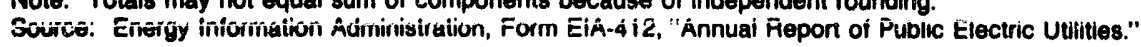



Table 36. Statement of Income by Major Publicly Owned Electric
Utility Within State, 1991 (Continued)

(Thousand Dollars)

\begin{tabular}{|c|c|c|c|c|c|c|}
\hline Item & $\begin{array}{l}\text { Arizona } \\
\text { Arizona } \\
\text { Power } \\
\text { Authority } \\
\text { June } 30\end{array}$ & $\begin{array}{l}\text { Arizona } \\
\text { Mesa } \\
\text { City of } \\
\text { June } 30\end{array}$ & $\begin{array}{c}\text { Arizona } \\
\text { Navajo } \\
\text { Tribal } \\
\text { Utility } \\
\text { Auth } \\
\text { December } 31\end{array}$ & $\begin{array}{l}\text { Arizona } \\
\text { Salt River } \\
\text { Pro] Ag } \\
\text { I \& P Dist } \\
\text { April } 30\end{array}$ & $\begin{array}{l}\text { Arkansas } \\
\text { Benton } \\
\text { City of } \\
\text { December } 31\end{array}$ & $\begin{array}{l}\text { Arkansas } \\
\begin{array}{c}\text { Bentonville } \\
\text { City of }\end{array} \\
\text { December } 31\end{array}$ \\
\hline 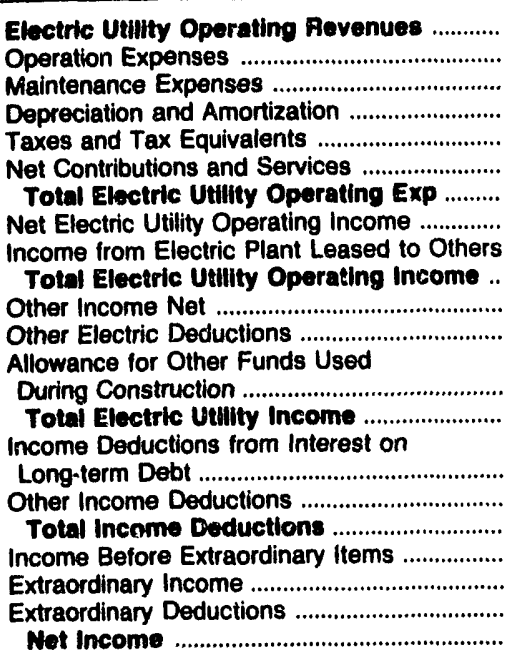 & $\begin{array}{r}15,457 \\
15,170 \\
0 \\
150 \\
0 \\
0 \\
15,321 \\
137 \\
0 \\
137 \\
4,583 \\
0 \\
\\
0 \\
4,719\end{array}$ & $\begin{array}{r}20,036 \\
13,919 \\
1,801 \\
1,288 \\
0 \\
2,827 \\
18,834 \\
202 \\
0 \\
202 \\
311 \\
0 \\
0 \\
513 \\
233 \\
0 \\
233 \\
280 \\
0 \\
0 \\
280\end{array}$ & $\begin{array}{r}30,037 \\
24,790 \\
751 \\
3,021 \\
0 \\
0 \\
28,582 \\
1,475 \\
0 \\
1,475 \\
279 \\
314 \\
\\
118 \\
1,558\end{array}$ & $\begin{array}{r}1,149,503 \\
477,126 \\
96,478 \\
146,272 \\
165,181 \\
0 \\
885,056 \\
264,447 \\
282 \\
264,728 \\
40,621 \\
0 \\
\\
107 \\
305,456 \\
\\
246,996 \\
238,374 \\
485,370 \\
-179,913 \\
0 \\
0 \\
-179,913\end{array}$ & $\begin{array}{r}12,981 \\
8,842 \\
204 \\
820 \\
559 \\
2,321 \\
12,746 \\
235 \\
0 \\
235 \\
0 \\
0 \\
0 \\
235\end{array}$ & $\begin{array}{r}9,059 \\
6,477 \\
160 \\
103 \\
456 \\
0 \\
7,195 \\
1,864 \\
0 \\
1,864 \\
0 \\
0 \\
\\
0 \\
1,864 \\
\\
118 \\
133 \\
251 \\
1,613 \\
0 \\
0 \\
1,613\end{array}$ \\
\hline
\end{tabular}

\begin{tabular}{|c|c|c|c|c|c|c|}
\hline Item & $\begin{array}{l}\text { Arkansas } \\
\text { Conway } \\
\text { Corp } \\
\text { December } 31\end{array}$ & $\begin{array}{c}\text { Arkansas } \\
\text { Hope } \\
\text { City of } \\
\text { December } 31\end{array}$ & $\begin{array}{c}\text { Arkansas } \\
\text { Jonesboro } \\
\text { City of } \\
\text { December } 31\end{array}$ & $\begin{array}{c}\text { Arkansas } \\
\text { North } \\
\text { Little } \\
\text { Pock } \\
\text { City of } \\
\text { December } 31\end{array}$ & $\begin{array}{c}\text { Arkansas } \\
\text { Osceola } \\
\text { City of } \\
\text { December } 31\end{array}$ & $\begin{array}{c}\text { Arkansas } \\
\text { Paragould } \\
\text { Light } \\
\text { Water Comm } \\
\text { December } 31\end{array}$ \\
\hline 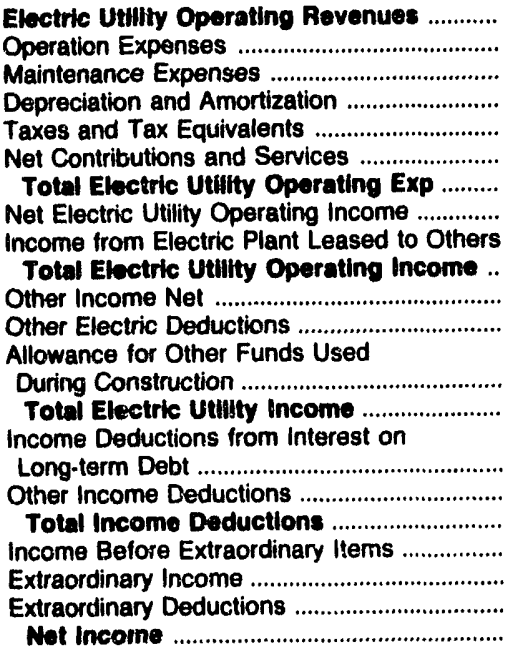 & $\begin{array}{r}21,912 \\
14,166 \\
1,085 \\
1,956 \\
0 \\
491 \\
17,698 \\
4,215 \\
0 \\
4,215 \\
1,139 \\
0 \\
0 \\
0 \\
5,354\end{array}$ & $\begin{array}{r}10,316 \\
7,643 \\
422 \\
337 \\
52 \\
746 \\
8,200 \\
1,116 \\
0 \\
1,116 \\
525 \\
482 \\
0 \\
1,159\end{array}$ & $\begin{array}{r}35,410 \\
22,746 \\
1,167 \\
5,261 \\
222 \\
624 \\
30,020 \\
5,390 \\
0 \\
5,390 \\
1,716 \\
0 \\
153 \\
7,259\end{array}$ & $\begin{array}{r}60,323 \\
37,028 \\
1,103 \\
3,611 \\
472 \\
6,225 \\
48,439 \\
11,884 \\
0 \\
11,884 \\
2,794 \\
0 \\
0 \\
14,678\end{array}$ & $\begin{array}{r}8,813 \\
6,905 \\
322 \\
294 \\
0 \\
208 \\
7,728 \\
1,085 \\
0 \\
1,085 \\
243 \\
0 \\
\\
0 \\
1,328\end{array}$ & $\begin{array}{r}11,061 \\
8,834 \\
0 \\
797 \\
0 \\
0 \\
9,631 \\
1,430 \\
0 \\
1,430 \\
137 \\
33 \\
\\
0 \\
1,533\end{array}$ \\
\hline
\end{tabular}

Note: Totals may not equal sum of components because of independent rounding.

Source: Energy Information Administration, Form EIA-412, "Annual Report of Public Electric Utilities." 
Table 36. Statement of Income by Major Publicly Owned Electric
Utility Within State, 1991 (Continued) (Thousand Dollars)

\begin{tabular}{|c|c|c|c|c|c|c|}
\hline Item & $\begin{array}{c}\text { Arkansas } \\
\text { Siloam } \\
\text { Springs } \\
\text { City of } \\
\text { December } 31\end{array}$ & $\begin{array}{c}\text { Arkansas } \\
\text { West } \\
\text { Memphis } \\
\text { City of } \\
\text { December } 31\end{array}$ & $\begin{array}{l}\text { California } \\
\text { Alameda } \\
\text { City of } \\
\text { June } 30\end{array}$ & $\begin{array}{l}\text { California } \\
\text { Anaheim } \\
\text { City of } \\
\text { June } 30\end{array}$ & $\begin{array}{l}\text { California } \\
\text { Azusa } \\
\text { City of } \\
\text { June } 30\end{array}$ & $\begin{array}{l}\text { California } \\
\text { Burbank } \\
\text { City of } \\
\text { June } 30\end{array}$ \\
\hline 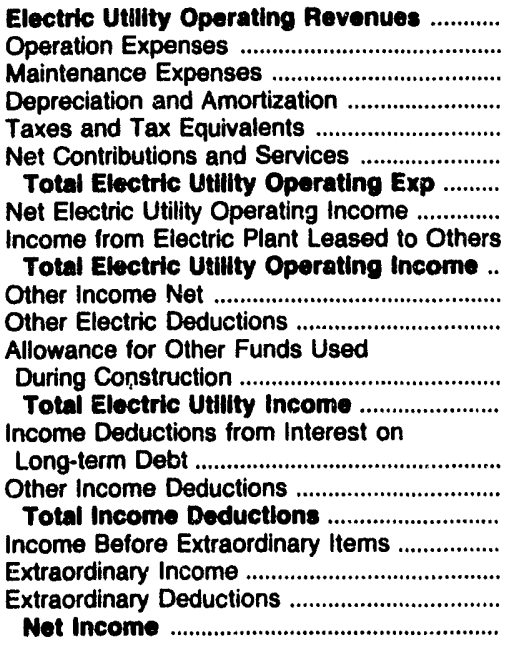 & $\begin{array}{r}8,650 \\
5,724 \\
361 \\
143 \\
0 \\
1,384 \\
7,611 \\
1,039 \\
0 \\
1,039 \\
0 \\
0 \\
\\
0 \\
1,039\end{array}$ & $\begin{array}{r}20,053 \\
12,227 \\
225 \\
1,975 \\
741 \\
225 \\
15,392 \\
4,660 \\
0 \\
4,660 \\
1,595 \\
0 \\
0 \\
6,256\end{array}$ & $\begin{array}{r}42,828 \\
37,705 \\
675 \\
1,404 \\
0 \\
1,396 \\
11,179 \\
1,749 \\
0 \\
1,749 \\
1,221 \\
0 \\
0 \\
2,969 \\
835 \\
121 \\
956 \\
2,013 \\
0 \\
0 \\
2,013\end{array}$ & $\begin{array}{r}212,130 \\
153,765 \\
12,175 \\
10,028 \\
0 \\
7,749 \\
183,717 \\
28,413 \\
0 \\
28,413 \\
7,741 \\
0 \\
0 \\
0 \\
36,154\end{array}$ & $\begin{array}{r}17,534 \\
8,888 \\
2,081 \\
262 \\
347 \\
2,321 \\
13,898 \\
3,636 \\
0 \\
3,636 \\
1,220 \\
0 \\
0 \\
4,857\end{array}$ & $\begin{array}{r}82,324 \\
66,270 \\
5,090 \\
4,342 \\
5,412 \\
0 \\
81,114 \\
1,210 \\
0 \\
1,210 \\
3,161 \\
186 \\
\\
0 \\
4,185\end{array}$ \\
\hline
\end{tabular}

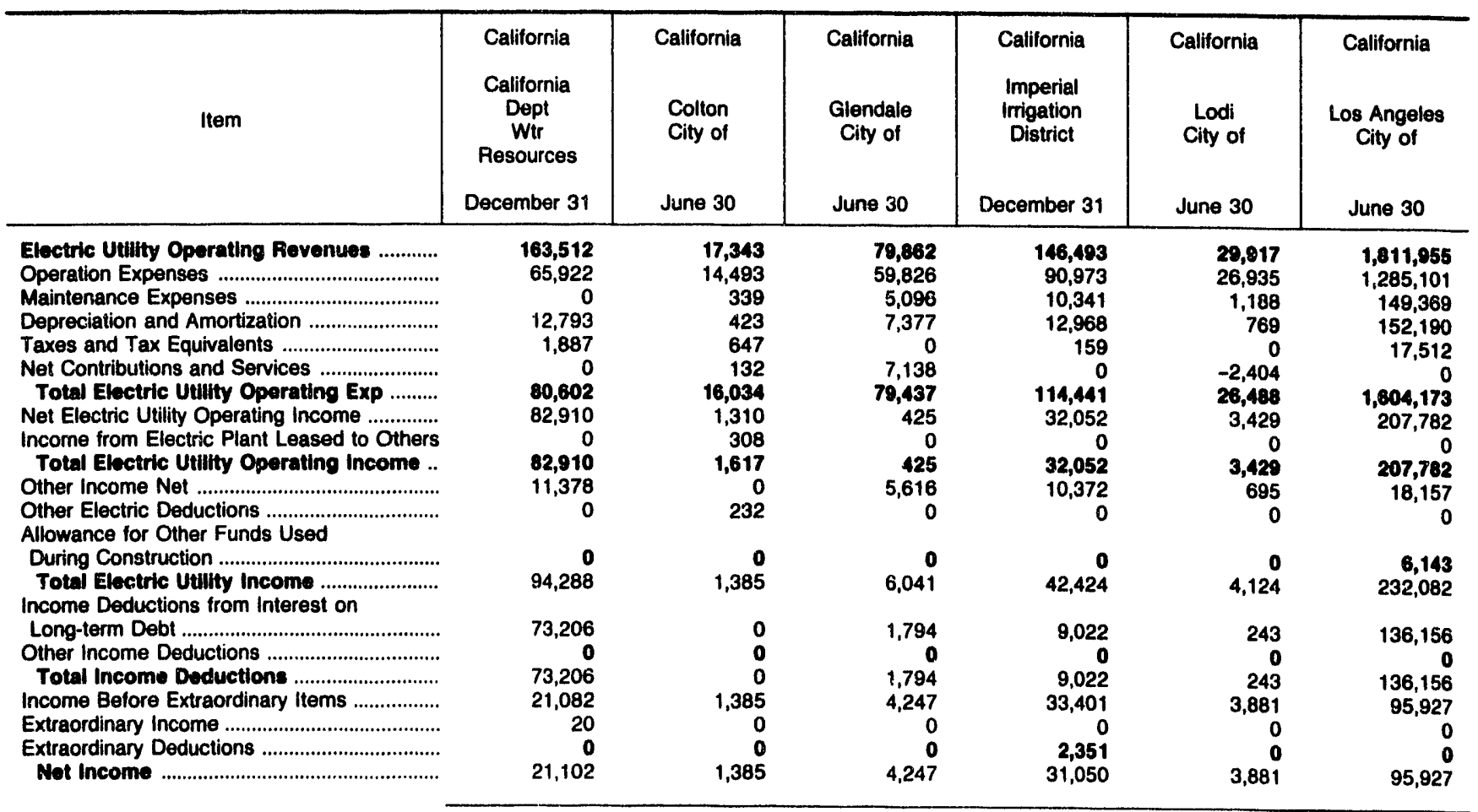

Note: Totals may not equal sum of components because of independent rounding.

Source: Energy Information Administration, Form EIA-412, "Annual Report of Public Electric Utilities." 
Table 36. Statement of Income by Major Publicly Owned Electric
Utility Within State, 1991 (Continued) (Thousand Dollars)

\begin{tabular}{|c|c|c|c|c|c|c|}
\hline ltem & $\begin{array}{l}\text { California } \\
\text { Metropolitan } \\
\text { Water } \\
\text { District } \\
\text { June } 30\end{array}$ & $\begin{array}{l}\text { California } \\
\text { Modesto } \\
\text { Irrigation } \\
\text { District } \\
\text { December } 31\end{array}$ & $\begin{array}{l}\text { California } \\
\text { MSR } \\
\text { Public } \\
\text { Power } \\
\text { Agency } \\
\text { December } 31\end{array}$ & $\begin{array}{l}\text { California } \\
\text { Northern } \\
\text { California } \\
\text { Power Agny } \\
\text { June } 30\end{array}$ & $\begin{array}{c}\text { California } \\
\text { Oakdale \& } \\
\text { South } \\
\text { San Joaquin } \\
\text { December } 31\end{array}$ & $\begin{array}{c}\text { California } \\
\text { Oroville } \\
\text { Wyandotte } \\
\text { Irrig Dist } \\
\text { December } 31\end{array}$ \\
\hline 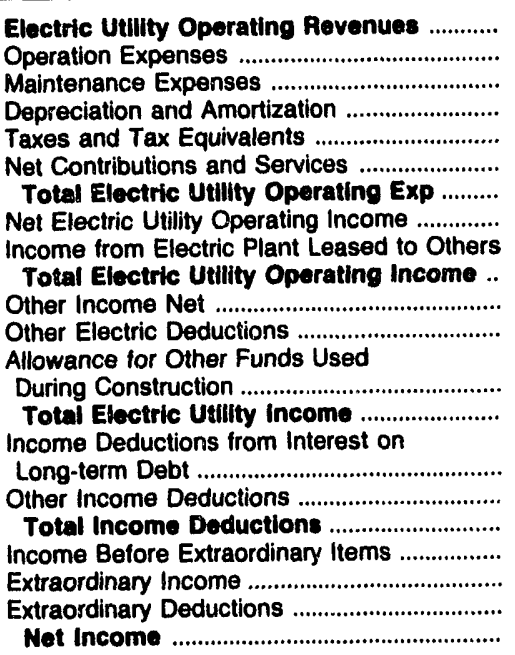 & $\begin{array}{r}15,064 \\
15,046 \\
0 \\
2,061 \\
0 \\
0 \\
17,107 \\
-2,043 \\
0 \\
-2,043 \\
0 \\
0 \\
0 \\
0 \\
-2,043\end{array}$ & $\begin{array}{r}116,423 \\
82,701 \\
5,534 \\
6,151 \\
4,187 \\
666 \\
99,239 \\
17,184 \\
0 \\
17,184 \\
20,152 \\
12,983 \\
\\
0 \\
24,353\end{array}$ & $\begin{array}{r}40,954 \\
16,968 \\
2,085 \\
8,415 \\
888 \\
0 \\
28,356 \\
12,599 \\
0 \\
12,599 \\
10,453 \\
0 \\
\\
0 \\
23,052\end{array}$ & $\begin{array}{r}150,808 \\
76,707 \\
5,303 \\
30,417 \\
0 \\
0 \\
112,428 \\
38,380 \\
0 \\
38,380 \\
36,829 \\
0 \\
0 \\
0 \\
75,209\end{array}$ & $\begin{array}{r}5,028 \\
1,586 \\
286 \\
799 \\
0 \\
0 \\
2,671 \\
2,357 \\
0 \\
2,357 \\
1,324 \\
153 \\
\\
0 \\
3,527\end{array}$ & $\begin{array}{r}14,817 \\
9,600 \\
1,009 \\
1,494 \\
0 \\
0 \\
12,103 \\
2,714 \\
0 \\
2,714 \\
260 \\
0\end{array}$ \\
\hline
\end{tabular}

\begin{tabular}{|c|c|c|c|c|c|c|}
\hline Item & $\begin{array}{l}\text { California } \\
\text { Palo Alto } \\
\text { City of } \\
\text { June } 30\end{array}$ & $\begin{array}{l}\text { California } \\
\text { Pasadena } \\
\text { City of } \\
\text { June } 30\end{array}$ & $\begin{array}{c}\text { California } \\
\text { Placer } \\
\text { County } \\
\text { Water } \\
\text { Agency } \\
\text { December } 31\end{array}$ & $\begin{array}{l}\text { California } \\
\text { Redding } \\
\text { City of } \\
\text { June } 30\end{array}$ & $\begin{array}{l}\text { California } \\
\text { Riverside } \\
\text { City of } \\
\text { June } 30\end{array}$ & $\begin{array}{l}\text { California } \\
\text { Roseville } \\
\text { City of } \\
\text { June } 30\end{array}$ \\
\hline
\end{tabular}

Note: Totals may not equal sum of components because of independent rounding

Source: Energy Information Administration, Form EIA-412, "Annual Report of Public Electric Utilities." 
Table 36. Statement of Income by Major Publicly Owned Electric Utility Within State, 1991 (Continued)

(Thousand Dollars)

\begin{tabular}{|c|c|c|c|c|c|c|}
\hline Item & $\begin{array}{l}\text { California } \\
\text { Sacramento } \\
\text { Municipal } \\
\text { Util Dist } \\
\text { December } 31\end{array}$ & $\begin{array}{c}\text { California } \\
\text { San Francisco } \\
\text { City } \\
\& \\
\text { County of } \\
\text { June } 30\end{array}$ & $\begin{array}{l}\text { California } \\
\text { Santa } \\
\text { Clara } \\
\text { City of } \\
\text { June } 30\end{array}$ & $\begin{array}{c}\text { California } \\
\text { Southern } \\
\text { California } \\
\text { P P } \\
\text { A } \\
\text { June } 30\end{array}$ & $\begin{array}{c}\text { California } \\
\text { Turlock } \\
\text { Irrigation } \\
\text { District } \\
\text { December } 31\end{array}$ & $\begin{array}{l}\text { California } \\
\text { Vernon } \\
\text { City of } \\
\text { June } 30\end{array}$ \\
\hline 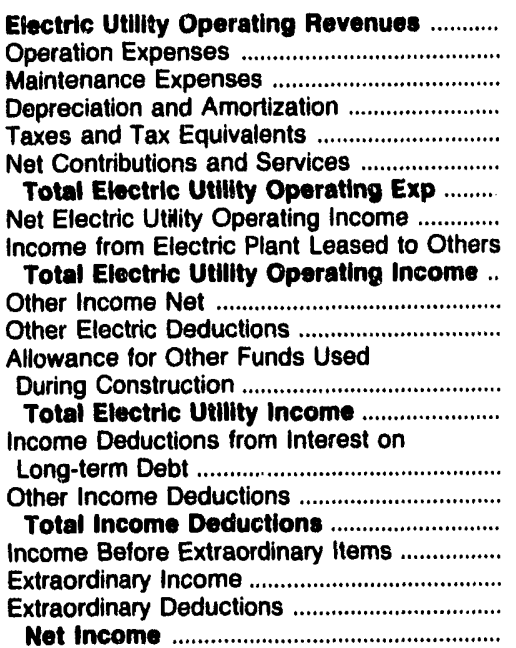 & $\begin{array}{r}644,393 \\
405,353 \\
25,848 \\
83,849 \\
961 \\
0 \\
516,011 \\
128,382 \\
0 \\
128,382 \\
38,653 \\
0\end{array}$ & $\begin{array}{r}53,317 \\
47,527 \\
3,435 \\
8,022 \\
800 \\
4,776 \\
64,559 \\
-11,242 \\
0 \\
-11,242 \\
9,858 \\
0 \\
0 \\
-1,384\end{array}$ & $\begin{array}{r}151,596 \\
140,827 \\
1,870 \\
3,850 \\
8,174 \\
-810 \\
153,910 \\
-2,314 \\
0 \\
-2,314 \\
7,769 \\
805 \\
0 \\
0 \\
4,650\end{array}$ & $\begin{array}{r}218,808 \\
56,870 \\
10,294 \\
45,356 \\
11,858 \\
0 \\
124,378 \\
94,430 \\
0 \\
94,430 \\
31,035 \\
0 \\
0 \\
125,465\end{array}$ & $\begin{array}{r}84,886 \\
62,887 \\
5,413 \\
6,544 \\
0 \\
0 \\
74,843 \\
10,042 \\
0 \\
0 \\
10,042 \\
5,957 \\
7,392 \\
0 \\
0 \\
8,608\end{array}$ & $\begin{array}{r}77,146 \\
50,437 \\
1,070 \\
1,412 \\
1,686 \\
0 \\
54,605 \\
22,542 \\
0 \\
22,542 \\
7,076 \\
274 \\
0 \\
29,344\end{array}$ \\
\hline
\end{tabular}

\begin{tabular}{|c|c|c|c|c|c|c|}
\hline Item & $\begin{array}{l}\text { California } \\
\text { Yuba } \\
\text { County } \\
\text { Water } \\
\text { Agency } \\
\text { June } 30\end{array}$ & $\begin{array}{l}\text { Colorado } \\
\text { Arkansas } \\
\text { River } \\
\text { Power } \\
\text { Authority } \\
\text { December } 31\end{array}$ & $\begin{array}{l}\text { Colorado } \\
\text { Colorado } \\
\text { Springs } \\
\text { City of } \\
\text { December } 31\end{array}$ & $\begin{array}{l}\text { Colorado } \\
\text { Fort Collins } \\
\text { City of } \\
\text { December } 31\end{array}$ & $\begin{array}{l}\text { Colorado } \\
\begin{array}{c}\text { Longmont } \\
\text { City of }\end{array} \\
\text { December } 31\end{array}$ & $\begin{array}{l}\text { Colorado } \\
\text { Loveland } \\
\text { City of } \\
\text { December } 31\end{array}$ \\
\hline 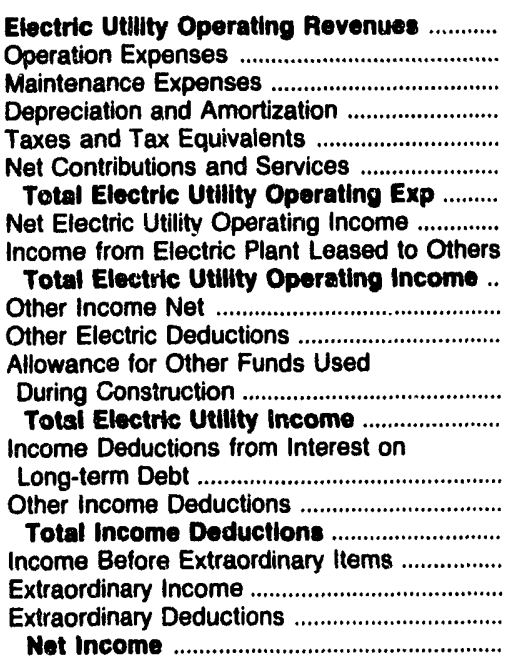 & $\begin{array}{r}11,730 \\
2,585 \\
1,283 \\
2,418 \\
0 \\
0 \\
6,285 \\
5,445 \\
1 \\
5,446 \\
154 \\
0 \\
0 \\
0 \\
5,600\end{array}$ & $\begin{array}{r}10,001 \\
9,331 \\
0 \\
90 \\
0 \\
0 \\
9,420 \\
581 \\
0 \\
581 \\
193 \\
0 \\
0 \\
774\end{array}$ & $\begin{array}{r}143,066 \\
81,331 \\
13,740 \\
21,657 \\
9,305 \\
0 \\
126,032 \\
17,033 \\
0 \\
17,033 \\
7,079 \\
0 \\
\\
436 \\
24,548\end{array}$ & $\begin{array}{r}39,242 \\
34,153 \\
774 \\
2,945 \\
2,355 \\
0 \\
40,227 \\
-985 \\
0 \\
-985 \\
2,145 \\
0 \\
0 \\
0 \\
1,161\end{array}$ & $\begin{array}{r}20,185 \\
17,376 \\
624 \\
1,021 \\
1,452 \\
0 \\
0 \\
20,473 \\
-288 \\
0 \\
-288 \\
840 \\
0 \\
0 \\
552\end{array}$ & $\begin{array}{r}19,342 \\
13,053 \\
482 \\
954 \\
1,354 \\
1,626 \\
17,468 \\
1,873 \\
0 \\
1,873 \\
1,026 \\
0 \\
0 \\
0 \\
2,899\end{array}$ \\
\hline
\end{tabular}

Note: Totals may not equal sum of components because of independent rounding.

Source: Energy Information Administration, Form ElA-412, "Annual Report of Public Electric Utilities." 


\section{Table 36. Statement of Income by Major Publicly Owned Electric Utility Within State, 1991 (Continued)}

(Thousand Dollars)

\begin{tabular}{|c|c|c|c|c|c|c|}
\hline Item & $\begin{array}{c}\text { Colorado } \\
\text { Platte River } \\
\text { Power } \\
\text { Authority } \\
\text { December } 31\end{array}$ & $\begin{array}{c}\text { Connecticut } \\
\text { Connecticut } \\
\text { Mun } \\
\text { Elec } \\
\text { Engy Coop } \\
\text { December } 31\end{array}$ & $\begin{array}{l}\text { Connecticut } \\
\text { Groton } \\
\text { City of } \\
\text { June } 30\end{array}$ & $\begin{array}{l}\text { Connecticut } \\
\text { Norwich } \\
\text { City of } \\
\text { June } 30\end{array}$ & $\begin{array}{l}\text { Connecticut } \\
\text { Wallingtord } \\
\text { Town of } \\
\text { June } 30\end{array}$ & $\begin{array}{l}\text { Delaware } \\
\text { Dover } \\
\text { City of } \\
\text { June } 30\end{array}$ \\
\hline 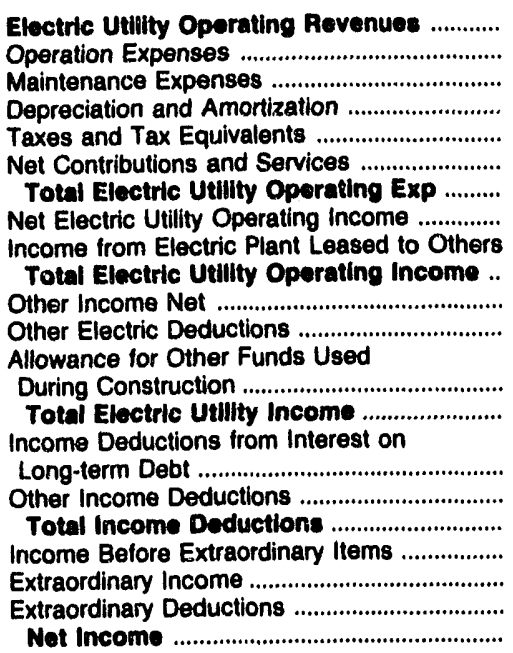 & $\begin{array}{r}138,232 \\
56,245 \\
11,071 \\
21,483 \\
0 \\
0 \\
88,799 \\
49,433 \\
0 \\
49,433 \\
31,070 \\
0\end{array}$ & $\begin{array}{r}58,695 \\
51,705 \\
510 \\
1,775 \\
0 \\
0 \\
53,990 \\
4,705 \\
0 \\
4,705 \\
4,396 \\
0 \\
\\
0 \\
9,102\end{array}$ & $\begin{array}{r}44,100 \\
37,046 \\
710 \\
1,064 \\
2,157 \\
1,100 \\
42,077 \\
2,023 \\
0 \\
2,023 \\
488 \\
0 \\
\\
0 \\
2,511\end{array}$ & $\begin{array}{r}24,960 \\
21,170 \\
631 \\
618 \\
1,335 \\
2,322 \\
26,076 \\
-1,116 \\
641 \\
-475 \\
141 \\
0 \\
0 \\
0 \\
-334 \\
39 \\
6 \\
45 \\
-379 \\
0 \\
0 \\
-379\end{array}$ & $\begin{array}{r}42,890 \\
35,594 \\
1,820 \\
1,300 \\
3,270 \\
0 \\
41,985 \\
905 \\
0 \\
905 \\
1,543 \\
0 \\
\end{array}$ & $\begin{array}{r}37,020 \\
29,573 \\
0 \\
1,780 \\
0 \\
3,066 \\
34,419 \\
2,601 \\
0 \\
2,601 \\
1,389 \\
0 \\
0 \\
3,989\end{array}$ \\
\hline
\end{tabular}

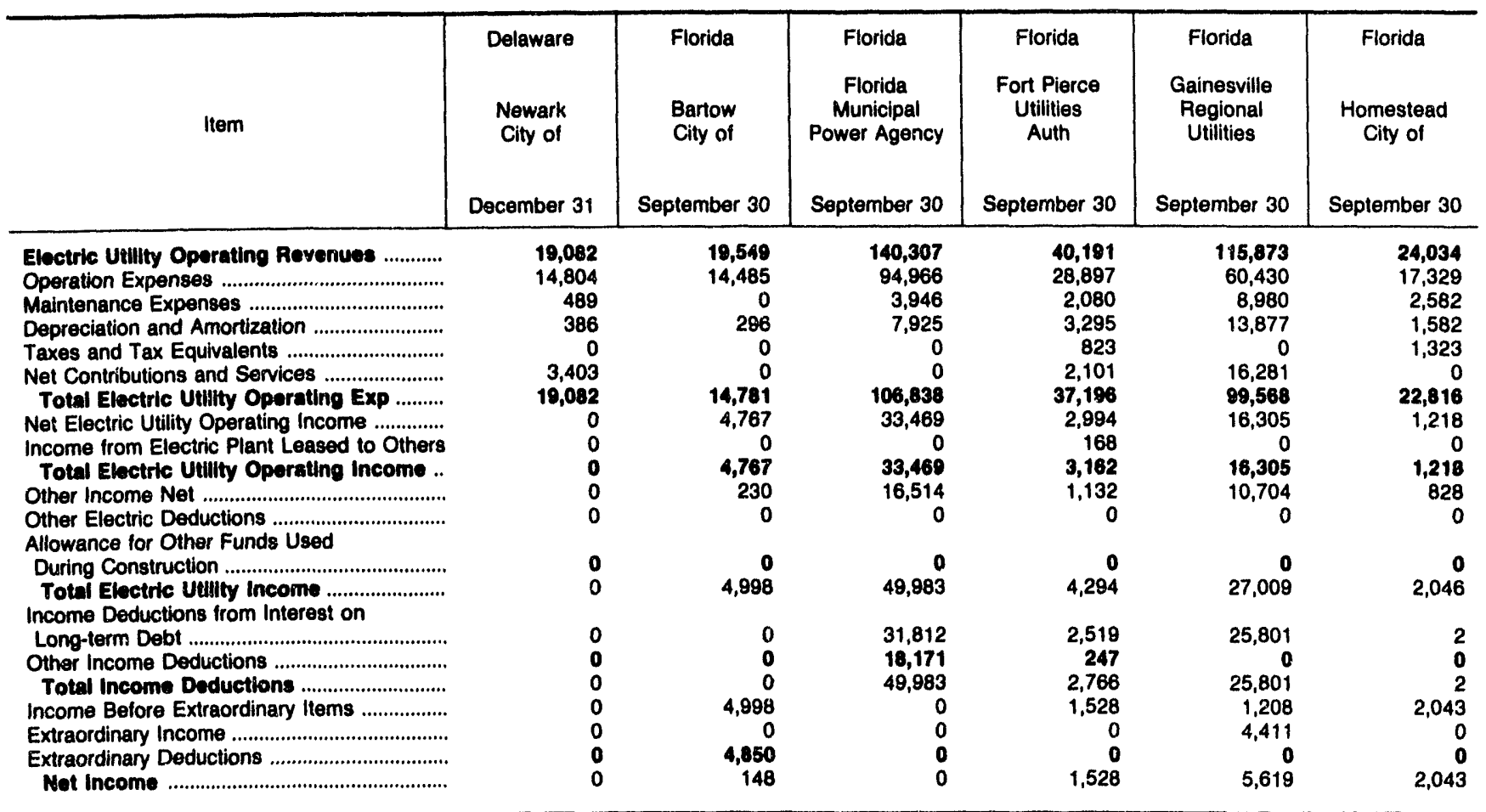

Note: Totals may not equal sum of components because of independent rounding.

Source: Energy Information Administration, Form EIA-412, "Annual Report of Public Electric Utilities." 
Table 36. Statement of Income by Major Publicly Owned Electric Utillty Within State, 1991 (Continued)

(Thousand Dollars)

\begin{tabular}{|c|c|c|c|c|c|c|}
\hline Item & $\begin{array}{c}\text { Florida } \\
\text { Jacksonville } \\
\text { Beach } \\
\text { City of } \\
\text { September } 30\end{array}$ & $\begin{array}{c}\text { Florida } \\
\text { Jacksonville } \\
\text { Electric } \\
\text { Auth } \\
\text { Seplamber } 30\end{array}$ & $\begin{array}{l}\text { Florida } \\
\text { Key West } \\
\text { City of } \\
\text { September } 30\end{array}$ & $\begin{array}{c}\text { Florida } \\
\text { Kissimmee } \\
\text { Utility } \\
\text { Authority } \\
\text { September } 30\end{array}$ & $\begin{array}{l}\text { Florida } \\
\begin{array}{c}\text { Lake Worth } \\
\text { Cily of }\end{array} \\
\text { September } 30\end{array}$ & $\begin{array}{l}\text { Florida } \\
\text { Lakeland } \\
\text { Clty of } \\
\text { September } 30\end{array}$ \\
\hline 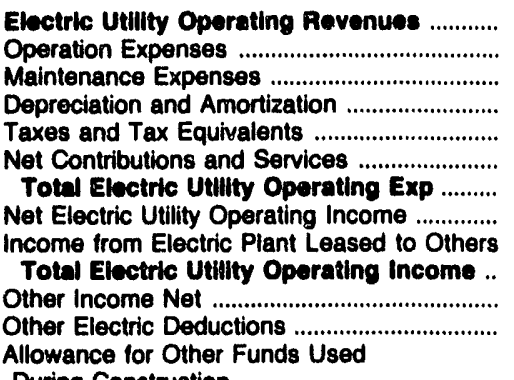 & $\begin{array}{r}37,737 \\
27,704 \\
2,842 \\
1,846 \\
310 \\
5,112 \\
37,814 \\
-77 \\
0 \\
-77 \\
507 \\
0\end{array}$ & $\begin{array}{r}651,219 \\
389,737 \\
45,930 \\
43,381 \\
11,994 \\
0 \\
491,042 \\
160,177 \\
0 \\
160,177 \\
116,875 \\
0\end{array}$ & $\begin{array}{r}47,265 \\
32,309 \\
3,004 \\
4,789 \\
1,296 \\
931 \\
42,329 \\
4,936 \\
0 \\
4,936 \\
2,997 \\
0\end{array}$ & $\begin{array}{r}61,581 \\
34,363 \\
3,154 \\
6,436 \\
10 \\
4,980 \\
48,943 \\
12,638 \\
0 \\
12,638 \\
3,850 \\
0\end{array}$ & $\begin{array}{r}33,395 \\
23,577 \\
1,385 \\
1,811 \\
510 \\
4,438 \\
31,721 \\
1,664 \\
0 \\
1,604 \\
1,145 \\
0\end{array}$ & $\begin{array}{r}147,536 \\
76,993 \\
16,107 \\
13,104 \\
3,545 \\
14,391 \\
124,139 \\
23,396 \\
0 \\
23,396 \\
9,191 \\
0\end{array}$ \\
\hline 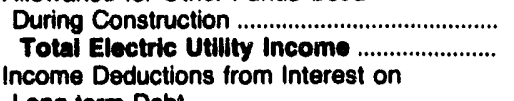 & $\begin{array}{r}0 \\
430\end{array}$ & $\begin{array}{r}0 \\
277,052\end{array}$ & $\begin{array}{r}0 \\
7,933\end{array}$ & $\begin{array}{r}0 \\
16,488\end{array}$ & $\begin{array}{r}0 \\
2,809\end{array}$ & $\begin{array}{r}0 \\
32,587\end{array}$ \\
\hline 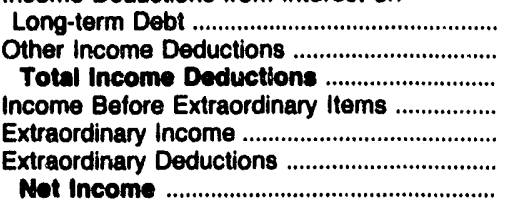 & $\begin{array}{r}0 \\
0 \\
0 \\
430 \\
0 \\
0 \\
430\end{array}$ & $\begin{array}{r}200,750 \\
28,727 \\
229,477 \\
47,575 \\
0 \\
0 \\
47,575\end{array}$ & $\begin{array}{r}6,987 \\
0 \\
6,987 \\
946 \\
0 \\
2,836 \\
-1,890\end{array}$ & $\begin{array}{r}7,428 \\
0 \\
7,428 \\
9,060 \\
689 \\
0 \\
9,749\end{array}$ & $\begin{array}{r}1,760 \\
0 \\
1,760 \\
1,049 \\
0 \\
0 \\
1,049\end{array}$ & $\begin{array}{r}17,419 \\
2,054 \\
19,473 \\
13,114 \\
1,397 \\
0 \\
14,511\end{array}$ \\
\hline
\end{tabular}

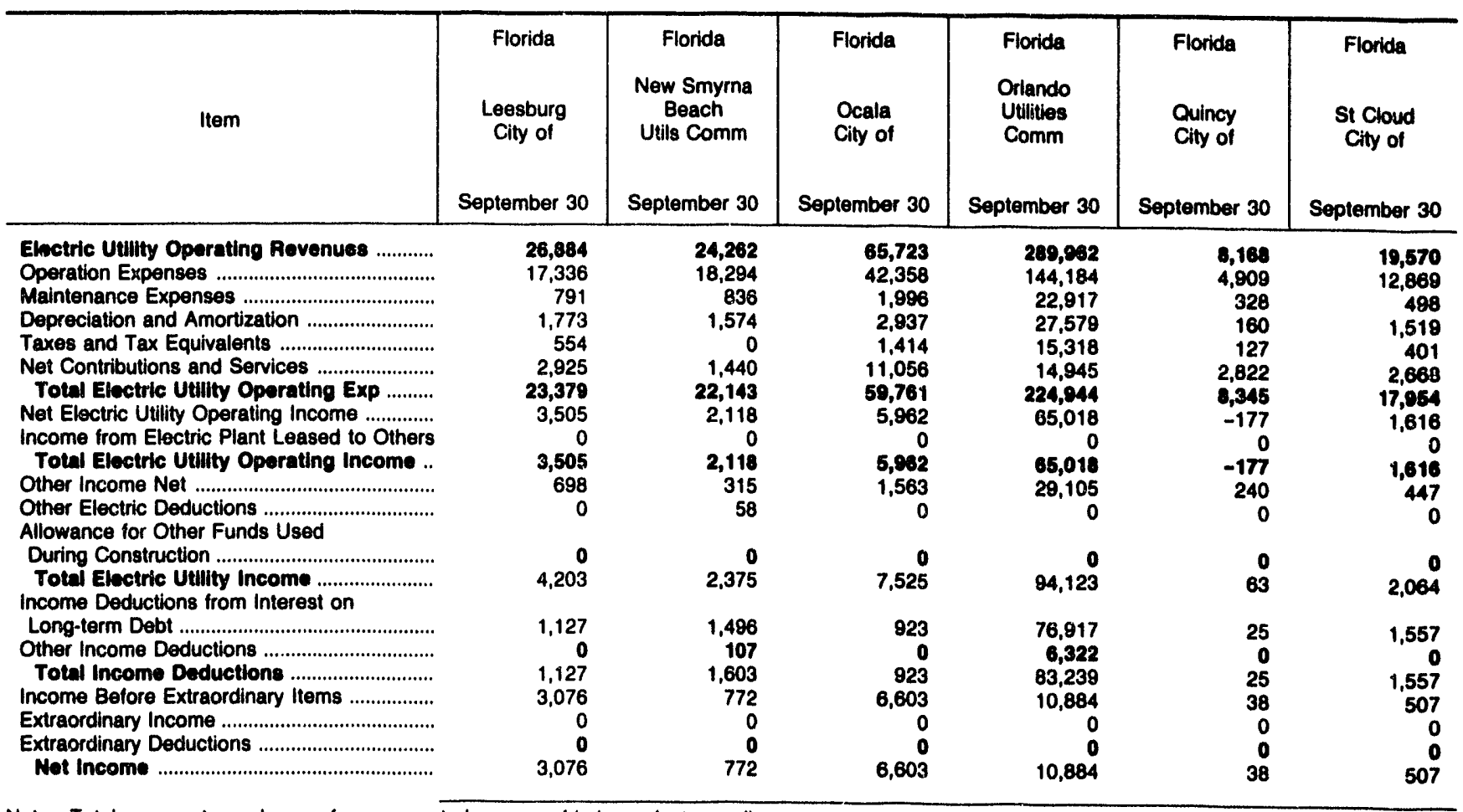

Note: Totals may not equal sum of components because of independent rounding.

Source: Energy Information Administration, Form EIA-412, "Annual Report of Public Electric Utilities." 
Table 36. Statement of Income by Major Publicly Owned Electric
Utility Within State, 1991 (Continued) (Thousand Dollars)

\begin{tabular}{|c|c|c|c|c|c|c|}
\hline Item & $\begin{array}{c}\text { Florida } \\
\text { Tallahassee } \\
\text { City of } \\
\text { September } 30\end{array}$ & $\begin{array}{c}\text { Florida } \\
\text { Vero } \\
\text { Beach } \\
\text { City of } \\
\text { September } 30\end{array}$ & $\begin{array}{l}\text { Georgia } \\
\text { Albany Water } \\
\text { Gas \& Light } \\
\text { Comm } \\
\text { June } 30\end{array}$ & $\begin{array}{l}\text { Georgia } \\
\text { Calhoun } \\
\text { City of } \\
\text { June } 30\end{array}$ & $\begin{array}{l}\text { Georgia } \\
\text { Cartersville } \\
\text { City of } \\
\text { June } 30\end{array}$ & $\begin{array}{c}\text { Georgia } \\
\text { College } \\
\text { Park City of } \\
\text { June } 30\end{array}$ \\
\hline 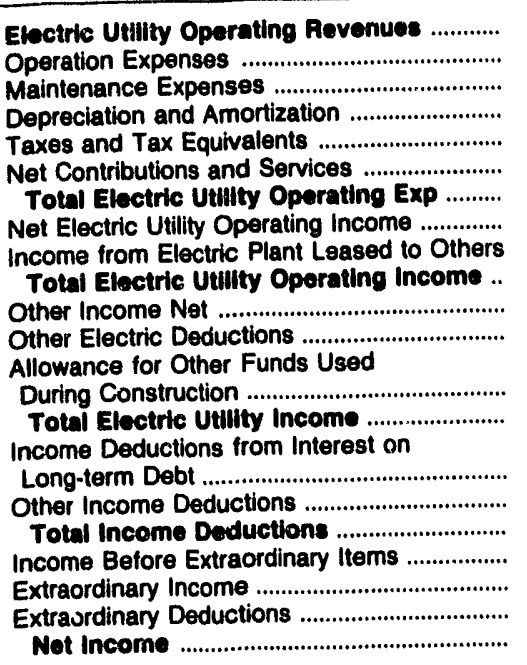 & $\begin{array}{r}151,046 \\
88,750 \\
3,269 \\
8,942 \\
0 \\
31,390 \\
132,351 \\
18,695 \\
0 \\
18,695 \\
11,658 \\
65 \\
0 \\
0 \\
30,288 \\
\\
8,523 \\
4,120 \\
12,642 \\
17,645 \\
0 \\
0 \\
17,645\end{array}$ & $\begin{array}{r}36,936 \\
28,254 \\
3,711 \\
2,515 \\
102 \\
2,882 \\
37,464 \\
-528 \\
0 \\
-528 \\
2,849 \\
180 \\
\\
0 \\
2,141\end{array}$ & $\begin{array}{r}53,033 \\
45,692 \\
1,371 \\
1,204 \\
0 \\
5,910 \\
54,177 \\
-1,144 \\
0 \\
-1,144 \\
473 \\
0 \\
0 \\
0 \\
-671 \\
0 \\
0 \\
0 \\
0 \\
-671 \\
0 \\
0 \\
-672\end{array}$ & $\begin{array}{r}17,734 \\
13,841 \\
112 \\
115 \\
0 \\
3,708 \\
17,776 \\
-42 \\
0 \\
-42 \\
84 \\
0 \\
0 \\
0 \\
42 \\
\\
527 \\
3,428 \\
3,955 \\
-3,913 \\
6,557 \\
1,030 \\
1,614\end{array}$ & $\begin{array}{r}21,855 \\
17,968 \\
299 \\
253 \\
1,139 \\
2,550 \\
22,211 \\
-355 \\
0 \\
-355 \\
622 \\
0\end{array}$ & $\begin{array}{r}15,183 \\
14,035 \\
126 \\
242 \\
0 \\
0 \\
14,403 \\
780 \\
0 \\
780 \\
703 \\
1,616 \\
\\
0 \\
-133 \\
0 \\
0 \\
0 \\
0 \\
-133 \\
0 \\
0 \\
-133\end{array}$ \\
\hline
\end{tabular}

\begin{tabular}{|c|c|c|c|c|c|c|}
\hline Item & $\begin{array}{l}\text { Georgia } \\
\text { Covington } \\
\text { City of } \\
\text { December } 31\end{array}$ & $\begin{array}{l}\text { Georgia } \\
\text { Crisp } \\
\text { County } \\
\text { Power } \\
\text { Comm } \\
\text { December } 31\end{array}$ & $\begin{array}{l}\text { Georgia } \\
\text { Dalton } \\
\text { City of } \\
\text { November } 30\end{array}$ & $\begin{array}{l}\text { Georgia } \\
\text { Douglas } \\
\text { City of } \\
\text { June } 30\end{array}$ & $\begin{array}{l}\text { Georgia } \\
\text { East } \\
\text { Point } \\
\text { City of } \\
\text { June } 30\end{array}$ & $\begin{array}{l}\text { Georgia } \\
\text { Fitzgerald } \\
\text { Wir Lgt } \\
\text { \& Bond Comm } \\
\text { December } 31\end{array}$ \\
\hline 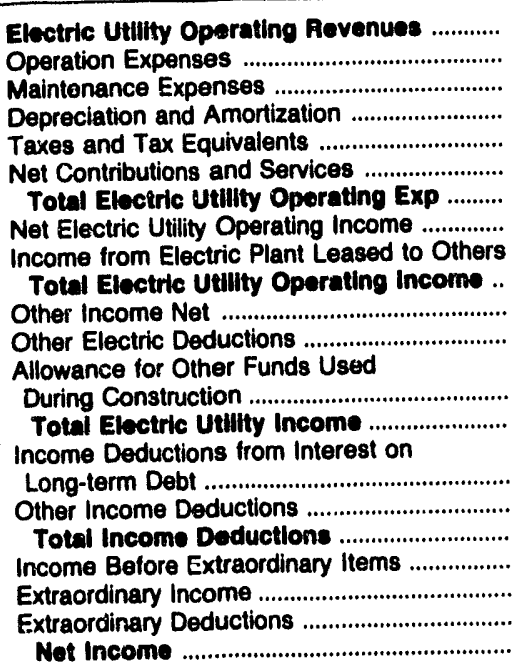 & $\begin{array}{r}13,083 \\
11,289 \\
145 \\
0 \\
0 \\
1,195 \\
12,629 \\
454 \\
0 \\
454 \\
37 \\
0 \\
0 \\
0 \\
491\end{array}$ & $\begin{array}{r}14,692 \\
11,041 \\
873 \\
1,123 \\
728 \\
242 \\
14,007 \\
685 \\
0 \\
685 \\
466 \\
38 \\
0 \\
1,113\end{array}$ & $\begin{array}{r}41,302 \\
24,252 \\
7,006 \\
6,171 \\
0 \\
304 \\
37,733 \\
3,569 \\
606 \\
4,175 \\
20,280 \\
1,780 \\
\\
0 \\
22,675\end{array}$ & $\begin{array}{r}12,216 \\
9,819 \\
122 \\
153 \\
0 \\
1,852 \\
11,946 \\
270 \\
0 \\
270 \\
87 \\
0 \\
0 \\
0 \\
357\end{array}$ & $\begin{array}{r}20,014 \\
17,222 \\
194 \\
367 \\
0 \\
0 \\
17,783 \\
2,232 \\
0 \\
2,232 \\
0 \\
0 \\
0 \\
0 \\
2,232\end{array}$ & $\begin{array}{r}9,600 \\
8,821 \\
527 \\
208 \\
0 \\
139 \\
9,694 \\
-14 \\
0 \\
-14 \\
984 \\
0 \\
0 \\
0 \\
989\end{array}$ \\
\hline
\end{tabular}

Note: Totals may not equal sum of components because of independent rounding.

Source: Energy Information Administration, Form EIA-412, "Annual Report of Public Electric Utilities." 
Table 36. Statement of Income by Major Publicly Owned Electric Utillty Within State, 1991 (Continued) (Thousand Dollars)

\begin{tabular}{|c|c|c|c|c|c|c|}
\hline Item & $\begin{array}{l}\text { Georgia } \\
\text { Griffin } \\
\text { City of } \\
\text { June } 30\end{array}$ & $\begin{array}{l}\text { Georgia } \\
\text { La Grange } \\
\text { City of } \\
\text { June } 30\end{array}$ & $\begin{array}{c}\text { Georgia } \\
\text { Lawrenceville } \\
\text { City of } \\
\text { August } 30\end{array}$ & $\begin{array}{l}\text { Georgia } \\
\text { Marietta } \\
\text { City of } \\
\text { June } 30\end{array}$ & $\begin{array}{l}\text { Georgia } \\
\text { Moultrie } \\
\text { City of } \\
\text { Seplember } 30\end{array}$ & $\begin{array}{l}\text { Georgia } \\
\text { Municipal } \\
\text { Electric } \\
\text { Authority } \\
\text { December } 31\end{array}$ \\
\hline 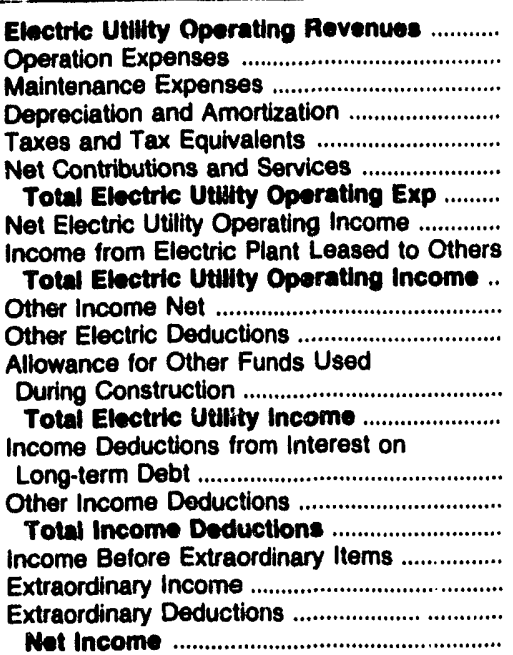 & $\begin{array}{r}19,945 \\
15,524 \\
7 \\
358 \\
0 \\
3,765 \\
19,653 \\
292 \\
0 \\
292 \\
-565 \\
0 \\
0 \\
0 \\
-273\end{array}$ & $\begin{array}{r}29,735 \\
23,895 \\
0 \\
0 \\
0 \\
4,999 \\
28,894 \\
841 \\
0 \\
841 \\
0 \\
0 \\
0 \\
041\end{array}$ & $\begin{array}{r}12,341 \\
10,931 \\
3 \\
430 \\
0 \\
977 \\
12,341 \\
0 \\
0 \\
0 \\
0 \\
0 \\
0 \\
0\end{array}$ & $\begin{array}{r}63,212 \\
43,392 \\
4,382 \\
1,275 \\
0 \\
1,236 \\
50,285 \\
12,928 \\
0 \\
12,928 \\
0 \\
0 \\
\\
0 \\
12,928\end{array}$ & $\begin{array}{r}11,133 \\
9,437 \\
0 \\
173 \\
0 \\
1,065 \\
10,675 \\
457 \\
0 \\
457 \\
163 \\
0 \\
\\
0 \\
620\end{array}$ & $\begin{array}{r}550,841 \\
168,472 \\
42,299 \\
123,014 \\
2,946 \\
0 \\
336,731 \\
214,110 \\
0 \\
214,110 \\
73,947 \\
0 \\
42 \\
48\end{array}$ \\
\hline
\end{tabular}

\begin{tabular}{|c|c|c|c|c|c|c|}
\hline Item & $\begin{array}{c}\text { Georgia } \\
\text { Thomasville } \\
\text { City of } \\
\text { December } 31\end{array}$ & $\begin{array}{l}\text { Idaho } \\
\text { Idaho } \\
\text { Falls } \\
\text { City of } \\
\text { September } 30\end{array}$ & $\begin{array}{l}\text { Illinois } \\
\text { Batavia } \\
\text { City of } \\
\text { December } 31\end{array}$ & $\begin{array}{l}\text { llinois } \\
\text { Geneva } \\
\text { City of } \\
\text { April } 30\end{array}$ & $\begin{array}{c}\text { Illinois } \\
\text { Illinois } \\
\text { Municipal } \\
\text { Elec Agency } \\
\text { April } 30\end{array}$ & $\begin{array}{l}\text { Illinois } \\
\text { Naperville } \\
\text { City of } \\
\text { April } 30\end{array}$ \\
\hline 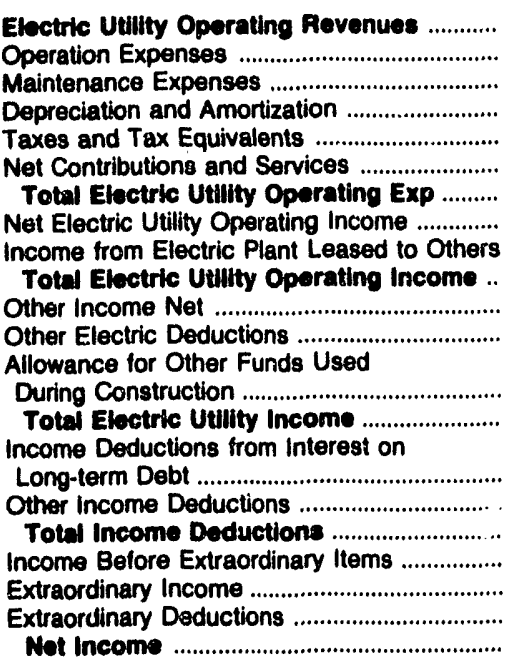 & $\begin{array}{r}23,123 \\
19,982 \\
525 \\
640 \\
873 \\
2,167 \\
24,187 \\
-1,064 \\
0 \\
-1,064 \\
91 \\
38 \\
0 \\
0 \\
-1,011 \\
0 \\
8 \\
8 \\
-1,019 \\
175 \\
0 \\
-844\end{array}$ & $\begin{array}{r}30,567 \\
16,710 \\
1,449 \\
3,285 \\
2,050 \\
19 \\
23,513 \\
7,053 \\
0 \\
7,053 \\
1,538 \\
394 \\
\\
0 \\
8,197 \\
\\
7,185 \\
127 \\
7,312 \\
885 \\
0 \\
3,407 \\
-2,522\end{array}$ & $\begin{array}{r}12,340 \\
11,383 \\
0 \\
504 \\
0 \\
291 \\
12,178 \\
162 \\
0 \\
162 \\
750 \\
0 \\
\\
0 \\
912 \\
\\
56 \\
0 \\
56 \\
855 \\
0 \\
0 \\
855\end{array}$ & $\begin{array}{r}8,813 \\
6,910 \\
0 \\
670 \\
354 \\
23 \\
7,956 \\
856 \\
0 \\
856 \\
36 \\
0 \\
\\
0 \\
892 \\
\\
0 \\
55 \\
55 \\
836 \\
0 \\
0 \\
836\end{array}$ & $\begin{array}{r}40,115 \\
39,864 \\
62 \\
519 \\
0 \\
0 \\
40,445 \\
-329 \\
0 \\
-329 \\
419 \\
110 \\
\\
0 \\
-20 \\
1,416 \\
163 \\
1,579 \\
-1,599 \\
1,439 \\
0 \\
-160\end{array}$ & $\begin{array}{r}50,431 \\
37,600 \\
284 \\
12,380 \\
2,046 \\
321 \\
52,631 \\
-2,200 \\
0 \\
-2,200 \\
5,914 \\
0 \\
\\
0 \\
3,715 \\
\\
825 \\
2,596 \\
3,421 \\
293 \\
0 \\
0 \\
2.93\end{array}$ \\
\hline
\end{tabular}

Note: Totals may not equal sum of components because of independent rounding.

Source: Energy Information Administration, Form ElA-412, "Annual Report of Public Electric Utilities." 
Table 36. Statement of Income by Major Publicly Owned Electric Utility Within State, 1991 (Continued) (Thousand Dollars)

\begin{tabular}{|c|c|c|c|c|c|c|}
\hline ltem & $\begin{array}{l}\text { Illinois } \\
\text { Rochelle } \\
\text { Municipal } \\
\text { Utilities } \\
\text { April } 30\end{array}$ & $\begin{array}{c}\text { Illinois } \\
\text { Springfield } \\
\text { City of } \\
\text { Februany } 28\end{array}$ & $\begin{array}{l}\text { Illinois } \\
\text { St Charles } \\
\text { City of } \\
\text { April } 30\end{array}$ & $\begin{array}{l}\text { Indiana } \\
\text { Anderson } \\
\text { City of } \\
\text { December } 31\end{array}$ & $\begin{array}{l}\text { Indiana } \\
\text { Auburn } \\
\text { City of } \\
\text { December } 31\end{array}$ & $\begin{array}{l}\text { Indiana } \\
\text { Bluffton } \\
\text { City of } \\
\text { December } 31\end{array}$ \\
\hline 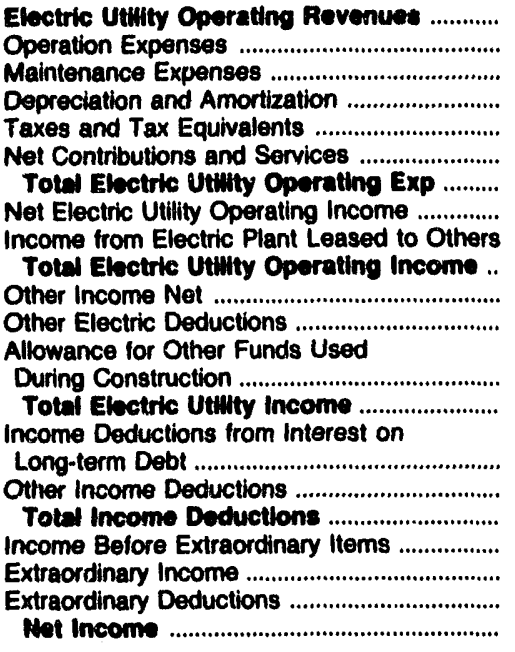 & $\begin{array}{r}10,441 \\
8,558 \\
527 \\
878 \\
0 \\
455 \\
10,418 \\
23 \\
0 \\
23 \\
499 \\
0 \\
0 \\
522 \\
496 \\
0 \\
496 \\
26 \\
0 \\
0 \\
26\end{array}$ & $\begin{array}{r}85,516 \\
48,441 \\
12,076 \\
11,510 \\
3,605 \\
0 \\
76,633 \\
9,884 \\
0 \\
9,894 \\
2,616 \\
0 \\
0 \\
12,500\end{array}$ & $\begin{array}{r}21,833 \\
14,807 \\
2,584 \\
773 \\
0 \\
1,569 \\
19,034 \\
2,000 \\
0 \\
2,000 \\
1,237 \\
0 \\
0 \\
0 \\
3,237 \\
0 \\
1,569 \\
1,569 \\
1,667 \\
0 \\
0 \\
1,667\end{array}$ & $\begin{array}{r}38,505 \\
32,107 \\
1,019 \\
1,272 \\
887 \\
0 \\
35,305 \\
1,120 \\
0 \\
1,120 \\
508 \\
0 \\
\\
0 \\
1,628 \\
\\
290 \\
11 \\
301 \\
1,327 \\
0 \\
0 \\
1,327\end{array}$ & $\begin{array}{r}13,765 \\
11,330 \\
257 \\
347 \\
161 \\
0 \\
12,095 \\
1,670 \\
0 \\
1,670 \\
347 \\
0 \\
\\
0 \\
2,017 \\
\\
51 \\
0 \\
51 \\
1,967 \\
0 \\
0 \\
1,967\end{array}$ & $\begin{array}{r}7,386 \\
6,832 \\
177 \\
242 \\
136 \\
0 \\
7,387 \\
9 \\
0 \\
9 \\
156 \\
6 \\
0 \\
159\end{array}$ \\
\hline
\end{tabular}

\begin{tabular}{|c|c|c|c|c|c|c|}
\hline Item & $\begin{array}{c}\text { Indiana } \\
\text { Crawfordsville } \\
\text { Elec } \\
\text { Lgt\&Pw Co } \\
\text { December } 31\end{array}$ & $\begin{array}{l}\text { Indiana } \\
\text { Frankfort } \\
\text { City of } \\
\text { December } 31\end{array}$ & $\begin{array}{c}\text { Indiana } \\
\text { Indiana } \\
\text { Municipal } \\
\text { Power Agency } \\
\text { December } 31\end{array}$ & $\begin{array}{l}\text { Indiana } \\
\text { Jasper } \\
\text { City of } \\
\text { December } 31\end{array}$ & $\begin{array}{c}\text { Indiana } \\
\text { Logansport } \\
\text { Clty of } \\
\text { December } 31\end{array}$ & $\begin{array}{c}\text { Indiana } \\
\text { Mishawaka } \\
\text { City of } \\
\text { December } 31\end{array}$ \\
\hline 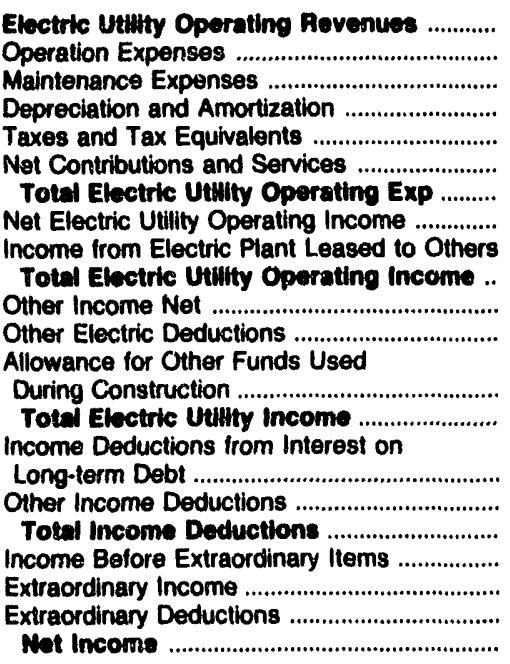 & $\begin{array}{r}17,581 \\
14,035 \\
1,085 \\
915 \\
420 \\
174 \\
18,629 \\
952 \\
0 \\
952 \\
211 \\
11 \\
3 \\
3 \\
1,155 \\
433 \\
240 \\
673 \\
482 \\
0 \\
0 \\
482\end{array}$ & $\begin{array}{r}14,694 \\
13,321 \\
325 \\
468 \\
227 \\
0 \\
14,339 \\
356 \\
0 \\
358 \\
243 \\
28\end{array}$ & $\begin{array}{r}141,097 \\
121,499 \\
3,098 \\
5,122 \\
697 \\
0 \\
130,415 \\
10,682 \\
0 \\
10,682 \\
5,574 \\
5 \\
3,725 \\
19,976\end{array}$ & $\begin{array}{r}12,767 \\
11,198 \\
277 \\
208 \\
249 \\
119 \\
12,051 \\
716 \\
0 \\
716 \\
26 \\
0 \\
0 \\
0 \\
742\end{array}$ & $\begin{array}{r}17,546 \\
13,220 \\
950 \\
1,581 \\
351 \\
0 \\
18,102 \\
1,444 \\
0 \\
1,444 \\
604 \\
0 \\
0 \\
0 \\
2,048\end{array}$ & $\begin{array}{r}24,066 \\
20,656 \\
825 \\
1,140 \\
180 \\
471 \\
23,273 \\
793 \\
0 \\
793 \\
0 \\
0 \\
0 \\
0 \\
793\end{array}$ \\
\hline
\end{tabular}

Note: Totals may not equal sum of components because of independent rounding.

Source: Energy Information Administration, Form ElA-412, "Annual Report of Public Electric Utilities." 
Table 36. Statement of Income by Major Publicly Owned Electric Utillty Within State, 1991 (Continued) (Thousand Dollars)

\begin{tabular}{|c|c|c|c|c|c|c|}
\hline Item & $\begin{array}{c}\text { Indiana } \\
\text { Peru } \\
\text { City of } \\
\text { December } 31\end{array}$ & $\begin{array}{l}\text { Indiana } \\
\text { Fichmond } \\
\text { City of } \\
\text { December } 31\end{array}$ & $\begin{array}{c}\text { Indiana } \\
\begin{array}{c}\text { Washington } \\
\text { City of }\end{array} \\
\text { December } 31\end{array}$ & $\begin{array}{l}\text { lowa } \\
\text { Ames } \\
\text { City of } \\
\text { June } 30\end{array}$ & $\begin{array}{c}\text { lowa } \\
\text { Cedar } \\
\text { Falls } \\
\text { City of } \\
\text { December } 31\end{array}$ & $\begin{array}{c}\text { lowa } \\
\text { Muscatine } \\
\text { City of } \\
\text { December } 31\end{array}$ \\
\hline 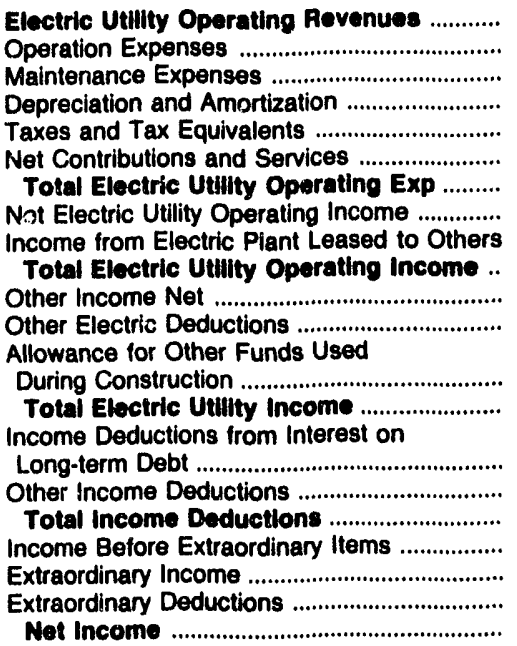 & $\begin{array}{r}8,615 \\
6,947 \\
398 \\
897 \\
322 \\
206 \\
8,770 \\
-155 \\
0 \\
-155 \\
169 \\
15\end{array}$ & $\begin{array}{r}34,838 \\
27,705 \\
2,382 \\
2,514 \\
1,650 \\
0 \\
34,251 \\
587 \\
0 \\
587 \\
1,180 \\
72 \\
0 \\
1,695\end{array}$ & $\begin{array}{r}7,738 \\
6,680 \\
210 \\
333 \\
171 \\
0 \\
7,394 \\
344 \\
0 \\
344 \\
84 \\
0 \\
\\
0 \\
428\end{array}$ & $\begin{array}{r}20,116 \\
10,555 \\
1,772 \\
3,306 \\
301 \\
427 \\
16,361 \\
3,755 \\
0 \\
3,755 \\
1,212 \\
0 \\
0 \\
4,967\end{array}$ & $\begin{array}{r}14,285 \\
7,844 \\
1,743 \\
2,147 \\
616 \\
506 \\
12,855 \\
1,430 \\
0 \\
1,430 \\
918 \\
47 \\
0 \\
0 \\
2,301\end{array}$ & $\begin{array}{r}72,702 \\
37,953 \\
4,687 \\
9,409 \\
109 \\
572 \\
52,729 \\
19,973 \\
0 \\
19,973 \\
13,894 \\
0 \\
0 \\
33,867\end{array}$ \\
\hline
\end{tabular}

\begin{tabular}{|c|c|c|c|c|c|c|}
\hline ltem & $\begin{array}{c}\text { Kansas } \\
\begin{array}{c}\text { Coffeyville } \\
\text { City of }\end{array} \\
\text { December } 31\end{array}$ & $\begin{array}{c}\text { Kansas } \\
\text { Garden } \\
\text { City City of } \\
\text { December } 31\end{array}$ & $\begin{array}{c}\text { Kansas } \\
\text { Kansas } \\
\text { City City of } \\
\text { December } 31\end{array}$ & $\begin{array}{c}\text { Kansas } \\
\text { Kansas } \\
\text { Municipal } \\
\text { Energy } \\
\text { Agency } \\
\text { December } 31\end{array}$ & $\begin{array}{c}\text { Kansas } \\
\begin{array}{c}\text { McPherson } \\
\text { City of }\end{array} \\
\text { December } 31\end{array}$ & $\begin{array}{c}\text { Kansas } \\
\text { Winfield } \\
\text { City of } \\
\text { December } 31\end{array}$ \\
\hline 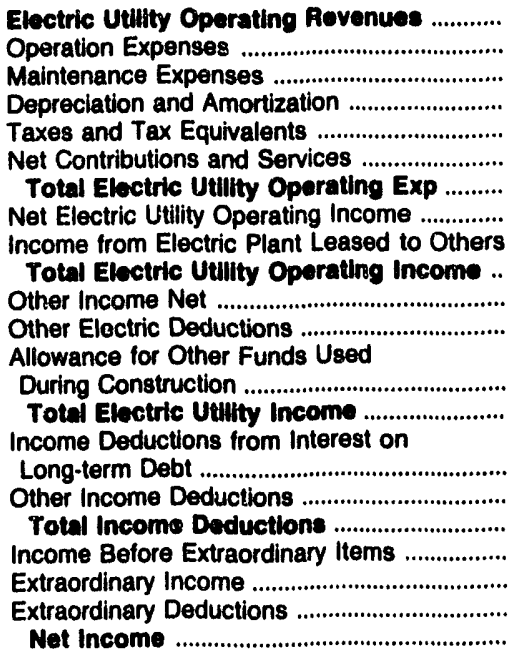 & $\begin{array}{r}10,823 \\
6,267 \\
691 \\
1,176 \\
550 \\
304 \\
8,989 \\
1,834 \\
0 \\
1,834 \\
521 \\
0 \\
0 \\
2,355\end{array}$ & $\begin{array}{r}10,819 \\
9,556 \\
0 \\
539 \\
0 \\
0 \\
10,095 \\
725 \\
0 \\
725 \\
5 \\
0 \\
0 \\
730\end{array}$ & $\begin{array}{r}122,169 \\
75,148 \\
18,674 \\
16,046 \\
1,941 \\
0 \\
111,809 \\
10,359 \\
0 \\
10,359 \\
3,772 \\
0 \\
0 \\
0 \\
14,132\end{array}$ & $\begin{array}{r}11,931 \\
11,742 \\
1 \\
889 \\
0 \\
0 \\
12,632 \\
-701 \\
0 \\
-701 \\
516 \\
0 \\
0 \\
0 \\
-185\end{array}$ & $\begin{array}{r}18,531 \\
14,451 \\
1,045 \\
1,586 \\
0 \\
650 \\
17,732 \\
799 \\
0 \\
799 \\
1,350 \\
0 \\
0 \\
0 \\
2,149\end{array}$ & $\begin{array}{r}11,615 \\
9,823 \\
257 \\
671 \\
0 \\
828 \\
11,579 \\
36 \\
0 \\
36 \\
861 \\
0 \\
\\
0 \\
898\end{array}$ \\
\hline
\end{tabular}

Note: Totals may not equal sum of components because of independent rounding.

Source: Energy Information Administration, Form EIA-412, "Annual Report of Public Electric Utilities." 


\section{Table 36. Statement of Income by Major Publicly Owned Electric Utility Within State, 1991 (Continued)}

(Thousand Dollars)

\begin{tabular}{|c|c|c|c|c|c|c|}
\hline Item & $\begin{array}{l}\text { Kentucky } \\
\text { Bowling } \\
\text { Green } \\
\text { City of } \\
\text { June } 30\end{array}$ & $\begin{array}{l}\text { Kentucky } \\
\text { Frankfort } \\
\text { City of } \\
\text { June } 30\end{array}$ & $\begin{array}{l}\text { Kentucky } \\
\text { Franklin } \\
\text { City of } \\
\text { June } 30\end{array}$ & $\begin{array}{l}\text { Kentucky } \\
\text { Glasgow } \\
\text { City of } \\
\text { June } 30\end{array}$ & $\begin{array}{l}\text { Kentucky } \\
\text { Henderson } \\
\text { City } \\
\text { Utility Comm } \\
\text { May } 31\end{array}$ & $\begin{array}{c}\text { Kentucky } \\
\text { Hopkinsville } \\
\text { City of } \\
\text { June } 30\end{array}$ \\
\hline 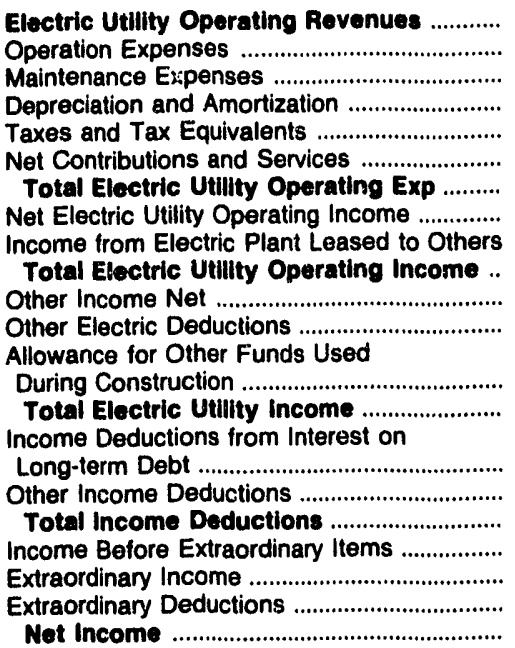 & $\begin{array}{r}36,197 \\
31,533 \\
853 \\
1,171 \\
399 \\
1,038 \\
34,994 \\
1,203 \\
0 \\
1,203 \\
326 \\
0\end{array}$ & $\begin{array}{r}21,913 \\
20,042 \\
948 \\
709 \\
74 \\
22 \\
21,795 \\
118 \\
0 \\
118 \\
5,184 \\
4,332\end{array}$ & $\begin{array}{r}9,382 \\
8,817 \\
158 \\
125 \\
339 \\
0 \\
9,439 \\
-57 \\
0 \\
-57 \\
15 \\
16 \\
\\
103 \\
45\end{array}$ & $\begin{array}{r}13,731 \\
12,864 \\
612 \\
549 \\
135 \\
0 \\
13,861 \\
-130 \\
0 \\
-130 \\
131 \\
16 \\
0 \\
0 \\
-15 \\
246 \\
0 \\
246 \\
-261 \\
0 \\
0 \\
-261\end{array}$ & $\begin{array}{r}22,860 \\
11,188 \\
4,208 \\
3,800 \\
0 \\
1,209 \\
20,403 \\
2,457 \\
0 \\
2,457 \\
2,338 \\
0 \\
0 \\
0 \\
4,795 \\
\\
3,035 \\
277 \\
3,311 \\
1,483 \\
0 \\
0 \\
1,483\end{array}$ & $\begin{array}{r}19,562 \\
18,102 \\
501 \\
495 \\
665 \\
0 \\
19,762 \\
-200 \\
0 \\
-200 \\
322 \\
0 \\
0 \\
0 \\
121\end{array}$ \\
\hline
\end{tabular}

\begin{tabular}{|c|c|c|c|c|c|c|}
\hline Item & $\begin{array}{l}\text { Kentucky } \\
\text { Madisonville } \\
\text { Municipal } \\
\text { Utils } \\
\text { June } 30\end{array}$ & $\begin{array}{l}\text { Kentucky } \\
\text { Mayfield } \\
\text { City of } \\
\text { June } 30\end{array}$ & $\begin{array}{l}\text { Kentucky } \\
\text { Murray } \\
\text { City of } \\
\text { June } 30\end{array}$ & $\begin{array}{l}\text { Kentucky } \\
\text { Owensboro } \\
\text { City of } \\
\text { May } 31\end{array}$ & $\begin{array}{l}\text { Kentucky } \\
\text { Paducah } \\
\text { City of } \\
\text { June } 30\end{array}$ & $\begin{array}{l}\text { Louisiana } \\
\text { Alexandria } \\
\text { City of } \\
\text { April } 30\end{array}$ \\
\hline 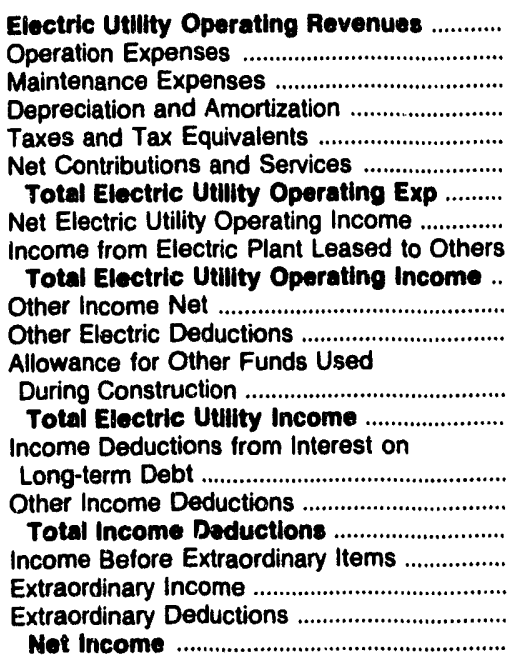 & $\begin{array}{r}12,022 \\
8,932 \\
613 \\
177 \\
0 \\
3,197 \\
12,019 \\
-897 \\
0 \\
-897 \\
424 \\
0 \\
0 \\
-472 \\
0 \\
0 \\
0 \\
-472 \\
0 \\
0 \\
-472\end{array}$ & $\begin{array}{r}7,957 \\
7,350 \\
327 \\
132 \\
339 \\
0 \\
8,148 \\
-192 \\
0 \\
-192 \\
21 \\
0 \\
\\
0 \\
-171 \\
0 \\
14 \\
14 \\
-184 \\
0 \\
0 \\
-184\end{array}$ & $\begin{array}{r}12,150 \\
11,250 \\
372 \\
296 \\
477 \\
0 \\
12,395 \\
-244 \\
0 \\
-244 \\
114 \\
0 \\
0 \\
0 \\
-130\end{array}$ & $\begin{array}{r}42,647 \\
26,664 \\
5,894 \\
4,403 \\
843 \\
2,499 \\
40,304 \\
2,343 \\
0 \\
2,343 \\
5,940 \\
0 \\
0 \\
0,283\end{array}$ & $\begin{array}{r}30,660 \\
26,483 \\
834 \\
1,272 \\
1,233 \\
0 \\
29,823 \\
838 \\
0 \\
838 \\
349 \\
1 \\
0 \\
1,185\end{array}$ & $\begin{array}{r}38,064 \\
25,224 \\
952 \\
1,647 \\
2,071 \\
1,552 \\
31,444 \\
6,620 \\
0 \\
6,620 \\
1,571 \\
0 \\
0 \\
0,191\end{array}$ \\
\hline
\end{tabular}

Note: Totals may not equal sum of components because of independent rounding.

Source: Energy Information Administration, Form EiA-412, "Annual Report of Public Electric Utilities." 
Table 36. Statement of Income by Major Publicly Owned Electric Utility Within State, 1991 (Continued)

(Thousand Dollars)

\begin{tabular}{|c|c|c|c|c|c|c|}
\hline Item & $\begin{array}{l}\text { Lovisiana } \\
\text { Lafayette } \\
\text { City of } \\
\text { October } 31\end{array}$ & $\begin{array}{l}\text { Louisiana } \\
\text { Louisiana } \\
\text { Energy } \\
\& \\
\text { Power Auth } \\
\text { December } 31\end{array}$ & $\begin{array}{l}\text { Louisiana } \\
\text { Morgan } \\
\text { City City of } \\
\text { December } 31\end{array}$ & $\begin{array}{l}\text { Louisiana } \\
\begin{array}{c}\text { Natchitoches } \\
\text { City of }\end{array} \\
\text { May } 31\end{array}$ & $\begin{array}{l}\text { Louisiana } \\
\text { Auston } \\
\text { City of } \\
\text { September } 30\end{array}$ & $\begin{array}{c}\text { Louisiana } \\
\text { Terrebonne } \\
\text { Parish } \\
\text { Consol Govt } \\
\text { December } 31\end{array}$ \\
\hline 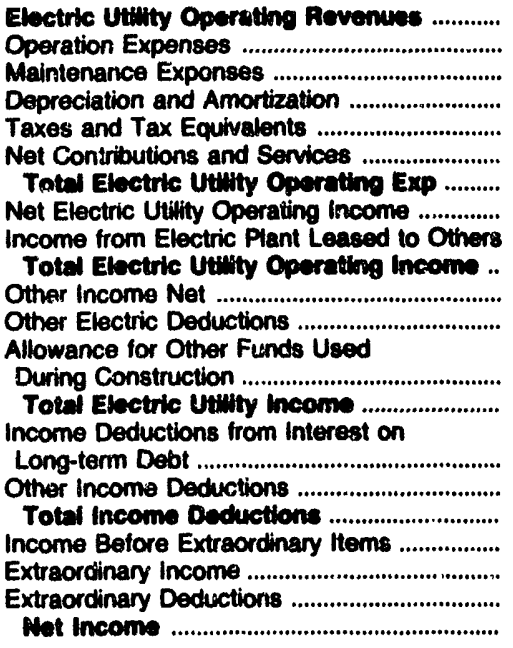 & $\begin{array}{r}0,092 \\
74,363 \\
2,675 \\
3,722 \\
6,808 \\
0 \\
07,59 \\
11,324 \\
0 \\
11,324 \\
3,729 \\
0 \\
0 \\
15,053\end{array}$ & $\begin{array}{r}61,597 \\
50,022 \\
0 \\
3,803 \\
0 \\
0 \\
53,924 \\
7,663 \\
0 \\
7,603 \\
2,773 \\
0 \\
0 \\
10,436\end{array}$ & $\begin{array}{r}10,197 \\
7,824 \\
265 \\
752 \\
0 \\
801 \\
9,242 \\
354 \\
0 \\
364 \\
0 \\
0 \\
0 \\
354 \\
471 \\
0 \\
471 \\
-117 \\
0 \\
0 \\
-117\end{array}$ & $\begin{array}{r}10,750 \\
8,926 \\
513 \\
759 \\
0 \\
0 \\
10,180 \\
551 \\
1,018 \\
1,1669 \\
0 \\
0 \\
0 \\
1,569 \\
385 \\
0 \\
385 \\
1,184 \\
0 \\
0 \\
1,184\end{array}$ & $\begin{array}{r}10,464 \\
7,553 \\
588 \\
756 \\
0 \\
858 \\
0,754 \\
710 \\
0 \\
710 \\
222 \\
0 \\
0 \\
932\end{array}$ & $\begin{array}{r}17,030 \\
13,205 \\
498 \\
1,822 \\
0 \\
340 \\
16,005 \\
1,174 \\
0 \\
1,174 \\
0 \\
314 \\
0 \\
0 \\
859\end{array}$ \\
\hline
\end{tabular}

\begin{tabular}{|c|c|c|c|c|c|c|}
\hline Item & $\begin{array}{l}\text { Maryland } \\
\text { Easton } \\
\text { Utilities } \\
\text { Comm } \\
\text { June } 30\end{array}$ & $\begin{array}{l}\text { Maryland } \\
\text { Hagerstown } \\
\text { City of } \\
\text { December } 31\end{array}$ & $\begin{array}{l}\text { Massechusetts } \\
\text { Braintree } \\
\text { Town of } \\
\text { December } 31\end{array}$ & $\begin{array}{l}\text { Massachusetts } \\
\text { Chicopee } \\
\text { City of } \\
\text { December } 31\end{array}$ & $\begin{array}{l}\text { Massachusetts } \\
\text { Concord } \\
\text { Town of } \\
\text { Desember } 31\end{array}$ & $\begin{array}{c}\text { Massachusetts } \\
\text { Danvers } \\
\text { Town of } \\
\text { December } 31\end{array}$ \\
\hline 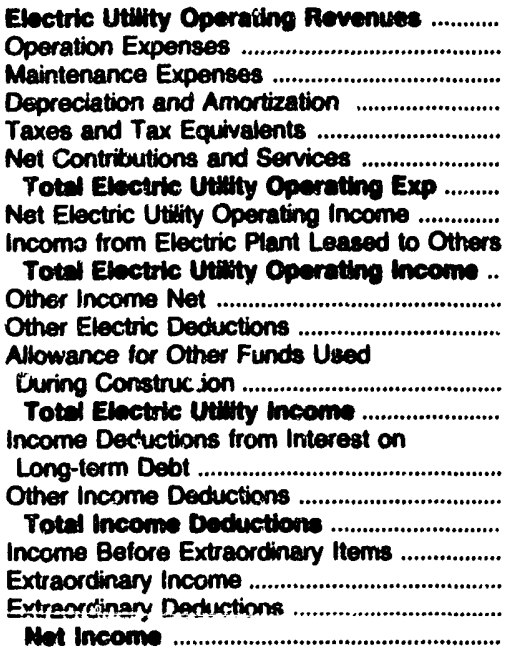 & $\begin{array}{r}13,127 \\
8,897 \\
805 \\
1,234 \\
395 \\
0 \\
11,380 \\
1,797 \\
0 \\
1,707 \\
183 \\
0 \\
0 \\
1,881\end{array}$ & $\begin{array}{r}15,025 \\
13,189 \\
236 \\
743 \\
367 \\
359 \\
14,004 \\
831 \\
0 \\
831 \\
253 \\
0 \\
0 \\
1,184\end{array}$ & $\begin{array}{r}31,570 \\
25,864 \\
2,200 \\
1,828 \\
23 \\
0 \\
29,915 \\
1,656 \\
0 \\
1,665 \\
157 \\
0 \\
0 \\
1,813\end{array}$ & $\begin{array}{r}30,020 \\
23,373 \\
1,726 \\
1,807 \\
200 \\
0 \\
27,107 \\
3,714 \\
0 \\
3,714 \\
1,480 \\
3 \\
0 \\
5,201\end{array}$ & $\begin{array}{r}14,614 \\
12,508 \\
207 \\
670 \\
235 \\
182 \\
13,802 \\
811 \\
0 \\
811 \\
545 \\
0 \\
0 \\
1,357\end{array}$ & $\begin{array}{r}32,702 \\
28,581 \\
872 \\
864 \\
0 \\
1,682 \\
31,808 \\
703 \\
0 \\
703 \\
524 \\
0 \\
0 \\
0 \\
1,067\end{array}$ \\
\hline
\end{tabular}

Note: Totals may not equal sum of components because of independent rounding.

Source: Energy information Administration, Form ElA-412, "Annual Report of Public Electric Utilities." 

Table 36. Statement of Income by Major Publicly Owned Electric
Utility Within State, 1991 (Continued)

(Thousand Dollars)

\begin{tabular}{|c|c|c|c|c|c|c|}
\hline Item & $\begin{array}{l}\text { Massachusetts } \\
\text { Hingham } \\
\text { City of } \\
\text { December } 31\end{array}$ & $\begin{array}{l}\text { Massachusetts } \\
\text { Holyoke } \\
\text { City of } \\
\text { Jecember } 31\end{array}$ & $\begin{array}{c}\text { Massachusetts } \\
\text { Hudson } \\
\text { Town of } \\
\text { December } 31\end{array}$ & $\begin{array}{c}\text { Massachusetts } \\
\text { Littleton } \\
\text { Town of } \\
\text { Deceinber } 31\end{array}$ & $\begin{array}{c}\text { Massachusetts } \\
\text { Mansfield } \\
\text { Town of } \\
\text { December } 31\end{array}$ & $\begin{array}{c}\text { Massachusetts } \\
\text { Massachusetts } \\
\text { Mun } \\
\text { Whis } \\
\text { Elec Co } \\
\text { December } 31\end{array}$ \\
\hline 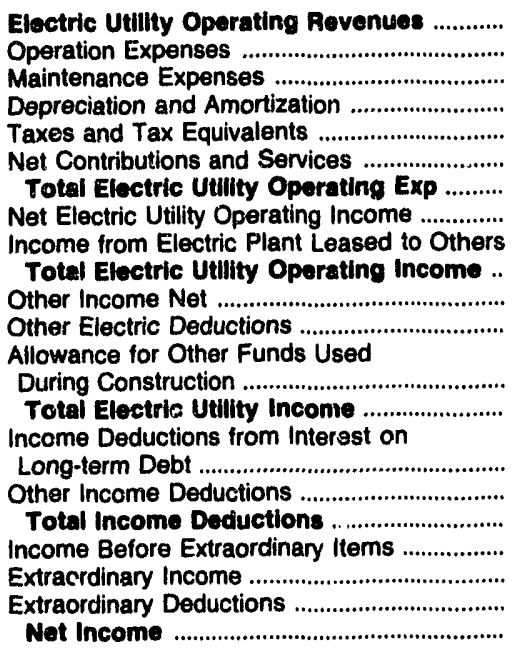 & $\begin{array}{r}14,19 \\
12,808 \\
730 \\
584 \\
0 \\
196 \\
14,318 \\
401 \\
0 \\
401 \\
46 \\
0 \\
0 \\
0 \\
447 \\
251 \\
15 \\
267 \\
181 \\
0 \\
0 \\
181\end{array}$ & $\begin{array}{r}26,443 \\
21,813 \\
1,386 \\
1,307 \\
0 \\
1,550 \\
28,056 \\
387 \\
0 \\
367 \\
552 \\
0\end{array}$ & $\begin{array}{r}30,212 \\
29,260 \\
544 \\
0 \\
230 \\
0 \\
30,034 \\
178 \\
0 \\
178 \\
494 \\
0 \\
0 \\
673 \\
0 \\
1 \\
1 \\
672 \\
1,264 \\
0 \\
1,936\end{array}$ & $\begin{array}{r}17,417 \\
15,378 \\
335 \\
524 \\
106 \\
0 \\
16,343 \\
1,074 \\
0 \\
1,074 \\
328 \\
0 \\
\\
0 \\
1,401\end{array}$ & $\begin{array}{r}19,483 \\
18,030 \\
439 \\
408 \\
198 \\
630 \\
19,705 \\
-222 \\
0 \\
-222 \\
95 \\
0 \\
0 \\
0 \\
-126\end{array}$ & $\begin{array}{r}276,487 \\
138,346 \\
11,303 \\
44,751 \\
8,094 \\
0 \\
202,484 \\
73,993 \\
0 \\
73,893 \\
18,924 \\
0 \\
\\
867 \\
93,885 \\
\\
133,926 \\
1,590 \\
135,525 \\
-41,640 \\
41,640 \\
0 \\
0\end{array}$ \\
\hline
\end{tabular}

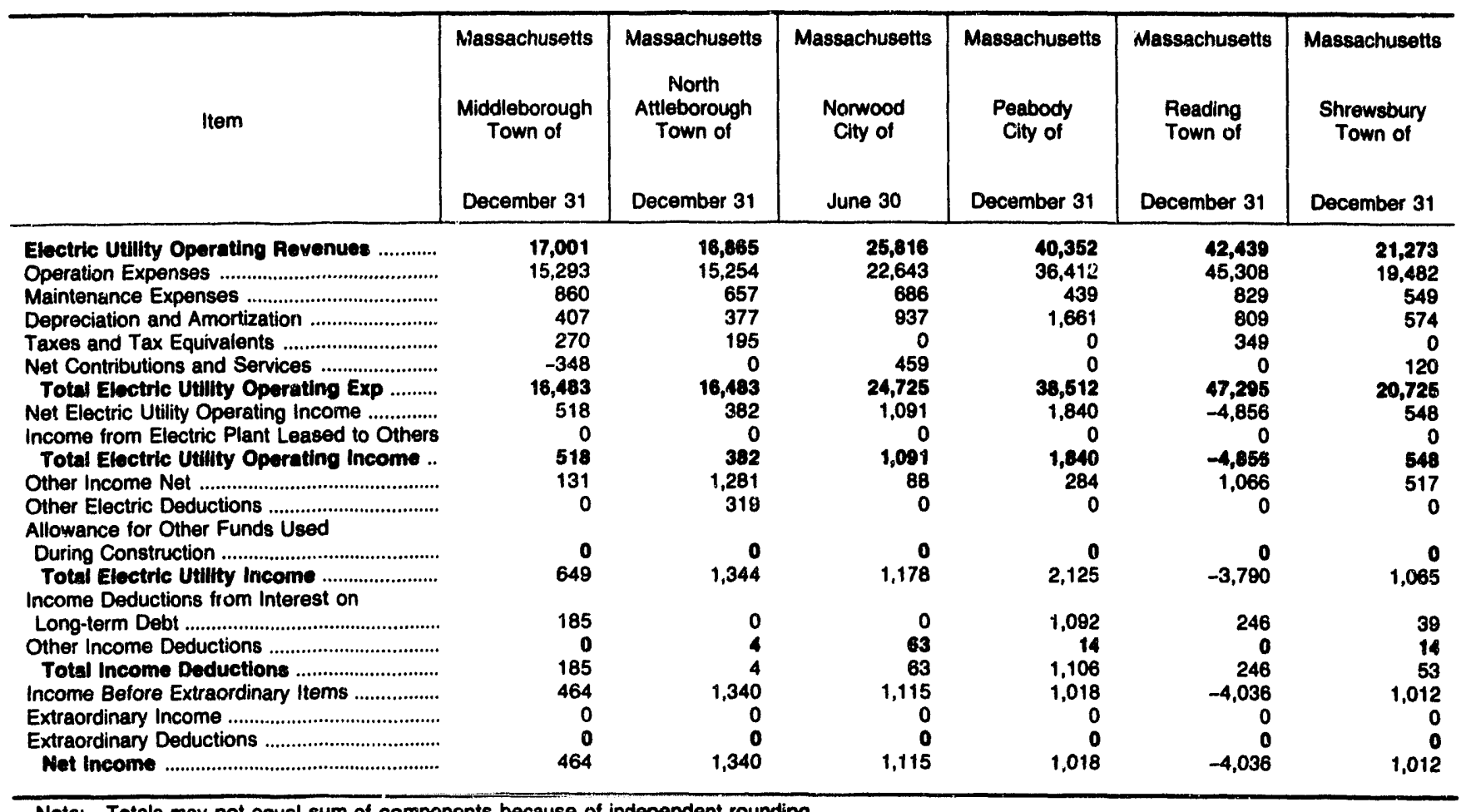

Note: Totals may not equal sum of components because of independent rounding.

Source: Energy Information Administration, Form ElA-412, "Annual Report of Public Electric Utilities." 


\section{Table 36. Statement of Income by Major Publicly Owned Electric Utllity Within State, 1991 (Continued)}

(Thousand Dollars)

\begin{tabular}{|c|c|c|c|c|c|c|}
\hline Item & $\begin{array}{l}\text { Massachusetts } \\
\text { Taunton } \\
\text { City of } \\
\text { December } 31\end{array}$ & $\begin{array}{l}\text { Massachusetts } \\
\text { Wakefield } \\
\text { Town of } \\
\text { December } 31\end{array}$ & $\begin{array}{l}\text { Massachusetts } \\
\text { Wellesley } \\
\text { Town of } \\
\text { December } 31\end{array}$ & $\begin{array}{c}\text { Massachusetts } \\
\text { Westfield } \\
\text { City of } \\
\text { December } 31\end{array}$ & $\begin{array}{l}\text { Michigan } \\
\text { Bay } \\
\text { City City of } \\
\text { June } 30\end{array}$ & $\begin{array}{l}\text { Michigan } \\
\text { Coldwater } \\
\text { Board } \\
\text { of } \\
\text { Public Util } \\
\text { June } 30\end{array}$ \\
\hline 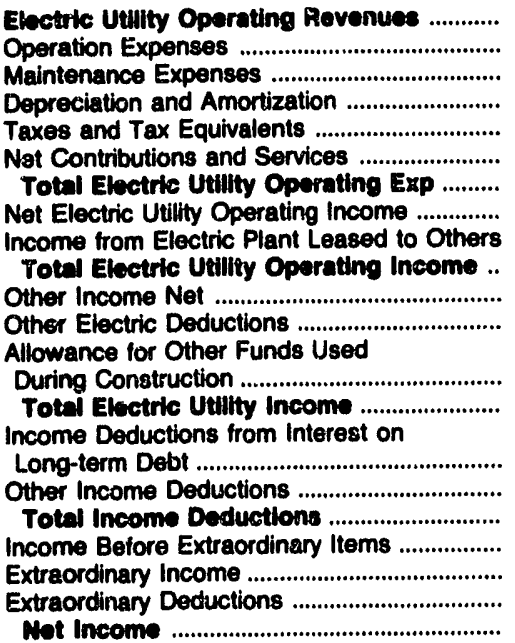 & $\begin{array}{r}36,522 \\
25,451 \\
3,353 \\
3,191 \\
2,360 \\
0 \\
34,355 \\
2,167 \\
0 \\
2,167 \\
501 \\
0 \\
\\
0 \\
2,668\end{array}$ & $\begin{array}{r}14,804 \\
13,787 \\
350 \\
585 \\
587 \\
0 \\
15,309 \\
-505 \\
0 \\
-505 \\
92 \\
0 \\
0 \\
-413 \\
4 \\
18 \\
21 \\
-435 \\
0 \\
0 \\
-435\end{array}$ & $\begin{array}{r}18,370 \\
16,098 \\
1,151 \\
556 \\
0 \\
0 \\
17,804 \\
566 \\
0 \\
566 \\
493 \\
0 \\
\\
0 \\
1,059\end{array}$ & $\begin{array}{r}32,682 \\
31,397 \\
1,141 \\
559 \\
180 \\
0 \\
33,276 \\
-594 \\
333 \\
-280 \\
0 \\
0 \\
0 \\
0 \\
-260\end{array}$ & $\begin{array}{r}15,228 \\
9,284 \\
900 \\
839 \\
210 \\
557 \\
11,791 \\
3,437 \\
0 \\
3,437 \\
1,061 \\
506 \\
0 \\
0,992\end{array}$ & $\begin{array}{r}10,085 \\
9,523 \\
218 \\
370 \\
707 \\
0 \\
10,819 \\
-734 \\
0 \\
-734 \\
421 \\
0 \\
0 \\
0 \\
-313\end{array}$ \\
\hline
\end{tabular}

\begin{tabular}{|c|c|c|c|c|c|c|}
\hline Item & $\begin{array}{l}\text { Michigan } \\
\text { Detroit } \\
\text { City of } \\
\text { June } 30\end{array}$ & $\begin{array}{c}\text { Michigan } \\
\text { Grand Haven } \\
\text { City of } \\
\text { June } 30\end{array}$ & $\begin{array}{l}\text { Michigan } \\
\text { Hillsdale } \\
\text { Board } \\
\text { of } \\
\text { Public Wks } \\
\text { June } 30\end{array}$ & $\begin{array}{l}\text { Michigan } \\
\text { Holland } \\
\text { City of } \\
\text { June } 30\end{array}$ & $\begin{array}{l}\text { Michigan } \\
\text { Lansing } \\
\text { City of } \\
\text { June } 30\end{array}$ & $\begin{array}{l}\text { Michigan } \\
\text { Marquette } \\
\text { City of } \\
\text { June } 30\end{array}$ \\
\hline 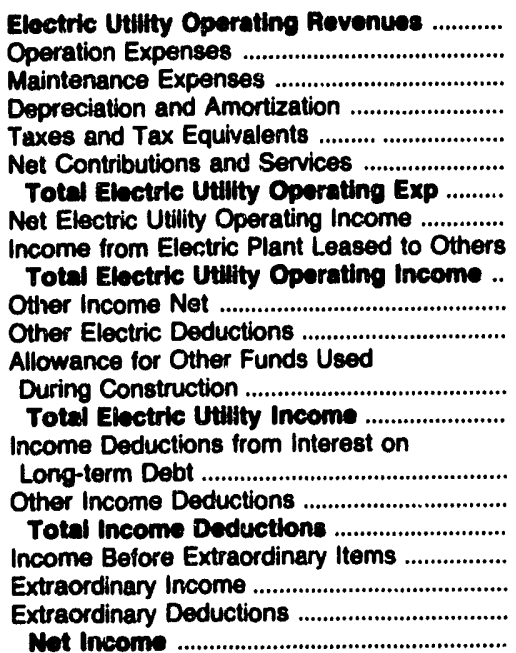 & $\begin{array}{r}77,216 \\
38,517 \\
12,180 \\
4,408 \\
0 \\
-544 \\
54,561 \\
22,655 \\
0 \\
22,655 \\
0 \\
0 \\
\\
0 \\
22,655\end{array}$ & $\begin{array}{r}20,169 \\
11,230 \\
931 \\
3,189 \\
0 \\
781 \\
16,130 \\
4,039 \\
0 \\
4,039 \\
1,276 \\
0 \\
\\
0 \\
5,315 \\
\\
6,832 \\
13 \\
6,845 \\
-1,530 \\
118 \\
0 \\
-1,412\end{array}$ & $\begin{array}{r}8,976 \\
7,922 \\
354 \\
420 \\
227 \\
0 \\
8,924 \\
52 \\
0 \\
52 \\
261 \\
0 \\
0 \\
313\end{array}$ & $\begin{array}{r}31,363 \\
23,239 \\
1,757 \\
2,800 \\
0 \\
935 \\
28,731 \\
2,633 \\
0 \\
2,633 \\
2,094 \\
0 \\
\\
0 \\
4,727 \\
856 \\
0 \\
056 \\
3,871 \\
0 \\
0 \\
3,871\end{array}$ & $\begin{array}{r}113,514 \\
85,725 \\
9,194 \\
12,275 \\
0 \\
3,674 \\
110,869 \\
2,645 \\
0 \\
2,645 \\
4,819 \\
0 \\
0 \\
7,464 \\
\\
671 \\
198 \\
869 \\
6,595 \\
0 \\
0 \\
6,595\end{array}$ & $\begin{array}{r}18,344 \\
9,822 \\
1,597 \\
2,984 \\
1,458 \\
0 \\
15,862 \\
2,482 \\
0 \\
2,482 \\
1,852 \\
0 \\
0 \\
0 \\
4,335 \\
\\
3,473 \\
69 \\
3,541 \\
794 \\
0 \\
0 \\
794\end{array}$ \\
\hline
\end{tabular}

PHote: Totâts may inot equal sum of compononts bacauss of indopondont reinding.

Source: Energy Information Administration, Form ElA-412, "Annual Report of Public Electric Utilities." 


\section{Table 36. Statement of Income by Major Publicly Owned Electric Utility Within State, 1991 (Continued) (Thousand Dollars)}

\begin{tabular}{|c|c|c|c|c|c|c|}
\hline Item & $\begin{array}{l}\text { Michigan } \\
\text { Michigan } \\
\text { Public } \\
\text { Power Agency } \\
\text { December } 31\end{array}$ & $\begin{array}{l}\text { Michigan } \\
\text { Michigan } \\
\text { South } \\
\text { Central } \\
\text { Pwr Agy } \\
\text { June } 30\end{array}$ & $\begin{array}{c}\text { Michigan } \\
\text { Sturgis } \\
\text { City of } \\
\text { September } 30\end{array}$ & $\begin{array}{l}\text { Michigan } \\
\text { Traverse } \\
\text { City City of } \\
\text { June } 30\end{array}$ & $\begin{array}{l}\text { Michigan } \\
\text { Wyandotte } \\
\text { Municipal } \\
\text { Serv Comm } \\
\text { September } 30\end{array}$ & $\begin{array}{l}\text { Minnesota } \\
\text { Alexandria } \\
\text { Clty of } \\
\text { December } 31\end{array}$ \\
\hline 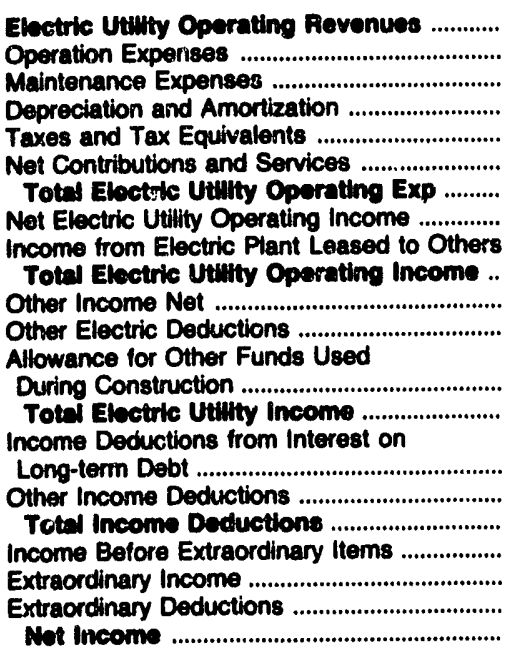 & $\begin{array}{r}93,602 \\
18,464 \\
4,029 \\
13,947 \\
622 \\
0 \\
37,062 \\
46,541 \\
0 \\
46,541 \\
12,484 \\
0\end{array}$ & $\begin{array}{r}24,726 \\
15,760 \\
1,036 \\
2,833 \\
40 \\
0 \\
19,668 \\
5,058 \\
0 \\
5,058 \\
1,756 \\
0 \\
0 \\
0 \\
6,814\end{array}$ & $\begin{array}{r}12,164 \\
8,635 \\
533 \\
917 \\
858 \\
402 \\
11,346 \\
818 \\
0 \\
818 \\
807 \\
0 \\
0 \\
1,625\end{array}$ & $\begin{array}{r}13,707 \\
9,292 \\
2,050 \\
764 \\
0 \\
695 \\
12,801 \\
906 \\
0 \\
806 \\
311 \\
0 \\
\\
0 \\
1,218\end{array}$ & $\begin{array}{r}17,419 \\
14,311 \\
812 \\
1,889 \\
0 \\
0 \\
17,022 \\
397 \\
0 \\
397 \\
743 \\
0\end{array}$ & $\begin{array}{r}7,272 \\
5,999 \\
444 \\
408 \\
0 \\
364 \\
7,214 \\
58 \\
0 \\
58 \\
315 \\
0 \\
\\
0 \\
372\end{array}$ \\
\hline
\end{tabular}

\begin{tabular}{|c|c|c|c|c|c|c|}
\hline ltem & $\begin{array}{l}\text { Minnesota } \\
\text { Anoka } \\
\text { City of } \\
\text { December } 31\end{array}$ & $\begin{array}{l}\text { Minnesota } \\
\text { Austin } \\
\text { City of } \\
\text { December } 31\end{array}$ & $\begin{array}{l}\text { Minnesota } \\
\text { Fairmont } \\
\text { Public } \\
\text { Utilities } \\
\text { Comm } \\
\text { December } 31\end{array}$ & $\begin{array}{c}\text { Minnesota } \\
\text { Hutchinson } \\
\text { Utilities } \\
\text { Comm } \\
\text { December } 31\end{array}$ & $\begin{array}{c}\text { Minnesota } \\
\text { Marshall } \\
\text { City of } \\
\text { December } 31\end{array}$ & $\begin{array}{l}\text { Minnesota } \\
\text { Moorhead } \\
\text { City of } \\
\text { December } 31\end{array}$ \\
\hline 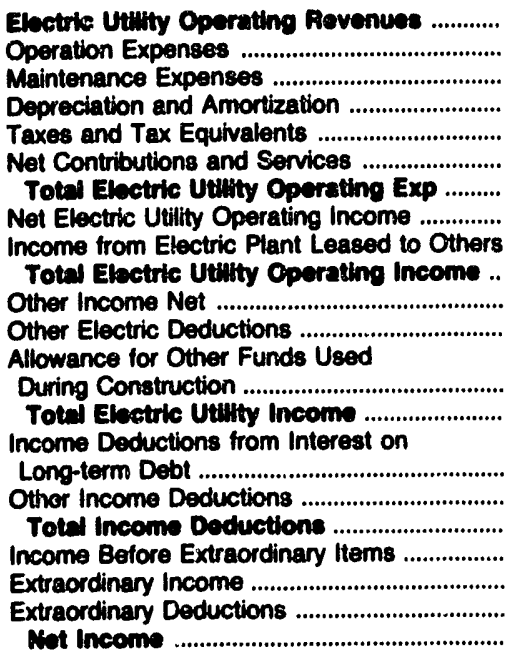 & $\begin{array}{r}11,079 \\
8,383 \\
146 \\
479 \\
0 \\
750 \\
9,758 \\
1,321 \\
0 \\
1,321 \\
146 \\
0 \\
0 \\
0 \\
1,467\end{array}$ & $\begin{array}{r}18,313 \\
16,788 \\
746 \\
853 \\
868 \\
0 \\
19,255 \\
-942 \\
303 \\
-638 \\
0 \\
0 \\
0 \\
0 \\
-639\end{array}$ & $\begin{array}{r}11,840 \\
10,246 \\
443 \\
536 \\
0 \\
516 \\
11,741 \\
99 \\
57 \\
156 \\
1,429 \\
0 \\
\\
0 \\
1,585\end{array}$ & $\begin{array}{r}9,448 \\
6,869 \\
387 \\
628 \\
0 \\
330 \\
8,213 \\
1,235 \\
0 \\
1,235 \\
615 \\
6 \\
\end{array}$ & $\begin{array}{r}8,782 \\
8,783 \\
0 \\
485 \\
218 \\
0 \\
9,486 \\
-704 \\
558 \\
-145 \\
1,019 \\
0 \\
\end{array}$ & $\begin{array}{r}11,923 \\
8,472 \\
442 \\
653 \\
0 \\
2,427 \\
11,093 \\
-71 \\
0 \\
-71 \\
505 \\
0 \\
0 \\
0 \\
434\end{array}$ \\
\hline
\end{tabular}

Note: Totals may not equal sum of components because of independent rounding.

Source: Enorgy iniómation Audministration, Form ElA-412, "Annival Raport of Putile Elsctric Utititiss." 


\section{Table 36. Statement of Income by Major Publicly Owned Electric Utility Within State, 1991 (Continued) (Thousand Dollars)}

\begin{tabular}{|c|c|c|c|c|c|c|}
\hline Item & $\begin{array}{l}\text { Minnesota } \\
\text { Now Uim } \\
\text { Public } \\
\text { Utilities } \\
\text { Comm } \\
\text { December } 31\end{array}$ & $\begin{array}{c}\text { Minnesota } \\
\text { Northern } \\
\text { Municipal } \\
\text { Power Agny } \\
\text { December } 31\end{array}$ & $\begin{array}{c}\text { Minnesota } \\
\text { Owatonna } \\
\text { City of }\end{array}$ & $\begin{array}{c}\text { Minnesota } \\
\text { Rochester } \\
\text { Public } \\
\text { Utilities } \\
\text { December } 31\end{array}$ & $\begin{array}{c}\text { Minnesota } \\
\text { Southern } \\
\text { Minnesota } \\
\text { Mun P } \\
\text { Agny } \\
\text { December } 31\end{array}$ & $\begin{array}{c}\text { Minnesota } \\
\text { Western } \\
\text { Minnesota } \\
\text { Mun } \\
\text { Pwr Agny } \\
\text { December } 31\end{array}$ \\
\hline 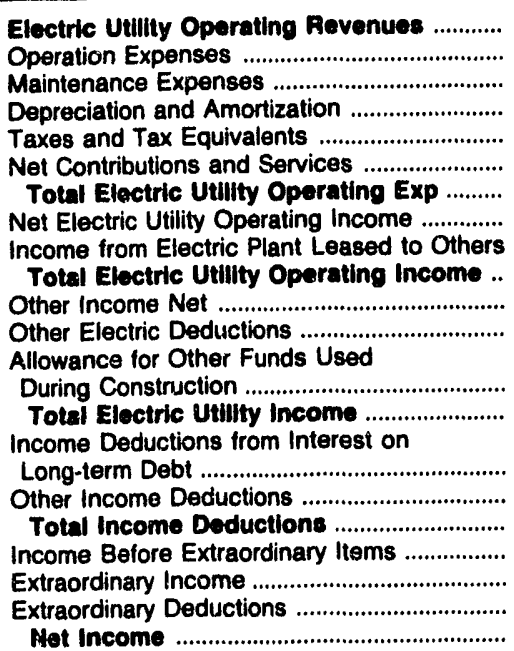 & $\begin{array}{r}9,233 \\
6,540 \\
615 \\
668 \\
492 \\
0 \\
8,314 \\
919 \\
0 \\
919 \\
270 \\
2 \\
0 \\
1,187\end{array}$ & $\begin{array}{r}29,316 \\
10,049 \\
3,028 \\
1,195 \\
0 \\
0 \\
14,272 \\
15,044 \\
0 \\
15,044 \\
6,806 \\
0\end{array}$ & $\begin{array}{r}16,790 \\
14,400 \\
654 \\
870 \\
0 \\
441 \\
16,364 \\
435 \\
0 \\
435 \\
312 \\
0 \\
0 \\
0 \\
746\end{array}$ & $\begin{array}{r}61,325 \\
50,991 \\
2,214 \\
2,163 \\
5,031 \\
0 \\
90,398 \\
926 \\
0 \\
926 \\
1,052 \\
57 \\
0 \\
0 \\
1,922\end{array}$ & $\begin{array}{r}123,068 \\
53,317 \\
4,757 \\
6,649 \\
6,979 \\
0 \\
71,703 \\
51,366 \\
0 \\
51,368 \\
10,321 \\
0 \\
\\
162 \\
61,649\end{array}$ & $\begin{array}{r}42,266 \\
16,759 \\
5,148 \\
3,590 \\
1,169 \\
0 \\
26,866 \\
15,600 \\
0 \\
15,600 \\
3,453 \\
0 \\
0 \\
19,052\end{array}$ \\
\hline
\end{tabular}

\begin{tabular}{|c|c|c|c|c|c|c|}
\hline Item & $\begin{array}{l}\text { Minnesota } \\
\text { Willmar } \\
\text { Municipal } \\
\text { Utils Comm } \\
\text { December } 31\end{array}$ & $\begin{array}{l}\text { Mississippi } \\
\text { Aberdeen } \\
\text { City of } \\
\text { June } 30\end{array}$ & $\begin{array}{l}\text { Mississippi } \\
\text { Clarksdale } \\
\text { City of } \\
\text { September } 30\end{array}$ & $\begin{array}{l}\text { Mississippi } \\
\text { Columbus } \\
\text { City of } \\
\text { June } 30\end{array}$ & $\begin{array}{l}\text { Mississippi } \\
\text { Greenwood } \\
\text { Utilities } \\
\text { Comm } \\
\text { September } 30\end{array}$ & $\begin{array}{c}\text { Mississippi } \\
\text { Holly } \\
\text { Springs } \\
\text { City of } \\
\text { June } 30\end{array}$ \\
\hline 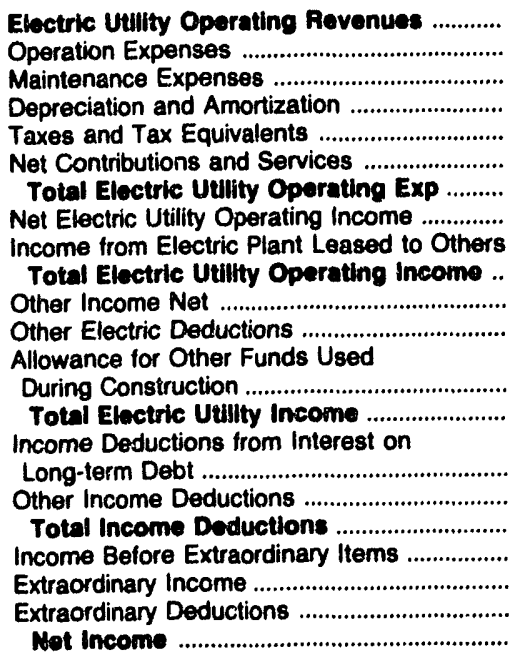 & $\begin{array}{r}10,395 \\
6,904 \\
533 \\
861 \\
0 \\
1,026 \\
9,324 \\
1,061 \\
0 \\
1,061 \\
1,015 \\
0 \\
0 \\
0 \\
2,076\end{array}$ & $\begin{array}{r}8,068 \\
7,542 \\
115 \\
117 \\
250 \\
0 \\
8,025 \\
44 \\
0 \\
44 \\
23 \\
7 \\
\\
0 \\
59\end{array}$ & $\begin{array}{r}10,803 \\
7,711 \\
1,359 \\
861 \\
0 \\
406 \\
10,337 \\
545 \\
0 \\
545 \\
388 \\
0 \\
\\
0 \\
944\end{array}$ & $\begin{array}{r}23,198 \\
22,249 \\
572 \\
472 \\
840 \\
0 \\
24,132 \\
-833 \\
0 \\
-933 \\
659 \\
3 \\
0 \\
-277 \\
0 \\
24 \\
24 \\
-302 \\
0 \\
0 \\
-302\end{array}$ & $\begin{array}{r}14,908 \\
11,404 \\
988 \\
749 \\
0 \\
589 \\
13,730 \\
1,266 \\
0 \\
1,268 \\
722 \\
0 \\
0 \\
0 \\
1,988\end{array}$ & $\begin{array}{r}11,145 \\
9,523 \\
383 \\
271 \\
604 \\
0 \\
10,781 \\
364 \\
0 \\
384 \\
89 \\
3 \\
0 \\
450\end{array}$ \\
\hline
\end{tabular}

Note: Totals may not equal sum of components because of independent rounding.

Source: Energy Information Administration, Form ElA-412, "Annual Repont of Public Electric Utilities." 
Table 36. Statement of Income by Major Publicly Owned Electric Utility Within State, 1991 (Continued) (Thousand Dollars)

\begin{tabular}{|c|c|c|c|c|c|c|}
\hline Hem & $\begin{array}{l}\text { Mississippi } \\
\text { Louisville } \\
\text { Electric } \\
\text { System } \\
\text { June } 30\end{array}$ & $\begin{array}{c}\text { Mississippi } \\
\text { Municipal } \\
\text { Energy } \\
\text { Agency } \\
\text { of MS } \\
\text { September } 30\end{array}$ & $\begin{array}{l}\text { Mississippi } \\
\text { Now Albany } \\
\text { City of } \\
\text { June } 30\end{array}$ & $\begin{array}{l}\text { Mississippi } \\
\text { Oxford } \\
\text { City of } \\
\text { June } 30\end{array}$ & $\begin{array}{l}\text { Mississippi } \\
\text { Starkville } \\
\text { City of } \\
\text { June } 30\end{array}$ & $\begin{array}{l}\text { Mississippi } \\
\text { Tupelo } \\
\text { City of } \\
\text { June } 30\end{array}$ \\
\hline 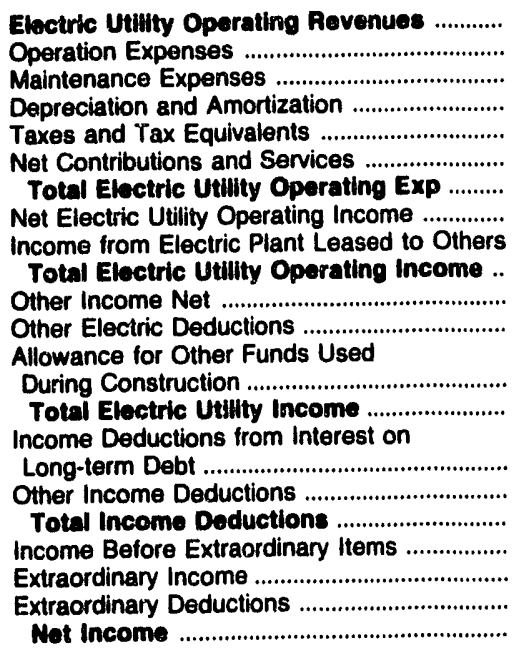 & $\begin{array}{r}8,252 \\
7,478 \\
146 \\
206 \\
215 \\
0 \\
8,046 \\
206 \\
0 \\
206 \\
125 \\
0 \\
\\
0 \\
331\end{array}$ & $\begin{array}{r}27,831 \\
27,781 \\
0 \\
87 \\
0 \\
0 \\
27,868 \\
-37 \\
0 \\
-37 \\
207 \\
0 \\
0 \\
0 \\
171\end{array}$ & $\begin{array}{r}12,086 \\
10,791 \\
240 \\
251 \\
456 \\
10 \\
11,749 \\
338 \\
0 \\
338 \\
200 \\
0 \\
0 \\
0 \\
538\end{array}$ & $\begin{array}{r}7,058 \\
6,943 \\
156 \\
129 \\
408 \\
6 \\
7,643 \\
-585 \\
0 \\
-585 \\
369 \\
4 \\
0 \\
0 \\
-220\end{array}$ & $\begin{array}{r}16,706 \\
14,712 \\
248 \\
426 \\
564 \\
-6 \\
15,944 \\
763 \\
0 \\
763 \\
179 \\
0 \\
\\
0 \\
942\end{array}$ & $\begin{array}{r}31,140 \\
28,876 \\
348 \\
585 \\
1,418 \\
0 \\
31,227 \\
-87 \\
0 \\
-87 \\
452 \\
0 \\
0 \\
0 \\
365\end{array}$ \\
\hline
\end{tabular}

\begin{tabular}{|c|c|c|c|c|c|c|}
\hline Item & $\begin{array}{l}\text { Mississippi } \\
\text { West } \\
\text { Point } \\
\text { City of } \\
\\
\text { June } 30\end{array}$ & $\begin{array}{l}\text { Missouri } \\
\text { Carthage } \\
\text { City of } \\
\text { June } 30\end{array}$ & $\begin{array}{l}\text { Missouri } \\
\text { Columbia } \\
\text { City of } \\
\text { September } 30\end{array}$ & $\begin{array}{l}\text { Missouri } \\
\text { Hannibal } \\
\text { City of } \\
\text { June } 30\end{array}$ & $\begin{array}{c}\text { Missouri } \\
\text { Independence } \\
\text { City of } \\
\text { June } 30\end{array}$ & $\begin{array}{l}\text { Missouri } \\
\text { Kennett } \\
\text { City of } \\
\text { June } 30\end{array}$ \\
\hline 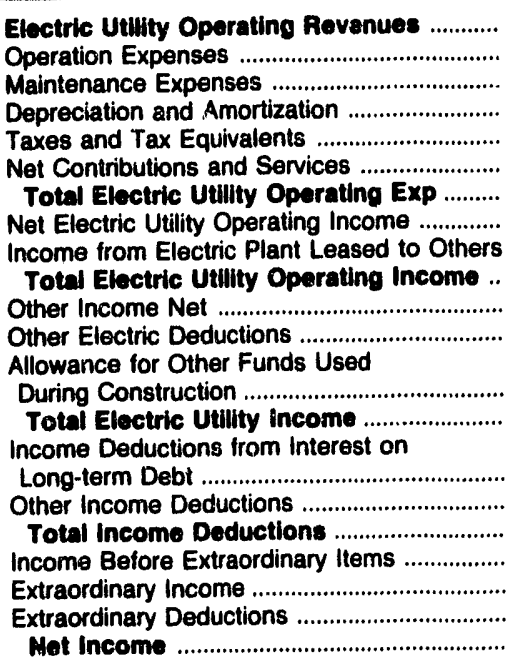 & $\begin{array}{r}9,958 \\
8,794 \\
159 \\
199 \\
483 \\
0 \\
9,634 \\
324 \\
0 \\
324 \\
19 \\
2 \\
\\
0 \\
341\end{array}$ & $\begin{array}{r}8,264 \\
7,343 \\
237 \\
434 \\
0 \\
122 \\
8,136 \\
128 \\
0 \\
128 \\
242 \\
0 \\
0 \\
0 \\
370\end{array}$ & $\begin{array}{r}43,678 \\
31,597 \\
1,744 \\
2,786 \\
3,730 \\
0 \\
39,857 \\
3,821 \\
0 \\
3,821 \\
3,672 \\
270 \\
\\
0 \\
7,223\end{array}$ & $\begin{array}{r}9,529 \\
8,130 \\
536 \\
297 \\
382 \\
305 \\
9,650 \\
-121 \\
0 \\
-121 \\
573 \\
0 \\
0 \\
0 \\
452\end{array}$ & $\begin{array}{r}55,095 \\
32,483 \\
5,028 \\
4,772 \\
5,194 \\
0 \\
47,477 \\
7,619 \\
0 \\
7,618 \\
3,373 \\
0 \\
\\
0 \\
10,992\end{array}$ & $\begin{array}{r}4,507 \\
4,061 \\
243 \\
504 \\
0 \\
74 \\
4,882 \\
-376 \\
0 \\
-376 \\
322 \\
0 \\
\\
0 \\
-54\end{array}$ \\
\hline
\end{tabular}

Note: Totals may not equal sum of components because of independent rounding.

Source: Energy Information Administration, Form EIA-412, "Annual Peport of Public Electric Utilities." 
Table 36. Statement of Income by Major Publicly Owned Electric Utility Within State, 1991 (Continued) (Thousand Dollars)

\begin{tabular}{|c|c|c|c|c|c|c|}
\hline Item & $\begin{array}{l}\text { Missouri } \\
\text { Kirkwood } \\
\text { City of } \\
\text { March } 31\end{array}$ & $\begin{array}{l}\text { Missouri } \\
\text { Lebanon } \\
\text { City of } \\
\text { October } 31\end{array}$ & $\begin{array}{c}\text { Missouri } \\
\text { Marshall } \\
\text { City of } \\
\text { September } 30\end{array}$ & $\begin{array}{l}\text { Missouri } \\
\text { Monett } \\
\text { City of } \\
\text { March } 31\end{array}$ & $\begin{array}{l}\text { Missouri } \\
\text { Poplar } \\
\text { Bluff } \\
\text { City of } \\
\text { December } 31\end{array}$ & $\begin{array}{c}\text { Missouri } \\
\text { Polla } \\
\text { City of } \\
\text { October } 31\end{array}$ \\
\hline 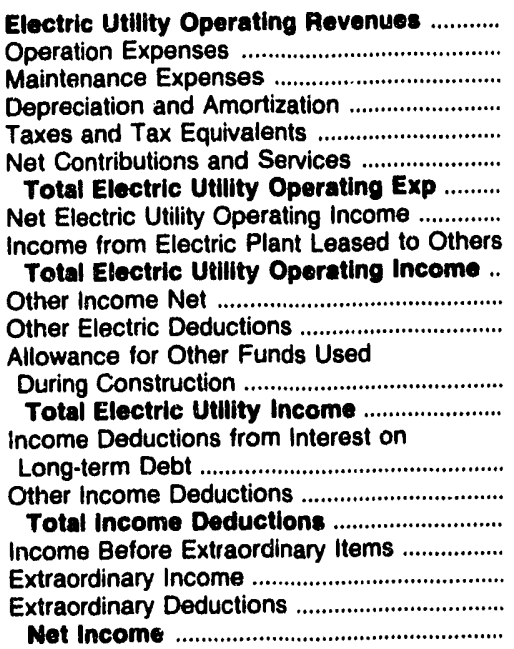 & $\begin{array}{r}13,044 \\
8,509 \\
583 \\
158 \\
972 \\
2,810 \\
13,033 \\
11 \\
0 \\
11 \\
0 \\
0 \\
0 \\
11\end{array}$ & $\begin{array}{r}7,724 \\
7,294 \\
37 \\
0 \\
0 \\
0 \\
7,331 \\
393 \\
18 \\
411 \\
0 \\
808\end{array}$ & $\begin{array}{r}8,965 \\
4,492 \\
1,246 \\
1,264 \\
0 \\
839 \\
7,842 \\
1,123 \\
0 \\
1,123 \\
519 \\
0 \\
\end{array}$ & $\begin{array}{r}7,197 \\
4,801 \\
0 \\
140 \\
0 \\
204 \\
5,145 \\
2,052 \\
0 \\
2,052 \\
34 \\
0 \\
\end{array}$ & $\begin{array}{r}8,540 \\
6,973 \\
546 \\
593 \\
0 \\
217 \\
8,329 \\
1,211 \\
0 \\
1,211 \\
973 \\
0 \\
\\
0 \\
2,184\end{array}$ & $\begin{array}{r}10,379 \\
8,668 \\
368 \\
364 \\
399 \\
61 \\
9,860 \\
519 \\
0 \\
519 \\
237 \\
23 \\
\\
0 \\
734\end{array}$ \\
\hline
\end{tabular}

\begin{tabular}{|c|c|c|c|c|c|c|}
\hline Item & $\begin{array}{l}\text { Missouri } \\
\text { Sikeston } \\
\text { City of } \\
\text { May } 31\end{array}$ & $\begin{array}{l}\text { Missouri } \\
\text { Springfield } \\
\text { City of }\end{array}$ & $\begin{array}{c}\text { Nebraska } \\
\text { Central } \\
\text { Nebraska } \\
\text { Pub } \\
\text { P\&I Dist } \\
\text { December } 31\end{array}$ & $\begin{array}{c}\text { Nebraska } \\
\text { Cornhusker } \\
\text { Public } \\
\text { Power Dist } \\
\text { December } 31\end{array}$ & $\begin{array}{c}\text { Nebraska } \\
\text { Dawson } \\
\text { County } \\
\text { Public } \\
\text { Pwr Dist } \\
\text { December } 31\end{array}$ & $\begin{array}{l}\text { Nebraska } \\
\text { Fremont } \\
\text { City of } \\
\text { July } 31\end{array}$ \\
\hline 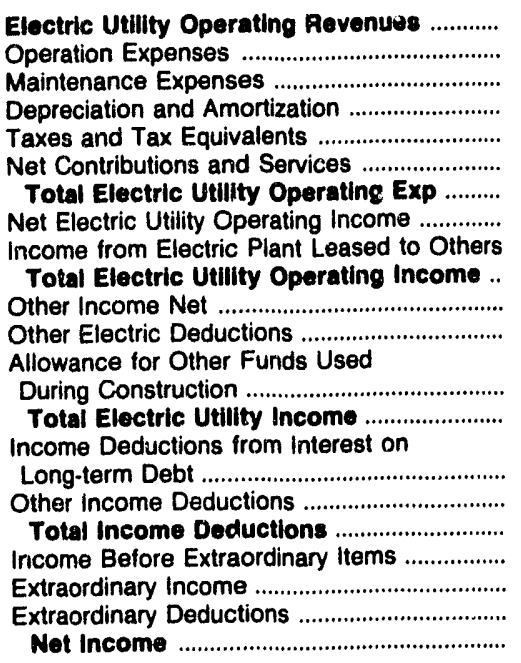 & $\begin{array}{r}60,037 \\
31,742 \\
3,728 \\
6,221 \\
0 \\
233 \\
41,924 \\
18,112 \\
0 \\
18,112 \\
2,337 \\
0 \\
\end{array}$ & $\begin{array}{r}101,063 \\
52,223 \\
13,254 \\
10,707 \\
3,023 \\
0 \\
79,207 \\
21,856 \\
0 \\
21,856 \\
0 \\
0 \\
\\
601 \\
22,457\end{array}$ & $\begin{array}{r}12,758 \\
7,563 \\
2,777 \\
2,673 \\
8 \\
0 \\
13,022 \\
-264 \\
12 \\
-252 \\
914 \\
0 \\
0 \\
663 \\
124 \\
319 \\
443 \\
220 \\
1,353 \\
0 \\
1,572\end{array}$ & $\begin{array}{r}10,827 \\
8,372 \\
511 \\
867 \\
114 \\
0 \\
9,863 \\
964 \\
0 \\
864 \\
344 \\
17 \\
0 \\
1,292\end{array}$ & $\begin{array}{r}15,577 \\
12,091 \\
420 \\
1,093 \\
148 \\
0 \\
13,753 \\
1,824 \\
0 \\
1,824 \\
507 \\
0 \\
\end{array}$ & $\begin{array}{r}13,983 \\
7,619 \\
1,439 \\
2,356 \\
1,024 \\
532 \\
12,869 \\
1,014 \\
0 \\
1,014 \\
2,067 \\
0 \\
\\
0 \\
3,081\end{array}$ \\
\hline
\end{tabular}

Note: Totals may not equal sum of components because of independent rounding.

Source: Energy Information Administration, Form EIA-412, "Annual Report of Public Electric Utilities." 


\section{Table 36. Statement of Income by Major Publicly Owned Electric Utility Within State, 1991 (Continued)}

(Thousand Dollars)

\begin{tabular}{|c|c|c|c|c|c|c|}
\hline Item & $\begin{array}{c}\text { Nebraska } \\
\text { Grand Island } \\
\text { City of } \\
\text { July } 31\end{array}$ & $\begin{array}{c}\text { Nebraska } \\
\text { Hastings } \\
\text { City of } \\
\text { December } 31\end{array}$ & $\begin{array}{c}\text { Nebraska } \\
\text { Lincoln } \\
\text { Electric } \\
\text { System } \\
\text { December } 31\end{array}$ & $\begin{array}{c}\text { Nebraska } \\
\text { Loup } \\
\text { River } \\
\text { Public } \\
\text { Power Dist } \\
\text { December } 31\end{array}$ & $\begin{array}{l}\text { Nebraska } \\
\text { Municipal } \\
\text { Energy } \\
\text { Agency } \\
\text { of NE } \\
\text { March } 31\end{array}$ & $\begin{array}{c}\text { Nebraska } \\
\text { Nebraska } \\
\text { Public } \\
\text { Power } \\
\text { District } \\
\text { December } 31\end{array}$ \\
\hline 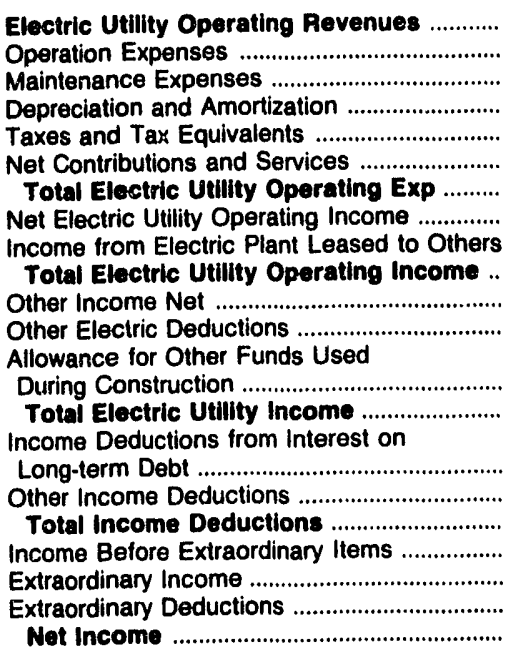 & $\begin{array}{r}23,806 \\
10,224 \\
1,291 \\
4,915 \\
614 \\
0 \\
17,044 \\
6,763 \\
0 \\
6,763 \\
2,237 \\
0\end{array}$ & $\begin{array}{r}13,864 \\
7,260 \\
837 \\
2,474 \\
516 \\
0 \\
11,087 \\
2,777 \\
0 \\
2,777 \\
2,744 \\
0 \\
0 \\
0 \\
5,521\end{array}$ & $\begin{array}{r}109,888 \\
70,273 \\
5,857 \\
11,303 \\
4,717 \\
0 \\
92,150 \\
17,737 \\
0 \\
17,737 \\
5,264 \\
0\end{array}$ & $\begin{array}{r}33,577 \\
28,262 \\
1,361 \\
1,073 \\
2,288 \\
0 \\
32,983 \\
594 \\
0 \\
594 \\
1,454 \\
0 \\
0 \\
2,048\end{array}$ & $\begin{array}{r}25,895 \\
24,124 \\
0 \\
1,069 \\
0 \\
0 \\
25,193 \\
702 \\
0 \\
702 \\
309 \\
0 \\
\\
0 \\
1,012\end{array}$ & $\begin{array}{r}674,527 \\
244,851 \\
45,447 \\
76,779 \\
5,203 \\
0 \\
372,280 \\
302,247 \\
0 \\
302,247 \\
42,858 \\
0 \\
1,344 \\
346,449\end{array}$ \\
\hline
\end{tabular}

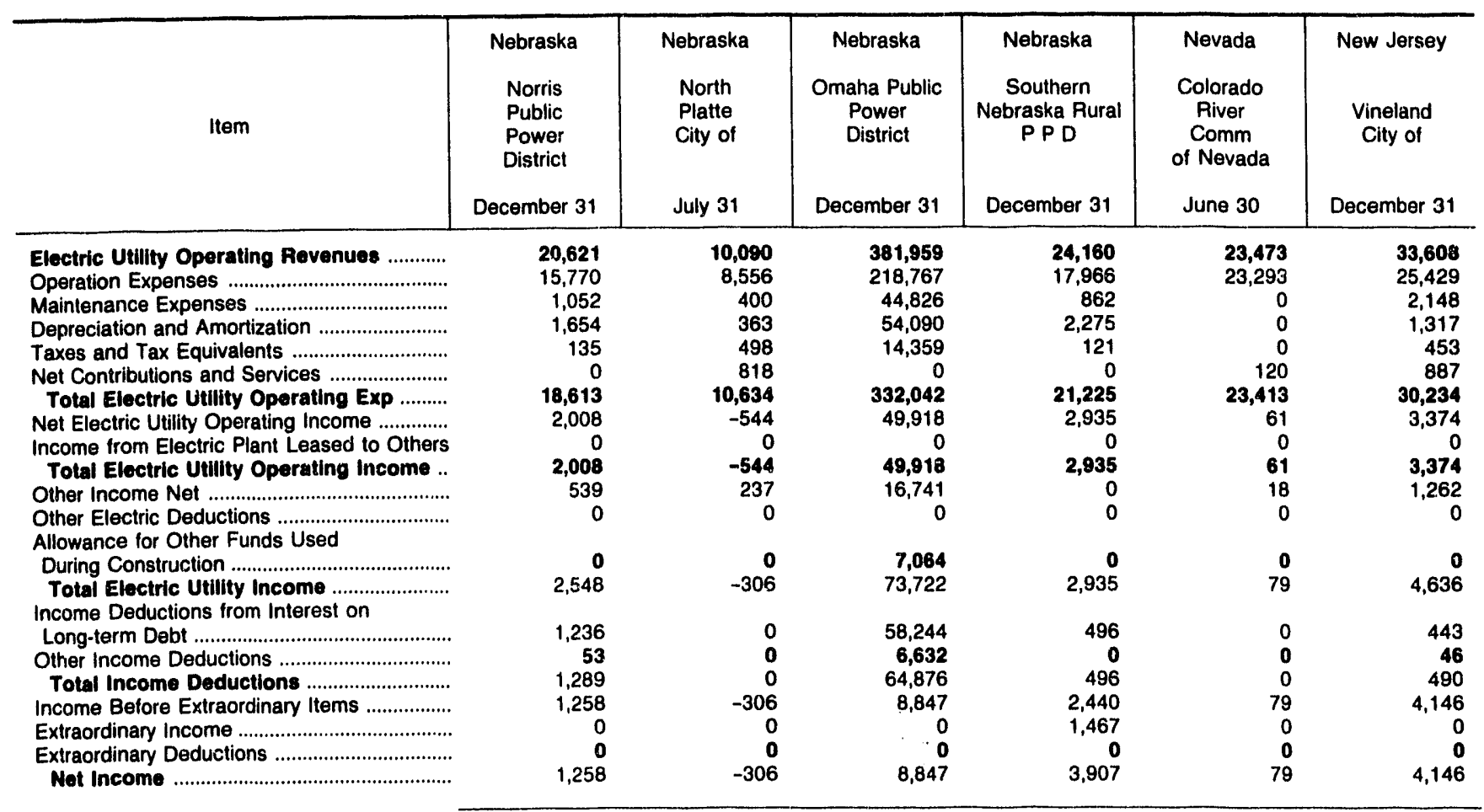

Note: Totals may not equal sum of components because of independent rounding

Source: Energy Information Administration, Form EIA-412, "Annual Report of Public Electric Utilities." 
Table 36. Statement of Income by Major Publicly Owned Electric Utility Within State, 1991 (Continued) (Thousand Dollars)

\begin{tabular}{|c|c|c|c|c|c|c|}
\hline Item & $\begin{array}{l}\text { New Mexico } \\
\text { Farmington } \\
\text { City of } \\
\text { June } 30\end{array}$ & $\begin{array}{l}\text { New Mexico } \\
\text { Gallup } \\
\text { City of } \\
\text { June } 30\end{array}$ & $\begin{array}{l}\text { New Mexico } \\
\text { Los Alamos } \\
\text { County } \\
\text { June } 30\end{array}$ & $\begin{array}{l}\text { New York } \\
\text { Fairport } \\
\text { Village of } \\
\text { May } 31\end{array}$ & $\begin{array}{c}\text { New York } \\
\text { Freeport } \\
\text { Village of } \\
\text { Inc }\end{array}$ & $\begin{array}{c}\text { New York } \\
\text { Jamestown } \\
\text { City of } \\
\text { December } 31\end{array}$ \\
\hline 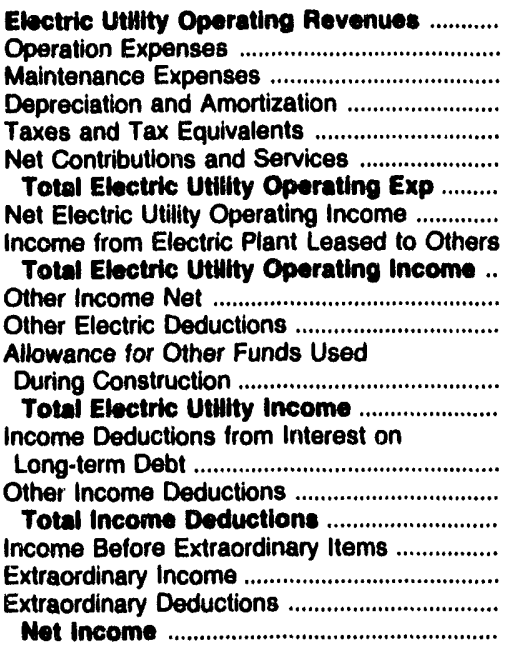 & $\begin{array}{r}38,718 \\
13,643 \\
2,302 \\
4,207 \\
2,781 \\
0 \\
22,934 \\
15,785 \\
0 \\
15,785 \\
2,230 \\
0\end{array}$ & $\begin{array}{r}14,156 \\
11,965 \\
157 \\
421 \\
611 \\
957 \\
14,110 \\
46 \\
0 \\
46 \\
48 \\
0 \\
0 \\
0 \\
94\end{array}$ & $\begin{array}{r}27,365 \\
11,022 \\
1,124 \\
2,470 \\
530 \\
412 \\
15,559 \\
11,806 \\
0 \\
11,006 \\
1,132 \\
0 \\
0 \\
12,938\end{array}$ & $\begin{array}{r}9,007 \\
6,646 \\
510 \\
532 \\
496 \\
143 \\
8,328 \\
760 \\
13 \\
773 \\
573 \\
5\end{array}$ & $\begin{array}{r}12,427 \\
8,585 \\
1,009 \\
900 \\
1,425 \\
25 \\
11,944 \\
483 \\
13 \\
195 \\
275 \\
0\end{array}$ & $\begin{array}{r}18,600 \\
12,926 \\
1,067 \\
1,744 \\
1,173 \\
33 \\
16,842 \\
1,658 \\
0 \\
1,650 \\
360 \\
0\end{array}$ \\
\hline
\end{tabular}

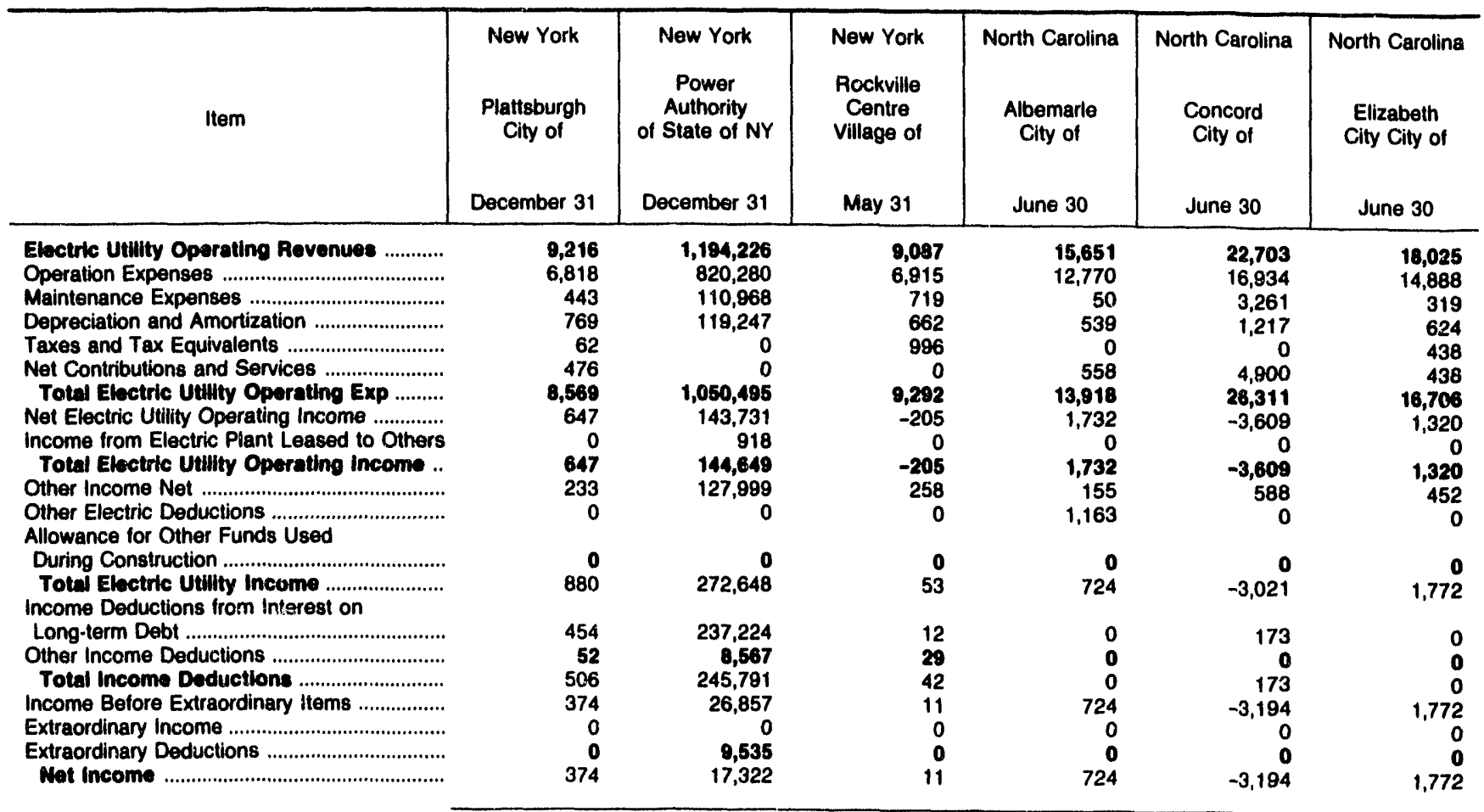

Note: Totals may not equal sum of components because of independent rounding.

Source: Energy Information Administration, Form EIA-412, "Annual Report of Public Electric Utilities." 
Table 36. Statement of Income by Major Publicly Owned Electric
Utillty Within State, 1991 (Continued) (Thousand Dollars)

\begin{tabular}{|c|c|c|c|c|c|c|}
\hline Item & $\begin{array}{l}\text { North Carolina } \\
\text { Fayetteville } \\
\text { Public } \\
\text { Works Comm } \\
\text { June } 30\end{array}$ & $\begin{array}{l}\text { North Carolina } \\
\text { Gastonia } \\
\text { City of } \\
\text { June } 30\end{array}$ & $\begin{array}{l}\text { North Carolina } \\
\text { Greenville } \\
\text { Utilities } \\
\text { Comm } \\
\text { June } 30\end{array}$ & $\begin{array}{l}\text { North Carolina } \\
\text { High } \\
\text { Point } \\
\text { Town } \\
\text { of } \\
\text { June } 30\end{array}$ & $\begin{array}{l}\text { North Carolina } \\
\text { Kinston } \\
\text { City of } \\
\text { June } 30\end{array}$ & $\begin{array}{l}\text { North Carolina } \\
\text { Lexington } \\
\text { City of } \\
\text { June } 30\end{array}$ \\
\hline 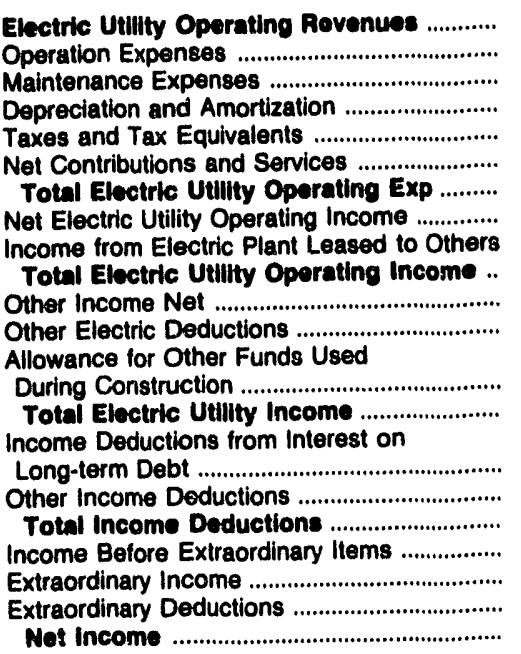 & $\begin{array}{r}115,585 \\
82,104 \\
3,075 \\
5,606 \\
0 \\
62 \\
80,846 \\
24,739 \\
0 \\
24,739 \\
2,256 \\
0 \\
0 \\
0\end{array}$ & $\begin{array}{r}37,301 \\
26,674 \\
1,002 \\
1,026 \\
0 \\
8,114 \\
36,815 \\
486 \\
0 \\
486 \\
386 \\
0 \\
0 \\
872\end{array}$ & $\begin{array}{r}83,649 \\
72,396 \\
1,709 \\
3,291 \\
0 \\
2,123 \\
79,520 \\
4,129 \\
0 \\
4,129 \\
774 \\
0 \\
0 \\
4,903\end{array}$ & $\begin{array}{r}52,622 \\
41,720 \\
2,498 \\
1,508 \\
0 \\
3,255 \\
48,981 \\
3,641 \\
0 \\
3,641 \\
467 \\
21 \\
0 \\
4,087\end{array}$ & $\begin{array}{r}32,575 \\
28,622 \\
0 \\
392 \\
0 \\
1,470 \\
30,484 \\
2,091 \\
0 \\
2,091 \\
504 \\
0 \\
0 \\
2,595\end{array}$ & $\begin{array}{r}28,630 \\
22,788 \\
93 \\
615 \\
610 \\
3,640 \\
27,746 \\
883 \\
0 \\
883 \\
237 \\
0 \\
0 \\
1,120\end{array}$ \\
\hline
\end{tabular}

\begin{tabular}{|c|c|c|c|c|c|c|}
\hline Item & $\begin{array}{l}\text { North Carolina } \\
\text { Lumberton } \\
\text { City of } \\
\text { June } 30\end{array}$ & $\begin{array}{l}\text { North Carolina } \\
\text { Monroe } \\
\text { City of } \\
\text { June } 30\end{array}$ & $\begin{array}{l}\text { North Carolina } \\
\begin{array}{c}\text { Morganton } \\
\text { City of }\end{array} \\
\text { June } 30\end{array}$ & $\begin{array}{l}\text { North Carolina } \\
\text { Murphy } \\
\text { City of } \\
\text { June } 30\end{array}$ & $\begin{array}{l}\text { North Carolina } \\
\text { New Bern } \\
\text { City of } \\
\text { June } 30\end{array}$ & $\begin{array}{c}\text { North Carolina } \\
\text { New River } \\
\text { Light } \\
\& \\
\text { Power Co } \\
\text { December } 31\end{array}$ \\
\hline 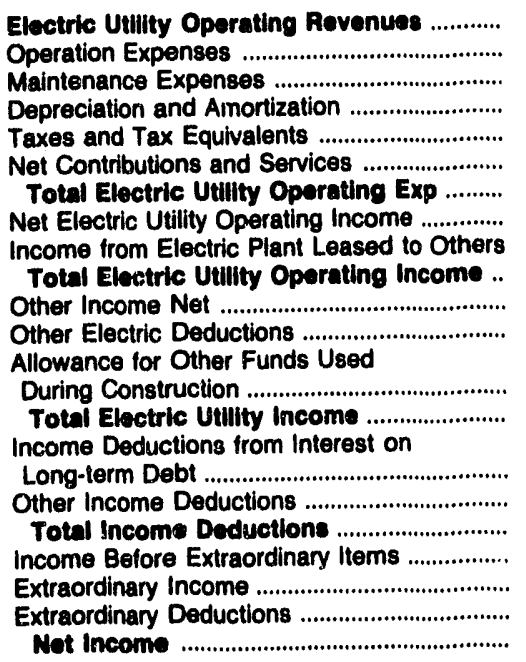 & $\begin{array}{r}20,099 \\
18,733 \\
109 \\
456 \\
0 \\
1,464 \\
20,762 \\
-663 \\
0 \\
-663 \\
950 \\
0 \\
0 \\
0 \\
288\end{array}$ & $\begin{array}{r}23,168 \\
19,371 \\
0 \\
472 \\
0 \\
2,000 \\
21,843 \\
1,325 \\
0 \\
1,325 \\
1,320 \\
0 \\
0 \\
0 \\
2,645\end{array}$ & $\begin{array}{r}15,768 \\
13,044 \\
0 \\
368 \\
0 \\
1,550 \\
14,962 \\
806 \\
0 \\
806 \\
455 \\
0 \\
0 \\
0 \\
1,262\end{array}$ & $\begin{array}{r}7,844 \\
7,180 \\
111 \\
157 \\
47 \\
0 \\
7,497 \\
348 \\
0 \\
348 \\
170 \\
0 \\
0 \\
0 \\
517\end{array}$ & $\begin{array}{r}25,984 \\
24,071 \\
529 \\
611 \\
0 \\
1,142 \\
26,354 \\
-370 \\
0 \\
-370 \\
245 \\
0 \\
0 \\
0 \\
-125\end{array}$ & $\begin{array}{r}11,099 \\
9,137 \\
0 \\
263 \\
356 \\
0 \\
9,756 \\
1,343 \\
0 \\
1,343 \\
149 \\
0 \\
\\
0 \\
1,492\end{array}$ \\
\hline
\end{tabular}

Note: Totals may not equal sum of components because of independent rounding.

Source: Energy Information Administration, Form ElA-412, "Annual Report of Public Electric Utilities." 


\section{Table 36. Statement of Income by Major Publicly Owned Electric Utility Within State, 1991 (Continued)}

(Thousand Dollars)

\begin{tabular}{|c|c|c|c|c|c|c|}
\hline Item & $\begin{array}{c}\text { North Carolina } \\
\text { North } \\
\text { Carolina } \\
\text { Eastern M P A } \\
\text { December } 31\end{array}$ & $\begin{array}{c}\text { North Carolina } \\
\text { North } \\
\text { Carolina } \\
\text { Mun } \\
\text { Power Agny } \\
\text { December } 31\end{array}$ & $\begin{array}{l}\text { North Carolina } \\
\text { Rocky Mount } \\
\text { City of } \\
\text { June } 30\end{array}$ & $\begin{array}{l}\text { North Carolina } \\
\text { Shelby } \\
\text { City of } \\
\text { June } 30\end{array}$ & $\begin{array}{l}\text { North Carolina } \\
\text { Statesville } \\
\text { City of } \\
\text { June } 30\end{array}$ & $\begin{array}{l}\text { North Carolina } \\
\text { Tarboro } \\
\text { Town of } \\
\text { June } 30\end{array}$ \\
\hline 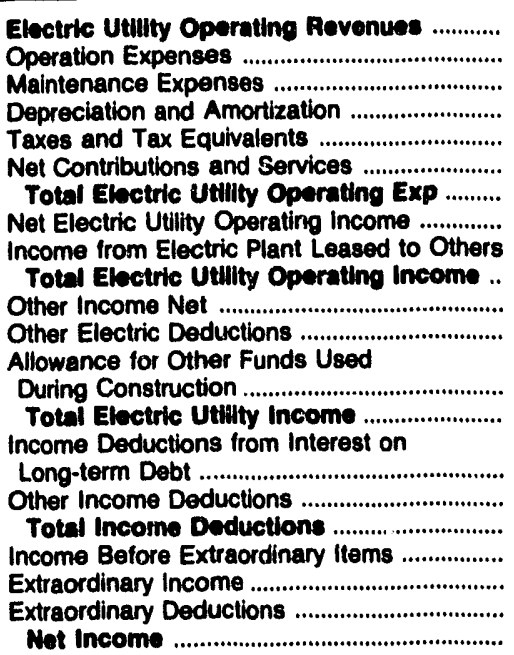 & $\begin{array}{r}398,000 \\
235,484 \\
13,173 \\
48,646 \\
18,391 \\
0 \\
315,604 \\
82,306 \\
0 \\
82,308 \\
167,948 \\
0 \\
0 \\
0 \\
250,254\end{array}$ & $\begin{array}{r}438,010 \\
221,271 \\
41,529 \\
43,443 \\
16,865 \\
0 \\
323,208 \\
115,602 \\
0 \\
115,602 \\
62,939 \\
0 \\
\end{array}$ & $\begin{array}{r}54,035 \\
51,585 \\
0 \\
1,003 \\
0 \\
0 \\
52,588 \\
2,247 \\
0 \\
2,247 \\
232 \\
0 \\
0 \\
0 \\
2,480\end{array}$ & $\begin{array}{r}10,808 \\
8,815 \\
360 \\
214 \\
0 \\
1,915 \\
11,306 \\
-496 \\
0 \\
-408 \\
85 \\
0 \\
0 \\
-411 \\
0 \\
0 \\
0 \\
-411 \\
0 \\
0 \\
-411\end{array}$ & $\begin{array}{r}24,403 \\
18,128 \\
0 \\
464 \\
0 \\
4,400 \\
22,902 \\
1,411 \\
0 \\
1,411 \\
513 \\
207 \\
0 \\
0 \\
1,717\end{array}$ & $\begin{array}{r}17,312 \\
15,297 \\
0 \\
389 \\
0 \\
1,336 \\
17,022 \\
290 \\
0 \\
290 \\
524 \\
0 \\
0 \\
0 \\
814\end{array}$ \\
\hline
\end{tabular}

\begin{tabular}{|c|c|c|c|c|c|c|}
\hline Item & $\begin{array}{l}\text { North Carolina } \\
\text { Washington } \\
\text { City of } \\
\text { June } 30\end{array}$ & $\begin{array}{l}\text { North Carolina } \\
\text { Wilson } \\
\text { City of } \\
\text { June } 30\end{array}$ & $\begin{array}{c}\text { Ohio } \\
\text { American } \\
\text { Mun } \\
\text { Power } \\
\text { Ohio Ine } \\
\text { December } 31\end{array}$ & $\begin{array}{l}\text { Ohio } \\
\text { Bowling } \\
\text { Green } \\
\text { City of } \\
\text { December } 31\end{array}$ & $\begin{array}{l}\text { Ohio } \\
\text { Bryan } \\
\text { City of } \\
\text { December } 31\end{array}$ & $\begin{array}{c}\text { Ohio } \\
\text { Celina } \\
\text { City of } \\
\text { December } 31\end{array}$ \\
\hline 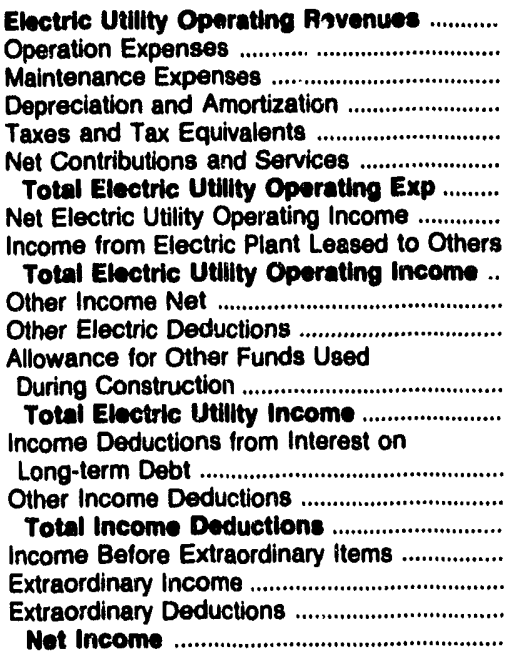 & $\begin{array}{r}21,195 \\
15,748 \\
1,092 \\
827 \\
0 \\
1,029 \\
18,697 \\
2,498 \\
0 \\
2,498 \\
0 \\
0 \\
0 \\
0\end{array}$ & $\begin{array}{r}69,230 \\
63,374 \\
468 \\
1,432 \\
0 \\
7,202 \\
72,475 \\
-3,236 \\
0 \\
-3,236 \\
2,694 \\
0 \\
0 \\
0 \\
-543\end{array}$ & $\begin{array}{r}143,757 \\
119,256 \\
6,637 \\
4,296 \\
6,907 \\
0 \\
137,095 \\
6,662 \\
0 \\
6,662 \\
2,133 \\
611 \\
0 \\
0,184\end{array}$ & $\begin{array}{r}14,591 \\
12,804 \\
832 \\
418 \\
0 \\
1,049 \\
15,203 \\
-612 \\
0 \\
-612 \\
863 \\
0 \\
0 \\
0 \\
251\end{array}$ & $\begin{array}{r}9,450 \\
8,370 \\
0 \\
1,088 \\
0 \\
0 \\
9,458 \\
1 \\
0 \\
1 \\
129 \\
0 \\
\\
0 \\
130\end{array}$ & $\begin{array}{r}7,340 \\
6,153 \\
505 \\
0 \\
113 \\
116 \\
6,888 \\
453 \\
0 \\
453 \\
81 \\
0 \\
0 \\
0 \\
534 \\
0 \\
0 \\
223 \\
223 \\
311 \\
0 \\
0 \\
311\end{array}$ \\
\hline
\end{tabular}

Note: Totals may not equal sum of components because of independent rounding.

Source: Energy information Administration, Form ElA-412, "Annual Report of Public Electric Utilities." 
Table 36. Statement of Income by Major Publicly Owned Electric Utility Within State, 1991 (Continued) (Thousand Dollars)

\begin{tabular}{|c|c|c|c|c|c|c|}
\hline Item & $\begin{array}{c}\text { Ohio } \\
\text { Cleveland } \\
\text { City of } \\
\text { December } 31\end{array}$ & $\begin{array}{c}\text { Ohio } \\
\text { Columbus } \\
\text { City of } \\
\text { December } 31\end{array}$ & $\begin{array}{c}\text { Onio } \\
\text { Cuyahoga } \\
\text { Falls } \\
\text { City of } \\
\text { December } 31\end{array}$ & $\begin{array}{l}\text { Ohio } \\
\text { Dover } \\
\text { City of } \\
\text { December } 31\end{array}$ & $\begin{array}{c}\text { Ohio } \\
\text { Hamilton } \\
\text { City of } \\
\text { December } 31\end{array}$ & $\begin{array}{c}\text { Ohio } \\
\text { Niles } \\
\text { City of } \\
\text { December } 31\end{array}$ \\
\hline 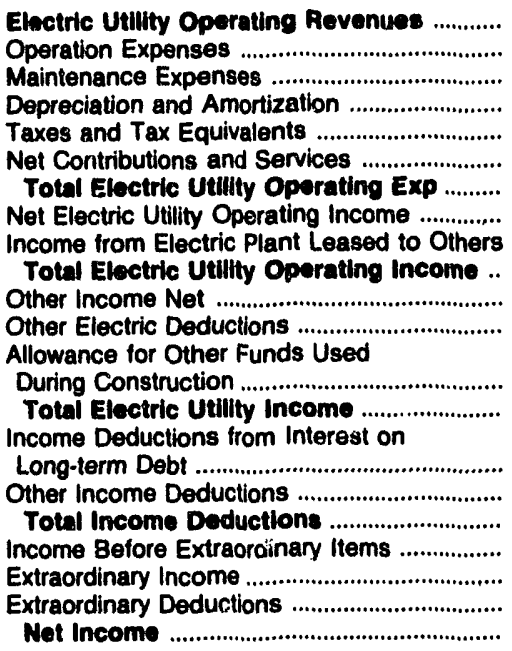 & $\begin{array}{r}53,398 \\
32,655 \\
9,775 \\
3,980 \\
0 \\
0 \\
46,411 \\
6,987 \\
0 \\
6,987 \\
2,220 \\
0 \\
0 \\
9,207 \\
97 \\
0 \\
97 \\
9,110 \\
0 \\
5,061 \\
4,048\end{array}$ & $\begin{array}{r}46,588 \\
44,108 \\
7,957 \\
10,649 \\
0 \\
0 \\
62,715 \\
-16,127 \\
0 \\
-16,127 \\
20,361 \\
0 \\
0 \\
0 \\
4,234\end{array}$ & $\begin{array}{r}19,100 \\
16,744 \\
0 \\
604 \\
0 \\
560 \\
17,807 \\
1,193 \\
0 \\
1,193 \\
0 \\
0 \\
0 \\
1,193 \\
0 \\
0 \\
0 \\
1,193 \\
0 \\
0 \\
1,193\end{array}$ & $\begin{array}{r}8,701 \\
6,180 \\
721 \\
276 \\
0 \\
0 \\
7,187 \\
1,514 \\
0 \\
1,514 \\
136 \\
0 \\
0 \\
0 \\
1,650 \\
\\
404 \\
19 \\
423 \\
1,227 \\
0 \\
0 \\
1,227\end{array}$ & $\begin{array}{r}37,406 \\
22,560 \\
1,114 \\
5,964 \\
0 \\
414 \\
30,051 \\
7,355 \\
0 \\
7,355 \\
2,244 \\
0 \\
0 \\
9,599\end{array}$ & $\begin{array}{r}14,382 \\
12,818 \\
410 \\
314 \\
0 \\
496 \\
14,038 \\
344 \\
0 \\
344 \\
180 \\
0 \\
0 \\
0 \\
524\end{array}$ \\
\hline
\end{tabular}

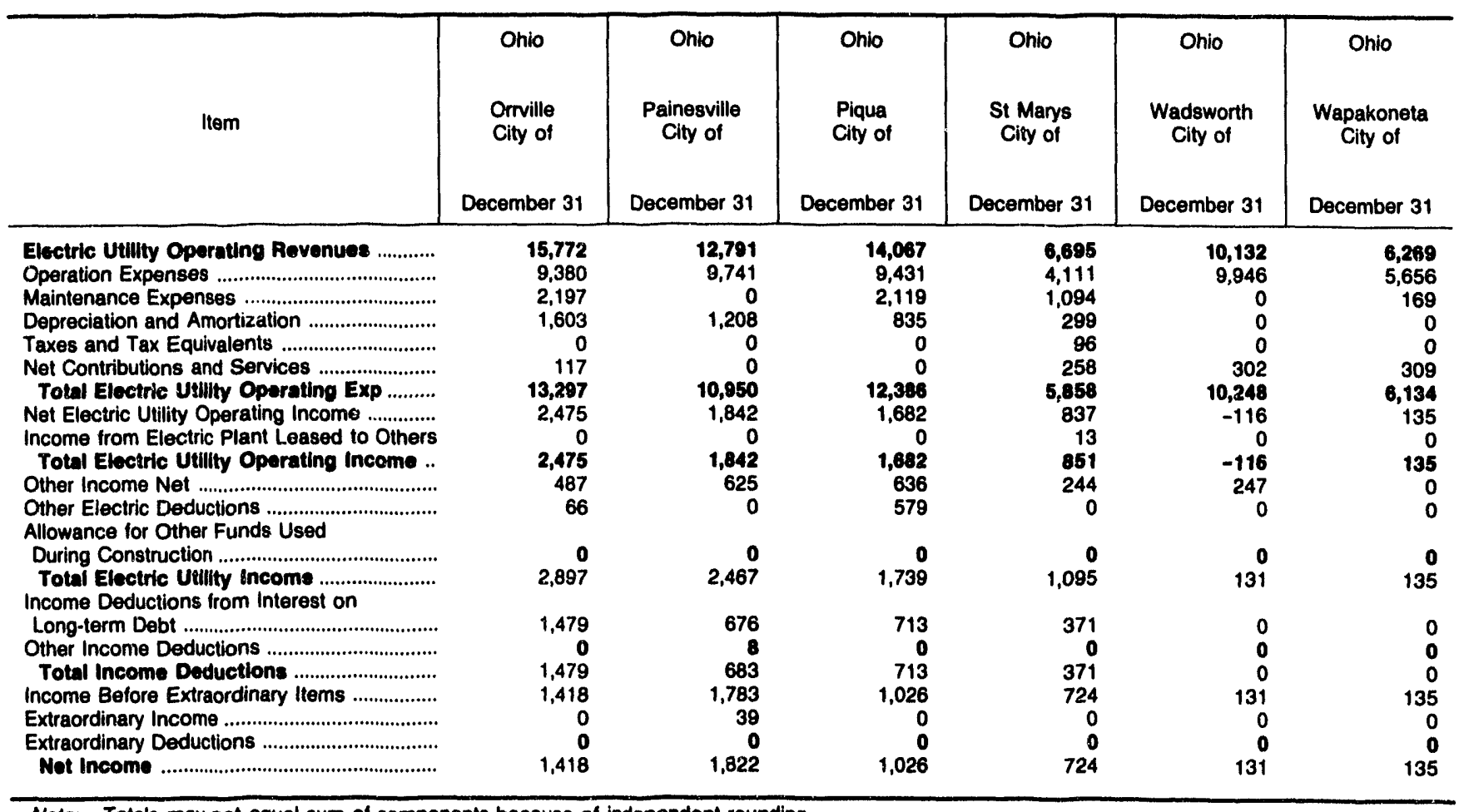

Note: Totals may not equal sum of components because of independent rounding.

Source: Energy Information Administration, Form ElA-412, "Annual Report of Public Electric Utilities." 
Table 36. Statement of Income by Major Publicly Owned Electric
Utility Within State, 1991 (Continued) (Thousand Dollars)

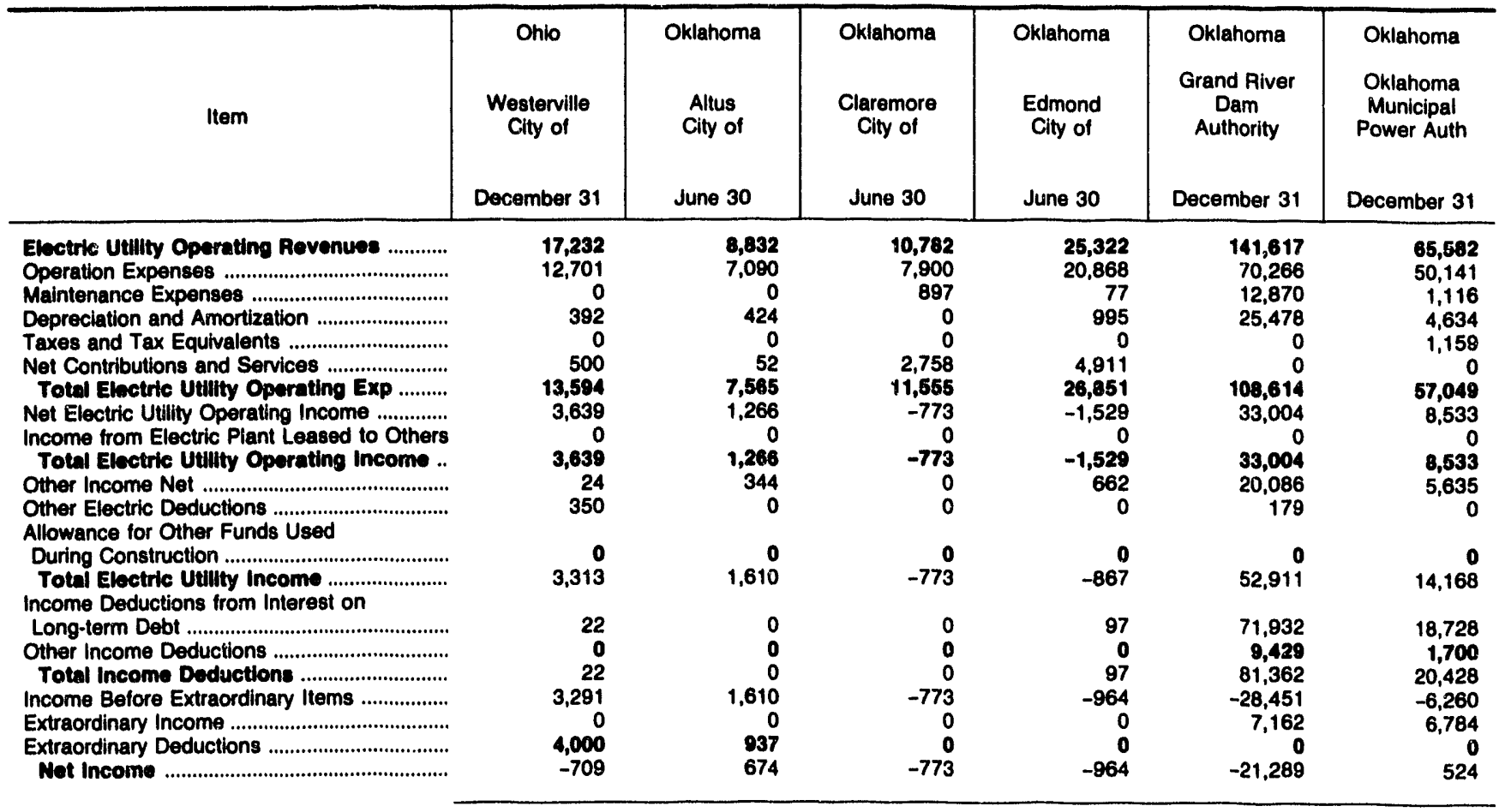

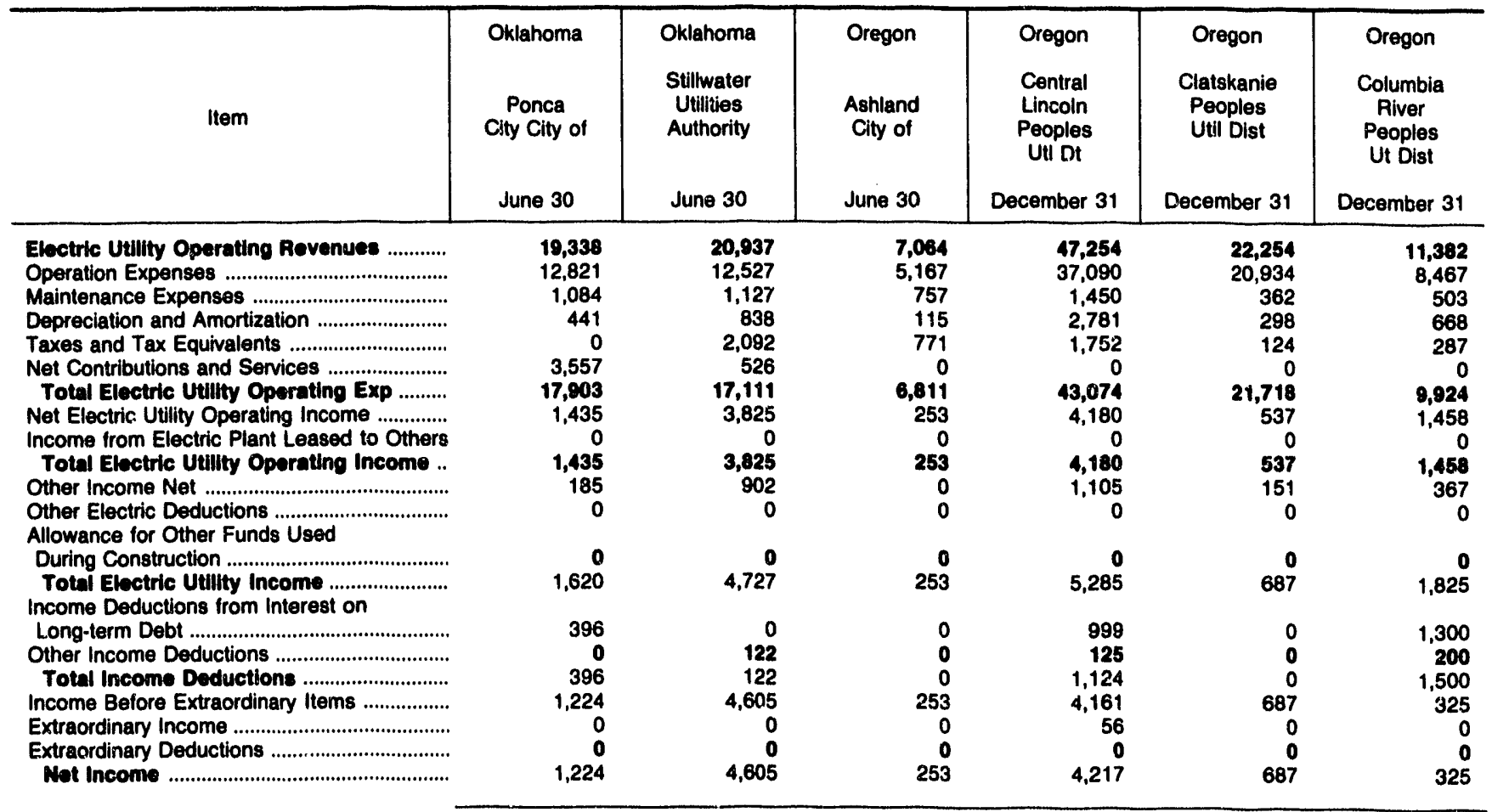

Note: Totals may not equal sum of components because of independent rounding.

Source: Energy Information Administration, Form EIA-412, "Annual Report of Public Electric Utilities." 
Table 36. Statement of Income by Major Publicly Owned Electric Utility Within State, 1991 (Continued)

(Thousand Dollars)

\begin{tabular}{|c|c|c|c|c|c|c|}
\hline Item & $\begin{array}{l}\text { Oregon } \\
\text { Emerald } \\
\text { Peoples } \\
\text { Utility Dist } \\
\text { December } 31\end{array}$ & $\begin{array}{l}\text { Oregon } \\
\text { Eugene } \\
\text { City of } \\
\text { December } 31\end{array}$ & $\begin{array}{c}\text { Oregon } \\
\begin{array}{l}\text { Forest Grove } \\
\text { City of }\end{array} \\
\text { June } 30\end{array}$ & $\begin{array}{l}\text { Oregon } \\
\text { McMinnville } \\
\text { City of } \\
\text { June } 30\end{array}$ & $\begin{array}{l}\text { Oregon } \\
\text { Northern } \\
\text { Wasco County } \\
\text { P U D } \\
\text { December } 31\end{array}$ & $\begin{array}{c}\text { Oregon } \\
\text { Springfield } \\
\text { Clity of } \\
\text { December } 31\end{array}$ \\
\hline 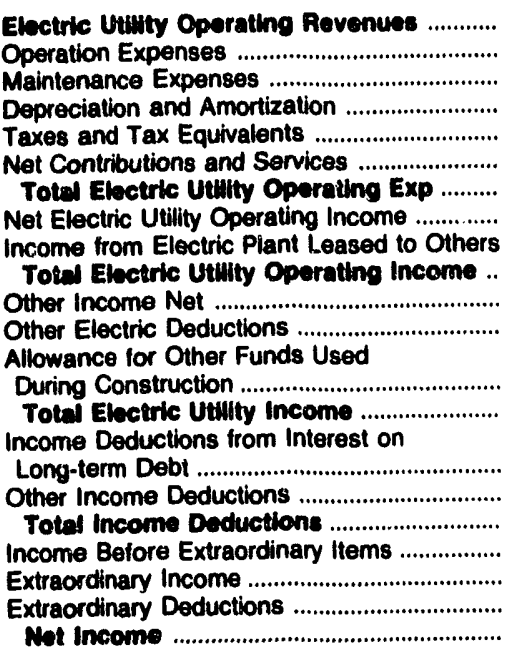 & $\begin{array}{r}17,931 \\
10,639 \\
383 \\
2,178 \\
664 \\
0 \\
13,864 \\
4,067 \\
0 \\
4,087 \\
779 \\
0\end{array}$ & $\begin{array}{r}88,605 \\
67,507 \\
4,310 \\
7,160 \\
6,358 \\
0 \\
85,334 \\
3,271 \\
411 \\
3,681 \\
1,323 \\
336 \\
\\
2223 \\
4,891\end{array}$ & $\begin{array}{r}6,215 \\
5,227 \\
295 \\
344 \\
329 \\
0 \\
6,186 \\
19 \\
0 \\
19 \\
49 \\
0 \\
\\
0 \\
68\end{array}$ & $\begin{array}{r}13,086 \\
11,655 \\
0 \\
596 \\
728 \\
140 \\
13,119 \\
-33 \\
0 \\
-33 \\
609 \\
0 \\
0 \\
075 \\
0 \\
27 \\
27 \\
548 \\
0 \\
0 \\
548\end{array}$ & $\begin{array}{r}8,871 \\
6,837 \\
437 \\
580 \\
522 \\
0 \\
8,377 \\
494 \\
0 \\
494 \\
280 \\
0 \\
\\
0 \\
774\end{array}$ & $\begin{array}{r}24,836 \\
20,344 \\
622 \\
1,051 \\
1,260 \\
0 \\
23,277 \\
1,660 \\
0 \\
1,680 \\
288 \\
0 \\
\\
38 \\
1,986\end{array}$ \\
\hline
\end{tabular}

\begin{tabular}{|c|c|c|c|c|c|c|}
\hline Item & $\begin{array}{l}\text { Oregon } \\
\text { Tillamook } \\
\text { Peoples } \\
\text { Utility Dist } \\
\text { December } 31\end{array}$ & $\begin{array}{c}\text { Pennsylvania } \\
\text { Chambersburg } \\
\text { Borough of } \\
\text { December } 31\end{array}$ & $\begin{array}{l}\text { South Carolina } \\
\text { Camden } \\
\text { City of } \\
\text { June } 30\end{array}$ & $\begin{array}{l}\text { South Carolina } \\
\text { Easley } \\
\text { Combined } \\
\text { Utility } \\
\text { System } \\
\text { March } 31\end{array}$ & $\begin{array}{l}\text { South Carolina } \\
\text { Gaffney } \\
\text { City of } \\
\text { March } 31\end{array}$ & $\begin{array}{l}\text { South Carolina } \\
\text { Greenwood } \\
\text { City of } \\
\text { December } 31\end{array}$ \\
\hline 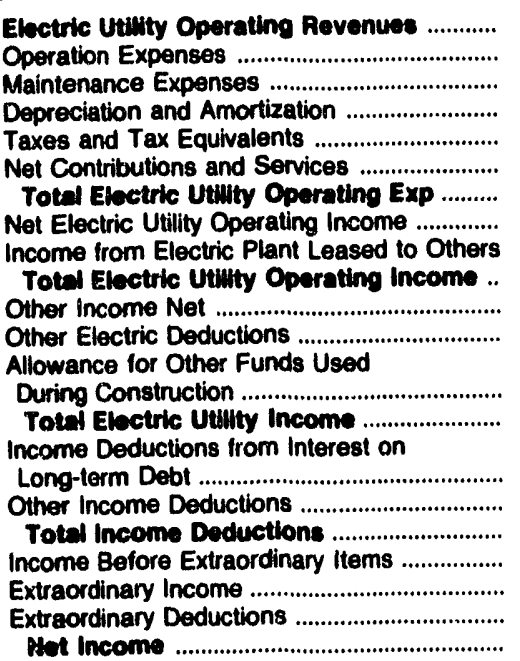 & $\begin{array}{r}14,211 \\
11,210 \\
824 \\
944 \\
537 \\
0 \\
13,516 \\
695 \\
0 \\
695 \\
652 \\
0 \\
\\
0 \\
1,347\end{array}$ & $\begin{array}{r}10,729 \\
9,414 \\
318 \\
751 \\
0 \\
500 \\
10,983 \\
-254 \\
0 \\
-254 \\
282 \\
0 \\
0 \\
0 \\
29\end{array}$ & $\begin{array}{r}11,700 \\
10,306 \\
0 \\
331 \\
0 \\
0 \\
10,637 \\
1,063 \\
0 \\
1,063 \\
1,238 \\
0 \\
0 \\
0 \\
2,301\end{array}$ & $\begin{array}{r}12,124 \\
9,865 \\
570 \\
375 \\
0 \\
231 \\
11,141 \\
983 \\
0 \\
983 \\
398 \\
0 \\
0 \\
1,381\end{array}$ & $\begin{array}{r}10,445 \\
9,724 \\
59 \\
408 \\
0 \\
0 \\
10,192 \\
253 \\
0 \\
253 \\
188 \\
0 \\
0 \\
440\end{array}$ & $\begin{array}{r}12,107 \\
10,761 \\
399 \\
444 \\
0 \\
203 \\
11,809 \\
300 \\
0 \\
300 \\
248 \\
0 \\
\\
0 \\
548\end{array}$ \\
\hline
\end{tabular}

Note: Totals may not equal sum of components because of independent rounding.

Source: Energy Information Administration, Form EIA-412. "Annual Report of Public Electric Utilities." 


\section{Table 36. Statement of Income by Major Publicly Owned Electric Utility Within State, 1991 (Continued) (Thousand Dollars)}

\begin{tabular}{|c|c|c|c|c|c|c|}
\hline Item & $\begin{array}{c}\text { South Carolina } \\
\text { Greer } \\
\text { Comm } \\
\text { of } \\
\text { Public Works } \\
\text { December } 31\end{array}$ & $\begin{array}{l}\text { South Carolina } \\
\text { Newberry } \\
\text { City of } \\
\text { June } 30\end{array}$ & $\begin{array}{l}\text { South Carolina } \\
\text { Orangeburg } \\
\text { City of } \\
\text { September } 30\end{array}$ & $\begin{array}{l}\text { Soutti Carolina } \\
\text { Piedmont } \\
\text { Municipal } \\
\text { Power Agny } \\
\text { December } 31\end{array}$ & $\begin{array}{l}\text { South Carolina } \\
\text { Rock Hill } \\
\text { City of } \\
\text { December } 31\end{array}$ & $\begin{array}{c}\text { South Carolina } \\
\text { South } \\
\text { Carolina } \\
\text { Pub } \\
\text { Serv Auth } \\
\text { December } 31\end{array}$ \\
\hline 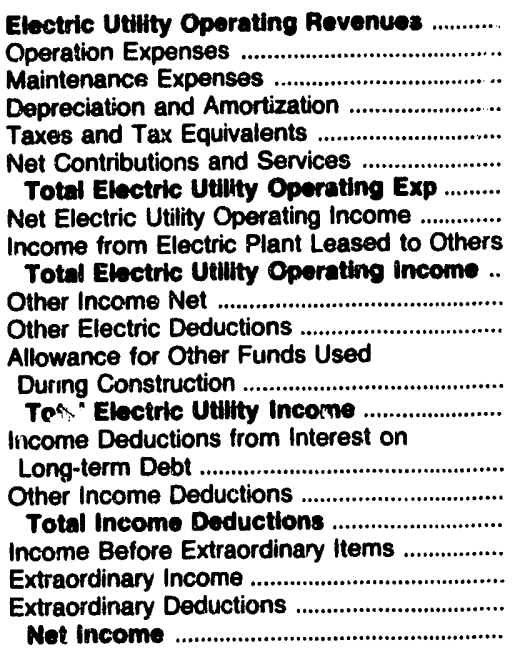 & $\begin{array}{r}9,252 \\
7.788 \\
0 \\
497 \\
0 \\
466 \\
8,751 \\
6,01 \\
0 \\
501 \\
2,035 \\
0\end{array}$ & $\begin{array}{r}8,494 \\
7,305 \\
0 \\
207 \\
0 \\
328 \\
7,841 \\
653 \\
0 \\
653 \\
582 \\
0\end{array}$ & $\begin{array}{r}33,065 \\
26,873 \\
100 \\
1,040 \\
0 \\
0 \\
28,013 \\
5,052 \\
0 \\
5,052 \\
675 \\
0\end{array}$ & $\begin{array}{r}153,325 \\
71,509 \\
16,819 \\
20,212 \\
3,130 \\
0 \\
111,670 \\
41,655 \\
0 \\
41,655 \\
41 \quad 7 \\
0 \\
\end{array}$ & $\begin{array}{r}36,983 \\
25,673 \\
846 \\
650 \\
0 \\
10,212 \\
37,380 \\
-397 \\
0 \\
-397 \\
642 \\
34\end{array}$ & $\begin{array}{r}562,578 \\
296,485 \\
47,835 \\
70,846 \\
3,364 \\
5,640 \\
424,170 \\
138,408 \\
0 \\
138,408 \\
29,354 \\
0 \\
0 \\
0 \\
167,762\end{array}$ \\
\hline
\end{tabular}

\begin{tabular}{|c|c|c|c|c|c|c|}
\hline Item & $\begin{array}{c}\text { South Dakota } \\
\text { Brookings } \\
\text { City of }\end{array}$ & $\begin{array}{l}\text { South Dakota } \\
\text { Heartland } \\
\text { Consumers } \\
\text { Power Dist } \\
\text { December } 31\end{array}$ & $\begin{array}{l}\text { South Dakota } \\
\text { Missouri } \\
\text { Basin } \\
\text { Mun } \\
\text { Power Agny } \\
\text { December } 31\end{array}$ & $\begin{array}{c}\text { South Dakota } \\
\text { Pierre } \\
\text { City of } \\
\text { December } 31\end{array}$ & $\begin{array}{l}\text { South Dakota } \\
\text { Watertown } \\
\text { Municipal } \\
\text { Utilities } \\
\text { December } 31\end{array}$ & $\begin{array}{c}\text { Tennessee } \\
\text { Alcoa } \\
\text { Utilities } \\
\text { June } 30\end{array}$ \\
\hline 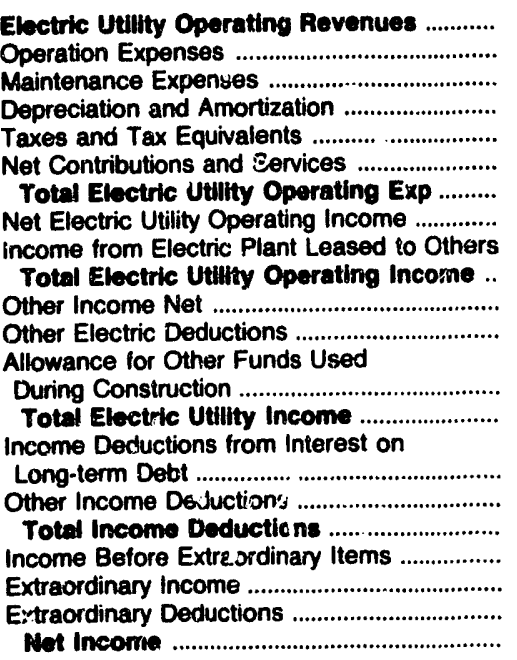 & $\begin{array}{r}7,138 \\
4,817 \\
730 \\
475 \\
0 \\
437 \\
6,453 \\
680 \\
0 \\
680 \\
149 \\
2 \\
\\
0 \\
827\end{array}$ & $\begin{array}{r}10,848 \\
6,774 \\
0 \\
911 \\
290 \\
0 \\
7,976 \\
2,873 \\
0 \\
2,873 \\
1,079 \\
0 \\
0 \\
3,951 \\
4,422 \\
-156 \\
4,266 \\
-315 \\
0 \\
0 \\
-0,5\end{array}$ & $\begin{array}{r}55,235 \\
54,745 \\
0 \\
71 \\
22 \\
0 \\
54,937 \\
398 \\
0 \\
398 \\
1,915 \\
0 \\
0 \\
0 \\
2,313\end{array}$ & $\begin{array}{r}5,583 \\
3,228 \\
49 \\
261 \\
0 \\
1,515 \\
5,052 \\
530 \\
0 \\
530 \\
0 \\
69 \\
\\
0 \\
462 \\
\\
0 \\
0 \\
0 \\
462 \\
0 \\
0 \\
462\end{array}$ & $\begin{array}{r}7,495 \\
5,378 \\
572 \\
722 \\
0 \\
450 \\
7,123 \\
372 \\
0 \\
372 \\
138 \\
1 \\
\\
0 \\
509 \\
\\
0 \\
0 \\
0 \\
509 \\
0 \\
0 \\
509\end{array}$ & $\begin{array}{r}22,372 \\
20,015 \\
881 \\
559 \\
434 \\
0 \\
21,899 \\
483 \\
0 \\
483 \\
203 \\
0 \\
\\
0 \\
686 \\
\\
210 \\
6 \\
216 \\
470 \\
0 \\
05 \\
384\end{array}$ \\
\hline
\end{tabular}

Note: Totals may not equal sum of corriponents because of independent rounding.

Source: Energy Information Administration, Form EIA-412, "Annual Report of Public Electric Utilities." 

Table 36. Statement of Income by Major Publicly Owned Electric
Utility Within State, 1991 (Continued) (Thousand Dollars)

\begin{tabular}{|c|c|c|c|c|c|c|}
\hline Item & $\begin{array}{l}\text { Tennessee } \\
\text { Athens } \\
\text { City of } \\
\text { June } 30\end{array}$ & $\begin{array}{l}\text { Tennessee } \\
\text { Benton } \\
\text { County } \\
\text { June } 30\end{array}$ & $\begin{array}{l}\text { Tennessee } \\
\text { Bolivar } \\
\text { City of } \\
\text { June } 30\end{array}$ & $\begin{array}{l}\text { Tennessee } \\
\text { Bristol } \\
\text { City of } \\
\text { June } 30\end{array}$ & $\begin{array}{c}\text { Tennessee } \\
\text { Brownsville } \\
\text { City of } \\
\text { June } 30\end{array}$ & $\begin{array}{l}\text { Tennessee } \\
\text { Carroll } \\
\text { County } \\
\text { June } 30\end{array}$ \\
\hline 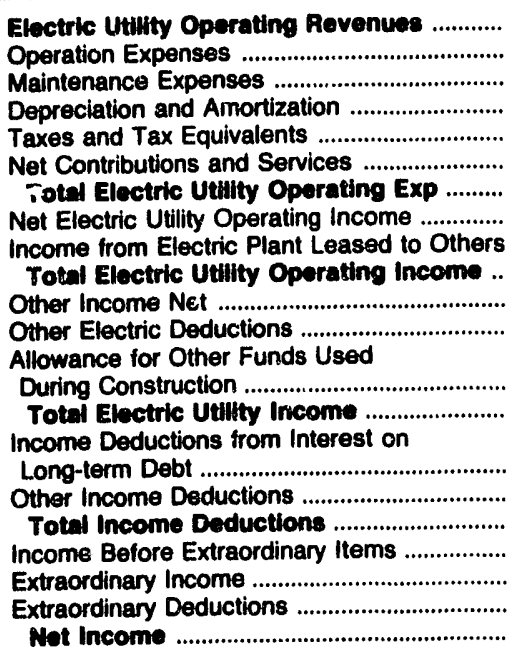 & $\begin{array}{r}25,186 \\
23,536 \\
520 \\
521 \\
418 \\
0 \\
24,995 \\
191 \\
0 \\
191 \\
19 \\
0 \\
\\
0 \\
210\end{array}$ & $\begin{array}{r}11,052 \\
9,257 \\
542 \\
406 \\
255 \\
0 \\
10,461 \\
591 \\
0 \\
591 \\
100 \\
0 \\
\\
0 \\
691\end{array}$ & $\begin{array}{r}12,433 \\
11,203 \\
342 \\
397 \\
222 \\
0 \\
12,164 \\
269 \\
0 \\
289 \\
83 \\
0 \\
\\
0 \\
352\end{array}$ & $\begin{array}{r}39,395 \\
33,652 \\
1,321 \\
1,205 \\
973 \\
0 \\
37,151 \\
1,244 \\
0 \\
1,244 \\
10 \\
0 \\
1,126 \\
2,379\end{array}$ & $\begin{array}{r}8,935 \\
8,631 \\
86 \\
178 \\
145 \\
31 \\
9,070 \\
-135 \\
0 \\
-135 \\
91 \\
0 \\
\end{array}$ & $\begin{array}{r}19,091 \\
17,239 \\
578 \\
473 \\
337 \\
0 \\
18,627 \\
463 \\
0 \\
463 \\
198 \\
14 \\
\\
0 \\
647\end{array}$ \\
\hline
\end{tabular}

\begin{tabular}{|c|c|c|c|c|c|c|}
\hline Item & $\begin{array}{c}\text { Tennessee } \\
\text { Chattanooga } \\
\text { City of } \\
\text { June } 30\end{array}$ & $\begin{array}{l}\text { Tennessee } \\
\text { Clarksville } \\
\text { City of } \\
\text { June } 30\end{array}$ & $\begin{array}{l}\text { Tennessee } \\
\text { Cieveland } \\
\text { City of } \\
\text { June } 30\end{array}$ & $\begin{array}{l}\text { Tennessee } \\
\text { Clinton } \\
\text { City of } \\
\text { June } \mathbf{3 0}\end{array}$ & $\begin{array}{l}\text { Tennessee } \\
\text { Columbia } \\
\text { City of } \\
\text { June } 30\end{array}$ & $\begin{array}{l}\text { Tennessee } \\
\text { Cookeville } \\
\text { City of } \\
\text { June } 30\end{array}$ \\
\hline 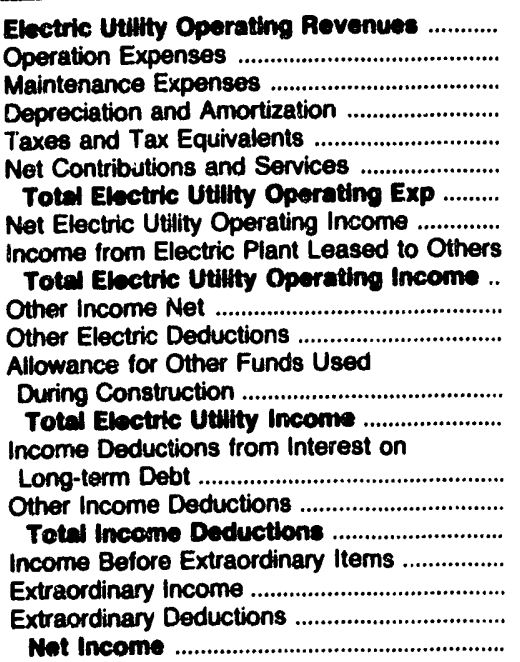 & $\begin{array}{r}276,178 \\
251,578 \\
7,778 \\
6,814 \\
6,741 \\
9 \\
272,921 \\
3,257 \\
0 \\
3,257 \\
2,577 \\
4 \\
0 \\
5,830 \\
46 \\
216 \\
262 \\
5,568 \\
13,196 \\
11,144 \\
7,619\end{array}$ & $\begin{array}{r}40,622 \\
36,952 \\
903 \\
2,456 \\
810 \\
0 \\
41,121 \\
-499 \\
0 \\
-490 \\
1,400 \\
1 \\
0 \\
899 \\
\\
361 \\
68 \\
428 \\
471 \\
0 \\
0 \\
47 i\end{array}$ & $\begin{array}{r}43,795 \\
38,754 \\
968 \\
1,205 \\
827 \\
-11 \\
41,743 \\
2,052 \\
0 \\
2,052 \\
151 \\
0 \\
\\
0 \\
2,203 \\
0 \\
0 \\
69 \\
69 \\
2,135 \\
0 \\
0 \\
2,135\end{array}$ & $\begin{array}{r}30,710 \\
27,715 \\
953 \\
900 \\
737 \\
0 \\
30,306 \\
404 \\
0 \\
404 \\
840 \\
10 \\
0 \\
1,234 \\
\\
0 \\
0 \\
0 \\
1,234 \\
0 \\
192 \\
i, 041\end{array}$ & $\begin{array}{r}26,542 \\
23,788 \\
796 \\
727 \\
424 \\
0 \\
25,735 \\
807 \\
0 \\
807 \\
281 \\
0 \\
0 \\
1,088 \\
\\
0 \\
36 \\
36 \\
1,052 \\
0 \\
0 \\
i, 052\end{array}$ & $\begin{array}{r}23,200 \\
21,296 \\
418 \\
603 \\
255 \\
0 \\
22,574 \\
627 \\
238 \\
865 \\
0 \\
0 \\
\\
0 \\
865 \\
116 \\
0 \\
116 \\
749 \\
0 \\
54 \\
694\end{array}$ \\
\hline
\end{tabular}

Note: Totals may not equal sum of components because of independent rounding.

Source: Energy Information Administration, Form ElA-412, "Annual Report of Public Electric, Utilities." 


\section{Table 36. Statement of Income by Major Publicly Owned Electric Utility Within State, 1991 (Continued) (Thousand Dollars)}

\begin{tabular}{|c|c|c|c|c|c|c|}
\hline llem & $\begin{array}{l}\text { Tennessee } \\
\text { Covington } \\
\text { City of } \\
\text { June } 30\end{array}$ & $\begin{array}{l}\text { Tennessee } \\
\text { Dayton } \\
\text { City of } \\
\text { June } 30\end{array}$ & $\begin{array}{l}\text { Tennessee } \\
\text { Dickson } \\
\text { City of } \\
\text { June } 30\end{array}$ & $\begin{array}{l}\text { Tennessee } \\
\text { Dyersburg } \\
\text { Electric } \\
\text { System } \\
\text { June } 30\end{array}$ & $\begin{array}{l}\text { Tennessee } \\
\text { Elizabethton } \\
\text { City of } \\
\text { June } 30\end{array}$ & $\begin{array}{l}\text { Tennessee } \\
\text { Enwin } \\
\text { Town of } \\
\text { June } 30\end{array}$ \\
\hline 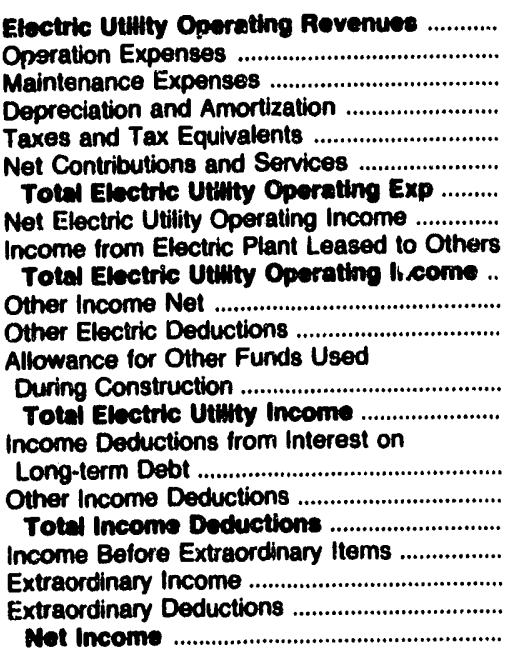 & $\begin{array}{r}10,155 \\
9,192 \\
140 \\
196 \\
174 \\
0 \\
9,702 \\
454 \\
\mathbf{6} \\
454 \\
333 \\
0 \\
0 \\
0 \\
787\end{array}$ & $\begin{array}{r}9,807 \\
8,609 \\
193 \\
189 \\
183 \\
0 \\
9,174 \\
633 \\
0 \\
633 \\
33 \\
0 \\
\end{array}$ & $\begin{array}{r}28,983 \\
25,559 \\
683 \\
766 \\
441 \\
0 \\
27,446 \\
1,539 \\
0 \\
1,539 \\
281 \\
0 \\
\\
0 \\
1,821\end{array}$ & $\begin{array}{r}26,629 \\
23,689 \\
797 \\
632 \\
533 \\
0 \\
25,652 \\
977 \\
0 \\
977 \\
327 \\
12 \\
0 \\
0 \\
1,292\end{array}$ & $\begin{array}{r}25,328 \\
22,924 \\
782 \\
603 \\
532 \\
0 \\
24,841 \\
487 \\
0 \\
487 \\
124 \\
0 \\
\\
0 \\
611\end{array}$ & $\begin{array}{r}10,249 \\
9,522 \\
171 \\
226 \\
171 \\
0 \\
10,089 \\
159 \\
0 \\
150 \\
42 \\
0 \\
0 \\
0 \\
201\end{array}$ \\
\hline
\end{tabular}

\begin{tabular}{|c|c|c|c|c|c|c|}
\hline Item & $\begin{array}{l}\text { Tennessee } \\
\text { Etowah } \\
\text { City of } \\
\text { June } 30\end{array}$ & $\begin{array}{c}\text { Tennessee } \\
\text { Fayetteville } \\
\text { City of } \\
\text { June } 30\end{array}$ & $\begin{array}{l}\text { Tennessee } \\
\text { Gallatin } \\
\text { City of } \\
\text { June } 30\end{array}$ & $\begin{array}{c}\text { Tennessee } \\
\text { Greeneville } \\
\text { City of } \\
\text { June } 30\end{array}$ & $\begin{array}{c}\text { Harriman } \\
\text { City of } \\
\text { June } 30\end{array}$ & $\begin{array}{l}\text { Tennessee } \\
\text { Humboldt } \\
\text { City of } \\
\text { June } 30\end{array}$ \\
\hline 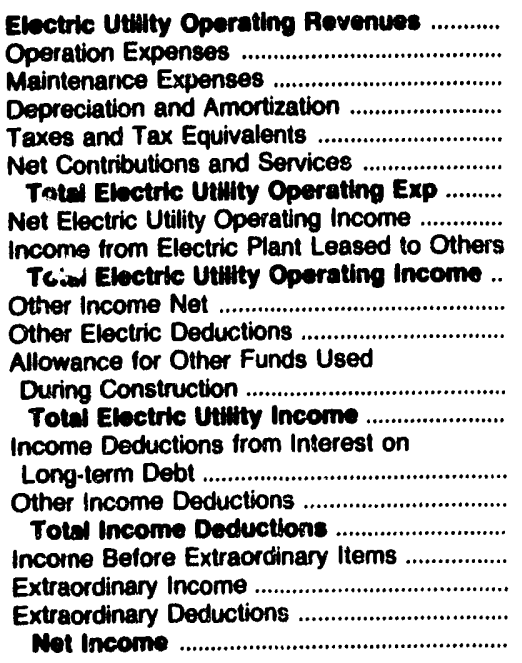 & $\begin{array}{r}7,110 \\
6,541 \\
254 \\
140 \\
116 \\
0 \\
7,051 \\
58 \\
0 \\
58 \\
53 \\
0 \\
\\
0 \\
111\end{array}$ & $\begin{array}{r}19,575 \\
16,670 \\
429 \\
640 \\
429 \\
3 \\
18,170 \\
1,405 \\
0 \\
1,405 \\
266 \\
18 \\
\\
0 \\
1,653\end{array}$ & $\begin{array}{r}20,488 \\
18,666 \\
336 \\
401 \\
208 \\
0 \\
19,610 \\
878 \\
0 \\
878 \\
318 \\
0 \\
0 \\
0 \\
1,196\end{array}$ & $\begin{array}{r}43,382 \\
39,147 \\
1,165 \\
1,130 \\
774 \\
0 \\
42,216 \\
1,175 \\
0 \\
1,175 \\
1,231 \\
0 \\
\\
0 \\
2,407\end{array}$ & $\begin{array}{r}15,351 \\
12,744 \\
665 \\
546 \\
251 \\
0 \\
14,205 \\
1,145 \\
0 \\
1,145 \\
89 \\
0 \\
\\
0 \\
1,234\end{array}$ & $\begin{array}{r}9,719 \\
9,456 \\
173 \\
178 \\
118 \\
0 \\
9,024 \\
-205 \\
0 \\
-205 \\
263 \\
2 \\
0 \\
0 \\
57\end{array}$ \\
\hline
\end{tabular}

Note: Totals may not equal sum of components because of independent rounding.

Source: Energy Information Administration, Form EIA-412, "Annual Report of Public Electric Utilities." 


\section{Table 36. Statement of Income by Major Publicly Owned Electric Utility Within State, 1991 (Continued) (Thousand Dollars)}

\begin{tabular}{|c|c|c|c|c|c|c|}
\hline Item & $\begin{array}{l}\text { Tennessee } \\
\text { Jackson } \\
\text { City of } \\
\text { June } 30\end{array}$ & $\begin{array}{l}\text { Tennessee } \\
\text { Johnson } \\
\text { City City of } \\
\text { June } 30\end{array}$ & $\begin{array}{l}\text { Tennessee } \\
\text { Knoxville } \\
\text { Utilities } \\
\text { Board } \\
\text { June } 30\end{array}$ & $\begin{array}{l}\text { Tennessee } \\
\text { Lawrenceburg } \\
\text { City of } \\
\text { June } 30\end{array}$ & $\begin{array}{c}\text { Tennessee } \\
\text { LaFollette } \\
\text { City of } \\
\text { December } 31\end{array}$ & $\begin{array}{l}\text { Lebanon } \\
\text { City of } \\
\text { June } 30\end{array}$ \\
\hline 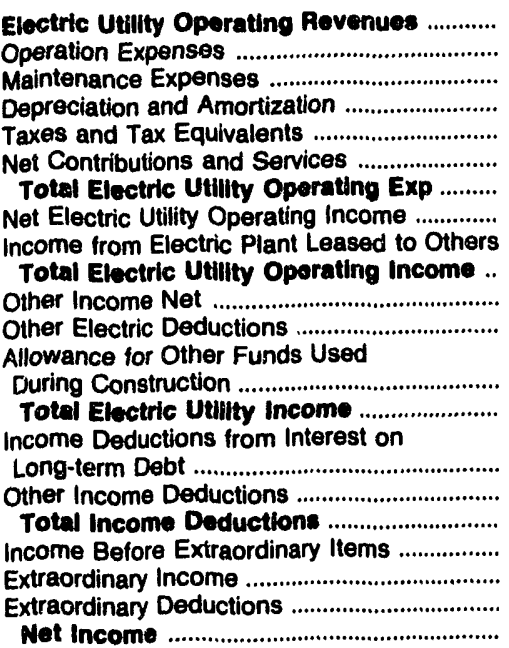 & $\begin{array}{r}56,611 \\
51,872 \\
1,035 \\
1,785 \\
1,042 \\
0 \\
55,733 \\
878 \\
0 \\
878 \\
406 \\
0 \\
0 \\
0 \\
1,283\end{array}$ & $\begin{array}{r}71,319 \\
65,949 \\
1,659 \\
1,228 \\
1,119 \\
0 \\
69,955 \\
1,364 \\
0 \\
1,364 \\
589 \\
0\end{array}$ & $\begin{array}{r}245,684 \\
223,047 \\
8,213 \\
7,822 \\
6,028 \\
0 \\
245,110 \\
574 \\
0 \\
574 \\
2,831 \\
0 \\
\\
0 \\
3,405 \\
2,536 \\
294 \\
2,830 \\
575 \\
0 \\
0 \\
575\end{array}$ & $\begin{array}{r}21,996 \\
20,099 \\
498 \\
614 \\
454 \\
0 \\
21,685 \\
331 \\
0 \\
331 \\
70 \\
16 \\
\\
0 \\
385\end{array}$ & $\begin{array}{r}18,439 \\
16,150 \\
631 \\
613 \\
342 \\
0 \\
17,736 \\
702 \\
0 \\
702 \\
212 \\
0 \\
0 \\
014 \\
912 \\
128 \\
46 \\
174 \\
741 \\
0 \\
49 \\
692\end{array}$ & $\begin{array}{r}16,136 \\
14,867 \\
566 \\
301 \\
264 \\
0 \\
16,008 \\
39 \\
159 \\
197 \\
0 \\
0 \\
0 \\
197\end{array}$ \\
\hline
\end{tabular}

\begin{tabular}{|c|c|c|c|c|c|c|}
\hline Item & $\begin{array}{l}\text { Tennessee } \\
\text { Lenoir } \\
\text { City City of } \\
\text { June } 30\end{array}$ & $\begin{array}{l}\text { Tennessee } \\
\text { Lewisburg } \\
\text { City of } \\
\text { June } 30\end{array}$ & $\begin{array}{l}\text { Tennessee } \\
\text { Lexington } \\
\text { City of } \\
\text { June } 30\end{array}$ & $\begin{array}{l}\text { Tennessee } \\
\text { Loudon } \\
\text { City of } \\
\text { June } 30\end{array}$ & $\begin{array}{c}\text { Tennessee } \\
\text { Maryville } \\
\text { Utilities } \\
\text { June } 30\end{array}$ & $\begin{array}{l}\text { Tennessee } \\
\text { McMinnville } \\
\text { Electric } \\
\text { System } \\
\text { June } 30\end{array}$ \\
\hline 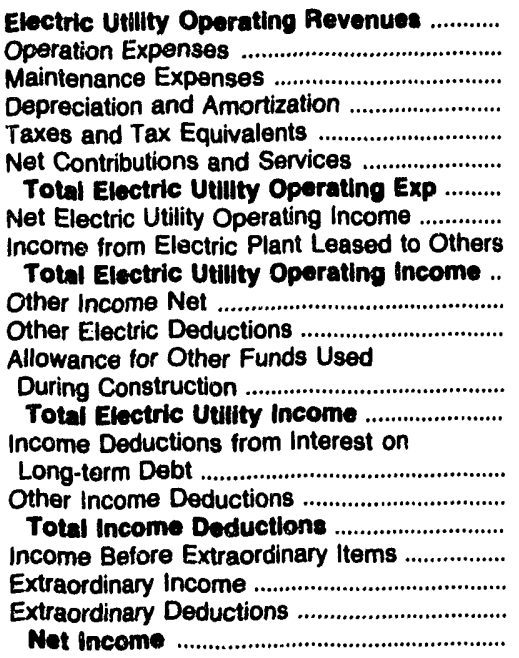 & $\begin{array}{r}53,300 \\
46,886 \\
959 \\
1,331 \\
825 \\
0 \\
50,001 \\
3,299 \\
0 \\
3,299 \\
454 \\
0 \\
\\
0 \\
3,753\end{array}$ & $\begin{array}{r}13,641 \\
12,572 \\
195 \\
289 \\
244 \\
3 \\
13,304 \\
337 \\
0 \\
337 \\
134 \\
0 \\
0 \\
472\end{array}$ & $\begin{array}{r}20,054 \\
17,691 \\
586 \\
575 \\
435 \\
0 \\
19,286 \\
768 \\
239 \\
1,007 \\
0 \\
0 \\
0 \\
0 \\
1,007\end{array}$ & $\begin{array}{r}11,611 \\
10,153 \\
160 \\
184 \\
168 \\
0 \\
10,685 \\
946 \\
0 \\
946 \\
136 \\
0 \\
\\
0 \\
1,082\end{array}$ & $\begin{array}{r}23,814 \\
21,093 \\
626 \\
777 \\
437 \\
0 \\
22,033 \\
880 \\
0 \\
880 \\
252 \\
0 \\
\\
0 \\
1.132\end{array}$ & $\begin{array}{r}11,521 \\
10,400 \\
327 \\
383 \\
257 \\
0 \\
11,366 \\
155 \\
0 \\
155 \\
152 \\
0 \\
\\
0 \\
307\end{array}$ \\
\hline
\end{tabular}

Note: Totals may not equal sum of components because of independent rounding.

Source: Energy Information Administration, Form EIA-412, "Annual Report of Public Electric Utilities." 
Table 36. Statement of Income by Major Publicly Owned Electric Utility Within State, 1991 (Continued)

(Thousand Dollars)

\begin{tabular}{|c|c|c|c|c|c|c|}
\hline Item & $\begin{array}{c}\text { Tennessee } \\
\text { Memphis } \\
\text { City of } \\
\text { December } 31\end{array}$ & $\begin{array}{l}\text { Tennessee } \\
\text { Milan } \\
\text { City of } \\
\text { June } 30\end{array}$ & $\begin{array}{l}\text { Tennessee } \\
\text { Morristown } \\
\text { City of } \\
\text { June } 30\end{array}$ & $\begin{array}{l}\text { Tennessee } \\
\text { Murfreesboro } \\
\text { City of } \\
\text { June } 30\end{array}$ & $\begin{array}{c}\text { Tennessee } \\
\text { Nashville } \\
\text { Electric } \\
\text { Service } \\
\text { June } 30\end{array}$ & $\begin{array}{c}\text { Tennessee } \\
\text { Newport } \\
\text { City of } \\
\text { June } 30\end{array}$ \\
\hline 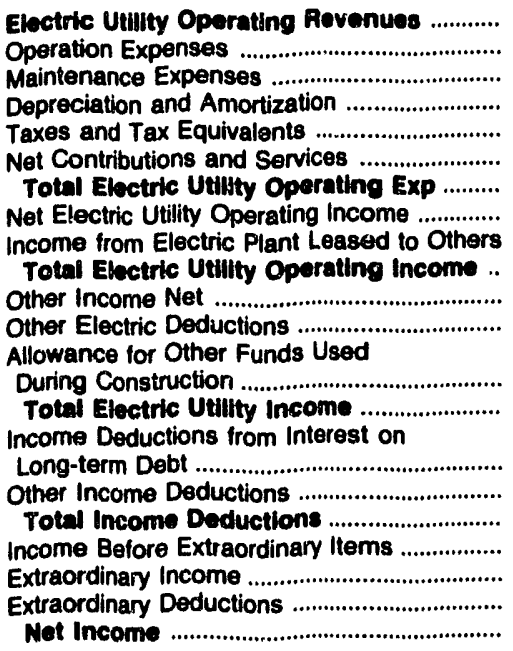 & $\begin{array}{r}657,033 \\
571,697 \\
20,965 \\
17,387 \\
14,691 \\
0 \\
624,741 \\
32,292 \\
0 \\
32,292 \\
11,809 \\
0 \\
0 \\
0 \\
44,101\end{array}$ & $\begin{array}{r}10,931 \\
10,242 \\
319 \\
209 \\
162 \\
0 \\
10,932 \\
0 \\
0 \\
0 \\
98 \\
0 \\
0 \\
98\end{array}$ & $\begin{array}{r}30,637 \\
27,985 \\
623 \\
753 \\
500 \\
6 \\
20,886 \\
771 \\
0 \\
771 \\
389 \\
70 \\
\\
0 \\
1,090\end{array}$ & $\begin{array}{r}40,623 \\
36,608 \\
669 \\
1,198 \\
862 \\
0 \\
39,337 \\
1,287 \\
0 \\
1,287 \\
320 \\
2 \\
0 \\
0 \\
1,605\end{array}$ & $\begin{array}{r}533,702 \\
482,373 \\
14,374 \\
16,223 \\
10,208 \\
0 \\
523,178 \\
10,524 \\
0 \\
10,524 \\
8,512 \\
0 \\
0 \\
19,036\end{array}$ & $\begin{array}{r}21,643 \\
18,864 \\
454 \\
710 \\
509 \\
0 \\
20,538 \\
1,105 \\
0 \\
1,105 \\
90 \\
12 \\
0 \\
1,184\end{array}$ \\
\hline
\end{tabular}

\begin{tabular}{|c|c|c|c|c|c|c|}
\hline Item & $\begin{array}{l}\text { Tennessee } \\
\text { Oak Aidge } \\
\text { City of } \\
\text { June } 30\end{array}$ & $\begin{array}{c}\text { Tennessee } \\
\text { Paris } \\
\text { City of } \\
\text { June } 30\end{array}$ & $\begin{array}{l}\text { Tennessee } \\
\text { Pulaski } \\
\text { City of } \\
\text { June } 30\end{array}$ & $\begin{array}{l}\text { Tennessee } \\
\text { Aipley } \\
\text { City of } \\
\text { June } 30\end{array}$ & $\begin{array}{l}\text { Tennessee } \\
\text { Rockwood } \\
\text { City of } \\
\text { June } 30\end{array}$ & $\begin{array}{l}\text { Tennessee } \\
\text { Sevier } \\
\text { County } \\
\text { Electric } \\
\text { System } \\
\text { June } 30\end{array}$ \\
\hline 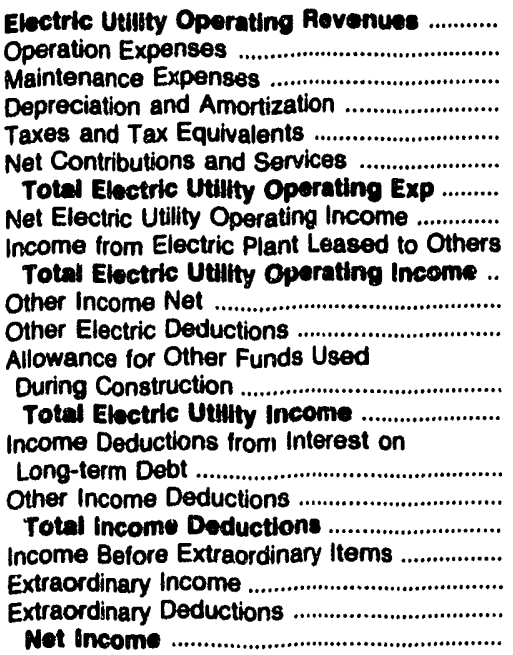 & $\begin{array}{r}22,200 \\
20,519 \\
572 \\
537 \\
438 \\
0 \\
22,066 \\
134 \\
0 \\
134 \\
149 \\
283\end{array}$ & $\begin{array}{r}20,925 \\
18,910 \\
589 \\
694 \\
529 \\
0 \\
20,721 \\
204 \\
0 \\
204 \\
345 \\
1 \\
0 \\
548 \\
163 \\
0 \\
163 \\
385 \\
0 \\
0 \\
385\end{array}$ & $\begin{array}{r}18,229 \\
16,654 \\
574 \\
577 \\
404 \\
0 \\
18,209 \\
20 \\
0 \\
20 \\
364 \\
0 \\
0 \\
384\end{array}$ & $\begin{array}{r}12,223 \\
11,598 \\
113 \\
192 \\
167 \\
0 \\
12,072 \\
151 \\
0 \\
151 \\
420 \\
0 \\
0 \\
0 \\
571\end{array}$ & $\begin{array}{r}14,010 \\
12,392 \\
386 \\
388 \\
359 \\
0 \\
13,525 \\
485 \\
0 \\
485 \\
21 \\
0 \\
\\
0 \\
506\end{array}$ & $\begin{array}{r}43,447 \\
37,737 \\
1,048 \\
1,581 \\
793 \\
0 \\
41,150 \\
2,288 \\
0 \\
2,288 \\
324 \\
0 \\
0 \\
0 \\
2,612\end{array}$ \\
\hline
\end{tabular}

Note: Totals may not Gqual sum of compononts bocutuse of indeponden! reunding.

Source: Energy Information Administration, Form EIA-412, "Annual Report of Public Electric Utilities." 
Table 36. Statement of Income by Major Publicly Owned Electric Utility Within State, 1991 (Continued) (Thousand Dollars)

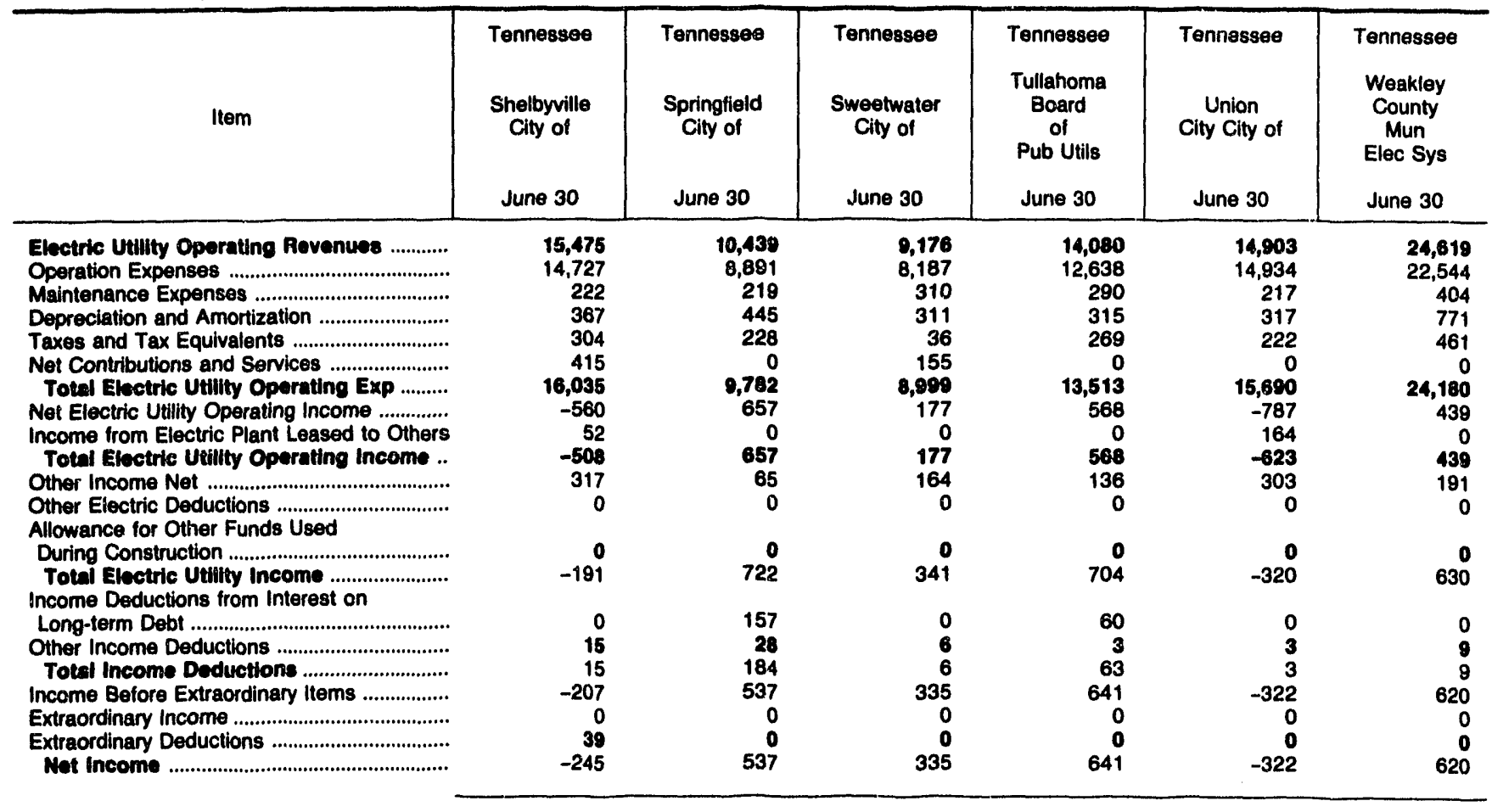

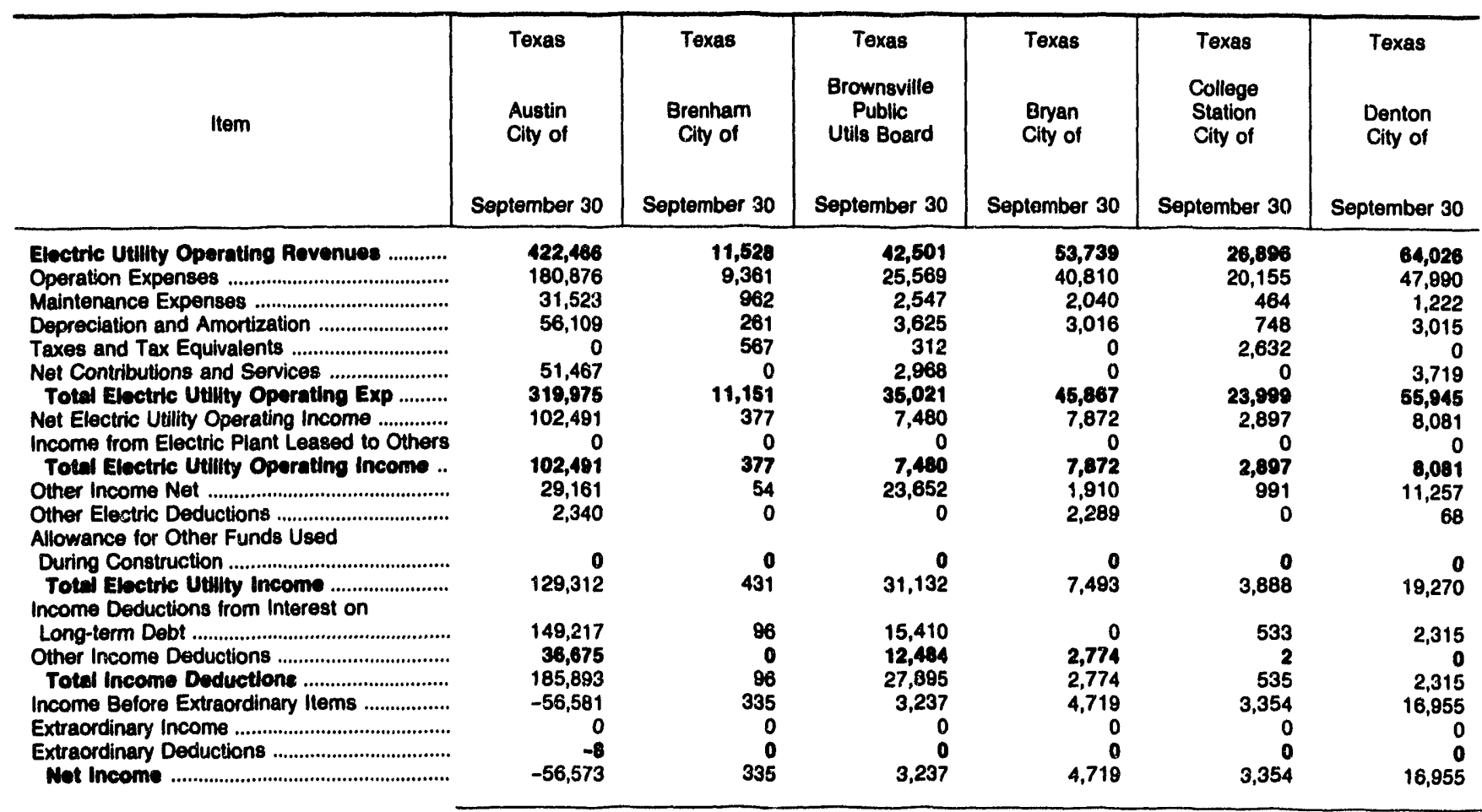

Note: Totals may not equal sum of components because of independent rounding.

Source: Energy iniormation Aứministiation, Form Elâ-412, "Annual Report of Public Elegtric Uytilitieg." 
Table 36. Statement of Income by Major Publicly Owned Electric Utility Within State, 1991 (Continued) (Thousand Dollars)

\begin{tabular}{|c|c|c|c|c|c|c|}
\hline Item & $\begin{array}{c}\text { Texas } \\
\text { Garland } \\
\text { City of } \\
\text { September } 30\end{array}$ & $\begin{array}{c}\text { Texas } \\
\text { Georgetown } \\
\text { City of } \\
\text { September } 30\end{array}$ & $\begin{array}{c}\text { Texas } \\
\text { Greenville } \\
\text { City of } \\
\text { September } 30\end{array}$ & $\begin{array}{c}\text { Texas } \\
\text { Kerrville } \\
\text { Public } \\
\text { Utility } \\
\text { Board } \\
\text { September } 30\end{array}$ & $\begin{array}{l}\text { Texas } \\
\text { Lower } \\
\text { Colorado } \\
\text { River } \\
\text { Authority } \\
\text { June } 30\end{array}$ & $\begin{array}{l}\text { Texas } \\
\text { Lubbock } \\
\text { City of } \\
\text { September } 30\end{array}$ \\
\hline 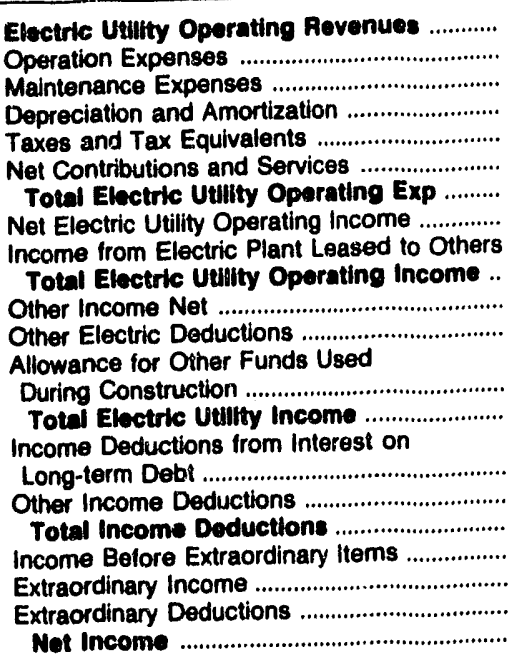 & $\begin{array}{r}125,389 \\
93,631 \\
7,060 \\
5,547 \\
4,674 \\
-770 \\
110,142 \\
15,247 \\
0 \\
15,247 \\
7,125 \\
0 \\
0 \\
0 \\
22,372 \\
2,045 \\
0 \\
2,045 \\
20,328 \\
0 \\
55 \\
20,272\end{array}$ & $\begin{array}{r}10,126 \\
7,693 \\
65 \\
173 \\
209 \\
1,176 \\
9,315 \\
811 \\
0 \\
811 \\
685 \\
0 \\
0 \\
1,496\end{array}$ & $\begin{array}{r}28,220 \\
21,584 \\
2,128 \\
2,015 \\
1,031 \\
1,024 \\
27,783 \\
437 \\
0 \\
437 \\
772 \\
0\end{array}$ & $\begin{array}{r}20,062 \\
16,487 \\
779 \\
827 \\
12 \\
455 \\
18,659 \\
2,302 \\
0 \\
2,302 \\
888 \\
0 \\
17 \\
3,208 \\
2,237 \\
0 \\
2,237 \\
971 \\
0 \\
3,199 \\
-2,228\end{array}$ & $\begin{array}{r}321,567 \\
159,721 \\
29,135 \\
35,859 \\
0 \\
0 \\
224,714 \\
96,853 \\
0 \\
96,853 \\
34,679 \\
0 \\
0 \\
0 \\
131,532 \\
103,301 \\
3,815 \\
107,116 \\
24,417 \\
0 \\
0 \\
0\end{array}$ & $\begin{array}{r}49,142 \\
32,698 \\
527 \\
3,082 \\
0 \\
9,240 \\
45,527 \\
3,615 \\
0 \\
3,615 \\
3,247 \\
0 \\
0 \\
0 \\
6,862\end{array}$ \\
\hline
\end{tabular}

\begin{tabular}{|c|c|c|c|c|c|c|}
\hline Item & $\begin{array}{c}\text { Texas } \\
\text { New Braunfels } \\
\text { City of } \\
\text { July } 31\end{array}$ & $\begin{array}{c}\text { Texas } \\
\text { Sam Rayburn } \\
\text { Municipal } \\
\text { Pwr } \\
\text { Agny } \\
\text { September } 30\end{array}$ & $\begin{array}{l}\text { Texas } \\
\text { San Antonio } \\
\text { City of } \\
\text { January } 31\end{array}$ & $\begin{array}{c}\text { Texas } \\
\text { San Marcos } \\
\text { City of } \\
\text { September } 30\end{array}$ & $\begin{array}{c}\text { Texas } \\
\text { Seguin } \\
\text { City of } \\
\text { September } 30\end{array}$ & $\begin{array}{c}\text { Texas } \\
\text { Texas } \\
\text { Municipal } \\
\text { Power Agency } \\
\text { September } 30\end{array}$ \\
\hline 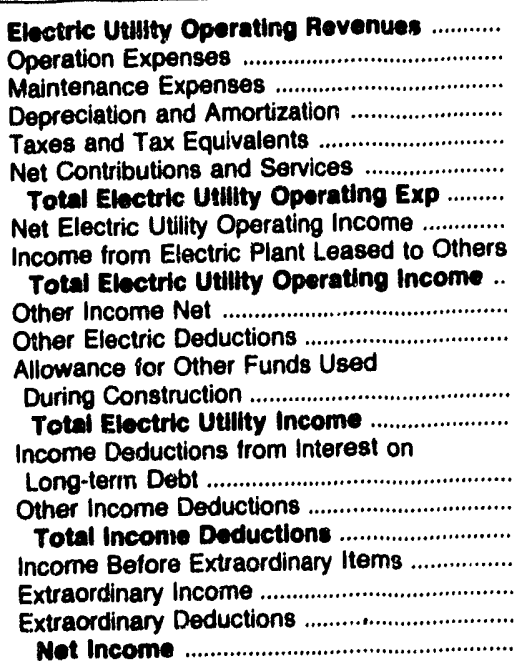 & $\begin{array}{r}34,473 \\
30,378 \\
688 \\
1,391 \\
0 \\
1,039 \\
33,495 \\
979 \\
696 \\
1,674 \\
663 \\
0 \\
0 \\
0 \\
2,358\end{array}$ & $\begin{array}{r}31,345 \\
16,124 \\
2,542 \\
3,920 \\
0 \\
0 \\
22,586 \\
8,759 \\
0 \\
8,759 \\
39,383 \\
0 \\
\\
0 \\
48,142\end{array}$ & $\begin{array}{r}675,180 \\
246,336 \\
56,870 \\
107,494 \\
14,163 \\
98,300 \\
523,162 \\
152,018 \\
1,882 \\
153,900 \\
141,448 \\
89,732\end{array}$ & $\begin{array}{r}18,372 \\
14,092 \\
745 \\
460 \\
1,446 \\
151 \\
16,894 \\
1,478 \\
0 \\
1,478 \\
643 \\
21 \\
0 \\
0 \\
2,100\end{array}$ & $\begin{array}{r}11,512 \\
8,074 \\
45 \\
252 \\
0 \\
2,451 \\
10,822 \\
690 \\
0 \\
690 \\
314 \\
0 \\
0 \\
0 \\
1,004\end{array}$ & $\begin{array}{r}169,248 \\
71,464 \\
10,114 \\
26,713 \\
0 \\
0 \\
108,291 \\
60,957 \\
0 \\
60,957 \\
22,098 \\
0 \\
21,317 \\
104,372 \\
103,367 \\
7,892 \\
111,249 \\
-6,877 \\
0 \\
0 \\
-6,877\end{array}$ \\
\hline
\end{tabular}

Note: Totals may not equal sum of components because of independent rounding.

Source: Energy Information Administration, Form EIA-412, "Annual Peport of Public Electric Utilities." 


\section{Table 36. Statement of Income by Major Publicly Owned Electric Utility Within State, 1991 (Continued)}

(Thousand Dollars)

\begin{tabular}{|c|c|c|c|c|c|c|}
\hline Item & $\begin{array}{l}\text { Texas } \\
\text { Toledo Bend } \\
\text { Project } \\
\text { Joint } \\
\text { Oper } \\
\text { August } 30\end{array}$ & $\begin{array}{c}\text { Texas } \\
\text { Weatherford } \\
\text { Mun } \\
\text { Utility } \\
\text { System } \\
\text { September } 30\end{array}$ & $\begin{array}{c}\text { Utah } \\
\text { Bountiful } \\
\text { City City of } \\
\text { June } 30\end{array}$ & $\begin{array}{c}\text { Utah } \\
\text { Intermountain } \\
\text { Power Agency } \\
\text { June } 30\end{array}$ & $\begin{array}{l}\text { Utah } \\
\text { Logan } \\
\text { City of } \\
\text { June } 30\end{array}$ & $\begin{array}{l}\text { Utah } \\
\text { Murray } \\
\text { City of } \\
\text { June } 30\end{array}$ \\
\hline 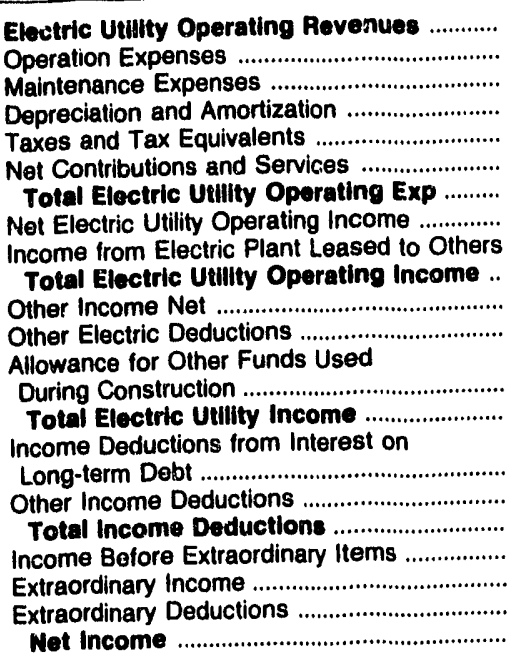 & $\begin{array}{r}8,666 \\
100 \\
5,753 \\
706 \\
0 \\
0 \\
6,559 \\
2,107 \\
0 \\
2,107 \\
0 \\
0 \\
0 \\
0 \\
2,107\end{array}$ & $\begin{array}{r}11,870 \\
9,556 \\
0 \\
791 \\
612 \\
1,506 \\
12,466 \\
-595 \\
0 \\
-595 \\
1,033 \\
0 \\
3,236 \\
3,673 \\
\\
396 \\
0 \\
396 \\
3,277 \\
0 \\
0 \\
3,277\end{array}$ & $\begin{array}{r}11,794 \\
5,574 \\
1,159 \\
1,912 \\
0 \\
1,967 \\
10,611 \\
1,182 \\
0 \\
1,182 \\
193 \\
42 \\
0 \\
1,332\end{array}$ & $\begin{array}{r}534,254 \\
199,637 \\
23,224 \\
108,872 \\
35,448 \\
0 \\
367,181 \\
167,073 \\
0 \\
167,073 \\
91,152 \\
0 \\
0 \\
0 \\
258,225\end{array}$ & $\begin{array}{r}15,204 \\
9,178 \\
268 \\
884 \\
891 \\
1,480 \\
12,700 \\
2,504 \\
0 \\
2,504 \\
763 \\
0 \\
\\
0 \\
3,268\end{array}$ & $\begin{array}{r}17,157 \\
11,331 \\
749 \\
1,497 \\
1,501 \\
408 \\
15,485 \\
1,673 \\
0 \\
1,673 \\
925 \\
0 \\
\\
0 \\
2,597 \\
\\
622 \\
0 \\
622 \\
1,975 \\
0 \\
0 \\
1,975\end{array}$ \\
\hline
\end{tabular}

\begin{tabular}{|c|c|c|c|c|c|c|}
\hline Item & $\begin{array}{l}\text { Utah } \\
\text { Provo } \\
\text { City Corp } \\
\text { June } 30\end{array}$ & $\begin{array}{l}\text { Utah } \\
\text { St George } \\
\text { City of } \\
\text { June } 30\end{array}$ & $\begin{array}{l}\text { Utah } \\
\text { Utah } \\
\text { Associated } \\
\text { Mun } \\
\text { Power Sys } \\
\text { March } 31\end{array}$ & $\begin{array}{c}\text { Utah } \\
\text { Utah } \\
\text { Municipal } \\
\text { Power Agency } \\
\text { June } 30\end{array}$ & $\begin{array}{c}\text { Vermont } \\
\text { Burlington } \\
\text { City of } \\
\text { December } 31\end{array}$ & $\begin{array}{l}\text { Vermont } \\
\text { Vermont } \\
\text { Public } \\
\text { Pwr } \\
\text { Supply Auth } \\
\text { December } 31\end{array}$ \\
\hline 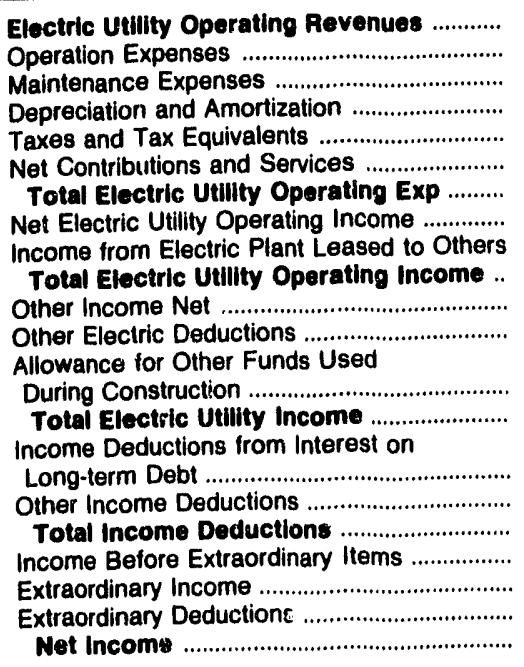 & $\begin{array}{r}28,694 \\
21,855 \\
0 \\
2,991 \\
0 \\
3,725 \\
28,572 \\
123 \\
0 \\
123 \\
2,305 \\
0 \\
0 \\
0 \\
2,428\end{array}$ & $\begin{array}{r}14,793 \\
11,137 \\
0 \\
873 \\
1,090 \\
0 \\
13,100 \\
1,692 \\
0 \\
1,692 \\
440 \\
0 \\
0 \\
0 \\
2,133\end{array}$ & $\begin{array}{r}26,238 \\
18,765 \\
539 \\
1,797 \\
488 \\
0 \\
21,589 \\
4,649 \\
0 \\
4,649 \\
1,209 \\
0 \\
\end{array}$ & $\begin{array}{r}26,183 \\
20,783 \\
0 \\
932 \\
169 \\
0 \\
21,884 \\
4,299 \\
0 \\
4,299 \\
1,018 \\
0 \\
0 \\
0 \\
5,317 \\
\\
3,661 \\
0 \\
3,661 \\
1,656 \\
2,519 \\
679 \\
3,497\end{array}$ & $\begin{array}{r}37,385 \\
23,101 \\
2,040 \\
2,785 \\
1,923 \\
370 \\
30,218 \\
7,165 \\
0 \\
7,165 \\
1,303 \\
62 \\
0 \\
8,406 \\
\\
7,210 \\
294 \\
7,504 \\
902 \\
0 \\
0 \\
902\end{array}$ & $\begin{array}{r}9,394 \\
5,906 \\
368 \\
894 \\
321 \\
0 \\
7,488 \\
1,906 \\
0 \\
1,906 \\
424 \\
18 \\
\\
0 \\
2,312 \\
\\
2,294 \\
713 \\
3,006 \\
-695 \\
0 \\
0 \\
-695\end{array}$ \\
\hline
\end{tabular}

Note: Totals may not equal sum of components because of independent rounding.

Source: Energy Information Administration, Form EIA-412, "Annual Report of Public Electric Utilities." 

Table 36. Statement of income by Major Publicly Owned Electric
Utility Within State, 1991 (Continued)

(Thousand Dollars)

\begin{tabular}{|c|c|c|c|c|c|c|}
\hline Item & $\begin{array}{l}\text { Virginia } \\
\text { Bedford } \\
\text { City of } \\
\text { June } 30\end{array}$ & $\begin{array}{l}\text { Virginia } \\
\text { Bristol } \\
\text { Utilities } \\
\text { Board } \\
\text { June } 30\end{array}$ & $\begin{array}{l}\text { Virginia } \\
\text { Danville } \\
\text { City of } \\
\text { June } 30\end{array}$ & $\begin{array}{c}\text { Virginia } \\
\begin{array}{c}\text { Harrisonburg } \\
\text { City of }\end{array} \\
\text { June } 30\end{array}$ & $\begin{array}{l}\text { Virginia } \\
\text { Manassas } \\
\text { City of } \\
\text { June } 30\end{array}$ & $\begin{array}{l}\text { Virginia } \\
\text { Martinsville } \\
\text { City of } \\
\text { June } 30\end{array}$ \\
\hline 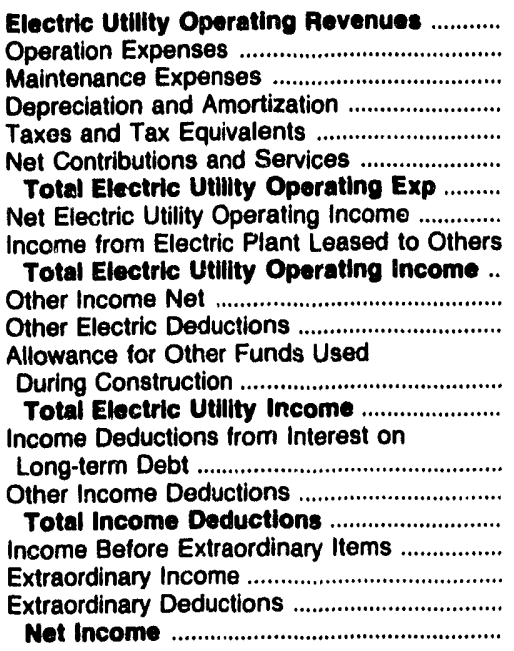 & $\begin{array}{r}10,400 \\
7,347 \\
162 \\
497 \\
0 \\
1,924 \\
9,930 \\
470 \\
0 \\
470 \\
166 \\
0 \\
0 \\
0 \\
636\end{array}$ & $\begin{array}{r}25,206 \\
23,975 \\
497 \\
656 \\
386 \\
0 \\
25,513 \\
-308 \\
0 \\
-308 \\
394 \\
0 \\
0 \\
0 \\
86\end{array}$ & $\begin{array}{r}38,956 \\
28,497 \\
1,065 \\
1,160 \\
0 \\
5,747 \\
36,488 \\
2,488 \\
77 \\
2,565 \\
40 \\
0 \\
0 \\
0 \\
2,606\end{array}$ & $\begin{array}{r}28,129 \\
22,323 \\
362 \\
1,317 \\
153 \\
1,800 \\
25,956 \\
2,173 \\
0 \\
2,173 \\
96 \\
0 \\
0 \\
0 \\
2,270 \\
235 \\
13 \\
13 \\
248 \\
2,022 \\
0 \\
0 \\
2,022\end{array}$ & $\begin{array}{r}17,275 \\
13,687 \\
357 \\
1,172 \\
329 \\
-658 \\
14,888 \\
2,387 \\
0 \\
2,387 \\
1,116 \\
0 \\
0 \\
0 \\
3,503\end{array}$ & $\begin{array}{r}10,587 \\
7,706 \\
359 \\
460 \\
77 \\
1,550 \\
10,152 \\
435 \\
0 \\
435 \\
151 \\
0 \\
0 \\
586\end{array}$ \\
\hline
\end{tabular}

\begin{tabular}{|c|c|c|c|c|c|c|}
\hline Item & $\begin{array}{l}\text { Virginia } \\
\text { Radford } \\
\text { City of } \\
\text { June } 30\end{array}$ & $\begin{array}{l}\text { Virginia } \\
\text { Salem } \\
\text { City of } \\
\text { June } 30\end{array}$ & $\begin{array}{l}\text { Virginia } \\
\text { Virginia } \\
\text { Tech } \\
\text { Electric } \\
\text { Service } \\
\text { June } 30\end{array}$ & $\begin{array}{c}\text { Washington } \\
\begin{array}{c}\text { Centralia } \\
\text { City of }\end{array} \\
\text { December } 31\end{array}$ & $\begin{array}{l}\text { Washington } \\
\text { Ellensburg } \\
\text { City of }\end{array}$ & $\begin{array}{l}\text { Washington } \\
\text { Port Angeles } \\
\text { City of }\end{array}$ \\
\hline 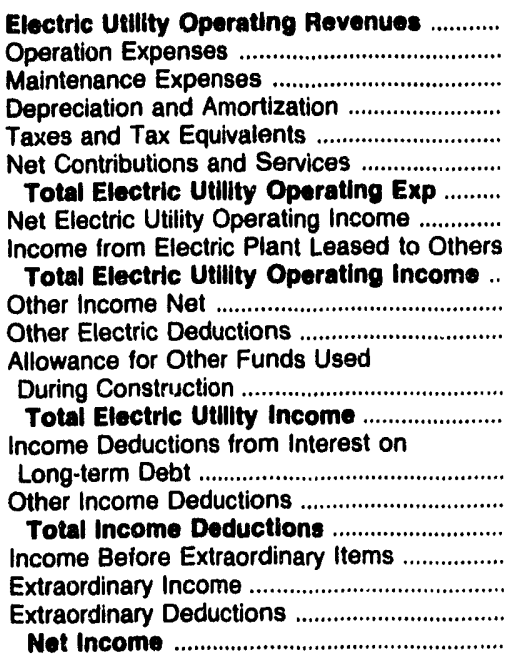 & $\begin{array}{r}11,407 \\
8,748 \\
526 \\
653 \\
120 \\
1,506 \\
11,553 \\
-146 \\
0 \\
-146 \\
388 \\
0\end{array}$ & $\begin{array}{r}15,257 \\
12,492 \\
172 \\
810 \\
635 \\
0 \\
14,108 \\
1,149 \\
0 \\
1,149 \\
158 \\
0 \\
0 \\
0 \\
1,306\end{array}$ & $\begin{array}{r}10,229 \\
8,673 \\
706 \\
0 \\
250 \\
0 \\
9,629 \\
600 \\
0 \\
600 \\
111 \\
0 \\
0 \\
710\end{array}$ & $\begin{array}{r}7,013 \\
6,786 \\
335 \\
370 \\
603 \\
0 \\
8,094 \\
-1,081 \\
0 \\
-1,081 \\
970 \\
0 \\
0 \\
0 \\
-111 \\
802 \\
40 \\
122 \\
-233 \\
0 \\
0 \\
-233\end{array}$ & $\begin{array}{r}6,083 \\
4,487 \\
176 \\
337 \\
646 \\
0 \\
5,647 \\
436 \\
0 \\
436 \\
363 \\
257 \\
0 \\
542 \\
73 \\
1 \\
74 \\
467 \\
0 \\
0 \\
467\end{array}$ & $\begin{array}{r}19,909 \\
17,533 \\
44 \\
561 \\
1,978 \\
275 \\
20,391 \\
-482 \\
0 \\
-482 \\
429 \\
0 \\
0 \\
-53\end{array}$ \\
\hline
\end{tabular}

Note: Totals may not equal sum of components because of independent rounding.

Source: Energy Information Administration, Form EIA-412, "Annual Report of Public Electric Utilities." 


\section{Table 36. Statement of Income by Major Publicly Owned Electric Utility Within State, 1991 (Continued)}

(Thousand Dollars)

\begin{tabular}{|c|c|c|c|c|c|c|}
\hline Item & $\begin{array}{c}\text { Washington } \\
\text { PUD No } 1 \\
\text { of } \\
\text { Benton } \\
\text { County } \\
\text { December } 31\end{array}$ & $\begin{array}{c}\text { Washington } \\
\text { PUD No } 1 \\
\text { of } \\
\text { Chelan } \\
\text { County } \\
\text { December } 31\end{array}$ & $\begin{array}{l}\text { Washington } \\
\text { PUD No } 1 \text { of } \\
\text { Clallam } \\
\text { County } \\
\text { December } 31\end{array}$ & $\begin{array}{c}\text { Washington } \\
\text { PUD No } 1 \\
\text { of } \\
\text { Clark } \\
\text { County } \\
\text { December } 31\end{array}$ & $\begin{array}{l}\text { Washington } \\
\text { PUD No } 1 \text { of } \\
\text { Cowlitz } \\
\text { County } \\
\text { December } 31\end{array}$ & $\begin{array}{c}\text { Washington } \\
\text { PUD No } 1 \text { of } \\
\text { Douglas } \\
\text { County } \\
\text { December } 31\end{array}$ \\
\hline 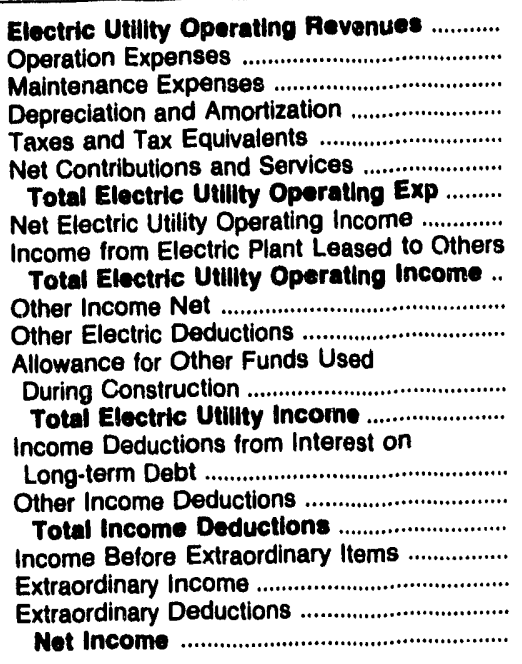 & $\begin{array}{r}51,481 \\
37,614 \\
1,812 \\
2,824 \\
5,022 \\
0 \\
47,273 \\
4,208 \\
0 \\
4,208 \\
1,343 \\
0\end{array}$ & $\begin{array}{r}105,946 \\
38,003 \\
8,044 \\
12,428 \\
5,044 \\
0 \\
63,519 \\
42,427 \\
0 \\
42,427 \\
13,159 \\
0 \\
0 \\
55,586\end{array}$ & $\begin{array}{r}21,582 \\
15,356 \\
1,070 \\
1,631 \\
1,156 \\
0 \\
19,213 \\
2,349 \\
0 \\
2,349 \\
819 \\
0 \\
\\
1 \\
3,168 \\
\\
660 \\
19 \\
679 \\
2,490 \\
0 \\
0 \\
2,490\end{array}$ & $\begin{array}{r}113,928 \\
92,532 \\
3,524 \\
7,030 \\
6,195 \\
0 \\
109,282 \\
4,646 \\
22 \\
4,668 \\
3,296 \\
1,852 \\
\\
0 \\
6,112 \\
4,583 \\
437 \\
5,020 \\
1,093 \\
0 \\
0 \\
1,093\end{array}$ & $\begin{array}{r}107,601 \\
94,092 \\
1,715 \\
3,229 \\
5,651 \\
0 \\
104,687 \\
2,913 \\
0 \\
2,913 \\
779 \\
0 \\
0 \\
0 \\
3,693 \\
\\
580 \\
5 \\
584 \\
3,108 \\
0 \\
1,657 \\
1,452\end{array}$ & $\begin{array}{r}42,465 \\
18,254 \\
2,298 \\
3,091 \\
1,822 \\
0 \\
25,465 \\
17,001 \\
0 \\
17,001 \\
4,009 \\
148 \\
0 \\
0 \\
20,862\end{array}$ \\
\hline
\end{tabular}

\begin{tabular}{|c|c|c|c|c|c|c|}
\hline Item & $\begin{array}{l}\text { Washington } \\
\text { PUD No } 1 \text { of } \\
\text { Franklin } \\
\text { County } \\
\text { December } 31\end{array}$ & $\begin{array}{c}\text { Washington } \\
\text { PUD No } 1 \\
\text { of } \\
\text { Grays } \\
\text { Harbor Cnty } \\
\text { December } 31\end{array}$ & $\begin{array}{l}\text { Washington } \\
\text { PUD No } 1 \text { of } \\
\text { Klickitat } \\
\text { County } \\
\text { December } 31\end{array}$ & $\begin{array}{c}\text { Washington } \\
\text { PUD No } 1 \\
\text { of } \\
\text { Lewis } \\
\text { County } \\
\text { December } 31\end{array}$ & $\begin{array}{l}\text { Washington } \\
\text { PUD No } 1 \text { of } \\
\text { Okanogan } \\
\text { County } \\
\text { December } 31\end{array}$ & $\begin{array}{l}\text { Washington } \\
\text { PuD No } 1 \text { of } \\
\text { Pend Oreille } \\
\text { Cnty }\end{array}$ \\
\hline 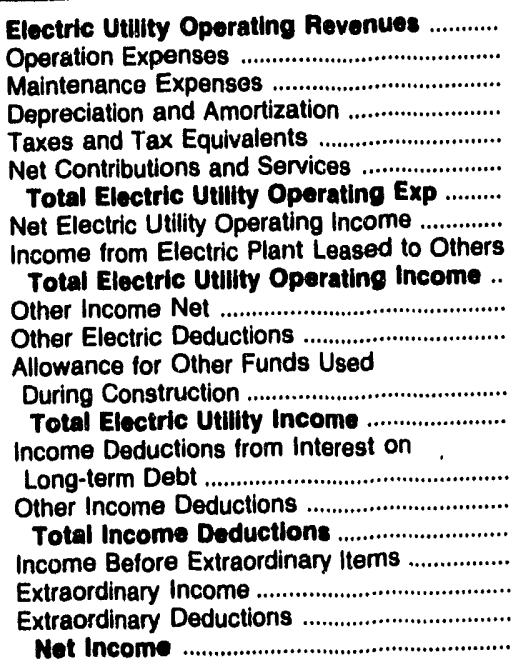 & $\begin{array}{r}21,592 \\
16,915 \\
709 \\
1,165 \\
1,497 \\
0 \\
20,287 \\
1,305 \\
0 \\
1,305 \\
1,122 \\
344 \\
0 \\
0 \\
2,082\end{array}$ & $\begin{array}{r}50,408 \\
37,853 \\
4,684 \\
2,686 \\
2,993 \\
0 \\
48,216 \\
2,192 \\
0 \\
2,192 \\
1,869 \\
0 \\
\\
20 \\
4,081\end{array}$ & $\begin{array}{r}11,039 \\
7,583 \\
518 \\
832 \\
748 \\
0 \\
9,680 \\
1,359 \\
0 \\
1,359 \\
384 \\
0 \\
0 \\
1,743 \\
\\
650 \\
8 \\
659 \\
1,084 \\
0 \\
0 \\
1,084\end{array}$ & $\begin{array}{r}25,193 \\
19,552 \\
1,394 \\
1,197 \\
1,552 \\
0 \\
23,695 \\
1,498 \\
0 \\
1,498 \\
278 \\
0 \\
0 \\
0 \\
1,776 \\
0 \\
0 \\
0 \\
0 \\
1,776 \\
0 \\
0 \\
1,776\end{array}$ & $\begin{array}{r}14,382 \\
8,723 \\
702 \\
1,495 \\
1,353 \\
0 \\
12,273 \\
2,108 \\
0 \\
2,108 \\
818 \\
0 \\
\\
0 \\
2,926\end{array}$ & $\begin{array}{r}17,128 \\
11,293 \\
915 \\
736 \\
1,007 \\
0 \\
13,952 \\
3,177 \\
0 \\
3,177 \\
788 \\
0 \\
0 \\
0 \\
3,964\end{array}$ \\
\hline
\end{tabular}

Note: Totals may not equal sum of components because of independent rounding.

Source: Energy Information Administration, Form ElA-412, "Annual Report of Public Electric Utilities." 
Table 36. Statement of Income by Major Publicly Owned Electric Utility Within State, 1991 (Continued) (Thousand Dollars)

\begin{tabular}{|c|c|c|c|c|c|c|}
\hline Item & $\begin{array}{l}\text { Washington } \\
\text { PUD No } 1 \text { of } \\
\text { Snohomish } \\
\text { County } \\
\text { December } 31\end{array}$ & $\begin{array}{l}\text { Washington } \\
\text { PUD No } 1 \text { of } \\
\text { Whatcom } \\
\text { County } \\
\text { December } 31\end{array}$ & $\begin{array}{c}\text { Washington } \\
\text { PUD No } 2 \\
\text { of } \\
\text { Grant } \\
\text { County } \\
\text { December } 31\end{array}$ & $\begin{array}{l}\text { Washington } \\
\text { PUD No } 2 \text { of } \\
\text { Pacific } \\
\text { County } \\
\text { December } 31\end{array}$ & $\begin{array}{c}\text { Washington } \\
\text { PUD No } 3 \\
\text { of } \\
\text { Mason } \\
\text { County } \\
\text { December } 31\end{array}$ & $\begin{array}{l}\text { Washington } \\
\text { Richland } \\
\text { City of } \\
\text { December } 31\end{array}$ \\
\hline 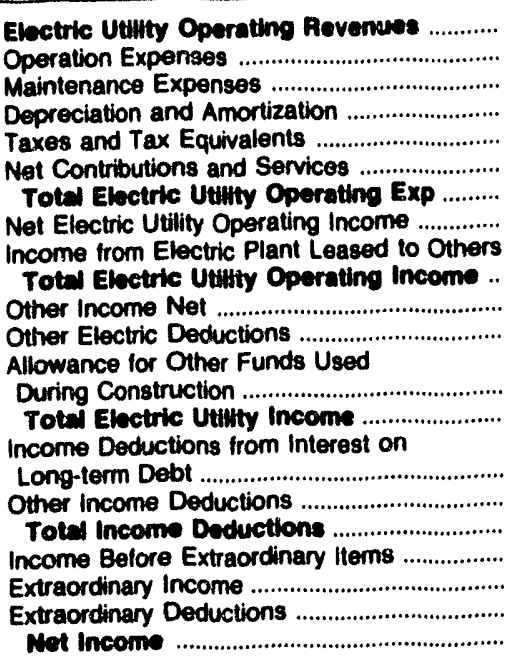 & $\begin{array}{r}247,764 \\
179,734 \\
11,351 \\
18,165 \\
8,423 \\
0 \\
217,673 \\
30,090 \\
0 \\
30,000 \\
10,914 \\
0 \\
\end{array}$ & $\begin{array}{r}3,208 \\
3,152 \\
22 \\
14 \\
193 \\
0 \\
3,381 \\
-173 \\
0 \\
-173 \\
203 \\
0 \\
\\
0 \\
31\end{array}$ & $\begin{array}{r}81,830 \\
27,042 \\
14,196 \\
13,000 \\
4,273 \\
0 \\
58,510 \\
23,319 \\
0 \\
23,319 \\
11,426 \\
0\end{array}$ & $\begin{array}{r}11,499 \\
8,076 \\
699 \\
1,305 \\
719 \\
0 \\
10,798 \\
701 \\
0 \\
701 \\
631 \\
307 \\
0 \\
1,025\end{array}$ & $\begin{array}{r}20,940 \\
14,595 \\
1,002 \\
1,636 \\
853 \\
0 \\
18,085 \\
2,854 \\
0 \\
2,854 \\
738 \\
0 \\
0 \\
0 \\
3,593\end{array}$ & $\begin{array}{r}21,298 \\
16,983 \\
556 \\
927 \\
2,226 \\
0 \\
20,692 \\
606 \\
0 \\
608 \\
889 \\
351 \\
\\
0 \\
1,144\end{array}$ \\
\hline
\end{tabular}

\begin{tabular}{|c|c|c|c|c|c|c|}
\hline Item & $\begin{array}{c}\text { Washington } \\
\text { Seattle } \\
\text { City of } \\
\text { December } 31\end{array}$ & $\begin{array}{c}\text { Washington } \\
\text { Tacoina } \\
\text { City of } \\
\text { December } 31\end{array}$ & $\begin{array}{c}\text { Washington } \\
\text { Vera } \\
\text { Imigation } \\
\text { District \#15 } \\
\text { December } 31\end{array}$ & $\begin{array}{l}\text { Washington } \\
\text { Washington } \\
\text { Pub } \\
\text { Pwr } \\
\text { Supply Sys } \\
\text { June } 30\end{array}$ & $\begin{array}{c}\text { Wisconsin } \\
\text { Jefterson } \\
\text { City of }\end{array}$ & $\begin{array}{c}\text { Wisconsin } \\
\text { Kaukauna } \\
\text { City of } \\
\text { December } 31\end{array}$ \\
\hline 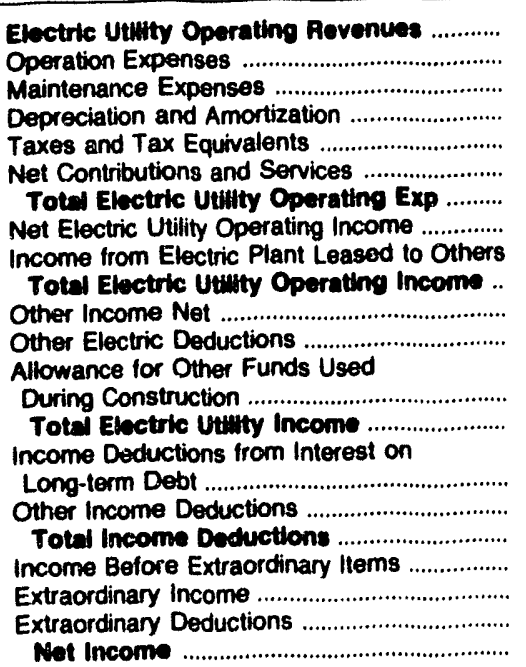 & $\begin{array}{r}283,386 \\
164,728 \\
27,203 \\
26,559 \\
31,287 \\
1,585 \\
251,362 \\
32,025 \\
0 \\
32,025 \\
8,601 \\
254 \\
\\
341 \\
40,713\end{array}$ & $\begin{array}{r}193,127 \\
115,389 \\
15,173 \\
13,811 \\
19,210 \\
0 \\
163,582 \\
29,545 \\
0 \\
29,545 \\
5,074 \\
371 \\
0 \\
0 \\
34,248\end{array}$ & $\begin{array}{r}5,825 \\
4,888 \\
308 \\
355 \\
221 \\
0 \\
5,772 \\
153 \\
4 \\
157 \\
214 \\
18 \\
\\
0 \\
352\end{array}$ & $\begin{array}{r}533,027 \\
134,536 \\
37,036 \\
109,636 \\
1,916 \\
0 \\
283,125 \\
249,902 \\
0 \\
249,902 \\
26,782 \\
0 \\
\end{array}$ & $\begin{array}{r}5,525 \\
5,147 \\
51 \\
136 \\
122 \\
94 \\
5,550 \\
-26 \\
0 \\
-26 \\
78 \\
0 \\
\\
0 \\
52\end{array}$ & $\begin{array}{r}20,061 \\
15,459 \\
971 \\
940 \\
840 \\
802 \\
18,012 \\
1,049 \\
0 \\
1,049 \\
668 \\
47 \\
0 \\
1,670\end{array}$ \\
\hline
\end{tabular}

Note: Totals may not equal sum of components because of independent rounding.

Source: Energy Information Administration, Form EIA-412, "Annual Peport of Public Electric Utilities." 
Table 36. Statement of Income by Major Publicly Owned Electric (Thousand Dollars)

\begin{tabular}{|c|c|c|c|c|c|c|}
\hline Item & $\begin{array}{c}\text { Wisconsin } \\
\text { Manitowoc } \\
\text { Public } \\
\text { Utillities } \\
\text { December } 31\end{array}$ & $\begin{array}{l}\text { Wisconsin } \\
\begin{array}{c}\text { Marshfieid } \\
\text { City of }\end{array} \\
\text { December } 31\end{array}$ & $\begin{array}{c}\text { Wisconsin } \\
\text { Menasha } \\
\text { City of } \\
\text { December } 31\end{array}$ & $\begin{array}{l}\text { Wisconsin } \\
\text { New London } \\
\text { City of } \\
\text { December } 31\end{array}$ & $\begin{array}{c}\text { Wisconsin } \\
\begin{array}{c}\text { Oconomowoc } \\
\text { City of }\end{array} \\
\text { December } 31\end{array}$ & $\begin{array}{l}\text { Wisconsin } \\
\text { Plymouth } \\
\text { City of } \\
\text { December } 31\end{array}$ \\
\hline 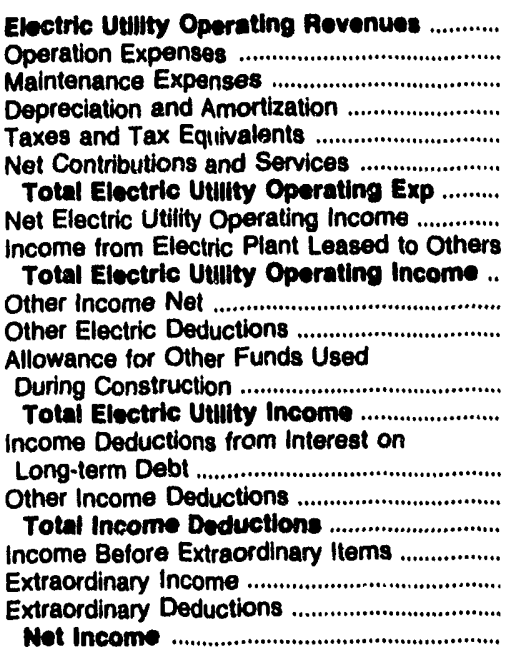 & $\begin{array}{r}23,389 \\
16,919 \\
1,310 \\
1,708 \\
1,480 \\
0 \\
21,418 \\
1,971 \\
0 \\
1,971 \\
847 \\
74 \\
0 \\
2,745\end{array}$ & $\begin{array}{r}15,889 \\
13,124 \\
463 \\
480 \\
421 \\
108 \\
14,595 \\
1,294 \\
0 \\
1,294 \\
165 \\
206 \\
0 \\
0 \\
1,253\end{array}$ & $\begin{array}{r}20,289 \\
18,473 \\
699 \\
648 \\
655 \\
214 \\
20,689 \\
-400 \\
0 \\
-400 \\
308 \\
4 \\
0 \\
-96\end{array}$ & $\begin{array}{r}7,128 \\
6,345 \\
89 \\
181 \\
234 \\
6 \\
6,865 \\
264 \\
0 \\
284 \\
0 \\
0 \\
\end{array}$ & $\begin{array}{r}7,810 \\
6,414 \\
134 \\
388 \\
299 \\
232 \\
7,466 \\
343 \\
0 \\
343 \\
188 \\
0 \\
\\
0 \\
531\end{array}$ & $\begin{array}{r}7,073 \\
5,799 \\
157 \\
377 \\
256 \\
12 \\
6,602 \\
472 \\
0 \\
472 \\
43 \\
30 \\
\\
0 \\
485\end{array}$ \\
\hline
\end{tabular}

\begin{tabular}{|c|c|c|c|c|c|c|}
\hline Item & $\begin{array}{l}\text { Wisconsin } \\
\text { Reedsburg } \\
\text { Utility Comm } \\
\text { December } 31\end{array}$ & $\begin{array}{c}\text { Wisconsin } \\
\text { Shawano } \\
\text { Municipal } \\
\text { Utilities } \\
\text { December } 31\end{array}$ & $\begin{array}{c}\text { Wisconsin } \\
\text { Sheboygan } \\
\text { Falls } \\
\text { City of } \\
\text { December } 31\end{array}$ & $\begin{array}{c}\text { Wisconsin } \\
\text { Sturgeon Bay } \\
\text { Combined } \\
\text { Utils }\end{array}$ & $\begin{array}{l}\text { Wisconsin } \\
\text { Wisconsin } \\
\text { Public } \\
\text { Power } \\
\text { Inc Sys } \\
\text { June } 30\end{array}$ & $\begin{array}{l}\text { Wisconsin } \\
\text { Wisconsin } \\
\text { Rapids W W } \\
\& \text { L } \\
\text { Comm } \\
\text { December } 31\end{array}$ \\
\hline 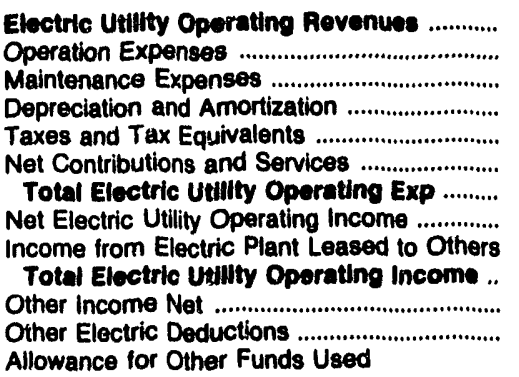 & $\begin{array}{r}5,908 \\
5,340 \\
56 \\
185 \\
0 \\
137 \\
5,710 \\
289 \\
0 \\
289 \\
123 \\
0\end{array}$ & $\begin{array}{r}7,611 \\
6,747 \\
84 \\
235 \\
155 \\
106 \\
7,328 \\
484 \\
0 \\
484 \\
159 \\
29\end{array}$ & $\begin{array}{r}6,713 \\
5,859 \\
0 \\
211 \\
141 \\
0 \\
6,212 \\
501 \\
0 \\
601 \\
36 \\
81\end{array}$ & $\begin{array}{r}7,556 \\
5,700 \\
219 \\
500 \\
364 \\
0 \\
6,783 \\
773 \\
0 \\
773 \\
128 \\
0\end{array}$ & $\begin{array}{r}115,277 \\
105,463 \\
804 \\
2,054 \\
1,358 \\
0 \\
109,679 \\
5,598 \\
0 \\
5,598 \\
4,081 \\
3\end{array}$ & $\begin{array}{r}10,591 \\
8,340 \\
321 \\
549 \\
485 \\
5 \\
9,700 \\
891 \\
0 \\
891 \\
213 \\
63\end{array}$ \\
\hline 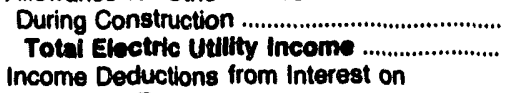 & $\begin{array}{r}0 \\
392\end{array}$ & $\begin{array}{r}0 \\
614\end{array}$ & $\begin{array}{r}0 \\
456\end{array}$ & $\begin{array}{r}0 \\
901\end{array}$ & $\begin{array}{r}0 \\
9,676\end{array}$ & $\begin{array}{r}0 \\
1,041\end{array}$ \\
\hline 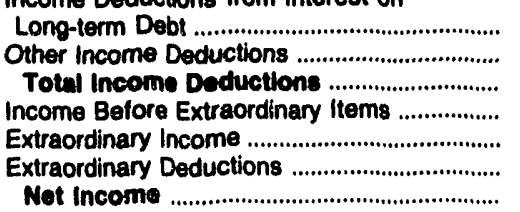 & $\begin{array}{r}185 \\
6 \\
192 \\
201 \\
0 \\
0 \\
201\end{array}$ & $\begin{array}{r}216 \\
84 \\
300 \\
315 \\
0 \\
0 \\
315\end{array}$ & $\begin{array}{r}0 \\
0 \\
0 \\
456 \\
0 \\
0 \\
456\end{array}$ & $\begin{array}{r}499 \\
16 \\
515 \\
386 \\
0 \\
0 \\
386\end{array}$ & $\begin{array}{r}6,453 \\
1,484 \\
7,937 \\
1,740 \\
0 \\
0 \\
1,740\end{array}$ & $\begin{array}{r}50 \\
7 \\
58 \\
983 \\
0 \\
0 \\
983\end{array}$ \\
\hline
\end{tabular}

Note: Totals may not equal sum of components because of independent rounding.

Source: Energy Information Adminiatration, Form EIA-412. "Annual Report of Public Electric Utilities." 


\section{Table 36. Statement of Income by Major Publicly Owned Electric Utility Within State, 1991 (Continued)}

(Thousand Dollars)

\begin{tabular}{|c|c|c|c|}
\hline Item & $\begin{array}{l}\text { Wyoming } \\
\text { Gillette } \\
\text { City of } \\
\text { June } 30\end{array}$ & $\begin{array}{l}\text { Wyoming } \\
\text { Wyoming } \\
\text { Municipal } \\
\text { Power Agency } \\
\text { December } 31\end{array}$ & \\
\hline 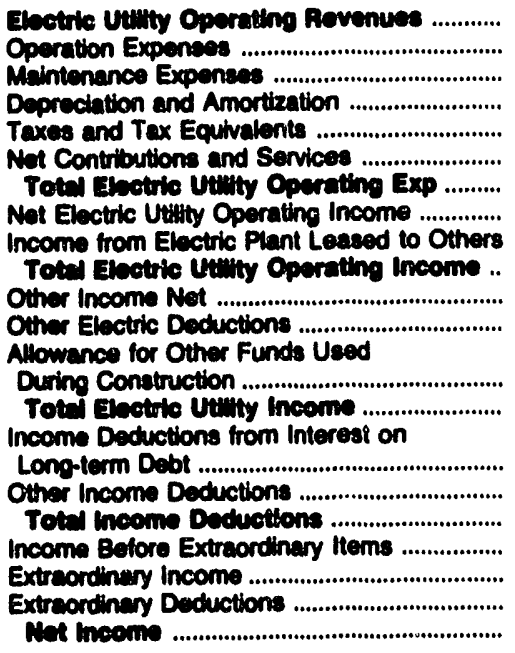 & $\begin{array}{r}9,910 \\
8,674 \\
0 \\
783 \\
66 \\
0 \\
9,623 \\
387 \\
0 \\
387 \\
32 \\
0 \\
\\
0 \\
419 \\
\\
240 \\
0 \\
2.40 \\
179 \\
0 \\
0 \\
179\end{array}$ & $\begin{array}{r}5,293 \\
3,055 \\
289 \\
651 \\
79 \\
0 \\
4,074 \\
1,159 \\
0 \\
1,189 \\
503 \\
0 \\
0\end{array}$ & \\
\hline
\end{tabular}

Note: Totals may not equal sum of components because of independent rounding.

Source: Eneroy Information Administration, Form EIA-412, "Annual Report of Public Electric Utilities." 
Table 37. Balance Sheet by Major Publicly Owned Electric UtIlity Within State at End of Period, 1991 (Thousand Dollars)

\begin{tabular}{|c|c|c|c|c|c|c|}
\hline Item & $\begin{array}{l}\text { Alabama } \\
\text { Alabama } \\
\text { Municipal } \\
\text { Elec Auth } \\
\text { December } 31\end{array}$ & $\begin{array}{l}\text { Alabama } \\
\text { Albertville } \\
\text { Municipal } \\
\text { Utils Bd } \\
\text { June } 30\end{array}$ & $\begin{array}{l}\text { Alabama } \\
\text { Andalusia } \\
\text { City of } \\
\text { September } 30\end{array}$ & $\begin{array}{l}\text { Alabama } \\
\text { Athens } \\
\text { City of } \\
\text { December } 31\end{array}$ & $\begin{array}{l}\text { Bessemer } \\
\text { City of } \\
\text { June } 30\end{array}$ & $\begin{array}{l}\text { Alabama } \\
\text { Cullman } \\
\text { Power Board } \\
\text { June } 30\end{array}$ \\
\hline 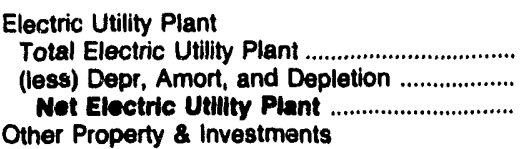 & $\begin{array}{l}0 \\
0 \\
0\end{array}$ & $\begin{array}{r}11,169 \\
3,963 \\
7,203\end{array}$ & $\begin{array}{r}3,439 \\
994 \\
2,445\end{array}$ & $\begin{array}{l}37,516 \\
12,164 \\
25,352\end{array}$ & $\begin{array}{r}19,765 \\
7,470 \\
12,294\end{array}$ & $\begin{array}{l}9,377 \\
4,766 \\
4,611\end{array}$ \\
\hline $\begin{array}{l}\text { Nonutility Property ..................................... } \\
\text { (less) Accum Provisions for Depr \& Amort .... } \\
\text { Advances to Municipality ..................................... } \\
\text { Invest \& Special Funds ................................... } \\
\text { Total Other Property Investments ........ } \\
\text { Current and Accrued Assets }\end{array}$ & $\begin{array}{r}1,652 \\
32 \\
0 \\
80,539 \\
82,169\end{array}$ & $\begin{array}{l}0 \\
0 \\
0 \\
5 \\
5\end{array}$ & $\begin{array}{r}11,789 \\
1,393 \\
0 \\
0 \\
10,309\end{array}$ & $\begin{array}{r}13 \\
0 \\
0 \\
7,627 \\
7,640\end{array}$ & $\begin{array}{r}0 \\
0 \\
0 \\
58 \\
58\end{array}$ & $\begin{array}{r}0 \\
0 \\
0 \\
635 \\
635\end{array}$ \\
\hline 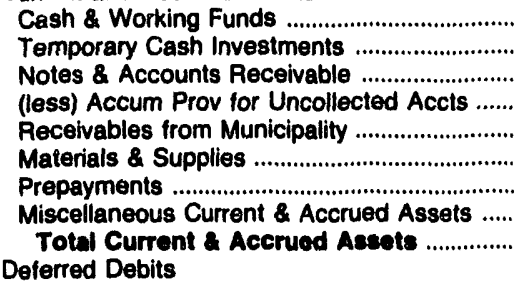 & $\begin{array}{r}5,548 \\
0 \\
0 \\
0 \\
8,561 \\
0 \\
69,106 \\
0 \\
83,215\end{array}$ & $\begin{array}{r}2,726 \\
0 \\
1,611 \\
0 \\
0 \\
153 \\
2 \\
43 \\
4,535\end{array}$ & $\begin{array}{r}1,628 \\
428 \\
1,094 \\
0 \\
0 \\
91 \\
0 \\
0 \\
3,241\end{array}$ & $\begin{array}{r}1,069 \\
0 \\
3,508 \\
0 \\
0 \\
598 \\
127 \\
154 \\
5,453\end{array}$ & $\begin{array}{r}-1,129 \\
2,703 \\
3,265 \\
107 \\
2,374 \\
313 \\
231 \\
34 \\
7,683\end{array}$ & $\begin{array}{r}102 \\
1,935 \\
2,055 \\
0 \\
24 \\
375 \\
6 \\
24 \\
4,522\end{array}$ \\
\hline 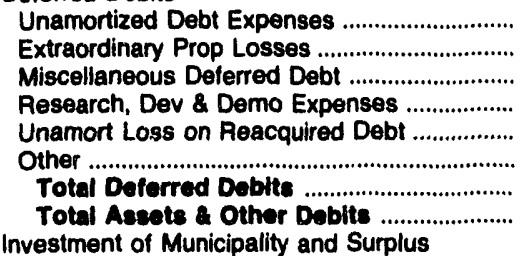 & $\begin{array}{r}5,255 \\
0 \\
0 \\
2,111 \\
0 \\
35,052 \\
42,418 \\
207,791\end{array}$ & $\begin{array}{r}0 \\
0 \\
921 \\
0 \\
0 \\
10 \\
931 \\
12,677\end{array}$ & $\begin{array}{r}205 \\
0 \\
0 \\
0 \\
0 \\
1,090 \\
1,295 \\
17,377\end{array}$ & $\begin{array}{r}640 \\
0 \\
1,664 \\
0 \\
0 \\
0 \\
2,304 \\
40,750\end{array}$ & $\begin{array}{r}14 \\
0 \\
550 \\
0 \\
0 \\
0 \\
584 \\
20,598\end{array}$ & $\begin{array}{r}29 \\
0 \\
876 \\
0 \\
0 \\
49 \\
954 \\
10,722\end{array}$ \\
\hline 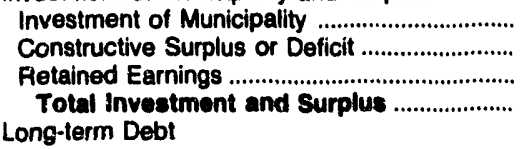 & $\begin{array}{r}0 \\
0 \\
420 \\
420\end{array}$ & $\begin{array}{r}0 \\
0 \\
9,408 \\
9,408\end{array}$ & $\begin{array}{r}5,341 \\
0 \\
5,631 \\
10,973\end{array}$ & $\begin{array}{r}0 \\
0 \\
16,265 \\
16,285\end{array}$ & $\begin{array}{r}0 \\
0 \\
10,845 \\
10,845\end{array}$ & $\begin{array}{r}0 \\
0 \\
6,084 \\
6,084\end{array}$ \\
\hline 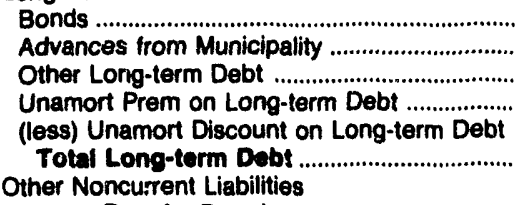 & $\begin{array}{r}198,115 \\
0 \\
0 \\
0 \\
0 \\
198,115\end{array}$ & $\begin{array}{r}949 \\
0 \\
0 \\
0 \\
0 \\
949\end{array}$ & $\begin{array}{r}4,640 \\
0 \\
0 \\
0 \\
0 \\
4,640\end{array}$ & $\begin{array}{r}16,750 \\
0 \\
0 \\
0 \\
0 \\
16,750\end{array}$ & $\begin{array}{r}2,430 \\
0 \\
601 \\
0 \\
23 \\
3,008\end{array}$ & $\begin{array}{r}1,500 \\
0 \\
0 \\
0 \\
0 \\
1,500\end{array}$ \\
\hline 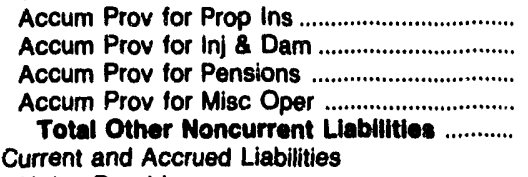 & $\begin{array}{l}0 \\
0 \\
0 \\
0 \\
0\end{array}$ & $\begin{array}{l}0 \\
0 \\
0 \\
0 \\
0\end{array}$ & $\begin{array}{l}0 \\
0 \\
0 \\
0 \\
0\end{array}$ & $\begin{array}{l}0 \\
0 \\
0 \\
0 \\
0\end{array}$ & $\begin{array}{l}0 \\
0 \\
0 \\
0 \\
0\end{array}$ & $\begin{array}{l}0 \\
0 \\
0 \\
0 \\
0\end{array}$ \\
\hline 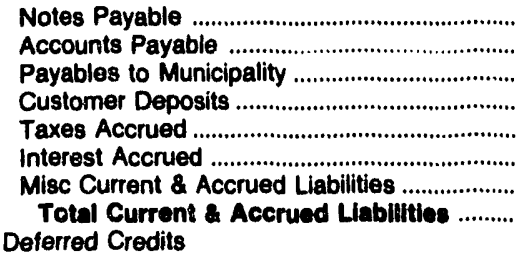 & $\begin{array}{r}0 \\
7,868 \\
0 \\
0 \\
0 \\
1,378 \\
11 \\
9,258\end{array}$ & $\begin{array}{r}0 \\
1,715 \\
0 \\
467 \\
2 \\
0 \\
136 \\
2,320\end{array}$ & $\begin{array}{r}180 \\
1,183 \\
0 \\
277 \\
1 \\
107 \\
16 \\
1,785\end{array}$ & $\begin{array}{r}630 \\
3,956 \\
0 \\
944 \\
0 \\
-35 \\
204 \\
5,690\end{array}$ & $\begin{array}{r}0 \\
1,855 \\
3,525 \\
1,030 \\
-74 \\
14 \\
296 \\
6,745\end{array}$ & $\begin{array}{r}0 \\
1,706 \\
0 \\
343 \\
11 \\
34 \\
128 \\
2,221\end{array}$ \\
\hline 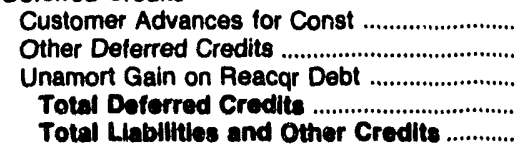 & $\begin{array}{r}0 \\
0 \\
0 \\
0 \\
207,791\end{array}$ & $\begin{array}{r}0 \\
0 \\
0 \\
0 \\
12,677\end{array}$ & $\begin{array}{r}0 \\
0 \\
0 \\
0 \\
17,377\end{array}$ & $\begin{array}{r}0 \\
2,036 \\
0 \\
2,038 \\
40,750\end{array}$ & $\begin{array}{r}0 \\
0 \\
0 \\
0 \\
20,598\end{array}$ & $\begin{array}{r}0 \\
917 \\
0 \\
917 \\
10,722\end{array}$ \\
\hline
\end{tabular}

Note: Totals may not equal sum of components because of independent rounding.

Source: Energy Information Administration, Form E|A-412, "Annual Report of Public Electric Utilities." 


\section{Table 37. B.slancie Sheet by Major Publicly Owned Electric Utility Within State at End of Period, 1991 (Continued)}

(Thousand Dollars)

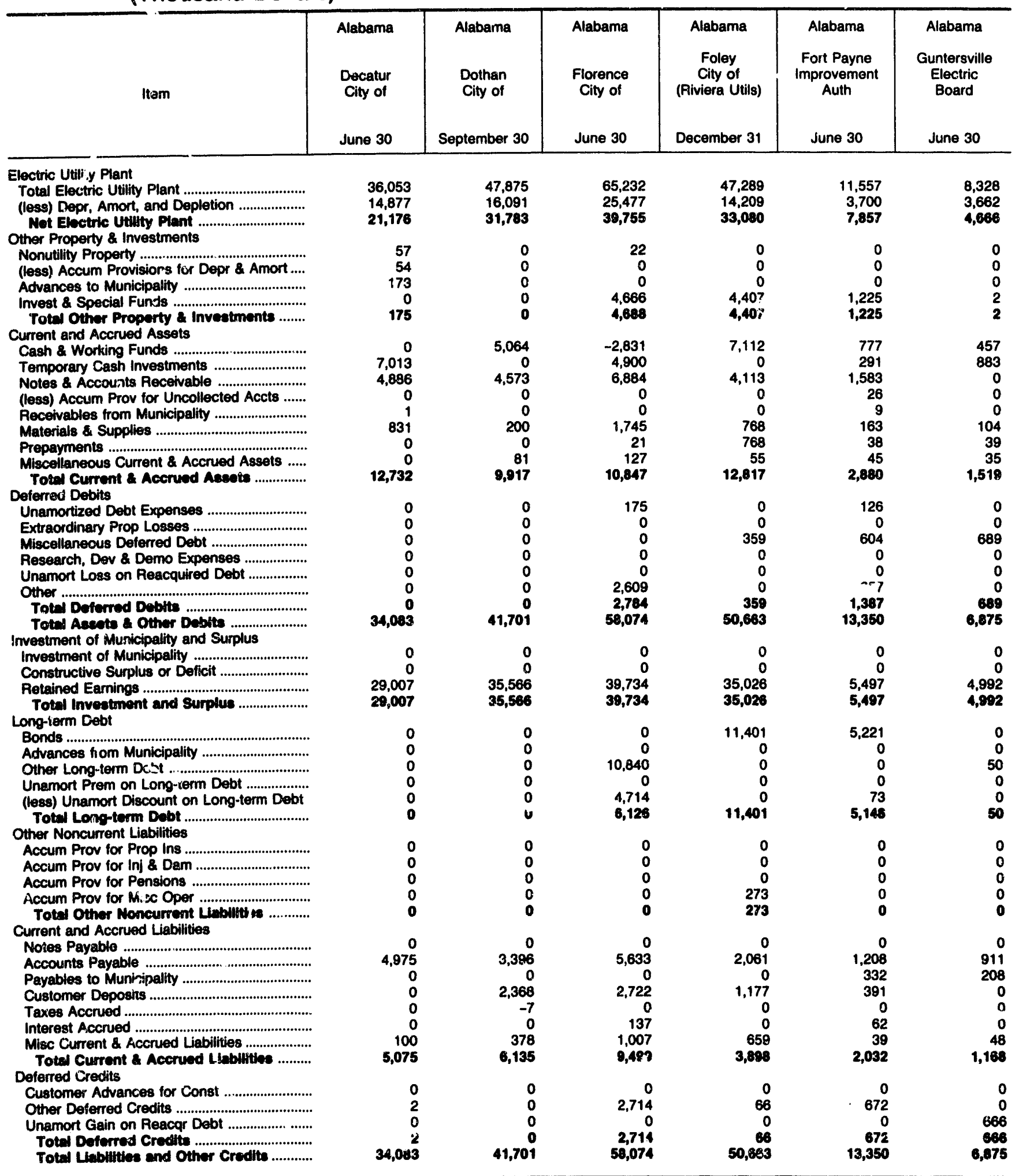

Note: Totals may not equal sum of components because of indop. indent rounding.

Source: Eneray Information Administration, Form EIA-412, "Annual Report of Public Electric Utilities." 
Table 37. Balance Sheet by Major Publicly Owned Electric Utility Within State at End of Period, 1991 (Contlnued) (Thousand Dollars)

\begin{tabular}{|c|c|c|c|c|c|c|}
\hline Item & $\begin{array}{l}\text { Alabama } \\
\text { Huntoville } \\
\text { City of } \\
\text { September } 30\end{array}$ & $\begin{array}{l}\text { Alabama } \\
\text { Muscle } \\
\text { Shoals } \\
\text { City of } \\
\text { June } 30\end{array}$ & $\begin{array}{l}\text { Alabama } \\
\text { Opelika } \\
\text { City of } \\
\text { September } 30\end{array}$ & $\begin{array}{l}\text { Alabama } \\
\text { Scotteboro } \\
\text { City of } \\
\text { June } 30\end{array}$ & $\begin{array}{l}\text { Alabama } \\
\text { Sheffield } \\
\text { Utilities } \\
\text { June } 30\end{array}$ & $\begin{array}{c}\text { Alabama } \\
\text { Sylacauga } \\
\text { Utilities } \\
\text { Board } \\
\text { September } 30\end{array}$ \\
\hline 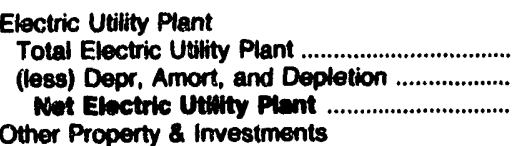 & $\begin{array}{r}145,805 \\
52,279 \\
83,526\end{array}$ & $\begin{array}{r}11,528 \\
3,342 \\
8,168\end{array}$ & $\begin{array}{r}15,325 \\
8,704 \\
6,620\end{array}$ & $\begin{array}{r}13,157 \\
4,388 \\
8,768\end{array}$ & $\begin{array}{l}30,201 \\
12,402 \\
17,700\end{array}$ & $\begin{array}{r}10,059 \\
6,054 \\
4,005\end{array}$ \\
\hline $\begin{array}{l}\text { Nonutility Pruperty .............................. } \\
\text { (less) Accum Provisions for Depr \& Amort.... } \\
\text { Advances to Municipality ................................ } \\
\text { Invest \& Special Funds .................................. } \\
\text { Total Other Propenty Inveetuments ........ } \\
\text { Current and Accrued Assets }\end{array}$ & $\begin{array}{r}0 \\
0 \\
0 \\
9,127 \\
9,127\end{array}$ & $\begin{array}{r}0 \\
0 \\
0 \\
186 \\
198\end{array}$ & $\begin{array}{r}0 \\
0 \\
214 \\
1,116 \\
1,320\end{array}$ & $\begin{array}{r}0 \\
0 \\
0 \\
922 \\
922\end{array}$ & $\begin{array}{r}158 \\
0 \\
0 \\
2,340 \\
2,498\end{array}$ & $\begin{array}{r}0 \\
0 \\
0 \\
3,454 \\
3,454\end{array}$ \\
\hline 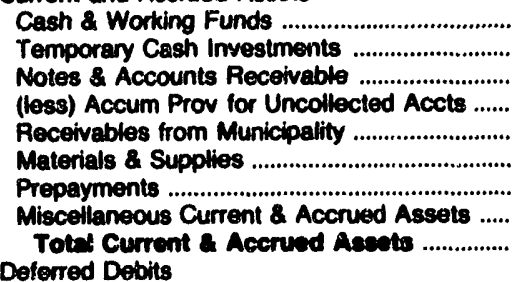 & $\begin{array}{r}30,283 \\
0 \\
10,711 \\
280 \\
0 \\
2,845 \\
458 \\
1,310 \\
45,328\end{array}$ & $\begin{array}{r}1,565 \\
0 \\
1,138 \\
0 \\
0 \\
197 \\
97 \\
34 \\
3,081\end{array}$ & $\begin{array}{r}2,818 \\
0 \\
2,115 \\
0 \\
1,461 \\
497 \\
9 \\
46 \\
6,946\end{array}$ & $\begin{array}{r}88 \\
0 \\
1,538 \\
4 \\
0 \\
131 \\
1 \\
47 \\
1,001\end{array}$ & $\begin{array}{r}1,201 \\
550 \\
2,255 \\
21 \\
398 \\
533 \\
121 \\
84 \\
5,122\end{array}$ & $\begin{array}{r}503 \\
300 \\
909 \\
0 \\
0 \\
213 \\
0 \\
0 \\
1,925\end{array}$ \\
\hline 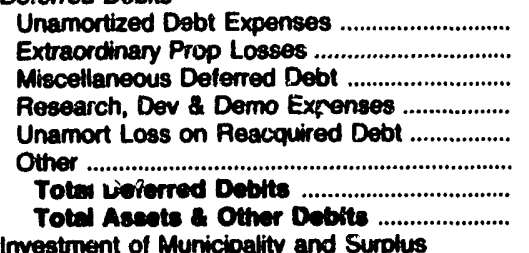 & $\begin{array}{r}217 \\
0 \\
0 \\
0 \\
0 \\
0 \\
217 \\
149,898\end{array}$ & $\begin{array}{r}38 \\
0 \\
594 \\
0 \\
0 \\
0 \\
682 \\
12,046\end{array}$ & $\begin{array}{r}0 \\
0 \\
0 \\
0 \\
0 \\
0 \\
0 \\
0 \\
14,098\end{array}$ & $\begin{array}{r}144 \\
0 \\
1,095 \\
0 \\
0 \\
3 \\
1,242 \\
12,735\end{array}$ & $\begin{array}{r}20 \\
0 \\
1,601 \\
0 \\
0 \\
0 \\
1,021 \\
27,040\end{array}$ & $\begin{array}{r}0 \\
0 \\
0 \\
0 \\
0 \\
0 \\
0 \\
9,324\end{array}$ \\
\hline 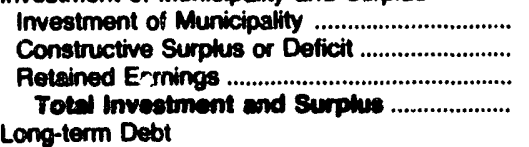 & $\begin{array}{r}109,630 \\
0 \\
0 \\
109,630\end{array}$ & $\begin{array}{r}0 \\
0 \\
8,847 \\
8,847\end{array}$ & $\begin{array}{r}0 \\
0 \\
10,723 \\
10,723\end{array}$ & $\begin{array}{r}0 \\
0 \\
6,008 \\
6,008\end{array}$ & $\begin{array}{r}0 \\
0 \\
19,546 \\
10,646\end{array}$ & $\begin{array}{r}0 \\
0 \\
6,139 \\
6,130\end{array}$ \\
\hline 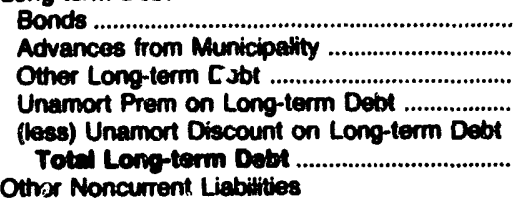 & $\begin{array}{r}9,275 \\
0 \\
0 \\
0 \\
0 \\
9,275\end{array}$ & $\begin{array}{r}1,050 \\
0 \\
575 \\
0 \\
0 \\
1,825\end{array}$ & $\begin{array}{r}1,745 \\
0 \\
435 \\
0 \\
0 \\
2,1100\end{array}$ & $\begin{array}{r}3,730 \\
0 \\
0 \\
0 \\
0 \\
3,730\end{array}$ & $\begin{array}{r}2,445 \\
0 \\
1,681 \\
0 \\
0 \\
4,128\end{array}$ & $\begin{array}{r}2,445 \\
0 \\
0 \\
0 \\
0 \\
2,445\end{array}$ \\
\hline 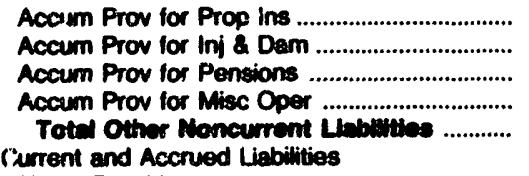 & $\begin{array}{l}0 \\
1 \\
0 \\
0 \\
1\end{array}$ & $\begin{array}{l}\mathbf{0} \\
\mathbf{0} \\
\mathbf{0} \\
\mathbf{0} \\
\mathbf{0}\end{array}$ & $\begin{array}{l}0 \\
0 \\
c \\
0 \\
0\end{array}$ & $\begin{array}{r}1,087 \\
0 \\
0 \\
0 \\
1,095\end{array}$ & $\begin{array}{l}0 \\
0 \\
0 \\
0 \\
\mathbf{0}\end{array}$ & $\begin{array}{l}\mathbf{0} \\
\mathbf{0} \\
\mathbf{0} \\
\mathbf{0} \\
\mathbf{0}\end{array}$ \\
\hline 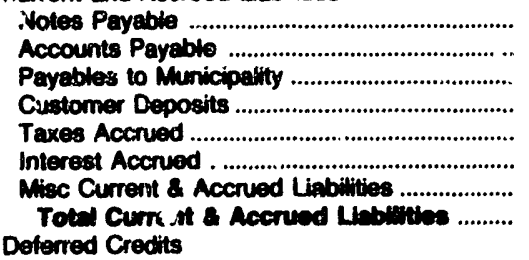 & $\begin{array}{r}19,127 \\
0 \\
0 \\
8,289 \\
0 \\
185 \\
1,681 \\
29,291\end{array}$ & $\begin{array}{r}0 \\
1,162 \\
0 \\
328 \\
0 \\
11 \\
69 \\
1,571\end{array}$ & $\begin{array}{r}150 \\
1,304 \\
78 \\
352 \\
0 \\
14 \\
94 \\
1,203\end{array}$ & $\begin{array}{r}0 \\
1,246 \\
0 \\
360 \\
19 \\
163 \\
62 \\
1,850\end{array}$ & $\begin{array}{r}0 \\
2,398 \\
0 \\
588 \\
0 \\
25 \\
356 \\
3,398\end{array}$ & $\begin{array}{r}104 \\
428 \\
0 \\
158 \\
0 \\
88 \\
0 \\
778\end{array}$ \\
\hline 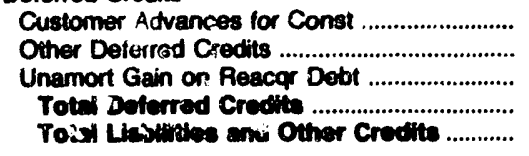 & $\begin{array}{r}0 \\
0 \\
0 \\
0 \\
149,198\end{array}$ & $\begin{array}{r}2 \\
0 \\
i \\
2 \\
12,045\end{array}$ & $\begin{array}{r}0 \\
0 \\
0 \\
0 \\
14,1,98\end{array}$ & $\begin{array}{r}0 \\
0 \\
n \\
0 \\
12,735\end{array}$ & $\begin{array}{r}0 \\
0 \\
0 \\
0 \\
0 \\
27,040\end{array}$ & $\begin{array}{r}22 \\
0 \\
0 \\
22 \\
8,384\end{array}$ \\
\hline
\end{tabular}

Note: Totals may not equal sum of components hecause of incependent rounding.

Source: Eriergy Information Adninistration, Form ElA-412, "Arnual Report of Public Electric Utilties." 
Table 37. Balance Sheet by Major Publicly Owned Electric Utility Within State at End of Period, 1991 (Continued) (Thousand Dollars)

\begin{tabular}{|c|c|c|c|c|c|c|}
\hline Item & $\begin{array}{c}\text { Alabsma } \\
\text { Troy } \\
\text { City of } \\
\text { September } 30\end{array}$ & $\begin{array}{l}\text { Alabama } \\
\text { Tuskegee } \\
\text { City of } \\
\text { September } 30\end{array}$ & $\begin{array}{l}\text { Alaska } \\
\text { Alaska } \\
\text { Energy } \\
\text { Authority } \\
\text { June } 30\end{array}$ & $\begin{array}{c}\text { Alaska } \\
\text { Anchorage } \\
\text { City of } \\
\text { December } 31\end{array}$ & $\begin{array}{l}\text { Alaska } \\
\text { Fairbanks } \\
\text { City of } \\
\text { December } 31\end{array}$ & $\begin{array}{l}\text { Alaska } \\
\text { Ketchikan } \\
\text { City of } \\
\text { December } 31\end{array}$ \\
\hline $\begin{array}{l}\text { Electric Utility Plant } \\
\text { Total Electric Utility Plant .................................. } \\
\text { (less) Depr, Amort, and Depletion .................... } \\
\text { Net Electric Utilty Piant ............................... } \\
\text { Other Property \& Investments }\end{array}$ & $\begin{array}{l}9,079 \\
4,747 \\
4,332\end{array}$ & $\begin{array}{l}6,477 \\
2,603 \\
3,875\end{array}$ & $\begin{array}{l}898,025 \\
106,036 \\
701,989\end{array}$ & $\begin{array}{r}225,372 \\
84,337 \\
141,035\end{array}$ & $\begin{array}{l}46,239 \\
23,964 \\
22,275\end{array}$ & $\begin{array}{l}39,479 \\
17,402 \\
22,078\end{array}$ \\
\hline 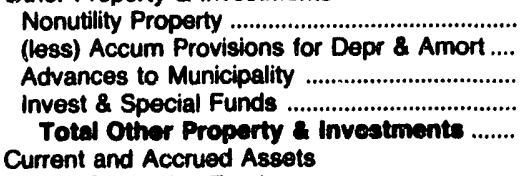 & $\begin{array}{r}0 \\
0 \\
0 \\
5,602 \\
5,602\end{array}$ & $\begin{array}{r}0 \\
0 \\
0 \\
474 \\
474\end{array}$ & $\begin{array}{r}4,143 \\
2,762 \\
0 \\
29,923 \\
31,304\end{array}$ & $\begin{array}{r}0 \\
0 \\
0 \\
25,341 \\
25,341\end{array}$ & $\begin{array}{r}244,998 \\
113,027 \\
0 \\
16,416 \\
148,387\end{array}$ & $\begin{array}{r}0 \\
0 \\
0 \\
3,358 \\
3,358\end{array}$ \\
\hline 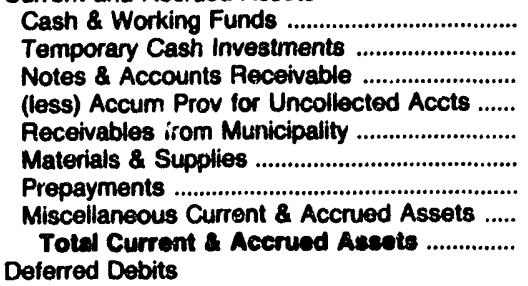 & $\begin{array}{r}170 \\
0 \\
1,770 \\
0 \\
0 \\
0 \\
8 \\
8 \\
184 \\
2,132\end{array}$ & $\begin{array}{r}1 \\
119 \\
2,993 \\
0 \\
374 \\
92 \\
0 \\
5 \\
3,584\end{array}$ & $\begin{array}{r}90,111 \\
0 \\
11,246 \\
0 \\
4,497 \\
0 \\
0 \\
3,986 \\
109,840\end{array}$ & $\begin{array}{r}26,288 \\
0 \\
4,519 \\
281 \\
0 \\
3,362 \\
1,857 \\
452 \\
36,197\end{array}$ & $\begin{array}{r}8,413 \\
0 \\
8,035 \\
0 \\
0 \\
3,923 \\
305 \\
0 \\
20,676\end{array}$ & $\begin{array}{r}6,925 \\
0 \\
3,034 \\
150 \\
0 \\
1,312 \\
344 \\
0 \\
11,465\end{array}$ \\
\hline 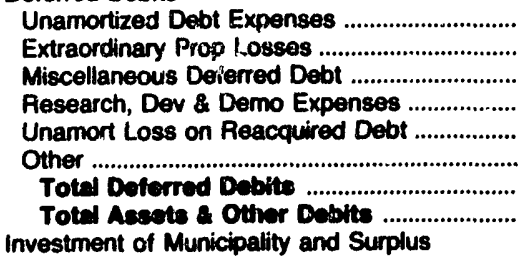 & $\begin{array}{r}0 \\
0 \\
0 \\
0 \\
0 \\
200 \\
200 \\
12,298\end{array}$ & $\begin{array}{r}347 \\
0 \\
0 \\
0 \\
0 \\
0 \\
347 \\
8,290\end{array}$ & $\begin{array}{r}47 \\
0 \\
0 \\
0 \\
0 \\
14,462 \\
14,509 \\
947,643\end{array}$ & $\begin{array}{r}2,804 \\
0 \\
2,866 \\
0 \\
29,397 \\
0 \\
35,067 \\
237,640\end{array}$ & $\begin{array}{r}2,081 \\
0 \\
0 \\
0 \\
0 \\
183 \\
2,284 \\
193,603\end{array}$ & $\begin{array}{r}377 \\
0 \\
0 \\
0 \\
0 \\
778 \\
1,155 \\
38,055\end{array}$ \\
\hline $\begin{array}{l}\text { Investment of Municipality .......................... } \\
\text { Constructive Surplus or Deficit ........................ } \\
\text { Retained Earnings ....................................... } \\
\text { Total Investment end Sumpius }\end{array}$ & $\begin{array}{r}3,448 \\
0 \\
0 \\
3,448\end{array}$ & $\begin{array}{r}3,475 \\
0 \\
587 \\
4,032\end{array}$ & $\begin{array}{r}629,630 \\
-101,511 \\
0 \\
528,118\end{array}$ & $\begin{array}{r}0 \\
0 \\
42,922 \\
42,922\end{array}$ & $\begin{array}{r}19,903 \\
58,071 \\
32,219 \\
110,103\end{array}$ & $\begin{array}{r}0 \\
0 \\
21,362 \\
21,362\end{array}$ \\
\hline 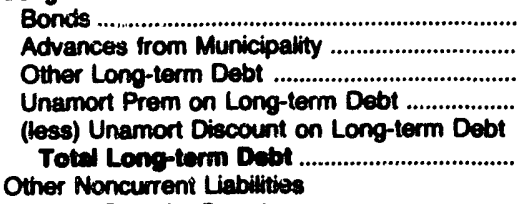 & $\begin{array}{r}7,770 \\
0 \\
45 \\
0 \\
195 \\
7,621\end{array}$ & $\begin{array}{r}1,339 \\
0 \\
148 \\
0 \\
0 \\
1,487\end{array}$ & $\begin{array}{r}182,485 \\
0 \\
215,716 \\
0 \\
0 \\
376,201\end{array}$ & $\begin{array}{r}194,435 \\
0 \\
0 \\
0 \\
8,987 \\
185,448\end{array}$ & $\begin{array}{r}59,824 \\
0 \\
5,644 \\
0 \\
0 \\
65,468\end{array}$ & $\begin{array}{r}15,109 \\
0 \\
0 \\
0 \\
0 \\
16,100\end{array}$ \\
\hline 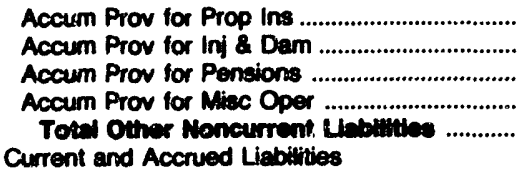 & $\begin{array}{l}0 \\
0 \\
0 \\
0 \\
0\end{array}$ & $\begin{array}{l}0 \\
0 \\
0 \\
0 \\
0\end{array}$ & $\begin{array}{l}0 \\
0 \\
0 \\
0 \\
0\end{array}$ & $\begin{array}{r}0 \\
0 \\
0 \\
350 \\
350\end{array}$ & $\begin{array}{l}0 \\
0 \\
0 \\
0 \\
0\end{array}$ & $\begin{array}{l}0 \\
0 \\
0 \\
0 \\
0\end{array}$ \\
\hline 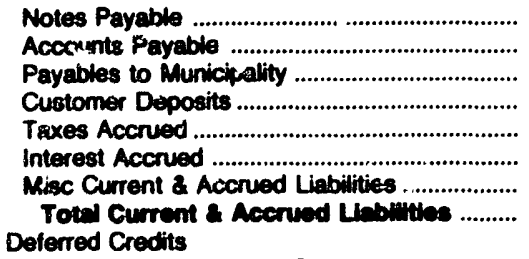 & $\begin{array}{r}2 C \\
780 \\
0 \\
187 \\
-1 \\
97 \\
115 \\
1,190\end{array}$ & $\begin{array}{r}26 \\
1,124 \\
951 \\
504 \\
127 \\
0 \\
0 \\
2,732\end{array}$ & $\begin{array}{r}1,541 \\
8,976 \\
10,733 \\
0 \\
0 \\
5,519 \\
0 \\
26,760\end{array}$ & $\begin{array}{r}0 \\
4,702 \\
0 \\
1,234 \\
0 \\
1,113 \\
945 \\
7,994\end{array}$ & $\begin{array}{r}3,875 \\
4,220 \\
0 \\
808 \\
0 \\
2,353 \\
6,685 \\
17,941\end{array}$ & $\begin{array}{r}0 \\
1,000 \\
0 \\
84 \\
0 \\
0 \\
0 \\
1,094\end{array}$ \\
\hline 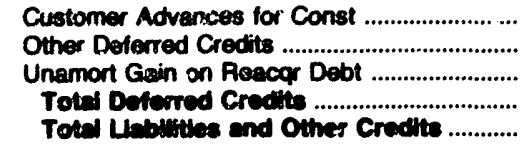 & $\begin{array}{r}0 \\
0 \\
0 \\
0 \\
12,298\end{array}$ & $\begin{array}{r}0 \\
0 \\
0 \\
0 \\
0 \\
\mathbf{8}, 200\end{array}$ & $\begin{array}{r}0 \\
14,554 \\
0 \\
14,684 \\
947,643\end{array}$ & $\begin{array}{r}256 \\
670 \\
0 \\
925 \\
237,640\end{array}$ & $\begin{array}{r}0 \\
0 \\
0 \\
0 \\
183,803\end{array}$ & $\begin{array}{r}0 \\
500 \\
0 \\
500 \\
38,055\end{array}$ \\
\hline
\end{tabular}

Note: Totals may not equal sum of components because of independent rounding.

Source: Energy Information Administation, Form ElA-412, "Annual Report of Public Electric Utilities." 
Table 37. Balance Sheet by Major Publicly Owned Electric Utility Within State at End of Period, 1991 (Continued) (Thousand Dollars)

\begin{tabular}{|c|c|c|c|c|c|c|}
\hline Item & $\begin{array}{l}\text { Arizona } \\
\text { Arizona } \\
\text { Power } \\
\text { Authority } \\
\text { June } 30\end{array}$ & $\begin{array}{l}\text { Mesa } \\
\text { City of } \\
\text { June } 30\end{array}$ & $\begin{array}{l}\text { Arizona } \\
\text { Navajo } \\
\text { Tribal } \\
\text { Utility } \\
\text { Auth } \\
\text { December } 31\end{array}$ & $\begin{array}{l}\text { Arizona } \\
\text { Salt River } \\
\text { Proj Ag } \\
\text { I \& P Dist } \\
\text { April } 30\end{array}$ & $\begin{array}{l}\text { Arkansas } \\
\text { Benton } \\
\text { City of } \\
\text { December } 31\end{array}$ & $\begin{array}{c}\text { Arkansas } \\
\text { Bentonville } \\
\text { City of } \\
\text { December } 31\end{array}$ \\
\hline 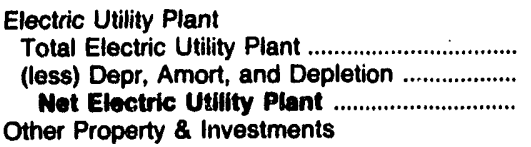 & $\begin{array}{r}1,101 \\
496 \\
605\end{array}$ & $\begin{array}{r}48,601 \\
9,914 \\
38,687\end{array}$ & $\begin{array}{l}95,012 \\
29,332 \\
65,678\end{array}$ & $\begin{array}{l}5,439,779 \\
1,333,769 \\
4,106,010\end{array}$ & $\begin{array}{l}6,265 \\
4,785 \\
1,480\end{array}$ & $\begin{array}{r}24,799 \\
5,819 \\
18,980\end{array}$ \\
\hline 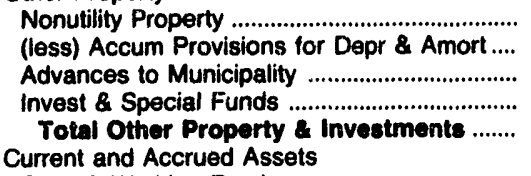 & $\begin{array}{r}0 \\
0 \\
0 \\
3,781 \\
3,781\end{array}$ & $\begin{array}{r}594,583 \\
89,044 \\
0 \\
0 \\
505,539\end{array}$ & $\begin{array}{r}790 \\
343 \\
0 \\
1,384 \\
1,831\end{array}$ & $\begin{array}{r}43,728 \\
1,136 \\
0 \\
138,997 \\
181,588\end{array}$ & $\begin{array}{r}0 \\
0 \\
0 \\
804 \\
804\end{array}$ & $\begin{array}{r}0 \\
0 \\
0 \\
8,945 \\
8,945\end{array}$ \\
\hline 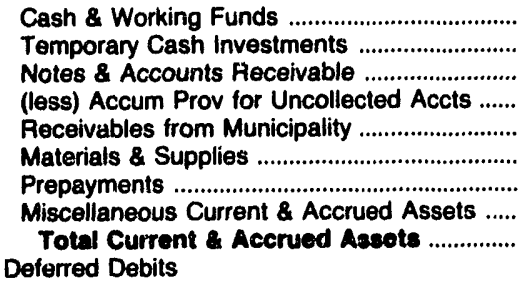 & $\begin{array}{r}7,109 \\
49,488 \\
2,214 \\
0 \\
0 \\
0 \\
98 \\
1,042 \\
59,951\end{array}$ & $\begin{array}{r}39,369 \\
0 \\
30,970 \\
752 \\
3,009 \\
0 \\
200 \\
0 \\
72,796\end{array}$ & $\begin{array}{r}673 \\
1,891 \\
4,569 \\
111 \\
0 \\
1,667 \\
159 \\
0 \\
6,847\end{array}$ & $\begin{array}{r}81,350 \\
304,403 \\
80,160 \\
1,959 \\
0 \\
152,926 \\
30,066 \\
6,330 \\
653,277\end{array}$ & $\begin{array}{r}379 \\
0 \\
1,583 \\
0 \\
0 \\
0 \\
163 \\
1,907 \\
2 \\
4,034\end{array}$ & $\begin{array}{r}1,237 \\
0 \\
2,102 \\
23 \\
0 \\
522 \\
7 \\
58 \\
3,903\end{array}$ \\
\hline 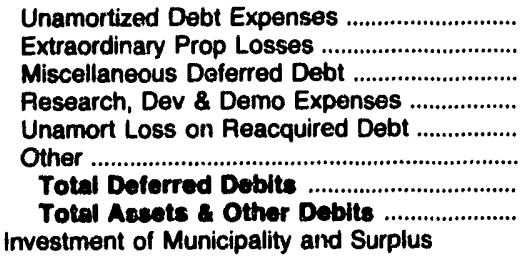 & $\begin{array}{r}32,777 \\
0 \\
893 \\
0 \\
0 \\
0 \\
33,670 \\
98,007\end{array}$ & $\begin{array}{r}379 \\
0 \\
0 \\
0 \\
10,351 \\
0 \\
10,729 \\
627,751\end{array}$ & $\begin{array}{r}0 \\
0 \\
2,321 \\
0 \\
0 \\
0 \\
2,321 \\
78,679\end{array}$ & $\begin{array}{r}7,430 \\
0 \\
120,691 \\
0 \\
103,753 \\
0 \\
231,875 \\
5,172,750\end{array}$ & $\begin{array}{r}0 \\
0 \\
0 \\
0 \\
0 \\
0 \\
0 \\
6,318\end{array}$ & $\begin{array}{r}320 \\
0 \\
0 \\
0 \\
0 \\
0 \\
320 \\
32,148\end{array}$ \\
\hline 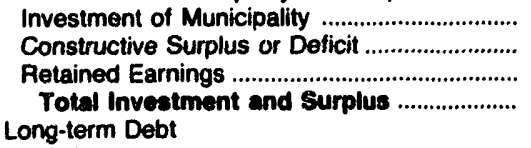 & $\begin{array}{r}0 \\
0 \\
4,242 \\
4,242\end{array}$ & $\begin{array}{r}40,805 \\
234,583 \\
83,061 \\
358,440\end{array}$ & $\begin{array}{r}0 \\
0 \\
48,692 \\
48,692\end{array}$ & $\begin{array}{r}0 \\
0 \\
1,057,943 \\
1,057,943\end{array}$ & $\begin{array}{r}0 \\
0 \\
5,091 \\
5,081\end{array}$ & $\begin{array}{r}4,695 \\
1,585 \\
14,890 \\
21,171\end{array}$ \\
\hline 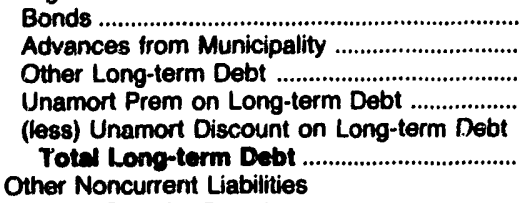 & $\begin{array}{r}89,820 \\
0 \\
0 \\
0 \\
0 \\
89,820\end{array}$ & $\begin{array}{r}221,341 \\
0 \\
13,925 \\
277 \\
0 \\
235,544\end{array}$ & $\begin{array}{r}0 \\
0 \\
24,038 \\
0 \\
0 \\
24,038\end{array}$ & $\begin{array}{r}3,377,881 \\
0 \\
380,580 \\
0 \\
99,557 \\
3,658,904\end{array}$ & $\begin{array}{l}0 \\
0 \\
0 \\
0 \\
0 \\
0\end{array}$ & $\begin{array}{r}9,980 \\
0 \\
0 \\
0 \\
0 \\
9,980\end{array}$ \\
\hline 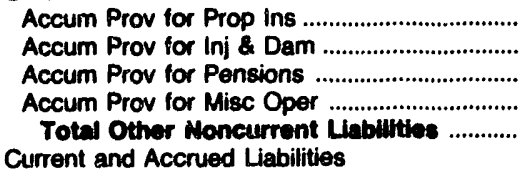 & $\begin{array}{l}0 \\
0 \\
0 \\
0 \\
0\end{array}$ & $\begin{array}{l}0 \\
0 \\
0 \\
0 \\
0\end{array}$ & $\begin{array}{l}0 \\
0 \\
0 \\
0 \\
0\end{array}$ & $\begin{array}{r}5 \\
9,795 \\
0 \\
12,971 \\
22,771\end{array}$ & $\begin{array}{l}0 \\
0 \\
0 \\
0 \\
0\end{array}$ & $\begin{array}{l}0 \\
0 \\
0 \\
0 \\
0\end{array}$ \\
\hline 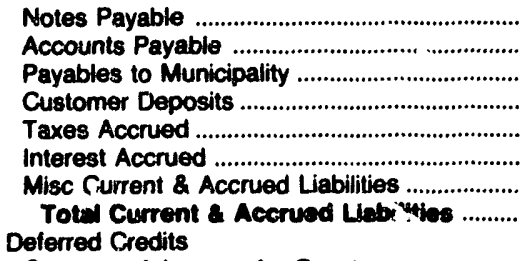 & $\begin{array}{r}0 \\
1,465 \\
0 \\
0 \\
0 \\
1,587 \\
0 \\
3,052\end{array}$ & $\begin{array}{r}15,215 \\
2,446 \\
1,768 \\
3,781 \\
0 \\
8,231 \\
2,317 \\
38,750\end{array}$ & $\begin{array}{r}0 \\
2,497 \\
0 \\
56 \\
0 \\
0 \\
2,149 \\
4,702\end{array}$ & $\begin{array}{r}19 \\
62,112 \\
0 \\
32,586 \\
70,709 \\
75,107 \\
135,376 \\
375,918\end{array}$ & $\begin{array}{r}0 \\
798 \\
0 \\
269 \\
61 \\
0 \\
99 \\
1,227\end{array}$ & $\begin{array}{r}0 \\
545 \\
8 \\
232 \\
43 \\
64 \\
84 \\
976\end{array}$ \\
\hline 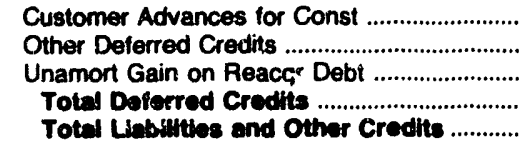 & $\begin{array}{r}0 \\
893 \\
0 \\
893 \\
88,007\end{array}$ & $\begin{array}{r}0 \\
0 \\
0 \\
0 \\
627,751\end{array}$ & $\begin{array}{r}1,076 \\
171 \\
0 \\
1,248 \\
78,679\end{array}$ & $\begin{array}{r}16,226 \\
40,987 \\
0 \\
57,213 \\
5,172,750\end{array}$ & $\begin{array}{r}0 \\
0 \\
0 \\
0 \\
6,318\end{array}$ & $\begin{array}{r}0 \\
21 \\
0 \\
21 \\
32,148\end{array}$ \\
\hline
\end{tabular}

Note: Totals may not equal sum of components because of independent rounding.

Source: Energy Information Administration, Form EIA-412. "Annual Report of Public Electric Utilities." 
Table 37. Balance Sheet by Major Publicly Owned Electric Utility Within State at End of Period, 1991 (Continued) (Thousand Dollars)

\begin{tabular}{|c|c|c|c|c|c|c|}
\hline Item & $\begin{array}{l}\text { Arkansas } \\
\text { Conway } \\
\text { Corp } \\
\text { December } 31\end{array}$ & $\begin{array}{c}\text { Arkansas } \\
\text { Hope } \\
\text { City of } \\
\text { December } 31\end{array}$ & $\begin{array}{c}\text { Arkansas } \\
\text { Jonesboro } \\
\text { City of } \\
\text { December } 31\end{array}$ & $\begin{array}{l}\text { Arkansas } \\
\text { North } \\
\text { Little } \\
\text { Rock } \\
\text { City of } \\
\text { December } 31\end{array}$ & $\begin{array}{l}\text { Arkansas } \\
\text { Osceola } \\
\text { City of } \\
\text { December } 31\end{array}$ & $\begin{array}{c}\text { Arkansas } \\
\text { Paragould } \\
\text { Light } \\
\& \\
\text { Water Comm } \\
\text { December } 31\end{array}$ \\
\hline 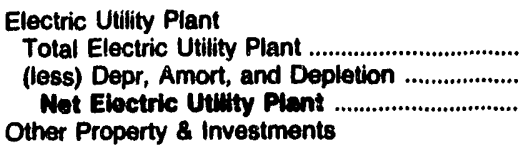 & $\begin{array}{l}58,588 \\
18,580 \\
39,997\end{array}$ & $\begin{array}{r}12,050 \\
6,241 \\
5,810\end{array}$ & $\begin{array}{r}130,113 \\
48,186 \\
81,917\end{array}$ & $\begin{array}{r}145,492 \\
22,291 \\
123,201\end{array}$ & $\begin{array}{r}17,344 \\
7,123 \\
10,221\end{array}$ & $\begin{array}{r}23,085 \\
7,082 \\
18,003\end{array}$ \\
\hline $\begin{array}{l}\text { Nonutility Property } \\
\text { (less) Accum Provisions for Depr \& Amort..... } \\
\text { Advances to Municipaity .................................... } \\
\text { Invest \& Special Funds ................................... } \\
\text { Total Other Property Investinente ....... } \\
\text { Current and Accrued Assets }\end{array}$ & $\begin{array}{r}400 \\
0 \\
1,133 \\
15,480 \\
17,013\end{array}$ & $\begin{array}{r}0 \\
0 \\
0 \\
3,452 \\
3,452\end{array}$ & $\begin{array}{r}0 \\
0 \\
15,535 \\
20,278 \\
35,814\end{array}$ & $\begin{array}{r}0 \\
0 \\
0 \\
33,992 \\
33,902\end{array}$ & $\begin{array}{r}0 \\
0 \\
0 \\
1,882 \\
1,892\end{array}$ & $\begin{array}{l}\mathbf{0} \\
\mathbf{0} \\
\mathbf{0} \\
\mathbf{0} \\
\mathbf{0}\end{array}$ \\
\hline 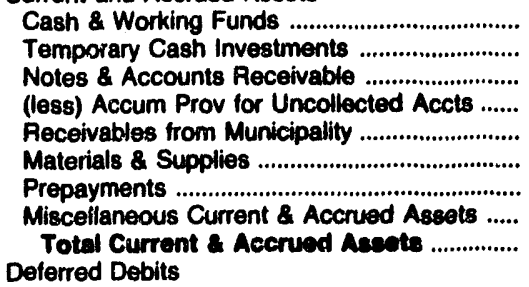 & $\begin{array}{r}1,366 \\
0 \\
2,143 \\
90 \\
0 \\
2,844 \\
19 \\
722 \\
7,003\end{array}$ & $\begin{array}{r}100 \\
4,419 \\
797 \\
0 \\
0 \\
189 \\
31 \\
18 \\
5,584\end{array}$ & $\begin{array}{r}4,491 \\
0 \\
2,384 \\
107 \\
0 \\
5,074 \\
491 \\
892 \\
13,225\end{array}$ & $\begin{array}{r}4,919 \\
9,281 \\
6,010 \\
424 \\
0 \\
620 \\
33 \\
0 \\
20,430\end{array}$ & $\begin{array}{r}100 \\
0 \\
1,002 \\
30 \\
0 \\
418 \\
18 \\
0 \\
1,608\end{array}$ & $\begin{array}{r}1,366 \\
0 \\
882 \\
0 \\
225 \\
279 \\
26 \\
0 \\
2,778\end{array}$ \\
\hline 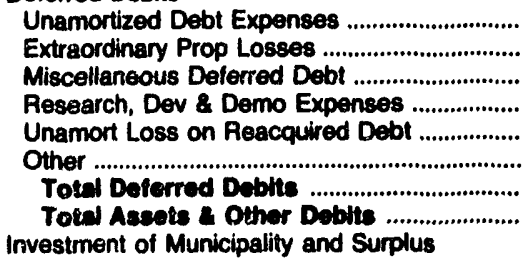 & $\begin{array}{r}84 \\
0 \\
0 \\
0 \\
0 \\
0 \\
84 \\
04,000\end{array}$ & $\begin{array}{r}0 \\
0 \\
0 \\
0 \\
0 \\
344 \\
344 \\
15,160\end{array}$ & $\begin{array}{r}784 \\
0 \\
0 \\
0 \\
0 \\
0 \\
784 \\
131,740\end{array}$ & $\begin{array}{r}3,207 \\
0 \\
0 \\
0 \\
0 \\
0 \\
3,207 \\
180,839\end{array}$ & $\begin{array}{r}130 \\
0 \\
0 \\
0 \\
0 \\
0 \\
130 \\
13,760\end{array}$ & $\begin{array}{r}1,048 \\
0 \\
0 \\
0 \\
0 \\
0 \\
1,048 \\
19,020\end{array}$ \\
\hline 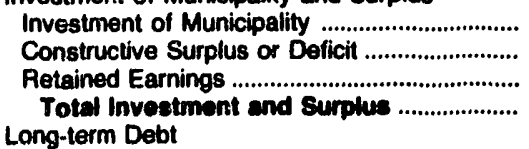 & $\begin{array}{r}179 \\
0 \\
29,676 \\
29,855\end{array}$ & $\begin{array}{r}0 \\
1,934 \\
5,655 \\
7,589\end{array}$ & $\begin{array}{r}0 \\
0 \\
57,055 \\
57,055\end{array}$ & $\begin{array}{r}20,134 \\
0 \\
0 \\
20,134\end{array}$ & $\begin{array}{r}1,308 \\
0 \\
7,567 \\
8,875\end{array}$ & $\begin{array}{r}0 \\
0 \\
20,338 \\
20,338\end{array}$ \\
\hline 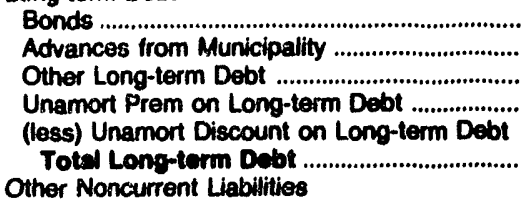 & $\begin{array}{r}30,680 \\
0 \\
0 \\
0 \\
224 \\
30,458\end{array}$ & $\begin{array}{r}5,680 \\
0 \\
31 \\
0 \\
0 \\
5,928\end{array}$ & $\begin{array}{r}59,100 \\
0 \\
7,340 \\
0 \\
1,350 \\
85,080\end{array}$ & $\begin{array}{r}151,550 \\
0 \\
0 \\
0 \\
0 \\
151,550\end{array}$ & $\begin{array}{r}4,300 \\
0 \\
23 \\
0 \\
0 \\
4,323\end{array}$ & $\begin{array}{r}8,633 \\
0 \\
0 \\
0 \\
0 \\
9,683\end{array}$ \\
\hline 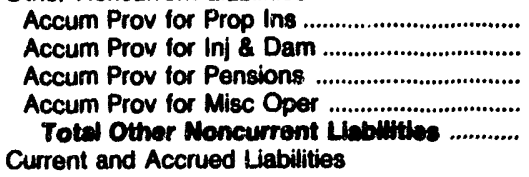 & $\begin{array}{l}0 \\
0 \\
0 \\
0 \\
0\end{array}$ & $\begin{array}{l}0 \\
0 \\
0 \\
0 \\
0\end{array}$ & $\begin{array}{r}0 \\
0 \\
40 \\
0 \\
40\end{array}$ & $\begin{array}{l}0 \\
0 \\
0 \\
0 \\
0\end{array}$ & $\begin{array}{l}\mathbf{0} \\
\mathbf{0} \\
\mathbf{0} \\
\mathbf{0} \\
\mathbf{0}\end{array}$ & $\begin{array}{l}0 \\
0 \\
0 \\
0 \\
0\end{array}$ \\
\hline 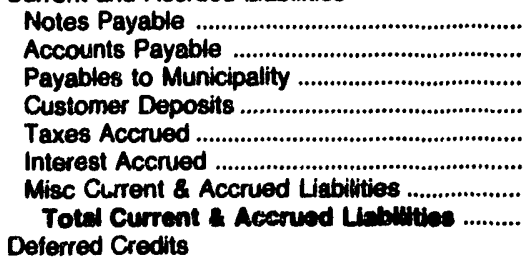 & $\begin{array}{r}0 \\
1,579 \\
0 \\
0 \\
189 \\
866 \\
0 \\
2,839\end{array}$ & $\begin{array}{r}223 \\
718 \\
0 \\
328 \\
51 \\
339 \\
0 \\
1,989\end{array}$ & $\begin{array}{r}0 \\
6,543 \\
0 \\
412 \\
93 \\
1,952 \\
300 \\
0,300\end{array}$ & $\begin{array}{r}0 \\
2,707 \\
0 \\
0 \\
0 \\
5,683 \\
786 \\
0,156\end{array}$ & $\begin{array}{r}0 \\
203 \\
86 \\
171 \\
34 \\
57 \\
0 \\
552\end{array}$ & $\begin{array}{r}0 \\
685 \\
0 \\
168 \\
0 \\
235 \\
0 \\
1,098\end{array}$ \\
\hline 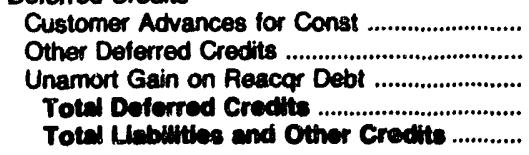 & $\begin{array}{r}1,154 \\
0 \\
0 \\
1,154 \\
4,0 \% 9\end{array}$ & $\begin{array}{r}0 \\
0 \\
0 \\
0 \\
15,100\end{array}$ & $\begin{array}{r}0 \\
255 \\
0 \\
265 \\
131,740\end{array}$ & $\begin{array}{r}0 \\
0 \\
0 \\
0 \\
100,00\end{array}$ & $\begin{array}{r}0 \\
0 \\
0 \\
0 \\
13,700\end{array}$ & $\begin{array}{r}0 \\
-11,228 \\
0 \\
-11,229 \\
10,220\end{array}$ \\
\hline
\end{tabular}

Note: Totals may not equal sum of components beceuse of independent rounding.

Source: Energy Information Administration, Form ElA-412, "Annual Repont of Public Electric Utilities." 
Table 37. Balance Sheet by Major Publicly Owned Electric Utility Within State at End of Period, 1991 (Continued) (Thousand Dollars)

\begin{tabular}{|c|c|c|c|c|c|c|}
\hline Item & $\begin{array}{c}\text { Arkansas } \\
\text { Siloam } \\
\text { Springs } \\
\text { City of } \\
\text { December } 31\end{array}$ & $\begin{array}{c}\text { Arkansas } \\
\text { West } \\
\text { Memphis } \\
\text { City of } \\
\text { December } 31\end{array}$ & $\begin{array}{l}\text { California } \\
\text { Alameda } \\
\text { City of } \\
\text { June } 30\end{array}$ & $\begin{array}{l}\text { California } \\
\text { Anaheim } \\
\text { City of } \\
\text { June } 30\end{array}$ & $\begin{array}{l}\text { California } \\
\text { Azusa } \\
\text { City of } \\
\text { June } 30\end{array}$ & $\begin{array}{l}\text { California } \\
\text { Burbank } \\
\text { City of } \\
\text { June } 30\end{array}$ \\
\hline 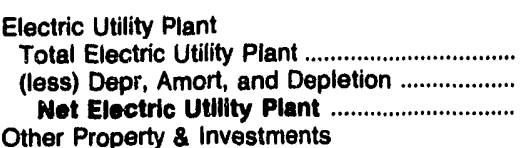 & $\begin{array}{l}5,215 \\
2,868 \\
2,347\end{array}$ & $\begin{array}{l}27,490 \\
10,504 \\
16,986\end{array}$ & $\begin{array}{r}36,705 \\
9,551 \\
27,154\end{array}$ & $\begin{array}{r}372,396 \\
84,136 \\
288,260\end{array}$ & $\begin{array}{r}10,882 \\
3,717 \\
7,175\end{array}$ & $\begin{array}{r}156,005 \\
83,028 \\
72,077\end{array}$ \\
\hline 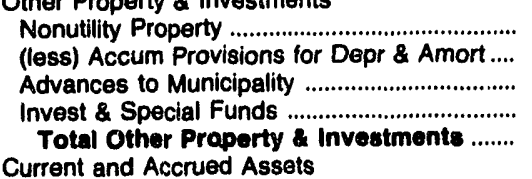 & $\begin{array}{r}0 \\
0 \\
99 \\
2,393 \\
2,492\end{array}$ & $\begin{array}{r}26,429 \\
14,125 \\
0 \\
0 \\
12,304\end{array}$ & $\begin{array}{r}0 \\
0 \\
0 \\
5,211 \\
5,211\end{array}$ & $\begin{array}{l}0 \\
0 \\
0 \\
0 \\
0\end{array}$ & $\begin{array}{r}0 \\
0 \\
1,950 \\
0 \\
1,950\end{array}$ & $\begin{array}{r}0 \\
0 \\
0 \\
3,071 \\
3,071\end{array}$ \\
\hline 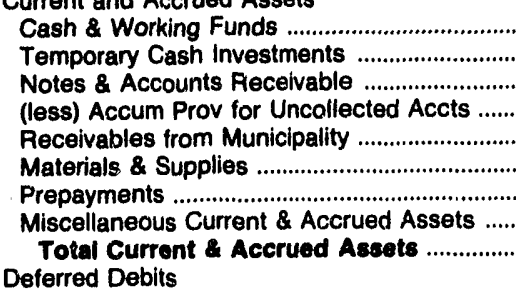 & $\begin{array}{r}2,083 \\
0 \\
214 \\
0 \\
99 \\
360 \\
39 \\
0 \\
2,795\end{array}$ & $\begin{array}{r}1,521 \\
22,309 \\
2,650 \\
150 \\
123 \\
1,246 \\
7 \\
0 \\
0 \\
27,705\end{array}$ & $\begin{array}{r}281 \\
8,633 \\
3,529 \\
0 \\
0 \\
1,513 \\
43 \\
315 \\
14,313\end{array}$ & $\begin{array}{r}147,424 \\
0 \\
21,364 \\
0 \\
0 \\
3,243 \\
2,719 \\
3,035 \\
177,785\end{array}$ & $\begin{array}{r}7,946 \\
0 \\
2,235 \\
0 \\
2,500 \\
403 \\
0 \\
800 \\
13,884\end{array}$ & $\begin{array}{r}10,492 \\
0 \\
11,679 \\
0 \\
509 \\
599 \\
5,681 \\
4,308 \\
0 \\
0 \\
32,759\end{array}$ \\
\hline 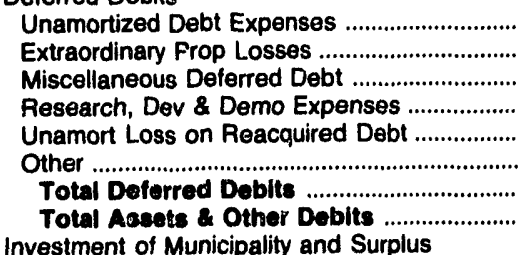 & $\begin{array}{r}0 \\
0 \\
0 \\
0 \\
0 \\
0 \\
\mathbf{0} \\
\mathbf{7 , 6 3 3}\end{array}$ & $\begin{array}{r}824 \\
0 \\
0 \\
0 \\
0 \\
0 \\
\mathbf{8 2 4} \\
\mathbf{5 7 , 8 2 0}\end{array}$ & $\begin{array}{r}438 \\
0 \\
1,027 \\
0 \\
0 \\
-3,385 \\
-1,920 \\
44,758\end{array}$ & $\begin{array}{r}23,226 \\
0 \\
6,344 \\
0 \\
0 \\
0 \\
29,570 \\
495,615\end{array}$ & $\begin{array}{r}0 \\
0 \\
0 \\
0 \\
0 \\
0 \\
0 \\
23,000\end{array}$ & $\begin{array}{r}0 \\
0 \\
0 \\
0 \\
0 \\
0 \\
0 \\
108,807\end{array}$ \\
\hline 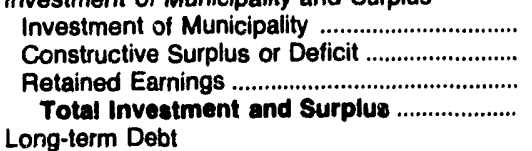 & $\begin{array}{r}0 \\
0 \\
6,278 \\
6,278\end{array}$ & $\begin{array}{r}2,654 \\
0 \\
31,260 \\
33,914\end{array}$ & $\begin{array}{r}0 \\
0 \\
33,458 \\
33,458\end{array}$ & $\begin{array}{r}14,629 \\
0 \\
111,921 \\
128,550\end{array}$ & $\begin{array}{r}0 \\
0 \\
20,922 \\
20,922\end{array}$ & $\begin{array}{r}0 \\
0 \\
68,755 \\
68,765\end{array}$ \\
\hline 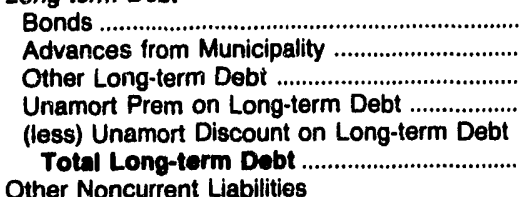 & $\begin{array}{r}451 \\
0 \\
0 \\
0 \\
0 \\
451\end{array}$ & $\begin{array}{r}22,545 \\
0 \\
0 \\
0 \\
1,221 \\
21,324\end{array}$ & $\begin{array}{r}0 \\
0 \\
8,665 \\
0 \\
195 \\
8,470\end{array}$ & $\begin{array}{r}221,079 \\
0 \\
87,051 \\
0 \\
11,108 \\
297,022\end{array}$ & $\begin{array}{r}0 \\
166 \\
109 \\
0 \\
166 \\
109\end{array}$ & $\begin{array}{r}24,075 \\
0 \\
1,546 \\
0 \\
0 \\
25,621\end{array}$ \\
\hline 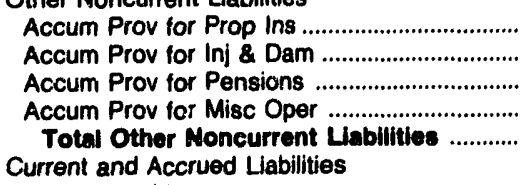 & $\begin{array}{r}39 \\
0 \\
0 \\
0 \\
39\end{array}$ & $\begin{array}{l}0 \\
0 \\
0 \\
0 \\
0\end{array}$ & $\begin{array}{l}0 \\
0 \\
0 \\
0 \\
0\end{array}$ & $\begin{array}{l}0 \\
0 \\
0 \\
0 \\
0\end{array}$ & $\begin{array}{l}0 \\
0 \\
0 \\
0 \\
0\end{array}$ & $\begin{array}{l}0 \\
0 \\
0 \\
0 \\
0\end{array}$ \\
\hline 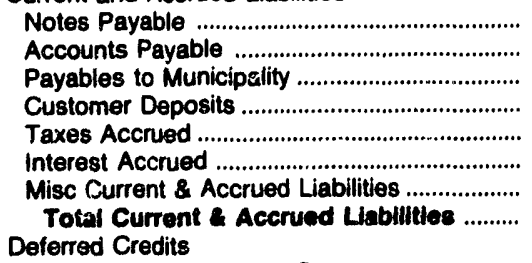 & $\begin{array}{r}0 \\
434 \\
61 \\
258 \\
27 \\
81 \\
4 \\
4 \\
865\end{array}$ & $\begin{array}{r}0 \\
769 \\
151 \\
648 \\
0 \\
350 \\
665 \\
2,582\end{array}$ & $\begin{array}{r}0 \\
1,393 \\
0 \\
150 \\
1,077 \\
0 \\
0 \\
2,620\end{array}$ & $\begin{array}{r}26,136 \\
4,033 \\
0 \\
978 \\
0 \\
3,514 \\
14,648 \\
49,300\end{array}$ & $\begin{array}{r}0 \\
1,098 \\
0 \\
844 \\
0 \\
0 \\
35 \\
1,978\end{array}$ & $\begin{array}{r}0 \\
1,715 \\
6,045 \\
1,383 \\
0 \\
131 \\
1,190 \\
10,474\end{array}$ \\
\hline 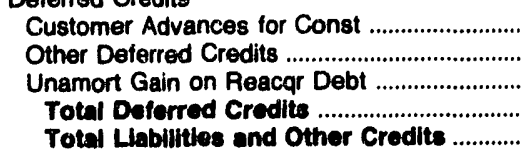 & $\begin{array}{r}0 \\
0 \\
0 \\
0 \\
7,633\end{array}$ & $\begin{array}{r}0 \\
0 \\
0 \\
0 \\
57,820\end{array}$ & $\begin{array}{r}0 \\
210 \\
0 \\
210 \\
44,758\end{array}$ & $\begin{array}{r}22,734 \\
0 \\
0 \\
22,734 \\
895,615\end{array}$ & $\begin{array}{r}0 \\
0 \\
0 \\
0 \\
23,000\end{array}$ & $\begin{array}{r}3,957 \\
0 \\
0 \\
3,957 \\
108,807\end{array}$ \\
\hline
\end{tabular}

Note: Totals may not equal sum of components because of independent rounding.

Source: Energy Information Administration, Form ElA-412, "Annual Report of Public Electric Utilities." 
Table 37. Balance Sheet by Major Publicly Owned Electric Utility Within State at End of Period, 1991 (Continued) (Thousand Dollars)

\begin{tabular}{|c|c|c|c|c|c|c|}
\hline Item & $\begin{array}{c}\text { California } \\
\text { California } \\
\text { Dept } \\
\text { Wtr } \\
\text { Resources } \\
\text { December } 31\end{array}$ & $\begin{array}{l}\text { California } \\
\text { Colton } \\
\text { City of } \\
\text { June } 30\end{array}$ & $\begin{array}{l}\text { California } \\
\text { Glendale } \\
\text { City of } \\
\text { June } 30\end{array}$ & $\begin{array}{c}\text { California } \\
\text { Imperial } \\
\text { Irrigation } \\
\text { District } \\
\text { December } 31\end{array}$ & $\begin{array}{l}\text { California } \\
\text { Lodi } \\
\text { City of } \\
\text { June } 30\end{array}$ & $\begin{array}{l}\text { California } \\
\text { Los Angeles } \\
\text { City of } \\
\text { June } 30\end{array}$ \\
\hline 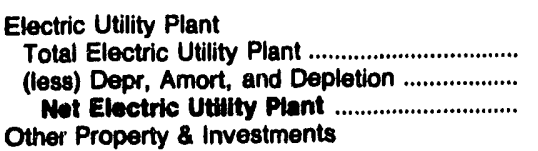 & $\begin{array}{l}999,366 \\
242,581 \\
768,785\end{array}$ & $\begin{array}{r}12,153 \\
4,240 \\
7,913\end{array}$ & $\begin{array}{l}231,334 \\
109,166 \\
122,188\end{array}$ & $\begin{array}{l}495,473 \\
149,102 \\
346,371\end{array}$ & $\begin{array}{r}26,711 \\
8,787 \\
17,924\end{array}$ & $\begin{array}{l}5,676,169 \\
1,688,977 \\
3,887,192\end{array}$ \\
\hline 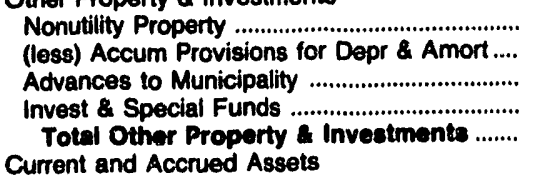 & $\begin{array}{r}0 \\
0 \\
0 \\
149,727 \\
149,727\end{array}$ & $\begin{array}{r}0 \\
0 \\
1,123 \\
1,487 \\
2,810\end{array}$ & $\begin{array}{l}0 \\
0 \\
0 \\
0 \\
0\end{array}$ & $\begin{array}{r}0 \\
0 \\
0 \\
127,593 \\
127,593\end{array}$ & $\begin{array}{l}0 \\
0 \\
0 \\
0 \\
0\end{array}$ & $\begin{array}{l}0 \\
0 \\
0 \\
0 \\
0\end{array}$ \\
\hline 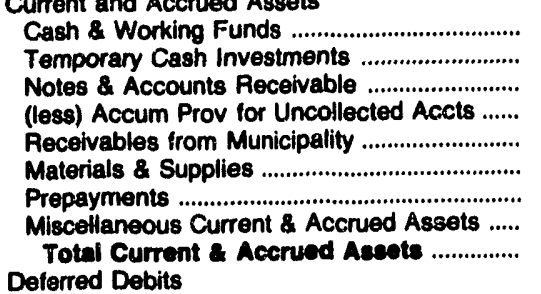 & $\begin{array}{r}828 \\
104,164 \\
25,235 \\
0 \\
0 \\
8,551 \\
360 \\
0 \\
139,136\end{array}$ & $\begin{array}{r}471 \\
0 \\
1,827 \\
0 \\
0 \\
1,609 \\
2,207 \\
0 \\
6,115\end{array}$ & $\begin{array}{r}19,087 \\
13,977 \\
7,834 \\
163 \\
0 \\
3,100 \\
1,164 \\
0 \\
44,999\end{array}$ & $\begin{array}{r}20,180 \\
0 \\
13,603 \\
959 \\
0 \\
11,638 \\
42 \\
0 \\
44,504\end{array}$ & $\begin{array}{r}3,989 \\
0 \\
1,950 \\
40 \\
1,137 \\
1,409 \\
0 \\
0 \\
8,445\end{array}$ & $\begin{array}{r}237,663 \\
0 \\
207,240 \\
3,568 \\
0 \\
115,216 \\
15,079 \\
199,208 \\
770,837\end{array}$ \\
\hline 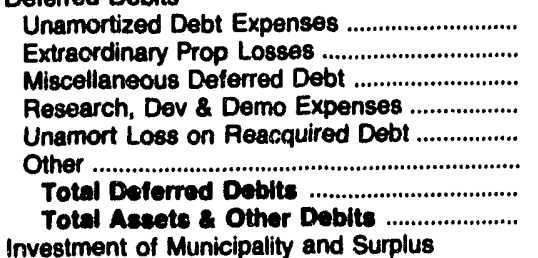 & $\begin{array}{r}0 \\
0 \\
158,937 \\
0 \\
0 \\
0 \\
168,037 \\
1,204,587\end{array}$ & $\begin{array}{r}0 \\
0 \\
0 \\
0 \\
0 \\
0 \\
0 \\
16,638\end{array}$ & $\begin{array}{r}0 \\
0 \\
0 \\
0 \\
0 \\
0 \\
0 \\
167,167\end{array}$ & $\begin{array}{r}0 \\
0 \\
0 \\
0 \\
0 \\
0 \\
0 \\
518,468\end{array}$ & $\begin{array}{r}0 \\
0 \\
0 \\
0 \\
0 \\
0 \\
0 \\
28,369\end{array}$ & $\begin{array}{r}1,815 \\
0 \\
0 \\
0 \\
0 \\
0 \\
1,815 \\
4,758,845\end{array}$ \\
\hline 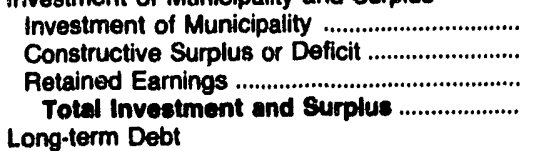 & $\begin{array}{r}34,230 \\
0 \\
-2,630 \\
31,600\end{array}$ & $\begin{array}{r}0 \\
0 \\
14,204 \\
14,204\end{array}$ & $\begin{array}{r}0 \\
19,740 \\
108,669 \\
128,409\end{array}$ & $\begin{array}{r}0 \\
0 \\
338,680 \\
338,680\end{array}$ & $\begin{array}{r}0 \\
0 \\
24,437 \\
24,437\end{array}$ & $\begin{array}{r}141,823 \\
0 \\
1,974,708 \\
2,116,530\end{array}$ \\
\hline 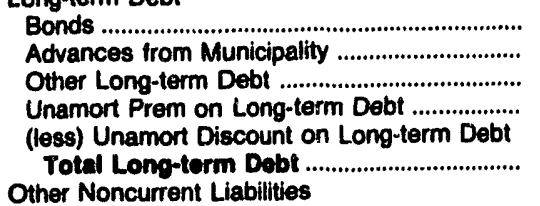 & $\begin{array}{r}950,666 \\
0 \\
0 \\
0 \\
14,768 \\
935,898\end{array}$ & $\begin{array}{r}810 \\
0 \\
178 \\
0 \\
0 \\
988\end{array}$ & $\begin{array}{r}23,090 \\
0 \\
0 \\
0 \\
0 \\
23,080\end{array}$ & $\begin{array}{r}0 \\
0 \\
131,985 \\
0 \\
2,363 \\
129,622\end{array}$ & $\begin{array}{l}0 \\
0 \\
0 \\
0 \\
0 \\
0\end{array}$ & $\begin{array}{r}2,161,357 \\
0 \\
0 \\
0 \\
70,337 \\
2,091,020\end{array}$ \\
\hline 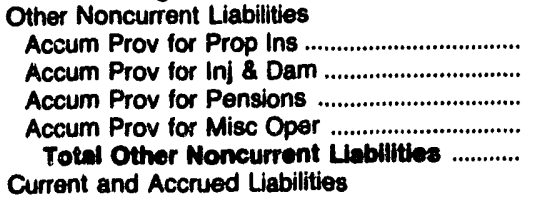 & $\begin{array}{r}0 \\
0 \\
0 \\
33,836 \\
33,836\end{array}$ & $\begin{array}{l}0 \\
0 \\
0 \\
0 \\
0\end{array}$ & $\begin{array}{l}0 \\
0 \\
0 \\
0 \\
0\end{array}$ & $\begin{array}{l}0 \\
0 \\
0 \\
0 \\
0\end{array}$ & $\begin{array}{l}0 \\
0 \\
0 \\
0 \\
0\end{array}$ & $\begin{array}{l}0 \\
0 \\
0 \\
0 \\
0\end{array}$ \\
\hline 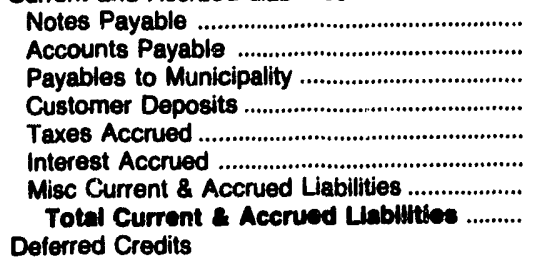 & $\begin{array}{r}0 \\
8,018 \\
17,357 \\
0 \\
0 \\
9,472 \\
18,762 \\
53,600\end{array}$ & $\begin{array}{r}0 \\
70 \\
415 \\
0 \\
0 \\
0 \\
961 \\
1,446\end{array}$ & $\begin{array}{r}5,658 \\
2,953 \\
0 \\
939 \\
535 \\
319 \\
4,644 \\
15,048\end{array}$ & $\begin{array}{r}0 \\
14,951 \\
0 \\
1,285 \\
0 \\
1,623 \\
28,333 \\
46,193\end{array}$ & $\begin{array}{r}0 \\
1,265 \\
0 \\
256 \\
7 \\
0 \\
406 \\
1,933\end{array}$ & $\begin{array}{r}55,050 \\
14,8,833 \\
90,000 \\
50,320 \\
9,808 \\
38,606 \\
54,618 \\
448,235\end{array}$ \\
\hline 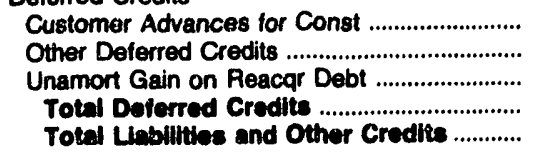 & $\begin{array}{r}0 \\
149,644 \\
0 \\
149,844 \\
1,204,587\end{array}$ & $\begin{array}{r}0 \\
0 \\
0 \\
0 \\
16,838\end{array}$ & $\begin{array}{r}620 \\
0 \\
0 \\
620 \\
167,167\end{array}$ & $\begin{array}{r}60 \\
3,914 \\
0 \\
3,974 \\
518,468\end{array}$ & $\begin{array}{r}0 \\
0 \\
0 \\
0 \\
26,380\end{array}$ & $\begin{array}{r}5,007 \\
4,248 \\
94,804 \\
104,060 \\
4,759,845\end{array}$ \\
\hline
\end{tabular}

Note: Totals may not equal sum of components because of independent rounding.

Source: Energy Information Administration, Form ElA-412, "Annual Report of Public Electric Utilities." 
Table 37. Balance Sheet by Major Publicly Owned Electric Utility Within State at End of Period, 1991 (Continued) (Thousand Dollars)

\begin{tabular}{|c|c|c|c|c|c|c|}
\hline Item & $\begin{array}{l}\text { California } \\
\text { Metropolitan } \\
\text { Water } \\
\text { District } \\
\text { June } 30\end{array}$ & $\begin{array}{c}\text { California } \\
\text { Modesto } \\
\text { Irrigation } \\
\text { District } \\
\text { December } 31\end{array}$ & $\begin{array}{c}\text { Calilornia } \\
\text { MSR } \\
\text { Public } \\
\text { Power } \\
\text { Agency } \\
\text { December } 31\end{array}$ & $\begin{array}{l}\text { California } \\
\text { Northern } \\
\text { Callfornia } \\
\text { Power Agny }\end{array}$ & $\begin{array}{c}\text { California } \\
\text { Oakdale } 8 \\
\text { South } \\
\text { San Joaquin } \\
\text { December } 31\end{array}$ & $\begin{array}{l}\text { Calitornia } \\
\text { Oroville } \\
\text { Wyandotte } \\
\text { Imig Dist } \\
\text { December } 31\end{array}$ \\
\hline 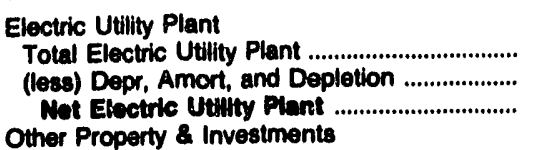 & $\begin{array}{r}103,038 \\
15,828 \\
87,110\end{array}$ & $\begin{array}{r}198,803 \\
70,165 \\
128,638\end{array}$ & $\begin{array}{r}278,031 \\
68,725 \\
207,308\end{array}$ & $\begin{array}{l}911,231 \\
140,352 \\
770,879\end{array}$ & $\begin{array}{l}60,246 \\
21,141 \\
39,105\end{array}$ & $\begin{array}{l}85,715 \\
33,959 \\
61,756\end{array}$ \\
\hline 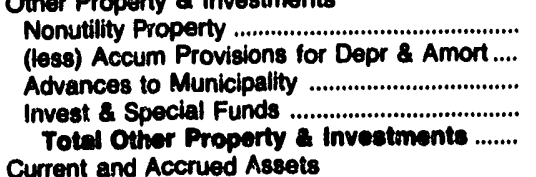 & $\begin{array}{r}4,000,826 \\
1,319,596 \\
0 \\
373,454 \\
3,054,694\end{array}$ & $\begin{array}{r}0 \\
0 \\
0 \\
15,289 \\
15,289\end{array}$ & $\begin{array}{r}15,383 \\
0 \\
0 \\
166,197 \\
181,690\end{array}$ & $\begin{array}{r}0 \\
0 \\
0 \\
353,830 \\
353,830\end{array}$ & $\begin{array}{l}\mathbf{0} \\
\mathbf{0} \\
\mathbf{0} \\
\mathbf{0} \\
\mathbf{0}\end{array}$ & $\begin{array}{l}0 \\
0 \\
0 \\
0 \\
0\end{array}$ \\
\hline 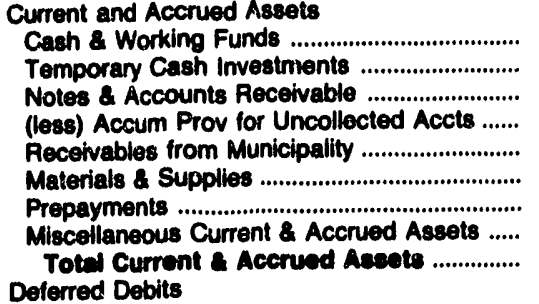 & $\begin{array}{r}-2,032 \\
417,675 \\
84,553 \\
0 \\
0 \\
19,374 \\
0 \\
0 \\
519,570\end{array}$ & $\begin{array}{r}7 \\
171,282 \\
8,391 \\
0 \\
0 \\
2,926 \\
3,598 \\
4,845 \\
191,047\end{array}$ & $\begin{array}{r}0 \\
25,013 \\
1,167 \\
0 \\
0 \\
3,206 \\
0 \\
88 \\
30,375\end{array}$ & $\begin{array}{r}3,219 \\
51,515 \\
554 \\
0 \\
2,261 \\
2,831 \\
735 \\
0 \\
01,115\end{array}$ & $\begin{array}{r}8,655 \\
6,607 \\
100 \\
0 \\
0 \\
7 \\
260 \\
0 \\
16,628\end{array}$ & $\begin{array}{r}5,768 \\
0 \\
348 \\
0 \\
0 \\
56 \\
0 \\
3 \\
6,174\end{array}$ \\
\hline 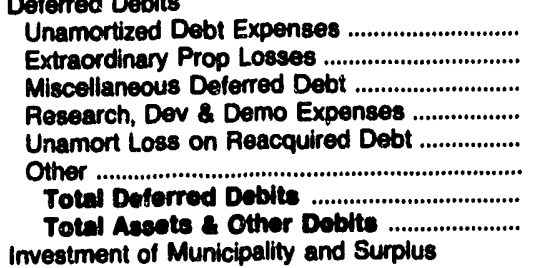 & $\begin{array}{r}1,780 \\
0 \\
199,002 \\
0 \\
0 \\
0 \\
200,702 \\
3,892,146\end{array}$ & $\begin{array}{r}3,112 \\
0 \\
0 \\
0 \\
0 \\
0 \\
3,112 \\
339,048\end{array}$ & $\begin{array}{r}11,723 \\
0 \\
0 \\
0 \\
0 \\
0 \\
11,723 \\
480,984\end{array}$ & $\begin{array}{r}28,762 \\
0 \\
142,791 \\
0 \\
201,885 \\
0 \\
373,438 \\
1,560,282\end{array}$ & $\begin{array}{r}0 \\
0 \\
0 \\
0 \\
0 \\
0 \\
0 \\
\mathbf{5 5 , 7 3 2}\end{array}$ & $\begin{array}{r}0 \\
0 \\
0 \\
0 \\
0 \\
0 \\
0 \\
57,020\end{array}$ \\
\hline 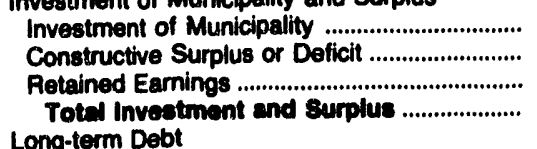 & $\begin{array}{r}0 \\
0 \\
2,295,795 \\
2,295,705\end{array}$ & $\begin{array}{r}0 \\
0 \\
105,900 \\
105,000\end{array}$ & $\begin{array}{r}0 \\
0 \\
-199,633 \\
-199,633\end{array}$ & $\begin{array}{r}0 \\
0 \\
32,622 \\
32,622\end{array}$ & $\begin{array}{r}0 \\
0 \\
54,814 \\
54,814\end{array}$ & $\begin{array}{r}0 \\
0 \\
1,131 \\
1,131\end{array}$ \\
\hline 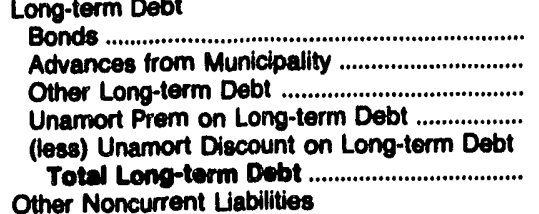 & $\begin{array}{r}1,035,193 \\
0 \\
200,527 \\
31 \\
9,700 \\
1,226,051\end{array}$ & $\begin{array}{r}220,471 \\
0 \\
1,061 \\
0 \\
10,211 \\
211,321\end{array}$ & $\begin{array}{r}648,185 \\
0 \\
0 \\
0 \\
33,652 \\
614,644\end{array}$ & $\begin{array}{r}1,516,450 \\
0 \\
0 \\
0 \\
73,400 \\
1,443,060\end{array}$ & $\begin{array}{r}0 \\
0 \\
451 \\
0 \\
0 \\
481\end{array}$ & $\begin{array}{r}52,768 \\
0 \\
1,948 \\
0 \\
978 \\
89,792\end{array}$ \\
\hline 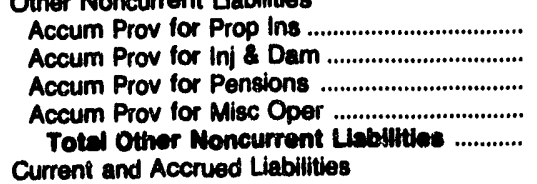 & $\begin{array}{l}0 \\
0 \\
0 \\
0 \\
0\end{array}$ & $\begin{array}{l}0 \\
0 \\
0 \\
0 \\
0\end{array}$ & $\begin{array}{l}0 \\
0 \\
0 \\
0 \\
0\end{array}$ & $\begin{array}{r}0 \\
0 \\
0 \\
3,343 \\
3,343\end{array}$ & $\begin{array}{l}0 \\
0 \\
0 \\
0 \\
0\end{array}$ & $\begin{array}{l}0 \\
0 \\
0 \\
0 \\
0\end{array}$ \\
\hline 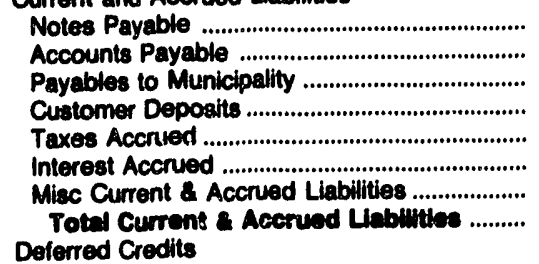 & $\begin{array}{r}0 \\
312,904 \\
0 \\
6,626 \\
0 \\
20,770 \\
0 \\
340,300\end{array}$ & $\begin{array}{r}0 \\
15,717 \\
0 \\
189 \\
377 \\
3,459 \\
800 \\
20,542\end{array}$ & $\begin{array}{r}0 \\
1,698 \\
0 \\
0 \\
0 \\
12,641 \\
1,735 \\
18,074\end{array}$ & $\begin{array}{r}0 \\
17,557 \\
0 \\
0 \\
0 \\
38,715 \\
326 \\
68,698\end{array}$ & $\begin{array}{r}0 \\
39 \\
0 \\
0 \\
0 \\
0 \\
428 \\
467\end{array}$ & $\begin{array}{r}0 \\
305 \\
28 \\
0 \\
0 \\
1,568 \\
1,178 \\
2,057\end{array}$ \\
\hline 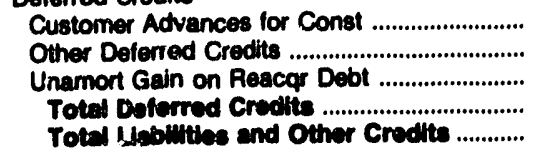 & $\begin{array}{r}0 \\
0 \\
0 \\
0 \\
0 \\
3,892,146\end{array}$ & $\begin{array}{r}323 \\
0 \\
0 \\
323 \\
339,088\end{array}$ & $\begin{array}{r}0 \\
0 \\
0 \\
0 \\
430,984\end{array}$ & $\begin{array}{r}0 \\
23,649 \\
0 \\
23,640 \\
1,650,282\end{array}$ & $\begin{array}{r}0 \\
0 \\
0 \\
0 \\
56,732\end{array}$ & $\begin{array}{r}0 \\
0 \\
0 \\
0 \\
07.920\end{array}$ \\
\hline
\end{tabular}

Note: Totals may not equal sum of components because of independent rounding.

Source: Eneroy Information Administration, Form EIA-412, "Annual Report of Public Electric Utilities." 
Table 37. Balance Sheet by Major Publicly Owned Electric Utility Within State at End of Period, 1991 (Continued) (Thousand Dollars)

\begin{tabular}{|c|c|c|c|c|c|c|}
\hline Item & $\begin{array}{l}\text { California } \\
\text { Palo Alto } \\
\text { City of } \\
\text { June } 30\end{array}$ & $\begin{array}{l}\text { California } \\
\text { Pasadena } \\
\text { City of } \\
\text { June } 30\end{array}$ & $\begin{array}{c}\text { California } \\
\text { Placer } \\
\text { County' } \\
\text { Water } \\
\text { Agency } \\
\text { December } 31\end{array}$ & $\begin{array}{l}\text { Calitornia } \\
\text { Redding } \\
\text { City of } \\
\text { June } 30\end{array}$ & $\begin{array}{c}\text { California } \\
\begin{array}{c}\text { Riverside } \\
\text { City of }\end{array} \\
\text { June } 30\end{array}$ & $\begin{array}{l}\text { California } \\
\text { Poseville } \\
\text { City of } \\
\text { June } 30\end{array}$ \\
\hline $\begin{array}{l}\text { Electric Utility Plant } \\
\text { Total Electric Utility Plant ..................................... } \\
\text { (less) Depr, Amort, and Depletion .................... } \\
\text { Not Electric Utility Plant ................................ } \\
\text { Other Property \& Investments }\end{array}$ & $\begin{array}{r}102,724 \\
35,721 \\
67,003\end{array}$ & $\begin{array}{r}209,889 \\
94,520 \\
115,370\end{array}$ & $\begin{array}{r}117,165 \\
38,121 \\
79,044\end{array}$ & $\begin{array}{r}110,031 \\
33,117 \\
76,915\end{array}$ & $\begin{array}{r}274,627 \\
78,914 \\
187,713\end{array}$ & $\begin{array}{r}59,755 \\
9,254 \\
80,502\end{array}$ \\
\hline 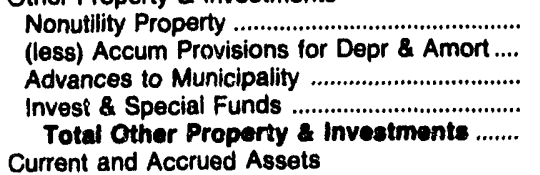 & $\begin{array}{l}0 \\
0 \\
0 \\
0 \\
0\end{array}$ & $\begin{array}{l}0 \\
0 \\
0 \\
0 \\
0\end{array}$ & $\begin{array}{r}0 \\
0 \\
0 \\
1,385 \\
1,385\end{array}$ & $\begin{array}{r}0 \\
0 \\
1,148 \\
23,417 \\
24,585\end{array}$ & $\begin{array}{r}62,737 \\
0 \\
0 \\
0 \\
62,737\end{array}$ & $\begin{array}{r}0 \\
0 \\
0 \\
1,831 \\
1,831\end{array}$ \\
\hline 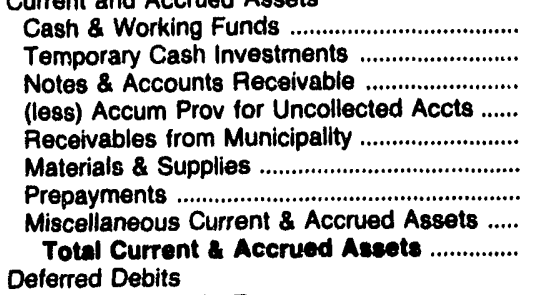 & $\begin{array}{r}53,340 \\
0 \\
8,636 \\
164 \\
0 \\
0 \\
249 \\
0 \\
62,081\end{array}$ & $\begin{array}{r}56,557 \\
0 \\
12,750 \\
365 \\
0 \\
7,754 \\
2,875 \\
0 \\
79,570\end{array}$ & $\begin{array}{r}366 \\
0 \\
68 \\
0 \\
0 \\
0 \\
315 \\
10 \\
759\end{array}$ & $\begin{array}{r}50 \\
7,803 \\
4,834 \\
158 \\
0 \\
3,567 \\
10 \\
850 \\
17,056\end{array}$ & $\begin{array}{r}19,830 \\
0 \\
24,671 \\
1,499 \\
0 \\
356 \\
4,598 \\
1,000 \\
49,055\end{array}$ & $\begin{array}{r}4,136 \\
0 \\
5,767 \\
0 \\
0 \\
2,510 \\
7,364 \\
0 \\
19,778\end{array}$ \\
\hline 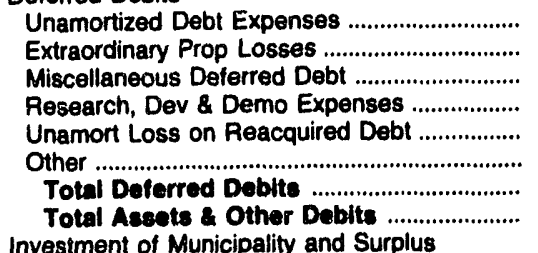 & $\begin{array}{r}0 \\
0 \\
0 \\
0 \\
0 \\
0 \\
0 \\
129,084\end{array}$ & $\begin{array}{r}0 \\
0 \\
0 \\
0 \\
0 \\
0 \\
0 \\
184,840\end{array}$ & $\begin{array}{r}0 \\
0 \\
0 \\
0 \\
0 \\
156 \\
156 \\
81,345\end{array}$ & $\begin{array}{r}1,077 \\
0 \\
0 \\
0 \\
0 \\
0 \\
1,077 \\
110,613\end{array}$ & $\begin{array}{r}1,174 \\
0 \\
0 \\
43 \\
0 \\
0 \\
1,217 \\
310,722\end{array}$ & $\begin{array}{r}301 \\
0 \\
0 \\
0 \\
0 \\
0 \\
301 \\
72,409\end{array}$ \\
\hline 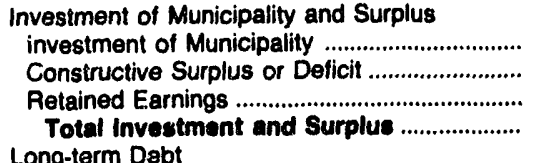 & $\begin{array}{r}c \\
14,66 \text { i } \\
109 \$ 376 \\
174,537\end{array}$ & $\begin{array}{r}0 \\
11,210 \\
104,324 \\
115,534\end{array}$ & $\begin{array}{r}0 \\
0 \\
7,061 \\
7,061\end{array}$ & $\begin{array}{r}21,050 \\
0 \\
33,368 \\
54,418\end{array}$ & $\begin{array}{r}0 \\
0 \\
63,038 \\
63,038\end{array}$ & $\begin{array}{r}0 \\
0 \\
56,749 \\
58,749\end{array}$ \\
\hline 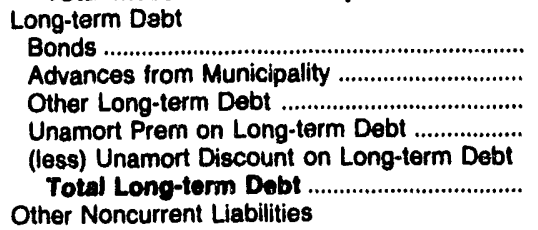 & $\begin{array}{r}341 \\
0 \\
0 \\
0 \\
6 \\
335\end{array}$ & $\begin{array}{r}55,290 \\
0 \\
0 \\
0 \\
0 \\
55,280\end{array}$ & $\begin{array}{r}71,635 \\
0 \\
509 \\
301 \\
0 \\
72,446\end{array}$ & $\begin{array}{r}58,938 \\
0 \\
12 \\
0 \\
0 \\
58,051\end{array}$ & $\begin{array}{r}192,885 \\
0 \\
370 \\
0 \\
4,584 \\
188,670\end{array}$ & $\begin{array}{r}11,655 \\
u \\
0 \\
0 \\
0 \\
11,655\end{array}$ \\
\hline 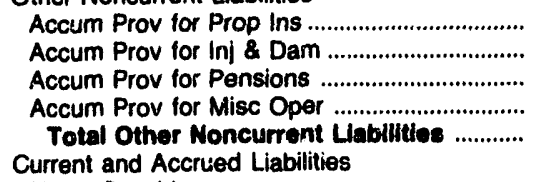 & $\begin{array}{r}309 \\
0 \\
0 \\
65 \\
374\end{array}$ & $\begin{array}{l}0 \\
0 \\
0 \\
0 \\
0\end{array}$ & $\begin{array}{r}0 \\
0 \\
0 \\
111 \\
111\end{array}$ & $\begin{array}{l}0 \\
0 \\
0 \\
0 \\
0\end{array}$ & $\begin{array}{l}0 \\
0 \\
0 \\
0 \\
0\end{array}$ & $\begin{array}{r}0 \\
475 \\
0 \\
0 \\
475\end{array}$ \\
\hline 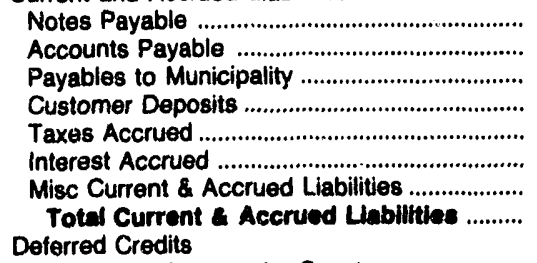 & $\begin{array}{r}0 \\
3,666 \\
0 \\
0 \\
0 \\
0 \\
152 \\
3,818\end{array}$ & $\begin{array}{r}0 \\
2,703 \\
0 \\
1,607 \\
0 \\
1,815 \\
0 \\
6,126\end{array}$ & $\begin{array}{r}0 \\
104 \\
0 \\
0 \\
0 \\
1,314 \\
308 \\
1,727\end{array}$ & $\begin{array}{r}0 \\
2,663 \\
0 \\
0 \\
0 \\
2,767 \\
689 \\
6,009\end{array}$ & $\begin{array}{r}0 \\
5,829 \\
0 \\
2,359 \\
0 \\
3,437 \\
30,431 \\
42,059\end{array}$ & $\begin{array}{r}1,214 \\
0 \\
0 \\
209 \\
0 \\
283 \\
430 \\
2,135\end{array}$ \\
\hline 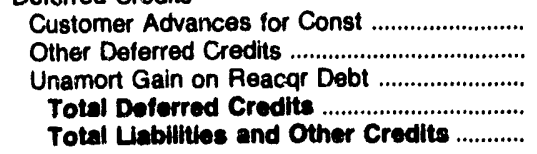 & $\begin{array}{r}0 \\
0 \\
0 \\
0 \\
129,064\end{array}$ & $\begin{array}{r}0 \\
17,890 \\
0 \\
17,900 \\
194,840\end{array}$ & $\begin{array}{r}0 \\
0 \\
0 \\
0 \\
81,345\end{array}$ & $\begin{array}{r}0 \\
155 \\
0 \\
155 \\
119,613\end{array}$ & $\begin{array}{r}0 \\
16,958 \\
0 \\
16,058 \\
310,722\end{array}$ & $\begin{array}{r}0 \\
1,395 \\
0 \\
1,305 \\
72,400\end{array}$ \\
\hline
\end{tabular}

Note: Totals may not equal sum of components because of independent rounding.

Source: Energy Information Administration, Form ElA-412, "Annual Report of Public Electric Utilities." 
Table 37. Balance Sheet by Major Publicly Owned Electric Utility Within State at End of Period, 1991 (Continued) (Thousand Dollars)

\begin{tabular}{|c|c|c|c|c|c|c|}
\hline Item & $\begin{array}{l}\text { California } \\
\text { Sacramento } \\
\text { Municipal } \\
\text { Util Dist } \\
\text { December } 31\end{array}$ & $\begin{array}{c}\text { California } \\
\text { San Francisco } \\
\text { City } \\
\& \\
\text { County of } \\
\text { June } 30\end{array}$ & $\begin{array}{l}\text { California } \\
\text { Santa } \\
\text { Clara } \\
\text { City of } \\
\text { June } 30\end{array}$ & $\begin{array}{c}\text { California } \\
\text { Southern } \\
\text { California } \\
\text { P P } \\
\text { A } \\
\text { June } 30\end{array}$ & $\begin{array}{c}\text { California } \\
\text { Turiock } \\
\text { Irrigation } \\
\text { District } \\
\text { December } 31\end{array}$ & $\begin{array}{l}\text { Vernon } \\
\text { City of } \\
\text { June } 30\end{array}$ \\
\hline 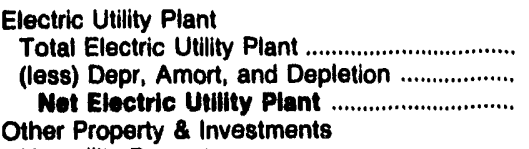 & $\begin{array}{r}1,497,699 \\
339,357 \\
1,158,343\end{array}$ & $\begin{array}{l}438,496 \\
170,012 \\
288,484\end{array}$ & $\begin{array}{r}178,537 \\
43,058 \\
135,480\end{array}$ & $\begin{array}{r}1,343,667 \\
198,118 \\
1,145,549\end{array}$ & $\begin{array}{r}211,403 \\
61,183 \\
150,220\end{array}$ & $\begin{array}{l}37,664 \\
17,438 \\
20,226\end{array}$ \\
\hline 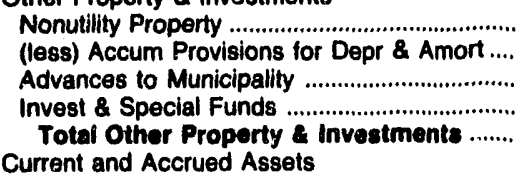 & $\begin{array}{r}0 \\
0 \\
0 \\
241,545 \\
241,545\end{array}$ & $\begin{array}{r}410 \\
0 \\
0 \\
0 \\
410\end{array}$ & $\begin{array}{r}0 \\
0 \\
0 \\
41,431 \\
41,431\end{array}$ & $\begin{array}{l}0 \\
0 \\
0 \\
0 \\
0\end{array}$ & $\begin{array}{r}32,553 \\
0 \\
0 \\
45,007 \\
77,559\end{array}$ & $\begin{array}{r}482 \\
0 \\
0 \\
47,839 \\
48,321\end{array}$ \\
\hline 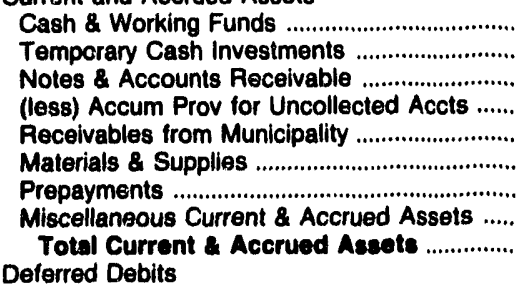 & $\begin{array}{r}223,157 \\
52,848 \\
94,791 \\
3,770 \\
0 \\
18,383 \\
4,055 \\
58,185 \\
447,649\end{array}$ & $\begin{array}{r}22,032 \\
0 \\
5,425 \\
0 \\
481 \\
2,193 \\
0 \\
0 \\
30,132\end{array}$ & $\begin{array}{r}138,170 \\
0 \\
20,053 \\
0 \\
1,089 \\
3,033 \\
0 \\
1,758 \\
185,003\end{array}$ & $\begin{array}{r}102 \\
1,033,939 \\
6,864 \\
0 \\
0 \\
11,237 \\
34,950 \\
27,587 \\
1,114,678\end{array}$ & $\begin{array}{r}6,079 \\
7,525 \\
7,890 \\
145 \\
0 \\
2,253 \\
885 \\
6,668 \\
31,155\end{array}$ & $\begin{array}{r}52,690 \\
0 \\
9,124 \\
626 \\
0 \\
0 \\
4,438 \\
2,877 \\
68,603\end{array}$ \\
\hline 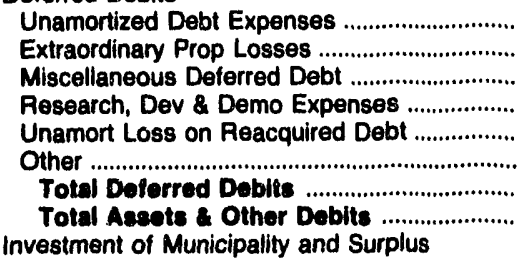 & $\begin{array}{r}29,139 \\
0 \\
217,709 \\
0 \\
58,567 \\
616,510 \\
921,926 \\
2,769,461\end{array}$ & $\begin{array}{r}0 \\
0 \\
0 \\
0 \\
0 \\
0 \\
0 \\
299,025\end{array}$ & $\begin{array}{r}0 \\
0 \\
0 \\
0 \\
0 \\
0 \\
0 \\
341,914\end{array}$ & $\begin{array}{r}29,053 \\
0 \\
0 \\
0 \\
366,824 \\
193,443 \\
589,421 \\
2,848,648\end{array}$ & $\begin{array}{r}0 \\
0 \\
2,604 \\
0 \\
0 \\
21,323 \\
23,927 \\
282,861\end{array}$ & $\begin{array}{r}0 \\
0 \\
0 \\
0 \\
0 \\
1,697 \\
1,697 \\
138,747\end{array}$ \\
\hline 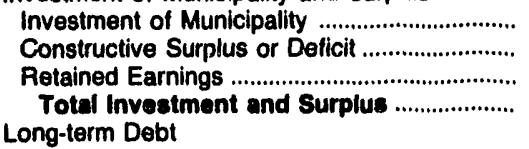 & $\begin{array}{r}0 \\
0 \\
149,886 \\
149,886\end{array}$ & $\begin{array}{r}34,087 \\
0 \\
254,789 \\
288,876\end{array}$ & $\begin{array}{r}644 \\
0 \\
167,356 \\
168,000\end{array}$ & $\begin{array}{l}0 \\
0 \\
0 \\
0\end{array}$ & $\begin{array}{r}0 \\
0 \\
115,504 \\
115,604\end{array}$ & $\begin{array}{r}0 \\
0 \\
126,251 \\
128,251\end{array}$ \\
\hline 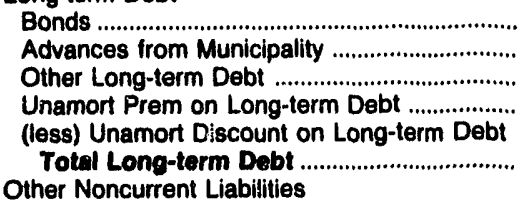 & $\begin{array}{r}1,750,860 \\
0 \\
15,205 \\
0 \\
25,420 \\
1,740,645\end{array}$ & $\begin{array}{r}22 \\
0 \\
1,579 \\
0 \\
0 \\
1,601\end{array}$ & $\begin{array}{r}157,578 \\
0 \\
0 \\
0 \\
0 \\
157,578\end{array}$ & $\begin{array}{r}3,014,800 \\
0 \\
0 \\
0 \\
307,041 \\
2,707,759\end{array}$ & $\begin{array}{r}83,438 \\
0 \\
67,800 \\
0 \\
4,576 \\
146,661\end{array}$ & $\begin{array}{r}0 \\
0 \\
3,824 \\
0 \\
0 \\
3,824\end{array}$ \\
\hline 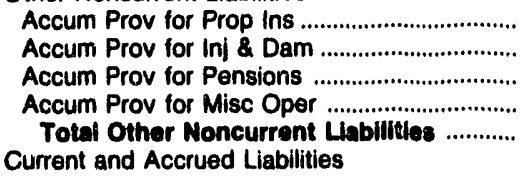 & $\begin{array}{r}997 \\
5,537 \\
0 \\
0 \\
6,534\end{array}$ & $\begin{array}{r}0 \\
687 \\
0 \\
0 \\
687\end{array}$ & $\begin{array}{l}0 \\
0 \\
0 \\
0 \\
0\end{array}$ & $\begin{array}{l}0 \\
0 \\
0 \\
0 \\
0\end{array}$ & $\begin{array}{l}0 \\
0 \\
0 \\
0 \\
0\end{array}$ & $\begin{array}{l}0 \\
0 \\
0 \\
0 \\
0\end{array}$ \\
\hline 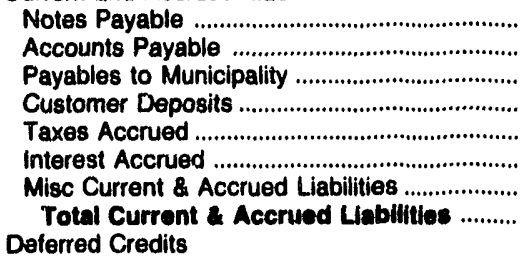 & $\begin{array}{r}195,121 \\
61,718 \\
0 \\
13,918 \\
5,795 \\
40,060 \\
67,842 \\
384,454\end{array}$ & $\begin{array}{r}18 \\
5,855 \\
1,348 \\
263 \\
55 \\
1 \\
0 \\
7,541\end{array}$ & $\begin{array}{r}2,725 \\
10,366 \\
0 \\
0 \\
0 \\
3,245 \\
0 \\
16,386\end{array}$ & $\begin{array}{r}0 \\
5,752 \\
0 \\
0 \\
5,097 \\
86,521 \\
30,471 \\
127,842\end{array}$ & $\begin{array}{r}2,538 \\
8,458 \\
0 \\
282 \\
0 \\
4,712 \\
2,968 \\
18,958\end{array}$ & $\begin{array}{r}0 \\
5,417 \\
1,258 \\
328 \\
612 \\
0 \\
1,057 \\
8,673\end{array}$ \\
\hline 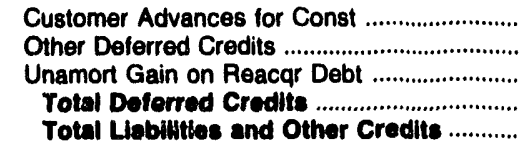 & $\begin{array}{r}2,939 \\
400,453 \\
84,550 \\
487,942 \\
2,769,461\end{array}$ & $\begin{array}{r}166 \\
154 \\
0 \\
320 \\
299,025\end{array}$ & $\begin{array}{r}0 \\
0 \\
0 \\
0 \\
341,914\end{array}$ & $\begin{array}{r}14,048 \\
0 \\
0 \\
14,048 \\
2,849,848\end{array}$ & $\begin{array}{r}1,413 \\
325 \\
0 \\
1,738 \\
282,861\end{array}$ & $\begin{array}{r}0 \\
0 \\
0 \\
0 \\
138,747\end{array}$ \\
\hline
\end{tabular}

Note: Totals may not equal sum of components because of independent rounding.

Source: Energy Iiformation Administration, Form EiA-412, "Annual Report of Public Electric Utilities." 
Table 37. Balance Sheet by Major Publicly Owned Electric Utility Within State at End of Period, 1991 (Continued) (Thousand Dollars)

\begin{tabular}{|c|c|c|c|c|c|c|}
\hline Item & $\begin{array}{c}\text { California } \\
\text { Yuba } \\
\text { County } \\
\text { Water } \\
\text { Agency } \\
\text { June } 30\end{array}$ & $\begin{array}{c}\text { Colorado } \\
\text { Arkansas } \\
\text { River } \\
\text { Power } \\
\text { Authority } \\
\text { December } 31\end{array}$ & $\begin{array}{l}\text { Colorado } \\
\text { Colorado } \\
\text { Springs } \\
\text { City of }\end{array}$ & $\begin{array}{l}\text { Colorado } \\
\text { Fort Collins } \\
\text { City of } \\
\text { December } 31\end{array}$ & $\begin{array}{l}\text { Colorado } \\
\text { Longmont } \\
\text { Clty of } \\
\text { December } 31\end{array}$ & $\begin{array}{l}\text { Colorado } \\
\text { Loveland } \\
\text { City of } \\
\text { December } 31\end{array}$ \\
\hline $\begin{array}{l}\text { Electric Utility Plant } \\
\text { Total Electric Utility Plant ..................................... } \\
\text { (less) Depr, Amort, and Depletion ..................... } \\
\text { Net Electric Utillty Plant ................................ } \\
\text { Other Property \& Investments }\end{array}$ & $\begin{array}{r}185,411 \\
47,459 \\
147,052\end{array}$ & $\begin{array}{r}2,710 \\
147 \\
2,663\end{array}$ & $\begin{array}{l}610,586 \\
163,486 \\
447,101\end{array}$ & $\begin{array}{l}75,568 \\
28,252 \\
67,315\end{array}$ & $\begin{array}{l}33,034 \\
12,657 \\
20,377\end{array}$ & $\begin{array}{r}38,384 \\
7,672 \\
30,712\end{array}$ \\
\hline 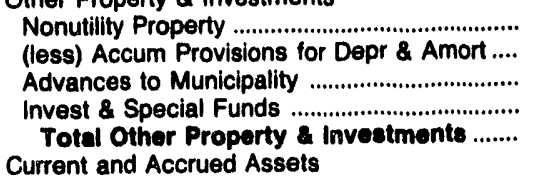 & $\begin{array}{r}527 \\
94 \\
0 \\
25,373 \\
25,805\end{array}$ & $\begin{array}{r}193 \\
51 \\
0 \\
1,336 \\
1,477\end{array}$ & $\begin{array}{r}0 \\
0 \\
0 \\
19,934 \\
19,934\end{array}$ & $\begin{array}{r}0 \\
0 \\
0 \\
12,339 \\
12,339\end{array}$ & $\begin{array}{l}0 \\
0 \\
0 \\
0 \\
0\end{array}$ & $\begin{array}{r}0 \\
0 \\
600 \\
5,898 \\
6,498\end{array}$ \\
\hline 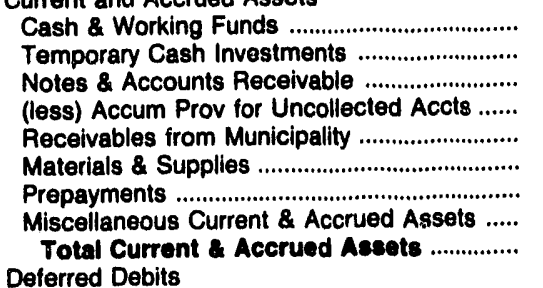 & $\begin{array}{r}183 \\
72 \\
123 \\
0 \\
0 \\
0 \\
90 \\
0 \\
487\end{array}$ & $\begin{array}{r}1,700 \\
11 \\
911 \\
0 \\
0 \\
33 \\
150 \\
0 \\
2,804\end{array}$ & $\begin{array}{r}144,187 \\
0 \\
18,049 \\
778 \\
0 \\
13,536 \\
430 \\
900 \\
176,324\end{array}$ & $\begin{array}{r}1,947 \\
0 \\
5,856 \\
150 \\
0 \\
2,527 \\
0 \\
0 \\
10,180\end{array}$ & $\begin{array}{r}8,463 \\
0 \\
3,739 \\
108 \\
1,471 \\
0 \\
1 \\
99 \\
13,685\end{array}$ & $\begin{array}{r}4,625 \\
0 \\
0 \\
1,033 \\
35 \\
0 \\
809 \\
4 \\
168 \\
6,604\end{array}$ \\
\hline 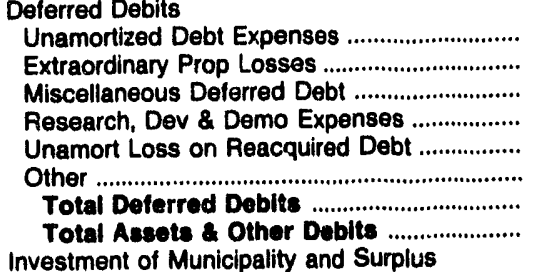 & $\begin{array}{r}1,768 \\
0 \\
0 \\
0 \\
0 \\
0 \\
1,788 \\
175,993\end{array}$ & $\begin{array}{r}106 \\
0 \\
0 \\
0 \\
0 \\
0 \\
108 \\
6,951\end{array}$ & $\begin{array}{r}6,043 \\
0 \\
1,012 \\
0 \\
0 \\
0 \\
7,054 \\
650,413\end{array}$ & $\begin{array}{r}0 \\
0 \\
0 \\
0 \\
0 \\
0 \\
0 \\
69,835\end{array}$ & $\begin{array}{r}0 \\
0 \\
0 \\
0 \\
0 \\
0 \\
0 \\
34,042\end{array}$ & $\begin{array}{r}48 \\
0 \\
0 \\
0 \\
0 \\
0 \\
48 \\
43,861\end{array}$ \\
\hline 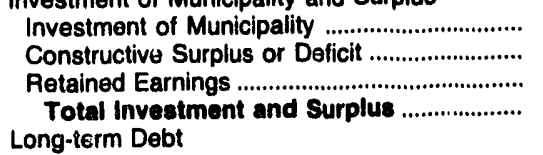 & $\begin{array}{r}0 \\
0 \\
39,555 \\
39,555\end{array}$ & $\begin{array}{r}0 \\
0 \\
2,759 \\
2,759\end{array}$ & $\begin{array}{r}430 \\
0 \\
203,809 \\
204,240\end{array}$ & $\begin{array}{r}27,324 \\
0 \\
39,153 \\
66,477\end{array}$ & $\begin{array}{r}8,359 \\
0 \\
22,180 \\
30,539\end{array}$ & $\begin{array}{r}0 \\
0 \\
33,957 \\
33,057\end{array}$ \\
\hline 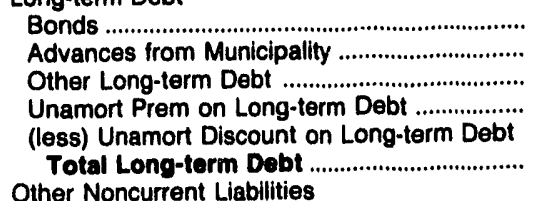 & $\begin{array}{r}113,166 \\
0 \\
2,180 \\
0 \\
0 \\
115,346\end{array}$ & $\begin{array}{r}0 \\
3,180 \\
0 \\
0 \\
74 \\
3,106\end{array}$ & $\begin{array}{r}277,853 \\
0 \\
4,958 \\
0 \\
0 \\
282,810\end{array}$ & $\begin{array}{l}0 \\
0 \\
0 \\
0 \\
0 \\
0\end{array}$ & $\begin{array}{l}0 \\
0 \\
0 \\
0 \\
0 \\
0\end{array}$ & $\begin{array}{r}5,021 \\
0 \\
0 \\
0 \\
0 \\
5,021\end{array}$ \\
\hline $\begin{array}{l}\text { Other Noncurrent Liabilities } \\
\text { Accum Prov for Prop Ins ..................................... } \\
\text { Accum Prov for Inj \& Dam ............................... } \\
\text { Accum Prov for Pensions ................................ } \\
\text { Accum Prov for Misc Oper ............................. } \\
\text { Total Other Noncurrent Liabillties ............ } \\
\text { Current and Accrued Liabilities }\end{array}$ & $\begin{array}{l}0 \\
0 \\
0 \\
0 \\
0\end{array}$ & $\begin{array}{l}0 \\
0 \\
0 \\
0 \\
0\end{array}$ & $\begin{array}{r}519 \\
1,773 \\
0 \\
977 \\
3,269\end{array}$ & $\begin{array}{l}0 \\
0 \\
u \\
0 \\
0\end{array}$ & $\begin{array}{l}0 \\
0 \\
0 \\
0 \\
0\end{array}$ & $\begin{array}{l}0 \\
0 \\
0 \\
0 \\
0\end{array}$ \\
\hline 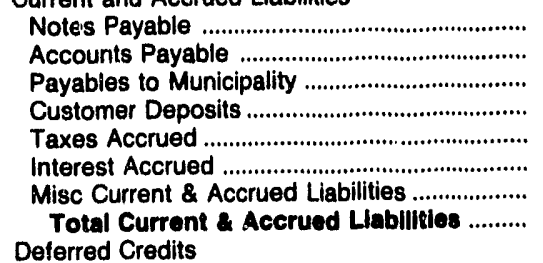 & $\begin{array}{r}0 \\
634 \\
0 \\
0 \\
0 \\
2,798 \\
0 \\
3,432\end{array}$ & $\begin{array}{r}0 \\
1,045 \\
0 \\
0 \\
0 \\
21 \\
21 \\
1,087\end{array}$ & $\begin{array}{r}0 \\
12,135 \\
0 \\
361 \\
0 \\
1,906 \\
4,414 \\
18,816\end{array}$ & $\begin{array}{r}0 \\
2,886 \\
0 \\
0 \\
0 \\
0 \\
473 \\
3,369\end{array}$ & $\begin{array}{r}0 \\
1,280 \\
1,407 \\
435 \\
57 \\
0 \\
325 \\
3,503\end{array}$ & $\begin{array}{r}215 \\
1,264 \\
0 \\
0 \\
0 \\
215 \\
115 \\
1,810\end{array}$ \\
\hline 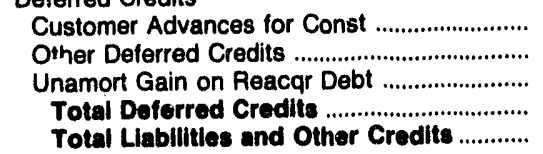 & $\begin{array}{r}0 \\
17,660 \\
0 \\
17,680 \\
175,993\end{array}$ & $\begin{array}{r}0 \\
0 \\
0 \\
0 \\
\mathbf{6 , 9 5 1}\end{array}$ & $\begin{array}{r}2,025 \\
-51 \\
139,304 \\
141,278 \\
650,413\end{array}$ & $\begin{array}{r}0 \\
0 \\
0 \\
0 \\
68,835\end{array}$ & $\begin{array}{r}0 \\
0 \\
0 \\
0 \\
34,042\end{array}$ & $\begin{array}{r}2 \\
3,071 \\
0 \\
3,073 \\
43,861\end{array}$ \\
\hline
\end{tabular}

Note: Totals may not equal sum of components because of independent rounding.

Source: Energy Information Administration, Form EIA-412, "Annual Report of Public Electric Utilities." 
Table 37. Balance Sheet by Major Publicly Owned Electric Utility Within State at End of Period, 1991 (Continued) (Thousand Dollars)

\begin{tabular}{|c|c|c|c|c|c|c|}
\hline Item & $\begin{array}{l}\text { Colorado } \\
\text { Platte River } \\
\text { Power } \\
\text { Authority } \\
\text { December } 31\end{array}$ & $\begin{array}{c}\text { Connecticut } \\
\text { Connecticut } \\
\text { Mun } \\
\text { Elec } \\
\text { Engy Coop } \\
\text { December } 31\end{array}$ & $\begin{array}{l}\text { Connecticut } \\
\text { Groton } \\
\text { City of } \\
\text { June } 30\end{array}$ & $\begin{array}{l}\text { Connecticut } \\
\text { Norwich } \\
\text { City of } \\
\text { June } 30\end{array}$ & $\begin{array}{l}\text { Connecticut } \\
\begin{array}{c}\text { Wallingford } \\
\text { Town of }\end{array} \\
\text { June } 30\end{array}$ & $\begin{array}{l}\text { Delaware } \\
\text { Dover } \\
\text { City of } \\
\text { June } 30\end{array}$ \\
\hline 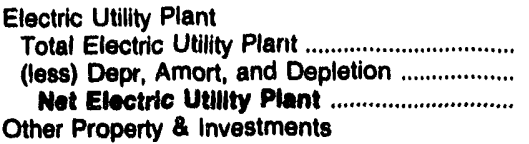 & $\begin{array}{l}758,404 \\
184,110 \\
574,294\end{array}$ & $\begin{array}{l}57,301 \\
11,277 \\
46,024\end{array}$ & $\begin{array}{l}22,542 \\
12,072 \\
10,470\end{array}$ & $\begin{array}{r}22,895 \\
15,218 \\
7,677\end{array}$ & $\begin{array}{l}38,915 \\
22,226 \\
16,689\end{array}$ & $\begin{array}{l}84,166 \\
25,422 \\
58,744\end{array}$ \\
\hline 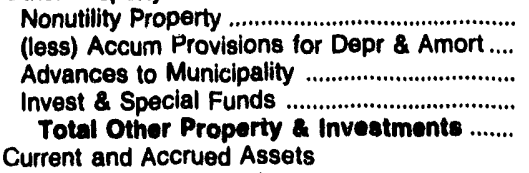 & $\begin{array}{r}0 \\
0 \\
0 \\
414,247 \\
414,247\end{array}$ & $\begin{array}{r}0 \\
0 \\
0 \\
18,153 \\
18,153\end{array}$ & $\begin{array}{l}0 \\
0 \\
0 \\
0 \\
0\end{array}$ & $\begin{array}{r}0 \\
0 \\
0 \\
545 \\
545\end{array}$ & $\begin{array}{l}0 \\
0 \\
0 \\
3 \\
3\end{array}$ & $\begin{array}{r}0 \\
0 \\
750 \\
19,894 \\
20,644\end{array}$ \\
\hline 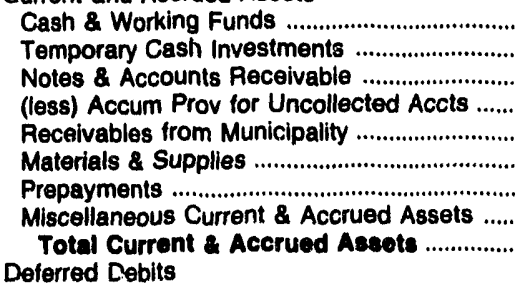 & $\begin{array}{r}1,859 \\
17,476 \\
9,977 \\
5 \\
5,936 \\
4,937 \\
12,437 \\
224 \\
2,496 \\
49,399\end{array}$ & $\begin{array}{r}470 \\
16,872 \\
9,366 \\
0 \\
0 \\
79 \\
79 \\
257 \\
66 \\
27,110\end{array}$ & $\begin{array}{r}18 \\
5,640 \\
5,048 \\
0 \\
0 \\
543 \\
0 \\
0 \\
2,204 \\
13,462\end{array}$ & $\begin{array}{r}703 \\
1,923 \\
3,585 \\
767 \\
3,982 \\
308 \\
86 \\
-240 \\
9,580\end{array}$ & $\begin{array}{r}565 \\
17.118 \\
5,856 \\
50 \\
0 \\
002 \\
2 \\
117 \\
24,410\end{array}$ & $\begin{array}{r}111 \\
0 \\
3,645 \\
0 \\
10 \\
2,762 \\
0 \\
0 \\
6,527\end{array}$ \\
\hline 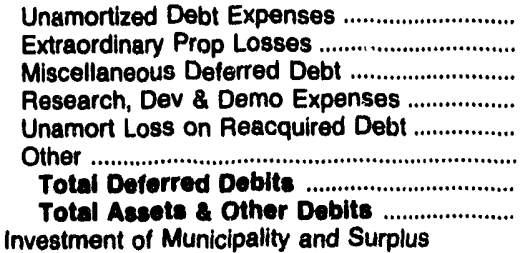 & $\begin{array}{r}12,432 \\
0 \\
25,196 \\
75 \\
52,860 \\
0 \\
90,563 \\
1,128,503\end{array}$ & $\begin{array}{r}2,448 \\
0 \\
23,942 \\
0 \\
15,690 \\
0 \\
0 \\
42,081 \\
133,368\end{array}$ & $\begin{array}{r}0 \\
0 \\
0 \\
0 \\
0 \\
0 \\
0 \\
23,923\end{array}$ & $\begin{array}{r}0 \\
0 \\
161 \\
0 \\
0 \\
0 \\
161 \\
17,964\end{array}$ & $\begin{array}{r}0 \\
0 \\
0 \\
0 \\
0 \\
0 \\
0 \\
41,103\end{array}$ & $\begin{array}{r}0 \\
0 \\
0 \\
0 \\
0 \\
0 \\
0 \\
85,816\end{array}$ \\
\hline 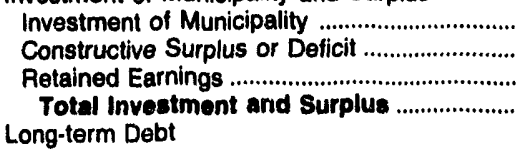 & $\begin{array}{r}356 \\
0 \\
188,418 \\
188,774\end{array}$ & $\begin{array}{r}806 \\
0 \\
3,106 \\
3,912\end{array}$ & $\begin{array}{r}0 \\
0 \\
9,744 \\
9,744\end{array}$ & $\begin{array}{r}0 \\
0 \\
12,603 \\
12,803\end{array}$ & $\begin{array}{r}0 \\
0 \\
30,608 \\
30,608\end{array}$ & $\begin{array}{r}0 \\
0 \\
37,400 \\
37,400\end{array}$ \\
\hline 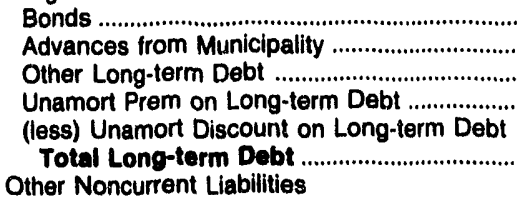 & $\begin{array}{r}896,345 \\
0 \\
41,955 \\
0 \\
11,400 \\
926,900\end{array}$ & $\begin{array}{r}105,450 \\
0 \\
0 \\
0 \\
5,411 \\
100,039\end{array}$ & $\begin{array}{r}5,973 \\
0 \\
0 \\
0 \\
0 \\
5,973\end{array}$ & $\begin{array}{r}546 \\
0 \\
118 \\
0 \\
0 \\
664\end{array}$ & $\begin{array}{r}1,020 \\
0 \\
0 \\
1 \\
0 \\
1,021\end{array}$ & $\begin{array}{r}30,886 \\
0 \\
0 \\
0 \\
0 \\
30,896\end{array}$ \\
\hline 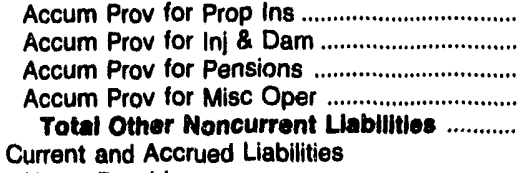 & $\begin{array}{r}0 \\
0 \\
1,836 \\
0 \\
1,836\end{array}$ & $\begin{array}{l}0 \\
0 \\
0 \\
0 \\
0\end{array}$ & $\begin{array}{l}0 \\
0 \\
0 \\
0 \\
0\end{array}$ & $\begin{array}{r}0 \\
246 \\
0 \\
0 \\
246\end{array}$ & $\begin{array}{r}0 \\
65 \\
313 \\
0 \\
379\end{array}$ & $\begin{array}{r}437 \\
0 \\
0 \\
13,260 \\
13,697\end{array}$ \\
\hline 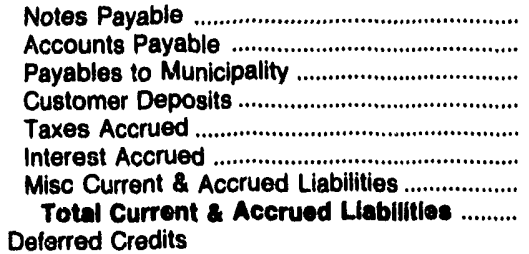 & $\begin{array}{r}0 \\
4,158 \\
0 \\
0 \\
0 \\
5,352 \\
1,483 \\
10,994\end{array}$ & $\begin{array}{r}1,249 \\
9,010 \\
0 \\
0 \\
347 \\
3,626 \\
33 \\
14,264\end{array}$ & $\begin{array}{r}0 \\
6,003 \\
0 \\
701 \\
564 \\
35 \\
902 \\
8,206\end{array}$ & $\begin{array}{r}0 \\
3,092 \\
0 \\
161 \\
269 \\
0 \\
807 \\
4,330\end{array}$ & $\begin{array}{r}0 \\
6,436 \\
860 \\
916 \\
608 \\
131 \\
60 \\
9,011\end{array}$ & $\begin{array}{r}0 \\
1,990 \\
0 \\
535 \\
0 \\
1,110 \\
287 \\
3,923\end{array}$ \\
\hline 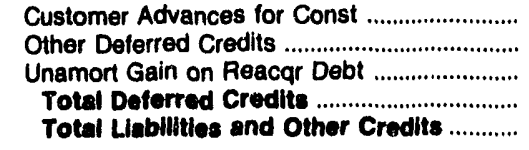 & $\begin{array}{r}0 \\
0 \\
0 \\
0 \\
1,128,503\end{array}$ & $\begin{array}{r}0 \\
15,153 \\
0 \\
15,153 \\
133,368\end{array}$ & $\begin{array}{r}0 \\
0 \\
0 \\
0 \\
23,923\end{array}$ & $\begin{array}{r}81 \\
41 \\
0 \\
122 \\
17,964\end{array}$ & $\begin{array}{r}84 \\
0 \\
0 \\
84 \\
41,103\end{array}$ & $\begin{array}{r}0 \\
0 \\
0 \\
0 \\
85,916\end{array}$ \\
\hline
\end{tabular}

Note: Totals may not equal sum of components because of independent rounding

Source: Energy Information Administration, Form ElA-412, "Annual Report of Public Electric Utilities." 
Table 37. Balance Sheet by Major Publicly Owned Electric Utility
Within State at End of Period, 1991 (Continued) (Thousand Dollars)

\begin{tabular}{|c|c|c|c|c|c|c|}
\hline Item & $\begin{array}{c}\text { Delaware } \\
\text { Newark } \\
\text { Clty of } \\
\text { December } 31\end{array}$ & $\begin{array}{l}\text { Bartow } \\
\text { City of }\end{array}$ & $\begin{array}{c}\text { Florida } \\
\text { Florida } \\
\text { Municipal } \\
\text { Power Agency } \\
\text { September } 30\end{array}$ & $\begin{array}{c}\text { Florida } \\
\text { Fort Pierce } \\
\text { Utilities } \\
\text { Auth } \\
\text { September } 30\end{array}$ & $\begin{array}{c}\text { Florida } \\
\text { Gainesville } \\
\text { Regional } \\
\text { Utilities } \\
\text { September } 30\end{array}$ & $\begin{array}{c}\text { Florida } \\
\text { Homestead } \\
\text { Clty of }\end{array}$ \\
\hline 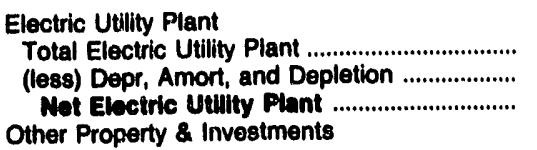 & $\begin{array}{l}0 \\
0 \\
0\end{array}$ & $\begin{array}{l}9,115 \\
4,244 \\
4,871\end{array}$ & $\begin{array}{r}252,503 \\
48,877 \\
203,627\end{array}$ & $\begin{array}{l}89,575 \\
35,709 \\
63,868\end{array}$ & $\begin{array}{l}394,204 \\
119,199 \\
275,004\end{array}$ & $\begin{array}{l}39,907 \\
17,319 \\
22,588\end{array}$ \\
\hline 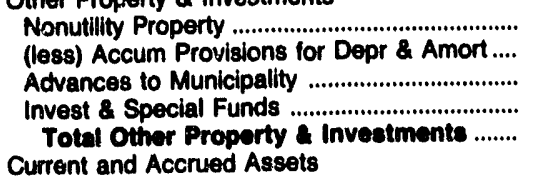 & $\begin{array}{l}0 \\
0 \\
0 \\
0 \\
0\end{array}$ & $\begin{array}{r}0 \\
0 \\
0 \\
\mathbf{5 , 4 5 9} \\
\mathbf{5 , 4 5 9}\end{array}$ & $\begin{array}{r}0 \\
0 \\
0 \\
88,021 \\
88,021\end{array}$ & $\begin{array}{r}0 \\
0 \\
0 \\
16,337 \\
18,337\end{array}$ & $\begin{array}{r}0 \\
0 \\
0 \\
128,358 \\
128,358\end{array}$ & $\begin{array}{l}0 \\
0 \\
0 \\
0 \\
0\end{array}$ \\
\hline 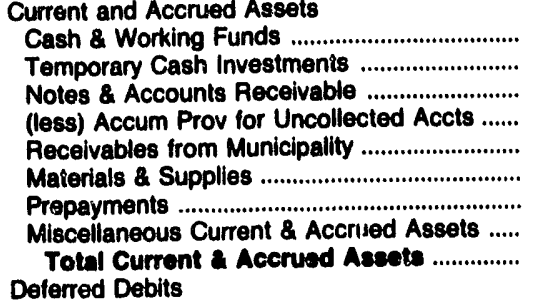 & $\begin{array}{l}0 \\
0 \\
0 \\
0 \\
0 \\
0 \\
0 \\
0 \\
0\end{array}$ & $\begin{array}{r}608 \\
545 \\
2,119 \\
100 \\
0 \\
711 \\
0 \\
0 \\
3,883\end{array}$ & $\begin{array}{r}0 \\
49,280 \\
14,226 \\
0 \\
0 \\
368 \\
2,021 \\
0 \\
65,895\end{array}$ & $\begin{array}{r}2,380 \\
0 \\
7,808 \\
31 \\
0 \\
3,823 \\
326 \\
397 \\
14,704\end{array}$ & $\begin{array}{r}18,211 \\
0 \\
18,855 \\
395 \\
0 \\
14,379 \\
27 \\
0 \\
51,078\end{array}$ & $\begin{array}{r}546 \\
5,038 \\
4,274 \\
1,066 \\
1,784 \\
1,925 \\
1 \\
21 \\
12,523\end{array}$ \\
\hline 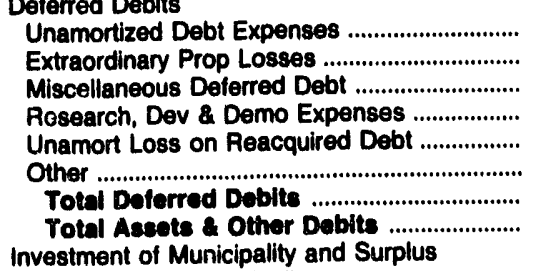 & $\begin{array}{l}0 \\
0 \\
0 \\
0 \\
0 \\
0 \\
0 \\
0\end{array}$ & $\begin{array}{r}0 \\
0 \\
0 \\
0 \\
0 \\
0 \\
0 \\
14,213\end{array}$ & $\begin{array}{r}7,396 \\
0 \\
82,925 \\
0 \\
0 \\
43,155 \\
133,475 \\
491,018\end{array}$ & $\begin{array}{r}465 \\
0 \\
372 \\
0 \\
0 \\
0 \\
837 \\
85,743\end{array}$ & $\begin{array}{r}5,898 \\
0 \\
26,076 \\
0 \\
0 \\
5 \\
31,880 \\
486,420\end{array}$ & $\begin{array}{r}0 \\
0 \\
28 \\
0 \\
0 \\
0 \\
28 \\
35,139\end{array}$ \\
\hline 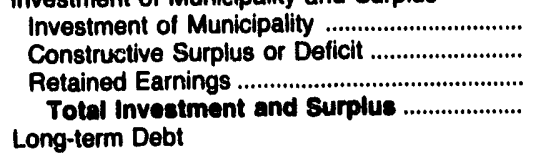 & $\begin{array}{l}0 \\
0 \\
0 \\
0\end{array}$ & $\begin{array}{r}27 \\
0 \\
5,599 \\
5,628\end{array}$ & $\begin{array}{l}0 \\
0 \\
0 \\
0\end{array}$ & $\begin{array}{r}0 \\
0 \\
37,117 \\
37,117\end{array}$ & $\begin{array}{r}0 \\
0 \\
153,620 \\
153,620\end{array}$ & $\begin{array}{r}4,685 \\
0 \\
26,149 \\
30,834\end{array}$ \\
\hline 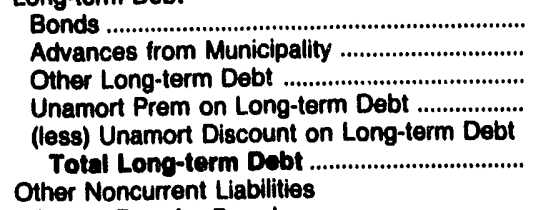 & $\begin{array}{l}0 \\
0 \\
0 \\
0 \\
0 \\
0\end{array}$ & $\begin{array}{r}0 \\
0 \\
42 \\
0 \\
0 \\
42\end{array}$ & $\begin{array}{r}450,620 \\
0 \\
6,639 \\
0 \\
11,514 \\
445,746\end{array}$ & $\begin{array}{r}37,707 \\
0 \\
0 \\
0 \\
0 \\
37,707\end{array}$ & $\begin{array}{r}255,397 \\
0 \\
55,113 \\
0 \\
5,851 \\
304,659\end{array}$ & $\begin{array}{r}0 \\
0 \\
238 \\
0 \\
0 \\
238\end{array}$ \\
\hline 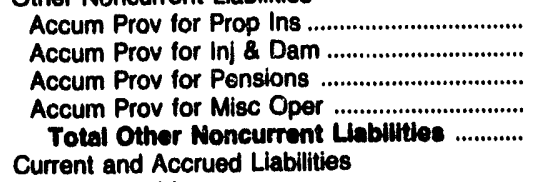 & $\begin{array}{l}0 \\
0 \\
0 \\
0 \\
0\end{array}$ & $\begin{array}{l}0 \\
0 \\
0 \\
0 \\
0\end{array}$ & $\begin{array}{l}0 \\
0 \\
0 \\
0 \\
0\end{array}$ & $\begin{array}{r}0 \\
0 \\
0 \\
1,159 \\
1,159\end{array}$ & $\begin{array}{l}0 \\
0 \\
0 \\
0 \\
0\end{array}$ & $\begin{array}{l}0 \\
0 \\
0 \\
0 \\
0\end{array}$ \\
\hline 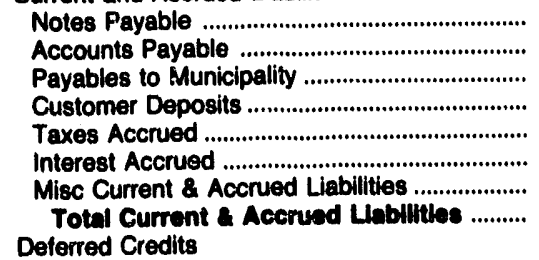 & $\begin{array}{l}0 \\
0 \\
0 \\
0 \\
0 \\
0 \\
0 \\
0\end{array}$ & $\begin{array}{r}0 \\
2,370 \\
0 \\
545 \\
149 \\
0 \\
22 \\
3,086\end{array}$ & $\begin{array}{r}6,005 \\
24,413 \\
0 \\
0 \\
0 \\
14,854 \\
0 \\
45,272\end{array}$ & $\begin{array}{r}1,287 \\
3,900 \\
347 \\
2,526 \\
471 \\
1,228 \\
0 \\
9,760\end{array}$ & $\begin{array}{r}0 \\
6,950 \\
1,656 \\
2,921 \\
0 \\
11,465 \\
2,264 \\
25,256\end{array}$ & $\begin{array}{r}132 \\
1,939 \\
614 \\
1,382 \\
0 \\
0 \\
0 \\
4,067\end{array}$ \\
\hline 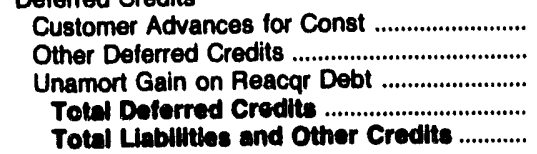 & $\begin{array}{l}0 \\
0 \\
0 \\
0 \\
\mathbf{0}\end{array}$ & $\begin{array}{r}0 \\
5,459 \\
0 \\
5,459 \\
14,213\end{array}$ & $\begin{array}{r}0 \\
0 \\
0 \\
0 \\
491,018\end{array}$ & $\begin{array}{r}0 \\
0 \\
0 \\
0 \\
85,743\end{array}$ & $\begin{array}{r}0 \\
2,884 \\
0 \\
2,884 \\
486,420\end{array}$ & $\begin{array}{r}0 \\
0 \\
0 \\
0 \\
35,130\end{array}$ \\
\hline
\end{tabular}

Note: Totals may not equal sum of components because of independent rounding.

Source: Energy Information Administration, Form EIA-412, "Annual Report of Public Electric Utilities." 
Table 37. Balance Sheet by Major Publicly Owned Electric Utility Within State at End of Period, 1991 (Continued) (Thousand Dollars)

\begin{tabular}{|c|c|c|c|c|c|c|}
\hline Item & $\begin{array}{l}\text { Florida } \\
\text { Jacksonville } \\
\text { Beach } \\
\text { City of } \\
\text { Soptember } 30\end{array}$ & $\begin{array}{c}\text { Florida } \\
\text { Jacksonville } \\
\text { Electric } \\
\text { Auth }\end{array}$ & $\begin{array}{l}\text { Florida } \\
\text { Key West } \\
\text { City of } \\
\text { September } 30\end{array}$ & $\begin{array}{c}\text { Florida } \\
\text { Kissimmee } \\
\text { Utility } \\
\text { Authority } \\
\text { September } 30\end{array}$ & $\begin{array}{l}\text { Florida } \\
\text { Lake Worth } \\
\text { City of } \\
\text { September } 30\end{array}$ & $\begin{array}{l}\text { Florida } \\
\text { Lakeland } \\
\text { City of } \\
\text { September } 30\end{array}$ \\
\hline 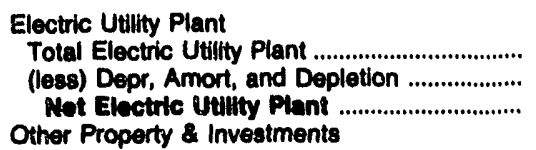 & $\begin{array}{l}52,507 \\
14,634 \\
37,874\end{array}$ & $\begin{array}{r}2,716,243 \\
460,191 \\
2,256,052\end{array}$ & $\begin{array}{r}138,561 \\
48,721 \\
68,840\end{array}$ & $\begin{array}{r}136,018 \\
38,244 \\
97,774\end{array}$ & $\begin{array}{l}64,913 \\
36,725 \\
28,188\end{array}$ & $\begin{array}{l}466,962 \\
133,791 \\
333,171\end{array}$ \\
\hline 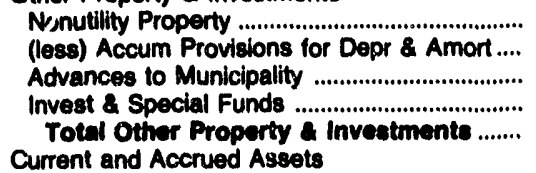 & $\begin{array}{r}0 \\
0 \\
91 \\
0 \\
91\end{array}$ & $\begin{array}{r}0 \\
0 \\
0 \\
648,707 \\
648,707\end{array}$ & $\begin{array}{r}0 \\
0 \\
0 \\
30,181 \\
30,181\end{array}$ & $\begin{array}{r}0 \\
0 \\
0 \\
50,685 \\
50,685\end{array}$ & $\begin{array}{r}0 \\
0 \\
0 \\
13,628 \\
13,628\end{array}$ & $\begin{array}{r}57,717 \\
12,484 \\
0 \\
174,556 \\
219,789\end{array}$ \\
\hline 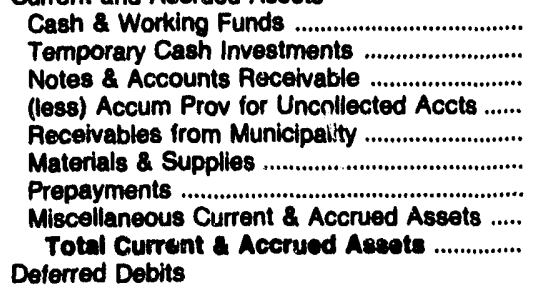 & $\begin{array}{r}5,089 \\
0 \\
5,723 \\
509 \\
0 \\
1,338 \\
0 \\
44 \\
11,685\end{array}$ & $\begin{array}{r}53,251 \\
69,905 \\
78,441 \\
520 \\
4,500 \\
73,229 \\
58 \\
10,641 \\
289,506\end{array}$ & $\begin{array}{r}1,779 \\
2,350 \\
4,525 \\
473 \\
0 \\
0 \\
3,426 \\
246 \\
0 \\
11,853\end{array}$ & $\begin{array}{r}11,214 \\
0 \\
8,005 \\
156 \\
102 \\
5,056 \\
46 \\
0 \\
0 \\
24,267\end{array}$ & $\begin{array}{r}0 \\
349 \\
1,739 \\
0 \\
84 \\
2,132 \\
33 \\
0 \\
4,336\end{array}$ & $\begin{array}{r}2,763 \\
14,537 \\
18,644 \\
547 \\
23 \\
23,182 \\
0 \\
7,732 \\
66,344\end{array}$ \\
\hline 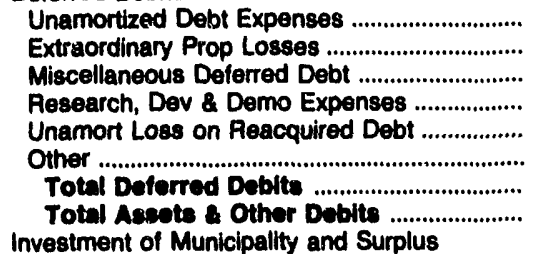 & $\begin{array}{r}0 \\
0 \\
0 \\
0 \\
0 \\
0 \\
0 \\
48,649\end{array}$ & $\begin{array}{r}41,254 \\
0 \\
0 \\
0 \\
200,220 \\
0 \\
241,474 \\
3,435,738\end{array}$ & $\begin{array}{r}4,567 \\
0 \\
0 \\
0 \\
0 \\
0 \\
4,567 \\
135,441\end{array}$ & $\begin{array}{r}1,067 \\
0 \\
0 \\
0 \\
0 \\
0 \\
1,067 \\
173,793\end{array}$ & $\begin{array}{r}1,040 \\
0 \\
148 \\
0 \\
0 \\
5,292 \\
6,480 \\
52,631\end{array}$ & $\begin{array}{r}1,708 \\
0 \\
6 \\
0 \\
0 \\
0 \\
1,714 \\
621,018\end{array}$ \\
\hline 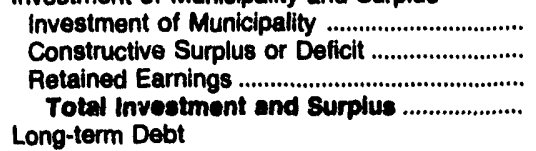 & $\begin{array}{r}0 \\
4,841 \\
39,447 \\
44,288\end{array}$ & $\begin{array}{r}0 \\
0 \\
487,109 \\
487,109\end{array}$ & $\begin{array}{r}0 \\
0 \\
13,105 \\
13,105\end{array}$ & $\begin{array}{r}0 \\
52,580 \\
10,503 \\
63,083\end{array}$ & $\begin{array}{r}0 \\
0 \\
16,024 \\
16,024\end{array}$ & $\begin{array}{r}0 \\
0 \\
172,181 \\
172,181\end{array}$ \\
\hline 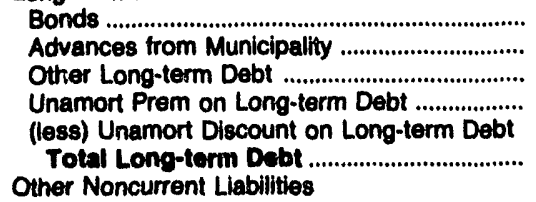 & $\begin{array}{l}0 \\
0 \\
0 \\
0 \\
0 \\
0\end{array}$ & $\begin{array}{r}2,815,504 \\
0 \\
14,321 \\
0 \\
134,274 \\
2,685,551\end{array}$ & $\begin{array}{r}114,052 \\
0 \\
0 \\
0 \\
0 \\
114,052\end{array}$ & $\begin{array}{r}100,625 \\
0 \\
0 \\
0 \\
4,926 \\
95,699\end{array}$ & $\begin{array}{r}31,599 \\
0 \\
0 \\
0 \\
0 \\
31,599\end{array}$ & $\begin{array}{r}410,011 \\
1,500 \\
22,606 \\
0 \\
27,943 \\
406,174\end{array}$ \\
\hline 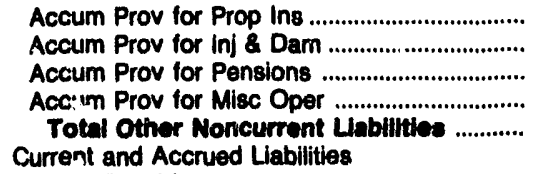 & $\begin{array}{l}0 \\
0 \\
0 \\
0 \\
0\end{array}$ & $\begin{array}{r}0 \\
0 \\
0 \\
110,273 \\
110,273\end{array}$ & $\begin{array}{l}0 \\
0 \\
0 \\
0 \\
0\end{array}$ & $\begin{array}{l}0 \\
0 \\
0 \\
0 \\
0\end{array}$ & $\begin{array}{l}0 \\
0 \\
0 \\
0 \\
0\end{array}$ & $\begin{array}{l}0 \\
0 \\
0 \\
0 \\
0\end{array}$ \\
\hline 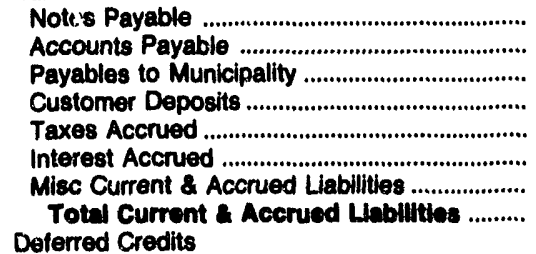 & $\begin{array}{r}0 \\
2,575 \\
0 \\
1,784 \\
122 \\
33 \\
847 \\
5,382\end{array}$ & $\begin{array}{r}0 \\
34,724 \\
3,339 \\
18,351 \\
1,128 \\
77,696 \\
3,070 \\
138,306\end{array}$ & $\begin{array}{r}43 \\
4,139 \\
0 \\
2,497 \\
274 \\
283 \\
890 \\
8,135\end{array}$ & $\begin{array}{r}0 \\
3,666 \\
1,917 \\
1,648 \\
544 \\
3,460 \\
3,576 \\
15,011\end{array}$ & $\begin{array}{r}1,398 \\
0 \\
2,830 \\
365 \\
0 \\
0 \\
415 \\
5,008\end{array}$ & $\begin{array}{r}0 \\
14,329 \\
0 \\
8,207 \\
1,332 \\
17,778 \\
1,003 \\
42,650\end{array}$ \\
\hline 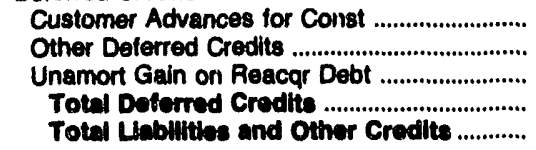 & $\begin{array}{r}n \\
0 \\
0 \\
0 \\
49,649\end{array}$ & $\begin{array}{r}0 \\
4,500 \\
0 \\
4,500 \\
3,435,739\end{array}$ & $\begin{array}{r}0 \\
149 \\
0 \\
149 \\
135,441\end{array}$ & $\begin{array}{r}0 \\
0 \\
0 \\
0 \\
173,793\end{array}$ & $\begin{array}{r}0 \\
0 \\
0 \\
0 \\
52,631\end{array}$ & $\begin{array}{r}4 \\
10 \\
0 \\
13 \\
621,018\end{array}$ \\
\hline
\end{tabular}

Note: Totals may not equal sum of components because of independent rounding

Source: Energy Information Administration, Form ElA-412, "Annual Report of Public Electric Utilities." 
Table 37. Balance Sheet by Major Publicly Owned Electric Utility Within State at End of Period, 1991 (Continued) (Thousand Dollars)

\begin{tabular}{|c|c|c|c|c|c|c|}
\hline Item & $\begin{array}{l}\text { Florida } \\
\text { Leesburg } \\
\text { City of } \\
\text { September } 30\end{array}$ & $\begin{array}{l}\text { Florida } \\
\text { New Smyma } \\
\text { Beach } \\
\text { Utils Comm } \\
\text { September } 30\end{array}$ & September 30 & $\begin{array}{l}\text { Florida } \\
\text { Orlando } \\
\text { Utilities } \\
\text { Comm }\end{array}$ & September 30 & $\begin{array}{l}\text { St Cloud } \\
\text { City of } \\
\text { September } 30\end{array}$ \\
\hline $\begin{array}{l}\text { Electric Utility Plant } \\
\text { Total Electric Utility Plant ................................... } \\
\text { (less) Depr, Amort, and Depletion ................... } \\
\text { Net Electric Utilty Plant ................................ } \\
\text { Other Property \& Investments }\end{array}$ & $\begin{array}{l}45,211 \\
14,094 \\
31,117\end{array}$ & $\begin{array}{l}48,438 \\
18,512 \\
29,927\end{array}$ & $\begin{array}{l}77,351 \\
25,033 \\
52,310\end{array}$ & $\begin{array}{r}1,182,267 \\
270,567 \\
911,700\end{array}$ & $\begin{array}{l}5,765 \\
2,337 \\
3,428\end{array}$ & $\begin{array}{l}49,132 \\
12,634 \\
38,490\end{array}$ \\
\hline $\begin{array}{l}\text { Nonutility Property ................................... } \\
\text { (less) Accum Provisions for Depr \& Amort.... } \\
\text { Advances to Municipality .................................... } \\
\text { Invest \& Special Funds ................................... } \\
\text { Toted Other Property \& Investments ....... } \\
\text { Current and Accrued Assets }\end{array}$ & $\begin{array}{r}0 \\
0 \\
0 \\
7,894 \\
7,894\end{array}$ & $\begin{array}{r}43,021 \\
11,289 \\
0 \\
19,373 \\
51,105\end{array}$ & $\begin{array}{r}0 \\
0 \\
669 \\
45,519 \\
48,188\end{array}$ & $\begin{array}{r}414 \\
6 \\
0 \\
364,949 \\
385,357\end{array}$ & $\begin{array}{r}0 \\
0 \\
0 \\
958 \\
958\end{array}$ & $\begin{array}{l}0 \\
0 \\
0 \\
0 \\
0\end{array}$ \\
\hline 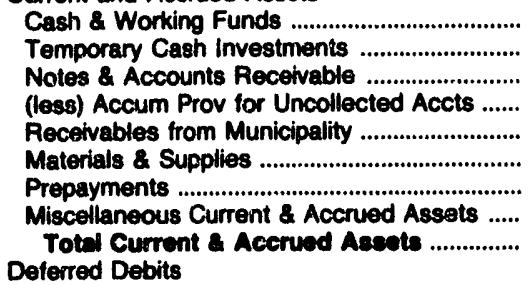 & $\begin{array}{r}5,396 \\
0 \\
4,288 \\
924 \\
0 \\
772 \\
80 \\
0 \\
9,612\end{array}$ & $\begin{array}{r}627 \\
0 \\
3,475 \\
55 \\
0 \\
0 \\
1,615 \\
218 \\
174 \\
6,055\end{array}$ & $\begin{array}{r}2 \\
0 \\
9,695 \\
358 \\
0 \\
2,040 \\
290 \\
0 \\
11,689\end{array}$ & $\begin{array}{r}533 \\
83,208 \\
31,017 \\
691 \\
0 \\
32,299 \\
665 \\
15,821 \\
182,862\end{array}$ & $\begin{array}{r}0 \\
665 \\
651 \\
117 \\
0 \\
89 \\
25 \\
0 \\
1,313\end{array}$ & $\begin{array}{r}0 \\
0 \\
4,050 \\
131 \\
0 \\
1,015 \\
11 \\
0 \\
4,945\end{array}$ \\
\hline 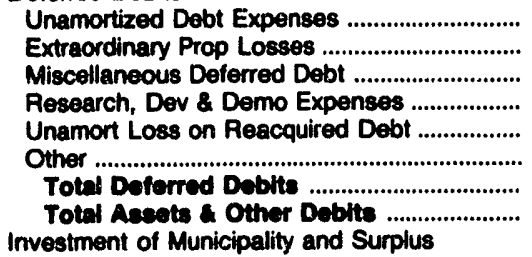 & $\begin{array}{r}184 \\
0 \\
0 \\
0 \\
0 \\
0 \\
184 \\
48,807\end{array}$ & $\begin{array}{r}751 \\
0 \\
15 \\
0 \\
0 \\
0 \\
768 \\
87,852\end{array}$ & $\begin{array}{r}369 \\
0 \\
0 \\
0 \\
0 \\
0 \\
399 \\
110,544\end{array}$ & $\begin{array}{r}2,154 \\
0 \\
0 \\
0 \\
0 \\
3,692 \\
5,846 \\
1,445,755\end{array}$ & $\begin{array}{r}4 \\
0 \\
0 \\
0 \\
0 \\
0 \\
4 \\
\mathbf{5 , 7 0 4}\end{array}$ & $\begin{array}{r}418 \\
0 \\
0 \\
0 \\
0 \\
7,188 \\
7,609 \\
49,050\end{array}$ \\
\hline $\begin{array}{l}\text { Investment of Municipality .................................. } \\
\text { Constructive Surplus or Deficit .......................... } \\
\text { Retained Earnings ............................................... } \\
\text { Total Investment and Surplus ..................... } \\
\text { Long-term Debt }\end{array}$ & $\begin{array}{r}0 \\
0 \\
28,688 \\
28,688\end{array}$ & $\begin{array}{r}20,460 \\
0 \\
7,149 \\
27,610\end{array}$ & $\begin{array}{r}0 \\
0 \\
57,032 \\
57,032\end{array}$ & $\begin{array}{r}0 \\
0 \\
258,212 \\
258,212\end{array}$ & $\begin{array}{r}0 \\
0 \\
4,279 \\
4,279\end{array}$ & $\begin{array}{r}0 \\
1,815 \\
19,775 \\
21,500\end{array}$ \\
\hline 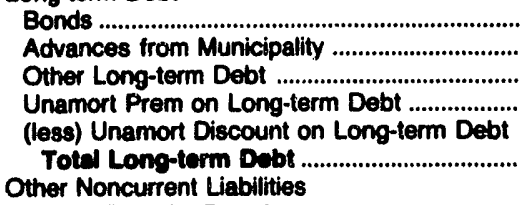 & $\begin{array}{r}14,629 \\
0 \\
0 \\
0 \\
152 \\
14,477\end{array}$ & $\begin{array}{r}50,810 \\
0 \\
2,865 \\
0 \\
797 \\
52,878\end{array}$ & $\begin{array}{r}39,113 \\
0 \\
0 \\
0 \\
0 \\
39,113\end{array}$ & $\begin{array}{r}1,131,597 \\
0 \\
0 \\
0 \\
69,997 \\
1,061,600\end{array}$ & $\begin{array}{r}360 \\
0 \\
0 \\
0 \\
0 \\
360\end{array}$ & $\begin{array}{r}24,809 \\
0 \\
0 \\
0 \\
257 \\
24,552\end{array}$ \\
\hline 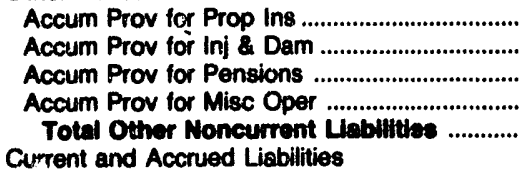 & $\begin{array}{l}0 \\
0 \\
0 \\
0 \\
0\end{array}$ & $\begin{array}{r}0 \\
0 \\
0 \\
648 \\
648\end{array}$ & $\begin{array}{l}0 \\
0 \\
0 \\
0 \\
0\end{array}$ & $\begin{array}{l}\mathbf{0} \\
\mathbf{0} \\
\mathbf{0} \\
\mathbf{0} \\
\mathbf{0}\end{array}$ & $\begin{array}{l}0 \\
0 \\
0 \\
0 \\
0\end{array}$ & $\begin{array}{l}0 \\
0 \\
0 \\
0 \\
0\end{array}$ \\
\hline 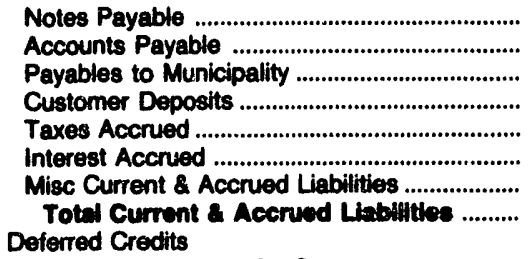 & $\begin{array}{r}0 \\
1,376 \\
0 \\
1,146 \\
0 \\
509 \\
602 \\
3,634\end{array}$ & $\begin{array}{r}0 \\
2,035 \\
410 \\
808 \\
0 \\
1,789 \\
801 \\
6,928\end{array}$ & $\begin{array}{r}0 \\
5,603 \\
748 \\
2,683 \\
0 \\
1,355 \\
171 \\
10,610\end{array}$ & $\begin{array}{r}5,242 \\
20,303 \\
3,363 \\
8,743 \\
553 \\
38,710 \\
7,303 \\
85,218\end{array}$ & $\begin{array}{r}0 \\
688 \\
0 \\
278 \\
0 \\
6 \\
92 \\
1,085\end{array}$ & $\begin{array}{r}475 \\
1,242 \\
210 \\
391 \\
0 \\
308 \\
284 \\
2,000\end{array}$ \\
\hline 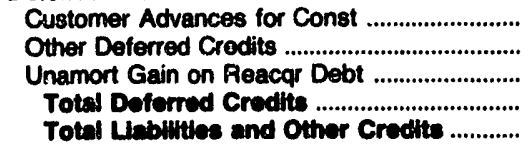 & $\begin{array}{r}46 \\
1,962 \\
0 \\
2,009 \\
48,007\end{array}$ & $\begin{array}{r}0 \\
794 \\
0 \\
784 \\
87,952\end{array}$ & $\begin{array}{r}3,046 \\
844 \\
0 \\
3,889 \\
110,544\end{array}$ & $\begin{array}{r}3,024 \\
37,701 \\
0 \\
40,725 \\
1,445,755\end{array}$ & $\begin{array}{r}0 \\
0 \\
0 \\
0 \\
\mathbf{5 , 7 0 4}\end{array}$ & $\begin{array}{r}0 \\
0 \\
0 \\
0 \\
49,050\end{array}$ \\
\hline
\end{tabular}

Note: Totals may not equal sum of components because of independent rounding.

Source: Energy Information Administration, Form ElA-412, "Annual Report of Public Electric Utilities." 
Table 37. Balance Sheet by Major Publicly Owned Electric Utility Within State at End of Period, 1991 (Continued) (Thousand Dollars)

\begin{tabular}{|c|c|c|c|c|c|c|}
\hline Item & $\begin{array}{l}\text { Florida } \\
\text { Tallahassee } \\
\text { City of } \\
\text { September } 30\end{array}$ & $\begin{array}{l}\text { Florida } \\
\text { Vero } \\
\text { Beach } \\
\text { City of } \\
\text { September } 30\end{array}$ & $\begin{array}{l}\text { Georgia } \\
\text { Albany Water } \\
\text { Gas \& Light } \\
\text { Comm } \\
\text { June } 30\end{array}$ & $\begin{array}{l}\text { Georgia } \\
\text { Calhoun } \\
\text { City of } \\
\text { June } 30\end{array}$ & $\begin{array}{l}\text { Georgia } \\
\text { Cartersville } \\
\text { City of } \\
\text { June } 30\end{array}$ & $\begin{array}{l}\text { Georgia } \\
\text { College } \\
\text { Park City of } \\
\text { June } 30\end{array}$ \\
\hline 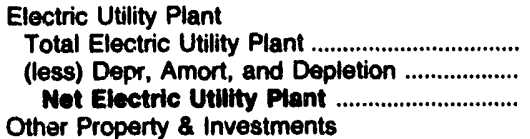 & $\begin{array}{l}335,035 \\
128,406 \\
208,628\end{array}$ & $\begin{array}{r}109,734 \\
37,372 \\
72,362\end{array}$ & $\begin{array}{r}25,868 \\
17,145 \\
8,723\end{array}$ & $\begin{array}{l}57,690 \\
11,067 \\
46,623\end{array}$ & $\begin{array}{l}8,840 \\
2,044 \\
6,797\end{array}$ & $\begin{array}{l}6,851 \\
2,478 \\
4,373\end{array}$ \\
\hline 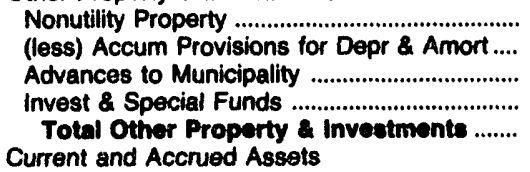 & $\begin{array}{r}5,578 \\
3,264 \\
0 \\
94,879 \\
97,193\end{array}$ & $\begin{array}{r}0 \\
0 \\
0 \\
22,417 \\
22,417\end{array}$ & $\begin{array}{r}39,664 \\
20,864 \\
0 \\
6,980 \\
25,780\end{array}$ & $\begin{array}{l}0 \\
0 \\
0 \\
0 \\
0\end{array}$ & $\begin{array}{l}0 \\
0 \\
0 \\
0 \\
0\end{array}$ & $\begin{array}{r}645 \\
449 \\
0 \\
8,140 \\
8,335\end{array}$ \\
\hline 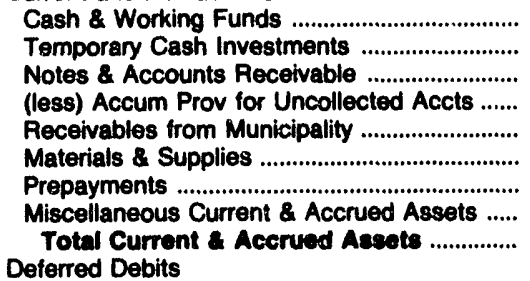 & $\begin{array}{r}11,893 \\
0 \\
12,070 \\
1,859 \\
1 \\
4,635 \\
0 \\
0 \\
26,640\end{array}$ & $\begin{array}{r}8,576 \\
0 \\
5,026 \\
553 \\
0 \\
3,748 \\
124 \\
2,064 \\
18,986\end{array}$ & $\begin{array}{r}545 \\
0 \\
9,592 \\
250 \\
0 \\
2,747 \\
272 \\
57 \\
12,983\end{array}$ & $\begin{array}{r}2,249 \\
1,914 \\
0 \\
0 \\
2,408 \\
0 \\
91 \\
24 \\
6,687\end{array}$ & $\begin{array}{r}1,154 \\
661 \\
2,817 \\
258 \\
3,345 \\
932 \\
0 \\
0 \\
8,652\end{array}$ & $\begin{array}{r}325 \\
0 \\
2,135 \\
210 \\
0 \\
0 \\
18 \\
0 \\
2,269\end{array}$ \\
\hline 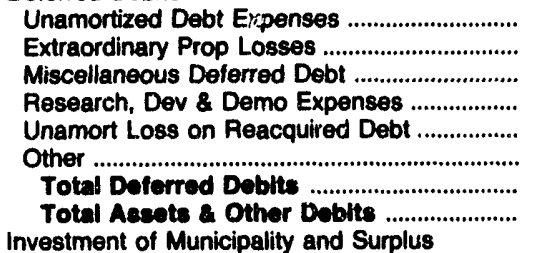 & $\begin{array}{r}408 \\
0 \\
0 \\
0 \\
0 \\
0 \\
408 \\
330,869\end{array}$ & $\begin{array}{r}719 \\
0 \\
0 \\
0 \\
0 \\
0 \\
719 \\
114,404\end{array}$ & $\begin{array}{r}0 \\
0 \\
716 \\
0 \\
0 \\
230 \\
846 \\
48,413\end{array}$ & $\begin{array}{r}0 \\
0 \\
0 \\
0 \\
0 \\
0 \\
0 \\
\mathbf{5 3 , 3 1 0}\end{array}$ & $\begin{array}{r}0 \\
0 \\
0 \\
0 \\
0 \\
0 \\
0 \\
15,448\end{array}$ & $\begin{array}{r}0 \\
0 \\
0 \\
0 \\
0 \\
0 \\
0 \\
14,976\end{array}$ \\
\hline 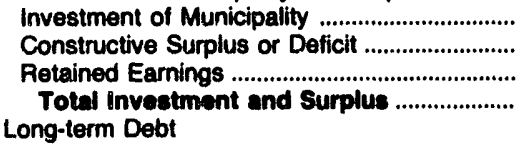 & $\begin{array}{r}0 \\
0 \\
219,346 \\
219,346\end{array}$ & $\begin{array}{r}0 \\
0 \\
43,450 \\
43,450\end{array}$ & $\begin{array}{r}0 \\
0 \\
38,461 \\
38,461\end{array}$ & $\begin{array}{r}5,652 \\
0 \\
27,068 \\
32,720\end{array}$ & $\begin{array}{r}0 \\
0 \\
13,223 \\
13,223\end{array}$ & $\begin{array}{r}1,163 \\
0 \\
11,366 \\
12,528\end{array}$ \\
\hline 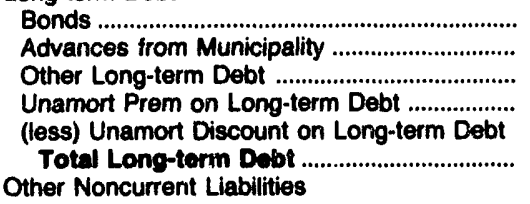 & $\begin{array}{r}96,486 \\
0 \\
0 \\
0 \\
1,759 \\
94,727\end{array}$ & $\begin{array}{r}61,122 \\
0 \\
1,039 \\
0 \\
43 \\
62,119\end{array}$ & $\begin{array}{r}710 \\
0 \\
0 \\
0 \\
0 \\
710\end{array}$ & $\begin{array}{r}7,525 \\
0 \\
9,199 \\
0 \\
0 \\
18,724\end{array}$ & $\begin{array}{l}0 \\
0 \\
0 \\
0 \\
0 \\
0\end{array}$ & $\begin{array}{l}0 \\
0 \\
0 \\
0 \\
0 \\
0\end{array}$ \\
\hline 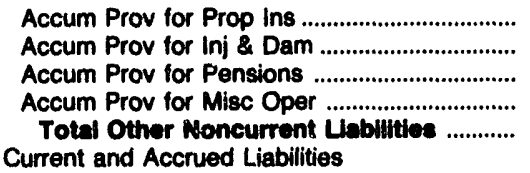 & $\begin{array}{l}0 \\
0 \\
0 \\
0 \\
0\end{array}$ & $\begin{array}{l}0 \\
0 \\
0 \\
0 \\
0\end{array}$ & $\begin{array}{l}0 \\
0 \\
0 \\
0 \\
0\end{array}$ & $\begin{array}{l}0 \\
0 \\
0 \\
0 \\
0\end{array}$ & $\begin{array}{l}0 \\
0 \\
0 \\
0 \\
0\end{array}$ & $\begin{array}{l}0 \\
0 \\
0 \\
0 \\
0\end{array}$ \\
\hline 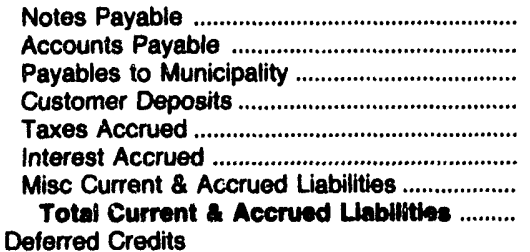 & $\begin{array}{r}0 \\
10,631 \\
0 \\
5,700 \\
0 \\
0 \\
0 \\
16,331\end{array}$ & $\begin{array}{r}697 \\
4,344 \\
0 \\
1,337 \\
0 \\
2,338 \\
199 \\
8,915\end{array}$ & $\begin{array}{r}325 \\
4,784 \\
1,617 \\
230 \\
0 \\
5 \\
1,564 \\
8,525\end{array}$ & $\begin{array}{r}629 \\
1,892 \\
433 \\
844 \\
1 \\
67 \\
0 \\
3,866\end{array}$ & $\begin{array}{r}0 \\
1,745 \\
1 \\
378 \\
0 \\
0 \\
0 \\
2,124\end{array}$ & $\begin{array}{r}0 \\
1,303 \\
0 \\
1,144 \\
0 \\
0 \\
1 \\
2,448\end{array}$ \\
\hline 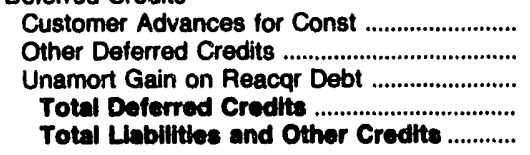 & $\begin{array}{r}115 \\
351 \\
0 \\
467 \\
330,869\end{array}$ & $\begin{array}{r}0 \\
0 \\
0 \\
0 \\
114,484\end{array}$ & $\begin{array}{r}0 \\
716 \\
0 \\
716 \\
48,413\end{array}$ & $\begin{array}{r}0 \\
0 \\
0 \\
0 \\
53,310\end{array}$ & $\begin{array}{r}100 \\
0 \\
0 \\
100 \\
15,448\end{array}$ & $\begin{array}{r}0 \\
0 \\
0 \\
0 \\
14,976\end{array}$ \\
\hline
\end{tabular}

Note: Totals may not equal sum of components because of independent rounding.

Source: Energy information Administration, Form EIA-412, "Annual Report of Public Electric Utilities." 
Table 37. Balance Sheet by Major Publicly Owned Electric Utility Within State at End of Period, 1991 (Continued) (Thousand Dollars)

\begin{tabular}{|c|c|c|c|c|c|c|}
\hline Item & $\begin{array}{l}\text { Georgia } \\
\text { Covington } \\
\text { City of } \\
\text { December } 31\end{array}$ & $\begin{array}{l}\text { Georgia } \\
\text { Crisp } \\
\text { County } \\
\text { Power } \\
\text { Comm } \\
\text { December } 31\end{array}$ & $\begin{array}{l}\text { Georgia } \\
\text { Dalton } \\
\text { City of } \\
\text { November } 30\end{array}$ & $\begin{array}{l}\text { Georgia } \\
\text { Douglas } \\
\text { City of } \\
\text { June } 30\end{array}$ & $\begin{array}{c}\text { Georgia } \\
\text { East } \\
\text { Point } \\
\text { City of } \\
\text { June } 30\end{array}$ & $\begin{array}{l}\text { Georgia } \\
\text { Fitzgerald } \\
\text { Wtr Lgt } \\
\text { \& Bond Comm } \\
\text { Docember } 31\end{array}$ \\
\hline $\begin{array}{l}\text { Electric Utility Plant } \\
\text { Total Electric Utility Plant ................................ } \\
\text { (less) Depr, Amort, and Depletion .................. } \\
\text { Net Electric Utulty Plant ............................... } \\
\text { Other Property \& Investments }\end{array}$ & $\begin{array}{l}5,698 \\
3,031 \\
2,667\end{array}$ & $\begin{array}{l}33,412 \\
18,725 \\
14,687\end{array}$ & $\begin{array}{r}209,439 \\
57,891 \\
151,549\end{array}$ & $\begin{array}{l}3,554 \\
1,897 \\
1,657\end{array}$ & $\begin{array}{l}8,668 \\
5,210 \\
3,459\end{array}$ & $\begin{array}{l}5,918 \\
2,455 \\
3,484\end{array}$ \\
\hline $\begin{array}{l}\text { Nonutility Property .................................... } \\
\text { (less) Accum Provisions for Depr \& Amort .... } \\
\text { Advances to Municipality ............................... } \\
\text { Invest \& Special Funds .............................. } \\
\text { Total Other Property \& Inveatments ........ } \\
\text { Current and Accrued Assets }\end{array}$ & $\begin{array}{l}\mathbf{0} \\
0 \\
0 \\
0 \\
0\end{array}$ & $\begin{array}{r}0 \\
0 \\
0 \\
905 \\
805\end{array}$ & $\begin{array}{r}1,243 \\
793 \\
0 \\
195,496 \\
195,946\end{array}$ & $\begin{array}{r}499 \\
278 \\
0 \\
887 \\
1,108\end{array}$ & $\begin{array}{l}0 \\
0 \\
0 \\
0 \\
0\end{array}$ & $\begin{array}{r}15,010 \\
3,527 \\
0 \\
2,604 \\
14,087\end{array}$ \\
\hline 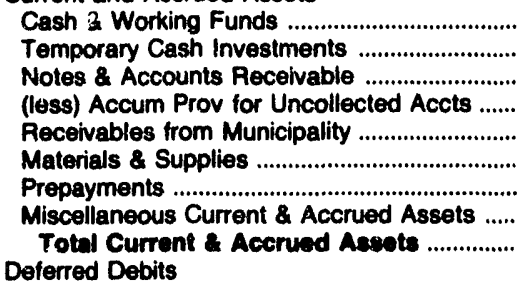 & $\begin{array}{r}1 \\
0 \\
1,346 \\
11 \\
0 \\
185 \\
42 \\
0 \\
1,563\end{array}$ & $\begin{array}{r}412 \\
0 \\
1,994 \\
45 \\
0 \\
669 \\
27 \\
63 \\
3,120\end{array}$ & $\begin{array}{r}18 \\
2,909 \\
4,435 \\
281 \\
0 \\
3,317 \\
60 \\
0 \\
10,460\end{array}$ & $\begin{array}{r}0 \\
241 \\
1,613 \\
7 \\
29 \\
539 \\
0 \\
0 \\
2,416\end{array}$ & $\begin{array}{r}0 \\
0 \\
3,400 \\
91 \\
0 \\
595 \\
20 \\
0 \\
3,924\end{array}$ & $\begin{array}{r}1,151 \\
0 \\
249 \\
79 \\
0 \\
592 \\
517 \\
0 \\
2,429\end{array}$ \\
\hline 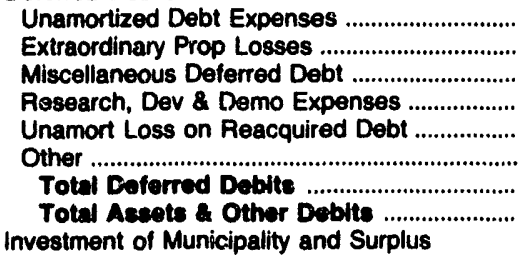 & $\begin{array}{r}115 \\
0 \\
17 \\
0 \\
0 \\
3 \\
135 \\
4,365\end{array}$ & $\begin{array}{r}0 \\
0 \\
0 \\
0 \\
0 \\
0 \\
0 \\
18,712\end{array}$ & $\begin{array}{r}1,050 \\
0 \\
0 \\
0 \\
0 \\
0 \\
1,050 \\
358,004\end{array}$ & $\begin{array}{r}0 \\
0 \\
0 \\
0 \\
0 \\
0 \\
0 \\
\mathbf{5}, 180\end{array}$ & $\begin{array}{r}0 \\
0 \\
0 \\
0 \\
0 \\
0 \\
0 \\
7,383\end{array}$ & $\begin{array}{r}0 \\
0 \\
0 \\
0 \\
0 \\
0 \\
0 \\
19,980\end{array}$ \\
\hline 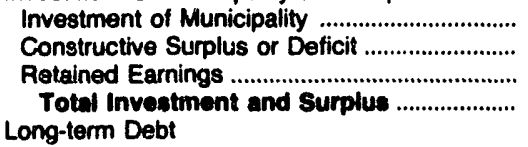 & $\begin{array}{r}0 \\
0 \\
2,785 \\
2,785\end{array}$ & $\begin{array}{r}17,169 \\
0 \\
0 \\
17,180\end{array}$ & $\begin{array}{r}0 \\
0 \\
241,143 \\
241,143\end{array}$ & $\begin{array}{r}280 \\
1,292 \\
2,296 \\
3,868\end{array}$ & $\begin{array}{r}0 \\
0 \\
3,295 \\
3,295\end{array}$ & $\begin{array}{r}0 \\
0 \\
13,387 \\
13,387\end{array}$ \\
\hline 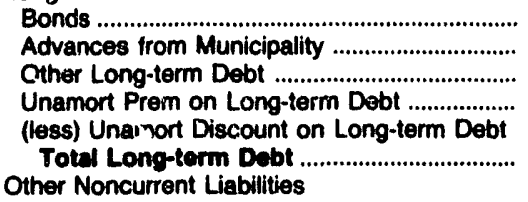 & $\begin{array}{r}438 \\
0 \\
0 \\
0 \\
0 \\
438\end{array}$ & $\begin{array}{l}0 \\
0 \\
0 \\
0 \\
0 \\
0\end{array}$ & $\begin{array}{r}100,880 \\
0 \\
0 \\
0 \\
171 \\
100,709\end{array}$ & $\begin{array}{l}0 \\
0 \\
0 \\
0 \\
0 \\
0\end{array}$ & $\begin{array}{l}0 \\
0 \\
0 \\
0 \\
0 \\
0\end{array}$ & $\begin{array}{r}3,775 \\
0 \\
1,967 \\
0 \\
0 \\
5,742\end{array}$ \\
\hline $\begin{array}{l}\text { Accum Prov for Prop Ins } \\
\text { Accum Prov for Inj \& Dam .............................. } \\
\text { Accum Prov for Pensions ............................ } \\
\text { Accum Prov for Misc Oper ........................ } \\
\text { Totel Other Noncurrent Llabilities } \\
\text { Current and Accrued Liabilities }\end{array}$ & $\begin{array}{l}0 \\
0 \\
0 \\
0 \\
0\end{array}$ & $\begin{array}{l}0 \\
0 \\
0 \\
0 \\
0\end{array}$ & $\begin{array}{l}0 \\
0 \\
0 \\
0 \\
0\end{array}$ & $\begin{array}{r}0 \\
0 \\
0 \\
876 \\
876\end{array}$ & $\begin{array}{l}0 \\
0 \\
0 \\
0 \\
0\end{array}$ & $\begin{array}{l}0 \\
0 \\
0 \\
0 \\
0\end{array}$ \\
\hline 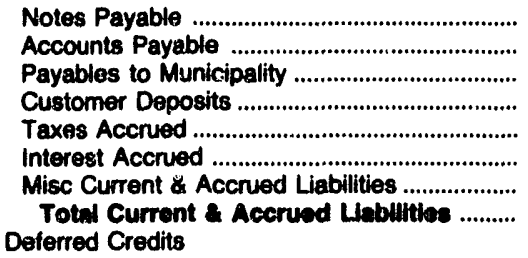 & $\begin{array}{r}84 \\
677 \\
315 \\
0 \\
0 \\
0 \\
49 \\
1,125\end{array}$ & $\begin{array}{r}0 \\
1,043 \\
0 \\
317 \\
47 \\
0 \\
136 \\
1,543\end{array}$ & $\begin{array}{r}0 \\
10,181 \\
375 \\
702 \\
0 \\
2,735 \\
3,160 \\
17,152\end{array}$ & $\begin{array}{r}0 \\
0 \\
0 \\
436 \\
0 \\
0 \\
0 \\
436\end{array}$ & $\begin{array}{r}0 \\
3,598 \\
0 \\
385 \\
0 \\
0 \\
105 \\
4,088\end{array}$ & $\begin{array}{r}0 \\
530 \\
0 \\
252 \\
0 \\
64 \\
0 \\
847\end{array}$ \\
\hline 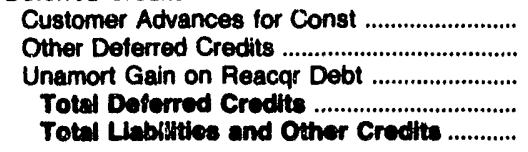 & $\begin{array}{r}2 \\
15 \\
0 \\
17 \\
4,365\end{array}$ & $\begin{array}{r}0 \\
0 \\
0 \\
0 \\
18,712\end{array}$ & $\begin{array}{r}0 \\
0 \\
0 \\
0 \\
359,004\end{array}$ & $\begin{array}{r}0 \\
0 \\
0 \\
0 \\
5,180\end{array}$ & $\begin{array}{r}0 \\
0 \\
0 \\
0 \\
\mathbf{7 , 3 9 3}\end{array}$ & $\begin{array}{r}0 \\
4 \\
0 \\
4 \\
19,080\end{array}$ \\
\hline
\end{tabular}

Note: Totals may not equal sum of components because of independent rounding.

Source: Energy Intormation Administration, Form EIA-412, "Annual Report of Public Electric Utilities." 
Table 37. Balance Sheet by Major Publicly Owned Electric Utility Within State at End of Period, 1991 (Continued) (Thousand Dollars)

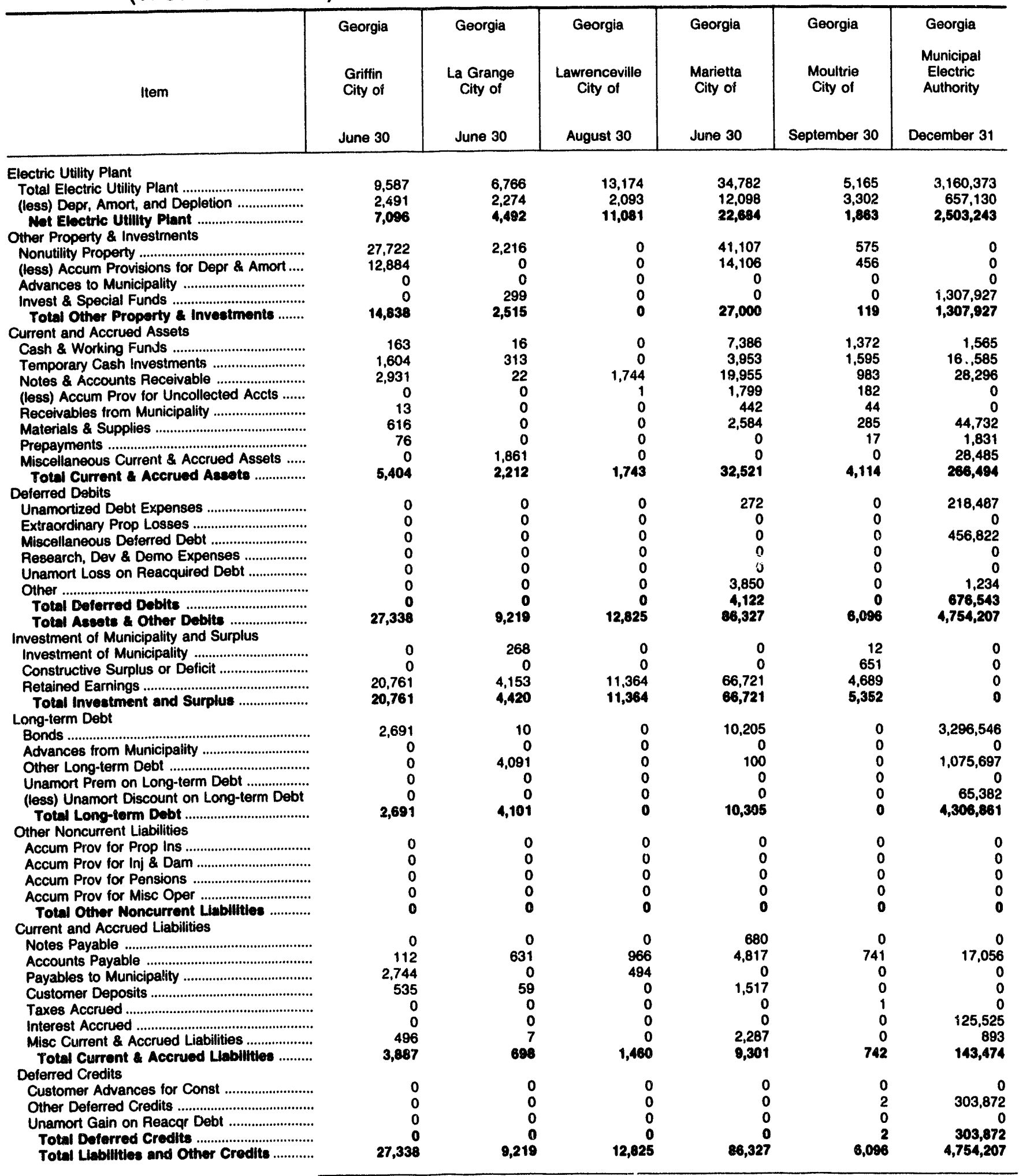

Note: Totals may not equal sum of components because of independent rounding.

Source: Energy Information Administration, Form ElA-412, "Annual Report of Public Electric Utilities." 
Table 37. Balance Sheet by Major Publicly Owned Electric Utility Within State at End of Period, 1991 (Continued) (Thousand Dollars)

\begin{tabular}{|c|c|c|c|c|c|c|}
\hline Item & $\begin{array}{c}\text { Georgia } \\
\text { Thomasville } \\
\text { City of }\end{array}$ & $\begin{array}{l}\text { Idaho } \\
\text { Idaho } \\
\text { Falls } \\
\text { City of }\end{array}$ & $\begin{array}{c}\text { Batavia } \\
\text { City of } \\
\text { December } 31\end{array}$ & $\begin{array}{l}\text { Geneva } \\
\text { City of } \\
\text { April } 30\end{array}$ & $\begin{array}{c}\text { Illinois } \\
\text { Illinois } \\
\text { Municipal } \\
\text { Elec Agency } \\
\text { April } 30\end{array}$ & $\begin{array}{l}\text { Naperville } \\
\text { City of } \\
\text { April } 30\end{array}$ \\
\hline \multicolumn{7}{|l|}{ Electric Utility Plant } \\
\hline 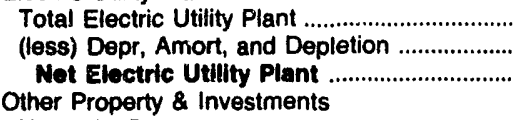 & $\begin{array}{r}11,508 \\
4,291 \\
7,217\end{array}$ & $\begin{array}{r}123,973 \\
24,181 \\
99,791\end{array}$ & $\begin{array}{r}14,012 \\
5,215 \\
8,797\end{array}$ & $\begin{array}{r}17,800 \\
6,762 \\
11,038\end{array}$ & $\begin{array}{r}95,230 \\
552 \\
94,678\end{array}$ & $\begin{array}{l}90,695 \\
53,314 \\
37,381\end{array}$ \\
\hline Nonutility Property & 0 & 0 & 0 & 0 & 0 & 0 \\
\hline (less) Accum Provisions for Depr \& Amort .... & 0 & 0 & 0 & 0 & 0 & 0 \\
\hline Advances to Municipality .................................... & 0 & 0 & 0 & 0 & 0 & 0 \\
\hline Invest \& Special Funds ................................ & 0 & 15,039 & 0 & 360 & 0 & 7,695 \\
\hline \multicolumn{7}{|l|}{ Current and Accrued Assets } \\
\hline 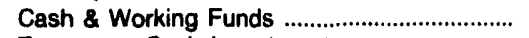 & 624 & 302 & 589 & 80 & 7,094 & 12,591 \\
\hline Temporary Cash investments ......................... & 0 & 5,920 & 2,451 & 443 & 19,781 & 0 \\
\hline Notes \& Accounts Receivable .......................... & 2,990 & 3,058 & 2,466 & 0 & 3,541 & 7,502 \\
\hline (less) Accum Prov for Uncollected Accts ...... & 0 & 929 & 0 & 0 & 0 & 279 \\
\hline Receivables from Municipality ............................. & 55 & 0 & 2,318 & 995 & 0 & 0 \\
\hline 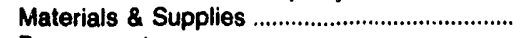 & 1.203 & 1,644 & 1,056 & 0 & 0 & 4,968 \\
\hline 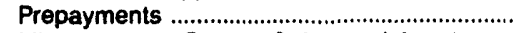 & 0 & 0 & 0 & 0 & 141 & 0 \\
\hline Miscellaneous Current \& Accrued Assets ..... & 0 & 42 & 0 & 68 & 0 & 0 \\
\hline $\begin{array}{l}\text { Total Current \& Accrued Assets ................ } \\
\text { Deferred Debits }\end{array}$ & 4,872 & 10,036 & 8,879 & 1,586 & 30,558 & 24,782 \\
\hline 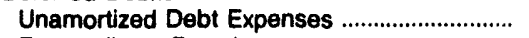 & 0 & 2.496 & 0 & 64 & 4,008 & 0 \\
\hline Extraordinary Prop Losses .................................. & 0 & 0 & 0 & 0 & 0 & 0 \\
\hline Miscellaneous Deferred Dobt ........................... & 0 & 0 & 0 & 0 & 0 & 0 \\
\hline Research, Dev \& Demo Expenses ..................... & 0 & 1,291 & 0 & 0 & 0 & 0 \\
\hline Unamort Loss on Reacquired Debt ................. & 0 & 0 & 0 & 0 & 0 & 0 \\
\hline 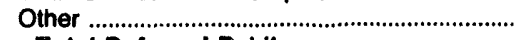 & 0 & 0 & 0 & 0 & 1,771 & 0 \\
\hline Total Deferred Debits ............................... & 12,089 & $\begin{array}{r}3,787 \\
128,653\end{array}$ & $\begin{array}{r}0 \\
17,676\end{array}$ & $\begin{array}{r}64 \\
13,048\end{array}$ & $\begin{array}{r}5,779 \\
131,014\end{array}$ & $\begin{array}{r}0 \\
69,858\end{array}$ \\
\hline \multicolumn{7}{|l|}{ Investment of Municipality and Surplus } \\
\hline 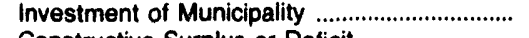 & 0 & 0 & 0 & 873 & 0 & 0 \\
\hline Constructive Surplus or Deficit ............................. & 0 & 0 & 0 & 0 & 0 & 0 \\
\hline 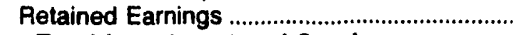 & 9,349 & 28,912 & 12,906 & 9,666 & 657 & 55,030 \\
\hline \multicolumn{7}{|l|}{ Long-term Debt } \\
\hline Bonds & 0 & 85,428 & 425 & 125 & 131,575 & 8,105 \\
\hline 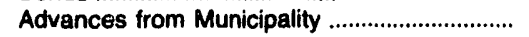 & 0 & 0 & 0 & 0 & 0 & $\begin{array}{r}0,100 \\
0\end{array}$ \\
\hline Other Long-term Debt ....................................... & 0 & 5,531 & 0 & 580 & 0 & 345 \\
\hline Unamort Prem on Long-term Debt .................. & 0 & 4,382 & 0 & 1,113 & 0 & 0 \\
\hline (less) Unamort Discount on Long-term Debt & 0 & 1,669 & 0 & 0 & 7,714 & 0 \\
\hline 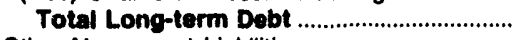 & 0 & 93,672 & 425 & 1,818 & 123,861 & 8,450 \\
\hline \multicolumn{7}{|l|}{ Other Noncurrent Liabilities } \\
\hline 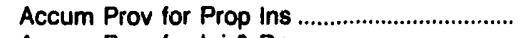 & 0 & 0 & 0 & 0 & 0 & $\mathbf{0}$ \\
\hline Accum Prov for Inj \& Dam .............................. & 0 & 0 & 0 & 0 & 0 & 0 \\
\hline Accum Prov for Pensions .................................. & 0 & 0 & 0 & 0 & 0 & 0 \\
\hline Accum Prov for Misc Oper ................................. & 0 & 0 & 0 & 0 & 0 & 0 \\
\hline Total Other Noncurrent Liabillties ............ & $\mathbf{0}$ & 0 & $\mathbf{0}$ & $\mathbf{0}$ & $\mathbf{0}$ & 0 \\
\hline \multicolumn{7}{|l|}{ Current and Accrued Liabilities } \\
\hline Notes Payable & 54 & 0 & 0 & 0 & 0 & 0 \\
\hline 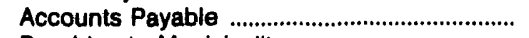 & 1,521 & 2,298 & 4,208 & 670 & 4,544 & 4,558 \\
\hline Payables to Municipality ......................................... & 0 & 950 & 0 & 0 & 0 & 254 \\
\hline 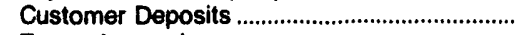 & 548 & 3 & 111 & 0 & 0 & 67 \\
\hline Taxes Accrued & 134 & 0 & 0 & 0 & 0 & 0 \\
\hline Interest Accrued & 0 & 282 & 26 & 0 & 1,905 & 0 \\
\hline Misc Current \& Accrued Liabilities ........................ & 483 & 2,536 & 0 & 21 & 21 & 1,203 \\
\hline $\begin{array}{l}\text { Total Current \& Accrued Llabilities .......... } \\
\text { Deferred Credits }\end{array}$ & 2,741 & 6,070 & 4,345 & 691 & 6,470 & 6,082 \\
\hline 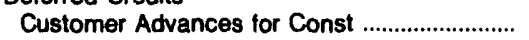 & 0 & 0 & 0 & 0 & 0 & Deferred Credits \\
\hline 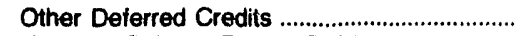 & 0 & 0 & 0 & 0 & 26 & 48 \\
\hline Unamort Gain on Reacqr Debt ........................ & 0 & 0 & 0 & $\mathbf{0}$ & 0 & 0 \\
\hline Total Doferred Credits ................................... & $\mathbf{0}$ & $\mathbf{0}$ & 0 & 0 & 26 & \\
\hline Total Llabllities and Other Credits ............ & 12,089 & 128,653 & 17,676 & 13,048 & 131,014 & 69,858 \\
\hline
\end{tabular}

Note: Totals may not equal sum of components because of independent rounding.

Source: Energy Information Administration, Form EIA-412, "Annual Report of Public Electric Utilities." 
Table 37. Balance Sheet by Major Publicly Owned Electric Utility Within State at End of Period, 1991 (Continued) (Thousand Dollars)

\begin{tabular}{|c|c|c|c|c|c|c|}
\hline Item & $\begin{array}{l}\text { Illinois } \\
\text { Rochelle } \\
\text { Municipal } \\
\text { Utilities } \\
\text { April } 30\end{array}$ & $\begin{array}{l}\text { Springtield } \\
\text { City of } \\
\text { February } 23\end{array}$ & $\begin{array}{l}\text { St Charles } \\
\text { City of } \\
\text { April } 30\end{array}$ & $\begin{array}{c}\text { Anderson } \\
\text { City of } \\
\text { December } 31\end{array}$ & $\begin{array}{c}\text { Auburn } \\
\text { City of } \\
\text { December } 31\end{array}$ & $\begin{array}{c}\text { Indiana } \\
\text { Blutfton } \\
\text { City of } \\
\text { December } 31\end{array}$ \\
\hline \multicolumn{7}{|l|}{ Electric Utility Plant } \\
\hline 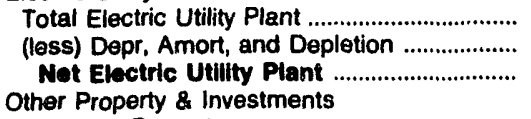 & $\begin{array}{r}22,115 \\
12,733 \\
9,382\end{array}$ & $\begin{array}{l}330,891 \\
144,478 \\
186,414\end{array}$ & $\begin{array}{r}24,084 \\
6,566 \\
17,518\end{array}$ & $\begin{array}{l}43,190 \\
17,738 \\
25,453\end{array}$ & $\begin{array}{r}12,249 \\
4,178 \\
8,071\end{array}$ & $\begin{array}{l}7,904 \\
3,612 \\
4,292\end{array}$ \\
\hline Nonutility Property & 0 & 4,987 & 0 & 0 & 0 & 0 \\
\hline (less) Accum Provisions for Depr \& Amort .... & 0 & 0 & 0 & 0 & 0 & 0 \\
\hline 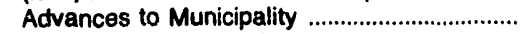 & 0 & 0 & 0 & 0 & 0 & 0 \\
\hline 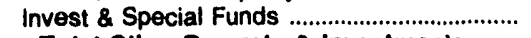 & 3,530 & 29,469 & 0 & 0 & 0 & 0 \\
\hline $\begin{array}{l}\text { Total Other Property a investments ........ } \\
\text { Current and Accrued Assets }\end{array}$ & 3,530 & 34,456 & $\mathbf{0}$ & 0 & $\mathbf{0}$ & $\mathbf{0}$ \\
\hline 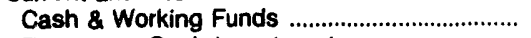 & 828 & 273 & 0 & 314 & 1,477 & 1,450 \\
\hline 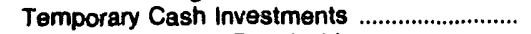 & 505 & 4,920 & 1,771 & 3,687 & 7,764 & 0 \\
\hline Notes \& Accounts Receivable ......................... & 1,003 & 11,531 & 1,905 & 1,787 & 174 & 344 \\
\hline (less) Accum Prov for Uncollected Accts ...... & 10 & 485 & 0 & 593 & 0 & 35 \\
\hline Receivables from Municipality ............................ & 0 & 23 & 123 & 238 & 0 & 0 \\
\hline 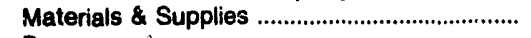 & 612 & 7,458 & 29 & 675 & 398 & 710 \\
\hline 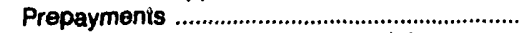 & 93 & 1,118 & 0 & 0 & 23 & 56 \\
\hline $\begin{array}{l}\text { Miscellaneous Current \& Accrued Assets ..... } \\
\text { Total Current A Accrued Aseets .............. }\end{array}$ & $\begin{array}{r}36 \\
3,068\end{array}$ & $\begin{array}{r}0 \\
24,839\end{array}$ & $\begin{array}{r}0 \\
3,829\end{array}$ & $\begin{array}{r}2 \\
6,110^{2}\end{array}$ & 9,835 & $\begin{array}{r}0 \\
2524\end{array}$ \\
\hline \multicolumn{7}{|l|}{ Deferred Debits } \\
\hline Unamortized Debt Expenses ................................ & 98 & 234 & 0 & 0 & 0 & 0 \\
\hline 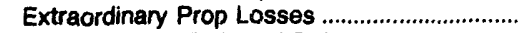 & 0 & 0 & 0 & 0 & 0 & 0 \\
\hline Miscellaneous Deferred Debt .............................. & 0 & 0 & 0 & 654 & 0 & 0 \\
\hline Research, Dev \& Demo Expenses ................... & 0 & 0 & 0 & 0 & 0 & 0 \\
\hline Unamort Loss on Reacquired Debt ................... & 0 & 0 & 0 & 0 & 0 & 0 \\
\hline Other & $\mathbf{0}$ & 0 & 0 & 0 & 0 & 0 \\
\hline Total Deforred Debits ................................. & 98 & 234 & 0 & 654 & 0 & $\mathbf{0}$ \\
\hline $\begin{array}{l}\text { Total Assets Other Debits } \\
\text { Investment of Municipality and Surplus................... }\end{array}$ & 16,078 & 245,943 & 21,347 & 32,216 & 17,906 & 6,816 \\
\hline 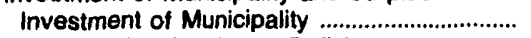 & 9.295 & 0 & 0 & 0 & 0 & 0 \\
\hline 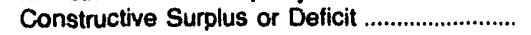 & 0 & 7,728 & 0 & 0 & 0 & 0 \\
\hline $\begin{array}{l}\text { Retained Earnings } \\
\text { Total Investment and Surplus }\end{array}$ & $\begin{array}{r}26 \\
9,321\end{array}$ & $\begin{array}{l}112,096 \\
119,824\end{array}$ & $\begin{array}{l}19,755 \\
19,755\end{array}$ & $\begin{array}{l}25,121 \\
25,121\end{array}$ & $\begin{array}{l}16,188 \\
16,188\end{array}$ & $\begin{array}{l}5,940 \\
5,940\end{array}$ \\
\hline \multicolumn{7}{|l|}{ Long-term Debt } \\
\hline Bonds & 6,270 & 95,870 & 0 & 1,400 & 795 & 0 \\
\hline 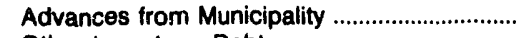 & 0 & 0 & 0 & 0 & 0 & 0 \\
\hline 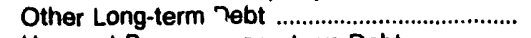 & 0 & 0 & 0 & 0 & 0 & 0 \\
\hline Unamort Prem on \& ong-term Debt .................. & 0 & 0 & 0 & 0 & 0 & 0 \\
\hline (less) Unamort Discount on Long-term Debt & 270 & 839 & 0 & 0 & 0 & 0 \\
\hline 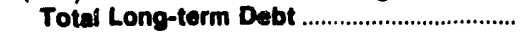 & 6,000 & 95,031 & $\mathbf{0}$ & 1,400 & 795 & $\mathbf{0}$ \\
\hline \multicolumn{7}{|l|}{ Other Noncurrent Liabilities } \\
\hline 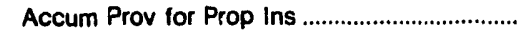 & 0 & 0 & 0 & 0 & 0 & 0 \\
\hline Accum Prov for Inj \& Dam ................................ & 0 & 0 & 0 & 56 & 0 & 0 \\
\hline Accum Prov for Pensions ................................... & 0 & 0 & 0 & 0 & 0 & 0 \\
\hline 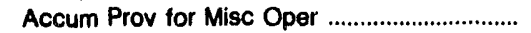 & 0 & 0 & 0 & 0 & 0 & 0 \\
\hline Total Other Noncurrent Llabilities ............. & $\mathbf{0}$ & 0 & $\mathbf{0}$ & 56 & 0 & 0 \\
\hline \multicolumn{7}{|l|}{ Current and Accrued Liabilities } \\
\hline 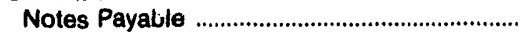 & 0 & 5,175 & 0 & 0 & 0 & 0 \\
\hline 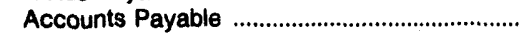 & 705 & 8,341 & 1,165 & 4,424 & 840 & 490 \\
\hline 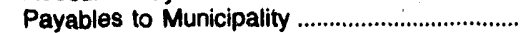 & 0 & 0 & 36 & 0 & 1 & 0 \\
\hline 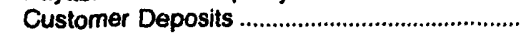 & 45 & 588 & 134 & 268 & 13 & 91 \\
\hline 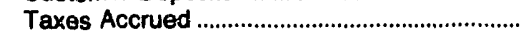 & 0 & 1 & 66 & 108 & 56 & 16 \\
\hline Interest Accrued & 0 & 3,565 & 1 & 0 & 13 & 0 \\
\hline Misc Current \& Accrued Liabilities .................... & 7 & 0 & 187 & 0 & 0 & 0 \\
\hline Total Current \& Accrued Liabilities ........... & 757 & 17,669 & 1,589 & 4,600 & 923 & 597 \\
\hline \multicolumn{7}{|l|}{ Deferred Credits } \\
\hline 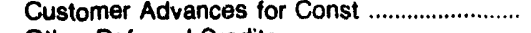 & 0 & 577 & 0 & 839 & 0 & 178 \\
\hline Other Deferred Credits ....................................... & 0 & 12,842 & 2 & 0 & 0 & 101 \\
\hline Unamort Gain on Reacqr Debt ........................ & 0 & 0 & 0 & 0 & 0 & 0 \\
\hline $\begin{array}{l}\text { Total Deferred Credits ............................. } \\
\text { Total Llabllitles and Other Credits }\end{array}$ & $\begin{array}{r}0 \\
16,078\end{array}$ & $\begin{array}{r}13,419 \\
245,943\end{array}$ & 21,347 & $\begin{array}{r}838 \\
32,216\end{array}$ & $\begin{array}{r}0 \\
17,906\end{array}$ & $\begin{array}{r}279 \\
6,816\end{array}$ \\
\hline
\end{tabular}

Note: Totals may not equal sum of components because of independent rounding.

Source: Energy information Administration, Form ElA-412, "Annual Report of Public Electric Utilities." 
Table 37. Balance Sheet by Major Publicly Owned Electric Utility Within State at End of Period, 1991 (Continued)

(Thousand Dollars)

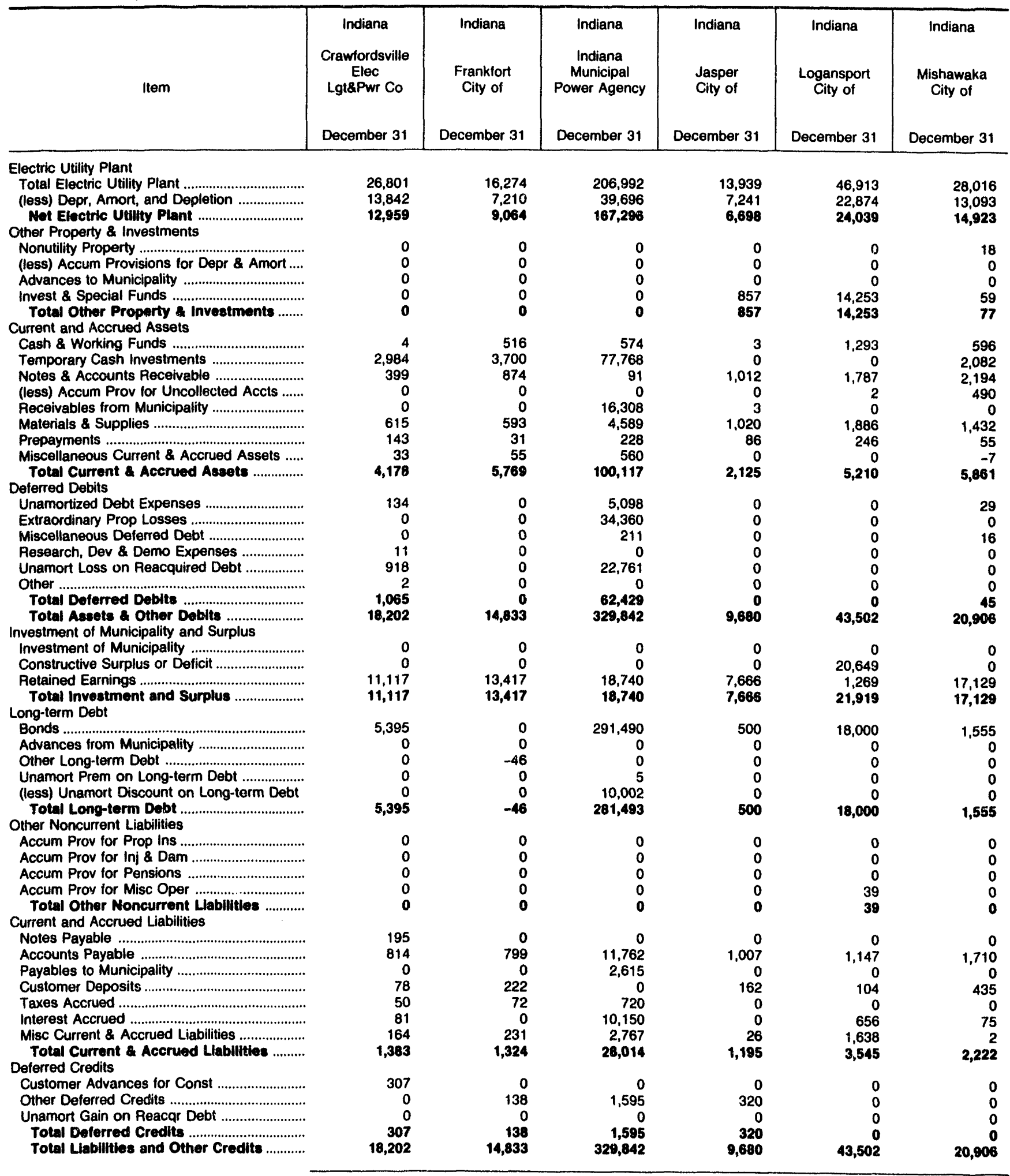

Note: Totals may not equal sum of components because of independent rounding.

Source: Energy Information Administration, Form ElA-412, "Annual Report of Public Electric Utilities." 

Table 37. Balance Sheet by Major Publicly Owned Electric Utility
Within State at End of Period, 1991 (Continued) (Thousand Dollars)

\begin{tabular}{|c|c|c|c|c|c|c|}
\hline Item & $\begin{array}{c}\text { Indiana } \\
\text { Peru } \\
\text { City of } \\
\text { December } 31\end{array}$ & $\begin{array}{l}\text { Indiana } \\
\text { Richmond } \\
\text { City of } \\
\text { December } 31\end{array}$ & $\begin{array}{c}\text { Indiana } \\
\text { Washington } \\
\text { City of } \\
\text { December } 31\end{array}$ & $\begin{array}{l}\text { lowa } \\
\text { Ames } \\
\text { City of } \\
\text { June } 30\end{array}$ & $\begin{array}{c}\text { lowa } \\
\text { Cedar } \\
\text { Falls } \\
\text { City of } \\
\text { December } 31\end{array}$ & $\begin{array}{c}\text { lowa } \\
\text { Muscatine } \\
\text { City of } \\
\text { December } 31\end{array}$ \\
\hline 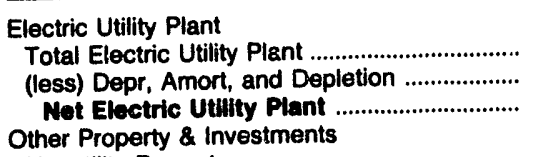 & $\begin{array}{r}25,757 \\
13,873 \\
11,884\end{array}$ & $\begin{array}{l}82,125 \\
33,037 \\
49,028\end{array}$ & $\begin{array}{r}10,578 \\
4,112 \\
6,463\end{array}$ & $\begin{array}{r}93,890 \\
44,701 \\
49,190\end{array}$ & $\begin{array}{l}66,511 \\
29,580 \\
36,931\end{array}$ & $\begin{array}{r}271,998 \\
98,489 \\
173,509\end{array}$ \\
\hline 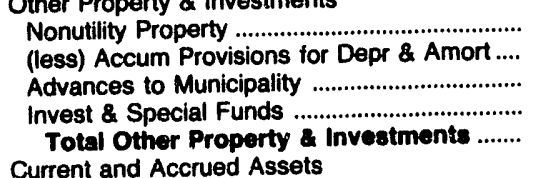 & $\begin{array}{r}22 \\
0 \\
0 \\
0 \\
22\end{array}$ & $\begin{array}{r}0 \\
0 \\
0 \\
9,319 \\
9,319\end{array}$ & $\begin{array}{r}0 \\
0 \\
0 \\
226 \\
226\end{array}$ & $\begin{array}{r}0 \\
0 \\
0 \\
7,389 \\
7,389\end{array}$ & $\begin{array}{r}0 \\
0 \\
0 \\
7,380 \\
7,380\end{array}$ & $\begin{array}{r}0 \\
0 \\
0 \\
157,266 \\
157,266\end{array}$ \\
\hline 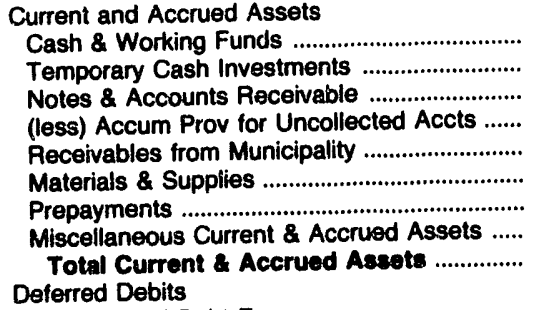 & $\begin{array}{r}579 \\
0 \\
492 \\
35 \\
0 \\
93 \\
33 \\
1,313 \\
2,475\end{array}$ & $\begin{array}{r}361 \\
6,912 \\
2,957 \\
5 \\
154 \\
5,027 \\
299 \\
380 \\
16,0815\end{array}$ & $\begin{array}{r}1,579 \\
0 \\
545 \\
104 \\
6 \\
207 \\
18 \\
0 \\
2,251\end{array}$ & $\begin{array}{r}283 \\
5,634 \\
2,704 \\
20 \\
64 \\
1,892 \\
0 \\
71 \\
10,627\end{array}$ & $\begin{array}{r}-149 \\
4,067 \\
1,233 \\
13 \\
0 \\
1,867 \\
178 \\
663 \\
7,846\end{array}$ & $\begin{array}{r}58 \\
1,028 \\
8,154 \\
20 \\
12 \\
7,340 \\
782 \\
0 \\
17,356\end{array}$ \\
\hline 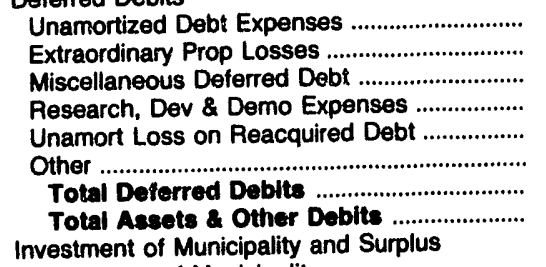 & $\begin{array}{r}13 \\
0 \\
0 \\
0 \\
0 \\
0 \\
13 \\
14,394\end{array}$ & $\begin{array}{r}0 \\
0 \\
34 \\
480 \\
0 \\
0 \\
514 \\
75,006\end{array}$ & $\begin{array}{r}0 \\
0 \\
0 \\
0 \\
0 \\
0 \\
0 \\
\mathbf{8 , 9 4 3}\end{array}$ & $\begin{array}{r}172 \\
0 \\
0 \\
0 \\
0 \\
0 \\
172 \\
67,378\end{array}$ & $\begin{array}{r}0 \\
0 \\
1,122 \\
0 \\
0 \\
0 \\
1,122 \\
53,279\end{array}$ & $\begin{array}{r}4,807 \\
0 \\
491 \\
0 \\
0 \\
0 \\
5,299 \\
353,429\end{array}$ \\
\hline 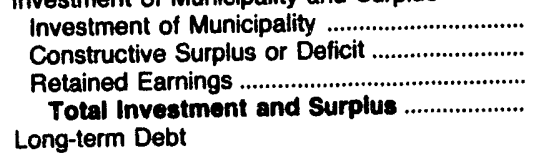 & $\begin{array}{r}608 \\
0 \\
12,775 \\
13,383\end{array}$ & $\begin{array}{r}0 \\
0 \\
66,466 \\
68,466\end{array}$ & $\begin{array}{r}466 \\
0 \\
7,184 \\
7,650\end{array}$ & $\begin{array}{r}0 \\
0 \\
30,900 \\
30,800\end{array}$ & $\begin{array}{r}0 \\
0 \\
46,652 \\
46,652\end{array}$ & $\begin{array}{r}0 \\
0 \\
122,493 \\
122,493\end{array}$ \\
\hline 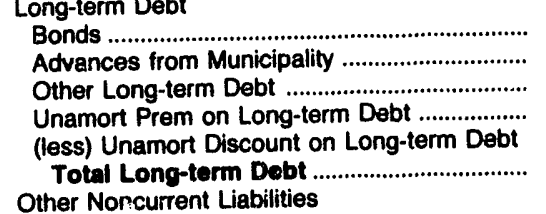 & $\begin{array}{r}260 \\
0 \\
0 \\
0 \\
0 \\
\mathbf{2 6 0}\end{array}$ & $\begin{array}{r}880 \\
0 \\
0 \\
0 \\
0 \\
\mathbf{8 8 0}\end{array}$ & $\begin{array}{l}0 \\
0 \\
0 \\
0 \\
0 \\
0\end{array}$ & $\begin{array}{r}31,966 \\
12 \\
0 \\
0 \\
0 \\
31,978\end{array}$ & $\begin{array}{r}4,320 \\
0 \\
0 \\
0 \\
63 \\
4,257\end{array}$ & $\begin{array}{r}232,290 \\
0 \\
0 \\
0 \\
13,509 \\
218,781\end{array}$ \\
\hline 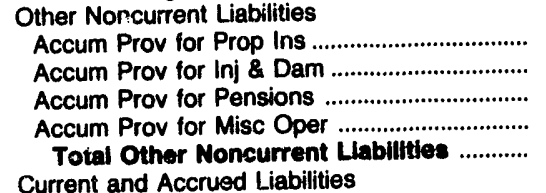 & $\begin{array}{l}0 \\
0 \\
0 \\
0 \\
0\end{array}$ & $\begin{array}{l}0 \\
0 \\
0 \\
0 \\
0\end{array}$ & $\begin{array}{l}0 \\
0 \\
0 \\
0 \\
0\end{array}$ & $\begin{array}{r}0 \\
0 \\
278 \\
0 \\
278\end{array}$ & $\begin{array}{l}0 \\
0 \\
0 \\
0 \\
0\end{array}$ & $\begin{array}{l}0 \\
0 \\
0 \\
0 \\
0\end{array}$ \\
\hline 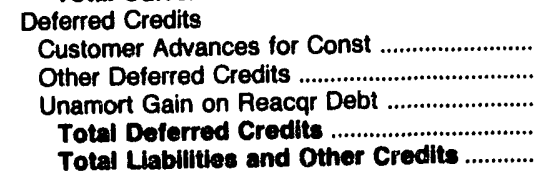 & $\begin{array}{r}0 \\
30 \\
0 \\
30 \\
14,394\end{array}$ & $\begin{array}{r}466 \\
76 \\
0 \\
542 \\
75,006\end{array}$ & $\begin{array}{r}78 \\
0 \\
0 \\
78 \\
8,843\end{array}$ & $\begin{array}{r}0 \\
0 \\
0 \\
0 \\
67,378\end{array}$ & $\begin{array}{r}0 \\
1,122 \\
0 \\
1,122 \\
53,279\end{array}$ & $\begin{array}{r}0 \\
0 \\
0 \\
0 \\
353,429\end{array}$ \\
\hline
\end{tabular}

Note: Totals may not equal sum of components because of independent rounding.

Source: Energy Information Administration, Form ElA-412, "Annual Report of Public Electric Utilities." 
Table 37. Balance Sheet by Major Publicly Owned Electric Utility
Within State at End of Period, 1991 (Continued) (Thousand Dollars)

\begin{tabular}{|c|c|c|c|c|c|c|}
\hline Item & $\begin{array}{c}\text { Kansas } \\
\text { Coffeyville } \\
\text { City of }\end{array}$ & $\begin{array}{l}\text { Kansas } \\
\text { Garden } \\
\text { City City of } \\
\text { December } 31\end{array}$ & $\begin{array}{l}\text { Kansas } \\
\text { Kansas } \\
\text { City City of } \\
\text { December } 31\end{array}$ & $\begin{array}{c}\text { Kansas } \\
\text { Kansas } \\
\text { Municipal } \\
\text { Energy } \\
\text { Agency } \\
\text { December } 31\end{array}$ & $\begin{array}{c}\text { Kansas } \\
\text { McPherson } \\
\text { City of } \\
\text { December } 31\end{array}$ & $\begin{array}{l}\text { Kansas } \\
\text { Winfield } \\
\text { City of } \\
\text { December } 31\end{array}$ \\
\hline 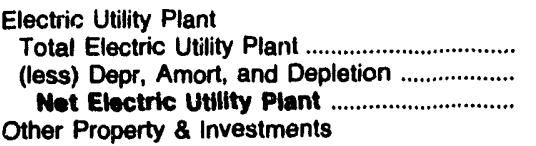 & $\begin{array}{r}29,407 \\
19,810 \\
8,597\end{array}$ & $\begin{array}{r}13,836 \\
7,333 \\
\mathbf{6 , 5 0 4}\end{array}$ & $\begin{array}{l}538,345 \\
196,716 \\
341,628\end{array}$ & $\begin{array}{l}4,814 \\
1,509 \\
3,305\end{array}$ & $\begin{array}{l}44,399 \\
21,965 \\
22,434\end{array}$ & $\begin{array}{r}28,465 \\
13,621 \\
14,844\end{array}$ \\
\hline 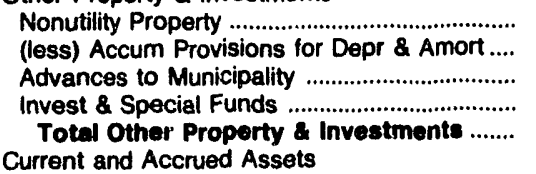 & $\begin{array}{r}0 \\
0 \\
0 \\
1,454 \\
1,454\end{array}$ & $\begin{array}{r}27 \\
17 \\
0 \\
0 \\
10\end{array}$ & $\begin{array}{r}0 \\
0 \\
0 \\
21,194 \\
21,194\end{array}$ & $\begin{array}{r}0 \\
0 \\
0 \\
8,652 \\
8,652\end{array}$ & $\begin{array}{r}154 \\
0 \\
0 \\
9,409 \\
9,563\end{array}$ & $\begin{array}{r}0 \\
0 \\
0 \\
837 \\
837\end{array}$ \\
\hline 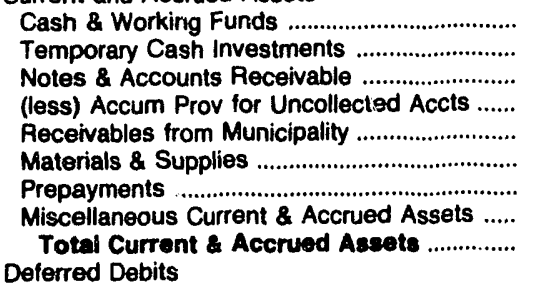 & $\begin{array}{r}6,141 \\
229 \\
386 \\
0 \\
0 \\
590 \\
0 \\
0 \\
7,346\end{array}$ & $\begin{array}{r}2,947 \\
0 \\
459 \\
0 \\
0 \\
0 \\
0 \\
0 \\
3,106\end{array}$ & $\begin{array}{r}37,237 \\
0 \\
18,513 \\
2,830 \\
0 \\
21,209 \\
481 \\
0 \\
74,610\end{array}$ & $\begin{array}{r}894 \\
0 \\
1,261 \\
0 \\
0 \\
0 \\
1,142 \\
0 \\
3,297\end{array}$ & $\begin{array}{r}1,045 \\
4,316 \\
1,423 \\
0 \\
0 \\
774 \\
21 \\
246 \\
7,826\end{array}$ & $\begin{array}{r}139 \\
1,734 \\
3 \\
0 \\
76 \\
322 \\
892 \\
0 \\
3,167\end{array}$ \\
\hline 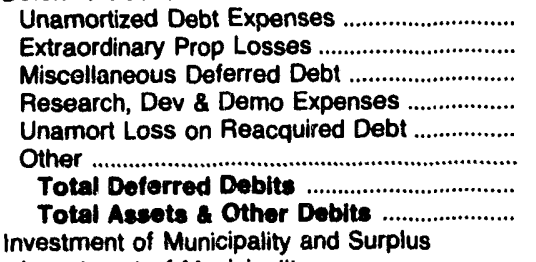 & $\begin{array}{r}0 \\
0 \\
0 \\
0 \\
0 \\
0 \\
0 \\
18,397\end{array}$ & $\begin{array}{r}0 \\
0 \\
0 \\
0 \\
0 \\
0 \\
0 \\
9,920\end{array}$ & $\begin{array}{r}2,367 \\
0 \\
70 \\
1,117 \\
0 \\
2,072 \\
5,625 \\
443,057\end{array}$ & $\begin{array}{r}295 \\
0 \\
7,963 \\
0 \\
0 \\
0 \\
8,258 \\
23,512\end{array}$ & $\begin{array}{r}0 \\
0 \\
0 \\
0 \\
0 \\
997 \\
997 \\
40,819\end{array}$ & $\begin{array}{r}0 \\
0 \\
0 \\
0 \\
0 \\
0 \\
0 \\
18,848\end{array}$ \\
\hline 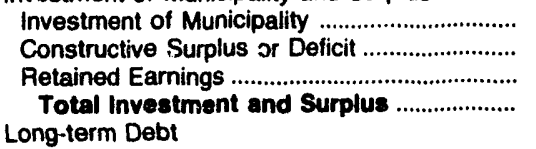 & $\begin{array}{r}9,159 \\
0 \\
6,828 \\
15,987\end{array}$ & $\begin{array}{r}9,284 \\
0 \\
0 \\
9,284\end{array}$ & $\begin{array}{r}0 \\
0 \\
289,227 \\
289,227\end{array}$ & $\begin{array}{r}0 \\
0 \\
1,907 \\
1,907\end{array}$ & $\begin{array}{r}0 \\
0 \\
27,285 \\
27,285\end{array}$ & $\begin{array}{r}12,196 \\
0 \\
1,101 \\
13,297\end{array}$ \\
\hline 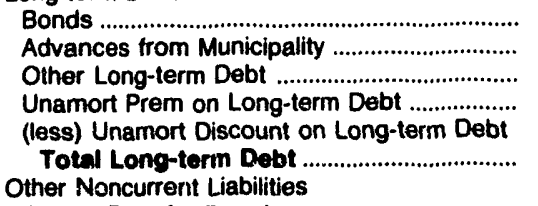 & $\begin{array}{r}990 \\
0 \\
0 \\
0 \\
0 \\
990\end{array}$ & $\begin{array}{l}0 \\
0 \\
0 \\
0 \\
0 \\
0\end{array}$ & $\begin{array}{r}126,969 \\
0 \\
0 \\
0 \\
0 \\
126,869\end{array}$ & $\begin{array}{r}18,570 \\
0 \\
0 \\
0 \\
221 \\
18,349\end{array}$ & $\begin{array}{r}12,048 \\
0 \\
0 \\
0 \\
0 \\
12,048\end{array}$ & $\begin{array}{r}5,315 \\
0 \\
0 \\
0 \\
0 \\
5,315\end{array}$ \\
\hline 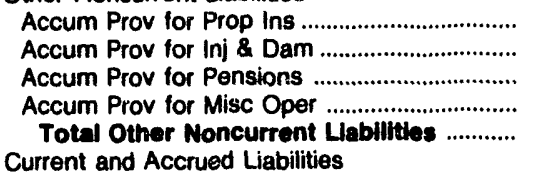 & $\begin{array}{l}0 \\
0 \\
0 \\
0 \\
0\end{array}$ & $\begin{array}{l}0 \\
0 \\
0 \\
0 \\
0\end{array}$ & $\begin{array}{r}0 \\
1,076 \\
0 \\
0 \\
1,076\end{array}$ & $\begin{array}{r}0 \\
0 \\
0 \\
58 \\
58\end{array}$ & $\begin{array}{l}0 \\
0 \\
0 \\
0 \\
0\end{array}$ & $\begin{array}{r}0 \\
0 \\
29 \\
44 \\
73\end{array}$ \\
\hline 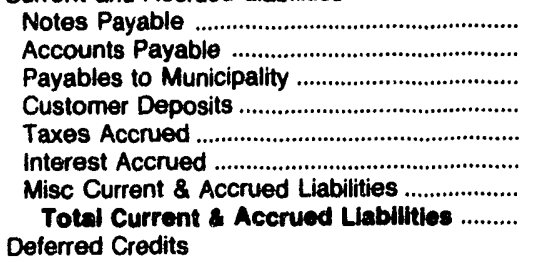 & $\begin{array}{r}0 \\
214 \\
0 \\
229 \\
590 \\
386 \\
0 \\
1,420\end{array}$ & $\begin{array}{r}0 \\
596 \\
0 \\
40 \\
0 \\
0 \\
0 \\
638\end{array}$ & $\begin{array}{r}0 \\
18,869 \\
1,619 \\
2,780 \\
528 \\
1,532 \\
292 \\
25,820\end{array}$ & $\begin{array}{r}0 \\
1,200 \\
0 \\
0 \\
0 \\
214 \\
0 \\
1,414\end{array}$ & $\begin{array}{r}0 \\
1,093 \\
0 \\
96 \\
0 \\
79 \\
218 \\
1,486\end{array}$ & $\begin{array}{r}0 \\
45 \\
0 \\
0 \\
0 \\
118 \\
0 \\
162\end{array}$ \\
\hline 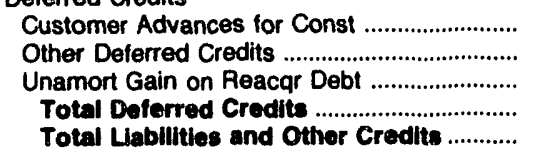 & $\begin{array}{r}0 \\
0 \\
0 \\
0 \\
18,397\end{array}$ & $\begin{array}{r}0 \\
0 \\
0 \\
0 \\
9,920\end{array}$ & $\begin{array}{r}0 \\
164 \\
0 \\
164 \\
443,057\end{array}$ & $\begin{array}{r}0 \\
1,784 \\
0 \\
1,784 \\
23,512\end{array}$ & $\begin{array}{r}0 \\
0 \\
0 \\
0 \\
40,819\end{array}$ & $\begin{array}{r}0 \\
0 \\
0 \\
0 \\
18,848\end{array}$ \\
\hline
\end{tabular}

Note: Totals may not equal sum of components because of independent rounding.

Source: Energy Information Administration, Form EIA-412, "Annual Report of Public Electric Utilities." 

Table 37. Balance Sheet by Major Publicly Owned Electric Utility
Within State at End of Period, 1991 (Continued) (Thousand Dollars)

\begin{tabular}{|c|c|c|c|c|c|c|}
\hline Item & $\begin{array}{l}\text { Kentucky } \\
\text { Bowling } \\
\text { Green } \\
\text { City of } \\
\text { June } 30\end{array}$ & $\begin{array}{l}\text { Frankfort } \\
\text { City of } \\
\text { June } 30\end{array}$ & $\begin{array}{l}\text { Kentucky } \\
\text { Franklin } \\
\text { City of } \\
\text { June } 30\end{array}$ & $\begin{array}{l}\text { Kentucky } \\
\text { Glasgow } \\
\text { City of } \\
\text { June } 30\end{array}$ & $\begin{array}{l}\text { Kentucky } \\
\text { Henderson } \\
\text { City } \\
\text { Utility Comm } \\
\text { May 31 }\end{array}$ & $\begin{array}{c}\text { Kentucky } \\
\text { Hopkinsville } \\
\text { City of } \\
\text { June } 30\end{array}$ \\
\hline 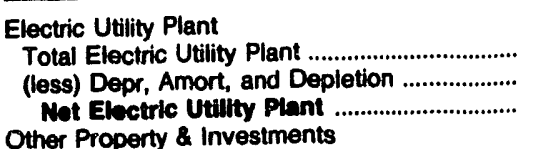 & $\begin{array}{r}32,424 \\
9,856 \\
22,569\end{array}$ & $\begin{array}{r}20,390 \\
10,419 \\
9,971\end{array}$ & $\begin{array}{l}4,765 \\
1,621 \\
3,144\end{array}$ & $\begin{array}{r}12,776 \\
3,960 \\
8,816\end{array}$ & $\begin{array}{l}99,748 \\
49,822 \\
49,927\end{array}$ & $\begin{array}{r}14,581 \\
5,632 \\
8,949\end{array}$ \\
\hline $\begin{array}{l}\text { Nonutility Property ....................................... } \\
\text { (less) Accum Provisions for Depr \& Amort.... } \\
\text { Advances to Municipality ............................. } \\
\text { Invest \& Special Funds .................................. } \\
\text { Total Other Property \& Investments ....... } \\
\text { Current and Accrued Assets }\end{array}$ & $\begin{array}{r}0 \\
0 \\
0 \\
1,369 \\
1,369\end{array}$ & $\begin{array}{r}21,541 \\
7,065 \\
0 \\
2,786 \\
17,264\end{array}$ & $\begin{array}{r}0 \\
0 \\
0 \\
569 \\
569\end{array}$ & $\begin{array}{r}0 \\
0 \\
0 \\
1,710 \\
1,710\end{array}$ & $\begin{array}{r}0 \\
0 \\
0 \\
10 \\
10\end{array}$ & $\begin{array}{r}298 \\
0 \\
0 \\
2,268 \\
2,566\end{array}$ \\
\hline 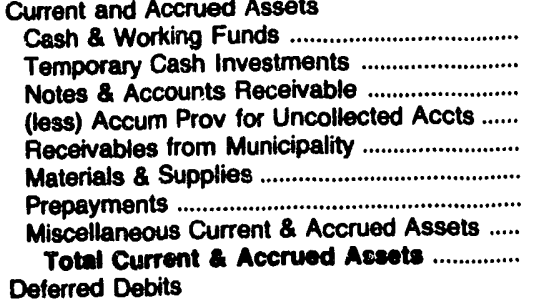 & $\begin{array}{r}3,564 \\
0 \\
2,622 \\
0 \\
0 \\
819 \\
163 \\
28 \\
7,197\end{array}$ & $\begin{array}{r}500 \\
0 \\
3,608 \\
2 \\
0 \\
2,218 \\
161 \\
25 \\
6,510\end{array}$ & $\begin{array}{r}41 \\
865 \\
904 \\
0 \\
0 \\
103 \\
19 \\
16 \\
1,947\end{array}$ & $\begin{array}{r}444 \\
0 \\
1,272 \\
0 \\
0 \\
230 \\
96 \\
10 \\
2,052\end{array}$ & $\begin{array}{r}9,001 \\
22,578 \\
874 \\
3 \\
0 \\
2,839 \\
312 \\
0 \\
35,602\end{array}$ & $\begin{array}{r}75 \\
1,025 \\
1,625 \\
4 \\
0 \\
0 \\
213 \\
204 \\
102 \\
3,239\end{array}$ \\
\hline 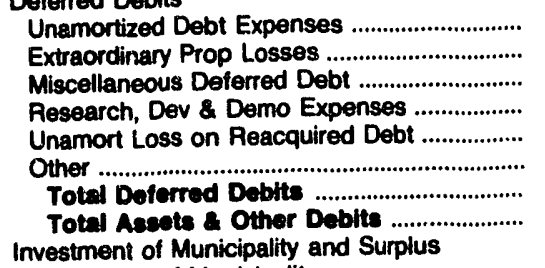 & $\begin{array}{r}32 \\
0 \\
0 \\
0 \\
0 \\
498 \\
531 \\
31,664\end{array}$ & $\begin{array}{r}0 \\
0 \\
0 \\
0 \\
0 \\
0 \\
0 \\
33,742\end{array}$ & $\begin{array}{r}0 \\
0 \\
224 \\
0 \\
0 \\
0 \\
224 \\
5,825\end{array}$ & $\begin{array}{r}59 \\
0 \\
8 \\
0 \\
0 \\
189 \\
256 \\
12,834\end{array}$ & $\begin{array}{r}700 \\
0 \\
0 \\
0 \\
0 \\
0 \\
700 \\
86,239\end{array}$ & $\begin{array}{r}21 \\
0 \\
298 \\
0 \\
0 \\
0 \\
319 \\
15,074\end{array}$ \\
\hline 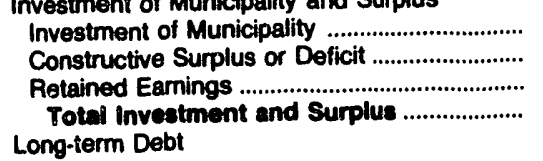 & $\begin{array}{r}0 \\
0 \\
18,479 \\
18,479\end{array}$ & $\begin{array}{r}0 \\
0 \\
26,905 \\
26,905\end{array}$ & $\begin{array}{r}0 \\
0 \\
4,596 \\
4,596\end{array}$ & $\begin{array}{r}0 \\
0 \\
7,231 \\
7,231\end{array}$ & $\begin{array}{r}0 \\
0 \\
30,486 \\
30,486\end{array}$ & $\begin{array}{r}0 \\
0 \\
10,689 \\
10,689\end{array}$ \\
\hline 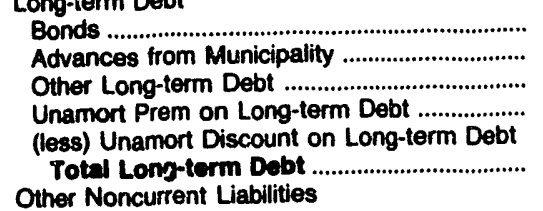 & $\begin{array}{r}5,950 \\
0 \\
0 \\
0 \\
72 \\
5,878\end{array}$ & $\begin{array}{r}2,364 \\
0 \\
3 \\
0 \\
0 \\
2,367\end{array}$ & $\begin{array}{l}0 \\
0 \\
0 \\
0 \\
0 \\
0\end{array}$ & $\begin{array}{r}4,062 \\
0 \\
61 \\
0 \\
74 \\
4,049\end{array}$ & $\begin{array}{r}47,925 \\
0 \\
0 \\
0 \\
0 \\
47,925\end{array}$ & $\begin{array}{r}1,918 \\
0 \\
303 \\
0 \\
23 \\
2,199\end{array}$ \\
\hline 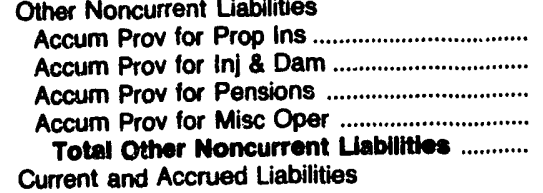 & $\begin{array}{l}0 \\
0 \\
0 \\
0 \\
0\end{array}$ & $\begin{array}{l}0 \\
0 \\
0 \\
0 \\
0\end{array}$ & $\begin{array}{l}0 \\
0 \\
0 \\
0 \\
0\end{array}$ & $\begin{array}{l}0 \\
0 \\
0 \\
0 \\
0\end{array}$ & $\begin{array}{r}0 \\
0 \\
0 \\
1,475 \\
1,475\end{array}$ & $\begin{array}{l}0 \\
0 \\
0 \\
0 \\
0\end{array}$ \\
\hline 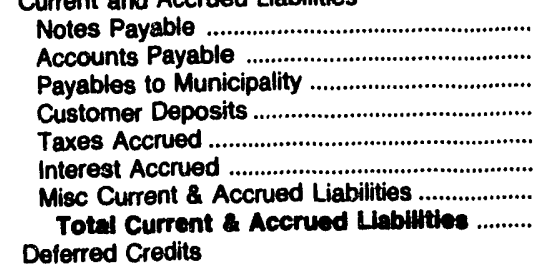 & $\begin{array}{r}519 \\
3,953 \\
0 \\
2,102 \\
129 \\
198 \\
397 \\
7,290\end{array}$ & $\begin{array}{r}0 \\
3,238 \\
0 \\
452 \\
205 \\
135 \\
268 \\
4,290\end{array}$ & $\begin{array}{r}213 \\
863 \\
0 \\
177 \\
19 \\
0 \\
6 \\
1,279\end{array}$ & $\begin{array}{r}0 \\
1,215 \\
0 \\
94 \\
42 \\
23 \\
159 \\
1,534\end{array}$ & $\begin{array}{r}0 \\
2,336 \\
0 \\
282 \\
0 \\
715 \\
3,020 \\
6,352\end{array}$ & $\begin{array}{r}0 \\
1,692 \\
0 \\
259 \\
104 \\
53 \\
70 \\
2,179\end{array}$ \\
\hline 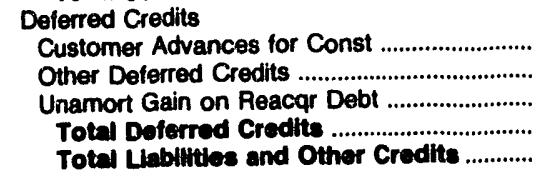 & $\begin{array}{r}9 \\
0 \\
0 \\
9 \\
31,664\end{array}$ & $\begin{array}{r}0 \\
170 \\
0 \\
170 \\
33,742\end{array}$ & $\begin{array}{r}0 \\
10 \\
0 \\
10 \\
5,885\end{array}$ & $\begin{array}{r}1 \\
19 \\
0 \\
20 \\
12,834\end{array}$ & $\begin{array}{r}0 \\
0 \\
0 \\
0 \\
86,239\end{array}$ & $\begin{array}{r}0 \\
7 \\
0 \\
7 \\
15,074\end{array}$ \\
\hline
\end{tabular}

Note: Totals may not equal sum of components because of independent rounding.

Source: Energy Information Administration, Form EIA-412, "Annual Report of Public Electric Utilities." 
Table 37. Balance Sheet by Major Publicly Owned Electric Utility
Within State at End of Period, 1991 (Continued) (Thousand Dollars)

\begin{tabular}{|c|c|c|c|c|c|c|}
\hline Item & $\begin{array}{l}\text { Kentucky } \\
\text { Madisonville } \\
\text { Municipal } \\
\text { Utils } \\
\text { June } 30\end{array}$ & $\begin{array}{l}\text { Kentucky } \\
\text { Mayfield } \\
\text { City of } \\
\text { June } 30\end{array}$ & $\begin{array}{l}\text { Kentucky } \\
\text { Murray } \\
\text { City of } \\
\text { June } 30\end{array}$ & $\begin{array}{l}\text { Kentucky } \\
\text { Owensboro } \\
\text { City of } \\
\text { May } 31\end{array}$ & $\begin{array}{l}\text { Kentucky } \\
\text { Paducah } \\
\text { City of } \\
\text { June } 30\end{array}$ & $\begin{array}{l}\text { Louisiana } \\
\begin{array}{c}\text { Alexandria } \\
\text { City of }\end{array} \\
\text { April } 30\end{array}$ \\
\hline 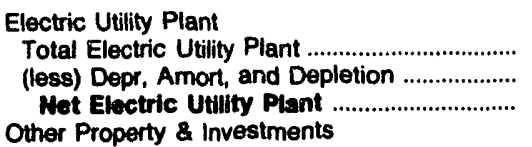 & $\begin{array}{l}5,816 \\
2,741 \\
3,076\end{array}$ & $\begin{array}{l}5,169 \\
2,035 \\
3,134\end{array}$ & $\begin{array}{l}7,783 \\
3,351 \\
4,432\end{array}$ & $\begin{array}{r}133,145 \\
64,826 \\
68,319\end{array}$ & $\begin{array}{l}37,647 \\
11,330 \\
26,317\end{array}$ & $\begin{array}{r}132,883 \\
50,913 \\
81,970\end{array}$ \\
\hline 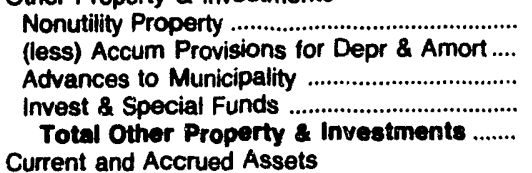 & $\begin{array}{l}0 \\
0 \\
0 \\
0 \\
0\end{array}$ & $\begin{array}{l}0 \\
0 \\
0 \\
2 \\
2\end{array}$ & $\begin{array}{r}0 \\
0 \\
0 \\
642 \\
642\end{array}$ & $\begin{array}{r}0 \\
0 \\
0 \\
66,200 \\
66,200\end{array}$ & $\begin{array}{r}0 \\
0 \\
0 \\
1,187 \\
1,187\end{array}$ & $\begin{array}{r}2,903 \\
0 \\
0 \\
27,830 \\
30,733\end{array}$ \\
\hline 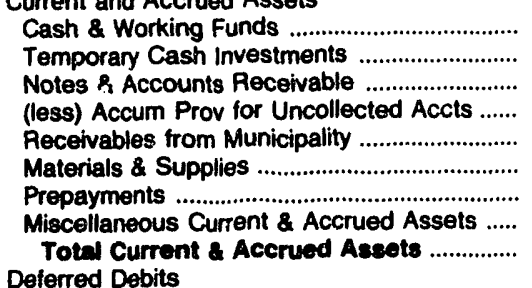 & $\begin{array}{r}1,842 \\
2,650 \\
1,812 \\
280 \\
508 \\
0 \\
23 \\
999 \\
7,553\end{array}$ & $\begin{array}{r}194 \\
0 \\
920 \\
0 \\
0 \\
107 \\
10 \\
5 \\
1,238\end{array}$ & $\begin{array}{r}176 \\
656 \\
1,128 \\
0 \\
0 \\
141 \\
0 \\
0 \\
23 \\
2,125\end{array}$ & $\begin{array}{r}1,486 \\
685 \\
1,888 \\
216 \\
84 \\
84 \\
1,058 \\
46 \\
0 \\
0 \\
5,032\end{array}$ & $\begin{array}{r}3,893 \\
0 \\
2,211 \\
0 \\
0 \\
731 \\
31 \\
65 \\
6,932\end{array}$ & $\begin{array}{r}6,264 \\
0 \\
5,438 \\
721 \\
248 \\
1,549 \\
0 \\
702 \\
13,481\end{array}$ \\
\hline 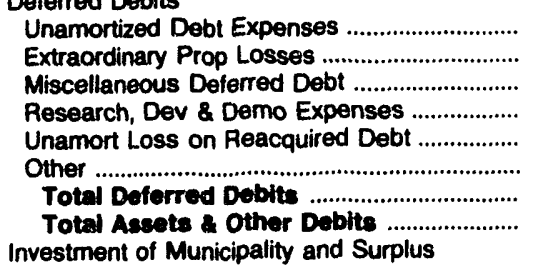 & $\begin{array}{r}0 \\
0 \\
0 \\
0 \\
0 \\
0 \\
0 \\
10,629\end{array}$ & $\begin{array}{r}0 \\
0 \\
28 \\
0 \\
0 \\
0 \\
28 \\
4,401\end{array}$ & $\begin{array}{r}0 \\
0 \\
31 \\
0 \\
0 \\
0 \\
31 \\
7,230\end{array}$ & $\begin{array}{r}856 \\
0 \\
2,458 \\
0 \\
0 \\
0 \\
3,314 \\
142,865\end{array}$ & $\begin{array}{r}2 \\
0 \\
0 \\
0 \\
0 \\
623 \\
625 \\
35,081\end{array}$ & $\begin{array}{r}0 \\
0 \\
0 \\
0 \\
0 \\
0 \\
0 \\
126,184\end{array}$ \\
\hline 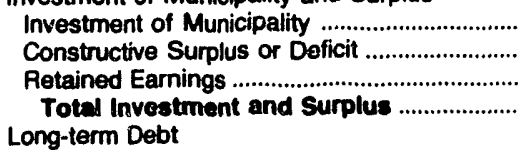 & $\begin{array}{r}0 \\
130 \\
9,162 \\
9,293\end{array}$ & $\begin{array}{r}3,437 \\
-184 \\
0 \\
3,252\end{array}$ & $\begin{array}{r}5,941 \\
-143 \\
0 \\
5,798\end{array}$ & $\begin{array}{r}1,773 \\
0 \\
46,220 \\
47,893\end{array}$ & $\begin{array}{r}0 \\
0 \\
30,580 \\
30,580\end{array}$ & $\begin{array}{r}37,097 \\
0 \\
32,725 \\
69,821\end{array}$ \\
\hline 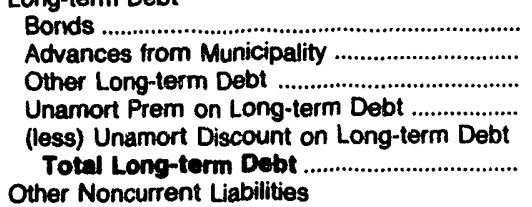 & $\begin{array}{l}0 \\
0 \\
0 \\
0 \\
0 \\
0\end{array}$ & $\begin{array}{r}0 \\
0 \\
25 \\
0 \\
0 \\
25\end{array}$ & $\begin{array}{r}0 \\
26 \\
0 \\
0 \\
0 \\
28\end{array}$ & $\begin{array}{r}66,209 \\
0 \\
5,709 \\
0 \\
0 \\
71,918\end{array}$ & $\begin{array}{r}450 \\
506 \\
0 \\
0 \\
0 \\
956\end{array}$ & $\begin{array}{r}45,720 \\
0 \\
637 \\
0 \\
0 \\
46,357\end{array}$ \\
\hline 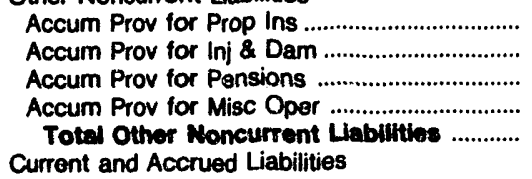 & $\begin{array}{l}0 \\
0 \\
0 \\
0 \\
0\end{array}$ & $\begin{array}{l}0 \\
0 \\
0 \\
0 \\
0\end{array}$ & $\begin{array}{l}0 \\
0 \\
0 \\
0 \\
0\end{array}$ & $\begin{array}{l}0 \\
0 \\
0 \\
0 \\
0\end{array}$ & $\begin{array}{l}0 \\
0 \\
0 \\
0 \\
0\end{array}$ & $\begin{array}{l}0 \\
0 \\
0 \\
0 \\
0\end{array}$ \\
\hline 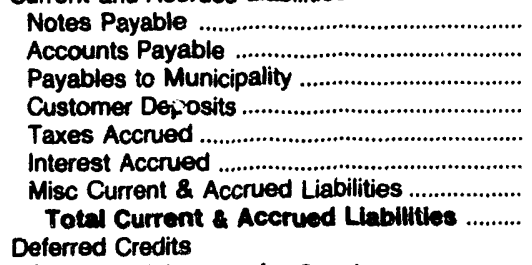 & $\begin{array}{r}0 \\
1,019 \\
0 \\
255 \\
0 \\
62 \\
0 \\
1,336\end{array}$ & $\begin{array}{r}0 \\
810 \\
0 \\
175 \\
52 \\
0 \\
76 \\
1,113\end{array}$ & $\begin{array}{r}0 \\
1,028 \\
0 \\
280 \\
71 \\
0 \\
27 \\
1,406\end{array}$ & $\begin{array}{r}0 \\
2,054 \\
0 \\
0 \\
0 \\
1,262 \\
907 \\
4,223\end{array}$ & $\begin{array}{r}0 \\
2,554 \\
0 \\
349 \\
257 \\
11 \\
279 \\
3,450\end{array}$ & $\begin{array}{r}575 \\
619 \\
733 \\
4,618 \\
0 \\
1,625 \\
1,835 \\
10,003\end{array}$ \\
\hline 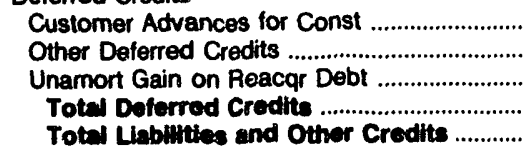 & $\begin{array}{r}0 \\
0 \\
0 \\
0 \\
10,629\end{array}$ & $\begin{array}{r}0 \\
10 \\
0 \\
10 \\
4,401\end{array}$ & $\begin{array}{r}0 \\
0 \\
0 \\
0 \\
7,230\end{array}$ & $\begin{array}{r}0 \\
18,731 \\
0 \\
18,731 \\
142,865\end{array}$ & $\begin{array}{r}0 \\
75 \\
0 \\
75 \\
35,081\end{array}$ & $\begin{array}{r}0 \\
0 \\
0 \\
0 \\
126,184\end{array}$ \\
\hline
\end{tabular}

Note: Totals may not equal sum of components because of independent rounding.

Source: Energy Information Administration, Form EJA-412, "Annual Report of Public Electric Utilities." 
Table 37. Balance Sheet by Major Publicly Owned Electric Utility
Within State at End of Period, 1991 (Continued) (Thousand Dollars)

\begin{tabular}{|c|c|c|c|c|c|c|}
\hline Item & $\begin{array}{l}\text { Louisiana } \\
\text { Lafayette } \\
\text { City of } \\
\text { October } 31\end{array}$ & $\begin{array}{c}\text { Louisiana } \\
\text { Louisiana } \\
\text { Energy } \\
\& \\
\text { Power Auth } \\
\text { December } 31\end{array}$ & $\begin{array}{l}\text { Louisiana } \\
\text { Morgan } \\
\text { City City of } \\
\text { December } 31\end{array}$ & $\begin{array}{l}\text { Louisiana } \\
\begin{array}{c}\text { Natchitoches } \\
\text { City of }\end{array} \\
\text { May } 31\end{array}$ & $\begin{array}{l}\text { Louisiana } \\
\text { Ruston } \\
\text { City of } \\
\text { September } 30\end{array}$ & $\begin{array}{c}\text { Louisiana } \\
\text { Terrebonne } \\
\text { Parish } \\
\text { Consol Govt } \\
\text { December } 31\end{array}$ \\
\hline 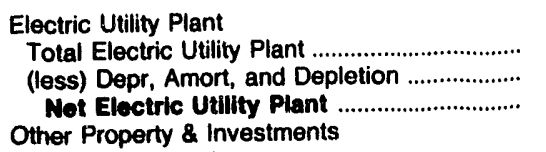 & $\begin{array}{r}193,081 \\
73,162 \\
119,920\end{array}$ & $\begin{array}{l}86,905 \\
11,947 \\
74,959\end{array}$ & $\begin{array}{l}42,860 \\
23,816 \\
19,044\end{array}$ & $\begin{array}{l}38,614 \\
12,785 \\
25,830\end{array}$ & $\begin{array}{l}28,236 \\
16,320 \\
11,917\end{array}$ & $\begin{array}{l}45,698 \\
31,059 \\
14,639\end{array}$ \\
\hline 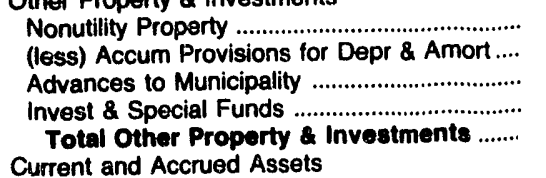 & $\begin{array}{r}0 \\
0 \\
0 \\
74,577 \\
\mathbf{7 4 , 5 7 7}\end{array}$ & $\begin{array}{r}77 \\
53 \\
0 \\
17,581 \\
17,605\end{array}$ & $\begin{array}{r}0 \\
0 \\
0 \\
2,821 \\
2,821\end{array}$ & $\begin{array}{l}0 \\
0 \\
0 \\
0 \\
0\end{array}$ & $\begin{array}{r}0 \\
0 \\
0 \\
2,650 \\
2,650\end{array}$ & $\begin{array}{r}14,713 \\
8,586 \\
0 \\
1,983 \\
8,110\end{array}$ \\
\hline 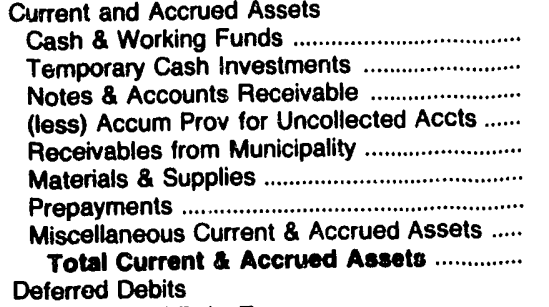 & $\begin{array}{r}4,132 \\
0 \\
15,042 \\
273 \\
0 \\
2,992 \\
8 \\
654 \\
22,555\end{array}$ & $\begin{array}{r}60 \\
13,536 \\
4,844 \\
0 \\
0 \\
3,462 \\
19 \\
80 \\
22,002\end{array}$ & $\begin{array}{r}0 \\
169 \\
1,748 \\
0 \\
1,579 \\
167 \\
0 \\
0 \\
3,664\end{array}$ & $\begin{array}{r}961 \\
0 \\
1,680 \\
0 \\
0 \\
579 \\
0 \\
22 \\
3,241\end{array}$ & $\begin{array}{r}2,400 \\
0 \\
491 \\
0 \\
530 \\
361 \\
0 \\
0 \\
3,782\end{array}$ & $\begin{array}{r}8,719 \\
0 \\
2,919 \\
0 \\
0 \\
1,632 \\
830 \\
0 \\
2,452 \\
16,552\end{array}$ \\
\hline 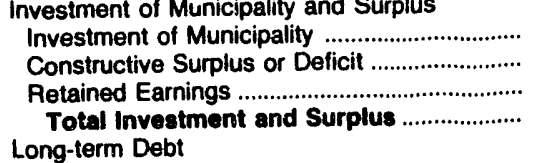 & $\begin{array}{r}5,318 \\
102,345 \\
0 \\
107,662\end{array}$ & $\begin{array}{r}0 \\
0 \\
8,388 \\
8,388\end{array}$ & $\begin{array}{r}2,874 \\
0 \\
7,261 \\
10,135\end{array}$ & $\begin{array}{r}0 \\
14,782 \\
7,507 \\
22,290\end{array}$ & $\begin{array}{r}0 \\
0 \\
9,639 \\
9,639\end{array}$ & $\begin{array}{r}5,377 \\
0 \\
22,173 \\
27,550\end{array}$ \\
\hline 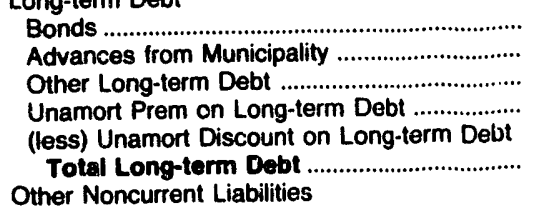 & $\begin{array}{r}68,820 \\
0 \\
0 \\
0 \\
0 \\
68,820\end{array}$ & $\begin{array}{r}131,525 \\
0 \\
0 \\
0 \\
6,069 \\
125,456\end{array}$ & $\begin{array}{r}11,500 \\
0 \\
0 \\
0 \\
0 \\
11,500\end{array}$ & $\begin{array}{r}5,483 \\
582 \\
165 \\
0 \\
0 \\
6,230\end{array}$ & $\begin{array}{r}6,050 \\
0 \\
56 \\
0 \\
0 \\
6,106\end{array}$ & $\begin{array}{r}7,540 \\
0 \\
0 \\
0 \\
0 \\
7,540\end{array}$ \\
\hline 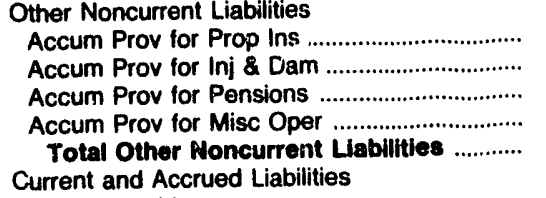 & $\begin{array}{l}0 \\
0 \\
0 \\
0 \\
0\end{array}$ & $\begin{array}{l}0 \\
0 \\
0 \\
0 \\
0\end{array}$ & $\begin{array}{l}0 \\
0 \\
0 \\
0 \\
0\end{array}$ & $\begin{array}{r}0 \\
0 \\
0 \\
75 \\
75\end{array}$ & $\begin{array}{l}0 \\
0 \\
0 \\
0 \\
0\end{array}$ & $\begin{array}{l}0 \\
0 \\
0 \\
0 \\
0\end{array}$ \\
\hline 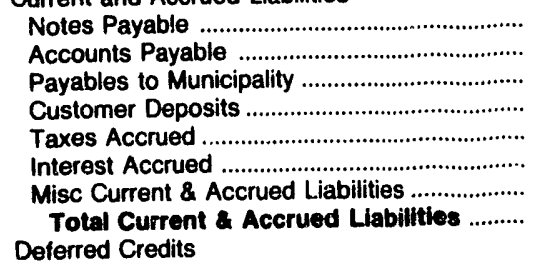 & $\begin{array}{r}0 \\
12,049 \\
0 \\
0 \\
0 \\
0 \\
0 \\
12,049\end{array}$ & $\begin{array}{r}0 \\
4,094 \\
0 \\
0 \\
0 \\
4,364 \\
6,863 \\
15,322\end{array}$ & $\begin{array}{r}724 \\
141 \\
1,463 \\
648 \\
0 \\
272 \\
646 \\
3,894\end{array}$ & $\begin{array}{r}711 \\
1,199 \\
0 \\
437 \\
0 \\
0 \\
0 \\
2,346\end{array}$ & $\begin{array}{r}925 \\
585 \\
361 \\
500 \\
0 \\
58 \\
173 \\
2,603\end{array}$ & $\begin{array}{r}1,450 \\
2,079 \\
342 \\
786 \\
0 \\
141 \\
0 \\
4,798\end{array}$ \\
\hline 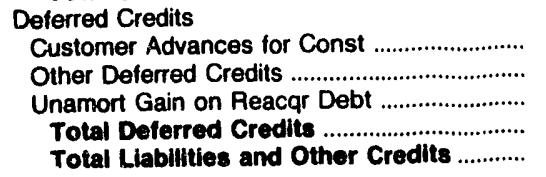 & $\begin{array}{r}30,167 \\
0 \\
0 \\
30,167 \\
218,698\end{array}$ & $\begin{array}{r}0 \\
1,831 \\
0 \\
1,831 \\
150,997\end{array}$ & $\begin{array}{r}0 \\
0 \\
0 \\
0 \\
25,529\end{array}$ & $\begin{array}{r}0 \\
0 \\
0 \\
0 \\
30,942\end{array}$ & $\begin{array}{r}0 \\
0 \\
0 \\
0 \\
18,348\end{array}$ & $\begin{array}{r}0 \\
0 \\
0 \\
0 \\
39,888\end{array}$ \\
\hline
\end{tabular}

Note: Totals may not equal sum of components because of independent rounding.

Source: Energy Information Administration, Form EIA-412, "Annual Report of Public Electric Utilities." 
Table 37. B: ance Sheet by Major Publicly Owned Electric Utility Within State at End of Period, 1991 (Continued) (Thousand Doilars)

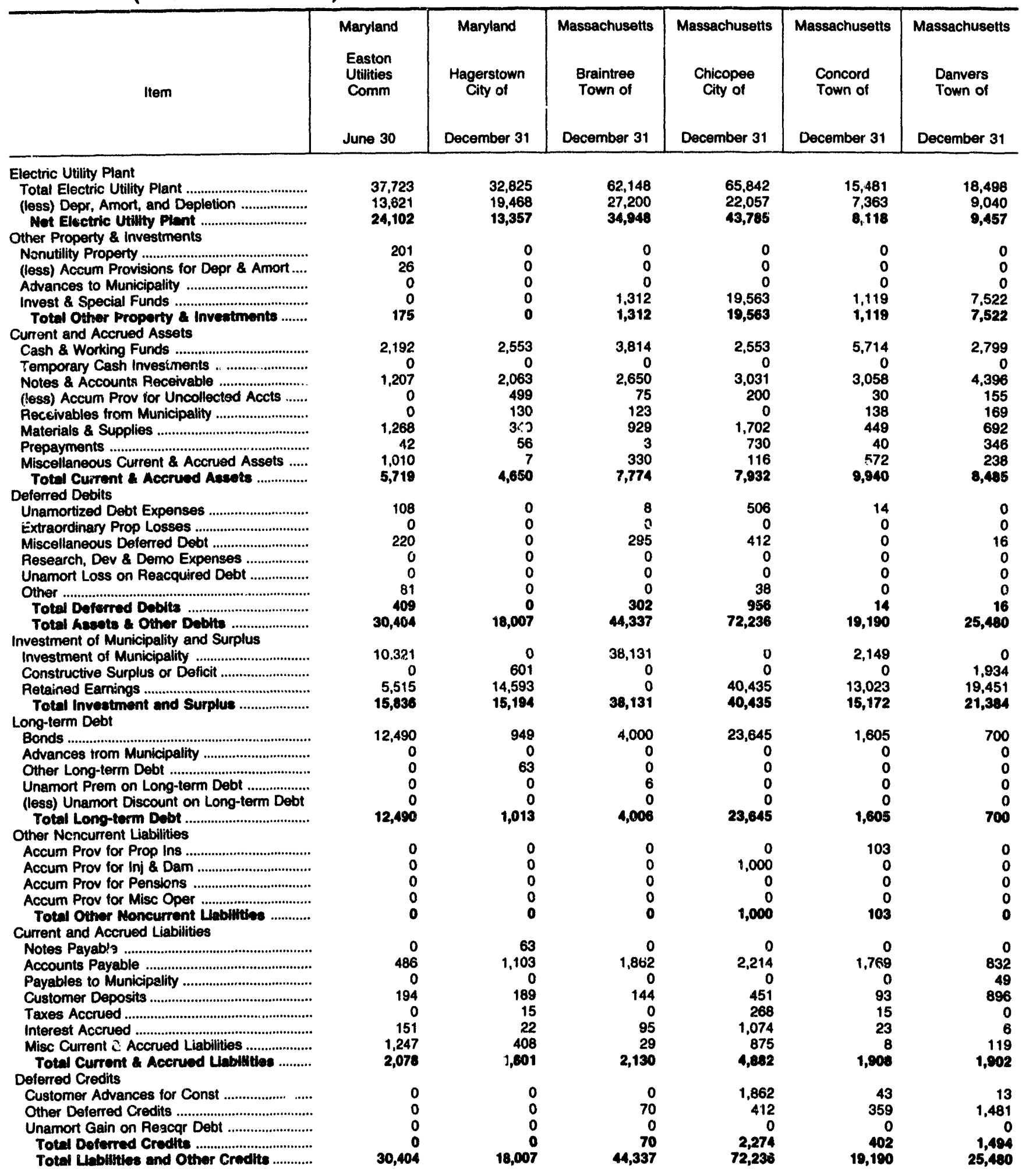

Note: Totals may not oqual sum of components because of indepencient rounding.

Source: Energy Information Administration, Form ElA-412, "Annual Report of Public Electric Utilities." 
Table 37. Balance Sheet by Major Publicly Owned Electric Utility Within State at End of Period, 1991 (Continued) (Thousand Dollars)

\begin{tabular}{|c|c|c|c|c|c|c|}
\hline Item & $\begin{array}{l}\text { Massachusetts } \\
\text { Hingham } \\
\text { City of } \\
\text { December } 31\end{array}$ & $\begin{array}{c}\text { Massachusetts } \\
\text { Holyoke } \\
\text { City of } \\
\text { December } 31\end{array}$ & $\begin{array}{l}\text { Massachusetts } \\
\text { Hudeon } \\
\text { Town of } \\
\text { December } 31\end{array}$ & $\begin{array}{l}\text { Massachusetts } \\
\text { Littleton } \\
\text { Town of } \\
\text { December } 31\end{array}$ & $\begin{array}{l}\text { Massachusetts } \\
\text { Mansfield } \\
\text { Town of } \\
\text { December } 31\end{array}$ & $\begin{array}{c}\text { Massachusetts } \\
\text { Massachusetts } \\
\text { Mun } \\
\text { Whis } \\
\text { Elec Co } \\
\text { December } 31\end{array}$ \\
\hline 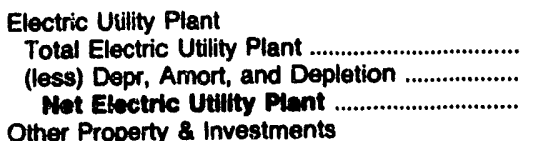 & $\begin{array}{r}19,829 \\
4,398 \\
15,480\end{array}$ & $\begin{array}{l}50,613 \\
27,112 \\
23,501\end{array}$ & $\begin{array}{r}17,129 \\
11,015 \\
8,114\end{array}$ & $\begin{array}{r}13,322 \\
4,893 \\
8,430\end{array}$ & $\begin{array}{l}8,645 \\
4,899 \\
3,746\end{array}$ & $\begin{array}{r}1,291,556 \\
185,606 \\
1,105,950\end{array}$ \\
\hline $\begin{array}{l}\text { Nonutility Property ............................... } \\
\text { (less) Accum Provisions for Depr \& Amort .... } \\
\text { Advances to Municipality ............................. } \\
\text { Invest \& Special Funds ............................... } \\
\text { Total Other Property \& Investments ...... } \\
\text { Current and Accrued Assets }\end{array}$ & $\begin{array}{r}0 \\
0 \\
0 \\
492 \\
492\end{array}$ & $\begin{array}{r}17,873 \\
9,702 \\
0 \\
1,648 \\
9,820\end{array}$ & $\begin{array}{r}0 \\
0 \\
0 \\
3,514 \\
\mathbf{3 , 5 1 4}\end{array}$ & $\begin{array}{r}0 \\
0 \\
0 \\
6,124 \\
6,124\end{array}$ & $\begin{array}{l}0 \\
0 \\
0 \\
0 \\
0\end{array}$ & $\begin{array}{l}0 \\
0 \\
0 \\
0 \\
0\end{array}$ \\
\hline 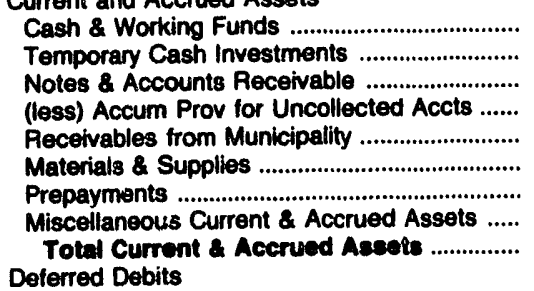 & $\begin{array}{r}352 \\
0 \\
1,610 \\
0 \\
0 \\
132 \\
707 \\
0 \\
2,801\end{array}$ & $\begin{array}{r}2,159 \\
0 \\
6,730 \\
500 \\
1,096 \\
1,713 \\
889 \\
326 \\
12,422\end{array}$ & $\begin{array}{r}1,378 \\
0 \\
3,224 \\
0 \\
2 \\
611 \\
550 \\
43 \\
5,807\end{array}$ & $\begin{array}{r}216 \\
0 \\
1,146 \\
0 \\
0 \\
392 \\
1,983 \\
0 \\
3,737\end{array}$ & $\begin{array}{r}157 \\
0 \\
2,071 \\
0 \\
154 \\
411 \\
628 \\
0 \\
3,421\end{array}$ & $\begin{array}{r}256,188 \\
1,829 \\
5,722 \\
0 \\
0 \\
19,663 \\
5,643 \\
8,718 \\
297,763\end{array}$ \\
\hline 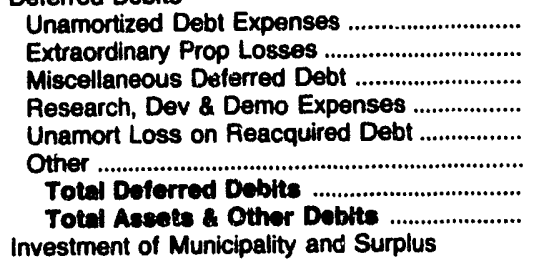 & $\begin{array}{r}0 \\
0 \\
135 \\
0 \\
0 \\
0 \\
135 \\
18,859\end{array}$ & $\begin{array}{r}141 \\
0 \\
3,663 \\
0 \\
0 \\
0 \\
3,804 \\
49,546\end{array}$ & $\begin{array}{r}0 \\
0 \\
369 \\
0 \\
0 \\
0 \\
309 \\
15,804\end{array}$ & $\begin{array}{r}26 \\
0 \\
0 \\
0 \\
0 \\
0 \\
26 \\
18,317\end{array}$ & $\begin{array}{r}0 \\
0 \\
3 \\
0 \\
0 \\
0 \\
3 \\
7,169\end{array}$ & $\begin{array}{r}35,322 \\
0 \\
41,246 \\
0 \\
0 \\
0 \\
76,588 \\
1,480,281\end{array}$ \\
\hline 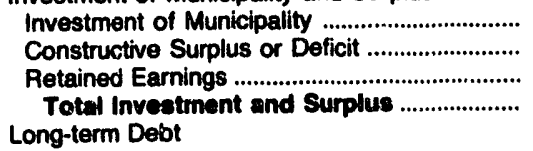 & $\begin{array}{r}0 \\
0 \\
12,828 \\
12,828\end{array}$ & $\begin{array}{r}0 \\
0 \\
34,409 \\
34,409\end{array}$ & $\begin{array}{r}20 \\
0 \\
14,253 \\
14,273\end{array}$ & $\begin{array}{r}400 \\
0 \\
13,212 \\
13,612\end{array}$ & $\begin{array}{r}0 \\
13 \\
5,613 \\
5,626\end{array}$ & $\begin{array}{l}0 \\
0 \\
0 \\
0\end{array}$ \\
\hline 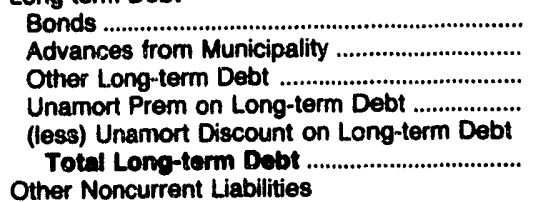 & $\begin{array}{r}3,470 \\
0 \\
0 \\
0 \\
0 \\
3,470\end{array}$ & $\begin{array}{r}7,450 \\
0 \\
0 \\
0 \\
0 \\
7,450\end{array}$ & $\begin{array}{l}0 \\
0 \\
0 \\
0 \\
0 \\
0\end{array}$ & $\begin{array}{r}535 \\
0 \\
0 \\
0 \\
0 \\
535\end{array}$ & $\begin{array}{r}0 \\
0 \\
11 \\
0 \\
0 \\
11\end{array}$ & $\begin{array}{r}1,380,955 \\
0 \\
0 \\
0 \\
0 \\
1,380,955\end{array}$ \\
\hline 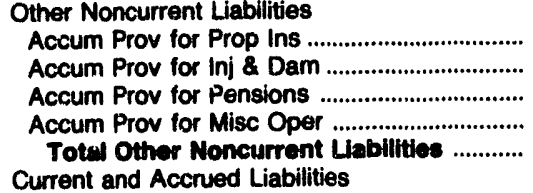 & $\begin{array}{r}0 \\
0 \\
205 \\
0 \\
205\end{array}$ & $\begin{array}{l}0 \\
0 \\
0 \\
0 \\
0\end{array}$ & $\begin{array}{r}0 \\
605 \\
0 \\
0 \\
605\end{array}$ & $\begin{array}{l}0 \\
0 \\
0 \\
0 \\
0\end{array}$ & $\begin{array}{r}0 \\
0 \\
64 \\
50 \\
114\end{array}$ & $\begin{array}{r}0 \\
4,848 \\
322 \\
2,193 \\
7,363\end{array}$ \\
\hline 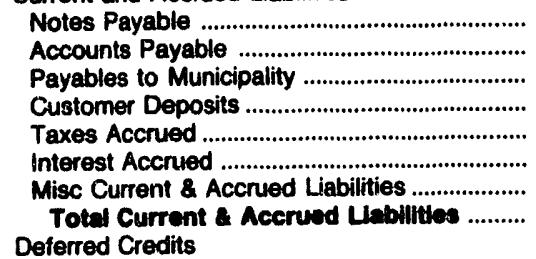 & $\begin{array}{r}0 \\
1,149 \\
297 \\
326 \\
19 \\
103 \\
0 \\
1,894\end{array}$ & $\begin{array}{r}0 \\
7,033 \\
0 \\
508 \\
0 \\
147 \\
0 \\
7,687\end{array}$ & $\begin{array}{r}0 \\
542 \\
0 \\
320 \\
0 \\
0 \\
32 \\
894\end{array}$ & $\begin{array}{r}0 \\
554 \\
0 \\
43 \\
0 \\
11 \\
3,145 \\
3,753\end{array}$ & $\begin{array}{r}0 \\
482 \\
220 \\
157 \\
18 \\
0 \\
541 \\
1,418\end{array}$ & $\begin{array}{r}0 \\
33,836 \\
0 \\
0 \\
1,860 \\
0 \\
25,965 \\
61,661\end{array}$ \\
\hline 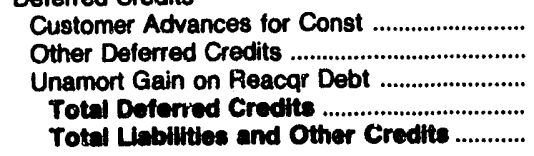 & $\begin{array}{r}462 \\
0 \\
0 \\
462 \\
18,859\end{array}$ & $\begin{array}{r}0 \\
0 \\
0 \\
0 \\
49,546\end{array}$ & $\begin{array}{r}16 \\
16 \\
0 \\
31 \\
15,804\end{array}$ & $\begin{array}{r}0 \\
417 \\
0 \\
417 \\
18,317\end{array}$ & $\begin{array}{r}0 \\
0 \\
0 \\
0 \\
7,169\end{array}$ & $\begin{array}{r}0 \\
30,302 \\
0 \\
30,302 \\
1,480,281\end{array}$ \\
\hline
\end{tabular}

Note: Totals may not equal sum of components because of independent rounding.

Source: Energy Information Administraiion, Form EIA-412, "Annual Report of Public Electric Utilities." 
Table 37. Balance Sheet by Major Publicly Owned Electric Utility Within State at End of Period, 1991 (Continued) (Thousand Dollars)

\begin{tabular}{|c|c|c|c|c|c|c|}
\hline Item & $\begin{array}{l}\text { Massachusetts } \\
\text { Middleborough } \\
\text { Town of } \\
\text { December } 31\end{array}$ & $\begin{array}{l}\text { Massachusetts } \\
\text { North } \\
\text { Attleborough } \\
\text { Town of } \\
\text { December } 31\end{array}$ & $\begin{array}{l}\text { Massachusetts } \\
\text { Norwood } \\
\text { City of } \\
\text { June } 30\end{array}$ & $\begin{array}{l}\text { Massachusetts } \\
\text { Peabody } \\
\text { City of } \\
\text { December } 31\end{array}$ & $\begin{array}{l}\text { Massachusetts } \\
\text { Reading } \\
\text { Town of } \\
\text { December } 31\end{array}$ & $\begin{array}{c}\text { Massachusetts } \\
\text { Shrewsbury } \\
\text { Town of } \\
\text { December } 31\end{array}$ \\
\hline 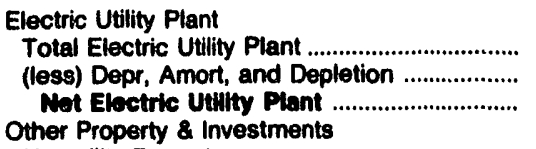 & $\begin{array}{r}14,357 \\
5,749 \\
8,609\end{array}$ & $\begin{array}{r}14,903 \\
4,801 \\
10,102\end{array}$ & $\begin{array}{r}19,435 \\
12,240 \\
7,196\end{array}$ & $\begin{array}{l}60,346 \\
20,893 \\
39,453\end{array}$ & $\begin{array}{l}37,989 \\
17,585 \\
20,404\end{array}$ & $\begin{array}{r}20,812 \\
9,771 \\
11,041\end{array}$ \\
\hline 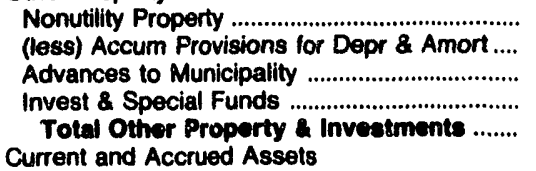 & $\begin{array}{r}0 \\
0 \\
0 \\
806 \\
806\end{array}$ & $\begin{array}{r}0 \\
0 \\
0 \\
3,051 \\
3,051\end{array}$ & $\begin{array}{r}0 \\
0 \\
0 \\
2,641 \\
2,641\end{array}$ & $\begin{array}{r}0 \\
0 \\
0 \\
4,855 \\
4,855\end{array}$ & $\begin{array}{r}0 \\
0 \\
0 \\
873 \\
873\end{array}$ & $\begin{array}{r}160 \\
0 \\
0 \\
2,173 \\
2,333\end{array}$ \\
\hline 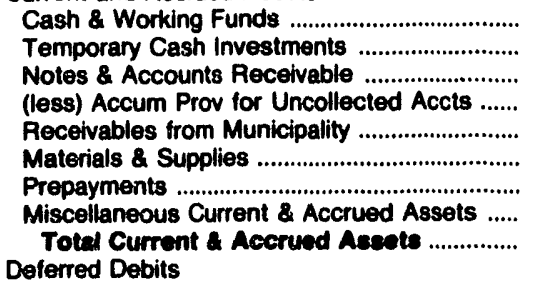 & $\begin{array}{r}1,689 \\
0 \\
2,490 \\
0 \\
0 \\
842 \\
1,441 \\
0 \\
6,462\end{array}$ & $\begin{array}{r}4,083 \\
0 \\
1,319 \\
50 \\
0 \\
787 \\
288 \\
0 \\
6,428\end{array}$ & $\begin{array}{r}2,095 \\
0 \\
1,783 \\
499 \\
0 \\
0 \\
0 \\
44 \\
3,423\end{array}$ & $\begin{array}{r}1,884 \\
0 \\
4,233 \\
100 \\
0 \\
835 \\
1,138 \\
0 \\
7,989\end{array}$ & $\begin{array}{r}12,568 \\
0 \\
4,099 \\
300 \\
33 \\
887 \\
840 \\
42 \\
48,168\end{array}$ & $\begin{array}{r}3,298 \\
318 \\
1,727 \\
0 \\
81 \\
120 \\
1,691 \\
0 \\
7,233\end{array}$ \\
\hline 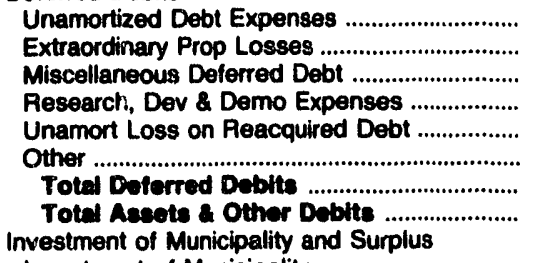 & $\begin{array}{r}0 \\
0 \\
483 \\
0 \\
0 \\
0 \\
483 \\
16,360\end{array}$ & $\begin{array}{r}51 \\
0 \\
71 \\
0 \\
0 \\
0 \\
122 \\
19,703\end{array}$ & $\begin{array}{r}0 \\
0 \\
0 \\
0 \\
0 \\
0 \\
0 \\
13,280\end{array}$ & $\begin{array}{r}119 \\
0 \\
0 \\
0 \\
0 \\
0 \\
119 \\
52,417\end{array}$ & $\begin{array}{r}0 \\
0 \\
-1,380 \\
0 \\
0 \\
0 \\
-1,380 \\
38,066\end{array}$ & $\begin{array}{r}0 \\
0 \\
3 \\
0 \\
0 \\
0 \\
3 \\
20,611\end{array}$ \\
\hline 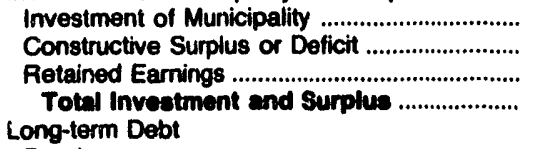 & $\begin{array}{r}1,502 \\
0 \\
9,865 \\
11,368\end{array}$ & $\begin{array}{r}0 \\
29 \\
13,664 \\
13,693\end{array}$ & $\begin{array}{r}8,367 \\
0 \\
2,586 \\
10,952\end{array}$ & $\begin{array}{r}2,150 \\
0 \\
20,308 \\
22,458\end{array}$ & $\begin{array}{r}26,144 \\
0 \\
0 \\
26,144\end{array}$ & $\begin{array}{r}0 \\
0 \\
17,619 \\
17,619\end{array}$ \\
\hline 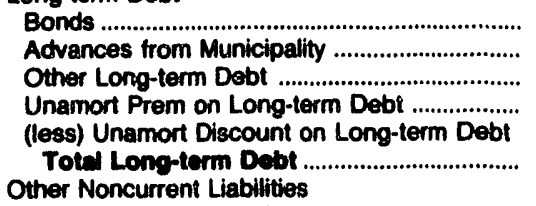 & $\begin{array}{r}1,625 \\
0 \\
0 \\
0 \\
0 \\
1,625\end{array}$ & $\begin{array}{r}4,234 \\
0 \\
0 \\
0 \\
0 \\
4,234\end{array}$ & $\begin{array}{l}0 \\
0 \\
0 \\
0 \\
0 \\
0\end{array}$ & $\begin{array}{r}24,250 \\
0 \\
0 \\
0 \\
0 \\
24,250\end{array}$ & $\begin{array}{r}3,078 \\
0 \\
0 \\
0 \\
0 \\
3,078\end{array}$ & $\begin{array}{r}385 \\
0 \\
170 \\
0 \\
0 \\
555\end{array}$ \\
\hline 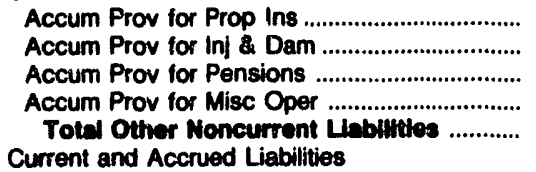 & $\begin{array}{r}0 \\
0 \\
363 \\
100 \\
463\end{array}$ & $\begin{array}{l}0 \\
0 \\
0 \\
0 \\
0\end{array}$ & $\begin{array}{l}0 \\
0 \\
0 \\
0 \\
0\end{array}$ & $\begin{array}{r}935 \\
0 \\
506 \\
393 \\
1,834\end{array}$ & $\begin{array}{l}0 \\
0 \\
0 \\
0 \\
0\end{array}$ & $\begin{array}{l}0 \\
0 \\
0 \\
0 \\
0\end{array}$ \\
\hline 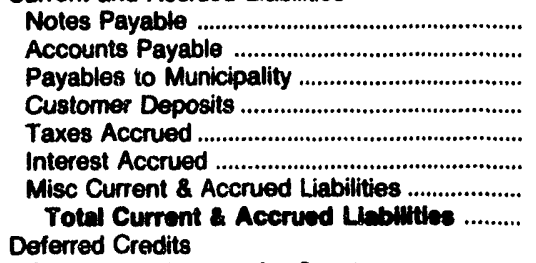 & $\begin{array}{r}1,064 \\
996 \\
0 \\
35 \\
8 \\
169 \\
260 \\
2,552\end{array}$ & $\begin{array}{r}0 \\
1,164 \\
0 \\
276 \\
8 \\
168 \\
159 \\
1,775\end{array}$ & $\begin{array}{r}0 \\
1,642 \\
0 \\
299 \\
129 \\
0 \\
102 \\
2,172\end{array}$ & $\begin{array}{r}0 \\
1,734 \\
173 \\
1,305 \\
0 \\
629 \\
34 \\
3,874\end{array}$ & $\begin{array}{r}5 \\
4,207 \\
0 \\
583 \\
0 \\
42 \\
362 \\
5,190\end{array}$ & $\begin{array}{r}0 \\
1,700 \\
0 \\
318 \\
0 \\
6 \\
0 \\
2,024\end{array}$ \\
\hline 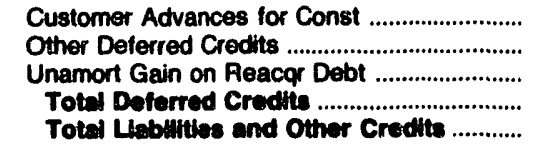 & $\begin{array}{r}0 \\
352 \\
0 \\
352 \\
16,360\end{array}$ & $\begin{array}{r}0 \\
0 \\
0 \\
0 \\
19,703\end{array}$ & $\begin{array}{r}135 \\
0 \\
0 \\
135 \\
13,260\end{array}$ & $\begin{array}{r}0 \\
0 \\
0 \\
0 \\
52,417\end{array}$ & $\begin{array}{r}2,566 \\
1,079 \\
0 \\
3,845 \\
38,066\end{array}$ & $\begin{array}{r}0 \\
414 \\
0 \\
414 \\
20,611\end{array}$ \\
\hline
\end{tabular}

Note: Totals may not equal sum of components beckuse of independent rounding.

Source: Energy Information Administration, Form ElA.412, "Annual Report of Public Electric Utilities." 
Table 37. Balance Sheet by Major Publicly Owned Electric Utility Within State at End of Period, 1991 (Continued) (Thousand Dollars)

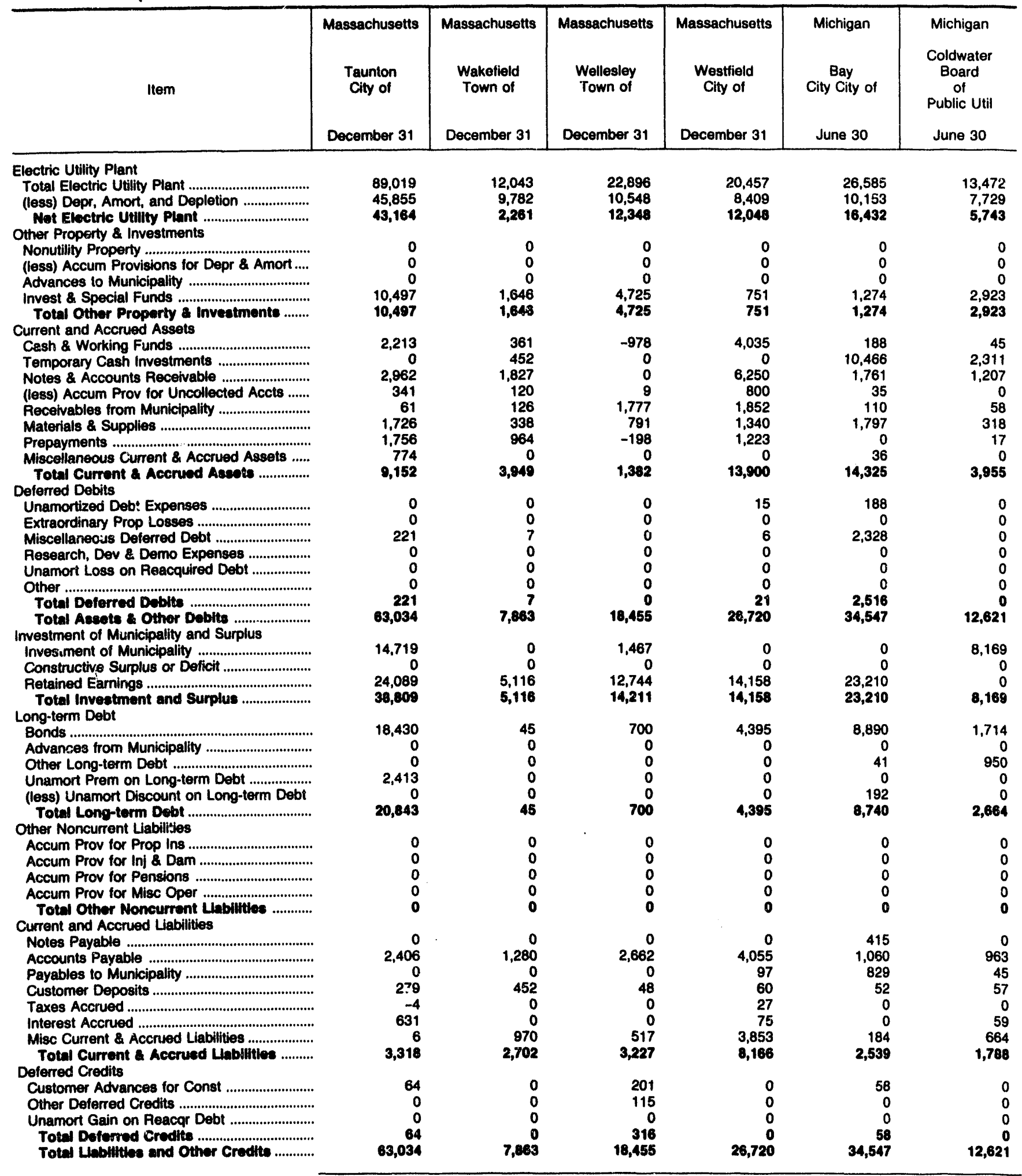

Note: Totais may not equal sum of components bocause of independent rounding.

Source: Energy Information Administration, Form ElA-412, "Annual Report of Public Electric Utilities." 
Table 37. Balance Sheet by Major Publicly Owred Electric Utility Within State at End of Period, 1991 (Continued) (Thousand Dollars)

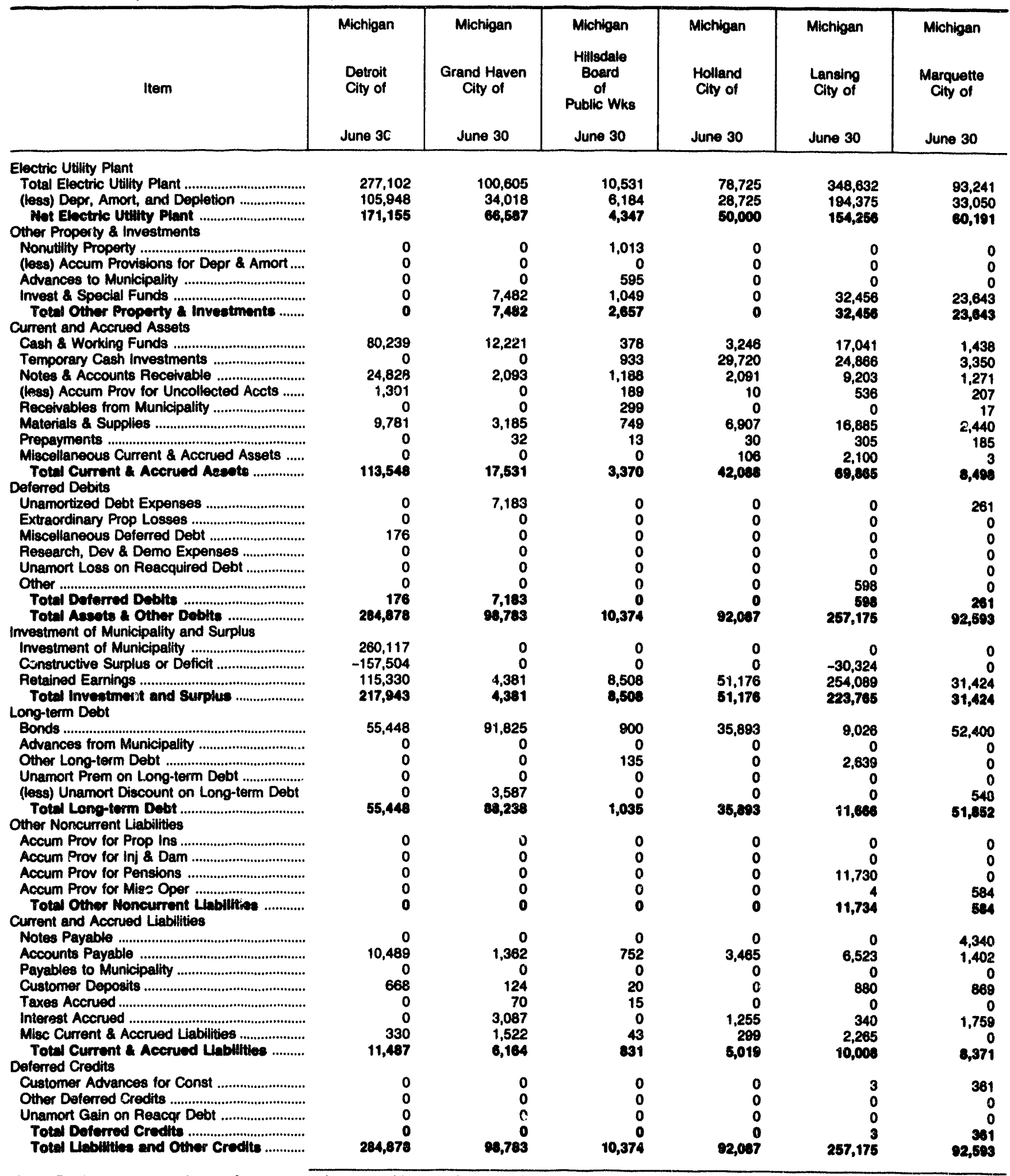

Note: Totals may not equal sum of components because of independent rounding.

Source: Energy Information Administration, Form EIA-412, "Annual Report of Public Electric Utilities." 
Table 37. Balance Sheet by Major Publicly Owned Electric Utility Within State at End of Period, 1991 (Continued) (Thousand Dollars)

\begin{tabular}{|c|c|c|c|c|c|c|}
\hline ltem & $\begin{array}{c}\text { Michigan } \\
\text { Michigan } \\
\text { Public } \\
\text { Power Agency } \\
\text { December } 31\end{array}$ & $\begin{array}{l}\text { Michigan } \\
\text { Michigan } \\
\text { South } \\
\text { Central } \\
\text { Pwr Agy } \\
\text { June } 30\end{array}$ & $\begin{array}{c}\text { Michigan } \\
\text { Sturgis } \\
\text { City of } \\
\text { September } 30\end{array}$ & $\begin{array}{l}\text { Michigan } \\
\text { Traverse } \\
\text { City City of } \\
\text { June } 30\end{array}$ & $\begin{array}{l}\text { Michigan } \\
\text { Wyandotte } \\
\text { Municipal } \\
\text { Serv Comm } \\
\text { September } 30\end{array}$ & $\begin{array}{c}\text { Minnesota } \\
\text { Alexandria } \\
\text { City of } \\
\text { December } 31\end{array}$ \\
\hline 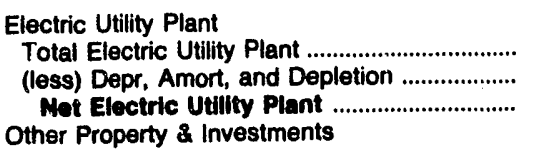 & $\begin{array}{r}453,310 \\
97,449 \\
355,861\end{array}$ & $\begin{array}{l}71,898 \\
16,469 \\
53,429\end{array}$ & $\begin{array}{l}25,323 \\
11,705 \\
13,618\end{array}$ & $\begin{array}{l}28,585 \\
10,015 \\
18,570\end{array}$ & $\begin{array}{l}92,418 \\
28,274 \\
64,143\end{array}$ & $\begin{array}{r}14,913 \\
0,770 \\
6,143\end{array}$ \\
\hline 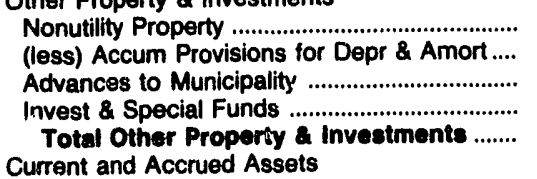 & $\begin{array}{r}73 \\
56 \\
0 \\
163,615 \\
163,631\end{array}$ & $\begin{array}{r}0 \\
0 \\
0 \\
26,665 \\
26,665\end{array}$ & $\begin{array}{r}0 \\
0 \\
149 \\
8,729 \\
8,878\end{array}$ & $\begin{array}{r}0 \\
0 \\
0 \\
861 \\
861\end{array}$ & $\begin{array}{r}0 \\
0 \\
0 \\
16,696 \\
16,696\end{array}$ & $\begin{array}{r}4,621 \\
1,744 \\
0 \\
4,472 \\
7,350\end{array}$ \\
\hline 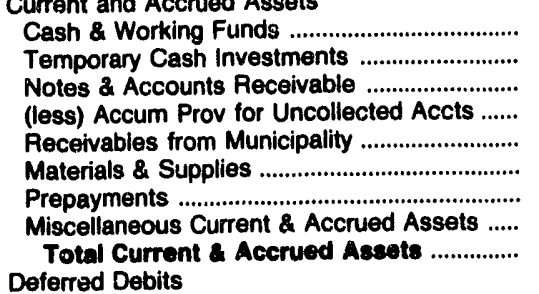 & $\begin{array}{r}72 \\
9,112 \\
2,038 \\
0 \\
0 \\
13,409 \\
0 \\
253 \\
24,884\end{array}$ & $\begin{array}{r}-1 \\
0 \\
2,182 \\
0 \\
0 \\
2,585 \\
27 \\
275 \\
5,067\end{array}$ & $\begin{array}{r}24 \\
0 \\
1,588 \\
0 \\
0 \\
398 \\
0 \\
0 \\
2,010\end{array}$ & $\begin{array}{r}1,829 \\
358 \\
1,515 \\
40 \\
0 \\
1,461 \\
9 \\
30 \\
5,162\end{array}$ & $\begin{array}{r}4,529 \\
0 \\
3,216 \\
87 \\
0 \\
2,648 \\
17 \\
115 \\
10,438\end{array}$ & $\begin{array}{r}-187 \\
702 \\
328 \\
11 \\
0 \\
408 \\
39 \\
0 \\
1,278\end{array}$ \\
\hline 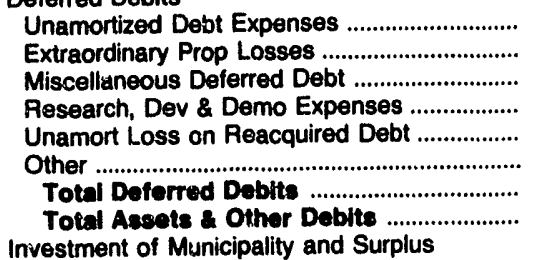 & $\begin{array}{r}7,612 \\
0 \\
1,351 \\
0 \\
0 \\
659 \\
9,622 \\
553,999\end{array}$ & $\begin{array}{r}2,599 \\
0 \\
15,418 \\
0 \\
0 \\
185 \\
18,202 \\
103,363\end{array}$ & $\begin{array}{r}0 \\
0 \\
0 \\
0 \\
0 \\
0 \\
0 \\
04505\end{array}$ & $\begin{array}{r}134 \\
0 \\
0 \\
0 \\
0 \\
0 \\
134 \\
24,727\end{array}$ & $\begin{array}{r}0 \\
0 \\
0 \\
0 \\
0 \\
0 \\
0 \\
91,277\end{array}$ & $\begin{array}{r}0 \\
0 \\
498 \\
0 \\
0 \\
0 \\
498 \\
15,268\end{array}$ \\
\hline 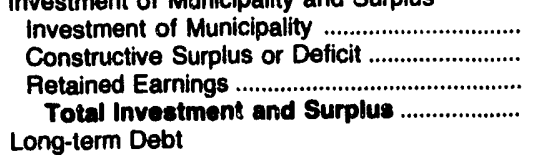 & $\begin{array}{r}609 \\
0 \\
52 \\
661\end{array}$ & $\begin{array}{r}0 \\
0 \\
3,972 \\
3,972\end{array}$ & $\begin{array}{r}0 \\
0 \\
17,797 \\
17,797\end{array}$ & $\begin{array}{r}56 \\
0 \\
19,993 \\
20,049\end{array}$ & $\begin{array}{r}0 \\
2,230 \\
20,824 \\
23,054\end{array}$ & $\begin{array}{r}2,006 \\
0 \\
11,636 \\
13,641\end{array}$ \\
\hline 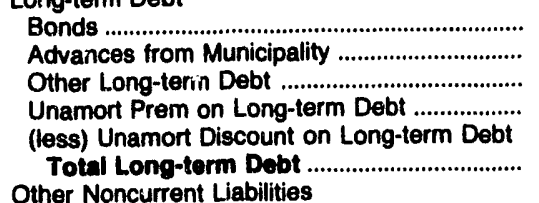 & $\begin{array}{r}448,968 \\
0 \\
0 \\
0 \\
0 \\
448,968\end{array}$ & $\begin{array}{r}100,405 \\
0 \\
0 \\
0 \\
5,472 \\
84,933\end{array}$ & $\begin{array}{r}4,355 \\
0 \\
0 \\
0 \\
0 \\
4,355\end{array}$ & $\begin{array}{r}3,175 \\
0 \\
0 \\
0 \\
0 \\
3,175\end{array}$ & $\begin{array}{r}53,940 \\
0 \\
102 \\
0 \\
0 \\
54,042\end{array}$ & $\begin{array}{l}0 \\
0 \\
0 \\
0 \\
0 \\
0\end{array}$ \\
\hline 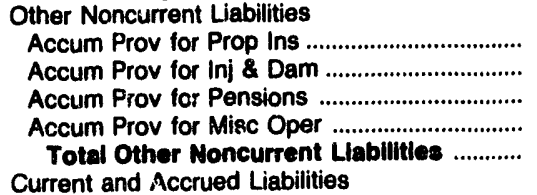 & $\begin{array}{l}0 \\
0 \\
0 \\
0 \\
0\end{array}$ & $\begin{array}{l}0 \\
0 \\
0 \\
0 \\
0\end{array}$ & $\begin{array}{r}0 \\
0 \\
0 \\
850 \\
850\end{array}$ & $\begin{array}{r}0 \\
0 \\
0 \\
270 \\
270\end{array}$ & $\begin{array}{r}4,971 \\
0 \\
0 \\
0 \\
4,971\end{array}$ & $\begin{array}{l}0 \\
0 \\
0 \\
0 \\
0\end{array}$ \\
\hline 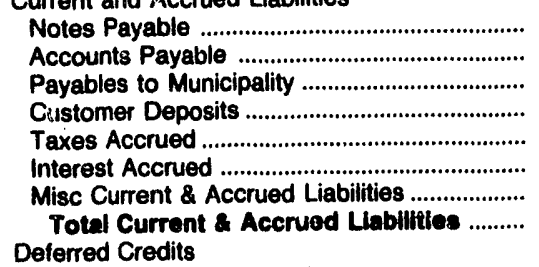 & $\begin{array}{r}27,712 \\
827 \\
0 \\
0 \\
0 \\
18,422 \\
544 \\
47,505\end{array}$ & $\begin{array}{r}0 \\
1,729 \\
0 \\
0 \\
0 \\
1,100 \\
174 \\
3,003\end{array}$ & $\begin{array}{r}0 \\
1,241 \\
0 \\
2 \\
21 \\
27 \\
0 \\
1,2 \% 0\end{array}$ & $\begin{array}{r}125 \\
715 \\
35 \\
0 \\
0 \\
0 \\
358 \\
1,234\end{array}$ & $\begin{array}{r}760 \\
0 \\
0 \\
112 \\
0 \\
36 \\
8,302 \\
8,210\end{array}$ & $\begin{array}{r}0 \\
520 \\
329 \\
65 \\
0 \\
0 \\
214 \\
1,129\end{array}$ \\
\hline 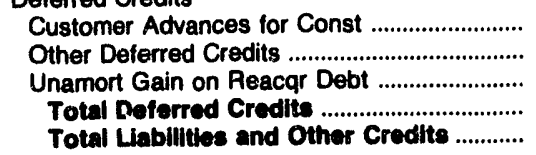 & $\begin{array}{r}0 \\
56,864 \\
0 \\
56,864 \\
553,999\end{array}$ & $\begin{array}{r}0 \\
1,456 \\
0 \\
1,456 \\
103,363\end{array}$ & $\begin{array}{r}213 \\
0 \\
0 \\
213 \\
24,605\end{array}$ & $\begin{array}{r}0 \\
0 \\
0 \\
0 \\
0 \\
24,727\end{array}$ & $\begin{array}{r}0 \\
0 \\
0 \\
0 \\
91,277\end{array}$ & $\begin{array}{r}0 \\
498 \\
0 \\
498 \\
15,268\end{array}$ \\
\hline
\end{tabular}

Note: Totals may not equal sum of components because of independent rounding.

Source: Energy Information Administration, Form ElA-412, "Annual Report of Public Electric Utilities." 
Table 37. Balance Sheet by Major Publicly Owned Electric Utility Within State at End of Period, 1991 (Continued) (Thousand Dollars)

\begin{tabular}{|c|c|c|c|c|c|c|}
\hline Item & $\begin{array}{l}\text { Minnesota } \\
\text { Anoka } \\
\text { City of } \\
\text { December } 31\end{array}$ & $\begin{array}{l}\text { Minnesota } \\
\begin{array}{l}\text { Austin } \\
\text { City of }\end{array} \\
\text { December } 31\end{array}$ & $\begin{array}{l}\text { Minnesota } \\
\text { Fairmont } \\
\text { Public } \\
\text { Utilities } \\
\text { Comm } \\
\text { December } 31\end{array}$ & $\begin{array}{l}\text { Minnesota } \\
\text { Hutchinson } \\
\text { Utilities } \\
\text { Comm } \\
\text { December } 31\end{array}$ & $\begin{array}{c}\text { Minnesota } \\
\text { Marshall } \\
\text { City of } \\
\text { December } 31\end{array}$ & $\begin{array}{l}\text { Minnesota } \\
\text { Moorhead } \\
\text { City of } \\
\text { December } 31\end{array}$ \\
\hline 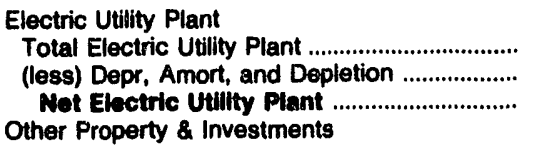 & $\begin{array}{r}11,816 \\
5,419 \\
6,397\end{array}$ & $\begin{array}{l}30,586 \\
18,670 \\
11,816\end{array}$ & $\begin{array}{r}17,753 \\
7,665 \\
10,087\end{array}$ & $\begin{array}{l}25,800 \\
12,716 \\
13,084\end{array}$ & $\begin{array}{r}12,850 \\
5,405 \\
7,445\end{array}$ & $\begin{array}{l}27,566 \\
13,615 \\
13,951\end{array}$ \\
\hline 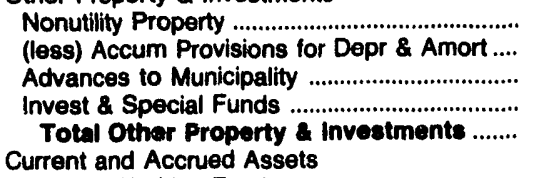 & $\begin{array}{l}0 \\
0 \\
0 \\
0 \\
0\end{array}$ & $\begin{array}{r}14,566 \\
6,345 \\
0 \\
4,261 \\
12,482\end{array}$ & $\begin{array}{r}0 \\
0 \\
0 \\
2,441 \\
2,441\end{array}$ & $\begin{array}{r}0 \\
0 \\
0 \\
4,998 \\
4,998\end{array}$ & $\begin{array}{r}0 \\
0 \\
2,373 \\
4,335 \\
6,709\end{array}$ & $\begin{array}{r}0 \\
0 \\
0 \\
4,977 \\
4,977\end{array}$ \\
\hline 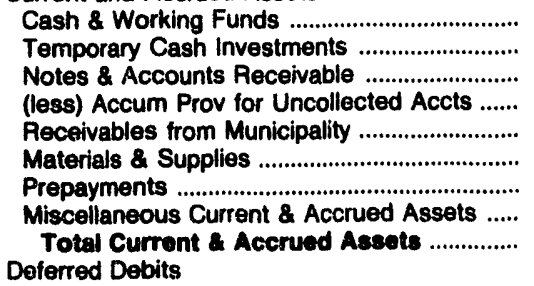 & $\begin{array}{r}2,911 \\
0 \\
1,525 \\
0 \\
457 \\
276 \\
5 \\
18 \\
5,191\end{array}$ & $\begin{array}{r}824 \\
5,650 \\
3,288 \\
72 \\
0 \\
1,065 \\
643 \\
201 \\
11,599\end{array}$ & $\begin{array}{r}484 \\
7,762 \\
978 \\
33 \\
0 \\
332 \\
0 \\
0 \\
9,522\end{array}$ & $\begin{array}{r}2,598 \\
89 \\
968 \\
0 \\
0 \\
346 \\
45 \\
43 \\
4,088\end{array}$ & $\begin{array}{r}750 \\
5,977 \\
1,224 \\
0 \\
0 \\
456 \\
41 \\
0 \\
8,448\end{array}$ & $\begin{array}{r}258 \\
0 \\
945 \\
0 \\
0 \\
378 \\
0 \\
0 \\
0 \\
1,582\end{array}$ \\
\hline 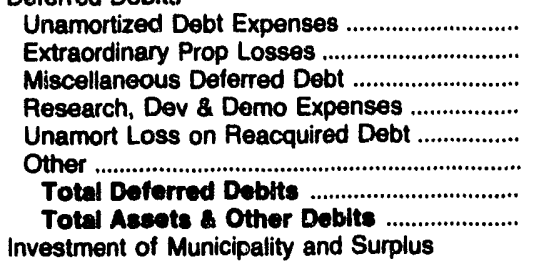 & $\begin{array}{r}0 \\
0 \\
0 \\
0 \\
0 \\
0 \\
0 \\
11,588\end{array}$ & $\begin{array}{r}3 \\
0 \\
741 \\
0 \\
0 \\
0 \\
744 \\
36,742\end{array}$ & $\begin{array}{r}95 \\
0 \\
0 \\
0 \\
0 \\
0 \\
95 \\
22,145\end{array}$ & $\begin{array}{r}48 \\
0 \\
0 \\
0 \\
0 \\
0 \\
48 \\
22,210\end{array}$ & $\begin{array}{r}103 \\
0 \\
0 \\
0 \\
-19 \\
0 \\
84 \\
22,685\end{array}$ & $\begin{array}{r}0 \\
0 \\
0 \\
0 \\
0 \\
0 \\
0 \\
20,510\end{array}$ \\
\hline 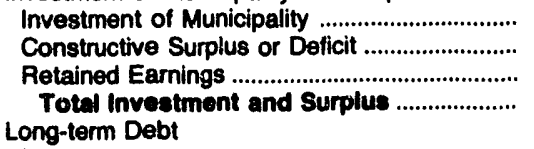 & $\begin{array}{r}0 \\
0 \\
9,896 \\
9,896\end{array}$ & $\begin{array}{r}0 \\
0 \\
31,090 \\
31,090\end{array}$ & $\begin{array}{r}20 \\
0 \\
16,026 \\
18,046\end{array}$ & $\begin{array}{r}17,561 \\
-330 \\
2,023 \\
19,254\end{array}$ & $\begin{array}{r}0 \\
0 \\
16,603 \\
16,603\end{array}$ & $\begin{array}{r}0 \\
0 \\
16,879 \\
16,879\end{array}$ \\
\hline 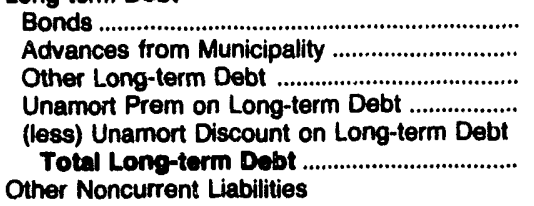 & $\begin{array}{l}0 \\
0 \\
0 \\
0 \\
0 \\
0\end{array}$ & $\begin{array}{l}0 \\
0 \\
0 \\
0 \\
0 \\
0\end{array}$ & $\begin{array}{r}5,000 \\
0 \\
46 \\
0 \\
0 \\
5,046\end{array}$ & $\begin{array}{r}1,670 \\
0 \\
0 \\
0 \\
0 \\
1,670\end{array}$ & $\begin{array}{r}5,116 \\
0 \\
0 \\
0 \\
0 \\
5.116\end{array}$ & $\begin{array}{r}2,267 \\
0 \\
0 \\
0 \\
0 \\
2,267\end{array}$ \\
\hline 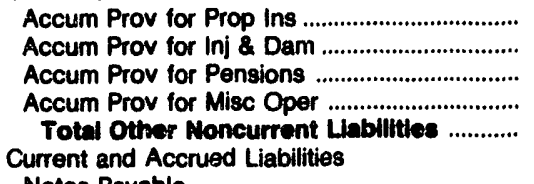 & $\begin{array}{l}0 \\
0 \\
0 \\
0 \\
0\end{array}$ & $\begin{array}{r}0 \\
0 \\
2,802 \\
0 \\
2,802\end{array}$ & $\begin{array}{l}0 \\
0 \\
0 \\
0 \\
0\end{array}$ & $\begin{array}{l}0 \\
0 \\
0 \\
0 \\
0\end{array}$ & $\begin{array}{l}0 \\
0 \\
0 \\
0 \\
0\end{array}$ & $\begin{array}{l}0 \\
0 \\
0 \\
0 \\
0\end{array}$ \\
\hline $\begin{array}{l}\text { Notes Payable } \\
\text { Accounts Payable }\end{array}$ & $\begin{array}{r}0 \\
617\end{array}$ & $\begin{array}{r}0 \\
1,912\end{array}$ & $\begin{array}{r}0 \\
677\end{array}$ & $\begin{array}{l}495 \\
598\end{array}$ & $\begin{array}{l}103 \\
782\end{array}$ & $\begin{array}{l}208 \\
851\end{array}$ \\
\hline 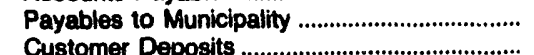 & $\begin{array}{r}0 \\
894\end{array}$ & $\begin{aligned} 0 \\
111\end{aligned}$ & $\begin{array}{r}211 \\
27\end{array}$ & $\begin{array}{r}0 \\
54\end{array}$ & $\begin{array}{r}0 \\
5 s\end{array}$ & 8 \\
\hline 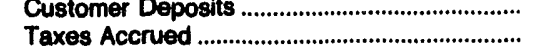 & $\begin{array}{r}894 \\
0\end{array}$ & 135 & 0 & 0 & 0 & $\begin{array}{r}135 \\
36\end{array}$ \\
\hline 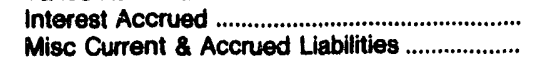 & $\begin{array}{r}62 \\
119\end{array}$ & $\begin{array}{r}3 \\
486\end{array}$ & $\begin{array}{r}138 \\
0\end{array}$ & $\begin{array}{r}10 \\
137\end{array}$ & $\begin{array}{r}0 \\
28\end{array}$ & $\begin{array}{r}25 \\
102\end{array}$ \\
\hline $\begin{array}{l}\text { Total Current A Accrued Llabilities ........... } \\
\text { Deferred Credits }\end{array}$ & 1,692 & 2,647 & 1,053 & 1,294 & 965 & 1,364 \\
\hline 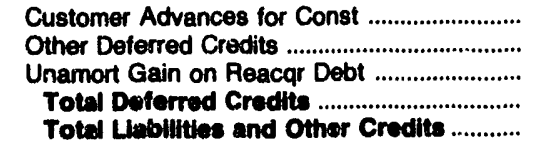 & $\begin{array}{r}0 \\
0 \\
0 \\
0 \\
11,588\end{array}$ & $\begin{array}{r}0 \\
203 \\
0 \\
203 \\
38,742\end{array}$ & $\begin{array}{r}0 \\
0 \\
0 \\
0 \\
22,145\end{array}$ & $\begin{array}{r}0 \\
0 \\
0 \\
0 \\
22,219\end{array}$ & $\begin{array}{r}0 \\
0 \\
0 \\
0 \\
22,685\end{array}$ & $\begin{array}{r}0 \\
0 \\
0 \\
0 \\
20,510\end{array}$ \\
\hline
\end{tabular}

Note: Totals may not equal sum of components because of independent rounding.

Source: Energy information Administration, Form EIA-412, "Annual Report of Public Electric Utilities." 


\section{Table 37. Balance Sheet by Major Publicly Owned Electric Utility Within State at End of Period, 1991 (Continued) (Thousand Dollars)}

\begin{tabular}{|c|c|c|c|c|c|c|}
\hline Item & $\begin{array}{l}\text { Minnesota } \\
\text { New Uim } \\
\text { Public } \\
\text { Utilities } \\
\text { Comm } \\
\text { December } 31\end{array}$ & $\begin{array}{l}\text { Minnesota } \\
\text { Northern } \\
\text { Municipal } \\
\text { Fower Agny } \\
\text { December } 31\end{array}$ & $\begin{array}{c}\text { Minnesota } \\
\text { Owatonna } \\
\text { City of } \\
\text { December } 31\end{array}$ & $\begin{array}{c}\text { Minnesota } \\
\text { Rochester } \\
\text { Public } \\
\text { Utilities } \\
\text { December } 31\end{array}$ & $\begin{array}{c}\text { Minnesota } \\
\text { Southern } \\
\text { Minnesota } \\
\text { Mun P } \\
\text { Agny } \\
\text { December } 31\end{array}$ & $\begin{array}{l}\text { Minnesota } \\
\text { Western } \\
\text { Minnesota } \\
\text { Mun } \\
\text { Pwr Agny } \\
\text { December } 31\end{array}$ \\
\hline 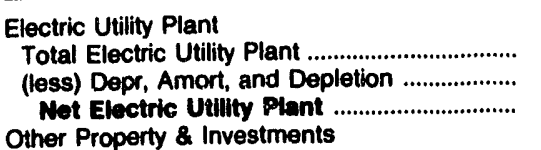 & $\begin{array}{l}23,163 \\
11,673 \\
11,490\end{array}$ & $\begin{array}{r}304,170 \\
4,015 \\
300,155\end{array}$ & $\begin{array}{r}26,450 \\
11,469 \\
14,981\end{array}$ & $\begin{array}{l}93,812 \\
47,871 \\
45,941\end{array}$ & $\begin{array}{r}512,807 \\
69,315 \\
443,492\end{array}$ & $\begin{array}{r}236,925 \\
37,410 \\
199,515\end{array}$ \\
\hline 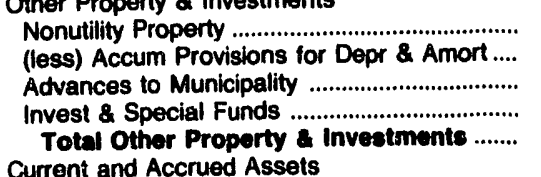 & $\begin{array}{r}0 \\
0 \\
0 \\
339 \\
339\end{array}$ & $\begin{array}{r}0 \\
0 \\
0 \\
50,820 \\
50,820\end{array}$ & $\begin{array}{r}0 \\
0 \\
0 \\
1,139 \\
1,139\end{array}$ & $\begin{array}{r}0 \\
0 \\
0 \\
211 \\
211\end{array}$ & $\begin{array}{r}44 \\
0 \\
0 \\
49,762 \\
49,805\end{array}$ & $\begin{array}{r}0 \\
0 \\
0 \\
51,668 \\
51,668\end{array}$ \\
\hline 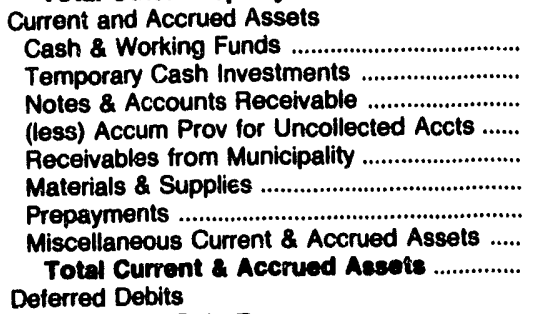 & $\begin{array}{r}0 \\
1,804 \\
923 \\
0 \\
63 \\
63 \\
1,085 \\
4 \\
310 \\
4,188\end{array}$ & $\begin{array}{r}168 \\
0 \\
1,166 \\
0 \\
0 \\
0 \\
0 \\
0 \\
1,334\end{array}$ & $\begin{array}{r}641 \\
4,127 \\
1,412 \\
79 \\
20 \\
528 \\
63 \\
746 \\
7,459\end{array}$ & $\begin{array}{r}114 \\
13,251 \\
5,173 \\
75 \\
19 \\
3,066 \\
235 \\
2,378 \\
24,161\end{array}$ & $\begin{array}{r}219 \\
103,485 \\
10,662 \\
0 \\
0 \\
7,227 \\
4,408 \\
7,090 \\
132,991\end{array}$ & $\begin{array}{r}0 \\
0 \\
5,178 \\
0 \\
0 \\
5,274 \\
28 \\
3,791 \\
14,271\end{array}$ \\
\hline 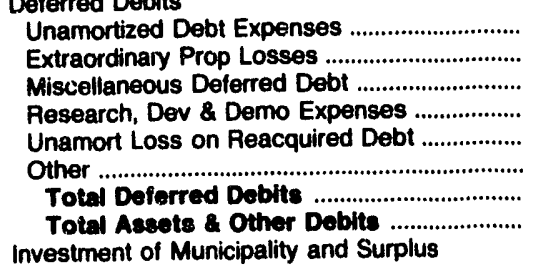 & $\begin{array}{r}0 \\
0 \\
0 \\
0 \\
0 \\
0 \\
0 \\
16,018\end{array}$ & $\begin{array}{r}0 \\
0 \\
0 \\
0 \\
0 \\
0 \\
0 \\
352,308\end{array}$ & $\begin{array}{r}116 \\
0 \\
36 \\
0 \\
0 \\
0 \\
152 \\
23,730\end{array}$ & $\begin{array}{r}0 \\
0 \\
0 \\
0 \\
0 \\
50 \\
50 \\
70,363\end{array}$ & $\begin{array}{r}88,674 \\
0 \\
60,162 \\
324 \\
0 \\
0 \\
149,159 \\
775,448\end{array}$ & $\begin{array}{r}8,016 \\
0 \\
6,677 \\
0 \\
0 \\
0 \\
14,693 \\
280,147\end{array}$ \\
\hline 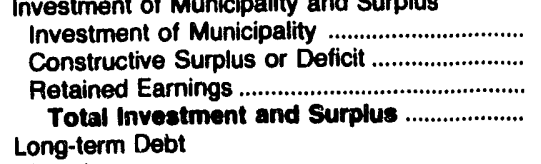 & $\begin{array}{r}0 \\
0 \\
12,896 \\
12,896\end{array}$ & $\begin{array}{l}0 \\
0 \\
0 \\
0\end{array}$ & $\begin{array}{r}0 \\
0 \\
15,550 \\
15,550\end{array}$ & $\begin{array}{r}0 \\
0 \\
55,871 \\
55,871\end{array}$ & $\begin{array}{r}0 \\
0 \\
14,878 \\
14,878\end{array}$ & $\begin{array}{l}0 \\
0 \\
0 \\
0\end{array}$ \\
\hline 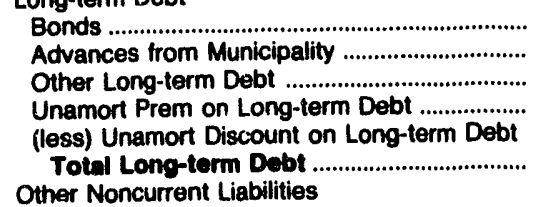 & $\begin{array}{r}2,150 \\
0 \\
0 \\
0 \\
19 \\
2,131\end{array}$ & $\begin{array}{r}340,385 \\
0 \\
0 \\
0 \\
0 \\
340,385\end{array}$ & $\begin{array}{r}6,497 \\
0 \\
0 \\
0 \\
132 \\
6,364\end{array}$ & $\begin{array}{r}0 \\
0 \\
292 \\
0 \\
0 \\
292\end{array}$ & $\begin{array}{r}754,675 \\
0 \\
0 \\
0 \\
72,636 \\
682,039\end{array}$ & $\begin{array}{r}271,380 \\
0 \\
0 \\
0 \\
11,705 \\
259,675\end{array}$ \\
\hline 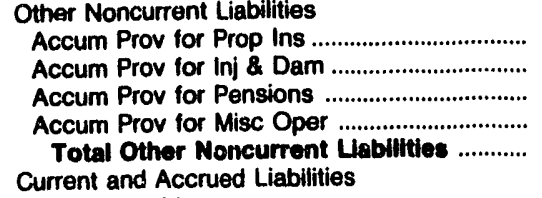 & $\begin{array}{l}0 \\
0 \\
0 \\
0 \\
0\end{array}$ & $\begin{array}{l}0 \\
0 \\
0 \\
0 \\
0\end{array}$ & $\begin{array}{l}0 \\
0 \\
0 \\
0 \\
0\end{array}$ & $\begin{array}{r}0 \\
321 \\
74 \\
5,300 \\
5,695\end{array}$ & $\begin{array}{l}0 \\
0 \\
0 \\
0 \\
0\end{array}$ & $\begin{array}{r}0 \\
0 \\
0 \\
8,350 \\
8,350\end{array}$ \\
\hline 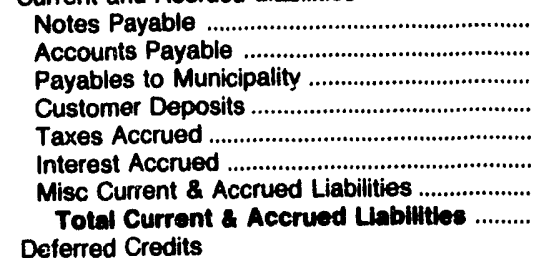 & $\begin{array}{r}125 \\
699 \\
72 \\
0 \\
0 \\
12 \\
83 \\
991\end{array}$ & $\begin{array}{r}0 \\
998 \\
0 \\
0 \\
0 \\
10,925 \\
0 \\
11,923\end{array}$ & $\begin{array}{r}0 \\
1,276 \\
3 \\
10 \\
0 \\
259 \\
267 \\
1,816\end{array}$ & $\begin{array}{r}0 \\
4,629 \\
553 \\
466 \\
349 \\
0 \\
1,110 \\
7,108\end{array}$ & $\begin{array}{r}0 \\
5,999 \\
0 \\
0 \\
6,848 \\
26,675 \\
28,569 \\
68,091\end{array}$ & $\begin{array}{r}0 \\
1,819 \\
0 \\
0 \\
777 \\
9,525 \\
0 \\
12,122\end{array}$ \\
\hline 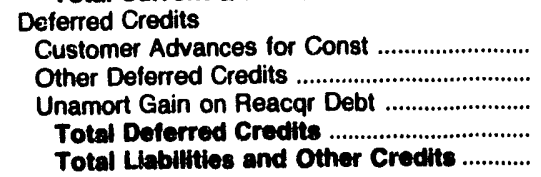 & $\begin{array}{r}0 \\
0 \\
0 \\
0 \\
16,018\end{array}$ & $\begin{array}{r}0 \\
0 \\
0 \\
0 \\
352,309\end{array}$ & $\begin{array}{r}0 \\
0 \\
0 \\
0 \\
23,730\end{array}$ & $\begin{array}{r}0 \\
1,398 \\
0 \\
1,398 \\
70,383\end{array}$ & $\begin{array}{r}0 \\
10,440 \\
0 \\
10,440 \\
775,449\end{array}$ & $\begin{array}{r}0 \\
0 \\
0 \\
0 \\
280,147\end{array}$ \\
\hline
\end{tabular}

Note: Totals may not equal sum of components because of independent rounding.

Source: Energy Information Administration, Form EIA-412, "Annual Report of Public Electric Utilities." 
Table 37. Balance Sheet by Major Publicly Owned Electric Utility Within State at End of Period, 1991 (Continued) (Thousand Dollars)

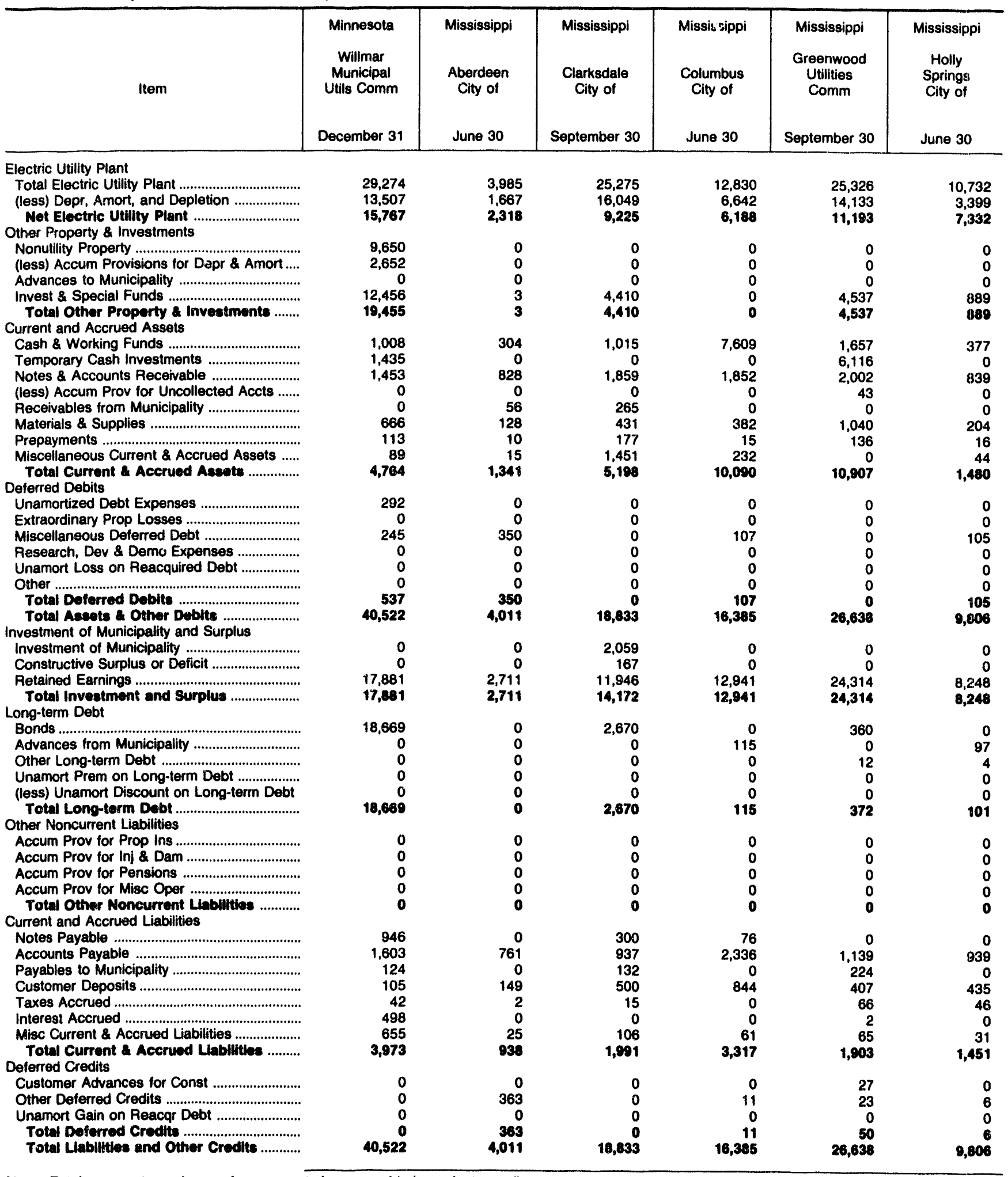

Note: Totals may not equal sum of components because of independent rounding

Source: Energy Information Administration, Form ElA-412, "Annual Report of Public Electric Utilities." 
Table 37. Balance Sheet by Major Publicly Owned Electric Utility Within State at End of Period, 1991 (Continued) (Thousand Dollars)

\begin{tabular}{|c|c|c|c|c|c|c|}
\hline Item & $\begin{array}{l}\text { Mississippi } \\
\text { Louisville } \\
\text { Electric } \\
\text { System } \\
\text { June } 30\end{array}$ & $\begin{array}{c}\text { Mississippi } \\
\text { Municipal } \\
\text { Energy } \\
\text { Agency } \\
\text { of MS } \\
\text { September } 30\end{array}$ & $\begin{array}{l}\text { Mississippi } \\
\text { New Albany } \\
\text { City of } \\
\text { June } 30\end{array}$ & $\begin{array}{l}\text { Mississippi } \\
\text { Oxford } \\
\text { City of } \\
\text { June } 30\end{array}$ & $\begin{array}{l}\text { Mississippi } \\
\text { Starkville } \\
\text { City of } \\
\text { June } 30\end{array}$ & $\begin{array}{l}\text { Mississippi } \\
\text { Tupelo } \\
\text { City of } \\
\text { June } 30\end{array}$ \\
\hline 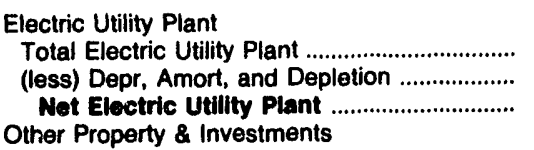 & $\begin{array}{l}6,340 \\
1,920 \\
4,420\end{array}$ & $\begin{array}{l}416 \\
113 \\
302\end{array}$ & $\begin{array}{l}9,855 \\
3,375 \\
6,480\end{array}$ & $\begin{array}{l}5,043 \\
1,916 \\
3,128\end{array}$ & $\begin{array}{l}9,583 \\
3,375 \\
6,208\end{array}$ & $\begin{array}{r}19,070 \\
6,002 \\
13,068\end{array}$ \\
\hline 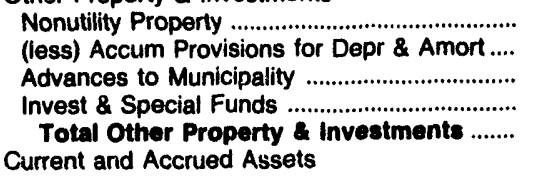 & $\begin{array}{l}0 \\
0 \\
0 \\
4 \\
4\end{array}$ & $\begin{array}{l}0 \\
0 \\
0 \\
0 \\
0\end{array}$ & $\begin{array}{r}0 \\
0 \\
0 \\
125 \\
125\end{array}$ & $\begin{array}{l}0 \\
0 \\
0 \\
6 \\
6\end{array}$ & $\begin{array}{r}0 \\
0 \\
0 \\
\mathbf{5 0 9} \\
\mathbf{5 0 9}\end{array}$ & $\begin{array}{l}0 \\
0 \\
0 \\
0 \\
0\end{array}$ \\
\hline 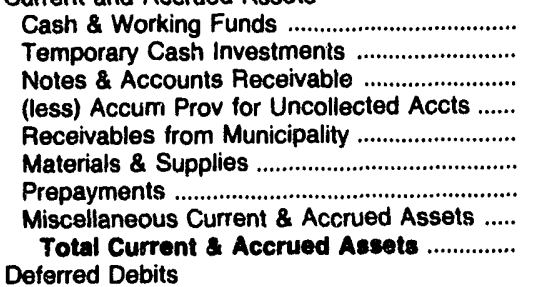 & $\begin{array}{r}0 \\
1,622 \\
1,568 \\
0 \\
0 \\
102 \\
2 \\
15 \\
3,310\end{array}$ & $\begin{array}{r}1,125 \\
2,295 \\
2,640 \\
0 \\
0 \\
0 \\
0 \\
95 \\
95 \\
6,155\end{array}$ & $\begin{array}{r}2,308 \\
1,186 \\
1,375 \\
0 \\
70 \\
189 \\
15 \\
15 \\
52 \\
5,196\end{array}$ & $\begin{array}{r}308 \\
3,733 \\
983 \\
0 \\
13 \\
118 \\
11 \\
56 \\
5,223\end{array}$ & $\begin{array}{r}1,386 \\
0 \\
1,474 \\
0 \\
24 \\
132 \\
0 \\
0 \\
21 \\
3,036\end{array}$ & $\begin{array}{r}2,084 \\
4,500 \\
3,590 \\
128 \\
5 \\
263 \\
13 \\
32 \\
10,359\end{array}$ \\
\hline 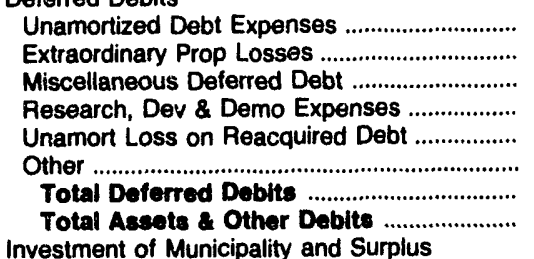 & $\begin{array}{r}0 \\
0 \\
12 \\
0 \\
0 \\
60 \\
71 \\
7,805\end{array}$ & $\begin{array}{r}0 \\
0 \\
0 \\
0 \\
0 \\
0 \\
0 \\
6,458\end{array}$ & $\begin{array}{r}2 \\
0 \\
166 \\
0 \\
0 \\
0 \\
168 \\
11,968\end{array}$ & $\begin{array}{r}0 \\
0 \\
97 \\
0 \\
0 \\
29 \\
126 \\
B, 483\end{array}$ & $\begin{array}{r}10 \\
0 \\
113 \\
0 \\
0 \\
0 \\
123 \\
9,876\end{array}$ & $\begin{array}{r}0 \\
0 \\
161 \\
0 \\
0 \\
0 \\
161 \\
23,588\end{array}$ \\
\hline 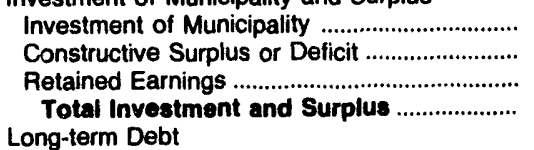 & $\begin{array}{r}0 \\
6,393 \\
326 \\
6,719\end{array}$ & $\begin{array}{r}3,824 \\
0 \\
0 \\
3,824\end{array}$ & $\begin{array}{r}0 \\
0 \\
9,768 \\
9,768\end{array}$ & $\begin{array}{r}0 \\
0 \\
6,487 \\
6,487\end{array}$ & $\begin{array}{r}0 \\
0 \\
7,076 \\
7,076\end{array}$ & $\begin{array}{r}0 \\
0 \\
19,474 \\
19,474\end{array}$ \\
\hline 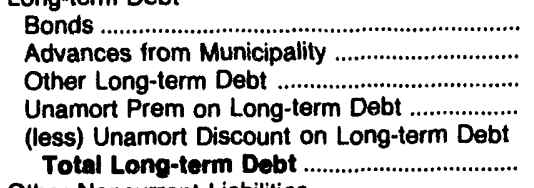 & $\begin{array}{r}0 \\
62 \\
0 \\
0 \\
0 \\
62\end{array}$ & $\begin{array}{l}0 \\
0 \\
0 \\
0 \\
0 \\
0\end{array}$ & $\begin{array}{r}286 \\
171 \\
0 \\
0 \\
0 \\
457\end{array}$ & $\begin{array}{r}0 \\
101 \\
0 \\
0 \\
0 \\
101\end{array}$ & $\begin{array}{r}0 \\
101 \\
0 \\
0 \\
0 \\
101\end{array}$ & $\begin{array}{r}0 \\
163 \\
0 \\
0 \\
0 \\
163\end{array}$ \\
\hline 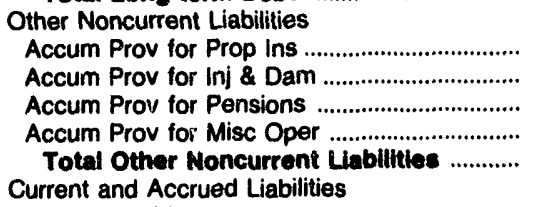 & $\begin{array}{l}0 \\
0 \\
0 \\
0 \\
0\end{array}$ & $\begin{array}{r}0 \\
0 \\
17 \\
0 \\
17\end{array}$ & $\begin{array}{l}0 \\
0 \\
0 \\
0 \\
0\end{array}$ & $\begin{array}{l}0 \\
0 \\
0 \\
0 \\
0\end{array}$ & $\begin{array}{l}0 \\
0 \\
0 \\
0 \\
0\end{array}$ & $\begin{array}{l}0 \\
0 \\
0 \\
0 \\
0\end{array}$ \\
\hline 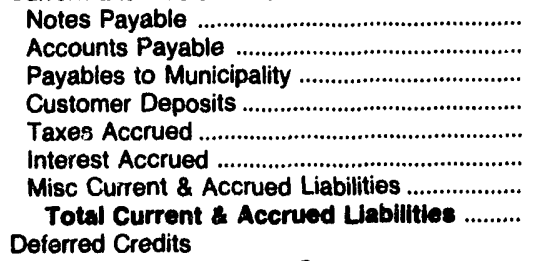 & $\begin{array}{r}0 \\
793 \\
0 \\
171 \\
18 \\
0 \\
39 \\
1,020\end{array}$ & $\begin{array}{r}0 \\
2,552 \\
0 \\
0 \\
0 \\
0 \\
65 \\
2,617\end{array}$ & $\begin{array}{r}0 \\
1,048 \\
123 \\
500 \\
2 \\
22 \\
48 \\
1,744\end{array}$ & $\begin{array}{r}0 \\
628 \\
538 \\
563 \\
72 \\
0 \\
82 \\
1,893\end{array}$ & $\begin{array}{r}0 \\
1,441 \\
278 \\
881 \\
2 \\
-2 \\
61 \\
2,680\end{array}$ & $\begin{array}{r}0 \\
3,033 \\
0 \\
789 \\
0 \\
0 \\
121 \\
3,943\end{array}$ \\
\hline 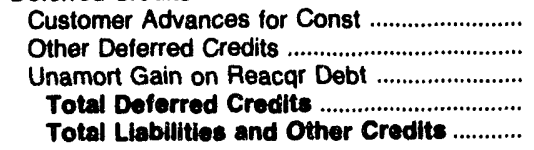 & $\begin{array}{r}0 \\
4 \\
0 \\
4 \\
7,805\end{array}$ & $\begin{array}{r}0 \\
0 \\
0 \\
0 \\
6,458\end{array}$ & $\begin{array}{r}0 \\
0 \\
0 \\
0 \\
11,969\end{array}$ & $\begin{array}{r}2 \\
0 \\
0 \\
2 \\
8,483\end{array}$ & $\begin{array}{r}0 \\
39 \\
0 \\
39 \\
9,876\end{array}$ & $\begin{array}{r}0 \\
9 \\
0 \\
9 \\
23,588\end{array}$ \\
\hline
\end{tabular}

Note: Totals may not equal sum of components because of independent rounding.

Source: Energy Information Administration, Form ElA-412. "Annual Report of Public Electric Utilities." 
Table 37. Balance Sheet by Major Publicly Owned Electric Utility
Within State at End of Period, 1991 (Continued) (Thousand Dollars)

\begin{tabular}{|c|c|c|c|c|c|c|}
\hline Item & $\begin{array}{l}\text { Mississippi } \\
\text { Wost } \\
\text { Point } \\
\text { City of } \\
\text { June } 30\end{array}$ & $\begin{array}{l}\text { Missouri } \\
\text { Carthage } \\
\text { City of } \\
\text { June } 30\end{array}$ & $\begin{array}{l}\text { Missouri } \\
\text { Columbia } \\
\text { City of } \\
\text { September } 30\end{array}$ & $\begin{array}{l}\text { Missouri } \\
\text { Hannibal } \\
\text { City of } \\
\text { June } 30\end{array}$ & $\begin{array}{c}\text { Missouri } \\
\text { Independence } \\
\text { City of } \\
\text { June } 30\end{array}$ & $\begin{array}{l}\text { Missouri } \\
\text { Kennett } \\
\text { City of } \\
\text { June } 30\end{array}$ \\
\hline 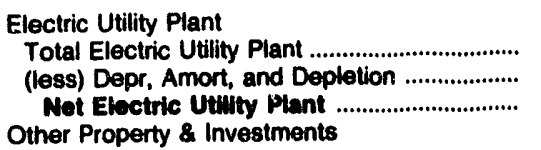 & $\begin{array}{r}6,338 \\
7 \\
6,331\end{array}$ & $\begin{array}{r}18,149 \\
12,168 \\
5,981\end{array}$ & $\begin{array}{r}69,723 \\
28,330 \\
41,383\end{array}$ & $\begin{array}{l}9,385 \\
6,080 \\
3,306\end{array}$ & $\begin{array}{r}148,597 \\
74,326 \\
74,271\end{array}$ & $\begin{array}{r}13,302 \\
9,220 \\
4,083\end{array}$ \\
\hline 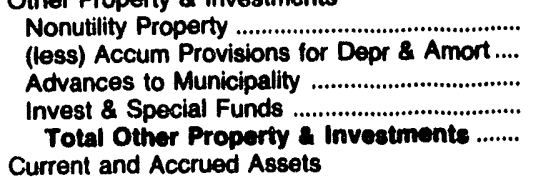 & $\begin{array}{r}0 \\
2,006 \\
0 \\
102 \\
-1,004\end{array}$ & $\begin{array}{r}0 \\
0 \\
0 \\
112 \\
112\end{array}$ & $\begin{array}{r}29,555 \\
8,541 \\
0 \\
15,138 \\
38,152\end{array}$ & $\begin{array}{l}0 \\
0 \\
0 \\
0 \\
0\end{array}$ & $\begin{array}{r}0 \\
0 \\
0 \\
17,159 \\
17,158\end{array}$ & $\begin{array}{r}0 \\
0 \\
0 \\
2,180 \\
2,180\end{array}$ \\
\hline 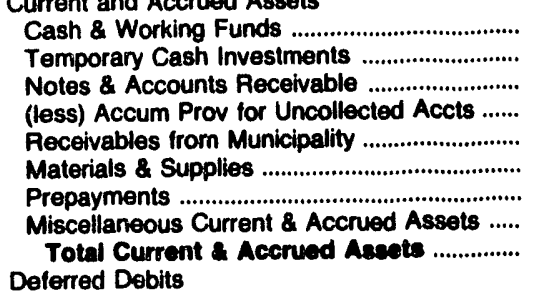 & $\begin{array}{r}118 \\
0 \\
1,153 \\
0 \\
0 \\
140 \\
32 \\
5 \\
1,448\end{array}$ & $\begin{array}{r}113 \\
1,551 \\
704 \\
18 \\
0 \\
384 \\
82 \\
0 \\
2,815\end{array}$ & $\begin{array}{r}16,396 \\
0 \\
7,917 \\
39 \\
0 \\
3,275 \\
31 \\
363 \\
27,042\end{array}$ & $\begin{array}{r}1,555 \\
5,347 \\
1,226 \\
25 \\
984 \\
270 \\
40 \\
0 \\
9,307\end{array}$ & $\begin{array}{r}1,153 \\
22,439 \\
8,540 \\
60 \\
54 \\
6,734 \\
46 \\
0 \\
38,806\end{array}$ & $\begin{array}{r}167 \\
0 \\
149 \\
0 \\
0 \\
150 \\
266 \\
0 \\
733\end{array}$ \\
\hline 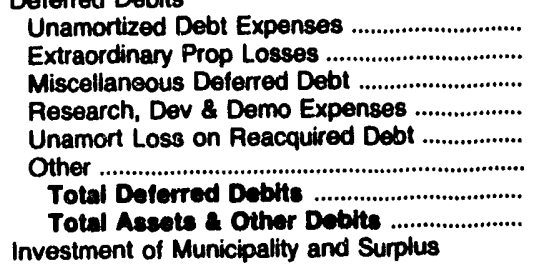 & $\begin{array}{r}12 \\
0 \\
106 \\
0 \\
0 \\
0 \\
118 \\
5,992\end{array}$ & $\begin{array}{r}0 \\
0 \\
14 \\
0 \\
0 \\
0 \\
14 \\
8,922\end{array}$ & $\begin{array}{r}322 \\
0 \\
0 \\
0 \\
0 \\
0 \\
322 \\
105,800\end{array}$ & $\begin{array}{r}0 \\
0 \\
0 \\
0 \\
0 \\
0 \\
0 \\
12,703\end{array}$ & $\begin{array}{r}2,719 \\
0 \\
0 \\
0 \\
0 \\
0 \\
2,719 \\
133,055\end{array}$ & $\begin{array}{r}1 \\
0 \\
0 \\
0 \\
0 \\
0 \\
1 \\
6,898\end{array}$ \\
\hline 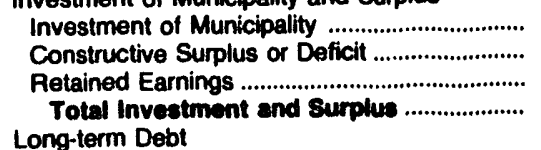 & $\begin{array}{r}0 \\
0 \\
3,893 \\
3,893\end{array}$ & $\begin{array}{r}236 \\
0 \\
8,269 \\
8,503\end{array}$ & $\begin{array}{r}417 \\
0 \\
53,526 \\
53,943\end{array}$ & $\begin{array}{r}0 \\
0 \\
11,293 \\
11,293\end{array}$ & $\begin{array}{r}0 \\
0 \\
88,754 \\
\mathbf{1 8 , 7 5 4}\end{array}$ & $\begin{array}{r}203 \\
0 \\
5,672 \\
5,875\end{array}$ \\
\hline 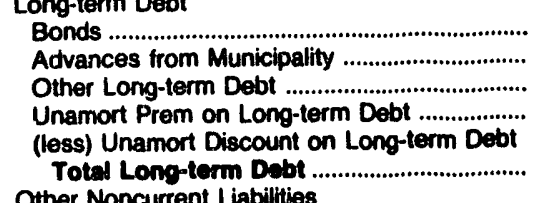 & $\begin{array}{r}0 \\
0 \\
605 \\
0 \\
0 \\
605\end{array}$ & $\begin{array}{l}0 \\
0 \\
0 \\
0 \\
0 \\
0\end{array}$ & $\begin{array}{r}42,850 \\
0 \\
52 \\
0 \\
0 \\
42,902\end{array}$ & $\begin{array}{l}0 \\
0 \\
0 \\
0 \\
0 \\
0\end{array}$ & $\begin{array}{r}36,350 \\
0 \\
0 \\
0 \\
0 \\
38,350\end{array}$ & $\begin{array}{r}420 \\
0 \\
0 \\
0 \\
0 \\
420\end{array}$ \\
\hline 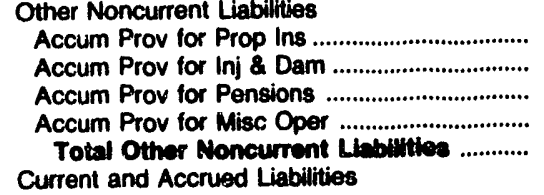 & $\begin{array}{r}0 \\
0 \\
0 \\
99 \\
9\end{array}$ & $\begin{array}{l}0 \\
0 \\
0 \\
0 \\
0\end{array}$ & $\begin{array}{l}0 \\
0 \\
0 \\
0 \\
0\end{array}$ & $\begin{array}{r}0 \\
0 \\
0 \\
181 \\
181\end{array}$ & $\begin{array}{r}0 \\
0 \\
0 \\
1,280 \\
1,280\end{array}$ & $\begin{array}{l}0 \\
0 \\
0 \\
0 \\
\mathbf{0}\end{array}$ \\
\hline 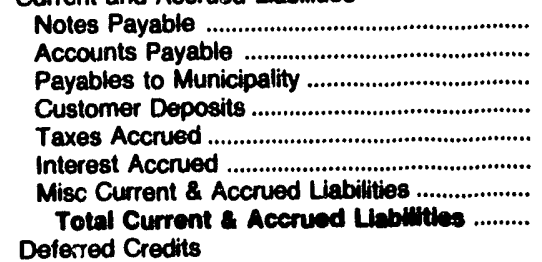 & $\begin{array}{r}0 \\
1,121 \\
0 \\
248 \\
0 \\
17 \\
11 \\
1,386\end{array}$ & $\begin{array}{r}0 \\
97 \\
0 \\
110 \\
0 \\
0 \\
209 \\
417\end{array}$ & $\begin{array}{r}26 \\
3,367 \\
1,303 \\
1,095 \\
83 \\
1,279 \\
1,812 \\
8,864\end{array}$ & $\begin{array}{r}0 \\
848 \\
211 \\
118 \\
0 \\
0 \\
53 \\
1,220\end{array}$ & $\begin{array}{r}0 \\
3,143 \\
761 \\
868 \\
0 \\
215 \\
849 \\
5,837\end{array}$ & $\begin{array}{r}0 \\
386 \\
0 \\
240 \\
10 \\
6 \\
59 \\
701\end{array}$ \\
\hline 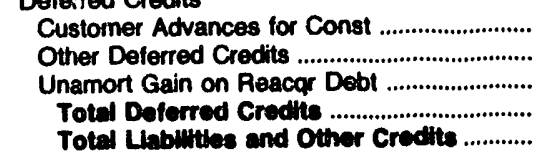 & $\begin{array}{r}0 \\
0 \\
0 \\
0 \\
\mathbf{5 , 9 2}\end{array}$ & $\begin{array}{r}0 \\
0 \\
0 \\
0 \\
0 \\
8,922\end{array}$ & $\begin{array}{r}0 \\
0 \\
0 \\
0 \\
105,800\end{array}$ & $\begin{array}{r}0 \\
0 \\
0 \\
0 \\
12,703\end{array}$ & $\begin{array}{r}835 \\
0 \\
0 \\
835 \\
133,055\end{array}$ & $\begin{array}{r}0 \\
0 \\
0 \\
0 \\
6,980\end{array}$ \\
\hline
\end{tabular}

Note: Totals may not equal sum of components because of independent rounding.

Source: Energy Information Administration, Form EIA-412, "Annual Report of Public Electric Utilities." 
Table 37. Balance Sheet by Major Publicly Owned Electric Utility Within State at End of Period, 1991 (Continued) (Thousand Dollars)

\begin{tabular}{|c|c|c|c|c|c|c|}
\hline Item & $\begin{array}{l}\text { Missouri } \\
\text { Kirkwood } \\
\text { City of } \\
\text { March } 31\end{array}$ & $\begin{array}{l}\text { Missouri } \\
\text { Lebanon } \\
\text { City of } \\
\text { October } 31\end{array}$ & $\begin{array}{l}\text { Missouri } \\
\text { Marshall } \\
\text { City of } \\
\text { September } 30\end{array}$ & $\begin{array}{l}\text { Missouri } \\
\text { Monett } \\
\text { City of } \\
\text { March } 31\end{array}$ & $\begin{array}{c}\text { Missouri } \\
\text { Poplar } \\
\text { Bluff } \\
\text { City of } \\
\text { December } 31\end{array}$ & $\begin{array}{l}\text { Missouri } \\
\text { Rolla } \\
\text { City of } \\
\text { October } 31\end{array}$ \\
\hline 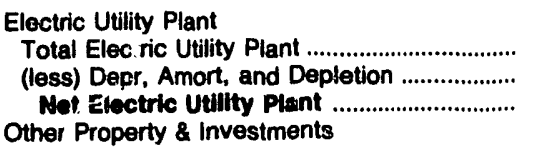 & $\begin{array}{l}5,132 \\
2,944 \\
2,188\end{array}$ & $\begin{array}{l}0 \\
0 \\
0\end{array}$ & $\begin{array}{l}30,402 \\
14,226 \\
18,177\end{array}$ & $\begin{array}{l}3,908 \\
2,743 \\
1,164\end{array}$ & $\begin{array}{r}17,020 \\
7,061 \\
9,959\end{array}$ & $\begin{array}{l}7,990 \\
5,128 \\
2,861\end{array}$ \\
\hline $\begin{array}{l}\text { Nonutility Property ................................ } \\
\text { (less) Accum Provisions for Depr \& Amort .... } \\
\text { Advances to Municipality ............................... } \\
\text { Invest \& Special Funds ................................ } \\
\text { Total Other Property \& Inveatmente....... } \\
\text { Current and Accrued Assets }\end{array}$ & $\begin{array}{r}3,221 \\
0 \\
0 \\
0 \\
3,221\end{array}$ & $\begin{array}{l}0 \\
0 \\
0 \\
0 \\
0\end{array}$ & $\begin{array}{r}0 \\
0 \\
0 \\
7,256 \\
7,256\end{array}$ & $\begin{array}{l}0 \\
0 \\
0 \\
0 \\
0\end{array}$ & $\begin{array}{r}0 \\
0 \\
0 \\
12,256 \\
12,256\end{array}$ & $\begin{array}{r}5,046 \\
2,225 \\
0 \\
2,821 \\
5,642\end{array}$ \\
\hline 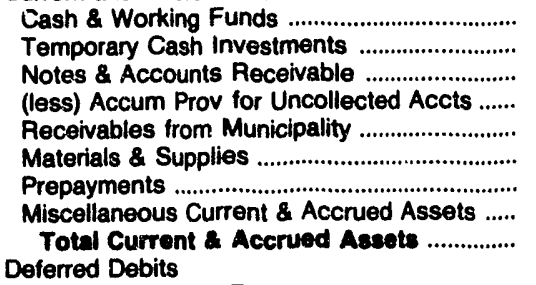 & $\begin{array}{r}101 \\
9,532 \\
2,013 \\
19 \\
0 \\
9 \\
0 \\
0 \\
0 \\
11,636\end{array}$ & $\begin{array}{l}0 \\
0 \\
0 \\
0 \\
0 \\
0 \\
0 \\
0 \\
0\end{array}$ & $\begin{array}{r}1,378 \\
0 \\
1,300 \\
0 \\
0 \\
708 \\
89 \\
0 \\
3,475\end{array}$ & $\begin{array}{r}12,512 \\
0 \\
582 \\
0 \\
0 \\
0 \\
0 \\
0 \\
13,094\end{array}$ & $\begin{array}{r}1,103 \\
0 \\
537 \\
95 \\
0 \\
357 \\
54 \\
543 \\
2,900\end{array}$ & $\begin{array}{r}622 \\
0 \\
478 \\
0 \\
0 \\
257 \\
13 \\
69 \\
1,439\end{array}$ \\
\hline 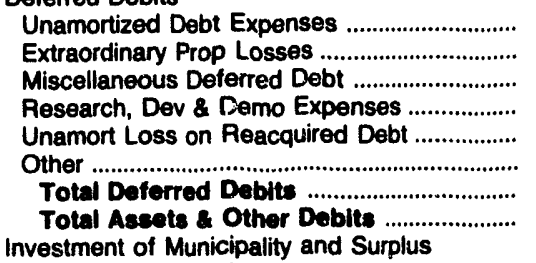 & $\begin{array}{r}0 \\
0 \\
0 \\
0 \\
0 \\
0 \\
0 \\
17,044\end{array}$ & $\begin{array}{l}0 \\
0 \\
0 \\
0 \\
0 \\
0 \\
0 \\
0\end{array}$ & $\begin{array}{r}0 \\
0 \\
0 \\
0 \\
0 \\
0 \\
0 \\
26,907\end{array}$ & $\begin{array}{r}0 \\
0 \\
0 \\
0 \\
0 \\
0 \\
0 \\
14,258\end{array}$ & $\begin{array}{r}0 \\
0 \\
0 \\
0 \\
0 \\
0 \\
0 \\
25,114\end{array}$ & $\begin{array}{r}0 \\
0 \\
0 \\
0 \\
0 \\
0 \\
0 \\
9,942\end{array}$ \\
\hline 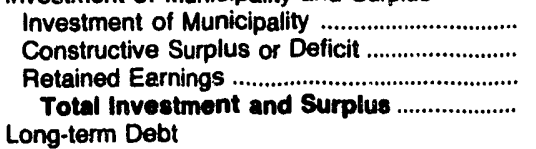 & $\begin{array}{r}526 \\
0 \\
13,197 \\
13,723\end{array}$ & $\begin{array}{l}0 \\
0 \\
0 \\
0\end{array}$ & $\begin{array}{r}180 \\
0 \\
22,464 \\
22,644\end{array}$ & $\begin{array}{r}0 \\
0 \\
13,793 \\
13,793\end{array}$ & $\begin{array}{r}0 \\
0 \\
23,994 \\
23,904\end{array}$ & $\begin{array}{r}28 \\
0 \\
8,881 \\
8,009\end{array}$ \\
\hline 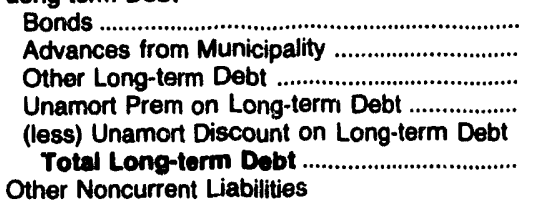 & $\begin{array}{r}310 \\
0 \\
1,275 \\
0 \\
0 \\
1,585\end{array}$ & $\begin{array}{l}0 \\
0 \\
0 \\
0 \\
0 \\
0\end{array}$ & $\begin{array}{r}2,330 \\
0 \\
0 \\
0 \\
0 \\
2,330\end{array}$ & $\begin{array}{l}0 \\
0 \\
0 \\
0 \\
0 \\
0\end{array}$ & $\begin{array}{r}306 \\
0 \\
0 \\
0 \\
0 \\
308\end{array}$ & $\begin{array}{l}0 \\
0 \\
0 \\
0 \\
0 \\
0\end{array}$ \\
\hline 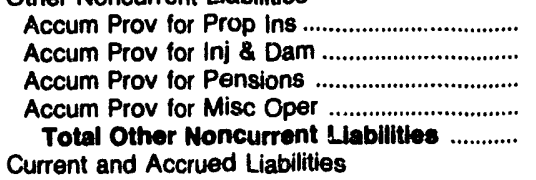 & $\begin{array}{l}0 \\
0 \\
0 \\
0 \\
0\end{array}$ & $\begin{array}{l}0 \\
0 \\
0 \\
0 \\
0\end{array}$ & $\begin{array}{l}0 \\
0 \\
0 \\
0 \\
0\end{array}$ & $\begin{array}{l}0 \\
0 \\
0 \\
0 \\
0\end{array}$ & $\begin{array}{l}0 \\
0 \\
0 \\
0 \\
0\end{array}$ & $\begin{array}{l}0 \\
0 \\
0 \\
0 \\
0\end{array}$ \\
\hline 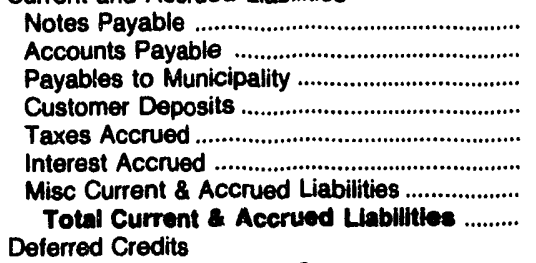 & $\begin{array}{r}0 \\
1,635 \\
0 \\
101 \\
0 \\
0 \\
0 \\
1,737\end{array}$ & $\begin{array}{l}0 \\
0 \\
0 \\
0 \\
0 \\
0 \\
0 \\
0\end{array}$ & $\begin{array}{r}0 \\
1,352 \\
0 \\
324 \\
219 \\
38 \\
0 \\
1,933\end{array}$ & $\begin{array}{r}0 \\
351 \\
2 \\
112 \\
0 \\
0 \\
0 \\
465\end{array}$ & $\begin{array}{r}0 \\
326 \\
0 \\
180 \\
48 \\
218 \\
0 \\
772\end{array}$ & $\begin{array}{r}0 \\
570 \\
140 \\
259 \\
0 \\
0 \\
65 \\
1,034\end{array}$ \\
\hline 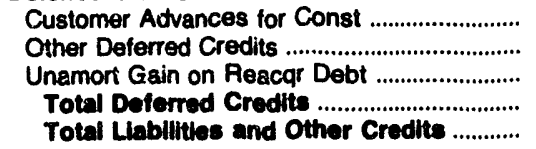 & $\begin{array}{r}0 \\
0 \\
0 \\
0 \\
17,044\end{array}$ & $\begin{array}{l}0 \\
0 \\
0 \\
0 \\
0\end{array}$ & $\begin{array}{r}0 \\
0 \\
0 \\
0 \\
26,907\end{array}$ & $\begin{array}{r}0 \\
0 \\
0 \\
0 \\
14,258\end{array}$ & $\begin{array}{r}41 \\
0 \\
0 \\
41 \\
25,114\end{array}$ & $\begin{array}{r}0 \\
0 \\
0 \\
0 \\
9,942\end{array}$ \\
\hline
\end{tabular}

Note: Totals may not equal sum of components because of independent rounding.

Source: Energy Information Administration, Form ElA-412, "Annual Report of Public Electric Utilities." 
Table 37. Balance Sheet by Major Publicly Owned Electric Utility Within State at End of Period, 1991 (Continued) (Thousand Dollars)

\begin{tabular}{|c|c|c|c|c|c|c|}
\hline Item & $\begin{array}{l}\text { Missouri } \\
\text { Sikeston } \\
\text { City of } \\
\text { May } 31\end{array}$ & $\begin{array}{c}\text { Missouri } \\
\text { Springfield } \\
\text { City of } \\
\text { September } 30\end{array}$ & $\begin{array}{c}\text { Nebraska } \\
\text { Centrai } \\
\text { Nebraska } \\
\text { Pub } \\
\text { P\&I Dist } \\
\text { December } 31\end{array}$ & $\begin{array}{c}\text { Nebraska } \\
\text { Cornhusker } \\
\text { Public } \\
\text { Power Dist } \\
\text { December } 31\end{array}$ & $\begin{array}{c}\text { Nebraska } \\
\text { Dawson } \\
\text { County } \\
\text { Public } \\
\text { Pwr } 2: 31 \\
\text { December } 31\end{array}$ & $\begin{array}{l}\text { Nebraska } \\
\text { Fremont } \\
\text { City of } \\
\text { July } 31\end{array}$ \\
\hline 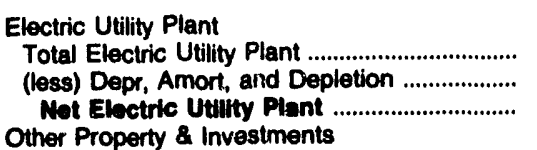 & $\begin{array}{r}217,295 \\
55,765 \\
161,530\end{array}$ & $\begin{array}{l}344,325 \\
108,582 \\
235,743\end{array}$ & $\begin{array}{r}136,121 \\
48,568 \\
87,553\end{array}$ & $\begin{array}{r}23,224 \\
9,006 \\
19,218\end{array}$ & $\begin{array}{l}41,301 \\
18,199 \\
23,102\end{array}$ & $\begin{array}{l}62,630 \\
41,004 \\
21,626\end{array}$ \\
\hline 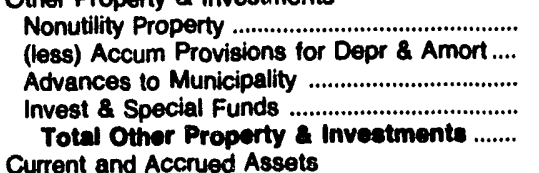 & $\begin{array}{r}0 \\
0 \\
0 \\
21,469 \\
21,469\end{array}$ & $\begin{array}{r}0 \\
0 \\
0 \\
108,427 \\
108,427\end{array}$ & $\begin{array}{r}185 \\
0 \\
0 \\
9,862 \\
10,047\end{array}$ & $\begin{array}{r}0 \\
0 \\
0 \\
2,374 \\
2,374\end{array}$ & $\begin{array}{r}0 \\
0 \\
0 \\
585 \\
585\end{array}$ & $\begin{array}{r}0 \\
0 \\
0 \\
23,071 \\
23,071\end{array}$ \\
\hline 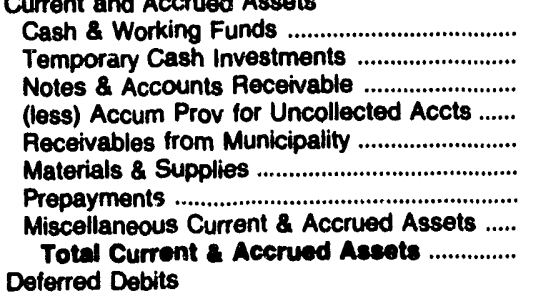 & $\begin{array}{r}133 \\
5,176 \\
8,231 \\
112 \\
166 \\
7,281 \\
230 \\
111 \\
21,215\end{array}$ & $\begin{array}{r}273 \\
8,607 \\
15,949 \\
88 \\
0 \\
12,124 \\
450 \\
0 \\
37,316\end{array}$ & $\begin{array}{r}3,361 \\
0 \\
26 \\
4 \\
2,754 \\
2,288 \\
0 \\
183 \\
8,608\end{array}$ & $\begin{array}{r}1,018 \\
1,634 \\
1,531 \\
0 \\
0 \\
518 \\
32 \\
53 \\
4,788\end{array}$ & $\begin{array}{r}295 \\
5,616 \\
1,957 \\
84 \\
0 \\
811 \\
93 \\
138 \\
8,825\end{array}$ & $\begin{array}{r}11 \\
0 \\
1,114 \\
11 \\
0 \\
2,664 \\
759 \\
1,824 \\
6,360\end{array}$ \\
\hline 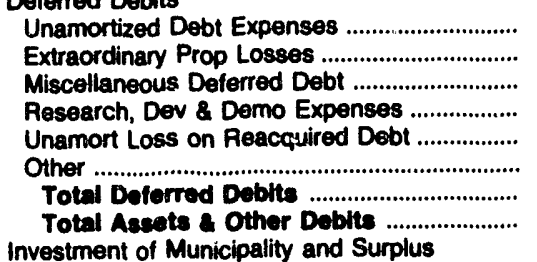 & $\begin{array}{r}4,768 \\
0 \\
1,337 \\
0 \\
0 \\
0 \\
6,108 \\
210,320\end{array}$ & $\begin{array}{r}589 \\
0 \\
5,229 \\
0 \\
0 \\
0 \\
5,818 \\
397,304\end{array}$ & $\begin{array}{r}8 \\
0 \\
896 \\
0 \\
0 \\
1,927 \\
2,831 \\
109,040\end{array}$ & $\begin{array}{r}0 \\
0 \\
312 \\
0 \\
0 \\
0 \\
312 \\
26,692\end{array}$ & $\begin{array}{r}0 \\
0 \\
0 \\
0 \\
0 \\
0 \\
0 \\
\mathbf{3 2 , 5 1 3}\end{array}$ & $\begin{array}{r}308 \\
0 \\
0 \\
0 \\
0 \\
639 \\
947 \\
52,004\end{array}$ \\
\hline 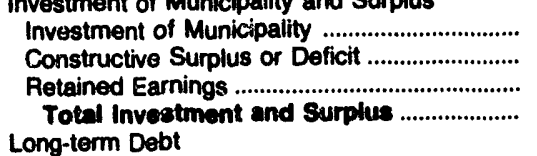 & $\begin{array}{r}0 \\
0 \\
-11,753 \\
-11,753\end{array}$ & $\begin{array}{r}0 \\
0 \\
265,924 \\
285,924\end{array}$ & $\begin{array}{r}0 \\
0 \\
31,149 \\
31,149\end{array}$ & $\begin{array}{r}0 \\
12,733 \\
0 \\
12,733\end{array}$ & $\begin{array}{r}0 \\
0 \\
26,171 \\
26,171\end{array}$ & $\begin{array}{r}0 \\
0 \\
34,117 \\
34,117\end{array}$ \\
\hline 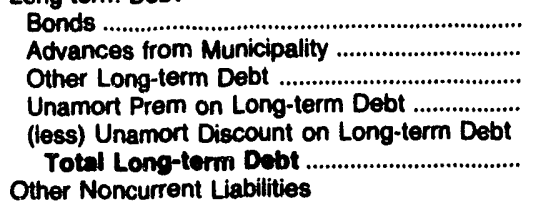 & $\begin{array}{r}213,300 \\
0 \\
0 \\
0 \\
2,311 \\
210,089\end{array}$ & $\begin{array}{r}66,896 \\
0 \\
28,597 \\
0 \\
7,357 \\
8 \times, 136\end{array}$ & $\begin{array}{r}2,450 \\
0 \\
0 \\
0 \\
0 \\
2,450\end{array}$ & $\begin{array}{r}8,805 \\
0 \\
39 \\
0 \\
0 \\
8,844\end{array}$ & $\begin{array}{r}0 \\
0 \\
4,137 \\
0 \\
0 \\
4,137\end{array}$ & $\begin{array}{r}12,785 \\
0 \\
0 \\
0 \\
0 \\
12,785\end{array}$ \\
\hline 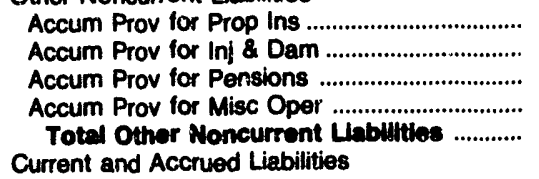 & $\begin{array}{l}0 \\
0 \\
0 \\
0 \\
0\end{array}$ & $\begin{array}{r}0 \\
397 \\
5,837 \\
0 \\
6,235\end{array}$ & $\begin{array}{r}1,122 \\
0 \\
0 \\
0 \\
1,122\end{array}$ & $\begin{array}{l}0 \\
0 \\
0 \\
0 \\
0\end{array}$ & $\begin{array}{l}0 \\
0 \\
0 \\
0 \\
0\end{array}$ & $\begin{array}{r}0 \\
150 \\
0 \\
0 \\
150\end{array}$ \\
\hline 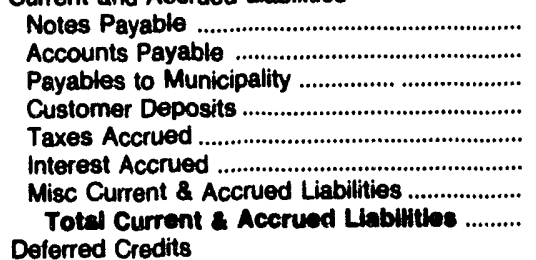 & $\begin{array}{r}0 \\
950 \\
4 \\
229 \\
0 \\
7,621 \\
541 \\
9,346\end{array}$ & $\begin{array}{r}0 \\
7,111 \\
818 \\
794 \\
31 \\
956 \\
12,700 \\
22,410\end{array}$ & $\begin{array}{r}0 \\
4,456 \\
0 \\
0 \\
9 \\
0 \\
313 \\
4,778\end{array}$ & $\begin{array}{r}0 \\
707 \\
0 \\
36 \\
41 \\
209 \\
116 \\
1,109\end{array}$ & $\begin{array}{r}0 \\
1,169 \\
0 \\
146 \\
79 \\
0 \\
673 \\
2,088\end{array}$ & $\begin{array}{r}0 \\
442 \\
0 \\
82 \\
65 \\
85 \\
14 \\
624\end{array}$ \\
\hline 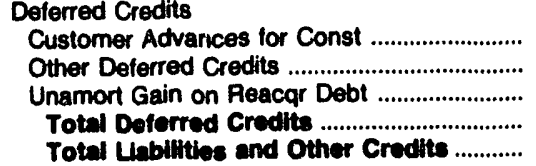 & $\begin{array}{r}0 \\
1,738 \\
0 \\
1,738 \\
210,320\end{array}$ & $\begin{array}{r}8 \\
4,591 \\
0 \\
4,640 \\
397,304\end{array}$ & $\begin{array}{r}0 \\
69,541 \\
0 \\
69,641 \\
109,040\end{array}$ & $\begin{array}{r}0 \\
4,005 \\
0 \\
4,005 \\
28,692\end{array}$ & $\begin{array}{r}0 \\
136 \\
0 \\
136 \\
32,513\end{array}$ & $\begin{array}{r}0 \\
12 \\
4,246 \\
4,258 \\
52,004\end{array}$ \\
\hline
\end{tabular}

Note: Totals may not equal sum of components because of independent rounding.

Source: Energy Information Administration, Form EIA-412, "Annual Peport of Public Electric Utilities." 
Table 37. Balance Sheet by Major Publicly Owned Electric Utility Within State at End of Period, 1991 (Continued) (Thousand Dollars)

\begin{tabular}{|c|c|c|c|c|c|c|}
\hline Item & $\begin{array}{l}\text { Nebraska } \\
\begin{array}{l}\text { Grand Istand } \\
\text { City of }\end{array} \\
\text { July } 31\end{array}$ & $\begin{array}{c}\text { Nebraska } \\
\text { Hastings } \\
\text { City of } \\
\text { December } 31\end{array}$ & $\begin{array}{l}\text { Nebraska } \\
\text { Lincoln } \\
\text { Electric } \\
\text { System } \\
\text { December } 31\end{array}$ & $\begin{array}{c}\text { Nebraska } \\
\text { Loup } \\
\text { River } \\
\text { Public } \\
\text { Power Dist } \\
\text { December } 31\end{array}$ & $\begin{array}{c}\text { Nebraska } \\
\text { Municipal } \\
\text { Energy } \\
\text { Agency } \\
\text { of NE } \\
\text { March } 31\end{array}$ & $\begin{array}{c}\text { Nebraska } \\
\text { Nebraska } \\
\text { Public } \\
\text { Power } \\
\text { District } \\
\text { December } 31\end{array}$ \\
\hline $\begin{array}{l}\text { Electric Utility Plant } \\
\text { Total Eloctric Utility Plant ................................. } \\
\text { (less) Depr, Amort, and Depletion .................. } \\
\text { Not Eloctric Utitty Plant ............................... } \\
\text { Other Property \& Investments }\end{array}$ & $\begin{array}{r}156,308 \\
53,060 \\
103,248\end{array}$ & $\begin{array}{l}97,827 \\
30,314 \\
67,513\end{array}$ & $\begin{array}{l}418,331 \\
107,971 \\
310,360\end{array}$ & $\begin{array}{l}47,140 \\
22,393 \\
24,747\end{array}$ & $\begin{array}{r}28,660 \\
1,384 \\
27,276\end{array}$ & $\begin{array}{r}1,896,023 \\
637,960 \\
1,258,063\end{array}$ \\
\hline 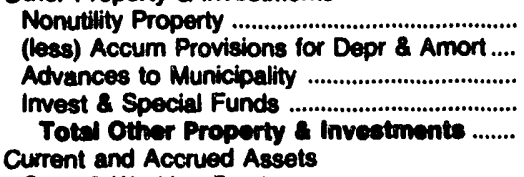 & $\begin{array}{r}470 \\
0 \\
0 \\
9,791 \\
10,281\end{array}$ & $\begin{array}{r}0 \\
0 \\
0 \\
10,238 \\
10,238\end{array}$ & $\begin{array}{r}0 \\
0 \\
0 \\
23,299 \\
23,299\end{array}$ & $\begin{array}{r}358 \\
0 \\
0 \\
12,149 \\
12,507\end{array}$ & $\begin{array}{r}2,753 \\
516 \\
0 \\
6,529 \\
8,766\end{array}$ & $\begin{array}{r}0 \\
0 \\
0 \\
131,473 \\
131,473\end{array}$ \\
\hline 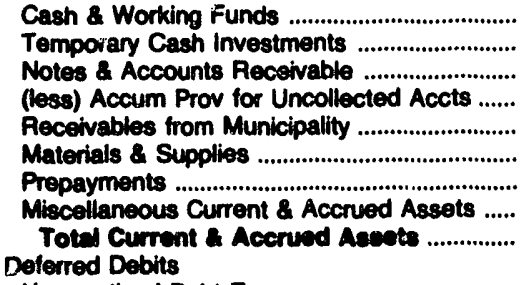 & $\begin{array}{r}2,757 \\
19,057 \\
3,400 \\
100 \\
111 \\
3,220 \\
137 \\
0 \\
28,582\end{array}$ & $\begin{array}{r}9,481 \\
0 \\
1,178 \\
0 \\
0 \\
1,776 \\
16 \\
264 \\
12,714\end{array}$ & $\begin{array}{r}594 \\
45,381 \\
7,290 \\
231 \\
0 \\
0 \\
5,957 \\
292 \\
2,844 \\
62,129\end{array}$ & $\begin{array}{r}1,172 \\
3,910 \\
2,672 \\
3 \\
0 \\
0 \\
925 \\
140 \\
109 \\
8,025\end{array}$ & $\begin{array}{r}777 \\
2,467 \\
3,082 \\
0 \\
0 \\
0 \\
50 \\
0 \\
6,376\end{array}$ & $\begin{array}{r}44,282 \\
282,086 \\
83,560 \\
400 \\
0 \\
106,265 \\
68,099 \\
0 \\
583,891\end{array}$ \\
\hline 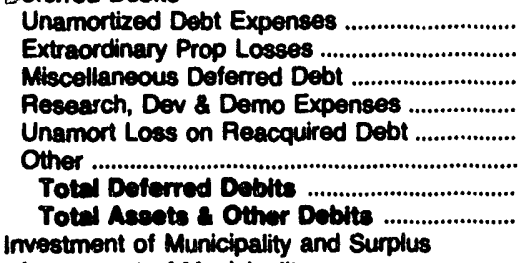 & $\begin{array}{r}988 \\
0 \\
1,716 \\
0 \\
0 \\
0 \\
2,704 \\
144,795\end{array}$ & $\begin{array}{r}0 \\
0 \\
1,127 \\
0 \\
0 \\
0 \\
1,127 \\
91,591\end{array}$ & $\begin{array}{r}19,893 \\
0 \\
9,702 \\
0 \\
0 \\
0 \\
29,595 \\
425,382\end{array}$ & $\begin{array}{r}0 \\
0 \\
813 \\
0 \\
0 \\
-45 \\
768 \\
46,947\end{array}$ & $\begin{array}{r}3,920 \\
0 \\
j, 547 \\
104 \\
2,190 \\
339 \\
10,090 \\
52,517\end{array}$ & $\begin{array}{r}1,425 \\
0 \\
24,607 \\
0 \\
0 \\
18,522 \\
\mathbf{4 4 , 5 5 4} \\
2,017,982\end{array}$ \\
\hline 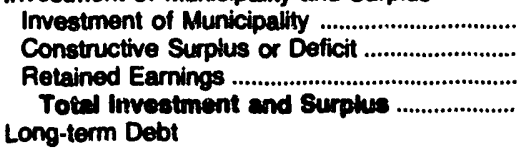 & $\begin{array}{r}0 \\
0 \\
69,645 \\
68,645\end{array}$ & $\begin{array}{r}0 \\
0 \\
25,408 \\
25,408\end{array}$ & $\begin{array}{r}0 \\
0 \\
106,537 \\
108,537\end{array}$ & $\begin{array}{r}0 \\
0 \\
41,822 \\
41,822\end{array}$ & $\begin{array}{r}0 \\
0 \\
4,240 \\
4,240\end{array}$ & $\begin{array}{r}0 \\
0 \\
220,518 \\
220,518\end{array}$ \\
\hline 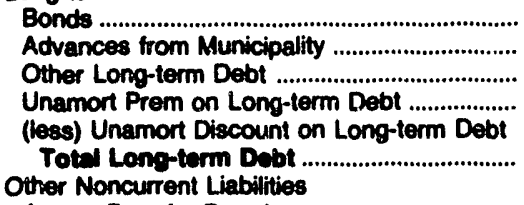 & $\begin{array}{r}70,770 \\
0 \\
1,078 \\
0 \\
0 \\
71,848\end{array}$ & $\begin{array}{r}64,210 \\
0 \\
0 \\
0 \\
702 \\
63,508\end{array}$ & $\begin{array}{r}279,482 \\
0 \\
0 \\
0 \\
0 \\
279,482\end{array}$ & $\begin{array}{l}0 \\
0 \\
0 \\
0 \\
0 \\
0\end{array}$ & $\begin{array}{r}44,630 \\
0 \\
0 \\
0 \\
0 \\
44,630\end{array}$ & $\begin{array}{r}1,391,114 \\
0 \\
58,915 \\
0 \\
954 \\
1,448,075\end{array}$ \\
\hline 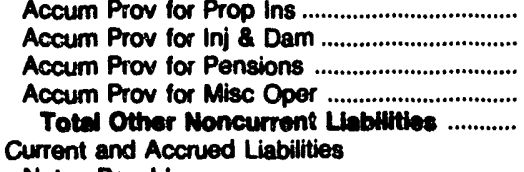 & $\begin{array}{l}0 \\
0 \\
0 \\
0 \\
0\end{array}$ & $\begin{array}{l}0 \\
0 \\
0 \\
0 \\
0\end{array}$ & $\begin{array}{l}0 \\
0 \\
0 \\
0 \\
0\end{array}$ & $\begin{array}{l}0 \\
0 \\
0 \\
0 \\
0\end{array}$ & $\begin{array}{l}0 \\
0 \\
0 \\
0 \\
0\end{array}$ & $\begin{array}{r}0 \\
0 \\
12,422 \\
169,029 \\
181,451\end{array}$ \\
\hline 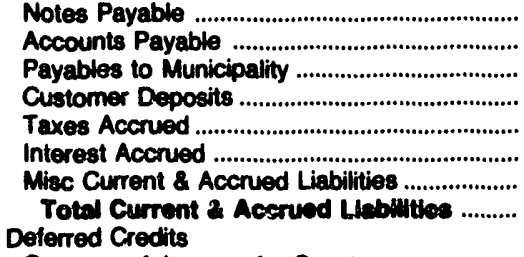 & $\begin{array}{r}0 \\
368 \\
0 \\
81 \\
715 \\
1,889 \\
249 \\
3,302\end{array}$ & $\begin{array}{r}0 \\
365 \\
0 \\
50 \\
0 \\
0,093 \\
0 \\
2,508\end{array}$ & $\begin{array}{r}6,925 \\
6,445 \\
0 \\
7 \\
4,845 \\
5,849 \\
2,754 \\
26,824\end{array}$ & $\begin{array}{r}0 \\
2,413 \\
0 \\
117 \\
1,607 \\
0 \\
231 \\
4,368\end{array}$ & $\begin{array}{r}0 \\
1,907 \\
0 \\
0 \\
96 \\
1,603 \\
42 \\
3,647\end{array}$ & $\begin{array}{r}54,865 \\
39,918 \\
0 \\
0 \\
0 \\
0 \\
13,021 \\
107,805\end{array}$ \\
\hline 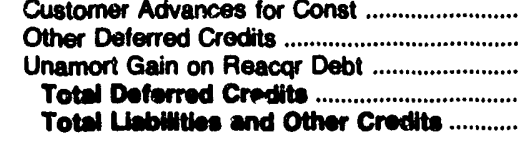 & $\begin{array}{r}0 \\
0 \\
0 \\
0 \\
144,795\end{array}$ & $\begin{array}{r}0 \\
168 \\
0 \\
168 \\
91,591\end{array}$ & $\begin{array}{r}0 \\
12,539 \\
0 \\
12,539 \\
425,382\end{array}$ & $\begin{array}{r}0 \\
757 \\
0 \\
757 \\
46,947\end{array}$ & $\begin{array}{r}0 \\
0 \\
0 \\
0 \\
52,517\end{array}$ & $\begin{array}{r}0 \\
58,097 \\
1,037 \\
159,133 \\
2,017,002\end{array}$ \\
\hline
\end{tabular}

Note: Totals may not equal sum of components because of independent rounding.

Source: Energy information Administration, Form ElA-412, "Annual Report of Public Electric Utilities." 


\section{Table 37. Balance Sheet by Major Publicly Owned Electric Utility Within State at End of Period, 1991 (Continued) (Thousand Do'liars)}

\begin{tabular}{|c|c|c|c|c|c|c|}
\hline Item & $\begin{array}{l}\text { Nebraska } \\
\text { Norris } \\
\text { Public } \\
\text { Power } \\
\text { Pistrict } \\
\text { December } 31\end{array}$ & $\begin{array}{l}\text { Nebraska } \\
\text { North } \\
\text { Platte } \\
\text { City of } \\
\text { July } 31\end{array}$ & $\begin{array}{l}\text { Nebraska } \\
\text { Omaha Public } \\
\text { Power } \\
\text { District } \\
\text { December } 31\end{array}$ & $\begin{array}{c}\text { Nebraska } \\
\text { Southern } \\
\text { Nebraska Rural } \\
\text { P P D } \\
\text { December } 31\end{array}$ & $\begin{array}{l}\text { Nevada } \\
\text { Colorado } \\
\text { River } \\
\text { Comm } \\
\text { of Nevada } \\
\text { June } 30\end{array}$ & $\begin{array}{l}\text { New Jersey } \\
\text { Vineland } \\
\text { Clty of } \\
\text { December } 31\end{array}$ \\
\hline $\begin{array}{l}\text { Elestiv Utility Plant } \\
\text { Total Jlectric Utility Plant .................................. } \\
\text { (less) Depr, Amort, and Depletion .................... } \\
\text { Not Electric Utilty Pient .............................. } \\
\text { Other Propeny \& Investments }\end{array}$ & $\begin{array}{l}54,812 \\
16,362 \\
3,630\end{array}$ & $\begin{array}{r}11,626 \\
7.240 \\
4,895\end{array}$ & $\begin{array}{r}2,062,520 \\
686,355 \\
1,376,165\end{array}$ & $\begin{array}{l}63,990 \\
27,935 \\
99,055\end{array}$ & $\begin{array}{l}0 \\
0 \\
0\end{array}$ & $\begin{array}{l}63,593 \\
29,605 \\
33,898\end{array}$ \\
\hline 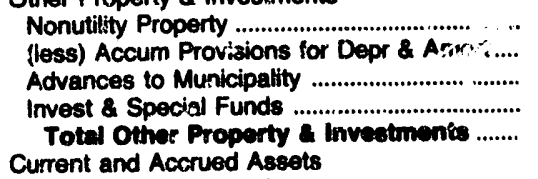 & $\begin{array}{r}0 \\
0 \\
0 \\
4,512 \\
4,512\end{array}$ & $\begin{array}{r}0 \\
0 \\
50 \\
0 \\
50\end{array}$ & $\begin{array}{r}0 \\
0 \\
0 \\
228,135 \\
228,135\end{array}$ & $\begin{array}{r}0 \\
0 \\
0 \\
2,574 \\
2,574\end{array}$ & $\begin{array}{r}253,692 \\
60,196 \\
0 \\
69,063 \\
292,659\end{array}$ & $\begin{array}{r}0 \\
0 \\
0 \\
2,577 \\
\mathbf{2 , 5 7 7}\end{array}$ \\
\hline 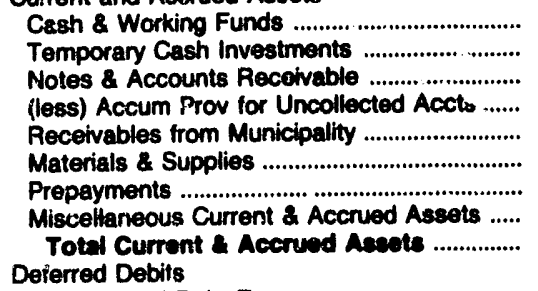 & $\begin{array}{r}87 \\
2,262 \\
1,832 \\
45 \\
0 \\
1,261 \\
101 \\
669 \\
6,267\end{array}$ & $\begin{array}{r}56 \\
2,369 \\
644 \\
77 \\
0 \\
509 \\
8 \\
78 \\
3,889\end{array}$ & $\begin{array}{r}18,743 \\
40,417 \\
27,876 \\
624 \\
0 \\
51,021 \\
368 \\
18,516 \\
168,318\end{array}$ & $\begin{array}{r}161 \\
12,055 \\
1,363 \\
0 \\
0 \\
1,609 \\
42 \\
184 \\
16,414\end{array}$ & $\begin{array}{r}8,080 \\
0 \\
6,730 \\
0 \\
0 \\
111 \\
5,011 \\
1 \\
19,033\end{array}$ & $\begin{array}{r}15,949 \\
0 \\
2,560 \\
0 \\
0 \\
1,733 \\
0 \\
0 \\
20,242\end{array}$ \\
\hline 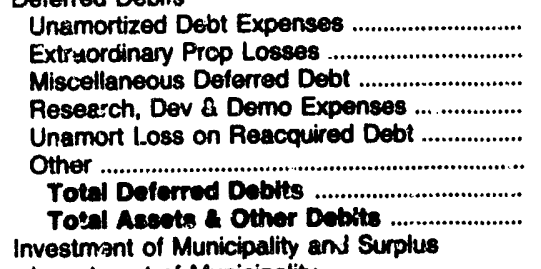 & $\begin{array}{r}555 \\
0 \\
202 \\
0 \\
0 \\
0 \\
757 \\
50,098\end{array}$ & $\begin{array}{r}0 \\
0 \\
0 \\
0 \\
0 \\
0 \\
0 \\
0,023\end{array}$ & $\begin{array}{r}1,085 \\
0 \\
41,675 \\
0 \\
30,198 \\
0 \\
72,959 \\
1,338,577\end{array}$ & $\begin{array}{r}0 \\
0 \\
771 \\
0 \\
0 \\
0 \\
771 \\
57,814\end{array}$ & $\begin{array}{r}605 \\
0 \\
726 \\
0 \\
0 \\
31,807 \\
33,137 \\
315,630\end{array}$ & $\begin{array}{r}0 \\
0 \\
0 \\
0 \\
0 \\
0 \\
0 \\
68,807\end{array}$ \\
\hline $\begin{array}{l}\text { Investment of Municipality .......................... } \\
\text { Constructive Surplus of Deficit ........................ } \\
\text { Retained Earnings .......................................... } \\
\text { Total Investment and Suppus .................... } \\
\text { Long-term Debt }\end{array}$ & $\begin{array}{r}0 \\
0 \\
25,224 \\
26,224\end{array}$ & $\begin{array}{r}0 \\
0 \\
6,814 \\
3,814\end{array}$ & $\begin{array}{r}0 \\
0 \\
635,695 \\
635,695\end{array}$ & $\begin{array}{r}0 \\
0 \\
47,862 \\
47,862\end{array}$ & $\begin{array}{r}1,526 \\
0 \\
-47,666 \\
-48,139\end{array}$ & $\begin{array}{r}0 \\
0 \\
40,846 \\
40,848\end{array}$ \\
\hline 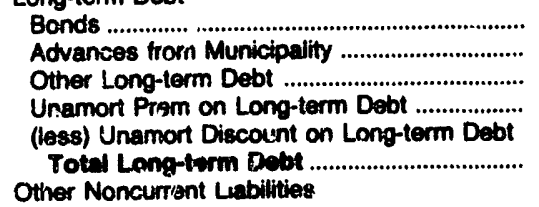 & $\begin{array}{r}21,515 \\
0 \\
0 \\
0 \\
0 \\
21,515\end{array}$ & $\begin{array}{l}0 \\
0 \\
0 \\
c \\
0 \\
0\end{array}$ & $\begin{array}{r}871,270 \\
0 \\
104,550 \\
0 \\
8,510 \\
898,310\end{array}$ & $\begin{array}{r}6,678 \\
0 \\
0 \\
0 \\
0 \\
6,878\end{array}$ & $\begin{array}{r}151,380 \\
0 \\
180,710 \\
5 \\
0 \\
342,005\end{array}$ & $\begin{array}{r}6,810 \\
0 \\
0 \\
0 \\
0 \\
6,810\end{array}$ \\
\hline 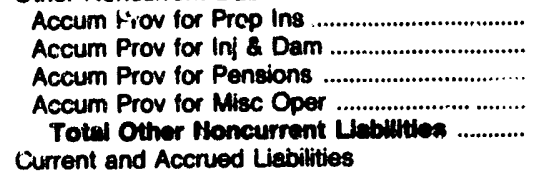 & $\begin{array}{l}0 \\
0 \\
0 \\
0 \\
0\end{array}$ & $\begin{array}{l}0 \\
0 \\
0 \\
0 \\
0\end{array}$ & $\begin{array}{r}688 \\
2,471 \\
0 \\
0 \\
3,189\end{array}$ & $\begin{array}{l}0 \\
0 \\
0 \\
0 \\
0\end{array}$ & $\begin{array}{l}0 \\
0 \\
0 \\
0 \\
0\end{array}$ & $\begin{array}{r}0 \\
0 \\
0 \\
2,577 \\
2,577\end{array}$ \\
\hline 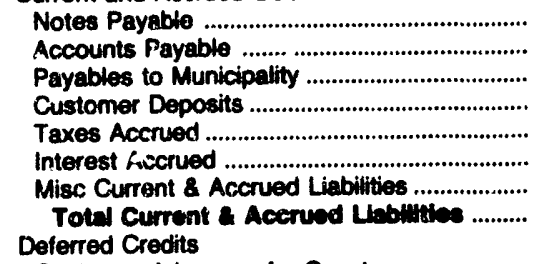 & $\begin{array}{r}0 \\
2,274 \\
0 \\
47 \\
156 \\
346 \\
523 \\
3,247\end{array}$ & $\begin{array}{r}0 \\
1,050 \\
0 \\
160 \\
0 \\
0 \\
0 \\
1,210\end{array}$ & $\begin{array}{r}20,521 \\
38,128 \\
0 \\
4,194 \\
13,431 \\
24,009 \\
38,225 \\
136,000\end{array}$ & $\begin{array}{r}0 \\
2,394 \\
0 \\
65 \\
0 \\
0 \\
815 \\
3,274\end{array}$ & $\begin{array}{r}0 \\
5,623 \\
0 \\
0 \\
0 \\
6,134 \\
4,791 \\
16,548\end{array}$ & $\begin{array}{r}0 \\
5,106 \\
0 \\
698 \\
0 \\
370 \\
346 \\
6,510\end{array}$ \\
\hline 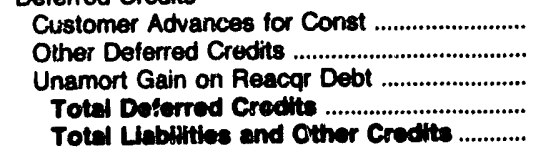 & $\begin{array}{r}0 \\
0 \\
0 \\
0 \\
50,000\end{array}$ & $\begin{array}{r}0 \\
0 \\
0 \\
0 \\
0\end{array}$ & $\begin{array}{r}484 \\
91,111 \\
0 \\
91,695 \\
1,038,677\end{array}$ & $\begin{array}{r}0 \\
0 \\
0 \\
0 \\
57,914\end{array}$ & $\begin{array}{r}0 \\
3,127 \\
0 \\
3,127 \\
316,630\end{array}$ & $\begin{array}{r}55 \\
0 \\
0 \\
55 \\
56,807\end{array}$ \\
\hline
\end{tabular}

Note: Totals may not equal sum of components because of independent rounding.

Source: Energy Information Administration, Form ElA-412, "Annual Report of Public Electric Utilities." 
Table 37. Balance Sheet by Major Publicly Owned Electric Utility Within Siate at End of Period, 1991 (Continued)

(Thousand Dollars)

\begin{tabular}{|c|c|c|c|c|c|c|}
\hline Item & $\begin{array}{l}\text { New Mexico } \\
\text { Farmington } \\
\text { City of } \\
\text { June } 30\end{array}$ & $\begin{array}{l}\text { New Mexico } \\
\text { Gallup } \\
\text { City of } \\
\text { June } 30\end{array}$ & $\begin{array}{l}\text { New Mexico } \\
\text { Los Alamos } \\
\text { County } \\
\text { June } 30\end{array}$ & $\begin{array}{l}\text { New York } \\
\text { Fairport } \\
\text { Village of } \\
\text { May } 31\end{array}$ & $\begin{array}{c}\text { New York } \\
\text { Freeport } \\
\text { Villege of } \\
\text { Inc }\end{array}$ & $\begin{array}{l}\text { New York } \\
\text { Jamestown } \\
\text { City of } \\
\text { December } 31\end{array}$ \\
\hline 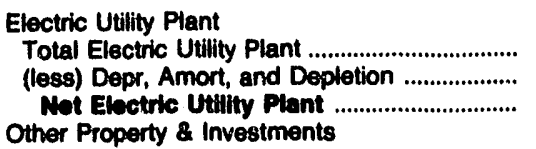 & $\begin{array}{r}164,780 \\
45,589 \\
110,191\end{array}$ & $\begin{array}{r}10,335 \\
4,994 \\
5,341\end{array}$ & $\begin{array}{r}109,449 \\
16,390 \\
93,059\end{array}$ & $\begin{array}{r}15,136 \\
6,573 \\
8,563\end{array}$ & $\begin{array}{l}29,059 \\
16,104 \\
12,956\end{array}$ & $\begin{array}{l}75,586 \\
23,493 \\
52,093\end{array}$ \\
\hline 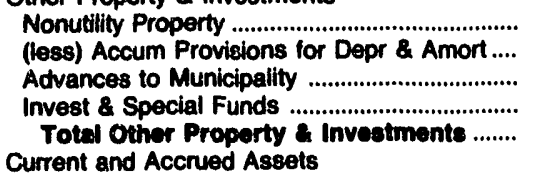 & $\begin{array}{l}0 \\
0 \\
0 \\
0 \\
0\end{array}$ & $\begin{array}{r}19,747 \\
9,485 \\
0 \\
0 \\
10,262\end{array}$ & $\begin{array}{r}0 \\
0 \\
0 \\
14,655 \\
14,655\end{array}$ & $\begin{array}{r}0 \\
0 \\
0 \\
763 \\
763\end{array}$ & $\begin{array}{l}0 \\
0 \\
0 \\
0 \\
0\end{array}$ & $\begin{array}{r}615 \\
0 \\
0 \\
16,046 \\
16,681\end{array}$ \\
\hline 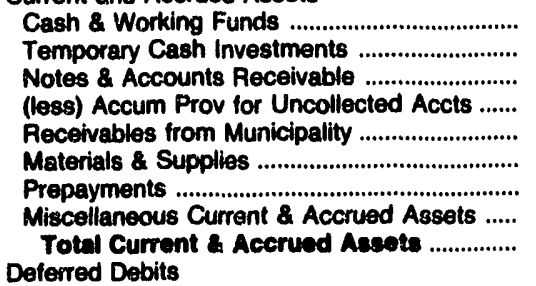 & $\begin{array}{r}3,706 \\
13,138 \\
2,054 \\
13 \\
0 \\
0 \\
1,985 \\
176 \\
14,871 \\
35,918\end{array}$ & $\begin{array}{r}38 \\
2,775 \\
1,742 \\
107 \\
475 \\
968 \\
0 \\
1,400 \\
7,300\end{array}$ & $\begin{array}{r}1,067 \\
211 \\
2,750 \\
213 \\
0 \\
1,074 \\
71 \\
370 \\
5,330\end{array}$ & $\begin{array}{r}582 \\
0 \\
783 \\
5 \\
3 \\
484 \\
118 \\
5 \\
1,081\end{array}$ & $\begin{array}{r}2,000 \\
2,561 \\
1,155 \\
144 \\
0 \\
1,471 \\
3 \\
0 \\
7,046\end{array}$ & $\begin{array}{r}-225 \\
0 \\
2,002 \\
65 \\
202 \\
942 \\
108 \\
87 \\
3,052\end{array}$ \\
\hline 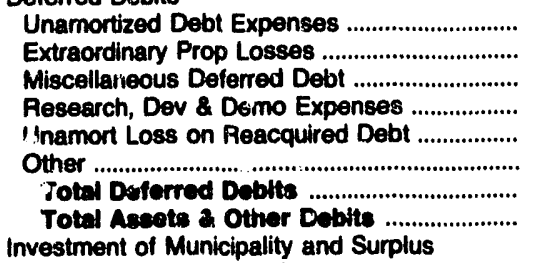 & $\begin{array}{r}5,991 \\
0 \\
0 \\
0 \\
0 \\
0 \\
5,991 \\
161,100\end{array}$ & $\begin{array}{r}96 \\
0 \\
0 \\
0 \\
0 \\
0 \\
96 \\
22,999\end{array}$ & $\begin{array}{r}5,911 \\
0 \\
0 \\
0 \\
0 \\
1,514 \\
7,425 \\
120,469\end{array}$ & $\begin{array}{r}0 \\
0 \\
0 \\
0 \\
0 \\
0 \\
0 \\
11,307\end{array}$ & $\begin{array}{r}0 \\
0 \\
-5 \\
0 \\
0 \\
0 \\
-5 \\
19,907\end{array}$ & $\begin{array}{r}0 \\
0 \\
213 \\
0 \\
0 \\
0 \\
213 \\
72,020\end{array}$ \\
\hline 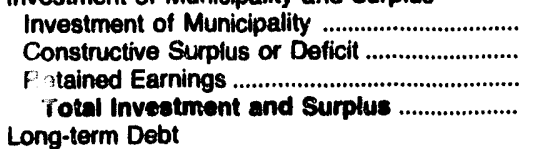 & $\begin{array}{r}12,457 \\
0 \\
5,588 \\
18,045\end{array}$ & $\begin{array}{r}10,464 \\
7,723 \\
0 \\
18,187\end{array}$ & $\begin{array}{r}2,168 \\
0 \\
4,532 \\
6,700\end{array}$ & $\begin{array}{r}-4,009 \\
0 \\
12,604 \\
8,595\end{array}$ & $\begin{array}{r}0 \\
0 \\
13,609 \\
13,600\end{array}$ & $\begin{array}{r}0 \\
-20,823 \\
57,888 \\
36,965\end{array}$ \\
\hline 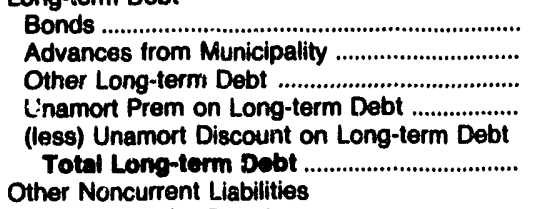 & $\begin{array}{r}135,632 \\
0 \\
0 \\
0 \\
0 \\
135,632\end{array}$ & $\begin{array}{r}2,950 \\
0 \\
80 \\
0 \\
0 \\
3,030\end{array}$ & $\begin{array}{r}102,865 \\
1,580 \\
0 \\
0 \\
0 \\
104,445\end{array}$ & $\begin{array}{r}1,550 \\
0 \\
0 \\
0 \\
0 \\
1,550\end{array}$ & $\begin{array}{r}1,560 \\
0 \\
0 \\
0 \\
0 \\
1,560\end{array}$ & $\begin{array}{r}31,850 \\
0 \\
0 \\
0 \\
0 \\
31,850\end{array}$ \\
\hline 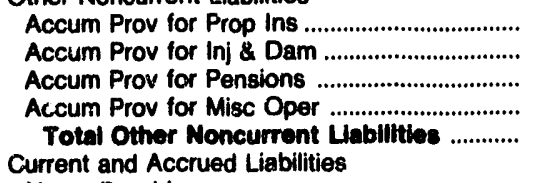 & $\begin{array}{l}0 \\
0 \\
0 \\
0 \\
0\end{array}$ & $\begin{array}{l}0 \\
0 \\
0 \\
0 \\
0\end{array}$ & $\begin{array}{l}0 \\
0 \\
0 \\
0 \\
0\end{array}$ & $\begin{array}{r}0 \\
0 \\
0 \\
327 \\
327\end{array}$ & $\begin{array}{r}0 \\
0 \\
2,202 \\
0 \\
2,202\end{array}$ & $\begin{array}{l}0 \\
0 \\
0 \\
0 \\
0\end{array}$ \\
\hline 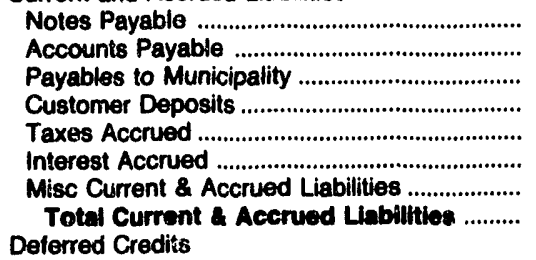 & $\begin{array}{r}0 \\
763 \\
0 \\
493 \\
0 \\
1,612 \\
1,222 \\
4,090\end{array}$ & $\begin{array}{r}0 \\
942 \\
0 \\
629 \\
60 \\
0 \\
92 \\
1,723\end{array}$ & $\begin{array}{r}1,775 \\
2,059 \\
842 \\
30 \\
59 \\
3,932 \\
137 \\
8,835\end{array}$ & $\begin{array}{r}158 \\
403 \\
26 \\
198 \\
0 \\
20 \\
32 \\
836\end{array}$ & $\begin{array}{r}363 \\
0 \\
788 \\
1,153 \\
0 \\
191 \\
2 \\
2,497\end{array}$ & $\begin{array}{r}0 \\
1,371 \\
11 \\
44 \\
0 \\
824 \\
754 \\
3,004\end{array}$ \\
\hline 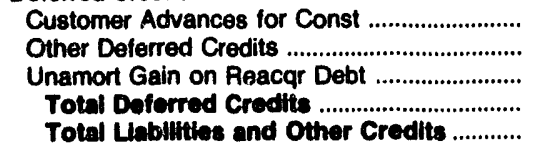 & $\begin{array}{r}1,709 \\
1,623 \\
0 \\
3,332 \\
161,100\end{array}$ & $\begin{array}{r}0 \\
58 \\
0 \\
58 \\
22,999\end{array}$ & $\begin{array}{r}0 \\
490 \\
0 \\
480 \\
120,460\end{array}$ & $\begin{array}{r}0 \\
0 \\
0 \\
0 \\
11,307\end{array}$ & $\begin{array}{r}128 \\
0 \\
0 \\
128 \\
19,997\end{array}$ & $\begin{array}{r}200 \\
0 \\
0 \\
200 \\
72,020\end{array}$ \\
\hline
\end{tabular}

Note: Totals may not equal sum of components because of independent rounding.

Source: Energy Information Administration, Form EIA-412, "Annual Report of Public Electric Utilities." 
Table 37. Balance Sheet by Major Publicly Owned Electric Utility Within State at End of Period, 1991 (Continued) (Thousand Dollars)

\begin{tabular}{|c|c|c|c|c|c|c|}
\hline Item & $\begin{array}{l}\text { Plattsburgh } \\
\text { City of } \\
\text { December } 31\end{array}$ & $\begin{array}{c}\text { New York } \\
\text { Power } \\
\text { Authority } \\
\text { of State of NY } \\
\text { December } 31\end{array}$ & $\begin{array}{l}\text { New York } \\
\text { Rockville } \\
\text { Centre } \\
\text { Village of } \\
\text { May } 31\end{array}$ & $\begin{array}{l}\text { North Carolina } \\
\text { Albemarle } \\
\text { City of } \\
\text { June } 30\end{array}$ & $\begin{array}{l}\text { North Carolina } \\
\text { Concord } \\
\text { City of } \\
\text { June } 30\end{array}$ & $\begin{array}{l}\text { North Carolina } \\
\text { Elizabeth } \\
\text { City City of } \\
\text { June } 30\end{array}$ \\
\hline 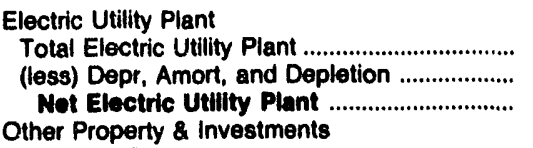 & $\begin{array}{r}27,973 \\
8,965 \\
19,008\end{array}$ & $\begin{array}{l}5,144,414 \\
1,362,617 \\
3,781,797\end{array}$ & $\begin{array}{r}21,831 \\
12,463 \\
9,387\end{array}$ & $\begin{array}{r}16,805 \\
8,497 \\
0,308\end{array}$ & $\begin{array}{r}25,371 \\
15,903 \\
9,468\end{array}$ & $\begin{array}{r}20,094 \\
5,591 \\
14,503\end{array}$ \\
\hline $\begin{array}{l}\text { Nonutility Property ..................................... } \\
\text { (less) Accum Provisions for Depr \& Amort .... } \\
\text { Advances to Municipality ...................................... } \\
\text { Invest \& Special Funds ................................... } \\
\text { Total Other Property Investmente ........ } \\
\text { Current and Accrued Assets }\end{array}$ & $\begin{array}{r}0 \\
0 \\
0 \\
3,581 \\
3,581\end{array}$ & $\begin{array}{r}0 \\
0 \\
0 \\
162,698 \\
162,698\end{array}$ & $\begin{array}{r}0 \\
0 \\
0 \\
149 \\
140\end{array}$ & $\begin{array}{l}0 \\
0 \\
0 \\
0 \\
0\end{array}$ & $\begin{array}{l}0 \\
0 \\
0 \\
0 \\
0\end{array}$ & $\begin{array}{r}0 \\
0 \\
4,648 \\
0 \\
4,648\end{array}$ \\
\hline 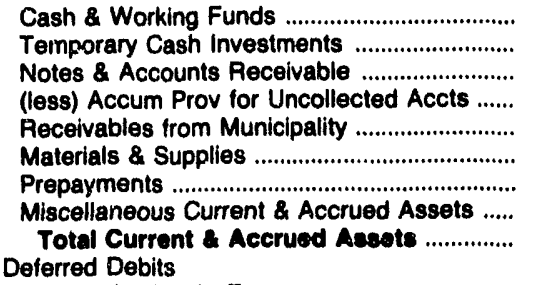 & $\begin{array}{r}424 \\
0 \\
1,145 \\
18 \\
57 \\
724 \\
41 \\
0 \\
2,374\end{array}$ & $\begin{array}{r}59,023 \\
1,464,352 \\
74,222 \\
0 \\
0 \\
77,845 \\
25,221 \\
35,685 \\
1,738,348\end{array}$ & $\begin{array}{r}138 \\
1,946 \\
1,293 \\
101 \\
20 \\
1,411 \\
84 \\
0 \\
4,793\end{array}$ & $\begin{array}{r}97 \\
1,744 \\
1,809 \\
0 \\
0 \\
1,046 \\
47 \\
0 \\
4,744\end{array}$ & $\begin{array}{r}8,570 \\
0 \\
2,721 \\
0 \\
0 \\
1,652 \\
0 \\
0 \\
12,943\end{array}$ & $\begin{array}{r}2,279 \\
200 \\
2,486 \\
100 \\
0 \\
1,185 \\
0 \\
8 \\
6,058\end{array}$ \\
\hline 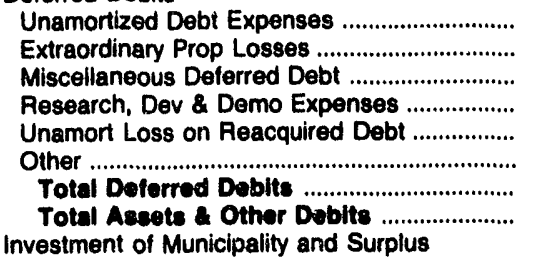 & $\begin{array}{r}36 \\
0 \\
0 \\
0 \\
0 \\
0 \\
36 \\
24,990\end{array}$ & $\begin{array}{r}35,406 \\
0 \\
39,077 \\
20,101 \\
0 \\
0 \\
94,684 \\
5,775,427\end{array}$ & $\begin{array}{r}0 \\
0 \\
0 \\
0 \\
0 \\
0 \\
0 \\
14,309\end{array}$ & $\begin{array}{r}0 \\
0 \\
0 \\
0 \\
0 \\
0 \\
0 \\
13,0.02\end{array}$ & $\begin{array}{r}0 \\
0 \\
0 \\
0 \\
0 \\
0 \\
0 \\
22,410\end{array}$ & $\begin{array}{r}0 \\
0 \\
0 \\
0 \\
0 \\
11 \\
0 \\
25,200\end{array}$ \\
\hline 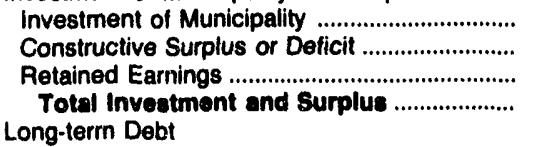 & $\begin{array}{r}-7,211 \\
23,605 \\
0 \\
16,394\end{array}$ & $\begin{array}{r}0 \\
0 \\
1,474,292 \\
1,474,292\end{array}$ & $\begin{array}{r}-6,839 \\
0 \\
18,499 \\
11,660\end{array}$ & $\begin{array}{r}5,315 \\
0 \\
6,287 \\
11,802\end{array}$ & $\begin{array}{r}0 \\
0 \\
15,375 \\
15,375\end{array}$ & $\begin{array}{r}35 \\
0 \\
22,896 \\
22,930\end{array}$ \\
\hline 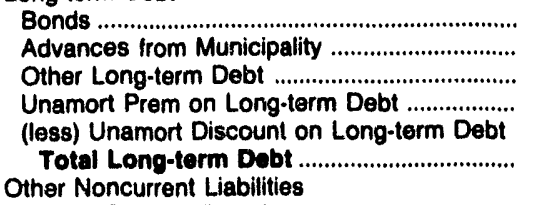 & $\begin{array}{r}6,950 \\
0 \\
0 \\
6 \\
0 \\
6,956\end{array}$ & $\begin{array}{r}3,371,585 \\
0 \\
200,000 \\
0 \\
77,975 \\
3,493,610\end{array}$ & $\begin{array}{r}143 \\
0 \\
0 \\
0 \\
0 \\
143\end{array}$ & $\begin{array}{l}0 \\
0 \\
0 \\
0 \\
0 \\
0\end{array}$ & $\begin{array}{r}1,860 \\
0 \\
154 \\
0 \\
0 \\
2,014\end{array}$ & $\begin{array}{l}0 \\
0 \\
0 \\
0 \\
0 \\
0\end{array}$ \\
\hline 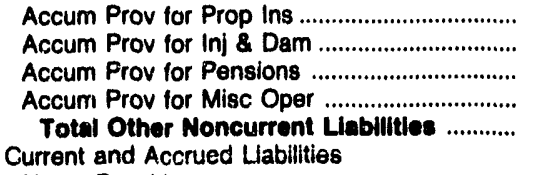 & $\begin{array}{l}0 \\
0 \\
0 \\
0 \\
0\end{array}$ & $\begin{array}{r}0 \\
0 \\
21,583 \\
0 \\
21,583\end{array}$ & $\begin{array}{r}0 \\
0 \\
0 \\
1,299 \\
1,290\end{array}$ & $\begin{array}{l}0 \\
0 \\
0 \\
0 \\
0\end{array}$ & $\begin{array}{l}0 \\
0 \\
0 \\
0 \\
0\end{array}$ & $\begin{array}{l}0 \\
0 \\
0 \\
0 \\
0\end{array}$ \\
\hline 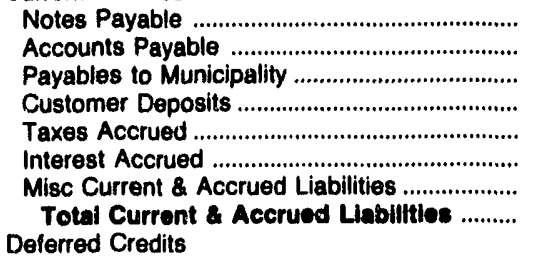 & $\begin{array}{r}0 \\
888 \\
0 \\
0 \\
-38 \\
130 \\
670 \\
1,648\end{array}$ & $\begin{array}{r}75,000 \\
23,884 \\
0 \\
0 \\
0 \\
4,771 \\
98,920 \\
202,875\end{array}$ & $\begin{array}{r}0 \\
622 \\
14 \\
329 \\
0 \\
8 \\
234 \\
1,207\end{array}$ & $\begin{array}{r}0 \\
1,194 \\
0 \\
236 \\
0 \\
0 \\
20 \\
1,450\end{array}$ & $\begin{array}{r}0 \\
2,020 \\
2,724 \\
206 \\
0 \\
13 \\
58 \\
5,022\end{array}$ & $\begin{array}{r}0 \\
1,704 \\
17 \\
496 \\
0 \\
0 \\
62 \\
2,279\end{array}$ \\
\hline 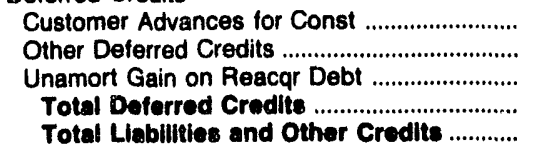 & $\begin{array}{r}0 \\
0 \\
0 \\
0 \\
24,899\end{array}$ & $\begin{array}{r}0 \\
583,267 \\
0 \\
683,267 \\
5,775,427\end{array}$ & $\begin{array}{r}0 \\
0 \\
0 \\
0 \\
+4,300\end{array}$ & $\begin{array}{r}0 \\
0 \\
0 \\
0 \\
13,052\end{array}$ & $\begin{array}{r}0 \\
0 \\
0 \\
0 \\
22,410\end{array}$ & $\begin{array}{r}0 \\
0 \\
0 \\
0 \\
25,209\end{array}$ \\
\hline
\end{tabular}

Note: Totals may not equal sum of components because of independent rounding.

Source: Energy Information Administration, Form EIA-412, "Annual Report of Public Electric Utilities." 
Table 37. Balance Sheet by Major Publicly Owned Electric Utility Within State at End of Period, 1991 (Continued) (Thousand Dollars)

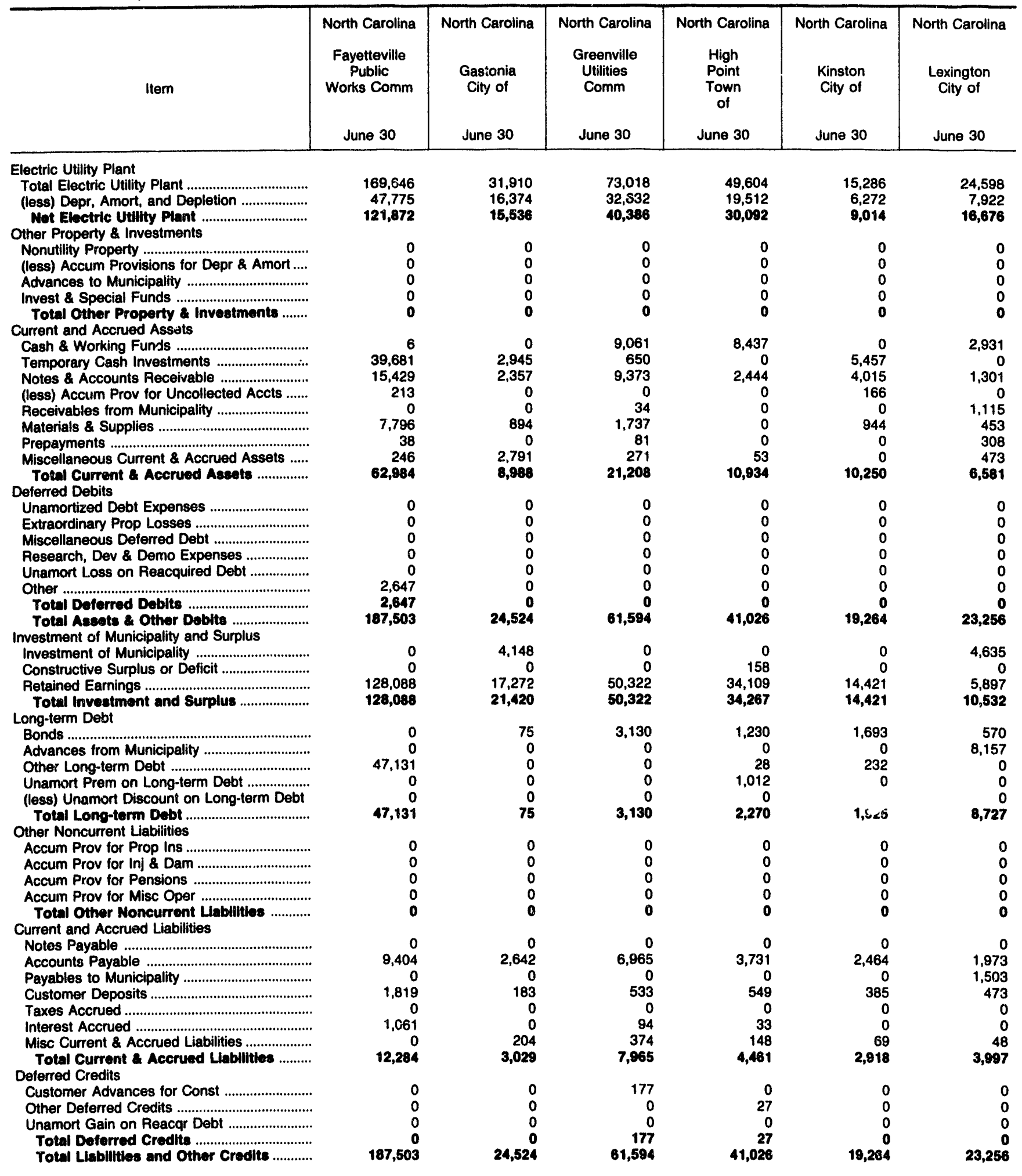

Note: Totals may not equal sum of components because of independent rounding.

Source: Energy Information Administration, Form EIA-412, "Annual Report of Public Electric Utilities." 
Table 37. Balance Sheet by Major Publicly Owned Electric Utility Within State at End of Perlod, 1991 (Continued) (Thousand Dollars)

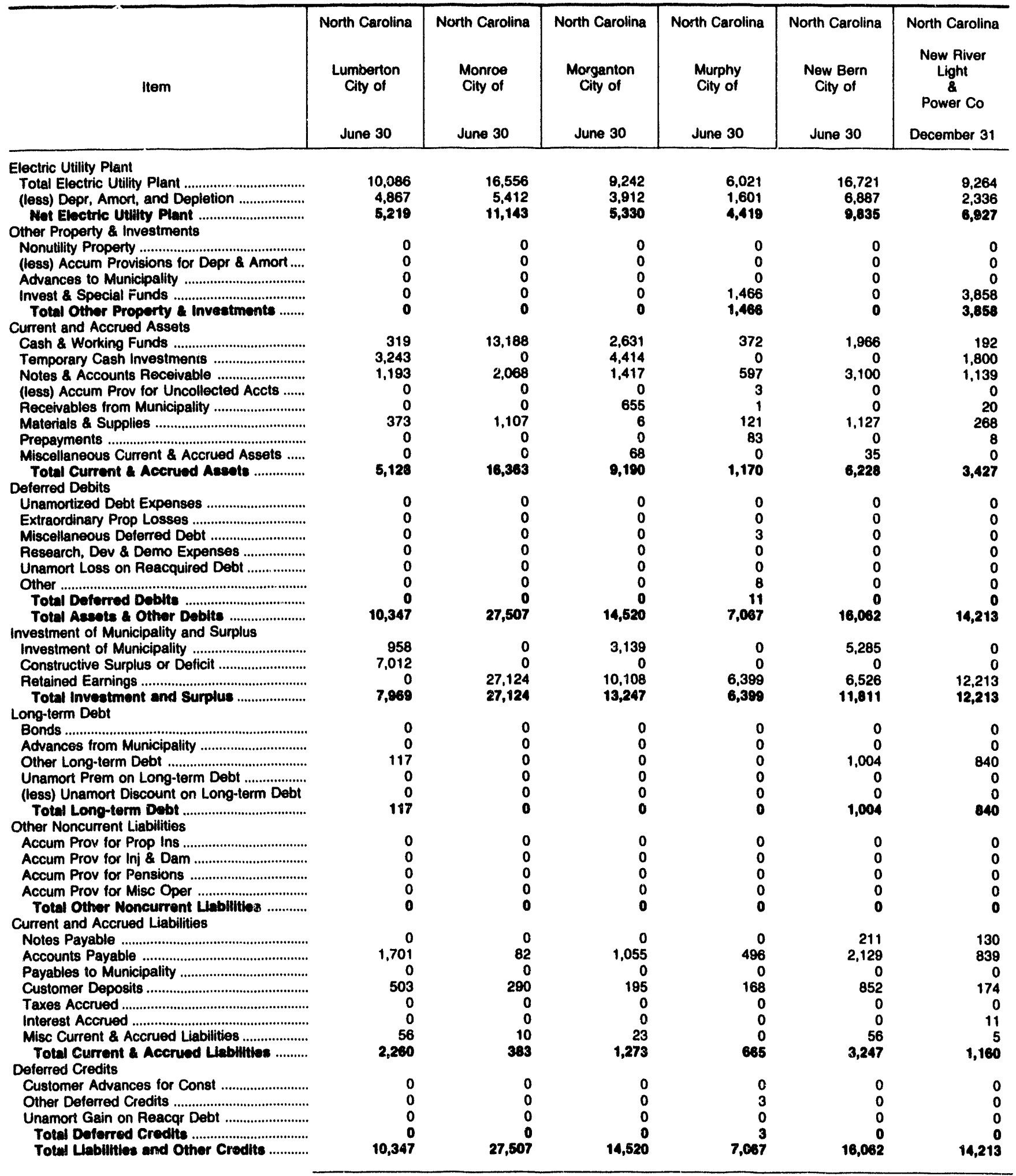

Note: Totals may not equal sum of components bocause of independent rounding.

Source: Energy information Administration, Form EIA-412, "Annual Report of Public Electric Utilities." 
Table 37. Balance Sheet by Major Publicly Owned Electric Utility Within State at End of Period, 1991 (Continued) (Thousand Dollars)

\begin{tabular}{|c|c|c|c|c|c|c|}
\hline Item & $\begin{array}{l}\text { North Carolina } \\
\text { North } \\
\text { Carolina } \\
\text { Eastern M P A } \\
\text { December } 31\end{array}$ & $\begin{array}{c}\text { North Carolina } \\
\text { North } \\
\text { Carolina } \\
\text { Mun } \\
\text { Power Agny } \\
\text { December } 31\end{array}$ & $\begin{array}{l}\text { North Carolina } \\
\text { Rocky Mount } \\
\text { City of } \\
\text { June } 30\end{array}$ & $\begin{array}{l}\text { Shelby } \\
\text { City of } \\
\text { June } 30\end{array}$ & $\begin{array}{c}\text { Statesville } \\
\text { City of } \\
\text { June } 30\end{array}$ & $\begin{array}{c}\text { North Carolina } \\
\text { Tarboro } \\
\text { Town of } \\
\text { June } 30\end{array}$ \\
\hline 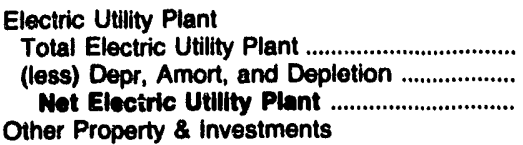 & $\begin{array}{r}1,392,020 \\
270,634 \\
1,121,386\end{array}$ & $\begin{array}{r}1,646,112 \\
401,067 \\
1,245,045\end{array}$ & $\begin{array}{l}30,255 \\
11,127 \\
19,127\end{array}$ & $\begin{array}{l}5,789 \\
3,865 \\
1,923\end{array}$ & $\begin{array}{r}14,179 \\
5,447 \\
\mathbf{8 , 7 3 2}\end{array}$ & $\begin{array}{r}13,635 \\
4,677 \\
8,958\end{array}$ \\
\hline $\begin{array}{l}\text { Nonutility Property .................................... } \\
\text { (less) Accum Provisions for Depr \& Amort .... } \\
\text { Advances to Municipality ..................................... } \\
\text { Invest \& Special Funds .................................. } \\
\text { Total Other Property \& Investments ....... } \\
\text { Current and Accrued Assets }\end{array}$ & $\begin{array}{r}3,024 \\
924 \\
0 \\
458,992 \\
461,092\end{array}$ & $\begin{array}{r}3,024 \\
924 \\
0 \\
396,352 \\
398,452\end{array}$ & $\begin{array}{l}0 \\
0 \\
0 \\
0 \\
0\end{array}$ & $\begin{array}{l}0 \\
0 \\
0 \\
0 \\
0\end{array}$ & $\begin{array}{r}837 \\
331 \\
0 \\
0 \\
505\end{array}$ & $\begin{array}{l}0 \\
0 \\
0 \\
0 \\
0\end{array}$ \\
\hline 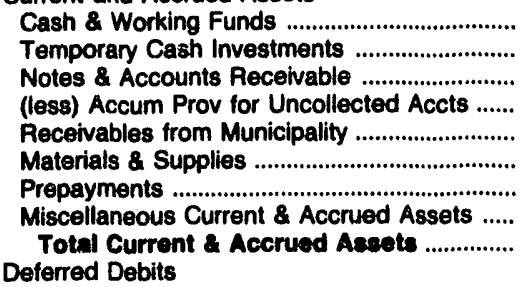 & $\begin{array}{r}271,037 \\
0 \\
0 \\
0 \\
31,428 \\
5,070 \\
4,073 \\
0 \\
311,608\end{array}$ & $\begin{array}{r}22,983 \\
446,583 \\
29,289 \\
0 \\
0 \\
15,457 \\
0 \\
0 \\
514,312\end{array}$ & $\begin{array}{r}1,828 \\
0 \\
5,720 \\
0 \\
0 \\
752 \\
0 \\
0 \\
8,300\end{array}$ & $\begin{array}{r}1,077 \\
0 \\
1,022 \\
0 \\
23 \\
255 \\
0 \\
0 \\
2,377\end{array}$ & $\begin{array}{r}7,109 \\
0 \\
3,391 \\
0 \\
0 \\
900 \\
0 \\
0 \\
11,400\end{array}$ & $\begin{array}{r}6,782 \\
0 \\
2,035 \\
28 \\
0 \\
723 \\
0 \\
0 \\
8,511\end{array}$ \\
\hline 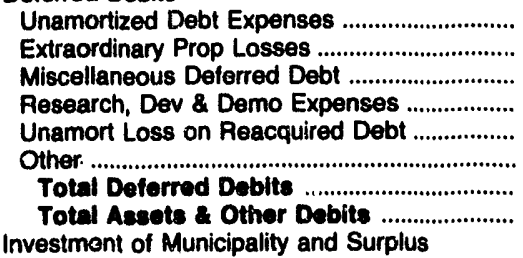 & $\begin{array}{r}43,102 \\
0 \\
1,343,227 \\
0 \\
0 \\
0 \\
1,386,329 \\
3,280,415\end{array}$ & $\begin{array}{r}41,268 \\
0 \\
46,585 \\
0 \\
0 \\
191,988 \\
279,841 \\
2,437,650\end{array}$ & $\begin{array}{r}0 \\
0 \\
0 \\
0 \\
0 \\
0 \\
0 \\
27,427\end{array}$ & $\begin{array}{r}0 \\
0 \\
2 \\
0 \\
0 \\
0 \\
2 \\
4,302\end{array}$ & $\begin{array}{r}0 \\
0 \\
0 \\
0 \\
0 \\
0 \\
0 \\
20,637\end{array}$ & $\begin{array}{r}0 \\
0 \\
0 \\
0 \\
0 \\
0 \\
0 \\
18,469\end{array}$ \\
\hline 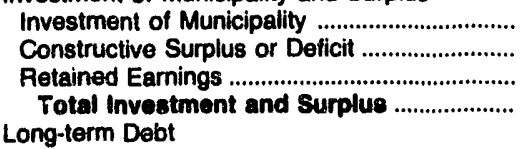 & $\begin{array}{r}0 \\
0 \\
5,168 \\
5,168\end{array}$ & $\begin{array}{r}0 \\
0 \\
10,078 \\
10,078\end{array}$ & $\begin{array}{r}0 \\
0 \\
19,825 \\
18,825\end{array}$ & $\begin{array}{r}0 \\
0 \\
2,876 \\
2,876\end{array}$ & $\begin{array}{r}16 \\
0 \\
17,810 \\
17,826\end{array}$ & $\begin{array}{r}812 \\
0 \\
16,008 \\
18,820\end{array}$ \\
\hline 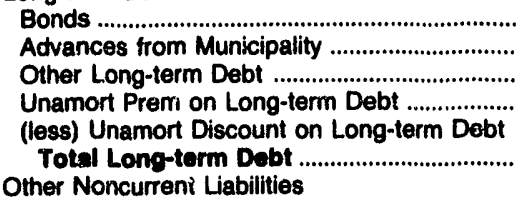 & $\begin{array}{r}3,207,155 \\
0 \\
15,849 \\
1,720 \\
218,246 \\
3,006,478\end{array}$ & $\begin{array}{r}2,473,222 \\
0 \\
26,359 \\
0 \\
173,812 \\
2,325,769\end{array}$ & $\begin{array}{r}1,979 \\
0 \\
0 \\
0 \\
0 \\
1,979\end{array}$ & $\begin{array}{r}200 \\
0 \\
0 \\
0 \\
0 \\
200\end{array}$ & $\begin{array}{r}661 \\
0 \\
123 \\
0 \\
0 \\
784\end{array}$ & $\begin{array}{l}0 \\
0 \\
0 \\
0 \\
0 \\
0\end{array}$ \\
\hline 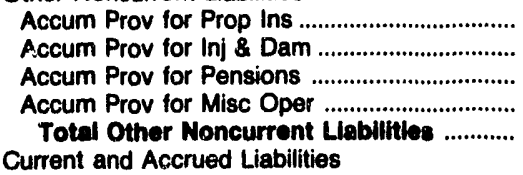 & $\begin{array}{l}0 \\
0 \\
0 \\
0 \\
0\end{array}$ & $\begin{array}{l}0 \\
0 \\
0 \\
0 \\
0\end{array}$ & $\begin{array}{l}0 \\
0 \\
0 \\
0 \\
0\end{array}$ & $\begin{array}{l}0 \\
0 \\
0 \\
0 \\
0\end{array}$ & $\begin{array}{l}0 \\
0 \\
0 \\
0 \\
0\end{array}$ & $\begin{array}{l}0 \\
0 \\
0 \\
0 \\
0\end{array}$ \\
\hline 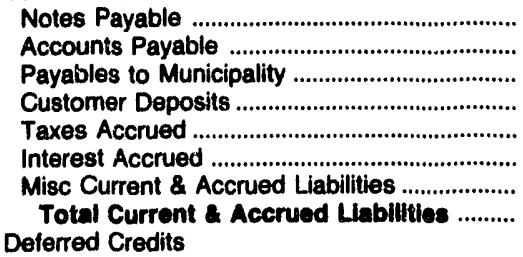 & $\begin{array}{r}145,278 \\
15,365 \\
0 \\
0 \\
9,024 \\
99,102 \\
0 \\
268,769\end{array}$ & $\begin{array}{r}0 \\
181 \\
0 \\
0 \\
11,273 \\
90,349 \\
0 \\
101,803\end{array}$ & $\begin{array}{r}0 \\
4,813 \\
0 \\
603 \\
0 \\
8 \\
199 \\
5,623\end{array}$ & $\begin{array}{r}0 \\
782 \\
128 \\
313 \\
0 \\
4 \\
0 \\
1,226\end{array}$ & $\begin{array}{r}0 \\
1,586 \\
0 \\
170 \\
0 \\
11 \\
259 \\
2,027\end{array}$ & $\begin{array}{r}0 \\
1,558 \\
0 \\
91 \\
0 \\
0 \\
0 \\
1,649\end{array}$ \\
\hline 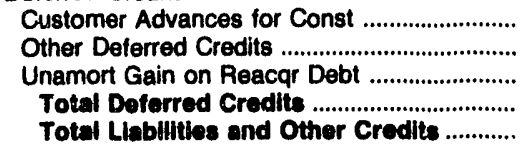 & $\begin{array}{r}0 \\
0 \\
0 \\
0 \\
3,280,415\end{array}$ & $\begin{array}{r}0 \\
0 \\
0 \\
0 \\
2,437,650\end{array}$ & $\begin{array}{r}0 \\
0 \\
0 \\
0 \\
27,427\end{array}$ & $\begin{array}{r}0 \\
0 \\
0 \\
0 \\
4,302\end{array}$ & $\begin{array}{r}0 \\
0 \\
0 \\
0 \\
20,637\end{array}$ & $\begin{array}{r}0 \\
0 \\
0 \\
0 \\
18,469\end{array}$ \\
\hline
\end{tabular}

Note: Totals may not equal sum of components because of independent rounding.

Source: Energy Information Administration, Form EIA-412, "Annual Report of Public Electric Utilitiss." 
Table 37. Balance Sheet by Major Publicly Owned Electric Utility Within State at End of Period, 1991 (Continued) (Thousand Dollars)

\begin{tabular}{|c|c|c|c|c|c|c|}
\hline Item & $\begin{array}{l}\text { North Carolina } \\
\text { Washington } \\
\text { City of } \\
\text { June } 30\end{array}$ & $\begin{array}{l}\text { Wilson } \\
\text { City of } \\
\text { June } 30\end{array}$ & $\begin{array}{c}\text { Ohio } \\
\text { American } \\
\text { Mun } \\
\text { Power } \\
\text { Ohio Inc } \\
\text { December } 31\end{array}$ & $\begin{array}{c}\text { Ohio } \\
\text { Bowling } \\
\text { Green } \\
\text { City of } \\
\text { December } 31\end{array}$ & $\begin{array}{c}\text { Ohio } \\
\text { Bryan } \\
\text { City of } \\
\text { December } 31\end{array}$ & $\begin{array}{l}\text { Ohio } \\
\text { Colina } \\
\text { City of }\end{array}$ \\
\hline $\begin{array}{l}\text { Elestric Utility Plant } \\
\text { Total Electric Utility Plant ................................... } \\
\text { (less) Depr, Amort, and Depletion .................... } \\
\text { Not Electric Utilty Plant ................................ } \\
\text { Other Property \& Investments }\end{array}$ & $\begin{array}{r}23,389 \\
9,277 \\
14,112\end{array}$ & $\begin{array}{l}45,153 \\
22,044 \\
23,100\end{array}$ & $\begin{array}{r}66,654 \\
9,885 \\
53,769\end{array}$ & $\begin{array}{r}12,657 \\
7,623 \\
5,034\end{array}$ & $\begin{array}{r}15,923 \\
12,607 \\
3,315\end{array}$ & $\begin{array}{r}17,331 \\
0 \\
17,331\end{array}$ \\
\hline 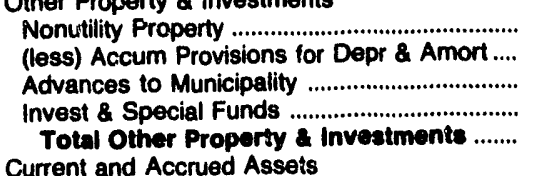 & $\begin{array}{l}0 \\
0 \\
0 \\
0 \\
0\end{array}$ & $\begin{array}{l}0 \\
0 \\
0 \\
0 \\
0\end{array}$ & $\begin{array}{r}1,764 \\
597 \\
0 \\
18,484 \\
17,651\end{array}$ & $\begin{array}{r}0 \\
0 \\
0 \\
5,163 \\
5,163\end{array}$ & $\begin{array}{l}0 \\
0 \\
0 \\
0 \\
0\end{array}$ & $\begin{array}{l}0 \\
0 \\
0 \\
0 \\
\mathbf{0}\end{array}$ \\
\hline 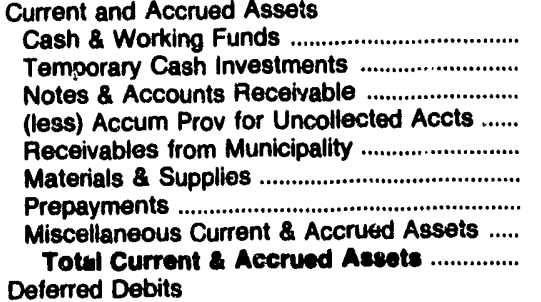 & $\begin{array}{r}5,901 \\
188 \\
2,501 \\
0 \\
17 \\
622 \\
0 \\
0 \\
9,228\end{array}$ & $\begin{array}{r}0 \\
28,419 \\
7,669 \\
117 \\
0 \\
1,646 \\
35 \\
0 \\
37,653\end{array}$ & $\begin{array}{r}8,960 \\
0 \\
12,292 \\
0 \\
0 \\
1,072 \\
291 \\
0 \\
22,614\end{array}$ & $\begin{array}{r}1 \\
1,238 \\
882 \\
0 \\
0 \\
1,074 \\
31 \\
754 \\
3,880\end{array}$ & $\begin{array}{r}1,292 \\
1,278 \\
828 \\
0 \\
188 \\
0 \\
22 \\
11 \\
3,610\end{array}$ & $\begin{array}{r}1 \\
1,582 \\
469 \\
0 \\
0 \\
527 \\
9 \\
3 \\
2,591\end{array}$ \\
\hline 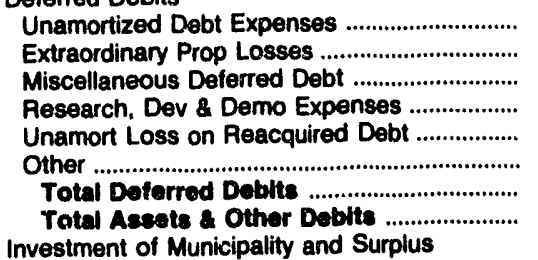 & $\begin{array}{r}0 \\
0 \\
0 \\
0 \\
0 \\
0 \\
0 \\
23,340\end{array}$ & $\begin{array}{r}0 \\
0 \\
0 \\
0 \\
0 \\
0 \\
0 \\
60,762\end{array}$ & $\begin{array}{r}0 \\
0 \\
0 \\
0 \\
0 \\
0 \\
0 \\
97,034\end{array}$ & $\begin{array}{r}0 \\
0 \\
0 \\
0 \\
0 \\
0 \\
0 \\
14,176\end{array}$ & $\begin{array}{r}0 \\
0 \\
0 \\
0 \\
0 \\
0 \\
0 \\
6,934\end{array}$ & $\begin{array}{r}0 \\
0 \\
0 \\
0 \\
0 \\
0 \\
0 \\
18,922\end{array}$ \\
\hline 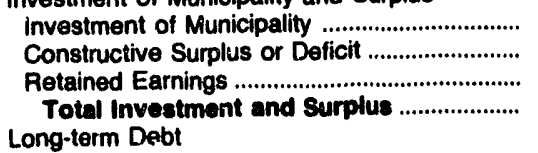 & $\begin{array}{r}309 \\
0 \\
16,675 \\
16,894\end{array}$ & $\begin{array}{r}59 \\
10 \\
48,226 \\
48,295\end{array}$ & $\begin{array}{r}566 \\
0 \\
4,053 \\
4,618\end{array}$ & $\begin{array}{r}0 \\
6,463 \\
5,011 \\
11,474\end{array}$ & $\begin{array}{r}0 \\
0 \\
3,649 \\
3,649\end{array}$ & $\begin{array}{r}17,858 \\
0 \\
1,515 \\
19,373\end{array}$ \\
\hline 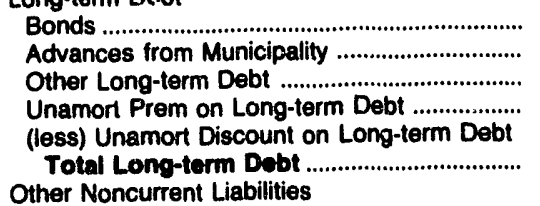 & $\begin{array}{r}4,198 \\
0 \\
415 \\
0 \\
0 \\
4,613\end{array}$ & $\begin{array}{r}350 \\
0 \\
0 \\
0 \\
0 \\
350\end{array}$ & $\begin{array}{r}69,968 \\
0 \\
0 \\
0 \\
0 \\
69,968\end{array}$ & $\begin{array}{l}0 \\
0 \\
0 \\
0 \\
0 \\
0\end{array}$ & $\begin{array}{r}2,290 \\
0 \\
360 \\
0 \\
0 \\
2,650\end{array}$ & $\begin{array}{l}0 \\
0 \\
0 \\
0 \\
0 \\
0\end{array}$ \\
\hline 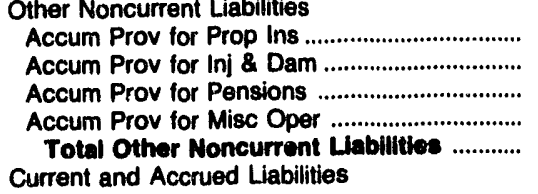 & $\begin{array}{l}0 \\
0 \\
0 \\
0 \\
0\end{array}$ & $\begin{array}{l}0 \\
0 \\
0 \\
0 \\
0\end{array}$ & $\begin{array}{l}0 \\
0 \\
0 \\
0 \\
0\end{array}$ & $\begin{array}{r}27 \\
0 \\
42 \\
0 \\
69\end{array}$ & $\begin{array}{l}0 \\
0 \\
0 \\
0 \\
0\end{array}$ & $\begin{array}{r}40 \\
116 \\
82 \\
151 \\
399\end{array}$ \\
\hline 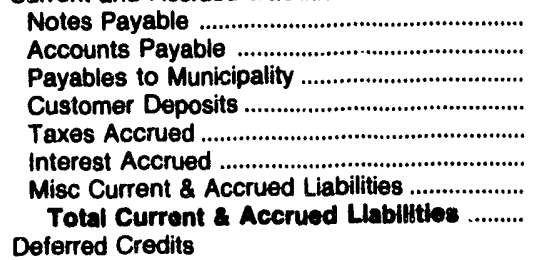 & $\begin{array}{r}0 \\
1,557 \\
0 \\
186 \\
0 \\
0 \\
0 \\
1,743\end{array}$ & $\begin{array}{r}0 \\
5,572 \\
5,624 \\
574 \\
0 \\
4 \\
342 \\
12,117\end{array}$ & $\begin{array}{r}0 \\
10,664 \\
0 \\
0 \\
4,576 \\
1,942 \\
2,971 \\
20,154\end{array}$ & $\begin{array}{r}795 \\
1,104 \\
0 \\
209 \\
0 \\
0 \\
244 \\
2,352\end{array}$ & $\begin{array}{r}0 \\
525 \\
98 \\
0 \\
0 \\
48 \\
-36 \\
635\end{array}$ & $\begin{array}{r}0 \\
68 \\
0 \\
93 \\
0 \\
0 \\
0 \\
161\end{array}$ \\
\hline 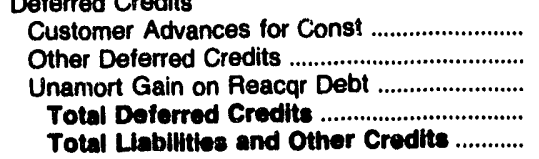 & $\begin{array}{r}0 \\
0 \\
0 \\
0 \\
23,340\end{array}$ & $\begin{array}{r}0 \\
0 \\
0 \\
0 \\
60,762\end{array}$ & $\begin{array}{r}0 \\
2,293 \\
0 \\
2,293 \\
97,034\end{array}$ & $\begin{array}{r}0 \\
281 \\
0 \\
281 \\
14,176\end{array}$ & $\begin{array}{r}0 \\
0 \\
0 \\
0 \\
6,934\end{array}$ & $\begin{array}{r}0 \\
0 \\
0 \\
0 \\
19,922\end{array}$ \\
\hline
\end{tabular}

Note: Totals may not equal sum of components because of independent rounding.

Source: Energy Information Administration, Form EIA-412, "Annual Report of Public Electric Utilities." 
Table 37. Balance Sheet by Major Publicly Owned Electric Utility Within State at End of Period, 1991 (Continued) (Thousand Dollars)

\begin{tabular}{|c|c|c|c|c|c|c|}
\hline Item & $\begin{array}{l}\text { Ohio } \\
\text { Cleveland } \\
\text { City of } \\
\text { December } 31\end{array}$ & $\begin{array}{c}\text { Ohio } \\
\text { Columbus } \\
\text { City of } \\
\text { December } 31\end{array}$ & $\begin{array}{c}\text { Ohio } \\
\text { Cuyahoga } \\
\text { Falls } \\
\text { City of } \\
\text { December } 31\end{array}$ & $\begin{array}{c}\text { Ohio } \\
\text { Dover } \\
\text { City of } \\
\text { December } 31\end{array}$ & $\begin{array}{l}\text { Hamilton } \\
\text { City of } \\
\text { December } 31\end{array}$ & $\begin{array}{l}\text { Ohio } \\
\text { Niles } \\
\text { City of } \\
\text { December } 31\end{array}$ \\
\hline 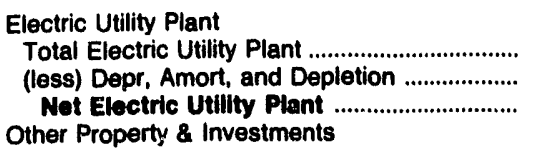 & $\begin{array}{r}181,464 \\
83,229 \\
98,235\end{array}$ & $\begin{array}{r}272,571 \\
90,113 \\
182,457\end{array}$ & $\begin{array}{r}18,083 \\
9,352 \\
8,731\end{array}$ & $\begin{array}{r}7,639 \\
0 \\
7,639\end{array}$ & $\begin{array}{r}219,504 \\
61,209 \\
158,295\end{array}$ & $\begin{array}{r}11,993 \\
6,233 \\
5,760\end{array}$ \\
\hline 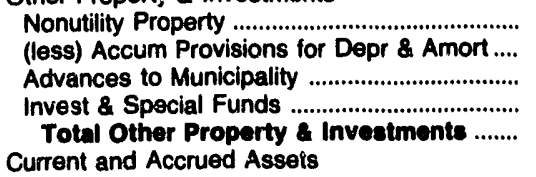 & $\begin{array}{r}0 \\
0 \\
0 \\
33,342 \\
33,342\end{array}$ & $\begin{array}{r}0 \\
0 \\
0 \\
13,656 \\
13,658\end{array}$ & $\begin{array}{l}0 \\
0 \\
0 \\
0 \\
0\end{array}$ & $\begin{array}{r}0 \\
0 \\
0 \\
2,659 \\
2,659\end{array}$ & $\begin{array}{r}0 \\
0 \\
0 \\
20,379 \\
20,379\end{array}$ & $\begin{array}{l}0 \\
0 \\
0 \\
0 \\
0\end{array}$ \\
\hline 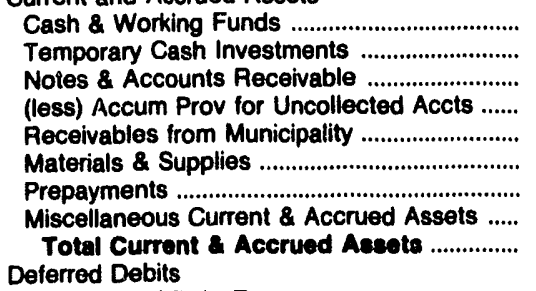 & $\begin{array}{r}15,060 \\
0 \\
5,178 \\
215 \\
2,412 \\
6,542 \\
133 \\
1,510 \\
30,621\end{array}$ & $\begin{array}{r}5,986 \\
0 \\
5,189 \\
0 \\
451 \\
5,016 \\
0 \\
68 \\
16,711\end{array}$ & $\begin{array}{r}1,690 \\
5,505 \\
2,257 \\
0 \\
864 \\
1,807 \\
48 \\
0 \\
12,170\end{array}$ & $\begin{array}{r}1,372 \\
1 \\
1,422 \\
0 \\
7 \\
777 \\
48 \\
11 \\
3,639\end{array}$ & $\begin{array}{r}2,445 \\
0 \\
3,940 \\
0 \\
0 \\
2,460 \\
0 \\
4,756 \\
13,601\end{array}$ & $\begin{array}{r}1,788 \\
2,000 \\
2,022 \\
250 \\
0 \\
557 \\
0 \\
165 \\
6,282\end{array}$ \\
\hline 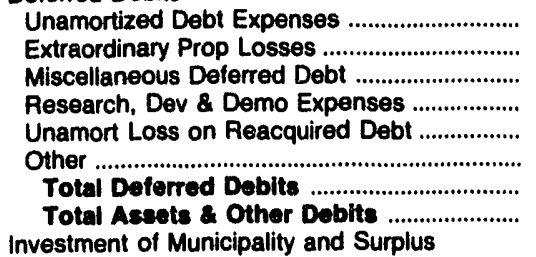 & $\begin{array}{r}533 \\
0 \\
0 \\
0 \\
0 \\
0 \\
533 \\
162,731\end{array}$ & $\begin{array}{r}0 \\
0 \\
0 \\
0 \\
0 \\
0 \\
0 \\
212,824\end{array}$ & $\begin{array}{r}0 \\
0 \\
0 \\
0 \\
0 \\
0 \\
0 \\
20,801\end{array}$ & $\begin{array}{r}0 \\
0 \\
0 \\
0 \\
0 \\
0 \\
0 \\
13,937\end{array}$ & $\begin{array}{r}5,849 \\
0 \\
0 \\
0 \\
0 \\
0 \\
5,849 \\
198,124\end{array}$ & $\begin{array}{r}0 \\
0 \\
0 \\
0 \\
0 \\
420 \\
420 \\
12,461\end{array}$ \\
\hline 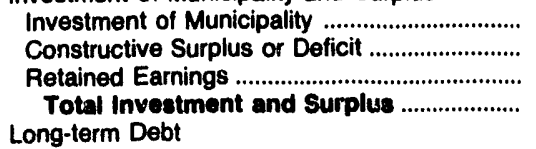 & $\begin{array}{r}28,636 \\
0 \\
56,697 \\
85,332\end{array}$ & $\begin{array}{r}18,814 \\
0 \\
-21,206 \\
-2,392\end{array}$ & $\begin{array}{r}0 \\
3 \\
15,111 \\
15,111\end{array}$ & $\begin{array}{r}135 \\
0 \\
5,779 \\
5,914\end{array}$ & $\begin{array}{r}0 \\
0 \\
21,370 \\
21,370\end{array}$ & $\begin{array}{r}0 \\
0 \\
8,598 \\
8,598\end{array}$ \\
\hline 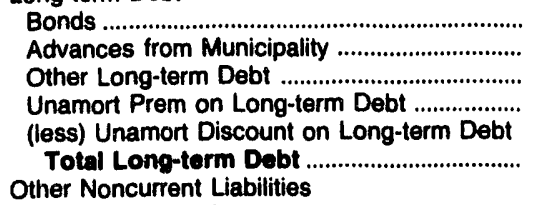 & $\begin{array}{r}65,640 \\
0 \\
0 \\
0 \\
0 \\
65,640\end{array}$ & $\begin{array}{r}206,856 \\
0 \\
0 \\
0 \\
0 \\
206,856\end{array}$ & $\begin{array}{r}3,990 \\
0 \\
0 \\
0 \\
0 \\
3,990\end{array}$ & $\begin{array}{r}1,730 \\
0 \\
67 \\
0 \\
0 \\
1,797\end{array}$ & $\begin{array}{r}168,920 \\
0 \\
0 \\
0 \\
0 \\
168,920\end{array}$ & $\begin{array}{r}2,780 \\
0 \\
0 \\
0 \\
0 \\
2,780\end{array}$ \\
\hline 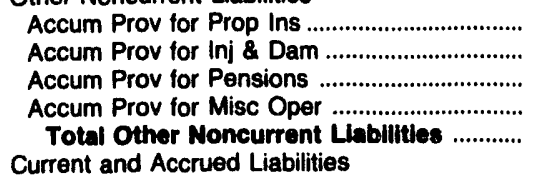 & $\begin{array}{l}0 \\
0 \\
0 \\
0 \\
0\end{array}$ & $\begin{array}{l}0 \\
0 \\
0 \\
0 \\
0\end{array}$ & $\begin{array}{l}0 \\
0 \\
0 \\
0 \\
0\end{array}$ & $\begin{array}{l}0 \\
0 \\
0 \\
0 \\
0\end{array}$ & $\begin{array}{l}0 \\
0 \\
0 \\
0 \\
0\end{array}$ & $\begin{array}{l}0 \\
0 \\
0 \\
0 \\
0\end{array}$ \\
\hline 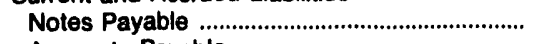 & 240 & 0 & 0 & 5,360 & 1,615 & 0 \\
\hline $\begin{array}{l}\text { Accounts Payable } \\
\text { Payables to Municipality }\end{array}$ & $\begin{array}{l}5,008 \\
118\end{array}$ & $\begin{array}{r}3,110 \\
294\end{array}$ & $\begin{array}{r}1.146 \\
87\end{array}$ & $\begin{array}{r}453 \\
0\end{array}$ & $\begin{array}{r}1,974 \\
0\end{array}$ & 876 \\
\hline 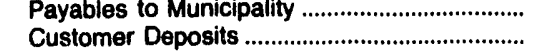 & $\begin{array}{r}118 \\
0\end{array}$ & $\begin{array}{l}294 \\
442\end{array}$ & 177 & 61 & 331 & 0 \\
\hline 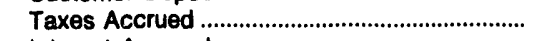 & 0 & 0 & 0 & 0 & 0 & 0 \\
\hline $\begin{array}{l}\text { Interest Accrued } \\
\text { Misc Current \& Accrued Liabilities .............................................. }\end{array}$ & $\begin{array}{r}1,484 \\
4,908 \\
11,759\end{array}$ & $\begin{array}{l}2,442 \\
1,944 \\
8,231\end{array}$ & $\begin{array}{r}20 \\
370 \\
1,800\end{array}$ & $\begin{array}{r}98 \\
253 \\
6,225\end{array}$ & $\begin{array}{l}2,810 \\
1,105 \\
7,834\end{array}$ & $\begin{array}{r}21 \\
187 \\
1,084\end{array}$ \\
\hline 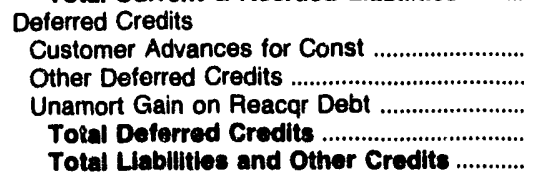 & $\begin{array}{r}0 \\
0 \\
0 \\
0 \\
162,731\end{array}$ & $\begin{array}{r}0 \\
129 \\
0 \\
129 \\
212,824\end{array}$ & $\begin{array}{r}0 \\
0 \\
0 \\
0 \\
20,901\end{array}$ & $\begin{array}{r}0 \\
0 \\
0 \\
0 \\
13,937\end{array}$ & $\begin{array}{r}0 \\
0 \\
0 \\
0 \\
198,124\end{array}$ & $\begin{array}{r}0 \\
0 \\
0 \\
0 \\
12,461\end{array}$ \\
\hline
\end{tabular}

Note: Totals may not equal sum of components because of independent rounding.

Source: Energy Information Administration, Form EIA-412, "Annual Report of Public Electric Utilities." 
Table 37. Balance Sheet by Major Publicly Owned Electric Utility Within State at End of Period, 1991 (Continued) (Thousand Dollars)

\begin{tabular}{|c|c|c|c|c|c|c|}
\hline Item & $\begin{array}{c}\text { Onio } \\
\text { Orrville } \\
\text { City of } \\
\text { December } 31\end{array}$ & $\begin{array}{c}\text { Ohio } \\
\text { Painesville } \\
\text { City of } \\
\text { December } 31\end{array}$ & $\begin{array}{c}\text { Piqua } \\
\text { City of } \\
\text { December } 31\end{array}$ & $\begin{array}{l}\text { St Marys } \\
\text { City of } \\
\text { December } 31\end{array}$ & $\begin{array}{c}\text { Ohio } \\
\text { Wadsworth } \\
\text { City of }\end{array}$ & $\begin{array}{l}\text { Wapakoneta } \\
\text { City of } \\
\text { December } 31\end{array}$ \\
\hline 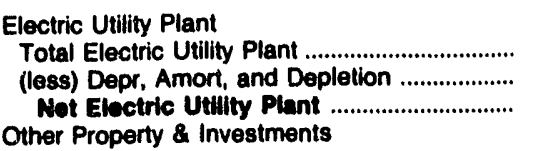 & $\begin{array}{l}54,850 \\
22,707 \\
32,143\end{array}$ & $\begin{array}{l}35,086 \\
19,532 \\
15,565\end{array}$ & $\begin{array}{l}40,518 \\
17,677 \\
22,041\end{array}$ & $\begin{array}{r}14,501 \\
9,673 \\
4,828\end{array}$ & $\begin{array}{l}9,256 \\
5,890 \\
3,365\end{array}$ & $\begin{array}{l}0 \\
0 \\
0\end{array}$ \\
\hline 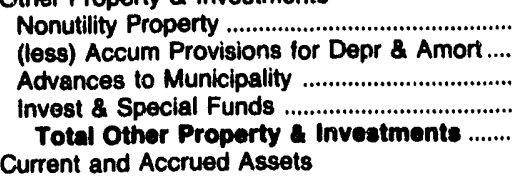 & $\begin{array}{r}0 \\
0 \\
0 \\
6,683 \\
6,683\end{array}$ & $\begin{array}{r}0 \\
0 \\
0 \\
7,167 \\
7,167\end{array}$ & $\begin{array}{r}0 \\
0 \\
0 \\
1,787 \\
1,787\end{array}$ & $\begin{array}{r}0 \\
0 \\
0 \\
1,232 \\
1,232\end{array}$ & $\begin{array}{l}0 \\
0 \\
0 \\
0 \\
0\end{array}$ & $\begin{array}{l}0 \\
0 \\
0 \\
0 \\
\mathbf{0}\end{array}$ \\
\hline 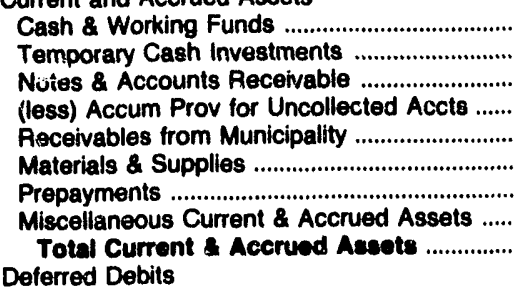 & $\begin{array}{r}0 \\
0 \\
1,081 \\
105 \\
0 \\
1,314 \\
635 \\
819 \\
3,744\end{array}$ & $\begin{array}{r}351 \\
0 \\
1,663 \\
0 \\
80 \\
1,134 \\
22 \\
241 \\
3,480\end{array}$ & $\begin{array}{r}0 \\
948 \\
1,449 \\
67 \\
0 \\
516 \\
108 \\
236 \\
3,190\end{array}$ & $\begin{array}{r}839 \\
2,135 \\
343 \\
0 \\
4 \\
187 \\
54 \\
0 \\
3,563\end{array}$ & $\begin{array}{r}2,038 \\
0 \\
1,214 \\
0 \\
1,217 \\
284 \\
0 \\
0 \\
4,753\end{array}$ & $\begin{array}{r}156 \\
2,232 \\
0 \\
0 \\
0 \\
0 \\
0 \\
0 \\
2,389\end{array}$ \\
\hline 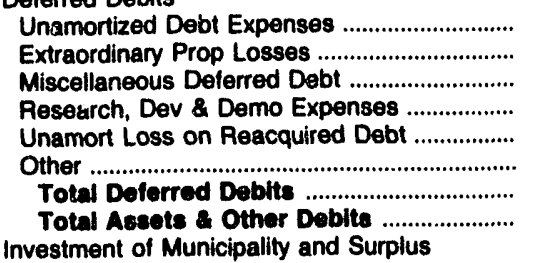 & $\begin{array}{r}0 \\
0 \\
0 \\
0 \\
0 \\
0 \\
0 \\
\mathbf{4 2 , 5 7 1}\end{array}$ & $\begin{array}{r}0 \\
0 \\
0 \\
0 \\
0 \\
0 \\
0 \\
28,212\end{array}$ & $\begin{array}{r}0 \\
0 \\
0 \\
0 \\
0 \\
0 \\
0 \\
27,818\end{array}$ & $\begin{array}{r}200 \\
0 \\
0 \\
0 \\
0 \\
0 \\
200 \\
9,822\end{array}$ & $\begin{array}{r}0 \\
0 \\
0 \\
0 \\
0 \\
0 \\
0 \\
8,118\end{array}$ & $\begin{array}{r}0 \\
0 \\
0 \\
0 \\
0 \\
0 \\
0 \\
2,388\end{array}$ \\
\hline 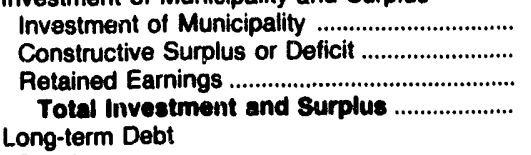 & $\begin{array}{r}0 \\
0 \\
21,851 \\
21,851\end{array}$ & $\begin{array}{r}62 \\
0 \\
18,063 \\
18,125\end{array}$ & $\begin{array}{r}0 \\
0 \\
16,165 \\
16,165\end{array}$ & $\begin{array}{r}0 \\
0 \\
3,424 \\
3,424\end{array}$ & $\begin{array}{r}0 \\
0 \\
6,656 \\
6,656\end{array}$ & $\begin{array}{r}244 \\
0 \\
2,144 \\
2,398\end{array}$ \\
\hline 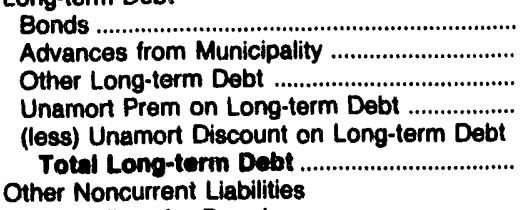 & $\begin{array}{r}19,631 \\
0 \\
0 \\
0 \\
0 \\
19,631\end{array}$ & $\begin{array}{r}6,420 \\
0 \\
0 \\
0 \\
0 \\
6,480\end{array}$ & $\begin{array}{r}10,113 \\
0 \\
0 \\
0 \\
0 \\
10,113\end{array}$ & $\begin{array}{r}5,665 \\
0 \\
0 \\
0 \\
0 \\
5,665\end{array}$ & $\begin{array}{l}0 \\
0 \\
0 \\
0 \\
0 \\
0\end{array}$ & $\begin{array}{l}0 \\
0 \\
0 \\
0 \\
0 \\
0\end{array}$ \\
\hline 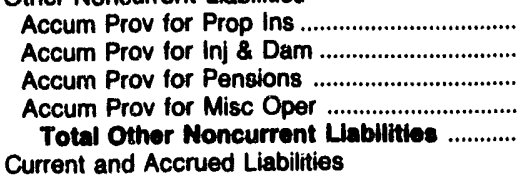 & $\begin{array}{l}0 \\
0 \\
0 \\
0 \\
0\end{array}$ & $\begin{array}{r}0 \\
0 \\
429 \\
0 \\
429\end{array}$ & $\begin{array}{r}0 \\
0 \\
212 \\
0 \\
212\end{array}$ & $\begin{array}{l}0 \\
0 \\
0 \\
0 \\
0\end{array}$ & $\begin{array}{l}0 \\
0 \\
0 \\
0 \\
0\end{array}$ & $\begin{array}{l}0 \\
0 \\
0 \\
0 \\
0\end{array}$ \\
\hline 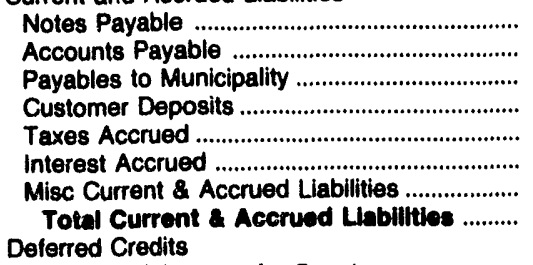 & $\begin{array}{r}0 \\
461 \\
0 \\
0 \\
0 \\
121 \\
507 \\
1,089\end{array}$ & $\begin{array}{r}0 \\
655 \\
63 \\
240 \\
0 \\
0 \\
280 \\
1,238\end{array}$ & $\begin{array}{r}0 \\
889 \\
0 \\
0 \\
0 \\
0 \\
439 \\
1,328\end{array}$ & $\begin{array}{r}0 \\
320 \\
2 \\
182 \\
0 \\
63 \\
166 \\
733\end{array}$ & $\begin{array}{r}326 \\
670 \\
0 \\
0 \\
0 \\
0 \\
466 \\
1,462\end{array}$ & $\begin{array}{l}0 \\
0 \\
0 \\
0 \\
0 \\
0 \\
0 \\
0\end{array}$ \\
\hline 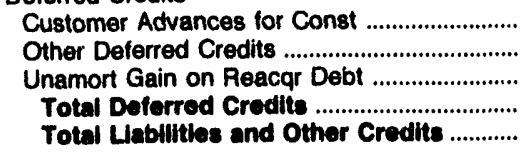 & $\begin{array}{r}0 \\
0 \\
0 \\
0 \\
42,571\end{array}$ & $\begin{array}{r}0 \\
0 \\
0 \\
0 \\
26,212\end{array}$ & $\begin{array}{r}0 \\
0 \\
0 \\
0 \\
27,818\end{array}$ & $\begin{array}{r}0 \\
0 \\
0 \\
0 \\
9,822\end{array}$ & $\begin{array}{r}0 \\
0 \\
0 \\
0 \\
8,118\end{array}$ & $\begin{array}{r}0 \\
0 \\
0 \\
0 \\
\mathbf{0}, 398\end{array}$ \\
\hline
\end{tabular}

Note: Totals may not equal sum of components because of independent rounding

Source: Energy Information Administration, Form ElA-412, "Annual Report of Public Electric Utilities." 
Table 37. Balance Sheet by Major Publicly Owned Electric Utility Within State at End of Period, 1991 (Continued) (Thousand Dollars)

\begin{tabular}{|c|c|c|c|c|c|c|}
\hline Item & $\begin{array}{c}\text { Ohio } \\
\text { Westerville } \\
\text { City of } \\
\text { December } 31\end{array}$ & $\begin{array}{l}\text { Oklahoma } \\
\text { Altus } \\
\text { City of } \\
\text { June } 30\end{array}$ & $\begin{array}{l}\text { Oklahoma } \\
\text { Claremore } \\
\text { City of } \\
\text { June } 30\end{array}$ & $\begin{array}{l}\text { Oklahoma } \\
\text { Edmond } \\
\text { City of } \\
\text { June } 30\end{array}$ & $\begin{array}{l}\text { Oklahoma } \\
\text { Grand Aiver } \\
\text { Dam } \\
\text { Authority } \\
\text { December } 31\end{array}$ & $\begin{array}{l}\text { Oklahoma } \\
\text { Oklahoma } \\
\text { Municipal } \\
\text { Power Auth } \\
\text { December } 31\end{array}$ \\
\hline 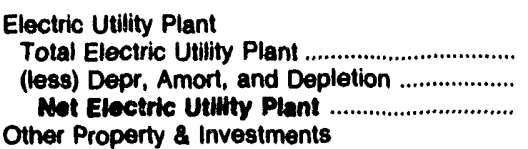 & $\begin{array}{r}10,059 \\
4,970 \\
5,089\end{array}$ & $\begin{array}{l}7,617 \\
4,061 \\
3,557\end{array}$ & $\begin{array}{l}0 \\
0 \\
0\end{array}$ & $\begin{array}{l}32,085 \\
13,541 \\
18,543\end{array}$ & $\begin{array}{l}888,212 \\
226,702 \\
681,510\end{array}$ & $\begin{array}{r}157,240 \\
20,749 \\
138,492\end{array}$ \\
\hline 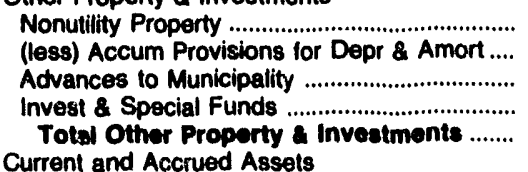 & $\begin{array}{l}0 \\
0 \\
0 \\
0 \\
0\end{array}$ & $\begin{array}{l}0 \\
0 \\
0 \\
0 \\
0\end{array}$ & $\begin{array}{l}0 \\
0 \\
0 \\
0 \\
0\end{array}$ & $\begin{array}{r}0 \\
0 \\
0 \\
2,205 \\
2,205\end{array}$ & $\begin{array}{r}33 \\
0 \\
0 \\
96,753 \\
98,786\end{array}$ & $\begin{array}{r}0 \\
0 \\
0 \\
50,642 \\
50,642\end{array}$ \\
\hline 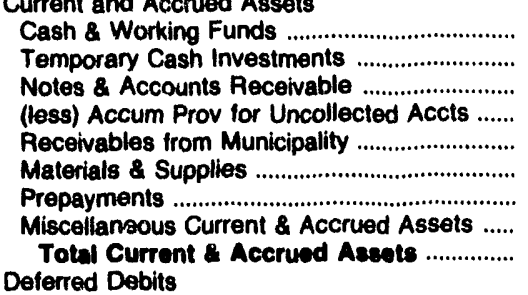 & $\begin{array}{r}18,072 \\
0 \\
2,578 \\
60 \\
0 \\
1,164 \\
0 \\
0 \\
21,754\end{array}$ & $\begin{array}{r}4,809 \\
0 \\
677 \\
167 \\
0 \\
508 \\
0 \\
0 \\
5,827\end{array}$ & $\begin{array}{r}370 \\
0 \\
1,380 \\
0 \\
0 \\
0 \\
0 \\
0 \\
1,750\end{array}$ & $\begin{array}{r}301 \\
0 \\
1,799 \\
59 \\
0 \\
0 \\
0 \\
9 \\
2,050\end{array}$ & $\begin{array}{r}9,819 \\
93,069 \\
33,619 \\
200 \\
0 \\
24,110 \\
704 \\
2,139 \\
163,260\end{array}$ & $\begin{array}{r}3,900 \\
22,200 \\
0 \\
0 \\
5,206 \\
0 \\
53 \\
2,943 \\
34,302\end{array}$ \\
\hline 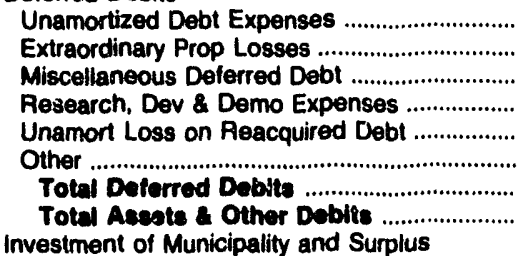 & $\begin{array}{r}0 \\
0 \\
0 \\
0 \\
0 \\
0 \\
0 \\
26,843\end{array}$ & $\begin{array}{r}0 \\
0 \\
0 \\
0 \\
0 \\
0 \\
0 \\
9,393\end{array}$ & $\begin{array}{r}0 \\
0 \\
0 \\
0 \\
0 \\
0 \\
0 \\
1,750\end{array}$ & $\begin{array}{r}0 \\
0 \\
0 \\
0 \\
0 \\
0 \\
0 \\
02,798\end{array}$ & $\begin{array}{r}10,181 \\
0 \\
123,544 \\
0 \\
80,931 \\
0 \\
214,655 \\
1,136,211\end{array}$ & $\begin{array}{r}31,561 \\
0 \\
0 \\
0 \\
30,914 \\
0 \\
62,475 \\
283,911\end{array}$ \\
\hline 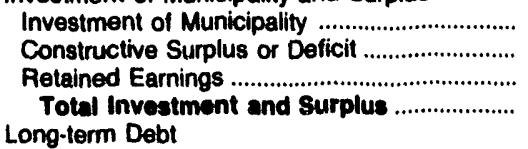 & $\begin{array}{r}27 \\
0 \\
25,049 \\
25,076\end{array}$ & $\begin{array}{r}3,184 \\
0 \\
5,415 \\
8,599\end{array}$ & $\begin{array}{r}0 \\
0 \\
870 \\
870\end{array}$ & $\begin{array}{r}0 \\
0 \\
18,328 \\
18,328\end{array}$ & $\begin{array}{r}0 \\
0 \\
43,874 \\
43,874\end{array}$ & $\begin{array}{r}0 \\
0 \\
6,570 \\
\mathbf{8 , 5 7 0}\end{array}$ \\
\hline 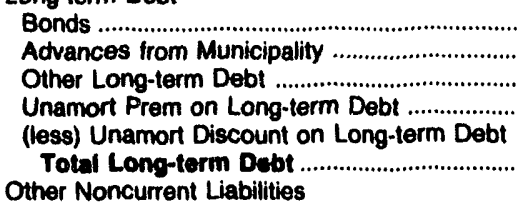 & $\begin{array}{l}0 \\
0 \\
0 \\
0 \\
0 \\
0\end{array}$ & $\begin{array}{l}0 \\
0 \\
0 \\
0 \\
0 \\
0\end{array}$ & $\begin{array}{l}0 \\
0 \\
0 \\
0 \\
0 \\
0\end{array}$ & $\begin{array}{r}0 \\
0 \\
818 \\
0 \\
0 \\
818\end{array}$ & $\begin{array}{r}1,109,410 \\
0 \\
2,236 \\
0 \\
34,271 \\
1,077,375\end{array}$ & $\begin{array}{r}264,610 \\
0 \\
0 \\
0 \\
10,640 \\
253,970\end{array}$ \\
\hline 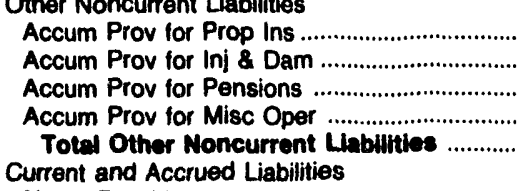 & $\begin{array}{l}0 \\
0 \\
0 \\
0 \\
0\end{array}$ & $\begin{array}{l}0 \\
0 \\
0 \\
0 \\
0\end{array}$ & $\begin{array}{l}0 \\
0 \\
0 \\
0 \\
0\end{array}$ & $\begin{array}{r}0 \\
0 \\
0 \\
43 \\
43\end{array}$ & $\begin{array}{l}0 \\
0 \\
0 \\
0 \\
0\end{array}$ & $\begin{array}{l}0 \\
0 \\
0 \\
0 \\
0\end{array}$ \\
\hline 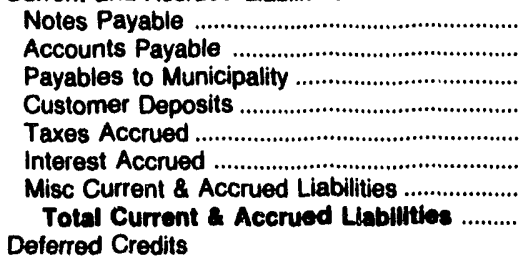 & $\begin{array}{r}350 \\
1,045 \\
0 \\
56 \\
0 \\
0 \\
318 \\
1,768\end{array}$ & $\begin{array}{r}0 \\
784 \\
0 \\
0 \\
0 \\
0 \\
0 \\
784\end{array}$ & $\begin{array}{r}0 \\
869 \\
11 \\
0 \\
0 \\
0 \\
0 \\
880\end{array}$ & $\begin{array}{r}0 \\
1,893 \\
30 \\
1,403 \\
0 \\
0 \\
184 \\
3,610\end{array}$ & $\begin{array}{r}0 \\
7,018 \\
0 \\
0 \\
-782 \\
5,843 \\
1,402 \\
13,580\end{array}$ & $\begin{array}{r}0 \\
3,727 \\
0 \\
0 \\
530 \\
9,124 \\
3,515 \\
16,896\end{array}$ \\
\hline 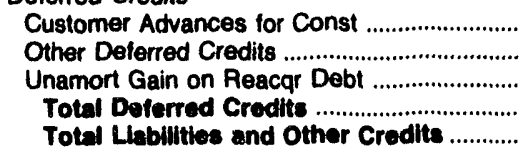 & $\begin{array}{r}0 \\
0 \\
0 \\
0 \\
26,843\end{array}$ & $\begin{array}{r}0 \\
0 \\
0 \\
0 \\
9,383\end{array}$ & $\begin{array}{r}0 \\
0 \\
0 \\
0 \\
1,750\end{array}$ & $\begin{array}{r}0 \\
0 \\
0 \\
0 \\
22,708\end{array}$ & $\begin{array}{r}0 \\
1,382 \\
0 \\
1,382 \\
1,136,211\end{array}$ & $\begin{array}{r}0 \\
6,475 \\
0 \\
6,475 \\
283,911\end{array}$ \\
\hline
\end{tabular}

Note: Totals may not equal sum of components because of independent rounding.

Source: Energy Information Administration, Form EIA-412, "Annual Report of Public Electric Utilities." 
Table 37. Balance Sheet by Major Publicly Owned Electric Utility Within State at End of Period, 1991 (Continued) (Thousand Dollars)

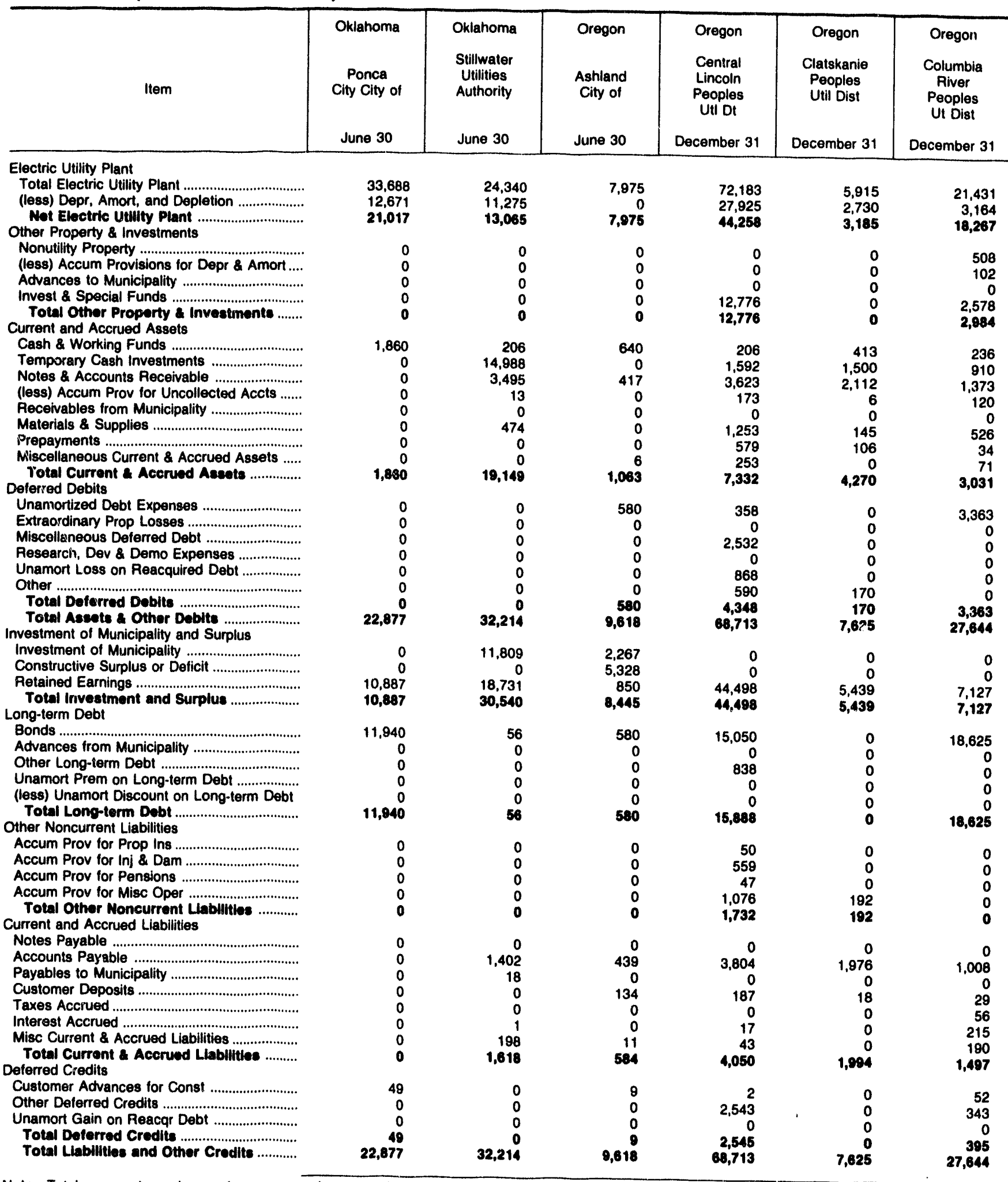

Note: Totals may not equal sum of components because of independent rounding.

Source: Energy Information Administration, Form EiA-412, "Annual Report of Public Electric Utilities." 
Table 37. Balance Sheet by Major Publicly Owned Electric Utility Within State at End of Period, 1991 (Continued) (Thousand Dollars)

\begin{tabular}{|c|c|c|c|c|c|c|}
\hline Item & $\begin{array}{l}\text { Oregon } \\
\text { Emerald } \\
\text { Peoples } \\
\text { Utility Dist } \\
\text { December } 31\end{array}$ & $\begin{array}{c}\text { Eugene } \\
\text { City of } \\
\text { December } 31\end{array}$ & $\begin{array}{l}\text { Oregon } \\
\begin{array}{l}\text { Forest Grove } \\
\text { City of }\end{array} \\
\text { June } 30\end{array}$ & $\begin{array}{l}\text { McMinnville } \\
\text { City of } \\
\text { June } 30\end{array}$ & $\begin{array}{c}\text { Oregon } \\
\text { Northern } \\
\text { Wasco County } \\
\text { P U D } \\
\text { December } 31\end{array}$ & $\begin{array}{l}\text { Oregon } \\
\text { Springfield } \\
\text { City of } \\
\text { December } 31\end{array}$ \\
\hline 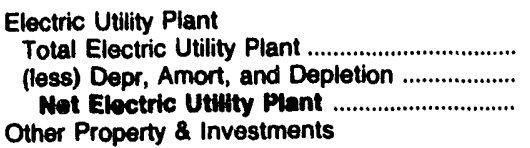 & $\begin{array}{l}66,271 \\
20,748 \\
45,523\end{array}$ & $\begin{array}{r}230,619 \\
99,429 \\
131,190\end{array}$ & $\begin{array}{r}10,170 \\
3,051 \\
7,119\end{array}$ & $\begin{array}{r}19,243 \\
4,223 \\
15,020\end{array}$ & $\begin{array}{r}31,239 \\
7,720 \\
23,519\end{array}$ & $\begin{array}{l}39,126 \\
10,061 \\
29,065\end{array}$ \\
\hline 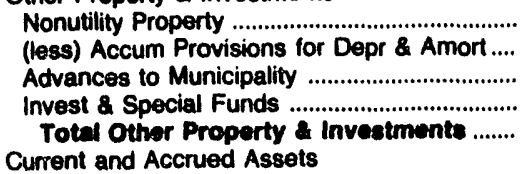 & $\begin{array}{r}0 \\
0 \\
0 \\
6,929 \\
6,929\end{array}$ & $\begin{array}{r}0 \\
0 \\
0 \\
12,877 \\
12,877\end{array}$ & $\begin{array}{l}0 \\
0 \\
0 \\
0 \\
0\end{array}$ & $\begin{array}{l}0 \\
0 \\
0 \\
0 \\
0\end{array}$ & $\begin{array}{r}0 \\
0 \\
0 \\
2,153 \\
2,153\end{array}$ & $\begin{array}{r}0 \\
0 \\
0 \\
4,633 \\
4,633\end{array}$ \\
\hline 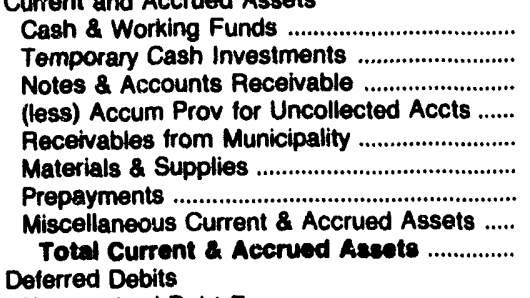 & $\begin{array}{r}705 \\
2,527 \\
1,800 \\
55 \\
0 \\
331 \\
501 \\
829 \\
6,637\end{array}$ & $\begin{array}{r}-855 \\
9,860 \\
13,296 \\
268 \\
0 \\
2,677 \\
636 \\
5,114 \\
30,460\end{array}$ & $\begin{array}{r}-88 \\
929 \\
392 \\
98 \\
11 \\
176 \\
0 \\
92 \\
1,414\end{array}$ & $\begin{array}{r}1 \\
2,481 \\
1.134 \\
5 \\
0 \\
204 \\
0 \\
0 \\
3,815\end{array}$ & $\begin{array}{r}856 \\
1,577 \\
812 \\
90 \\
0 \\
0 \\
267 \\
156 \\
0 \\
3,579\end{array}$ & $\begin{array}{r}419 \\
3,502 \\
3,015 \\
44 \\
0 \\
1,030 \\
0 \\
104 \\
8,026\end{array}$ \\
\hline 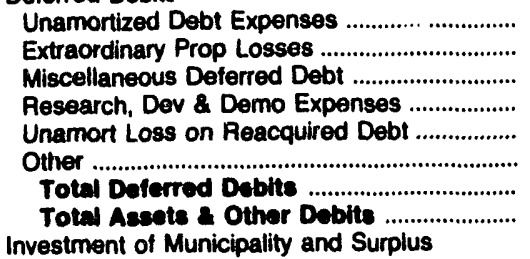 & $\begin{array}{r}1,482 \\
0 \\
7,413 \\
0 \\
0 \\
0 \\
8,895 \\
67,983\end{array}$ & $\begin{array}{r}302 \\
0 \\
5,271 \\
956 \\
0 \\
10,623 \\
17,151 \\
191,677\end{array}$ & $\begin{array}{r}0 \\
0 \\
0 \\
0 \\
0 \\
0 \\
0 \\
8,583\end{array}$ & $\begin{array}{r}0 \\
0 \\
581 \\
0 \\
0 \\
0 \\
581 \\
18,417\end{array}$ & $\begin{array}{r}601 \\
0 \\
1,167 \\
0 \\
0 \\
0 \\
1,768 \\
31,010\end{array}$ & $\begin{array}{r}163 \\
0 \\
91 \\
0 \\
0 \\
649 \\
804 \\
42,628\end{array}$ \\
\hline 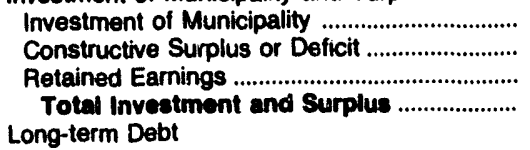 & $\begin{array}{r}0 \\
0 \\
-2,689 \\
-2,689\end{array}$ & $\begin{array}{r}0 \\
0 \\
125,882 \\
125,882\end{array}$ & $\begin{array}{r}8,277 \\
0 \\
16 \\
8,294\end{array}$ & $\begin{array}{r}440 \\
2,089 \\
14,572 \\
17,101\end{array}$ & $\begin{array}{r}76 \\
0 \\
9,664 \\
9,740\end{array}$ & $\begin{array}{r}0 \\
0 \\
29,246 \\
29,246\end{array}$ \\
\hline 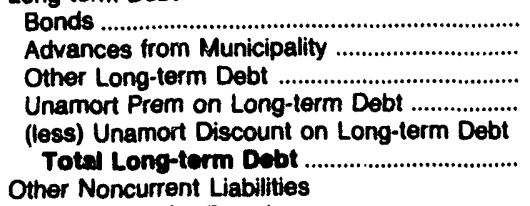 & $\begin{array}{r}67,659 \\
0 \\
0 \\
0 \\
0 \\
67,659\end{array}$ & $\begin{array}{r}45,377 \\
0 \\
0 \\
0 \\
372 \\
45,005\end{array}$ & $\begin{array}{l}0 \\
0 \\
0 \\
0 \\
0 \\
0\end{array}$ & $\begin{array}{r}0 \\
0 \\
566 \\
0 \\
0 \\
586\end{array}$ & $\begin{array}{r}18,135 \\
0 \\
0 \\
0 \\
0 \\
18,135\end{array}$ & $\begin{array}{r}6,110 \\
0 \\
0 \\
0 \\
0 \\
8,110\end{array}$ \\
\hline 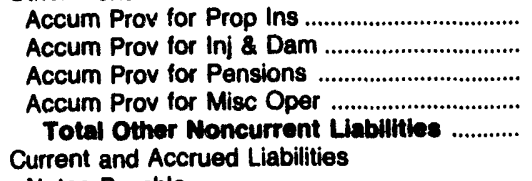 & $\begin{array}{l}0 \\
0 \\
0 \\
0 \\
0\end{array}$ & $\begin{array}{l}0 \\
0 \\
0 \\
0 \\
0\end{array}$ & $\begin{array}{l}0 \\
0 \\
0 \\
0 \\
0\end{array}$ & $\begin{array}{l}0 \\
0 \\
0 \\
0 \\
0\end{array}$ & $\begin{array}{l}0 \\
0 \\
0 \\
0 \\
0\end{array}$ & $\begin{array}{l}0 \\
0 \\
0 \\
0 \\
0\end{array}$ \\
\hline 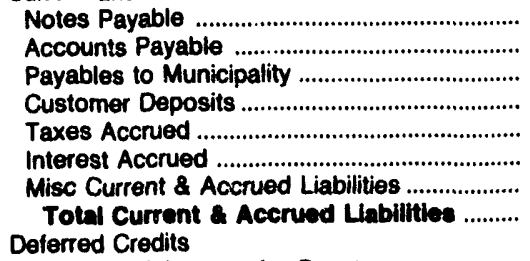 & $\begin{array}{r}0 \\
1,663 \\
0 \\
4 \\
-20 \\
665 \\
677 \\
2,990\end{array}$ & $\begin{array}{r}0 \\
11,394 \\
0 \\
166 \\
865 \\
2,075 \\
2,450 \\
16,950\end{array}$ & $\begin{array}{r}0 \\
93 \\
0 \\
0 \\
0 \\
0 \\
0 \\
93\end{array}$ & $\begin{array}{r}0 \\
1,560 \\
0 \\
21 \\
0 \\
0 \\
169 \\
1,749\end{array}$ & $\begin{array}{r}0 \\
1,542 \\
0 \\
57 \\
0 \\
623 \\
664 \\
2,886\end{array}$ & $\begin{array}{r}0 \\
5,269 \\
0 \\
580 \\
0 \\
190 \\
521 \\
6,560\end{array}$ \\
\hline 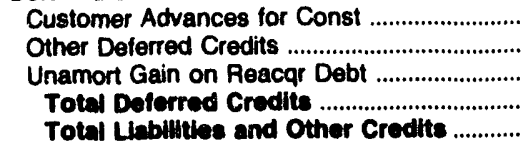 & $\begin{array}{r}0 \\
23 \\
0 \\
23 \\
67,983\end{array}$ & $\begin{array}{r}89 \\
696 \\
3,057 \\
3,841 \\
191,677\end{array}$ & $\begin{array}{r}105 \\
41 \\
0 \\
146 \\
8,533\end{array}$ & $\begin{array}{r}0 \\
0 \\
0 \\
0 \\
19,417\end{array}$ & $\begin{array}{r}5 \\
253 \\
0 \\
258 \\
31,019\end{array}$ & $\begin{array}{r}63 \\
649 \\
0 \\
712 \\
42,628\end{array}$ \\
\hline
\end{tabular}

Note: Totals may not equal sum of components because of independent rounding.

Source: Energy Information Administration, Form EIA-412, "Annual Report of Public Electric Utilities." 
Table 37. Balance Sheet by Major Publicly Owned Electric Utility
Within State at End of Period, 1991 (Continued)
(Thousand Dollars)

\begin{tabular}{|c|c|c|c|c|c|c|}
\hline Item & $\begin{array}{c}\text { Oregon } \\
\text { Tillamook } \\
\text { Peoples } \\
\text { Utility Dist } \\
\text { December } 31\end{array}$ & $\begin{array}{l}\text { Pennsylvania } \\
\text { Chambersburg } \\
\text { Borough of } \\
\text { December } 31\end{array}$ & $\begin{array}{l}\text { Camden } \\
\text { City of } \\
\text { June } 30\end{array}$ & $\begin{array}{l}\text { South Carolina } \\
\text { Easley } \\
\text { Combined } \\
\text { Utility } \\
\text { System } \\
\text { March } 31\end{array}$ & $\begin{array}{l}\text { South Carolina } \\
\text { Gaffney } \\
\text { City of } \\
\text { March } 31\end{array}$ & $\begin{array}{l}\text { South Carolina } \\
\text { Greenwood } \\
\text { City of } \\
\text { December } 31\end{array}$ \\
\hline 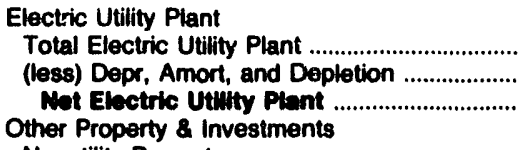 & $\begin{array}{r}30,325 \\
7,281 \\
23,044\end{array}$ & $\begin{array}{l}24,295 \\
11,730 \\
12,695\end{array}$ & $\begin{array}{r}20,786 \\
9,273 \\
11,514\end{array}$ & $\begin{array}{r}12,408 \\
3,929 \\
8,400\end{array}$ & $\begin{array}{r}1,564 \\
626 \\
938\end{array}$ & $\begin{array}{r}13,681 \\
8,290 \\
5,370\end{array}$ \\
\hline $\begin{array}{l}\text { Nonutility Property } \\
\text { (less) Accum Provisions for Depr \& Amort .... } \\
\text { Advances to Municipality .............................. } \\
\text { Invest \& Special Funds ............................... } \\
\text { Totel Other Property \& Inveetments ....... } \\
\text { Current and Accrued Assets }\end{array}$ & $\begin{array}{r}0 \\
0 \\
0 \\
3,516 \\
3,516\end{array}$ & $\begin{array}{r}0 \\
0 \\
232 \\
1,870 \\
2,102\end{array}$ & $\begin{array}{r}0 \\
0 \\
0 \\
1,061 \\
1,061\end{array}$ & $\begin{array}{r}30,702 \\
9,374 \\
0 \\
2,791 \\
24,119\end{array}$ & $\begin{array}{r}8,120 \\
4,096 \\
0 \\
0 \\
4,024\end{array}$ & $\begin{array}{r}58,805 \\
17,534 \\
0 \\
14,104 \\
55,375\end{array}$ \\
\hline 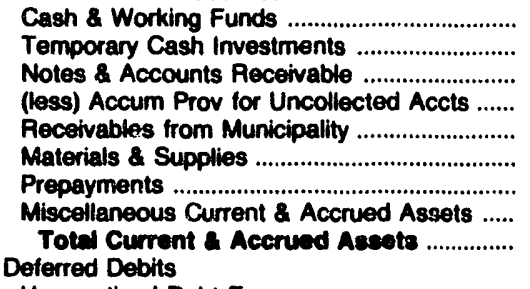 & $\begin{array}{r}-7 \\
4,265 \\
1,097 \\
116 \\
0 \\
526 \\
234 \\
180 \\
6,179\end{array}$ & $\begin{array}{r}1,754 \\
0 \\
1,248 \\
2 \\
0 \\
52 \\
9 \\
90 \\
3,101\end{array}$ & $\begin{array}{r}1 \\
3,063 \\
933 \\
0 \\
0 \\
516 \\
53 \\
0 \\
4,565\end{array}$ & $\begin{array}{r}1,546 \\
0 \\
1,563 \\
2 \\
0 \\
0 \\
478 \\
0 \\
30 \\
3,614\end{array}$ & $\begin{array}{r}228 \\
1,219 \\
1,161 \\
21 \\
0 \\
434 \\
31 \\
0 \\
3,051\end{array}$ & $\begin{array}{r}260 \\
3,378 \\
3,885 \\
94 \\
240 \\
1,188 \\
3 \\
3 \\
57 \\
8,916\end{array}$ \\
\hline 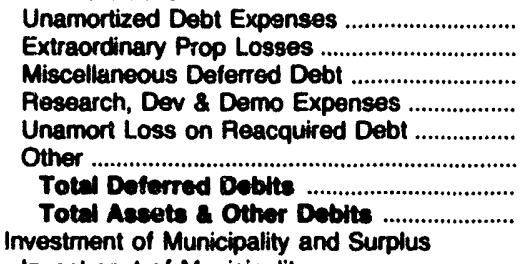 & $\begin{array}{r}158 \\
0 \\
563 \\
11 \\
0 \\
0 \\
732 \\
33,472\end{array}$ & $\begin{array}{r}0 \\
0 \\
0 \\
0 \\
0 \\
0 \\
0 \\
17,768\end{array}$ & $\begin{array}{r}0 \\
0 \\
0 \\
0 \\
0 \\
0 \\
0 \\
17,140\end{array}$ & $\begin{array}{r}0 \\
0 \\
24 \\
0 \\
0 \\
0 \\
24 \\
36,238\end{array}$ & $\begin{array}{r}0 \\
0 \\
0 \\
0 \\
0 \\
0 \\
0 \\
\mathbf{8}, 013\end{array}$ & $\begin{array}{r}590 \\
0 \\
0 \\
0 \\
0 \\
17 \\
607 \\
70,289\end{array}$ \\
\hline 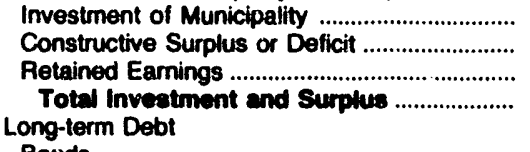 & $\begin{array}{r}0 \\
0 \\
21,055 \\
21,055\end{array}$ & $\begin{array}{r}997 \\
0 \\
15,810 \\
16,806\end{array}$ & $\begin{array}{r}0 \\
0 \\
11,498 \\
11,498\end{array}$ & $\begin{array}{r}178 \\
0 \\
29,535 \\
29,713\end{array}$ & $\begin{array}{r}1,429 \\
0 \\
5,612 \\
7,042\end{array}$ & $\begin{array}{r}0 \\
0 \\
35,534 \\
35,534\end{array}$ \\
\hline $\begin{array}{l}\text { Bdvances from Municipality ............................... } \\
\text { Other Long-term Debt ............................... } \\
\text { Unamort Prem on Long-term Debt ................. } \\
\text { (less) Unamort Discount on Long-term Debt } \\
\text { Totit Long-term Debt .............................. } \\
\text { Other Noncurrent Liabilities }\end{array}$ & $\begin{array}{r}10,276 \\
0 \\
0 \\
0 \\
0 \\
10,276\end{array}$ & $\begin{array}{r}10 \\
0 \\
0 \\
0 \\
0 \\
10\end{array}$ & $\begin{array}{r}3,835 \\
0 \\
8 \\
0 \\
0 \\
3,843\end{array}$ & $\begin{array}{r}2,575 \\
0 \\
39 \\
0 \\
0 \\
2,614\end{array}$ & $\begin{array}{l}0 \\
0 \\
0 \\
0 \\
0 \\
0\end{array}$ & $\begin{array}{r}23,210 \\
0 \\
0 \\
0 \\
0 \\
23,210\end{array}$ \\
\hline 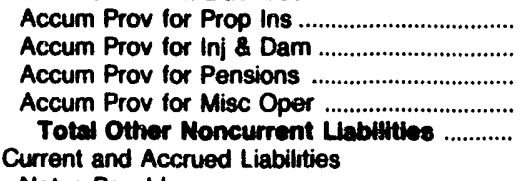 & $\begin{array}{l}0 \\
0 \\
0 \\
0 \\
0\end{array}$ & $\begin{array}{l}0 \\
0 \\
0 \\
0 \\
0\end{array}$ & $\begin{array}{l}0 \\
0 \\
0 \\
0 \\
0\end{array}$ & $\begin{array}{l}\mathbf{0} \\
\mathbf{0} \\
\mathbf{0} \\
\mathbf{0} \\
\mathbf{0}\end{array}$ & $\begin{array}{l}0 \\
0 \\
0 \\
0 \\
0\end{array}$ & $\begin{array}{l}0 \\
0 \\
0 \\
0 \\
0\end{array}$ \\
\hline 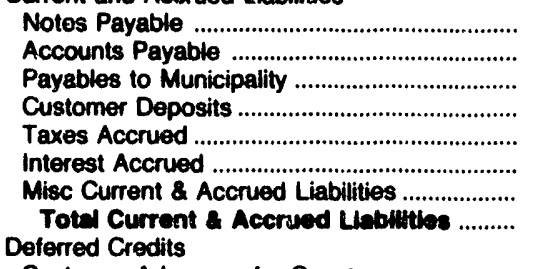 & $\begin{array}{r}0 \\
1,032 \\
0 \\
71 \\
0 \\
273 \\
199 \\
1,576\end{array}$ & $\begin{array}{r}0 \\
728 \\
0 \\
0 \\
0 \\
1 \\
96 \\
925\end{array}$ & $\begin{array}{r}0 \\
1,337 \\
6 \\
302 \\
19 \\
49 \\
85 \\
1,790\end{array}$ & $\begin{array}{r}180 \\
265 \\
0 \\
232 \\
0 \\
61 \\
888 \\
1,627\end{array}$ & $\begin{array}{r}0 \\
91 \\
0 \\
231 \\
37 \\
0 \\
614 \\
972\end{array}$ & $\begin{array}{r}0 \\
4,068 \\
0 \\
190 \\
0 \\
142 \\
964 \\
5,365\end{array}$ \\
\hline 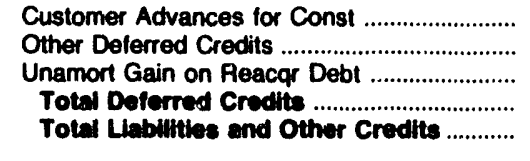 & $\begin{array}{r}0 \\
565 \\
0 \\
565 \\
33,472\end{array}$ & $\begin{array}{r}127 \\
0 \\
0 \\
127 \\
17,768\end{array}$ & $\begin{array}{r}0 \\
0 \\
0 \\
0 \\
17,140\end{array}$ & $\begin{array}{r}375 \\
1,909 \\
0 \\
2,284 \\
38,238\end{array}$ & $\begin{array}{r}0 \\
0 \\
0 \\
0 \\
8,013\end{array}$ & $\begin{array}{r}6,160 \\
0 \\
0 \\
6,180 \\
70,289\end{array}$ \\
\hline
\end{tabular}

Note: Totals may not equal sum of components because of independent rounding.

Source: Energy Information Administration, Form EIA-412, "Annual Raport of Public Electric Utilities." 
Table 37. Balance Sheet by Major Publicly Owned Electric Utility Within State at End of Period, 1991 (Continued) (Thousand Dollars)

\begin{tabular}{|c|c|c|c|c|c|c|}
\hline Item & $\begin{array}{c}\text { South Carolina } \\
\text { Greer } \\
\text { Comm } \\
\text { of } \\
\text { Public Works } \\
\text { December } 31\end{array}$ & $\begin{array}{l}\text { South Carolina } \\
\text { Newberry } \\
\text { City of } \\
\text { June } 30\end{array}$ & $\begin{array}{l}\text { South Carolina } \\
\text { Orangeburg } \\
\text { City of }\end{array}$ & $\begin{array}{l}\text { South Carolina } \\
\text { Piedmont } \\
\text { Municipal } \\
\text { Power Agny } \\
\text { December } 31\end{array}$ & $\begin{array}{l}\text { South Carolina } \\
\text { Rock Hill } \\
\text { City of } \\
\text { December } 31\end{array}$ & $\begin{array}{c}\text { South Carolina } \\
\text { South } \\
\text { Carolina } \\
\text { Pub } \\
\text { Serv Auth } \\
\text { Docember } 31\end{array}$ \\
\hline 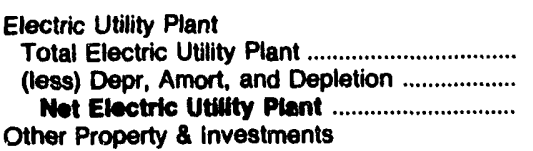 & $\begin{array}{r}65,718 \\
17,773 \\
47,945\end{array}$ & $\begin{array}{l}7,739 \\
3,591 \\
4,148\end{array}$ & $\begin{array}{r}41,903 \\
9,395 \\
32,507\end{array}$ & $\begin{array}{l}586,460 \\
119,266 \\
467,194\end{array}$ & $\begin{array}{r}25,746 \\
9,641 \\
18,105\end{array}$ & $\begin{array}{r}2,542,281 \\
689,810 \\
1,852,471\end{array}$ \\
\hline 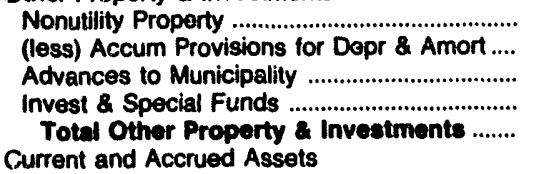 & $\begin{array}{r}0 \\
0 \\
0 \\
7,412 \\
7,412\end{array}$ & $\begin{array}{r}20,465 \\
7,980 \\
0 \\
7,318 \\
19,803\end{array}$ & $\begin{array}{r}0 \\
0 \\
0 \\
15,842 \\
15,842\end{array}$ & $\begin{array}{r}0 \\
0 \\
0 \\
176,383 \\
176,383\end{array}$ & $\begin{array}{r}99,024 \\
16,714 \\
0 \\
0 \\
82,311\end{array}$ & $\begin{array}{r}1,094 \\
167 \\
0 \\
525,863 \\
526,790\end{array}$ \\
\hline 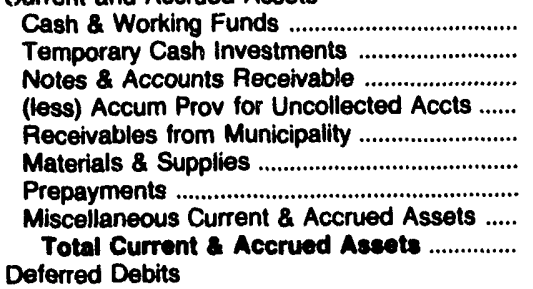 & $\begin{array}{r}445 \\
0 \\
749 \\
0 \\
0 \\
539 \\
0 \\
0 \\
1,733\end{array}$ & $\begin{array}{r}2,047 \\
0 \\
793 \\
0 \\
0 \\
599 \\
0 \\
128 \\
3,567\end{array}$ & $\begin{array}{r}1,609 \\
0 \\
1,527 \\
23 \\
0 \\
2,951 \\
437 \\
49,108 \\
55,608\end{array}$ & $\begin{array}{r}294,715 \\
0 \\
3,672 \\
0 \\
5,298 \\
3,278 \\
0 \\
0 \\
306,863\end{array}$ & $\begin{array}{r}10,130 \\
0 \\
5,866 \\
0 \\
0 \\
838 \\
0 \\
0 \\
16,834\end{array}$ & $\begin{array}{r}50,023 \\
0 \\
46,932 \\
1,336 \\
0 \\
65,669 \\
1,056 \\
4,090 \\
166,434\end{array}$ \\
\hline 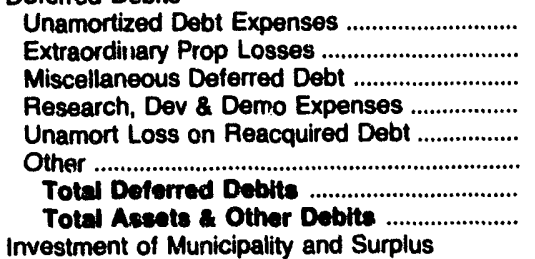 & $\begin{array}{r}0 \\
0 \\
0 \\
0 \\
0 \\
0 \\
0 \\
57,090\end{array}$ & $\begin{array}{r}0 \\
0 \\
0 \\
0 \\
0 \\
0 \\
0 \\
27,518\end{array}$ & $\begin{array}{r}0 \\
0 \\
0 \\
0 \\
0 \\
0 \\
0 \\
103,957\end{array}$ & $\begin{array}{r}21,945 \\
0 \\
162,499 \\
960 \\
196,316 \\
0 \\
381,720 \\
1,332,280\end{array}$ & $\begin{array}{r}2,836 \\
0 \\
0 \\
0 \\
0 \\
0 \\
2,838 \\
118,087\end{array}$ & $\begin{array}{r}16,924 \\
0 \\
23,322 \\
0 \\
217,712 \\
317,328 \\
575,288 \\
3,120,981\end{array}$ \\
\hline 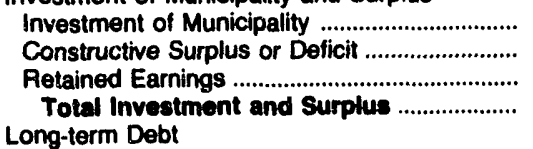 & $\begin{array}{r}0 \\
9,957 \\
44,487 \\
54,444\end{array}$ & $\begin{array}{r}300 \\
0 \\
14,624 \\
14,924\end{array}$ & $\begin{array}{r}0 \\
0 \\
88,990 \\
88,990\end{array}$ & $\begin{array}{r}0 \\
0 \\
12,912 \\
12,912\end{array}$ & $\begin{array}{r}0 \\
34,247 \\
23,707 \\
57,954\end{array}$ & $\begin{array}{r}34,438 \\
0 \\
566,197 \\
600,635\end{array}$ \\
\hline 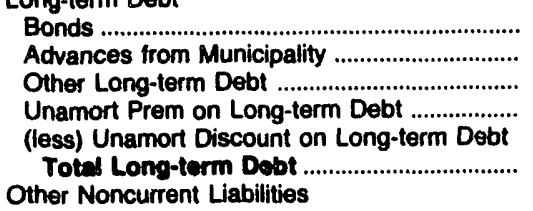 & $\begin{array}{r}545 \\
0 \\
0 \\
0 \\
0 \\
545\end{array}$ & $\begin{array}{r}11,510 \\
0 \\
0 \\
0 \\
0 \\
11,510\end{array}$ & $\begin{array}{r}8,475 \\
0 \\
595 \\
0 \\
0 \\
9,070\end{array}$ & $\begin{array}{r}1,362,581 \\
0 \\
0 \\
0 \\
93,095 \\
1,269,486\end{array}$ & $\begin{array}{r}55,020 \\
0 \\
0 \\
0 \\
0 \\
55,020\end{array}$ & $\begin{array}{r}2,148,560 \\
0 \\
58,871 \\
0 \\
40,256 \\
2,167,175\end{array}$ \\
\hline 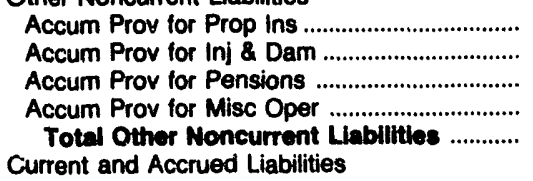 & $\begin{array}{l}0 \\
0 \\
0 \\
0 \\
0\end{array}$ & $\begin{array}{l}0 \\
0 \\
0 \\
0 \\
0\end{array}$ & $\begin{array}{r}0 \\
0 \\
392 \\
0 \\
392\end{array}$ & $\begin{array}{r}0 \\
0 \\
371 \\
5,603 \\
5,974\end{array}$ & $\begin{array}{l}0 \\
0 \\
0 \\
0 \\
0\end{array}$ & $\begin{array}{l}0 \\
0 \\
0 \\
0 \\
0\end{array}$ \\
\hline 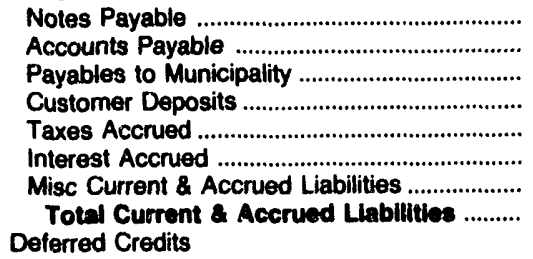 & $\begin{array}{r}0 \\
1,689 \\
0 \\
118 \\
0 \\
11 \\
282 \\
2,101\end{array}$ & $\begin{array}{r}0 \\
812 \\
0 \\
0 \\
0 \\
204 \\
68 \\
1,084\end{array}$ & $\begin{array}{r}0 \\
3,850 \\
0 \\
708 \\
0 \\
0 \\
947 \\
5,505\end{array}$ & $\begin{array}{r}0 \\
3,963 \\
0 \\
0 \\
0 \\
39,925 \\
0 \\
43,888\end{array}$ & $\begin{array}{r}0 \\
4,004 \\
0 \\
1,108 \\
0 \\
0 \\
0 \\
5,113\end{array}$ & $\begin{array}{r}207,514 \\
33,852 \\
0 \\
5,276 \\
1,835 \\
72,296 \\
31,292 \\
352,005\end{array}$ \\
\hline 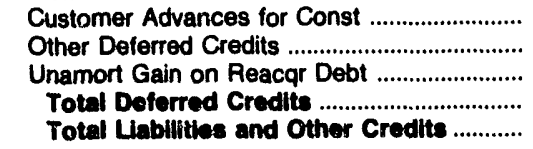 & $\begin{array}{r}0 \\
0 \\
0 \\
0 \\
\mathbf{5 7 , 0 9 0}\end{array}$ & $\begin{array}{r}0 \\
0 \\
0 \\
0 \\
27,518\end{array}$ & $\begin{array}{r}0 \\
0 \\
0 \\
0 \\
103,957\end{array}$ & $\begin{array}{r}0 \\
0 \\
0 \\
0 \\
1,332,280\end{array}$ & $\begin{array}{r}0 \\
0 \\
0 \\
0 \\
118,087\end{array}$ & $\begin{array}{r}0 \\
233 \\
873 \\
1,108 \\
3,120,981\end{array}$ \\
\hline
\end{tabular}

Note: Totals may not equal sum of components because of independent rounding.

Source: Energy information Administration, Form ElA-412, "Annual Report of Public Electric Utilities." 
Table 37. Balance Sheet by Major Publicly Owned Electric Utilliy Within State at End of Period, 1991 (Continued) (Thousand Dollars)

\begin{tabular}{|c|c|c|c|c|c|c|}
\hline Item & $\begin{array}{l}\text { South Dakota } \\
\text { Brookings } \\
\text { City of } \\
\text { December } 31\end{array}$ & $\begin{array}{l}\text { South Dakota } \\
\text { Heartland } \\
\text { Consumers } \\
\text { Power Dist } \\
\text { December } 31\end{array}$ & $\begin{array}{l}\text { South Dakota } \\
\text { Missouri } \\
\text { Basin } \\
\text { Mun } \\
\text { Power Agny } \\
\text { December } 31\end{array}$ & $\begin{array}{c}\text { South Dakota } \\
\text { Pierre } \\
\text { City of } \\
\text { December } 31\end{array}$ & $\begin{array}{c}\text { South Dakota } \\
\text { Watertown } \\
\text { Municipal } \\
\text { Utilities } \\
\text { December } 31\end{array}$ & $\begin{array}{l}\text { Tennessee } \\
\text { Alcoa } \\
\text { Utilities } \\
\text { June } 30\end{array}$ \\
\hline 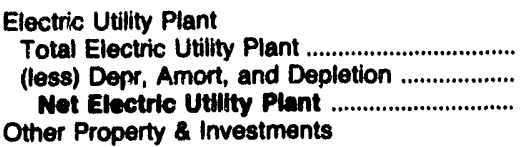 & $\begin{array}{r}15,332 \\
4,136 \\
11,196\end{array}$ & $\begin{array}{r}57,263 \\
5,362 \\
51,900\end{array}$ & $\begin{array}{r}2,580 \\
545 \\
2,035\end{array}$ & $\begin{array}{l}7,370 \\
2,159 \\
5,211\end{array}$ & $\begin{array}{r}14,497 \\
7,963 \\
6,534\end{array}$ & $\begin{array}{r}17,327 \\
5,235 \\
12,092\end{array}$ \\
\hline 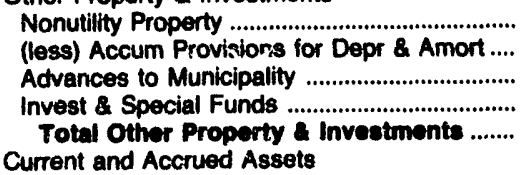 & $\begin{array}{l}0 \\
0 \\
0 \\
0 \\
0\end{array}$ & $\begin{array}{r}C \\
0 \\
0 \\
8,664 \\
8,684\end{array}$ & $\begin{array}{l}0 \\
0 \\
0 \\
0 \\
0\end{array}$ & $\begin{array}{l}0 \\
0 \\
0 \\
0 \\
0\end{array}$ & $\begin{array}{l}0 \\
0 \\
0 \\
0 \\
0\end{array}$ & $\begin{array}{r}0 \\
0 \\
0 \\
1,119 \\
1,119\end{array}$ \\
\hline 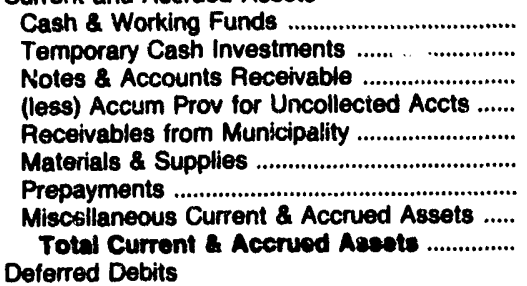 & $\begin{array}{r}1,273 \\
0 \\
1,030 \\
8 \\
51 \\
222 \\
4 \\
25 \\
2,597\end{array}$ & $\begin{array}{r}4,895 \\
0 \\
1,209 \\
0 \\
0 \\
2,191 \\
17 \\
96 \\
8,408\end{array}$ & $\begin{array}{r}0 \\
18,131 \\
6,367 \\
0 \\
0 \\
51 \\
51,649 \\
574 \\
28,77^{\circ}\end{array}$ & $\begin{array}{r}689 \\
1,178 \\
734 \\
57 \\
0 \\
497 \\
0 \\
4 \\
4,046\end{array}$ & $\begin{array}{r}1,968 \\
0 \\
0 \\
1,081 \\
8 \\
230 \\
326 \\
0 \\
7 \\
3,803\end{array}$ & $\begin{array}{r}295 \\
1,433 \\
1,725 \\
80 \\
0 \\
202 \\
8 \\
8 \\
79 \\
3,663\end{array}$ \\
\hline 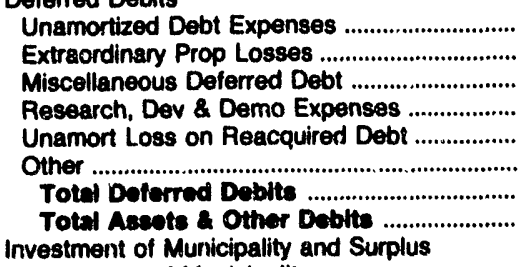 & $\begin{array}{r}0 \\
0 \\
0 \\
0 \\
0 \\
0 \\
0 \\
13,793\end{array}$ & $\begin{array}{r}4,522 \\
0 \\
864 \\
0 \\
0 \\
0 \\
5,487 \\
74,480\end{array}$ & $\begin{array}{r}0 \\
0 \\
147 \\
0 \\
0 \\
0 \\
147 \\
28,95 e\end{array}$ & $\begin{array}{r}0 \\
0 \\
0 \\
0 \\
0 \\
0 \\
0 \\
8,257\end{array}$ & $\begin{array}{r}0 \\
0 \\
0 \\
0 \\
0 \\
0 \\
0 \\
10,138\end{array}$ & $\begin{array}{r}34 \\
0 \\
1,022 \\
0 \\
0 \\
0 \\
1,056 \\
17,930\end{array}$ \\
\hline 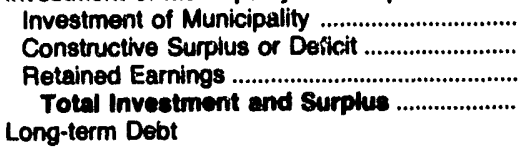 & $\begin{array}{r}0 \\
0 \\
13,019 \\
13,019\end{array}$ & $\begin{array}{r}0 \\
0 \\
866 \\
866\end{array}$ & $\begin{array}{r}0 \\
0 \\
22,662 \\
22,682\end{array}$ & $\begin{array}{r}62 \\
0 \\
7,564 \\
7,626\end{array}$ & $\begin{array}{r}0 \\
0 \\
8,801 \\
8,801\end{array}$ & $\begin{array}{r}0 \\
0 \\
10,438 \\
10,438\end{array}$ \\
\hline 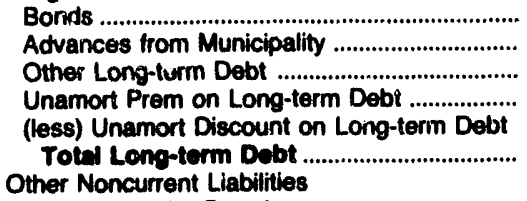 & $\begin{array}{l}0 \\
0 \\
0 \\
0 \\
0 \\
0\end{array}$ & $\begin{array}{r}59,475 \\
0 \\
0 \\
0 \\
0 \\
59,475\end{array}$ & $\begin{array}{l}0 \\
0 \\
0 \\
0 \\
0 \\
0\end{array}$ & $\begin{array}{l}0 \\
0 \\
0 \\
0 \\
0 \\
0\end{array}$ & $\begin{array}{l}0 \\
0 \\
0 \\
0 \\
0 \\
0\end{array}$ & $\begin{array}{r}3,211 \\
0 \\
0 \\
0 \\
37 \\
3,174\end{array}$ \\
\hline 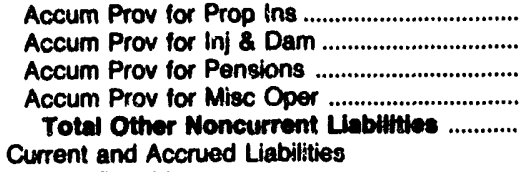 & $\begin{array}{l}0 \\
0 \\
0 \\
0 \\
0\end{array}$ & $\begin{array}{l}0 \\
0 \\
0 \\
0 \\
0\end{array}$ & $\begin{array}{l}0 \\
0 \\
0 \\
0 \\
0\end{array}$ & $\begin{array}{r}0 \\
0 \\
0 \\
35 \\
35\end{array}$ & $\begin{array}{l}0 \\
0 \\
0 \\
0 \\
0\end{array}$ & $\begin{array}{l}0 \\
0 \\
0 \\
0 \\
0\end{array}$ \\
\hline 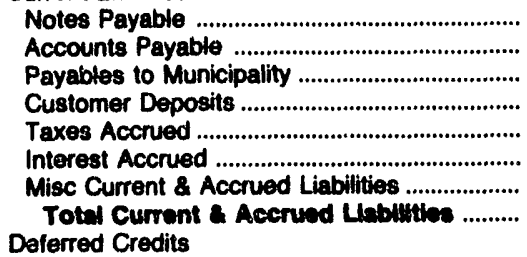 & $\begin{array}{r}0 \\
681 \\
3 \\
0 \\
28 \\
0 \\
63 \\
774\end{array}$ & $\begin{array}{r}0 \\
564 \\
0 \\
0 \\
3 \\
2,211 \\
947 \\
3,728\end{array}$ & $\begin{array}{r}0 \\
6,266 \\
0 \\
0 \\
24 \\
0 \\
1 \\
6,292\end{array}$ & $\begin{array}{r}0 \\
336 \\
0 \\
236 \\
20 \\
0 \\
0 \\
592\end{array}$ & $\begin{array}{r}0 \\
550 \\
8 \\
111 \\
56 \\
0 \\
613 \\
1,337\end{array}$ & $\begin{array}{r}0 \\
2,068 \\
0 \\
1,146 \\
0 \\
40 \\
176 \\
3,431\end{array}$ \\
\hline 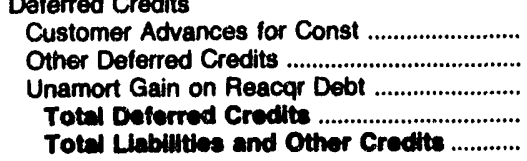 & $\begin{array}{r}0 \\
0 \\
0 \\
0 \\
13,793\end{array}$ & $\begin{array}{r}0 \\
142 \\
10,252 \\
10,393 \\
74,460\end{array}$ & $\begin{array}{r}0 \\
0 \\
0 \\
0 \\
28,954\end{array}$ & $\begin{array}{r}5 \\
0 \\
0 \\
5 \\
8,267\end{array}$ & $\begin{array}{r}0 \\
0 \\
0 \\
0 \\
10,138\end{array}$ & $\begin{array}{r}15 \\
r 72 \\
0 \\
897 \\
17,930\end{array}$ \\
\hline
\end{tabular}

Note: Totals may not equal sum of comporients because of independent rounding.

Source: Energy Information Administration, Form EIA-412, "Annual Peport of Public Electric Utilities." 
Table 37. Balance Sheet by Major Pubilicly Owned Electric Utillty Within State at End of Period, 1991 (Continued) (Thousand Dollars)

\begin{tabular}{|c|c|c|c|c|c|c|}
\hline Item & $\begin{array}{l}\text { Tennessee } \\
\text { Athens } \\
\text { City of } \\
\text { June } 30\end{array}$ & $\begin{array}{l}\text { Tennessee } \\
\text { Benton } \\
\text { County } \\
\text { June } 30\end{array}$ & $\begin{array}{l}\text { Tennessee } \\
\text { Bolvar } \\
\text { City of } \\
\text { June } 30\end{array}$ & $\begin{array}{l}\text { Tennessee } \\
\text { Bristol } \\
\text { City of } \\
\text { June } 30\end{array}$ & $\begin{array}{c}\text { Tennessee } \\
\text { Brownsville } \\
\text { Clty of } \\
\text { June } 30\end{array}$ & $\begin{array}{l}\text { Tennessee } \\
\text { Carroll } \\
\text { County } \\
\text { June } 30\end{array}$ \\
\hline $\begin{array}{l}\text { Electhis Utility Plant } \\
\text { Total Electric Utility Plant .................................. } \\
\text { i.wd8) Depr, Amort, and Depletion ................... } \\
\text { Net Electric Utilty Plant ................................ } \\
\text { Other Property \& Investments }\end{array}$ & $\begin{array}{r}16,302 \\
5,883 \\
10,419\end{array}$ & $\begin{array}{r}13,078 \\
4,719 \\
0,367\end{array}$ & $\begin{array}{r}12,440 \\
4,464 \\
7,978\end{array}$ & $\begin{array}{l}37,070 \\
18,913 \\
18,167\end{array}$ & $\begin{array}{l}6,506 \\
1,583 \\
4,823\end{array}$ & $\begin{array}{r}16,162 \\
5,265 \\
10,897\end{array}$ \\
\hline $\begin{array}{l}\text { Nonutility Property ..................................... } \\
\text { (less) Accum Provisions for Depr \& Amort .... } \\
\text { Advances to Municipality ..................................... } \\
\text { Invest \& Special Funds .................................. } \\
\text { Total Other Property \& Investments ........ } \\
\text { Current and Accruad Assets }\end{array}$ & $\begin{array}{r}0 \\
0 \\
0 \\
17 \\
17\end{array}$ & $\begin{array}{r}0 \\
0 \\
0 \\
1,323 \\
1,323\end{array}$ & $\begin{array}{r}0 \\
0 \\
0 \\
130 \\
130\end{array}$ & $\begin{array}{r}210 \\
0 \\
0 \\
10,000 \\
10,210\end{array}$ & $\begin{array}{r}0 \\
0 \\
0 \\
702 \\
702\end{array}$ & $\begin{array}{r}40 \\
3 \\
0 \\
910 \\
947\end{array}$ \\
\hline 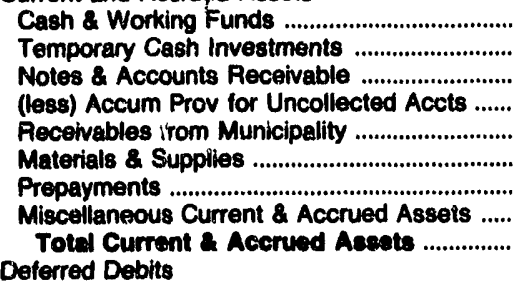 & $\begin{array}{r}291 \\
212 \\
2,240 \\
50 \\
0 \\
240 \\
7 \\
91 \\
3,031\end{array}$ & $\begin{array}{r}66 \\
0 \\
879 \\
39 \\
0 \\
107 \\
79 \\
12 \\
1,104\end{array}$ & $\begin{array}{r}54 \\
975 \\
1,533 \\
2 \\
0 \\
289 \\
15 \\
5 \\
2,809\end{array}$ & $\begin{array}{r}107 \\
5,083 \\
1,332 \\
0 \\
470 \\
113 \\
0 \\
84 \\
7,189\end{array}$ & $\begin{array}{r}1,046 \\
0 \\
486 \\
116 \\
0 \\
144 \\
49 \\
180 \\
1,789\end{array}$ & $\begin{array}{r}523 \\
100 \\
1,676 \\
0 \\
1 \\
357 \\
74 \\
39 \\
2,769\end{array}$ \\
\hline 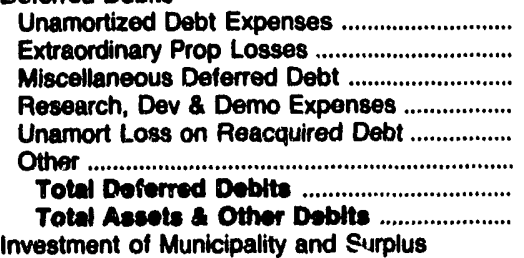 & $\begin{array}{r}0 \\
0 \\
955 \\
0 \\
0 \\
0 \\
955 \\
14,422\end{array}$ & $\begin{array}{r}5 \\
0 \\
104 \\
0 \\
0 \\
0 \\
100 \\
10,893\end{array}$ & $\begin{array}{r}55 \\
0 \\
972 \\
0 \\
0 \\
0 \\
1,027 \\
12,002\end{array}$ & $\begin{array}{r}0 \\
0 \\
4,033 \\
0 \\
0 \\
-10 \\
4,023 \\
39,500\end{array}$ & $\begin{array}{r}6 \\
0 \\
63 \\
0 \\
0 \\
0 \\
69 \\
7,483\end{array}$ & $\begin{array}{r}18 \\
0 \\
389 \\
0 \\
0 \\
0 \\
407 \\
15,019\end{array}$ \\
\hline 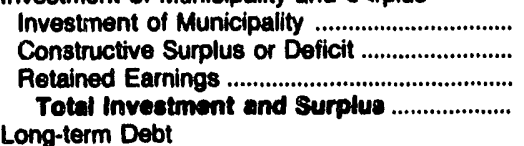 & $\begin{array}{r}0 \\
0 \\
11,212 \\
11,212\end{array}$ & $\begin{array}{r}0 \\
0 \\
8,110 \\
8,110\end{array}$ & $\begin{array}{r}0 \\
0 \\
7,267 \\
7,267\end{array}$ & $\begin{array}{r}0 \\
2,349 \\
29,876 \\
32,226\end{array}$ & $\begin{array}{r}0 \\
0 \\
5,054 \\
5,054\end{array}$ & $\begin{array}{r}10,345 \\
0 \\
560 \\
10,905\end{array}$ \\
\hline 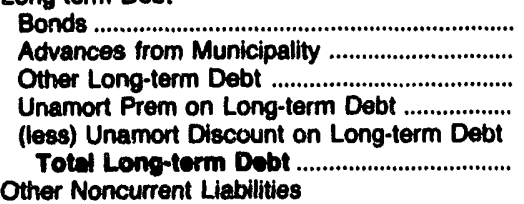 & $\begin{array}{l}0 \\
0 \\
0 \\
0 \\
0 \\
0\end{array}$ & $\begin{array}{r}980 \\
0 \\
106 \\
0 \\
0 \\
1,086\end{array}$ & $\begin{array}{r}1,330 \\
0 \\
489 \\
0 \\
0 \\
1,819\end{array}$ & $\begin{array}{r}0 \\
3,753 \\
0 \\
0 \\
0 \\
3,753\end{array}$ & $\begin{array}{r}835 \\
0 \\
0 \\
21 \\
0 \\
856\end{array}$ & $\begin{array}{r}1,220 \\
0 \\
340 \\
0 \\
10 \\
1,650\end{array}$ \\
\hline 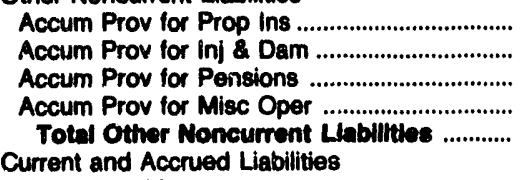 & $\begin{array}{l}0 \\
0 \\
0 \\
0 \\
0\end{array}$ & $\begin{array}{l}0 \\
0 \\
0 \\
0 \\
0\end{array}$ & $\begin{array}{l}0 \\
0 \\
0 \\
0 \\
0\end{array}$ & $\begin{array}{l}0 \\
0 \\
0 \\
0 \\
0\end{array}$ & $\begin{array}{l}0 \\
0 \\
0 \\
0 \\
0\end{array}$ & $\begin{array}{l}0 \\
0 \\
0 \\
0 \\
0\end{array}$ \\
\hline 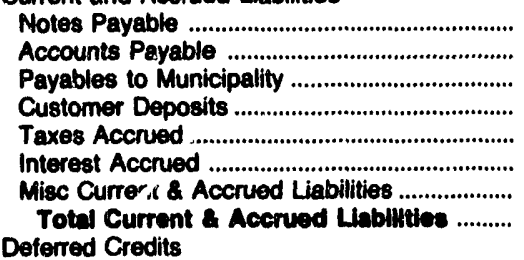 & $\begin{array}{r}0 \\
2,079 \\
0 \\
0 \\
0 \\
0 \\
133 \\
2,213\end{array}$ & $\begin{array}{r}0 \\
857 \\
0 \\
346 \\
0 \\
18 \\
475 \\
1,698\end{array}$ & $\begin{array}{r}0 \\
1,334 \\
0 \\
389 \\
0 \\
10 \\
175 \\
1,908\end{array}$ & $\begin{array}{r}0 \\
2,498 \\
0 \\
595 \\
228 \\
0 \\
256 \\
3,677\end{array}$ & $\begin{array}{r}0 \\
4,169 \\
0 \\
175 \\
0 \\
3 \\
3 \\
1,360\end{array}$ & $\begin{array}{r}0 \\
1,588 \\
0 \\
325 \\
259 \\
20 \\
362 \\
2,565\end{array}$ \\
\hline 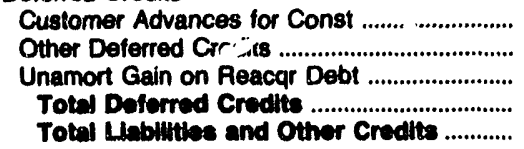 & $\begin{array}{r}0 \\
898 \\
0 \\
998 \\
14,422\end{array}$ & $\begin{array}{r}0 \\
0 \\
0 \\
0 \\
10,093\end{array}$ & $\begin{array}{r}0 \\
1,007 \\
0 \\
1,007 \\
12,002\end{array}$ & $\begin{array}{r}0 \\
24 \\
0 \\
24 \\
39,680\end{array}$ & $\begin{array}{r}0 \\
223 \\
0 \\
223 \\
7,493\end{array}$ & $\begin{array}{r}8 \\
0 \\
0 \\
8 \\
15,019\end{array}$ \\
\hline
\end{tabular}

Nc .e: Totals may not equal sum of components because of independent rounding.

Source: Energy Information Administration, Form ElA-412, "Annual Peport of Public Electric Utilities." 
Table 37. Balance Sheet by Major Publicly Owned Electric Utility Within State at End of Period, 1991 (Continued) (Thousand Dollars)

\begin{tabular}{|c|c|c|c|c|c|c|}
\hline Item & $\begin{array}{c}\text { Tennessee } \\
\text { Chattanooga } \\
\text { City of } \\
\text { June } 30\end{array}$ & $\begin{array}{c}\text { Tennessee } \\
\text { Clarksville } \\
\text { City of } \\
\text { June } 30\end{array}$ & $\begin{array}{l}\text { Tennessee } \\
\text { Cleveland } \\
\text { City of } \\
\text { June } 30\end{array}$ & $\begin{array}{l}\text { Clinton } \\
\text { City of } \\
\text { June } 30\end{array}$ & $\begin{array}{l}\text { Columbia } \\
\text { City of } \\
\text { June } 30\end{array}$ & $\begin{array}{l}\text { Cookeville } \\
\text { City of } \\
\text { June } 30\end{array}$ \\
\hline 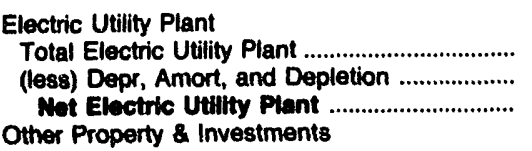 & $\begin{array}{r}220,985 \\
84,876 \\
138,109\end{array}$ & $\begin{array}{r}40,936 \\
8,018 \\
32,918\end{array}$ & $\begin{array}{l}43,948 \\
13,516 \\
30,432\end{array}$ & $\begin{array}{r}29,110 \\
9,234 \\
19,877\end{array}$ & $\begin{array}{r}22,487 \\
8,546 \\
13,841\end{array}$ & $\begin{array}{r}15,292 \\
3,227 \\
12,086\end{array}$ \\
\hline 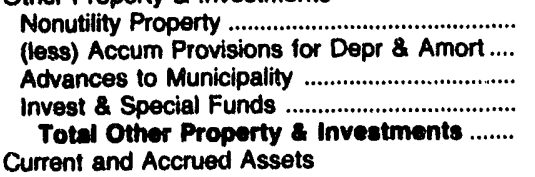 & $\begin{array}{r}0 \\
0 \\
0 \\
12,561 \\
12,561\end{array}$ & $\begin{array}{r}509 \\
2 \\
0 \\
5,799 \\
6,308\end{array}$ & $\begin{array}{r}0 \\
0 \\
0 \\
11 \\
11\end{array}$ & $\begin{array}{r}0 \\
0 \\
0 \\
1,101 \\
1,101\end{array}$ & $\begin{array}{r}0 \\
0 \\
0 \\
1,205 \\
1,205\end{array}$ & $\begin{array}{r}0 \\
0 \\
0 \\
284 \\
204\end{array}$ \\
\hline 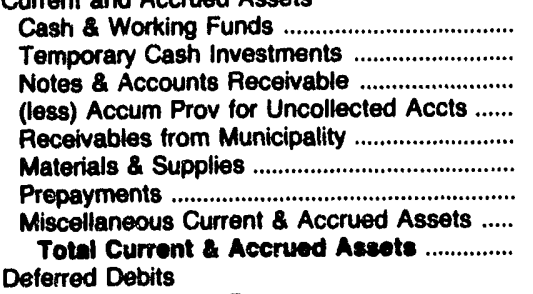 & $\begin{array}{r}1,392 \\
31,979 \\
18,364 \\
669 \\
0 \\
3,481 \\
561 \\
14,058 \\
69,165\end{array}$ & $\begin{array}{r}3,307 \\
0 \\
2,763 \\
0 \\
0 \\
505 \\
0 \\
141 \\
6,716\end{array}$ & $\begin{array}{r}1,206 \\
0 \\
4,450 \\
64 \\
0 \\
786 \\
0 \\
51 \\
6,420\end{array}$ & $\begin{array}{r}713 \\
697 \\
3,161 \\
75 \\
33 \\
573 \\
5 \\
139 \\
5,246\end{array}$ & $\begin{array}{r}1,460 \\
374 \\
1,895 \\
75 \\
10 \\
567 \\
2 \\
65 \\
4,298\end{array}$ & $\begin{array}{r}689 \\
1,270 \\
13 \\
0 \\
2,191 \\
565 \\
3 \\
46 \\
4,777\end{array}$ \\
\hline 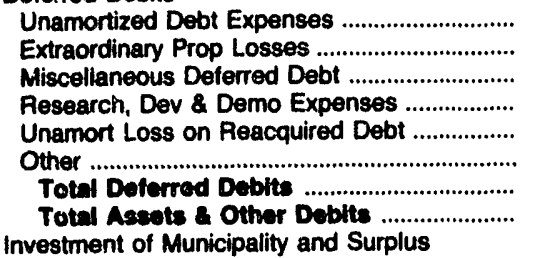 & $\begin{array}{r}0 \\
0 \\
13,655 \\
0 \\
0 \\
0 \\
13,655 \\
231,489\end{array}$ & $\begin{array}{r}55 \\
0 \\
3,915 \\
0 \\
0 \\
1 \\
3,972 \\
49,912\end{array}$ & $\begin{array}{r}0 \\
0 \\
1,310 \\
0 \\
0 \\
0 \\
1,310 \\
38,182\end{array}$ & $\begin{array}{r}0 \\
0 \\
1,670 \\
0 \\
0 \\
0 \\
1,670 \\
27,884\end{array}$ & $\begin{array}{r}0 \\
0 \\
1,242 \\
0 \\
0 \\
0 \\
1,242 \\
20,680\end{array}$ & $\begin{array}{r}11 \\
0 \\
449 \\
0 \\
0 \\
0 \\
480 \\
17,586\end{array}$ \\
\hline 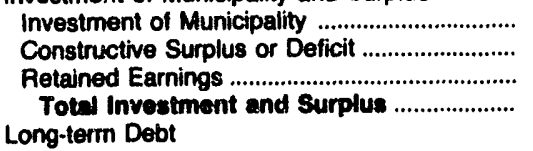 & $\begin{array}{r}0 \\
0 \\
150,229 \\
150,229\end{array}$ & $\begin{array}{r}0 \\
0 \\
24,332 \\
24,332\end{array}$ & $\begin{array}{r}0 \\
0 \\
29,892 \\
29,892\end{array}$ & $\begin{array}{r}0 \\
0 \\
22,573 \\
22,573\end{array}$ & $\begin{array}{r}0 \\
0 \\
16,938 \\
16,938\end{array}$ & $\begin{array}{r}0 \\
0 \\
12,426 \\
12,426\end{array}$ \\
\hline 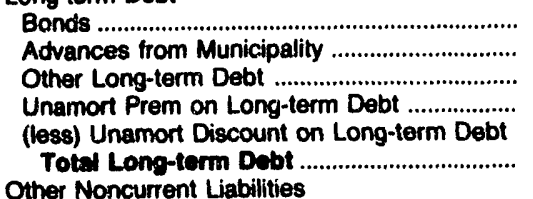 & $\begin{array}{r}750 \\
0 \\
15,191 \\
0 \\
0 \\
15,941\end{array}$ & $\begin{array}{r}7,515 \\
2,491 \\
77 \\
0 \\
38 \\
10,045\end{array}$ & $\begin{array}{l}0 \\
0 \\
0 \\
0 \\
0 \\
0\end{array}$ & $\begin{array}{r}0 \\
1,341 \\
0 \\
0 \\
0 \\
1,341\end{array}$ & $\begin{array}{r}0 \\
1,020 \\
0 \\
0 \\
0 \\
1,020\end{array}$ & $\begin{array}{r}1,415 \\
0 \\
0 \\
0 \\
0 \\
1,415\end{array}$ \\
\hline $\begin{array}{l}\text { Accum Prov for Prop Ins ............................... } \\
\text { Accum Prov for Inj \& Dam ............................... } \\
\text { Accum Prov for Pensions ............................. } \\
\text { Accum Prov for Misc Oper ............................ } \\
\text { Total Other Noncurrent Liabilttes ........... } \\
\text { Current and Accrued Liabilitios }\end{array}$ & $\begin{array}{r}0 \\
0 \\
11,668 \\
0 \\
11,668\end{array}$ & $\begin{array}{l}0 \\
0 \\
0 \\
0 \\
0\end{array}$ & $\begin{array}{l}0 \\
0 \\
0 \\
0 \\
0\end{array}$ & $\begin{array}{l}0 \\
0 \\
0 \\
0 \\
0\end{array}$ & $\begin{array}{l}0 \\
0 \\
0 \\
0 \\
0\end{array}$ & $\begin{array}{l}0 \\
0 \\
0 \\
0 \\
0\end{array}$ \\
\hline 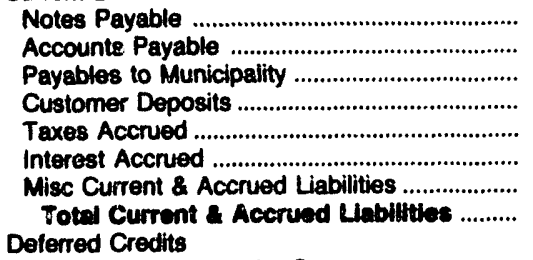 & $\begin{array}{r}0 \\
40,403 \\
0 \\
4,345 \\
5,664 \\
854 \\
705 \\
51,971\end{array}$ & $\begin{array}{r}0 \\
3,460 \\
0 \\
1,406 \\
0 \\
170 \\
771 \\
5,807\end{array}$ & $\begin{array}{r}0 \\
4,182 \\
0 \\
856 \\
0 \\
0 \\
96 \\
5,134\end{array}$ & $\begin{array}{r}0 \\
2,531 \\
0 \\
924 \\
0 \\
0 \\
516 \\
3,971\end{array}$ & $\begin{array}{r}0 \\
1,544 \\
0 \\
799 \\
0 \\
0 \\
385 \\
2,728\end{array}$ & $\begin{array}{r}0 \\
2,682 \\
0 \\
389 \\
0 \\
27 \\
56 \\
3,154\end{array}$ \\
\hline 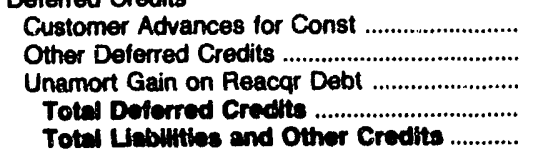 & $\begin{array}{r}0 \\
1,681 \\
0 \\
1,681 \\
231,489\end{array}$ & $\begin{array}{r}0 \\
9,728 \\
0 \\
9,726 \\
49,912\end{array}$ & $\begin{array}{r}0 \\
3,156 \\
0 \\
3,158 \\
38,182\end{array}$ & $\begin{array}{r}0 \\
10 \\
0 \\
10 \\
27,094\end{array}$ & $\begin{array}{r}0 \\
0 \\
0 \\
0 \\
20,688\end{array}$ & $\begin{array}{r}0 \\
591 \\
0 \\
501 \\
17,606\end{array}$ \\
\hline
\end{tabular}

Note: Totals may not equal sum of components because of independent rounding.

Source: Energy Information Administration, Form EIA-412, "Annual Report of Public Electric Utilities." 
Table 37. Balance Sheet by Major Publicly Owned Electric Utility Within State at End of Period, 1991 (Continued) (Thousand Dollars)

\begin{tabular}{|c|c|c|c|c|c|c|}
\hline Item : & $\begin{array}{l}\text { Tennessee } \\
\text { Covington } \\
\text { City of } \\
\text { June } 30\end{array}$ & $\begin{array}{l}\text { Tennessee } \\
\text { Dayton } \\
\text { City of } \\
\text { June } 30\end{array}$ & $\begin{array}{l}\text { Tennessee } \\
\text { Dickson } \\
\text { City of } \\
\text { June } 30\end{array}$ & $\begin{array}{c}\text { Tennessee } \\
\text { Dyersburg } \\
\text { Electric } \\
\text { System } \\
\text { June } 30\end{array}$ & $\begin{array}{c}\text { Tennessee } \\
\text { Elizabethton } \\
\text { City of } \\
\text { June } 30\end{array}$ & $\begin{array}{l}\text { Tennessee } \\
\text { Erwin } \\
\text { Town of } \\
\text { June } 30\end{array}$ \\
\hline 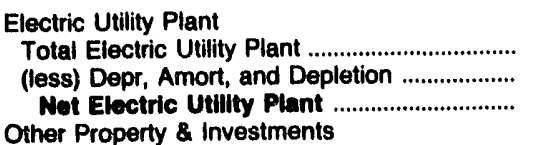 & $\begin{array}{l}8,054 \\
1,768 \\
6,286\end{array}$ & $\begin{array}{l}8,853 \\
2,755 \\
6,098\end{array}$ & $\begin{array}{r}29,244 \\
9,220 \\
20,025\end{array}$ & $\begin{array}{r}15,914 \\
47 \\
15,867\end{array}$ & $\begin{array}{r}22,183 \\
7,499 \\
14,684\end{array}$ & $\begin{array}{l}7,553 \\
3,146 \\
4,407\end{array}$ \\
\hline 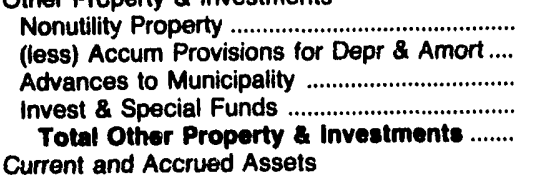 & $\begin{array}{r}0 \\
0 \\
0 \\
552 \\
552\end{array}$ & $\begin{array}{l}0 \\
0 \\
1 \\
0 \\
1\end{array}$ & $\begin{array}{r}0 \\
0 \\
0 \\
4,771 \\
4,771\end{array}$ & $\begin{array}{r}0 \\
0 \\
0 \\
3,220 \\
3,220\end{array}$ & $\begin{array}{r}0 \\
0 \\
0 \\
658 \\
658\end{array}$ & $\begin{array}{l}0 \\
0 \\
0 \\
4 \\
4\end{array}$ \\
\hline 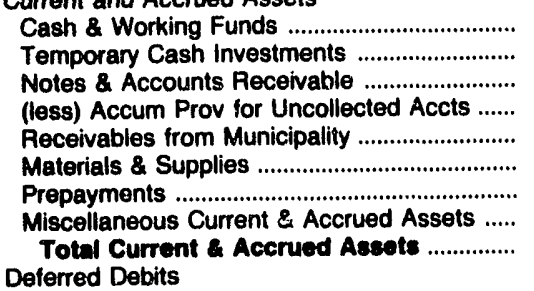 & $\begin{array}{r}853 \\
2,825 \\
970 \\
0 \\
1 \\
135 \\
49 \\
13 \\
4,846\end{array}$ & $\begin{array}{r}342 \\
324 \\
1,000 \\
21 \\
0 \\
87 \\
5 \\
45 \\
1,783\end{array}$ & $\begin{array}{r}3,299 \\
0 \\
2,212 \\
0 \\
0 \\
493 \\
156 \\
117 \\
6,276\end{array}$ & $\begin{array}{r}-77 \\
694 \\
2,309 \\
43 \\
0 \\
350 \\
69 \\
47 \\
3,351\end{array}$ & $\begin{array}{r}896 \\
107 \\
1,454 \\
0 \\
0 \\
406 \\
0 \\
121 \\
2,984\end{array}$ & $\begin{array}{r}19 \\
492 \\
878 \\
38 \\
260 \\
196 \\
56 \\
23 \\
1,886\end{array}$ \\
\hline 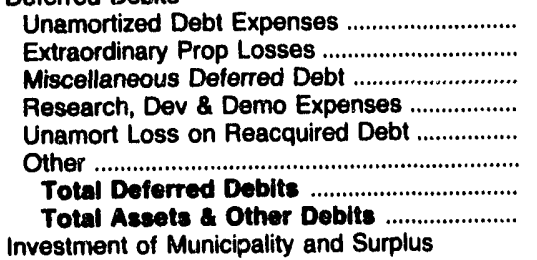 & $\begin{array}{r}15 \\
0 \\
379 \\
0 \\
0 \\
0 \\
394 \\
12,078\end{array}$ & $\begin{array}{r}0 \\
0 \\
84 \\
0 \\
0 \\
12 \\
96 \\
7,979\end{array}$ & $\begin{array}{r}103 \\
0 \\
87 \\
0 \\
0 \\
0 \\
190 \\
31,261\end{array}$ & $\begin{array}{r}59 \\
0 \\
26 \\
0 \\
0 \\
1,068 \\
1,153 \\
23,591\end{array}$ & $\begin{array}{r}0 \\
0 \\
1,640 \\
0 \\
0 \\
0 \\
1,640 \\
18,865\end{array}$ & $\begin{array}{r}0 \\
0 \\
550 \\
0 \\
0 \\
0 \\
550 \\
6,847\end{array}$ \\
\hline 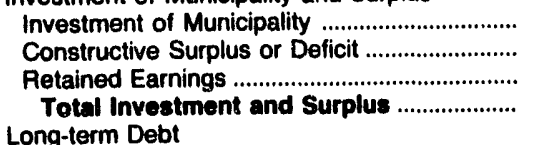 & $\begin{array}{r}0 \\
0 \\
8,063 \\
8,063\end{array}$ & $\begin{array}{r}0 \\
0 \\
6,744 \\
6,744\end{array}$ & $\begin{array}{r}0 \\
0 \\
12,888 \\
12,888\end{array}$ & $\begin{array}{r}0 \\
0 \\
12,721 \\
12,721\end{array}$ & $\begin{array}{r}0 \\
0 \\
15,010 \\
15,010\end{array}$ & $\begin{array}{r}0 \\
0 \\
5,156 \\
5,156\end{array}$ \\
\hline 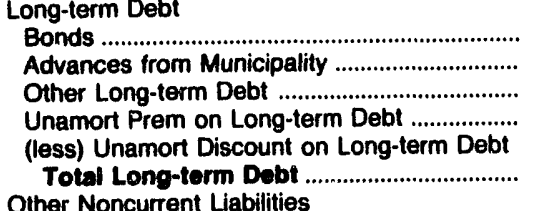 & $\begin{array}{r}695 \\
0 \\
119 \\
0 \\
9 \\
805\end{array}$ & $\begin{array}{l}0 \\
0 \\
0 \\
0 \\
0 \\
0\end{array}$ & $\begin{array}{r}14,580 \\
0 \\
0 \\
0 \\
0 \\
14,580\end{array}$ & $\begin{array}{r}6,885 \\
1,076 \\
0 \\
0 \\
68 \\
7,894\end{array}$ & $\begin{array}{r}0 \\
1,196 \\
0 \\
0 \\
0 \\
1,196\end{array}$ & $\begin{array}{r}0 \\
541 \\
0 \\
0 \\
0 \\
541\end{array}$ \\
\hline $\begin{array}{l}\text { Other Noncurrent Liabilities } \\
\text { Accum Prov for Prop Ins ............................... } \\
\text { Accum Prov for Inj \& Dam ............................. } \\
\text { Accum Prov for Pensions .............................. } \\
\text { Accum Prov for Misc Oper .......................... } \\
\text { Total Other Noncurrent Liabilities ............ } \\
\text { Current and Accrued Liabilities }\end{array}$ & $\begin{array}{l}0 \\
0 \\
0 \\
0 \\
0\end{array}$ & $\begin{array}{l}0 \\
0 \\
0 \\
0 \\
0\end{array}$ & $\begin{array}{l}0 \\
0 \\
0 \\
0 \\
0\end{array}$ & $\begin{array}{l}0 \\
0 \\
0 \\
0 \\
0\end{array}$ & $\begin{array}{l}0 \\
0 \\
0 \\
0 \\
0\end{array}$ & $\begin{array}{l}0 \\
0 \\
0 \\
0 \\
0\end{array}$ \\
\hline 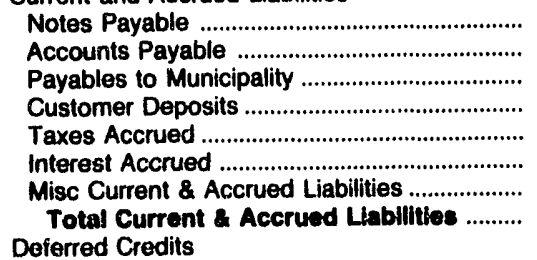 & $\begin{array}{r}0 \\
1,373 \\
0 \\
231 \\
0 \\
12 \\
34 \\
1,650\end{array}$ & $\begin{array}{r}0 \\
964 \\
0 \\
145 \\
0 \\
0 \\
127 \\
1,235\end{array}$ & $\begin{array}{r}0 \\
2,460 \\
0 \\
900 \\
0 \\
241 \\
180 \\
3,781\end{array}$ & $\begin{array}{r}0 \\
2,440 \\
0 \\
202 \\
0 \\
200 \\
108 \\
2,949\end{array}$ & $\begin{array}{r}0 \\
1,598 \\
0 \\
737 \\
0 \\
0 \\
1,424 \\
3,750\end{array}$ & $\begin{array}{r}0 \\
929 \\
0 \\
168 \\
0 \\
0 \\
40 \\
1,137\end{array}$ \\
\hline 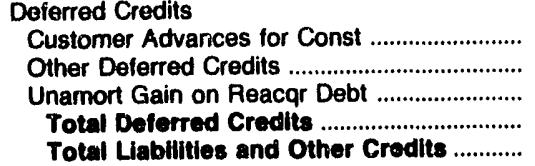 & $\begin{array}{r}0 \\
1,561 \\
0 \\
1,561 \\
12,078\end{array}$ & $\begin{array}{r}0 \\
0 \\
0 \\
\mathbf{0} \\
7,079\end{array}$ & $\begin{array}{r}0 \\
12 \\
0 \\
12 \\
31,281\end{array}$ & $\begin{array}{r}0 \\
26 \\
0 \\
26 \\
23,591\end{array}$ & $\begin{array}{r}0 \\
0 \\
0 \\
0 \\
19,965\end{array}$ & $\begin{array}{r}1 \\
11 \\
0 \\
12 \\
6,847\end{array}$ \\
\hline
\end{tabular}

Note: Totals may not equal sum of components because of independent rounding.

Source: Energy Information Administration, Form EIA-412, "Annual Peport of Public Electric Utilities." 
Table 37. Balance Sheet by Major Publicly Owned Electric Utility Within State at End of Period, 1991 (Continued) (Thousand Dollars)

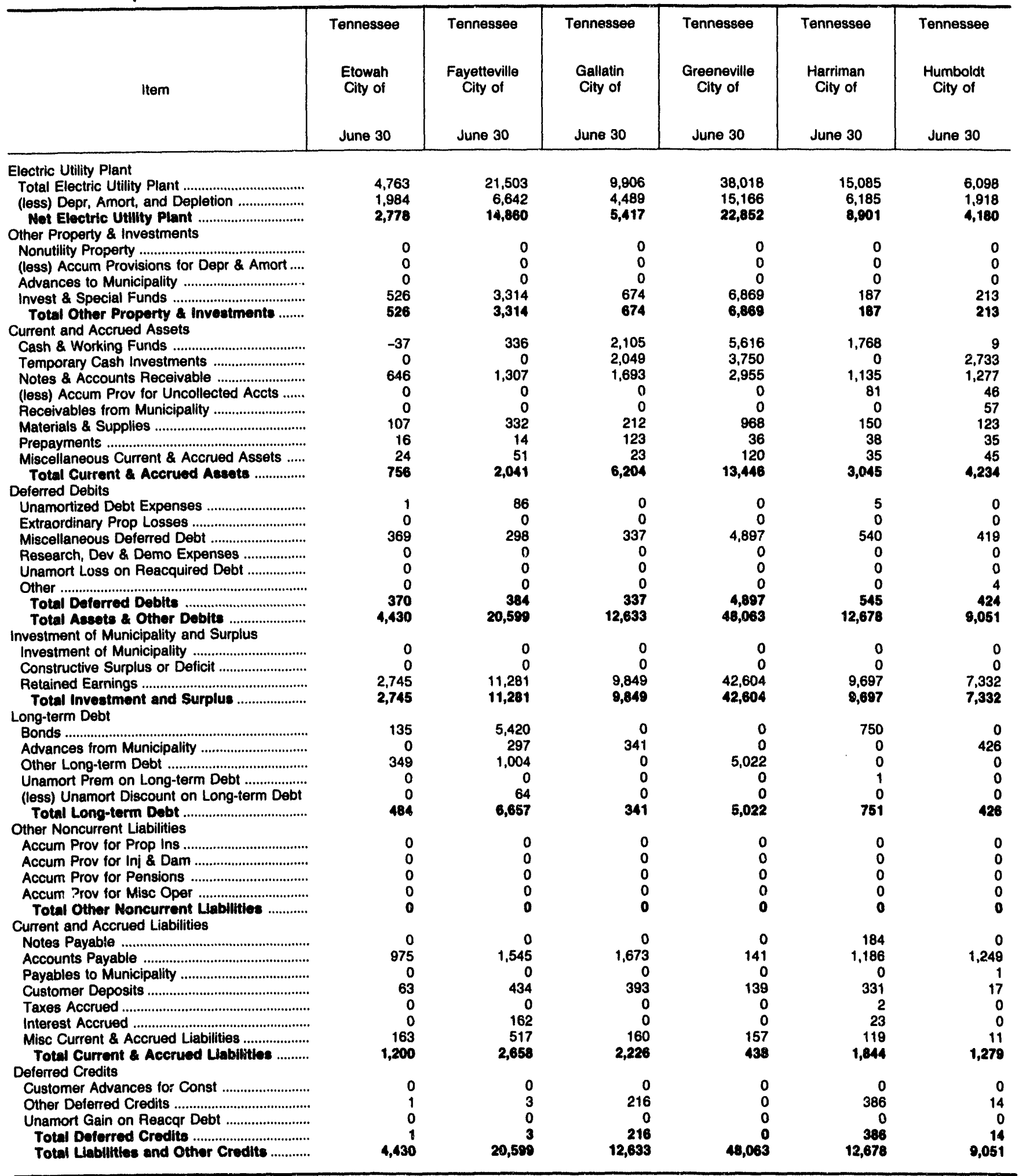

Note: Totals may not equal sum of components because of independent rounding.

Source: Energy Information Administration, Form ElA-412, "Annual Report of Public Electric Utilities." 

Table 37. Balance Sheet by Major Publicly Owned Electric Utility
Within State at End of Period, 1991 (Continued) (Thousand Dollars)

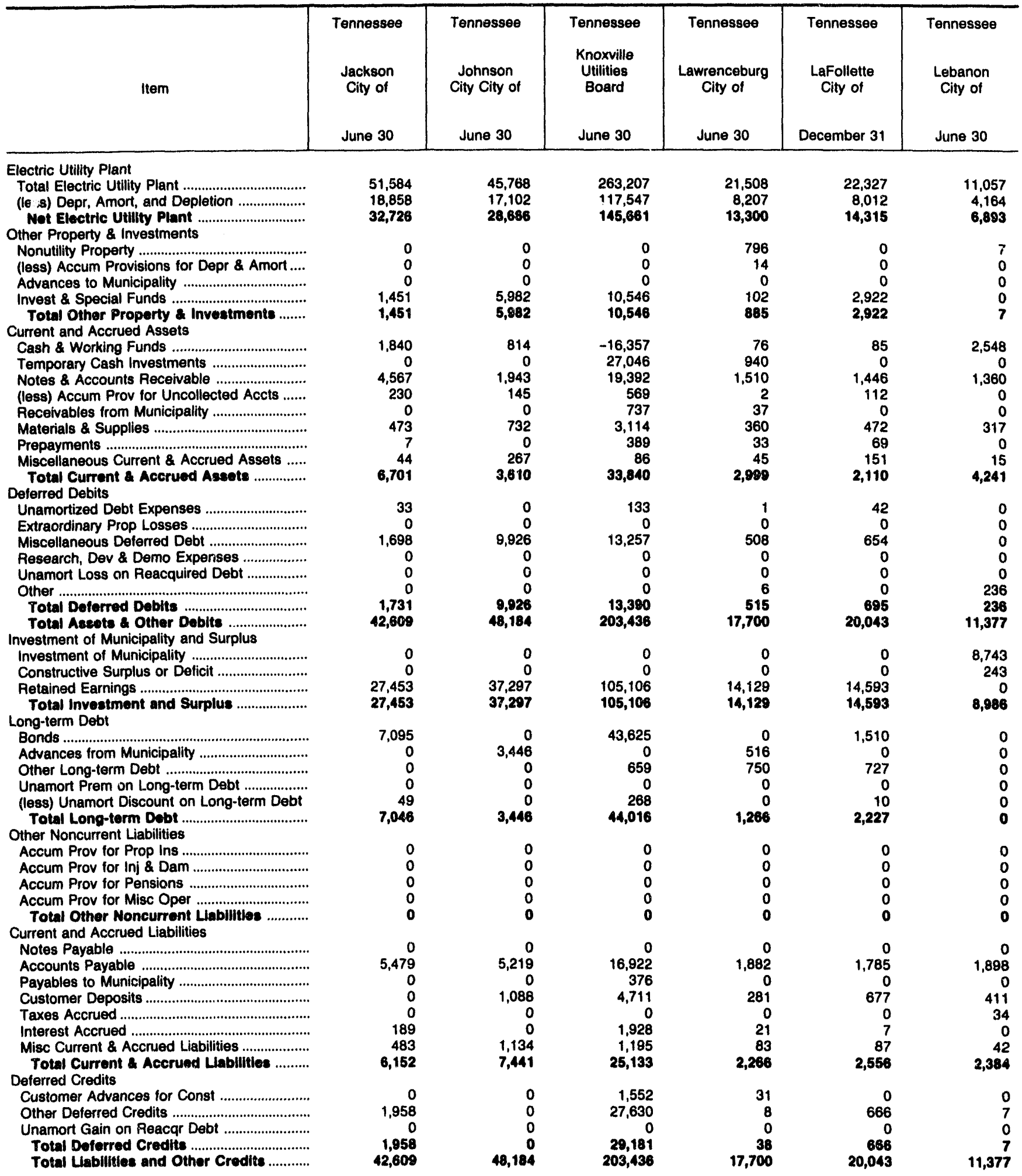

Note: Totals may not equal sum of components because of independent rounding.

Source: Energy Information Administration, Form EIA-412, "Annual Report of Public Electric Utilities." 
Table 37. Balance Sheet by Major Publicly Owned Electric Utility Within State at End of Period, 1991 (Continued) (Thousand Dollars)

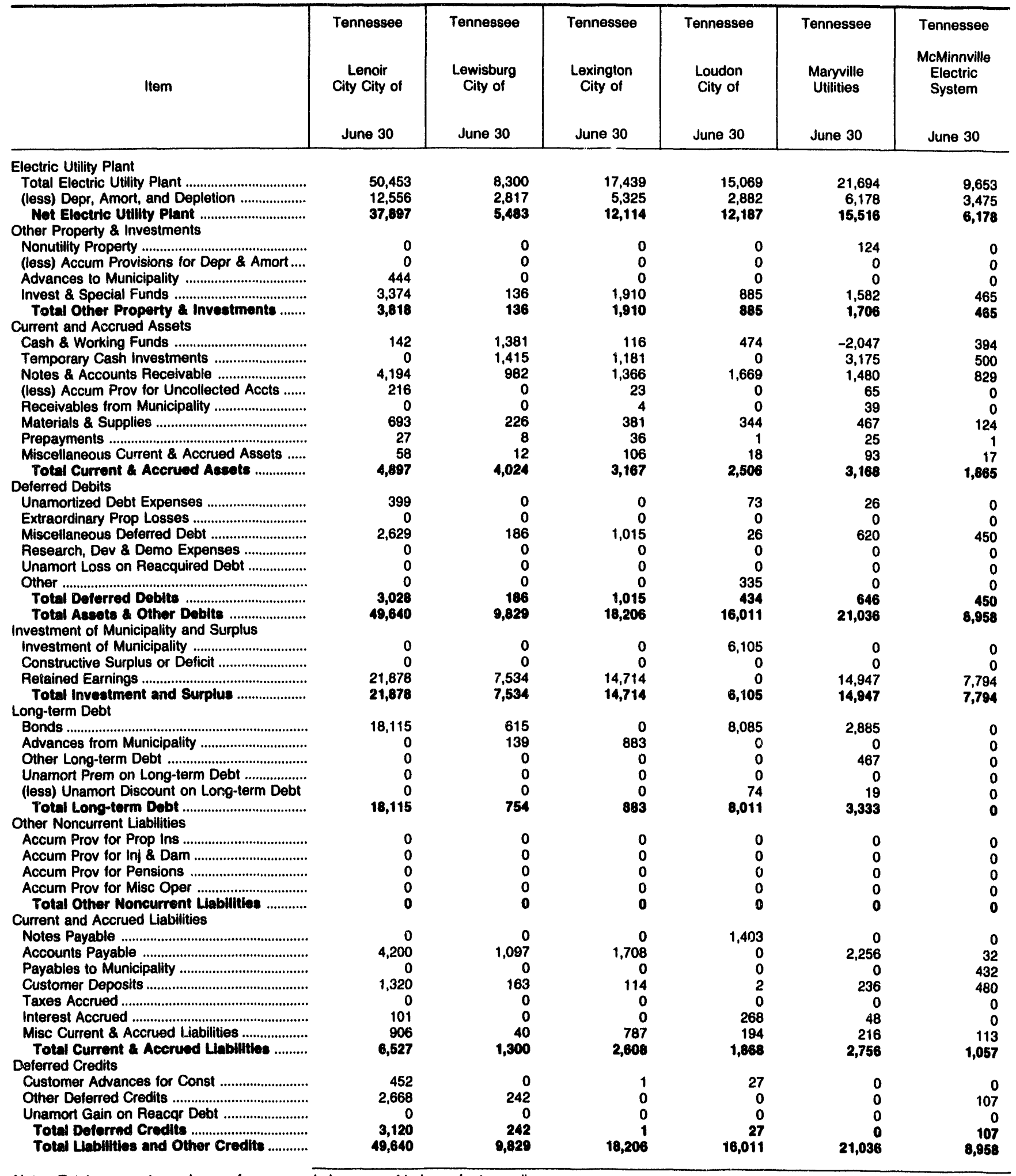

Note: Totals may not equal sum of components because of independent rounding.

Source: Energy Information Administration, Form EIA-412, "Annual Report of Public Electric Utilities." 
Table 37. Balance Sheet by Major Publicly Owned Electric Utility Within State at End of Period, 1991 (Continued) (Thousand Dollars)

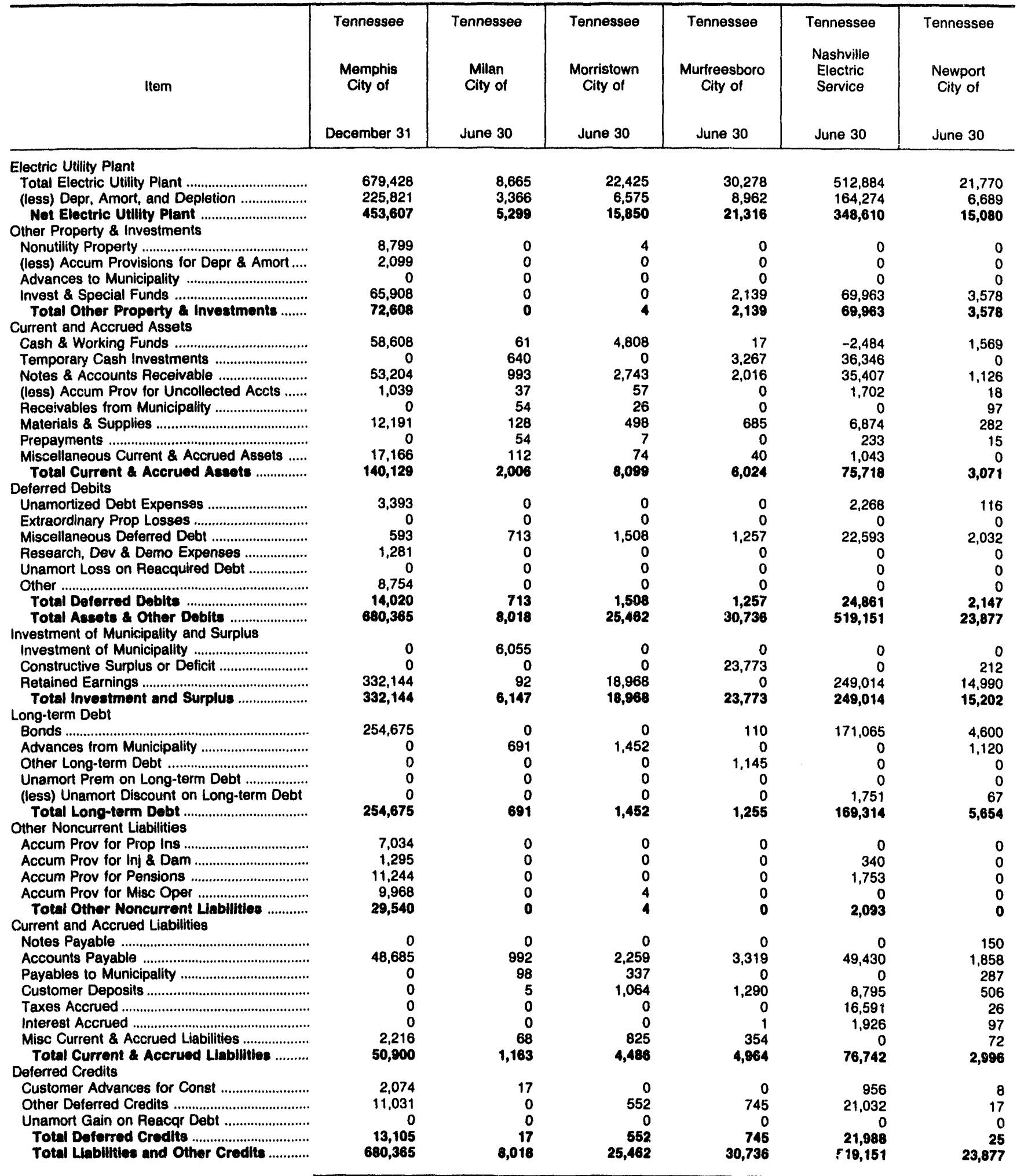

Note: Totals may not equal sum of components because of independent rounding.

Source: Energy Information Administration, Form EIA-412, "Annual Report of Public Electric Utilities." 
Table 37. Balance Sheet by Major Publicly Owned Electric Utility Within State at End of Period, 1991 (Continued) (Thousand Dollars)

\begin{tabular}{|c|c|c|c|c|c|c|}
\hline Item & $\begin{array}{c}\text { Tennessee } \\
\text { Oak Plidge } \\
\text { City of } \\
\text { June } 30\end{array}$ & $\begin{array}{c}\text { Tennessee } \\
\text { Paris } \\
\text { City of } \\
\text { June } 30\end{array}$ & $\begin{array}{l}\text { Tennessee } \\
\text { Pulaski } \\
\text { City of } \\
\text { June } 30\end{array}$ & $\begin{array}{l}\text { Tennessee } \\
\begin{array}{l}\text { Ripley } \\
\text { City of }\end{array} \\
\text { June } 30\end{array}$ & $\begin{array}{l}\text { Tennessee } \\
\text { Rockwood } \\
\text { City of } \\
\text { June } 30\end{array}$ & $\begin{array}{c}\text { Tennessee } \\
\text { Sevier } \\
\text { County } \\
\text { Electric } \\
\text { System } \\
\text { June } 30\end{array}$ \\
\hline $\begin{array}{l}\text { Electric Utility Plant } \\
\text { Total Electric Utility Plant .................................... } \\
\text { (less) Depr, Amort, and Depletion ................. } \\
\text { Net Electric Utility Plant ................................ } \\
\text { Other Property \& Investments }\end{array}$ & $\begin{array}{r}20,827 \\
7,507 \\
13,320\end{array}$ & $\begin{array}{r}23,384 \\
9,210 \\
14,174\end{array}$ & $\begin{array}{r}18,360 \\
7,301 \\
11,058\end{array}$ & $\begin{array}{l}6,551 \\
1,741 \\
4,810\end{array}$ & $\begin{array}{r}14,651 \\
4,685 \\
9,966\end{array}$ & $\begin{array}{l}53,668 \\
12,501 \\
41,167\end{array}$ \\
\hline 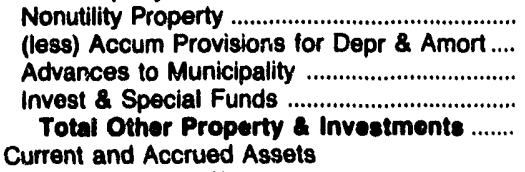 & $\begin{array}{r}0 \\
0 \\
0 \\
434 \\
434\end{array}$ & $\begin{array}{r}0 \\
0 \\
0 \\
2,567 \\
2,567\end{array}$ & $\begin{array}{r}0 \\
0 \\
0 \\
4,115 \\
4,115\end{array}$ & $\begin{array}{r}0 \\
0 \\
0 \\
4,960 \\
4,960\end{array}$ & $\begin{array}{l}0 \\
0 \\
3 \\
0 \\
3\end{array}$ & $\begin{array}{r}0 \\
0 \\
0 \\
1,207 \\
1,207\end{array}$ \\
\hline 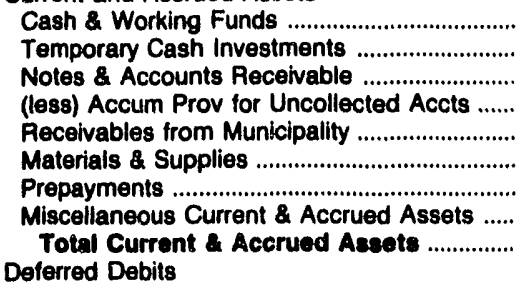 & $\begin{array}{r}0 \\
627 \\
2,363 \\
0 \\
0 \\
355 \\
0 \\
23 \\
23 \\
3,368\end{array}$ & $\begin{array}{r}312 \\
492 \\
1,026 \\
6 \\
141 \\
202 \\
18 \\
40 \\
2,225\end{array}$ & $\begin{array}{r}26 \\
71 \\
1,642 \\
22 \\
21 \\
188 \\
85 \\
85 \\
134 \\
2,146\end{array}$ & $\begin{array}{r}0 \\
396 \\
1,238 \\
0 \\
0 \\
177 \\
48 \\
19 \\
1,878\end{array}$ & $\begin{array}{r}10 \\
285 \\
628 \\
23 \\
0 \\
158 \\
0 \\
0 \\
57 \\
1,116\end{array}$ & $\begin{array}{r}649 \\
600 \\
2,644 \\
8 \\
0 \\
584 \\
37 \\
165 \\
4,670\end{array}$ \\
\hline 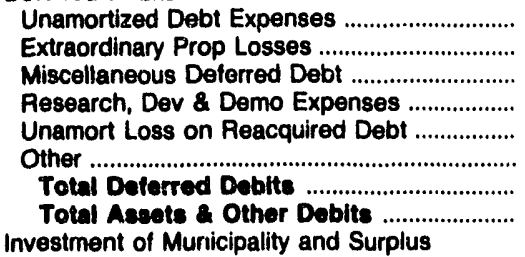 & $\begin{array}{r}32 \\
0 \\
321 \\
0 \\
0 \\
5 \\
358 \\
17,480\end{array}$ & $\begin{array}{r}43 \\
0 \\
1,399 \\
0 \\
0 \\
19 \\
1,461 \\
20,427\end{array}$ & $\begin{array}{r}0 \\
0 \\
533 \\
0 \\
0 \\
0 \\
533 \\
17,852\end{array}$ & $\begin{array}{r}0 \\
0 \\
556 \\
0 \\
0 \\
29 \\
585 \\
12,233\end{array}$ & $\begin{array}{r}0 \\
0 \\
41 \\
0 \\
0 \\
0 \\
41 \\
11,127\end{array}$ & $\begin{array}{r}37 \\
0 \\
0 \\
0 \\
0 \\
1,686 \\
1,724 \\
48,760\end{array}$ \\
\hline 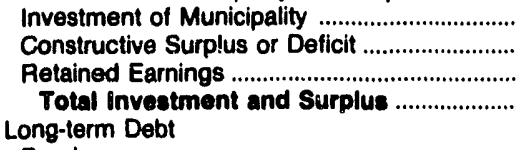 & $\begin{array}{r}0 \\
0 \\
11,240 \\
11,240\end{array}$ & $\begin{array}{r}0 \\
0 \\
14,631 \\
14,631\end{array}$ & $\begin{array}{r}13,440 \\
0 \\
0 \\
13,440\end{array}$ & $\begin{array}{r}0 \\
0 \\
9,742 \\
9,742\end{array}$ & $\begin{array}{r}0 \\
0 \\
9,304 \\
0,304\end{array}$ & $\begin{array}{r}0 \\
0 \\
35,723 \\
35,723\end{array}$ \\
\hline 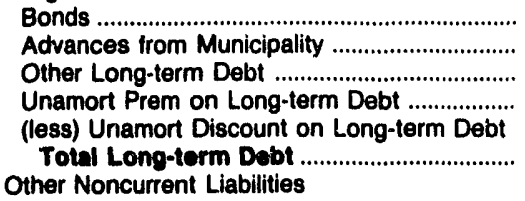 & $\begin{array}{r}3,310 \\
0 \\
0 \\
0 \\
36 \\
3,274\end{array}$ & $\begin{array}{r}2,100 \\
0 \\
0 \\
0 \\
0 \\
2,100\end{array}$ & $\begin{array}{r}3,070 \\
527 \\
0 \\
0 \\
0 \\
3,597\end{array}$ & $\begin{array}{l}0 \\
0 \\
0 \\
0 \\
0 \\
0\end{array}$ & $\begin{array}{r}0 \\
47 \\
0 \\
0 \\
0 \\
47\end{array}$ & $\begin{array}{r}5,045 \\
0 \\
11 \\
0 \\
31 \\
5,025\end{array}$ \\
\hline 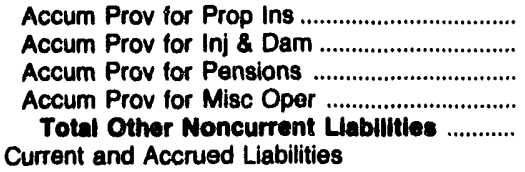 & $\begin{array}{l}0 \\
0 \\
0 \\
0 \\
0\end{array}$ & $\begin{array}{l}0 \\
0 \\
0 \\
0 \\
0\end{array}$ & $\begin{array}{l}0 \\
0 \\
0 \\
0 \\
0\end{array}$ & $\begin{array}{l}0 \\
0 \\
0 \\
0 \\
0\end{array}$ & $\begin{array}{l}0 \\
0 \\
0 \\
0 \\
0\end{array}$ & $\begin{array}{r}0 \\
0 \\
0 \\
1,453 \\
1,453\end{array}$ \\
\hline 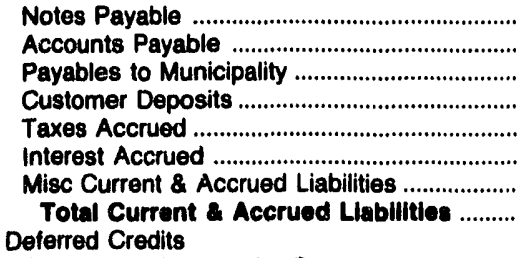 & $\begin{array}{r}0 \\
2,147 \\
0 \\
198 \\
0 \\
77 \\
96 \\
2,518\end{array}$ & $\begin{array}{r}0 \\
1,693 \\
0 \\
438 \\
0 \\
11 \\
129 \\
2,272\end{array}$ & $\begin{array}{r}0 \\
396 \\
0 \\
301 \\
27 \\
17 \\
57 \\
790\end{array}$ & $\begin{array}{r}0 \\
1,170 \\
0 \\
315 \\
0 \\
0 \\
671 \\
2,156\end{array}$ & $\begin{array}{r}0 \\
1,015 \\
0 \\
337 \\
0 \\
0 \\
247 \\
1,500\end{array}$ & $\begin{array}{r}0 \\
3,623 \\
0 \\
2,476 \\
0 \\
157 \\
294 \\
6,550\end{array}$ \\
\hline 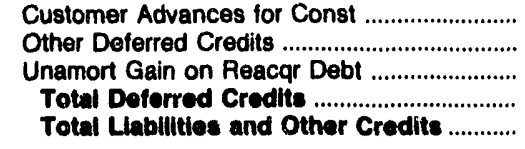 & $\begin{array}{r}0 \\
448 \\
0 \\
448 \\
17,480\end{array}$ & $\begin{array}{r}0 \\
1,423 \\
0 \\
1,423 \\
20,427\end{array}$ & $\begin{array}{r}0 \\
15 \\
0 \\
15 \\
17,852\end{array}$ & $\begin{array}{r}0 \\
335 \\
0 \\
335 \\
12,233\end{array}$ & $\begin{array}{r}0 \\
177 \\
0 \\
177 \\
11,127\end{array}$ & $\begin{array}{r}0 \\
17 \\
0 \\
17 \\
48,780\end{array}$ \\
\hline
\end{tabular}

Note: Totals may not equal sum of components because of independent rounding.

Source: Energy Information Administration, Form EIA-412, "Annual Report of Public Electric Utilities." 
Table 37. Balance Sheet by Major Publicly Owned Electric Utility Within State at End of Period, 1991 (Continued) (Thousand Dollars)

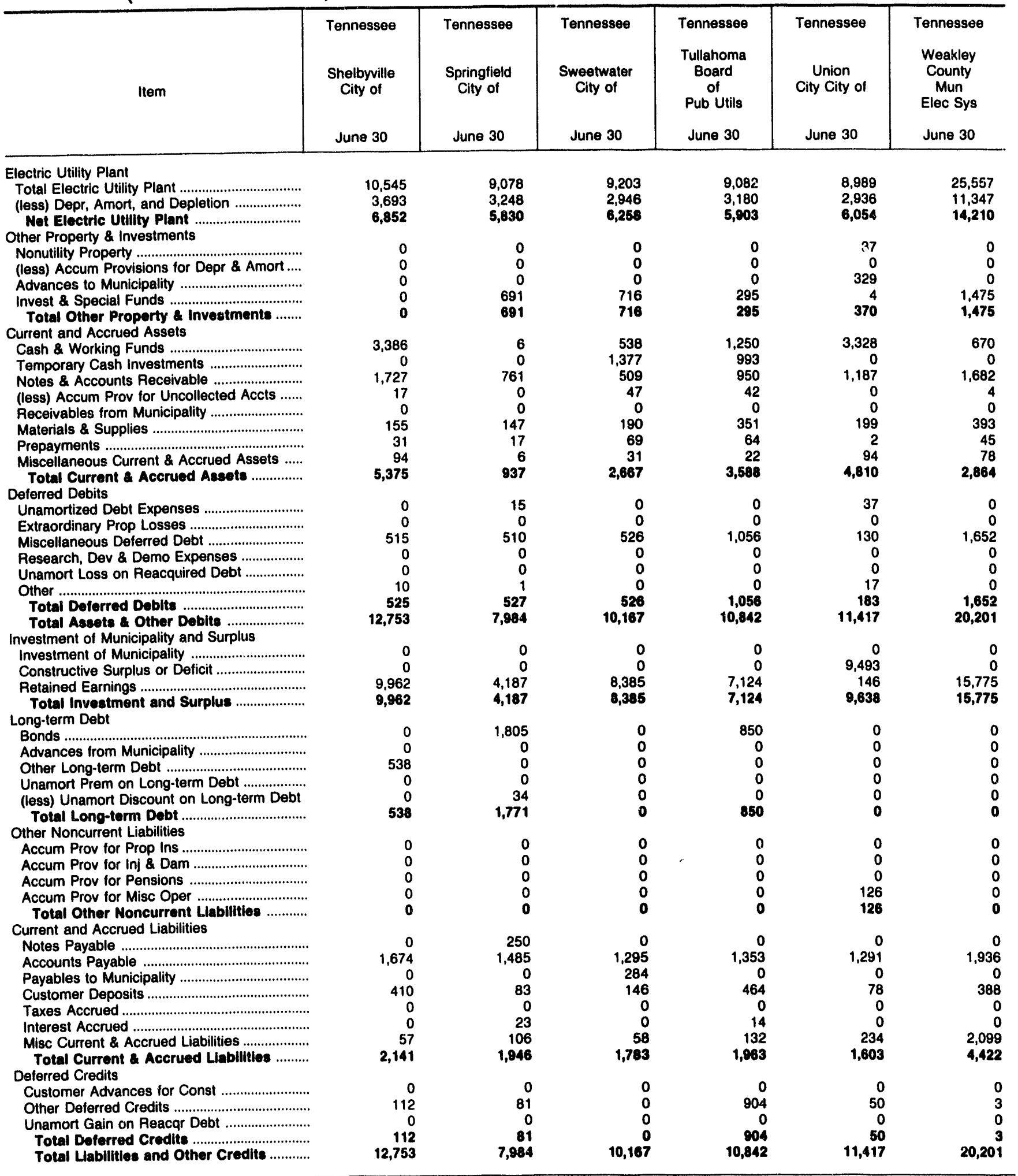

Note: Totals may not equal sum of components because of independent rounding.

Source: Energy Information Administration, Form EIA-412, "Annual Report of Public Electric Utilities." 
Table 37. Balance Sheet by Major Publicly Owned Electric Utility Within State at End of Period, 1991 (Continued) (Thousand Dollars)

\begin{tabular}{|c|c|c|c|c|c|c|}
\hline Item & $\begin{array}{l}\text { Texas } \\
\text { Austin } \\
\text { City of } \\
\text { September } 30\end{array}$ & $\begin{array}{c}\text { Texas } \\
\text { Brenham } \\
\text { City of } \\
\text { September } 30\end{array}$ & $\begin{array}{c}\text { Texas } \\
\text { Brownsville } \\
\text { Public } \\
\text { Utils Board } \\
\text { September } 30\end{array}$ & $\begin{array}{c}\text { Texas } \\
\text { Bryan } \\
\text { City of } \\
\text { September } 30\end{array}$ & $\begin{array}{l}\text { Texas } \\
\text { College } \\
\text { Station } \\
\text { City of } \\
\text { September } 30\end{array}$ & $\begin{array}{l}\text { Texas } \\
\text { Denton } \\
\text { City of } \\
\text { September } 30\end{array}$ \\
\hline $\begin{array}{l}\text { Electric Utility Plant } \\
\text { Total Electric Utility Plant ................................ } \\
\text { (less) Depr, Amort, and Depletion .................. } \\
\text { Not Electric Utility Plant .............................. } \\
\text { Other Property \& Investments }\end{array}$ & $\begin{array}{r}2,101,600 \\
444,809 \\
1,656,791\end{array}$ & $\begin{array}{l}8,094 \\
2,515 \\
5,580\end{array}$ & $\begin{array}{r}237,469 \\
66,085 \\
171,384\end{array}$ & $\begin{array}{l}90,926 \\
40,060 \\
50,886\end{array}$ & $\begin{array}{r}22,078 \\
6,786 \\
16,291\end{array}$ & $\begin{array}{l}80,907 \\
42,020 \\
38,886\end{array}$ \\
\hline 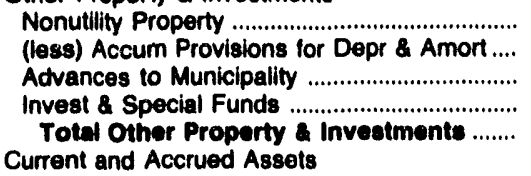 & $\begin{array}{r}0 \\
0 \\
1,912 \\
358,993 \\
360,905\end{array}$ & $\begin{array}{r}0 \\
0 \\
0 \\
1,726 \\
1,726\end{array}$ & $\begin{array}{r}0 \\
0 \\
0 \\
95,367 \\
95,367\end{array}$ & $\begin{array}{r}0 \\
0 \\
0 \\
15,311 \\
15,311\end{array}$ & $\begin{array}{r}77 \\
0 \\
0 \\
0 \\
77\end{array}$ & $\begin{array}{r}0 \\
0 \\
6,500 \\
0 \\
6,600\end{array}$ \\
\hline 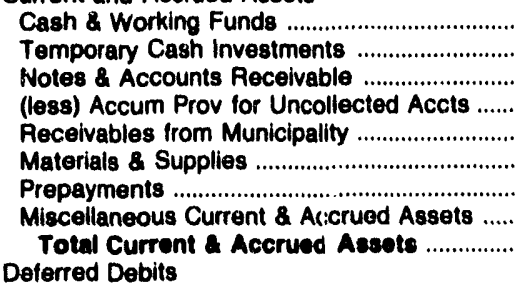 & $\begin{array}{r}4,804 \\
19,443 \\
81,704 \\
40,488 \\
814 \\
45,610 \\
2,057 \\
0 \\
113,943\end{array}$ & $\begin{array}{r}1,388 \\
0 \\
948 \\
0 \\
0 \\
81 \\
0 \\
0 \\
2,427\end{array}$ & $\begin{array}{r}870 \\
14,427 \\
4,811 \\
141 \\
0 \\
2,817 \\
153 \\
2,707 \\
25,642\end{array}$ & $\begin{array}{r}3,608 \\
6,914 \\
4,853 \\
154 \\
216 \\
2,073 \\
6 \\
3,583 \\
21,100\end{array}$ & $\begin{array}{r}1,938 \\
9,669 \\
4,086 \\
621 \\
0 \\
911 \\
0 \\
781 \\
16,746\end{array}$ & $\begin{array}{r}28,743 \\
0 \\
14,475 \\
5,379 \\
2,405 \\
1,331 \\
0 \\
0 \\
41,575\end{array}$ \\
\hline 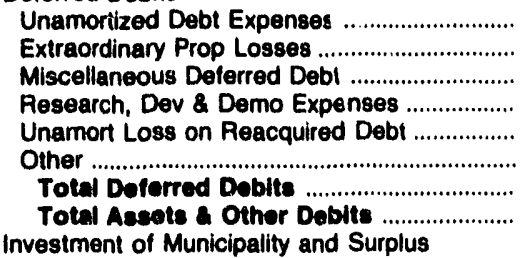 & $\begin{array}{r}6,648 \\
0 \\
118,822 \\
0 \\
0 \\
0 \\
125,471 \\
2,257,111\end{array}$ & $\begin{array}{r}0 \\
0 \\
0 \\
0 \\
0 \\
0 \\
0 \\
9,732\end{array}$ & $\begin{array}{r}10,734 \\
0 \\
1,882 \\
0 \\
0 \\
0 \\
12,616 \\
305,000\end{array}$ & $\begin{array}{r}436 \\
0 \\
0 \\
0 \\
0 \\
0 \\
438 \\
87,713\end{array}$ & $\begin{array}{r}19 \\
0 \\
0 \\
0 \\
0 \\
0 \\
10 \\
32,132\end{array}$ & $\begin{array}{r}472 \\
0 \\
0 \\
0 \\
0 \\
16,146 \\
16,618 \\
103,580\end{array}$ \\
\hline 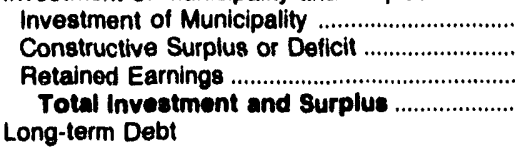 & $\begin{array}{r}36,394 \\
0 \\
391,296 \\
427,600\end{array}$ & $\begin{array}{r}0 \\
0 \\
7,128 \\
7,128\end{array}$ & $\begin{array}{r}0 \\
0 \\
84,074 \\
84,074\end{array}$ & $\begin{array}{r}0 \\
0 \\
51,688 \\
51,688\end{array}$ & $\begin{array}{r}3,105 \\
0 \\
17,967 \\
21,072\end{array}$ & $\begin{array}{r}0 \\
1,274 \\
64,129 \\
65,403\end{array}$ \\
\hline 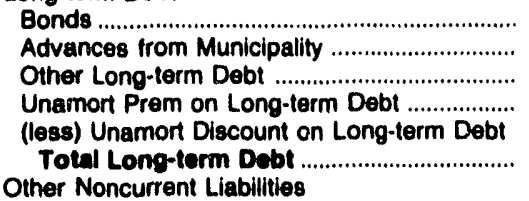 & $\begin{array}{r}1,693,001 \\
0 \\
20,081 \\
202 \\
57,449 \\
1,655,834\end{array}$ & $\begin{array}{r}990 \\
0 \\
0 \\
0 \\
0 \\
990\end{array}$ & $\begin{array}{r}201,425 \\
0 \\
123 \\
0 \\
0 \\
201,548\end{array}$ & $\begin{array}{r}31,094 \\
0 \\
0 \\
0 \\
0 \\
31,094\end{array}$ & $\begin{array}{r}6,538 \\
0 \\
171 \\
0 \\
0 \\
6,700\end{array}$ & $\begin{array}{r}26,696 \\
0 \\
0 \\
0 \\
0 \\
26,696\end{array}$ \\
\hline 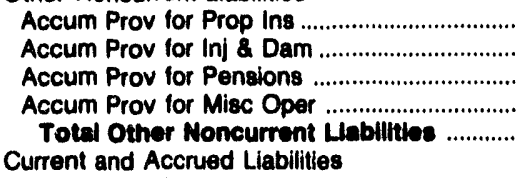 & $\begin{array}{r}0 \\
0 \\
0 \\
7,683 \\
7,683\end{array}$ & $\begin{array}{l}0 \\
0 \\
0 \\
0 \\
0\end{array}$ & $\begin{array}{l}0 \\
0 \\
0 \\
0 \\
0\end{array}$ & $\begin{array}{l}0 \\
0 \\
0 \\
0 \\
0\end{array}$ & $\begin{array}{l}0 \\
0 \\
0 \\
0 \\
0\end{array}$ & $\begin{array}{r}0 \\
0 \\
244 \\
0 \\
244\end{array}$ \\
\hline 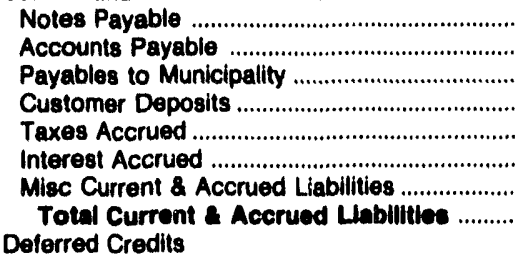 & $\begin{array}{r}0 \\
33,313 \\
0 \\
5,386 \\
896 \\
62,938 \\
6,122 \\
108,656\end{array}$ & $\begin{array}{r}0 \\
1,047 \\
0 \\
543 \\
0 \\
23 \\
1 \\
1,614\end{array}$ & $\begin{array}{r}2,445 \\
11,188 \\
0 \\
1,456 \\
211 \\
1,362 \\
2,663 \\
19,325\end{array}$ & $\begin{array}{r}565 \\
1,801 \\
295 \\
1,001 \\
0 \\
492 \\
776 \\
4,031\end{array}$ & $\begin{array}{r}0 \\
2,006 \\
0 \\
1,919 \\
0 \\
101 \\
289 \\
4,316\end{array}$ & $\begin{array}{r}0 \\
3,711 \\
1,983 \\
1,114 \\
0 \\
761 \\
0 \\
7,568\end{array}$ \\
\hline 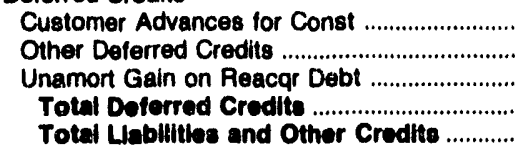 & $\begin{array}{r}0 \\
5,436 \\
51,813 \\
57,249 \\
2,257,111\end{array}$ & $\begin{array}{r}0 \\
0 \\
0 \\
0 \\
9,732\end{array}$ & $\begin{array}{r}0 \\
62 \\
0 \\
62 \\
305,000\end{array}$ & $\begin{array}{r}0 \\
0 \\
0 \\
0 \\
87,713\end{array}$ & $\begin{array}{r}35 \\
0 \\
0 \\
35 \\
32,132\end{array}$ & $\begin{array}{r}0 \\
3,668 \\
0 \\
3,688 \\
103,580\end{array}$ \\
\hline
\end{tabular}

Note: Totals may not equal sum of components because of independent rounding.

Source: Energy Information Administration, Form ElA.412, "Annual Report of Public Electric Utilities." 
Table 37. Balance Sheet by Major Publicly Owned Electric Utility Within State at End of Period, 1991 (Continued) (Thousand Dollars)

\begin{tabular}{|c|c|c|c|c|c|c|}
\hline Item & $\begin{array}{c}\text { Texas } \\
\text { Gariand } \\
\text { City of } \\
\text { September } 30\end{array}$ & $\begin{array}{c}\text { Texas } \\
\text { Georgetown } \\
\text { City of } \\
\text { Seplember } 30\end{array}$ & $\begin{array}{c}\text { Texas } \\
\text { Greenville } \\
\text { City of }\end{array}$ & $\begin{array}{c}\text { Texas } \\
\text { Kerrville } \\
\text { Public } \\
\text { Utility } \\
\text { Board } \\
\text { Seplember } 30\end{array}$ & $\begin{array}{l}\text { Texas } \\
\text { Lower } \\
\text { Colorado } \\
\text { River } \\
\text { Authority } \\
\text { June } 30\end{array}$ & $\begin{array}{c}\text { Texas } \\
\text { Lubbock } \\
\text { City of } \\
\text { September } 30\end{array}$ \\
\hline 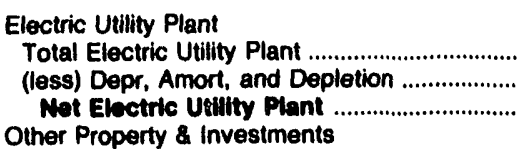 & $\begin{array}{r}187,382 \\
72,987 \\
114,396\end{array}$ & $\begin{array}{l}3,965 \\
1,661 \\
2,304\end{array}$ & $\begin{array}{l}43,381 \\
24,276 \\
19,0.6\end{array}$ & $\begin{array}{r}24,731 \\
7,286 \\
17,444\end{array}$ & $\begin{array}{r}1,419,409 \\
319,441 \\
1,099,968\end{array}$ & $\begin{array}{r}126,314 \\
44,870 \\
81,444\end{array}$ \\
\hline 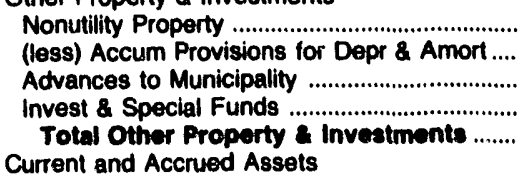 & $\begin{array}{r}0 \\
0 \\
5,519 \\
5,568 \\
11,087\end{array}$ & $\begin{array}{r}31,932 \\
6,119 \\
0 \\
5,868 \\
31,681\end{array}$ & $\begin{array}{r}0 \\
0 \\
0 \\
4,598 \\
4,598\end{array}$ & $\begin{array}{r}0 \\
0 \\
0 \\
4,251 \\
4,251\end{array}$ & $\begin{array}{r}3,922 \\
1,167 \\
0 \\
214,899 \\
217,654\end{array}$ & $\begin{array}{l}0 \\
0 \\
0 \\
0 \\
0\end{array}$ \\
\hline 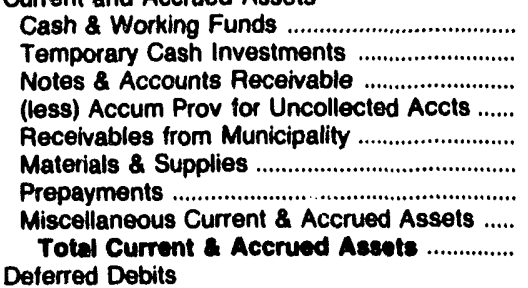 & $\begin{array}{r}0 \\
25,091 \\
17,223 \\
0 \\
0 \\
7,971 \\
23 \\
216 \\
50,524\end{array}$ & $\begin{array}{r}153 \\
5,617 \\
1,376 \\
69 \\
620 \\
128 \\
0 \\
16 \\
7,841\end{array}$ & $\begin{array}{r}7,661 \\
0 \\
4,241 \\
604 \\
198 \\
1,350 \\
0 \\
0 \\
12,946\end{array}$ & $\begin{array}{r}8,132 \\
0 \\
2,658 \\
61 \\
0 \\
461 \\
0 \\
40 \\
11,229\end{array}$ & $\begin{array}{r}-2,481 \\
41,486 \\
40,598 \\
361 \\
0 \\
59,147 \\
3,911 \\
10,208 \\
152,509\end{array}$ & $\begin{array}{r}11,107 \\
0 \\
4,812 \\
0 \\
0 \\
200 \\
0 \\
11 \\
16,130\end{array}$ \\
\hline 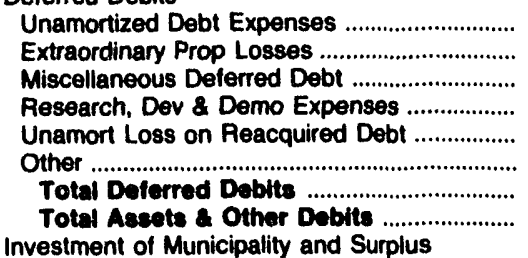 & $\begin{array}{r}0 \\
0 \\
0 \\
0 \\
0 \\
0 \\
0 \\
178,008\end{array}$ & $\begin{array}{r}0 \\
0 \\
0 \\
0 \\
0 \\
347 \\
347 \\
42,173\end{array}$ & $\begin{array}{r}0 \\
0 \\
0 \\
0 \\
0 \\
510 \\
\mathbf{5 1 0} \\
\mathbf{3 7 , 0 4 0}\end{array}$ & $\begin{array}{r}818 \\
0 \\
135 \\
0 \\
0 \\
0 \\
953 \\
33,876\end{array}$ & $\begin{array}{r}18,094 \\
0 \\
296,603 \\
549 \\
119,628 \\
0 \\
434,875 \\
1,905,005\end{array}$ & $\begin{array}{r}0 \\
0 \\
1,147 \\
0 \\
0 \\
28,608 \\
29,755 \\
127,320\end{array}$ \\
\hline 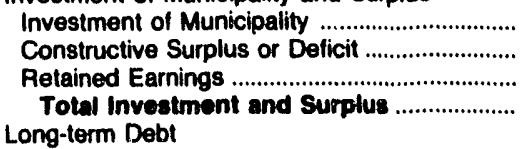 & $\begin{array}{r}0 \\
0 \\
134,975 \\
134,975\end{array}$ & $\begin{array}{r}3,654 \\
0 \\
22,605 \\
28,260\end{array}$ & $\begin{array}{r}200 \\
0 \\
13,060 \\
13,259\end{array}$ & $\begin{array}{r}0 \\
0 \\
-399 \\
-390\end{array}$ & $\begin{array}{r}11,346 \\
0 \\
407,045 \\
418,391\end{array}$ & $\begin{array}{r}7,918 \\
0 \\
69,322 \\
77,240\end{array}$ \\
\hline 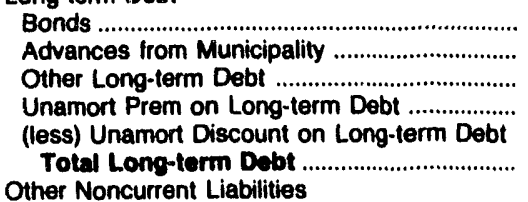 & $\begin{array}{r}31,036 \\
0 \\
0 \\
0 \\
0 \\
31,036\end{array}$ & $\begin{array}{r}12,635 \\
0 \\
730 \\
0 \\
0 \\
13,385\end{array}$ & $\begin{array}{r}19,453 \\
0 \\
0 \\
0 \\
0 \\
18,453\end{array}$ & $\begin{array}{r}32,115 \\
0 \\
0 \\
0 \\
1,361 \\
30,754\end{array}$ & $\begin{array}{r}1,434,070 \\
0 \\
6,938 \\
0 \\
107,062 \\
1,333,946\end{array}$ & $\begin{array}{r}39,257 \\
0 \\
1,211 \\
0 \\
0 \\
40,468\end{array}$ \\
\hline 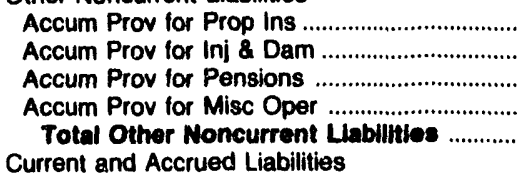 & $\begin{array}{l}0 \\
0 \\
0 \\
0 \\
0\end{array}$ & $\begin{array}{l}0 \\
0 \\
0 \\
0 \\
0\end{array}$ & $\begin{array}{l}0 \\
0 \\
0 \\
0 \\
0\end{array}$ & $\begin{array}{l}0 \\
0 \\
0 \\
0 \\
0\end{array}$ & $\begin{array}{l}0 \\
0 \\
0 \\
0 \\
0\end{array}$ & $\begin{array}{l}0 \\
0 \\
0 \\
0 \\
0\end{array}$ \\
\hline 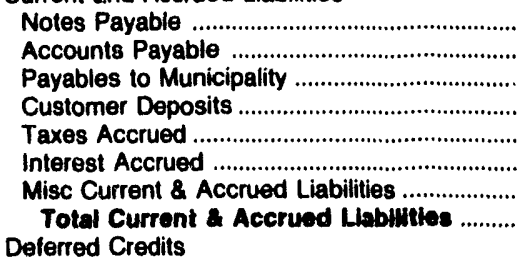 & $\begin{array}{r}0 \\
4,907 \\
25 \\
3,382 \\
0 \\
161 \\
1,475 \\
9,950\end{array}$ & $\begin{array}{r}0 \\
1,440 \\
0 \\
281 \\
0 \\
235 \\
535 \\
2,491\end{array}$ & $\begin{array}{r}1,252 \\
1,007 \\
283 \\
591 \\
0 \\
146 \\
581 \\
3,860\end{array}$ & $\begin{array}{r}555 \\
1,509 \\
0 \\
159 \\
0 \\
1,033 \\
0 \\
3,258\end{array}$ & $\begin{array}{r}0 \\
17,889 \\
0 \\
15 \\
1,168 \\
43,643 \\
8,981 \\
71,696\end{array}$ & $\begin{array}{r}0 \\
7,484 \\
0 \\
46 \\
165 \\
1,213 \\
715 \\
9,622\end{array}$ \\
\hline 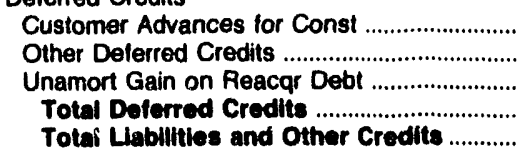 & $\begin{array}{r}44 \\
0 \\
0 \\
44 \\
176,006\end{array}$ & $\begin{array}{r}0 \\
58 \\
0 \\
58 \\
42,173\end{array}$ & $\begin{array}{r}468 \\
0 \\
0 \\
488 \\
37,040\end{array}$ & $\begin{array}{r}0 \\
265 \\
0 \\
285 \\
33,076\end{array}$ & $\begin{array}{r}1,360 \\
789 \\
78,822 \\
80,971 \\
1,905,005\end{array}$ & $\begin{array}{r}0 \\
0 \\
0 \\
0 \\
127,329\end{array}$ \\
\hline
\end{tabular}

Note: Totals may not equal sum of components because of independent rounding.

Source: Energy Information Administration, Form EIA-412, "Annual Report of Public Electric Utilities." 
Table 37. Balance Sheet by Major Publicly Owned Electric Utility Within State at End of Period, 1991 (Confinued) (Thousand Dollars)

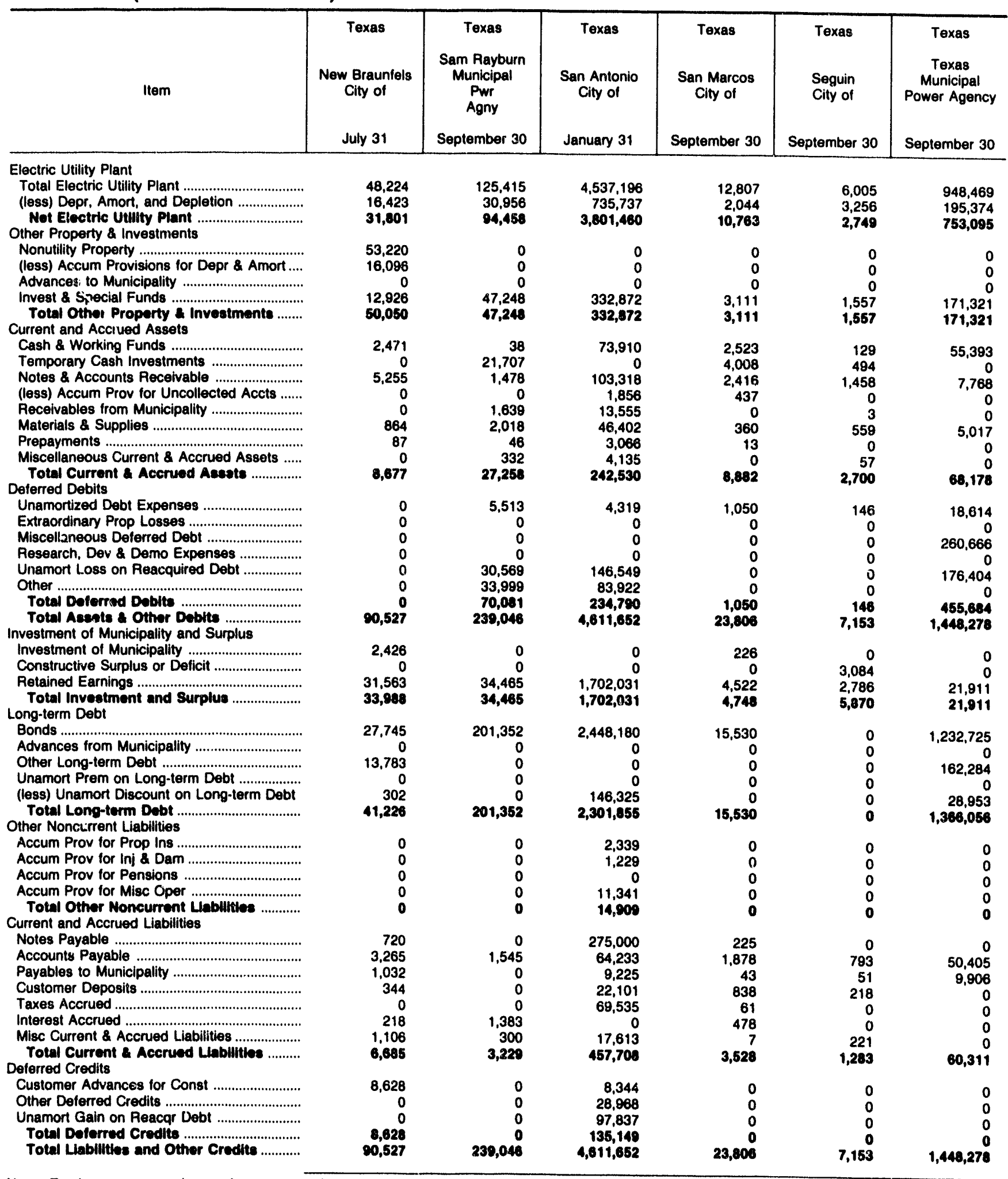

Note: Totals may not equal sum of components because of independent rounding.

Source: Energy Information Administration, Form ElA-412, "Annual Report of Public Electric Utilities." 
Table 37. Balance Sheet by Major Publicly Owned Electric Utility Within State at End of Period, 1991 (Continued)

(Thousand Dollars)

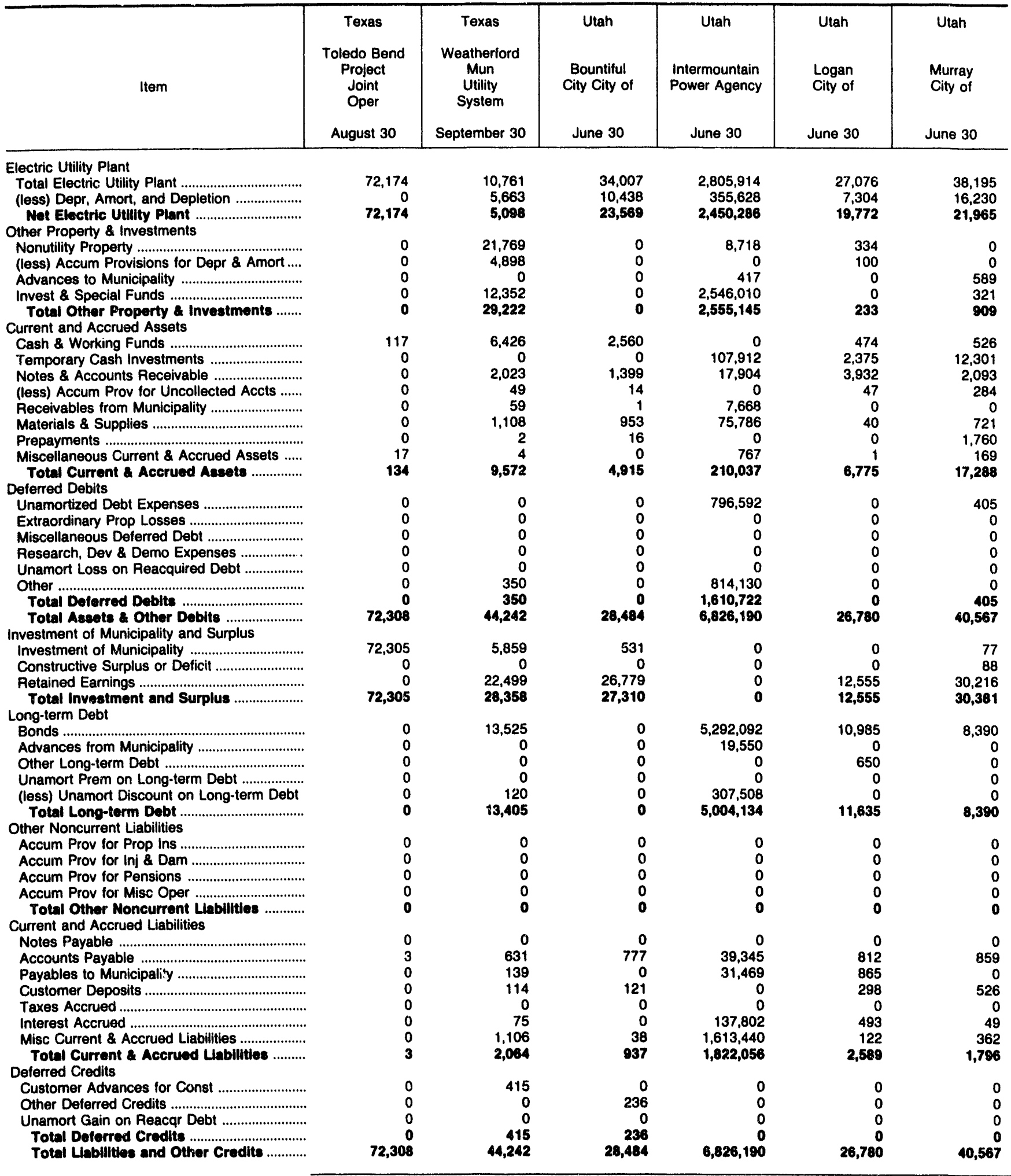

Note: Totals may not equal sum of components because of independent rounding.

Source: Energy Information Administration, Form ElA-412, "Annual Report of Public Electric Utilities." 
Table 37. Balance Sheet by Major Publicly Owned Electric Utility Within State at End of Period, 1991 (Continued) (Thousand Doliars)

\begin{tabular}{|c|c|c|c|c|c|c|}
\hline Item & $\begin{array}{c}\text { Utah } \\
\text { Provo } \\
\text { City Corp } \\
\text { June } 30\end{array}$ & $\begin{array}{l}\text { Utah } \\
\text { St George } \\
\text { City of } \\
\text { June } 30\end{array}$ & $\begin{array}{c}\text { Utah } \\
\text { Utah } \\
\text { Associated } \\
\text { Mun } \\
\text { Power Sys } \\
\text { March } 31\end{array}$ & $\begin{array}{c}\text { Utah } \\
\text { Utah } \\
\text { Municipal } \\
\text { Power Agency } \\
\text { June } 30\end{array}$ & $\begin{array}{l}\text { Burlington } \\
\text { City of } \\
\text { December } 31\end{array}$ & $\begin{array}{l}\text { Vermont } \\
\text { Vermont } \\
\text { Public } \\
\text { Pwr } \\
\text { Supply Auth } \\
\text { December } 31\end{array}$ \\
\hline $\begin{array}{l}\text { Electric Utility Plant } \\
\text { Total Electric Utility Plant .................................. } \\
\text { (less) Depr, Amort, and Depletion ................... } \\
\text { Net Eleciric Utilty Pant ............................... } \\
\text { Other Property \& Investments }\end{array}$ & $\begin{array}{l}79,042 \\
28,414 \\
50,82\end{array}$ & $\begin{array}{r}23,088 \\
6,323 \\
16,784\end{array}$ & $\begin{array}{r}75,666 \\
17,047 \\
58,619\end{array}$ & $\begin{array}{r}33,725 \\
4,654 \\
29,072\end{array}$ & $\begin{array}{c}76,438 \\
15,191 \\
61,247\end{array}$ & $\begin{array}{r}20,468 \\
6,263 \\
14,205\end{array}$ \\
\hline 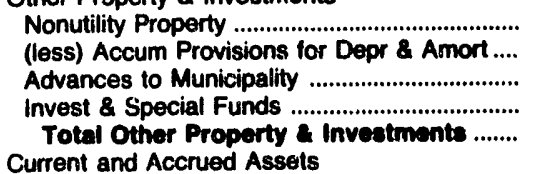 & $\begin{array}{r}0 \\
0 \\
0 \\
7,135 \\
7,135\end{array}$ & $\begin{array}{l}0 \\
0 \\
0 \\
0 \\
0\end{array}$ & $\begin{array}{r}0 \\
0 \\
0 \\
25,583 \\
25,523\end{array}$ & $\begin{array}{r}230 \\
0 \\
0 \\
13,662 \\
13,092\end{array}$ & $\begin{array}{r}776 \\
0 \\
0 \\
2,845 \\
3,620\end{array}$ & $\begin{array}{r}0 \\
0 \\
0 \\
6,668 \\
6,668\end{array}$ \\
\hline 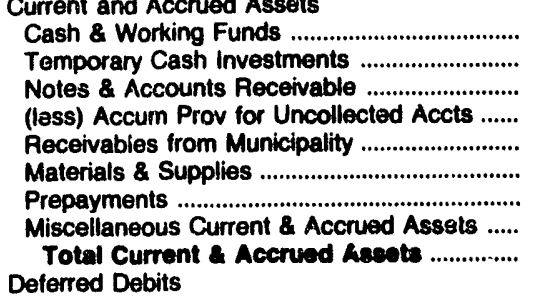 & $\begin{array}{r}6,911 \\
0 \\
4,830 \\
86 \\
0 \\
967 \\
0 \\
0 \\
12,722\end{array}$ & $\begin{array}{r}6,713 \\
0 \\
2,094 \\
280 \\
69 \\
2,928 \\
0 \\
0 \\
11,625\end{array}$ & $\begin{array}{r}0 \\
3,091 \\
9,040 \\
0 \\
0 \\
0 \\
1,430 \\
0 \\
13,561\end{array}$ & $\begin{array}{r}1,662 \\
0 \\
2,022 \\
0 \\
0 \\
2,040 \\
55 \\
0 \\
5,779\end{array}$ & $\begin{array}{r}12,917 \\
0 \\
3,785 \\
92 \\
0 \\
1,808 \\
26 \\
2,083 \\
20,527\end{array}$ & $\begin{array}{r}84 \\
200 \\
1,510 \\
0 \\
0 \\
321 \\
0 \\
0 \\
2,115\end{array}$ \\
\hline 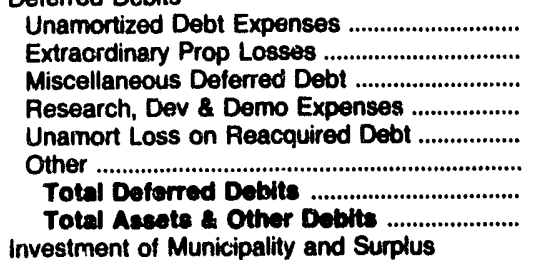 & $\begin{array}{r}0 \\
0 \\
0 \\
0 \\
0 \\
0 \\
0 \\
70,485\end{array}$ & $\begin{array}{r}0 \\
0 \\
0 \\
0 \\
0 \\
0 \\
0 \\
0\end{array}$ & $\begin{array}{r}6,266 \\
0 \\
27,371 \\
0 \\
0 \\
0 \\
33,037 \\
131,300\end{array}$ & $\begin{array}{r}2,201 \\
0 \\
2,826 \\
0 \\
0 \\
3,060 \\
8,087 \\
E 8,930\end{array}$ & $\begin{array}{r}4,068 \\
0 \\
10,677 \\
0 \\
20,157 \\
85 \\
34,987 \\
172,381\end{array}$ & $\begin{array}{r}1,483 \\
0 \\
109 \\
0 \\
11,200 \\
276 \\
13,068 \\
38,057\end{array}$ \\
\hline 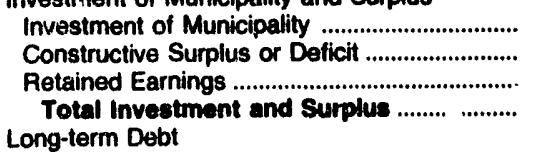 & $\begin{array}{r}0 \\
0 \\
14,155 \\
14,155\end{array}$ & $\begin{array}{r}0 \\
0 \\
26,604 \\
26,604\end{array}$ & $\begin{array}{r}127 \\
0 \\
0 \\
127\end{array}$ & $\begin{array}{l}3 \\
0 \\
0 \\
3\end{array}$ & $\begin{array}{r}0 \\
0 \\
16,573 \\
16,573\end{array}$ & $\begin{array}{r}0 \\
0 \\
-811 \\
-811\end{array}$ \\
\hline 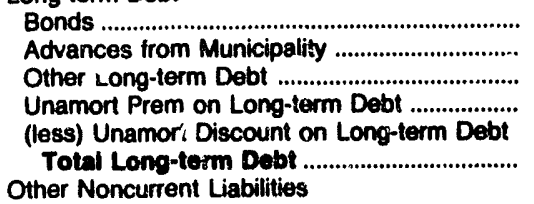 & $\begin{array}{r}59,015 \\
0 \\
647 \\
0 \\
6,931 \\
52,730\end{array}$ & $\begin{array}{l}0 \\
0 \\
0 \\
0 \\
0 \\
0\end{array}$ & $\begin{array}{r}109,709 \\
9,510 \\
0 \\
0 \\
0 \\
119,219\end{array}$ & $\begin{array}{r}52,650 \\
0 \\
0 \\
0 \\
0 \\
52,850\end{array}$ & $\begin{array}{r}88,746 \\
0 \\
10,412 \\
4 \\
1,551 \\
87,611\end{array}$ & $\begin{array}{r}37,415 \\
0 \\
0 \\
0 \\
3,817 \\
39,698\end{array}$ \\
\hline $\begin{array}{l}\text { Accum Prov for Prop Ins ................................... } \\
\text { Accum Prov for Inj \& Dam ............................. } \\
\text { Accum Prov for Pensions ............................... } \\
\text { Accum Prov for Misc Oper .......................... } \\
\text { Total Other Noncurrent Liabitties ........... } \\
\text { Current and Accrued Liabilities }\end{array}$ & $\begin{array}{l}0 \\
0 \\
0 \\
0 \\
0\end{array}$ & $\begin{array}{l}0 \\
0 \\
0 \\
0 \\
0\end{array}$ & $\begin{array}{l}0 \\
0 \\
0 \\
0 \\
0\end{array}$ & $\begin{array}{l}0 \\
0 \\
0 \\
0 \\
0\end{array}$ & $\begin{array}{l}0 \\
0 \\
0 \\
0 \\
0\end{array}$ & $\begin{array}{l}0 \\
0 \\
0 \\
0 \\
0\end{array}$ \\
\hline 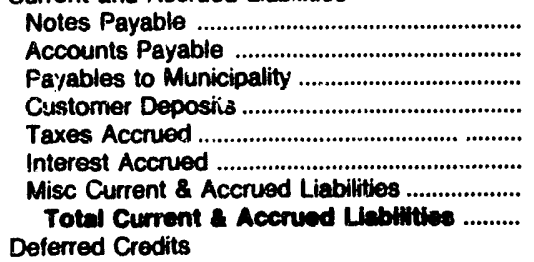 & $\begin{array}{r}1,865 \\
277 \\
0 \\
732 \\
68 \\
120 \\
537 \\
3,500\end{array}$ & $\begin{array}{r}0 \\
1,253 \\
0 \\
433 \\
0 \\
0 \\
0 \\
1,898\end{array}$ & $\begin{array}{r}0 \\
2,725 \\
830 \\
6,317 \\
0 \\
1,876 \\
305 \\
12,053\end{array}$ & $\begin{array}{r}0 \\
1,846 \\
0 \\
0 \\
0 \\
1,830 \\
400 \\
4,177\end{array}$ & $\begin{array}{r}0 \\
1,681 \\
0 \\
11 \\
327 \\
3,571 \\
376 \\
5,968\end{array}$ & $\begin{array}{r}325 \\
926 \\
835 \\
0 \\
0 \\
1,144 \\
41 \\
3,270\end{array}$ \\
\hline 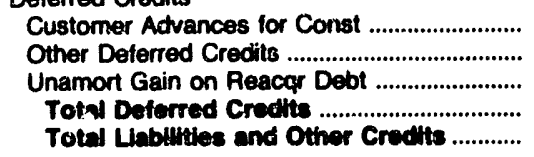 & $\begin{array}{r}0 \\
0 \\
0 \\
0 \\
70,485\end{array}$ & $\begin{array}{r}0 \\
0 \\
0 \\
0 \\
28,209\end{array}$ & $\begin{array}{r}0 \\
0 \\
0 \\
0 \\
131,300\end{array}$ & $\begin{array}{r}0 \\
0 \\
0 \\
0 \\
58,830\end{array}$ & $\begin{array}{r}0 \\
231 \\
0 \\
231 \\
120,381\end{array}$ & $\begin{array}{r}0 \\
0 \\
0 \\
0 \\
36,057\end{array}$ \\
\hline
\end{tabular}

Note: Totals may not equal sum of components because of independent rounding

Source: Energy intormation Administration, Form EIA-412, "Annual Report of Public Electric Utilities." 

Table 37. Balance Sheet by Major Publicly Owned Electric Utility
Within State at End of Period, 1991 (Continued) (Thousand Dollars)

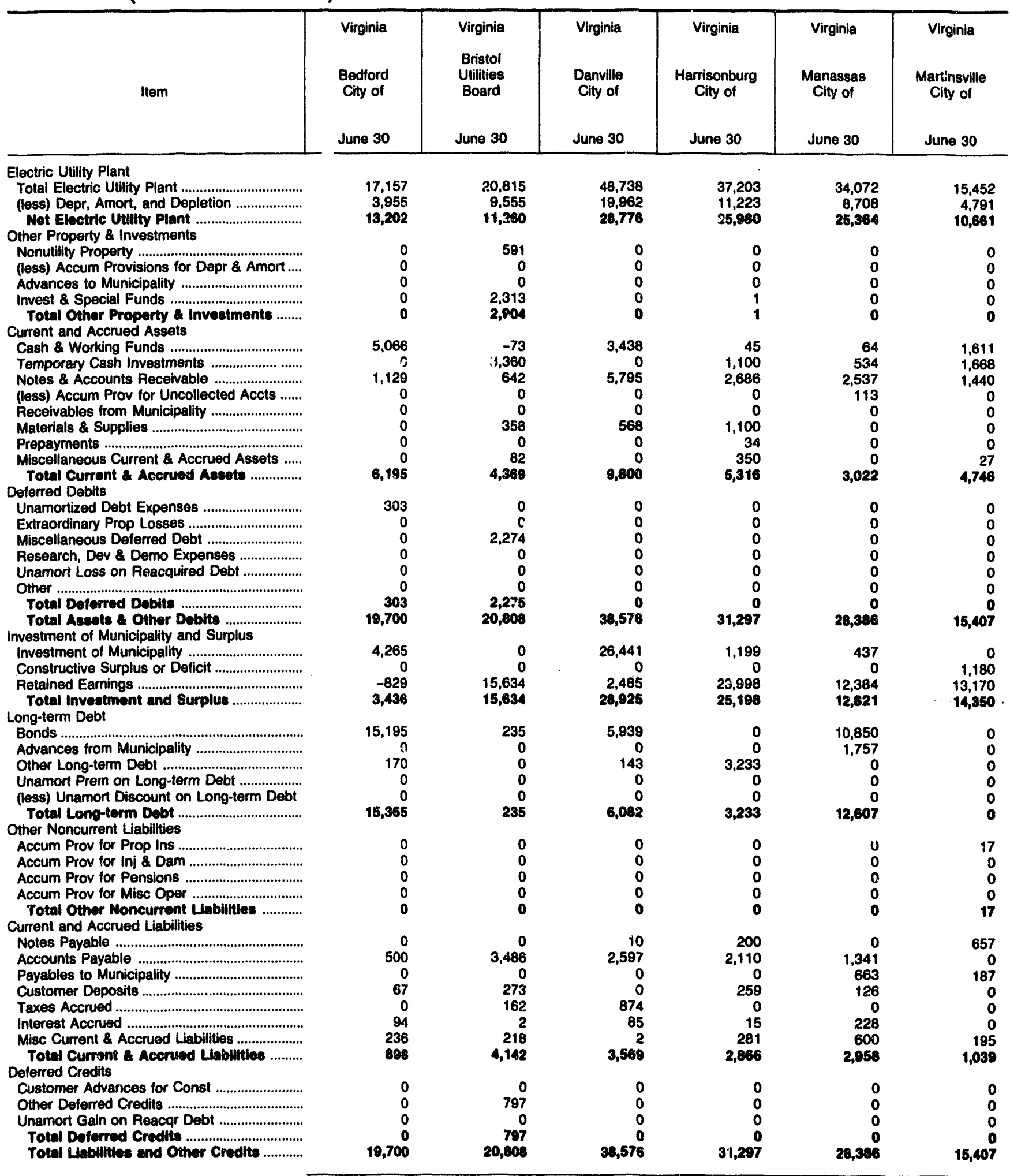

Note: Totals may not equal sum of components because of independent rourding.

Source: Energy Information Administration, Form ElA-412, "Annual Report of Public Electric Utilities." 
Table 37. Balance Sheet by Major Publicly Owned Electric Utility Within State at End of Period, 1991 (Continued) (Thousand Dollars)

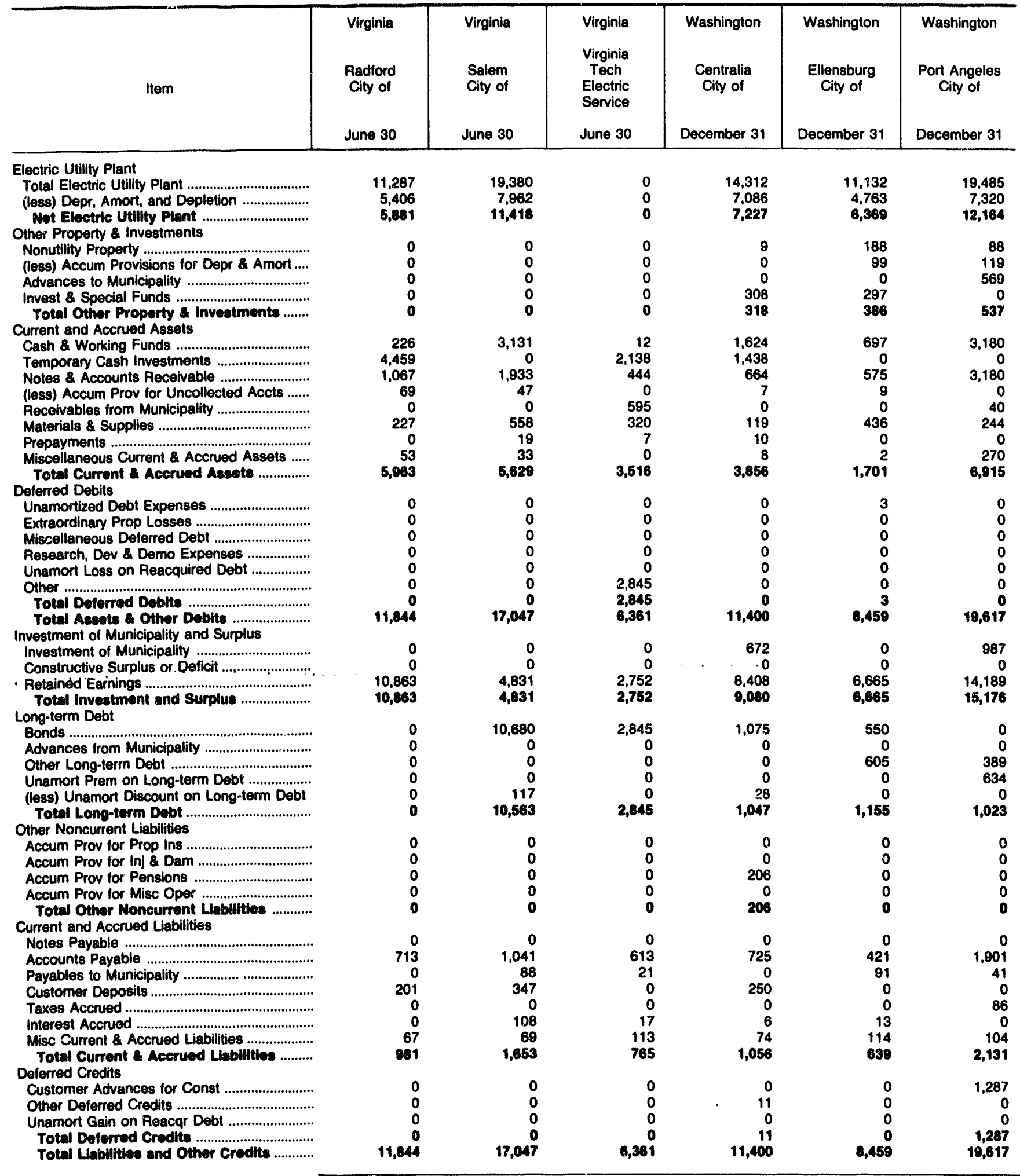

Note: Totals may not equal sum of components because of independent rounding.

Source: Energy Inicrmation Administration, Form EIA-412, "Annual Report of Public Electric Utilities." 
Table 37. Balance Sheet by Major Publicly Owned Electric Utility Within State at End of Perlod, 1991 (Continued) (Thousand Dollars)

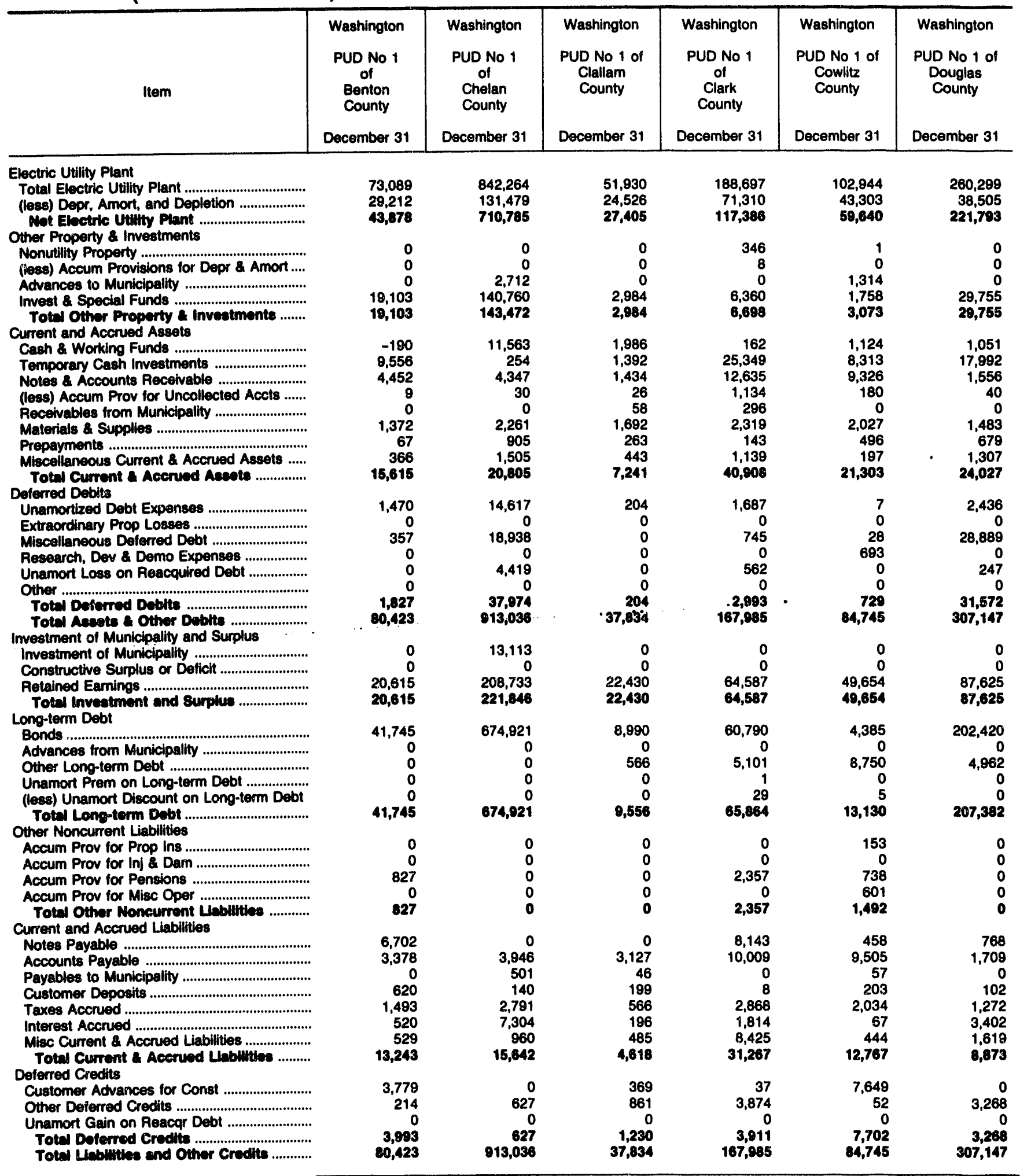

Note: Totals may not equal sum of components because of independent rounding

Source: Energy Information Administration, Form ElA-412, "Annual Report of Public Electric Utilities." 
Table 37. Balance Sheet by Major Publicly Owned Electric Utility Within State at End of Period, 1991 (Continued) (Thousand Dollars)

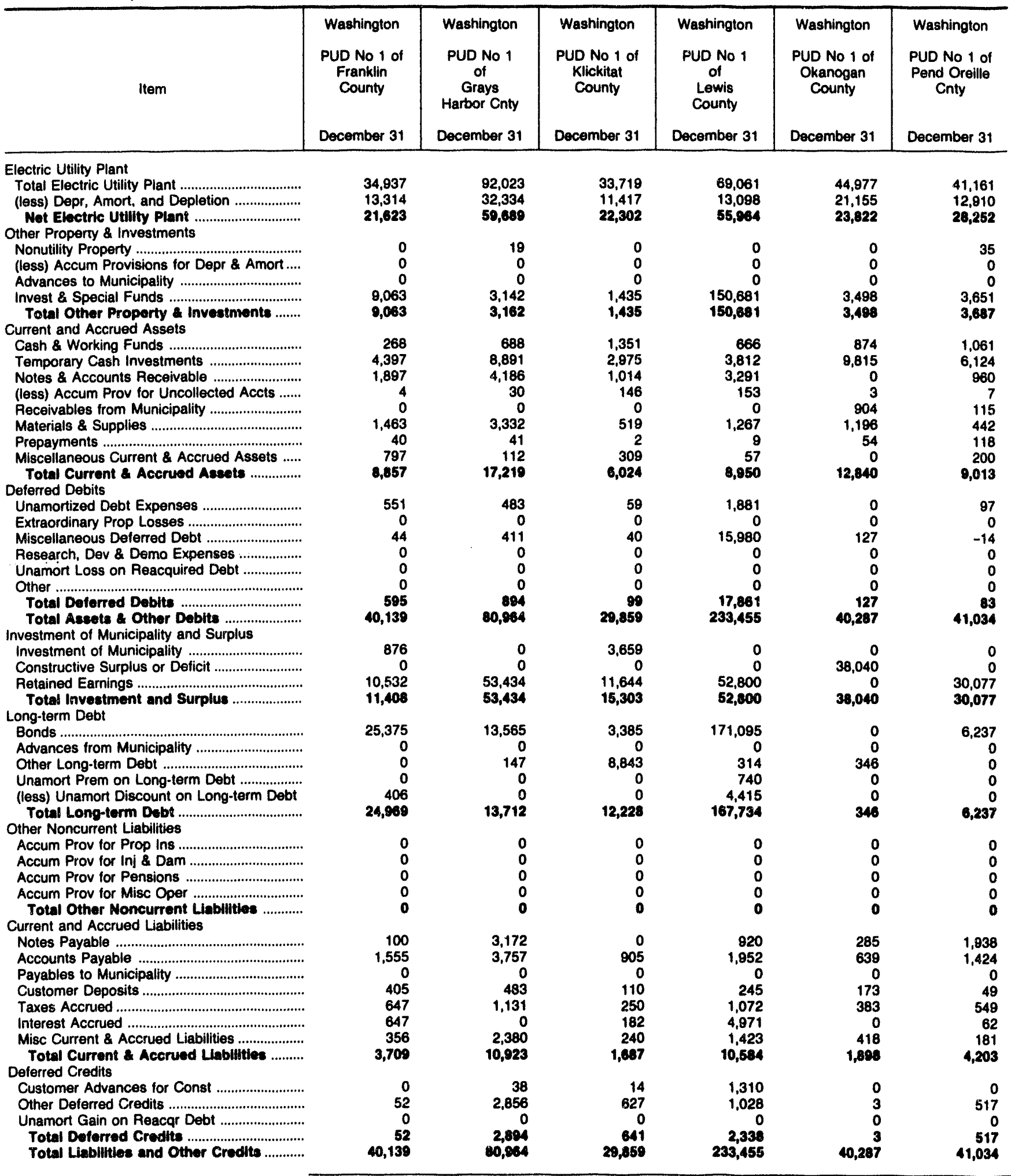

Note: Totals may not equal sum of components because of independent rounding.

Source: Energy Information Administration, Form EIA-412, "Annual Report of Public Electric Utilities." 
Table 37. Balance Sheet by Major Publicly Owned Electric Utility Within State at End of Period, 1991 (Continued) (Thousand Dollars)

\begin{tabular}{|c|c|c|c|c|c|c|}
\hline Item & $\begin{array}{l}\text { Washington } \\
\text { PUD No } 1 \text { of } \\
\text { Snohomish } \\
\text { County } \\
\text { December } 31\end{array}$ & $\begin{array}{l}\text { Washington } \\
\text { PUD No } 1 \text { of } \\
\text { Whatcom } \\
\text { County } \\
\text { December } 31\end{array}$ & $\begin{array}{c}\text { Washington } \\
\text { PUD No } 2 \\
\text { of } \\
\text { Grant } \\
\text { County } \\
\text { December } 31\end{array}$ & $\begin{array}{l}\text { Washington } \\
\text { PUD No } 2 \text { of } \\
\text { Pacific } \\
\text { County } \\
\text { December } 31\end{array}$ & $\begin{array}{c}\text { Washington } \\
\text { PUD No } 3 \\
\text { of } \\
\text { Mason } \\
\text { County } \\
\text { December } 31\end{array}$ & $\begin{array}{l}\text { Washington } \\
\text { Richland } \\
\text { City of } \\
\text { December } 31\end{array}$ \\
\hline 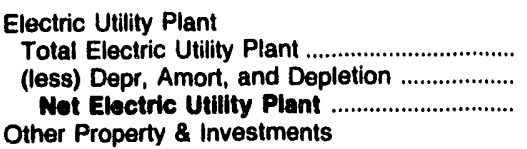 & $\begin{array}{l}677,795 \\
156,823 \\
520,972\end{array}$ & $\begin{array}{l}983 \\
592 \\
391\end{array}$ & $\begin{array}{l}594,402 \\
183,818 \\
410,584\end{array}$ & $\begin{array}{l}27,142 \\
11,650 \\
15,482\end{array}$ & $\begin{array}{l}52,511 \\
14,030 \\
38,481\end{array}$ & $\begin{array}{l}38,303 \\
13,614 \\
24,689\end{array}$ \\
\hline 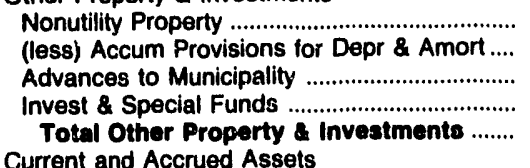 & $\begin{array}{r}0 \\
0 \\
35,874 \\
158,182 \\
194,056\end{array}$ & $\begin{array}{l}0 \\
0 \\
0 \\
0 \\
\mathbf{0}\end{array}$ & $\begin{array}{r}0 \\
0 \\
0 \\
126,640 \\
126,640\end{array}$ & $\begin{array}{r}0 \\
0 \\
0 \\
2,295 \\
2,285\end{array}$ & $\begin{array}{r}0 \\
0 \\
0 \\
3,708 \\
3,708\end{array}$ & $\begin{array}{r}0 \\
0 \\
0 \\
5,596 \\
5,596\end{array}$ \\
\hline 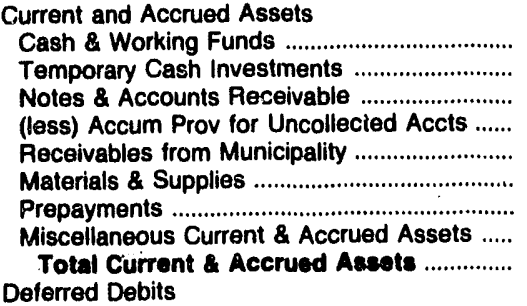 & $\begin{array}{r}643 \\
19,076 \\
41,905 \\
1,831 \\
0 \\
8,806 \\
203 \\
3,542 \\
72,344\end{array}$ & $\begin{array}{r}249 \\
3,100 \\
520 \\
0 \\
0 \\
0 \\
1 \\
0 \\
3,871\end{array}$ & $\begin{array}{r}244 \\
66,161 \\
4,845 \\
0 \\
7,983 \\
6,211 \\
684 \\
1,875 \\
68,003\end{array}$ & $\begin{array}{r}955 \\
1,175 \\
847 \\
54 \\
0 \\
961 \\
46 \\
45 \\
3,975\end{array}$ & $\begin{array}{r}6,700 \\
3,485 \\
2,502 \\
33 \\
0 \\
1,964 \\
14 \\
70 \\
14,701\end{array}$ & $\begin{array}{r}94 \\
941 \\
2,670 \\
105 \\
0 \\
858 \\
39 \\
163 \\
4,660\end{array}$ \\
\hline 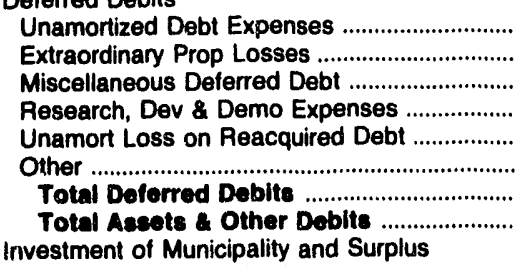 & $\begin{array}{r}17,828 \\
0 \\
6,462 \\
0 \\
57,611 \\
0 \\
81,801 \\
869,272\end{array}$ & $\begin{array}{r}0 \\
0 \\
0 \\
0 \\
0 \\
0 \\
0 \\
\mathbf{4 , 2 6 2}\end{array}$ & $\begin{array}{r}2,110 \\
0 \\
933 \\
0 \\
0 \\
0 \\
3,043 \\
628,269\end{array}$ & $\begin{array}{r}87 \\
0 \\
128 \\
0 \\
0 \\
0 \\
215 \\
21,978\end{array}$ & $\begin{array}{r}172 \\
0 \\
5 \\
0 \\
0 \\
54 \\
230 \\
57,121\end{array}$ & $\begin{array}{r}57 \\
0 \\
0 \\
0 \\
0 \\
0 \\
57 \\
35,002\end{array}$ \\
\hline 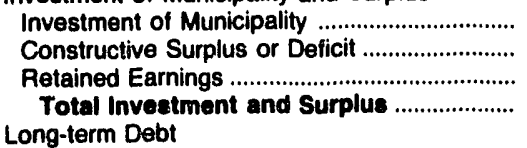 & $\begin{array}{r}0 \\
0 \\
215,525 \\
215,525\end{array}$ & $\begin{array}{r}0 \\
0 \\
3,866 \\
3,866\end{array}$ & $\begin{array}{r}0 \\
0 \\
250,219 \\
250,219\end{array}$ & $\begin{array}{r}0 \\
2,012 \\
13,718 \\
15,730\end{array}$ & $\begin{array}{r}0 \\
0 \\
37,302 \\
37,302\end{array}$ & $\begin{array}{r}0 \\
0 \\
10,728 \\
10,728\end{array}$ \\
\hline 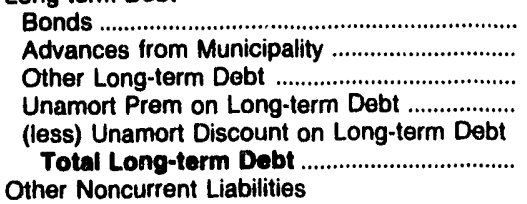 & $\begin{array}{r}441,789 \\
35,874 \\
0 \\
0 \\
0 \\
477,663\end{array}$ & $\begin{array}{l}0 \\
0 \\
0 \\
0 \\
0 \\
0\end{array}$ & $\begin{array}{r}295,872 \\
0 \\
0 \\
316 \\
3,683 \\
292,506\end{array}$ & $\begin{array}{r}3,460 \\
0 \\
248 \\
0 \\
0 \\
3,708\end{array}$ & $\begin{array}{r}9,090 \\
0 \\
0 \\
0 \\
0 \\
9,080\end{array}$ & $\begin{array}{r}13,955 \\
0 \\
0 \\
0 \\
410 \\
13,545\end{array}$ \\
\hline 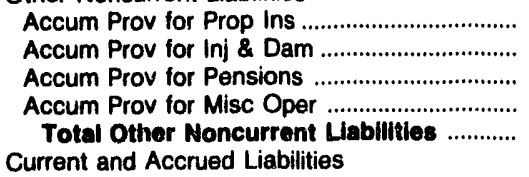 & $\begin{array}{r}0 \\
975 \\
0 \\
0 \\
975\end{array}$ & $\begin{array}{l}0 \\
0 \\
0 \\
0 \\
0\end{array}$ & $\begin{array}{l}0 \\
0 \\
0 \\
0 \\
\mathbf{0}\end{array}$ & $\begin{array}{l}0 \\
0 \\
0 \\
0 \\
0\end{array}$ & $\begin{array}{l}0 \\
0 \\
0 \\
0 \\
0\end{array}$ & $\begin{array}{l}0 \\
0 \\
0 \\
0 \\
0\end{array}$ \\
\hline 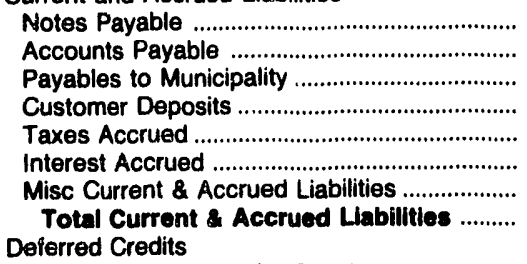 & $\begin{array}{r}1,004 \\
39,755 \\
0 \\
619 \\
5,552 \\
16,928 \\
7,503 \\
71,361\end{array}$ & $\begin{array}{r}0 \\
315 \\
0 \\
0 \\
81 \\
0 \\
0 \\
380\end{array}$ & $\begin{array}{r}549 \\
5,530 \\
7,469 \\
340 \\
3,050 \\
7,867 \\
59,754 \\
\mathbf{8 4 , 5 5 8}\end{array}$ & $\begin{array}{r}5 \\
1,743 \\
0 \\
231 \\
290 \\
42 \\
158 \\
2,468\end{array}$ & $\begin{array}{r}236 \\
2,322 \\
0 \\
152 \\
488 \\
309 \\
679 \\
4,187\end{array}$ & $\begin{array}{r}0 \\
2,338 \\
0 \\
0 \\
0 \\
177 \\
0 \\
2,515\end{array}$ \\
\hline 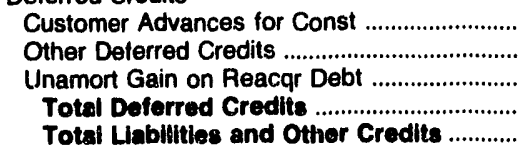 & $\begin{array}{r}0 \\
103,747 \\
0 \\
103,747 \\
869,272\end{array}$ & $\begin{array}{r}0 \\
0 \\
0 \\
0 \\
4,282\end{array}$ & $\begin{array}{r}557 \\
430 \\
0 \\
887 \\
628,269\end{array}$ & $\begin{array}{r}46 \\
24 \\
0 \\
70 \\
21,878\end{array}$ & $\begin{array}{r}6,319 \\
26 \\
197 \\
6,542 \\
57,121\end{array}$ & $\begin{array}{r}8,214 \\
0 \\
0 \\
8,214 \\
35,002\end{array}$ \\
\hline
\end{tabular}

Note: Totals may not equal sum of components because of independent rounding.

Source: Energy Information Administration, Form ElA-412, "Annual Report of Public Electric Utilities." 
Table 37. Balance Sheet by Major Publicly Owned Electric Utility Within State at End of Period, 1991 (Continued) (Thousand Dollars)

\begin{tabular}{|c|c|c|c|c|c|c|}
\hline Item & $\begin{array}{c}\text { Washington } \\
\text { Seattle } \\
\text { City of } \\
\text { December } 31\end{array}$ & $\begin{array}{c}\text { Washington } \\
\text { Tacoma } \\
\text { City of } \\
\text { December } 31\end{array}$ & $\begin{array}{c}\text { Washington } \\
\text { Vera } \\
\text { Irrigation } \\
\text { District \#15 } \\
\text { December } 31\end{array}$ & $\begin{array}{l}\text { Washington } \\
\text { Washington } \\
\text { Pub } \\
\text { Pwr } \\
\text { Supply Sys } \\
\text { June } 30\end{array}$ & $\begin{array}{c}\text { Wisconsin } \\
\text { Jefferson } \\
\text { City of } \\
\text { December } 31\end{array}$ & $\begin{array}{c}\text { Wisconsin } \\
\text { Kaukauna } \\
\text { City of } \\
\text { December } 31\end{array}$ \\
\hline \multicolumn{7}{|l|}{ Electric Utility Plant } \\
\hline 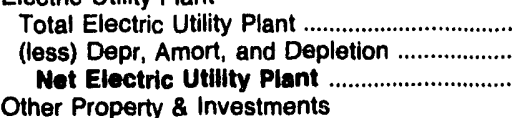 & $\begin{array}{r}1,175,644 \\
462,917 \\
712,727\end{array}$ & $\begin{array}{l}617,931 \\
196,994 \\
420,937\end{array}$ & $\begin{array}{r}10,372 \\
3,414 \\
6,958\end{array}$ & $\begin{array}{r}3,624,781 \\
852,389 \\
2,772,392\end{array}$ & $\begin{array}{l}4,381 \\
1,699 \\
2,682\end{array}$ & $\begin{array}{l}35,016 \\
14,410 \\
20,606\end{array}$ \\
\hline 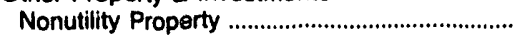 & 10,137 & 175 & 0 & 0 & 0 & 651 \\
\hline (less) Accum Provisions for Depr \& Amort .... & 4,399 & 0 & 0 & 0 & 0 & 149 \\
\hline 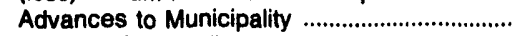 & 0 & 0 & 0 & 0 & 0 & 0 \\
\hline 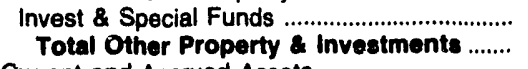 & $\begin{array}{l}51,388 \\
57,126\end{array}$ & $\begin{array}{l}48,549 \\
48,724\end{array}$ & $\begin{array}{l}165 \\
165\end{array}$ & $\begin{array}{l}229,005 \\
229,005\end{array}$ & $\begin{array}{l}0 \\
0\end{array}$ & $\begin{array}{l}5,941 \\
6,443\end{array}$ \\
\hline \multicolumn{7}{|l|}{ Current and Accrued Assets } \\
\hline 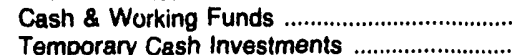 & $\begin{array}{r}6,394 \\
35,652\end{array}$ & $\begin{array}{r}6,021 \\
103,538\end{array}$ & $\begin{array}{l}420 \\
100\end{array}$ & $\begin{array}{r}2,762 \\
36018\end{array}$ & $\begin{array}{r}189 \\
5170\end{array}$ & 748 \\
\hline 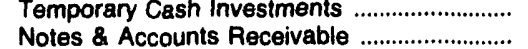 & $\begin{array}{l}30,052 \\
29,178\end{array}$ & 28,825 & 496 & $\begin{array}{l}36,018 \\
31,753\end{array}$ & $\begin{array}{r}5,178 \\
497\end{array}$ & $\begin{array}{r}96 \\
1864\end{array}$ \\
\hline (less) Accum Prov for Uncollected Accts ....... & 1,767 & 647 & 0 & 250 & 0 & 35 \\
\hline Receivables from Municipality .............................. & 1,242 & 976 & 539 & 7 & 0 & 700 \\
\hline 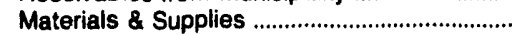 & 21,977 & 8,637 & 239 & 36,508 & 84 & 578 \\
\hline 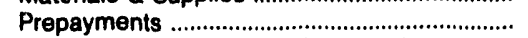 & 1,245 & 59 & 12 & 1,308 & 1 & 420 \\
\hline Miscellaneous Current \& Accrued Assets ..... & 23,201 & 807 & 0 & 14 & 6 & -21 \\
\hline \multicolumn{6}{|l|}{ Deferred Debits } & 4,360 \\
\hline 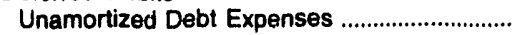 & 1,241 & 2,825 & 118 & 17,473 & 135 & 405 \\
\hline 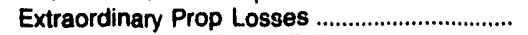 & & & 0 & 0 & 0 & 0 \\
\hline Miscellaneous Deferred Debt .............................. & 1,276 & 3,802 & 0 & 3,192 & 4 & 346 \\
\hline Research, Dev \& Demo Expenses ..................... & & 11 & 0 & 0 & 0 & 0 \\
\hline Unamort Loss on Reacquired Debt ...................... & 30,380 & 0 & 0 & 0 & 0 & 0 \\
\hline Other & 52,840 & 0 & 0 & 3,687 & 0 & 0 \\
\hline Total Deferred Debits ………………………....... & 85,737 & 6,638 & 118 & 24,352 & 139 & 751 \\
\hline \multicolumn{6}{|l|}{ Investment of Municipality and Surplus } & 32,161 \\
\hline 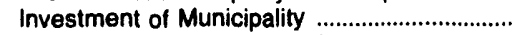 & 0 & 0 & 0 & 0 & 153 & 0 \\
\hline Constructive Surplus or Deficit .............................. & & 0 & 0 & 0 & 214 & 0 \\
\hline 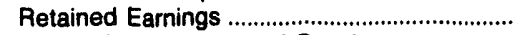 & 295,803 & 247,907 & 7,174 & 0 & 2,586 & 13,221 \\
\hline \multicolumn{6}{|l|}{ Long-term Debt } & 13,221 \\
\hline 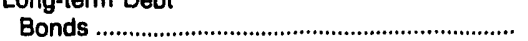 & 515,045 & 340,627 & 1,187 & $2,489,111$ & 0 & 13,550 \\
\hline Advances from Municipality .................................. & & 0 & 0 & 0 & 0 & 0 \\
\hline 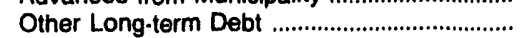 & 0 & 0 & 0 & 0 & 0 & 74 \\
\hline Unamort Prem on Long-term Debt ....................... & & 0 & 0 & 656 & 0 & 2,000 \\
\hline (less) Unamort Discount on Long-term Debt & 6,976 & 4,088 & & 84,258 & 0 & \\
\hline Total Long-term Debt ......................................... & 508,070 & 336,540 & 1,187 & $2, \mathbf{4 0 5 , 5 1 0}$ & 0 & 15,624 \\
\hline \multicolumn{7}{|l|}{ Other Noncurrent Liabilities } \\
\hline 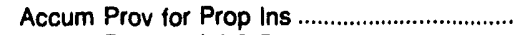 & 720 & 0 & 0 & 0 & 0 & 0 \\
\hline 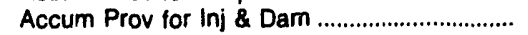 & 5,633 & 0 & 0 & 0 & 0 & 0 \\
\hline Accum Prov for Pensions ..................................... & & 0 & 0 & 0 & 0 & 0 \\
\hline 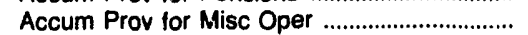 & 113,733 & 0 & 0 & 0 & 0 & 0 \\
\hline Total Other Noncurrent Liabillties ............. & 120,086 & 0 & 0 & 0 & 0 & 0 \\
\hline \multicolumn{7}{|l|}{ Current and Accrued Liabilities } \\
\hline 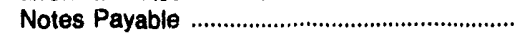 & 2 & 0 & 0 & 0 & 5,000 & 0 \\
\hline Accounts Payable .................................................. & 25,619 & 16,784 & 645 & 74,545 & 518 & 1,294 \\
\hline 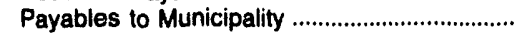 & 7,410 & 748 & 0 & 3,567 & 44 & 10 \\
\hline Customer Deposits .................................................. & 228 & 1,147 & 0 & 0 & 128 & 42 \\
\hline Taxes Accrued ................................................. & 18 & 2,503 & 0 & 1,048 & 90 & 604 \\
\hline 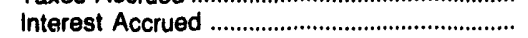 & 8,733 & 11,009 & 0 & 243 & 29 & 47 \\
\hline Misc Current \& Accrued Liabilities ......................... & 5,792 & 5,190 & 42 & 53,059 & 0 & \\
\hline $\begin{array}{l}\text { Total Current \& Accrued Llabilities .......... } \\
\text { Deferred Credits }\end{array}$ & 47,801 & 37,381 & 687 & 132,461 & 5,809 & 1,997 \\
\hline Customer Advances for Const ............................... & 0 & 1,810 & 0 & 0 & 14 & 1,228 \\
\hline Other Deferred Credits .......................................... & 952 & 878 & 0 & 595,339 & 0 & 91 \\
\hline Unamort Gain on Reacqr Debt .......................... & 0 & 0 & 0 & 559 & 0 & \\
\hline Total Deferred Credits ................................. & 952 & 2,688 & & 595,898 & 14 & 1,319 \\
\hline Total Llabilities and Other Credits ............ & 972,713 & 624,515 & 9,048 & $3,133,869$ & 8,777 & 32,161 \\
\hline
\end{tabular}

Note: Totals may not equal sum of components because of independent rounding.

Source: Energy Information Administration, Form ElA-412, "Annual Report of Public Electric Utilities." 
Table 37. Balance Sheet by Major Publicly Owned Electric Utility Within State at End of Period, 1991 (Continued) (Thousand Dollars)

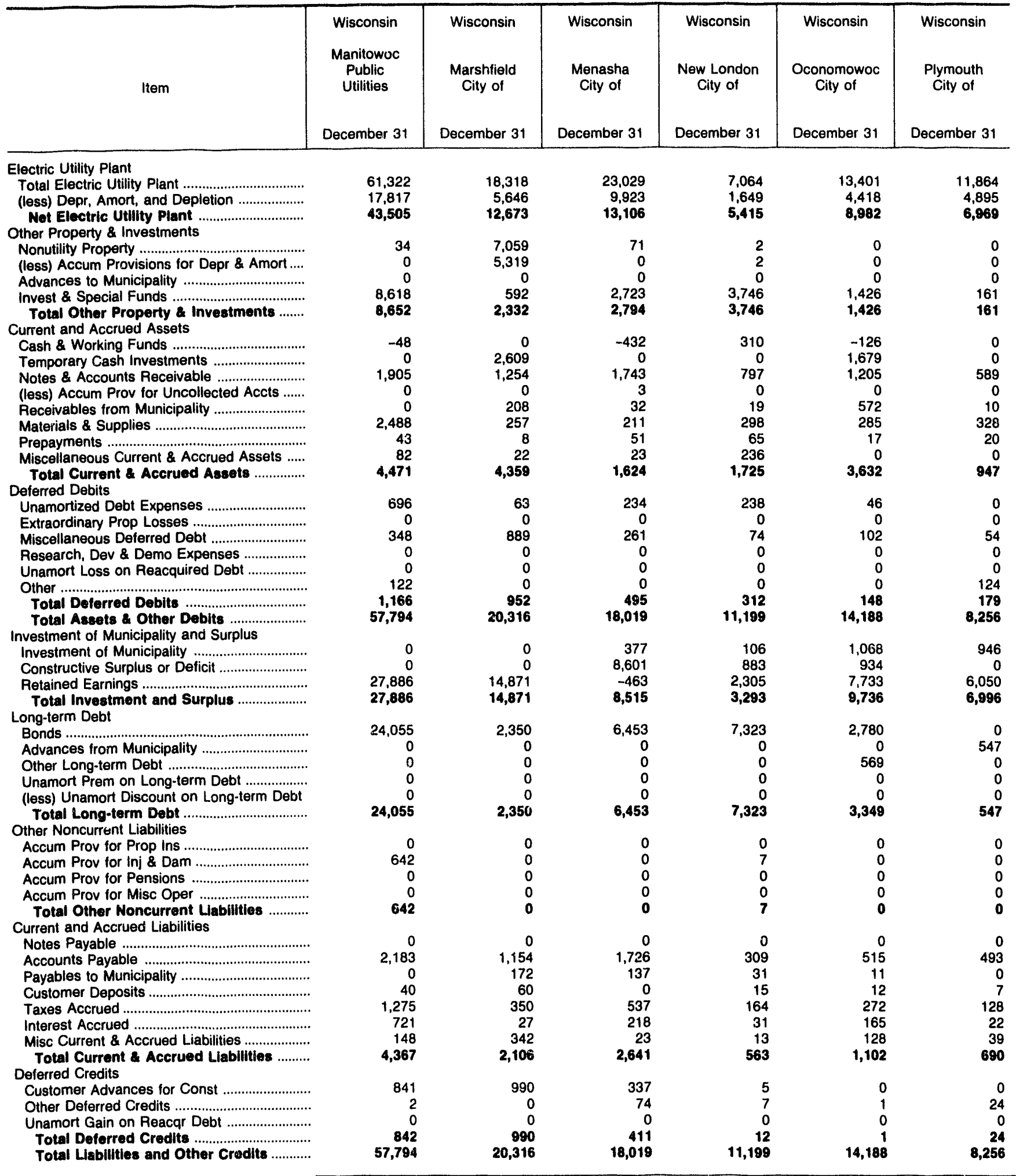

Note: Totals may not equal sum of components because of independent rounding.

Source: Energy Information Administration, Form EIA-412, "Annual Report of Public Electric Utilities." 
Table 37. Balance Sheet by Major Publicly Owned Electric Utility Within State at End of Period, 1991 (Continued) (Thousand Dollars)

\begin{tabular}{|c|c|c|c|c|c|c|}
\hline Item & $\begin{array}{c}\text { Wisconsin } \\
\text { Reedsburg } \\
\text { Utility Comm } \\
\text { December } 31\end{array}$ & $\begin{array}{c}\text { Wisconsin } \\
\text { Shawano } \\
\text { Municipal } \\
\text { Utilities } \\
\text { December } 31\end{array}$ & $\begin{array}{c}\text { Wisconsin } \\
\text { Sheboygan } \\
\text { Falls } \\
\text { City of } \\
\text { December } 31\end{array}$ & $\begin{array}{c}\text { Wisconsin } \\
\text { Sturgeon Bay } \\
\text { Combined } \\
\text { Utils }\end{array}$ & $\begin{array}{l}\text { Wisconsin } \\
\text { Wisconsin } \\
\text { Public } \\
\text { Power } \\
\text { Inc Sys } \\
\text { June } 30\end{array}$ & $\begin{array}{l}\text { Wisconsin } \\
\text { Wisconsin } \\
\text { Rapids W W } \\
\& \text { L } \\
\text { Comm } \\
\text { December } 31\end{array}$ \\
\hline 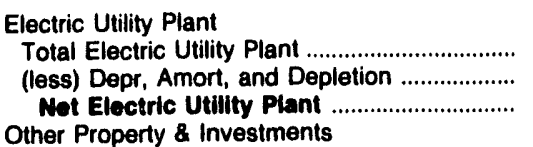 & $\begin{array}{r}10,936 \\
4,321 \\
6,615\end{array}$ & $\begin{array}{l}7,615 \\
2,299 \\
5,316\end{array}$ & $\begin{array}{l}6,937 \\
2,507 \\
4,430\end{array}$ & $\begin{array}{r}15,040 \\
3,870 \\
11,170\end{array}$ & $\begin{array}{r}110,885 \\
24,303 \\
88,582\end{array}$ & $\begin{array}{r}15,239 \\
587 \\
14,652\end{array}$ \\
\hline 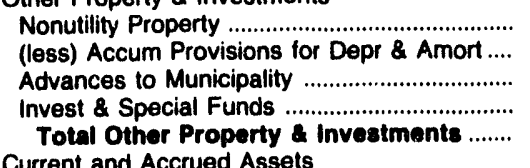 & $\begin{array}{r}0 \\
0 \\
0 \\
404 \\
404\end{array}$ & $\begin{array}{r}5,664 \\
12 \\
0 \\
513 \\
6,165\end{array}$ & $\begin{array}{r}0 \\
0 \\
0 \\
608 \\
608\end{array}$ & $\begin{array}{r}0 \\
0 \\
0 \\
1,567 \\
1,567\end{array}$ & $\begin{array}{r}0 \\
0 \\
0 \\
11,685 \\
11,685\end{array}$ & $\begin{array}{r}0 \\
0 \\
0 \\
1,680 \\
1,680\end{array}$ \\
\hline 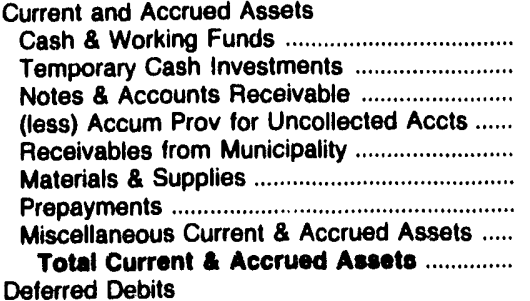 & $\begin{array}{r}699 \\
0 \\
734 \\
0 \\
579 \\
263 \\
0 \\
0 \\
2,276\end{array}$ & $\begin{array}{r}1 \\
1,249 \\
943 \\
0 \\
10 \\
294 \\
111 \\
0 \\
2,607\end{array}$ & $\begin{array}{r}432 \\
504 \\
862 \\
92 \\
40 \\
228 \\
251 \\
185 \\
2,410\end{array}$ & $\begin{array}{r}193 \\
0 \\
910 \\
12 \\
26 \\
523 \\
44 \\
30 \\
1,715\end{array}$ & $\begin{array}{r}16,122 \\
637 \\
8,643 \\
0 \\
0 \\
88 \\
188 \\
23 \\
25,701\end{array}$ & $\begin{array}{r}300 \\
521 \\
836 \\
0 \\
257 \\
449 \\
86 \\
4 \\
2,452\end{array}$ \\
\hline 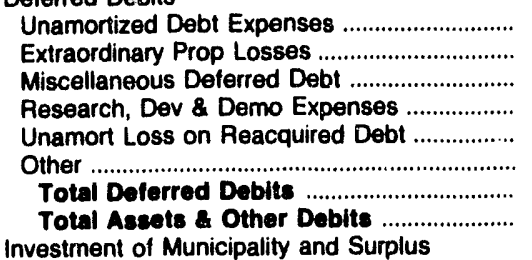 & $\begin{array}{r}64 \\
0 \\
7 \\
0 \\
0 \\
0 \\
71 \\
9,366\end{array}$ & $\begin{array}{r}39 \\
0 \\
0 \\
0 \\
0 \\
224 \\
263 \\
14,352\end{array}$ & $\begin{array}{r}13 \\
0 \\
31 \\
0 \\
0 \\
0 \\
74 \\
7,491\end{array}$ & $\begin{array}{r}239 \\
0 \\
16 \\
0 \\
0 \\
0 \\
255 \\
14,707\end{array}$ & $\begin{array}{r}3,083 \\
0 \\
995 \\
0 \\
0 \\
2,364 \\
6,441 \\
130,410\end{array}$ & $\begin{array}{r}19 \\
0 \\
42 \\
0 \\
0 \\
0 \\
62 \\
18,846\end{array}$ \\
\hline 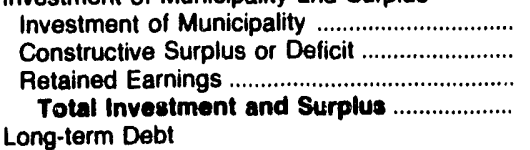 & $\begin{array}{r}879 \\
1,218 \\
4,167 \\
6,264\end{array}$ & $\begin{array}{r}1,331 \\
0 \\
5,919 \\
7,250\end{array}$ & $\begin{array}{r}250 \\
339 \\
4,915 \\
5,504\end{array}$ & $\begin{array}{r}26 \\
0 \\
5,512 \\
5,538\end{array}$ & $\begin{array}{r}0 \\
0 \\
3,879 \\
3,879\end{array}$ & $\begin{array}{r}738 \\
0 \\
11,150 \\
11,889\end{array}$ \\
\hline 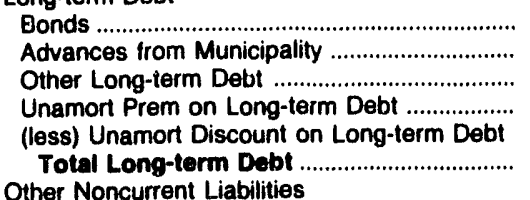 & $\begin{array}{r}0 \\
0 \\
1,915 \\
0 \\
0 \\
1,815\end{array}$ & $\begin{array}{r}2,625 \\
1,516 \\
0 \\
0 \\
0 \\
4,141\end{array}$ & $\begin{array}{r}0 \\
0 \\
1,120 \\
0 \\
0 \\
1,120\end{array}$ & $\begin{array}{r}6,825 \\
0 \\
0 \\
0 \\
0 \\
6,825\end{array}$ & $\begin{array}{r}111,930 \\
0 \\
0 \\
0 \\
1,975 \\
109,955\end{array}$ & $\begin{array}{r}753 \\
1,375 \\
0 \\
0 \\
0 \\
2,127\end{array}$ \\
\hline $\begin{array}{l}\text { Other Noncurrent Liabilities } \\
\text { Accum Prov for Prop Ins ................................... } \\
\text { Accum Prov for Inj \& Dam ............................. } \\
\text { Accum Prov for Pensions .............................. } \\
\text { Accum Prov for Misc Oper ............................. } \\
\text { Total Other Noncurrent Liabilities } \\
\text { Current and Accrued Liabilities }\end{array}$ & $\begin{array}{r}75 \\
0 \\
0 \\
24 \\
99\end{array}$ & $\begin{array}{l}0 \\
0 \\
0 \\
0 \\
0\end{array}$ & $\begin{array}{l}0 \\
0 \\
0 \\
0 \\
0\end{array}$ & $\begin{array}{r}0 \\
0 \\
33 \\
0 \\
32\end{array}$ & $\begin{array}{l}0 \\
0 \\
0 \\
0 \\
0\end{array}$ & $\begin{array}{l}0 \\
0 \\
0 \\
0 \\
0\end{array}$ \\
\hline 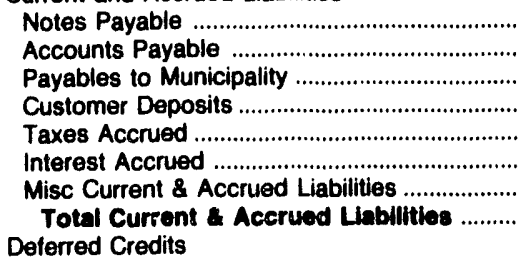 & $\begin{array}{r}50 \\
633 \\
147 \\
7 \\
213 \\
20 \\
17 \\
1,088\end{array}$ & $\begin{array}{r}0 \\
655 \\
0 \\
37 \\
218 \\
50 \\
22 \\
881\end{array}$ & $\begin{array}{r}0 \\
652 \\
40 \\
3 \\
89 \\
9 \\
53 \\
848\end{array}$ & $\begin{array}{r}0 \\
500 \\
0 \\
34 \\
312 \\
253 \\
67 \\
1,166\end{array}$ & $\begin{array}{r}0 \\
9,959 \\
0 \\
0 \\
1,293 \\
4,119 \\
1,205 \\
16,576\end{array}$ & $\begin{array}{r}0 \\
806 \\
71 \\
19 \\
488 \\
46 \\
19 \\
1,449\end{array}$ \\
\hline 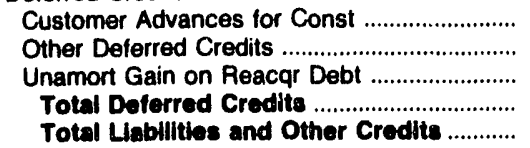 & $\begin{array}{r}0 \\
0 \\
0 \\
0 \\
9,366\end{array}$ & $\begin{array}{r}1,944 \\
35 \\
0 \\
1,979 \\
14,362\end{array}$ & $\begin{array}{r}12 \\
10 \\
0 \\
22 \\
7,491\end{array}$ & $\begin{array}{r}6 \\
113 \\
1,027 \\
1,146 \\
14,707\end{array}$ & $\begin{array}{r}0 \\
0 \\
0 \\
0 \\
130,410\end{array}$ & $\begin{array}{r}4 \\
3,377 \\
0 \\
3,381 \\
18,846\end{array}$ \\
\hline
\end{tabular}

Note: Totals may not equal sum of components because of independent rounding

Source: Energy Information Administration, Form ElA-412, "Annual Report of Public Electric Utilities." 


\section{Table 37. Balance Sheet by Major Publicly Owned Electric Utility Within State at End of Period, 1991 (Continued)}

(Thousand Dollars)

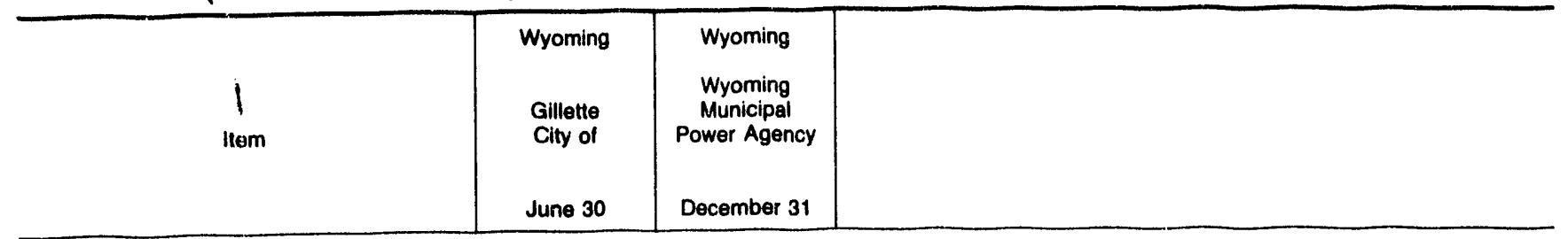

Electric Utility Plant

Total Electric Utility Plant

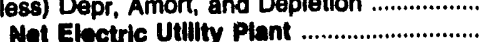

Other Property \& Investments

Nonutility Property ............................................

(less) Accum Provisions for Depr \& Amort ...

Advances to Municipality

Invest \& Special Funds .......................................

Total Other Property \& Investment .......

Current and Accrued Assets

Cash \& Working Funds ...

Temporary Cagh Investments

Notes \& Accounts Receivable .......................

(les8) Accum Prov for Uncollected Accts ......

Receivables from Municipality

Materials \& Supplies .

Prepayments ......................................................

Miscellaneous Current \& Accrued Assets ....

Total Current a Accrued Aseats

Deferred Debits

Unamortized Debt Expenses

Extraordinary Prop Losses .

.

Research, Dev \& Demo Expenses.....

Unamort Loss on Reacquired Debt

Other

Total Deferred Debits

Total Aseots \& Other Doblts

December 31

Investment of Municipality and Surplus

Investment of Municipality

Constructive Surplus or Deticit ......

Retained Earnings ............................................

Total Investment and Surplus ...................

Long-term Debt

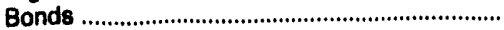

Advances trom Municipality

Other Long-term Debt

Unamort Prem on Long-term Debt ..........

(less) Unamort Discount on Long-term Debt

Total Long-term Debt

Other Noncurrent Liabilities

Accum Prov for Prop Ins.

Accum Prov for Inj \& Dam

Accum Prov for Pensions

Accum Prov for Misc Oper

Totel Other Moncurrent Llabilltios

Current and Accrued Liabilities

Notes Payable

Accounte Paygble

Payables to Municipality

Customer Deposits .

Taxes Accrued

Interest Accrued ...

Misc Current \& Accrued Liabilities ...................

Total Current a Accrued Liablilties ..........

Deferred Credits

Customer Advances for Const ..........................

Other Deferred Credits .................

$16,678 \quad 21,912$

$6,487 \quad 5,439$

$10,191 \quad 16,473$

Unamort Gain on Reacqr Debt

Total Deterred Credits .u.

Totel Labillties and Other Credits ...............

$\begin{array}{rr}0 & \\ 0 & \\ 0 & \\ 0 & 4,91 \\ 0 & 4,911 \\ 0 & 350 \\ 2,270 & 2,30 \\ 847 & 754 \\ 81 & \\ 0 & \\ 0 & 844 \\ 0 & 11 \\ 0 & 121 \\ 3,036 & 4,38 \\ 203 & 451 \\ 0 & \\ 0 & \\ 0 & \\ 0 & \\ 0 & 53 \\ 203 & 983 \\ 13,429 & 26,752 \\ & \end{array}$

$\begin{array}{rr}0 & \\ 0 & \\ 6,883 & 6,29 \\ 6,883 & 6,295\end{array}$

$5,560 \quad 19,000$

$\begin{array}{ll}0 & 0 \\ 0 & 0 \\ 0 & 0 \\ 0 & 0\end{array}$

5,560

19,000

Note: Totals may not equal sum of components because of independent rounding

Source: Energy Information Administration, Form EIA-412, "Annual Report of Public Electric Utilities." 
Table 38. Electric Operation and Maintenance Expenses by Major Publicly Owned Electric Utillty Within State, 1991

(Thousand Dollars)

\begin{tabular}{|c|c|c|c|c|c|c|}
\hline Item & $\begin{array}{l}\text { Alabama } \\
\text { Alabama } \\
\text { Municipal } \\
\text { Elec Auth } \\
\text { December } 31\end{array}$ & $\begin{array}{l}\text { Alabama } \\
\text { Albertville } \\
\text { Municipal } \\
\text { Utils Bd } \\
\text { June } 30\end{array}$ & $\begin{array}{l}\text { Alabama } \\
\text { Andalusia } \\
\text { City of } \\
\text { September } 30\end{array}$ & $\begin{array}{l}\text { Alabama } \\
\text { Athens } \\
\text { City of } \\
\text { December } 31\end{array}$ & $\begin{array}{l}\text { Alabama } \\
\text { Bessemer } \\
\text { City of } \\
\text { June } 30\end{array}$ & $\begin{array}{l}\text { Alabama } \\
\text { Cullman } \\
\text { Power Board } \\
\text { June } 30\end{array}$ \\
\hline 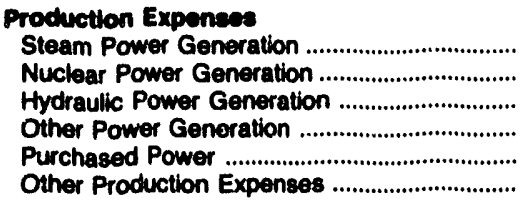 & $\begin{array}{r}0 \\
0 \\
0 \\
0 \\
74,039 \\
0\end{array}$ & $\begin{array}{r}0 \\
0 \\
0 \\
0 \\
16,306 \\
0\end{array}$ & $\begin{array}{r}0 \\
0 \\
0 \\
0 \\
9,380 \\
0\end{array}$ & $\begin{array}{r}0 \\
0 \\
0 \\
0 \\
29,339 \\
0\end{array}$ & $\begin{array}{r}0 \\
0 \\
0 \\
0 \\
13,543 \\
0\end{array}$ & $\begin{array}{r}0 \\
0 \\
0 \\
0 \\
13,758 \\
0\end{array}$ \\
\hline Total Production Expenses ............................. & 74,080 & 18,306 & 9,300 & 29,339 & 13,543 & 13,768 \\
\hline 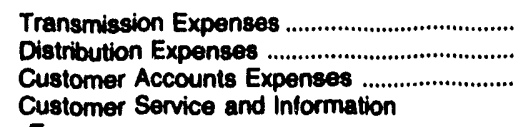 & $\begin{array}{l}\mathbf{0} \\
\mathbf{0} \\
\mathbf{0}\end{array}$ & $\begin{array}{r}0 \\
673 \\
222\end{array}$ & $\begin{array}{r}0 \\
83 \\
32\end{array}$ & $\begin{array}{r}193 \\
1,464 \\
514\end{array}$ & $\begin{array}{r}0 \\
608 \\
414\end{array}$ & $\begin{array}{r}0 \\
747 \\
259\end{array}$ \\
\hline 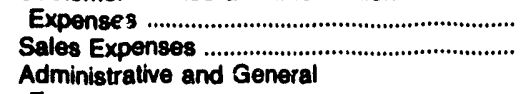 & $\begin{array}{l}0 \\
0\end{array}$ & $\begin{array}{r}22 \\
8\end{array}$ & $\begin{array}{r}35 \\
0\end{array}$ & $\begin{array}{l}30 \\
26\end{array}$ & $\begin{array}{r}15 \\
0\end{array}$ & $\begin{array}{r}23 \\
8\end{array}$ \\
\hline 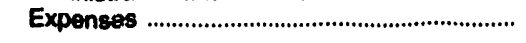 & 370 & 371 & 614 & 648 & 860 & 547 \\
\hline $\begin{array}{l}\text { Total Electric Operation and } \\
\text { Melntenance Expenses }\end{array}$ & 74,408 & 17,602 & 10,154 & 32,214 & 15,441 & 15,343 \\
\hline
\end{tabular}

\begin{tabular}{|c|c|c|c|c|c|c|}
\hline Item & $\begin{array}{l}\text { Alabama } \\
\text { Decatur } \\
\text { City of } \\
\text { June } 30\end{array}$ & $\begin{array}{l}\text { Alabama } \\
\text { Dothan } \\
\text { City of } \\
\text { September } 30\end{array}$ & $\begin{array}{l}\text { Alabama } \\
\text { Florence } \\
\text { City of } \\
\text { June } 30\end{array}$ & $\begin{array}{c}\text { Alabama } \\
\text { Foley } \\
\text { City of } \\
\text { (Riviera Utils) } \\
\text { December } 31\end{array}$ & $\begin{array}{c}\text { Alabama } \\
\text { Fort Payne } \\
\text { linprovement } \\
\text { Auth } \\
\text { June } 30\end{array}$ & $\begin{array}{l}\text { Alabama } \\
\text { Guntersville } \\
\text { Electric } \\
\text { Board } \\
\text { June } 30\end{array}$ \\
\hline 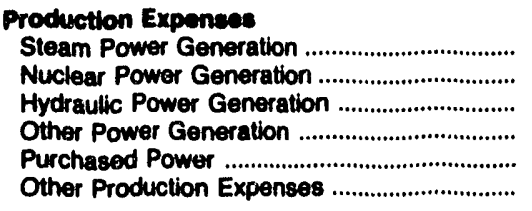 & $\begin{array}{r}0 \\
0 \\
0 \\
0 \\
53,517 \\
0\end{array}$ & $\begin{array}{r}0 \\
0 \\
0 \\
0 \\
37,561 \\
0\end{array}$ & $\begin{array}{r}0 \\
0 \\
0 \\
0 \\
44,138 \\
0\end{array}$ & $\begin{array}{r}0 \\
0 \\
0 \\
0 \\
18,826 \\
0\end{array}$ & $\begin{array}{r}0 \\
0 \\
0 \\
0 \\
12,757 \\
0\end{array}$ & $\begin{array}{r}0 \\
0 \\
0 \\
0 \\
8,384 \\
0\end{array}$ \\
\hline Total Production Expensese .......................... & 53,517 & 37,681 & 4,130 & 18,023 & 12,757 & 9,394 \\
\hline 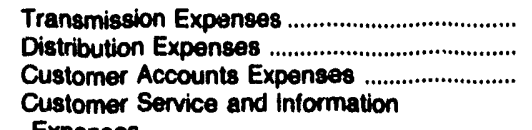 & $\begin{array}{r}0 \\
1,536 \\
430\end{array}$ & $\begin{array}{r}0 \\
2,027 \\
0\end{array}$ & $\begin{array}{r}388 \\
2,363 \\
695\end{array}$ & $\begin{array}{l}248 \\
867 \\
420\end{array}$ & $\begin{array}{r}0 \\
527 \\
202\end{array}$ & $\begin{array}{r}0 \\
488 \\
184\end{array}$ \\
\hline 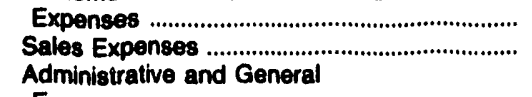 & $\begin{array}{l}25 \\
23\end{array}$ & $\begin{array}{l}0 \\
0\end{array}$ & $\begin{array}{r}123 \\
83\end{array}$ & $\begin{array}{r}0 \\
58\end{array}$ & $\begin{array}{l}11 \\
25\end{array}$ & $\begin{array}{l}9 \\
7\end{array}$ \\
\hline 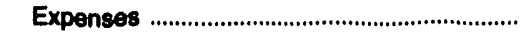 & 711 & 725 & 2,280 & 1,387 & 370 & 305 \\
\hline 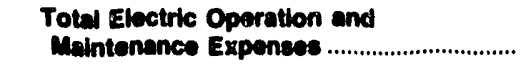 & 56,242 & 40,312 & 50,080 & 21,724 & 13,003 & 10,397 \\
\hline
\end{tabular}

Note: Totals may not equal sum of components because of independent rounding.

Source: Energy Information Administration, Form EIA-412, "Annual Report of Public Electric Utilities." 
Table 38. Electric Operation and Maintenance Expenses by Major Publicly Owned Electric Utility Within State, 1991 (Continued) (Thousand Dollars)

\begin{tabular}{c|c|c|c|c|c|c}
\hline & Alabama & Alabama & Alabama & Alabama & Alabama \\
Item & $\begin{array}{c}\text { Muntsville } \\
\text { City of }\end{array}$ & $\begin{array}{c}\text { Muscle } \\
\text { Shoals } \\
\text { City of }\end{array}$ & $\begin{array}{c}\text { Opelika } \\
\text { City of }\end{array}$ & $\begin{array}{c}\text { Scottsboro } \\
\text { City of }\end{array}$ & $\begin{array}{c}\text { Sheffield } \\
\text { Utilities }\end{array}$ & $\begin{array}{c}\text { Sylacauga } \\
\text { Utilities } \\
\text { Board }\end{array}$ \\
September 30 & June 30 & September 30 & June 30 & June 30 & September 30 \\
\hline
\end{tabular}

\section{Production Expenses}

Steam Power Generation

Nuclear Power Generation

Hydraulic Power Generation

Other Power Generation

Purchased Power

Other Production Expenses

Total Production Expenses

Transmission Expenses

Distribution Expenses ..........................................

Customer Accounts Expenses

Customer Service and information

Expenses .................................................................

Sales Expenses .................................................

Administrative and General

Expenses

Total Electric Operation and

Maintenance Expenses

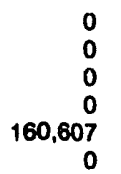

0

8,712

180,607

0
4,218

4,218
1,844

0

2,697

169,368
0
0

0

0
0
0
0

13,083
0

13,003

0

422

101

41
0

336

9,612

0
0
0
0
13,260
0

0
0

0
18,471

13,280

18,471

$\begin{array}{rrrr}0 & 0 & 38 & 0\end{array}$

$\begin{array}{rrrr}064 & 0 & 38 & 0 \\ 0 & 788 & 1,568 & 433\end{array}$

$254 \quad 433 \quad 122$

$21 \quad 25 \quad 16$

$401 \quad 389$

$\begin{array}{llll}749 & 401 & 1,007 & 389\end{array}$

14,735

21,581

7,347

\begin{tabular}{|c|c|c|c|c|c|c|}
\hline Item & $\begin{array}{c}\text { Alabama } \\
\text { Troy } \\
\text { City of } \\
\text { September } 30\end{array}$ & $\begin{array}{c}\text { Alabama } \\
\text { Tuskegee } \\
\text { City of } \\
\text { September } 30\end{array}$ & $\begin{array}{l}\text { Alaska } \\
\text { Alaska } \\
\text { Energy } \\
\text { Authority } \\
\text { June } 30\end{array}$ & $\begin{array}{c}\text { Alaska } \\
\text { Anchorage } \\
\text { City of } \\
\text { December } 31\end{array}$ & $\begin{array}{c}\text { Alaska } \\
\text { Fairbanks } \\
\text { City of } \\
\text { December } 31\end{array}$ & $\begin{array}{l}\text { Alaska } \\
\text { Ketchikan } \\
\text { City of } \\
\text { December } 31\end{array}$ \\
\hline 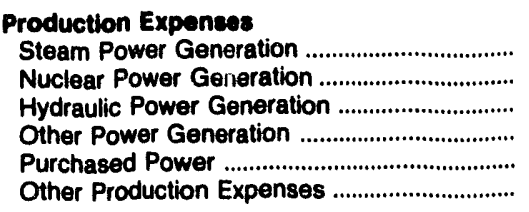 & $\begin{array}{r}0 \\
0 \\
0 \\
0 \\
7,480 \\
0\end{array}$ & $\begin{array}{r}0 \\
0 \\
0 \\
0 \\
5,894 \\
0\end{array}$ & $\begin{array}{r}0 \\
0 \\
2,812 \\
0 \\
0 \\
0\end{array}$ & $\begin{array}{r}1,309 \\
0 \\
0 \\
25,242 \\
3,733 \\
515\end{array}$ & $\begin{array}{r}8,637 \\
0 \\
0 \\
0 \\
1,463 \\
0\end{array}$ & $\begin{array}{r}0 \\
0 \\
1,531 \\
371 \\
3,902 \\
0\end{array}$ \\
\hline Total Production Expenses .......................... & 7,480 & 5,894 & 2,812 & 30,798 & 10,100 & 5,805 \\
\hline 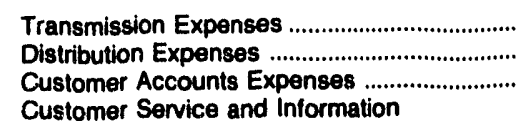 & $\begin{array}{r}0 \\
138 \\
53\end{array}$ & $\begin{array}{r}0 \\
653 \\
228\end{array}$ & $\begin{array}{l}0 \\
0 \\
0\end{array}$ & $\begin{array}{r}288 \\
5,064 \\
2,897\end{array}$ & $\begin{array}{r}0 \\
503 \\
0\end{array}$ & $\begin{array}{r}19 \\
1,899 \\
0\end{array}$ \\
\hline 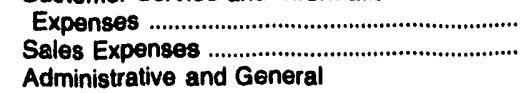 & $\begin{array}{r}457 \\
0\end{array}$ & $\begin{array}{l}\mathbf{0} \\
\mathbf{0}\end{array}$ & $\begin{array}{l}0 \\
0\end{array}$ & $\begin{array}{r}140 \\
5\end{array}$ & $\begin{array}{l}0 \\
0\end{array}$ & $\begin{array}{r}163 \\
0\end{array}$ \\
\hline Expenses & 260 & 320 & 895 & 3,747 & 1,243 & 1,580 \\
\hline $\begin{array}{l}\text { Total Electric Operation and } \\
\text { Malntenance Expenses ............................... }\end{array}$ & 8,388 & 7,094 & 3,807 & 43,039 & 11,846 & 9,486 \\
\hline
\end{tabular}

Note: Totals may not equal sum of components because of independent rounding.

Source: Energy Information Administration, Form ElA-412, "Annual Report of Public Electric Utilities." 
Table 38. Electric Operation and Maintenance Expenses by Major Publicly Owned Electric Utility Within State, 1991 (Continued) (Thousand Dollars)

\begin{tabular}{|c|c|c|c|c|c|c|}
\hline Item & $\begin{array}{c}\text { Arizona } \\
\text { Arizona } \\
\text { Power } \\
\text { Authority } \\
\\
\text { June } 30\end{array}$ & $\begin{array}{l}\text { Arizona } \\
\text { Mesa } \\
\text { City of } \\
\text { June } 30\end{array}$ & $\begin{array}{c}\text { Arizona } \\
\text { Navajo } \\
\text { Tribal } \\
\text { Utility } \\
\text { Auth } \\
\text { December } 31\end{array}$ & $\begin{array}{l}\text { Arizona } \\
\text { Salt River } \\
\text { Proj Ag } \\
\text { I \& P Dist } \\
\text { April } 30\end{array}$ & $\begin{array}{l}\text { Arkansas } \\
\text { Benton } \\
\text { City of } \\
\text { December } 31\end{array}$ & $\begin{array}{c}\text { Arkansas } \\
\text { Bentonville } \\
\text { City of }\end{array}$ \\
\hline 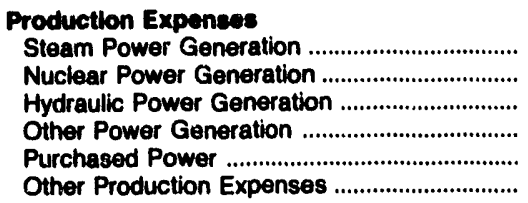 & $\begin{array}{r}0 \\
0 \\
0 \\
0 \\
11,596 \\
0\end{array}$ & $\begin{array}{r}0 \\
0 \\
0 \\
0 \\
11,849 \\
0\end{array}$ & $\begin{array}{r}0 \\
0 \\
0 \\
0 \\
18,144 \\
0\end{array}$ & $\begin{array}{r}255,633 \\
95,578 \\
6,148 \\
17,837 \\
38,428 \\
3,414\end{array}$ & $\begin{array}{r}0 \\
0 \\
0 \\
163 \\
7,276 \\
0\end{array}$ & $\begin{array}{r}0 \\
0 \\
0 \\
0 \\
6,065 \\
0\end{array}$ \\
\hline Total Production Expenses ............................. & 11,596 & 11,849 & 18,144 & 417,039 & 7,439 & 6,065 \\
\hline 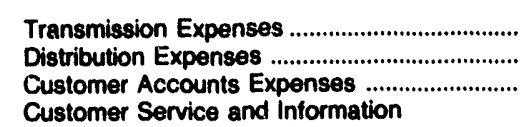 & $\begin{array}{r}2,809 \\
11 \\
0\end{array}$ & $\begin{array}{r}0 \\
2,518 \\
0\end{array}$ & $\begin{array}{r}570 \\
2,406 \\
1,462\end{array}$ & $\begin{array}{l}11,031 \\
32,131 \\
20,941\end{array}$ & $\begin{array}{r}0 \\
1,049 \\
0\end{array}$ & $\begin{array}{r}0 \\
160 \\
0\end{array}$ \\
\hline 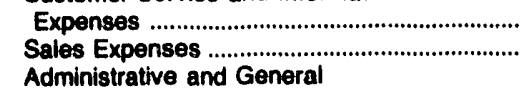 & $\begin{array}{l}0 \\
0\end{array}$ & $\begin{array}{l}472 \\
110\end{array}$ & $\begin{array}{l}0 \\
0\end{array}$ & $\begin{array}{l}4,599 \\
5,110\end{array}$ & $\begin{array}{r}0 \\
97\end{array}$ & $\begin{array}{l}0 \\
0\end{array}$ \\
\hline 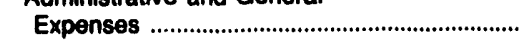 & 754 & 771 & 2,957 & 82,753 & 461 & 412 \\
\hline $\begin{array}{l}\text { Total Electric Operation and } \\
\text { Malntenance Expenses ................................. }\end{array}$ & 15,170 & 15,719 & 25,541 & 573,604 & 9,046 & 6,636 \\
\hline
\end{tabular}

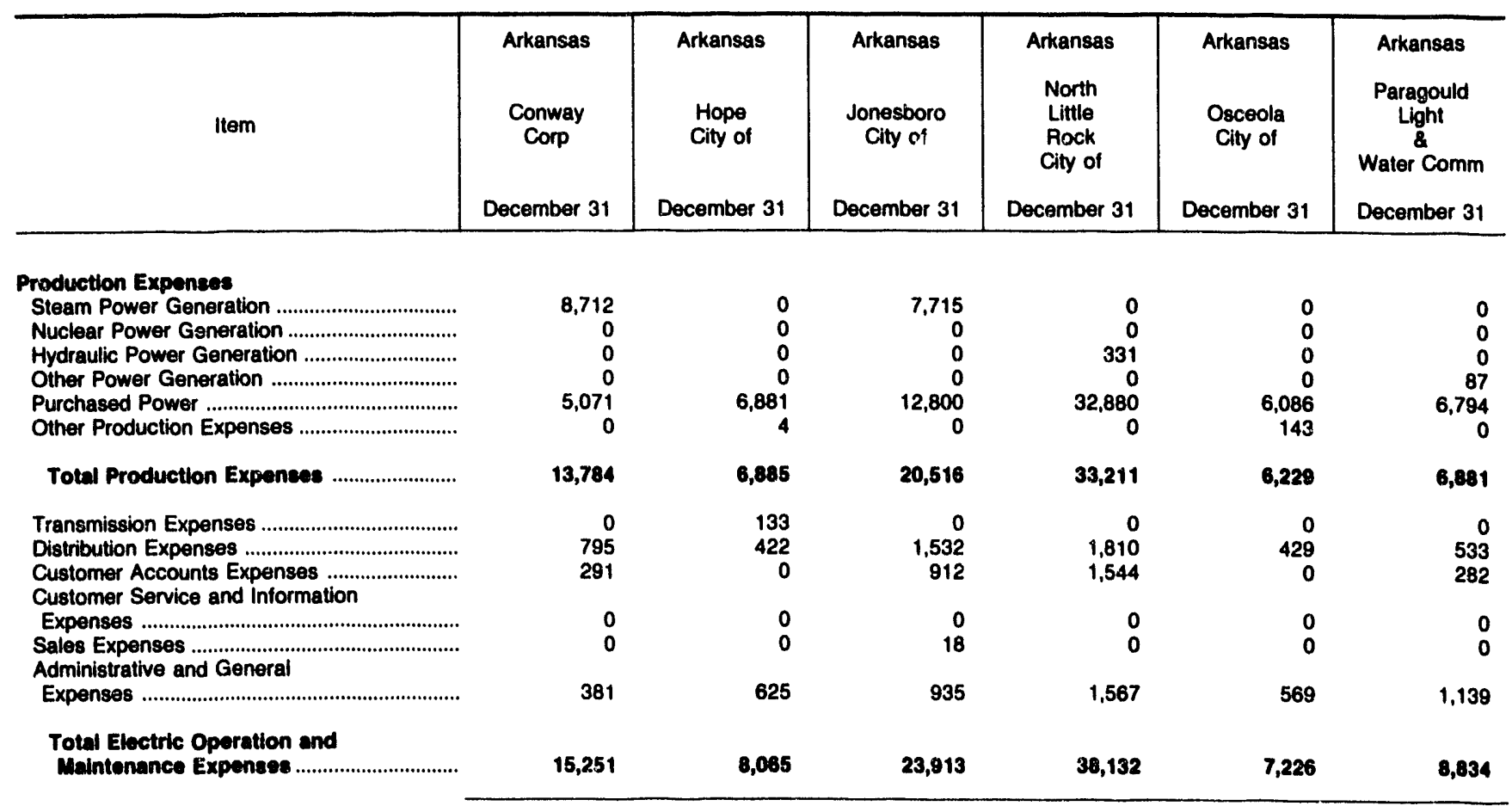

Note: Totals may not equal sum of components because of independent rounding.

Source: Energy Information Administration, Form EIA-412, "Annual Report of Public Electric Utilities." 
Table 38. Electric Operation and Maintenance Expenses by Major Publicly Owned Electric Utility Within State, 1991 (Continued) (Thousand Dollars)

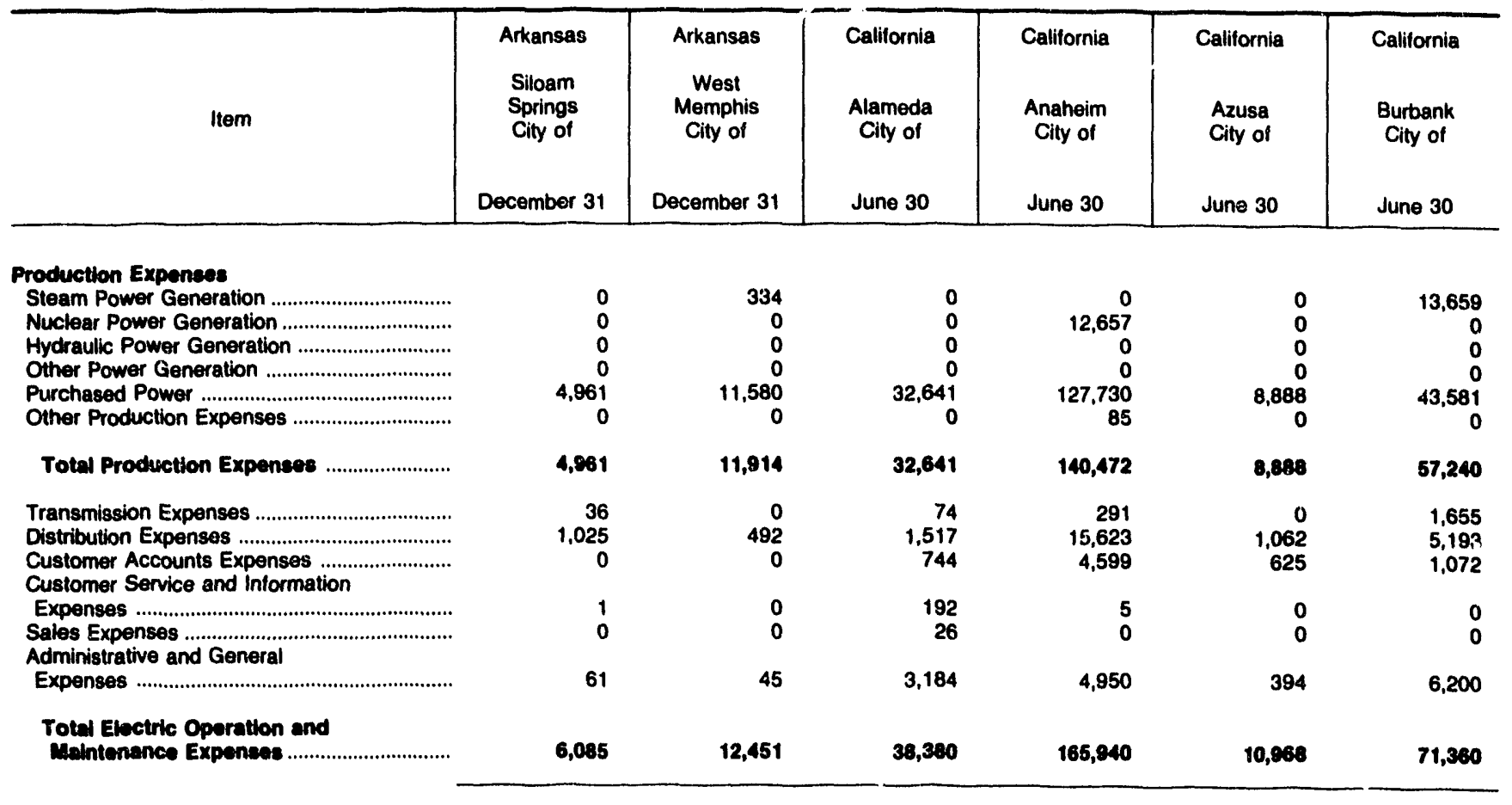

\begin{tabular}{|c|c|c|c|c|c|c|}
\hline llem & $\begin{array}{c}\text { California } \\
\text { California } \\
\text { Dept } \\
\text { Wtr } \\
\text { Resources } \\
\text { December } 31\end{array}$ & $\begin{array}{l}\text { California } \\
\text { Colton } \\
\text { City of } \\
\text { June } 30\end{array}$ & $\begin{array}{l}\text { California } \\
\text { Glendale } \\
\text { City of } \\
\text { June } 30\end{array}$ & $\begin{array}{c}\text { Calitornia } \\
\text { Imperial } \\
\text { Imigation } \\
\text { District } \\
\text { December } 31\end{array}$ & $\begin{array}{l}\text { California } \\
\text { Lodi } \\
\text { City of } \\
\text { June } 30\end{array}$ & $\begin{array}{l}\text { California } \\
\text { Los Angeles } \\
\text { City of } \\
\text { June } 30\end{array}$ \\
\hline 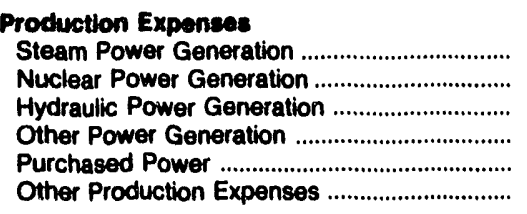 & $\begin{array}{r}20,806 \\
0 \\
9,466 \\
0 \\
35,650 \\
0\end{array}$ & $\begin{array}{r}0 \\
0 \\
0 \\
0 \\
11,484 \\
0\end{array}$ & $\begin{array}{r}9,163 \\
0 \\
0 \\
2,609 \\
33,060 \\
4,116\end{array}$ & $\begin{array}{r}14,092 \\
0 \\
2,090 \\
806 \\
61,052 \\
739\end{array}$ & $\begin{array}{r}0 \\
0 \\
0 \\
0 \\
23,731 \\
0\end{array}$ & $\begin{array}{r}285,055 \\
32,852 \\
21,155 \\
363 \\
664,389 \\
0\end{array}$ \\
\hline Total Production Expenses .......................... & 65,822 & 11,484 & 48,848 & 78,778 & 23,731 & $1,003,814$ \\
\hline 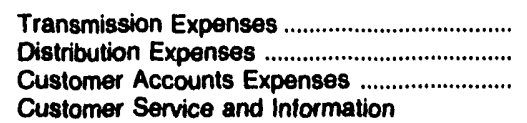 & $\begin{array}{l}0 \\
0 \\
0\end{array}$ & $\begin{array}{r}0 \\
529 \\
0\end{array}$ & $\begin{array}{r}657 \\
4,536 \\
2,539\end{array}$ & $\begin{array}{l}2,019 \\
7,182 \\
2,579\end{array}$ & $\begin{array}{r}0 \\
1,188 \\
1,345\end{array}$ & $\begin{array}{r}28,645 \\
141,692 \\
52,144\end{array}$ \\
\hline 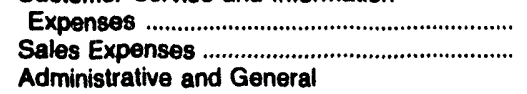 & $\begin{array}{l}0 \\
0\end{array}$ & $\begin{array}{l}0 \\
0\end{array}$ & $\begin{array}{l}0 \\
0\end{array}$ & $\begin{array}{l}0 \\
0\end{array}$ & $\begin{array}{l}0 \\
0\end{array}$ & $\begin{array}{r}13,845 \\
0\end{array}$ \\
\hline 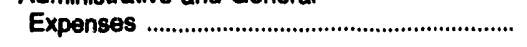 & 0 & 2,817 & 8,242 & 10,756 & 1,860 & 194,330 \\
\hline $\begin{array}{l}\text { Total Electric Operation and } \\
\text { Malntenance Expenses ................................... }\end{array}$ & 65,922 & 14,831 & 64,922 & 101,314 & 28,123 & $1,434,470$ \\
\hline
\end{tabular}

Note: Totals may not equal sum of components because of independent rounding.

Source: Energy Information Administration, Form EIA-412, "Annual Report of Public Electric Utilities." 
Table 38. Electric Operation and Maintenance Expenses by Major Publicly Owned Electric Utility Within State, 1991 (Continued) (Thousand Dollars)

\begin{tabular}{|c|c|c|c|c|c|c|}
\hline Item & $\begin{array}{l}\text { California } \\
\text { Metropolitan } \\
\text { Water } \\
\text { District } \\
\text { June } 30\end{array}$ & $\begin{array}{c}\text { California } \\
\text { Modesto } \\
\text { Irrigation } \\
\text { District } \\
\text { December } 31\end{array}$ & $\begin{array}{c}\text { California } \\
\text { MSR } \\
\text { Public } \\
\text { Power } \\
\text { Agency } \\
\text { December } 31\end{array}$ & $\begin{array}{c}\text { California } \\
\text { Norihern } \\
\text { California } \\
\text { Power Agny } \\
\text { June } 30\end{array}$ & $\begin{array}{c}\text { California } \\
\text { Oakdale \& } \\
\text { South } \\
\text { San Joaquin } \\
\text { Dacember } 31\end{array}$ & $\begin{array}{c}\text { California } \\
\text { Oroville } \\
\text { Wyandotte } \\
\text { Irrig Dist } \\
\text { December } 31\end{array}$ \\
\hline 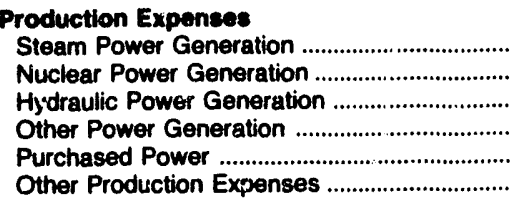 & $\begin{array}{r}0 \\
0 \\
1,909 \\
0 \\
13,137 \\
0\end{array}$ & $\begin{array}{r}0 \\
0 \\
862 \\
631 \\
65,914 \\
116\end{array}$ & $\begin{array}{r}19,627 \\
0 \\
0 \\
0 \\
0 \\
52\end{array}$ & $\begin{array}{r}58,960 \\
0 \\
1,836 \\
1,434 \\
7,498 \\
2,291\end{array}$ & $\begin{array}{r}0 \\
0 \\
745 \\
0 \\
0 \\
0\end{array}$ & $\begin{array}{r}0 \\
0 \\
8,425 \\
0 \\
0 \\
0\end{array}$ \\
\hline Total Production Expenses .......................... & 15,046 & 67,524 & 19,679 & 72,019 & 745 & 8,425 \\
\hline 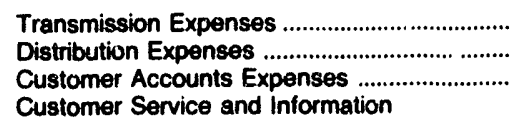 & $\begin{array}{l}0 \\
0 \\
0\end{array}$ & $\begin{array}{r}330 \\
6,066 \\
2,654\end{array}$ & $\begin{array}{r}219 \\
0 \\
0\end{array}$ & $\begin{array}{r}5,657 \\
0 \\
0\end{array}$ & $\begin{array}{l}0 \\
0 \\
0\end{array}$ & $\begin{array}{r}0 \\
2,184 \\
0\end{array}$ \\
\hline 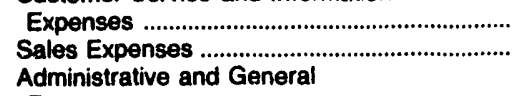 & $\begin{array}{l}0 \\
0\end{array}$ & $\begin{array}{r}1,093 \\
36\end{array}$ & $\begin{array}{l}0 \\
0\end{array}$ & $\begin{array}{l}0 \\
0\end{array}$ & $\begin{array}{l}0 \\
0\end{array}$ & $\begin{array}{l}0 \\
0\end{array}$ \\
\hline 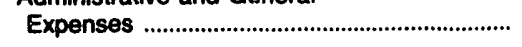 & 0 & 10,532 & -844 & 4,335 & 1,126 & 0 \\
\hline $\begin{array}{l}\text { Total Electric Operation and } \\
\text { Maintenance Expenses ................................ }\end{array}$ & 15,046 & 84,235 & 19,053 & 82,011 & 1,871 & 10,609 \\
\hline
\end{tabular}

\begin{tabular}{|c|c|c|c|c|c|c|}
\hline Item & $\begin{array}{l}\text { California } \\
\text { Palo Alto } \\
\text { City of } \\
\text { June } 30\end{array}$ & $\begin{array}{l}\text { California } \\
\text { Pasadena } \\
\text { City of } \\
\text { June } 30\end{array}$ & $\begin{array}{c}\text { California } \\
\text { Placer } \\
\text { County } \\
\text { Water } \\
\text { Agency } \\
\text { December } 31\end{array}$ & $\begin{array}{l}\text { California } \\
\text { Redding } \\
\text { City of } \\
\text { June } 30\end{array}$ & $\begin{array}{l}\text { California } \\
\text { Riverside } \\
\text { City of } \\
\text { June } 30\end{array}$ & $\begin{array}{l}\text { California } \\
\text { Roseville } \\
\text { City of } \\
\text { June } 30\end{array}$ \\
\hline 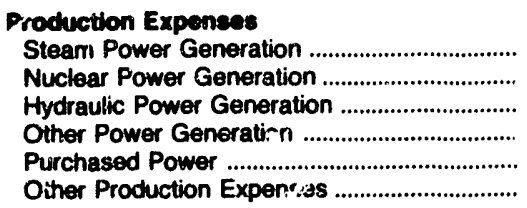 & $\begin{array}{r}0 \\
0 \\
0 \\
0 \\
31,484 \\
\vdots\end{array}$ & $\begin{array}{r}15,982 \\
0 \\
16 \\
0 \\
51,303 \\
526\end{array}$ & $\begin{array}{r}0 \\
0 \\
1,425 \\
0 \\
0 \\
0\end{array}$ & $\begin{array}{r}0 \\
0 \\
0 \\
0 \\
24,199 \\
0\end{array}$ & $\begin{array}{r}0 \\
7,347 \\
0 \\
0 \\
78,483 \\
1,021\end{array}$ & $\begin{array}{r}0 \\
0 \\
0 \\
0 \\
20,429 \\
608\end{array}$ \\
\hline Total Production Expenses ........................... & 31,464 & 67,827 & 1,425 & 24,199 & 86,851 & 21,038 \\
\hline 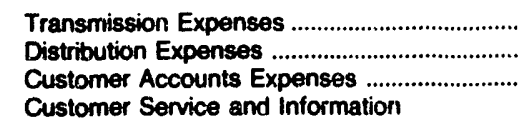 & $\begin{array}{l}0 \\
0 \\
0\end{array}$ & $\begin{array}{r}231 \\
3,912 \\
0\end{array}$ & $\begin{array}{r}53 \\
0 \\
0\end{array}$ & $\begin{array}{l}0 \\
0 \\
0\end{array}$ & $\begin{array}{r}14,587 \\
6,394 \\
2,691\end{array}$ & $\begin{array}{r}0 \\
5,043 \\
840\end{array}$ \\
\hline 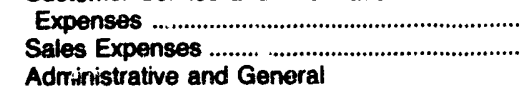 & $\begin{array}{r}0 \\
3,126\end{array}$ & $\begin{array}{r}1,129 \\
834\end{array}$ & $\begin{array}{l}0 \\
0\end{array}$ & $\begin{array}{r}1,007 \\
0\end{array}$ & $\begin{array}{r}572 \\
4\end{array}$ & $\begin{array}{l}0 \\
0\end{array}$ \\
\hline 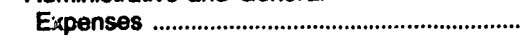 & 6,718 & 6,702 & 887 & 5,665 & 9,265 & 1,163 \\
\hline $\begin{array}{l}\text { Totel theiric Opertation and } \\
\text { Maintenance Expentes ............................... }\end{array}$ & 41,328 & 81,334 & 2,364 & 30,870 & 120,363 & 28,082 \\
\hline
\end{tabular}

Note: Totals may not equal sum of components because of independent rounding.

Source: Energy Information Administration, Form EIA-412, "Annun!? Report of Public Electric Utilities." 
Table 38. Electric Operation and Maintenance Expenses by Major Publicly Owned Electric Utility Within State, 1991 (Continued)

(Thousand Dollars)

\begin{tabular}{|c|c|c|c|c|c|c|}
\hline Item & $\begin{array}{l}\text { California } \\
\text { Sacramento } \\
\text { Municipal } \\
\text { Util Dist } \\
\text { December } 31\end{array}$ & $\begin{array}{c}\text { California } \\
\text { San Francisco } \\
\text { City } \\
8 \\
\text { County of } \\
\text { June } 30\end{array}$ & $\begin{array}{l}\text { California } \\
\text { Santa } \\
\text { Clara } \\
\text { City of } \\
\text { June } 30\end{array}$ & $\begin{array}{l}\text { California } \\
\text { Southern } \\
\text { California } \\
\text { P P } \\
\text { A } \\
\text { June } 30\end{array}$ & $\begin{array}{c}\text { California } \\
\text { Turiock } \\
\text { Irrigation } \\
\text { District } \\
\text { December } 31\end{array}$ & $\begin{array}{l}\text { California } \\
\text { Vernon } \\
\text { City of } \\
\text { June } 30\end{array}$ \\
\hline 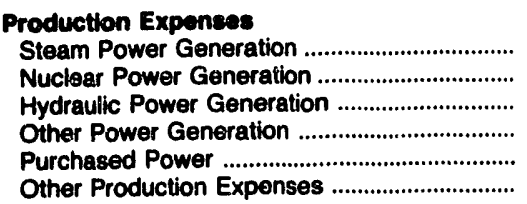 & $\begin{array}{r}17,244 \\
0 \\
6,329 \\
922 \\
316,915 \\
3,629\end{array}$ & $\begin{array}{r}0 \\
0 \\
3,037 \\
0 \\
24,980 \\
8,232\end{array}$ & $\begin{array}{r}0 \\
0 \\
66 \\
2,738 \\
114,037 \\
435\end{array}$ & $\begin{array}{r}0 \\
32,265 \\
0 \\
0 \\
1,395 \\
99\end{array}$ & $\begin{array}{r}0 \\
0 \\
5,368 \\
339 \\
43,959 \\
0\end{array}$ & $\begin{array}{r}1,142 \\
0 \\
0 \\
0 \\
39,669 \\
413\end{array}$ \\
\hline Total Production Expenses ............................ & 345,038 & $\mathbf{3 6 , 2 4 9}$ & 117,276 & 33,758 & 49,665 & 41,224 \\
\hline 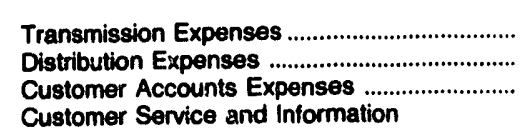 & $\begin{array}{l}10,489 \\
21,549 \\
20,865\end{array}$ & $\begin{array}{r}1,880 \\
0 \\
0\end{array}$ & $\begin{array}{r}78 \\
3,087 \\
6\end{array}$ & $\begin{array}{r}15,956 \\
0 \\
0\end{array}$ & $\begin{array}{r}948 \\
5,824 \\
0\end{array}$ & $\begin{array}{r}2,802 \\
3,289 \\
626\end{array}$ \\
\hline 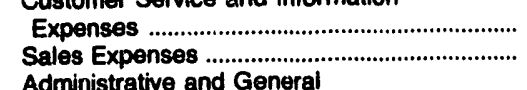 & $\begin{array}{r}5,127 \\
0\end{array}$ & $\begin{array}{l}0 \\
0\end{array}$ & $\begin{array}{r}0 \\
43\end{array}$ & $\begin{array}{l}0 \\
0\end{array}$ & $\begin{array}{l}0 \\
0\end{array}$ & $\begin{array}{r}317 \\
1,897\end{array}$ \\
\hline $\begin{array}{l}\text { Administrative and General } \\
\text { Expenses }\end{array}$ & 28,132 & 12,832 & 22,206 & 17,450 & 11,862 & 1,351 \\
\hline 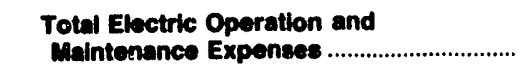 & 431,202 & 50,861 & 142,697 & 87,164 & 68,299 & 51,507 \\
\hline
\end{tabular}

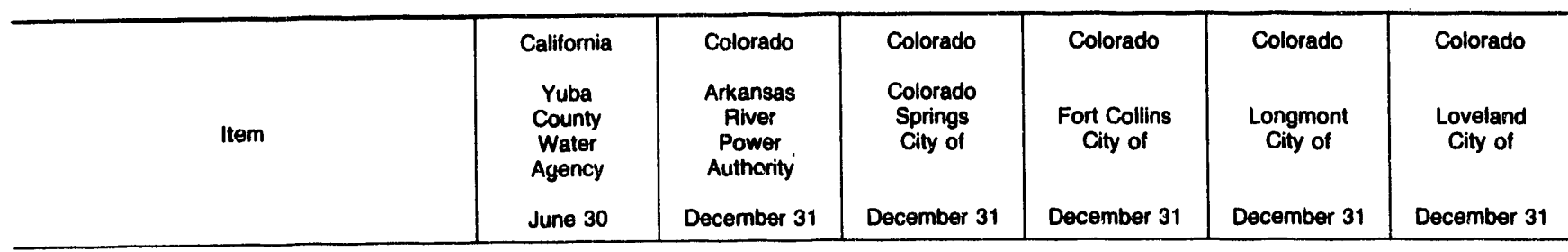

\section{Production Expenses}

Steam Power Generation

Nuclear Power Generation

Hydraulic Power Generation

Other Power Generation

Purchased Power .................................................

Other Production Expenses

Totel Production Expense:

Transmission Expenses

Distribution Expenses

Customer Accounts Expenses

Customer Service and Information

Expenses ....

Sales Expenses .......

Administrative and Genera

Expenses

Total Electric Operation and

Mnintenance Expentes

$\begin{array}{rr}0 & \\ 0 & \\ 2,543 & \\ 0 & \\ 0 & 7,78 \\ 0 & 940\end{array}$

2,543

8,720

$0 \quad 58,666$

$\begin{array}{rr}0 & 0 \\ 0 & 294\end{array}$

294
0

8,681

67,641

1,543

11,622
4,672

4,672

199
0

95,070

9,331
0
0
0
0
28,410
0

28,410

14,316

0
3,382

993

256

0

1,886

34,928

18,000

13,534

Nutc: Totals may not equa! sum of componen!s becelıse of independent rounding

Source: Energy Information Administration, Form ElA-412, "Annual Report of Public Electric Utilities." 


\section{Table 38. Electric Operation and Maintenance Expenses by Major Publicly Owned Electric Utility Within State, 1991 (Continued) (Thousand Dollars)}

\begin{tabular}{|c|c|c|c|c|c|c|}
\hline Item & $\begin{array}{c}\text { Colorado } \\
\text { Platte River } \\
\text { Power } \\
\text { Authority } \\
\text { December } 31\end{array}$ & $\begin{array}{l}\text { Connecticut } \\
\text { Connecticut } \\
\text { Mun } \\
\text { Elec } \\
\text { Engy Coop } \\
\text { December } 31\end{array}$ & $\begin{array}{l}\text { Connecticut } \\
\text { Groton } \\
\text { City of } \\
\text { June } 30\end{array}$ & $\begin{array}{l}\text { Connecticut } \\
\text { Norwich } \\
\text { City of } \\
\text { June } 30\end{array}$ & $\begin{array}{l}\text { Connecticut } \\
\text { Wallingford } \\
\text { Town of } \\
\text { June } 30\end{array}$ & $\begin{array}{l}\text { Delaware } \\
\text { Dover } \\
\text { City of } \\
\text { June } 30\end{array}$ \\
\hline 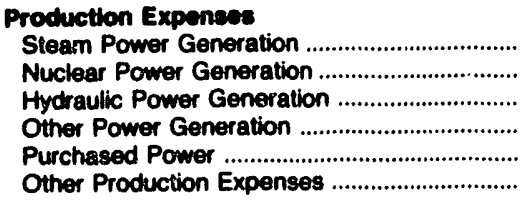 & $\begin{array}{r}47,017 \\
0 \\
0 \\
0 \\
12,148 \\
572\end{array}$ & $\begin{array}{r}0 \\
1,140 \\
0 \\
0 \\
45,836 \\
0\end{array}$ & $\begin{array}{r}0 \\
0 \\
0 \\
0 \\
34,273 \\
0\end{array}$ & $\begin{array}{r}0 \\
0 \\
292 \\
0 \\
15,424 \\
0\end{array}$ & $\begin{array}{r}928 \\
0 \\
0 \\
0 \\
30,550 \\
0\end{array}$ & $\begin{array}{r}19,614 \\
0 \\
0 \\
0 \\
4,609 \\
0\end{array}$ \\
\hline Totel Production Expennes ............................. & 58,737 & 46,076 & 34,273 & 15,718 & 31,478 & 24,223 \\
\hline 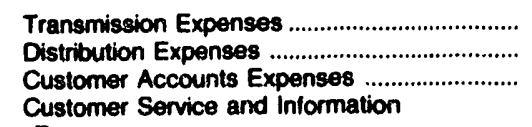 & $\begin{array}{r}2,016 \\
0 \\
0\end{array}$ & $\begin{array}{r}2,704 \\
0 \\
0\end{array}$ & $\begin{array}{r}59 \\
1,088 \\
439\end{array}$ & $\begin{array}{l}167 \\
711 \\
758\end{array}$ & $\begin{array}{r}24 \\
1.743 \\
945\end{array}$ & $\begin{array}{r}3,128 \\
0 \\
0\end{array}$ \\
\hline 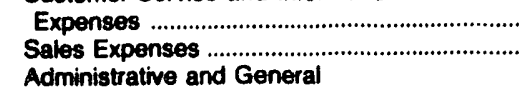 & $\begin{array}{l}0 \\
0\end{array}$ & $\begin{array}{l}0 \\
0\end{array}$ & $\begin{array}{l}0 \\
0\end{array}$ & $\begin{array}{l}2 \\
0\end{array}$ & $\begin{array}{r}39 \\
0\end{array}$ & $\begin{array}{l}0 \\
0\end{array}$ \\
\hline 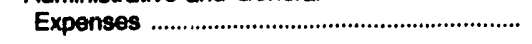 & 5,564 & 2,535 & 1,898 & 4,447 & 3,184 & 2,222 \\
\hline $\begin{array}{l}\text { Total Electric Operation and } \\
\text { Menintenance Expentes }\end{array}$ & 67,316 & 52,215 & 37,756 & 21,801 & 37,414 & 20,573 \\
\hline
\end{tabular}

\begin{tabular}{|c|c|c|c|c|c|c|}
\hline Item & $\begin{array}{l}\text { Delaware } \\
\text { Newark } \\
\text { City of } \\
\text { December } 31\end{array}$ & $\begin{array}{l}\text { Florida } \\
\text { Bantow } \\
\text { City of } \\
\text { September } 30\end{array}$ & $\begin{array}{c}\text { Florida } \\
\text { Florida } \\
\text { Municipal } \\
\text { Power Agency } \\
\text { September } 30\end{array}$ & $\begin{array}{l}\text { Florida } \\
\text { Fort Pierce } \\
\text { Utilities } \\
\text { Auth } \\
\text { September } 30\end{array}$ & $\begin{array}{l}\text { Florida } \\
\text { Gainesville } \\
\text { Regional } \\
\text { Utilities } \\
\text { September } 30\end{array}$ & $\begin{array}{l}\text { Florida } \\
\text { Homestead } \\
\text { City of } \\
\text { September } 30\end{array}$ \\
\hline 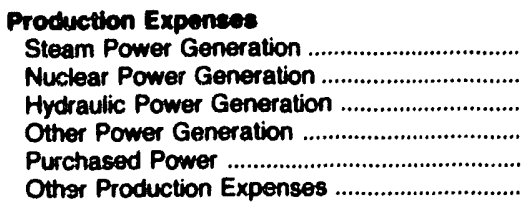 & $\begin{array}{r}0 \\
0 \\
0 \\
0 \\
13,140 \\
0\end{array}$ & $\begin{array}{r}0 \\
0 \\
0 \\
0 \\
11,413 \\
0\end{array}$ & $\begin{array}{r}10,889 \\
10,235 \\
0 \\
381 \\
64,450 \\
491\end{array}$ & $\begin{array}{r}10,929 \\
0 \\
0 \\
36 \\
14,051 \\
0\end{array}$ & $\begin{array}{r}47,765 \\
1,287 \\
0 \\
869 \\
2,473 \\
511\end{array}$ & $\begin{array}{r}0 \\
0 \\
0 \\
4,619 \\
9,465 \\
361\end{array}$ \\
\hline Totel Production Expenses ......................... & 13,140 & 11,413 & 86,447 & 25,016 & 52,004 & 14,445 \\
\hline 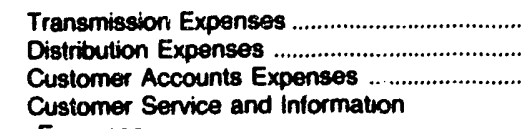 & $\begin{array}{r}0 \\
2,153 \\
0\end{array}$ & $\begin{array}{l}215 \\
935 \\
118\end{array}$ & $\begin{array}{r}9,157 \\
54 \\
0\end{array}$ & $\begin{array}{r}741 \\
1,329 \\
611\end{array}$ & $\begin{array}{r}633 \\
5,002 \\
1,837\end{array}$ & $\begin{array}{r}187 \\
1,646 \\
1,317\end{array}$ \\
\hline 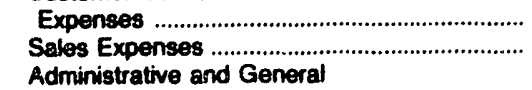 & $\begin{array}{l}0 \\
0\end{array}$ & $\begin{array}{l}0 \\
0\end{array}$ & $\begin{array}{l}0 \\
0\end{array}$ & $\begin{array}{l}0 \\
0\end{array}$ & $\begin{array}{r}27 \\
346\end{array}$ & $\begin{array}{l}0 \\
0\end{array}$ \\
\hline 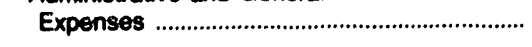 & 0 & 1,804 & 3,254 & 3,280 & 8,660 & 2,315 \\
\hline $\begin{array}{l}\text { Total Electric Operation end } \\
\text { Melntenance Expensea }\end{array}$ & 15,293 & 14,495 & 88,912 & 30,976 & 69,409 & 18,011 \\
\hline
\end{tabular}

Note: Totals may not equal sum of components because of independent rounding.

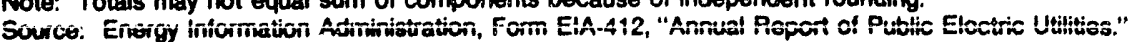


Table 38. Electric Operation and Maintenance Expenses by Major Publicly Owned Electric Utillty Within State, 1991 (Continued) (Thousand Dollars)

\begin{tabular}{|c|c|c|c|c|c|c|}
\hline Item & $\begin{array}{c}\text { Florida } \\
\text { Jacksonville } \\
\text { Beach } \\
\text { City of } \\
\text { September } 30\end{array}$ & $\begin{array}{c}\text { Florida } \\
\text { Jacksonville } \\
\text { Electric } \\
\text { Auth } \\
\text { September } 30\end{array}$ & $\begin{array}{l}\text { Florida } \\
\text { Key West } \\
\text { City of } \\
\text { September } 30\end{array}$ & $\begin{array}{c}\text { Florida } \\
\text { Kissimmee } \\
\text { Utility } \\
\text { Authority } \\
\text { September } 30\end{array}$ & $\begin{array}{c}\text { Florida } \\
\text { Lake Worth } \\
\text { City of } \\
\text { September } 30\end{array}$ & $\begin{array}{c}\text { Florida } \\
\text { Lakeland } \\
\text { City of } \\
\text { September } 30\end{array}$ \\
\hline 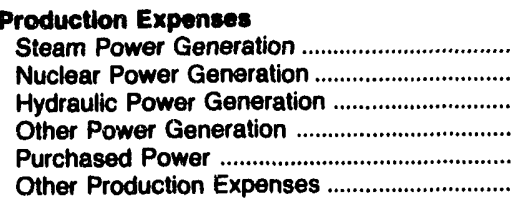 & $\begin{array}{r}0 \\
0 \\
0 \\
0 \\
24,598 \\
0\end{array}$ & $\begin{array}{r}257,087 \\
0 \\
0 \\
2,280 \\
102,791 \\
5\end{array}$ & $\begin{array}{r}8,484 \\
0 \\
0 \\
1,180 \\
15,762 \\
245\end{array}$ & $\begin{array}{r}4,654 \\
1,063 \\
0 \\
0 \\
6,025 \\
18,001 \\
0\end{array}$ & $\begin{array}{r}7,728 \\
0 \\
0 \\
911 \\
13,540 \\
0\end{array}$ & $\begin{array}{r}55,401 \\
0 \\
0 \\
307 \\
13,663 \\
0\end{array}$ \\
\hline Total Production Expenses .......................... & 24,598 & 362,163 & 25,671 & 29,743 & 22,180 & 69,371 \\
\hline 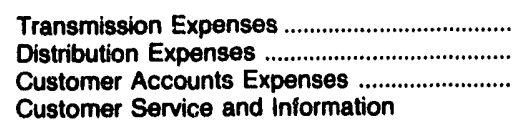 & $\begin{array}{r}21 \\
1,066 \\
79\end{array}$ & $\begin{array}{r}6,853 \\
18,487 \\
12,249\end{array}$ & $\begin{array}{r}139 \\
1,998 \\
448\end{array}$ & $\begin{array}{l}1,093 \\
2,077 \\
1,773\end{array}$ & $\begin{array}{r}435 \\
1,354 \\
487\end{array}$ & $\begin{array}{l}1,171 \\
7,339 \\
3,008\end{array}$ \\
\hline $\begin{array}{l}\text { Expenses } \\
\text { Sales Expenses } \\
\text { Administrative and General }\end{array}$ & $\begin{array}{l}0 \\
0\end{array}$ & $\begin{array}{r}959 \\
0\end{array}$ & $\begin{array}{r}633 \\
11\end{array}$ & $\begin{array}{r}569 \\
0\end{array}$ & $\begin{array}{l}0 \\
0\end{array}$ & $\begin{array}{r}468 \\
0\end{array}$ \\
\hline 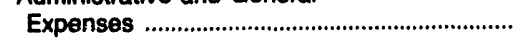 & 4,781 & 34,956 & 6,413 & 2,262 & 507 & 11,742 \\
\hline $\begin{array}{l}\text { Total Electrlc Operation and } \\
\text { Maintenance Expenses ................................... }\end{array}$ & 30,546 & 435,667 & 35,314 & 37,517 & 24,962 & 93,100 \\
\hline
\end{tabular}

\begin{tabular}{|c|c|c|c|c|c|c|}
\hline item & $\begin{array}{l}\text { Florida } \\
\text { Leesburg } \\
\text { City of } \\
\text { September } 30\end{array}$ & $\begin{array}{c}\text { Florida } \\
\text { New Smyrna } \\
\text { Beach } \\
\text { Utils Comm } \\
\text { September } 30\end{array}$ & $\begin{array}{l}\text { Florida } \\
\text { Ocala } \\
\text { City of } \\
\text { September } 30\end{array}$ & $\begin{array}{l}\text { Florida } \\
\text { Orlando } \\
\text { Utilities } \\
\text { Comm } \\
\text { September } 30\end{array}$ & $\begin{array}{l}\text { Florida } \\
\text { Quincy } \\
\text { City of } \\
\text { September } 30\end{array}$ & $\begin{array}{c}\text { Florida } \\
\text { St Cloud } \\
\text { City of } \\
\text { September } 30\end{array}$ \\
\hline 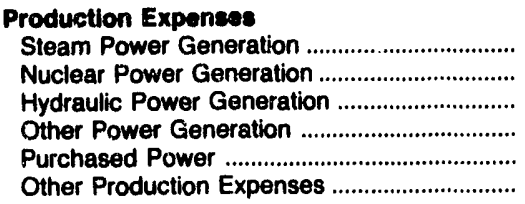 & $\begin{array}{r}0 \\
409 \\
0 \\
0 \\
15,089 \\
0\end{array}$ & $\begin{array}{r}0 \\
944 \\
0 \\
1,069 \\
12,540 \\
386\end{array}$ & $\begin{array}{r}0 \\
2,117 \\
0 \\
0 \\
36,642 \\
0\end{array}$ & $\begin{array}{r}118,483 \\
9,526 \\
0 \\
1,304 \\
4,537 \\
242\end{array}$ & $\begin{array}{r}0 \\
0 \\
0 \\
0 \\
4,558 \\
0\end{array}$ & $\begin{array}{r}0 \\
0 \\
0 \\
2,792 \\
7,070 \\
0\end{array}$ \\
\hline Total Production Expenses .......................... & 15,498 & 14,938 & 38,760 & 134,002 & 4,558 & 9,862 \\
\hline 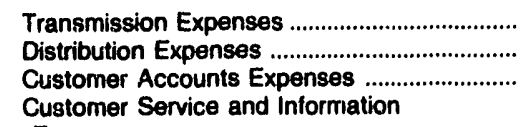 & $\begin{array}{r}0 \\
1,509 \\
608\end{array}$ & $\begin{array}{r}168 \\
1,295 \\
464\end{array}$ & $\begin{array}{r}364 \\
3,239 \\
471\end{array}$ & $\begin{array}{l}5,153 \\
4,526 \\
4,909\end{array}$ & $\begin{array}{r}0 \\
328 \\
191\end{array}$ & $\begin{array}{r}0 \\
2,380 \\
0\end{array}$ \\
\hline 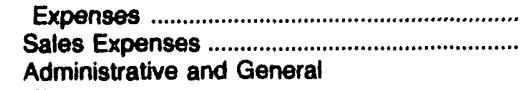 & $\begin{array}{l}0 \\
0\end{array}$ & $\begin{array}{l}0 \\
0\end{array}$ & $\begin{array}{r}151 \\
0\end{array}$ & $\begin{array}{r}1,094 \\
31\end{array}$ & $\begin{array}{l}0 \\
0\end{array}$ & $\begin{array}{r}795 \\
0\end{array}$ \\
\hline 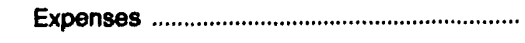 & 512 & 2,264 & 1,370 & 17,297 & 160 & 329 \\
\hline 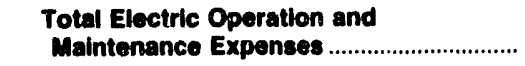 & 18,127 & 19,130 & 44,354 & 167,101 & 5,236 & 13,366 \\
\hline
\end{tabular}

Note: Totals may not equal sum of components because of independent rounding.

Souice: Enorgy Information Adminietration, Form ElA-412. "Annual Report of Public Electric Utilities." 
Table 38. Electric Operation and Maintenance Expenses by Major Publicly Owned Electric Utility Within State, 1991 (Continued) (Thousand Dollars)

\begin{tabular}{|c|c|c|c|c|c|c|}
\hline Item & $\begin{array}{c}\text { Florida } \\
\text { Tallahasseo } \\
\text { City of } \\
\text { September } 30\end{array}$ & $\begin{array}{l}\text { Flosida } \\
\text { Vero } \\
\text { Beach } \\
\text { City of } \\
\text { September } 30\end{array}$ & $\begin{array}{l}\text { Georgia } \\
\text { Albany Water } \\
\text { Gas \& Light } \\
\text { Comm } \\
\text { June } 30\end{array}$ & $\begin{array}{l}\text { Georgia } \\
\text { Calhoun } \\
\text { City of } \\
\text { June } 30\end{array}$ & $\begin{array}{c}\text { Georgia } \\
\text { Cartersville } \\
\text { City of } \\
\text { June } 30\end{array}$ & $\begin{array}{l}\text { Georgia } \\
\text { College } \\
\text { Park City of } \\
\text { June } 30\end{array}$ \\
\hline 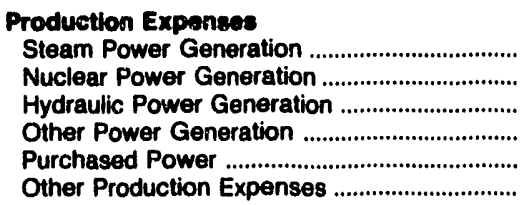 & $\begin{array}{r}39,885 \\
1,752 \\
0 \\
0 \\
31,318 \\
1,930\end{array}$ & $\begin{array}{r}11,715 \\
0 \\
0 \\
0 \\
15,053 \\
192\end{array}$ & $\begin{array}{r}0 \\
0 \\
0 \\
0 \\
40,942 \\
2,759\end{array}$ & $\begin{array}{r}0 \\
0 \\
0 \\
0 \\
13,150 \\
0\end{array}$ & $\begin{array}{r}0 \\
0 \\
0 \\
0 \\
16,077 \\
0\end{array}$ & $\begin{array}{r}0 \\
0 \\
0 \\
0 \\
13,250 \\
0\end{array}$ \\
\hline Total Production Expenses ............................ & 74,885 & 26,980 & $\mathbf{4 3 , 7 0 1}$ & 13,150 & 16,077 & 13,250 \\
\hline $\begin{array}{l}\text { Expenses } \\
\text { Sales Expenses } \\
\text { Administrative and General }\end{array}$ & $\begin{array}{l}0 \\
0\end{array}$ & $\begin{array}{r}496 \\
0\end{array}$ & $\begin{array}{l}\mathbf{0} \\
\mathbf{0}\end{array}$ & $\begin{array}{l}0 \\
0\end{array}$ & $\begin{array}{l}170 \\
392\end{array}$ & $\begin{array}{l}\mathbf{0} \\
0\end{array}$ \\
\hline 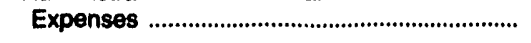 & 5,186 & 2,341 & 3,362 & 0 & 0 & 3 \\
\hline $\begin{array}{l}\text { Total Electric Operation and } \\
\text { Malntenancu Expenses ................................. }\end{array}$ & 92,019 & 31,985 & 47,083 & 13,953 & 18,268 & 14,161 \\
\hline
\end{tabular}

\begin{tabular}{|c|c|c|c|c|c|c|}
\hline Item & $\begin{array}{l}\text { Georgia } \\
\text { Covington } \\
\text { City of } \\
\text { December } 31\end{array}$ & $\begin{array}{l}\text { Georgia } \\
\text { Crisp } \\
\text { County } \\
\text { Power } \\
\text { Comm } \\
\text { December } 31\end{array}$ & $\begin{array}{c}\text { Georgia } \\
\text { Dalton } \\
\text { City of } \\
\text { November } 30\end{array}$ & $\begin{array}{l}\text { Georgia } \\
\text { Douglas } \\
\text { City of } \\
\text { June } 30\end{array}$ & $\begin{array}{c}\text { Georgia } \\
\text { East } \\
\text { Point } \\
\text { City of } \\
\\
\text { June } 30\end{array}$ & $\begin{array}{c}\text { Georgia } \\
\text { Fitzgerald } \\
\text { Wtr Lgt } \\
\text { \& Bond Comm } \\
\text { December } 31\end{array}$ \\
\hline
\end{tabular}

Production Expences

Steam Power Generation

Nuclear Power Generation

Hydraulic Power Generation

Other Power Generation

Purchased Power ..................................................

Other Production Expenses

Total Production Expenses

Transmission Expenses

Distribution Expenses

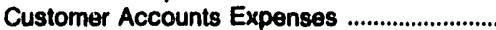

Customer Service and Information

Expenses ....

Sales Expenses

Administrative and General

Expenses

0
0
0
0
10,248
0

10,248

883

134

34

0
0

170

11,434
350
320
8,930

9,608

12

862

362

$\mathbf{0}$
$\mathbf{0}$

1,072

11,914
4,699
11,456
0
0
11,776

27,931

1,323

1,325

0

0

679

31,258

0
0
0
0
9,068
0

0
0
0
0
14,529

9,068

14,529

0
2,863
0

0

24

17,416
0
0
0
0
8,210
5

8,215

0
822
0

0
0

311

Total Electric Operation and

Note: Totals may not equal sum of components because of independent rounding.

Source: Energy Information Administration, Form EIA-412, "Annual Report of Public Electric Utilities." 

Table 38. Electric Operation and Maintenance Expenses by Major Publicly
Owned Electric Utility Within State, 1991 (Continued)

(Thousand Dollars)

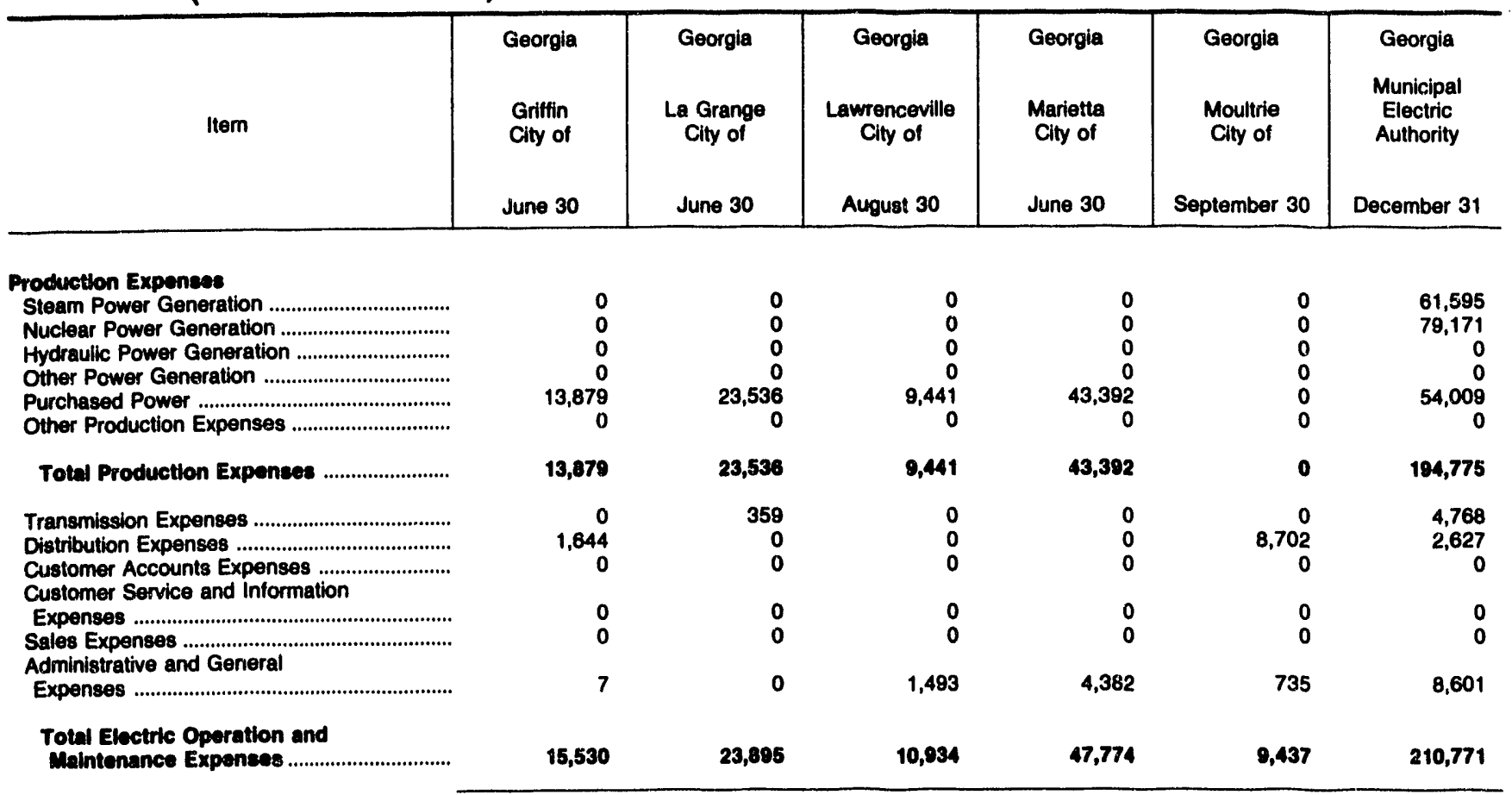

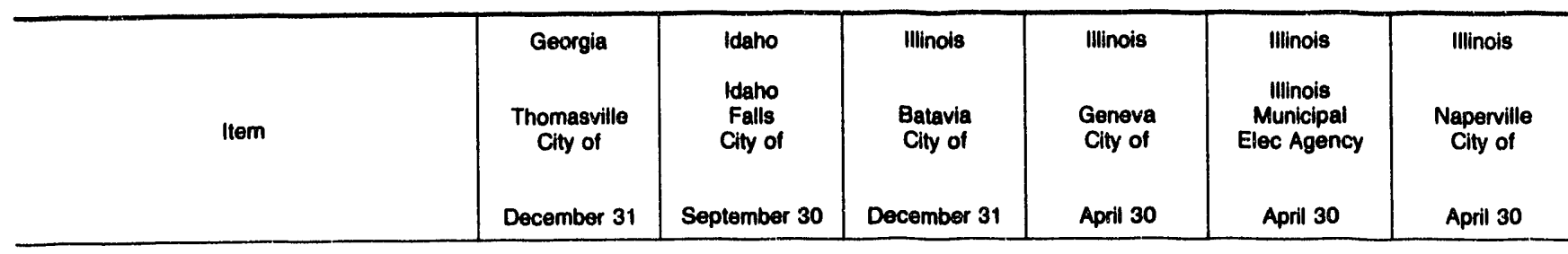

\section{Production Expeneses}

Steam Power Generation

Nuclear Power Generation

Hydraulic Power Generation

Other Power Generation

Other Production Expenses

Total Production Expences

Transmission Expenses

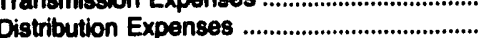

Customer Accounts Expenses

Customer Service and Information

Expenses ............

Sales Expenses

Administrative and General

Expenses

Total Electric Operatton and

Mainterence Expenses

0
0
0
0
17,952
0

0
0
1,144
0
13,151
0

17,952

14,294

0
904

904
327

0

1,323

20,507
0
0
0
0
10,103
0

10,103

0
789
254

1,152

1,152
791

7
0

1,821

18,150

237

11,383
0
0
0
0
5,953
0

902

$$
\begin{array}{r}
0 \\
0 \\
0 \\
37,492
\end{array}
$$

37,492

38,393

5,953

743

0
622
0

0
1,718

260

734

286

1,462

335

6,910

39,926

37,884

Note: Totals may not equal sum of components because of independent rounding.

Source: Energy Information Administration, Form EIA-412, "Annual Report of Public Electric Utilities." 
Table 38. Electric Operation and Maintenance Expenses by Major Publicly Owned Electric Utility Within State, 1991 (Continued) (Thousand Dollars)

\begin{tabular}{|c|c|c|c|c|c|c|}
\hline Item & $\begin{array}{l}\text { Illinois } \\
\text { Rochelle } \\
\text { Municipal } \\
\text { Utilities } \\
\text { April } 30\end{array}$ & $\begin{array}{c}\text { Illinois } \\
\text { Springfield } \\
\text { City of } \\
\text { February } 28\end{array}$ & $\begin{array}{l}\text { Illinois } \\
\text { St Charles } \\
\text { City of } \\
\text { April } 30\end{array}$ & $\begin{array}{c}\text { Indiana } \\
\text { Anderson } \\
\text { City of } \\
\text { December } 31\end{array}$ & $\begin{array}{l}\text { Indiana } \\
\text { Auburn } \\
\text { City of } \\
\text { December } 31\end{array}$ & $\begin{array}{c}\text { Indiana } \\
\text { Bluffton } \\
\text { City of } \\
\text { December } 31\end{array}$ \\
\hline 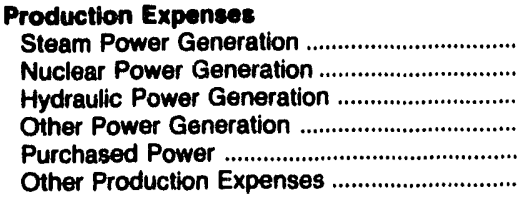 & $\begin{array}{r}3,508 \\
0 \\
0 \\
712 \\
3,043 \\
0\end{array}$ & $\begin{array}{r}42.830 \\
0 \\
0 \\
137 \\
324 \\
0\end{array}$ & $\begin{array}{r}0 \\
0 \\
0 \\
0 \\
14,907 \\
0\end{array}$ & $\begin{array}{r}0 \\
0 \\
0 \\
0 \\
27,960 \\
0\end{array}$ & $\begin{array}{r}0 \\
0 \\
0 \\
0 \\
10,340 \\
0\end{array}$ & $\begin{array}{r}0 \\
0 \\
0 \\
383 \\
5,676 \\
0\end{array}$ \\
\hline Total Production Expenses .......................... & 7,263 & 43,290 & 14,907 & 27,960 & 10,340 & 6,050 \\
\hline 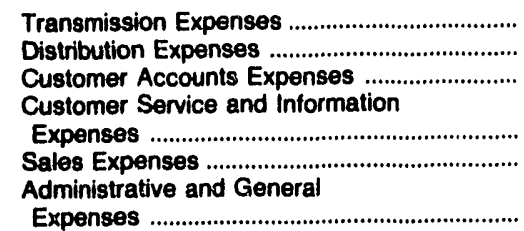 & $\begin{array}{r}0 \\
630 \\
0\end{array}$ & $\begin{array}{r}845 \\
5,209 \\
3,664 \\
\\
527 \\
0\end{array}$ & $\begin{array}{r}0 \\
2,030 \\
172\end{array}$ & $\begin{array}{r}2 \\
2,241 \\
432\end{array}$ & $\begin{array}{r}0 \\
699 \\
28\end{array}$ & $\begin{array}{r}0 \\
528 \\
39\end{array}$ \\
\hline $\begin{array}{l}\text { Total Electric Operation and } \\
\text { Malntenance Expenses }\end{array}$ & 9,085 & 60,517 & 17,492 & 33,126 & 11,587 & 7,009 \\
\hline
\end{tabular}

\begin{tabular}{|c|c|c|c|c|c|c|}
\hline Item & $\begin{array}{c}\text { Indiana } \\
\text { Crawiordsville } \\
\text { Elec } \\
\text { Lgt\&Pwr Co } \\
\text { December } 31\end{array}$ & $\begin{array}{l}\text { Indiana } \\
\text { Frankfort } \\
\text { City of } \\
\text { December } 31\end{array}$ & $\begin{array}{c}\text { Indiana } \\
\text { Indiana } \\
\text { Municipal } \\
\text { Fower Agency } \\
\text { December } 31\end{array}$ & $\begin{array}{c}\text { Indiana } \\
\text { Jasper } \\
\text { City of } \\
\text { December } 31\end{array}$ & $\begin{array}{l}\text { Indiana } \\
\text { Logansport } \\
\text { City of } \\
\text { December } 31\end{array}$ & $\begin{array}{c}\text { Indiana } \\
\text { Mishawaka } \\
\text { City of } \\
\text { December } 31\end{array}$ \\
\hline 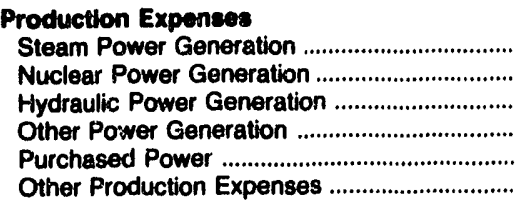 & $\begin{array}{r}1,409 \\
0 \\
0 \\
0 \\
11,628 \\
0\end{array}$ & $\begin{array}{r}0 \\
0 \\
0 \\
0 \\
9,370 \\
0\end{array}$ & $\begin{array}{r}19,761 \\
0 \\
0 \\
0 \\
99,254 \\
189\end{array}$ & $\begin{array}{r}2,127 \\
0 \\
0 \\
0 \\
8,104 \\
0\end{array}$ & $\begin{array}{r}5,612 \\
0 \\
0 \\
457 \\
5,394 \\
0\end{array}$ & $\begin{array}{r}0 \\
0 \\
0 \\
0 \\
17,987 \\
0\end{array}$ \\
\hline Total Production Expenses ........................... & 13,037 & 9,370 & 119,203 & 10,231 & 11,462 & 17,987 \\
\hline 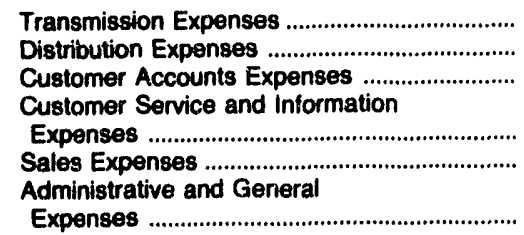 & $\begin{array}{r}14 \\
797 \\
205 \\
\\
0 \\
0\end{array}$ & $\begin{array}{r}0 \\
1,159 \\
171\end{array}$ & $\begin{array}{r}3,406 \\
415 \\
0 \\
0 \\
0\end{array}$ & $\begin{array}{r}1 \\
563 \\
54\end{array}$ & $\begin{array}{r}0 \\
1,396 \\
106 \\
21 \\
0\end{array}$ & $\begin{array}{r}0 \\
2,045 \\
558\end{array}$ \\
\hline $\begin{array}{l}\text { Total Electric Operation and } \\
\text { Maintenance Expenses }\end{array}$ & 15,120 & 13,646 & 124,598 & 11,475 & 14,170 & 21,481 \\
\hline
\end{tabular}

Note: Totals may not equal sum of components because of independent rounding.

Source: Energy Information Administration, Form ElA-412, "Annual Report of Public Electric Utilities." 
Table 38. Electric Operation and Maintenance Expenses by Major Publicly Owned Electric Utility Within State, 1991 (Continued)

(Thousand Dollars)

\begin{tabular}{|c|c|c|c|c|c|c|}
\hline Item & $\begin{array}{l}\text { Indiana } \\
\text { Peru } \\
\text { City of } \\
\text { December } 31\end{array}$ & $\begin{array}{l}\text { Indiana } \\
\text { Richmiond } \\
\text { City of } \\
\text { December } 31\end{array}$ & $\begin{array}{l}\text { Indiana } \\
\text { Washington } \\
\text { City of } \\
\text { December } 31\end{array}$ & $\begin{array}{l}\text { lowa } \\
\text { Ames } \\
\text { City of } \\
\text { June } 30\end{array}$ & $\begin{array}{l}\text { lowa } \\
\text { Cedar } \\
\text { Falls } \\
\text { City of } \\
\text { December } 31\end{array}$ & $\begin{array}{l}\text { lowa } \\
\text { Muscatine } \\
\text { City of } \\
\text { December } 31\end{array}$ \\
\hline 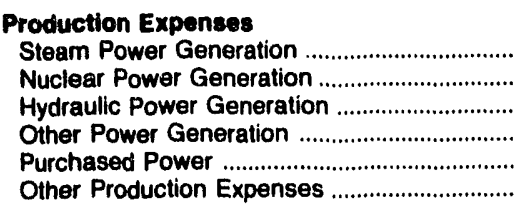 & $\begin{array}{r}596 \\
0 \\
0 \\
0 \\
5,050 \\
0\end{array}$ & $\begin{array}{r}11,729 \\
0 \\
0 \\
0 \\
12,123 \\
8\end{array}$ & $\begin{array}{r}0 \\
0 \\
0 \\
0 \\
5,911 \\
0\end{array}$ & $\begin{array}{r}7,512 \\
0 \\
0 \\
0 \\
1,118 \\
419\end{array}$ & $\begin{array}{r}5,123 \\
0 \\
0 \\
141 \\
1,242 \\
25\end{array}$ & $\begin{array}{r}32,548 \\
0 \\
0 \\
0 \\
2,921 \\
849\end{array}$ \\
\hline Total Production Expenses ............................. & 5,645 & 23,860 & 5,911 & 9,049 & 6,531 & 36,317 \\
\hline 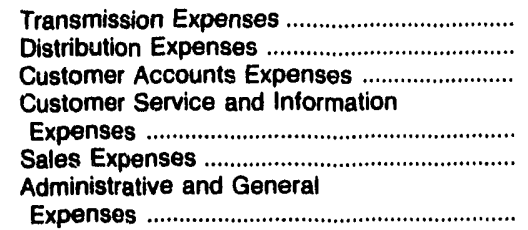 & $\begin{array}{r}26 \\
514 \\
144\end{array}$ & $\begin{array}{r}66 \\
1,712 \\
514\end{array}$ & $\begin{array}{r}0 \\
539 \\
190\end{array}$ & $\begin{array}{r}0 \\
1,690 \\
0 \\
246 \\
0\end{array}$ & $\begin{array}{r}347 \\
1,035 \\
330\end{array}$ & $\begin{array}{r}1,960 \\
0 \\
301\end{array}$ \\
\hline $\begin{array}{l}\text { Total Electric Operation and } \\
\text { Maintenance Expenses }\end{array}$ & 7,345 & 30,087 & 6,890 & 12,327 & 9,587 & 42,639 \\
\hline
\end{tabular}

\begin{tabular}{|c|c|c|c|c|c|c|}
\hline Item & $\begin{array}{l}\text { Kansas } \\
\text { Coffeyville } \\
\text { City of }\end{array}$ & $\begin{array}{c}\text { Kansas } \\
\text { Garden } \\
\text { City City of } \\
\text { December } 31\end{array}$ & $\begin{array}{c}\text { Kansas } \\
\text { Kansas } \\
\text { City City of } \\
\text { December } 31\end{array}$ & $\begin{array}{c}\text { Kansas } \\
\text { Kansas } \\
\text { Municipal } \\
\text { Energy } \\
\text { Agency } \\
\text { December } 31\end{array}$ & $\begin{array}{l}\text { Kansas } \\
\begin{array}{l}\text { McPherson } \\
\text { City of }\end{array} \\
\text { December } 31\end{array}$ & $\begin{array}{c}\text { Kansas } \\
\begin{array}{c}\text { Winfield } \\
\text { City of }\end{array} \\
\text { December } 31\end{array}$ \\
\hline \multicolumn{7}{|l|}{ Production Expenses } \\
\hline Steam Power Generation ...................................... & 1,784 & 0 & 61,298 & 0 & 477 & 2,335 \\
\hline Nuclear Power Generation ................................. & & 0 & & 0 & 0 & 0 \\
\hline 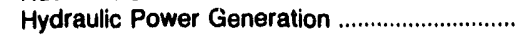 & 0 & 0 & 0 & 0 & 0 & 0 \\
\hline 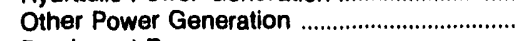 & & 0 & 252 & 0 & 901 & 0 \\
\hline 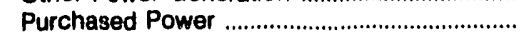 & 3,365 & 8,093 & 7,048 & 10,882 & 11,656 & 5,650 \\
\hline 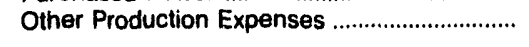 & 0 & 96 & 922 & 0 & 442 & 845 \\
\hline Total Production Expenses .......................... & 5,149 & 8,189 & 69,519 & 10,882 & 13,477 & 8,830 \\
\hline Transmission Expenses ............................................ & 0 & 0 & 479 & 166 & 38 & 0 \\
\hline Distribution Expenses ............................................... & 652 & 488 & 8,403 & 0 & 1,408 & 760 \\
\hline Customer Accounts Expenses ......................... & 0 & 0 & 3,503 & 0 & 114 & 184 \\
\hline $\begin{array}{l}\text { Customer Service and Iniormation } \\
\text { Expenses .................................................. }\end{array}$ & 150 & 0 & 0 & 0 & 2 & 0 \\
\hline $\begin{array}{l}\text { Sales Expenses ............................................. } \\
\text { Adiministrative and General }\end{array}$ & 0 & 0 & 0 & 0 & 18 & 0 \\
\hline 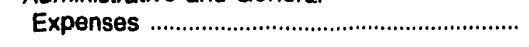 & 1,008 & 879 & 11,919 & 695 & 439 & 306 \\
\hline $\begin{array}{l}\text { Total Electric Cperation and } \\
\text { Maintenance Expenses }\end{array}$ & 6,958 & 9,556 & 93,823 & 11,743 & 15,496 & 10,080 \\
\hline
\end{tabular}

Note: Totals may not equal sum of components because of independent rounding.

Source: Energy Information Administration, Form EIA-412, "Annual Report of Public Electric Utilities." 
Table 38. Electric Operation and Maintenance Expenses by Major Publicly Owned Electric Utility Within State, 1991 (Continued) (Thousand Dollars)

\begin{tabular}{|c|c|c|c|c|c|c|}
\hline Item & $\begin{array}{l}\text { Kentucky } \\
\text { Bowling } \\
\text { Green } \\
\text { City of } \\
\text { June } 30\end{array}$ & $\begin{array}{l}\text { Kentucky } \\
\text { Frankfort } \\
\text { City of } \\
\text { June } 30\end{array}$ & $\begin{array}{l}\text { Kentucky } \\
\text { Franklin } \\
\text { City of } \\
\text { June } 30\end{array}$ & $\begin{array}{l}\text { Kentucky } \\
\text { Glasgow } \\
\text { City of } \\
\text { June } 30\end{array}$ & $\begin{array}{l}\text { Kentucky } \\
\text { Henderson } \\
\text { City } \\
\text { Utility Comm } \\
\text { May } 31\end{array}$ & $\begin{array}{l}\text { Kentucky } \\
\text { Hopkinsville } \\
\text { City of } \\
\text { June } 30\end{array}$ \\
\hline 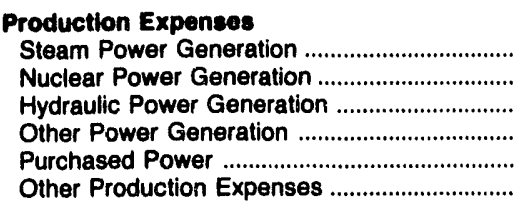 & $\begin{array}{r}0 \\
0 \\
0 \\
0 \\
29,179 \\
0\end{array}$ & $\begin{array}{r}0 \\
0 \\
0 \\
0 \\
18,162 \\
0\end{array}$ & $\begin{array}{r}0 \\
0 \\
0 \\
0 \\
8,039 \\
0\end{array}$ & $\begin{array}{r}0 \\
0 \\
0 \\
0 \\
11,867 \\
0\end{array}$ & $\begin{array}{r}10,928 \\
0 \\
0 \\
0 \\
444 \\
50\end{array}$ & $\begin{array}{r}0 \\
0 \\
0 \\
0 \\
16,603 \\
0\end{array}$ \\
\hline Total Production Expenses ............................ & 29,179 & 18,162 & 8,039 & 11,867 & 11,422 & 16,603 \\
\hline 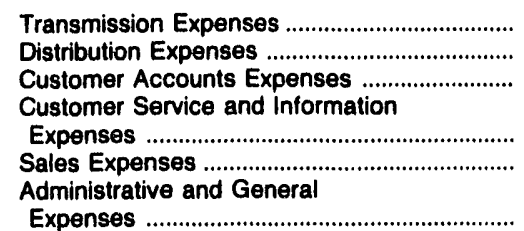 & $\begin{array}{r}0 \\
1.712 \\
398 \\
174 \\
6 \\
917\end{array}$ & $\begin{array}{r}47 \\
901 \\
361\end{array}$ & $\begin{array}{r}0 \\
371 \\
106 \\
30 \\
20\end{array}$ & $\begin{array}{r}0 \\
608 \\
163 \\
\\
109 \\
0\end{array}$ & $\begin{array}{r}21 \\
830 \\
213\end{array}$ & $\begin{array}{r}3 \\
920 \\
288\end{array}$ \\
\hline $\begin{array}{l}\text { Total Electric Operation and } \\
\text { Maintenance Expenses }\end{array}$ & 32,386 & 20,990 & 8,975 & 13,176 & 15,395 & 18,603 \\
\hline
\end{tabular}

\begin{tabular}{|c|c|c|c|c|c|c|}
\hline Item & $\begin{array}{l}\text { Kentucky } \\
\text { Madisonville } \\
\text { Municipal } \\
\text { Utits } \\
\text { June } 30\end{array}$ & $\begin{array}{c}\text { Kentucky } \\
\text { Mayijeld } \\
\text { City of } \\
\text { June } 30\end{array}$ & $\begin{array}{l}\text { Kentucky } \\
\text { Murray } \\
\text { City of } \\
\text { June } 30\end{array}$ & $\begin{array}{c}\text { Kentucky } \\
\text { Owensboro } \\
\text { City of } \\
\text { May } 31\end{array}$ & $\begin{array}{l}\text { Kentucky } \\
\text { Paducah } \\
\text { City of } \\
\text { June } 30\end{array}$ & $\begin{array}{l}\text { Louisiana } \\
\text { Alexandria } \\
\text { City of } \\
\text { April } 30\end{array}$ \\
\hline 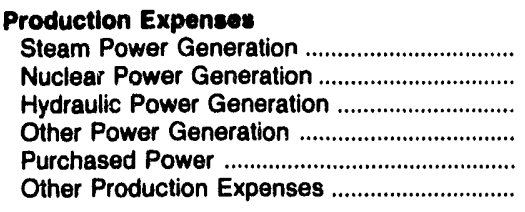 & $\begin{array}{r}0 \\
0 \\
0 \\
0 \\
8,553 \\
0\end{array}$ & $\begin{array}{r}0 \\
0 \\
0 \\
0 \\
6,389 \\
0\end{array}$ & $\begin{array}{r}0 \\
0 \\
0 \\
0 \\
10,490 \\
0\end{array}$ & $\begin{array}{r}26,423 \\
0 \\
0 \\
0 \\
538 \\
0\end{array}$ & $\begin{array}{r}0 \\
0 \\
0 \\
0 \\
23,545 \\
0\end{array}$ & $\begin{array}{r}1,109 \\
0 \\
0 \\
0 \\
20,631 \\
0\end{array}$ \\
\hline Total Production Expenses ............................ & 8,553 & 6,389 & 10,490 & 26,961 & 23,545 & 21,740 \\
\hline 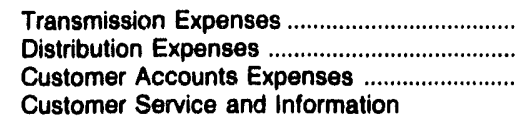 & $\begin{array}{r}0 \\
613 \\
199\end{array}$ & $\begin{array}{r}0 \\
565 \\
169\end{array}$ & $\begin{array}{r}0 \\
593 \\
160\end{array}$ & $\begin{array}{r}109 \\
1,904 \\
553\end{array}$ & $\begin{array}{r}34 \\
1,521 \\
700\end{array}$ & $\begin{array}{r}0 \\
3,009 \\
0\end{array}$ \\
\hline 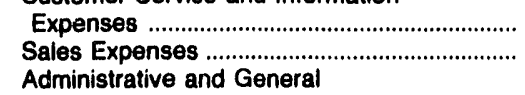 & $\begin{array}{l}0 \\
0\end{array}$ & $\begin{array}{l}50 \\
38\end{array}$ & $\begin{array}{r}18 \\
8\end{array}$ & $\begin{array}{l}0 \\
0\end{array}$ & $\begin{array}{r}76 \\
239\end{array}$ & $\begin{array}{l}0 \\
0\end{array}$ \\
\hline 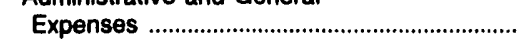 & 180 & 468 & 354 & 3,031 & 1,202 & 1,426 \\
\hline $\begin{array}{l}\text { Total Electric Operation and } \\
\text { Malntenance Expenses ............................... }\end{array}$ & 9,545 & 7,678 & 11,623 & 32,558 & 27,317 & 26,175 \\
\hline
\end{tabular}

Note: Totals may not equal sum of components because of independent rounding.

Source: Energy Information Administration, Form ElA-412, "Annual Report of Public Electric Utilities." 


\section{Table 38. Electric Operation and Maintenance Expenses by Major Publicly Owned Electric Utility Within State, 1991 (Continued)}

(Thousand Dollars)

\begin{tabular}{|c|c|c|c|c|c|c|}
\hline Item & $\begin{array}{l}\text { Louisiana } \\
\text { Lafayette } \\
\text { City of } \\
\text { October } 31\end{array}$ & $\begin{array}{c}\text { Louisiana } \\
\text { Louisiana } \\
\text { Energy } \\
8 \\
\text { Power Auth } \\
\text { December } 31\end{array}$ & $\begin{array}{l}\text { Louisiana } \\
\text { Morgan } \\
\text { City City of } \\
\text { December } 31\end{array}$ & $\begin{array}{l}\text { Louisiana } \\
\text { Natchitoches } \\
\text { City of } \\
\text { May } 31\end{array}$ & $\begin{array}{l}\text { Louisiana } \\
\text { Ruston } \\
\text { City of } \\
\text { September } 30\end{array}$ & $\begin{array}{c}\text { Louisiana } \\
\text { Terrebonne } \\
\text { Parish } \\
\text { Consol Govt } \\
\text { December } 31\end{array}$ \\
\hline 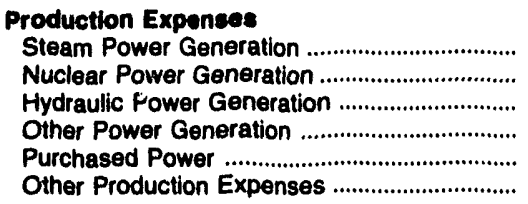 & $\begin{array}{r}8,385 \\
0 \\
0 \\
0 \\
58,801 \\
0\end{array}$ & $\begin{array}{r}19,443 \\
0 \\
0 \\
0 \\
23,990 \\
0\end{array}$ & $\begin{array}{r}0 \\
0 \\
0 \\
0 \\
7,077 \\
0\end{array}$ & $\begin{array}{r}0 \\
0 \\
0 \\
0 \\
7,979 \\
0\end{array}$ & $\begin{array}{r}5,091 \\
0 \\
0 \\
49 \\
1,015 \\
0\end{array}$ & $\begin{array}{r}5,922 \\
0 \\
0 \\
0 \\
5,585 \\
0\end{array}$ \\
\hline Total Production Expenses .......................... & 67,185 & 43,433 & 7,077 & 7,979 & 6,154 & 11,508 \\
\hline 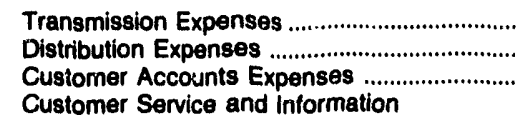 & $\begin{array}{r}0 \\
2,425 \\
3,554\end{array}$ & $\begin{array}{r}4,920 \\
0 \\
0\end{array}$ & $\begin{array}{r}739 \\
0 \\
0\end{array}$ & $\begin{array}{r}0 \\
513 \\
0\end{array}$ & $\begin{array}{r}0 \\
1,044 \\
289\end{array}$ & $\begin{array}{r}0 \\
788 \\
0\end{array}$ \\
\hline 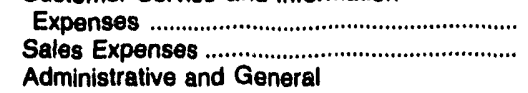 & $\begin{array}{l}17 \\
21\end{array}$ & $\begin{array}{l}0 \\
0\end{array}$ & $\begin{array}{l}0 \\
0\end{array}$ & $\begin{array}{l}0 \\
0\end{array}$ & $\begin{array}{l}0 \\
0\end{array}$ & $\begin{array}{r}691 \\
0\end{array}$ \\
\hline 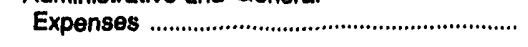 & 3,835 & 1,668 & 374 & 948 & 653 & 716 \\
\hline 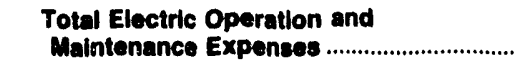 & 77,038 & 50,022 & 8,190 & 9,439 & 8,140 & 13,703 \\
\hline
\end{tabular}

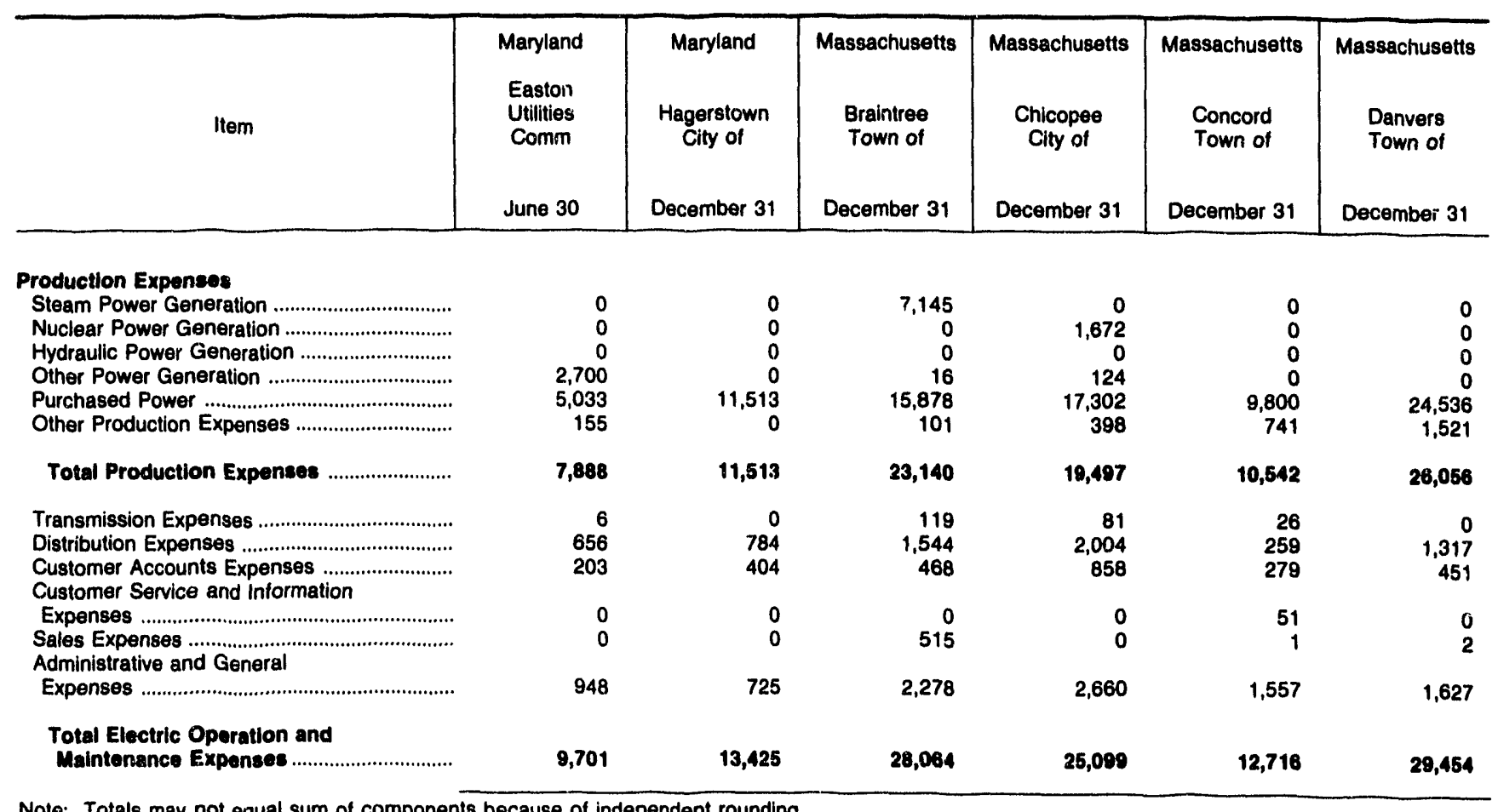

Note: Totals may not equal sum of components because of independent rounding.

Source: Energy Information Administration, Form ElA-412, "Annual Report of Public Electric Utilities." 
Table 38. Electric Operation and Maintenance Expenses by Major Publicly Owned Electric Utillty Within State, 1991 (Continued) (Thousand Dollars)

\begin{tabular}{|c|c|c|c|c|c|c|}
\hline Item & $\begin{array}{l}\text { Massachusetts } \\
\text { Hingham } \\
\text { Clty of } \\
\text { December } 31\end{array}$ & $\begin{array}{c}\text { Massachusetts } \\
\text { Holyoke } \\
\text { City of } \\
\text { December } 31\end{array}$ & $\begin{array}{l}\text { Massachusetts } \\
\text { Hudson } \\
\text { Town of } \\
\text { December } 31\end{array}$ & $\begin{array}{l}\text { Massachusetts } \\
\text { Littleton } \\
\text { Town of } \\
\text { December } 31\end{array}$ & $\begin{array}{l}\text { Massachusetts } \\
\text { Mansfield } \\
\text { Town of } \\
\text { December } 31\end{array}$ & $\begin{array}{c}\text { Massachusetts } \\
\text { Massachuselts } \\
\text { Mun } \\
\text { Whls } \\
\text { Elec Co } \\
\text { December } 31\end{array}$ \\
\hline 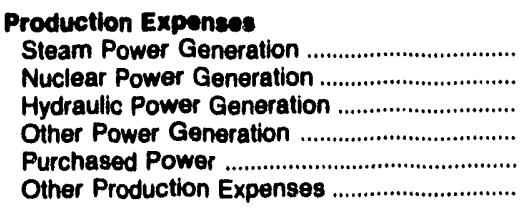 & $\begin{array}{r}0 \\
0 \\
0 \\
0 \\
10,929 \\
177\end{array}$ & $\begin{array}{r}935 \\
0 \\
357 \\
0 \\
16,333 \\
0\end{array}$ & $\begin{array}{r}0 \\
139 \\
0 \\
677 \\
26,059 \\
97\end{array}$ & $\begin{array}{r}153 \\
0 \\
0 \\
0 \\
12,460 \\
191\end{array}$ & $\begin{array}{r}0 \\
0 \\
0 \\
0 \\
15,818 \\
150\end{array}$ & $\begin{array}{r}1,035 \\
31,400 \\
0 \\
21,130 \\
76,351 \\
44\end{array}$ \\
\hline 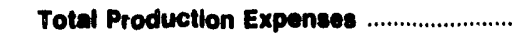 & 11,105 & 17,625 & 26,972 & 12,803 & 15,888 & 129,981 \\
\hline 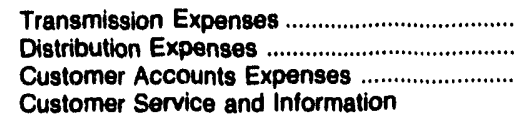 & $\begin{array}{l}493 \\
996 \\
324\end{array}$ & $\begin{array}{r}1,009 \\
1,536 \\
827\end{array}$ & $\begin{array}{r}1,064 \\
356 \\
252\end{array}$ & $\begin{array}{l}682 \\
711 \\
216\end{array}$ & $\begin{array}{l}937 \\
703 \\
169\end{array}$ & $\begin{array}{r}3,152 \\
0 \\
0\end{array}$ \\
\hline 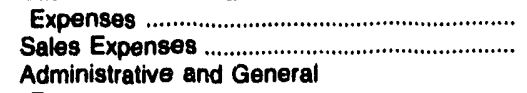 & $\begin{array}{l}0 \\
0\end{array}$ & $\begin{array}{l}0 \\
6\end{array}$ & $\begin{array}{r}0 \\
13\end{array}$ & $\begin{array}{r}0 \\
86\end{array}$ & $\begin{array}{l}0 \\
0\end{array}$ & $\begin{array}{l}0 \\
0\end{array}$ \\
\hline 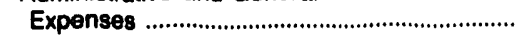 & 620 & 2,196 & 1,147 & 1,216 & 692 & 16,536 \\
\hline $\begin{array}{l}\text { Total Electric Operation and } \\
\text { Malntenance Expenses }\end{array}$ & 13,538 & 23,189 & 29,804 & 15,713 & 18,469 & 149,649 \\
\hline
\end{tabular}

\begin{tabular}{|c|c|c|c|c|c|c|}
\hline Item & $\begin{array}{l}\text { Massachusetts } \\
\text { Middleborough } \\
\text { Town of }\end{array}$ & $\begin{array}{c}\text { Massachusetts } \\
\text { North } \\
\text { Attleborough } \\
\text { Town of }\end{array}$ & $\begin{array}{l}\text { Massachusetts } \\
\text { Norwood } \\
\text { City of }\end{array}$ & $\begin{array}{l}\text { Massachusetts } \\
\text { Peabody } \\
\text { City of }\end{array}$ & $\begin{array}{l}\text { Massachusetts } \\
\text { Reading } \\
\text { Town of }\end{array}$ & Massachuselts \\
\hline & December 31 & December 31 & June 30 & December $\mathbf{3 1}$ & December 31 & December 31 \\
\hline
\end{tabular}

Production Expenses

Steam Power Generation

Nuclear Power Generation

Hydraulic Power Generation

Other Power Generation

Purchased Power

Other Production Expenses

Total Production Expenses

Transmission Expenses ...

Distributlon Expens

Customer Accounts Expenses

Customer Service and Information

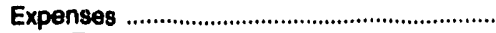

Sales Expenses .

Administrative and General

Expenses

\section{Total Electric Operation and}

Maintenance Expenees

0
0
0
0
12,964
-455

314
0
0
0
12,244
245

12,510

12,803

733

1,209

559

0

33

1,110

16,153

1,062

15,912
0
0
0
0
20,171
0

0
0
0
884
30,422
266

0
0
0
0
39,863
0

31,673

39,863

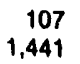

1,441
552

$$
\begin{array}{r}
13 \\
2,387
\end{array}
$$

1,459

1,212
486

0

16

1,443

0
0
0
176
16,838
315

17,330

508

854

328

0

977

3,175

2,228

977

23,329

36,851

46,137

20,031

Note: Totals may not equal sum of components because of independent rounding.

Source: Energy Information Administration, Form ElA-412, "Annual Peport of Public Electric Utilities." 


\section{Table 38. Electric Operation and Maintenance Expenses by Major Publicly Owned Electric Utility Within State, 1991 (Continued)}

(Thousand Dollars)

\begin{tabular}{|c|c|c|c|c|c|c|}
\hline Item & $\begin{array}{l}\text { Massachuselts } \\
\text { Taunton } \\
\text { Clty of } \\
\text { December } 31\end{array}$ & $\begin{array}{l}\text { Massachusetts } \\
\text { Wakefield } \\
\text { Town of } \\
\text { December } 31\end{array}$ & $\begin{array}{c}\text { Massachusetts } \\
\text { Wellesley } \\
\text { Town of } \\
\text { December } 31\end{array}$ & $\begin{array}{l}\text { Massachusetts } \\
\text { Westfield } \\
\text { City of } \\
\text { December } 31\end{array}$ & $\begin{array}{l}\text { Michigan } \\
\text { Bay } \\
\text { City City of } \\
\text { June } 30\end{array}$ & $\begin{array}{l}\text { Michigan } \\
\text { Coldwater } \\
\text { Board } \\
\text { of } \\
\text { Public Util } \\
\text { June } 30\end{array}$ \\
\hline 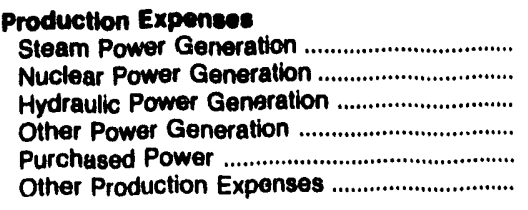 & $\begin{array}{r}9,322 \\
0 \\
0 \\
259 \\
10,492 \\
45\end{array}$ & $\begin{array}{r}0 \\
0 \\
0 \\
0 \\
11,802 \\
0\end{array}$ & $\begin{array}{r}0 \\
0 \\
0 \\
0 \\
13,558 \\
0\end{array}$ & $\begin{array}{r}0 \\
0 \\
0 \\
0 \\
25,588 \\
0\end{array}$ & $\begin{array}{r}0 \\
0 \\
0 \\
0 \\
7,815 \\
0\end{array}$ & $\begin{array}{r}117 \\
0 \\
0 \\
197 \\
8,248 \\
0\end{array}$ \\
\hline Total Production Expenees .......................... & 20,117 & 11,802 & 13,658 & 25,568 & 7,815 & 8,563 \\
\hline 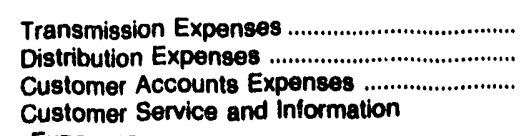 & $\begin{array}{r}236 \\
1,900 \\
1,184\end{array}$ & $\begin{array}{r}0 \\
1,032 \\
383\end{array}$ & $\begin{array}{r}626 \\
1,505 \\
321\end{array}$ & $\begin{array}{r}0 \\
3,715 \\
0\end{array}$ & $\begin{array}{r}0 \\
1,033 \\
0\end{array}$ & $\begin{array}{r}0 \\
299 \\
123\end{array}$ \\
\hline 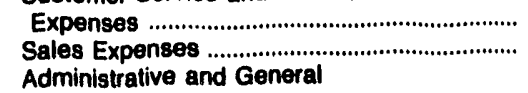 & $\begin{array}{r}0 \\
11\end{array}$ & $\begin{array}{l}0 \\
0\end{array}$ & $\begin{array}{r}0 \\
38\end{array}$ & $\begin{array}{l}\mathbf{0} \\
\mathbf{0}\end{array}$ & $\begin{array}{l}0 \\
0\end{array}$ & $\begin{array}{l}0 \\
0\end{array}$ \\
\hline 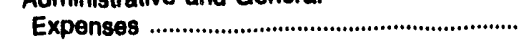 & 5,355 & 919 & 1,189 & 3,254 & 1,337 & 757 \\
\hline $\begin{array}{l}\text { Total Electric Oporation and } \\
\text { Maintenance Expenses ............................... }\end{array}$ & 28,003 & 14,137 & 17,248 & 32,537 & 10,186 & 9,741 \\
\hline
\end{tabular}

\begin{tabular}{|c|c|c|c|c|c|c|}
\hline Item & $\begin{array}{l}\text { Michigan } \\
\text { Detroit } \\
\text { City of } \\
\text { June } 30\end{array}$ & $\begin{array}{l}\text { Michigan } \\
\text { Grand Haven } \\
\text { City of } \\
\text { June } 30\end{array}$ & $\begin{array}{l}\text { Michigan } \\
\text { Hillsdale } \\
\text { Board } \\
\text { of } \\
\text { Public Wks } \\
\text { June } 30\end{array}$ & $\begin{array}{l}\text { Michigan } \\
\text { Holland } \\
\text { City of } \\
\text { June } 30\end{array}$ & $\begin{array}{l}\text { Michigan } \\
\text { Lansing } \\
\text { City of } \\
\text { June } 30\end{array}$ & $\begin{array}{l}\text { Michigan } \\
\text { Marquette } \\
\text { City of } \\
\text { June } 30\end{array}$ \\
\hline 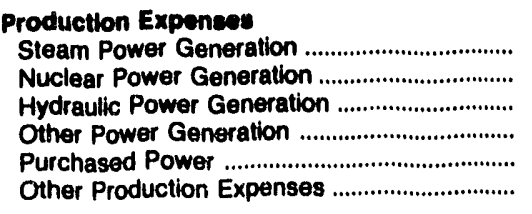 & $\begin{array}{r}17,578 \\
0 \\
0 \\
0 \\
9,812 \\
0\end{array}$ & $\begin{array}{r}9,760 \\
0 \\
0 \\
143 \\
230 \\
56\end{array}$ & $\begin{array}{r}0 \\
0 \\
0 \\
579 \\
6,839 \\
0\end{array}$ & $\begin{array}{r}10,675 \\
0 \\
0 \\
0 \\
10,691 \\
0\end{array}$ & $\begin{array}{r}61,348 \\
0 \\
26 \\
0 \\
3,245 \\
0\end{array}$ & $\begin{array}{r}7,713 \\
0 \\
157 \\
58 \\
361 \\
0\end{array}$ \\
\hline Total Production Expenses ........................... & 27,390 & 10,189 & 7,418 & 21,396 & 64,819 & 8,290 \\
\hline 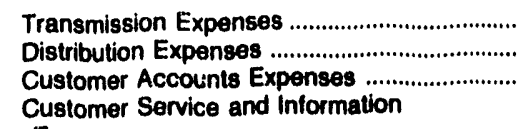 & $\begin{array}{r}1,084 \\
10,382 \\
0\end{array}$ & $\begin{array}{r}0 \\
495 \\
217\end{array}$ & $\begin{array}{r}0 \\
416 \\
86\end{array}$ & $\begin{array}{r}0 \\
1,460 \\
589\end{array}$ & $\begin{array}{r}756 \\
4,776 \\
3,382\end{array}$ & $\begin{array}{r}1 \\
803 \\
349\end{array}$ \\
\hline 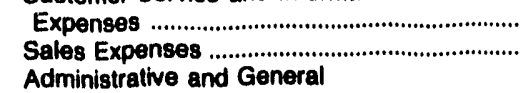 & $\begin{array}{l}0 \\
0\end{array}$ & $\begin{array}{l}0 \\
7\end{array}$ & $\begin{array}{l}2 \\
0\end{array}$ & $\begin{array}{r}0 \\
18\end{array}$ & $\begin{array}{r}0 \\
203\end{array}$ & $\begin{array}{r}19 \\
8\end{array}$ \\
\hline 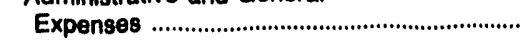 & 11,840 & 1,253 & 355 & 1,583 & 21,184 & 1,950 \\
\hline $\begin{array}{l}\text { Total Electric Operation and } \\
\text { Maintensnce Expenses }\end{array}$ & 60,697 & 12,160 & 8,276 & 24,098 & 94,920 & 11,420 \\
\hline
\end{tabular}

Note: Totals may not equal sum of components because of independent rounding.

Source: Energy Information Administration, Form ElA-412, "Annual Peport of Public Electric Utilities." 
Table 38. Electric Operation and Maintenance Expenses by Major Publicly Owned Electric Utility Within State, 1991 (Continued) (Thousand Dollars)

\begin{tabular}{|c|c|c|c|c|c|c|}
\hline Item & $\begin{array}{l}\text { Michigan } \\
\text { Michigan } \\
\text { Public } \\
\text { Power Ajency } \\
\text { December } 31\end{array}$ & $\begin{array}{l}\text { Michigan } \\
\text { Michigan } \\
\text { South } \\
\text { Central } \\
\text { Pwr Agy } \\
\text { June } 30\end{array}$ & $\begin{array}{c}\text { Michigan } \\
\text { Sturgis } \\
\text { City of } \\
\text { September } 30\end{array}$ & $\begin{array}{l}\text { Michigan } \\
\text { Traverse } \\
\text { City City of } \\
\text { June } 30\end{array}$ & $\begin{array}{l}\text { Michigan } \\
\text { Wyandotte } \\
\text { Municipal } \\
\text { Serv Comm } \\
\text { September } 30\end{array}$ & $\begin{array}{l}\text { Minnosota } \\
\text { Alexandria } \\
\text { City of } \\
\text { December } 31\end{array}$ \\
\hline 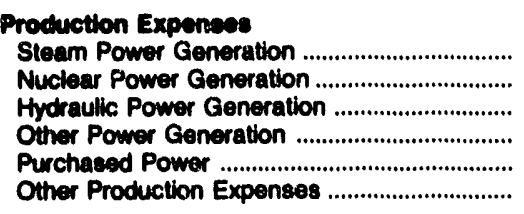 & $\begin{array}{r}13,164 \\
0 \\
0 \\
0 \\
4,270 \\
0\end{array}$ & $\begin{array}{r}10,609 \\
0 \\
0 \\
0 \\
4,891 \\
0\end{array}$ & $\begin{array}{r}0 \\
0 \\
79 \\
727 \\
6,527 \\
0\end{array}$ & $\begin{array}{r}3,968 \\
0 \\
212 \\
0 \\
4,052 \\
0\end{array}$ & $\begin{array}{r}9,854 \\
0 \\
0 \\
0 \\
935 \\
0\end{array}$ & $\begin{array}{r}0 \\
0 \\
0 \\
189 \\
5,131 \\
24\end{array}$ \\
\hline Toted Production Expensese ......................... & 17,434 & 15,500 & 7,334 & 8,280 & 10,890 & 8,344 \\
\hline 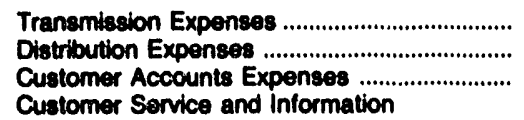 & $\begin{array}{r}819 \\
0 \\
0\end{array}$ & $\begin{array}{r}86 \\
0 \\
0\end{array}$ & $\begin{array}{r}47 \\
558 \\
182\end{array}$ & $\begin{array}{r}56 \\
1,541 \\
17\end{array}$ & $\begin{array}{l}748 \\
195 \\
244\end{array}$ & $\begin{array}{r}0 \\
450 \\
219\end{array}$ \\
\hline 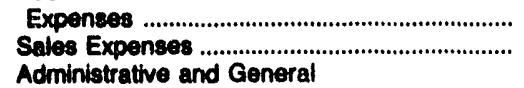 & $\begin{array}{l}0 \\
0\end{array}$ & $\begin{array}{l}0 \\
0\end{array}$ & $\begin{array}{l}0 \\
0\end{array}$ & $\begin{array}{r}260 \\
58\end{array}$ & $\begin{array}{r}408 \\
94\end{array}$ & $\begin{array}{l}4 \\
0\end{array}$ \\
\hline 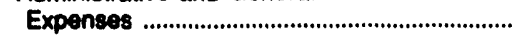 & 4,239 & 1,209 & 1,041 & 1,180 & 2,546 & 428 \\
\hline $\begin{array}{l}\text { Total Electric Operation and } \\
\text { Meintenance Expenase ............................... }\end{array}$ & 22,493 & 16,795 & 9,189 & 11,342 & 15,123 & 8,443 \\
\hline
\end{tabular}

\begin{tabular}{|c|c|c|c|c|c|c|}
\hline Item & $\begin{array}{c}\text { Minnesota } \\
\text { Anoka } \\
\text { City of } \\
\text { December } 31\end{array}$ & $\begin{array}{l}\text { Minnesota } \\
\text { Austin } \\
\text { City of } \\
\text { December } 31\end{array}$ & $\begin{array}{l}\text { Minnesota } \\
\text { Fairmont } \\
\text { Public } \\
\text { Utilities } \\
\text { Comm } \\
\text { December } 31\end{array}$ & $\begin{array}{l}\text { Minnesota } \\
\text { Hutchinson } \\
\text { Utilities } \\
\text { Comm } \\
\text { December } 31\end{array}$ & $\begin{array}{l}\text { Minnesota } \\
\text { Marshall } \\
\text { City of } \\
\text { December } 31\end{array}$ & $\begin{array}{l}\text { Minnesota } \\
\text { Moorhead } \\
\text { City of } \\
\text { December } 31\end{array}$ \\
\hline 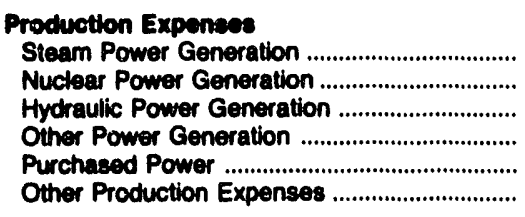 & $\begin{array}{r}0 \\
0 \\
0 \\
0 \\
7,095 \\
0\end{array}$ & $\begin{array}{r}2,224 \\
0 \\
0 \\
51 \\
13,214 \\
45\end{array}$ & $\begin{array}{r}1,294 \\
0 \\
0 \\
0 \\
8,847 \\
0\end{array}$ & $\begin{array}{r}0 \\
0 \\
0 \\
835 \\
5,299 \\
0\end{array}$ & $\begin{array}{r}0 \\
0 \\
0 \\
0 \\
6,899 \\
252\end{array}$ & $\begin{array}{r}97 \\
0 \\
0 \\
97 \\
6,729 \\
0\end{array}$ \\
\hline Toted Production Expenses ............................ & 7,005 & 15,533 & 10,141 & 6,134 & 7,251 & 6,923 \\
\hline 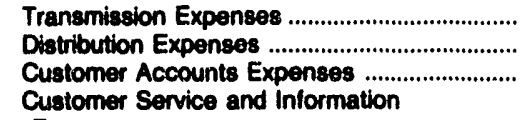 & $\begin{array}{r}0 \\
589 \\
451\end{array}$ & $\begin{array}{r}0 \\
755 \\
201\end{array}$ & $\begin{array}{r}103 \\
445 \\
0\end{array}$ & $\begin{array}{r}54 \\
292 \\
78\end{array}$ & $\begin{array}{r}0 \\
844 \\
0\end{array}$ & $\begin{array}{r}0 \\
769 \\
250\end{array}$ \\
\hline 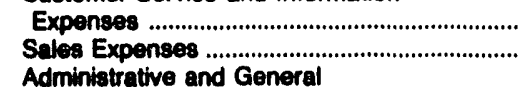 & $\begin{array}{l}0 \\
0\end{array}$ & $\begin{array}{r}33 \\
0\end{array}$ & $\begin{array}{l}\mathbf{0} \\
\mathbf{0}\end{array}$ & $\begin{array}{r}10 \\
0\end{array}$ & $\begin{array}{r}25 \\
0\end{array}$ & $\begin{array}{r}117 \\
41\end{array}$ \\
\hline Expenses & 393 & 1,012 & $\mathbf{0}$ & 689 & 663 & 813 \\
\hline $\begin{array}{l}\text { Total Electrle Operation and } \\
\text { Maintentence Expenses ............................... }\end{array}$ & 8,529 & 17,534 & 10,600 & 7,256 & 8,703 & 8,814 \\
\hline
\end{tabular}

Note: Totals may not equal sum of components because of independent rounding.

Source: Energy Information Administration, Form ElA-412, "Annual Report of Public Electric Utilities." 
Table 38. Electric Operation and Maintenance Expenses by Major Publicly Owned Electric Utility Within State, 1991 (Continued) (Thousand Dollars)

\begin{tabular}{|c|c|c|c|c|c|c|}
\hline Item & $\begin{array}{l}\text { Minnesota } \\
\text { New Ulm } \\
\text { Public } \\
\text { Utilities } \\
\text { Comm } \\
\text { December } 31\end{array}$ & $\begin{array}{c}\text { Minnesota } \\
\text { Northern } \\
\text { Municipal } \\
\text { Power Agny } \\
\\
\text { December } 31\end{array}$ & $\begin{array}{c}\text { Minnesota } \\
\text { Owatonna } \\
\text { City of } \\
\text { Decernber } 31\end{array}$ & $\begin{array}{c}\text { Minnesote } \\
\text { Rochester } \\
\text { Public } \\
\text { Utilities } \\
\text { December } 31\end{array}$ & $\begin{array}{c}\text { Minnesota } \\
\text { Southern } \\
\text { Minnesota } \\
\text { Mun P } \\
\text { Agny } \\
\text { December 31 }\end{array}$ & $\begin{array}{l}\text { Minnesota } \\
\text { Western } \\
\text { Minnesota } \\
\text { Mun } \\
\text { Pwr Agny } \\
\text { December } 31\end{array}$ \\
\hline 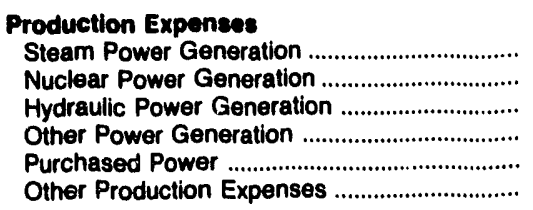 & $\begin{array}{r}3,317 \\
0 \\
0 \\
0 \\
2,319 \\
0\end{array}$ & $\begin{array}{r}12,160 \\
0 \\
0 \\
0 \\
0 \\
0\end{array}$ & $\begin{array}{r}0 \\
0 \\
0 \\
0 \\
13,232 \\
336\end{array}$ & $\begin{array}{r}2,345 \\
0 \\
84 \\
442 \\
43,169 \\
262\end{array}$ & $\begin{array}{r}33,546 \\
0 \\
0 \\
0 \\
17,742 \\
1,292\end{array}$ & $\begin{array}{r}18,458 \\
0 \\
0 \\
0 \\
69 \\
50\end{array}$ \\
\hline Total Production Expenses ........................... & 5,636 & 12,160 & 13,567 & 46,303 & 52,579 & 18,577 \\
\hline 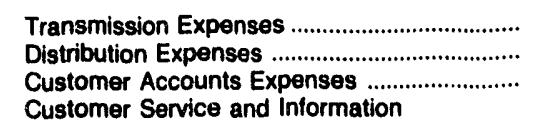 & $\begin{array}{r}34 \\
414 \\
65\end{array}$ & $\begin{array}{r}706 \\
0 \\
0\end{array}$ & $\begin{array}{r}0 \\
805 \\
252\end{array}$ & $\begin{array}{r}150 \\
2,277 \\
1,023\end{array}$ & $\begin{array}{r}478 \\
0 \\
0\end{array}$ & $\begin{array}{r}1,206 \\
0 \\
0\end{array}$ \\
\hline 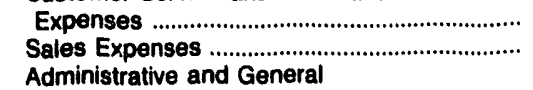 & $\begin{array}{l}0 \\
0\end{array}$ & $\begin{array}{l}0 \\
0\end{array}$ & $\begin{array}{r}0 \\
28\end{array}$ & $\begin{array}{l}87 \\
10\end{array}$ & $\begin{array}{l}0 \\
0\end{array}$ & $\begin{array}{l}0 \\
0\end{array}$ \\
\hline 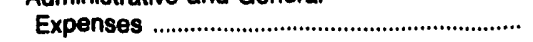 & 1,005 & 211 & 302 & 3,357 & 5,017 & 2,125 \\
\hline $\begin{array}{l}\text { Total Electric Oporation and } \\
\text { Malntenance Expenses }\end{array}$ & 7,155 & 13,077 & 15,054 & 53,205 & 58,074 & 21,907 \\
\hline
\end{tabular}

\begin{tabular}{|c|c|c|c|c|c|c|}
\hline Item & $\begin{array}{c}\text { Minnesota } \\
\text { Willmar } \\
\text { Municipal } \\
\text { Utils Comm } \\
\text { December } 31\end{array}$ & $\begin{array}{l}\text { Mississippi } \\
\text { Aberdeen } \\
\text { City of } \\
\text { June } 30\end{array}$ & $\begin{array}{l}\text { Mississippi } \\
\text { Clarksdale } \\
\text { City of } \\
\text { September } 30\end{array}$ & $\begin{array}{l}\text { Mississippi } \\
\text { Columbus } \\
\text { City of } \\
\text { June } 30\end{array}$ & $\begin{array}{l}\text { Mississippi } \\
\text { Greenwood } \\
\text { Utilities } \\
\text { Comm } \\
\text { September } 30\end{array}$ & $\begin{array}{c}\text { Mississippi } \\
\text { Holly } \\
\text { Springs } \\
\text { City of } \\
\text { June } 30\end{array}$ \\
\hline 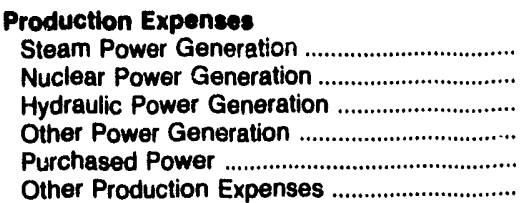 & $\begin{array}{r}1,931 \\
0 \\
0 \\
0 \\
3,704 \\
0\end{array}$ & $\begin{array}{r}0 \\
0 \\
0 \\
0 \\
7,037 \\
0\end{array}$ & $\begin{array}{r}2,164 \\
0 \\
0 \\
0 \\
5,748 \\
0\end{array}$ & $\begin{array}{r}0 \\
0 \\
0 \\
0 \\
20,967 \\
0\end{array}$ & $\begin{array}{r}2,041 \\
0 \\
0 \\
0 \\
8,531 \\
0\end{array}$ & $\begin{array}{r}0 \\
0 \\
0 \\
0 \\
8,751 \\
0\end{array}$ \\
\hline Total Production Expenses ............................ & 5,634 & 7,037 & 7,012 & 20,987 & 10,572 & 8,751 \\
\hline 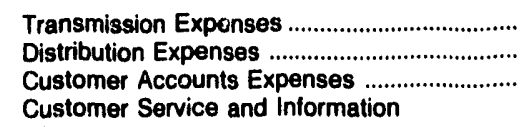 & $\begin{array}{r}34 \\
513 \\
164\end{array}$ & $\begin{array}{r}0 \\
258 \\
115\end{array}$ & $\begin{array}{r}0 \\
346 \\
177\end{array}$ & $\begin{array}{r}0 \\
849 \\
218\end{array}$ & $\begin{array}{r}0 \\
687 \\
189\end{array}$ & $\begin{array}{r}0 \\
648 \\
178\end{array}$ \\
\hline $\begin{array}{l}\text { Expenses } \\
\text { Sales Expenses } \\
\text { Administrative and General }\end{array}$ & $\begin{array}{l}0 \\
0\end{array}$ & $\begin{array}{l}37 \\
12\end{array}$ & $\begin{array}{l}0 \\
0\end{array}$ & $\begin{array}{r}3 \\
72\end{array}$ & $\begin{array}{l}0 \\
0\end{array}$ & $\begin{array}{r}10 \\
9\end{array}$ \\
\hline 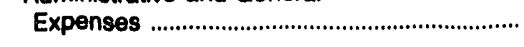 & 1,092 & 197 & 635 & 712 & 944 & 309 \\
\hline $\begin{array}{l}\text { Total Electric Operation and } \\
\text { Maintenance Expenses }\end{array}$ & 7,438 & 7,657 & 9,070 & 22,821 & 12,392 & 8,006 \\
\hline
\end{tabular}

Note: Totals may not equal sum of components because of independent rounding.

Source: Energy Information Administration, Form ElA-412, "Annual Report of Public Electric Utilities." 
Table 38. Electric Operakion and Maintenance Expenses by Major Publicly Owned Electric Utility Within State, 1991 (Continued) (Thousand Dollars)

\begin{tabular}{|c|c|c|c|c|c|c|}
\hline Item & $\begin{array}{l}\text { Mississippi } \\
\text { Louisville } \\
\text { Electric } \\
\text { System } \\
\text { June } 30\end{array}$ & $\begin{array}{l}\text { Mississippi } \\
\text { Municipsl } \\
\text { Energy } \\
\text { Agency } \\
\text { of MS } \\
\text { September } 30\end{array}$ & $\begin{array}{l}\text { Mississippi } \\
\text { New Albany } \\
\text { City of } \\
\text { June } 30\end{array}$ & $\begin{array}{l}\text { Mississippi } \\
\text { Oxford } \\
\text { City of } \\
\text { June } 30\end{array}$ & $\begin{array}{l}\text { Mississippi } \\
\text { Starkville } \\
\text { City of } \\
\text { June } 30\end{array}$ & $\begin{array}{l}\text { Mississippi } \\
\text { Tupelo } \\
\text { City of } \\
\text { June } 30\end{array}$ \\
\hline 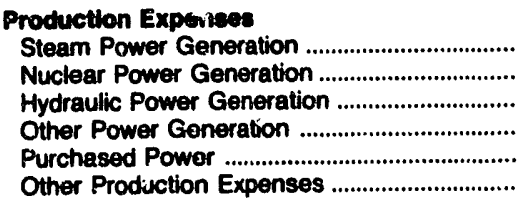 & $\begin{array}{r}0 \\
0 \\
0 \\
0 \\
6,998 \\
0\end{array}$ & $\begin{array}{r}0 \\
0 \\
0 \\
0 \\
24,342 \\
0\end{array}$ & $\begin{array}{r}0 \\
0 \\
0 \\
0 \\
10,040 \\
0\end{array}$ & $\begin{array}{r}0 \\
0 \\
0 \\
0 \\
6,399 \\
0\end{array}$ & $\begin{array}{r}0 \\
0 \\
0 \\
0 \\
14,071 \\
0\end{array}$ & $\begin{array}{r}0 \\
0 \\
0 \\
0 \\
27,586 \\
0\end{array}$ \\
\hline Total Production Expenses .......................... & 6,998 & 24,342 & 10,040 & 6,399 & 14,071 & 27,586 \\
\hline 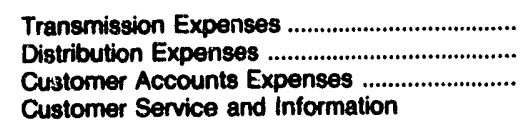 & $\begin{array}{r}0 \\
294 \\
91\end{array}$ & $\begin{array}{r}2,981 \\
0 \\
0\end{array}$ & $\begin{array}{r}0 \\
550 \\
215\end{array}$ & $\begin{array}{r}0 \\
289 \\
135\end{array}$ & $\begin{array}{r}0 \\
481 \\
173\end{array}$ & $\begin{array}{r}1 \\
807 \\
310\end{array}$ \\
\hline 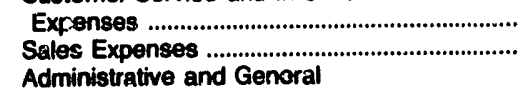 & $\begin{array}{r}8 \\
16\end{array}$ & $\begin{array}{l}0 \\
0\end{array}$ & $\begin{array}{r}3 \\
12\end{array}$ & $\begin{array}{l}26 \\
18\end{array}$ & $\begin{array}{l}12 \\
13\end{array}$ & $\begin{array}{l}64 \\
39\end{array}$ \\
\hline 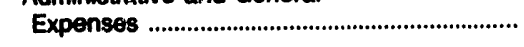 & 216 & 458 & 212 & 232 & 210 & 417 \\
\hline $\begin{array}{l}\text { Total Electric Operntion and } \\
\text { Malntemence Expenses ................................. }\end{array}$ & 7,625 & 27,781 & 11,032 & 7,099 & 14,960 & 29,224 \\
\hline
\end{tabular}

\begin{tabular}{|c|c|c|c|c|c|c|}
\hline Item & $\begin{array}{l}\text { Mississippi } \\
\text { West } \\
\text { Point } \\
\text { City of } \\
\text { June } 30\end{array}$ & $\begin{array}{l}\text { Missouri } \\
\text { Carthage } \\
\text { City of } \\
\text { June } 30\end{array}$ & $\begin{array}{l}\text { Missouri } \\
\text { Columbia } \\
\text { City of } \\
\text { September } 30\end{array}$ & $\begin{array}{l}\text { Missouri } \\
\text { Hannibal } \\
\text { City of } \\
\text { June } 30\end{array}$ & $\begin{array}{c}\text { Missouri } \\
\text { Independence } \\
\text { Cit; of } \\
\text { June } 30\end{array}$ & $\begin{array}{l}\text { Missouri } \\
\text { Kennett } \\
\text { Ciky of } \\
\text { June } 30\end{array}$ \\
\hline 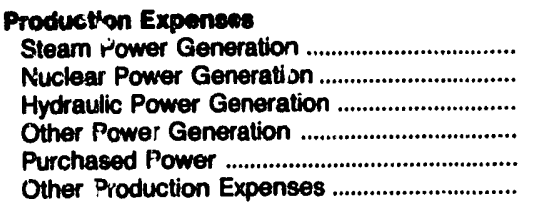 & $\begin{array}{r}0 \\
0 \\
0 \\
0 \\
8,440 \\
0\end{array}$ & $\begin{array}{r}0 \\
0 \\
0 \\
319 \\
5,347 \\
64\end{array}$ & $\begin{array}{r}4,521 \\
0 \\
0 \\
0 \\
22,021 \\
14\end{array}$ & $\begin{array}{r}0 \\
0 \\
0 \\
0 \\
7,483 \\
0\end{array}$ & $\begin{array}{r}5,844 \\
0 \\
0 \\
983 \\
18,209 \\
529\end{array}$ & $\begin{array}{r}0 \\
0 \\
0 \\
426 \\
2,710 \\
0\end{array}$ \\
\hline Total Production Expenees ......................... & 8,440 & 6,730 & 27,458 & 7,493 & 25,545 & $*, 138$ \\
\hline $\begin{array}{l}\text { Transmission Expenses ................................. } \\
\text { Distribution Expenses ........................................... } \\
\text { Customer Accounts Expenses ....................... } \\
\text { Customer Service arnd Information }\end{array}$ & $\begin{array}{r}0 \\
262 \\
53\end{array}$ & $\begin{array}{r}1 \\
270 \\
129\end{array}$ & $\begin{array}{r}0 \\
2,647 \\
998\end{array}$ & $\begin{array}{r}0 \\
536 \\
104\end{array}$ & $\begin{array}{l}2232 \\
4,177 \\
1,722\end{array}$ & $\begin{array}{r}0 \\
749 \\
68\end{array}$ \\
\hline 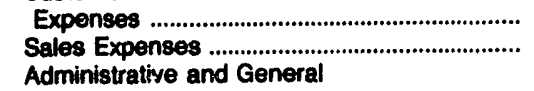 & $\begin{array}{l}13 \\
10\end{array}$ & $\begin{array}{l}3 \\
0\end{array}$ & $\begin{array}{l}0 \\
0\end{array}$ & $\begin{array}{l}20 \\
83\end{array}$ & $\begin{array}{r}169 \\
0\end{array}$ & $\begin{array}{l}0 \\
0\end{array}$ \\
\hline 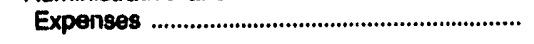 & 174 & 439 & 2,241 & 430 & 3,666 & 353 \\
\hline 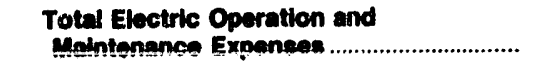 & 8,952 & 7,580 & 33,341 & $8,66 \%$ & 37,511 & 4,305 \\
\hline
\end{tabular}

Note: Totals may not equal sum of components because of incependent rounding.

Source: Energy Irformation Administration, For,n ElA-412, "Annual Report of Pu' Vic Electric Utilities." 
Table 38. Electric Operation and Maintenance Expenses by Major Publicly Owned Electric Utility Within State, 1991 (Continued) (Thousand Dollars)

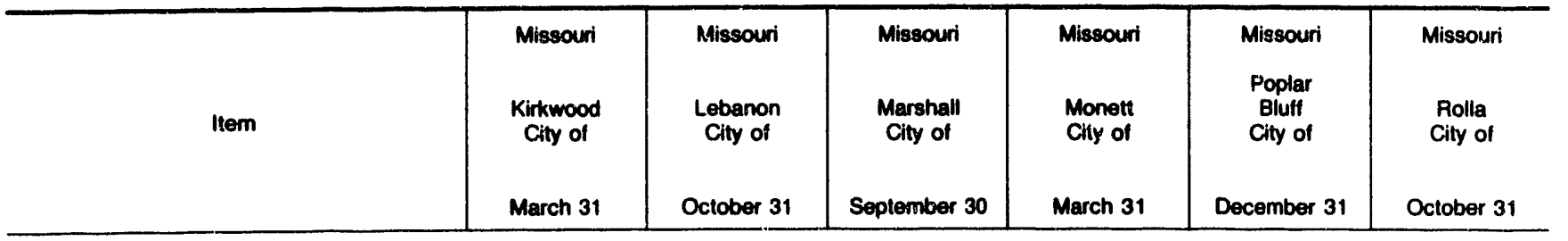

\section{Production Expentes:}

Steam Power Generation

Nuclear Power Generation

Hydraulic Power Generation

Other Power Generation

Purchased Power

Other Production Expenses

Total Production Expenses

Transmission Expenses

Distribution Expenses

Customer Accounts Expenses

Customer Service and Information

Expenses

Sales Expenses

Administrative and General

Expenses

and General

Total Electic Operation and

Mointensence Expenses

0
0
0
0
7,816
0

7,816

0

583

173

$\mathbf{0}$
$\mathbf{0}$

521

9,092
0

0
0
0
5,929

5,929
0

5,929

2,790
0
0
0
0
1,776

4,568

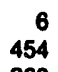

454

0

344

1,365

7,331

5,730

0
0
0
0
4,459
0

0

0
0
8
5,314

5,314
137

4,459

5,480

0
335
0

0
862

862

0

131

$\mathbf{0}$
$\mathbf{0}$

397

................................

9,002

4,801

9,036

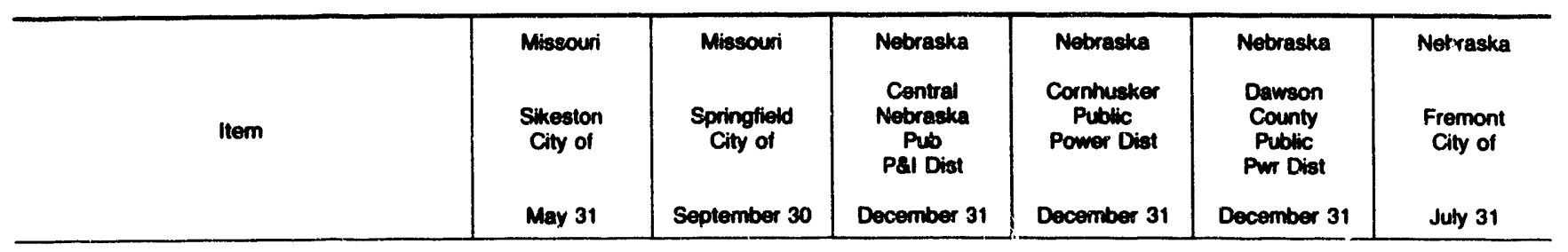

\section{Production Expenses}

Steam Power Generation

Nuclear Power Generation.

Hydraulic Power Generation

Other Power Generation

Other Production Expenses

Totw Productian Exponaes

Transmision Expenses

Distribution Expenses .........................................

Customer Accounts Experses

Customer Sorvice and Information

Expenses

Sexpes Expenses

Administrative and General

Expenses

Toild Electurlc Operation and

Meintenance Expeneses.
30,737

30,737
0
0
0
1,330
0

45,847

0
0
1,419
3,606
0

4,753

0

2,671
0

0
0
0

7,424

32,047

50,872

0
748

155

6,194

6,184
1,570

15
0

0

2,37

6,671

65,477

35,470
42

42
0
0

0

2,874

10,340
0
0
0
0
9,866
0

5,495

0

0

0
654
6

8,158

39

$\$ 06$

6

0

1.738

Note: Totals may not equal sum of components because of independent rcunding.

Source: Energy Information Administration, Form EIA-412, "Annual Report of Public Electric Utilities." 
Table 38. Electric Operation and Maintenance Expenses by Major Publicly Owned Electric Utillty Within State, 1991 (Continued) (Thousand Dollars)

\begin{tabular}{|c|c|c|c|c|c|c|}
\hline Item & $\begin{array}{c}\text { Nebraska } \\
\text { Grand Island } \\
\text { City of } \\
\text { July } 31\end{array}$ & $\begin{array}{c}\text { Nebraska } \\
\text { Hastings } \\
\text { City of } \\
\text { December } 31\end{array}$ & $\begin{array}{c}\text { Nebraska } \\
\text { Lincoln } \\
\text { Electric } \\
\text { System } \\
\text { December } 31\end{array}$ & $\begin{array}{c}\text { Nebraska } \\
\text { Loup } \\
\text { Piver } \\
\text { Public } \\
\text { Power Dist } \\
\text { December } 31\end{array}$ & $\begin{array}{c}\text { Nebraska } \\
\text { Municipal } \\
\text { Energy } \\
\text { Agency } \\
\text { of NE } \\
\text { March } 31\end{array}$ & $\begin{array}{c}\text { Nebraska } \\
\text { Nobraska } \\
\text { Public } \\
\text { Power } \\
\text { District } \\
\text { December } 31\end{array}$ \\
\hline 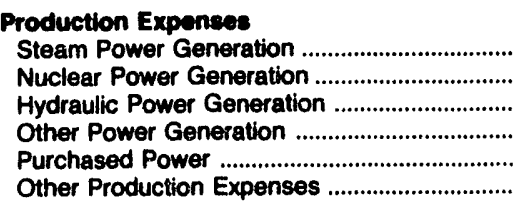 & $\begin{array}{r}6,829 \\
0 \\
0 \\
0 \\
1,051 \\
0\end{array}$ & $\begin{array}{r}5,363 \\
0 \\
0 \\
17 \\
796 \\
0\end{array}$ & $\begin{array}{r}13,076 \\
0 \\
0 \\
734 \\
45,316 \\
917\end{array}$ & $\begin{array}{r}0 \\
0 \\
1,185 \\
0 \\
24,835 \\
0\end{array}$ & $\begin{array}{r}2,110 \\
0 \\
0 \\
0 \\
17,645 \\
0\end{array}$ & $\begin{array}{r}92,601 \\
88,491 \\
2,558 \\
1,156 \\
41,426 \\
867\end{array}$ \\
\hline Total Production Expenses ........................... & 7,880 & 8,176 & 60,043 & 26,021 & 19,755 & 227,099 \\
\hline 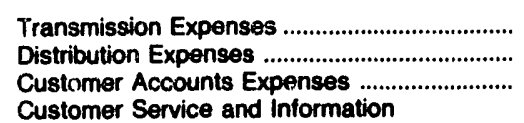 & $\begin{array}{l}119 \\
783 \\
497\end{array}$ & $\begin{array}{r}83 \\
394 \\
244\end{array}$ & $\begin{array}{l}1,986 \\
5,346 \\
1,968\end{array}$ & $\begin{array}{l}163 \\
868 \\
478\end{array}$ & $\begin{array}{r}2,648 \\
0 \\
0\end{array}$ & $\begin{array}{r}11,903 \\
9,203 \\
6,075\end{array}$ \\
\hline 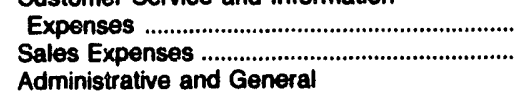 & $\begin{array}{l}0 \\
0\end{array}$ & $\begin{array}{r}36 \\
0\end{array}$ & $\begin{array}{r}1,549 \\
0\end{array}$ & $\begin{array}{r}113 \\
31\end{array}$ & $\begin{array}{l}0 \\
0\end{array}$ & $\begin{array}{l}1,651 \\
4,424\end{array}$ \\
\hline 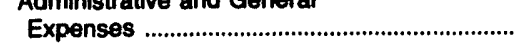 & 2,237 & 1,164 & 5,238 & 1,950 & 1,721 & 29,943 \\
\hline $\begin{array}{l}\text { Total Electric Operation and } \\
\text { Malntenance Expenses .................................. }\end{array}$ & 11,515 & 8,007 & 78,130 & 29,623 & 24,124 & 240,298 \\
\hline
\end{tabular}

\begin{tabular}{|c|c|c|c|c|c|c|}
\hline Item & $\begin{array}{l}\text { Nebraska } \\
\text { Norris } \\
\text { Public } \\
\text { Power } \\
\text { District } \\
\text { December } 31\end{array}$ & $\begin{array}{l}\text { Nebraska } \\
\text { North } \\
\text { Platte } \\
\text { City of } \\
\text { Juhy } 31\end{array}$ & $\begin{array}{l}\text { Nebraska } \\
\text { Omaha Public } \\
\text { Power } \\
\text { District } \\
\\
\text { December } 31\end{array}$ & $\begin{array}{l}\text { Nebraska } \\
\text { Southern } \\
\text { Nebraska Rural } \\
\text { P P D } \\
\text { December } 31\end{array}$ & $\begin{array}{l}\text { Nevada } \\
\text { Colorado } \\
\text { River } \\
\text { Comm } \\
\text { of Nevada } \\
\end{array}$ & $\begin{array}{l}\text { New Jersey } \\
\text { Vineland } \\
\text { City of }\end{array}$ \\
\hline
\end{tabular}

Produktion Exponses

Steam Power Generation

Nuclear Sume; Generation.

Hydraulic Power Generation

Other Power Generation

Other Production Exfynses

Total Froduction Expereses

Transmission Exponses

Distribution Expenses .........................................

Customer Accounts Expenses

Customer Service and Information

Expenses

Sales Expenses ..................................................

Administrative and General

Expenses

\section{Total Eloctic Operation and}

Mointenarve Expentes

0
0
0
0
13,627
0

0
0
0
0
7,639
0

13,627

7,839

47
1,787
384

170

170
0

807

16,023

\section{3}

450
336

76,646

$\mathbf{9 9 , 5 3 7}$

0
1,576

3,894

6,536

189,180

3,523

26,320

10,488

3,782

408

30,882

424

8,955

263,503
0
0
0
0
15,875
0

0

0
0

21,071

21.071

1,371

\section{9}

1,113
376

0
0

0

0

850

1,327

18,828

23,293

Note: Totals may not equal sum of components because of independent rounding.

Source: Energy Information Administration, Form ElA-412, "Annual Report of Public Electric Utilities." 
Table 38. Electric Operation and Maintenance Expenses by Major Publicly Owned Electric Utility Within State, 1991 (Continued) (Thousand Dollars)

\begin{tabular}{|c|c|c|c|c|c|c|}
\hline Itern & $\begin{array}{c}\text { New Mexico } \\
\text { Farmington } \\
\text { City of } \\
\text { June } 30\end{array}$ & $\begin{array}{l}\text { New Mexico } \\
\text { Gallup } \\
\text { City of } \\
\text { June } 30\end{array}$ & $\begin{array}{l}\text { New Mexico } \\
\text { Los Alamos } \\
\text { County } \\
\text { June } 30\end{array}$ & $\begin{array}{l}\text { New York } \\
\text { Fairport } \\
\text { Village of } \\
\text { May } 31\end{array}$ & $\begin{array}{c}\text { New York } \\
\text { Freeport } \\
\begin{array}{c}\text { Village of } \\
\text { Inc }\end{array} \\
\text { February } 28\end{array}$ & $\begin{array}{c}\text { New York } \\
\text { Jamestown } \\
\text { City of } \\
\text { December } 31\end{array}$ \\
\hline 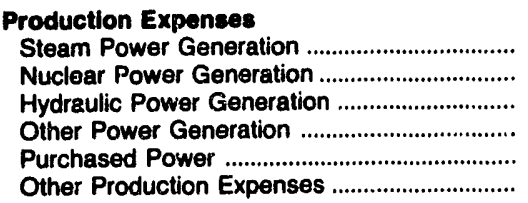 & $\begin{array}{r}9,064 \\
0 \\
408 \\
0 \\
2,183 \\
761\end{array}$ & $\begin{array}{r}0 \\
0 \\
0 \\
0 \\
10,623 \\
0\end{array}$ & $\begin{array}{r}1,263 \\
0 \\
240 \\
0 \\
6,245 \\
472\end{array}$ & $\begin{array}{r}0 \\
0 \\
0 \\
0 \\
5,195 \\
0\end{array}$ & $\begin{array}{r}0 \\
0 \\
0 \\
2,112 \\
4,330 \\
0\end{array}$ & $\begin{array}{r}6,649 \\
0 \\
0 \\
0 \\
4,493 \\
0\end{array}$ \\
\hline Total Production Expenses ............................. & 12,416 & 10,623 & 8,220 & 5,195 & 6,443 & 11,143 \\
\hline 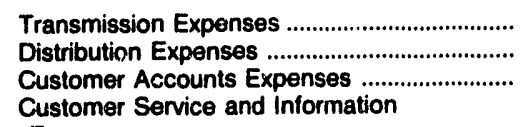 & $\begin{array}{r}335 \\
1,504 \\
740\end{array}$ & $\begin{array}{r}0 \\
145 \\
122\end{array}$ & $\begin{array}{r}2,000 \\
408 \\
75\end{array}$ & $\begin{array}{r}30 \\
1,091 \\
228\end{array}$ & $\begin{array}{r}48 \\
602 \\
499\end{array}$ & $\begin{array}{r}68 \\
880 \\
353\end{array}$ \\
\hline 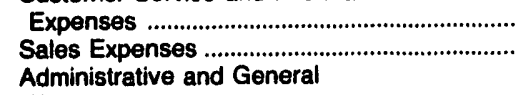 & $\begin{array}{r}19 \\
2\end{array}$ & $\begin{array}{r}202 \\
0\end{array}$ & $\begin{array}{l}2 \\
0\end{array}$ & $\begin{array}{r}0 \\
-20\end{array}$ & $\begin{array}{l}0 \\
0\end{array}$ & $\begin{array}{r}0 \\
-116\end{array}$ \\
\hline 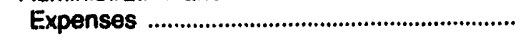 & 928 & 1,030 & 1,440 & 630 & 2,003 & 1,664 \\
\hline $\begin{array}{l}\text { Total Electric Operation and } \\
\text { Maintenance Experises }\end{array}$ & 15,945 & 12,122 & 12,147 & 7,156 & 8,594 & 13,992 \\
\hline
\end{tabular}

\begin{tabular}{|c|c|c|c|c|c|c|}
\hline Item & $\begin{array}{c}\text { New York } \\
\text { Plattsburgh } \\
\text { City of }\end{array}$ & $\begin{array}{c}\text { New York } \\
\text { Power } \\
\text { Authority } \\
\text { of State of NY }\end{array}$ & $\begin{array}{l}\text { New York } \\
\text { Rockville } \\
\text { Centre } \\
\text { Village of }\end{array}$ & $\begin{array}{l}\text { North Carolina } \\
\text { Albemarle } \\
\text { City of }\end{array}$ & $\begin{array}{c}\text { North Carolina } \\
\text { Concord } \\
\text { City of }\end{array}$ & $\begin{array}{c}\text { North Carolina } \\
\text { Elizabeth } \\
\text { City City of }\end{array}$ \\
\hline & December 31 & December 31 & May 31 & June 30 & June 30 & June 30 \\
\hline
\end{tabular}

Production Expenses

Steam Power Generation

Nuclear Power Generation

Hydraulic Power Generation

Other Power Generation .

Purchased Power ...................

Other Production Expenses

Total Production Expenses

Transmission Expenses

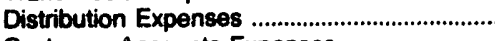

Customer Accounts Expenses .

Customer Service and Information

Expenses ...........................................................

Salas Expenses ..................................................

Administrative and General

Expenses

\section{Total Electric Operation and}

Malntenance Expenses

$\begin{array}{rr}0 & 100,351 \\ 0 & 260,264 \\ 0 & 45,829 \\ 0 & 0 \\ 4,751 & 76,186 \\ 0 & 0\end{array}$

4,751

403
818

512

0

$-12$

789

7,261

168,362

931,248

0
0
0
3,496
2,481
0

5,977

117

1,015

262

0

263

7,634
0
0
0
0
12,262
0

12,282

0
559

559
0

0

0

12,821 $\begin{array}{rr}0 & 0 \\ 0 & 0 \\ 0 & 0 \\ 0 & 0 \\ 15,904 & 13,360 \\ 0 & 0\end{array}$

15,904

13,360

0
3,261

1,619
0

175

53

20,185

15,207

Note: Totals may not equal sum of components tecause of independent rounding.

Source: Energ]' Information Administration, Form EIA-412, "Annual Report of Public Electric Utilities." 
Table 38. Electric Operation and Maintenance Expenses by Major Publicly Owned Electric Utility Within State, 1991 (Continued) (Thousand Dollars)

\begin{tabular}{|c|c|c|c|c|c|c|}
\hline Item & $\begin{array}{l}\text { North Carolina } \\
\text { Fayetteville } \\
\text { Public } \\
\text { Works Comm } \\
\text { June } 30\end{array}$ & $\begin{array}{l}\text { North Carolina } \\
\text { Gastonia } \\
\text { City of } \\
\text { June } 30\end{array}$ & $\begin{array}{c}\text { North Carolina } \\
\text { Greenville } \\
\text { Utilities } \\
\text { Comm } \\
\text { June } 30\end{array}$ & $\begin{array}{l}\text { North Carolina } \\
\text { High } \\
\text { Point } \\
\text { Town } \\
\text { of } \\
\text { June } 30\end{array}$ & $\begin{array}{l}\text { North Carolina } \\
\text { Kinston } \\
\text { City of } \\
\text { June } 30\end{array}$ & $\begin{array}{l}\text { North Carolina } \\
\text { Lexington } \\
\text { City of } \\
\text { June } 30\end{array}$ \\
\hline 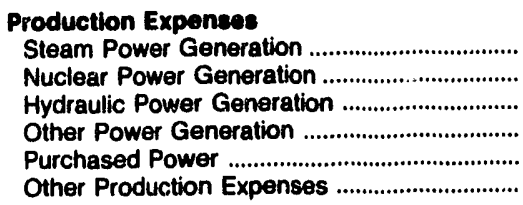 & $\begin{array}{r}0 \\
0 \\
0 \\
10,627 \\
65,983 \\
5\end{array}$ & $\begin{array}{r}0 \\
0 \\
0 \\
0 \\
25,357 \\
0\end{array}$ & $\begin{array}{r}0 \\
0 \\
0 \\
0 \\
66,882 \\
0\end{array}$ & $\begin{array}{r}0 \\
0 \\
0 \\
0 \\
37,987 \\
437\end{array}$ & $\begin{array}{r}0 \\
0 \\
0 \\
0 \\
24,958 \\
0\end{array}$ & $\begin{array}{r}0 \\
0 \\
0 \\
0 \\
20,429 \\
0\end{array}$ \\
\hline Total Production Expenses .......................... & 78,615 & 25,357 & 68,882 & 38,424 & 24,958 & 20,429 \\
\hline 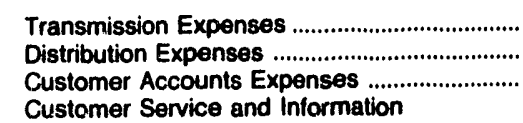 & $\begin{array}{r}164 \\
4,144 \\
1,507\end{array}$ & $\begin{array}{r}0 \\
1,635 \\
0\end{array}$ & $\begin{array}{r}95 \\
2,338 \\
723\end{array}$ & $\begin{array}{r}2,334 \\
809 \\
624\end{array}$ & $\begin{array}{r}0 \\
2,617 \\
0\end{array}$ & $\begin{array}{r}0 \\
93 \\
377\end{array}$ \\
\hline 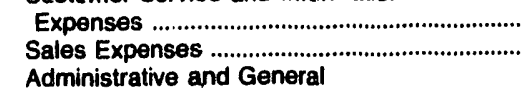 & $\begin{array}{r}121 \\
0\end{array}$ & $\begin{array}{l}0 \\
0\end{array}$ & $\begin{array}{l}400 \\
105\end{array}$ & $\begin{array}{r}523 \\
0\end{array}$ & $\begin{array}{l}0 \\
0\end{array}$ & $\begin{array}{r}233 \\
0\end{array}$ \\
\hline 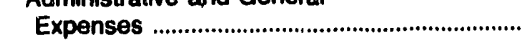 & 2,627 & 684 & 3,563 & 1,503 & 1,047 & 1,748 \\
\hline $\begin{array}{l}\text { Total Electric Operation and } \\
\text { Maintenance Expenses ................................. }\end{array}$ & 85,179 & 27,676 & 74,108 & 4,217 & 28,622 & 22,881 \\
\hline
\end{tabular}

\begin{tabular}{|c|c|c|c|c|c|c|}
\hline Item & $\begin{array}{l}\text { North Carolina } \\
\text { Lumberton } \\
\text { City of } \\
\text { June } 30\end{array}$ & $\begin{array}{l}\text { North Carolina } \\
\text { Monroe } \\
\text { City of } \\
\text { June } 30\end{array}$ & $\begin{array}{l}\text { North Carolina } \\
\text { Morganton } \\
\text { City of } \\
\text { June } 30\end{array}$ & $\begin{array}{l}\text { North Carolina } \\
\text { Murphy } \\
\text { City of } \\
\text { June } 30\end{array}$ & $\begin{array}{l}\text { North Carolina } \\
\text { New Bern } \\
\text { City of } \\
\text { June } 30\end{array}$ & $\begin{array}{l}\text { North Carolina } \\
\text { New River } \\
\text { Light } \\
\text { Power Co } \\
\text { December } 31\end{array}$ \\
\hline 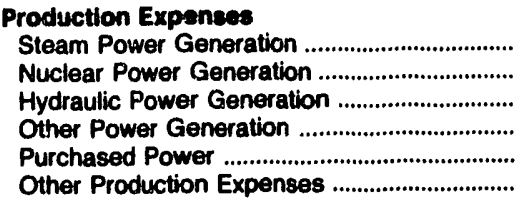 & $\begin{array}{r}0 \\
0 \\
0 \\
0 \\
17,002 \\
0\end{array}$ & $\begin{array}{r}0 \\
0 \\
0 \\
0 \\
18,603 \\
0\end{array}$ & $\begin{array}{r}0 \\
0 \\
0 \\
0 \\
11,182 \\
0\end{array}$ & $\begin{array}{r}0 \\
0 \\
0 \\
0 \\
6,578 \\
0\end{array}$ & $\begin{array}{r}0 \\
0 \\
0 \\
0 \\
22,118 \\
243\end{array}$ & $\begin{array}{r}0 \\
0 \\
0 \\
0 \\
8,134 \\
0\end{array}$ \\
\hline Total Production Expensese .......................... & 17,002 & 18,603 & 11,182 & 6,578 & 22,360 & 8,134 \\
\hline 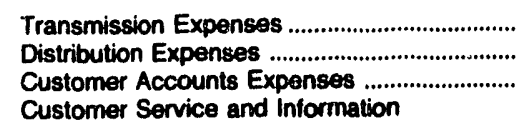 & $\begin{array}{l}411 \\
815 \\
155\end{array}$ & $\begin{array}{r}0 \\
613 \\
112\end{array}$ & $\begin{array}{l}0 \\
0 \\
0\end{array}$ & $\begin{array}{r}0 \\
303 \\
58\end{array}$ & $\begin{array}{r}0 \\
529 \\
100\end{array}$ & $\begin{array}{r}0 \\
388 \\
289\end{array}$ \\
\hline 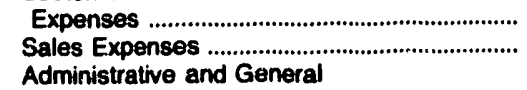 & $\begin{array}{l}0 \\
0\end{array}$ & $\begin{array}{l}0 \\
0\end{array}$ & $\begin{array}{l}0 \\
0\end{array}$ & $\begin{array}{r}8 \\
12\end{array}$ & $\begin{array}{l}0 \\
0\end{array}$ & $\begin{array}{r}20 \\
0\end{array}$ \\
\hline 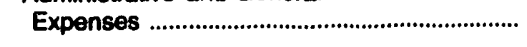 & 458 & 43 & 1,862 & 333 & 1,610 & 306 \\
\hline 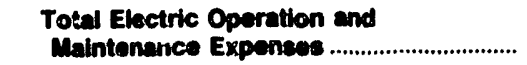 & 18,841 & 10,371 & 13,044 & $7,8: 2$ & 24,600 & 9,137 \\
\hline
\end{tabular}

Note: Totals may not equal sum of components because of independent rounding.

Source: Energy Informatior. Administration, Form ElA-412, "Annual Report of Public Electric Utilities." 
Table 38. Electric Operation and Maintenance Expenses by Major Publicly Owned Electric Utility Within State, 1991 (Continued) (Thousand Dollars)

\begin{tabular}{|c|c|c|c|c|c|c|}
\hline Item & $\begin{array}{c}\text { North Carolina } \\
\text { North } \\
\text { Carolina } \\
\text { Eastern M P A } \\
\text { December } 31\end{array}$ & $\begin{array}{c}\text { North Carolina } \\
\text { North } \\
\text { Carolina } \\
\text { Mun } \\
\text { Power Agny } \\
\text { December } 31\end{array}$ & $\begin{array}{c}\text { North Carolina } \\
\text { Rocky Mount } \\
\text { City of } \\
\text { June } 30\end{array}$ & $\begin{array}{l}\text { North Carolina } \\
\text { Shelby } \\
\text { City of } \\
\text { June } 30\end{array}$ & $\begin{array}{l}\text { North Carolina } \\
\text { Statesville } \\
\text { City of } \\
\text { June } 30\end{array}$ & $\begin{array}{c}\text { North Carolina } \\
\text { Tarboro } \\
\text { Town of } \\
\text { June } 30\end{array}$ \\
\hline 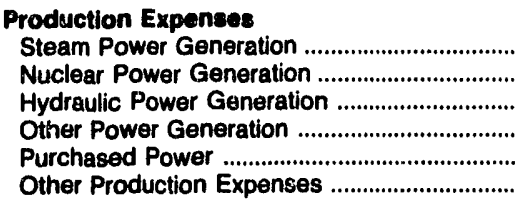 & $\begin{array}{r}24,215 \\
49,477 \\
0 \\
0 \\
122,018 \\
4,112\end{array}$ & $\begin{array}{r}0 \\
92,782 \\
0 \\
0 \\
121,469 \\
13,283\end{array}$ & $\begin{array}{r}0 \\
0 \\
0 \\
0 \\
47,768 \\
0\end{array}$ & $\begin{array}{r}0 \\
0 \\
0 \\
0 \\
7,744 \\
152\end{array}$ & $\begin{array}{r}0 \\
0 \\
0 \\
0 \\
16,518 \\
0\end{array}$ & $\begin{array}{r}0 \\
0 \\
0 \\
0 \\
14,223 \\
0\end{array}$ \\
\hline Totel Production Expenses .......................... & 199,822 & 227,534 & 47,768 & 7,896 & 16,518 & 14,223 \\
\hline 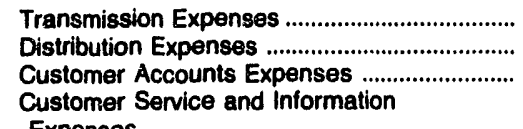 & $\begin{array}{r}15,461 \\
2,190 \\
0\end{array}$ & $\begin{array}{r}9,708 \\
2,153 \\
0\end{array}$ & $\begin{array}{l}0 \\
0 \\
0\end{array}$ & $\begin{array}{r}0 \\
1,279 \\
0\end{array}$ & $\begin{array}{l}0 \\
0 \\
0\end{array}$ & $\begin{array}{l}0 \\
0 \\
0\end{array}$ \\
\hline 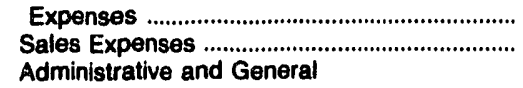 & $\begin{array}{l}0 \\
0\end{array}$ & $\begin{array}{l}0 \\
0\end{array}$ & $\begin{array}{l}0 \\
0\end{array}$ & $\begin{array}{l}0 \\
0\end{array}$ & $\begin{array}{l}0 \\
0\end{array}$ & $\begin{array}{l}\mathbf{0} \\
\mathbf{0}\end{array}$ \\
\hline 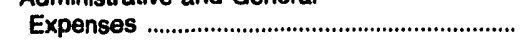 & 31,184 & 23,405 & 3,816 & 0 & 1,610 & 1,074 \\
\hline $\begin{array}{l}\text { Total Electric Operation and } \\
\text { Maintenance Expenses ............................... }\end{array}$ & 248,657 & 262,800 & 51,585 & 9,176 & 18,128 & 15,297 \\
\hline
\end{tabular}

\begin{tabular}{|c|c|c|c|c|c|c|}
\hline Item & $\begin{array}{c}\text { North Carolina } \\
\text { Washington } \\
\text { City of } \\
\text { June } 30\end{array}$ & $\begin{array}{l}\text { North Carolina } \\
\text { Wilson } \\
\text { City of } \\
\text { June } 30\end{array}$ & $\begin{array}{c}\text { Ohio } \\
\text { American } \\
\text { Mun } \\
\text { Power } \\
\text { Ohio Inc } \\
\text { December } 31\end{array}$ & $\begin{array}{c}\text { Ohio } \\
\text { Bowling } \\
\text { Green } \\
\text { City of } \\
\text { December } 31\end{array}$ & $\begin{array}{c}\text { Ohio } \\
\text { Bryan } \\
\text { City of } \\
\text { December } 31\end{array}$ & $\begin{array}{l}\text { Ohio } \\
\text { Celina } \\
\text { City of } \\
\text { December } 31\end{array}$ \\
\hline
\end{tabular}

Production Expenses

Steam Power Generation

Nuclear Power Generation

Hydraulic Power Generation

Other Power Generation

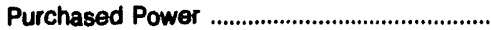

Other Production Expenses

Total Production Expenses

Transmission Expenses .

Distribution Expenses

Customer Accounts Expenses

Customer Service and Information

Expenses

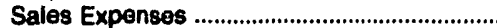

Administrative and General

Expenses

Total Electric Uperation and

Maintenance Expenses.

$\begin{array}{rr}0 & 0 \\ 0 & 0 \\ 0 & 0 \\ 0 & 0 \\ 15,281 & 57,880 \\ 0 & 0 \\ 15,281 & 57,880\end{array}$

0

1,092
0

0

0

467

16,840

$20,40 \theta$
0
0
410
99,832

0

120,651

0

2,454
1,627

0

1,829

63,841

0
0
0
0
11,309
0

0
0

0
6,171

11,300

6,171

$\begin{array}{rr}0 & 221\end{array}$

1,017

420

0
0

0

487

487
128

0

0

2,199

141

604

13,736

8,370

6,657

Note: Totals may not equal sum of components because of independent rounding.

Source: Energy Information Administration, Form ElA-412, "Annual Report of Public Electric Utilities." 
Table 38. Electric Operation and Maintenance Expenses by Major Publicly Owned Electric Utillty Within State, 1991 (Continued) (Thousand Dollars)

\begin{tabular}{|c|c|c|c|c|c|c|}
\hline Item & $\begin{array}{c}\text { Ohio } \\
\text { Clevelend } \\
\text { City of } \\
\text { December } 31\end{array}$ & $\begin{array}{c}\text { Ohio } \\
\text { Columbus } \\
\text { City of } \\
\text { December } 31\end{array}$ & $\begin{array}{c}\text { Ohio } \\
\text { Cuyahoga } \\
\text { Falis } \\
\text { City of } \\
\text { December } 31\end{array}$ & $\begin{array}{c}\text { Ohio } \\
\text { Dover } \\
\text { City of } \\
\text { December } 31\end{array}$ & $\begin{array}{c}\text { Ohio } \\
\begin{array}{c}\text { Hamilton } \\
\text { City of }\end{array} \\
\text { December } 31\end{array}$ & $\begin{array}{c}\text { Ohio } \\
\text { Niles } \\
\text { City of } \\
\text { December } 31\end{array}$ \\
\hline 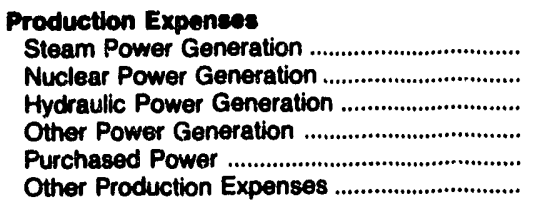 & $\begin{array}{r}186 \\
0 \\
0 \\
548 \\
24,788 \\
0\end{array}$ & $\begin{array}{r}2,071 \\
0 \\
173 \\
20,998 \\
9,586 \\
0\end{array}$ & $\begin{array}{r}0 \\
0 \\
0 \\
0 \\
13,110 \\
0\end{array}$ & $\begin{array}{r}2,092 \\
0 \\
0 \\
0 \\
3,562 \\
106\end{array}$ & $\begin{array}{r}10,532 \\
0 \\
818 \\
184 \\
5,363 \\
1,019\end{array}$ & $\begin{array}{r}0 \\
0 \\
0 \\
0 \\
10,338 \\
2,790\end{array}$ \\
\hline Total Production Expences .......................... & 25,522 & 32,828 & 13,110 & 5,760 & 17,916 & 13,127 \\
\hline 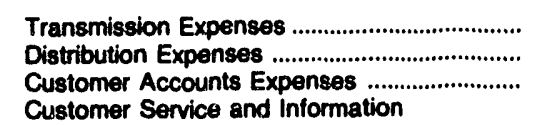 & $\begin{array}{r}548 \\
11,144 \\
1,310\end{array}$ & $\begin{array}{r}0 \\
3,591 \\
392\end{array}$ & $\begin{array}{r}0 \\
1,295 \\
440\end{array}$ & $\begin{array}{r}0 \\
1,152 \\
0\end{array}$ & $\begin{array}{r}296 \\
1,451 \\
525\end{array}$ & $\begin{array}{l}0 \\
0 \\
0\end{array}$ \\
\hline 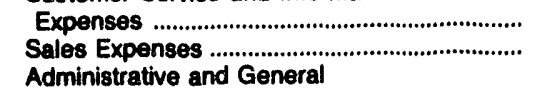 & $\begin{array}{r}289 \\
0\end{array}$ & $\begin{array}{r}106 \\
0\end{array}$ & $\begin{array}{l}0 \\
0\end{array}$ & $\begin{array}{l}0 \\
0\end{array}$ & $\begin{array}{l}0 \\
0\end{array}$ & $\begin{array}{l}0 \\
0\end{array}$ \\
\hline 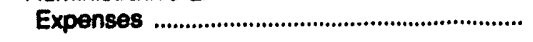 & 3,616 & 15,149 & 1,898 & 0 & 3,486 & 101 \\
\hline $\begin{array}{l}\text { Total Electric Operation and } \\
\text { Maintenance Expences }\end{array}$ & 42,430 & 52,066 & 16,744 & 6,912 & 23,673 & 13,228 \\
\hline
\end{tabular}

\begin{tabular}{|c|c|c|c|c|c|c|}
\hline \multirow{3}{*}{ Item } & Ohio & Onio & Ohio & Ohio & Ohio & Ohio \\
\hline & $\begin{array}{l}\text { Orrville } \\
\text { City of }\end{array}$ & $\begin{array}{c}\text { Painesville } \\
\text { City of }\end{array}$ & $\begin{array}{l}\text { Piqua } \\
\text { City of }\end{array}$ & $\begin{array}{l}\text { St Marys } \\
\text { City of }\end{array}$ & $\begin{array}{c}\text { Wadsworth } \\
\text { City of }\end{array}$ & $\begin{array}{c}\text { Wapakoneta } \\
\text { City of }\end{array}$ \\
\hline & December 31 & December 31 & December 31 & December 31 & December 31 & December 31 \\
\hline
\end{tabular}

\section{Production Expenses}

Steam Power Generation

Nuclear Power Generation

Hydraulic Power Generation

Other Power Generation

Purchased Power

Other Production Expenses

Total Production Expenses

Transmission Expenses

Distribution Expenses ...

Customer Sorvice and Information

Expenses

Sales Expenses ...................................................

Administrative and General

Expenses

Total Electric Operation and

Meintenance Expenses.
Customer Accounts Expenses .........................

$\begin{array}{rr}6,069 & 3,269 \\ 0 & 0 \\ 0 & 0 \\ 0 & 0 \\ 2,878 & 1,089 \\ 0 & 0\end{array}$

8,946

$$
\begin{array}{r}
0 \\
748 \\
0
\end{array}
$$

$$
5,383
$$

$$
\begin{aligned}
& 0 \\
& 0
\end{aligned}
$$

1,883

11,577
4,358

383
0

6,129
0
0
0
3,621
56

8,006

37

598
214

0

94

802

0

0,741

11,551 $\begin{array}{rr}0 & 0 \\ 0 & 0 \\ 0 & 0 \\ 0 & 0 \\ 7,600 & 4,707 \\ 0 & 0\end{array}$

7,600

4,707

4,466

\section{0}

1,384
194

0

975
69

0

73

Note: Totals may not equal sum of components because of inidependent rounding.

Source: Eneroy Information Administration, Form EIA-412, "Annual Report of Public Electric Utilities." 
Table 38. Electric Operation and Maintenance Expenses by Major Publicly Owned Electric Utility Within State, 1991 (Continued) (Thousand Dollars)

\begin{tabular}{|c|c|c|c|c|c|c|}
\hline Item & $\begin{array}{c}\text { Onio } \\
\text { Westerville } \\
\text { City of }\end{array}$ & $\begin{array}{l}\text { Oklahoma } \\
\text { Altus } \\
\text { City of } \\
\text { June } 30\end{array}$ & $\begin{array}{l}\text { Oklahoma } \\
\text { Claremore } \\
\text { City of } \\
\text { June } 30\end{array}$ & $\begin{array}{l}\text { Oklahoma } \\
\text { Edmond } \\
\text { City of } \\
\text { June } 30\end{array}$ & $\begin{array}{c}\text { Oklahoma } \\
\text { Grand River } \\
\text { Dam } \\
\text { Authority } \\
\text { December } 31\end{array}$ & $\begin{array}{c}\text { Oklahoma } \\
\text { Oklahoma } \\
\text { Municipal } \\
\text { Power Auth } \\
\text { December } 31\end{array}$ \\
\hline 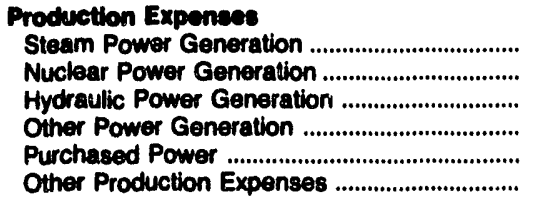 & $\begin{array}{r}0 \\
0 \\
0 \\
0 \\
10,272 \\
0\end{array}$ & $\begin{array}{r}0 \\
0 \\
0 \\
0 \\
6,093 \\
996\end{array}$ & $\begin{array}{r}0 \\
0 \\
0 \\
0 \\
7,900 \\
897\end{array}$ & $\begin{array}{r}0 \\
0 \\
0 \\
0 \\
19,137 \\
0\end{array}$ & $\begin{array}{r}58,945 \\
0 \\
3,093 \\
0 \\
7,195 \\
0\end{array}$ & $\begin{array}{r}12,498 \\
0 \\
215 \\
0 \\
27,720 \\
0\end{array}$ \\
\hline Total Production Expenses .............................. & 10,272 & 7,000 & 8,707 & 19,137 & 68,233 & 40,434 \\
\hline 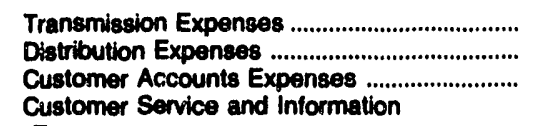 & $\begin{array}{r}0 \\
2,312 \\
0\end{array}$ & $\begin{array}{l}0 \\
0 \\
0\end{array}$ & $\begin{array}{l}0 \\
0 \\
0\end{array}$ & $\begin{array}{r}0 \\
1,173 \\
145\end{array}$ & $\begin{array}{r}5,084 \\
0 \\
283\end{array}$ & $\begin{array}{r}9,228 \\
0 \\
0\end{array}$ \\
\hline 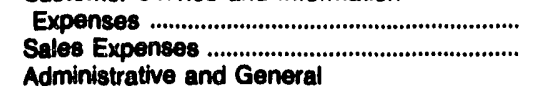 & $\begin{array}{l}0 \\
0\end{array}$ & $\begin{array}{l}0 \\
0\end{array}$ & $\begin{array}{l}0 \\
0\end{array}$ & $\begin{array}{r}216 \\
0\end{array}$ & $\begin{array}{r}51 \\
0\end{array}$ & $\begin{array}{l}0 \\
0\end{array}$ \\
\hline 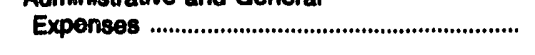 & 118 & 0 & 0 & 274 & 8,486 & 1,594 \\
\hline 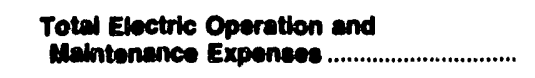 & 12,701 & 7,090 & 8,797 & 20,945 & 83,136 & 51,258 \\
\hline
\end{tabular}

\begin{tabular}{|c|c|c|c|c|c|c|}
\hline Item & $\begin{array}{l}\text { Oklahoma } \\
\text { Ponca } \\
\text { City City of } \\
\text { June } 30\end{array}$ & $\begin{array}{l}\text { Oklahoma } \\
\text { Stillwater } \\
\text { Utilities } \\
\text { Authority } \\
\text { June } 30\end{array}$ & $\begin{array}{l}\text { Oregon } \\
\text { Ashland } \\
\text { City of } \\
\text { June } 30\end{array}$ & $\begin{array}{l}\text { Oregon } \\
\text { Central } \\
\text { Lincoln } \\
\text { Peoples } \\
\text { Uti Dt } \\
\text { December 3i }\end{array}$ & $\begin{array}{c}\text { Oregon } \\
\text { Clatskanie } \\
\text { Peoples } \\
\text { Util Dist } \\
\text { December } 31\end{array}$ & $\begin{array}{c}\text { Oregon } \\
\text { Columbia } \\
\text { River } \\
\text { Peoples } \\
\text { UI Dist } \\
\text { December } 31\end{array}$ \\
\hline 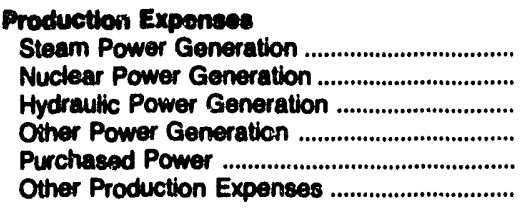 & $\begin{array}{r}663 \\
0 \\
0 \\
442 \\
11,684 \\
0\end{array}$ & $\begin{array}{r}146 \\
0 \\
0 \\
0 \\
10,602 \\
0\end{array}$ & $\begin{array}{r}0 \\
0 \\
0 \\
0 \\
4,024 \\
14\end{array}$ & $\begin{array}{r}0 \\
0 \\
0 \\
0 \\
32,518 \\
0\end{array}$ & $\begin{array}{r}0 \\
0 \\
0 \\
0 \\
19,828 \\
0\end{array}$ & $\begin{array}{r}0 \\
0 \\
0 \\
0 \\
6,301 \\
0\end{array}$ \\
\hline Total Production Expeneses ............................ & 12,708 & 10,748 & 4,038 & 32,518 & 18,828 & 6,301 \\
\hline 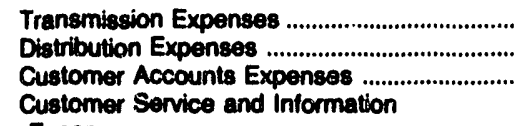 & $\begin{array}{r}0 \\
1,008 \\
0\end{array}$ & $\begin{array}{r}173 \\
1,405 \\
15\end{array}$ & $\begin{array}{r}0 \\
438 \\
0\end{array}$ & $\begin{array}{r}0 \\
2,661 \\
946\end{array}$ & $\begin{array}{r}0 \\
410 \\
171\end{array}$ & $\begin{array}{r}0 \\
866 \\
364\end{array}$ \\
\hline $\begin{array}{l}\text { Expenses } \\
\text { Sales Expenses } \\
\text { Administrative and Generai }\end{array}$ & $\begin{array}{r}109 \\
0\end{array}$ & $\begin{array}{r}235 \\
51\end{array}$ & $\begin{array}{r}478 \\
0\end{array}$ & $\begin{array}{r}244 \\
0\end{array}$ & $\begin{array}{r}100 \\
0\end{array}$ & $\begin{array}{l}204 \\
110\end{array}$ \\
\hline Expenses & 0 & 1,027 & 970 & 2,172 & 787 & 1,025 \\
\hline $\begin{array}{l}\text { Total Electric Operation and } \\
\text { Medmienence Expenees .................................. }\end{array}$ & 13,005 & 13,655 & 5,026 & 38,540 & 21,296 & 8,080 \\
\hline
\end{tabular}

Note: Totals may not equal sum of components becsuse of independent rounding.

Source: Energy Information Administration, Form EIA-412, "Annual Report of Public Electric Utilities." 
Table 38. Electric Operation and Maintenance Expenses by Major Publicly Owned Electric Utility Within State, 1991 (Continued) (Thousand Dollars)

\begin{tabular}{|c|c|c|c|c|c|c|}
\hline Item & $\begin{array}{l}\text { Oregon } \\
\text { Emerald } \\
\text { Peoples } \\
\text { Utility Dist } \\
\text { December } 31\end{array}$ & $\begin{array}{l}\text { Oregon } \\
\text { Eugene } \\
\text { City of } \\
\text { December } 31\end{array}$ & $\begin{array}{c}\text { Oregon } \\
\text { Forest Grove } \\
\text { City of } \\
\text { June } 30\end{array}$ & $\begin{array}{c}\text { Oregon } \\
\begin{array}{c}\text { McMinnville } \\
\text { City of }\end{array} \\
\text { June } 30\end{array}$ & $\begin{array}{l}\text { Oregon } \\
\text { Northern } \\
\text { Wasco County } \\
\text { P U D } \\
\text { December } 31\end{array}$ & $\begin{array}{c}\text { Oregon } \\
\begin{array}{c}\text { Springfield } \\
\text { Clty of }\end{array} \\
\text { December } 31\end{array}$ \\
\hline 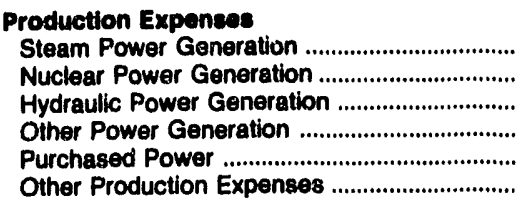 & $\begin{array}{r}0 \\
0 \\
0 \\
0 \\
8,949 \\
0\end{array}$ & $\begin{array}{r}3,425 \\
0 \\
1,822 \\
0 \\
43,674 \\
1,093\end{array}$ & $\begin{array}{r}0 \\
0 \\
0 \\
0 \\
4,058 \\
0\end{array}$ & $\begin{array}{r}0 \\
0 \\
0 \\
0 \\
10,127 \\
0\end{array}$ & $\begin{array}{r}0 \\
0 \\
0 \\
0 \\
5,727 \\
0\end{array}$ & $\begin{array}{r}0 \\
0 \\
0 \\
0 \\
18,111 \\
0\end{array}$ \\
\hline Total Production Exponses .......................... & 8,249 & 50,115 & 4,058 & 10,127 & 6,727 & 18,111 \\
\hline 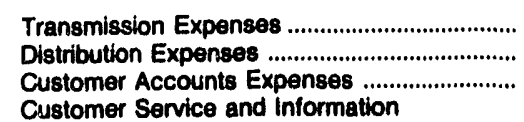 & $\begin{array}{r}0 \\
745 \\
547\end{array}$ & $\begin{array}{l}1,329 \\
6,114 \\
2,834\end{array}$ & $\begin{array}{r}0 \\
417 \\
75\end{array}$ & $\begin{array}{r}0 \\
768 \\
121\end{array}$ & $\begin{array}{r}7 \\
546 \\
217\end{array}$ & $\begin{array}{r}0 \\
838 \\
695\end{array}$ \\
\hline 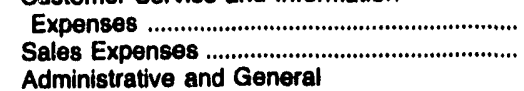 & $\begin{array}{r}301 \\
0\end{array}$ & $\begin{array}{r}2,298 \\
0\end{array}$ & $\begin{array}{l}0 \\
0\end{array}$ & $\begin{array}{l}0 \\
0\end{array}$ & $\begin{array}{r}116 \\
0\end{array}$ & $\begin{array}{r}471 \\
0\end{array}$ \\
\hline 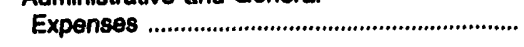 & 480 & 9,128 & 972 & 640 & 661 & 851 \\
\hline $\begin{array}{l}\text { Total Electric Operation and } \\
\text { Malntenance Expenses ................................. }\end{array}$ & 11,022 & 71,816 & 5,522 & 11,655 & 7,274 & 20,867 \\
\hline
\end{tabular}

\begin{tabular}{|c|c|c|c|c|c|c|}
\hline Item & $\begin{array}{c}\text { Cregon } \\
\text { Tillamook } \\
\text { Peoples } \\
\text { Utility Dist } \\
\text { December } 31\end{array}$ & $\begin{array}{c}\text { Pennsyivania } \\
\text { Chambersburg } \\
\text { Borough of } \\
\text { December } 31\end{array}$ & $\begin{array}{l}\text { South Carolina } \\
\text { Camden } \\
\text { rity of } \\
\text { June } 30\end{array}$ & $\begin{array}{l}\text { South Carolina } \\
\text { Easley } \\
\text { Combined } \\
\text { Utility } \\
\text { System } \\
\text { March } 31\end{array}$ & $\begin{array}{l}\text { South Carolina } \\
\text { Gatiney } \\
\text { City of } \\
\text { March } 31\end{array}$ & $\begin{array}{l}\text { South Carolina } \\
\text { Greenwood } \\
\text { City of } \\
\text { necember } 31\end{array}$ \\
\hline
\end{tabular}

\section{Production Expenses}

Steam Power Generation

Nuclear Power Generatior

Hydraulic Power Generation

Other Power Generation

Other Production Expenses

Total Production Expenses

Transmission Expenses .

Distribution Expense8 ........................................

Customer Service and Information

Expenses ...

Sales Expenses

Administrative and Genera

Expenses

Total Eloctric Operation and

Meintenence Expeness .......

$\begin{array}{rr}0 & \\ 0 & \\ 0 & \\ 0 & \\ 8,248 & 8,208 \\ 0 & 308\end{array}$

$8,249 \quad 8,690$

$0 \quad 36$

1,552

384

234

51

1,568

12,034

$\begin{array}{rr}0 & 0 \\ 0 & 0 \\ 0 & 0 \\ 153 & 0 \\ 8,205 & 8,513 \\ 302 & 794\end{array}$

10,308

0
0

0
0
0

176

0
0

385

9,732

0

0

10,908

0
0
0
0
9,401
0

0
0
0
0
8,054
0

0

0

0

9,898

0,401

8,054

9,898

0
887

687
43

$\begin{array}{rr}0 & 0 \\ 755 & 734\end{array}$

0

72

○

398

0
0

0
0

457

10,536

9,784

11,181

Note: Totals may not squal sum of components because of independent rounding.

Source: Enargy Inforritation Administration, Form EIA-412, "Annual Pieport of Public Electric Utilities." 
Table 38. Electric Operation and Maintenance Expenses by Major Publicly Owned Electric Utility Within State, 1991 (Continued) (Thousand Dollars)

\begin{tabular}{|c|c|c|c|c|c|c|}
\hline Item & $\begin{array}{c}\text { South Carolina } \\
\text { Greer } \\
\text { Comm } \\
\text { of } \\
\text { Public Works } \\
\text { December } 31\end{array}$ & $\begin{array}{l}\text { South Carolina } \\
\text { Newberry } \\
\text { City of } \\
\text { June } 30\end{array}$ & $\begin{array}{l}\text { South Carolina } \\
\text { Orangeburg } \\
\text { City of } \\
\text { September } 30\end{array}$ & $\begin{array}{l}\text { South Carolina } \\
\text { Piedmont } \\
\text { Municipal } \\
\text { Power Agny } \\
\text { December } 31\end{array}$ & $\begin{array}{l}\text { South Carolina } \\
\text { Rock Hill } \\
\text { City of }\end{array}$ & $\begin{array}{c}\text { South Carolina } \\
\text { South } \\
\text { Carolina } \\
\text { Pub } \\
\text { Serv Auth } \\
\text { December } 31\end{array}$ \\
\hline 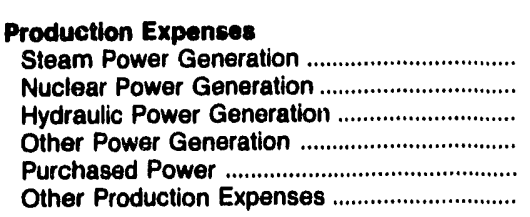 & $\begin{array}{r}0 \\
0 \\
0 \\
0 \\
6,511 \\
0\end{array}$ & $\begin{array}{r}0 \\
0 \\
0 \\
0 \\
6,620 \\
0\end{array}$ & $\begin{array}{r}0 \\
0 \\
0 \\
475 \\
24,297 \\
0\end{array}$ & $\begin{array}{r}0 \\
40,286 \\
0 \\
0 \\
40,929 \\
0\end{array}$ & $\begin{array}{r}0 \\
0 \\
0 \\
0 \\
23,362 \\
0\end{array}$ & $\begin{array}{r}233,606 \\
30,880 \\
4,877 \\
1,188 \\
9,220 \\
571\end{array}$ \\
\hline Total Production Expenses ............................ & 6,511 & 6,620 & 24,773 & 81,215 & 23,362 & 280,342 \\
\hline 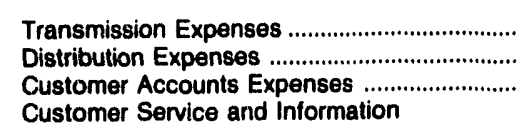 & $\begin{array}{r}1,099 \\
0 \\
60\end{array}$ & $\begin{array}{r}0 \\
315 \\
62\end{array}$ & $\begin{array}{r}2,200 \\
0 \\
0\end{array}$ & $\begin{array}{r}4,943 \\
0 \\
0\end{array}$ & $\begin{array}{r}0 \\
2,310 \\
0\end{array}$ & $\begin{array}{l}9,356 \\
6,393 \\
2,754\end{array}$ \\
\hline 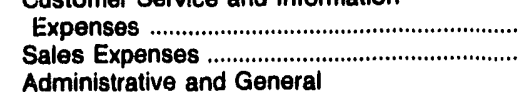 & $\begin{array}{l}0 \\
0\end{array}$ & $\begin{array}{r}0 \\
170\end{array}$ & $\begin{array}{l}0 \\
0\end{array}$ & $\begin{array}{l}0 \\
0\end{array}$ & $\begin{array}{l}0 \\
0\end{array}$ & $\begin{array}{r}885 \\
1,266\end{array}$ \\
\hline 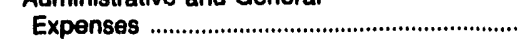 & 118 & 138 & 0 & 2,170 & 846 & 43,324 \\
\hline $\begin{array}{l}\text { Total Electric Operation and } \\
\text { Malntenance Expenaes }\end{array}$ & 7,788 & 7,305 & 26,973 & 88,328 & 26,518 & 344,320 \\
\hline
\end{tabular}

\begin{tabular}{|c|c|c|c|c|c|c|}
\hline Item & $\begin{array}{l}\text { South Dakota } \\
\begin{array}{c}\text { Brookings } \\
\text { City of }\end{array} \\
\text { December } 31\end{array}$ & $\begin{array}{l}\text { South Dakota } \\
\text { Heartland } \\
\text { Consumers } \\
\text { Power Dist } \\
\text { December } 31\end{array}$ & $\begin{array}{l}\text { South Dakota } \\
\text { Missouri } \\
\text { Basin } \\
\text { Mun } \\
\text { Power Agny } \\
\text { December } 31\end{array}$ & $\begin{array}{l}\text { South Dakota } \\
\text { Pierre } \\
\text { City of } \\
\text { Decemiber } 31\end{array}$ & $\begin{array}{l}\text { South Dakota } \\
\text { Watertown } \\
\text { Municipal } \\
\text { Utilities } \\
\text { December } 31\end{array}$ & $\begin{array}{l}\text { Tennessee } \\
\text { Alcoa } \\
\text { Utilities } \\
\text { June } 30\end{array}$ \\
\hline 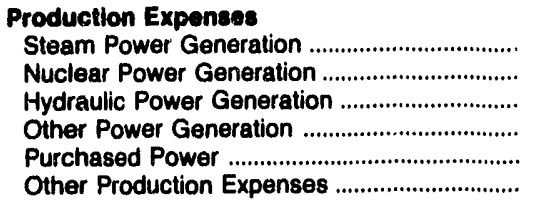 & $\begin{array}{r}0 \\
0 \\
0 \\
0 \\
4,178 \\
31\end{array}$ & $\begin{array}{r}3,650 \\
0 \\
0 \\
0 \\
992 \\
\text { ij }\end{array}$ & $\begin{array}{r}0 \\
0 \\
0 \\
0 \\
42,889 \\
63\end{array}$ & $\begin{array}{r}0 \\
0 \\
0 \\
0 \\
2,871 \\
0\end{array}$ & $\begin{array}{r}0 \\
0 \\
0 \\
0 \\
4,655 \\
18\end{array}$ & $\begin{array}{r}0 \\
0 \\
0 \\
0 \\
18,065 \\
0\end{array}$ \\
\hline 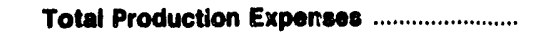 & 4,208 & 4,642 & 42,952 & 2,871 & 4,673 & 18,085 \\
\hline 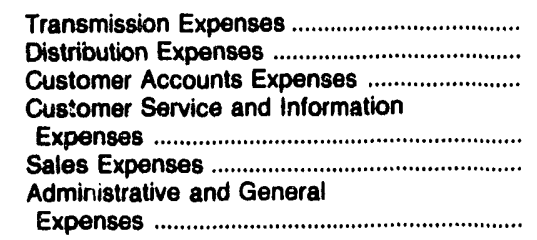 & $\begin{array}{r}72 \\
759 \\
135\end{array}$ & $\begin{array}{r}1,382 \\
0 \\
0\end{array}$ & $\begin{array}{r}10,281 \\
0 \\
4\end{array}$ & $\begin{array}{r}0 \\
i 06 \\
0\end{array}$ & $\begin{array}{r}0 \\
763 \\
248\end{array}$ & $\begin{array}{r}183 \\
1,235 \\
494\end{array}$ \\
\hline 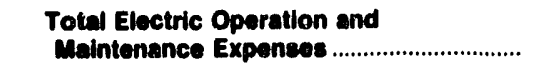 & 5,547 & 6,774 & 54,745 & 3,277 & 5,951 & 20,896 \\
\hline
\end{tabular}

Note: Totals may not equal sum of components because of independent rounding.

Source: Energy Iniormation Administration, Form EIA-412, "Annual Report of Public Electric Utilities." 
Table 38. Electric Operation and Maintenance Expenses by Major Publicly Owned Electric Utility Within State, 1991 (Continued) (Thousand Dollars)

\begin{tabular}{|c|c|c|c|c|c|c|}
\hline Item & $\begin{array}{l}\text { Tennessee } \\
\text { Athens } \\
\text { City of } \\
\text { June } 30\end{array}$ & $\begin{array}{l}\text { Tennessee } \\
\text { Benton } \\
\text { County } \\
\text { June } 30\end{array}$ & $\begin{array}{l}\text { Tennessee } \\
\text { Bolivar } \\
\text { City of } \\
\text { June } 30\end{array}$ & $\begin{array}{l}\text { Tennessee } \\
\text { Bristol } \\
\text { City of } \\
\text { June } 30\end{array}$ & $\begin{array}{c}\text { Tennessee } \\
\text { Brownsville } \\
\text { City of } \\
\text { June } 30\end{array}$ & $\begin{array}{l}\text { Tennessee } \\
\text { Carroll } \\
\text { County } \\
\text { June } 30\end{array}$ \\
\hline 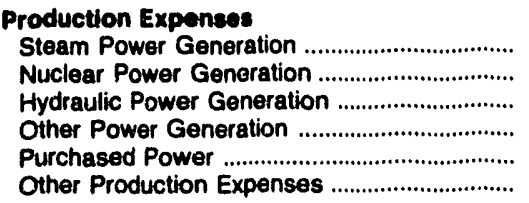 & $\begin{array}{r}0 \\
0 \\
0 \\
0 \\
21,873 \\
0\end{array}$ & $\begin{array}{r}0 \\
0 \\
0 \\
0 \\
8,339 \\
0\end{array}$ & $\begin{array}{r}0 \\
0 \\
0 \\
0 \\
10,312 \\
0\end{array}$ & $\begin{array}{r}0 \\
0 \\
0 \\
0 \\
31,406 \\
0\end{array}$ & $\begin{array}{r}0 \\
0 \\
0 \\
0 \\
8,092 \\
0\end{array}$ & $\begin{array}{r}0 \\
0 \\
0 \\
0 \\
15,689 \\
0\end{array}$ \\
\hline Total Production Expenses ............................ & 21,873 & 8,339 & 10,312 & 31,406 & 8,092 & 15,689 \\
\hline 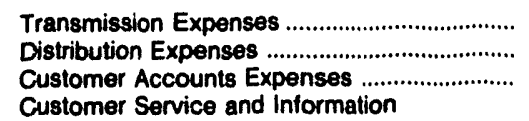 & $\begin{array}{r}86 \\
1,111 \\
386\end{array}$ & $\begin{array}{r}0 \\
691 \\
348\end{array}$ & $\begin{array}{r}0 \\
555 \\
224\end{array}$ & $\begin{array}{r}142 \\
1,786 \\
634\end{array}$ & $\begin{array}{r}0 \\
316 \\
108\end{array}$ & $\begin{array}{r}6 \\
1,148 \\
513\end{array}$ \\
\hline 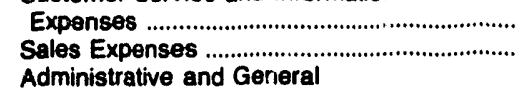 & $\begin{array}{l}11 \\
18\end{array}$ & $\begin{array}{r}4 \\
26\end{array}$ & $\begin{array}{l}17 \\
10\end{array}$ & $\begin{array}{l}78 \\
73\end{array}$ & $\begin{array}{r}9 \\
10\end{array}$ & $\begin{array}{l}17 \\
11\end{array}$ \\
\hline 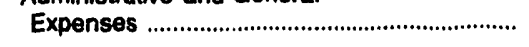 & 571 & 390 & 427 & 854 & 182 & 433 \\
\hline $\begin{array}{l}\text { Total Electric Operation and } \\
\text { Maintenance Expenses }\end{array}$ & 24,056 & 9,799 & 11,545 & 34,973 & 8,716 & 17,818 \\
\hline
\end{tabular}

\begin{tabular}{|c|c|c|c|c|c|c|}
\hline Item & $\begin{array}{c}\text { Tennessee } \\
\text { Chattanooga } \\
\text { City of } \\
\text { June } 30\end{array}$ & $\begin{array}{c}\text { Tennessee } \\
\text { Clarksville } \\
\text { City of } \\
\text { June } 30\end{array}$ & $\begin{array}{c}\text { Tennessee } \\
\text { Cleveland } \\
\text { City of } \\
\text { June } 30\end{array}$ & $\begin{array}{l}\text { Tennessee } \\
\text { Clint '1 } \\
\text { City of } \\
\text { June } 30\end{array}$ & $\begin{array}{c}\text { Tennessee } \\
\text { Columbia } \\
\text { City of } \\
\text { June } 30\end{array}$ & $\begin{array}{l}\text { Tennessee } \\
\text { Cookeville } \\
\text { City of } \\
\text { June } 30\end{array}$ \\
\hline 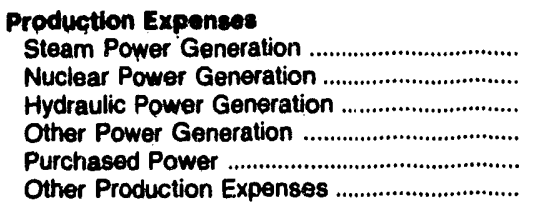 & $\begin{array}{r}0 \\
0 \\
0 \\
0 \\
230,583 \\
0\end{array}$ & $\begin{array}{r}0 \\
0 \\
0 \\
0 \\
34,062 \\
0\end{array}$ & $\begin{array}{r}0 \\
0 \\
0 \\
0 \\
36,402 \\
0\end{array}$ & $\begin{array}{r}0 \\
0 \\
0 \\
0 \\
25,288 \\
0\end{array}$ & $\begin{array}{r}0 \\
0 \\
0 \\
0 \\
22,347 \\
0\end{array}$ & $\begin{array}{r}0 \\
0 \\
0 \\
0 \\
20,033 \\
0\end{array}$ \\
\hline Total Production Expences ........................... & 230,583 & 34,062 & 38,402 & 25,289 & 22,347 & 20,033 \\
\hline 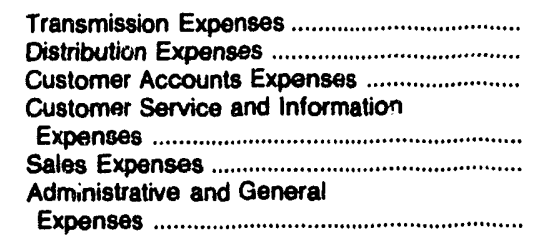 & $\begin{array}{r}1,168 \\
13,654 \\
4,918 \\
0 \\
1,029 \\
8,006\end{array}$ & $\begin{array}{r}211 \\
1,738 \\
754 \\
156 \\
15 \\
919\end{array}$ & $\begin{array}{r}122 \\
1,482 \\
587 \\
140 \\
44 \\
946\end{array}$ & $\begin{array}{r}218 \\
1,469 \\
708 \\
18 \\
20 \\
346\end{array}$ & $\begin{array}{r}0 \\
1,333 \\
350 \\
22 \\
0 \\
533\end{array}$ & $\begin{array}{r}0 \\
998 \\
338\end{array}$ \\
\hline $\begin{array}{l}\text { Totel Electric Operation and } \\
\text { Malntenance Expences ................................. }\end{array}$ & 259,357 & 37,855 & 39,723 & 28,669 & 24,584 & 21,716 \\
\hline
\end{tabular}

Note: Totals may not equal sum of components because of independent rounding.

Source: Energy Information Administration, Form EIA-412, "Annual Report of Public Electric Utilities." 
Table 38. Electric Operation and Maintenance Expenses by Major Publicly Owned Electric Utility Within State, 1991 (Continued) (Thousand Dollars)

\begin{tabular}{|c|c|c|c|c|c|c|}
\hline Item & $\begin{array}{l}\text { Tennessee } \\
\text { Covington } \\
\text { City of } \\
\text { June } 30\end{array}$ & $\begin{array}{l}\text { Tennessee } \\
\text { Dayton } \\
\text { City of } \\
\text { June } 30\end{array}$ & $\begin{array}{l}\text { Tennessee } \\
\text { Dickson } \\
\text { City of } \\
\text { June } 30\end{array}$ & $\begin{array}{l}\text { Tennessee } \\
\text { Dyersburg } \\
\text { Electric } \\
\text { System } \\
\text { June } 30\end{array}$ & $\begin{array}{c}\text { Tennessee } \\
\text { Elizabethton } \\
\text { City of } \\
\text { June } 30\end{array}$ & $\begin{array}{c}\text { Tennessee } \\
\text { Erwin } \\
\text { Town of } \\
\text { June } 30\end{array}$ \\
\hline 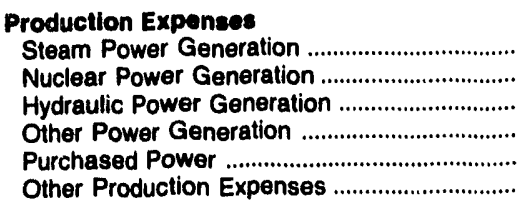 & $\begin{array}{r}0 \\
0 \\
0 \\
0 \\
8,651 \\
0\end{array}$ & $\begin{array}{r}0 \\
0 \\
0 \\
0 \\
8,080 \\
0\end{array}$ & $\begin{array}{r}0 \\
0 \\
0 \\
0 \\
23,608 \\
0\end{array}$ & $\begin{array}{r}0 \\
0 \\
0 \\
0 \\
22,018 \\
0\end{array}$ & $\begin{array}{r}0 \\
0 \\
0 \\
0 \\
20,589 \\
0\end{array}$ & $\begin{array}{r}0 \\
0 \\
0 \\
0 \\
8,821 \\
0\end{array}$ \\
\hline Total Production Expenses & 8,851 & 8,080 & 23,608 & 22,018 & 20,589 & 8,821 \\
\hline 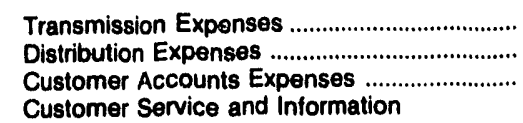 & $\begin{array}{r}0 \\
271 \\
117\end{array}$ & $\begin{array}{r}0 \\
326 \\
188\end{array}$ & $\begin{array}{r}0 \\
1,304 \\
818\end{array}$ & $\begin{array}{r}12 \\
1,177 \\
379\end{array}$ & $\begin{array}{r}37 \\
1,590 \\
610\end{array}$ & $\begin{array}{r}0 \\
400 \\
198\end{array}$ \\
\hline 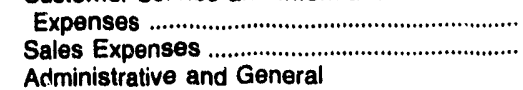 & $\begin{array}{l}5 \\
9\end{array}$ & $\begin{array}{r}3 \\
17\end{array}$ & $\begin{array}{r}1 \\
13\end{array}$ & $\begin{array}{l}35 \\
85\end{array}$ & $\begin{array}{l}38 \\
43\end{array}$ & $\begin{array}{r}21 \\
0\end{array}$ \\
\hline 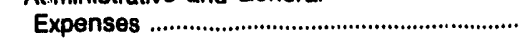 & 279 & 188 & 499 & 781 & 799 & 253 \\
\hline $\begin{array}{l}\text { Total Electric Operation and } \\
\text { Maintenance Expenses }\end{array}$ & 9,331 & 8,802 & 26,242 & 24,487 & 23,706 & 9,693 \\
\hline
\end{tabular}

\begin{tabular}{|c|c|c|c|c|c|c|}
\hline \multirow{3}{*}{ Item } & Tennessee & Tennessee & Tennessee & Tennessee & Tennessee & Tennessee \\
\hline & $\begin{array}{l}\text { Etowah } \\
\text { City of }\end{array}$ & $\begin{array}{c}\text { Fayetteville } \\
\text { City of }\end{array}$ & $\begin{array}{c}\text { Gallatin } \\
\text { City of }\end{array}$ & $\begin{array}{c}\text { Greeneville } \\
\text { City of }\end{array}$ & $\begin{array}{c}\text { Harriman } \\
\text { City of }\end{array}$ & $\begin{array}{l}\text { Humboldt } \\
\text { City of }\end{array}$ \\
\hline & June 30 & June 30 & June 30 & June 30 & June 30 & June 30 \\
\hline
\end{tabular}

\section{Production Expenses}

Steam Power Generation .

Nuclear Power Generation

Hydraulic Power Generation

Other Power Generation

Purchased Power .

Other Production Exp

Other Production Expenses

0
0
0
0
6,094
0

0
0
0
0
15,028
0

0
0
0
0
17,712
0

0
0
0
0
36,173
0

0
0
0
0
11,241
0

15,028

$$
17,712
$$

36,173

11,241

8,888

Transmission Expenses

3
376
116

Distribution Expenses

Customer Accounts Expenses .........................

Customer Service and Information

Expenses ...............

Sales Expenses ...................................................

Administrative and General

Expenses

0
859

859

4
677

273

104
2,013

653

0
787

723

12
389

16403

72

5
12

17

190

720

8
14

82

104

315

1,184

19,001

40,313

13,409

9,628

Note: Totals may not equal sum of components because of independent rounding.

Source: Energy Information Administration, Form ElA-412, "Annual Report of Public Electric Utilities." 
Table 38. Electric Operation and Maintenance Expenses by Major Publicly Owned Electric Utility Within State, 1991 (Continued) (Thousand Dollars)

\begin{tabular}{|c|c|c|c|c|c|c|}
\hline Item & $\begin{array}{l}\text { Tennessee } \\
\text { Jackson } \\
\text { City of } \\
\text { June } 30\end{array}$ & $\begin{array}{l}\text { Tennessee } \\
\text { Johnson } \\
\text { City City of } \\
\text { June } 30\end{array}$ & $\begin{array}{l}\text { Tennessee } \\
\text { Knoxville } \\
\text { Utilities } \\
\text { Board } \\
\text { June } 30\end{array}$ & $\begin{array}{c}\text { Tennessee } \\
\text { Lawrenceburg } \\
\text { City of } \\
\text { June } 30\end{array}$ & $\begin{array}{c}\text { Tennessee } \\
\text { LaFollette } \\
\text { City of }\end{array}$ & $\begin{array}{c}\text { Tennessee } \\
\text { Lebanon } \\
\text { City of } \\
\text { June } 30\end{array}$ \\
\hline 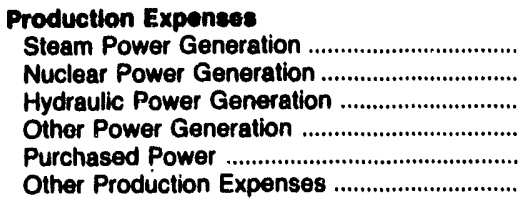 & $\begin{array}{r}0 \\
0 \\
0 \\
0 \\
49,105 \\
0\end{array}$ & $\begin{array}{r}0 \\
0 \\
0 \\
0 \\
62,018 \\
0\end{array}$ & $\begin{array}{r}0 \\
0 \\
0 \\
0 \\
204,054 \\
0\end{array}$ & $\begin{array}{r}0 \\
0 \\
0 \\
0 \\
18,556 \\
0\end{array}$ & $\begin{array}{r}0 \\
0 \\
0 \\
0 \\
14,394 \\
0\end{array}$ & $\begin{array}{r}0 \\
0 \\
0 \\
0 \\
14,112 \\
0\end{array}$ \\
\hline Total Production Expenses ............................ & 49,105 & 62,018 & 204,054 & 18,556 & 14,394 & 14,112 \\
\hline 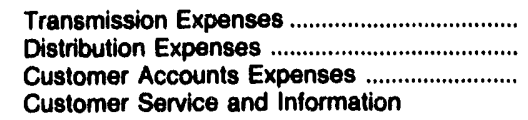 & $\begin{array}{r}131 \\
1,546 \\
697\end{array}$ & $\begin{array}{r}737 \\
2,661 \\
1,147\end{array}$ & $\begin{array}{r}0 \\
12,558 \\
5,430\end{array}$ & $\begin{array}{r}17 \\
825 \\
415\end{array}$ & $\begin{array}{r}136 \\
1,101 \\
525\end{array}$ & $\begin{array}{r}0 \\
566 \\
0\end{array}$ \\
\hline 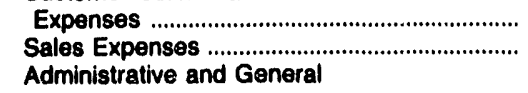 & $\begin{array}{r}133 \\
27\end{array}$ & $\begin{array}{r}48 \\
134\end{array}$ & $\begin{array}{r}559 \\
0\end{array}$ & $\begin{array}{l}30 \\
12\end{array}$ & $\begin{array}{r}35 \\
0\end{array}$ & $\begin{array}{l}0 \\
0\end{array}$ \\
\hline 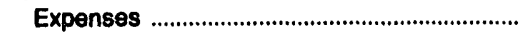 & 1,268 & 863 & 8,660 & 742 & 589 & 854 \\
\hline 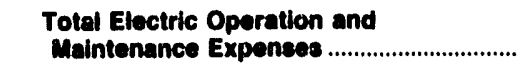 & 62,907 & 67,608 & 231,280 & 20,597 & 16,781 & 16,533 \\
\hline
\end{tabular}

\begin{tabular}{|c|c|c|c|c|c|c|}
\hline Item & $\begin{array}{c}\text { Tennessee } \\
\text { Lenoir } \\
\text { City City of } \\
\text { June } 30\end{array}$ & $\begin{array}{c}\text { Tennessee } \\
\text { Lewisburg } \\
\text { Gity of } \\
\text { June } 30\end{array}$ & $\begin{array}{c}\text { Tennessee } \\
\text { Lexington } \\
\text { City of } \\
\text { June } 30\end{array}$ & $\begin{array}{l}\text { Tennessee } \\
\text { Loudon } \\
\text { City of } \\
\text { June } 30\end{array}$ & $\begin{array}{c}\text { Tennessee } \\
\text { Maryville } \\
\text { Utilities } \\
\text { June } 30\end{array}$ & $\begin{array}{l}\text { Tennessee } \\
\text { McMinnville } \\
\text { Electric } \\
\text { System } \\
\text { June } 30\end{array}$ \\
\hline 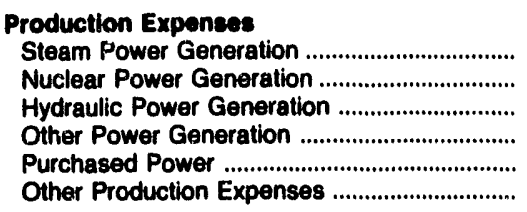 & $\begin{array}{r}0 \\
0 \\
0 \\
0 \\
43,384 \\
0\end{array}$ & $\begin{array}{r}0 \\
0 \\
0 \\
0 \\
11,744 \\
0\end{array}$ & $\begin{array}{r}0 \\
0 \\
0 \\
0 \\
15,678 \\
0\end{array}$ & $\begin{array}{r}0 \\
0 \\
0 \\
0 \\
9,569 \\
0\end{array}$ & $\begin{array}{r}0 \\
0 \\
0 \\
0 \\
19,805 \\
0\end{array}$ & $\begin{array}{r}0 \\
0 \\
0 \\
0 \\
9,472 \\
0\end{array}$ \\
\hline Total Production Exponses ............................. & 43,384 & 11,764 & 15,678 & 9,569 & 18,805 & $\mathbf{9 , 4 7 2}$ \\
\hline 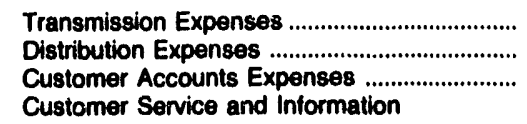 & $\begin{array}{r}0 \\
1,963 \\
990\end{array}$ & $\begin{array}{r}0 \\
473 \\
126\end{array}$ & $\begin{array}{r}-75 \\
1,415 \\
405\end{array}$ & $\begin{array}{r}0 \\
160 \\
0\end{array}$ & $\begin{array}{r}69 \\
889 \\
332\end{array}$ & $\begin{array}{r}0 \\
581 \\
164\end{array}$ \\
\hline 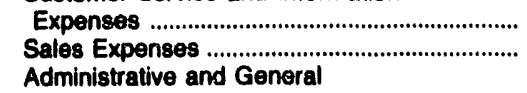 & $\begin{array}{r}0 \\
14\end{array}$ & $\begin{array}{r}18 \\
5\end{array}$ & $\begin{array}{l}21 \\
29\end{array}$ & $\begin{array}{l}0 \\
0\end{array}$ & $\begin{array}{r}7 \\
10\end{array}$ & $\begin{array}{l}37 \\
24\end{array}$ \\
\hline 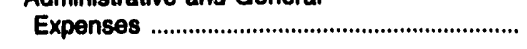 & 1,493 & 402 & 803 & 583 & 608 & 449 \\
\hline $\begin{array}{l}\text { Totel Electric Operation and } \\
\text { Maintenance Expenses ................................. }\end{array}$ & 47,845 & 12,767 & 18,276 & 10,313 & 21,719 & 10,727 \\
\hline
\end{tabular}

Note: Totels may not equal sum of components because of independent rounding.

Source: Energy Information Administration, Form ElA-412, "Annual Report of Public Electric Utilities." 

Table 38. Electric Operation and Maintenance Expenses by Major Publicly
Owned Electric Utility Within State, 1991 (Continued) (Thousand Dollars)

\begin{tabular}{|c|c|c|c|c|c|c|}
\hline Item & $\begin{array}{c}\text { Tennessee } \\
\text { Memphis } \\
\text { City of } \\
\text { December } 31\end{array}$ & $\begin{array}{l}\text { Tennessee } \\
\text { Milan } \\
\text { City of } \\
\text { June } 30\end{array}$ & $\begin{array}{c}\text { Tennessee } \\
\text { Morristown } \\
\text { City of } \\
\text { June } 30\end{array}$ & $\begin{array}{c}\text { Tennessee } \\
\text { Murfreesboro } \\
\text { City of } \\
\text { June } 30\end{array}$ & $\begin{array}{c}\text { Tennessee } \\
\text { Nashville } \\
\text { Electric } \\
\text { Service } \\
\text { June } 30\end{array}$ & $\begin{array}{l}\text { Tennessee } \\
\text { Newport } \\
\text { City of } \\
\text { June } 30\end{array}$ \\
\hline 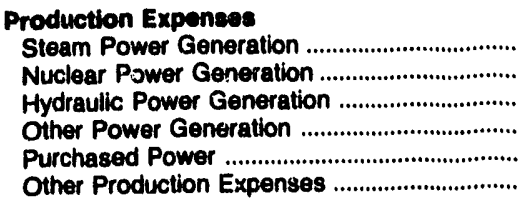 & $\begin{array}{r}0 \\
0 \\
0 \\
0 \\
511,167 \\
0\end{array}$ & $\begin{array}{r}0 \\
0 \\
0 \\
0 \\
9,426 \\
0\end{array}$ & $\begin{array}{r}0 \\
0 \\
0 \\
0 \\
26,268 \\
0\end{array}$ & $\begin{array}{r}0 \\
0 \\
0 \\
0 \\
34,536 \\
0\end{array}$ & $\begin{array}{r}0 \\
0 \\
0 \\
0 \\
0 \\
441,119 \\
0\end{array}$ & $\begin{array}{r}0 \\
0 \\
0 \\
0 \\
17,077 \\
0\end{array}$ \\
\hline Total Production Exponses ............................ & 511,167 & 9,426 & 26,288 & 34,536 & 441,118 & 17,077 \\
\hline 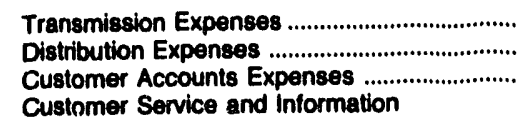 & $\begin{array}{r}3,463 \\
36,439 \\
7,473\end{array}$ & $\begin{array}{r}72 \\
434 \\
225\end{array}$ & $\begin{array}{r}43 \\
1,192 \\
266\end{array}$ & $\begin{array}{r}0 \\
1,330 \\
510\end{array}$ & $\begin{array}{r}0 \\
22,553 \\
13,075\end{array}$ & $\begin{array}{r}0 \\
1,166 \\
475\end{array}$ \\
\hline $\begin{array}{l}\text { Expenses } \\
\text { Sales Expenses }\end{array}$ & $\begin{array}{l}834 \\
666\end{array}$ & $\begin{array}{r}13 \\
134\end{array}$ & $\begin{array}{r}0 \\
121\end{array}$ & $\begin{array}{l}51 \\
33\end{array}$ & $\begin{array}{l}1,478 \\
2,352\end{array}$ & $\begin{array}{l}10 \\
17\end{array}$ \\
\hline 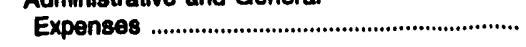 & 32,621 & 257 & 719 & 816 & 16,170 & 572 \\
\hline $\begin{array}{l}\text { Totyl Electric Operation and } \\
\text { Melntenance Expenses .................................. }\end{array}$ & 592,682 & 10,561 & 28,808 & 37,277 & 496,747 & 19,318 \\
\hline
\end{tabular}

\begin{tabular}{|c|c|c|c|c|c|c|}
\hline Item & $\begin{array}{l}\text { Tennessee } \\
\text { Oak Ridge } \\
\text { City of } \\
\text { June } 30\end{array}$ & $\begin{array}{c}\text { Tennessee } \\
\text { Paris } \\
\text { City of } \\
\text { June } 30\end{array}$ & $\begin{array}{l}\text { Tennessee } \\
\text { Pulaski } \\
\text { City of } \\
\text { June } 30\end{array}$ & $\begin{array}{l}\text { Tennessee } \\
\text { Ripley } \\
\text { City of } \\
\text { June } 30\end{array}$ & $\begin{array}{c}\text { Tennessee } \\
\text { Rockwood } \\
\text { City of } \\
\text { June } 30\end{array}$ & $\begin{array}{c}\text { Tennessee } \\
\text { Sevier } \\
\text { County } \\
\text { Electric } \\
\text { System } \\
\text { June } 30\end{array}$ \\
\hline
\end{tabular}

\section{Production Expences}

Steam Power Generation

Nuclear Power Generation

Hydraulic Power Generation

Other Power Generation

Other Production Expenses

Totel Production Expenses

Transmission Expenses

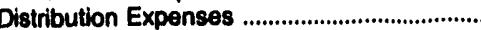

Cugtomer Accounts Expenses

Customer Service and Information

Eales Expenses

Administrative and General

Expenses

Total Electric Oparation and

Mintenonce Expenses.

$\begin{array}{rr}0 & 0 \\ 0 & 0 \\ 0 & 0 \\ 0 & 0 \\ 19,250 & 17,728 \\ 0 & 0\end{array}$

19,250

17,728

28

30
856

856
421

17

17
32

485

21,091

390

18,498

0
0
0
0
15,297
0

0
0
0
0
10,690

0
0
0
0
11,408
0

10,754

11,408

34,847

$0 \quad 43$

0
1,013

223

43
130

330
134

0
591

591
306

167

70

10

4

36

411

7

11

454

$\$ 1,713$

12,778

17,229

38,786

Source: Energy Information Administration, Form EIA-412, "Annual Report of Public Electric Utilities." 
Table 38. Electric Operation and Maintenance Expenses by Major Publicly
Owned Electric Utility Within State, 1991 (Continued) (Thousand Dollars)

\begin{tabular}{|c|c|c|c|c|c|c|}
\hline Item & $\begin{array}{c}\text { Tennessee } \\
\text { Shelbyville } \\
\text { City of } \\
\text { June } 30\end{array}$ & $\begin{array}{l}\text { Tennessee } \\
\text { Springfield } \\
\text { City of } \\
\text { June } 30\end{array}$ & $\begin{array}{c}\text { Tennessee } \\
\text { Sweetwater } \\
\text { City of } \\
\text { June } 30\end{array}$ & $\begin{array}{c}\text { Tennessee } \\
\text { Tullahoma } \\
\text { Board } \\
\text { of } \\
\text { Pub Utils } \\
\text { June } 30\end{array}$ & $\begin{array}{l}\text { Tennessee } \\
\text { Union } \\
\text { City City of } \\
\text { June } 30\end{array}$ & $\begin{array}{l}\text { Tennessee } \\
\text { Weakley } \\
\text { County } \\
\text { Mun } \\
\text { Elec Sys } \\
\text { June } 30\end{array}$ \\
\hline 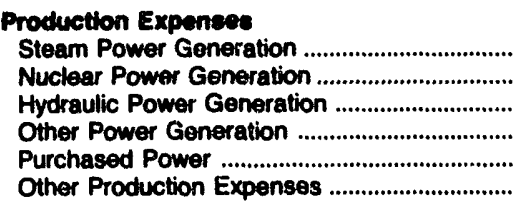 & $\begin{array}{r}0 \\
0 \\
0 \\
0 \\
13,817 \\
0\end{array}$ & $\begin{array}{r}0 \\
0 \\
0 \\
0 \\
8,132 \\
0\end{array}$ & $\begin{array}{r}0 \\
0 \\
0 \\
0 \\
7,679 \\
0\end{array}$ & $\begin{array}{r}0 \\
0 \\
0 \\
0 \\
11,722 \\
0\end{array}$ & $\begin{array}{r}0 \\
0 \\
0 \\
0 \\
13,504 \\
0\end{array}$ & $\begin{array}{r}0 \\
0 \\
0 \\
0 \\
20,757 \\
0\end{array}$ \\
\hline Total Production Expenses .......................... & 13,817 & 8,192 & 7,870 & 11,722 & 13,504 & 20,757 \\
\hline 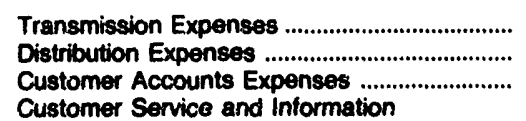 & $\begin{array}{r}0 \\
569 \\
187\end{array}$ & $\begin{array}{r}0 \\
514 \\
176\end{array}$ & $\begin{array}{r}0 \\
408 \\
138\end{array}$ & $\begin{array}{r}0 \\
564 \\
188\end{array}$ & $\begin{array}{r}48 \\
393 \\
169\end{array}$ & $\begin{array}{r}21 \\
931 \\
479\end{array}$ \\
\hline 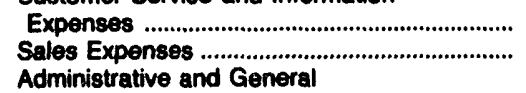 & $\begin{array}{r}16 \\
0\end{array}$ & $\begin{array}{r}37 \\
7\end{array}$ & $\begin{array}{r}9 \\
10\end{array}$ & $\begin{array}{l}13 \\
26\end{array}$ & $\begin{array}{l}24 \\
63\end{array}$ & $\begin{array}{l}50 \\
48\end{array}$ \\
\hline 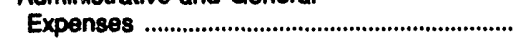 & 351 & 243 & 253 & 415 & 950 & 661 \\
\hline $\begin{array}{l}\text { Totad Electric Operation and } \\
\text { Malntenance Expenses }\end{array}$ & 14,949 & 9,110 & 8,497 & 12,928 & 15,161 & 22,949 \\
\hline
\end{tabular}

\begin{tabular}{|c|c|c|c|c|c|c|}
\hline Item & $\begin{array}{l}\text { Texas } \\
\text { Austin } \\
\text { City of } \\
\text { September } 30\end{array}$ & $\begin{array}{c}\text { Texas } \\
\text { Brenham } \\
\text { City of } \\
\text { September } 30\end{array}$ & $\begin{array}{c}\text { Texas } \\
\text { Brownsville } \\
\text { Public } \\
\text { Utils Board } \\
\text { September } 30\end{array}$ & $\begin{array}{l}\text { Texas } \\
\text { Bryan } \\
\text { City of } \\
\text { September } 30\end{array}$ & $\begin{array}{l}\text { Texas } \\
\text { College } \\
\text { Station } \\
\text { City of } \\
\text { September } 30\end{array}$ & $\begin{array}{l}\text { Texas } \\
\text { Denton } \\
\text { City of } \\
\text { September } 30\end{array}$ \\
\hline 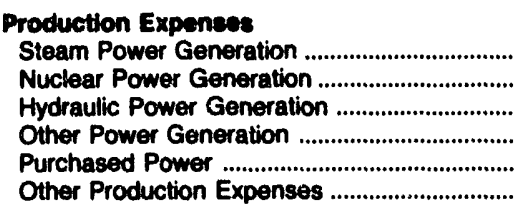 & $\begin{array}{r}109,972 \\
39,885 \\
0 \\
0 \\
3,667 \\
4,051 \\
0\end{array}$ & $\begin{array}{r}0 \\
0 \\
0 \\
0 \\
9,361 \\
0\end{array}$ & $\begin{array}{r}13,768 \\
0 \\
0 \\
0 \\
5,569 \\
2,187\end{array}$ & $\begin{array}{r}8,046 \\
0 \\
0 \\
3,306 \\
27,200 \\
123\end{array}$ & $\begin{array}{r}0 \\
0 \\
0 \\
0 \\
19,073 \\
0\end{array}$ & $\begin{array}{r}4,083 \\
0 \\
5 \\
0 \\
40,378 \\
0\end{array}$ \\
\hline Totel Production Exponces ........................... & 157,575 & 9,381 & 21,525 & 30,674 & 19,073 & 44,488 \\
\hline 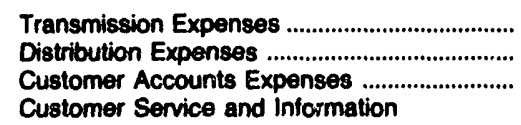 & $\begin{array}{r}1,286 \\
15,753 \\
14,806\end{array}$ & $\begin{array}{r}0 \\
463 \\
0\end{array}$ & $\begin{array}{r}1.493 \\
858 \\
576\end{array}$ & $\begin{array}{r}0 \\
1,679 \\
1,213\end{array}$ & $\begin{array}{r}55 \\
552 \\
747\end{array}$ & $\begin{array}{r}2,249 \\
1,779 \\
0\end{array}$ \\
\hline 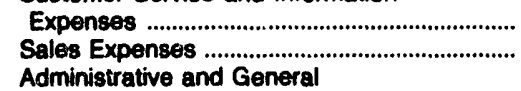 & $\begin{array}{r}3,775 \\
0\end{array}$ & $\begin{array}{l}0 \\
0\end{array}$ & $\begin{array}{l}0 \\
0\end{array}$ & $\begin{array}{l}0 \\
0\end{array}$ & $\begin{array}{l}0 \\
0\end{array}$ & $\begin{array}{l}0 \\
0\end{array}$ \\
\hline 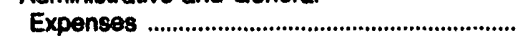 & 19,204 & 500 & 3,664 & 1,284 & 193 & 718 \\
\hline $\begin{array}{l}\text { Total Eloctric Operation and } \\
\text { Malntenence Expentes ................................. }\end{array}$ & 212,390 & 10,323 & 28,116 & 42,851 & 20,610 & 49,212 \\
\hline
\end{tabular}

Note: Totals may not equal sum of components because of independent rounding.

Source: Energy Information Administration, Form EIA-412, "Annual Report of Public Electric Utilities." 
Table 38. Electric Operation and Maintenance Expenses by Major Publicly
Owned Electric Utility Within State, 1991 (Continued) (Thousand Dollars)

\begin{tabular}{|c|c|c|c|c|c|c|}
\hline Item & $\begin{array}{l}\text { Texas } \\
\text { Garland } \\
\text { City of } \\
\text { September } 30\end{array}$ & $\begin{array}{c}\text { Texas } \\
\text { Georgetown } \\
\text { City of } \\
\text { September } 30\end{array}$ & $\begin{array}{c}\text { Texas } \\
\text { Greenville } \\
\text { City of } \\
\text { September } 30\end{array}$ & $\begin{array}{c}\text { Texas } \\
\text { Kerrville } \\
\text { Public } \\
\text { Utility } \\
\text { Board } \\
\text { September } 30\end{array}$ & $\begin{array}{l}\text { Texas } \\
\text { Lower } \\
\text { Colorado } \\
\text { Piver } \\
\text { Authority } \\
\text { June } 30\end{array}$ & $\begin{array}{l}\text { Texas } \\
\text { Lubbock } \\
\text { City of } \\
\text { September } 30\end{array}$ \\
\hline 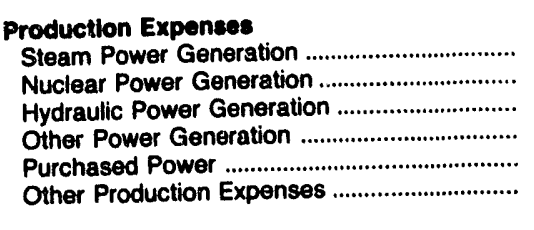 & $\begin{array}{r}19,360 \\
0 \\
0 \\
0 \\
67,984 \\
991\end{array}$ & $\begin{array}{r}0 \\
0 \\
0 \\
0 \\
7,166 \\
0\end{array}$ & $\begin{array}{r}2,722 \\
0 \\
0 \\
179 \\
16,562 \\
0\end{array}$ & $\begin{array}{r}0 \\
0 \\
0 \\
0 \\
14,468 \\
0\end{array}$ & $\begin{array}{r}157,920 \\
0 \\
3,714 \\
0 \\
1,660 \\
3,745\end{array}$ & $\begin{array}{r}17,463 \\
0 \\
0 \\
3,267 \\
7,145 \\
0\end{array}$ \\
\hline Total Production Expenses ......................... & 88,335 & 7,168 & 19,463 & 14,468 & 167,039 & 27,874 \\
\hline 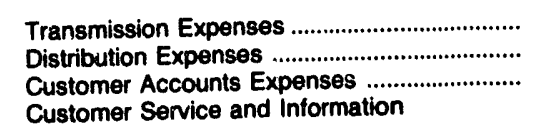 & $\begin{array}{r}715 \\
6,265 \\
2,548\end{array}$ & $\begin{array}{r}0 \\
65 \\
0\end{array}$ & $\begin{array}{r}0 \\
1,262 \\
0\end{array}$ & $\begin{array}{r}0 \\
1,293 \\
437\end{array}$ & $\begin{array}{r}18,481 \\
-1 \\
824\end{array}$ & $\begin{array}{r}0 \\
2,660 \\
1,549\end{array}$ \\
\hline 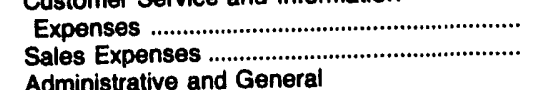 & $\begin{array}{l}845 \\
895\end{array}$ & $\begin{array}{l}0 \\
0\end{array}$ & $\begin{array}{l}0 \\
0\end{array}$ & $\begin{array}{r}48 \\
0\end{array}$ & $\begin{array}{r}1,601 \\
0\end{array}$ & $\begin{array}{r}0 \\
823\end{array}$ \\
\hline $\begin{array}{l}\text { Administrative and General } \\
\text { Expenses }\end{array}$ & 1,088 & 527 & 2,987 & 1,019 & 911 & 320 \\
\hline 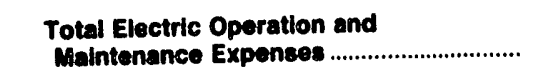 & 100,691 & 7,757 & 23,713 & 17,266 & 188,855 & 33,225 \\
\hline
\end{tabular}

\begin{tabular}{|c|c|c|c|c|c|c|}
\hline Item & $\begin{array}{l}\text { Texas } \\
\text { New Braunfels } \\
\text { City of } \\
\text { July } 31\end{array}$ & $\begin{array}{c}\text { Texas } \\
\text { Sam Rayburn } \\
\text { Municipal } \\
\text { Pwr } \\
\text { Agny } \\
\text { September } 30\end{array}$ & $\begin{array}{l}\text { Texas } \\
\text { San Antonio } \\
\text { City of } \\
\text { January } 31\end{array}$ & $\begin{array}{c}\text { Texas } \\
\text { San Marcos } \\
\text { City of } \\
\text { September } 30\end{array}$ & $\begin{array}{l}\text { Texas } \\
\text { Seguin } \\
\text { City of } \\
\text { September } 30\end{array}$ & $\begin{array}{c}\text { Texas } \\
\text { Texas } \\
\text { Municipal } \\
\text { Power Agency } \\
\text { September } 30\end{array}$ \\
\hline 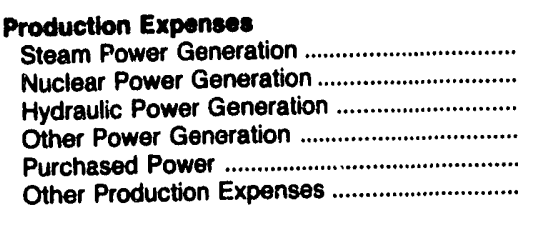 & $\begin{array}{r}0 \\
0 \\
7 \\
0 \\
27,832 \\
0\end{array}$ & $\begin{array}{r}15,174 \\
0 \\
0 \\
0 \\
3,058 \\
0\end{array}$ & $\begin{array}{r}160,848 \\
59,980 \\
0 \\
0 \\
469 \\
70\end{array}$ & $\begin{array}{r}0 \\
0 \\
0 \\
0 \\
12,250 \\
0\end{array}$ & $\begin{array}{r}0 \\
0 \\
0 \\
0 \\
7,536 \\
0\end{array}$ & $\begin{array}{r}66,468 \\
0 \\
0 \\
0 \\
0 \\
0\end{array}$ \\
\hline 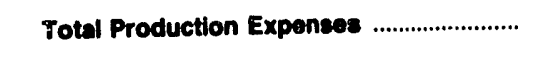 & 27,839 & 18,232 & 221,367 & 12,250 & 7,536 & 66,468 \\
\hline 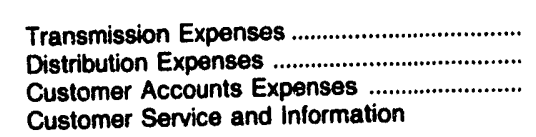 & $\begin{array}{r}111 \\
1,010 \\
303\end{array}$ & $\begin{array}{l}0 \\
0 \\
0\end{array}$ & $\begin{array}{r}2,587 \\
27,372 \\
5,769\end{array}$ & $\begin{array}{r}0 \\
1,272 \\
546\end{array}$ & $\begin{array}{r}0 \\
583 \\
0\end{array}$ & $\begin{array}{r}3,840 \\
0 \\
0\end{array}$ \\
\hline 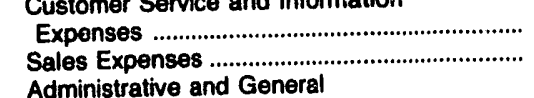 & $\begin{array}{l}0 \\
0\end{array}$ & $\begin{array}{l}0 \\
0\end{array}$ & $\begin{array}{r}1,953 \\
0\end{array}$ & $\begin{array}{r}104 \\
0\end{array}$ & $\begin{array}{l}0 \\
0\end{array}$ & $\begin{array}{l}0 \\
0\end{array}$ \\
\hline $\begin{array}{l}\text { Administrative and General } \\
\text { Expenses }\end{array}$ & 1,802 & 434 & 44,157 & 665 & 0 & 11,270 \\
\hline 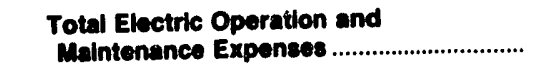 & 31,085 & 18,666 & 303,206 & 14,837 & 8,119 & 81,578 \\
\hline
\end{tabular}

Note: Totals may not equal sum of components because of independent rounding.

Source: Energy Information Administration, Form EIA-412, "Annual Peport of Public Electric Utilities." 
Table 38. Electric Operation and Maintenance Expenses by Major Publicly Owned Electric Utility Within State, 1991 (Continued) (Thousand Dollars)

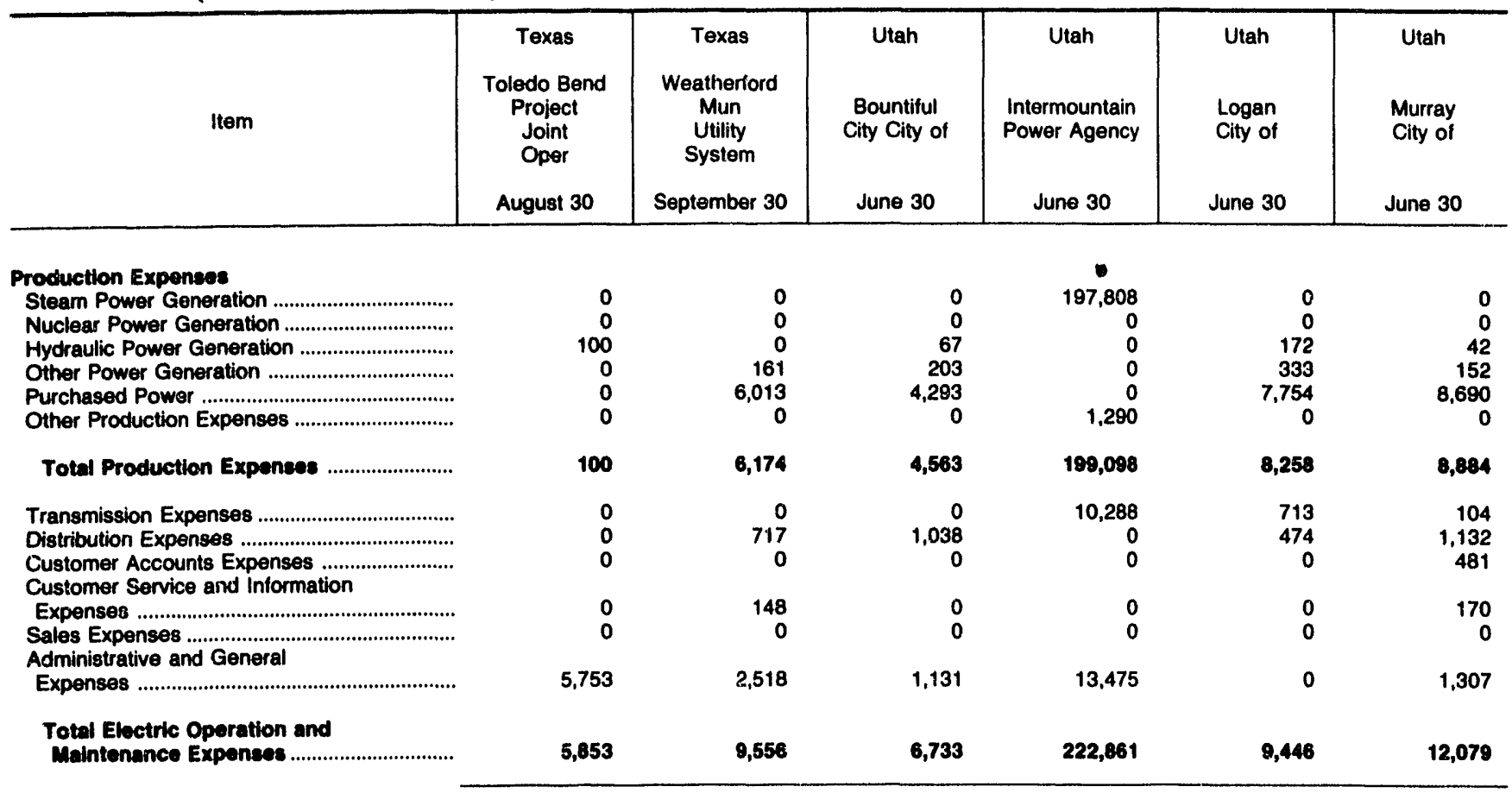

\begin{tabular}{|c|c|c|c|c|c|c|}
\hline Item & $\begin{array}{c}\text { Utah } \\
\text { Provo } \\
\text { City Corp } \\
\text { June } 30\end{array}$ & $\begin{array}{c}\text { Utah } \\
\text { St George } \\
\text { City of } \\
\text { June } 30\end{array}$ & $\begin{array}{c}\text { Utah } \\
\text { Utah } \\
\text { Associated } \\
\text { Mun } \\
\text { Power Sys } \\
\text { March } 31\end{array}$ & $\begin{array}{c}\text { Utah } \\
\text { Utah } \\
\text { Municipal } \\
\text { Power Agency } \\
\text { June } 30\end{array}$ & $\begin{array}{l}\text { Vermont } \\
\text { Burlington } \\
\text { City of } \\
\text { December } 31\end{array}$ & $\begin{array}{c}\text { Vermont } \\
\text { Vermont } \\
\text { Public } \\
\text { Pwr } \\
\text { Supply Auth } \\
\text { December } 31\end{array}$ \\
\hline 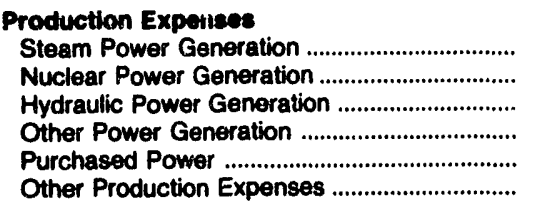 & $\begin{array}{r}0 \\
0 \\
0 \\
0 \\
17,451 \\
0\end{array}$ & $\begin{array}{r}0 \\
0 \\
0 \\
190 \\
8,552 \\
0\end{array}$ & $\begin{array}{r}3,932 \\
0 \\
0 \\
0 \\
7,783 \\
2,650\end{array}$ & $\begin{array}{r}4,234 \\
0 \\
9,660 \\
0 \\
5,524 \\
0\end{array}$ & $\begin{array}{r}4,985 \\
0 \\
0 \\
181 \\
12,877 \\
564\end{array}$ & $\begin{array}{r}1,889 \\
0 \\
0 \\
0 \\
3,097 \\
3\end{array}$ \\
\hline Total Production Expenses .......................... & 17,451 & 8,742 & 14,365 & 19,418 & 18,607 & 4,889 \\
\hline 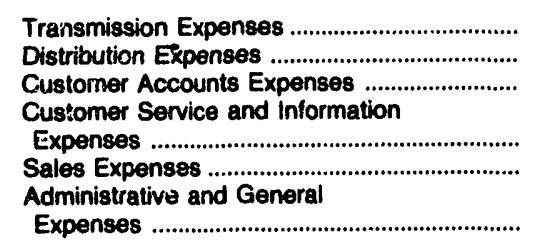 & $\begin{array}{r}566 \\
1,322 \\
509 \\
520 \\
0\end{array}$ & $\begin{array}{l}0 \\
0 \\
0\end{array}$ & $\begin{array}{r}3,375 \\
0 \\
40\end{array}$ & $\begin{array}{r}885 \\
0 \\
0 \\
0 \\
0\end{array}$ & $\begin{array}{r}312 \\
2,131 \\
1,140 \\
382 \\
0\end{array}$ & $\begin{array}{r}25 \\
0 \\
0\end{array}$ \\
\hline $\begin{array}{l}\text { Total Electric Operation and } \\
\text { Maintenance Expenses }\end{array}$ & 21,855 & 11,137 & 19,304 & 20,783 & 25,141 & 6,274 \\
\hline
\end{tabular}

Note: Totais may not equal sum of components because of independent rounding.

Source: Energy Information Administration, Form EIA-412, "Annual Report of Public Electric Utilities." 
Table 38. Electric Operation and Maintenance Expenses by Major Publicly Owned Electric Utility Within State, 1991 (Continued) (Thousand Dollars)

\begin{tabular}{|c|c|c|c|c|c|c|}
\hline Item & $\begin{array}{l}\text { Virginia } \\
\text { Bedford } \\
\text { City of } \\
\text { June } 30\end{array}$ & $\begin{array}{l}\text { Virginia } \\
\text { Bristol } \\
\text { Utilities } \\
\text { Board } \\
\text { June } 30\end{array}$ & $\begin{array}{l}\text { Virginia } \\
\text { Danville } \\
\text { City of } \\
\text { June } 30\end{array}$ & $\begin{array}{l}\text { Virginia } \\
\text { Harrisonburg } \\
\text { City of } \\
\text { June } 30\end{array}$ & $\begin{array}{l}\text { Virginia } \\
\text { Manassas } \\
\text { City of } \\
\text { June } 30\end{array}$ & $\begin{array}{l}\text { Virginia } \\
\text { Martinsvilie } \\
\text { City of } \\
\text { June } 30\end{array}$ \\
\hline 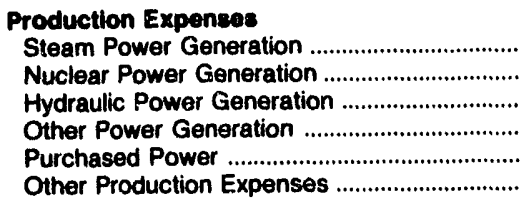 & $\begin{array}{r}0 \\
0 \\
107 \\
0 \\
6,340 \\
0\end{array}$ & $\begin{array}{r}0 \\
0 \\
0 \\
0 \\
22,293 \\
0\end{array}$ & $\begin{array}{r}0 \\
0 \\
338 \\
0 \\
25,944 \\
47\end{array}$ & $\begin{array}{r}0 \\
0 \\
0 \\
0 \\
20,890 \\
0\end{array}$ & $\begin{array}{r}0 \\
0 \\
0 \\
0 \\
10,910 \\
0\end{array}$ & $\begin{array}{r}0 \\
0 \\
166 \\
0 \\
6,946 \\
0\end{array}$ \\
\hline Totat Production Expenses .......................... & 6,447 & 22,293 & 26,329 & 20,890 & 10,810 & 7,112 \\
\hline 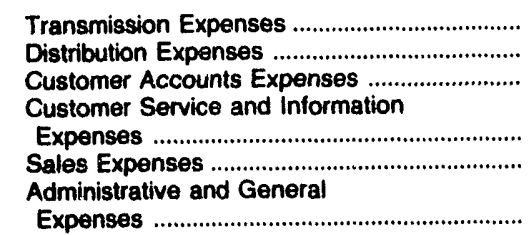 & $\begin{array}{r}444 \\
188 \\
102 \\
0 \\
0\end{array}$ & $\begin{array}{r}0 \\
1,032 \\
316\end{array}$ & $\begin{array}{r}224 \\
1,298 \\
1,104 \\
\\
0 \\
0\end{array}$ & $\begin{array}{r}6 \\
812 \\
385 \\
\\
0 \\
6\end{array}$ & $\begin{array}{r}0 \\
1,786 \\
0 \\
414 \\
0\end{array}$ & $\begin{array}{r}0 \\
591 \\
0\end{array}$ \\
\hline $\begin{array}{l}\text { Total Electric Operation and } \\
\text { Maintenance Expenses ................................ }\end{array}$ & 7,509 & 24,472 & 29,561 & 22,686 & 14,045 & 8,085 \\
\hline
\end{tabular}

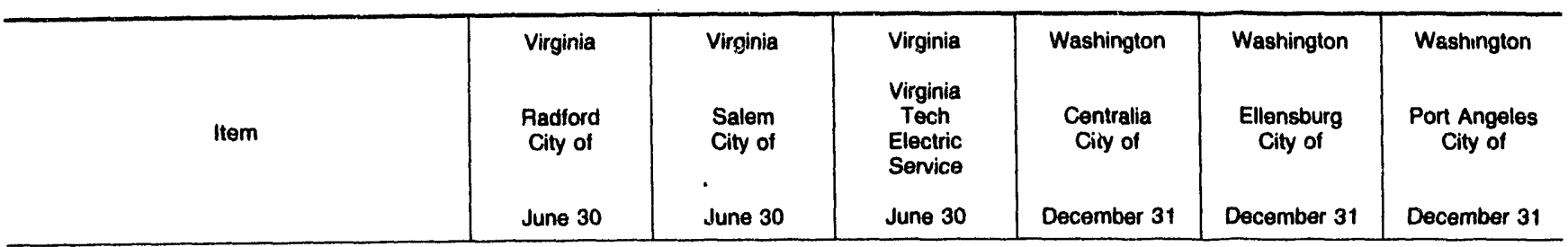

\section{Production Expenses}

Steam Power Generation

Nuclear Power Generation .........

Hydraulic Power General

Other Power Generation

Purchased Power

Other Production Expenses

Total Production Expenses

Transmission Expenses

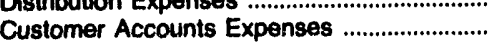

Customer Service and Information

Expenses ...............................................................

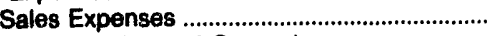

Administrative and General

Expenses

Total Eloctric Operation and

Malntenance Expenses

0
0
6
0
8,289
83

0
0
0
0
11,003
0

78
0
0
0
6,671
0

0
0
509
0
3,698
0

4,207

0
505

505
135

0

257

9,274
11,003

1,060

0
0

6,748

0
1.434

1,434

256

0

941

420

12,664

9,379

$\begin{array}{rr}0 & 0 \\ 0 & 0 \\ 0 & 7 \\ 0 & 0 \\ 3,772 & 15,893 \\ 0 & 38 \\ 3,772 & 15,938 \\ 0 & 3 \\ 251 & 280 \\ 164 & 416 \\ 109 & 4 \\ 2 & 0 \\ 365 & 938\end{array}$

4,864

17,577

Note: Totals may not equal surn of components because of independent rounding.

Source: Energy Information Administration, Form EIA-412, "Annual Report of Public Electric Utilities." 
Table 38. Electric Operation and Maintenance Expenses by Major Publicly Owned Electric Utility Within State, 1991 (Continued) (Thousand Dollars)

\begin{tabular}{|c|c|c|c|c|c|c|}
\hline Item & $\begin{array}{c}\text { Washington } \\
\text { PUD No } 1 \\
\text { of } \\
\text { Benton } \\
\text { County } \\
\text { December } 31\end{array}$ & $\begin{array}{c}\text { Washington } \\
\text { PUD No } 1 \\
\text { of } \\
\text { Chelan } \\
\text { County } \\
\text { December } 31\end{array}$ & $\begin{array}{l}\text { Washington } \\
\text { PUD No } 1 \text { of } \\
\text { Clallam } \\
\text { County } \\
\text { December } 31\end{array}$ & $\begin{array}{l}\text { Washington } \\
\text { PUD No } 1 \\
\text { of } \\
\text { Clark } \\
\text { County } \\
\text { December } 31\end{array}$ & $\begin{array}{l}\text { Washington } \\
\text { PUD No } 1 \text { of } \\
\text { Cowlitz } \\
\text { County } \\
\text { December } 31\end{array}$ & $\begin{array}{l}\text { Washington } \\
\text { PUD No } 1 \text { of } \\
\text { Douglas } \\
\text { County } \\
\text { December } 31\end{array}$ \\
\hline 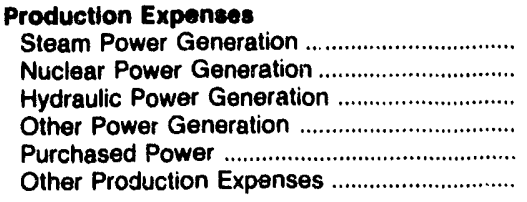 & $\begin{array}{r}0 \\
0 \\
0 \\
0 \\
32,662 \\
0\end{array}$ & $\begin{array}{r}0 \\
0 \\
15,975 \\
0 \\
9,015 \\
171\end{array}$ & $\begin{array}{r}0 \\
0 \\
0 \\
0 \\
11,264 \\
0\end{array}$ & $\begin{array}{r}0 \\
0 \\
0 \\
0 \\
76,373 \\
\mathbf{3 4 8}\end{array}$ & $\begin{array}{r}0 \\
0 \\
178 \\
0 \\
87,951 \\
51\end{array}$ & $\begin{array}{r}0 \\
0 \\
4,783 \\
0 \\
9,206 \\
233\end{array}$ \\
\hline Total Production Expenses ........................... & 32,662 & 25,161 & 11,264 & 76,722 & 88,180 & 14,222 \\
\hline 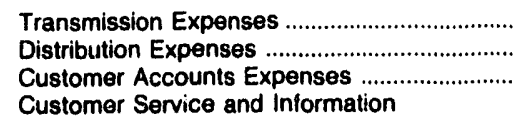 & $\begin{array}{r}8 \\
2,728 \\
1,012\end{array}$ & $\begin{array}{r}1,598 \\
4,352 \\
620\end{array}$ & $\begin{array}{r}83 \\
1,596 \\
963\end{array}$ & $\begin{array}{r}39 \\
6,831 \\
4,808\end{array}$ & $\begin{array}{r}328 \\
2,497 \\
1,156\end{array}$ & $\begin{array}{r}761 \\
1,496 \\
284\end{array}$ \\
\hline 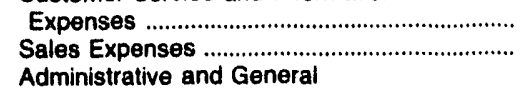 & $\begin{array}{r}288 \\
0\end{array}$ & $\begin{array}{r}636 \\
0\end{array}$ & $\begin{array}{r}-16 \\
0\end{array}$ & $\begin{array}{r}638 \\
41\end{array}$ & $\begin{array}{r}221 \\
0\end{array}$ & $\begin{array}{r}86 \\
0\end{array}$ \\
\hline 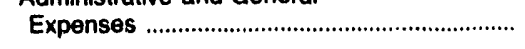 & 2,728 & 13,680 & 2,537 & 6,977 & 3,425 & 3,702 \\
\hline 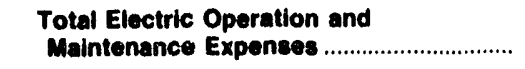 & 39,426 & 46,047 & 16,426 & 86,056 & 95,807 & 20,552 \\
\hline
\end{tabular}

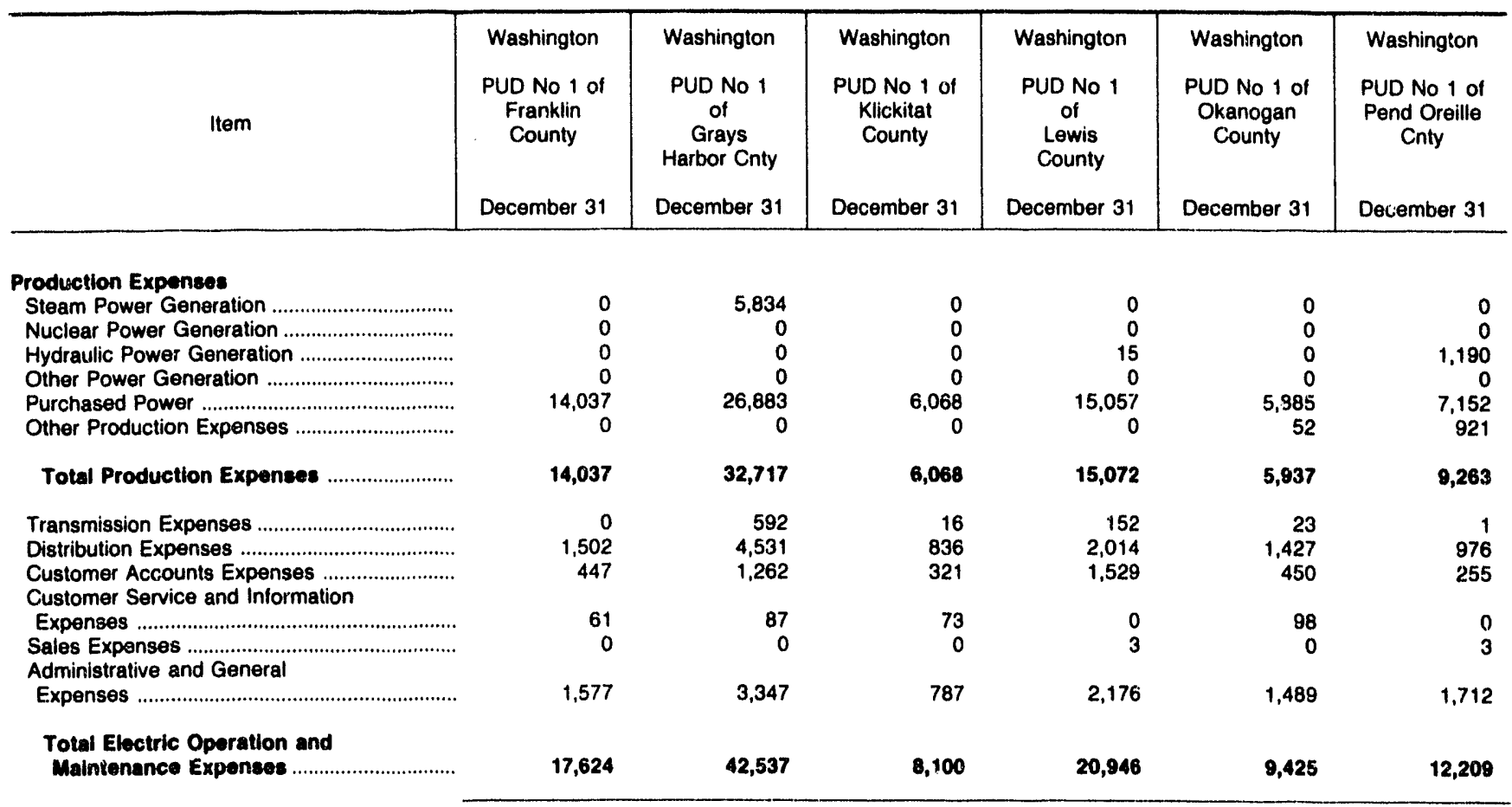

Note: Totals may not equal sum of components because of independent rounding.

Source: Energy Information Administration, Form EIA-412, "Annual Report of Public Electric Utilities." 


\section{Table 38. Electric Operation and Maintenance Expenses by Major Publicly Owned Electric Utility Within State, 1991 (Continued)}

(Thousand Dollars)

\begin{tabular}{|c|c|c|c|c|c|c|}
\hline Item & $\begin{array}{l}\text { Washington } \\
\text { PUD No } 1 \text { of } \\
\text { Snohomish } \\
\text { County } \\
\text { December } 31\end{array}$ & $\begin{array}{l}\text { Washington } \\
\text { PUD No } 1 \text { of } \\
\text { Whatcom } \\
\text { County } \\
\text { December } 31\end{array}$ & $\begin{array}{c}\text { Washington } \\
\text { PUD No } 2 \\
\text { of } \\
\text { Grant } \\
\text { County } \\
\text { December } 31\end{array}$ & $\begin{array}{l}\text { Washington } \\
\text { PUD No } 2 \text { of } \\
\text { Pacific } \\
\text { County } \\
\text { December } 31\end{array}$ & $\begin{array}{c}\text { Washington } \\
\text { PUD No } 3 \\
\text { of } \\
\text { Mason } \\
\text { County } \\
\text { December } 31\end{array}$ & $\begin{array}{l}\text { Washington } \\
\text { Richland } \\
\text { City of } \\
\text { December } 31\end{array}$ \\
\hline 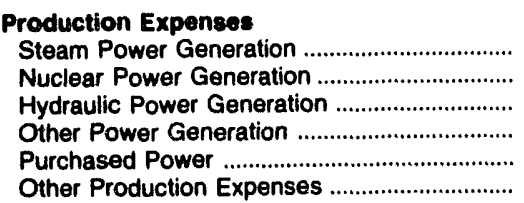 & $\begin{array}{r}10,222 \\
0 \\
1,402 \\
0 \\
133,371 \\
0\end{array}$ & $\begin{array}{r}0 \\
0 \\
0 \\
0 \\
3,038 \\
0\end{array}$ & $\begin{array}{r}0 \\
0 \\
18,644 \\
0 \\
3,890 \\
0\end{array}$ & $\begin{array}{r}0 \\
0 \\
0 \\
0 \\
6,509 \\
0\end{array}$ & $\begin{array}{r}0 \\
0 \\
0 \\
0 \\
11,086 \\
0\end{array}$ & $\begin{array}{r}0 \\
0 \\
0 \\
0 \\
14,512 \\
0\end{array}$ \\
\hline Total Production Expenses ............................. & 144,996 & 3,038 & 22,534 & 6,509 & 11,086 & 14,512 \\
\hline 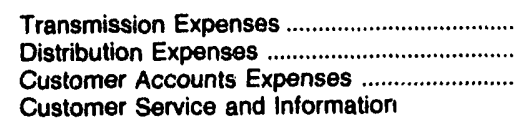 & $\begin{array}{r}1,739 \\
17,576 \\
8,081\end{array}$ & $\begin{array}{r}27 \\
0 \\
0\end{array}$ & $\begin{array}{l}1,148 \\
4,716 \\
1,710\end{array}$ & $\begin{array}{r}0 \\
941 \\
410\end{array}$ & $\begin{array}{r}0 \\
1,887 \\
821\end{array}$ & $\begin{array}{r}9 \\
1,636 \\
397\end{array}$ \\
\hline 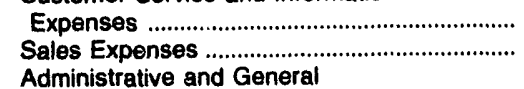 & $\begin{array}{r}4,575 \\
0\end{array}$ & $\begin{array}{l}0 \\
0\end{array}$ & $\begin{array}{r}651 \\
0\end{array}$ & $\begin{array}{r}70 \\
0\end{array}$ & $\begin{array}{r}282 \\
0\end{array}$ & $\begin{array}{r}186 \\
0\end{array}$ \\
\hline 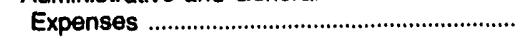 & 14,119 & 109 & 10,480 & 845 & 1,520 & 800 \\
\hline $\begin{array}{l}\text { Total Electric Operation and } \\
\text { Maintenance Expenses .................................. }\end{array}$ & 191,085 & 3,174 & 41,238 & 8,775 & 15,597 & 17,539 \\
\hline
\end{tabular}

\begin{tabular}{|c|c|c|c|c|c|c|}
\hline Item & $\begin{array}{c}\text { Washington } \\
\text { Seattle } \\
\text { City of } \\
\text { December } 31\end{array}$ & $\begin{array}{c}\text { Washington } \\
\text { Tacoma } \\
\text { City of } \\
\text { December } 31\end{array}$ & $\begin{array}{c}\text { Washington } \\
\text { Vera } \\
\text { Irrigation } \\
\text { District \#15 } \\
\text { December } 31\end{array}$ & $\begin{array}{l}\text { Washington } \\
\text { Washington } \\
\text { Pub } \\
\text { Pwr } \\
\text { Supply Sys } \\
\text { June } 30\end{array}$ & $\begin{array}{c}\text { Wisconsin } \\
\text { Jefferson } \\
\text { City of } \\
\text { December } 31\end{array}$ & $\begin{array}{l}\text { Wisconsin } \\
\text { Kaukauna } \\
\text { City of } \\
\text { December } 31\end{array}$ \\
\hline 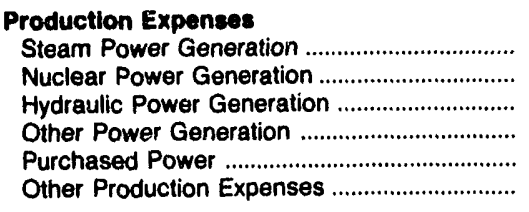 & $\begin{array}{r}12,006 \\
0 \\
15,371 \\
0 \\
53,077 \\
2,021\end{array}$ & $\begin{array}{r}14,778 \\
0 \\
8,878 \\
0 \\
66,588 \\
410\end{array}$ & $\begin{array}{r}0 \\
0 \\
0 \\
0 \\
4,149 \\
0\end{array}$ & $\begin{array}{r}0 \\
12.2,974 \\
230 \\
0 \\
0 \\
0\end{array}$ & $\begin{array}{r}0 \\
0 \\
0 \\
0 \\
4,883 \\
0\end{array}$ & $\begin{array}{r}0 \\
0 \\
812 \\
52 \\
13,905 \\
193\end{array}$ \\
\hline Total Production Expenses ......................... & 82,475 & 90,654 & 4,149 & 123,204 & 4,883 & 14,962 \\
\hline 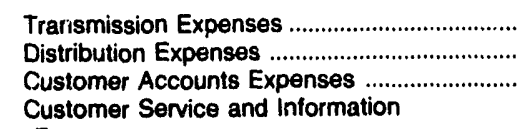 & $\begin{array}{l}14,454 \\
33,007 \\
16,142\end{array}$ & $\begin{array}{r}4,134 \\
12,916 \\
4,072\end{array}$ & $\begin{array}{r}0 \\
455 \\
314\end{array}$ & $\begin{array}{r}198 \\
0 \\
0\end{array}$ & $\begin{array}{r}0 \\
125 \\
41\end{array}$ & $\begin{array}{r}15 \\
503 \\
170\end{array}$ \\
\hline 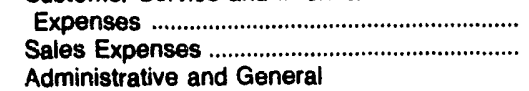 & $\begin{array}{r}7,384 \\
0\end{array}$ & $\begin{array}{r}2,601 \\
282\end{array}$ & $\begin{array}{r}35 \\
0\end{array}$ & $\begin{array}{l}0 \\
0\end{array}$ & $\begin{array}{l}0 \\
4\end{array}$ & $\begin{array}{r}0 \\
24\end{array}$ \\
\hline 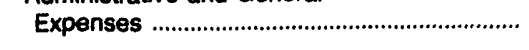 & 38,469 & 15,902 & 243 & 48,170 & 145 & 755 \\
\hline $\begin{array}{l}\text { Total Electric Oparation and } \\
\text { Maintenance Exponses }\end{array}$ & 191,931 & 130,561 & 5,196 & 171,572 & 5,198 & 16,430 \\
\hline
\end{tabular}

Note: Totals may not equal sum of components because of independent rounding.

Source: Energy Information Administration, Form ElA-412, "Annual Report of Public Electric Utilities." 

Table 38. Electric Operation and Maintenance Expenses by Major Publicly
Owned Electric Utility Within State, 1991 (Continued)

(Thousand Dollars)

\begin{tabular}{|c|c|c|c|c|c|c|}
\hline Item & $\begin{array}{l}\text { Wisconsin } \\
\text { Manitowoc } \\
\text { Public } \\
\text { Utilities }\end{array}$ & $\begin{array}{c}\text { Wisconsin } \\
\text { Marshfield } \\
\text { City of }\end{array}$ & $\begin{array}{c}\text { Wisconsin } \\
\text { Menasha } \\
\text { City of }\end{array}$ & $\begin{array}{l}\text { Wisconsin } \\
\text { New London } \\
\text { City of }\end{array}$ & $\begin{array}{l}\text { Wisconsin } \\
\text { Oconomowoc } \\
\text { City of }\end{array}$ & Wisconsin \\
\hline & December 31 & December 31 & December 31 & December 31 & December 31 & December 31 \\
\hline
\end{tabular}

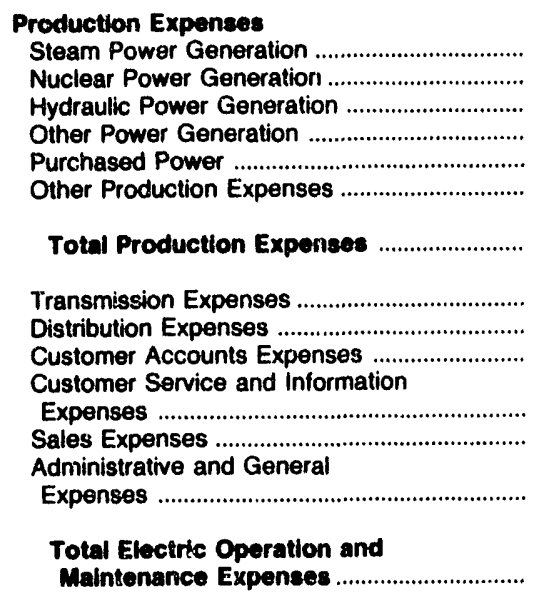

Maintenance Expenses

9,530
0
0
168
6,218
0

359
0
0
0
11,702
0

15,916

12,061
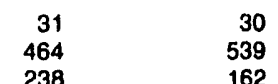

30
539

162

238

0
207

1,374

18,229

13,587

0
37

757

0
0
0
0
5,945
0

17,862

21
323

143

0
20

703

19,172

6,433

0
0
0
0
5,796
0

0

0

0

5,198

5,198

0

368

118

0

23

250

5,958

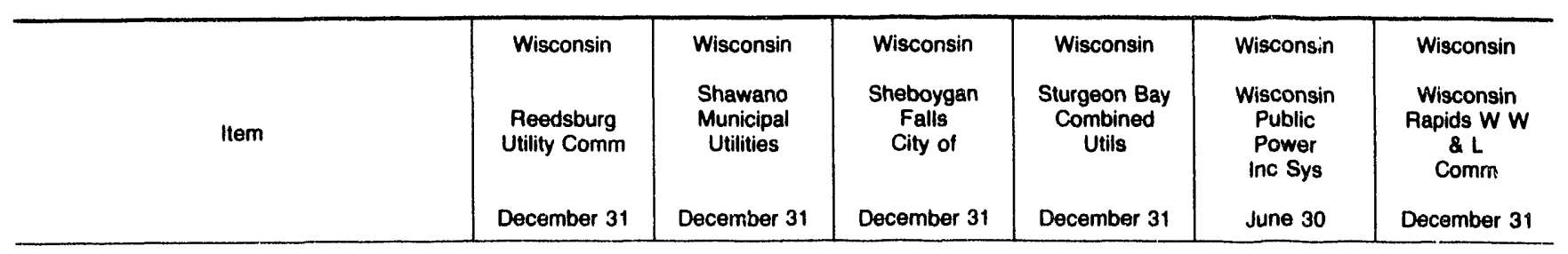

Production Expenses

Steam Power Generation

Nuclear Power Generation.

Hydraulic Power Generation

Other Power Generation

Purchased Power

Other Production Expenses

Total Production Expenses

Transmission Expenses

Distribution Expenses

Customer Accounts Expenses .........................

Customer Service and Iniormation

Expenses ...

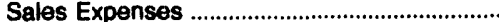

Administrative and General

Expenses

0
0
0
0
5,065

0
0
0
0
6,392

0
0
0
0
5,151

366

5,065

6,392

5,517

$\begin{array}{rr}21 & 2 \\ 109 & 137\end{array}$

109

2
137
64

0
194

39

0

0
0

150
Total Electric Operation and

Maintenance Expenses

\section{and}

Note: Totals may not equal sum of components because of independent rounding.

Source: Energy Information Administration, Form EIA-412, "Annual Report of Public Electric Utilities."

\begin{tabular}{rrr}
0 & 9,976 & 0 \\
0 & 0 & 0 \\
0 & 0 & 0 \\
0 & 0 & 0 \\
5,201 & 92,468 & 7,494 \\
0 & 1,518 & 0 \\
5,201 & 103,962 & 7,494 \\
4 & 0 & 0 \\
374 & 0 & 518 \\
118 & 0 & 235 \\
0 & 0 & 0 \\
0 & 0 & 3 \\
223 & 2,305 & 411 \\
& & \\
5,919 & 106,267 & 8,661 \\
\hline
\end{tabular}


Table 38. Electric Operation and Maintenance Expenses by Major Publicly Owned Electric Utility Within State, 1991 (Continued)

(Thousand Dollars)

\begin{tabular}{|c|c|c|}
\hline Item & $\begin{array}{l}\text { Wyoming } \\
\text { Gillette } \\
\text { City of } \\
\text { June } 30\end{array}$ & $\begin{array}{l}\text { Wyoming } \\
\text { Wyoming } \\
\text { Municipal } \\
\text { Power Agency } \\
\text { December } 31\end{array}$ \\
\hline
\end{tabular}

\section{Production Expenses}

Steam Power Generation

Nuclear Power Generation

Hydraulic Power Generation

Other Power Generation

Purchased Power

Other Production Expenses

Total Production Expenses

$\begin{array}{rr}0 & 1,712 \\ 0 & 0 \\ 0 & 0 \\ 0 & 0 \\ 7,731 & 1,010 \\ 0 & 2\end{array}$

Transmission Expenses

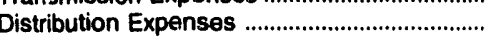

Customer Accounts Expenses

Customer Service and Information

Expenses

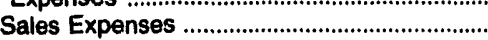

Administrative and General

Expenses

$\mathbf{7 , 7 3 1} \quad 2,724$

$24 \quad 261$

$\begin{array}{rr}287 & 0 \\ 53 & 0\end{array}$

$184 \quad 49$

$0 \quad 0$

Total Electric Operation and

Maintenance Expenses

395

310

Note: Totals may not equal sum of components because of independent rounding

Source: Energy Information Administration, Form EIA-412, "Annual Report of Public Electric Utilities." 
Table 39. Electric Utility Plant by Major Publicly Owned Electric Utility Within State at End of Period, 1991 (Thousand Dollars)

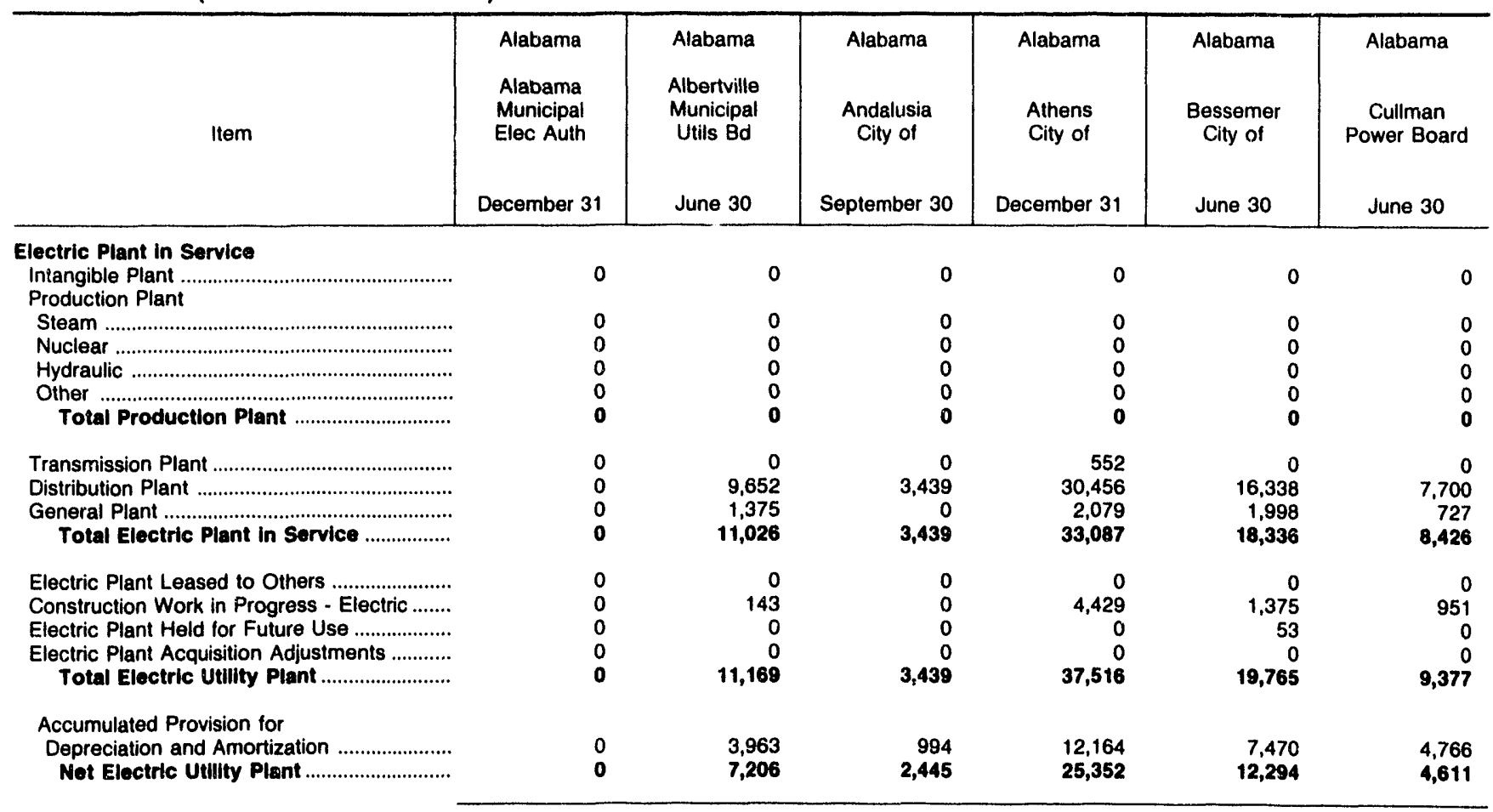

\begin{tabular}{|c|c|c|c|c|c|c|}
\hline Item & $\begin{array}{l}\text { Alabama } \\
\text { Decatur } \\
\text { City of } \\
\text { June } 30\end{array}$ & $\begin{array}{l}\text { Alabama } \\
\text { Dothan } \\
\text { City of } \\
\text { September } 30\end{array}$ & $\begin{array}{l}\text { Alabama } \\
\text { Florence } \\
\text { City of } \\
\text { June } 30\end{array}$ & $\begin{array}{c}\text { Alabama } \\
\text { Foley } \\
\text { City of } \\
\text { (Riviera Utils) } \\
\text { December } 31\end{array}$ & $\begin{array}{c}\text { Alabama } \\
\begin{array}{c}\text { Fort Payne } \\
\text { Improvement } \\
\text { Auth }\end{array} \\
\text { June } 30\end{array}$ & $\begin{array}{l}\text { Alabama } \\
\text { Guntersville } \\
\text { Electric } \\
\text { Board } \\
\text { June } 30\end{array}$ \\
\hline 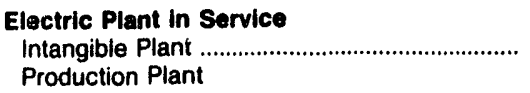 & 0 & 0 & 0 & 0 & 0 & 0 \\
\hline 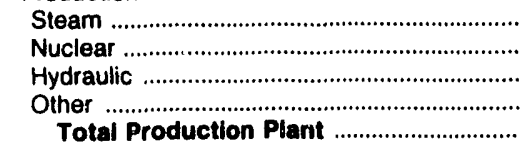 & $\begin{array}{l}0 \\
0 \\
0 \\
0 \\
0\end{array}$ & $\begin{array}{l}0 \\
0 \\
0 \\
0 \\
0\end{array}$ & $\begin{array}{l}0 \\
0 \\
0 \\
0 \\
0\end{array}$ & $\begin{array}{l}0 \\
0 \\
0 \\
4 \\
4\end{array}$ & $\begin{array}{l}0 \\
0 \\
0 \\
0 \\
0\end{array}$ & $\begin{array}{l}0 \\
0 \\
0 \\
0 \\
0\end{array}$ \\
\hline 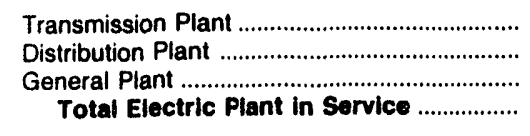 & $\begin{array}{r}0 \\
31,818 \\
2,640 \\
34,458\end{array}$ & $\begin{array}{r}0 \\
47,875 \\
0 \\
47,875\end{array}$ & $\begin{array}{r}12,278 \\
46,180 \\
5,468 \\
63,926\end{array}$ & $\begin{array}{r}12,080 \\
27,817 \\
7,389 \\
47,289\end{array}$ & $\begin{array}{r}0 \\
8,067 \\
1,329 \\
9,395\end{array}$ & $\begin{array}{r}0 \\
7,493 \\
709 \\
8,202\end{array}$ \\
\hline 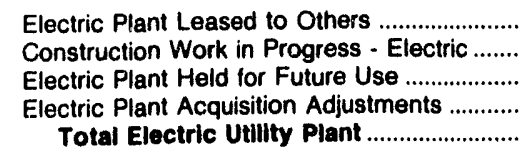 & $\begin{array}{r}0 \\
1,179 \\
417 \\
0 \\
36,053\end{array}$ & $\begin{array}{r}0 \\
0 \\
0 \\
0 \\
47,875\end{array}$ & $\begin{array}{r}0 \\
1,305 \\
0 \\
0 \\
65,232\end{array}$ & $\begin{array}{r}0 \\
0 \\
0 \\
0 \\
47,289\end{array}$ & $\begin{array}{r}0 \\
2,162 \\
0 \\
0 \\
11,557\end{array}$ & $\begin{array}{r}0 \\
126 \\
0 \\
0 \\
8,328\end{array}$ \\
\hline 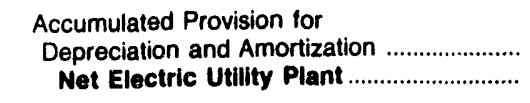 & $\begin{array}{l}14,877 \\
21,176\end{array}$ & $\begin{array}{l}16,091 \\
31,783\end{array}$ & $\begin{array}{l}25,477 \\
39,755\end{array}$ & $\begin{array}{l}14,209 \\
33,080\end{array}$ & $\begin{array}{l}3,700 \\
7,857\end{array}$ & $\begin{array}{l}3,662 \\
4,666\end{array}$ \\
\hline
\end{tabular}

Note: Totals may not equal sum of components because of independent rounding.

Source: Energy Information Administration, Form EIA-412, "Annual Peport of Public Electric Utilities." 

Table 39. Electric Utility Plant by Major Publicly Owned Electric Utility
Within State at End of Period, 1991 (Continued)

(Thousand Dollars)

\begin{tabular}{|c|c|c|c|c|c|c|}
\hline Item & $\begin{array}{c}\text { Alabama } \\
\text { Huntsville } \\
\text { City of } \\
\text { September } 30\end{array}$ & $\begin{array}{l}\text { Alabama } \\
\text { Muscle } \\
\text { Shoals } \\
\text { City of } \\
\text { June } 30\end{array}$ & $\begin{array}{c}\text { Alabama } \\
\text { Opelika } \\
\text { City of } \\
\text { September } 30\end{array}$ & $\begin{array}{l}\text { Alabama } \\
\begin{array}{c}\text { Scottsboro } \\
\text { City of }\end{array} \\
\text { June } 30\end{array}$ & $\begin{array}{l}\text { Alabama } \\
\text { Sheffield } \\
\text { Utilities } \\
\text { June } 30\end{array}$ & $\begin{array}{l}\text { Alabama } \\
\text { Sylacauga } \\
\text { Utilities } \\
\text { Board } \\
\text { September } 30\end{array}$ \\
\hline Electric Plant in Service & 0 & 0 & 0 & 0 & 0 & 0 \\
\hline 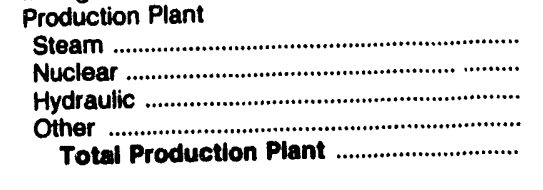 & $\begin{array}{l}0 \\
0 \\
0 \\
0 \\
0\end{array}$ & $\begin{array}{l}0 \\
0 \\
0 \\
0 \\
0\end{array}$ & $\begin{array}{l}0 \\
0 \\
0 \\
0 \\
0\end{array}$ & $\begin{array}{l}0 \\
0 \\
0 \\
0 \\
0\end{array}$ & $\begin{array}{l}0 \\
0 \\
0 \\
0 \\
0\end{array}$ & $\begin{array}{l}0 \\
0 \\
0 \\
0 \\
0\end{array}$ \\
\hline 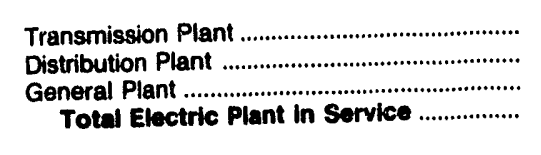 & $\begin{array}{r}0 \\
129,894 \\
8,805 \\
138,698\end{array}$ & $\begin{array}{r}0 \\
0 \\
10,930 \\
10,930\end{array}$ & $\begin{array}{r}15,325 \\
0 \\
0 \\
15,325\end{array}$ & $\begin{array}{r}0 \\
11,735 \\
1,376 \\
13,111\end{array}$ & $\begin{array}{r}1,107 \\
24,909 \\
3,241 \\
29,256\end{array}$ & $\begin{array}{r}0 \\
9,016 \\
1,044 \\
10,058\end{array}$ \\
\hline 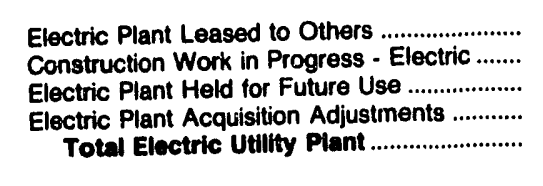 & $\begin{array}{r}0 \\
7,107 \\
0 \\
0 \\
145,805\end{array}$ & $\begin{array}{r}0 \\
598 \\
0 \\
0 \\
11,528\end{array}$ & $\begin{array}{r}0 \\
0 \\
0 \\
0 \\
15,325\end{array}$ & $\begin{array}{r}0 \\
46 \\
0 \\
0 \\
13,157\end{array}$ & $\begin{array}{r}0 \\
692 \\
0 \\
253 \\
30,201\end{array}$ & $\begin{array}{r}0 \\
0 \\
0 \\
0 \\
10,059\end{array}$ \\
\hline 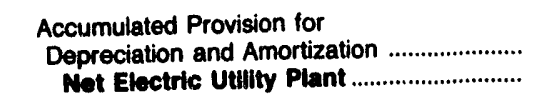 & $\begin{array}{l}52,279 \\
93,526\end{array}$ & $\begin{array}{l}3,342 \\
8,186\end{array}$ & $\begin{array}{l}8,704 \\
6,620\end{array}$ & $\begin{array}{l}4,388 \\
8,769\end{array}$ & $\begin{array}{l}12,402 \\
17,799\end{array}$ & $\begin{array}{l}6,054 \\
4,005\end{array}$ \\
\hline
\end{tabular}

\begin{tabular}{|c|c|c|c|c|c|c|}
\hline Item & $\begin{array}{c}\text { Alabama } \\
\text { Troy } \\
\text { City of } \\
\text { September } 30\end{array}$ & $\begin{array}{l}\text { Alabama } \\
\text { Tuskegee } \\
\text { City of } \\
\text { September } 30\end{array}$ & $\begin{array}{l}\text { Alaska } \\
\text { Alaska } \\
\text { Energy } \\
\text { Authority } \\
\text { June } 30\end{array}$ & $\begin{array}{c}\text { Alaska } \\
\text { Anchorage } \\
\text { City of } \\
\text { December } 31\end{array}$ & $\begin{array}{l}\text { Alaska } \\
\text { Fairbanks } \\
\text { City of } \\
\text { December } 31\end{array}$ & $\begin{array}{c}\text { Alaska } \\
\text { Ketchikan } \\
\text { City of } \\
\text { December } 31\end{array}$ \\
\hline 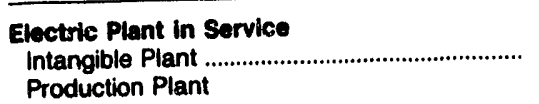 & 0 & 0 & 2,947 & 12,683 & 120 & 0 \\
\hline 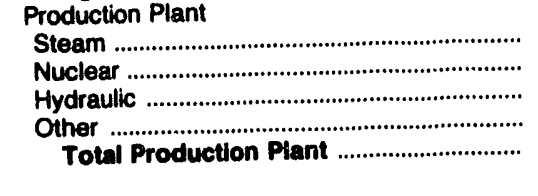 & $\begin{array}{l}0 \\
0 \\
0 \\
0 \\
0\end{array}$ & $\begin{array}{l}0 \\
0 \\
0 \\
0 \\
0\end{array}$ & $\begin{array}{r}3,535 \\
0 \\
340,338 \\
0 \\
343,873\end{array}$ & $\begin{array}{r}17,046 \\
0 \\
0 \\
64,836 \\
81,882\end{array}$ & $\begin{array}{r}28,714 \\
0 \\
0 \\
4,311 \\
33,025\end{array}$ & $\begin{array}{r}13,827 \\
0 \\
0 \\
6,743 \\
20,570\end{array}$ \\
\hline 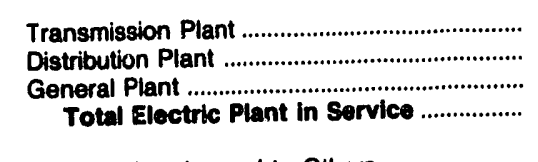 & $\begin{array}{r}0 \\
8,165 \\
914 \\
9,079\end{array}$ & $\begin{array}{r}0 \\
6,477 \\
0 \\
6,477\end{array}$ & $\begin{array}{r}277,180 \\
0 \\
2,535 \\
626,535\end{array}$ & $\begin{array}{r}16,207 \\
81,420 \\
24,109 \\
218,301\end{array}$ & $\begin{array}{r}3,632 \\
7,428 \\
1,127 \\
45,332\end{array}$ & $\begin{array}{r}0 \\
16,299 \\
2,534 \\
39,403\end{array}$ \\
\hline 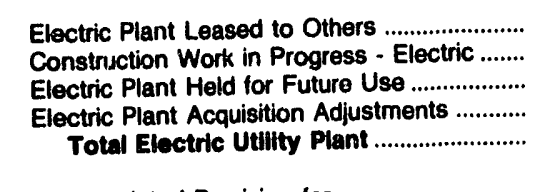 & $\begin{array}{r}0 \\
0 \\
0 \\
0 \\
9,079\end{array}$ & $\begin{array}{r}0 \\
0 \\
0 \\
0 \\
6,477\end{array}$ & $\begin{array}{r}0 \\
271,490 \\
0 \\
0 \\
898,025\end{array}$ & $\begin{array}{r}739 \\
5,799 \\
0 \\
2,533 \\
225,372\end{array}$ & $\begin{array}{r}0 \\
908 \\
0 \\
0 \\
46,239\end{array}$ & $\begin{array}{r}0 \\
0 \\
76 \\
0 \\
38,479\end{array}$ \\
\hline 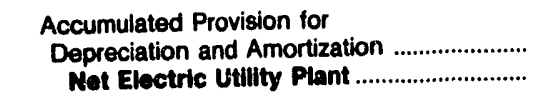 & $\begin{array}{l}4,747 \\
4,332\end{array}$ & $\begin{array}{l}2,603 \\
3,875\end{array}$ & $\begin{array}{l}106,036 \\
791,989\end{array}$ & $\begin{array}{r}84,337 \\
141,035\end{array}$ & $\begin{array}{l}23,964 \\
22,275\end{array}$ & $\begin{array}{l}17,402 \\
22,078\end{array}$ \\
\hline
\end{tabular}

Note: Totals may not equal sum of componenis because of independent rounding.

Source: Energy information Administration, Form EIA-412, "Annual Report of Public Electric Utilities." 
Table 39. Electric Utility Plant by Major Publicly Owned Electric Utility Within State at End of Period, 1991 (Continued) (Thousand Dollars)

\begin{tabular}{|c|c|c|c|c|c|c|}
\hline Item & $\begin{array}{l}\text { Arizona } \\
\text { Arizona } \\
\text { Power } \\
\text { Authority } \\
\\
\text { June } 30\end{array}$ & $\begin{array}{l}\text { Arizona } \\
\text { Mesa } \\
\text { City of } \\
\text { June } 30\end{array}$ & $\begin{array}{c}\text { Arizona } \\
\text { Navajo } \\
\text { Tribal } \\
\text { Utility } \\
\text { Auth } \\
\text { December } 31\end{array}$ & $\begin{array}{l}\text { Arizona } \\
\text { Salt River } \\
\text { Proj Ag } \\
\text { I \& P Dist } \\
\text { April } 30\end{array}$ & $\begin{array}{l}\text { Arkansas } \\
\text { Benton } \\
\text { City of } \\
\text { December } 31\end{array}$ & $\begin{array}{c}\text { Arkansas } \\
\text { Bentonville } \\
\text { City of }\end{array}$ \\
\hline 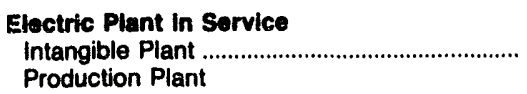 & 0 & 0 & 0 & 17,501 & 0 & 5,293 \\
\hline 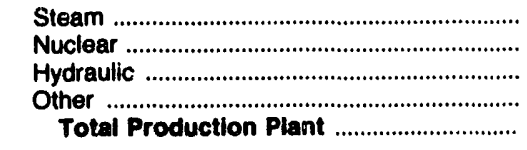 & $\begin{array}{l}0 \\
0 \\
0 \\
0 \\
0\end{array}$ & $\begin{array}{l}0 \\
0 \\
0 \\
0 \\
0\end{array}$ & $\begin{array}{l}0 \\
0 \\
0 \\
0 \\
0\end{array}$ & $\begin{array}{r}1,504,401 \\
1,530,954 \\
66,844 \\
110,682 \\
3,212,880\end{array}$ & $\begin{array}{r}0 \\
0 \\
0 \\
1,696 \\
1,696\end{array}$ & $\begin{array}{l}\mathbf{0} \\
\mathbf{0} \\
\mathbf{0} \\
\mathbf{0} \\
\mathbf{0}\end{array}$ \\
\hline 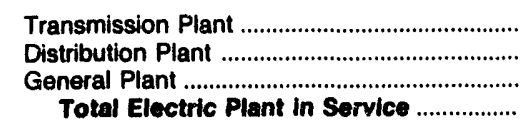 & $\begin{array}{r}289 \\
150 \\
662 \\
1,101\end{array}$ & $\begin{array}{r}0 \\
0 \\
45,713 \\
45,713\end{array}$ & $\begin{array}{r}7,249 \\
72,789 \\
8,854 \\
88,892\end{array}$ & $\begin{array}{r}444,017 \\
908,206 \\
459,345 \\
5,041,950\end{array}$ & $\begin{array}{r}0 \\
4,569 \\
0 \\
6,265\end{array}$ & $\begin{array}{r}0 \\
0 \\
19,507 \\
24,799\end{array}$ \\
\hline 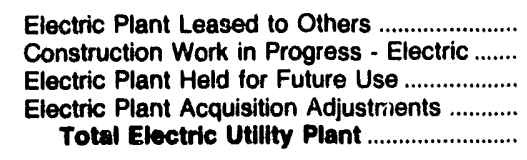 & $\begin{array}{r}0 \\
0 \\
0 \\
0 \\
1,101\end{array}$ & $\begin{array}{r}0 \\
2,888 \\
0 \\
0 \\
48,601\end{array}$ & $\begin{array}{r}0 \\
6,120 \\
0 \\
0 \\
95,012\end{array}$ & $\begin{array}{r}58,437 \\
206,819 \\
90,726 \\
41,847 \\
5,439,779\end{array}$ & $\begin{array}{r}0 \\
0 \\
0 \\
0 \\
6,265\end{array}$ & $\begin{array}{r}0 \\
0 \\
0 \\
0 \\
24,799\end{array}$ \\
\hline 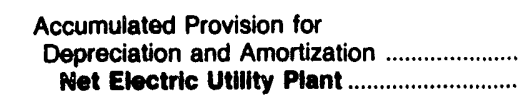 & $\begin{array}{l}496 \\
605\end{array}$ & $\begin{array}{r}9,914 \\
38,687\end{array}$ & $\begin{array}{l}29,332 \\
65,679\end{array}$ & $\begin{array}{l}1,333,769 \\
4,106,010\end{array}$ & $\begin{array}{l}4,785 \\
1,480\end{array}$ & $\begin{array}{r}5,819 \\
18,880\end{array}$ \\
\hline
\end{tabular}

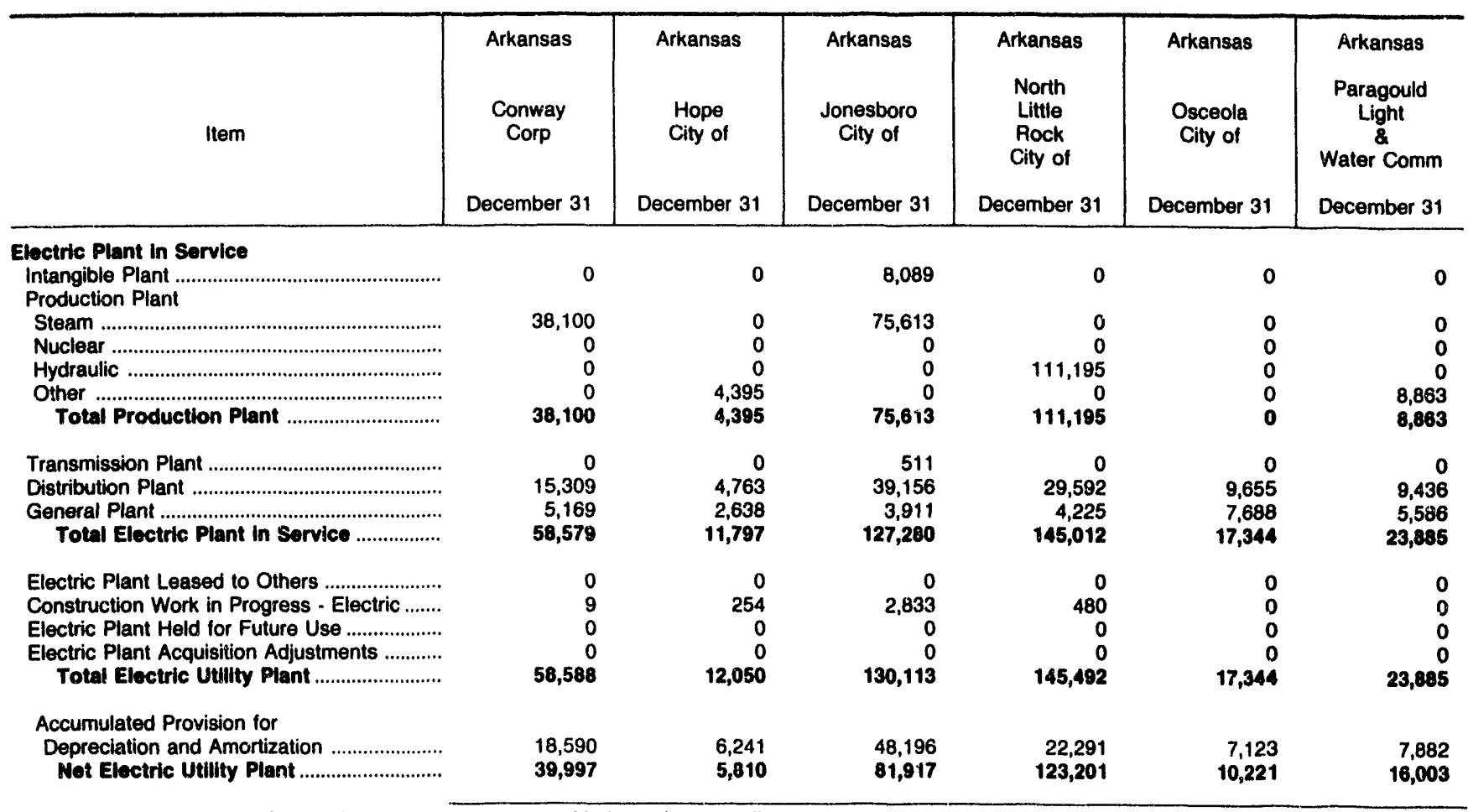

Note: Totals may not equal sum of components because of independent rounding.

Source: Energy Information Administration, Form EIA-412, "Annual Report of Public Electric Utilities." 
Table 39. Electric Utility Plant by Major Publicly Owned Electric Utility Within State at End of Period, 1991 (Continued) (Thousand Dollars)

\begin{tabular}{|c|c|c|c|c|c|c|}
\hline Item & $\begin{array}{l}\text { Arkansas } \\
\text { Siloam } \\
\text { Springs } \\
\text { City of } \\
\text { December } 31\end{array}$ & $\begin{array}{l}\text { Arkansas } \\
\text { West } \\
\text { Mernphis } \\
\text { City of } \\
\text { December } 31\end{array}$ & $\begin{array}{l}\text { California } \\
\text { Alameda } \\
\text { City of } \\
\text { June } 30\end{array}$ & $\begin{array}{l}\text { California } \\
\text { Anaheim } \\
\text { City of } \\
\text { June } 30\end{array}$ & $\begin{array}{l}\text { California } \\
\text { Azusa } \\
\text { City of } \\
\text { June } 30\end{array}$ & $\begin{array}{l}\text { California } \\
\text { Burbank } \\
\text { City of } \\
\text { June } 30\end{array}$ \\
\hline 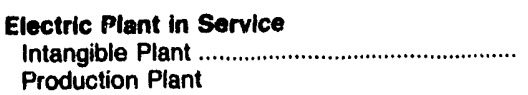 & 0 & 9,164 & 0 & 0 & 0 & 15,943 \\
\hline 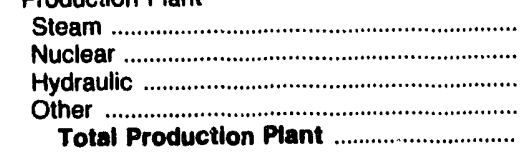 & $\begin{array}{l}0 \\
0 \\
0 \\
0 \\
0\end{array}$ & $\begin{array}{r}18,327 \\
0 \\
0 \\
0 \\
18,327\end{array}$ & $\begin{array}{l}0 \\
0 \\
0 \\
0 \\
0\end{array}$ & $\begin{array}{r}0 \\
179,544 \\
0 \\
30,253 \\
209,797\end{array}$ & $\begin{array}{l}0 \\
0 \\
0 \\
0 \\
0\end{array}$ & $\begin{array}{r}41,683 \\
0 \\
0 \\
0 \\
41,683\end{array}$ \\
\hline 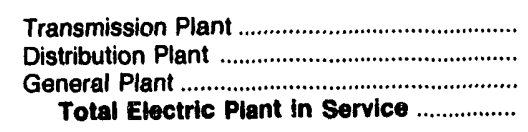 & $\begin{array}{r}550 \\
4,615 \\
50 \\
5,215\end{array}$ & $\begin{array}{r}0 \\
0 \\
0 \\
27,490\end{array}$ & $\begin{array}{r}3,487 \\
29,372 \\
3,845 \\
36,705\end{array}$ & $\begin{array}{r}15,357 \\
106,286 \\
12,198 \\
343,638\end{array}$ & $\begin{array}{r}0 \\
10,892 \\
0 \\
10,892\end{array}$ & $\begin{array}{r}15,652 \\
65,893 \\
9,511 \\
148,682\end{array}$ \\
\hline 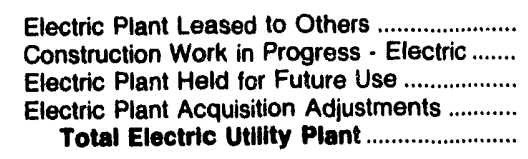 & $\begin{array}{r}0 \\
0 \\
0 \\
0 \\
5,215\end{array}$ & $\begin{array}{r}0 \\
0 \\
0 \\
0 \\
27,490\end{array}$ & $\begin{array}{r}0 \\
0 \\
0 \\
0 \\
36,705\end{array}$ & $\begin{array}{r}0 \\
28,758 \\
0 \\
0 \\
372,396\end{array}$ & $\begin{array}{r}0 \\
0 \\
0 \\
0 \\
10,892\end{array}$ & $\begin{array}{r}0 \\
7,323 \\
0 \\
0 \\
156,005\end{array}$ \\
\hline 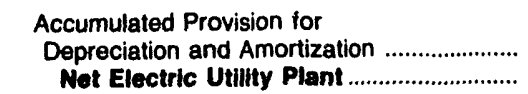 & $\begin{array}{l}2,868 \\
2,347\end{array}$ & $\begin{array}{l}10,504 \\
16,986\end{array}$ & $\begin{array}{r}9,551 \\
27,154\end{array}$ & $\begin{array}{r}84,136 \\
288,260\end{array}$ & $\begin{array}{l}3,717 \\
?, 175\end{array}$ & $\begin{array}{l}83,028 \\
72,977\end{array}$ \\
\hline
\end{tabular}

\begin{tabular}{|c|c|c|c|c|c|c|}
\hline Item & $\begin{array}{l}\text { California } \\
\text { California } \\
\text { Dept } \\
\text { Wtr } \\
\text { Resources } \\
\text { December } 31\end{array}$ & $\begin{array}{l}\text { California } \\
\text { Colton } \\
\text { City of } \\
\text { June } 30\end{array}$ & $\begin{array}{l}\text { California } \\
\text { Glendale } \\
\text { City of } \\
\text { June } 30\end{array}$ & $\begin{array}{c}\text { California } \\
\text { Imperial } \\
\text { Irrigation } \\
\text { District } \\
\text { December } 31\end{array}$ & $\begin{array}{l}\text { California } \\
\text { Lodi } \\
\text { City of } \\
\text { June } 30\end{array}$ & $\begin{array}{l}\text { California } \\
\text { Los Angeles } \\
\text { City of } \\
\text { June } 30\end{array}$ \\
\hline 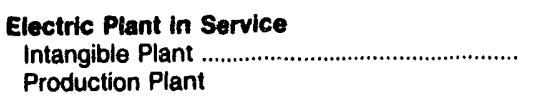 & 0 & 0 & 0 & 769 & 0 & 0 \\
\hline 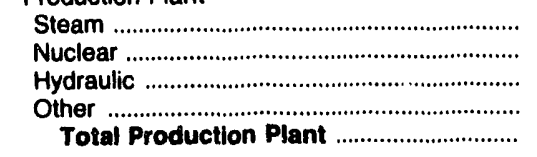 & $\begin{array}{r}142,548 \\
0 \\
541,063 \\
310,903 \\
994,514\end{array}$ & $\begin{array}{l}0 \\
0 \\
0 \\
0 \\
0\end{array}$ & $\begin{array}{r}60,412 \\
0 \\
0 \\
0 \\
60,412\end{array}$ & $\begin{array}{r}30,279 \\
0 \\
51,246 \\
21,104 \\
102,629\end{array}$ & $\begin{array}{l}0 \\
0 \\
0 \\
0 \\
0\end{array}$ & $\begin{array}{r}917,842 \\
508,408 \\
471,539 \\
10,599 \\
1,908,389\end{array}$ \\
\hline 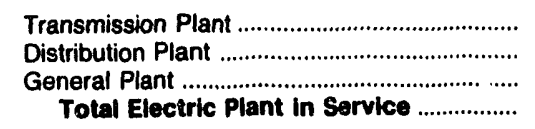 & $\begin{array}{r}0 \\
0 \\
0 \\
994,514\end{array}$ & $\begin{array}{r}0 \\
0 \\
12,153 \\
12,153\end{array}$ & $\begin{array}{r}51,919 \\
101,507 \\
17,496 \\
231,334\end{array}$ & $\begin{array}{r}173,045 \\
157,938 \\
44,892 \\
479,273\end{array}$ & $\begin{array}{r}0 \\
26,711 \\
0 \\
26,711\end{array}$ & $\begin{array}{r}680,492 \\
2,404,479 \\
446,484 \\
5,439,844\end{array}$ \\
\hline 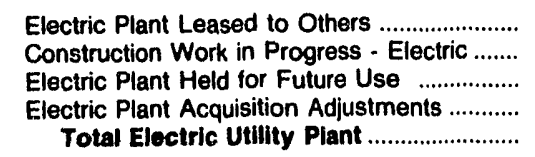 & $\begin{array}{r}0 \\
4,852 \\
0 \\
0 \\
999,366\end{array}$ & $\begin{array}{r}0 \\
0 \\
0 \\
0 \\
12,153\end{array}$ & $\begin{array}{r}0 \\
0 \\
0 \\
0 \\
231,334\end{array}$ & $\begin{array}{r}0 \\
15,522 \\
677 \\
0 \\
495,473\end{array}$ & $\begin{array}{r}0 \\
0 \\
0 \\
0 \\
26,711\end{array}$ & $\begin{array}{r}0 \\
278,947 \\
0 \\
-42,622 \\
5,676,169\end{array}$ \\
\hline 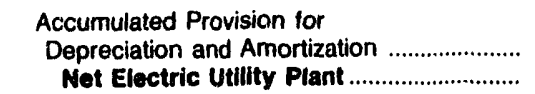 & $\begin{array}{l}242,581 \\
756,785\end{array}$ & $\begin{array}{l}4,240 \\
7,913\end{array}$ & $\begin{array}{l}109,166 \\
122,168\end{array}$ & $\begin{array}{l}149,102 \\
346,371\end{array}$ & $\begin{array}{r}8,787 \\
17,924\end{array}$ & $\begin{array}{l}1,688,977 \\
3,987,192\end{array}$ \\
\hline
\end{tabular}

Note: Totals may not equal sum of components because of independent rounding.

Source: Energy Information Administration, Form ElA-412, "Annual Report of Public Electric Utilities." 
Table 39. Electric Utility Plant by Major Publicly Owned Electric Utillty Within State at End of Period, 1991 (Continued) (Thousand Dollars)

\begin{tabular}{|c|c|c|c|c|c|c|}
\hline item & $\begin{array}{l}\text { California } \\
\text { Metropolitan } \\
\text { Water } \\
\text { District } \\
\text { June } 30\end{array}$ & $\begin{array}{c}\text { Ualifornia } \\
\text { Modesto } \\
\text { Irrigation } \\
\text { District } \\
\text { December } 31\end{array}$ & $\begin{array}{c}\text { California } \\
\text { M'R } \\
\text { Public } \\
\text { Power } \\
\text { Agency } \\
\text { December } 31\end{array}$ & $\begin{array}{l}\text { California } \\
\text { rorthern } \\
\text { California } \\
\text { Power Agny } \\
\text { June } 30\end{array}$ & $\begin{array}{c}\text { California } \\
\text { Oakdale \& } \\
\text { South } \\
\text { San Joaquin } \\
\text { December } 31\end{array}$ & $\begin{array}{c}\text { California } \\
\text { Oroville } \\
\text { Wyandotte } \\
\text { Irrig Dist } \\
\text { December } 31\end{array}$ \\
\hline 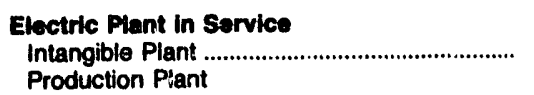 & 0 & 122 & 99 & 0 & 0 & 0 \\
\hline 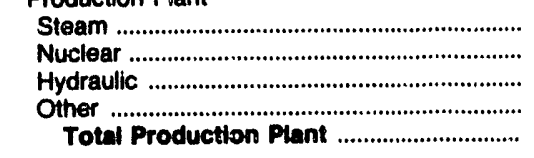 & $\begin{array}{r}0 \\
0 \\
103,038 \\
0 \\
103,038\end{array}$ & $\begin{array}{r}0 \\
0 \\
26,335 \\
22,524 \\
48,860\end{array}$ & $\begin{array}{r}273,958 \\
0 \\
0 \\
0 \\
273,858\end{array}$ & $\begin{array}{r}488,814 \\
0 \\
357,416 \\
46,607 \\
892,837\end{array}$ & $\begin{array}{r}0 \\
0 \\
57,958 \\
0 \\
57,958\end{array}$ & $\begin{array}{l}0 \\
0 \\
0 \\
0 \\
0\end{array}$ \\
\hline 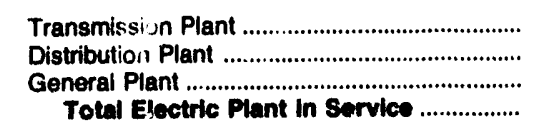 & $\begin{array}{r}0 \\
0 \\
0 \\
103,038\end{array}$ & $\begin{array}{r}9,153 \\
99,455 \\
35,488 \\
193,078\end{array}$ & $\begin{array}{r}0 \\
0 \\
921 \\
274,978\end{array}$ & $\begin{array}{r}5,010 \\
0 \\
4,416 \\
802,263\end{array}$ & $\begin{array}{r}0 \\
0 \\
1,866 \\
59,825\end{array}$ & $\begin{array}{r}1,136 \\
79,611 \\
3,921 \\
84,668\end{array}$ \\
\hline 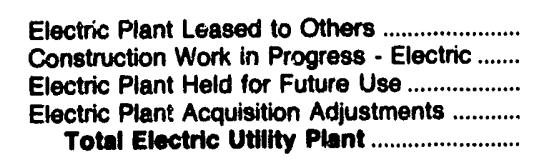 & $\begin{array}{r}0 \\
0 \\
0 \\
0 \\
105,038\end{array}$ & $\begin{array}{r}0 \\
5,726 \\
0 \\
0 \\
198,803\end{array}$ & $\begin{array}{r}0 \\
1,053 \\
0 \\
0 \\
276,031\end{array}$ & $\begin{array}{r}0 \\
8,968 \\
0 \\
0 \\
911,281\end{array}$ & $\begin{array}{r}0 \\
421 \\
0 \\
0 \\
60,248\end{array}$ & $\begin{array}{r}0 \\
1,046 \\
0 \\
0 \\
85,716\end{array}$ \\
\hline 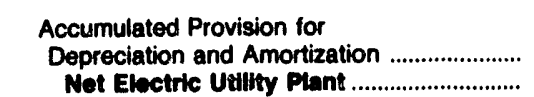 & $\begin{array}{l}15,928 \\
87,110\end{array}$ & $\begin{array}{r}70,165 \\
128,638\end{array}$ & $\begin{array}{r}68,725 \\
207,306\end{array}$ & $\begin{array}{l}140,352 \\
770,879\end{array}$ & $\begin{array}{l}21,141 \\
39,105\end{array}$ & $\begin{array}{l}33,959 \\
51,755\end{array}$ \\
\hline
\end{tabular}

\begin{tabular}{|c|c|c|c|c|c|c|}
\hline Item & $\begin{array}{l}\text { California } \\
\text { Palo Alto } \\
\text { City of } \\
\text { June } 30\end{array}$ & $\begin{array}{l}\text { California } \\
\text { Pasadena } \\
\text { City of } \\
\text { June } 30\end{array}$ & $\begin{array}{c}\text { California } \\
\text { Placer } \\
\text { County } \\
\text { Water } \\
\text { Agency } \\
\text { December is }\end{array}$ & $\begin{array}{l}\text { California } \\
\text { Redding } \\
\text { City of } \\
\text { June } 30\end{array}$ & $\begin{array}{l}\text { California } \\
\text { Riverside } \\
\text { City of } \\
\text { June } 30\end{array}$ & $\begin{array}{l}\text { California } \\
\text { Roseville } \\
\text { City of } \\
\text { June } 30\end{array}$ \\
\hline 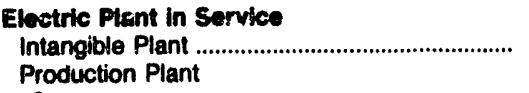 & 0 & 0 & 143 & 0 & 0 & 0 \\
\hline 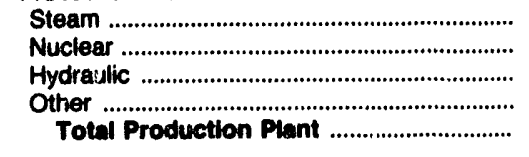 & $\begin{array}{l}0 \\
0 \\
0 \\
0 \\
0\end{array}$ & $\begin{array}{r}36,095 \\
0 \\
5,600 \\
6,388 \\
48,083\end{array}$ & $\begin{array}{r}0 \\
0 \\
110,905 \\
8 \\
110,913\end{array}$ & $\begin{array}{l}0 \\
0 \\
0 \\
0 \\
0\end{array}$ & $\begin{array}{r}0 \\
114,811 \\
0 \\
0 \\
114,811\end{array}$ & $\begin{array}{l}0 \\
0 \\
0 \\
0 \\
0\end{array}$ \\
\hline 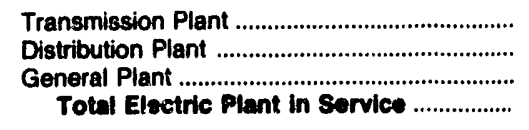 & $\begin{array}{r}0 \\
92,254 \\
0 \\
82,254\end{array}$ & $\begin{array}{r}34,055 \\
112,386 \\
4,005 \\
198,528\end{array}$ & $\begin{array}{r}431 \\
0 \\
5,678 \\
117,165\end{array}$ & $\begin{array}{r}0 \\
0 \\
107,981 \\
107,981\end{array}$ & $\begin{array}{r}10,934 \\
115,571 \\
6,931 \\
248,248\end{array}$ & $\begin{array}{r}0 \\
58,874 \\
722 \\
59,505\end{array}$ \\
\hline 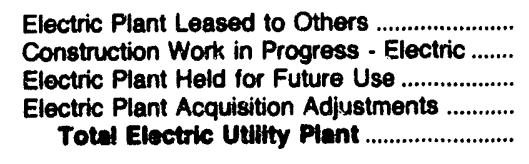 & $\begin{array}{r}0 \\
10,470 \\
0 \\
0 \\
102,724\end{array}$ & $\begin{array}{r}0 \\
11,361 \\
0 \\
0 \\
209,888\end{array}$ & $\begin{array}{r}0 \\
0 \\
0 \\
0 \\
1: 7,165\end{array}$ & $\begin{array}{r}0 \\
2,051 \\
0 \\
0 \\
110,031\end{array}$ & $\begin{array}{r}0 \\
21,029 \\
5,350 \\
0 \\
274,627\end{array}$ & $\begin{array}{r}0 \\
160 \\
n \\
0 \\
59,755\end{array}$ \\
\hline 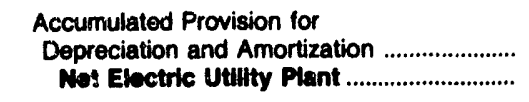 & $\begin{array}{l}35,721 \\
67,003\end{array}$ & $\begin{array}{r}94,520 \\
115,370\end{array}$ & $\begin{array}{l}38,121 \\
79,044\end{array}$ & $\begin{array}{l}33,117 \\
76,915\end{array}$ & $\begin{array}{r}76,914 \\
197,713\end{array}$ & $\begin{array}{r}9,254 \\
50,502\end{array}$ \\
\hline
\end{tabular}

Note: Totels mey not exyel sum of components because of independent rounding.

Source: Energy Information Administration, Form EIA-412, "Annual Report of Public Electric Utilities." 
Table 39. Electric Utility Plant by Major Publicly Owned Electric Utility Within State at End of Period, 1991 (Continued) (Thousand Dollars)

\begin{tabular}{|c|c|c|c|c|c|c|}
\hline Itern & $\begin{array}{l}\text { California } \\
\text { Sacramento } \\
\text { Municipal } \\
\text { Util Dist } \\
\text { December } 31\end{array}$ & $\begin{array}{c}\text { California } \\
\text { San Francisco } \\
\text { City } \\
\& \\
\text { County of } \\
\text { June } 30\end{array}$ & $\begin{array}{c}\text { California } \\
\text { Santa } \\
\text { Clara } \\
\text { City of } \\
. \\
\text { June } \mathbf{3 0}\end{array}$ & $\begin{array}{c}\text { California } \\
\text { Southern } \\
\text { California } \\
\text { P P } \\
\text { A } \\
\text { June } 30\end{array}$ & $\begin{array}{c}\text { California } \\
\text { Turlock } \\
\text { Irrigation } \\
\text { District } \\
\text { December } 31\end{array}$ & $\begin{array}{l}\text { California } \\
\text { Vernon } \\
\text { City of } \\
\text { June } 30\end{array}$ \\
\hline 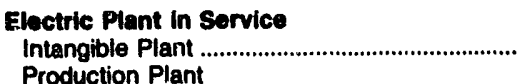 & 147 & 7,658 & 0 & 6,696 & 0 & 0 \\
\hline 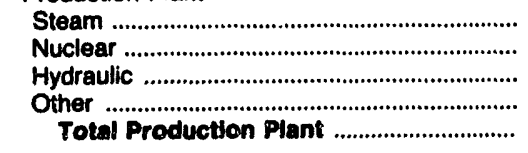 & $\begin{array}{r}190,043 \\
0 \\
227,108 \\
31,888 \\
449,040\end{array}$ & $\begin{array}{r}0 \\
0 \\
90,850 \\
0 \\
90,850\end{array}$ & $\begin{array}{r}0 \\
0 \\
34,455 \\
15,010 \\
49,485\end{array}$ & $\begin{array}{r}0 \\
590,184 \\
0 \\
0 \\
590,184\end{array}$ & $\begin{array}{r}0 \\
0 \\
79,513 \\
0 \\
79,513\end{array}$ & $\begin{array}{r}0 \\
0 \\
0 \\
4,279 \\
4,279\end{array}$ \\
\hline 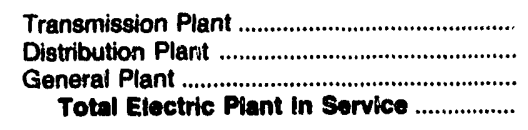 & $\begin{array}{r}123,254 \\
581,972 \\
165,258 \\
1,319,671\end{array}$ & $\begin{array}{r}13,012 \\
78,157 \\
2,734 \\
192,412\end{array}$ & $\begin{array}{r}0 \\
0 \\
69,473 \\
118,938\end{array}$ & $\begin{array}{r}682,527 \\
0 \\
21,152 \\
1,300,559\end{array}$ & $\begin{array}{r}18,757 \\
75,058 \\
32,843 \\
208,171\end{array}$ & $\begin{array}{r}3,244 \\
19,078 \\
1,208 \\
27,810\end{array}$ \\
\hline 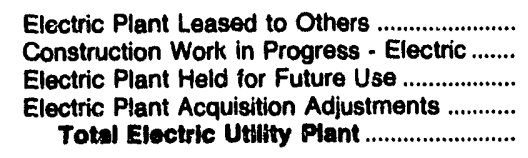 & $\begin{array}{r}15,570 \\
162,347 \\
111 \\
0 \\
1,497,699\end{array}$ & $\begin{array}{r}0 \\
4,817 \\
241,268 \\
0 \\
438,488\end{array}$ & $\begin{array}{r}0 \\
59,599 \\
0 \\
0 \\
178,537\end{array}$ & $\begin{array}{r}0 \\
25,449 \\
17,659 \\
0 \\
1,343,667\end{array}$ & $\begin{array}{r}0 \\
5,232 \\
0 \\
0 \\
211,403\end{array}$ & $\begin{array}{r}0 \\
9,854 \\
0 \\
0 \\
37,684\end{array}$ \\
\hline 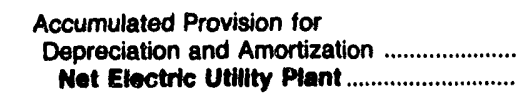 & $\begin{array}{r}339,357 \\
1,158,343\end{array}$ & $\begin{array}{l}170,012 \\
268,484\end{array}$ & $\begin{array}{r}43,058 \\
135,480\end{array}$ & $\begin{array}{r}198,118 \\
1,145,549\end{array}$ & $\begin{array}{r}61,183 \\
150,220\end{array}$ & $\begin{array}{l}17,438 \\
20,226\end{array}$ \\
\hline
\end{tabular}

\begin{tabular}{|c|c|c|c|c|c|c|}
\hline Item & $\begin{array}{c}\text { California } \\
\text { Yuba } \\
\text { County } \\
\text { Water } \\
\text { Agency } \\
\text { June } 30\end{array}$ & $\begin{array}{l}\text { Colorado } \\
\text { Arkansas } \\
\text { River } \\
\text { Power } \\
\text { Authority } \\
\text { December } 31\end{array}$ & $\begin{array}{l}\text { Colorado } \\
\text { Colorado } \\
\text { Springs } \\
\text { City of } \\
\text { December } 31\end{array}$ & $\begin{array}{l}\text { Colorado } \\
\text { Fort Collins } \\
\text { City of } \\
\text { December } 31\end{array}$ & $\begin{array}{c}\text { Colorado } \\
\text { Longmont } \\
\text { City of } \\
\text { December } 31\end{array}$ & $\begin{array}{l}\text { Colorado } \\
\text { Loveland } \\
\text { City of } \\
\text { December } 31\end{array}$ \\
\hline 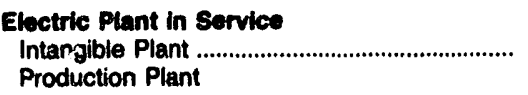 & 334 & 0 & 0 & 2 & 0 & 0 \\
\hline 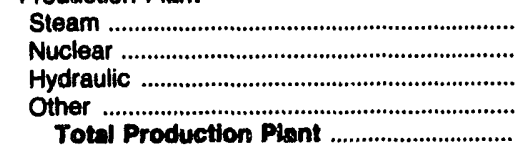 & $\begin{array}{r}0 \\
0 \\
187,657 \\
0 \\
187,657\end{array}$ & $\begin{array}{l}0 \\
0 \\
0 \\
0 \\
0\end{array}$ & $\begin{array}{r}233,086 \\
0 \\
1,596 \\
0 \\
234,682\end{array}$ & $\begin{array}{l}0 \\
0 \\
0 \\
0 \\
0\end{array}$ & $\begin{array}{r}0 \\
0 \\
380 \\
3,358 \\
3,738\end{array}$ & $\begin{array}{r}0 \\
0 \\
1,278 \\
0 \\
1,278\end{array}$ \\
\hline 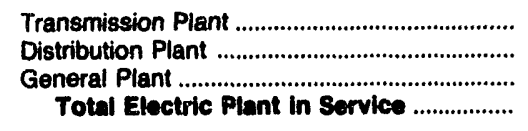 & $\begin{array}{r}605 \\
0 \\
2,329 \\
190,926\end{array}$ & $\begin{array}{r}2,710 \\
0 \\
0 \\
2,710\end{array}$ & $\begin{array}{r}45,918 \\
292,512 \\
24,748 \\
597,960\end{array}$ & $\begin{array}{r}1,782 \\
61,207 \\
11,007 \\
73,007\end{array}$ & $\begin{array}{r}0 \\
29,052 \\
244 \\
33,034\end{array}$ & $\begin{array}{r}3,933 \\
28,936 \\
3,130 \\
37,277\end{array}$ \\
\hline 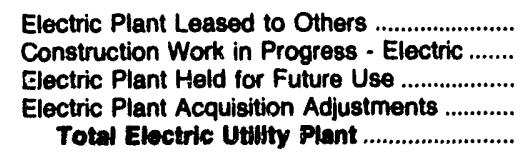 & $\begin{array}{r}0 \\
0 \\
0 \\
4,485 \\
195,411\end{array}$ & $\begin{array}{r}0 \\
0 \\
0 \\
0 \\
2,710\end{array}$ & $\begin{array}{r}377 \\
12,349 \\
0 \\
0 \\
610,586\end{array}$ & $\begin{array}{r}0 \\
1,571 \\
0 \\
0 \\
75,589\end{array}$ & $\begin{array}{r}0 \\
0 \\
0 \\
0 \\
33,034\end{array}$ & $\begin{array}{r}0 \\
1,107 \\
0 \\
0 \\
38,384\end{array}$ \\
\hline 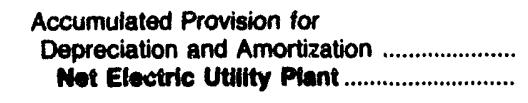 & $\begin{array}{r}47,459 \\
147,052\end{array}$ & $\begin{array}{r}147 \\
2,583\end{array}$ & $\begin{array}{l}163,486 \\
44,, 101\end{array}$ & $\begin{array}{l}28,252 \\
47,315\end{array}$ & $\begin{array}{l}12,657 \\
20,377\end{array}$ & $\begin{array}{r}7,672 \\
30,712\end{array}$ \\
\hline
\end{tabular}

Note: Totals may not equal sum of components because of independent rounding.

Suitics: Enargy information Administration, Form EIA-412; "Annual Report of Public Electric Utilities." 

Table 39. Electric Utility Plant by Major Publicly Owned Electric Utility
Within State at End of Period, 1991 (Continued) (Thousand Dollars)

\begin{tabular}{|c|c|c|c|c|c|c|}
\hline Item & $\begin{array}{c}\text { Colorado } \\
\text { Platte River } \\
\text { Power } \\
\text { Authority } \\
\text { December } 31\end{array}$ & $\begin{array}{c}\text { Connecticut } \\
\text { Connecticut } \\
\text { Mun } \\
\text { Elec } \\
\text { Engy Coop } \\
\text { December } 31\end{array}$ & $\begin{array}{l}\text { Connecticut } \\
\text { Groton } \\
\text { City of } \\
\text { June } 30\end{array}$ & $\begin{array}{l}\text { Connecticut } \\
\text { Norwich } \\
\text { City of } \\
\text { June } 30\end{array}$ & $\begin{array}{l}\text { Connecticut } \\
\text { Wallingford } \\
\text { Town of } \\
\text { June } 30\end{array}$ & $\begin{array}{l}\text { Delaware } \\
\text { Dover } \\
\text { City of } \\
\text { June } 30\end{array}$ \\
\hline 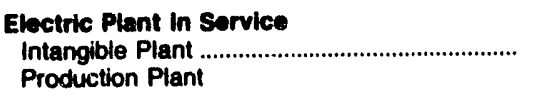 & 0 & 743 & 0 & 0 & 0 & 39,074 \\
\hline 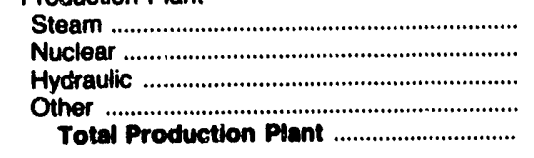 & $\begin{array}{r}628,299 \\
0 \\
0 \\
0 \\
628,299\end{array}$ & $\begin{array}{r}0 \\
53,538 \\
0 \\
0 \\
53,538\end{array}$ & $\begin{array}{l}0 \\
0 \\
0 \\
0 \\
0\end{array}$ & $\begin{array}{r}0 \\
0 \\
2,476 \\
2,371 \\
4,848\end{array}$ & $\begin{array}{r}6,096 \\
0 \\
0 \\
0 \\
6,096\end{array}$ & $\begin{array}{l}0 \\
0 \\
0 \\
0 \\
0\end{array}$ \\
\hline 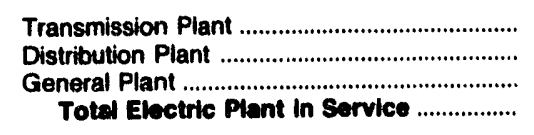 & $\begin{array}{r}117,007 \\
0 \\
11,294 \\
756,600\end{array}$ & $\begin{array}{r}272 \\
0 \\
1,789 \\
56,343\end{array}$ & $\begin{array}{r}5,116 \\
14,630 \\
2,755 \\
22,501\end{array}$ & $\begin{array}{r}2,378 \\
12,096 \\
2,960 \\
22,282\end{array}$ & $\begin{array}{r}1,269 \\
27,449 \\
3,571 \\
38,385\end{array}$ & $\begin{array}{r}12,580 \\
14,428 \\
1,372 \\
67,453\end{array}$ \\
\hline 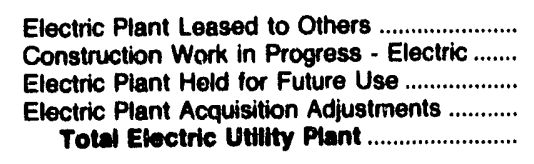 & $\begin{array}{r}0 \\
1,805 \\
0 \\
0 \\
758,404\end{array}$ & $\begin{array}{r}0 \\
958 \\
0 \\
0 \\
57,301\end{array}$ & $\begin{array}{r}0 \\
41 \\
0 \\
0 \\
22,542\end{array}$ & $\begin{array}{r}0 \\
614 \\
0 \\
0 \\
22,895\end{array}$ & $\begin{array}{r}0 \\
530 \\
0 \\
0 \\
38,915\end{array}$ & $\begin{array}{r}0 \\
16,713 \\
0 \\
0 \\
84,168\end{array}$ \\
\hline 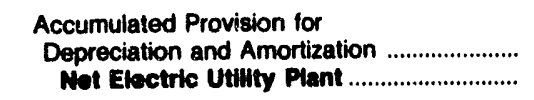 & $\begin{array}{l}184,110 \\
574,294\end{array}$ & $\begin{array}{l}11,277 \\
46,024\end{array}$ & $\begin{array}{l}12,072 \\
10,470\end{array}$ & $\begin{array}{r}15,218 \\
7,677\end{array}$ & $\begin{array}{l}22,226 \\
16,009\end{array}$ & $\begin{array}{l}25,422 \\
58,744\end{array}$ \\
\hline
\end{tabular}

\begin{tabular}{|c|c|c|c|c|c|c|}
\hline Item & $\begin{array}{l}\text { Delaware } \\
\text { Newark } \\
\text { City of } \\
\text { December } 31\end{array}$ & $\begin{array}{l}\text { Florida } \\
\text { Bartow } \\
\text { City of } \\
\text { September } 30\end{array}$ & $\begin{array}{c}\text { Florida } \\
\text { Florida } \\
\text { Municipal } \\
\text { Power Agency } \\
\text { September } 30\end{array}$ & $\begin{array}{l}\text { Florida } \\
\text { Fort Pierce } \\
\text { Utilities } \\
\text { Auth } \\
\text { September } 30\end{array}$ & $\begin{array}{c}\text { Florida } \\
\text { Gainesville } \\
\text { Regional } \\
\text { Utilities } \\
\text { September } 30\end{array}$ & $\begin{array}{c}\text { Florida } \\
\text { Homestead } \\
\text { City of } \\
\text { September } 30\end{array}$ \\
\hline 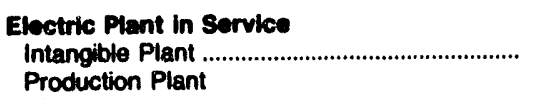 & 0 & 0 & 42 & 0 & 0 & 0 \\
\hline 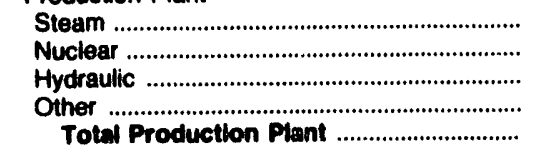 & $\begin{array}{l}0 \\
0 \\
0 \\
0 \\
0\end{array}$ & $\begin{array}{l}0 \\
0 \\
0 \\
0 \\
0\end{array}$ & $\begin{array}{r}62,033 \\
183,535 \\
0 \\
0 \\
245,596\end{array}$ & $\begin{array}{r}38,736 \\
0 \\
0 \\
781 \\
39,518\end{array}$ & $\begin{array}{r}244,272 \\
4,376 \\
0 \\
0 \\
248,648\end{array}$ & $\begin{array}{l}0 \\
0 \\
0 \\
0 \\
0\end{array}$ \\
\hline 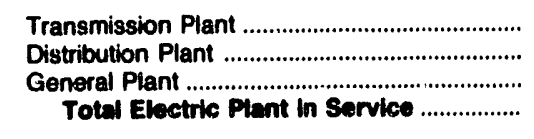 & $\begin{array}{l}0 \\
0 \\
0 \\
0\end{array}$ & $\begin{array}{r}0 \\
9,115 \\
0 \\
9,115\end{array}$ & $\begin{array}{r}0 \\
0 \\
54 \\
245,685\end{array}$ & $\begin{array}{r}14,963 \\
25,662 \\
5,846 \\
85,889\end{array}$ & $\begin{array}{r}121,787 \\
0 \\
14,612 \\
385,047\end{array}$ & $\begin{array}{r}0 \\
0 \\
38,370 \\
38,370\end{array}$ \\
\hline 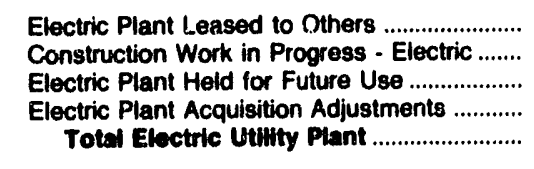 & $\begin{array}{l}0 \\
0 \\
0 \\
0 \\
0\end{array}$ & $\begin{array}{r}0 \\
0 \\
0 \\
0 \\
9,115\end{array}$ & $\begin{array}{r}0 \\
6,839 \\
0 \\
0 \\
252,503\end{array}$ & $\begin{array}{r}0 \\
3,587 \\
0 \\
0 \\
89,575\end{array}$ & $\begin{array}{r}0 \\
9,157 \\
0 \\
0 \\
394,204\end{array}$ & $\begin{array}{r}0 \\
1,537 \\
0 \\
0 \\
39,807\end{array}$ \\
\hline 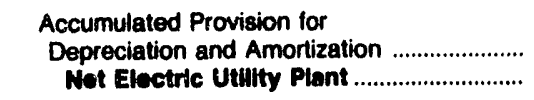 & $\begin{array}{l}0 \\
\mathbf{0}\end{array}$ & $\begin{array}{l}4,244 \\
4,871\end{array}$ & $\begin{array}{r}48,877 \\
203,627\end{array}$ & $\begin{array}{l}35,709 \\
53,866\end{array}$ & $\begin{array}{l}119,199 \\
275,004\end{array}$ & $\begin{array}{l}17,319 \\
22,588\end{array}$ \\
\hline
\end{tabular}

Note: Totals may not equal sum of components because of independent rounding.

Source: Energy Information Administration, Form EIA-412, "Annual Report of Public Electric Utilities." 
Table 39. Electric Utility Plant by Major Publicly Owned Electric Utility Within State at End of Period, 1991 (Continued)

(Thousand Dollars)

\begin{tabular}{|c|c|c|c|c|c|c|}
\hline liem & $\begin{array}{c}\text { Florida } \\
\text { Jacksomille } \\
\text { Beach } \\
\text { City of } \\
\text { September } 30\end{array}$ & $\begin{array}{c}\text { Florida } \\
\text { Jacksonvilie } \\
\text { Electric } \\
\text { Auth }\end{array}$ & $\begin{array}{l}\text { Florida } \\
\text { Key West } \\
\text { City of } \\
\text { September } 30\end{array}$ & $\begin{array}{c}\text { Florida } \\
\text { Kissimmee } \\
\text { Utility } \\
\text { Authority } \\
\text { September } 30\end{array}$ & $\begin{array}{c}\text { Florida } \\
\text { Lake Worth } \\
\text { City of } \\
\text { September } 30\end{array}$ & $\begin{array}{l}\text { Florida } \\
\text { Lakeland } \\
\text { City of } \\
\text { September } 30\end{array}$ \\
\hline $\begin{array}{l}\text { Electric Plant in Service } \\
\text { Intangible Plant ................................................ } \\
\text { Production Plant }\end{array}$ & 0 & 1,853 & 220 & 232 & 59 & 0 \\
\hline $\begin{array}{l}\text { Steam } \\
\text { Nuclear } \\
\text { Hydraulic } \\
\text { Other } \\
\text { Total Production Plant }\end{array}$ & $\begin{array}{l}0 \\
0 \\
0 \\
0 \\
0\end{array}$ & $\begin{array}{r}1,791,924 \\
0 \\
0 \\
53,393 \\
1,845,318\end{array}$ & $\begin{array}{r}39,066 \\
0 \\
0 \\
16,407 \\
55,474\end{array}$ & $\begin{array}{r}17,430 \\
4,418 \\
0 \\
43,098 \\
64,948\end{array}$ & $\begin{array}{r}18,141 \\
0 \\
0 \\
16,739 \\
34,881\end{array}$ & $\begin{array}{r}237,178 \\
0 \\
0 \\
7,016 \\
244,194\end{array}$ \\
\hline $\begin{array}{l}\text { Transmission Plant } \\
\text { Distribution Plant } \\
\text { General Plant ............................................................ } \\
\text { Total Electric Plant in Sorvlce }\end{array}$ & $\begin{array}{r}0 \\
52,507 \\
0 \\
52,507\end{array}$ & $\begin{array}{r}243,682 \\
497,169 \\
89,865 \\
2,677,887\end{array}$ & $\begin{array}{r}30,896 \\
25,803 \\
6,792 \\
118,185\end{array}$ & $\begin{array}{r}21,455 \\
33,338 \\
9,351 \\
129,322\end{array}$ & $\begin{array}{r}24,681 \\
0 \\
0 \\
59,621\end{array}$ & $\begin{array}{r}36,286 \\
93,375 \\
38,801 \\
412,656\end{array}$ \\
\hline $\begin{array}{l}\text { Electric Plant Leased to Others .................... } \\
\text { Construction Work in Progress - Electric ........ } \\
\text { Electric Plant Held for Future Use ................... } \\
\text { Electric Plant Acquisition Adjustments ............ } \\
\text { Totel Electric Utilty Plant .............................. }\end{array}$ & $\begin{array}{r}0 \\
0 \\
0 \\
0 \\
52,507\end{array}$ & $\begin{array}{r}0 \\
37,308 \\
1,048 \\
0 \\
2,716,243\end{array}$ & $\begin{array}{r}0 \\
19,376 \\
0 \\
0 \\
138,561\end{array}$ & $\begin{array}{r}0 \\
6,244 \\
451 \\
0 \\
136,018\end{array}$ & $\begin{array}{r}0 \\
5,223 \\
68 \\
0 \\
64,913\end{array}$ & $\begin{array}{r}0 \\
54,306 \\
0 \\
0 \\
466,882\end{array}$ \\
\hline 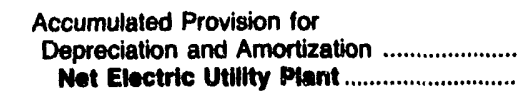 & $\begin{array}{l}14,634 \\
37,874\end{array}$ & $\begin{array}{r}460,191 \\
2,256,052\end{array}$ & $\begin{array}{l}49,721 \\
88,840\end{array}$ & $\begin{array}{l}38,244 \\
97,774\end{array}$ & $\begin{array}{l}36,725 \\
28,1108\end{array}$ & $\begin{array}{l}133,791 \\
333,171\end{array}$ \\
\hline
\end{tabular}

\begin{tabular}{|c|c|c|c|c|c|c|}
\hline Item & $\begin{array}{l}\text { Florida } \\
\text { Leesburg } \\
\text { City of }\end{array}$ & $\begin{array}{c}\text { Florida } \\
\text { New Smyrna } \\
\text { Beach } \\
\text { Utils Comm } \\
\text { September } 30\end{array}$ & $\begin{array}{l}\text { Fiorida } \\
\text { Ocala } \\
\text { City of } \\
\text { September } 30\end{array}$ & $\begin{array}{l}\text { Florida } \\
\text { Oriando } \\
\text { Utilities } \\
\text { Comm } \\
\text { September } 30\end{array}$ & $\begin{array}{l}\text { Florida } \\
\text { Quincy } \\
\text { City of } \\
\text { September } 30\end{array}$ & $\begin{array}{l}\text { Florida } \\
\text { St Cloud } \\
\text { City of } \\
\text { September } 30\end{array}$ \\
\hline $\begin{array}{l}\text { Eloctric Plant in Service } \\
\text { Intangible Plant .................................................. } \\
\text { Production Plant }\end{array}$ & 97 & 0 & 0 & 254 & 0 & 0 \\
\hline $\begin{array}{l}\text { Steam } \\
\text { Huclear } \\
\text { Other } \\
\text { Total }\end{array}$ & $\begin{array}{r}0 \\
7,171 \\
0 \\
0 \\
7,171\end{array}$ & $\begin{array}{r}0 \\
5,276 \\
0 \\
6,483 \\
11,758\end{array}$ & $\begin{array}{r}0 \\
11,986 \\
0 \\
0 \\
11,989\end{array}$ & $\begin{array}{r}622,879 \\
119,956 \\
0 \\
12,580 \\
755,416\end{array}$ & $\begin{array}{l}0 \\
0 \\
0 \\
0 \\
\mathbf{0}\end{array}$ & $\begin{array}{r}0 \\
0 \\
0 \\
35,010 \\
35,010\end{array}$ \\
\hline 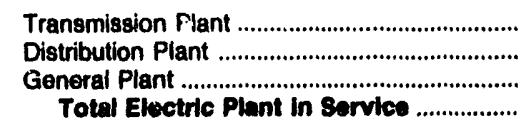 & $\begin{array}{r}0 \\
31,851 \\
5,334 \\
44,453\end{array}$ & $\begin{array}{r}5,731 \\
26,200 \\
2,920 \\
48,609\end{array}$ & $\begin{array}{r}6,867 \\
46,906 \\
830 \\
68,580\end{array}$ & $\begin{array}{r}120,949 \\
199,159 \\
30,475 \\
1,108,254\end{array}$ & $\begin{array}{r}0 \\
5,444 \\
321 \\
5,765\end{array}$ & $\begin{array}{r}113 \\
13,568 \\
0 \\
46,690\end{array}$ \\
\hline $\begin{array}{l}\text { Electric Plant Leased to Others ..................... } \\
\text { Construction Work in Progress - Electric ........ } \\
\text { Electric Plant Held for Future Use .................. } \\
\text { Electric Plant Acquisition Adjustments ............ } \\
\text { Total Electric Uthity Plant ........................ }\end{array}$ & $\begin{array}{r}0 \\
758 \\
0 \\
0 \\
45,211\end{array}$ & $\begin{array}{r}0 \\
1,829 \\
0 \\
0 \\
48,438\end{array}$ & $\begin{array}{r}0 \\
10,763 \\
0 \\
0 \\
77,351\end{array}$ & $\begin{array}{r}0 \\
76,013 \\
0 \\
0 \\
1,182,287\end{array}$ & $\begin{array}{r}0 \\
0 \\
0 \\
0 \\
5,765\end{array}$ & $\begin{array}{r}0 \\
442 \\
0 \\
0 \\
49,132\end{array}$ \\
\hline 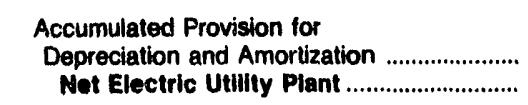 & $\begin{array}{l}14,094 \\
31,117\end{array}$ & $\begin{array}{l}18,512 \\
29,927\end{array}$ & $\begin{array}{l}25,033 \\
52,318\end{array}$ & $\begin{array}{l}270,567 \\
911,700\end{array}$ & $\begin{array}{l}2,337 \\
3,428\end{array}$ & $\begin{array}{l}12,634 \\
38,490\end{array}$ \\
\hline
\end{tabular}

Note: Totals may not equal sum of components because of independent rounding.

Source: Energy Information Administration, Form EIA-412, "Annual Report of Public Electric Utilities." 
Table 39. Electric Utility Plant by Major Publicly Owned Electric Utility Within State at End of Period, 1991 (Continued) (Thousand Dollars)

\begin{tabular}{|c|c|c|c|c|c|c|}
\hline Item & $\begin{array}{c}\text { Florida } \\
\text { Tallahassee } \\
\text { City of }\end{array}$ & $\begin{array}{c}\text { Florida } \\
\text { Vero } \\
\text { Beach } \\
\text { City of } \\
\text { September } 30\end{array}$ & $\begin{array}{l}\text { Georgia } \\
\text { Albany Water } \\
\text { Gas \& Light } \\
\text { Comm } \\
\text { June } 30\end{array}$ & $\begin{array}{l}\text { Georgia } \\
\text { Calhoun } \\
\text { City of } \\
\text { June } 30\end{array}$ & $\begin{array}{l}\text { Georgia } \\
\text { Cartersville } \\
\text { City of } \\
\text { June } 30\end{array}$ & $\begin{array}{c}\text { Georgia } \\
\text { College } \\
\text { Park City of } \\
\text { June } 30\end{array}$ \\
\hline $\begin{array}{l}\text { Electric Plant In Service } \\
\text { Intang"ble Plant ................................................ } \\
\text { Production Piant }\end{array}$ & 0 & 2,504 & 0 & 0 & 0 & 0 \\
\hline 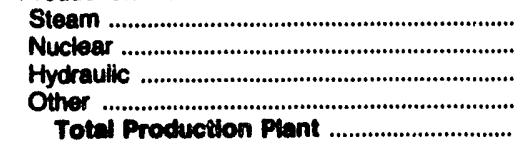 & $\begin{array}{r}87,103 \\
7,944 \\
0 \\
8,711 \\
103,759\end{array}$ & $\begin{array}{r}33,846 \\
0 \\
0 \\
3,556 \\
37,401\end{array}$ & $\begin{array}{l}0 \\
0 \\
0 \\
0 \\
0\end{array}$ & $\begin{array}{l}0 \\
0 \\
0 \\
0 \\
0\end{array}$ & $\begin{array}{l}0 \\
0 \\
0 \\
0 \\
0\end{array}$ & $\begin{array}{l}0 \\
0 \\
0 \\
0 \\
0\end{array}$ \\
\hline 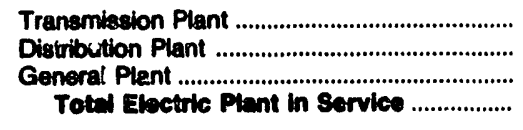 & $\begin{array}{r}31,376 \\
131,218 \\
7,465 \\
273,817\end{array}$ & $\begin{array}{r}14,279 \\
29,720 \\
2,725 \\
86,628\end{array}$ & $\begin{array}{r}25,868 \\
0 \\
0 \\
25,888\end{array}$ & $\begin{array}{r}57,690 \\
0 \\
0 \\
57,690\end{array}$ & $\begin{array}{r}0 \\
8,840 \\
0 \\
8,840\end{array}$ & $\begin{array}{r}0 \\
6,851 \\
0 \\
6,851\end{array}$ \\
\hline 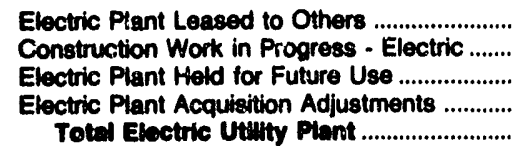 & $\begin{array}{r}0 \\
61,218 \\
0 \\
0 \\
335,035\end{array}$ & $\begin{array}{r}0 \\
23,105 \\
0 \\
0 \\
109,734\end{array}$ & $\begin{array}{r}0 \\
0 \\
0 \\
0 \\
25,868\end{array}$ & $\begin{array}{r}0 \\
0 \\
0 \\
0 \\
57,890\end{array}$ & $\begin{array}{r}0 \\
0 \\
0 \\
0 \\
8,840\end{array}$ & $\begin{array}{r}0 \\
0 \\
0 \\
0 \\
6,851\end{array}$ \\
\hline 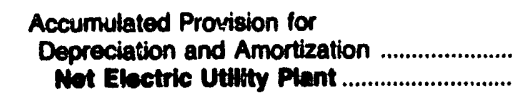 & $\begin{array}{l}128,406 \\
206,629\end{array}$ & $\begin{array}{l}37,372 \\
72,362\end{array}$ & $\begin{array}{r}17,145 \\
8,723\end{array}$ & $\begin{array}{l}11,067 \\
46,623\end{array}$ & $\begin{array}{l}2,044 \\
6,707\end{array}$ & $\begin{array}{l}2,478 \\
4,373\end{array}$ \\
\hline
\end{tabular}

\begin{tabular}{|c|c|c|c|c|c|c|}
\hline Item & $\begin{array}{l}\text { Georgia } \\
\text { Covington } \\
\text { City of } \\
\text { December } 31\end{array}$ & $\begin{array}{l}\text { Georgia } \\
\text { Crisp } \\
\text { County } \\
\text { Power } \\
\text { Comm } \\
\text { December } 31\end{array}$ & $\begin{array}{l}\text { Georgia } \\
\text { Dalton } \\
\text { City of } \\
\text { November } 30\end{array}$ & $\begin{array}{l}\text { Georgia } \\
\text { Douglas } \\
\text { City of } \\
\text { June } 30\end{array}$ & $\begin{array}{l}\text { Georgia } \\
\text { East } \\
\text { Point } \\
\text { City of } \\
\text { June } 30\end{array}$ & $\begin{array}{l}\text { Georgia } \\
\text { Fitzgerald } \\
\text { Wtr Lgt } \\
\text { a Bond Comm } \\
\text { December } 31\end{array}$ \\
\hline $\begin{array}{l}\text { Eiectuic Plent in Service } \\
\text { Intangible Piant ................................................. } \\
\text { Production Plant }\end{array}$ & 0 & 108 & 0 & 0 & 0 & 0 \\
\hline 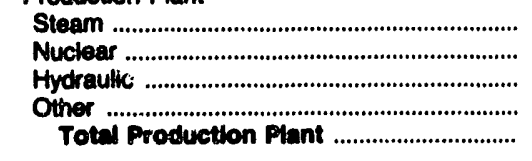 & $\begin{array}{l}0 \\
0 \\
0 \\
0 \\
0\end{array}$ & $\begin{array}{r}4,711 \\
0 \\
4,230 \\
0 \\
8,841\end{array}$ & $\begin{array}{r}22,074 \\
147,170 \\
0 \\
0 \\
189,244\end{array}$ & $\begin{array}{l}0 \\
0 \\
0 \\
0 \\
0\end{array}$ & $\begin{array}{l}\mathbf{0} \\
\mathbf{0} \\
\mathbf{0} \\
\mathbf{0} \\
\mathbf{0}\end{array}$ & $\begin{array}{l}0 \\
0 \\
0 \\
0 \\
0\end{array}$ \\
\hline 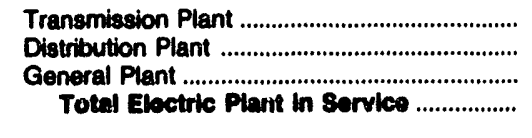 & $\begin{array}{r}0 \\
5,698 \\
0 \\
5,698\end{array}$ & $\begin{array}{r}1,799 \\
19,021 \\
3,432 \\
33,248\end{array}$ & $\begin{array}{r}23,883 \\
14,928 \\
1,243 \\
209,290\end{array}$ & $\begin{array}{r}0 \\
3,554 \\
0 \\
3,554\end{array}$ & $\begin{array}{r}0 \\
1,504 \\
7,164 \\
8,688\end{array}$ & $\begin{array}{l}1,772 \\
2,946 \\
1,201 \\
5,918\end{array}$ \\
\hline $\begin{array}{l}\text { Electric Plant Leased to Others ..................... } \\
\text { Construction Work in Progress - Electric ....... } \\
\text { Electric Plant Held for Future Use ................... } \\
\text { Electric Plant Acquisition Adjustments .......... } \\
\text { Totw Electrle Utithty Piant ......................... }\end{array}$ & $\begin{array}{r}0 \\
0 \\
0 \\
0 \\
5,688\end{array}$ & $\begin{array}{r}0 \\
114 \\
0 \\
0 \\
33,412\end{array}$ & $\begin{array}{r}0 \\
141 \\
0 \\
0 \\
200_{5} 439\end{array}$ & $\begin{array}{r}0 \\
0 \\
0 \\
0 \\
3,554\end{array}$ & $\begin{array}{r}0 \\
0 \\
0 \\
0 \\
\mathbf{8 , 6 6 8}\end{array}$ & $\begin{array}{r}0 \\
0 \\
0 \\
0 \\
5,918\end{array}$ \\
\hline 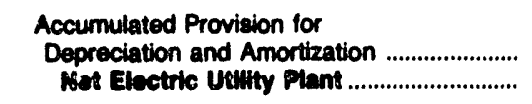 & $\begin{array}{l}3,031 \\
2,687\end{array}$ & $\begin{array}{l}18,725 \\
14,687\end{array}$ & $\begin{array}{r}57,891 \\
151,64\end{array}$ & $\begin{array}{l}1,897 \\
1,657\end{array}$ & $\begin{array}{l}5,210 \\
3,480\end{array}$ & $\begin{array}{l}2,455 \\
3,484\end{array}$ \\
\hline
\end{tabular}

Note: Totals may not equal sum of components because of independent rounding.

Source: Energy Intormation Administration, Form EIA-412, "Annual Report of Public Electric Utilities." 
Table 39. Electric Utility Plant by Major Publicly Owned Electric Utility Within State at End of Period, 1991 (Continued) (Thousand Dollars)

\begin{tabular}{|c|c|c|c|c|c|c|}
\hline Item & $\begin{array}{l}\text { Georgia } \\
\text { Griffin } \\
\text { City of } \\
\text { June } 30\end{array}$ & $\begin{array}{l}\text { Georgia } \\
\text { La Grange } \\
\text { City of } \\
\text { June } 30\end{array}$ & $\begin{array}{c}\text { Georgia } \\
\text { Lawrenceville } \\
\text { City of } \\
\text { August } 30\end{array}$ & $\begin{array}{l}\text { Georgia } \\
\text { Marietta } \\
\text { City of } \\
\text { June } 30\end{array}$ & $\begin{array}{l}\text { Georgia } \\
\text { Moultrie } \\
\text { City of } \\
\text { September } 30\end{array}$ & $\begin{array}{l}\text { Goorgia } \\
\text { Municipal } \\
\text { Electric } \\
\text { Authority } \\
\text { December } 31\end{array}$ \\
\hline 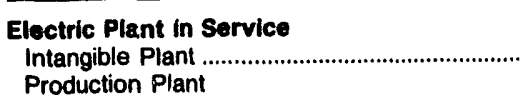 & 0 & 0 & 0 & 0 & 0 & 6,094 \\
\hline 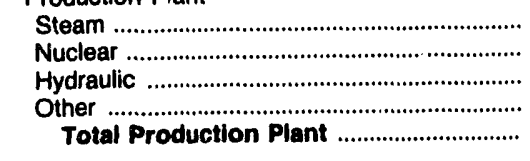 & $\begin{array}{l}0 \\
0 \\
0 \\
0 \\
0\end{array}$ & $\begin{array}{l}0 \\
0 \\
0 \\
0 \\
0\end{array}$ & $\begin{array}{l}0 \\
0 \\
0 \\
0 \\
0\end{array}$ & $\begin{array}{l}0 \\
0 \\
0 \\
0 \\
0\end{array}$ & $\begin{array}{l}0 \\
0 \\
0 \\
0 \\
0\end{array}$ & $\begin{array}{r}429,224 \\
2,346,904 \\
0 \\
2,005 \\
2,778,133\end{array}$ \\
\hline 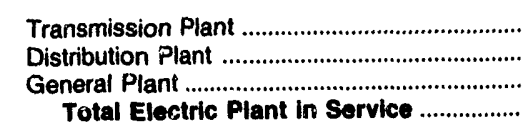 & $\begin{array}{r}0 \\
0 \\
9,587 \\
9,587\end{array}$ & $\begin{array}{r}3,805 \\
0 \\
2,962 \\
6,766\end{array}$ & $\begin{array}{r}0 \\
13,174 \\
0 \\
13,174\end{array}$ & $\begin{array}{r}0 \\
34,782 \\
0 \\
34,782\end{array}$ & $\begin{array}{r}0 \\
5,116 \\
49 \\
5,165\end{array}$ & $\begin{array}{r}165,299 \\
71,235 \\
4,555 \\
3,025,316\end{array}$ \\
\hline 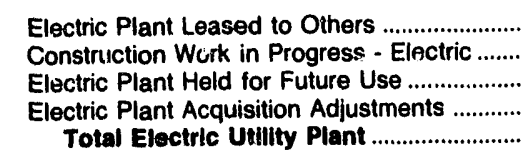 & $\begin{array}{r}0 \\
0 \\
0 \\
0 \\
9,587\end{array}$ & $\begin{array}{r}0 \\
0 \\
0 \\
0 \\
6,786\end{array}$ & $\begin{array}{r}0 \\
0 \\
0 \\
0 \\
13,174\end{array}$ & $\begin{array}{r}0 \\
0 \\
0 \\
0 \\
34,782\end{array}$ & $\begin{array}{r}0 \\
0 \\
0 \\
0 \\
5,165\end{array}$ & $\begin{array}{r}0 \\
26,639 \\
0 \\
108,418 \\
3,160,373\end{array}$ \\
\hline 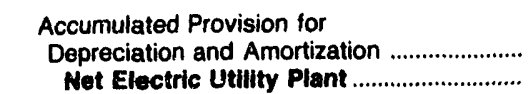 & $\begin{array}{l}2,491 \\
7,096\end{array}$ & $\begin{array}{l}2,274 \\
4,492\end{array}$ & $\begin{array}{r}2,093 \\
11,081\end{array}$ & $\begin{array}{l}12,098 \\
22,684\end{array}$ & $\begin{array}{l}3,302 \\
1,863\end{array}$ & $\begin{array}{r}657,130 \\
2,503,243\end{array}$ \\
\hline
\end{tabular}

\begin{tabular}{|c|c|c|c|c|c|c|}
\hline Item & $\begin{array}{c}\text { Georgia } \\
\text { Thomasville } \\
\text { City of }\end{array}$ & $\begin{array}{l}\text { Idaho } \\
\text { Idaho } \\
\text { Falls } \\
\text { City of } \\
\text { September } 30\end{array}$ & $\begin{array}{l}\text { Illinois } \\
\text { Batavia } \\
\text { City of } \\
\text { December } 31\end{array}$ & $\begin{array}{l}\text { Illinois } \\
\text { Geneva } \\
\text { City of } \\
\text { April } 30\end{array}$ & $\begin{array}{c}\text { Illinois } \\
\text { Illinois } \\
\text { Municipal } \\
\text { Elec Agency } \\
\text { April } 30\end{array}$ & $\begin{array}{c}\text { Illinois } \\
\text { Naperville } \\
\text { City of } \\
\text { April } 30\end{array}$ \\
\hline 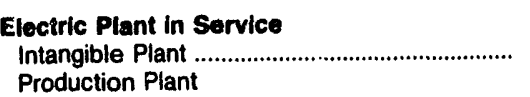 & 0 & 2,036 & 0 & 0 & 0 & 0 \\
\hline 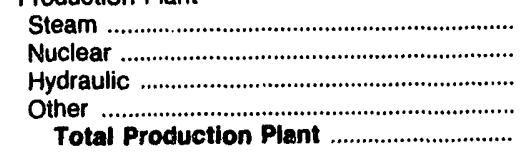 & $\begin{array}{l}0 \\
0 \\
0 \\
0 \\
0\end{array}$ & $\begin{array}{r}0 \\
0 \\
92,715 \\
0 \\
92,715\end{array}$ & $\begin{array}{l}0 \\
0 \\
0 \\
0 \\
0\end{array}$ & $\begin{array}{l}0 \\
0 \\
0 \\
0 \\
0\end{array}$ & $\begin{array}{r}94,164 \\
0 \\
0 \\
0 \\
94,164\end{array}$ & $\begin{array}{l}0 \\
0 \\
0 \\
0 \\
\mathbf{0}\end{array}$ \\
\hline 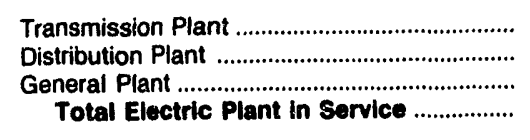 & $\begin{array}{r}0 \\
9,670 \\
1,792 \\
11,462\end{array}$ & $\begin{array}{r}5,703 \\
19,772 \\
3,427 \\
123,653\end{array}$ & $\begin{array}{r}0 \\
12,524 \\
1,488 \\
14,012\end{array}$ & $\begin{array}{r}0 \\
0 \\
16,691 \\
18,691\end{array}$ & $\begin{array}{r}0 \\
0 \\
1,066 \\
95,230\end{array}$ & $\begin{array}{r}0 \\
0 \\
90,695 \\
90,695\end{array}$ \\
\hline 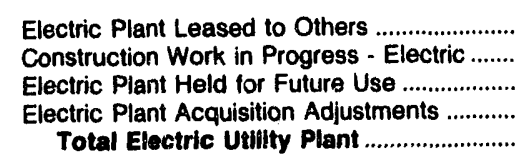 & $\begin{array}{r}0 \\
46 \\
0 \\
0 \\
11,508\end{array}$ & $\begin{array}{r}0 \\
320 \\
0 \\
0 \\
123,973\end{array}$ & $\begin{array}{r}0 \\
0 \\
0 \\
0 \\
14,012\end{array}$ & $\begin{array}{r}0 \\
1,109 \\
0 \\
0 \\
17,800\end{array}$ & $\begin{array}{r}0 \\
0 \\
0 \\
0 \\
95,230\end{array}$ & $\begin{array}{r}0 \\
0 \\
0 \\
0 \\
90,695\end{array}$ \\
\hline 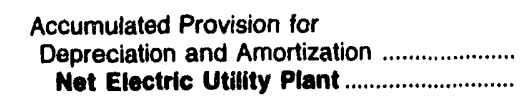 & $\begin{array}{l}4,291 \\
7,217\end{array}$ & $\begin{array}{l}24,181 \\
99,791\end{array}$ & $\begin{array}{l}5,215 \\
8,797\end{array}$ & $\begin{array}{r}6,762 \\
11,038\end{array}$ & $\begin{array}{r}552 \\
94,678\end{array}$ & $\begin{array}{l}53,314 \\
37,381\end{array}$ \\
\hline
\end{tabular}

Note: Totals may not equal sum of components because of independent rounding.

Source: Energy Information Administration. Form EIA-412, "Annual Report of Public Electric Utilities." 
Table 39. Electric Utility Plant by Major Publicly Owned Electric Utility Within State at End of Period, 1991 (Continued) (Thousand Dollars)

\begin{tabular}{|c|c|c|c|c|c|c|}
\hline Item & $\begin{array}{l}\text { Illinois } \\
\text { Rochelle } \\
\text { Municipal } \\
\text { Utilities } \\
\text { April } 30\end{array}$ & $\begin{array}{l}\text { Illinois } \\
\text { Springfield } \\
\text { City of } \\
\text { February } 28\end{array}$ & $\begin{array}{l}\text { Illinois } \\
\text { St Charles } \\
\text { City of } \\
\text { April } 30\end{array}$ & $\begin{array}{c}\text { Indiana } \\
\text { Anderson } \\
\text { City of } \\
\text { December } 31\end{array}$ & $\begin{array}{l}\text { Indiana } \\
\text { Auburn } \\
\text { City of } \\
\text { December } 31\end{array}$ & $\begin{array}{l}\text { Indiana } \\
\text { Blutfton } \\
\text { City of } \\
\text { December } 31\end{array}$ \\
\hline 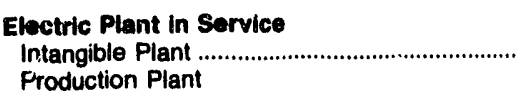 & 0 & 0 & 0 & 0 & 0 & 0 \\
\hline 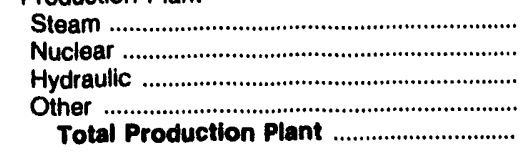 & $\begin{array}{r}5,660 \\
0 \\
0 \\
5,513 \\
11,174\end{array}$ & $\begin{array}{r}171,447 \\
0 \\
0 \\
6,508 \\
177,956\end{array}$ & $\begin{array}{l}\mathbf{0} \\
\mathbf{0} \\
\mathbf{0} \\
\mathbf{0} \\
\mathbf{0}\end{array}$ & $\begin{array}{l}5 \\
0 \\
0 \\
0 \\
5\end{array}$ & $\begin{array}{r}0 \\
0 \\
0 \\
26 \\
26\end{array}$ & $\begin{array}{r}0 \\
0 \\
0 \\
1,231 \\
1,231\end{array}$ \\
\hline 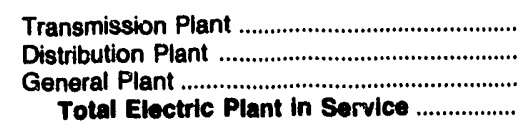 & $\begin{array}{r}1,682 \\
7,120 \\
2,139 \\
22,115\end{array}$ & $\begin{array}{r}32,248 \\
91,142 \\
17,608 \\
318,953\end{array}$ & $\begin{array}{r}0 \\
24,017 \\
67 \\
24,084\end{array}$ & $\begin{array}{r}1,077 \\
35,319 \\
6,495 \\
42,886\end{array}$ & $\begin{array}{r}267 \\
10,509 \\
1,117 \\
11,921\end{array}$ & $\begin{array}{r}268 \\
5,500 \\
906 \\
7,904\end{array}$ \\
\hline 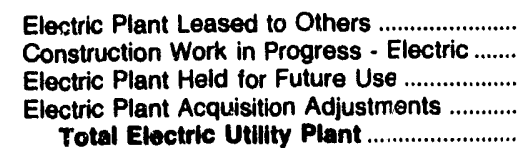 & $\begin{array}{r}0 \\
0 \\
0 \\
0 \\
22,115\end{array}$ & $\begin{array}{r}0 \\
4,686 \\
4,987 \\
2,266 \\
330,891\end{array}$ & $\begin{array}{r}0 \\
0 \\
0 \\
0 \\
24,084\end{array}$ & $\begin{array}{r}0 \\
295 \\
0 \\
0 \\
43,190\end{array}$ & $\begin{array}{r}0 \\
328 \\
0 \\
0 \\
12,249\end{array}$ & $\begin{array}{r}0 \\
0 \\
0 \\
0 \\
7,904\end{array}$ \\
\hline 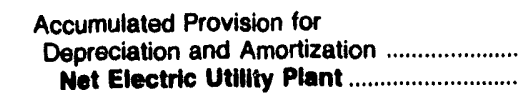 & $\begin{array}{r}12,733 \\
9,382\end{array}$ & $\begin{array}{l}144,478 \\
186,414\end{array}$ & $\begin{array}{r}6,566 \\
17,518\end{array}$ & $\begin{array}{l}17,738 \\
25,453\end{array}$ & $\begin{array}{l}4,178 \\
8,071\end{array}$ & $\begin{array}{l}3,612 \\
4,292\end{array}$ \\
\hline
\end{tabular}

\begin{tabular}{|c|c|c|c|c|c|c|}
\hline Item & $\begin{array}{c}\text { Indiana } \\
\text { Crawtordsville } \\
\text { Elec } \\
\text { Lgt\&Pwr Co } \\
\text { December } 31\end{array}$ & $\begin{array}{l}\text { Indiana } \\
\text { Frankfort } \\
\text { City of } \\
\text { December } 31\end{array}$ & $\begin{array}{c}\text { Indiana } \\
\text { Indiana } \\
\text { Municipal } \\
\text { Power Agency } \\
\text { December } 31\end{array}$ & $\begin{array}{l}\text { Indiana } \\
\text { Jasper } \\
\text { City of } \\
\text { December } \mathbf{3 1}\end{array}$ & $\begin{array}{c}\text { Indiana } \\
\text { Logansport } \\
\text { City of } \\
\text { December } 31\end{array}$ & $\begin{array}{c}\text { Indiana } \\
\text { Mishawaka } \\
\text { City of } \\
\text { December } 31\end{array}$ \\
\hline 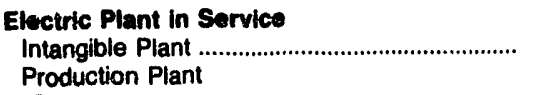 & 184 & 0 & 0 & 0 & G & 0 \\
\hline 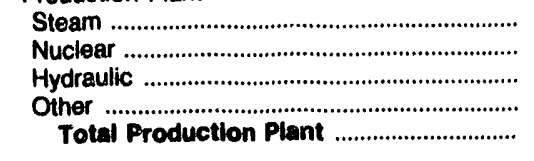 & $\begin{array}{r}9,598 \\
0 \\
0 \\
0 \\
9,598\end{array}$ & $\begin{array}{l}0 \\
0 \\
0 \\
0 \\
0\end{array}$ & $\begin{array}{r}101,925 \\
0 \\
0 \\
0 \\
101,925\end{array}$ & $\begin{array}{r}5,684 \\
0 \\
0 \\
0 \\
5,684\end{array}$ & $\begin{array}{r}12,942 \\
0 \\
0 \\
0 \\
12,942\end{array}$ & $\begin{array}{l}0 \\
0 \\
0 \\
0 \\
0\end{array}$ \\
\hline 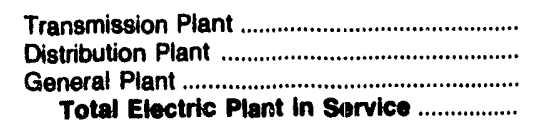 & $\begin{array}{r}1,034 \\
12,843 \\
2,984 \\
26,644\end{array}$ & $\begin{array}{r}0 \\
14,284 \\
1,990 \\
16,274\end{array}$ & $\begin{array}{r}31,421 \\
6,256 \\
1,890 \\
141,492\end{array}$ & $\begin{array}{r}8 \\
6,966 \\
754 \\
13,410\end{array}$ & $\begin{array}{r}5,490 \\
22,978 \\
5,503 \\
46,913\end{array}$ & $\begin{array}{r}0 \\
25,474 \\
2,541 \\
28,016\end{array}$ \\
\hline 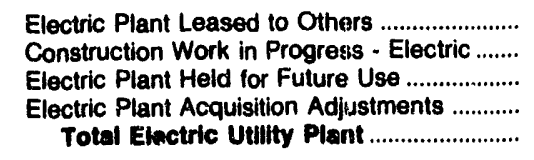 & $\begin{array}{r}0 \\
77 \\
51 \\
30 \\
26,801\end{array}$ & $\begin{array}{r}0 \\
0 \\
0 \\
0 \\
16,274\end{array}$ & $\begin{array}{r}0 \\
65,500 \\
0 \\
0 \\
206,992\end{array}$ & $\begin{array}{r}0 \\
452 \\
0 \\
76 \\
13,939\end{array}$ & $\begin{array}{r}0 \\
0 \\
0 \\
0 \\
46,813\end{array}$ & $\begin{array}{r}0 \\
0 \\
0 \\
0 \\
28,016\end{array}$ \\
\hline 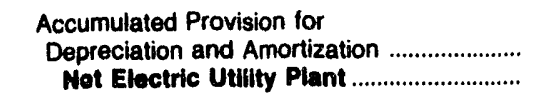 & $\begin{array}{l}13,842 \\
12,959\end{array}$ & $\begin{array}{l}7,210 \\
9,064\end{array}$ & $\begin{array}{r}39,696 \\
167,296\end{array}$ & $\begin{array}{l}7,241 \\
6,698\end{array}$ & $\begin{array}{l}22,874 \\
24,039\end{array}$ & $\begin{array}{l}13,093 \\
14,923\end{array}$ \\
\hline
\end{tabular}

Note: Totals may not equal sum of components because of independent rounding.

Source: Energy Information Administration, Form EIA-412, "Annual Report of Public Electric Utilities." 


\section{Table 39. Electric Utility Plant by Major Publicly Owned Electric Utility Within State at End of Period, 1991 (Continued)}

(Thousand Dollars)

\begin{tabular}{|c|c|c|c|c|c|c|}
\hline Item & $\begin{array}{l}\text { Indiana } \\
\text { Peru } \\
\text { City of } \\
\text { December } 31\end{array}$ & $\begin{array}{l}\text { Indiana } \\
\text { Richmond } \\
\text { City of } \\
\text { December } 31\end{array}$ & $\begin{array}{c}\text { Indiana } \\
\text { Washington } \\
\text { City of } \\
\text { December } 31\end{array}$ & $\begin{array}{l}\text { lowa } \\
\text { Ames } \\
\text { City of } \\
\text { June } 30\end{array}$ & $\begin{array}{c}\text { lowa } \\
\text { Cedar } \\
\text { Falls } \\
\text { City of } \\
\text { December } 31\end{array}$ & $\begin{array}{c}\text { lowa } \\
\text { Muscatine } \\
\text { City of } \\
\text { December } 31\end{array}$ \\
\hline $\begin{array}{l}\text { Electric Plant in Sorvice } \\
\text { Intangible Plant } \\
\text { Production Plant }\end{array}$ & 0 & 0 & 0 & 0 & 0 & 0 \\
\hline 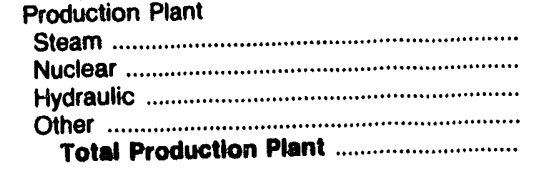 & $\begin{array}{r}7,585 \\
0 \\
0 \\
0 \\
7,585\end{array}$ & $\begin{array}{r}27,817 \\
0 \\
0 \\
0 \\
27,817\end{array}$ & $\begin{array}{l}0 \\
0 \\
0 \\
0 \\
0\end{array}$ & $\begin{array}{l}0 \\
0 \\
0 \\
0 \\
0\end{array}$ & $\begin{array}{r}37,395 \\
0 \\
0 \\
2,509 \\
39,904\end{array}$ & $\begin{array}{r}232,626 \\
0 \\
0 \\
0 \\
232,626\end{array}$ \\
\hline 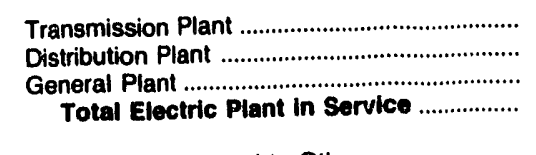 & $\begin{array}{r}2,886 \\
13,550 \\
1,736 \\
25,757\end{array}$ & $\begin{array}{r}5,246 \\
35,138 \\
9,802 \\
78,003\end{array}$ & $\begin{array}{r}500 \\
9,092 \\
986 \\
10,578\end{array}$ & $\begin{array}{r}0 \\
0 \\
93,890 \\
93,890\end{array}$ & $\begin{array}{r}6,289 \\
15,053 \\
3,568 \\
64,813\end{array}$ & $\begin{array}{r}28,826 \\
0 \\
7,707 \\
269,159\end{array}$ \\
\hline 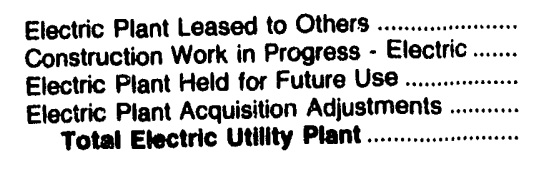 & $\begin{array}{r}0 \\
0 \\
0 \\
0 \\
25,757\end{array}$ & $\begin{array}{r}0 \\
3,646 \\
476 \\
0 \\
82,125\end{array}$ & $\begin{array}{r}0 \\
0 \\
0 \\
0 \\
10,578\end{array}$ & $\begin{array}{r}0 \\
0 \\
0 \\
0 \\
93,890\end{array}$ & $\begin{array}{r}0 \\
388 \\
0 \\
1,309 \\
66,511\end{array}$ & $\begin{array}{r}0 \\
2,839 \\
0 \\
0 \\
271,998\end{array}$ \\
\hline 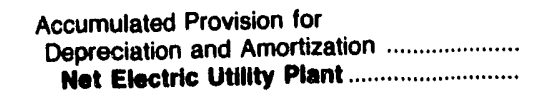 & $\begin{array}{l}13,873 \\
11,884\end{array}$ & $\begin{array}{l}33,037 \\
49,088\end{array}$ & $\begin{array}{l}4,112 \\
6,466\end{array}$ & $\begin{array}{l}44,701 \\
49,190\end{array}$ & $\begin{array}{l}29,580 \\
36,931\end{array}$ & $\begin{array}{r}98,489 \\
173,509\end{array}$ \\
\hline
\end{tabular}

\begin{tabular}{|c|c|c|c|c|c|c|}
\hline Item & $\begin{array}{c}\text { Kansas } \\
\begin{array}{c}\text { Coffeyville } \\
\text { City of }\end{array} \\
\text { December } 31\end{array}$ & $\begin{array}{l}\text { Kansas } \\
\text { Garden } \\
\text { City City of } \\
\text { December } 31\end{array}$ & $\begin{array}{c}\text { Kansas } \\
\text { Kansas } \\
\text { City City of } \\
\text { December } 31\end{array}$ & $\begin{array}{l}\text { Kansas } \\
\text { Kansas } \\
\text { Municipal } \\
\text { Energy } \\
\text { Agency } \\
\text { December } 31\end{array}$ & $\begin{array}{c}\text { Kansas } \\
\text { McPherson } \\
\text { City of } \\
\text { December } 31\end{array}$ & $\begin{array}{l}\text { Kansas } \\
\text { Winfield } \\
\text { City of } \\
\text { December } 31\end{array}$ \\
\hline Electric Plant in Service & 0 & 0 & 0 & 0 & 78 & 0 \\
\hline 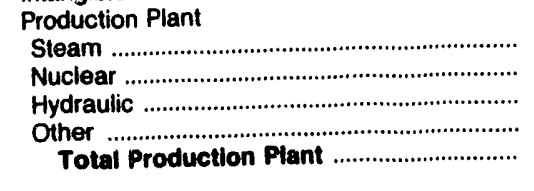 & $\begin{array}{r}16,666 \\
0 \\
0 \\
0 \\
16,666\end{array}$ & $\begin{array}{l}0 \\
0 \\
0 \\
0 \\
0\end{array}$ & $\begin{array}{r}272,813 \\
0 \\
0 \\
13,792 \\
286,606\end{array}$ & $\begin{array}{l}0 \\
0 \\
0 \\
0 \\
0\end{array}$ & $\begin{array}{r}5,365 \\
0 \\
0 \\
18,249 \\
23,613\end{array}$ & $\begin{array}{r}10,584 \\
0 \\
0 \\
1,111 \\
11,696\end{array}$ \\
\hline 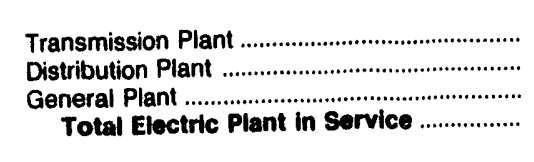 & $\begin{array}{r}262 \\
11,525 \\
954 \\
29,407\end{array}$ & $\begin{array}{r}0 \\
13,836 \\
0 \\
13,836\end{array}$ & $\begin{array}{r}27,439 \\
127,765 \\
38,899 \\
480,709\end{array}$ & $\begin{array}{r}4,723 \\
0 \\
91 \\
4,814\end{array}$ & $\begin{array}{r}6,066 \\
10,026 \\
877 \\
40,660\end{array}$ & $\begin{array}{r}0 \\
8,789 \\
1,876 \\
22,361\end{array}$ \\
\hline 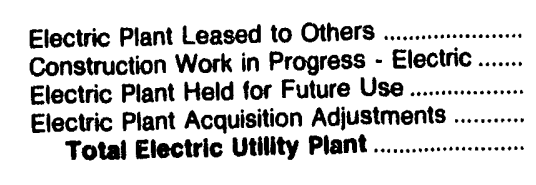 & $\begin{array}{r}0 \\
0 \\
0 \\
0 \\
29,407\end{array}$ & $\begin{array}{r}0 \\
0 \\
0 \\
0 \\
13,836\end{array}$ & $\begin{array}{r}0 \\
56,688 \\
0 \\
948 \\
538,345\end{array}$ & $\begin{array}{r}0 \\
0 \\
0 \\
0 \\
4,814\end{array}$ & $\begin{array}{r}0 \\
3,739 \\
0 \\
0 \\
44,399\end{array}$ & $\begin{array}{r}0 \\
6,104 \\
0 \\
0 \\
28,465\end{array}$ \\
\hline 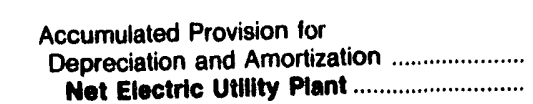 & $\begin{array}{r}19,810 \\
9,597\end{array}$ & $\begin{array}{l}7,333 \\
6,504\end{array}$ & $\begin{array}{l}196,716 \\
\mathbf{3 4 1 , 6 2 8}\end{array}$ & $\begin{array}{l}1,509 \\
3,305\end{array}$ & $\begin{array}{l}21,965 \\
22,434\end{array}$ & $\begin{array}{l}13,621 \\
14,844\end{array}$ \\
\hline
\end{tabular}

Note: Totals may not equal sum of components because of independent rounding.

Source: Energy Information Administration, Form EIA-412, "Annual Report of Public Electric Utilities." 
Table 39. Electric Utility Plant by Major Publicly Owned Electric Utility Within State at End of Period, 1991 (Continued) (Thousand Dollars)

\begin{tabular}{|c|c|c|c|c|c|c|}
\hline Item & $\begin{array}{l}\text { Kentucky } \\
\text { Bowling } \\
\text { Green } \\
\text { City of } \\
\text { June } 30\end{array}$ & $\begin{array}{l}\text { Kentucky } \\
\text { Frankfort } \\
\text { City of } \\
\text { June } 30\end{array}$ & $\begin{array}{l}\text { Kentucky } \\
\text { Franklin } \\
\text { City of } \\
\text { June } 30\end{array}$ & $\begin{array}{l}\text { Kentucky } \\
\text { Glasgow } \\
\text { City of } \\
\text { June } 30\end{array}$ & $\begin{array}{l}\text { Kentucky } \\
\text { Henderson } \\
\text { City } \\
\text { Utility Comm } \\
\text { May } 31\end{array}$ & $\begin{array}{c}\text { Kentucky } \\
\text { Hopkinsville } \\
\text { City of } \\
\text { June } 30\end{array}$ \\
\hline 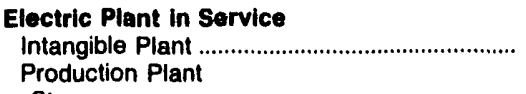 & 0 & 0 & 0 & 0 & 0 & 0 \\
\hline 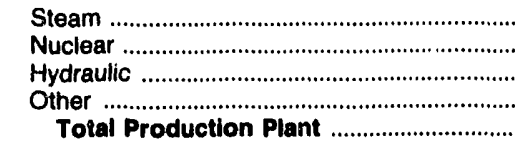 & $\begin{array}{l}0 \\
0 \\
0 \\
0 \\
0\end{array}$ & $\begin{array}{l}0 \\
0 \\
0 \\
0 \\
0\end{array}$ & $\begin{array}{l}0 \\
0 \\
0 \\
0 \\
0\end{array}$ & $\begin{array}{l}0 \\
0 \\
0 \\
0 \\
0\end{array}$ & $\begin{array}{r}82,213 \\
0 \\
0 \\
413 \\
82,626\end{array}$ & $\begin{array}{l}0 \\
0 \\
0 \\
0 \\
0\end{array}$ \\
\hline 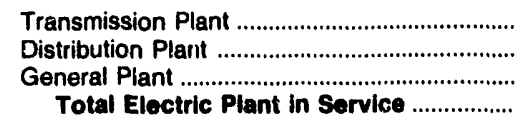 & $\begin{array}{r}0 \\
28,589 \\
3,544 \\
32,133\end{array}$ & $\begin{array}{r}7,799 \\
12,591 \\
0 \\
20,390\end{array}$ & $\begin{array}{r}0 \\
3,701 \\
946 \\
4,647\end{array}$ & $\begin{array}{r}954 \\
7,980 \\
3,470 \\
12,405\end{array}$ & $\begin{array}{r}5,666 \\
10,316 \\
1,140 \\
99,748\end{array}$ & $\begin{array}{r}435 \\
10,318 \\
3,782 \\
14,535\end{array}$ \\
\hline 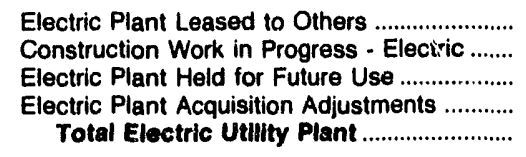 & $\begin{array}{r}0 \\
291 \\
0 \\
0 \\
32,424\end{array}$ & $\begin{array}{r}0 \\
0 \\
0 \\
0 \\
20,390\end{array}$ & $\begin{array}{r}0 \\
118 \\
0 \\
0 \\
4,765\end{array}$ & $\begin{array}{r}0 \\
371 \\
0 \\
0 \\
12,776\end{array}$ & $\begin{array}{r}0 \\
0 \\
0 \\
0 \\
99,748\end{array}$ & $\begin{array}{r}0 \\
46 \\
0 \\
0 \\
14,581\end{array}$ \\
\hline 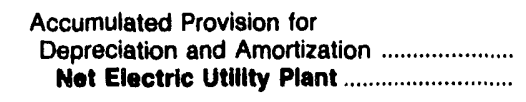 & $\begin{array}{r}9,856 \\
22,569\end{array}$ & $\begin{array}{r}10,419 \\
9,971\end{array}$ & $\begin{array}{l}1,621 \\
3,144\end{array}$ & $\begin{array}{l}3,960 \\
8,816\end{array}$ & $\begin{array}{l}49,822 \\
49,927\end{array}$ & $\begin{array}{l}5,632 \\
8,949\end{array}$ \\
\hline
\end{tabular}

\begin{tabular}{|c|c|c|c|c|c|c|}
\hline Item & $\begin{array}{l}\text { Kentucky } \\
\text { Madisonville } \\
\text { Municipal } \\
\text { Utils } \\
\text { June } 30\end{array}$ & $\begin{array}{l}\text { Kentucky } \\
\text { Mayfield } \\
\text { City of } \\
\text { June } 30\end{array}$ & $\begin{array}{l}\text { Kentucky } \\
\text { Murray } \\
\text { City of } \\
\text { June } 30\end{array}$ & $\begin{array}{c}\text { Kentucky } \\
\text { Owensboro } \\
\text { City of } \\
\text { May } 31\end{array}$ & $\begin{array}{l}\text { Kentucky } \\
\text { Paducah } \\
\text { City of } \\
\text { June } 30\end{array}$ & $\begin{array}{l}\text { Louisiana } \\
\text { Alexandria } \\
\text { City of } \\
\text { April } 30\end{array}$ \\
\hline 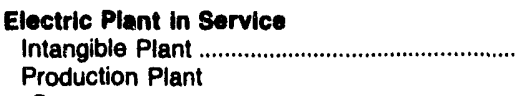 & 0 & 0 & 0 & 0 & 0 & 0 \\
\hline 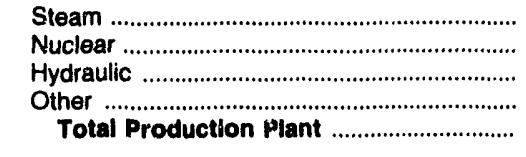 & $\begin{array}{l}0 \\
0 \\
0 \\
0 \\
0\end{array}$ & $\begin{array}{l}0 \\
0 \\
0 \\
0 \\
0\end{array}$ & $\begin{array}{l}0 \\
0 \\
0 \\
0 \\
0\end{array}$ & $\begin{array}{r}73,779 \\
0 \\
0 \\
0 \\
73,779\end{array}$ & $\begin{array}{l}0 \\
0 \\
0 \\
0 \\
0\end{array}$ & $\begin{array}{r}12,714 \\
0 \\
0 \\
0 \\
12,714\end{array}$ \\
\hline 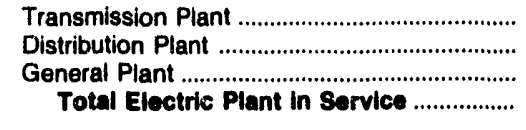 & $\begin{array}{r}0 \\
5,816 \\
0 \\
5,816\end{array}$ & $\begin{array}{r}0 \\
4,117 \\
773 \\
4,890\end{array}$ & $\begin{array}{r}430 \\
6,383 \\
933 \\
7,747\end{array}$ & $\begin{array}{r}15,314 \\
28,852 \\
4,063 \\
122,008\end{array}$ & $\begin{array}{r}2,222 \\
30,325 \\
3,404 \\
35,951\end{array}$ & $\begin{array}{r}0 \\
32,502 \\
0 \\
45,217\end{array}$ \\
\hline 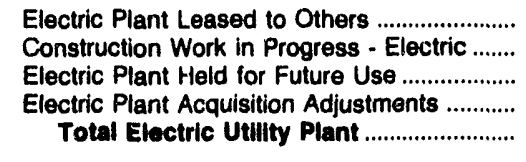 & $\begin{array}{r}0 \\
0 \\
0 \\
0 \\
5,816\end{array}$ & $\begin{array}{r}0 \\
278 \\
0 \\
0 \\
5,169\end{array}$ & $\begin{array}{r}0 \\
36 \\
0 \\
0 \\
7,783\end{array}$ & $\begin{array}{r}0 \\
11,137 \\
0 \\
0 \\
\$ 33,145\end{array}$ & $\begin{array}{r}0 \\
347 \\
1,349 \\
0 \\
37,647\end{array}$ & $\begin{array}{r}0 \\
2,782 \\
84,884 \\
0 \\
132,883\end{array}$ \\
\hline 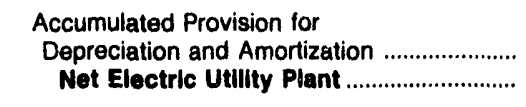 & $\begin{array}{l}2,741 \\
3,076\end{array}$ & $\begin{array}{l}2,035 \\
3,134\end{array}$ & $\begin{array}{l}3,351 \\
4,432\end{array}$ & $\begin{array}{l}64,826 \\
68,319\end{array}$ & $\begin{array}{l}11,330 \\
26,317\end{array}$ & $\begin{array}{l}50,913 \\
81,970\end{array}$ \\
\hline
\end{tabular}

Note: Totals may not equal sum of components bocause of independent rounding

Source: Energy Information Administration, Form EIA-412, "Annual Report of Public Electric Utilities." 
Table 39. Electric Utility Plant by Major Publicly Owned Electric Utility Within State at End of Period, 1991 (Continued) (Thousand Dollars)

\begin{tabular}{|c|c|c|c|c|c|c|}
\hline Item & $\begin{array}{l}\text { Louisiana } \\
\text { Lafayette } \\
\text { City of } \\
\text { October } 31\end{array}$ & $\begin{array}{c}\text { Louisiana } \\
\text { Louisiana } \\
\text { Energy } \\
\& \\
\text { Power Auth } \\
\text { December } 31\end{array}$ & $\begin{array}{l}\text { Louisiana } \\
\text { Morgan } \\
\text { City City of } \\
\text { December } 31\end{array}$ & $\begin{array}{c}\text { Louisiana } \\
\begin{array}{c}\text { Natchitoches } \\
\text { City of }\end{array} \\
\text { May } 31\end{array}$ & $\begin{array}{l}\text { Louisiana } \\
\text { Ruston } \\
\text { City of } \\
\text { September } 30\end{array}$ & $\begin{array}{c}\text { Louisiana } \\
\text { Terrebonne } \\
\text { Parish } \\
\text { Consol Govt } \\
\text { December } 31\end{array}$ \\
\hline 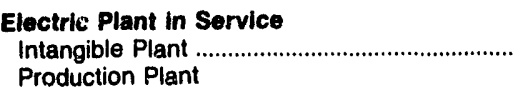 & 31 & 8,939 & 948 & 0 & 0 & 0 \\
\hline 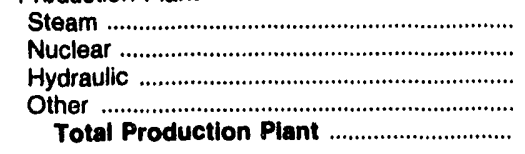 & $\begin{array}{r}50,653 \\
0 \\
0 \\
157 \\
50,809\end{array}$ & $\begin{array}{r}57,285 \\
0 \\
0 \\
0 \\
57,285\end{array}$ & $\begin{array}{r}18,280 \\
0 \\
0 \\
85 \\
18,365\end{array}$ & $\begin{array}{l}0 \\
0 \\
0 \\
0 \\
0\end{array}$ & $\begin{array}{r}13,037 \\
0 \\
0 \\
3,190 \\
16,227\end{array}$ & $\begin{array}{r}25,308 \\
0 \\
0 \\
0 \\
25,308\end{array}$ \\
\hline 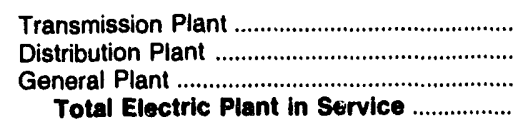 & $\begin{array}{r}2,699 \\
66,927 \\
17,206 \\
137,671\end{array}$ & $\begin{array}{r}236 \\
322 \\
4,402 \\
71,184\end{array}$ & $\begin{array}{r}8,739 \\
6,714 \\
7,955 \\
42,722\end{array}$ & $\begin{array}{r}0 \\
38,614 \\
0 \\
38,614\end{array}$ & $\begin{array}{r}0 \\
11,460 \\
549 \\
28,236\end{array}$ & $\begin{array}{r}0 \\
20,017 \\
0 \\
45,325\end{array}$ \\
\hline 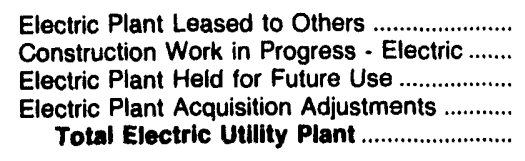 & $\begin{array}{r}0 \\
344 \\
0 \\
55,066 \\
193,081\end{array}$ & $\begin{array}{r}0 \\
0 \\
0 \\
15,722 \\
86,905\end{array}$ & $\begin{array}{r}0 \\
138 \\
0 \\
0 \\
42,860\end{array}$ & $\begin{array}{r}0 \\
0 \\
0 \\
0 \\
38,614\end{array}$ & $\begin{array}{r}0 \\
0 \\
0 \\
0 \\
28,236\end{array}$ & $\begin{array}{r}0 \\
373 \\
0 \\
0 \\
45,698\end{array}$ \\
\hline 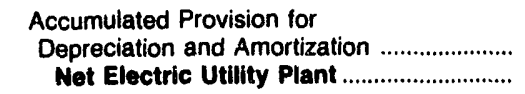 & $\begin{array}{r}73,162 \\
119,920\end{array}$ & $\begin{array}{l}11,947 \\
74,959\end{array}$ & $\begin{array}{l}23,816 \\
19,044\end{array}$ & $\begin{array}{l}12,785 \\
25,830\end{array}$ & $\begin{array}{l}16,320 \\
11,917\end{array}$ & $\begin{array}{l}31,059 \\
14,639\end{array}$ \\
\hline
\end{tabular}

\begin{tabular}{|c|c|c|c|c|c|c|}
\hline Item & $\begin{array}{l}\text { Maryland } \\
\text { Easton } \\
\text { Utilities } \\
\text { Comm } \\
\text { June } 30\end{array}$ & $\begin{array}{l}\text { Maryland } \\
\text { Hagerstown } \\
\text { City of } \\
\text { December } 31\end{array}$ & $\begin{array}{c}\text { Massachusetts } \\
\text { Braintree } \\
\text { Town of } \\
\text { December } 31\end{array}$ & $\begin{array}{l}\text { Massachusetts } \\
\text { Chicopee } \\
\text { City of } \\
\text { December } 31\end{array}$ & $\begin{array}{l}\text { Massachusetts } \\
\text { Concord } \\
\text { Town of } \\
\text { December } 31\end{array}$ & $\begin{array}{c}\text { Massachusetts } \\
\text { Danvers } \\
\text { Town of } \\
\text { December } 31\end{array}$ \\
\hline 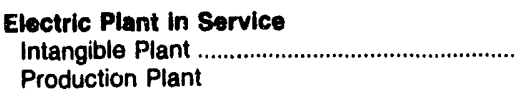 & 0 & 0 & 0 & 0 & 1,056 & 0 \\
\hline $\begin{array}{l}\text { Steam } \\
\text { Hydraulic . . } \\
\text { Other } \\
\text { Total Production Plant }\end{array}$ & $\begin{array}{r}0 \\
0 \\
0 \\
20,404 \\
20,404\end{array}$ & $\begin{array}{r}11,710 \\
0 \\
0 \\
8 \\
11,718\end{array}$ & $\begin{array}{r}26,927 \\
0 \\
0 \\
755 \\
27,682\end{array}$ & $\begin{array}{r}0 \\
41,945 \\
0 \\
1,717 \\
43,661\end{array}$ & $\begin{array}{l}0 \\
0 \\
0 \\
0 \\
0\end{array}$ & $\begin{array}{l}0 \\
0 \\
0 \\
0 \\
0\end{array}$ \\
\hline 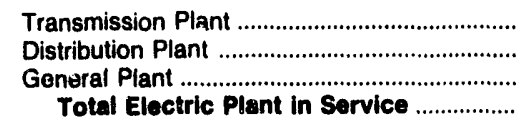 & $\begin{array}{r}0 \\
13,268 \\
1,990 \\
35,662\end{array}$ & $\begin{array}{r}1,839 \\
17,866 \\
1,402 \\
32,825\end{array}$ & $\begin{array}{r}13,066 \\
19,092 \\
2,308 \\
62,148\end{array}$ & $\begin{array}{r}204 \\
16,740 \\
4,540 \\
65,145\end{array}$ & $\begin{array}{r}2,438 \\
9,612 \\
1,593 \\
14,699\end{array}$ & $\begin{array}{r}0 \\
16,139 \\
2,358 \\
18,498\end{array}$ \\
\hline 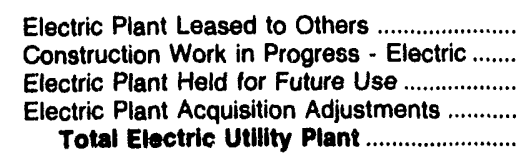 & $\begin{array}{r}0 \\
2,061 \\
0 \\
0 \\
37,723\end{array}$ & $\begin{array}{r}0 \\
0 \\
0 \\
0 \\
32,825\end{array}$ & $\begin{array}{r}0 \\
0 \\
0 \\
0 \\
62,148\end{array}$ & $\begin{array}{r}0 \\
697 \\
0 \\
0 \\
65,842\end{array}$ & $\begin{array}{r}0 \\
782 \\
0 \\
n \\
15,481\end{array}$ & $\begin{array}{r}0 \\
0 \\
0 \\
0 \\
18,498\end{array}$ \\
\hline 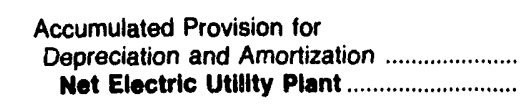 & $\begin{array}{l}13,621 \\
24,102\end{array}$ & $\begin{array}{l}19,468 \\
13,357\end{array}$ & $\begin{array}{l}27,200 \\
34,948\end{array}$ & $\begin{array}{l}22,057 \\
43,785\end{array}$ & $\begin{array}{l}7,363 \\
8,118\end{array}$ & $\begin{array}{l}9,040 \\
9,457\end{array}$ \\
\hline
\end{tabular}

Note: Totals may not equal sum of components because of independent riunding.

Source: Energy Information Administration, Form ElA-412, "Annual Report of Public Electric Utilities." 
Table 39. Electric Utility Plant by Major Publicly Owned Electric Utility Within State at End of Period, 1991 (Continued) (Thousand Dollars)

\begin{tabular}{|c|c|c|c|c|c|c|}
\hline Item & $\begin{array}{l}\text { Massachusetts } \\
\text { Hingham } \\
\text { City of } \\
\text { December } 31\end{array}$ & $\begin{array}{c}\text { Massachusetts } \\
\text { Holyoke } \\
\text { City of } \\
\text { December } 31\end{array}$ & $\begin{array}{l}\text { Massachusetts } \\
\text { Hudson } \\
\text { Town of } \\
\text { December } 31\end{array}$ & $\begin{array}{c}\text { Massachusetts } \\
\text { Littleton } \\
\text { Town of } \\
\text { December } 31\end{array}$ & $\begin{array}{l}\text { Massachusetts } \\
\text { Mansfield } \\
\text { Town of } \\
\text { December } 31\end{array}$ & $\begin{array}{c}\text { Massachusetts } \\
\text { Massachusetts } \\
\text { Mun } \\
\text { Whis } \\
\text { Elec Co } \\
\text { December } 31\end{array}$ \\
\hline 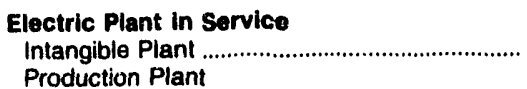 & 0 & 0 & 4 & 0 & 0 & 1,172 \\
\hline 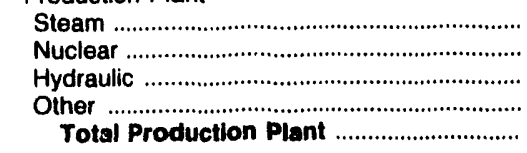 & $\begin{array}{l}0 \\
0 \\
0 \\
0 \\
0\end{array}$ & $\begin{array}{r}16,869 \\
0 \\
1,768 \\
1,922 \\
20,559\end{array}$ & $\begin{array}{r}0 \\
2,797 \\
0 \\
4,090 \\
6,888\end{array}$ & $\begin{array}{r}337 \\
0 \\
0 \\
0 \\
337\end{array}$ & $\begin{array}{l}0 \\
0 \\
0 \\
0 \\
0\end{array}$ & $\begin{array}{r}7,271 \\
993,675 \\
0 \\
180,653 \\
1,181,598\end{array}$ \\
\hline 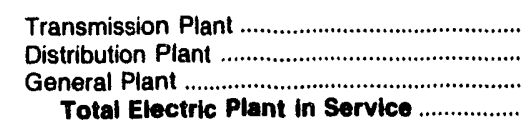 & $\begin{array}{r}1,432 \\
17,235 \\
1,162 \\
19,829\end{array}$ & $\begin{array}{r}6,178 \\
20,686 \\
1,801 \\
49,224\end{array}$ & $\begin{array}{r}1,631 \\
7,055 \\
1,552 \\
17,129\end{array}$ & $\begin{array}{r}15 \\
8,302 \\
3,435 \\
12,089\end{array}$ & $\begin{array}{r}0 \\
7,753 \\
892 \\
\mathbf{8 , 6 4 5}\end{array}$ & $\begin{array}{r}30,804 \\
0 \\
16,774 \\
1,230,349\end{array}$ \\
\hline 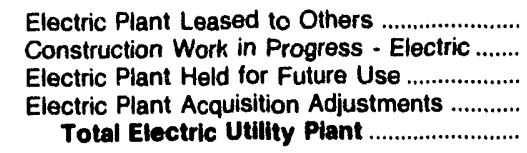 & $\begin{array}{r}0 \\
0 \\
0 \\
0 \\
19,829\end{array}$ & $\begin{array}{r}0 \\
1,389 \\
0 \\
0 \\
50,613\end{array}$ & $\begin{array}{r}0 \\
0 \\
0 \\
0 \\
17,129\end{array}$ & $\begin{array}{r}0 \\
1,233 \\
0 \\
0 \\
13,322\end{array}$ & $\begin{array}{r}0 \\
0 \\
0 \\
0 \\
8,645\end{array}$ & $\begin{array}{r}0 \\
61,207 \\
0 \\
0 \\
1,291,558\end{array}$ \\
\hline 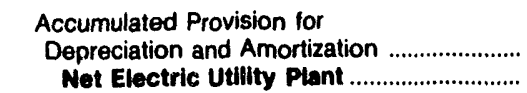 & $\begin{array}{r}4,398 \\
15,430\end{array}$ & $\begin{array}{l}27,112 \\
23,501\end{array}$ & $\begin{array}{r}11,015 \\
6,114\end{array}$ & $\begin{array}{l}4,893 \\
8,430\end{array}$ & $\begin{array}{l}4,899 \\
3,746\end{array}$ & $\begin{array}{r}185,606 \\
1,105,950\end{array}$ \\
\hline
\end{tabular}

\begin{tabular}{|c|c|c|c|c|c|c|}
\hline Item & $\begin{array}{l}\text { Massachusetts } \\
\text { Middleborough } \\
\text { Town of } \\
\text { December } 31\end{array}$ & $\begin{array}{c}\text { Massachusetts } \\
\text { North } \\
\text { Attleborough } \\
\text { Town of } \\
\text { December } 31\end{array}$ & $\begin{array}{l}\text { Massachusetts } \\
\text { Norwood } \\
\text { City of } \\
\text { June } 30\end{array}$ & $\begin{array}{l}\text { Massachusetts } \\
\text { Peabody } \\
\text { City of } \\
\text { December } 31\end{array}$ & $\begin{array}{l}\text { Massachusetts } \\
\text { Reading } \\
\text { Town of } \\
\text { December } 31\end{array}$ & $\begin{array}{c}\text { Massachusetts } \\
\text { Shrewsbury } \\
\text { Town of } \\
\text { December } 31\end{array}$ \\
\hline 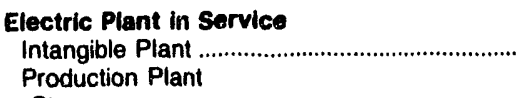 & 0 & 0 & 0 & 0 & 0 & 0 \\
\hline 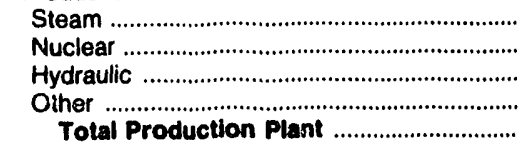 & $\begin{array}{l}0 \\
0 \\
0 \\
0 \\
0\end{array}$ & $\begin{array}{r}666 \\
0 \\
0 \\
0 \\
666\end{array}$ & $\begin{array}{l}0 \\
0 \\
0 \\
0 \\
0\end{array}$ & $\begin{array}{r}0 \\
0 \\
0 \\
24,180 \\
24,180\end{array}$ & $\begin{array}{l}0 \\
0 \\
0 \\
0 \\
0\end{array}$ & $\begin{array}{r}0 \\
0 \\
0 \\
2,975 \\
2,975\end{array}$ \\
\hline 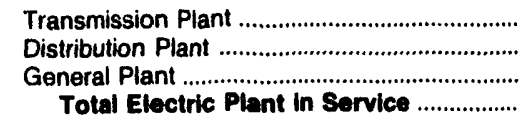 & $\begin{array}{r}2,762 \\
9,410 \\
2,186 \\
14,357\end{array}$ & $\begin{array}{r}1,774 \\
10,707 \\
931 \\
14,078\end{array}$ & $\begin{array}{r}509 \\
17,463 \\
1,464 \\
18,435\end{array}$ & $\begin{array}{r}7,353 \\
20,155 \\
8,658 \\
60,346\end{array}$ & $\begin{array}{r}2,201 \\
30,119 \\
5,669 \\
37,989\end{array}$ & $\begin{array}{r}2,244 \\
12,761 \\
2,832 \\
20,812\end{array}$ \\
\hline 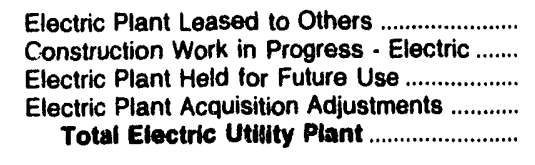 & $\begin{array}{r}0 \\
0 \\
0 \\
0 \\
14,357\end{array}$ & $\begin{array}{r}0 \\
825 \\
0 \\
0 \\
14,803\end{array}$ & $\begin{array}{r}0 \\
0 \\
0 \\
0 \\
19,435\end{array}$ & $\begin{array}{r}0 \\
0 \\
0 \\
0 \\
60,346\end{array}$ & $\begin{array}{r}0 \\
0 \\
0 \\
0 \\
37,989\end{array}$ & $\begin{array}{r}0 \\
0 \\
0 \\
0 \\
20,812\end{array}$ \\
\hline 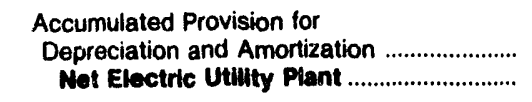 & $\begin{array}{l}5,749 \\
8,609\end{array}$ & $\begin{array}{r}4,801 \\
10,102\end{array}$ & $\begin{array}{r}12,240 \\
7,193\end{array}$ & $\begin{array}{l}20,893 \\
39,453\end{array}$ & $\begin{array}{l}17,585 \\
20,404\end{array}$ & $\begin{array}{r}9,771 \\
11,041\end{array}$ \\
\hline
\end{tabular}

Note: Totals may not equal sum of components because of independent rounding.

Source: Energy Information Administration, Form ElA-412, "Annual Peport of Public Electric Utilities." 
Table 39. Electric Utility Plant by Major Publicly Owned Electric Utility Within State at End of Period, 1991 (Continued) (Thousand Dollars)

\begin{tabular}{|c|c|c|c|c|c|c|}
\hline Item & $\begin{array}{l}\text { Massachusetts } \\
\text { Taunton } \\
\text { City of } \\
\text { December } 31\end{array}$ & $\begin{array}{c}\text { Massachusetts } \\
\text { Wakefield } \\
\text { Town of } \\
\text { December } 31\end{array}$ & $\begin{array}{c}\text { Massachusetts } \\
\text { Wellesley } \\
\text { Town of } \\
\text { December } 31\end{array}$ & $\begin{array}{l}\text { Massachusetts } \\
\text { Westfield } \\
\text { City of } \\
\text { December } 31\end{array}$ & $\begin{array}{c}\text { Michigan } \\
\text { Bay } \\
\text { City City of } \\
\text { June } 30\end{array}$ & $\begin{array}{l}\text { Michigan } \\
\text { Coldwater } \\
\text { Board } \\
\text { of } \\
\text { Public Util } \\
\text { June } 30\end{array}$ \\
\hline 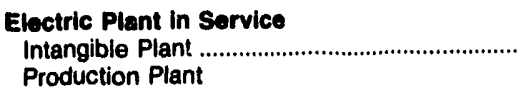 & 0 & 0 & 0 & 0 & 0 & 0 \\
\hline 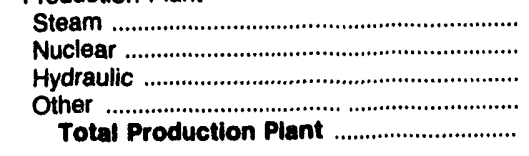 & $\begin{array}{r}43,489 \\
0 \\
0 \\
4,640 \\
48,129\end{array}$ & $\begin{array}{l}0 \\
0 \\
0 \\
0 \\
\mathbf{0}\end{array}$ & $\begin{array}{l}0 \\
0 \\
0 \\
0 \\
0\end{array}$ & $\begin{array}{l}0 \\
0 \\
0 \\
0 \\
0\end{array}$ & $\begin{array}{r}0 \\
0 \\
0 \\
7,812 \\
7,812\end{array}$ & $\begin{array}{r}7,006 \\
0 \\
0 \\
0 \\
7,006\end{array}$ \\
\hline 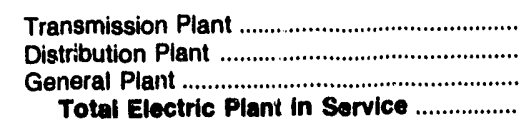 & $\begin{array}{r}7,025 \\
23,612 \\
3,202 \\
81,969\end{array}$ & $\begin{array}{r}0 \\
11,596 \\
447 \\
12,043\end{array}$ & $\begin{array}{r}3,672 \\
17,018 \\
1,485 \\
22,174\end{array}$ & $\begin{array}{r}0 \\
17,384 \\
3,059 \\
20,443\end{array}$ & $\begin{array}{r}0 \\
17,957 \\
816 \\
26,585\end{array}$ & $\begin{array}{r}0 \\
4,251 \\
2,215 \\
13,472\end{array}$ \\
\hline 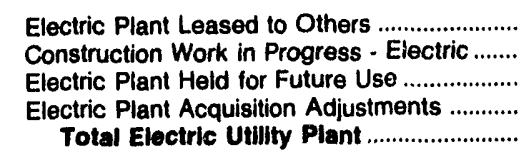 & $\begin{array}{r}0 \\
7,050 \\
0 \\
0 \\
89,019\end{array}$ & $\begin{array}{r}0 \\
0 \\
0 \\
0 \\
12,043\end{array}$ & $\begin{array}{r}0 \\
72 ? \\
0 \\
0 \\
22,296\end{array}$ & $\begin{array}{r}0 \\
15 \\
0 \\
0 \\
20,457\end{array}$ & $\begin{array}{r}0 \\
0 \\
0 \\
0 \\
26,585\end{array}$ & $\begin{array}{r}0 \\
0 \\
0 \\
0 \\
13,472\end{array}$ \\
\hline 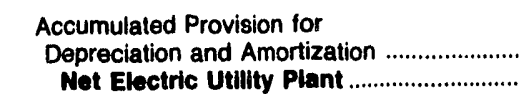 & $\begin{array}{l}45,855 \\
43,164\end{array}$ & $\begin{array}{l}9,782 \\
2,261\end{array}$ & $\begin{array}{l}10,548 \\
12,348\end{array}$ & $\begin{array}{r}8,409 \\
12,048\end{array}$ & $\begin{array}{l}10,153 \\
16,432\end{array}$ & $\begin{array}{l}7,729 \\
5,743\end{array}$ \\
\hline
\end{tabular}

\begin{tabular}{|c|c|c|c|c|c|c|}
\hline Item & $\begin{array}{l}\text { Michigan } \\
\text { Detroit } \\
\text { City of } \\
\text { June } 30\end{array}$ & $\begin{array}{c}\text { Michigan } \\
\text { Grand Haven } \\
\text { City of } \\
\text { June } 30\end{array}$ & $\begin{array}{c}\text { Michigan } \\
\text { Hillsdale } \\
\text { Board } \\
\text { of } \\
\text { Public Wks } \\
\text { June } 30\end{array}$ & $\begin{array}{l}\text { Michigan } \\
\text { Holland } \\
\text { City of } \\
\text { June } 30\end{array}$ & $\begin{array}{l}\text { Michigan } \\
\text { Lansing } \\
\text { City of } \\
\text { June } 30\end{array}$ & $\begin{array}{l}\text { Michigan } \\
\text { Marquette } \\
\text { City of } \\
\text { June } 30\end{array}$ \\
\hline 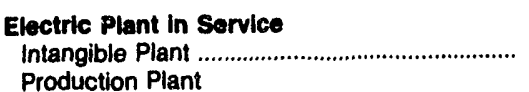 & 0 & 0 & 0 & 0 & 718 & 0 \\
\hline 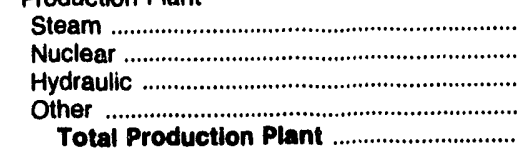 & $\begin{array}{r}94,459 \\
0 \\
0 \\
0 \\
94,459\end{array}$ & $\begin{array}{r}80,548 \\
0 \\
0 \\
4,428 \\
84,976\end{array}$ & $\begin{array}{r}0 \\
0 \\
0 \\
5,230 \\
5,230\end{array}$ & $\begin{array}{r}53,794 \\
0 \\
0 \\
0 \\
53,794\end{array}$ & $\begin{array}{r}172,904 \\
0 \\
2,071 \\
0 \\
174,975\end{array}$ & $\begin{array}{r}65,453 \\
0 \\
5,141 \\
5,345 \\
75,938\end{array}$ \\
\hline 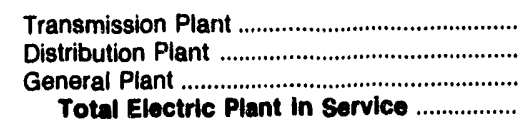 & $\begin{array}{r}22,130 \\
135,866 \\
11,253 \\
263,708\end{array}$ & $\begin{array}{r}0 \\
14,066 \\
1,222 \\
100,264\end{array}$ & $\begin{array}{r}25 \\
3,014 \\
489 \\
8,759\end{array}$ & $\begin{array}{r}0 \\
16,070 \\
8,861 \\
78,725\end{array}$ & $\begin{array}{r}27,422 \\
104,301 \\
26,046 \\
333,463\end{array}$ & $\begin{array}{r}1,204 \\
13,540 \\
2,539 \\
93,222\end{array}$ \\
\hline $\begin{array}{l}\text { Electric Plant Leased to Others ..................... } \\
\text { Construction Work in Progress - Electric ....... } \\
\text { Electric Plant Held for Future Use ................... } \\
\text { Electric Plant Acquisition Adjustments ........... } \\
\text { Total Electric Utilty Plant .................................. }\end{array}$ & $\begin{array}{r}0 \\
13,395 \\
0 \\
0 \\
277,102\end{array}$ & $\begin{array}{r}0 \\
341 \\
0 \\
0 \\
100,605\end{array}$ & $\begin{array}{r}655 \\
1,100 \\
17 \\
0 \\
10,531\end{array}$ & $\begin{array}{r}0 \\
0 \\
0 \\
0 \\
78,725\end{array}$ & $\begin{array}{r}0 \\
15,168 \\
0 \\
0 \\
348,632\end{array}$ & $\begin{array}{r}0 \\
20 \\
0 \\
0 \\
93,241\end{array}$ \\
\hline 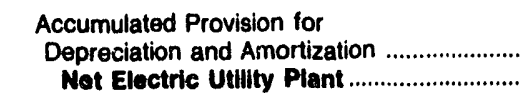 & $\begin{array}{l}105,948 \\
171,155\end{array}$ & $\begin{array}{l}34,018 \\
68,587\end{array}$ & $\begin{array}{l}6,184 \\
4,347\end{array}$ & $\begin{array}{l}28,725 \\
50,000\end{array}$ & $\begin{array}{l}194,375 \\
154,256\end{array}$ & $\begin{array}{l}33,050 \\
60,191\end{array}$ \\
\hline
\end{tabular}

Note: Totals may not equal sum of components because of independent rounding.

Source: Energy Information Administration, Form EIA-412, "Annuai Report of Public Electric Utilities." 

Table 39. Electric Utility Plant by Major Publicly Owned Electric Utility
Within State at End of Period, 1991 (Continued) (Thousand Dollars)

\begin{tabular}{|c|c|c|c|c|c|c|}
\hline Item & $\begin{array}{c}\text { Michigan } \\
\text { Michigan } \\
\text { Public } \\
\text { Power Agency } \\
\text { December } 31\end{array}$ & $\begin{array}{l}\text { Michigan } \\
\text { Michigan } \\
\text { South } \\
\text { Central } \\
\text { Pwr Agy } \\
\text { June } 30\end{array}$ & $\begin{array}{c}\text { Michigan } \\
\text { Sturgis } \\
\text { City of } \\
\text { September } 30\end{array}$ & $\begin{array}{l}\text { Michigan } \\
\text { Traverse } \\
\text { City City of } \\
\text { June: } 30\end{array}$ & $\begin{array}{l}\text { Michigan } \\
\text { Wyandotte } \\
\text { Municipal } \\
\text { Serv Comm } \\
\text { September } 30\end{array}$ & $\begin{array}{c}\text { Minnesota } \\
\text { Alexandria } \\
\text { City of } \\
\text { December } 31\end{array}$ \\
\hline 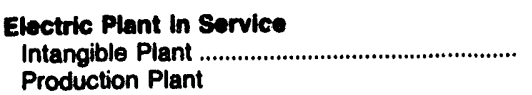 & 0 & 0 & 0 & 0 & 0 & 0 \\
\hline 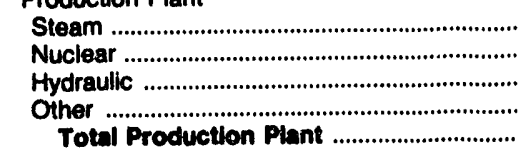 & $\begin{array}{r}425,748 \\
0 \\
0 \\
0 \\
425,748\end{array}$ & $\begin{array}{r}52,251 \\
0 \\
0 \\
0 \\
52,251\end{array}$ & $\begin{array}{r}0 \\
0 \\
5,296 \\
3,985 \\
9,281\end{array}$ & $\begin{array}{r}9,279 \\
0 \\
4,540 \\
972 \\
14,792\end{array}$ & $\begin{array}{r}35,999 \\
0 \\
0 \\
0 \\
35,998\end{array}$ & $\begin{array}{r}1,842 \\
0 \\
0 \\
1,951 \\
3,794\end{array}$ \\
\hline 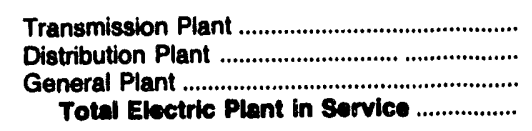 & $\begin{array}{r}25,358 \\
0 \\
2,203 \\
453,310\end{array}$ & $\begin{array}{r}15,577 \\
265 \\
3,552 \\
71,646\end{array}$ & $\begin{array}{r}0 \\
13,157 \\
2,884 \\
25,323\end{array}$ & $\begin{array}{r}4,206 \\
8,883 \\
370 \\
28,251\end{array}$ & $\begin{array}{r}5,764 \\
15,437 \\
2,375 \\
59,575\end{array}$ & $\begin{array}{r}837 \\
8,879 \\
1,399 \\
14,808\end{array}$ \\
\hline 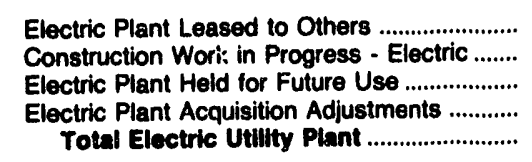 & $\begin{array}{r}0 \\
0 \\
0 \\
0 \\
453,310\end{array}$ & $\begin{array}{r}0 \\
252 \\
0 \\
0 \\
71,888\end{array}$ & $\begin{array}{r}0 \\
0 \\
0 \\
0 \\
25,323\end{array}$ & $\begin{array}{r}0 \\
334 \\
0 \\
0 \\
28,585\end{array}$ & $\begin{array}{r}0 \\
32,843 \\
0 \\
0 \\
92,418\end{array}$ & $\begin{array}{r}0 \\
4 \\
0 \\
0 \\
14,913\end{array}$ \\
\hline 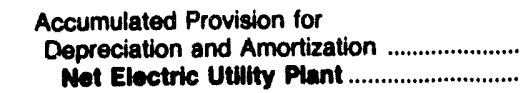 & $\begin{array}{r}97,449 \\
255,861\end{array}$ & $\begin{array}{l}18,469 \\
53,429\end{array}$ & $\begin{array}{r}11,705 \\
13,618\end{array}$ & $\begin{array}{l}10,015 \\
18,570\end{array}$ & $\begin{array}{l}28,274 \\
64,143\end{array}$ & $\begin{array}{l}8,770 \\
6,143\end{array}$ \\
\hline
\end{tabular}

\begin{tabular}{|c|c|c|c|c|c|c|}
\hline Item & $\begin{array}{l}\text { Minnesota } \\
\text { Anoka } \\
\text { City of } \\
\text { December } 31\end{array}$ & $\begin{array}{c}\text { Minnesota } \\
\text { Austin } \\
\text { City of } \\
\text { December } 31\end{array}$ & $\begin{array}{l}\text { Minnesota } \\
\text { Fairmont } \\
\text { Public } \\
\text { Utilities } \\
\text { Comm } \\
\text { December } 31\end{array}$ & $\begin{array}{c}\text { Minnesota } \\
\text { Hutchinson } \\
\text { Utilities } \\
\text { Comm } \\
\text { December } 31\end{array}$ & $\begin{array}{c}\text { Minnesota } \\
\text { Marshall } \\
\text { City of } \\
\text { December } 31\end{array}$ & $\begin{array}{c}\text { Minnesota } \\
\text { Moorhead } \\
\text { City of } \\
\text { December } 31\end{array}$ \\
\hline 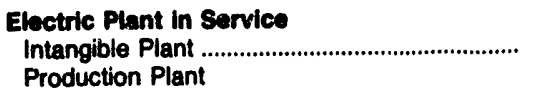 & 0 & 15,254 & 390 & 0 & 0 & 254 \\
\hline 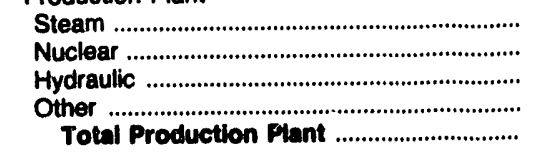 & $\begin{array}{l}0 \\
0 \\
0 \\
0 \\
0\end{array}$ & $\begin{array}{l}0 \\
0 \\
0 \\
0 \\
0\end{array}$ & $\begin{array}{r}3,089 \\
0 \\
0 \\
2,135 \\
5,224\end{array}$ & $\begin{array}{r}0 \\
0 \\
0 \\
10,222 \\
10,222\end{array}$ & $\begin{array}{r}0 \\
0 \\
0 \\
1,771 \\
1,771\end{array}$ & $\begin{array}{r}2,545 \\
0 \\
0 \\
0 \\
2,545\end{array}$ \\
\hline 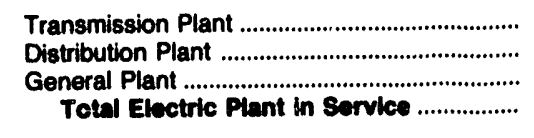 & $\begin{array}{r}0 \\
0 \\
11,816 \\
11,816\end{array}$ & $\begin{array}{r}1,175 \\
13,092 \\
-112 \\
28,408\end{array}$ & $\begin{array}{r}3,271 \\
4,415 \\
4,411 \\
17,711\end{array}$ & $\begin{array}{r}5,922 \\
7,086 \\
1,284 \\
24,514\end{array}$ & $\begin{array}{r}1,886 \\
8,076 \\
966 \\
12,699\end{array}$ & $\begin{array}{r}2,586 \\
11,675 \\
1,129 \\
18,189\end{array}$ \\
\hline 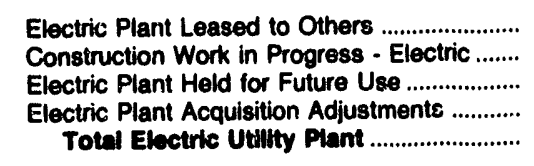 & $\begin{array}{r}0 \\
0 \\
0 \\
0 \\
11,816\end{array}$ & $\begin{array}{r}1,065 \\
112 \\
0 \\
0 \\
30,586\end{array}$ & $\begin{array}{r}0 \\
41 \\
0 \\
0 \\
17,753\end{array}$ & $\begin{array}{r}0 \\
1,286 \\
0 \\
0 \\
25,800\end{array}$ & $\begin{array}{r}0 \\
151 \\
0 \\
0 \\
12,850\end{array}$ & $\begin{array}{r}0 \\
183 \\
9,194 \\
0 \\
27,568\end{array}$ \\
\hline 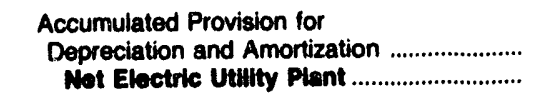 & $\begin{array}{l}5,419 \\
6,397\end{array}$ & $\begin{array}{l}18,670 \\
11,916\end{array}$ & $\begin{array}{r}7,665 \\
10,087\end{array}$ & $\begin{array}{l}12,716 \\
13,084\end{array}$ & $\begin{array}{l}5,405 \\
7,445\end{array}$ & $\begin{array}{l}13,615 \\
13,951\end{array}$ \\
\hline
\end{tabular}

Note: Totals may not equal sum of components because of independent rounding.

Source: Energy Information Administration, Form EIA-412. "Annual Report of Public Electric Utilities." 


\section{Table 39. Electric Utility Plant by Major Publicly Owned Electric Utility Within State at End of Period, 1991 (Continued)}

(Thousand Dollars)

\begin{tabular}{|c|c|c|c|c|c|c|}
\hline Item & $\begin{array}{l}\text { Minnesota } \\
\text { New Uim } \\
\text { Public } \\
\text { Utilities } \\
\text { Comm } \\
\text { December } 31\end{array}$ & $\begin{array}{c}\text { Minnesota } \\
\text { Northern } \\
\text { Municipal } \\
\text { Power Agny } \\
\text { December } 31\end{array}$ & $\begin{array}{c}\text { Minnesota } \\
\text { Owatonna } \\
\text { City of } \\
\text { December } 31\end{array}$ & $\begin{array}{c}\text { Minnesota } \\
\text { Rochester } \\
\text { Public } \\
\text { Utilities } \\
\text { December } 31\end{array}$ & $\begin{array}{c}\text { Minnesota } \\
\text { Southern } \\
\text { Minnesota } \\
\text { Mun P } \\
\text { Agny } \\
\text { December } 31\end{array}$ & $\begin{array}{l}\text { Minnesota } \\
\text { Western } \\
\text { Minnesota } \\
\text { Mun } \\
\text { Pwr Agny } \\
\text { December } 31\end{array}$ \\
\hline \multirow{2}{*}{ 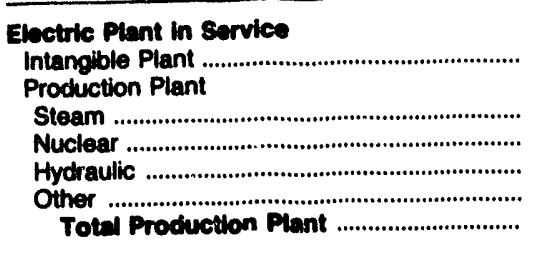 } & 0 & 0 & 0 & 148 & 15,991 & 0 \\
\hline & $\begin{array}{r}12,029 \\
0 \\
0 \\
0 \\
12,020\end{array}$ & $\begin{array}{r}279,570 \\
0 \\
0 \\
0 \\
279,570\end{array}$ & $\begin{array}{r}6,872 \\
0 \\
0 \\
1,952 \\
8,824\end{array}$ & $\begin{array}{r}25,288 \\
0 \\
2,465 \\
2,554 \\
30,307\end{array}$ & $\begin{array}{r}433,139 \\
0 \\
0 \\
0 \\
433,139\end{array}$ & $\begin{array}{r}168,362 \\
0 \\
0 \\
0 \\
168,382\end{array}$ \\
\hline 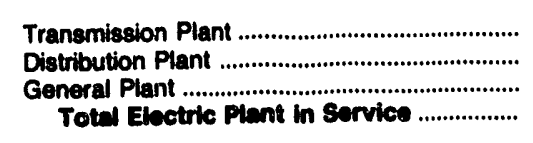 & $\begin{array}{r}4,059 \\
7,075 \\
0 \\
23,163\end{array}$ & $\begin{array}{r}24,600 \\
0 \\
0 \\
304,170\end{array}$ & $\begin{array}{r}1,685 \\
10,576 \\
3,071 \\
24,155\end{array}$ & $\begin{array}{l}13,705 \\
27,988 \\
17,332 \\
89,480\end{array}$ & $\begin{array}{r}55,226 \\
0 \\
4,470 \\
508,828\end{array}$ & $\begin{array}{r}55,675 \\
0 \\
0 \\
222,037\end{array}$ \\
\hline $\begin{array}{l}\text { Electric Plant Leased to Others ...................... } \\
\text { Construction Work in Progress - Electric ........ } \\
\text { Electric Plant Held for Future Use ................... } \\
\text { Electric Plant Acquisition Adjustments ............ } \\
\text { Totin Electrk Ututy Plent ......................... }\end{array}$ & $\begin{array}{r}0 \\
0 \\
0 \\
0 \\
23,183\end{array}$ & $\begin{array}{r}0 \\
0 \\
0 \\
0 \\
304,170\end{array}$ & $\begin{array}{r}0 \\
2,295 \\
0 \\
0 \\
28,450\end{array}$ & $\begin{array}{r}0 \\
4,332 \\
0 \\
0 \\
93,812\end{array}$ & $\begin{array}{r}0 \\
3,574 \\
0 \\
407 \\
512,807\end{array}$ & $\begin{array}{r}0 \\
794 \\
14,094 \\
0 \\
238,925\end{array}$ \\
\hline 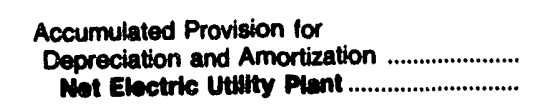 & $\begin{array}{l}11,673 \\
11,490\end{array}$ & $\begin{array}{r}4,015 \\
300,155\end{array}$ & $\begin{array}{l}11,469 \\
14,881\end{array}$ & $\begin{array}{l}47,871 \\
45,841\end{array}$ & $\begin{array}{r}69,315 \\
443,492\end{array}$ & $\begin{array}{r}37,410 \\
190,515\end{array}$ \\
\hline
\end{tabular}

\begin{tabular}{|c|c|c|c|c|c|c|}
\hline Item & $\begin{array}{l}\text { Minnesota } \\
\text { Willmar } \\
\text { Municipal } \\
\text { Utils Comm } \\
\text { December } 31\end{array}$ & $\begin{array}{l}\text { Mississippi } \\
\text { Aberdeen } \\
\text { City of } \\
\text { June } 30\end{array}$ & $\begin{array}{l}\text { Mississippi } \\
\text { Clarksdale } \\
\text { City of } \\
\text { September } 30\end{array}$ & $\begin{array}{l}\text { Mississippi } \\
\text { Columbus } \\
\text { City of } \\
\text { June } 30\end{array}$ & $\begin{array}{l}\text { Mississippi } \\
\text { Greenwood } \\
\text { Utilities } \\
\text { Comm } \\
\text { September } 30\end{array}$ & $\begin{array}{l}\text { Mississippi } \\
\text { Holly } \\
\text { Springs } \\
\text { City of } \\
\text { June } 30\end{array}$ \\
\hline $\begin{array}{l}\text { Ebetric Plant in servlce } \\
\text { Intangible Plant .................................................. } \\
\text { Production Plant }\end{array}$ & 0 & 0 & 0 & 0 & 0 & 0 \\
\hline 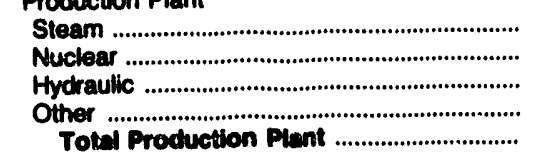 & $\begin{array}{r}6,794 \\
0 \\
0 \\
0 \\
6,794\end{array}$ & $\begin{array}{l}0 \\
0 \\
0 \\
0 \\
0\end{array}$ & $\begin{array}{r}14,443 \\
0 \\
0 \\
0 \\
14,443\end{array}$ & $\begin{array}{l}0 \\
0 \\
0 \\
0 \\
0\end{array}$ & $\begin{array}{r}13,773 \\
0 \\
0 \\
1,163 \\
14,983\end{array}$ & $\begin{array}{l}0 \\
0 \\
0 \\
0 \\
0\end{array}$ \\
\hline 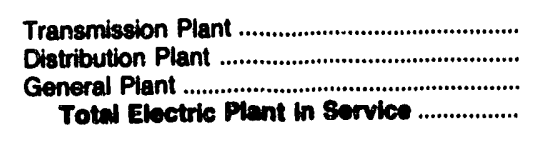 & $\begin{array}{r}6,084 \\
10,794 \\
2,645 \\
26,317\end{array}$ & $\begin{array}{r}0 \\
3,177 \\
804 \\
3,882\end{array}$ & $\begin{array}{r}1,753 \\
8,173 \\
881 \\
25,250\end{array}$ & $\begin{array}{r}10 \\
11,621 \\
969 \\
12,600\end{array}$ & $\begin{array}{r}731 \\
7,845 \\
1,814 \\
25,326\end{array}$ & $\begin{array}{r}0 \\
8,588 \\
1,879 \\
10,467\end{array}$ \\
\hline $\begin{array}{l}\text { Electric Plant Leased to Others ..................... } \\
\text { Construction Work in Progress - Electric ........ } \\
\text { Electric Plant Held for Future Use .................... } \\
\text { Electric Piant Acquisition Adjustments ............ } \\
\text { Tot Electric Ut'lty Plant .......................... }\end{array}$ & $\begin{array}{r}806 \\
2,151 \\
0 \\
0 \\
29,274\end{array}$ & $\begin{array}{r}0 \\
3 \\
0 \\
0 \\
3,985\end{array}$ & $\begin{array}{r}0 \\
24 \\
0 \\
0 \\
25,275\end{array}$ & $\begin{array}{r}0 \\
192 \\
0 \\
37 \\
12,830\end{array}$ & $\begin{array}{r}0 \\
0 \\
0 \\
0 \\
25,326\end{array}$ & $\begin{array}{r}0 \\
285 \\
0 \\
0 \\
10,732\end{array}$ \\
\hline 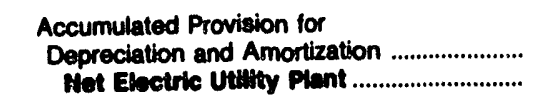 & $\begin{array}{l}13,507 \\
15,787\end{array}$ & $\begin{array}{l}1,667 \\
2,318\end{array}$ & $\begin{array}{r}16,049 \\
9,225\end{array}$ & $\begin{array}{l}6,642 \\
6,188\end{array}$ & $\begin{array}{l}14,133 \\
11,193\end{array}$ & $\begin{array}{l}3,399 \\
7,392\end{array}$ \\
\hline
\end{tabular}

Note: Totals may not equal sum of components becsuse of independent rounding.

Source: Energy Information Administration, Form EIA-412, "Annual Report of Public Electric Utilities." 
Table 39. Electric Utility Plant by Major Publicly Owned Electric Utility Within State at End of Period, 1991 (Continued) (Thousand Dollars)

\begin{tabular}{|c|c|c|c|c|c|c|}
\hline Item & $\begin{array}{l}\text { Mississippi } \\
\text { Louieville } \\
\text { Electrin } \\
\text { System } \\
\text { June } 30\end{array}$ & $\begin{array}{l}\text { Missiscippi } \\
\text { Muninipal } \\
\text { Energy } \\
\text { Agency } \\
\text { of MS } \\
\text { september } 30\end{array}$ & $\begin{array}{l}\text { Mississippi } \\
\text { Now Albany } \\
\text { City of } \\
\text { June } 30\end{array}$ & $\begin{array}{l}\text { Mississippi } \\
\begin{array}{l}\text { Oxford } \\
\text { City of }\end{array} \\
\text { June } 30\end{array}$ & $\begin{array}{l}\text { Mississippi } \\
\text { Starkville } \\
\text { City of } \\
\text { June } 30\end{array}$ & $\begin{array}{l}\text { Mississippi } \\
\text { Tupelo } \\
\text { City of } \\
\text { June } 30\end{array}$ \\
\hline 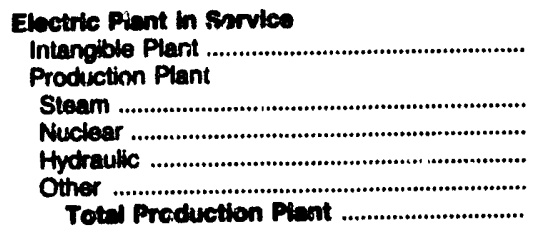 & $\begin{array}{l}\ddot{i} \\
0 \\
0 \\
0\end{array}$ & $\begin{array}{l}0 \\
0 \\
0 \\
0 \\
0\end{array}$ & $\begin{array}{l}0 \\
0 \\
0 \\
0 \\
0\end{array}$ & $\begin{array}{l}0 \\
0 \\
0 \\
0 \\
0\end{array}$ & $\begin{array}{l}0 \\
0 \\
0 \\
0 \\
0\end{array}$ & $\begin{array}{l}0 \\
0 \\
0 \\
0 \\
0\end{array}$ \\
\hline 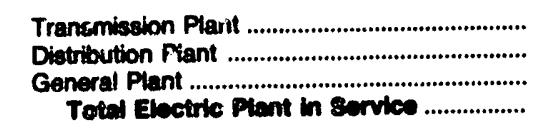 & $\begin{array}{r}262 \\
5,171 \\
897 \\
6,270\end{array}$ & $\begin{array}{r}0 \\
0 \\
220 \\
416\end{array}$ & $\begin{array}{r}0 \\
8,224 \\
887 \\
9,110\end{array}$ & $\begin{array}{r}0 \\
3,859 \\
778 \\
4,737\end{array}$ & $\begin{array}{r}303 \\
7,689 \\
1,302 \\
9,404\end{array}$ & $\begin{array}{r}868 \\
16,202 \\
1,755 \\
18,825\end{array}$ \\
\hline 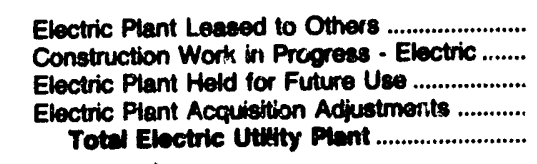 & $\begin{array}{r}0 \\
71 \\
0 \\
0 \\
6,340\end{array}$ & $\begin{array}{r}0 \\
0 \\
0 \\
0 \\
418\end{array}$ & $\begin{array}{r}0 \\
744 \\
0 \\
0 \\
8,855\end{array}$ & $\begin{array}{r}0 \\
306 \\
0 \\
0 \\
5,043\end{array}$ & $\begin{array}{r}0 \\
90 \\
0 \\
0 \\
0,503\end{array}$ & $\begin{array}{r}0 \\
245 \\
0 \\
0 \\
19,070\end{array}$ \\
\hline 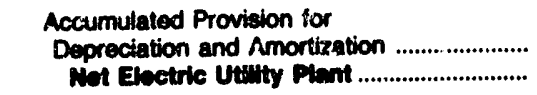 & $\begin{array}{l}1.920 \\
\text { Q,A20 }\end{array}$ & $\begin{array}{l}113 \\
302\end{array}$ & $\begin{array}{l}3,375 \\
6,480\end{array}$ & $\begin{array}{l}1,916 \\
3,128\end{array}$ & $\begin{array}{l}3,375 \\
6,200\end{array}$ & $\begin{array}{r}6,002 \\
13,060\end{array}$ \\
\hline
\end{tabular}

\begin{tabular}{|c|c|c|c|c|c|c|}
\hline Item & $\begin{array}{l}\text { Mosibeippi } \\
\text { West } \\
\text { Point } \\
\text { City of } \\
\text { June } 30\end{array}$ & $\begin{array}{l}\text { Misepuri } \\
\text { Carthege } \\
\text { City of } \\
\text { June } 30\end{array}$ & $\begin{array}{l}\text { Miseouri } \\
\text { Columbia } \\
\text { City of } \\
\text { September } 30\end{array}$ & $\begin{array}{l}\text { Misecuri } \\
\text { Hannibal } \\
\text { City of } \\
\text { June } 30\end{array}$ & $\begin{array}{l}\text { Missouri } \\
\text { Independence } \\
\text { City of } \\
\text { June } 30\end{array}$ & $\begin{array}{l}\text { Missouri } \\
\text { Kennett } \\
\text { City of } \\
\text { June } 30\end{array}$ \\
\hline $\begin{array}{l}\text { Electric Plant in Service } \\
\text { Intangible Plant .................................................... } \\
\text { Production Plant }\end{array}$ & 0 & 0 & 0 & 0 & 0 & 0 \\
\hline 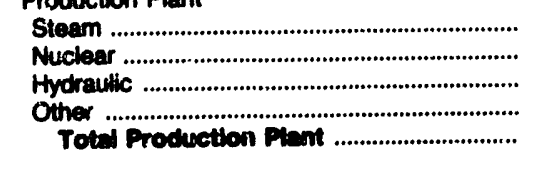 & $\begin{array}{l}0 \\
0 \\
0 \\
0 \\
0\end{array}$ & $\begin{array}{r}0 \\
0 \\
0 \\
8,169 \\
0,160\end{array}$ & $\begin{array}{r}21,124 \\
0 \\
0 \\
1,899 \\
28,023\end{array}$ & $\begin{array}{l}0 \\
0 \\
0 \\
0 \\
0\end{array}$ & $\begin{array}{r}48,45 ? \\
0 \\
0 \\
20,888 \\
69,345\end{array}$ & $\begin{array}{r}0 \\
0 \\
0 \\
7,029 \\
7,029\end{array}$ \\
\hline 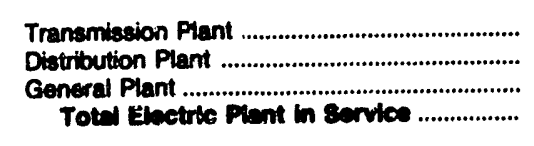 & $\begin{array}{r}76 \\
5,380 \\
770 \\
6,220\end{array}$ & $\begin{array}{r}1,140 \\
7,486 \\
1,285 \\
1,000\end{array}$ & $\begin{array}{r}14,154 \\
26,754 \\
3,785 \\
87,716\end{array}$ & $\begin{array}{l}1,887 \\
5,561 \\
1,504 \\
8,058\end{array}$ & $\begin{array}{r}16,062 \\
44,784 \\
9,623 \\
130,815\end{array}$ & $\begin{array}{r}401 \\
4,076 \\
896 \\
13,302\end{array}$ \\
\hline $\begin{array}{l}\text { Electric Plant Leased to Others ...................... } \\
\text { Construction Work in Progress - Electric ........ } \\
\text { Electric Plant Held for Future Use ................... } \\
\text { Electric Plant Acquisition Adjustments ............ } \\
\text { Totel Electric Utinty Ptant ........................ }\end{array}$ & $\begin{array}{r}0 \\
112 \\
0 \\
0 \\
6,339\end{array}$ & $\begin{array}{r}0 \\
69 \\
0 \\
0 \\
18,140\end{array}$ & $\begin{array}{r}0 \\
2,007 \\
0 \\
0 \\
0,728\end{array}$ & $\begin{array}{r}0 \\
333 \\
0 \\
0 \\
9,305\end{array}$ & $\begin{array}{r}0 \\
7,464 \\
0 \\
1,319 \\
148,597\end{array}$ & $\begin{array}{r}0 \\
0 \\
0 \\
0 \\
13,302\end{array}$ \\
\hline $\begin{array}{l}\text { Accumulated Provision for } \\
\text { Depreciation and Amortization ..................... } \\
\text { Net Elective Wtity Pient............................. }\end{array}$ & $\begin{array}{r}7 \\
6,331\end{array}$ & $\begin{array}{r}12,188 \\
6,81\end{array}$ & $\begin{array}{l}28,330 \\
41,200\end{array}$ & $\begin{array}{l}6,080 \\
3,200\end{array}$ & $\begin{array}{l}74,326 \\
74,271\end{array}$ & $\begin{array}{l}9,220 \\
4,038\end{array}$ \\
\hline
\end{tabular}

Note: Totels may not equal sum of components because of independent rixunding.

Source: Energy Information Administration, Form EIA-412, "Annual Report of Public Electric Utilities." 


\section{Table 39. Electric Utility Plant by Major Publicly Owned Electric Utility Within State at End of Period, 1991 (Continued) (Thousand Dollars)}

\begin{tabular}{|c|c|c|c|c|c|c|}
\hline Item & $\begin{array}{l}\text { Missouri } \\
\text { Kirkwood } \\
\text { City of } \\
\text { March } 31\end{array}$ & $\begin{array}{l}\text { Missouri } \\
\text { Lebanon } \\
\text { City of } \\
\text { October } 31\end{array}$ & $\begin{array}{c}\text { Missouri } \\
\text { Marshall } \\
\text { City of } \\
\text { September } 30\end{array}$ & $\begin{array}{l}\text { Missouri } \\
\text { Monett } \\
\text { City of } \\
\text { March } 31\end{array}$ & $\begin{array}{c}\text { Missouri } \\
\begin{array}{c}\text { Poplar } \\
\text { Bluff } \\
\text { City of }\end{array} \\
\text { December } 31\end{array}$ & $\begin{array}{l}\text { Missouri } \\
\text { Rolla } \\
\text { City of } \\
\text { October } 31\end{array}$ \\
\hline 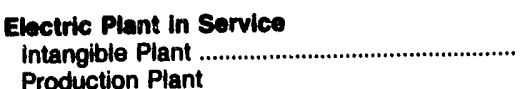 & 0 & 0 & 0 & 0 & 0 & 0 \\
\hline 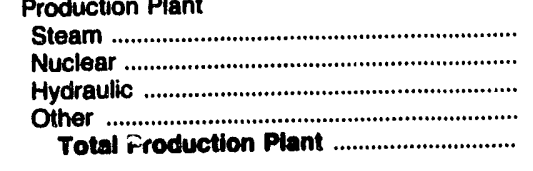 & $\begin{array}{l}0 \\
0 \\
0 \\
0 \\
0\end{array}$ & $\begin{array}{l}0 \\
0 \\
0 \\
0 \\
0\end{array}$ & $\begin{array}{r}12,518 \\
0 \\
0 \\
7,062 \\
18,580\end{array}$ & $\begin{array}{l}0 \\
0 \\
0 \\
0 \\
0\end{array}$ & $\begin{array}{r}0 \\
0 \\
0 \\
3,120 \\
3,120\end{array}$ & $\begin{array}{l}0 \\
0 \\
0 \\
0 \\
0\end{array}$ \\
\hline 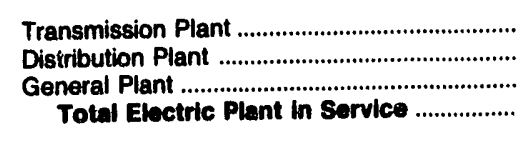 & $\begin{array}{r}0 \\
4,326 \\
806 \\
5,132\end{array}$ & $\begin{array}{l}\mathbf{0} \\
0 \\
0 \\
\mathbf{0}\end{array}$ & $\begin{array}{r}4,843 \\
3,725 \\
1,694 \\
29,842\end{array}$ & $\begin{array}{r}0 \\
3,908 \\
0 \\
3,908\end{array}$ & $\begin{array}{r}0 \\
12,076 \\
1,823 \\
17,020\end{array}$ & $\begin{array}{r}108 \\
5,789 \\
2,092 \\
7,990\end{array}$ \\
\hline 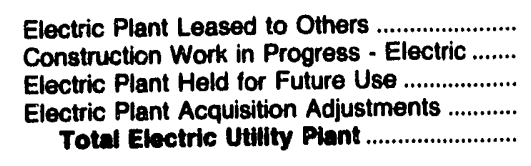 & $\begin{array}{r}0 \\
0 \\
0 \\
0 \\
5,132\end{array}$ & $\begin{array}{l}0 \\
0 \\
0 \\
0 \\
0\end{array}$ & $\begin{array}{r}0 \\
560 \\
0 \\
0 \\
30,402\end{array}$ & $\begin{array}{r}0 \\
0 \\
0 \\
0 \\
3,908\end{array}$ & $\begin{array}{r}0 \\
0 \\
0 \\
0 \\
17,020\end{array}$ & $\begin{array}{r}0 \\
0 \\
0 \\
0 \\
7,990\end{array}$ \\
\hline 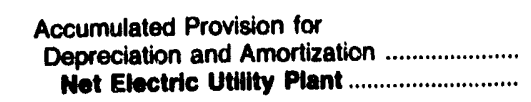 & $\begin{array}{l}2,944 \\
2,188\end{array}$ & $\begin{array}{l}0 \\
0\end{array}$ & $\begin{array}{l}14,226 \\
16,177\end{array}$ & $\begin{array}{l}2,743 \\
1,164\end{array}$ & $\begin{array}{l}7,061 \\
9,959\end{array}$ & $\begin{array}{l}5,128 \\
2,861\end{array}$ \\
\hline
\end{tabular}

\begin{tabular}{|c|c|c|c|c|c|c|}
\hline Item & $\begin{array}{l}\text { Missouri } \\
\text { Sikeston } \\
\text { City of } \\
\text { May } 31\end{array}$ & $\begin{array}{c}\text { Missouri } \\
\text { Springfield } \\
\text { City of } \\
\text { September } 30\end{array}$ & $\begin{array}{c}\text { Nebraska } \\
\text { Central } \\
\text { Nebraska } \\
\text { Pub } \\
\text { P\&I Dist } \\
\text { December } 31\end{array}$ & $\begin{array}{c}\text { Nebraska } \\
\text { Cornhusker } \\
\text { Public } \\
\text { Power Dist } \\
\text { December } 31\end{array}$ & $\begin{array}{c}\text { Nebraska } \\
\text { Dawson } \\
\text { County } \\
\text { Public } \\
\text { Pwr Dist } \\
\text { December } 31\end{array}$ & $\begin{array}{l}\text { Nebraska } \\
\text { Fremont } \\
\text { City of } \\
\text { July } 31\end{array}$ \\
\hline 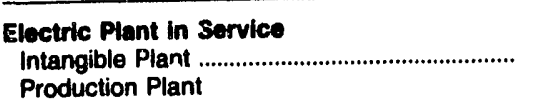 & 0 & 0 & 11,508 & 1 & 3 & 0 \\
\hline $\begin{array}{l}\text { Steam } \\
\text { Hydraul } \\
\text { Other } \\
\text { Tord Production Piant }\end{array}$ & $\begin{array}{r}197,524 \\
0 \\
0 \\
0 \\
197,524\end{array}$ & $\begin{array}{r}144,497 \\
0 \\
0 \\
32,190 \\
176,687\end{array}$ & $\begin{array}{r}15,551 \\
0 \\
95,898 \\
0 \\
111,450\end{array}$ & $\begin{array}{l}0 \\
0 \\
0 \\
0 \\
0\end{array}$ & $\begin{array}{l}0 \\
0 \\
0 \\
0 \\
0\end{array}$ & $\begin{array}{r}47,865 \\
0 \\
0 \\
0 \\
47,865\end{array}$ \\
\hline 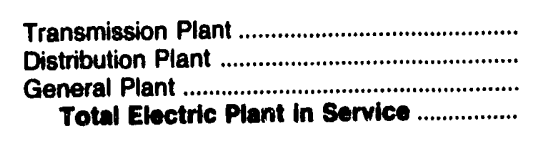 & $\begin{array}{r}4,594 \\
12,323 \\
2,252 \\
216,893\end{array}$ & $\begin{array}{r}46,439 \\
98,510 \\
7,469 \\
329,105\end{array}$ & $\begin{array}{r}5,732 \\
0 \\
6,407 \\
135,097\end{array}$ & $\begin{array}{r}2,465 \\
22,674 \\
2,883 \\
28,023\end{array}$ & $\begin{array}{r}3,959 \\
32,726 \\
4,495 \\
41,183\end{array}$ & $\begin{array}{r}288 \\
11,723 \\
2,121 \\
61,998\end{array}$ \\
\hline 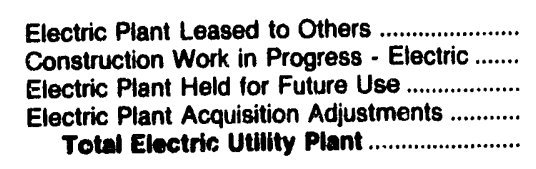 & $\begin{array}{r}0 \\
602 \\
0 \\
0 \\
217,295\end{array}$ & $\begin{array}{r}0 \\
15,220 \\
0 \\
0 \\
344,325\end{array}$ & $\begin{array}{r}0 \\
1,024 \\
0 \\
0 \\
136,121\end{array}$ & $\begin{array}{r}0 \\
201 \\
0 \\
0 \\
28,224\end{array}$ & $\begin{array}{r}4 \\
114 \\
1 \\
0 \\
41,301\end{array}$ & $\begin{array}{r}0 \\
632 \\
0 \\
0 \\
62,630\end{array}$ \\
\hline 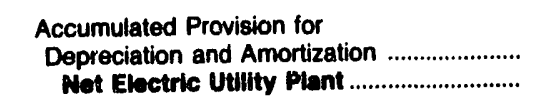 & $\begin{array}{r}55,765 \\
161,530\end{array}$ & $\begin{array}{l}108,582 \\
235,743\end{array}$ & $\begin{array}{l}48,568 \\
87,553\end{array}$ & $\begin{array}{r}9,006 \\
19,218\end{array}$ & $\begin{array}{r}18,199 \\
23,102\end{array}$ & $\begin{array}{l}41,004 \\
21,626\end{array}$ \\
\hline
\end{tabular}

Note: Totals may not equal sum of components because of independent rounding.

Source: Energy Information Administration, Form ElA-412, "Annual Report of Public Electric Utilities." 
Table 39. Electric Utility Plant by Major Publicly Owned Electric Utility Within State at End of Period, 1991 (Continued) (Thousand Dollars)

\begin{tabular}{|c|c|c|c|c|c|c|}
\hline & & & \multirow[b]{2}{*}{$\begin{array}{l}\text { Nebraska } \\
\text { Municipal } \\
\text { Energy } \\
\text { Agency } \\
\text { of NE } \\
\text { March } 31\end{array}$} & \multirow[b]{2}{*}{$\begin{array}{c}\text { Nebraska } \\
\text { Nebraska } \\
\text { Public } \\
\text { Power } \\
\text { District } \\
\text { December } 31\end{array}$} \\
\hline Item & $\begin{array}{c}\text { Nebraska } \\
\begin{array}{c}\text { Grand Island } \\
\text { City of }\end{array} \\
\text { July } 31\end{array}$ & $\begin{array}{c}\text { Nebraska } \\
\text { Hastings } \\
\text { Clty of } \\
\text { December } 31\end{array}$ & $\begin{array}{l}\text { Nobraska } \\
\text { Lincoln } \\
\text { Electric } \\
\text { System } \\
\text { Decamber } 31\end{array}$ & $\begin{array}{c}\text { Nebraska } \\
\text { Loup } \\
\text { River } \\
\text { Public } \\
\text { Power Dist } \\
\text { December } 31\end{array}$ & & \\
\hline 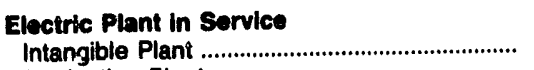 & 3,058 & 0 & 8,535 & 2,397 & 28,660 & 1,452 \\
\hline 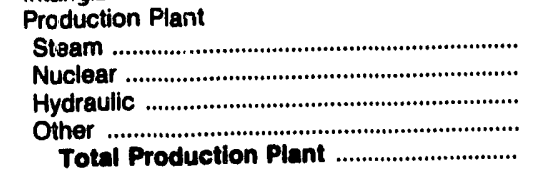 & $\begin{array}{r}116,321 \\
0 \\
0 \\
0 \\
116,321\end{array}$ & $\begin{array}{r}74,592 \\
0 \\
0 \\
2,454 \\
\mathbf{7 7 , 0 4 7}\end{array}$ & $\begin{array}{r}138,039 \\
0 \\
0 \\
9,877 \\
147,916\end{array}$ & $\begin{array}{r}0 \\
0 \\
8,586 \\
0 \\
8,586\end{array}$ & $\begin{array}{l}0 \\
0 \\
0 \\
0 \\
0\end{array}$ & $\begin{array}{r}747,246 \\
332,932 \\
15,508 \\
15,108 \\
1,110,795\end{array}$ \\
\hline 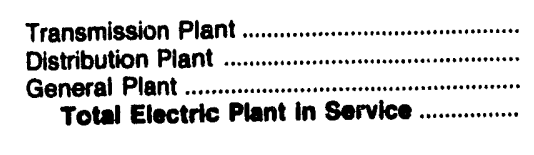 & $\begin{array}{r}9,251 \\
23,285 \\
2,111 \\
154,025\end{array}$ & $\begin{array}{r}6,343 \\
12,065 \\
1,625 \\
97,080\end{array}$ & $\begin{array}{r}81,026 \\
133,492 \\
22,722 \\
393,691\end{array}$ & $\begin{array}{r}8,609 \\
18,026 \\
5,633 \\
43,251\end{array}$ & $\begin{array}{r}0 \\
0 \\
0 \\
28,680\end{array}$ & $\begin{array}{r}446,307 \\
88,720 \\
94,275 \\
1,741,548\end{array}$ \\
\hline 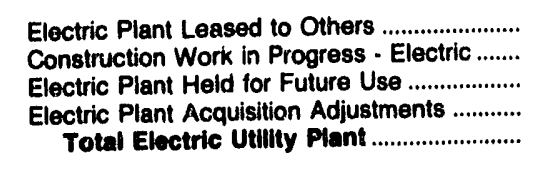 & $\begin{array}{r}0 \\
116 \\
0 \\
2,167 \\
156,308\end{array}$ & $\begin{array}{r}0 \\
748 \\
0 \\
0 \\
97,827\end{array}$ & $\begin{array}{r}0 \\
19,810 \\
0 \\
4,829 \\
418,331\end{array}$ & $\begin{array}{r}0 \\
3,451 \\
32 \\
407 \\
47,140\end{array}$ & $\begin{array}{r}0 \\
0 \\
0 \\
0 \\
28,680\end{array}$ & $\begin{array}{r}0 \\
154,475 \\
0 \\
0 \\
1,886,023\end{array}$ \\
\hline 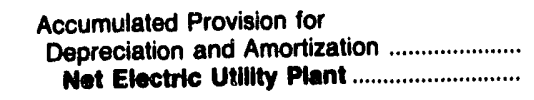 & $\begin{array}{r}53,060 \\
103,248\end{array}$ & $\begin{array}{l}30,314 \\
67,513\end{array}$ & $\begin{array}{l}107,971 \\
310,360\end{array}$ & $\begin{array}{l}22,393 \\
24,747\end{array}$ & $\begin{array}{r}1,384 \\
27,276\end{array}$ & $\begin{array}{r}637,960 \\
1,258,063\end{array}$ \\
\hline
\end{tabular}

\begin{tabular}{|c|c|c|c|c|c|c|}
\hline Item & $\begin{array}{c}\text { Nebraska } \\
\text { Norris } \\
\text { Public } \\
\text { Power } \\
\text { District } \\
\text { December } 31\end{array}$ & $\begin{array}{l}\text { Nebraska } \\
\text { North } \\
\text { Platte } \\
\text { City of } \\
\\
\text { July } 31\end{array}$ & $\begin{array}{c}\text { Nebraska } \\
\text { Omaha Public } \\
\text { Power } \\
\text { District } \\
\text { December } 31\end{array}$ & $\begin{array}{l}\text { Nebraska } \\
\text { Southern } \\
\text { Nebraska Rural } \\
\text { P P D } \\
\text { December } 31\end{array}$ & $\begin{array}{c}\text { Nevada } \\
\text { Colorado } \\
\text { River } \\
\text { Comm } \\
\text { of Nevada } \\
\text { June } 30\end{array}$ & $\begin{array}{l}\text { New Jersey } \\
\text { Vineland } \\
\text { City of } \\
\text { December } 31\end{array}$ \\
\hline $\begin{array}{l}\text { Electric Plant in Service } \\
\text { Intangible Plant ................................................. } \\
\text { Production Plant }\end{array}$ & 2 & 0 & 0 & 0 & 0 & 0 \\
\hline $\begin{array}{l}\text { Steam } \\
\text { Hyclear } \\
\text { Other } \\
\text { Totel Production Plant }\end{array}$ & $\begin{array}{l}0 \\
0 \\
0 \\
0 \\
0\end{array}$ & $\begin{array}{l}0 \\
0 \\
0 \\
0 \\
0\end{array}$ & $\begin{array}{r}598,381 \\
365,225 \\
0 \\
20,968 \\
884,574\end{array}$ & $\begin{array}{l}0 \\
0 \\
0 \\
0 \\
0\end{array}$ & $\begin{array}{l}0 \\
0 \\
0 \\
0 \\
0\end{array}$ & $\begin{array}{r}28,299 \\
0 \\
0 \\
3,804 \\
32,103\end{array}$ \\
\hline 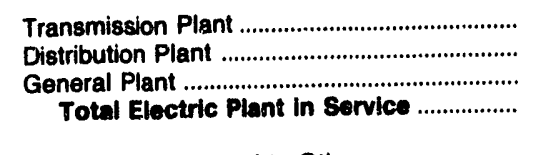 & $\begin{array}{r}6,989 \\
41,122 \\
6,212 \\
54,326\end{array}$ & $\begin{array}{r}554 \\
8,142 \\
2,502 \\
11,199\end{array}$ & $\begin{array}{r}135,757 \\
466,526 \\
380,080 \\
1,966,937\end{array}$ & $\begin{array}{r}3,115 \\
59,066 \\
4,809 \\
68,990\end{array}$ & $\begin{array}{l}0 \\
0 \\
0 \\
\mathbf{0}\end{array}$ & $\begin{array}{r}1,469 \\
20,600 \\
2,227 \\
56,400\end{array}$ \\
\hline 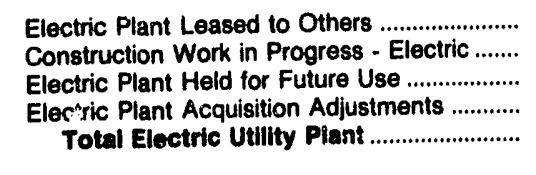 & $\begin{array}{r}0 \\
128 \\
0 \\
459 \\
54,912\end{array}$ & $\begin{array}{r}0 \\
427 \\
0 \\
0 \\
11,626\end{array}$ & $\begin{array}{r}0 \\
95,583 \\
0 \\
0 \\
2,062,520\end{array}$ & $\begin{array}{r}0 \\
0 \\
0 \\
0 \\
66,990\end{array}$ & $\begin{array}{l}0 \\
0 \\
0 \\
0 \\
0\end{array}$ & $\begin{array}{r}0 \\
7,193 \\
0 \\
0 \\
63,583\end{array}$ \\
\hline 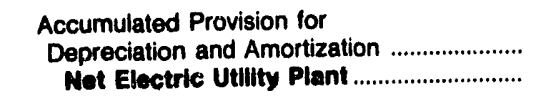 & $\begin{array}{l}16,362 \\
39,550\end{array}$ & $\begin{array}{l}7,240 \\
4,385\end{array}$ & $\begin{array}{r}686,355 \\
1,376,165\end{array}$ & $\begin{array}{l}27,935 \\
39,055\end{array}$ & $\begin{array}{l}0 \\
0\end{array}$ & $\begin{array}{l}29,605 \\
33,888\end{array}$ \\
\hline
\end{tabular}

Note: Totals may not equal sum of components because of independent rounding.

Source: Energy Information Administration, Form EIA-412. "Annual Peport of Public Electric Utilities." 
Table 39. Electric Utility Plant by Major Publicly Owned Electric Utility Within State at End of Period, 1991 (Continued) (Thousand Dollars)

\begin{tabular}{|c|c|c|c|c|c|c|}
\hline Item & $\begin{array}{c}\text { New Mexico } \\
\text { Farmington } \\
\text { City of } \\
\text { June } 30\end{array}$ & $\begin{array}{l}\text { New Mexico } \\
\text { Gallup } \\
\text { City of } \\
\text { June } 30\end{array}$ & $\begin{array}{l}\text { New Mexico } \\
\text { Los Alamos } \\
\text { County } \\
\text { June } 30\end{array}$ & $\begin{array}{c}\text { New York } \\
\text { Fairport } \\
\text { Village of } \\
\text { May } 31\end{array}$ & $\begin{array}{c}\text { New York } \\
\text { Freeport } \\
\begin{array}{c}\text { Village of } \\
\text { Inc }\end{array} \\
\text { February } 28\end{array}$ & $\begin{array}{c}\text { New York } \\
\text { Jamestown } \\
\text { City of } \\
\text { December } 31\end{array}$ \\
\hline 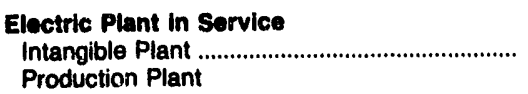 & 5,784 & 0 & 22 & 0 & 0 & 0 \\
\hline 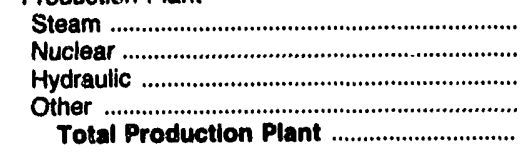 & $\begin{array}{r}72,225 \\
0 \\
16,367 \\
0 \\
88,592\end{array}$ & $\begin{array}{l}0 \\
0 \\
0 \\
0 \\
0\end{array}$ & $\begin{array}{r}41,737 \\
0 \\
51,120 \\
0 \\
92,857\end{array}$ & $\begin{array}{l}0 \\
0 \\
0 \\
0 \\
0\end{array}$ & $\begin{array}{r}0 \\
0 \\
0 \\
14,129 \\
14,129\end{array}$ & $\begin{array}{r}37,318 \\
0 \\
0 \\
0 \\
37,318\end{array}$ \\
\hline 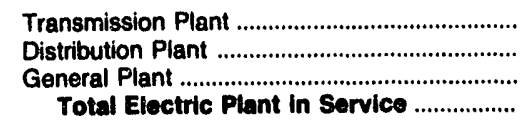 & $\begin{array}{r}14,764 \\
47,142 \\
5,937 \\
162,219\end{array}$ & $\begin{array}{r}0 \\
9,211 \\
1,124 \\
10,335\end{array}$ & $\begin{array}{r}334 \\
7,096 \\
1,907 \\
102,217\end{array}$ & $\begin{array}{r}3,794 \\
9,998 \\
1,181 \\
14,973\end{array}$ & $\begin{array}{r}1,676 \\
10,665 \\
1,223 \\
27,693\end{array}$ & $\begin{array}{r}7,711 \\
19,528 \\
3,666 \\
68,223\end{array}$ \\
\hline 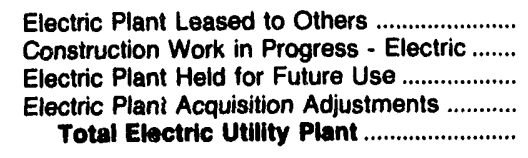 & $\begin{array}{r}0 \\
2,561 \\
0 \\
0 \\
164,780\end{array}$ & $\begin{array}{r}0 \\
0 \\
0 \\
0 \\
10,335\end{array}$ & $\begin{array}{r}0 \\
368 \\
0 \\
6,864 \\
109,449\end{array}$ & $\begin{array}{r}0 \\
163 \\
0 \\
0 \\
15,138\end{array}$ & $\begin{array}{r}0 \\
1,354 \\
13 \\
0 \\
29,059\end{array}$ & $\begin{array}{r}0 \\
7,364 \\
0 \\
0 \\
75,586\end{array}$ \\
\hline 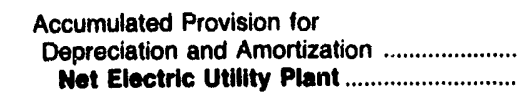 & $\begin{array}{r}45,589 \\
119,191\end{array}$ & $\begin{array}{l}4,994 \\
5,341\end{array}$ & $\begin{array}{l}16,390 \\
93,059\end{array}$ & $\begin{array}{l}6,573 \\
8,563\end{array}$ & $\begin{array}{l}16,104 \\
12,956\end{array}$ & $\begin{array}{l}23,493 \\
52,093\end{array}$ \\
\hline
\end{tabular}

\begin{tabular}{|c|c|c|c|c|c|c|}
\hline Item & $\begin{array}{l}\text { New York } \\
\text { Plattsburgh } \\
\text { City of } \\
\text { December } 31\end{array}$ & $\begin{array}{c}\text { New York } \\
\text { Power } \\
\text { Authority } \\
\text { of State of NY } \\
\text { December } 31\end{array}$ & $\begin{array}{l}\text { New York } \\
\text { izockville } \\
\text { Centre } \\
\text { Village of } \\
\text { May } 31\end{array}$ & $\begin{array}{l}\text { North Carolina } \\
\text { Albemarle } \\
\text { City of } \\
\text { June } 30\end{array}$ & $\begin{array}{l}\text { North Carolina } \\
\text { Concord } \\
\text { City of } \\
\text { June } 30\end{array}$ & $\begin{array}{l}\text { North Carolina } \\
\text { Elizabeth } \\
\text { City City of } \\
\text { June } 30\end{array}$ \\
\hline 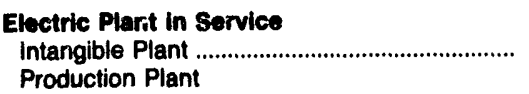 & 4 & 0 & 0 & 0 & 0 & 0 \\
\hline 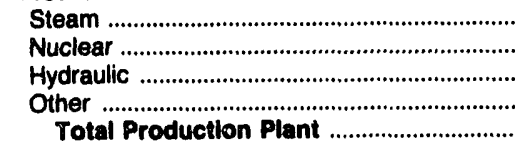 & $\begin{array}{l}0 \\
0 \\
0 \\
0 \\
0\end{array}$ & $\begin{array}{r}426,435 \\
1,582,273 \\
1,240,526 \\
0 \\
3,249,234\end{array}$ & $\begin{array}{r}0 \\
0 \\
0 \\
7,244 \\
7,244\end{array}$ & $\begin{array}{l}0 \\
0 \\
0 \\
0 \\
0\end{array}$ & $\begin{array}{l}0 \\
0 \\
0 \\
0 \\
0\end{array}$ & $\begin{array}{l}0 \\
0 \\
0 \\
0 \\
0\end{array}$ \\
\hline 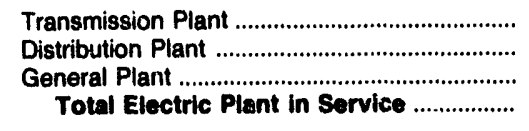 & $\begin{array}{r}7,930 \\
14,557 \\
3,012 \\
25,503\end{array}$ & $\begin{array}{r}1,456,889 \\
0 \\
207,115 \\
4,813,238\end{array}$ & $\begin{array}{r}1,265 \\
10,980 \\
1,084 \\
20,572\end{array}$ & $\begin{array}{r}0 \\
0 \\
16,805 \\
16,805\end{array}$ & $\begin{array}{r}0 \\
0 \\
25,371 \\
25,371\end{array}$ & $\begin{array}{r}0 \\
14,069 \\
4,557 \\
18,626\end{array}$ \\
\hline 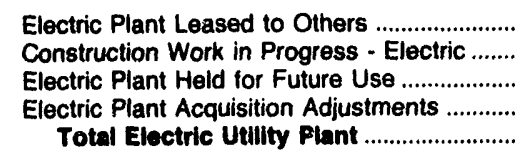 & $\begin{array}{r}0 \\
2,470 \\
0 \\
0 \\
27,973\end{array}$ & $\begin{array}{r}0 \\
231,176 \\
0 \\
0 \\
5,144,414\end{array}$ & $\begin{array}{r}0 \\
1,258 \\
0 \\
0 \\
21,831\end{array}$ & $\begin{array}{r}0 \\
0 \\
0 \\
0 \\
16,805\end{array}$ & $\begin{array}{r}0 \\
0 \\
0 \\
0 \\
25,371\end{array}$ & $\begin{array}{r}0 \\
1,468 \\
0 \\
0 \\
20,094\end{array}$ \\
\hline 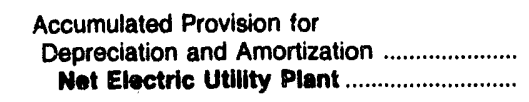 & $\begin{array}{r}8,965 \\
19,008\end{array}$ & $\begin{array}{l}1,362,617 \\
3,781,797\end{array}$ & $\begin{array}{r}12,463 \\
9,367\end{array}$ & $\begin{array}{l}8,497 \\
8,308\end{array}$ & $\begin{array}{r}15,903 \\
9,463\end{array}$ & $\begin{array}{r}5,591 \\
14,503\end{array}$ \\
\hline
\end{tabular}

Note: Totals may not equal sum of components because of independent rounding.

Source: Energy Information Administration, Form EIA-412, "Annual Report of Public Electric Utilities." 
Table 39. Electric Utility Plant by Major Publicly Owned Electric Utility Within State at End of Period, 1991 (Continued) (Thousand Dollars)

\begin{tabular}{|c|c|c|c|c|c|c|}
\hline Item & $\begin{array}{l}\text { North Carolina } \\
\text { Fayetteville } \\
\text { Public } \\
\text { Works Comm } \\
\\
\text { June } 30\end{array}$ & $\begin{array}{l}\text { North Carolina } \\
\text { Gastonia } \\
\text { City of } \\
\text { June } 30\end{array}$ & $\begin{array}{l}\text { North Carolina } \\
\text { Greenville } \\
\text { Utilities } \\
\text { Comm } \\
\text { June } 30\end{array}$ & $\begin{array}{l}\text { North Carolina } \\
\text { High } \\
\text { Point } \\
\text { Town } \\
\text { of } \\
\text { June } 30\end{array}$ & $\begin{array}{l}\text { North Carolina } \\
\text { Kinston } \\
\text { City of } \\
\text { June } 30\end{array}$ & $\begin{array}{l}\text { North Carolina } \\
\begin{array}{c}\text { Lexington } \\
\text { City of }\end{array} \\
\text { June } 30\end{array}$ \\
\hline 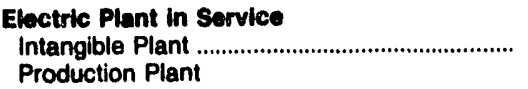 & 792 & 0 & 0 & 0 & 0 & 0 \\
\hline 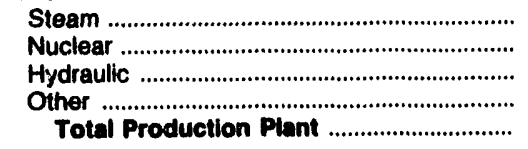 & $\begin{array}{r}38,121 \\
0 \\
0 \\
38,578 \\
76,899\end{array}$ & $\begin{array}{l}0 \\
0 \\
0 \\
0 \\
0\end{array}$ & $\begin{array}{l}0 \\
0 \\
0 \\
0 \\
0\end{array}$ & $\begin{array}{l}0 \\
0 \\
0 \\
0 \\
0\end{array}$ & $\begin{array}{l}0 \\
0 \\
0 \\
0 \\
0\end{array}$ & $\begin{array}{l}0 \\
0 \\
0 \\
0 \\
0\end{array}$ \\
\hline 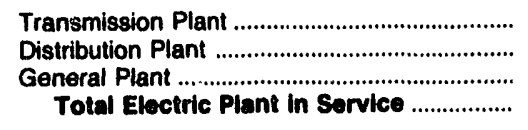 & $\begin{array}{r}10,130 \\
66,182 \\
7,584 \\
161,387\end{array}$ & $\begin{array}{r}30,992 \\
0 \\
0 \\
30,992\end{array}$ & $\begin{array}{r}0 \\
64,737 \\
8,281 \\
73,018\end{array}$ & $\begin{array}{r}0 \\
0 \\
49,604 \\
49,604\end{array}$ & $\begin{array}{r}6,887 \\
6,400 \\
0 \\
15,286\end{array}$ & $\begin{array}{r}3,486 \\
17,446 \\
2,466 \\
23,399\end{array}$ \\
\hline 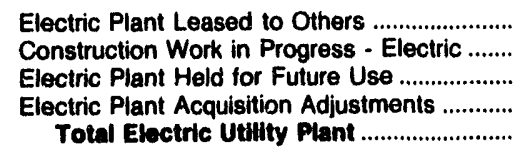 & $\begin{array}{r}0 \\
8,259 \\
0 \\
0 \\
169,648\end{array}$ & $\begin{array}{r}0 \\
918 \\
0 \\
0 \\
31,910\end{array}$ & $\begin{array}{r}0 \\
0 \\
0 \\
0 \\
73,018\end{array}$ & $\begin{array}{r}0 \\
0 \\
0 \\
0 \\
49,604\end{array}$ & $\begin{array}{r}0 \\
0 \\
0 \\
0 \\
15,286\end{array}$ & $\begin{array}{r}0 \\
1,199 \\
0 \\
0 \\
24,588\end{array}$ \\
\hline 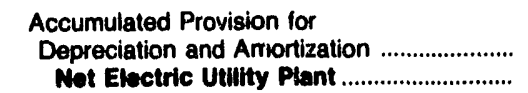 & $\begin{array}{r}47,775 \\
121,872\end{array}$ & $\begin{array}{l}16,374 \\
15,536\end{array}$ & $\begin{array}{l}32,632 \\
40,386\end{array}$ & $\begin{array}{l}19,512 \\
30,092\end{array}$ & $\begin{array}{l}6,272 \\
9,014\end{array}$ & $\begin{array}{r}7,922 \\
16,676\end{array}$ \\
\hline
\end{tabular}

\begin{tabular}{|c|c|c|c|c|c|c|}
\hline Item & $\begin{array}{l}\text { North Carolina } \\
\text { Lumberton } \\
\text { City of } \\
\text { June } 30\end{array}$ & $\begin{array}{l}\text { North Carolina } \\
\text { Monroe } \\
\text { City of } \\
\text { June } 30\end{array}$ & $\begin{array}{l}\text { North Carolina } \\
\text { Morganton } \\
\text { City of } \\
\text { June } 30\end{array}$ & $\begin{array}{l}\text { North Carolina } \\
\text { Murphy } \\
\text { City of } \\
\text { June } 30\end{array}$ & $\begin{array}{l}\text { North Carolina } \\
\text { New Bern } \\
\text { City of } \\
\text { June } 30\end{array}$ & $\begin{array}{c}\text { North Carolina } \\
\text { New River } \\
\text { Light } \\
\& \\
\text { Power Co } \\
\text { December } 31\end{array}$ \\
\hline 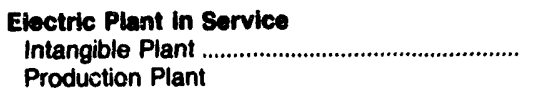 & 0 & 0 & 0 & 0 & 0 & 0 \\
\hline 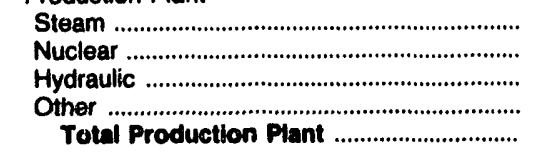 & $\begin{array}{l}0 \\
0 \\
0 \\
0 \\
0\end{array}$ & $\begin{array}{l}0 \\
0 \\
0 \\
0 \\
0\end{array}$ & $\begin{array}{l}0 \\
0 \\
0 \\
0 \\
0\end{array}$ & $\begin{array}{l}0 \\
0 \\
0 \\
0 \\
0\end{array}$ & $\begin{array}{l}0 \\
0 \\
0 \\
0 \\
0\end{array}$ & $\begin{array}{l}0 \\
0 \\
0 \\
0 \\
0\end{array}$ \\
\hline 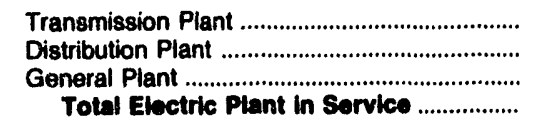 & $\begin{array}{r}0 \\
8,212 \\
1,867 \\
10,078\end{array}$ & $\begin{array}{r}0 \\
16,556 \\
0 \\
18,556\end{array}$ & $\begin{array}{r}0 \\
9,242 \\
0 \\
9,242\end{array}$ & $\begin{array}{r}0 \\
4,830 \\
604 \\
5,434\end{array}$ & $\begin{array}{r}0 \\
0 \\
16,721 \\
16,721\end{array}$ & $\begin{array}{r}0 \\
7,736 \\
1,528 \\
8,264\end{array}$ \\
\hline 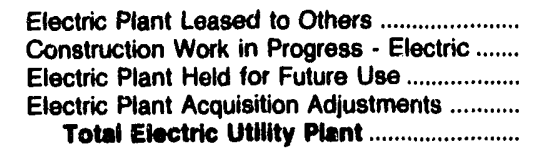 & $\begin{array}{r}0 \\
8 \\
0 \\
0 \\
10,086\end{array}$ & $\begin{array}{r}0 \\
0 \\
0 \\
0 \\
16,556\end{array}$ & $\begin{array}{r}0 \\
0 \\
0 \\
0 \\
9,242\end{array}$ & $\begin{array}{r}0 \\
587 \\
0 \\
0 \\
6,021\end{array}$ & $\begin{array}{r}0 \\
0 \\
0 \\
0 \\
16,721\end{array}$ & $\begin{array}{r}0 \\
0 \\
0 \\
0 \\
8,284\end{array}$ \\
\hline 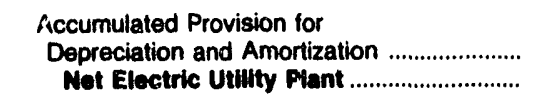 & $\begin{array}{l}4,867 \\
5,218\end{array}$ & $\begin{array}{r}5,412 \\
11,143\end{array}$ & $\begin{array}{l}3,912 \\
5,330\end{array}$ & $\begin{array}{l}1,601 \\
4,419\end{array}$ & $\begin{array}{l}6,887 \\
9,835\end{array}$ & $\begin{array}{l}2,336 \\
6,927\end{array}$ \\
\hline
\end{tabular}

Note: Totals may not equal sum of components because of independent rounding.

Source: Energy Information Administration, Form EIA-412, "Annual Report of Public Electric Utilities." 
Table 39. Electric Utility Plant by Major Publicly Owned Electric Utility Within State at End of Period, 1991 (Continued) (Thousand Dollars)

\begin{tabular}{|c|c|c|c|c|c|c|}
\hline Item & $\begin{array}{c}\text { North Carolina } \\
\text { North } \\
\text { Carolina } \\
\text { Eastern M P A } \\
\text { December } 31\end{array}$ & $\begin{array}{c}\text { North Carolina } \\
\text { North } \\
\text { Carolina } \\
\text { Mun } \\
\text { Power Agny } \\
\text { December } 31\end{array}$ & $\begin{array}{l}\text { North Carolina } \\
\text { Rocky Mount } \\
\text { City of } \\
\text { June } 30\end{array}$ & $\begin{array}{l}\text { North Carolina } \\
\text { Shelby } \\
\text { City of } \\
\text { June } 30\end{array}$ & $\begin{array}{c}\text { North Carolina } \\
\text { Statesville } \\
\text { City of } \\
\text { June } 30\end{array}$ & $\begin{array}{c}\text { North Carolina } \\
\text { Tarboro } \\
\text { Town of } \\
\text { June } 30\end{array}$ \\
\hline 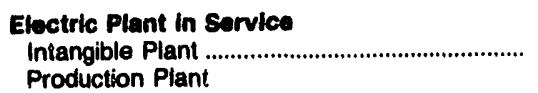 & 0 & 0 & 0 & 0 & 0 & 1 \\
\hline 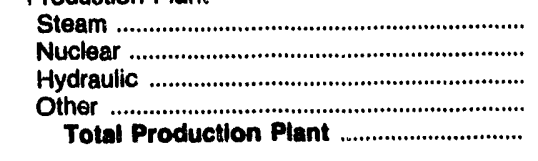 & $\begin{array}{r}126,999 \\
1,095,349 \\
0 \\
0 \\
1,222,348\end{array}$ & $\begin{array}{r}0 \\
1,640,217 \\
0 \\
0 \\
1,640,217\end{array}$ & $\begin{array}{l}0 \\
0 \\
0 \\
0 \\
0\end{array}$ & $\begin{array}{l}0 \\
0 \\
0 \\
0 \\
0\end{array}$ & $\begin{array}{l}0 \\
0 \\
0 \\
0 \\
0\end{array}$ & $\begin{array}{l}0 \\
0 \\
0 \\
0 \\
0\end{array}$ \\
\hline 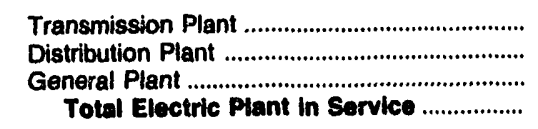 & $\begin{array}{r}0 \\
0 \\
0 \\
1,232,348\end{array}$ & $\begin{array}{r}0 \\
0 \\
0 \\
1,640,217\end{array}$ & $\begin{array}{r}0 \\
30,255 \\
0 \\
30,255\end{array}$ & $\begin{array}{r}0 \\
5,789 \\
0 \\
5,789\end{array}$ & $\begin{array}{r}0 \\
14,179 \\
0 \\
14,179\end{array}$ & $\begin{array}{r}0 \\
13,634 \\
0 \\
13,635\end{array}$ \\
\hline 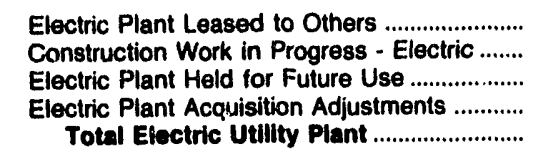 & $\begin{array}{r}0 \\
14,164 \\
60,884 \\
94,624 \\
1,392,020\end{array}$ & $\begin{array}{r}0 \\
5,895 \\
0 \\
0 \\
1,646,112\end{array}$ & $\begin{array}{r}0 \\
0 \\
0 \\
0 \\
30,255\end{array}$ & $\begin{array}{r}0 \\
0 \\
0 \\
0 \\
5,789\end{array}$ & $\begin{array}{r}0 \\
0 \\
0 \\
0 \\
14,179\end{array}$ & $\begin{array}{r}0 \\
0 \\
0 \\
0 \\
13,635\end{array}$ \\
\hline 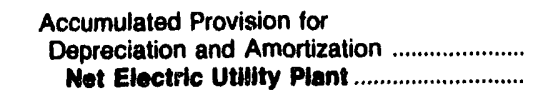 & $\begin{array}{r}270,634 \\
1,12 \gamma, 386\end{array}$ & $\begin{array}{r}401,067 \\
1,245,045\end{array}$ & $\begin{array}{l}11,127 \\
19,127\end{array}$ & $\begin{array}{l}3,865 \\
1,923\end{array}$ & $\begin{array}{l}5,447 \\
8,732\end{array}$ & $\begin{array}{l}4,677 \\
8,958\end{array}$ \\
\hline
\end{tabular}

\begin{tabular}{|c|c|c|c|c|c|c|}
\hline Item & $\begin{array}{l}\text { North Carolina } \\
\text { Washington } \\
\text { City of } \\
\text { June } 30\end{array}$ & $\begin{array}{l}\text { North Carolina } \\
\text { Wilson } \\
\text { City of } \\
\text { June } 30\end{array}$ & $\begin{array}{c}\text { Ohio } \\
\text { American } \\
\text { Mun } \\
\text { Power } \\
\text { Ohio Inc } \\
\text { December } 31\end{array}$ & $\begin{array}{c}\text { Onio } \\
\text { Bowling } \\
\text { Green } \\
\text { City of } \\
\text { December } 31\end{array}$ & $\begin{array}{c}\text { Ohio } \\
\text { Bryan } \\
\text { City of } \\
\text { December } 31\end{array}$ & $\begin{array}{c}\text { Ohio } \\
\text { Celina } \\
\text { City of } \\
\text { December } 31\end{array}$ \\
\hline 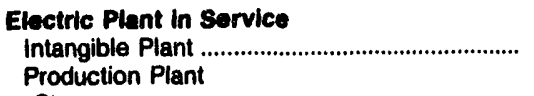 & 0 & 0 & 7,718 & 0 & 0 & 0 \\
\hline 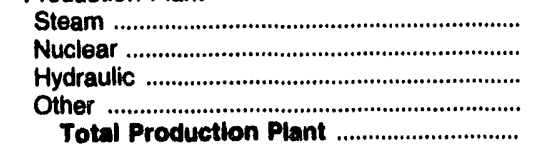 & $\begin{array}{l}0 \\
0 \\
0 \\
0 \\
0\end{array}$ & $\begin{array}{l}0 \\
0 \\
0 \\
0 \\
0\end{array}$ & $\begin{array}{r}53,696 \\
0 \\
0 \\
0 \\
53,698\end{array}$ & $\begin{array}{l}0 \\
0 \\
0 \\
0 \\
0\end{array}$ & $\begin{array}{l}0 \\
0 \\
0 \\
0 \\
0\end{array}$ & $\begin{array}{r}5,882 \\
0 \\
0 \\
0 \\
5,882\end{array}$ \\
\hline 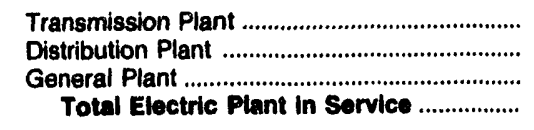 & $\begin{array}{r}20,847 \\
0 \\
2,440 \\
23,286\end{array}$ & $\begin{array}{r}0 \\
40,772 \\
4,378 \\
45,149\end{array}$ & $\begin{array}{r}0 \\
0 \\
4,137 \\
65,550\end{array}$ & $\begin{array}{r}588 \\
8,152 \\
2,967 \\
11,707\end{array}$ & $\begin{array}{r}0 \\
0 \\
15,923 \\
15,823\end{array}$ & $\begin{array}{r}0 \\
10,935 \\
514 \\
17,331\end{array}$ \\
\hline 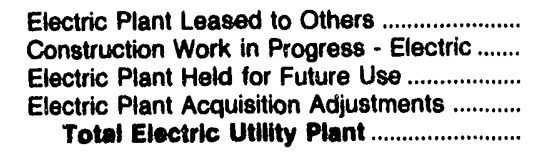 & $\begin{array}{r}0 \\
102 \\
0 \\
0 \\
23,389\end{array}$ & $\begin{array}{r}0 \\
4 \\
0 \\
0 \\
45,153\end{array}$ & $\begin{array}{r}0 \\
1,104 \\
0 \\
0 \\
66,654\end{array}$ & $\begin{array}{r}0 \\
950 \\
0 \\
0 \\
12,657\end{array}$ & $\begin{array}{r}0 \\
0 \\
0 \\
0 \\
15,923\end{array}$ & $\begin{array}{r}0 \\
0 \\
0 \\
0 \\
17,331\end{array}$ \\
\hline 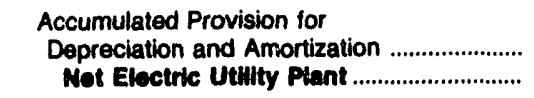 & $\begin{array}{r}9,277 \\
14,112\end{array}$ & $\begin{array}{l}22,044 \\
23,109\end{array}$ & $\begin{array}{r}9,885 \\
56,769\end{array}$ & $\begin{array}{l}7,623 \\
5,034\end{array}$ & $\begin{array}{r}12,607 \\
3,315\end{array}$ & $\begin{array}{r}0 \\
17,331\end{array}$ \\
\hline
\end{tabular}

Note: Totals may not equal sum of components because of independent rounding.

Source: Energy Information Administration, Form ElA-412, "Annual Report of Public Electric Utilities." 
Table 39. Electric Utility Plant by Major Publicly Owned Electric Utility Within State at End of Period, 1991 (Continued) (Thousand Dollars)

\begin{tabular}{|c|c|c|c|c|c|c|}
\hline Item & $\begin{array}{c}\text { Ohio } \\
\text { Cleveland } \\
\text { City of } \\
\text { December } 31\end{array}$ & $\begin{array}{c}\text { Onio } \\
\text { Columbus } \\
\text { City of } \\
\text { December } 31\end{array}$ & $\begin{array}{c}\text { Ohio } \\
\text { Cuyahoga } \\
\text { Falls } \\
\text { City of } \\
\text { December } 31\end{array}$ & $\begin{array}{l}\text { Ohio } \\
\text { Dover } \\
\text { City of } \\
\text { December } 31\end{array}$ & $\begin{array}{c}\text { Onio } \\
\text { Hamilton } \\
\text { City of } \\
\text { December } 31\end{array}$ & $\begin{array}{c}\text { Ohio } \\
\text { Niles } \\
\text { City of } \\
\text { December } 31\end{array}$ \\
\hline 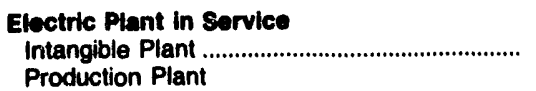 & 0 & 0 & 0 & 0 & 0 & 0 \\
\hline 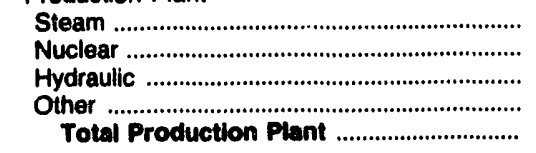 & $\begin{array}{r}37,037 \\
0 \\
0 \\
6,525 \\
43,563\end{array}$ & $\begin{array}{r}11,313 \\
0 \\
0 \\
0 \\
11,313\end{array}$ & $\begin{array}{l}0 \\
0 \\
0 \\
0 \\
0\end{array}$ & $\begin{array}{l}0 \\
0 \\
0 \\
0 \\
0\end{array}$ & $\begin{array}{r}24,679 \\
0 \\
140,434 \\
5,973 \\
171,086\end{array}$ & $\begin{array}{l}0 \\
0 \\
0 \\
0 \\
0\end{array}$ \\
\hline 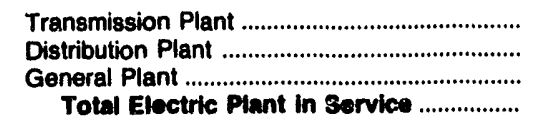 & $\begin{array}{r}21,746 \\
52,956 \\
8,850 \\
127,114\end{array}$ & $\begin{array}{r}143,906 \\
30,434 \\
86,916 \\
272,571\end{array}$ & $\begin{array}{r}702 \\
16,097 \\
1,284 \\
18,083\end{array}$ & $\begin{array}{r}0 \\
0 \\
7,639 \\
7,639\end{array}$ & $\begin{array}{r}24,301 \\
18,674 \\
5,442 \\
219,504\end{array}$ & $\begin{array}{r}0 \\
11,993 \\
0 \\
11,093\end{array}$ \\
\hline 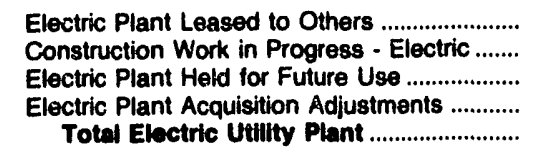 & $\begin{array}{r}0 \\
54,350 \\
0 \\
0 \\
181,464\end{array}$ & $\begin{array}{r}0 \\
0 \\
0 \\
0 \\
272,571\end{array}$ & $\begin{array}{r}0 \\
0 \\
0 \\
0 \\
18,083\end{array}$ & $\begin{array}{r}0 \\
0 \\
0 \\
0 \\
7,639\end{array}$ & $\begin{array}{r}0 \\
0 \\
0 \\
0 \\
219,504\end{array}$ & $\begin{array}{r}0 \\
0 \\
0 \\
0 \\
11,903\end{array}$ \\
\hline 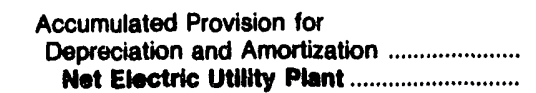 & $\begin{array}{l}83,229 \\
98,235\end{array}$ & $\begin{array}{r}90,113 \\
182,457\end{array}$ & $\begin{array}{l}9,352 \\
8,731\end{array}$ & $\begin{array}{r}0 \\
7,639\end{array}$ & $\begin{array}{r}61,209 \\
158,205\end{array}$ & $\begin{array}{l}6,233 \\
5,760\end{array}$ \\
\hline
\end{tabular}

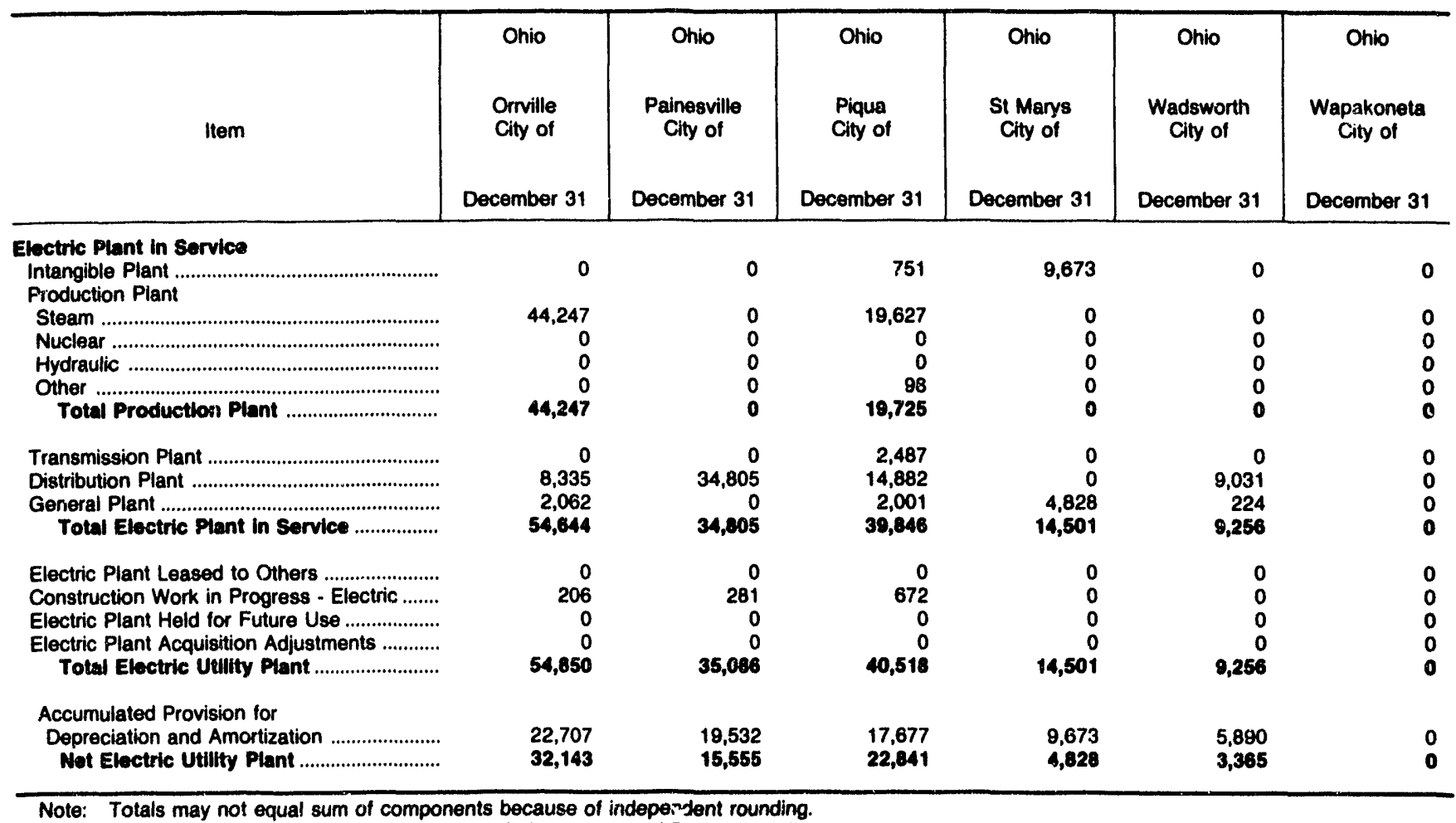

Note: Totals may not equal sum of components because of independent rounding.

Source: Energy Information Administration, Form EIA-412، "Annual Report of Public Electric Utilities." 
Table 39. Electric Utility Plant by Major Publicly Owned Electric Utility Within State at End of Period, 1991 (Continued) (Thousand Dollars)

\begin{tabular}{|c|c|c|c|c|c|c|}
\hline Item & $\begin{array}{c}\text { Ohio } \\
\begin{array}{c}\text { Westerville } \\
\text { City of }\end{array} \\
\text { December } 31\end{array}$ & $\begin{array}{l}\text { Oklahoma } \\
\text { Altus } \\
\text { City of } \\
\text { June } 30\end{array}$ & $\begin{array}{c}\text { Oklahoma } \\
\text { Claremore } \\
\text { City of } \\
\text { June } 30\end{array}$ & $\begin{array}{l}\text { Oklahoma } \\
\text { Edmond } \\
\text { City of } \\
\text { June } 30\end{array}$ & $\begin{array}{c}\text { Oklahoma } \\
\text { Grand River } \\
\text { Dam } \\
\text { Authority } \\
\text { December } 31\end{array}$ & $\begin{array}{c}\text { Oklahoma } \\
\text { Oklahoma } \\
\text { Municipal } \\
\text { Power Auth } \\
\text { December } 31\end{array}$ \\
\hline 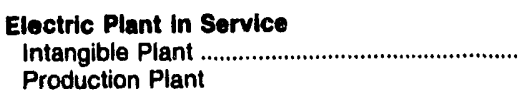 & 0 & 0 & 0 & 0 & 0 & 0 \\
\hline 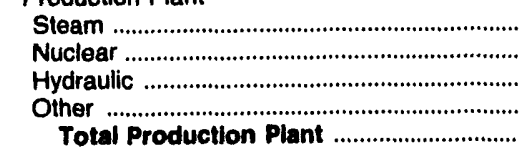 & $\begin{array}{l}0 \\
0 \\
0 \\
0 \\
0\end{array}$ & $\begin{array}{l}0 \\
0 \\
0 \\
0 \\
0\end{array}$ & $\begin{array}{l}0 \\
0 \\
0 \\
0 \\
0\end{array}$ & $\begin{array}{l}0 \\
0 \\
0 \\
0 \\
0\end{array}$ & $\begin{array}{r}607,957 \\
0 \\
68,951 \\
0 \\
676,908\end{array}$ & $\begin{array}{r}111,486 \\
0 \\
0 \\
35,282 \\
146,768\end{array}$ \\
\hline 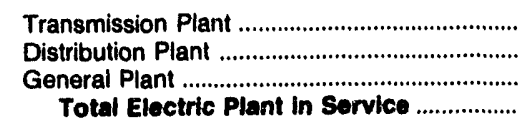 & $\begin{array}{r}0 \\
10,059 \\
0 \\
10,059\end{array}$ & $\begin{array}{r}7,617 \\
0 \\
0 \\
7,617\end{array}$ & $\begin{array}{l}0 \\
0 \\
0 \\
\mathbf{0}\end{array}$ & $\begin{array}{r}0 \\
32,085 \\
0 \\
32,085\end{array}$ & $\begin{array}{r}68,617 \\
0 \\
11,925 \\
757,450\end{array}$ & $\begin{array}{r}3,852 \\
0 \\
2,374 \\
152,994\end{array}$ \\
\hline $\begin{array}{l}\text { Electric Plant Leased to Others ................... } \\
\text { Construction Work in Progress - Electric ....... } \\
\text { Electric Plant Held for Future Use .................. } \\
\text { Electric Plant Acquisition Adjustments ............ } \\
\text { Total Electric Utillty Plant ......................... }\end{array}$ & $\begin{array}{r}0 \\
0 \\
0 \\
0 \\
10,059\end{array}$ & $\begin{array}{r}0 \\
0 \\
0 \\
0 \\
7,617\end{array}$ & $\begin{array}{l}0 \\
0 \\
0 \\
0 \\
0\end{array}$ & $\begin{array}{r}0 \\
0 \\
0 \\
0 \\
32,085\end{array}$ & $\begin{array}{r}0 \\
130,748 \\
14 \\
0 \\
888,212\end{array}$ & $\begin{array}{r}0 \\
600 \\
3,646 \\
0 \\
157,240\end{array}$ \\
\hline 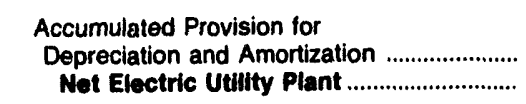 & $\begin{array}{l}4,970 \\
5,089\end{array}$ & $\begin{array}{l}4,061 \\
3,557\end{array}$ & $\begin{array}{l}0 \\
0\end{array}$ & $\begin{array}{l}13,541 \\
18,543\end{array}$ & $\begin{array}{l}226,702 \\
661,510\end{array}$ & $\begin{array}{r}20,749 \\
136,492\end{array}$ \\
\hline
\end{tabular}

\begin{tabular}{|c|c|c|c|c|c|c|}
\hline Item & $\begin{array}{l}\text { Oklahoma } \\
\text { Ponca } \\
\text { City City of } \\
\text { June } 30\end{array}$ & $\begin{array}{l}\text { Oklahoma } \\
\text { Stillwater } \\
\text { Utilities } \\
\text { Authority } \\
\text { June } 30\end{array}$ & $\begin{array}{l}\text { Oregon } \\
\text { Ashland } \\
\text { City of } \\
\text { June } 30\end{array}$ & $\begin{array}{l}\text { Oregon } \\
\text { Central } \\
\text { Lincoln } \\
\text { Peoples } \\
\text { UtI Dt } \\
\text { December } 31\end{array}$ & $\begin{array}{c}\text { Oregon } \\
\text { Clatskanie } \\
\text { Peoples } \\
\text { Util Dist } \\
\text { December } 31\end{array}$ & $\begin{array}{l}\text { Oregon } \\
\text { Columbia } \\
\text { Aiver } \\
\text { Peoples } \\
\text { Ut Dist } \\
\text { December } 31\end{array}$ \\
\hline $\begin{array}{l}\text { Intangible Plant ...................................................... } \\
\text { Production Plant }\end{array}$ & 0 & 0 & 0 & 148 & 7 & 0 \\
\hline Steam & 13,443 & 3,405 & 0 & 0 & 0 & 0 \\
\hline Nuclear & 3,057 & 0 & 0 & 0 & 0 & 0 \\
\hline 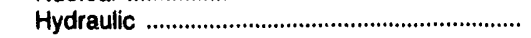 & 0 & 0 & 1,076 & 0 & 0 & 0 \\
\hline Other & 0 & 0 & 0 & 0 & 0 & 0 \\
\hline 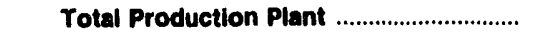 & 16,500 & 3,405 & 1,076 & $\mathbf{0}$ & $\mathbf{0}$ & $\mathbf{0}$ \\
\hline 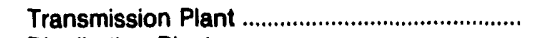 & 1,888 & 1,015 & 0 & $\mathbf{0}$ & 0 & 693 \\
\hline Total Electric Plant in Service .................. & & & & & 5,853 & 13,341 \\
\hline 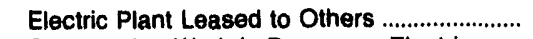 & 0 & 0 & 0 & 0 & 0 & 0 \\
\hline Construction Work in Progress - Electric ........ & 0 & 17 & 0 & 5,349 & 62 & 217 \\
\hline Electric Plant Held for Future Use .................... & 0 & 0 & 0 & 0 & 0 & 0 \\
\hline Electric Plant Acquisition Adjustments ............. & & & $\begin{array}{r}0 \\
7975\end{array}$ & $\begin{array}{r}0 \\
72183\end{array}$ & & $\begin{array}{r}7,874 \\
21,431\end{array}$ \\
\hline 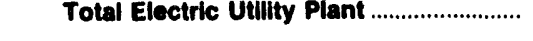 & 33,688 & 24,340 & 7,975 & 72,183 & 5,915 & 21,431 \\
\hline Accumulated Provision for & & & & & & \\
\hline 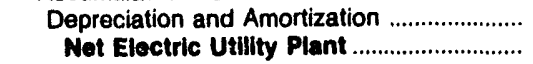 & $\begin{array}{l}12,671 \\
21,017\end{array}$ & $\begin{array}{l}11,275 \\
13,065\end{array}$ & $\begin{array}{r}0 \\
7,975\end{array}$ & $\begin{array}{l}27,925 \\
44,258\end{array}$ & $\begin{array}{l}2,730 \\
3,185\end{array}$ & $\begin{array}{r}3,164 \\
18,267\end{array}$ \\
\hline
\end{tabular}

Note: Totals may not equal sum of components because of independent rounding.

Source: Energy Information Administration, Form ElA-412, "Annual Report of Public Electric Utilities." 
Table 39. Electric Utility Plant by Major Publicly Owned Electric Utility Within State at End of Period, 1991 (Continued) (Thousand Dollars)

\begin{tabular}{|c|c|c|c|c|c|c|}
\hline Item & $\begin{array}{l}\text { Oregon } \\
\text { Emerald } \\
\text { Peoples } \\
\text { Utility Dist } \\
\text { December } 31\end{array}$ & $\begin{array}{l}\text { Oregon } \\
\text { Eugene } \\
\text { City of } \\
\text { December } 31\end{array}$ & $\begin{array}{c}\text { Oregon } \\
\text { Forest Grove } \\
\text { City of } \\
\text { June } 30\end{array}$ & $\begin{array}{c}\text { Oregon } \\
\text { McMinnville } \\
\text { City of } \\
\text { June } 30\end{array}$ & $\begin{array}{c}\text { Oregon } \\
\text { Northern } \\
\text { Wasco County } \\
\text { PU D } \\
\text { December } 31\end{array}$ & $\begin{array}{c}\text { Oregon } \\
\text { Springfield } \\
\text { City of }\end{array}$ \\
\hline 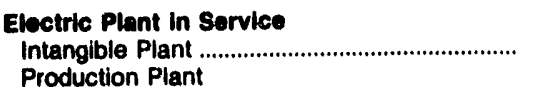 & 158 & 0 & 0 & 0 & 0 & 0 \\
\hline 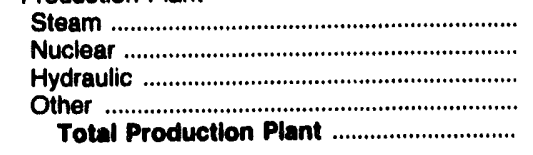 & $\begin{array}{l}0 \\
0 \\
0 \\
0 \\
0\end{array}$ & $\begin{array}{r}13,192 \\
0 \\
42,339 \\
0 \\
55,532\end{array}$ & $\begin{array}{l}0 \\
0 \\
0 \\
0 \\
0\end{array}$ & $\begin{array}{l}0 \\
0 \\
0 \\
0 \\
0\end{array}$ & $\begin{array}{l}0 \\
0 \\
0 \\
0 \\
0\end{array}$ & $\begin{array}{l}0 \\
0 \\
0 \\
0 \\
0\end{array}$ \\
\hline 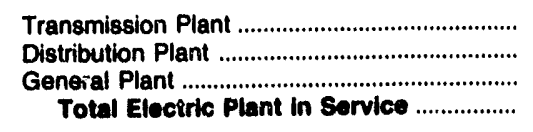 & $\begin{array}{r}881 \\
34,976 \\
8,837 \\
44,853\end{array}$ & $\begin{array}{r}23,003 \\
107,286 \\
39,076 \\
224,896\end{array}$ & $\begin{array}{r}22 \\
8,652 \\
1,399 \\
10,073\end{array}$ & $\begin{array}{r}1,629 \\
14,006 \\
3,448 \\
19,084\end{array}$ & $\begin{array}{r}1,317 \\
11,921 \\
2,014 \\
15,251\end{array}$ & $\begin{array}{r}2,032 \\
27,635 \\
4,276 \\
33,942\end{array}$ \\
\hline 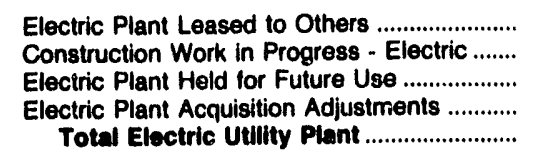 & $\begin{array}{r}0 \\
4,888 \\
0 \\
16,530 \\
68,271\end{array}$ & $\begin{array}{r}0 \\
4,004 \\
500 \\
1,219 \\
230,619\end{array}$ & $\begin{array}{r}0 \\
97 \\
0 \\
0 \\
10,170\end{array}$ & $\begin{array}{r}0 \\
160 \\
0 \\
0 \\
19,243\end{array}$ & $\begin{array}{r}0 \\
14,598 \\
0 \\
1,390 \\
31,239\end{array}$ & $\begin{array}{r}0 \\
442 \\
627 \\
4,114 \\
38,126\end{array}$ \\
\hline 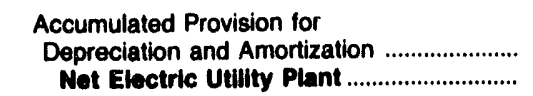 & $\begin{array}{l}20,748 \\
45,523\end{array}$ & $\begin{array}{r}99,429 \\
131,190\end{array}$ & $\begin{array}{l}3,051 \\
7,119\end{array}$ & $\begin{array}{r}4,223 \\
15,020\end{array}$ & $\begin{array}{r}7,720 \\
23,519\end{array}$ & $\begin{array}{l}10,061 \\
29,065\end{array}$ \\
\hline
\end{tabular}

\begin{tabular}{|c|c|c|c|c|c|c|}
\hline Item & $\begin{array}{c}\text { Oregon } \\
\text { Tillamook } \\
\text { Peoples } \\
\text { Utility Dist } \\
\text { December } 31\end{array}$ & $\begin{array}{c}\text { Pennsylvania } \\
\text { Chambersburg } \\
\text { Borough of } \\
\text { December } 31\end{array}$ & $\begin{array}{l}\text { South Carolina } \\
\text { Camden } \\
\text { City of } \\
\text { June } 30\end{array}$ & $\begin{array}{l}\text { South Carolina } \\
\text { Easley } \\
\text { Combined } \\
\text { Utility } \\
\text { System } \\
\text { March } 31\end{array}$ & $\begin{array}{l}\text { South Carolina } \\
\text { Gaffney } \\
\text { City of } \\
\text { March } 31\end{array}$ & $\begin{array}{l}\text { South Carolina } \\
\text { Greenwood } \\
\text { City of } \\
\text { December } 31\end{array}$ \\
\hline 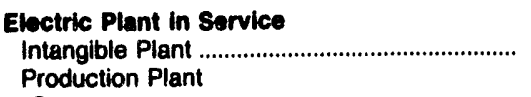 & 1 & 5 & 0 & 0 & 0 & 0 \\
\hline 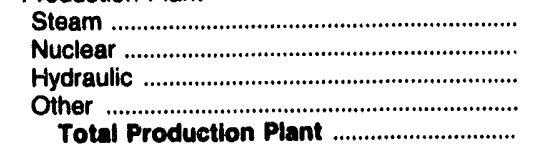 & $\begin{array}{l}0 \\
0 \\
0 \\
0 \\
0\end{array}$ & $\begin{array}{r}4,151 \\
0 \\
0 \\
1,362 \\
5,513\end{array}$ & $\begin{array}{l}0 \\
0 \\
0 \\
0 \\
0\end{array}$ & $\begin{array}{l}0 \\
0 \\
0 \\
0 \\
0\end{array}$ & $\begin{array}{l}0 \\
0 \\
0 \\
0 \\
0\end{array}$ & $\begin{array}{l}0 \\
0 \\
0 \\
0 \\
0\end{array}$ \\
\hline 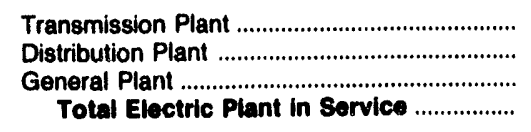 & $\begin{array}{r}1,032 \\
21,602 \\
5,332 \\
27,966\end{array}$ & $\begin{array}{r}3,963 \\
13,638 \\
866 \\
23,895\end{array}$ & $\begin{array}{r}0 \\
0 \\
20,786 \\
20,786\end{array}$ & $\begin{array}{r}0 \\
12,408 \\
0 \\
12,408\end{array}$ & $\begin{array}{r}0 \\
1,564 \\
0 \\
1,564\end{array}$ & $\begin{array}{r}0 \\
13,644 \\
0 \\
13,644\end{array}$ \\
\hline $\begin{array}{l}\text { Electric Plant Leased to Others .................... } \\
\text { Construction Work in Progress - Electric ........ } \\
\text { Electric Plant Held for Future Use ................. } \\
\text { Electric Plant Acquisition Adjustments ........... } \\
\text { Total Electric Utility Plant ........................ }\end{array}$ & $\begin{array}{r}0 \\
755 \\
0 \\
1,603 \\
30,325\end{array}$ & $\begin{array}{r}0 \\
310 \\
0 \\
0 \\
24,295\end{array}$ & $\begin{array}{r}0 \\
0 \\
0 \\
0 \\
20,786\end{array}$ & $\begin{array}{r}0 \\
0 \\
0 \\
0 \\
12,408\end{array}$ & $\begin{array}{r}0 \\
0 \\
0 \\
0 \\
1,564\end{array}$ & $\begin{array}{r}0 \\
17 \\
0 \\
0 \\
13,661\end{array}$ \\
\hline 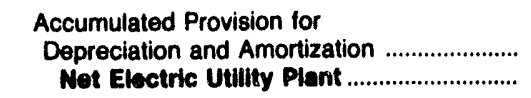 & $\begin{array}{r}7,281 \\
23,044\end{array}$ & $\begin{array}{l}11,730 \\
12,585\end{array}$ & $\begin{array}{r}9,273 \\
11,514\end{array}$ & $\begin{array}{l}3,929 \\
8,480\end{array}$ & $\begin{array}{l}626 \\
938\end{array}$ & $\begin{array}{l}\mathbf{8}, 290 \\
\mathbf{5 , 3 7 0}\end{array}$ \\
\hline
\end{tabular}

Note: Totals may not equal sum of components because of indepindent rounding.

Source: Energy Information Administration, Form ElA-412, "Annual Report of Public Electric Utilities." 
Table 39. Electric Utility Plant by Major Publicly Owned Electric Utility Within State at End of Period, 1991 (Continued) (Thousand Dollars)

\begin{tabular}{|c|c|c|c|c|c|c|}
\hline Item & $\begin{array}{c}\text { South Carolina } \\
\text { Greer } \\
\text { Comm } \\
\text { of } \\
\text { Public Works } \\
\text { December } 31\end{array}$ & $\begin{array}{l}\text { South Carolina } \\
\text { Newberry } \\
\text { City of } \\
\text { June } 30\end{array}$ & $\begin{array}{l}\text { South Carolina } \\
\text { Orangeburg } \\
\text { City of } \\
\text { September } 30\end{array}$ & $\begin{array}{l}\text { South Carolina } \\
\text { Piedmont } \\
\text { Municipal } \\
\text { Power Agny } \\
\text { December } 31\end{array}$ & $\begin{array}{l}\text { South Carolina } \\
\text { Pock Hill } \\
\text { City of } \\
\text { December } 31\end{array}$ & $\begin{array}{c}\text { South Carolina } \\
\text { South } \\
\text { Carolina } \\
\text { Pub } \\
\text { Serv Auth } \\
\text { December } 31\end{array}$ \\
\hline 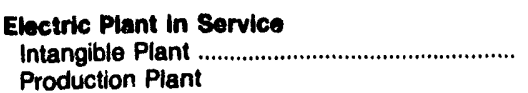 & 0 & 0 & 0 & 0 & 0 & 4,987 \\
\hline 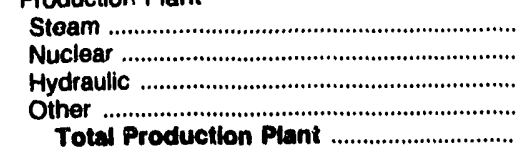 & $\begin{array}{l}0 \\
0 \\
0 \\
0 \\
0\end{array}$ & $\begin{array}{l}0 \\
0 \\
0 \\
0 \\
0\end{array}$ & $\begin{array}{r}0 \\
0 \\
0 \\
6,524 \\
6,524\end{array}$ & $\begin{array}{r}0 \\
581,551 \\
0 \\
0 \\
581,551\end{array}$ & $\begin{array}{l}0 \\
0 \\
0 \\
0 \\
0\end{array}$ & $\begin{array}{r}979,233 \\
457,869 \\
70,808 \\
24,659 \\
1,532,569\end{array}$ \\
\hline 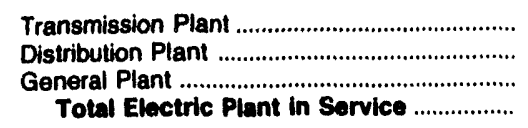 & $\begin{array}{r}9,109 \\
0 \\
52,096 \\
61,204\end{array}$ & $\begin{array}{r}0 \\
0 \\
7,739 \\
7,739\end{array}$ & $\begin{array}{r}35.378 \\
0 \\
0 \\
41,903\end{array}$ & $\begin{array}{r}0 \\
0 \\
1,466 \\
583,047\end{array}$ & $\begin{array}{r}0 \\
25,746 \\
0 \\
25,746\end{array}$ & $\begin{array}{r}482,259 \\
208,643 \\
150,828 \\
2,378,286\end{array}$ \\
\hline $\begin{array}{l}\text { Electric Plant Leased to Others ..................... } \\
\text { Construction Work in Progress - Electric ........ } \\
\text { Electric Plant Held for Future Use ................... } \\
\text { Electric Plant Acquisition Adjustments ............ } \\
\text { Total Electric Utillty Plant ........................... }\end{array}$ & $\begin{array}{r}0 \\
4,514 \\
0 \\
0 \\
65,718\end{array}$ & $\begin{array}{r}0 \\
0 \\
0 \\
0 \\
7,739\end{array}$ & $\begin{array}{r}0 \\
0 \\
0 \\
0 \\
41,9003\end{array}$ & $\begin{array}{r}0 \\
3,443 \\
0 \\
0 \\
586,460\end{array}$ & $\begin{array}{r}0 \\
0 \\
0 \\
0 \\
26,746\end{array}$ & $\begin{array}{r}0 \\
150,649 \\
12,346 \\
0 \\
0 \\
2,542,281\end{array}$ \\
\hline 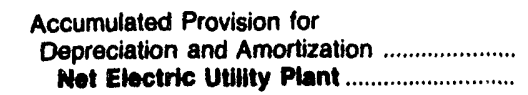 & $\begin{array}{r}17,773 \\
47,945\end{array}$ & $\begin{array}{l}3,591 \\
4,148\end{array}$ & $\begin{array}{r}9,395 \\
\mathbf{3 2 , 5 0 7}\end{array}$ & $\begin{array}{l}119,266 \\
467,194\end{array}$ & $\begin{array}{r}9,641 \\
16,105\end{array}$ & $\begin{array}{r}689,810 \\
1,852,471\end{array}$ \\
\hline
\end{tabular}

\begin{tabular}{|c|c|c|c|c|c|c|}
\hline Item & $\begin{array}{c}\text { South Dakota } \\
\text { Brookings } \\
\text { City of }\end{array}$ & $\begin{array}{l}\text { South Dakota } \\
\text { Heartland } \\
\text { Consumers } \\
\text { Power Dist } \\
\text { December } 31\end{array}$ & $\begin{array}{l}\text { South Dakota } \\
\text { Missouri } \\
\text { Basin } \\
\text { Mun } \\
\text { Power Agny } \\
\text { December } 31\end{array}$ & $\begin{array}{c}\text { South Dakota } \\
\text { Pierre } \\
\text { City of } \\
\text { December } 31\end{array}$ & $\begin{array}{l}\text { South Dakota } \\
\text { Watertown } \\
\text { Municipai } \\
\text { Utilities } \\
\text { December } 31\end{array}$ & $\begin{array}{c}\text { Tennessee } \\
\text { Alcoa } \\
\text { Utilities } \\
\text { June } 30\end{array}$ \\
\hline 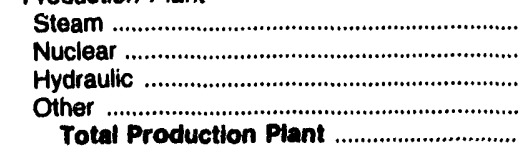 & $\begin{array}{l}0 \\
0 \\
0 \\
0 \\
0\end{array}$ & $\begin{array}{r}47,943 \\
0 \\
0 \\
0 \\
47,843\end{array}$ & $\begin{array}{l}0 \\
0 \\
0 \\
0 \\
0\end{array}$ & $\begin{array}{l}0 \\
0 \\
0 \\
0 \\
0\end{array}$ & $\begin{array}{r}0 \\
0 \\
0 \\
156 \\
156\end{array}$ & $\begin{array}{l}0 \\
0 \\
0 \\
0 \\
0\end{array}$ \\
\hline 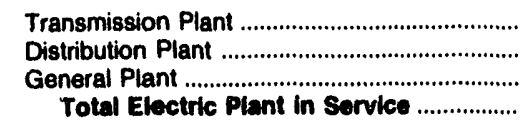 & $\begin{array}{r}3,672 \\
8,546 \\
2,537 \\
14,755\end{array}$ & $\begin{array}{r}8,377 \\
0 \\
798 \\
57,118\end{array}$ & $\begin{array}{r}0 \\
0 \\
2,580 \\
2,580\end{array}$ & $\begin{array}{r}0 \\
6,445 \\
925 \\
7,370\end{array}$ & $\begin{array}{r}364 \\
12,924 \\
1,009 \\
14,466\end{array}$ & $\begin{array}{r}1,126 \\
14,331 \\
1,470 \\
16,928\end{array}$ \\
\hline 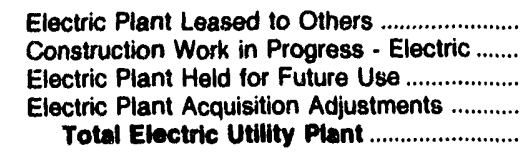 & $\begin{array}{r}0 \\
577 \\
0 \\
0 \\
15,332\end{array}$ & $\begin{array}{r}0 \\
145 \\
0 \\
0 \\
57,263\end{array}$ & $\begin{array}{r}0 \\
0 \\
0 \\
0 \\
2,580\end{array}$ & $\begin{array}{r}0 \\
0 \\
0 \\
0 \\
7,370\end{array}$ & $\begin{array}{r}0 \\
32 \\
0 \\
0 \\
14,497\end{array}$ & $\begin{array}{r}0 \\
400 \\
0 \\
0 \\
17,327\end{array}$ \\
\hline 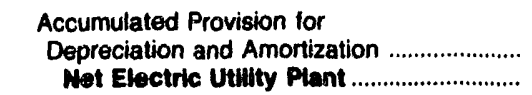 & $\begin{array}{r}4,136 \\
11,196\end{array}$ & $\begin{array}{r}5,362 \\
51,900\end{array}$ & $\begin{array}{r}545 \\
2,035\end{array}$ & $\begin{array}{l}2,159 \\
5,211\end{array}$ & $\begin{array}{l}7,963 \\
6,534\end{array}$ & $\begin{array}{r}5,235 \\
12,092\end{array}$ \\
\hline
\end{tabular}

Note: Totals may not equal sum of components because of independent rounding

Source: Energy Information Administration, Form EIA.412, "Annual Report of Public Electric Utilities." 
Tabie 39. Electric Utility Plant by Major Publicly Owned Electric Utility Within State at End of Period, 1991 (Continued) (Thousand Dollars)

\begin{tabular}{|c|c|c|c|c|c|c|}
\hline Item & $\begin{array}{l}\text { Tennessee } \\
\text { Athens } \\
\text { City of } \\
\text { June } 30\end{array}$ & $\begin{array}{l}\text { Tennessee } \\
\text { Benton } \\
\text { County } \\
\text { June } 30\end{array}$ & $\begin{array}{l}\text { Tennessee } \\
\text { Bolivar } \\
\text { City of } \\
\text { June } \mathbf{3 0}\end{array}$ & $\begin{array}{l}\text { Tennessee } \\
\text { Bristol } \\
\text { City of } \\
\text { June } 30\end{array}$ & $\begin{array}{c}\text { Tennessee } \\
\text { Brownsville } \\
\text { City of } \\
\text { June } 30\end{array}$ & $\begin{array}{l}\text { Tennessee } \\
\text { Carroll } \\
\text { County } \\
\text { June } 30\end{array}$ \\
\hline 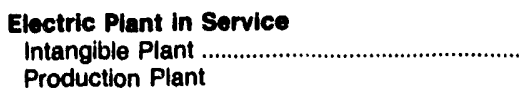 & 0 & 0 & 0 & 0 & 0 & 0 \\
\hline 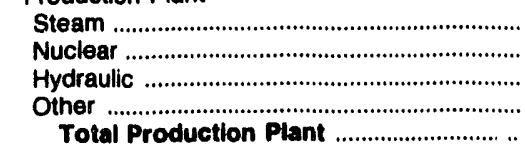 & $\begin{array}{l}0 \\
0 \\
0 \\
0 \\
0\end{array}$ & $\begin{array}{l}0 \\
0 \\
0 \\
0 \\
0\end{array}$ & $\begin{array}{l}0 \\
0 \\
0 \\
0 \\
0\end{array}$ & $\begin{array}{l}0 \\
0 \\
0 \\
0 \\
0\end{array}$ & $\begin{array}{l}0 \\
0 \\
0 \\
0 \\
0\end{array}$ & $\begin{array}{l}0 \\
0 \\
0 \\
0 \\
0\end{array}$ \\
\hline 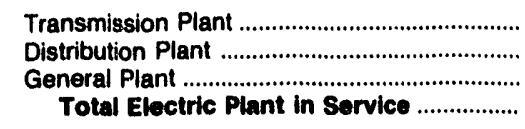 & $\begin{array}{r}1,340 \\
13,253 \\
1,558 \\
16,151\end{array}$ & $\begin{array}{r}303 \\
11,791 \\
954 \\
13,048\end{array}$ & $\begin{array}{r}45 \\
10,759 \\
1,193 \\
11,997\end{array}$ & $\begin{array}{r}7,829 \\
25,423 \\
2,626 \\
35,877\end{array}$ & $\begin{array}{r}284 \\
4,322 \\
1,350 \\
5,956\end{array}$ & $\begin{array}{r}92 \\
13,594 \\
1,161 \\
14,848\end{array}$ \\
\hline 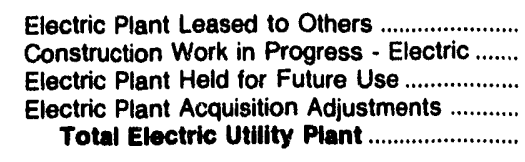 & $\begin{array}{r}0 \\
152 \\
0 \\
0 \\
16,302\end{array}$ & $\begin{array}{r}0 \\
28 \\
0 \\
0 \\
13,076\end{array}$ & $\begin{array}{r}0 \\
443 \\
0 \\
0 \\
12,440\end{array}$ & $\begin{array}{r}0 \\
1,193 \\
0 \\
0 \\
37,070\end{array}$ & $\begin{array}{r}0 \\
550 \\
0 \\
0 \\
6,506\end{array}$ & $\begin{array}{r}0 \\
496 \\
0 \\
818 \\
16,162\end{array}$ \\
\hline 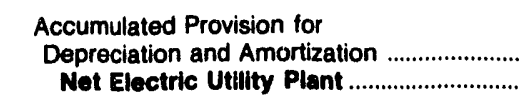 & $\begin{array}{r}5,883 \\
10,419\end{array}$ & $\begin{array}{l}4,719 \\
8,357\end{array}$ & $\begin{array}{l}4,464 \\
7,976\end{array}$ & $\begin{array}{l}18,913 \\
18,157\end{array}$ & $\begin{array}{l}1,583 \\
4,923\end{array}$ & $\begin{array}{r}5,265 \\
10,897\end{array}$ \\
\hline
\end{tabular}

\begin{tabular}{|c|c|c|c|c|c|c|}
\hline Item & $\begin{array}{c}\text { Tennessee } \\
\begin{array}{c}\text { Chattanooga } \\
\text { City of }\end{array} \\
\text { June } 30\end{array}$ & $\begin{array}{c}\text { Tennessee } \\
\text { Clarksville } \\
\text { City of } \\
\text { June } 30\end{array}$ & $\begin{array}{l}\text { Tennessee } \\
\text { Cleveland } \\
\text { City of } \\
\text { June } 30\end{array}$ & $\begin{array}{l}\text { Tennessee } \\
\text { Clinton } \\
\text { City of } \\
\text { June } 30\end{array}$ & $\begin{array}{l}\text { Tennessee } \\
\text { Columbia } \\
\text { City of } \\
\text { June } 30\end{array}$ & $\begin{array}{c}\text { Tennessee } \\
\text { Cookeville } \\
\text { City of } \\
\text { June } 30\end{array}$ \\
\hline $\begin{array}{l}\text { Electric Plant in Service } \\
\text { Intangible Plant ............................................... } \\
\text { Production Plant }\end{array}$ & 0 & 0 & 0 & 0 & 0 & 0 \\
\hline 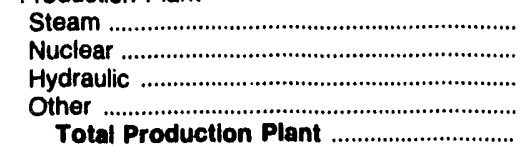 & $\begin{array}{l}0 \\
0 \\
0 \\
0 \\
0\end{array}$ & $\begin{array}{l}0 \\
0 \\
0 \\
0 \\
0\end{array}$ & $\begin{array}{l}0 \\
0 \\
0 \\
0 \\
0\end{array}$ & $\begin{array}{l}0 \\
0 \\
0 \\
0 \\
0\end{array}$ & $\begin{array}{l}0 \\
0 \\
0 \\
0 \\
0\end{array}$ & $\begin{array}{l}0 \\
0 \\
0 \\
0 \\
0\end{array}$ \\
\hline 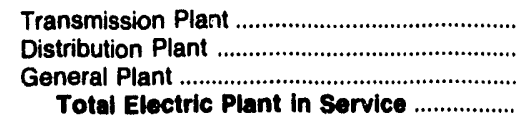 & $\begin{array}{r}21,449 \\
167,681 \\
24,357 \\
213,488\end{array}$ & $\begin{array}{r}401 \\
22,741 \\
4,497 \\
27,639\end{array}$ & $\begin{array}{r}2,895 \\
33,513 \\
3,426 \\
39,835\end{array}$ & $\begin{array}{r}3,151 \\
22,476 \\
3,096 \\
28,722\end{array}$ & $\begin{array}{r}1,726 \\
17,634 \\
2,641 \\
22,001\end{array}$ & $\begin{array}{r}265 \\
10,978 \\
2,657 \\
13,900\end{array}$ \\
\hline 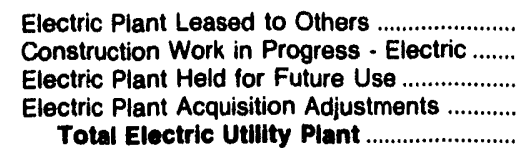 & $\begin{array}{r}0 \\
7,496 \\
0 \\
0 \\
220,985\end{array}$ & $\begin{array}{r}0 \\
990 \\
69 \\
12,238 \\
40,936\end{array}$ & $\begin{array}{r}0 \\
1,784 \\
0 \\
2,330 \\
43,948\end{array}$ & $\begin{array}{r}0 \\
388 \\
0 \\
0 \\
29,110\end{array}$ & $\begin{array}{r}0 \\
480 \\
0 \\
6 \\
22,487\end{array}$ & $\begin{array}{r}0 \\
1,392 \\
0 \\
0 \\
15,292\end{array}$ \\
\hline 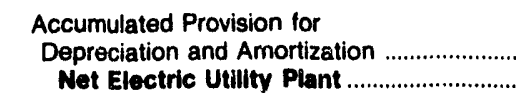 & $\begin{array}{r}84,876 \\
136,109\end{array}$ & $\begin{array}{r}8,018 \\
32,918\end{array}$ & $\begin{array}{l}13,516 \\
30,432\end{array}$ & $\begin{array}{r}9,234 \\
19,877\end{array}$ & $\begin{array}{r}8,546 \\
13,941\end{array}$ & $\begin{array}{r}3,227 \\
12,065\end{array}$ \\
\hline
\end{tabular}

Note: Totals may not equal sum of components because of independent rounding.

Source: Energy Information Administration, Form EIA-412, "Annual Report of Public Electric Utilities." 
Table 39. Electric Utility Plant by Major Publicly Owned Electric Utility Within State at End of Period, 1991 (Continued) (Thousand Dollars)

\begin{tabular}{|c|c|c|c|c|c|c|}
\hline Item & $\begin{array}{l}\text { Tennessee } \\
\text { Covington } \\
\text { Clty of } \\
\text { June } 30\end{array}$ & $\begin{array}{l}\text { Tennessee } \\
\text { Dayton } \\
\text { City of } \\
\text { June } 30\end{array}$ & $\begin{array}{l}\text { Tennessee } \\
\begin{array}{c}\text { Dickson } \\
\text { City of }\end{array} \\
\text { June } 30\end{array}$ & $\begin{array}{l}\text { Tennessee } \\
\text { Dyersburg } \\
\text { Electric } \\
\text { System } \\
\text { June } 30\end{array}$ & $\begin{array}{l}\text { Tennessee } \\
\text { Elizabethton } \\
\text { City of } \\
\text { June } 30\end{array}$ & $\begin{array}{l}\text { Tennessee } \\
\text { Erwin } \\
\text { Town of } \\
\text { June } 30\end{array}$ \\
\hline 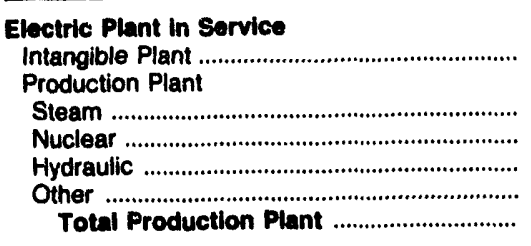 & $\begin{array}{l}0 \\
0 \\
0 \\
0 \\
0\end{array}$ & $\begin{array}{l}0 \\
0 \\
0 \\
0 \\
0\end{array}$ & $\begin{array}{l}0 \\
0 \\
0 \\
0 \\
0\end{array}$ & $\begin{array}{l}0 \\
0 \\
0 \\
0 \\
0\end{array}$ & $\begin{array}{l}0 \\
0 \\
0 \\
0 \\
0\end{array}$ & $\begin{array}{l}0 \\
0 \\
0 \\
0 \\
0\end{array}$ \\
\hline 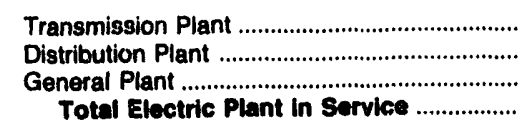 & $\begin{array}{r}1,307 \\
3,688 \\
804 \\
5,798\end{array}$ & $\begin{array}{r}0 \\
7,639 \\
1,148 \\
8,787\end{array}$ & $\begin{array}{r}0 \\
26,994 \\
1,710 \\
28,704\end{array}$ & $\begin{array}{r}1,924 \\
15,099 \\
3,542 \\
20,565\end{array}$ & $\begin{array}{r}578 \\
18,194 \\
3,199 \\
21,970\end{array}$ & $\begin{array}{r}0 \\
6,113 \\
1,273 \\
7,386\end{array}$ \\
\hline 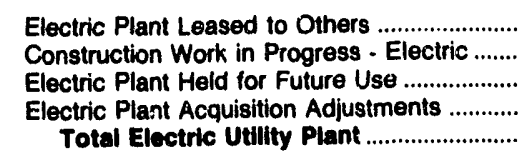 & $\begin{array}{r}0 \\
487 \\
0 \\
1,770 \\
8,054\end{array}$ & $\begin{array}{r}0 \\
66 \\
0 \\
0 \\
8,853\end{array}$ & $\begin{array}{r}0 \\
405 \\
135 \\
0 \\
29,244\end{array}$ & $\begin{array}{r}0 \\
1,468 \\
0 \\
-6,119 \\
15,914\end{array}$ & $\begin{array}{r}0 \\
213 \\
0 \\
0 \\
22,183\end{array}$ & $\begin{array}{r}0 \\
167 \\
0 \\
0 \\
7,553\end{array}$ \\
\hline 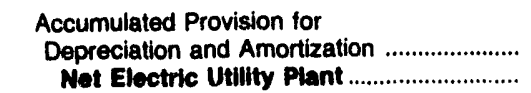 & $\begin{array}{l}1,768 \\
6,286\end{array}$ & $\begin{array}{l}2,755 \\
6,098\end{array}$ & $\begin{array}{r}9,220 \\
20,025\end{array}$ & $\begin{array}{r}47 \\
15,867\end{array}$ & $\begin{array}{r}7,499 \\
14,684\end{array}$ & $\begin{array}{l}3,146 \\
4,407\end{array}$ \\
\hline
\end{tabular}

\begin{tabular}{|c|c|c|c|c|c|c|}
\hline Item & $\begin{array}{l}\text { Tennessee } \\
\text { Etowah } \\
\text { City of } \\
\text { June } 30\end{array}$ & $\begin{array}{l}\text { Tennessee } \\
\text { Fayetteville } \\
\text { City of } \\
\text { June } 30\end{array}$ & $\begin{array}{l}\text { Tennessee } \\
\text { Gallatin } \\
\text { City of } \\
\text { June } 30\end{array}$ & $\begin{array}{l}\text { Tennessee } \\
\text { Greeneville } \\
\text { City of } \\
\text { June } 30\end{array}$ & $\begin{array}{l}\text { Tennessee } \\
\text { Harriman } \\
\text { City of } \\
\text { June } 30\end{array}$ & $\begin{array}{l}\text { Tennessee } \\
\text { Humboldt } \\
\text { City of } \\
\text { June } 30\end{array}$ \\
\hline 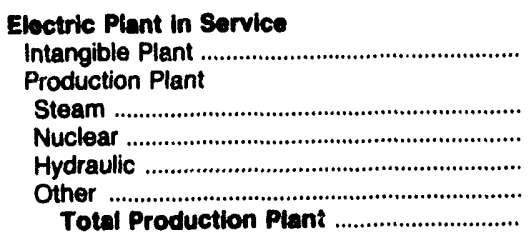 & $\begin{array}{l}0 \\
0 \\
0 \\
0 \\
0\end{array}$ & $\begin{array}{l}0 \\
0 \\
0 \\
0 \\
0\end{array}$ & $\begin{array}{l}0 \\
0 \\
0 \\
0 \\
0\end{array}$ & $\begin{array}{l}0 \\
0 \\
0 \\
0 \\
0\end{array}$ & $\begin{array}{l}0 \\
0 \\
0 \\
0 \\
0\end{array}$ & $\begin{array}{l}0 \\
0 \\
0 \\
0 \\
0\end{array}$ \\
\hline 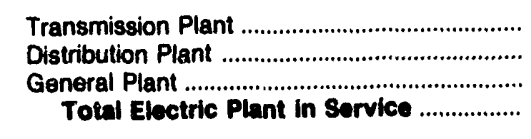 & $\begin{array}{r}0 \\
4,304 \\
390 \\
4,694\end{array}$ & $\begin{array}{r}66 \\
15,513 \\
3,566 \\
19,145\end{array}$ & $\begin{array}{r}501 \\
7,856 \\
1,247 \\
8,604\end{array}$ & $\begin{array}{r}6,154 \\
26,596 \\
4,617 \\
37,366\end{array}$ & $\begin{array}{r}0 \\
12,991 \\
1,914 \\
14,906\end{array}$ & $\begin{array}{r}603 \\
3,695 \\
1,296 \\
5,594\end{array}$ \\
\hline 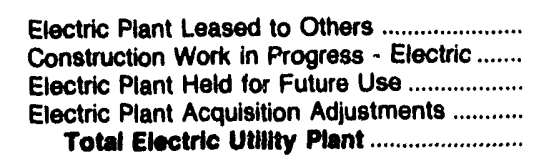 & $\begin{array}{r}0 \\
69 \\
0 \\
0 \\
4,763\end{array}$ & $\begin{array}{r}0 \\
2,357 \\
0 \\
0 \\
21,503\end{array}$ & $\begin{array}{r}0 \\
90 \\
0 \\
212 \\
9,906\end{array}$ & $\begin{array}{r}0 \\
652 \\
0 \\
0 \\
38,018\end{array}$ & $\begin{array}{r}0 \\
180 \\
0 \\
0 \\
15,085\end{array}$ & $\begin{array}{r}0 \\
129 \\
0 \\
375 \\
6,098\end{array}$ \\
\hline 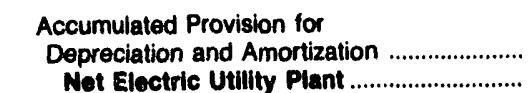 & $\begin{array}{l}1,984 \\
2,778\end{array}$ & $\begin{array}{r}6,642 \\
14,860\end{array}$ & $\begin{array}{l}4,489 \\
5,417\end{array}$ & $\begin{array}{l}15,166 \\
22,852\end{array}$ & $\begin{array}{l}6,185 \\
8,001\end{array}$ & $\begin{array}{l}1,918 \\
4,180\end{array}$ \\
\hline
\end{tabular}

Note: Totals may not equal sum of components because of independent rounding.

Source: Energy Information Administration, Form EIA-412, "Annual Report of Public Electric Utilities." 
Table 39. Electric Utility Plant by Major Publicly Owned Electric Utility Within State at End of Period, 1991 (Continued) (Thousand Dollars)

\begin{tabular}{|c|c|c|c|c|c|c|}
\hline Item & $\begin{array}{l}\text { Tennessee } \\
\text { Jackson } \\
\text { City of } \\
\text { June } 30\end{array}$ & $\begin{array}{l}\text { Tennessee } \\
\text { Johnson } \\
\text { City City of } \\
\text { June } 30\end{array}$ & $\begin{array}{l}\text { Tennessee } \\
\text { Knoxville } \\
\text { Utilities } \\
\text { Board } \\
\text { June } 30\end{array}$ & $\begin{array}{l}\text { Tennessee } \\
\text { Lawrenceburg } \\
\text { City of } \\
\text { June } 30\end{array}$ & $\begin{array}{l}\text { Tennessee } \\
\text { Lafollette } \\
\text { City of } \\
\text { December } 31\end{array}$ & $\begin{array}{l}\text { Tennessee } \\
\text { Lebanon } \\
\text { City of } \\
\text { June } 30\end{array}$ \\
\hline 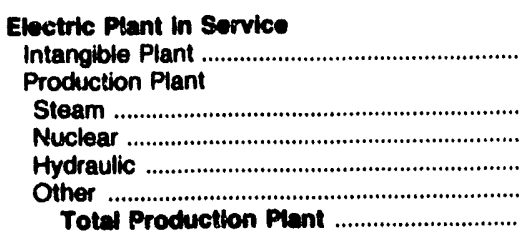 & $\begin{array}{l}0 \\
0 \\
0 \\
0 \\
0\end{array}$ & $\begin{array}{l}0 \\
0 \\
0 \\
0 \\
0\end{array}$ & $\begin{array}{l}0 \\
0 \\
0 \\
0 \\
0\end{array}$ & $\begin{array}{l}0 \\
0 \\
0 \\
0 \\
0\end{array}$ & $\begin{array}{l}0 \\
0 \\
0 \\
0 \\
0\end{array}$ & $\begin{array}{l}0 \\
0 \\
0 \\
0 \\
0\end{array}$ \\
\hline 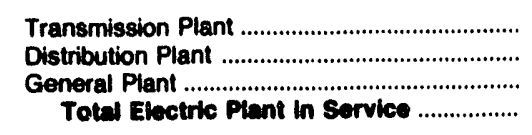 & $\begin{array}{r}8,731 \\
34,121 \\
7,294 \\
50,146\end{array}$ & $\begin{array}{r}3,175 \\
37,045 \\
2,066 \\
42,287\end{array}$ & $\begin{array}{r}0 \\
237,338 \\
20,615 \\
257,953\end{array}$ & $\begin{array}{r}3,877 \\
15,227 \\
2,273 \\
21,377\end{array}$ & $\begin{array}{r}0 \\
19,765 \\
1,948 \\
21,713\end{array}$ & $\begin{array}{r}0 \\
9,772 \\
705 \\
10,477\end{array}$ \\
\hline 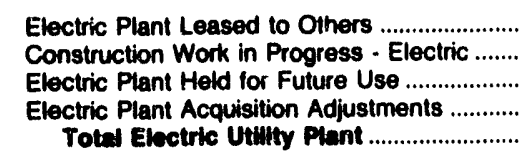 & $\begin{array}{r}0 \\
1,060 \\
0 \\
378 \\
51,584\end{array}$ & $\begin{array}{r}0 \\
3,481 \\
0 \\
0 \\
45,768\end{array}$ & $\begin{array}{r}0 \\
5,254 \\
0 \\
0 \\
263,207\end{array}$ & $\begin{array}{r}0 \\
131 \\
0 \\
0 \\
21,508\end{array}$ & $\begin{array}{r}0 \\
614 \\
0 \\
0 \\
22,327\end{array}$ & $\begin{array}{r}0 \\
580 \\
0 \\
0 \\
11,057\end{array}$ \\
\hline 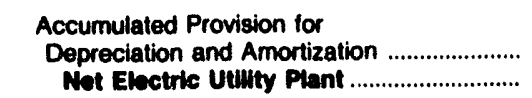 & $\begin{array}{l}18,858 \\
32,726\end{array}$ & $\begin{array}{l}17,102 \\
28,666\end{array}$ & $\begin{array}{l}117,547 \\
145,661\end{array}$ & $\begin{array}{r}8,207 \\
13,300\end{array}$ & $\begin{array}{r}8,012 \\
14,315\end{array}$ & $\begin{array}{l}4,164 \\
6,893\end{array}$ \\
\hline
\end{tabular}

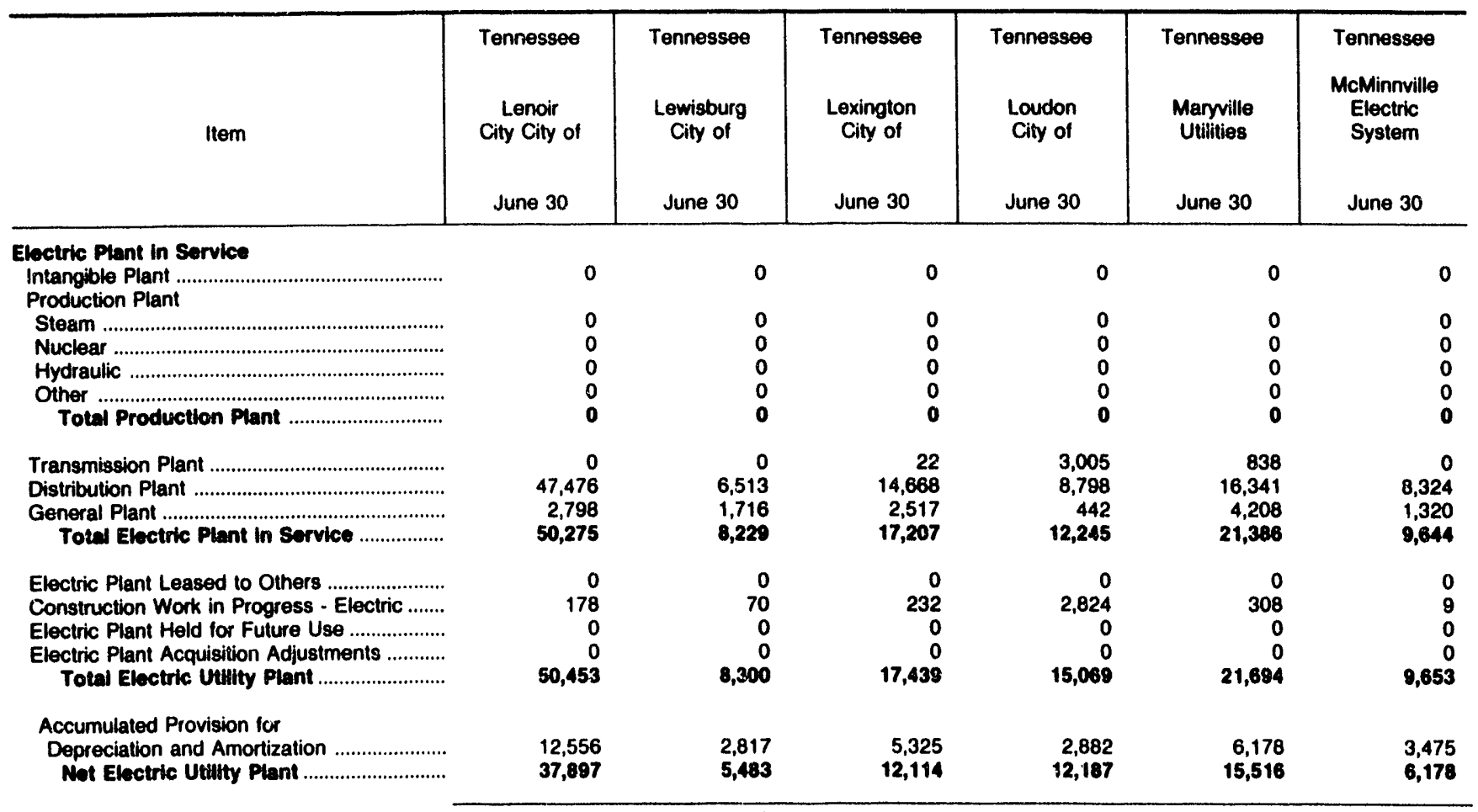

Note: Totals may not equal sum of components because of independent rounding.

Source: Energy Information Administration, Form EIA-412, "Annual Report of Public Electric Utilities." 


\section{Table 39. Electric Utility Plant by Major Publicly Owned Electric Utility Within State at End of Period, 1991 (Continued) (Thousand Dollars)}

\begin{tabular}{|c|c|c|c|c|c|c|}
\hline Item & $\begin{array}{c}\text { Tennessee } \\
\text { Memphis } \\
\text { City of } \\
\text { December } 31\end{array}$ & $\begin{array}{l}\text { Tennessee } \\
\text { Milan } \\
\text { City of } \\
\text { June } 30\end{array}$ & $\begin{array}{l}\text { Tennessee } \\
\text { Morristown } \\
\text { City of } \\
\text { June } 30\end{array}$ & $\begin{array}{c}\text { Tennessee } \\
\text { Murtreesboro } \\
\text { City of } \\
\text { June } 30\end{array}$ & $\begin{array}{c}\text { Tennessee } \\
\text { Nashville } \\
\text { Electric } \\
\text { Service } \\
\\
\text { June } 30\end{array}$ & $\begin{array}{l}\text { Tennessee } \\
\text { Newport } \\
\text { City of } \\
\text { June } 30\end{array}$ \\
\hline 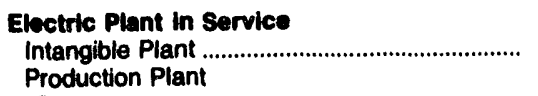 & 0 & 0 & 0 & 0 & 0 & 0 \\
\hline 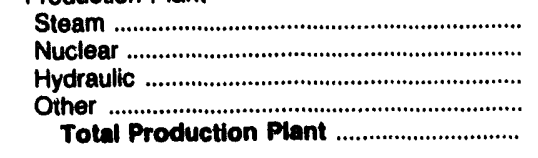 & $\begin{array}{l}0 \\
0 \\
0 \\
0 \\
0\end{array}$ & $\begin{array}{l}0 \\
0 \\
0 \\
0 \\
0\end{array}$ & $\begin{array}{l}0 \\
0 \\
0 \\
0 \\
0\end{array}$ & $\begin{array}{l}0 \\
0 \\
0 \\
0 \\
0\end{array}$ & $\begin{array}{l}0 \\
0 \\
0 \\
0 \\
0\end{array}$ & $\begin{array}{l}0 \\
0 \\
0 \\
0 \\
0\end{array}$ \\
\hline 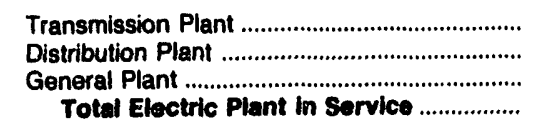 & $\begin{array}{r}120,106 \\
501,792 \\
27,727 \\
649,625\end{array}$ & $\begin{array}{r}598 \\
6,740 \\
847 \\
8,185\end{array}$ & $\begin{array}{r}3,437 \\
15,152 \\
3,381 \\
21,971\end{array}$ & $\begin{array}{r}0 \\
25,066 \\
3,717 \\
28,784\end{array}$ & $\begin{array}{r}0 \\
442,847 \\
54,393 \\
497,240\end{array}$ & $\begin{array}{r}0 \\
17,867 \\
3,826 \\
21,693\end{array}$ \\
\hline 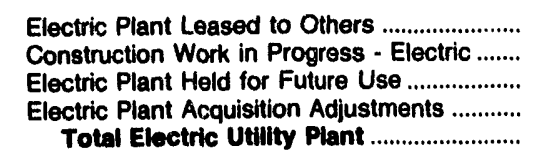 & $\begin{array}{r}0 \\
29,803 \\
0 \\
0 \\
679,428\end{array}$ & $\begin{array}{r}0 \\
36 \\
10 \\
434 \\
8,665\end{array}$ & $\begin{array}{r}0 \\
454 \\
0 \\
0 \\
22,425\end{array}$ & $\begin{array}{r}0 \\
726 \\
0 \\
769 \\
30,278\end{array}$ & $\begin{array}{r}0 \\
15,753 \\
0 \\
-109 \\
512,884\end{array}$ & $\begin{array}{r}0 \\
77 \\
0 \\
0 \\
21,770\end{array}$ \\
\hline 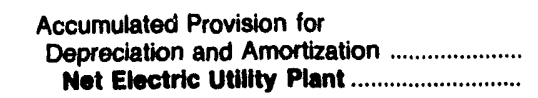 & $\begin{array}{l}225,821 \\
453,607\end{array}$ & $\begin{array}{l}3,366 \\
5,299\end{array}$ & $\begin{array}{r}6,575 \\
15,850\end{array}$ & $\begin{array}{r}8,962 \\
21,316\end{array}$ & $\begin{array}{l}164,274 \\
348,610\end{array}$ & $\begin{array}{r}6,689 \\
15,080\end{array}$ \\
\hline
\end{tabular}

\begin{tabular}{|c|c|c|c|c|c|c|}
\hline Item & $\begin{array}{c}\text { Tennessee } \\
\text { Oak Ridge } \\
\text { City of } \\
\text { June } 30\end{array}$ & $\begin{array}{c}\text { Tennessee } \\
\text { Paris } \\
\text { City of } \\
\text { June } 30\end{array}$ & $\begin{array}{l}\text { Tennessee } \\
\text { Pulaski } \\
\text { City of } \\
\text { June } 30\end{array}$ & $\begin{array}{l}\text { Tennessee } \\
\text { Pipley } \\
\text { City of } \\
\text { June } \mathbf{3 0}\end{array}$ & $\begin{array}{l}\text { Tennessee } \\
\text { Rockwood } \\
\text { City of } \\
\text { June } 30\end{array}$ & $\begin{array}{c}\text { Tennessee } \\
\text { Sevier } \\
\text { County } \\
\text { Electric } \\
\text { System } \\
\text { June } 30\end{array}$ \\
\hline 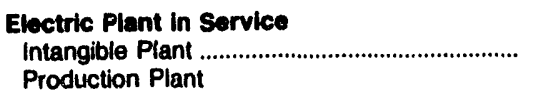 & 0 & 0 & 0 & 0 & 0 & 0 \\
\hline 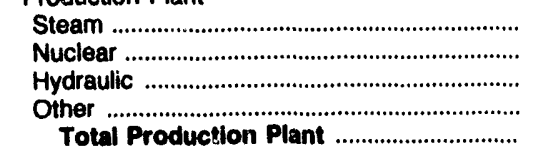 & $\begin{array}{l}0 \\
0 \\
0 \\
0 \\
0\end{array}$ & $\begin{array}{l}0 \\
0 \\
0 \\
0 \\
0\end{array}$ & $\begin{array}{l}0 \\
0 \\
0 \\
0 \\
0\end{array}$ & $\begin{array}{l}0 \\
0 \\
0 \\
0 \\
0\end{array}$ & $\begin{array}{l}0 \\
0 \\
0 \\
0 \\
0\end{array}$ & $\begin{array}{l}0 \\
0 \\
0 \\
0 \\
0\end{array}$ \\
\hline 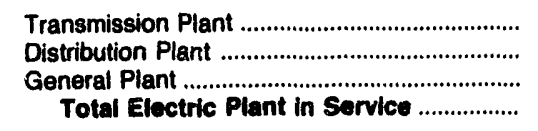 & $\begin{array}{r}0 \\
18,904 \\
976 \\
19,880\end{array}$ & $\begin{array}{r}1,864 \\
18,995 \\
1,539 \\
22,398\end{array}$ & $\begin{array}{r}0 \\
15,267 \\
2,699 \\
17,866\end{array}$ & $\begin{array}{r}584 \\
4,689 \\
1,240 \\
6,513\end{array}$ & $\begin{array}{r}0 \\
13,283 \\
964 \\
14,248\end{array}$ & $\begin{array}{r}9,629 \\
37,898 \\
4,704 \\
52,231\end{array}$ \\
\hline 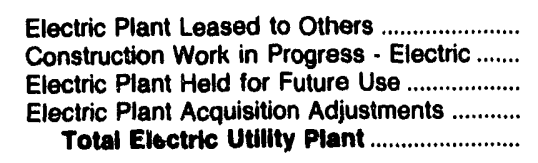 & $\begin{array}{r}0 \\
803 \\
0 \\
144 \\
20,827\end{array}$ & $\begin{array}{r}0 \\
706 \\
0 \\
281 \\
23,384\end{array}$ & $\begin{array}{r}0 \\
393 \\
0 \\
0 \\
18,360\end{array}$ & $\begin{array}{r}0 \\
38 \\
0 \\
0 \\
6.551\end{array}$ & $\begin{array}{r}0 \\
111 \\
0 \\
292 \\
14,651\end{array}$ & $\begin{array}{r}0 \\
893 \\
0 \\
544 \\
53,668\end{array}$ \\
\hline 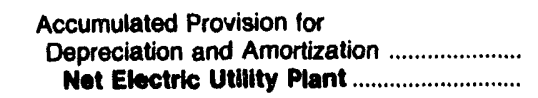 & $\begin{array}{r}7,507 \\
13,320\end{array}$ & $\begin{array}{r}9,210 \\
14,174\end{array}$ & $\begin{array}{r}7,301 \\
11,058\end{array}$ & $\begin{array}{l}1,741 \\
4,810\end{array}$ & $\begin{array}{l}4,685 \\
9,966\end{array}$ & $\begin{array}{l}12,501 \\
41,167\end{array}$ \\
\hline
\end{tabular}

Note: Totals may not equal sum of components because of independent rounding.

Source: Energy Information Administration, Form EIA-412, "Annual Report of Public Electric Utilities." 
Table 39. Electric Utility Plant by Major Publicly Owned Electric Utility Within State at End of Period, 1991 (Continued) (Thousand Dollars)

\begin{tabular}{|c|c|c|c|c|c|c|}
\hline Item & $\begin{array}{c}\text { Tennessee } \\
\text { Shelbyville } \\
\text { Clty of } \\
\text { June } 30\end{array}$ & $\begin{array}{l}\text { Tennessee } \\
\text { Springfieid } \\
\text { City of } \\
\text { June } 30\end{array}$ & $\begin{array}{l}\text { Tennessee } \\
\text { Sweetwater } \\
\text { City of } \\
\text { June } 30\end{array}$ & $\begin{array}{c}\text { Tennessee } \\
\text { Tullahoma } \\
\text { Board } \\
\text { of } \\
\text { Pub Utils } \\
\text { June } 30\end{array}$ & $\begin{array}{c}\text { Tennessee } \\
\text { Union } \\
\text { City City of } \\
\text { June } 30\end{array}$ & $\begin{array}{c}\text { Tennessee } \\
\text { Weakley } \\
\text { County } \\
\text { Mun } \\
\text { Elec Sys } \\
\text { June } 30\end{array}$ \\
\hline 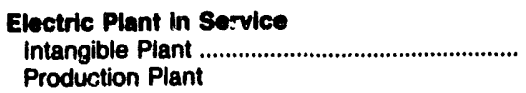 & 0 & 0 & 0 & 0 & 0 & 0 \\
\hline 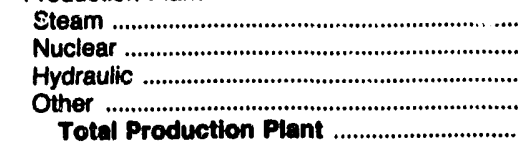 & $\begin{array}{l}0 \\
0 \\
0 \\
0 \\
0\end{array}$ & $\begin{array}{l}0 \\
0 \\
0 \\
0 \\
0\end{array}$ & $\begin{array}{l}0 \\
0 \\
0 \\
0 \\
0\end{array}$ & $\begin{array}{l}0 \\
0 \\
0 \\
0 \\
0\end{array}$ & $\begin{array}{l}0 \\
0 \\
0 \\
0 \\
0\end{array}$ & $\begin{array}{l}0 \\
0 \\
0 \\
0 \\
0\end{array}$ \\
\hline 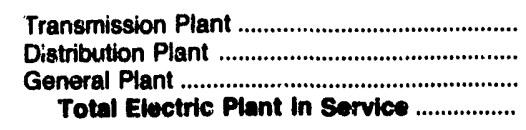 & $\begin{array}{r}0 \\
\forall, 252 \\
1,208 \\
10,460\end{array}$ & $\begin{array}{r}0 \\
7,169 \\
1,243 \\
\mathbf{8 , 4 1 2}\end{array}$ & $\begin{array}{r}0 \\
8,257 \\
920 \\
9,177\end{array}$ & $\begin{array}{r}0 \\
7,226 \\
1,766 \\
8,982\end{array}$ & $\begin{array}{l}1,060 \\
6,264 \\
1,282 \\
8.606\end{array}$ & $\begin{array}{r}2,711 \\
19,319 \\
2,457 \\
24,488\end{array}$ \\
\hline 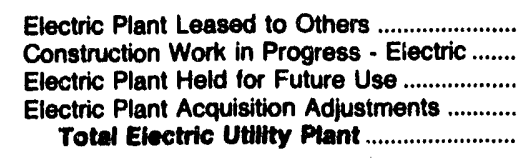 & $\begin{array}{r}0 \\
85 \\
0 \\
0 \\
10,545\end{array}$ & $\begin{array}{r}0 \\
666 \\
0 \\
0 \\
9,078\end{array}$ & $\begin{array}{r}0 \\
26 \\
0 \\
0 \\
9,203\end{array}$ & $\begin{array}{r}0 \\
90 \\
0 \\
0 \\
9,082\end{array}$ & $\begin{array}{r}0 \\
279 \\
104 \\
\vdots \\
0,984\end{array}$ & $\begin{array}{r}0 \\
0 \\
1,069 \\
0 \\
25,557\end{array}$ \\
\hline 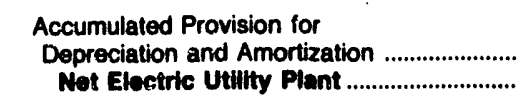 & $\begin{array}{l}3,693 \\
6,852\end{array}$ & $\begin{array}{l}3,248 \\
5,830\end{array}$ & $\begin{array}{l}2,946 \\
6,258\end{array}$ & $\begin{array}{l}3,180 \\
5,903\end{array}$ & $\begin{array}{l}2,936 \\
6,054\end{array}$ & $\begin{array}{l}11,347 \\
14,210\end{array}$ \\
\hline
\end{tabular}

\begin{tabular}{|c|c|c|c|c|c|c|}
\hline Item & $\begin{array}{l}\text { Taxas } \\
\text { Austin } \\
\text { City of } \\
\text { September } 30\end{array}$ & $\begin{array}{c}\text { Texas } \\
\text { Brenham } \\
\text { City of } \\
\text { September } 30\end{array}$ & $\begin{array}{c}\text { Texas } \\
\text { Brownsville } \\
\text { Publlic } \\
\text { Utils Board } \\
\text { September } 30\end{array}$ & $\begin{array}{c}\text { Texas } \\
\text { Bryan } \\
\text { City of } \\
\text { September } 30\end{array}$ & $\begin{array}{c}\text { Texas } \\
\text { College } \\
\text { Station } \\
\text { City of } \\
\text { September } 30\end{array}$ & $\begin{array}{c}\text { Texas } \\
\text { Denton } \\
\text { City of } \\
\text { September } 30\end{array}$ \\
\hline $\begin{array}{l}\text { Electric Plant in Service } \\
\text { Intangible Plant .................................................. } \\
\text { Production Plant }\end{array}$ & 0 & 0 & 0 & 0 & 0 & -321 \\
\hline 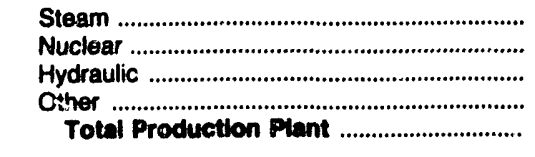 & $\begin{array}{r}431,189 \\
948,585 \\
0 \\
3,295 \\
1,383,069\end{array}$ & $\begin{array}{l}0 \\
0 \\
0 \\
0 \\
0\end{array}$ & $\begin{array}{r}20,254 \\
0 \\
0 \\
268 \\
20,522\end{array}$ & $\begin{array}{r}48,710 \\
0 \\
0 \\
127 \\
48,937\end{array}$ & $\begin{array}{l}0 \\
0 \\
0 \\
0 \\
0\end{array}$ & $\begin{array}{r}26,415 \\
0 \\
4,072 \\
0 \\
30,486\end{array}$ \\
\hline 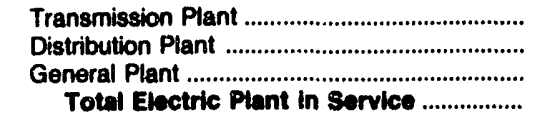 & $\begin{array}{r}98,901 \\
449,516 \\
59,443 \\
1,090,929\end{array}$ & $\begin{array}{r}0 \\
8,094 \\
0 \\
8,094\end{array}$ & $\begin{array}{r}65,236 \\
39,502 \\
102,039 \\
227,300\end{array}$ & $\begin{array}{r}41,134 \\
0 \\
955 \\
00,926\end{array}$ & $\begin{array}{r}6,383 \\
8,606 \\
3,379 \\
18,368\end{array}$ & $\begin{array}{r}8,543 \\
33,267 \\
4,167 \\
76,143\end{array}$ \\
\hline 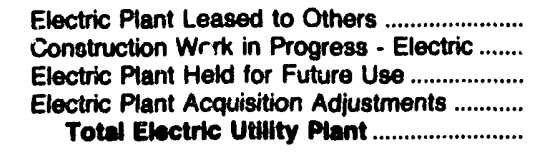 & $\begin{array}{r}0 \\
67,445 \\
43,226 \\
0 \\
2,101,600\end{array}$ & $\begin{array}{r}0 \\
0 \\
0 \\
0 \\
8,004\end{array}$ & $\begin{array}{r}0 \\
10,169 \\
0 \\
0 \\
237,469\end{array}$ & $\begin{array}{r}0 \\
0 \\
0 \\
0 \\
90,926\end{array}$ & $\begin{array}{r}0 \\
3,710 \\
0 \\
0 \\
22,078\end{array}$ & $\begin{array}{r}358 \\
4,406 \\
0 \\
0 \\
80,907\end{array}$ \\
\hline 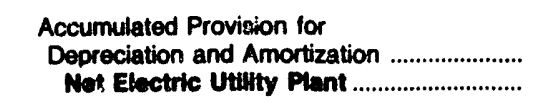 & $\begin{array}{r}444,809 \\
1,656,791\end{array}$ & $\begin{array}{l}2,515 \\
5,580\end{array}$ & $\begin{array}{r}66,085 \\
171,384\end{array}$ & $\begin{array}{l}40,060 \\
50,066\end{array}$ & $\begin{array}{r}6,786 \\
15,291\end{array}$ & $\begin{array}{l}42,020 \\
38,886\end{array}$ \\
\hline
\end{tabular}

Note: Totals may not equal sum of components because of independent rounding.

Source: Energy Informo'son Administration, Form EIA-412, "Annual Report of Public Electric Utilities." 
Table 39. Electric Utility Plant by Major Publicly Owned Electric Utility Within State at End of Period, 1991 (Continued) (Thousand Dollars)

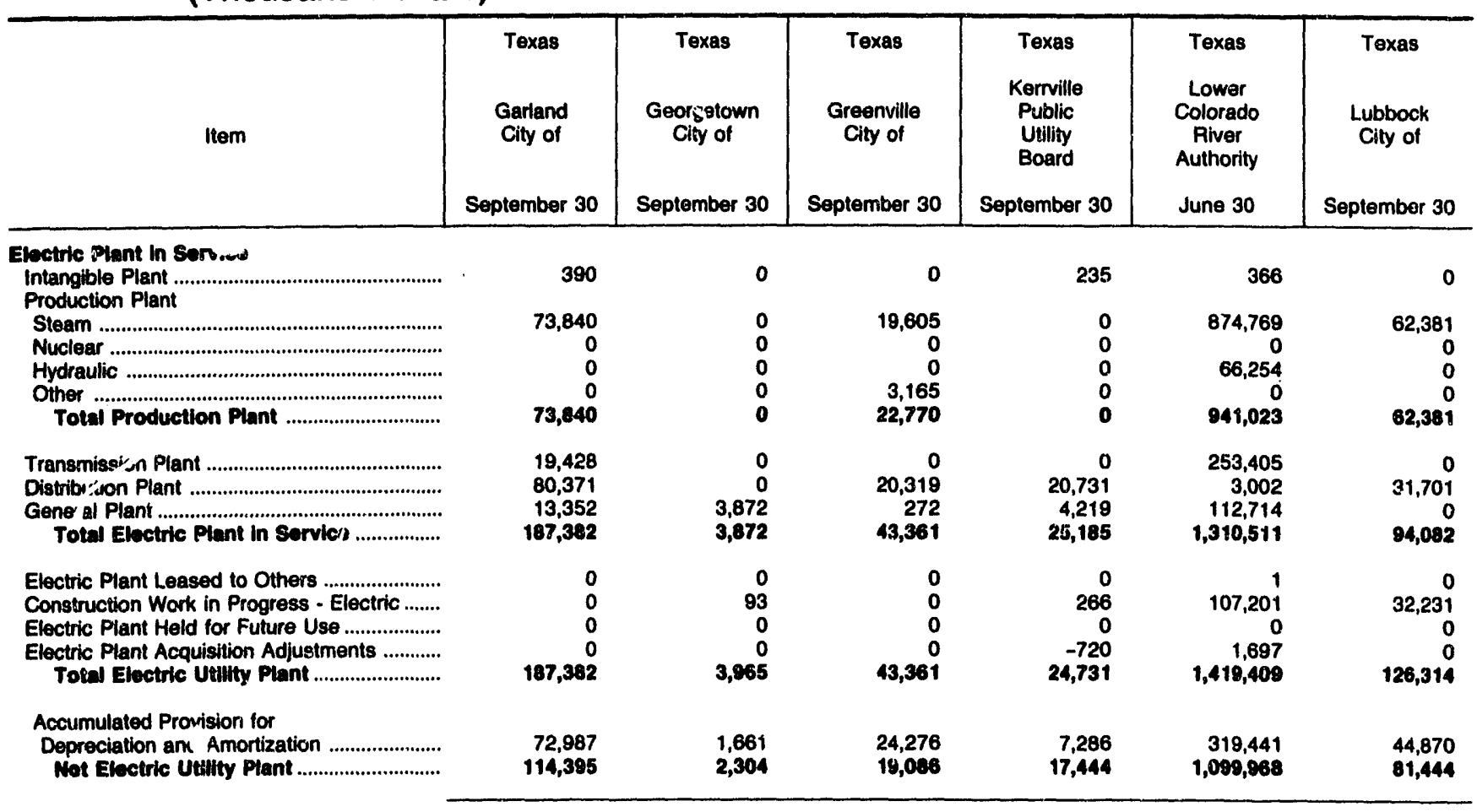

\begin{tabular}{|c|c|c|c|c|c|c|}
\hline Item & $\begin{array}{c}\text { Texas } \\
\text { Now Braunfels } \\
\text { City of } \\
\text { July } 31\end{array}$ & $\begin{array}{c}\text { Texas } \\
\text { Sam Rayburn } \\
\text { Municipal } \\
\text { Pwr } \\
\text { Agny } \\
\text { September } 30\end{array}$ & $\begin{array}{c}\text { Texas } \\
\text { San Antonio } \\
\text { City of } \\
\text { January } 31\end{array}$ & $\begin{array}{c}\text { Texas } \\
\text { San Marcos } \\
\text { City of } \\
\text { September } 30\end{array}$ & $\begin{array}{c}\text { Texas } \\
\text { Seguin } \\
\text { City oi } \\
\text { September } 30\end{array}$ & $\begin{array}{c}\text { Texas } \\
\text { Texas } \\
\text { Municipal } \\
\text { Power Agency } \\
\text { September } 30\end{array}$ \\
\hline 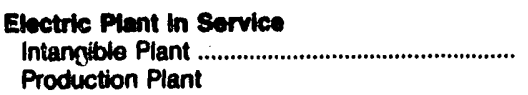 & 0 & 337 & 0 & 0 & 0 & 0 \\
\hline 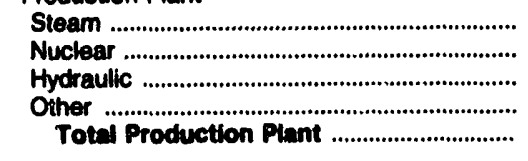 & $\begin{array}{r}0 \\
0 \\
14,752 \\
0 \\
14,752\end{array}$ & $\begin{array}{r}120,147 \\
0 \\
0 \\
0 \\
120,147\end{array}$ & $\begin{array}{r}543,680 \\
2,114,960 \\
0 \\
0 \\
2,658,640\end{array}$ & $\begin{array}{l}0 \\
0 \\
0 \\
0 \\
0\end{array}$ & $\begin{array}{r}0 \\
0 \\
521 \\
0 \\
521\end{array}$ & $\begin{array}{r}585,187 \\
0 \\
0 \\
0 \\
595,187\end{array}$ \\
\hline 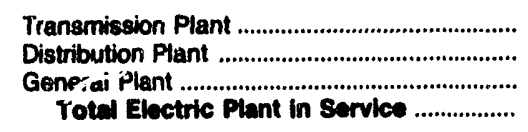 & $\begin{array}{r}8,377 \\
19,747 \\
4,909 \\
47,784\end{array}$ & $\begin{array}{r}0 \\
4,661 \\
0 \\
125,145\end{array}$ & $\begin{array}{r}179,503 \\
660,812 \\
43,263 \\
3,542,218\end{array}$ & $\begin{array}{r}0 \\
9,972 \\
1,156 \\
11,128\end{array}$ & $\begin{array}{r}880 \\
3,705 \\
899 \\
6,005\end{array}$ & $\begin{array}{r}139,211 \\
0 \\
3,605 \\
738,003\end{array}$ \\
\hline $\begin{array}{l}\text { Electric Plant Leased to Others ..................... } \\
\text { Construction Work ir. Progress - Electric ........ } \\
\text { Electric Plant Held for Future Use ................... } \\
\text { Electric Plant Acquisition Adjustments ............ } \\
\text { Total Electric Uttity Plant ........................... }\end{array}$ & $\begin{array}{r}0 \\
439 \\
0 \\
0 \\
48,224\end{array}$ & $\begin{array}{r}0 \\
270 \\
0 \\
0 \\
125,415\end{array}$ & $\begin{array}{r}487,537 \\
455,905 \\
33,500 \\
18,036 \\
4,537,196\end{array}$ & $\begin{array}{r}0 \\
1,679 \\
0 \\
0 \\
2,807\end{array}$ & $\begin{array}{r}0 \\
0 \\
0 \\
0 \\
6,005\end{array}$ & $\begin{array}{r}403 \\
202,648 \\
7,415 \\
0 \\
248,469\end{array}$ \\
\hline 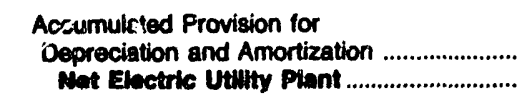 & $\begin{array}{l}16,423 \\
31,801\end{array}$ & $\begin{array}{l}30,856 \\
94,458\end{array}$ & $\begin{array}{r}735,737 \\
3,801,460\end{array}$ & $\begin{array}{r}2,044 \\
10,763\end{array}$ & $\begin{array}{l}3,256 \\
2,740\end{array}$ & $\begin{array}{l}195,374 \\
753,005\end{array}$ \\
\hline
\end{tabular}

Note: Totals may not equal sum of comronents because of independent rounding.

Source: Energy Information Administratic.3, Form EIA-412, "Annual Peport of Public Electric Utilities." 
Table 39. Electric Utility Plant by Major Publicly Owned Electric Utility Within State at End of Period, 1991 (Continued) (Thousand Dollars)

\begin{tabular}{|c|c|c|c|c|c|c|}
\hline Item & $\begin{array}{c}\text { Texas } \\
\text { Toledo Bend } \\
\text { Project } \\
\text { Joint } \\
\text { Oper } \\
\text { August } 30\end{array}$ & $\begin{array}{c}\text { Texas } \\
\text { Weatherford } \\
\text { Mun } \\
\text { Utility } \\
\text { System } \\
\text { September } 30\end{array}$ & $\begin{array}{c}\text { Utah } \\
\text { Bountiful } \\
\text { City City of } \\
\text { June } 30\end{array}$ & $\begin{array}{c}\text { Utah } \\
\text { Intermountain } \\
\text { Power Agency } \\
\text { June } 30\end{array}$ & $\begin{array}{l}\text { Utah } \\
\text { Logan } \\
\text { City of } \\
\text { June } 30\end{array}$ & $\begin{array}{l}\text { Utah } \\
\text { Murray } \\
\text { City of } \\
\text { June } 30\end{array}$ \\
\hline 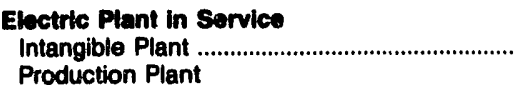 & 0 & 0 & 0 & 43,893 & 334 & 0 \\
\hline 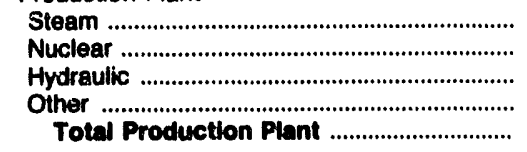 & $\begin{array}{r}0 \\
0 \\
71,415 \\
0 \\
71,415\end{array}$ & $\begin{array}{r}0 \\
0 \\
0 \\
970 \\
970\end{array}$ & $\begin{array}{r}0 \\
0 \\
4,504 \\
6,282 \\
10,787\end{array}$ & $\begin{array}{r}2,565,513 \\
0 \\
0 \\
0 \\
2,565,513\end{array}$ & $\begin{array}{r}0 \\
0 \\
14,168 \\
0 \\
14,168\end{array}$ & $\begin{array}{r}0 \\
0 \\
8,167 \\
1,800 \\
9,887\end{array}$ \\
\hline 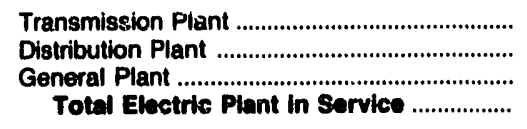 & $\begin{array}{r}0 \\
0 \\
758 \\
72,174\end{array}$ & $\begin{array}{r}0 \\
8,726 \\
1,065 \\
10,761\end{array}$ & $\begin{array}{r}0 \\
16,505 \\
2,786 \\
30,078\end{array}$ & $\begin{array}{r}41,207 \\
0 \\
111,941 \\
2,762,554\end{array}$ & $\begin{array}{r}774 \\
9,624 \\
2,126 \\
27,028\end{array}$ & $\begin{array}{r}4,236 \\
18,278 \\
5,560 \\
38,041\end{array}$ \\
\hline 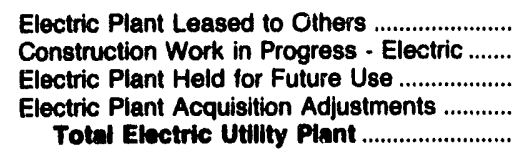 & $\begin{array}{r}0 \\
0 \\
0 \\
0 \\
72,174\end{array}$ & $\begin{array}{r}0 \\
0 \\
0 \\
0 \\
10,761\end{array}$ & $\begin{array}{r}0 \\
3,929 \\
0 \\
0 \\
34,007\end{array}$ & $\begin{array}{r}0 \\
43,360 \\
0 \\
0 \\
2,805,914\end{array}$ & $\begin{array}{r}0 \\
50 \\
0 \\
0 \\
27,078\end{array}$ & $\begin{array}{r}0 \\
154 \\
0 \\
0 \\
38,185\end{array}$ \\
\hline 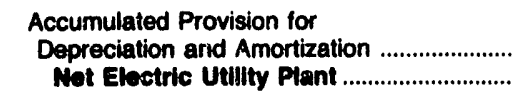 & $\begin{array}{r}0 \\
72,174\end{array}$ & $\begin{array}{l}5,663 \\
5,098\end{array}$ & $\begin{array}{l}10,438 \\
23,569\end{array}$ & $\begin{array}{r}355,628 \\
2,450,286\end{array}$ & $\begin{array}{r}7,304 \\
19,772\end{array}$ & $\begin{array}{l}16,230 \\
21,965\end{array}$ \\
\hline
\end{tabular}

\begin{tabular}{|c|c|c|c|c|c|c|}
\hline Item & $\begin{array}{l}\text { Utah } \\
\text { Provo } \\
\text { City Corp } \\
\text { June } 30\end{array}$ & $\begin{array}{c}\text { Utah } \\
\text { St George } \\
\text { City of } \\
\text { June } 30\end{array}$ & $\begin{array}{c}\text { Utah } \\
\text { Utah } \\
\text { Associated } \\
\text { Mun } \\
\text { Power Sys } \\
\text { March } 31\end{array}$ & $\begin{array}{c}\text { Utah } \\
\text { Utah } \\
\text { Municipal } \\
\text { Power Agency } \\
\text { June } 30\end{array}$ & $\begin{array}{c}\text { Vermont } \\
\text { Burlington } \\
\text { City of } \\
\text { December } 31\end{array}$ & $\begin{array}{l}\text { Vermont } \\
\text { Vermont } \\
\text { Public } \\
\text { Pwr } \\
\text { Supply Auth } \\
\text { December } 31\end{array}$ \\
\hline 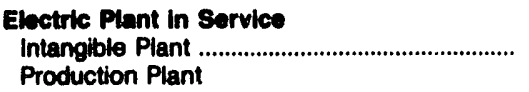 & 0 & 0 & 0 & 0 & 383 & 0 \\
\hline 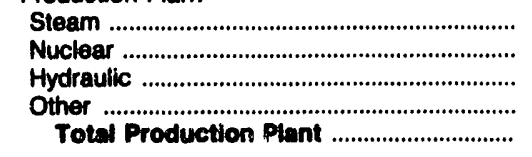 & $\begin{array}{r}40,125 \\
0 \\
0 \\
10,230 \\
50,355\end{array}$ & $\begin{array}{r}0 \\
0 \\
554 \\
6,198 \\
6,752\end{array}$ & $\begin{array}{r}43,792 \\
0 \\
0 \\
0 \\
43,782\end{array}$ & $\begin{array}{r}25,672 \\
0 \\
0 \\
0 \\
25,672\end{array}$ & $\begin{array}{r}39,289 \\
0 \\
0 \\
3,571 \\
42,890\end{array}$ & $\begin{array}{r}16,776 \\
0 \\
0 \\
0 \\
16,776\end{array}$ \\
\hline 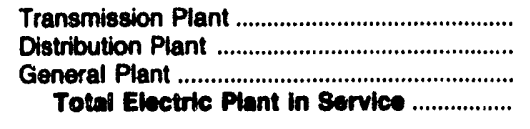 & $\begin{array}{r}8,567 \\
16,470 \\
3,649 \\
79,042\end{array}$ & $\begin{array}{r}7,250 \\
7,187 \\
1,898 \\
23,088\end{array}$ & $\begin{array}{r}16,917 \\
0 \\
606 \\
61,315\end{array}$ & $\begin{array}{r}8,054 \\
0 \\
0 \\
33,725\end{array}$ & $\begin{array}{r}3,670 \\
18,238 \\
5,534 \\
70,683\end{array}$ & $\begin{array}{r}2,954 \\
0 \\
738 \\
20,468\end{array}$ \\
\hline 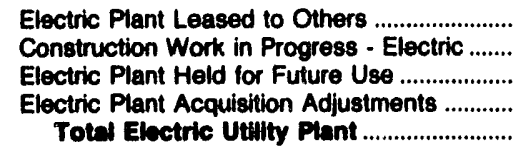 & $\begin{array}{r}0 \\
0 \\
0 \\
0 \\
79,042\end{array}$ & $\begin{array}{r}0 \\
0 \\
0 \\
0 \\
23,088\end{array}$ & $\begin{array}{r}0 \\
10,097 \\
0 \\
4,254 \\
75,686\end{array}$ & $\begin{array}{r}0 \\
0 \\
0 \\
0 \\
33,725\end{array}$ & $\begin{array}{r}0 \\
5,665 \\
89 \\
0 \\
78,438\end{array}$ & $\begin{array}{r}0 \\
0 \\
0 \\
0 \\
20,488\end{array}$ \\
\hline 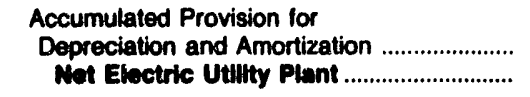 & $\begin{array}{l}28,414 \\
50,628\end{array}$ & $\begin{array}{r}6,323 \\
16,764\end{array}$ & $\begin{array}{l}17,047 \\
58,819\end{array}$ & $\begin{array}{r}4,654 \\
29,072\end{array}$ & $\begin{array}{l}15,191 \\
61,247\end{array}$ & $\begin{array}{r}6,263 \\
14,205\end{array}$ \\
\hline
\end{tabular}

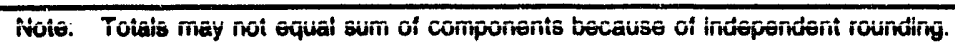

Source: Energy Information Administration, Form EIA-412, "Annual Report of Public Electric Utilities." 
Table 39. Electric Utillty Plant by Major Publicly Owned Electric Utility Within State at End of Period, 1991 (Continued) (Thousand Dollars)

\begin{tabular}{|c|c|c|c|c|c|c|}
\hline Item & $\begin{array}{l}\text { Virginia } \\
\text { Bedford } \\
\text { City of } \\
\text { June } 30\end{array}$ & $\begin{array}{l}\text { Virginia } \\
\text { Bristol } \\
\text { Utilities } \\
\text { Board } \\
\text { June } 30\end{array}$ & $\begin{array}{l}\text { Virginia } \\
\text { Danville } \\
\text { City of } \\
\text { June } 30\end{array}$ & $\begin{array}{c}\text { Virginia } \\
\begin{array}{c}\text { Harrisonburg } \\
\text { City of }\end{array} \\
\text { June } 30\end{array}$ & $\begin{array}{c}\text { Virginia } \\
\begin{array}{c}\text { Manassas } \\
\text { City of }\end{array} \\
\text { June } 30\end{array}$ & $\begin{array}{l}\text { Virginia } \\
\text { Martinsville } \\
\text { City of } \\
\text { June } 30\end{array}$ \\
\hline $\begin{array}{l}\text { Electrlc Plant in Sorvice } \\
\text { Intangible Plant } \\
\text { Production Plant }\end{array}$ & 164 & 0 & 781 & 0 & $\mathbf{0}$ & 0 \\
\hline 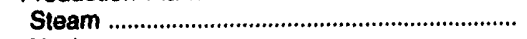 & 0 & 0 & 0 & 286 & 0 & 0 \\
\hline Nuclear ………………………………………... & 0 & 0 & 0 & 0 & 0 & 0 \\
\hline 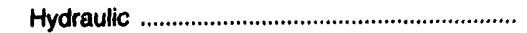 & 11,065 & 0 & 2,977 & 0 & 0 & 255 \\
\hline 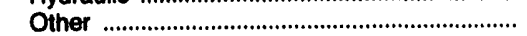 & & 0 & 0 & 2,392 & 0 & \\
\hline Total Production Plant .............................. & 11,065 & 0 & 2,977 & 2,678 & $\mathbf{0}$ & 255 \\
\hline 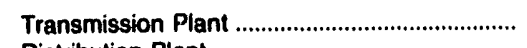 & 2,168 & $\begin{array}{r}0 \\
17496\end{array}$ & $\begin{array}{r}1,807 \\
39,201\end{array}$ & $\begin{array}{r}4,033 \\
23 ? 10\end{array}$ & $\begin{array}{r}15 \\
34057\end{array}$ & \\
\hline 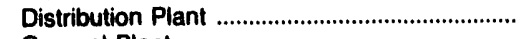 & 3,181 & 17,496 & 39,201 & $\begin{array}{r}23,210 \\
2,285\end{array}$ & 34,057 & 14,521 \\
\hline 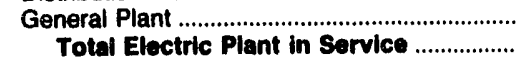 & $\begin{array}{r}369 \\
16,946\end{array}$ & $\begin{array}{r}2,749 \\
20,245\end{array}$ & $\begin{array}{r}1,880 \\
46,646\end{array}$ & $\begin{array}{r}2,285 \\
32,206\end{array}$ & $\begin{array}{r}0 \\
34,072\end{array}$ & $\begin{array}{r}675 \\
15,452\end{array}$ \\
\hline Electric Plant Leased to Others ........................... & 0 & 0 & 0 & 0 & 0 & 0 \\
\hline Construction Work in Progress - Electric ....... & 210 & 570 & 2,091 & 1,258 & 0 & 0 \\
\hline Electric Plant Held for Future Use ................... & 0 & $\mathbf{0}$ & 0 & & 0 & 0 \\
\hline Electric Plant Acquisition Adjustments ............. & & & & $\begin{array}{r}3,739 \\
\end{array}$ & & $\begin{aligned} 0 \\
15\end{aligned}$ \\
\hline Total Electric Utility Plant .............................. & 17,157 & 20,815 & 48,738 & 37,203 & 34,072 & 15,452 \\
\hline Accumulated Provision for & & & & & & \\
\hline 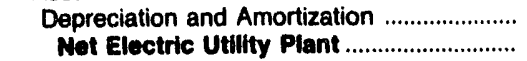 & $\begin{array}{r}3,955 \\
13,202\end{array}$ & $\begin{array}{r}9,555 \\
11,260\end{array}$ & $\begin{array}{l}19,962 \\
28,776\end{array}$ & $\begin{array}{l}11,223 \\
25,980\end{array}$ & $\begin{array}{r}8,708 \\
25,364\end{array}$ & $\begin{array}{r}4,791 \\
10,661\end{array}$ \\
\hline
\end{tabular}

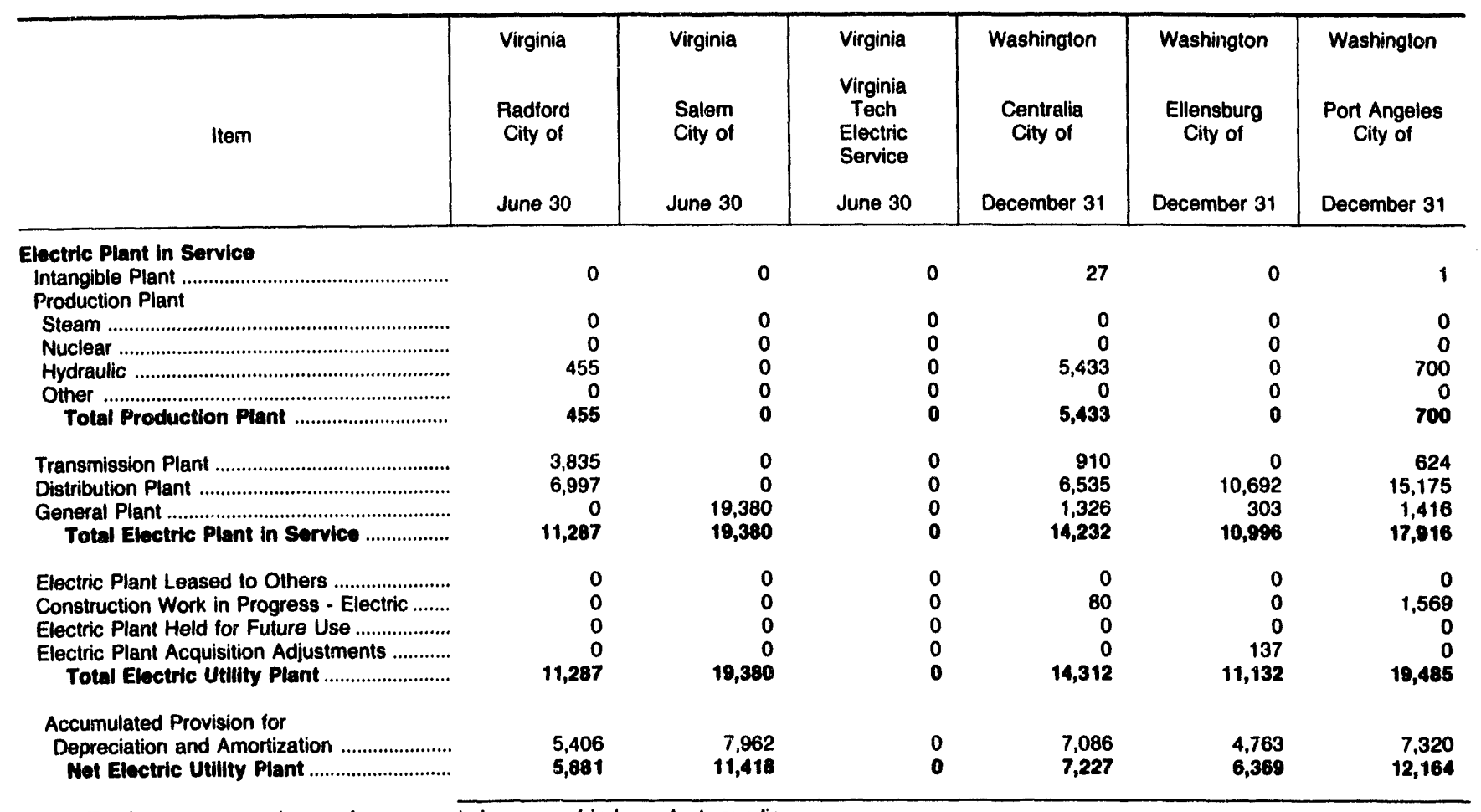

Note: Totals may not equal sum of components because of independent rounding.

Source: Energy infourination Autminiatration, Form E!A.412. "Annula) Repport of Public Electric Utilities." 
Table 39. Electric Utility Plant by Major Publicly Owned Electric Utility Within State at End of Period, 1991 (Continued) (Thousand Dollars)

\begin{tabular}{|c|c|c|c|c|c|c|}
\hline liem & $\begin{array}{l}\text { Washington } \\
\text { PUD No } 1 \\
\text { of } \\
\text { Benton } \\
\text { County } \\
\text { December } 31\end{array}$ & $\begin{array}{c}\text { Washington } \\
\text { PUD No } 1 \\
\text { of } \\
\text { Chelan } \\
\text { County } \\
\text { December } 31\end{array}$ & $\begin{array}{l}\text { Washington } \\
\text { PUD No } 1 \text { of } \\
\text { Clallam } \\
\text { County } \\
\text { December } 31\end{array}$ & $\begin{array}{c}\text { Washington } \\
\text { PUD No } 1 \\
\text { of } \\
\text { Clark } \\
\text { County } \\
\text { December } 31\end{array}$ & $\begin{array}{l}\text { Washington } \\
\text { PUD No } 1 \text { of } \\
\text { Cowlitz } \\
\text { County } \\
\text { December } 31\end{array}$ & $\begin{array}{l}\text { Washington } \\
\text { PUD No } 1 \text { of } \\
\text { Douglas } \\
\text { County } \\
\text { December } 31\end{array}$ \\
\hline 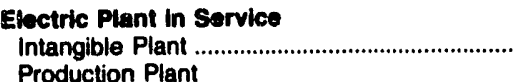 & 58 & 1,641 & 17 & 389 & 145 & 160 \\
\hline 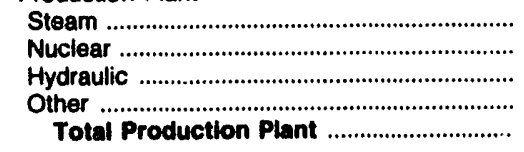 & $\begin{array}{l}0 \\
0 \\
0 \\
0 \\
0\end{array}$ & $\begin{array}{r}0 \\
0 \\
679,349 \\
0 \\
679,349\end{array}$ & $\begin{array}{l}0 \\
0 \\
0 \\
0 \\
0\end{array}$ & $\begin{array}{l}0 \\
0 \\
0 \\
0 \\
0\end{array}$ & $\begin{array}{r}0 \\
0 \\
19,504 \\
0 \\
19,504\end{array}$ & $\begin{array}{r}0 \\
0 \\
178,267 \\
0 \\
178,287\end{array}$ \\
\hline 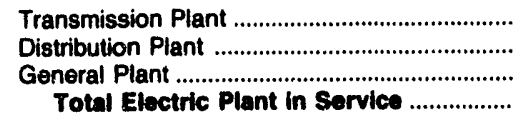 & $\begin{array}{r}2,288 \\
61,836 \\
7,498 \\
71,680\end{array}$ & $\begin{array}{r}44,687 \\
83,916 \\
19,020 \\
828,613\end{array}$ & $\begin{array}{r}4,594 \\
38,495 \\
6,924 \\
50,030\end{array}$ & $\begin{array}{r}7,062 \\
152,140 \\
22,852 \\
182,442\end{array}$ & $\begin{array}{r}7,650 \\
64,413 \\
10,924 \\
102,636\end{array}$ & $\begin{array}{r}18,864 \\
46,713 \\
7,895 \\
251,897\end{array}$ \\
\hline 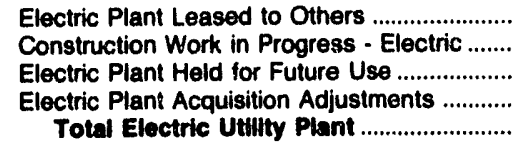 & $\begin{array}{r}0 \\
1,164 \\
245 \\
0 \\
73,089\end{array}$ & $\begin{array}{r}0 \\
13,651 \\
0 \\
0 \\
842,264\end{array}$ & $\begin{array}{r}0 \\
1,815 \\
86 \\
0 \\
51,830\end{array}$ & $\begin{array}{r}658 \\
2,899 \\
105 \\
2,593 \\
188,697\end{array}$ & $\begin{array}{r}0 \\
308 \\
0 \\
0 \\
102,944\end{array}$ & $\begin{array}{r}0 \\
7,439 \\
0 \\
862 \\
260,299\end{array}$ \\
\hline 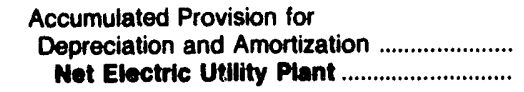 & $\begin{array}{l}29,212 \\
43,878\end{array}$ & $\begin{array}{l}131,479 \\
710,785\end{array}$ & $\begin{array}{l}24,526 \\
27,405\end{array}$ & $\begin{array}{r}71,310 \\
117,386\end{array}$ & $\begin{array}{l}43,303 \\
59,640\end{array}$ & $\begin{array}{r}38,505 \\
221,793\end{array}$ \\
\hline
\end{tabular}

\begin{tabular}{|c|c|c|c|c|c|c|}
\hline Item & $\begin{array}{l}\text { Washington } \\
\text { PUD No } 1 \text { of } \\
\text { Franklin } \\
\text { County } \\
\text { December } 31\end{array}$ & $\begin{array}{c}\text { Washington } \\
\text { PUD No } 1 \\
\text { of } \\
\text { Grays } \\
\text { Harbor Cnty } \\
\text { December } 31\end{array}$ & $\begin{array}{l}\text { Washington } \\
\text { PUD No } 1 \text { of } \\
\text { Klickitat } \\
\text { County } \\
\text { December } 31\end{array}$ & $\begin{array}{c}\text { Washington } \\
\text { PUD No } 1 \\
\text { of } \\
\text { Lewis } \\
\text { County } \\
\text { December } 31\end{array}$ & $\begin{array}{l}\text { Washington } \\
\text { PUD No } 1 \text { of } \\
\text { Okanogan } \\
\text { County } \\
\text { December } 31\end{array}$ & $\begin{array}{l}\text { Washington } \\
\text { PUD No } 1 \text { of } \\
\text { Pend Oreille } \\
\text { Cnty } \\
\text { December } 31\end{array}$ \\
\hline 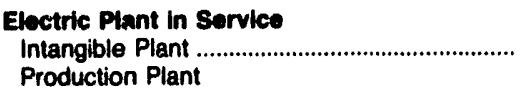 & 115 & 188 & 238 & 121 & 92 & 117 \\
\hline 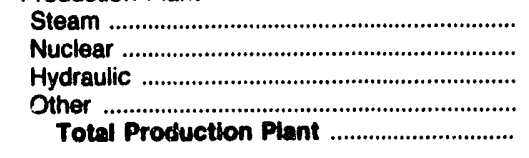 & $\begin{array}{l}0 \\
0 \\
0 \\
0 \\
0\end{array}$ & $\begin{array}{r}13,402 \\
0 \\
125 \\
0 \\
13,527\end{array}$ & $\begin{array}{l}0 \\
0 \\
0 \\
0 \\
0\end{array}$ & $\begin{array}{r}0 \\
0 \\
19,084 \\
0 \\
19,084\end{array}$ & $\begin{array}{r}0 \\
0 \\
582 \\
0 \\
582\end{array}$ & $\begin{array}{r}0 \\
0 \\
23,928 \\
0 \\
23,928\end{array}$ \\
\hline 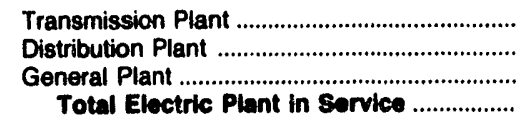 & $\begin{array}{r}1,281 \\
28,933 \\
4,388 \\
34,717\end{array}$ & $\begin{array}{l}11,951 \\
51,993 \\
12,784 \\
80,442\end{array}$ & $\begin{array}{r}1,934 \\
23,543 \\
3,226 \\
28,242\end{array}$ & $\begin{array}{r}4,693 \\
41,094 \\
4,068 \\
69,081\end{array}$ & $\begin{array}{r}2,416 \\
35,748 \\
5,001 \\
43,839\end{array}$ & $\begin{array}{r}625 \\
14,091 \\
2,220 \\
40,090\end{array}$ \\
\hline 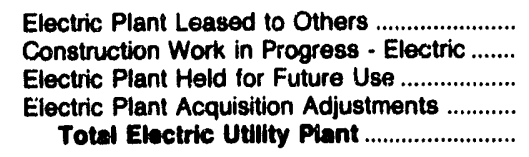 & $\begin{array}{r}0 \\
220 \\
0 \\
0 \\
34,937\end{array}$ & $\begin{array}{r}0 \\
1,581 \\
0 \\
0 \\
92,023\end{array}$ & $\begin{array}{r}0 \\
4,274 \\
0 \\
503 \\
33,719\end{array}$ & $\begin{array}{r}0 \\
0 \\
0 \\
0 \\
69,081\end{array}$ & $\begin{array}{r}0 \\
1,138 \\
0 \\
0 \\
44,977\end{array}$ & $\begin{array}{r}0 \\
181 \\
0 \\
0 \\
41,161\end{array}$ \\
\hline 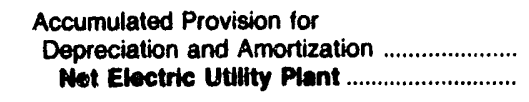 & $\begin{array}{l}13,314 \\
21,623\end{array}$ & $\begin{array}{l}32,334 \\
59,689\end{array}$ & $\begin{array}{l}11,417 \\
22,302\end{array}$ & $\begin{array}{l}13,098 \\
55,936\end{array}$ & $\begin{array}{l}21,155 \\
23,822\end{array}$ & $\begin{array}{l}12,910 \\
28,252\end{array}$ \\
\hline
\end{tabular}

Note: Totals may not equal sum of components because of independent rounding.

Source: Energy Information Administration, Form EIA-412, "Annual Report of Public Electric Utilities." 
Table 39. Electric Utility Plant by Major Publicly Owned Electric Utility Within State at End of Period, 1991 (Continued) (Thousand Dollars)

\begin{tabular}{|c|c|c|c|c|c|c|}
\hline Item & $\begin{array}{l}\text { Washington } \\
\text { PUD No } 1 \text { of } \\
\text { Snohomish } \\
\text { County } \\
\text { December } 31\end{array}$ & $\begin{array}{l}\text { Washington } \\
\text { PUD No } 1 \text { of } \\
\text { Whatcom } \\
\text { County } \\
\text { December } 31\end{array}$ & $\begin{array}{c}\text { Washington } \\
\text { PUD No } 2 \\
\text { of } \\
\text { Grant } \\
\text { County } \\
\text { December } 31\end{array}$ & $\begin{array}{l}\text { Washington } \\
\text { PUD No } 2 \text { of } \\
\text { Pacific } \\
\text { County } \\
\text { December } 31\end{array}$ & $\begin{array}{c}\text { Washington } \\
\text { PUD No } 3 \\
\text { of } \\
\text { Mason } \\
\text { County } \\
\text { December } 31\end{array}$ & $\begin{array}{c}\text { Washington } \\
\text { Richland } \\
\text { City of } \\
\text { December } 31\end{array}$ \\
\hline 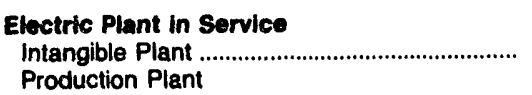 & 14 & 0 & 33,048 & 0 & 12 & 0 \\
\hline 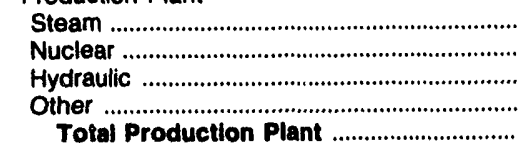 & $\begin{array}{r}27,224 \\
0 \\
208,020 \\
0 \\
235,244\end{array}$ & $\begin{array}{l}0 \\
0 \\
0 \\
0 \\
0\end{array}$ & $\begin{array}{r}0 \\
0 \\
318,207 \\
0 \\
318,207\end{array}$ & $\begin{array}{l}0 \\
0 \\
0 \\
0 \\
0\end{array}$ & $\begin{array}{l}0 \\
0 \\
0 \\
0 \\
0\end{array}$ & $\begin{array}{l}0 \\
0 \\
0 \\
0 \\
0\end{array}$ \\
\hline 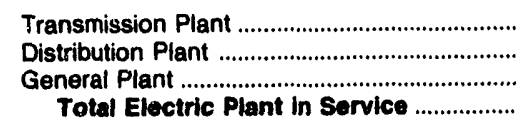 & $\begin{array}{r}30,368 \\
316,186 \\
67,830 \\
649,642\end{array}$ & $\begin{array}{r}916 \\
0 \\
66 \\
983\end{array}$ & $\begin{array}{r}50,496 \\
123,874 \\
42,916 \\
568,541\end{array}$ & $\begin{array}{r}1,191 \\
20,245 \\
2,449 \\
23,885\end{array}$ & $\begin{array}{r}928 \\
44,416 \\
3,982 \\
49,338\end{array}$ & $\begin{array}{r}659 \\
35,141 \\
1,303 \\
37,103\end{array}$ \\
\hline $\begin{array}{l}\text { Electric Plant Leased to Others ..................... } \\
\text { Construction Work in Progress - Electric ........ } \\
\text { Electric Plant Held for Future Use ................... } \\
\text { Electric Plant Acquisition Adjustments ............ } \\
\text { Total Electric Utllity Plant .............................. }\end{array}$ & $\begin{array}{r}0 \\
27,943 \\
211 \\
0 \\
677,795\end{array}$ & $\begin{array}{r}0 \\
0 \\
0 \\
0 \\
983\end{array}$ & $\begin{array}{r}0 \\
25,184 \\
0 \\
677 \\
594,402\end{array}$ & $\begin{array}{r}0 \\
3,257 \\
0 \\
0 \\
27,142\end{array}$ & $\begin{array}{r}0 \\
3,173 \\
0 \\
0 \\
52,511\end{array}$ & $\begin{array}{r}0 \\
1,200 \\
0 \\
0 \\
38,303\end{array}$ \\
\hline 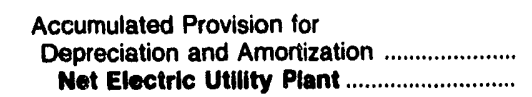 & $\begin{array}{l}156,823 \\
520,972\end{array}$ & $\begin{array}{l}592 \\
391\end{array}$ & $\begin{array}{l}183,818 \\
410,584\end{array}$ & $\begin{array}{l}11,650 \\
15,492\end{array}$ & $\begin{array}{l}14,030 \\
38,481\end{array}$ & $\begin{array}{l}13,614 \\
24,689\end{array}$ \\
\hline
\end{tabular}

\begin{tabular}{|c|c|c|c|c|c|c|}
\hline Item & $\begin{array}{c}\text { Washington } \\
\text { Seattle } \\
\text { City of } \\
\text { December } 31\end{array}$ & $\begin{array}{c}\text { Washington } \\
\text { Tacoma } \\
\text { City of } \\
\text { December } 31\end{array}$ & $\begin{array}{c}\text { Washington } \\
\text { Vera } \\
\text { Irrigation } \\
\text { District \#15 } \\
\text { December } 31\end{array}$ & $\begin{array}{l}\text { Washington } \\
\text { Washington } \\
\text { Pub } \\
\text { Pwr } \\
\text { Supply Sys } \\
\text { June } 30\end{array}$ & $\begin{array}{c}\text { Wisconsin } \\
\text { Jefferson } \\
\text { City of } \\
\text { December } 31\end{array}$ & $\begin{array}{c}\text { Wisconsin } \\
\begin{array}{c}\text { Kaukauna } \\
\text { City of }\end{array} \\
\text { December } 31\end{array}$ \\
\hline 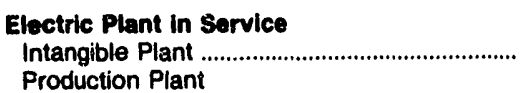 & 0 & 1,444 & 0 & 0 & 0 & 0 \\
\hline 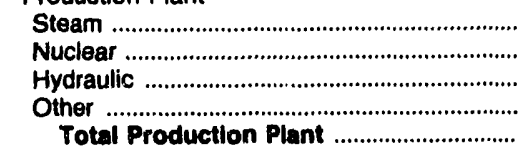 & $\begin{array}{r}25,087 \\
0 \\
328,631 \\
0 \\
353,718\end{array}$ & $\begin{array}{r}81,901 \\
0 \\
243,636 \\
0 \\
325,538\end{array}$ & $\begin{array}{l}0 \\
0 \\
0 \\
0 \\
0\end{array}$ & $\begin{array}{r}0 \\
3,463,870 \\
12,061 \\
0 \\
3,475,930\end{array}$ & $\begin{array}{l}0 \\
0 \\
0 \\
0 \\
0\end{array}$ & $\begin{array}{r}0 \\
0 \\
15,693 \\
2,423 \\
18,116\end{array}$ \\
\hline 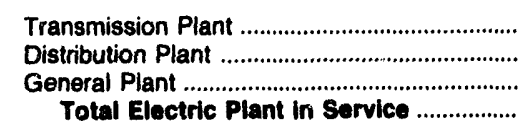 & $\begin{array}{r}75,042 \\
502,459 \\
88,121 \\
1,019,341\end{array}$ & $\begin{array}{r}64,055 \\
167,280 \\
28,613 \\
586,929\end{array}$ & $\begin{array}{r}0 \\
7,959 \\
2,356 \\
10,315\end{array}$ & $\begin{array}{r}12,373 \\
0 \\
88,167 \\
3,578,470\end{array}$ & $\begin{array}{r}0 \\
3,372 \\
615 \\
3,987\end{array}$ & $\begin{array}{r}1,029 \\
11,322 \\
2,956 \\
33,423\end{array}$ \\
\hline 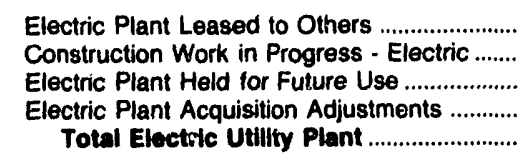 & $\begin{array}{r}0 \\
40,212 \\
2,358 \\
113,733 \\
1,175,644\end{array}$ & $\begin{array}{r}0 \\
30,780 \\
222 \\
0 \\
617,931\end{array}$ & $\begin{array}{r}0 \\
57 \\
0 \\
0 \\
10,372\end{array}$ & $\begin{array}{r}0 \\
48,311 \\
0 \\
0 \\
3,624,781\end{array}$ & $\begin{array}{r}0 \\
0 \\
394 \\
0 \\
4,381\end{array}$ & $\begin{array}{r}0 \\
1,594 \\
0 \\
0 \\
35,016\end{array}$ \\
\hline 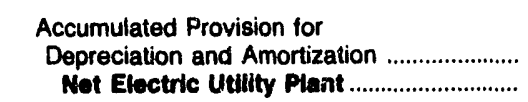 & $\begin{array}{l}462,917 \\
712,727\end{array}$ & $\begin{array}{l}196,994 \\
420,937\end{array}$ & $\begin{array}{l}3,414 \\
6,058\end{array}$ & $\begin{array}{r}852,389 \\
2,772,392\end{array}$ & $\begin{array}{l}1,699 \\
2,682\end{array}$ & $\begin{array}{l}14,410 \\
20,606\end{array}$ \\
\hline
\end{tabular}

Note: Totals may not equal sum of components because of independent rounding.

Source: Energy Information Administration, Form ElA-412, "Annual Report of Public Electric Utilities." 
Table 39. Electric Utility Plant by Major Publicly Owned Electric Utility Within State at End of Period, 1991 (Continued) (Thousand Dollars)

\begin{tabular}{|c|c|c|c|c|c|c|}
\hline Item & $\begin{array}{c}\text { Wisconsin } \\
\text { Manitowoc } \\
\text { Public } \\
\text { Utilities } \\
\text { December } 31\end{array}$ & $\begin{array}{l}\text { Wisconsin } \\
\text { Marshfield } \\
\text { City of }\end{array}$ & $\begin{array}{c}\text { Wisconsin } \\
\begin{array}{c}\text { Menasha } \\
\text { City of }\end{array} \\
\text { December } 31\end{array}$ & $\begin{array}{l}\text { Wisconsin } \\
\begin{array}{c}\text { New London } \\
\text { City of }\end{array} \\
\text { December ?1 }\end{array}$ & $\begin{array}{c}\text { Wisconsin } \\
\begin{array}{c}\text { Oconomowoc } \\
\text { City of }\end{array} \\
\text { December } 31\end{array}$ & $\begin{array}{l}\text { Wisconsin } \\
\text { Plymouth } \\
\text { City of } \\
\text { December } 31\end{array}$ \\
\hline $\begin{array}{l}\text { Electric Plant In Service } \\
\text { Intangible Plant ................................................ } \\
\text { Production Plant }\end{array}$ & 0 & 0 & 0 & 0 & 0 & 0 \\
\hline 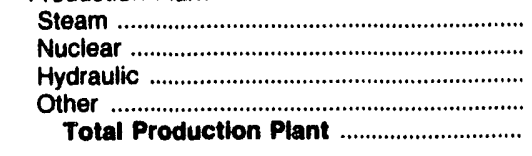 & $\begin{array}{r}37,701 \\
0 \\
0 \\
6,104 \\
43,805\end{array}$ & $\begin{array}{r}636 \\
0 \\
0 \\
0 \\
636\end{array}$ & $\begin{array}{r}7,745 \\
0 \\
0 \\
122 \\
7,866\end{array}$ & $\begin{array}{l}0 \\
0 \\
0 \\
0 \\
0\end{array}$ & $\begin{array}{l}0 \\
0 \\
0 \\
0 \\
0\end{array}$ & $\begin{array}{l}0 \\
0 \\
0 \\
0 \\
0\end{array}$ \\
\hline 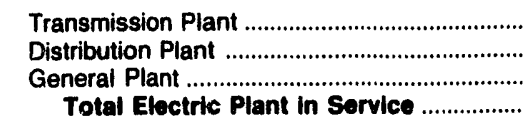 & $\begin{array}{r}2,979 \\
11,007 \\
2,733 \\
60,524\end{array}$ & $\begin{array}{r}7,214 \\
8,569 \\
1,430 \\
17,850\end{array}$ & $\begin{array}{r}1,568 \\
5,709 \\
944 \\
16,088\end{array}$ & $\begin{array}{r}372 \\
5,326 \\
910 \\
6,609\end{array}$ & $\begin{array}{r}0 \\
11,904 \\
719 \\
12,623\end{array}$ & $\begin{array}{r}218 \\
10,742 \\
887 \\
11,847\end{array}$ \\
\hline 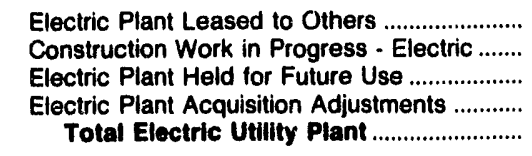 & $\begin{array}{r}0 \\
400 \\
314 \\
84 \\
61,322\end{array}$ & $\begin{array}{r}0 \\
469 \\
0 \\
0 \\
18,318\end{array}$ & $\begin{array}{r}0 \\
6,820 \\
61 \\
59 \\
23,029\end{array}$ & $\begin{array}{r}0 \\
456 \\
0 \\
0 \\
7,064\end{array}$ & $\begin{array}{r}0 \\
79 \\
0 \\
699 \\
13,401\end{array}$ & $\begin{array}{r}0 \\
17 \\
0 \\
0 \\
11,864\end{array}$ \\
\hline 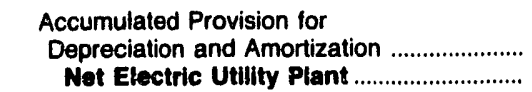 & $\begin{array}{l}17,817 \\
43,505\end{array}$ & $\begin{array}{r}5,646 \\
12,673\end{array}$ & $\begin{array}{r}9,923 \\
13,106\end{array}$ & $\begin{array}{l}1,649 \\
5,415\end{array}$ & $\begin{array}{l}4,418 \\
8,982\end{array}$ & $\begin{array}{l}4,895 \\
6,969\end{array}$ \\
\hline
\end{tabular}

\begin{tabular}{|c|c|c|c|c|c|c|}
\hline Item & $\begin{array}{l}\text { Wisconsin } \\
\begin{array}{l}\text { Peedsburg } \\
\text { Utility Comm }\end{array} \\
\text { December } 31\end{array}$ & $\begin{array}{c}\text { Wisconsin } \\
\text { Shawano } \\
\text { Municipal } \\
\text { Utilities } \\
\text { December } 31\end{array}$ & $\begin{array}{c}\text { Wisconsin } \\
\text { Sheboygan } \\
\text { Falls } \\
\text { City of } \\
\text { December } 31\end{array}$ & $\begin{array}{c}\text { Wisconsin } \\
\text { Sturgeon Bay } \\
\text { Combined } \\
\text { Utils } \\
\text { December } 31\end{array}$ & $\begin{array}{l}\text { Wisconsin } \\
\text { Wisconsin } \\
\text { Public } \\
\text { Power } \\
\text { Inc Sys } \\
\text { June } 30\end{array}$ & $\begin{array}{l}\text { Wisconsin } \\
\text { Wisconsin } \\
\text { Rapids W W } \\
\& \text { L } \\
\text { Comm } \\
\text { December } 31\end{array}$ \\
\hline $\begin{array}{l}\text { Electric Plant in Service } \\
\text { Intangible Plant .............................................. } \\
\text { Production Plant }\end{array}$ & 0 & 0 & 0 & 0 & 15,931 & 0 \\
\hline 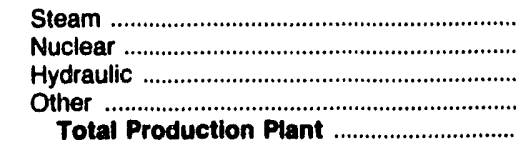 & $\begin{array}{l}0 \\
0 \\
0 \\
0 \\
0\end{array}$ & $\begin{array}{l}0 \\
0 \\
0 \\
0 \\
0\end{array}$ & $\begin{array}{l}0 \\
0 \\
0 \\
0 \\
0\end{array}$ & $\begin{array}{l}0 \\
0 \\
0 \\
0 \\
0\end{array}$ & $\begin{array}{r}76,021 \\
0 \\
0 \\
0 \\
76,021\end{array}$ & $\begin{array}{l}0 \\
0 \\
0 \\
0 \\
0\end{array}$ \\
\hline 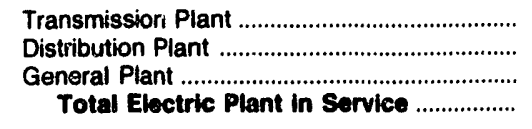 & $\begin{array}{r}574 \\
4,626 \\
5,735 \\
10,936\end{array}$ & $\begin{array}{r}353 \\
6,155 \\
1,028 \\
7,536\end{array}$ & $\begin{array}{r}512 \\
5,836 \\
556 \\
6,904\end{array}$ & $\begin{array}{r}2,153 \\
10,630 \\
2,189 \\
14,973\end{array}$ & $\begin{array}{r}0 \\
0 \\
3,284 \\
95,236\end{array}$ & $\begin{array}{r}0 \\
13,937 \\
1,109 \\
15,047\end{array}$ \\
\hline 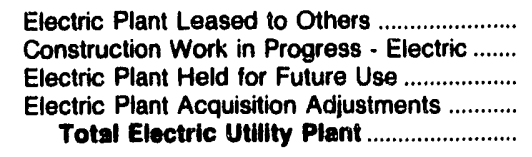 & $\begin{array}{r}0 \\
0 \\
0 \\
0 \\
10,936\end{array}$ & $\begin{array}{r}0 \\
79 \\
0 \\
0 \\
7,615\end{array}$ & $\begin{array}{r}0 \\
33 \\
0 \\
0 \\
6,937\end{array}$ & $\begin{array}{r}0 \\
45 \\
0 \\
23 \\
15,040\end{array}$ & $\begin{array}{r}0 \\
475 \\
0 \\
15,174 \\
110,885\end{array}$ & $\begin{array}{r}0 \\
156 \\
1 \\
35 \\
15,239\end{array}$ \\
\hline 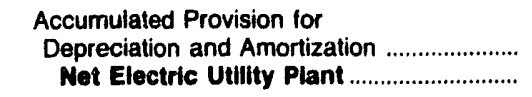 & $\begin{array}{l}4,321 \\
6,615\end{array}$ & $\begin{array}{l}2,299 \\
5,316\end{array}$ & $\begin{array}{l}2,507 \\
4,430\end{array}$ & $\begin{array}{r}3,870 \\
11,170\end{array}$ & $\begin{array}{l}24,303 \\
86,582\end{array}$ & $\begin{array}{r}587 \\
14,652\end{array}$ \\
\hline
\end{tabular}

Note: Totals may not equal sum of components because of independent rounding.

Source: Energy Information Administration, Form EIA-412, "Annual Report of Public Electric Utilities." 
Table 39. Electric Utility Plant by Major Publicly Owned Electric Utility Within State at End of Period, 1991 (Continued)

(Thousand Dollars)

\begin{tabular}{l|l|c|c}
\hline Item & Wyoming & $\begin{array}{c}\text { Wyoming } \\
\text { Wyoming } \\
\text { Municipal } \\
\text { Power Agency } \\
\text { Gillette } \\
\text { City of } \\
\text { June 30 }\end{array}$ & December 31
\end{tabular} \mid

\section{Electric Plant In Service}

intangible Plant

Production Plant

Steam ...

Nuclear

Hydraulic

Other

Total Production Plant

Transmission Plant

Distribution Plant

General Plant

Total Electric Plant in Service

Electric Plant Leased to Others ......................

Construction Work in Progress - Electric ........

Electric Plant Held for Future Use ..........

Electric Plant Acquisition Adjustments Total Electric Uttity Plant.

$\begin{array}{rr}0 & 828 \\ 0 & 15,187 \\ 0 & 0 \\ 0 & 0 \\ 0 & 0 \\ 0 & 15,187 \\ 685 & 5,128 \\ 15,784 & 0 \\ 209 & 764 \\ 16,678 & 21,906 \\ & \\ 0 & 0 \\ 0 & 3 \\ 0 & 0 \\ 0 & 2 \\ 18,678 & 21,912 \\ & \\ 6,487 & 5,439 \\ 10,191 & 16,473\end{array}$

Accumulated Provision for

Depreciation and Amortization ...................... Not Electric Utility Plant

Note: Totals may not equal sum of components because of independent rounding.

Source: Energy Information Administration, Form ElA-412, "Annual Report of Public Electric Utilities." 
Table 40. Number of Consumers, Sales, and Operating Revenue by Major Publicly Owned Electric Utility Within State, 1991

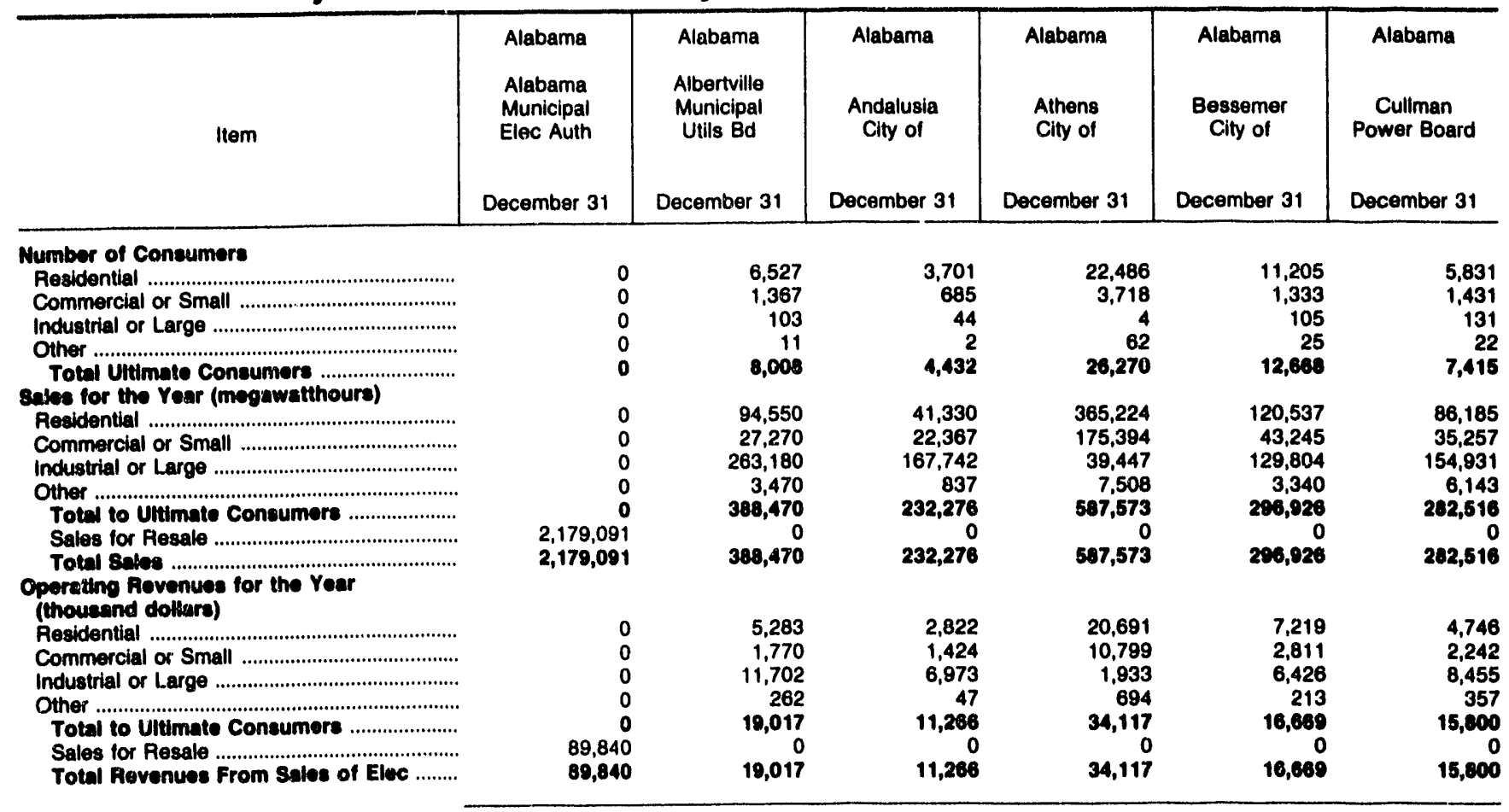

\begin{tabular}{|c|c|c|c|c|c|c|}
\hline Item & $\begin{array}{c}\text { Alabama } \\
\text { Decatur } \\
\text { City of } \\
\text { December } 31\end{array}$ & $\begin{array}{l}\text { Alabama } \\
\text { Dothan } \\
\text { City of } \\
\text { December } 31\end{array}$ & $\begin{array}{c}\text { Alabama } \\
\text { Florence } \\
\text { City of } \\
\text { December } 31\end{array}$ & $\begin{array}{c}\text { Alabama } \\
\text { Foley } \\
\text { Cily of } \\
\text { (Riviera Utils) } \\
\text { December } 31\end{array}$ & $\begin{array}{c}\text { Alabama } \\
\text { Fort Payne } \\
\text { Improvement } \\
\text { Auth } \\
\text { December } 31\end{array}$ & $\begin{array}{l}\text { Alabama } \\
\text { Guntersville } \\
\text { Electric } \\
\text { Board } \\
\text { December } 31\end{array}$ \\
\hline 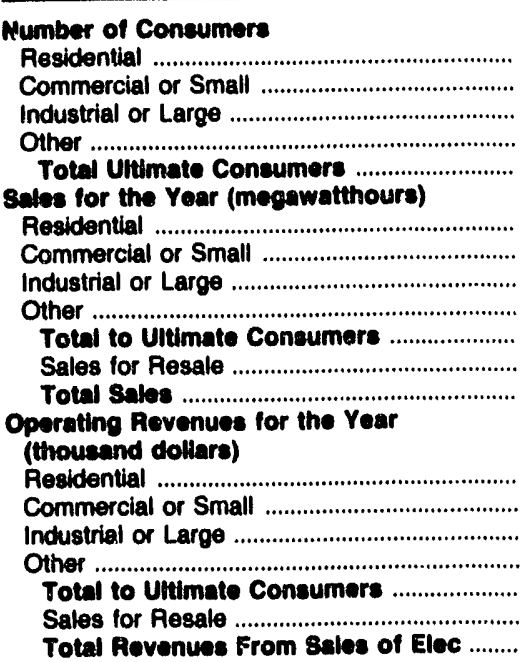 & $\begin{array}{r}342,933 \\
79,523 \\
893,724 \\
7,221 \\
1,323,401 \\
0 \\
1,323,401\end{array}$ & $\begin{array}{r}331,111 \\
107,598 \\
275,234 \\
169,507 \\
883,450 \\
0 \\
883,450\end{array}$ & $\begin{array}{r}33,016 \\
5,529 \\
7 \\
42 \\
38,594 \\
\\
536,198 \\
328,390 \\
63,417 \\
5,420 \\
931,425 \\
0 \\
931,425\end{array}$ & $\begin{array}{r}17,360 \\
3,308 \\
4 \\
81 \\
20,753 \\
\\
247,798 \\
128,547 \\
38,215 \\
8,367 \\
422,927 \\
0 \\
422,927\end{array}$ & $\begin{array}{r}5,596 \\
1,366 \\
141 \\
11 \\
7,114 \\
79,019 \\
30,118 \\
145,711 \\
4,805 \\
250,753 \\
0 \\
259,753\end{array}$ & $\begin{array}{r}4,261 \\
1,005 \\
81 \\
15 \\
5,362 \\
\\
57,758 \\
21,394 \\
120,171 \\
3,867 \\
203,200 \\
0 \\
203,200\end{array}$ \\
\hline
\end{tabular}

Note: Totals may not equal sum of components because of independent rounding.

Source: Energy Information Administration, Form ElA-861, "Annual Electric Utility Report." Data are submitted on a calendar year. 
Table 40. Number of Consumers, Sales, and Operating Revenue by Major Publicly Owned Electric Utility Within State, 1991 (Continued)

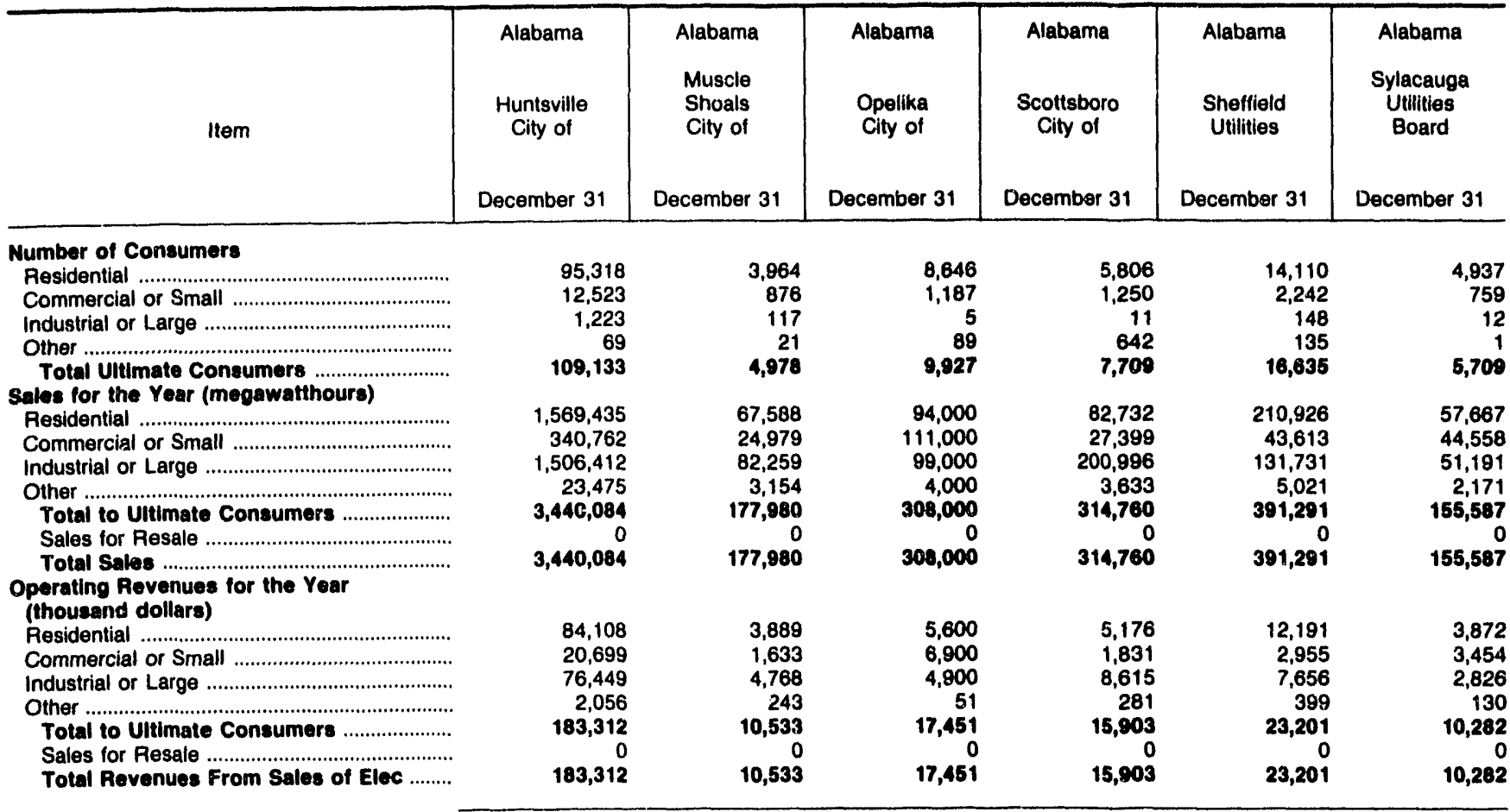

\begin{tabular}{|c|c|c|c|c|c|c|}
\hline Item & $\begin{array}{c}\text { Alabama } \\
\text { Troy } \\
\text { City of } \\
\text { December } 31\end{array}$ & $\begin{array}{l}\text { Alabama } \\
\text { Tuskegee } \\
\text { City of } \\
\text { December } 31\end{array}$ & $\begin{array}{c}\text { Alaska } \\
\text { Alaska } \\
\text { Energy } \\
\text { Authority } \\
\text { December } 31\end{array}$ & $\begin{array}{c}\text { Alaska } \\
\text { Anchorage } \\
\text { City of } \\
\text { December } 31\end{array}$ & $\begin{array}{c}\text { Alaska } \\
\text { Fairbanks } \\
\text { City of } \\
\text { December } 31\end{array}$ & $\begin{array}{c}\text { Alaska } \\
\begin{array}{c}\text { Ketchikan } \\
\text { City of }\end{array} \\
\text { December } 31\end{array}$ \\
\hline \multicolumn{7}{|l|}{ Number of Consumers } \\
\hline 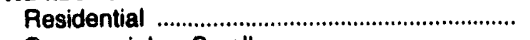 & 4,829 & 6,431 & 0 & 23,477 & 4,369 & 5,230 \\
\hline Commercial or Small & 907 & 622 & 0 & 5,394 & 1,360 & 926 \\
\hline Industrial or Large & 101 & 75 & 0 & 0 & 0 & 10 \\
\hline Other & 65 & 0 & 0 & 4,387 & 168 & 483 \\
\hline $\begin{array}{l}\text { Total Uitimate Consumers ......................... } \\
\text { Sales for the Year (megawatthours) }\end{array}$ & 5,902 & 7,128 & $\mathbf{0}$ & 33,258 & 5,897 & 6,640 \\
\hline Residential & 62,763 & 48,546 & 0 & 148,520 & 25,953 & 46,287 \\
\hline 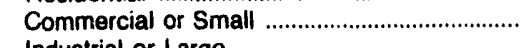 & $\begin{array}{r}19,712 \\
107561\end{array}$ & 12,572 & 0 & 639,195 & 102,271 & 57,492 \\
\hline Industrial or Large & 107,561 & 63,359 & 0 & & 0 & 12,123 \\
\hline 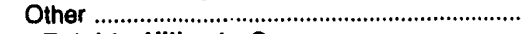 & 6,497 & 0 & 0 & 10,903 & 15,280 & 13,010 \\
\hline Total to Uitimate Consumers & $\begin{array}{r}186,533 \\
0 \\
109532\end{array}$ & $\begin{array}{r}124,477 \\
0\end{array}$ & $\begin{array}{r}0 \\
388,804\end{array}$ & $\begin{array}{r}798,618 \\
6,187\end{array}$ & $\begin{array}{r}143,504 \\
334\end{array}$ & $\begin{array}{r}128,912 \\
0\end{array}$ \\
\hline \multicolumn{7}{|l|}{$\begin{array}{l}\text { Operating Revenues for the Year } \\
\text { (thousand dollars) }\end{array}$} \\
\hline 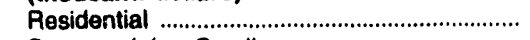 & 3,370 & 4,095 & 0 & 14,952 & 2,558 & 4,447 \\
\hline 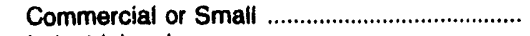 & 1,217 & 1,028 & 0 & 53,079 & 10,969 & 3,953 \\
\hline Industrial or Large & 5,957 & 3,234 & 0 & 0 & 0 & 994 \\
\hline 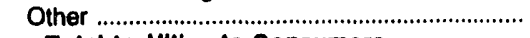 & 350 & & 0 & 1,419 & 1,501 & 660 \\
\hline 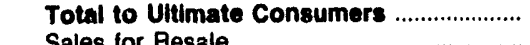 & 10,894 & $\begin{array}{r}8,357 \\
0\end{array}$ & & $\begin{array}{r}89,460 \\
219\end{array}$ & $\begin{array}{r}15,028 \\
14\end{array}$ & 10,054 \\
\hline $\begin{array}{l}\text { Sales for Resale ............................................ } \\
\text { Total Revenues From Sales of Elec ........ }\end{array}$ & $\begin{array}{r}0 \\
10,894\end{array}$ & $\begin{array}{r}0 \\
8,357\end{array}$ & $\begin{array}{l}20,385 \\
20,385\end{array}$ & $\begin{array}{r}219 \\
69,669\end{array}$ & $\begin{array}{r}14 \\
15,042\end{array}$ & $\begin{array}{r}0 \\
10,054\end{array}$ \\
\hline
\end{tabular}

Note: Totals may not equal sum of components because of independent rounding.

Source: Energy Information Administration, Form EIA-861, "Annual Electric Utility Report." Data are submitted on a calendar year. 
Table 40. Number of Consumers, Sales, and Operating Revenue by Major Publicly Owned Electric Utility Within State, 1991 (Continued)

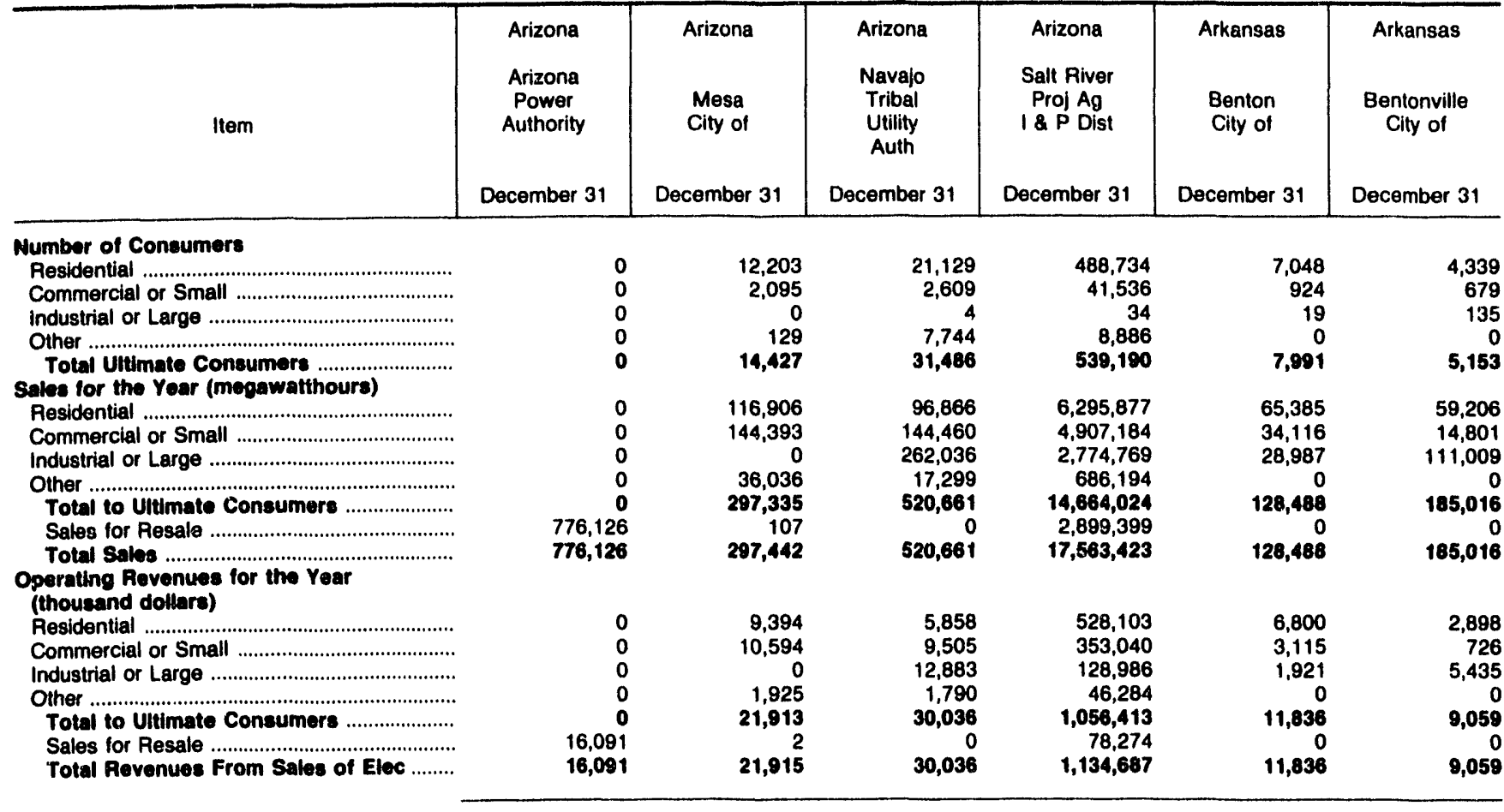

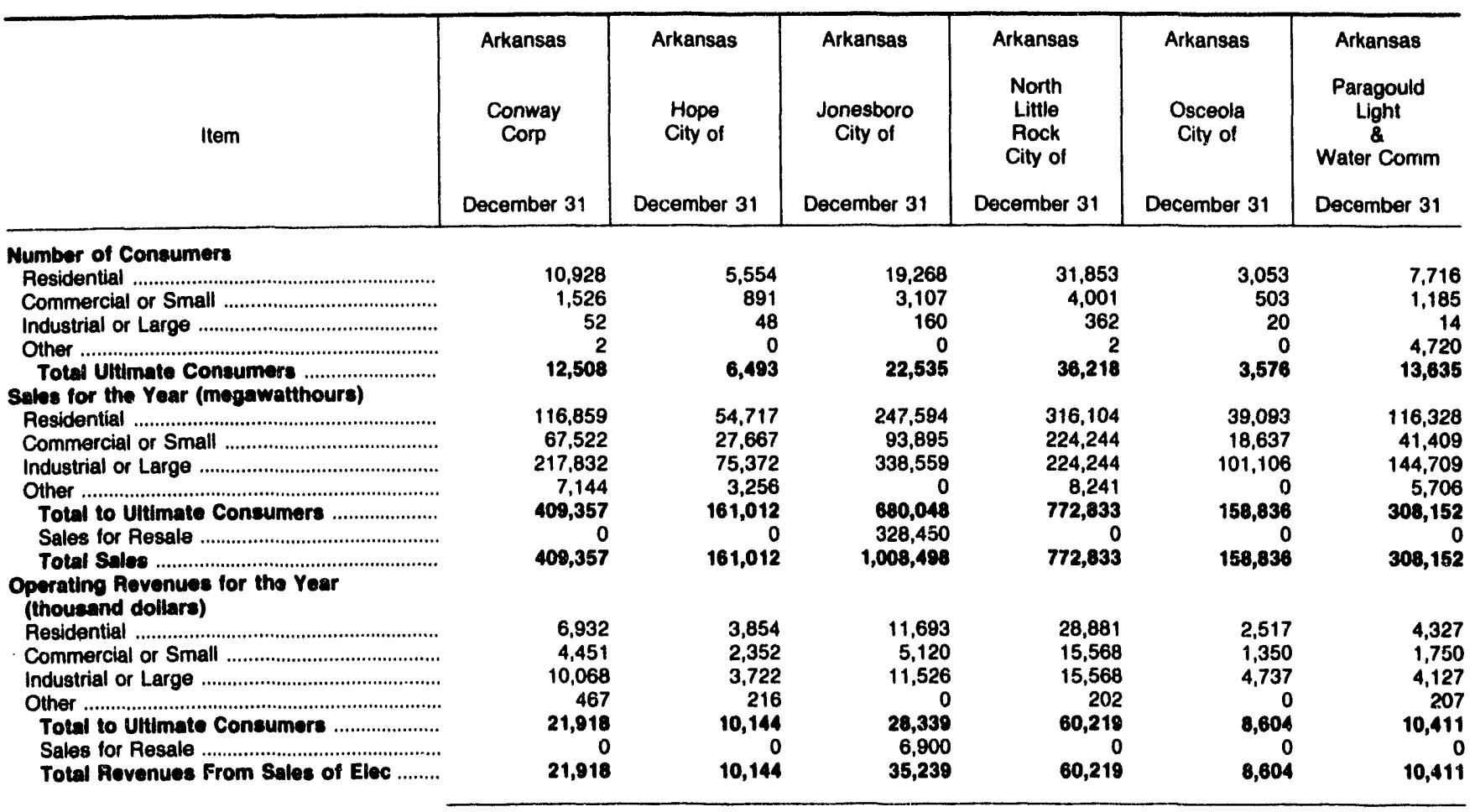

Note: Totals may not equal sum of components because of independent rounding.

Source: Energy Information Administration, Form ElA-861, "Annual Electric Utility Report." Data are submitted on a calendar year. 
Table 40. Number of Consumers, Sales, and Operating Revenue by Major Publicly Owned Electric Utility Within State, 1991 (Continued)

\begin{tabular}{|c|c|c|c|c|c|c|}
\hline Item & $\begin{array}{l}\text { Arkansas } \\
\text { Siloam } \\
\text { Springs } \\
\text { City of } \\
\text { December } 31\end{array}$ & $\begin{array}{c}\text { Arkansas } \\
\text { West } \\
\text { Memphis } \\
\text { Cily of } \\
\text { December } 31\end{array}$ & $\begin{array}{l}\text { California } \\
\text { Alameda } \\
\text { City of } \\
\text { December } 31\end{array}$ & $\begin{array}{l}\text { California } \\
\text { Anaheim } \\
\text { City of } \\
\text { December } 31\end{array}$ & $\begin{array}{c}\text { California } \\
\text { Azusa } \\
\text { City of } \\
\text { December } 31\end{array}$ & $\begin{array}{c}\text { California } \\
\text { Burbank } \\
\text { City of } \\
\text { December } 31\end{array}$ \\
\hline \multicolumn{7}{|l|}{ Number of Consumers } \\
\hline 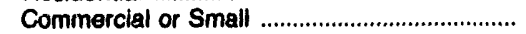 & 518 & 1,267 & 2,832 & 14,600 & 1,305 & 6,251 \\
\hline Industrial or Large & 82 & 0 & 292 & 610 & 30 & 183 \\
\hline 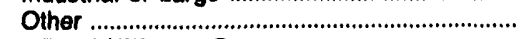 & 0 & 40 & 211 & 629 & 163 & 63 \\
\hline $\begin{array}{l}\text { Totil Uitimute Consumers ........................ } \\
\text { Sales for the Year (megawatthours) }\end{array}$ & 4,280 & 11,253 & 31,666 & 102,473 & 13,797 & 50,189 \\
\hline 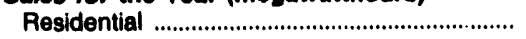 & 36,722 & 129,064 & 128,174 & 493,932 & 62,949 & 220,045 \\
\hline 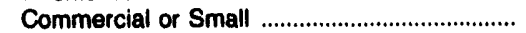 & 9,049 & 148,978 & 40,470 & 473,055 & 63,752 & 244,929 \\
\hline Industrial or Large & 121,430 & 0 & 131,813 & $1,120,778$ & 61,613 & 462,839 \\
\hline Other & 0 & 3,581 & 162,058 & 85,779 & 5,713 & 30,685 \\
\hline 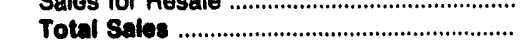 & 167,201 & 281,623 & 462,515 & $2,531,487$ & 194,027 & 959,351 \\
\hline \multicolumn{7}{|l|}{$\begin{array}{l}\text { Operating Revenues for the Year } \\
\text { (thousand dollars) }\end{array}$} \\
\hline 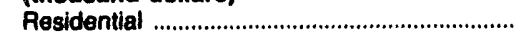 & 2,276 & 8,130 & 12,967 & 44,886 & 5,242 & 19,584 \\
\hline 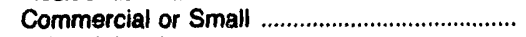 & 706 & 9,297 & 4,440 & 47,295 & 6,352 & 21,555 \\
\hline 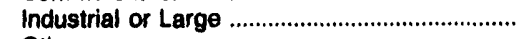 & 5,620 & 0 & 12,368 & 93,536 & 5,323 & 37,047 \\
\hline Other & & 203 & 12,229 & 7,107 & 470 & 2,906 \\
\hline Total to Uttimate Consumers ......................... & 8,602 & 17,630 & 42,004 & 192,824 & 17,387 & 81,092 \\
\hline Sales for Resale & & & & 5,603 & & \\
\hline Total Revenues From Sales of Elec ......... & 8,602 & 17,630 & 42,004 & 198,427 & 17,387 & 81,107 \\
\hline
\end{tabular}

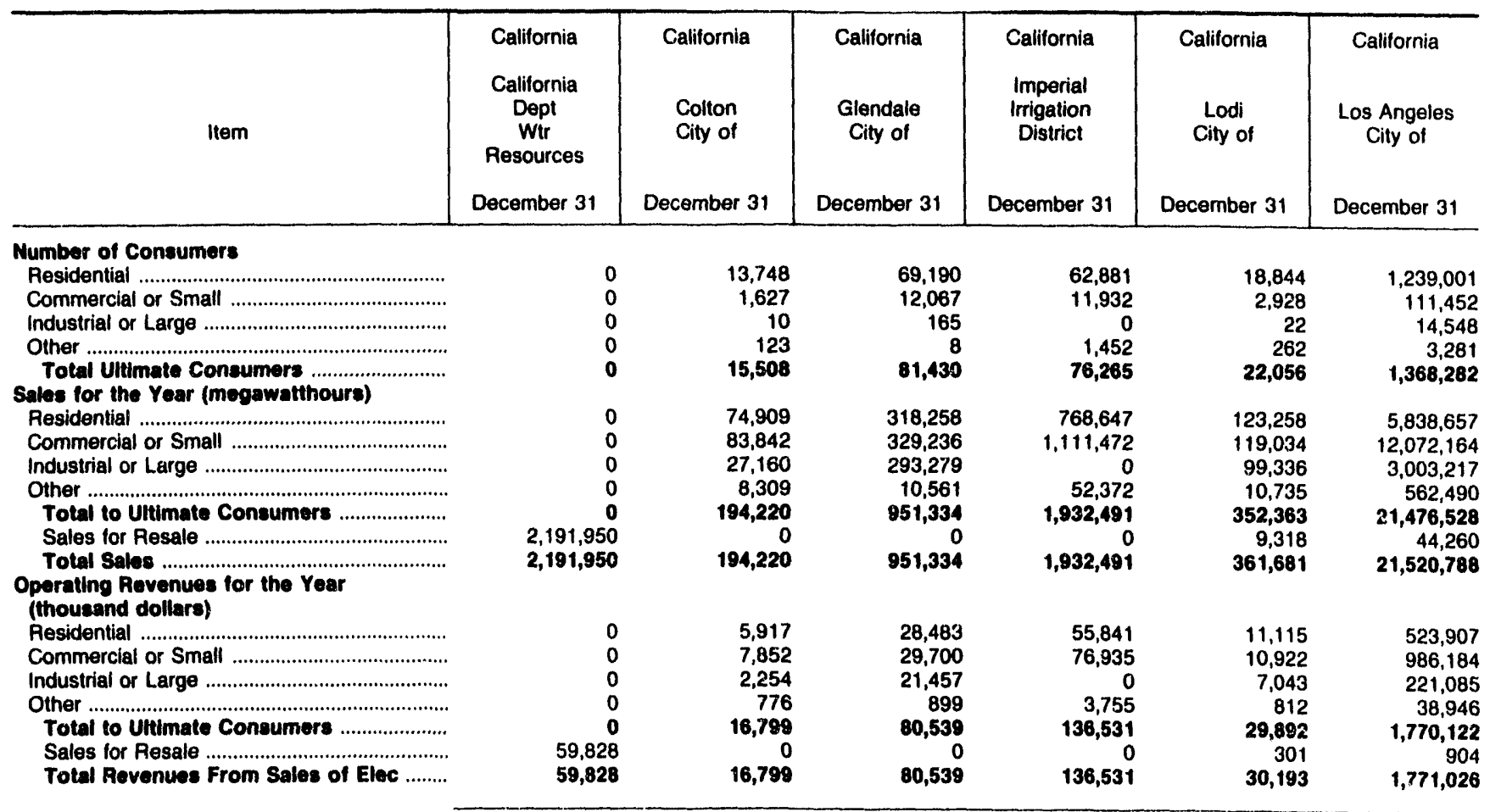

Note: Totals may not equal sum of components because of independent rounding

Source: Energy Information Administration, Form EIA-861, "Annual Electric Utility Report." Data are submitted on a calendar year. 
Table 40. Number of Consumers, Sales, and Operating Revenue by Major Publicly Owned Electric Utility Within State, 1991 (Continued)

\begin{tabular}{|c|c|c|c|c|c|c|}
\hline Item & $\begin{array}{l}\text { California } \\
\text { Metropolitan } \\
\text { Water } \\
\text { District } \\
\text { December } 31\end{array}$ & $\begin{array}{c}\text { California } \\
\text { Modesto } \\
\text { Irrigation } \\
\text { District } \\
\text { December } 31\end{array}$ & $\begin{array}{c}\text { California } \\
\text { MSR } \\
\text { Public } \\
\text { Power } \\
\text { Agency } \\
\text { December } 31\end{array}$ & $\begin{array}{l}\text { California } \\
\text { Northern } \\
\text { California } \\
\text { Power Agny } \\
\text { December } 31\end{array}$ & $\begin{array}{c}\text { California } \\
\text { Oakdale \& } \\
\text { South } \\
\text { San Joaquin } \\
\text { December } 31\end{array}$ & $\begin{array}{c}\text { California } \\
\text { Oroville } \\
\text { Wyandotte } \\
\text { Irrig Dist } \\
\text { December } 31\end{array}$ \\
\hline 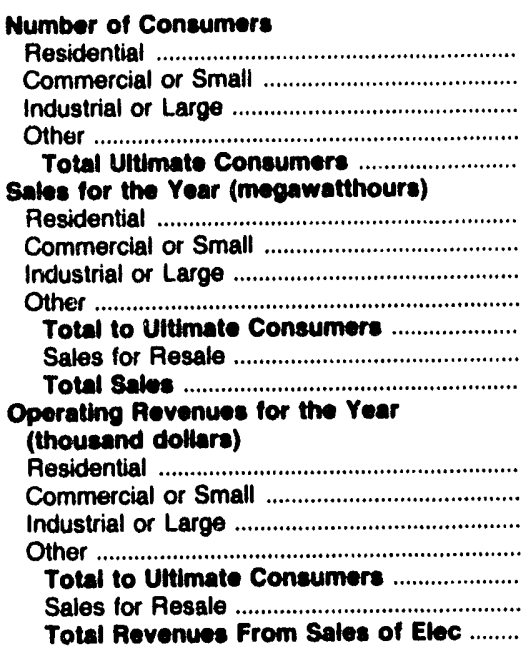 & $\begin{array}{r}0 \\
0 \\
0 \\
0 \\
0 \\
260,907 \\
280,907\end{array}$ & $\begin{array}{r}657,214 \\
629,488 \\
357,295 \\
67,960 \\
1,711,957 \\
384 \\
1,712,341\end{array}$ & $\begin{array}{r}0 \\
0 \\
0 \\
0 \\
0 \\
779,502 \\
779,502\end{array}$ & $\begin{array}{r}0 \\
0 \\
0 \\
0 \\
0 \\
0 \\
1,558,463 \\
1,558,463\end{array}$ & $\begin{array}{r}0 \\
0 \\
0 \\
0 \\
0 \\
328,646 \\
328,646\end{array}$ & $\begin{array}{r}0 \\
0 \\
0 \\
0 \\
0 \\
314,520 \\
314,520\end{array}$ \\
\hline
\end{tabular}

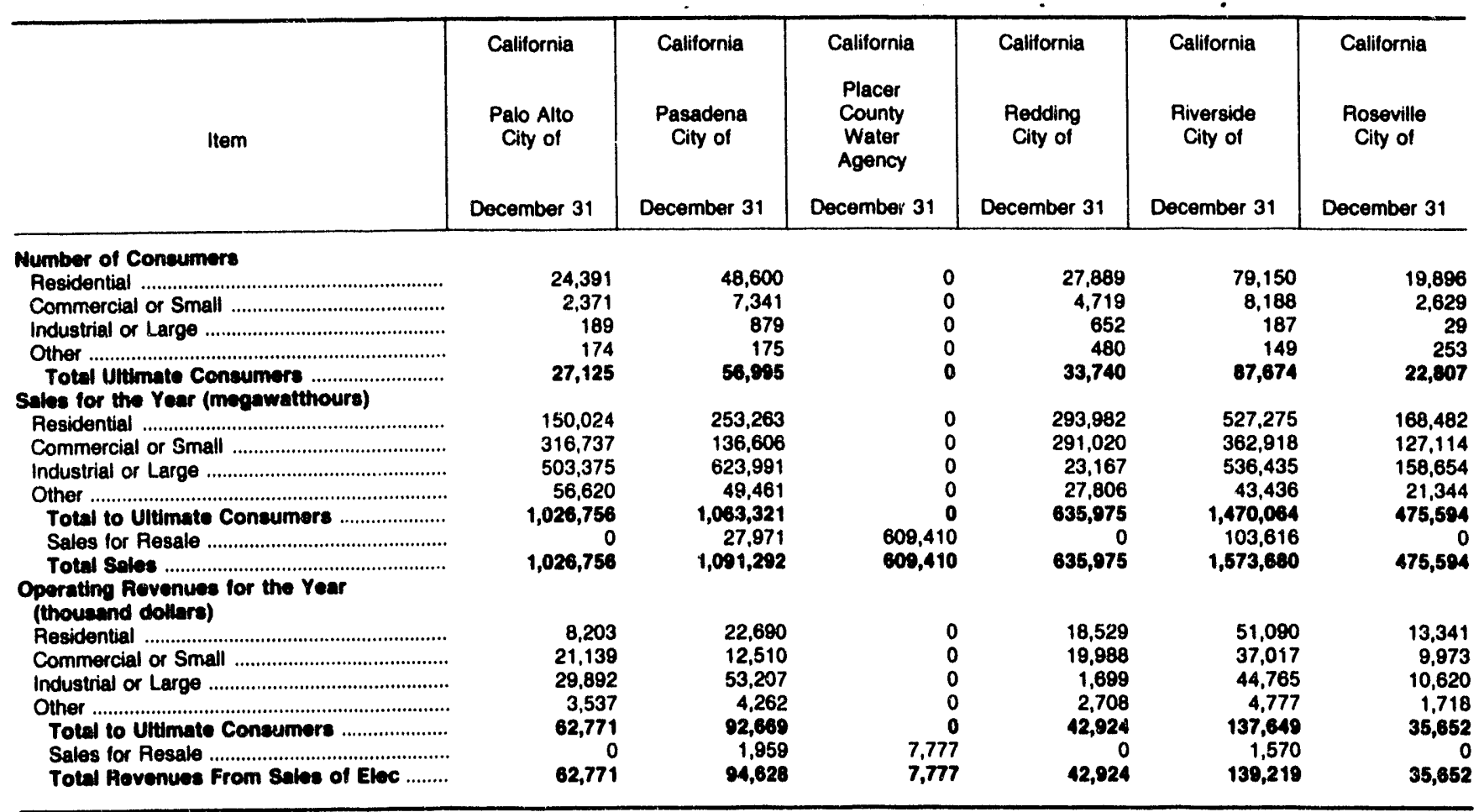

Note: Totals may not equal sum of components because of independentrounding.

Source: Energy Information Administration, Form ElA-861, "Annual Electric Utility Report." Data are submitted on a calendar year. 
Table 40. Number of Consumers, Sales, and Operating Revenue by Major Publicly Owned Electric Utility Within State, 1991 (Continued)

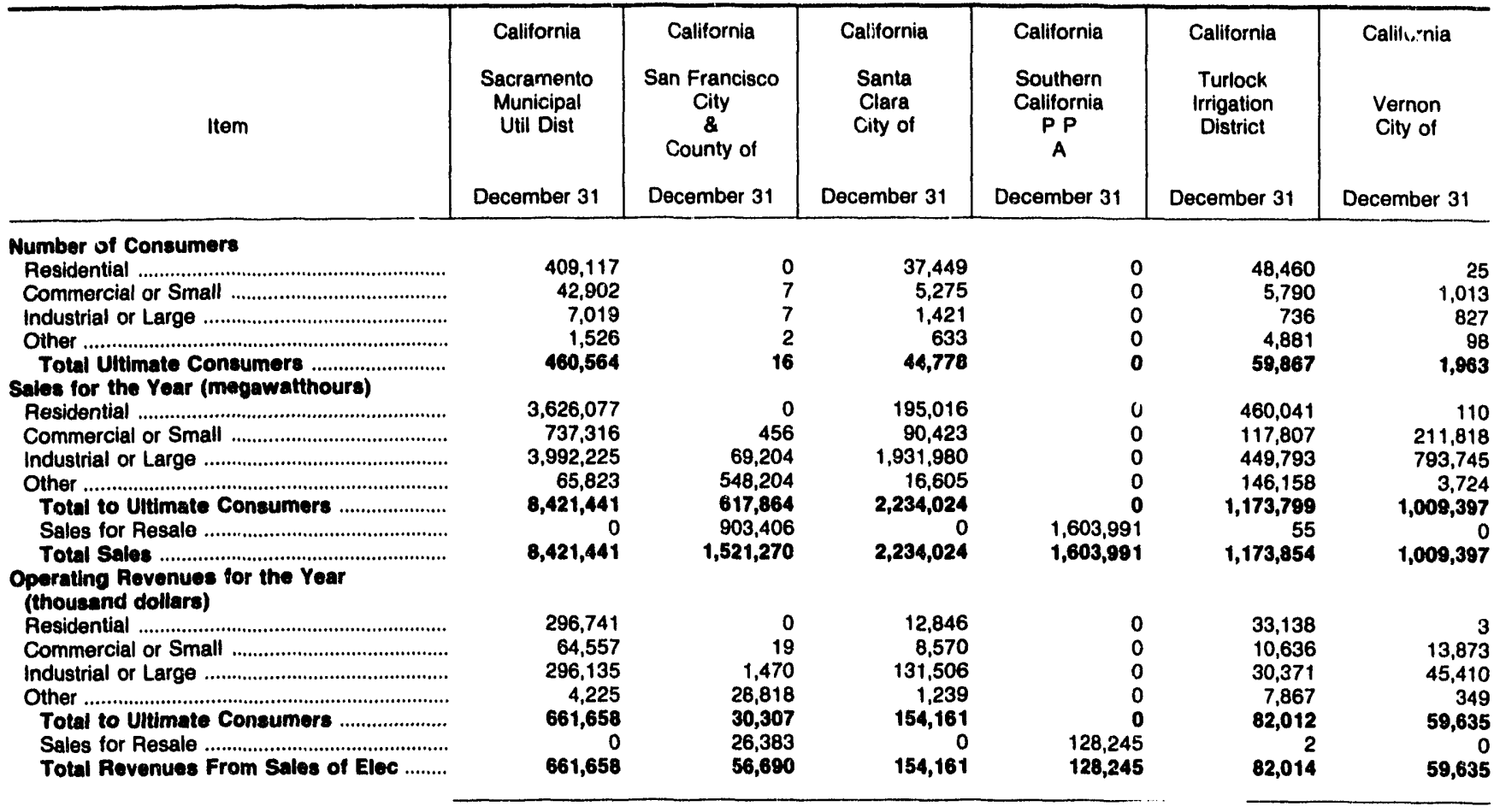

\begin{tabular}{|c|c|c|c|c|c|c|}
\hline Item & $\begin{array}{c}\text { California } \\
\text { Yuba } \\
\text { County } \\
\text { Water } \\
\text { Agency } \\
\text { December } 31\end{array}$ & $\begin{array}{l}\text { Colorado } \\
\text { Arkansas } \\
\text { River } \\
\text { Power } \\
\text { Authority } \\
\text { December } 31\end{array}$ & $\begin{array}{l}\text { Colorado } \\
\text { Colorado } \\
\text { Springs } \\
\text { City of } \\
\text { December } 31\end{array}$ & $\begin{array}{l}\text { Colorado } \\
\text { Fort Collins } \\
\text { City of } \\
\text { December } 31\end{array}$ & $\begin{array}{l}\text { Colorado } \\
\text { Longmont } \\
\text { City of } \\
\text { December } 31\end{array}$ & $\begin{array}{l}\text { Colorado } \\
\text { Loveland } \\
\text { City of } \\
\text { December } 31\end{array}$ \\
\hline \multicolumn{7}{|l|}{ Number of Consumers } \\
\hline 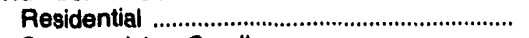 & 0 & 0 & 127,039 & 32,735 & 20,677 & 15,402 \\
\hline 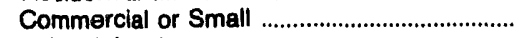 & 0 & 0 & 17,770 & 4,536 & 2,514 & 1,929 \\
\hline 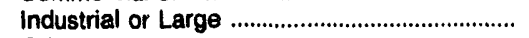 & 0 & 0 & 312 & 11 & 6 & 157 \\
\hline 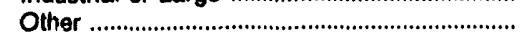 & 0 & 0 & 446 & 1 & 0 & 130 \\
\hline $\begin{array}{l}\text { Total Ultimate Consumers ...................... } \\
\text { Sales for the Year (megawatthours) }\end{array}$ & $\mathbf{0}$ & 0 & 145,567 & 37,283 & 23,197 & 17,618 \\
\hline 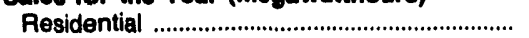 & 0 & 0 & 899,093 & 260,732 & 154,223 & 108,204 \\
\hline 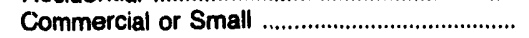 & 0 & 0 & 719,128 & 274,303 & 194,714 & 34,745 \\
\hline Industrial or Large & 0 & 0 & $1,203,539$ & 278,530 & 50,087 & 226,310 \\
\hline Other & 0 & 0 & 77,263 & 1,746 & 454 & 110 \\
\hline 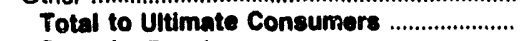 & $\mathbf{0}$ & $\mathbf{0}$ & $2,899,023$ & 815,311 & 399,478 & 369,369 \\
\hline Sales for Resale & 895,497 & 263,863 & 108,649 & 0 & 0 & \\
\hline \multicolumn{7}{|l|}{$\begin{array}{l}\text { Operating Aevenues for the Year } \\
\text { (thouaand dollars) }\end{array}$} \\
\hline 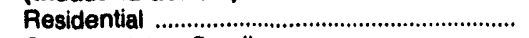 & 0 & 0 & 49,274 & 14,163 & 9,130 & 7,205 \\
\hline Commercial or Small & 0 & 0 & 36,304 & 14,661 & 9,012 & 2,321 \\
\hline Industrial or Large & 0 & 0 & 48,578 & 10,348 & 1,819 & 9,805 \\
\hline Other & 0 & 0 & 5,287 & 70 & 16 & 11 \\
\hline Total to Ultimate Consumers ......................... & $\mathbf{0}$ & 0 & 137,443 & 39,242 & 20,077 & 19,342 \\
\hline 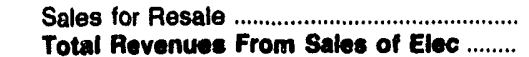 & $\begin{array}{l}7,700 \\
7,700\end{array}$ & $\begin{array}{l}9,379 \\
9,379\end{array}$ & $\begin{array}{r}3,859 \\
141,302\end{array}$ & $\begin{array}{r}0 \\
39,242\end{array}$ & $\begin{array}{r}0 \\
20,077\end{array}$ & $\begin{array}{r}0 \\
19,342\end{array}$ \\
\hline
\end{tabular}

Note: Totals may not equal sum of components because of independent rounding.

Source: Energy Information Administration, Form EIA-861, "Annual Electric Utility Report." Date are submitted on a calendar year. 
Table 40. Number of Consumers, Sales, and Operating Revenue by Major Publicly Owned Electric Utility Within State, 1991 (Continued)

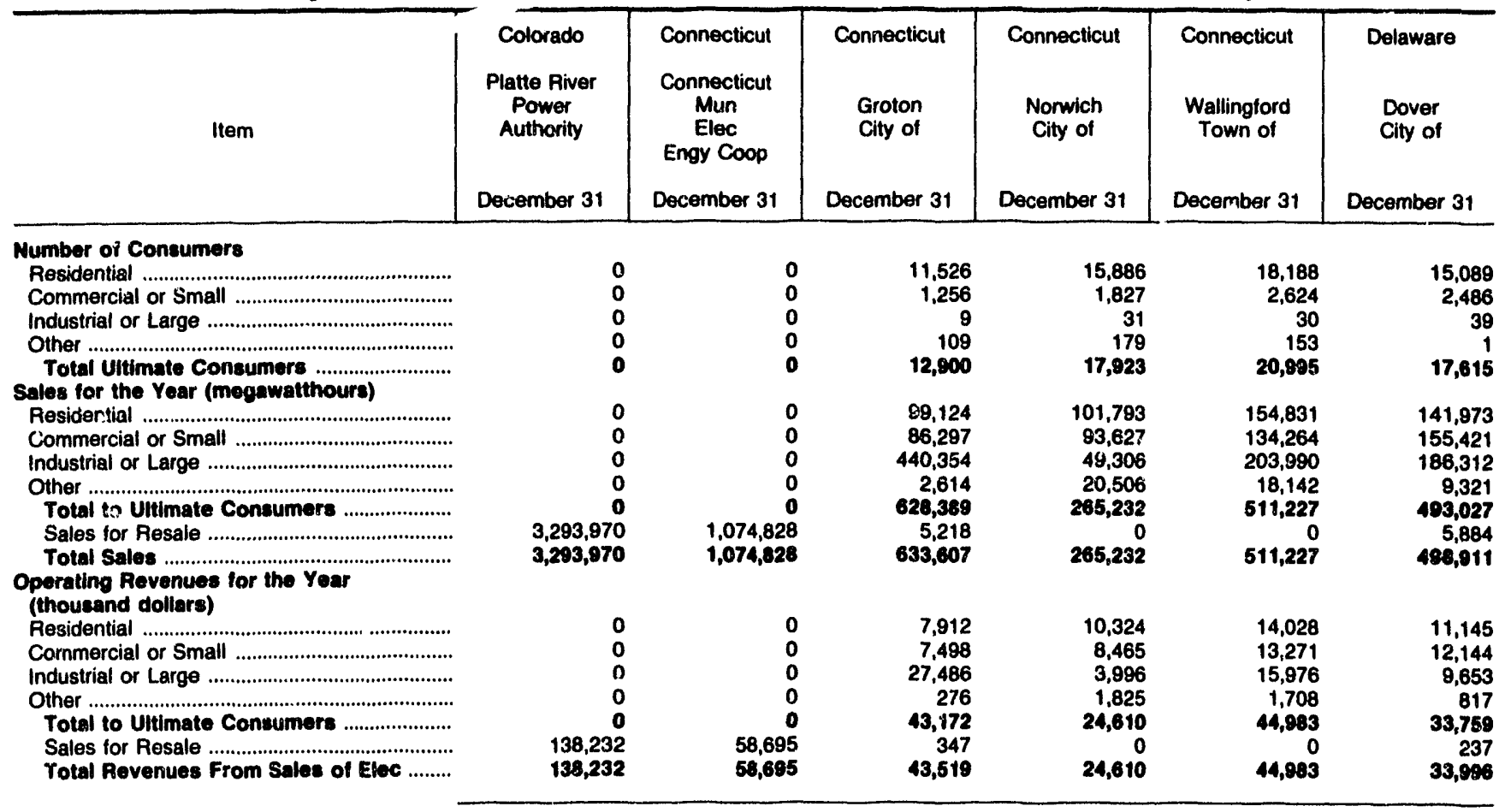

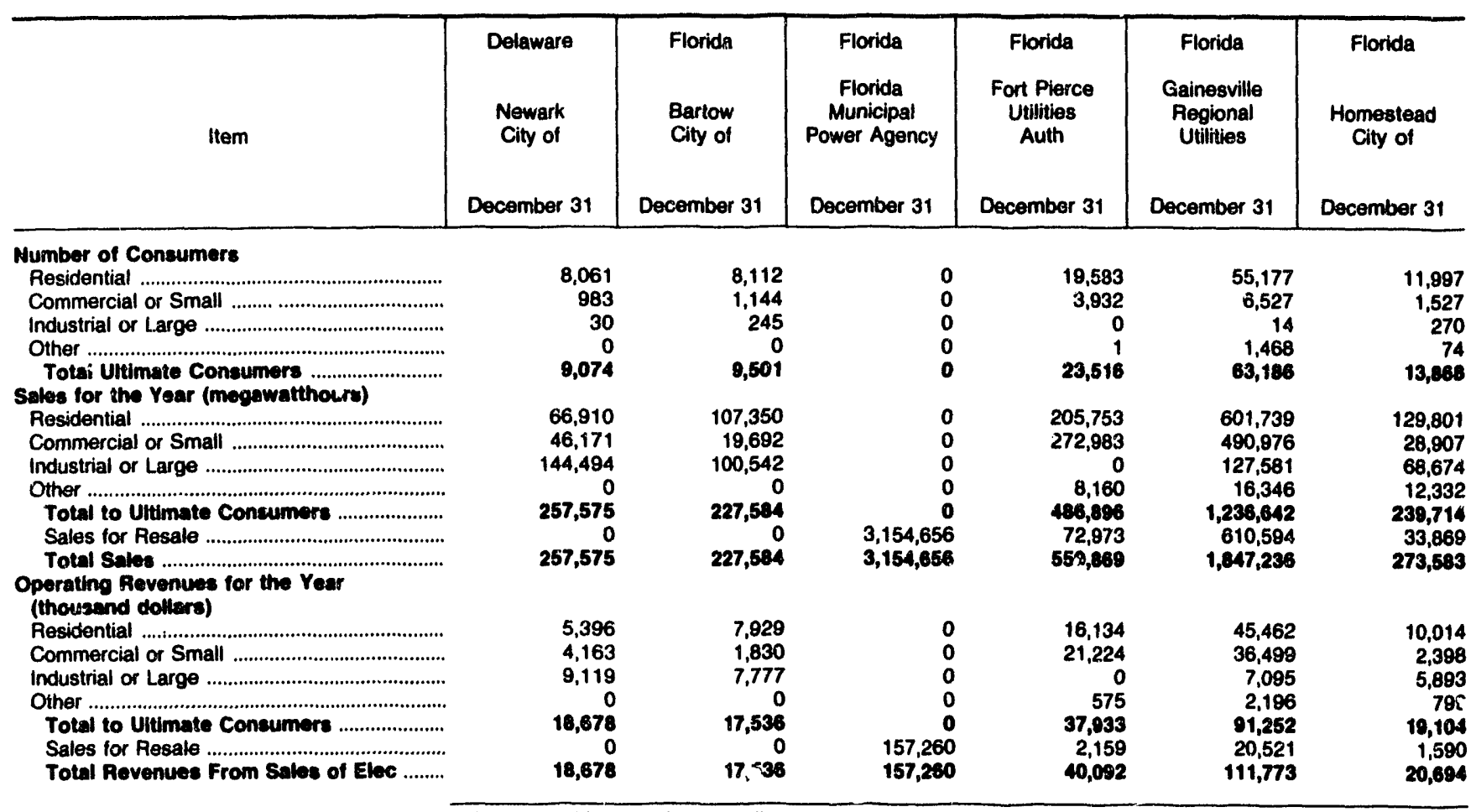

Note: Totals may not equal sum of components because oi inciepencieni rounuing.

Source: Energy Information Administration, Form ElA-861, "Annual Electric Utility Report." Data are submitted or a calender year. 
Table 40. Number of Consumers, Sales, and Operating Revenue by Major Publicly Owned Electric Utility Within State, 1991 (Continued)

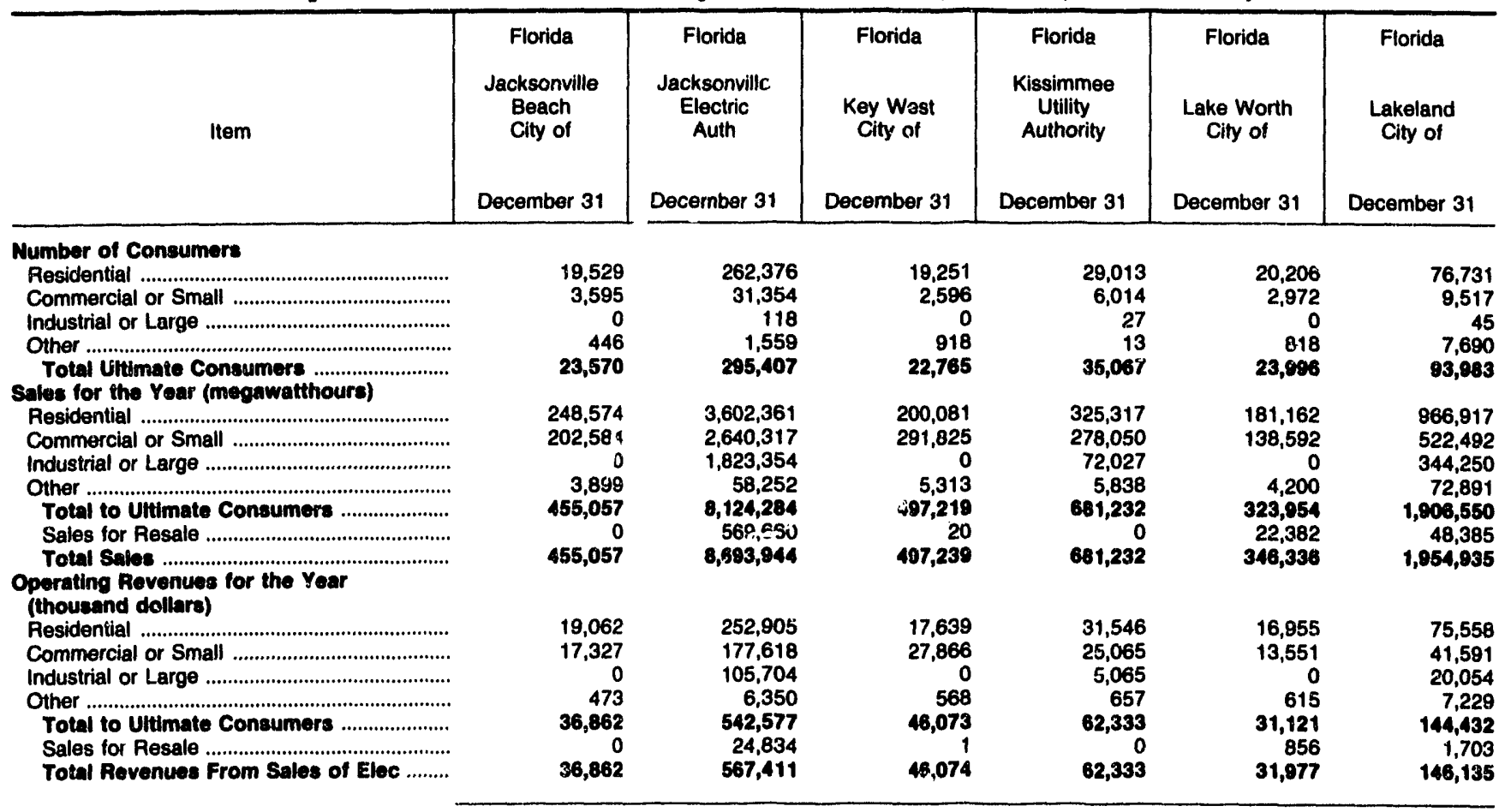

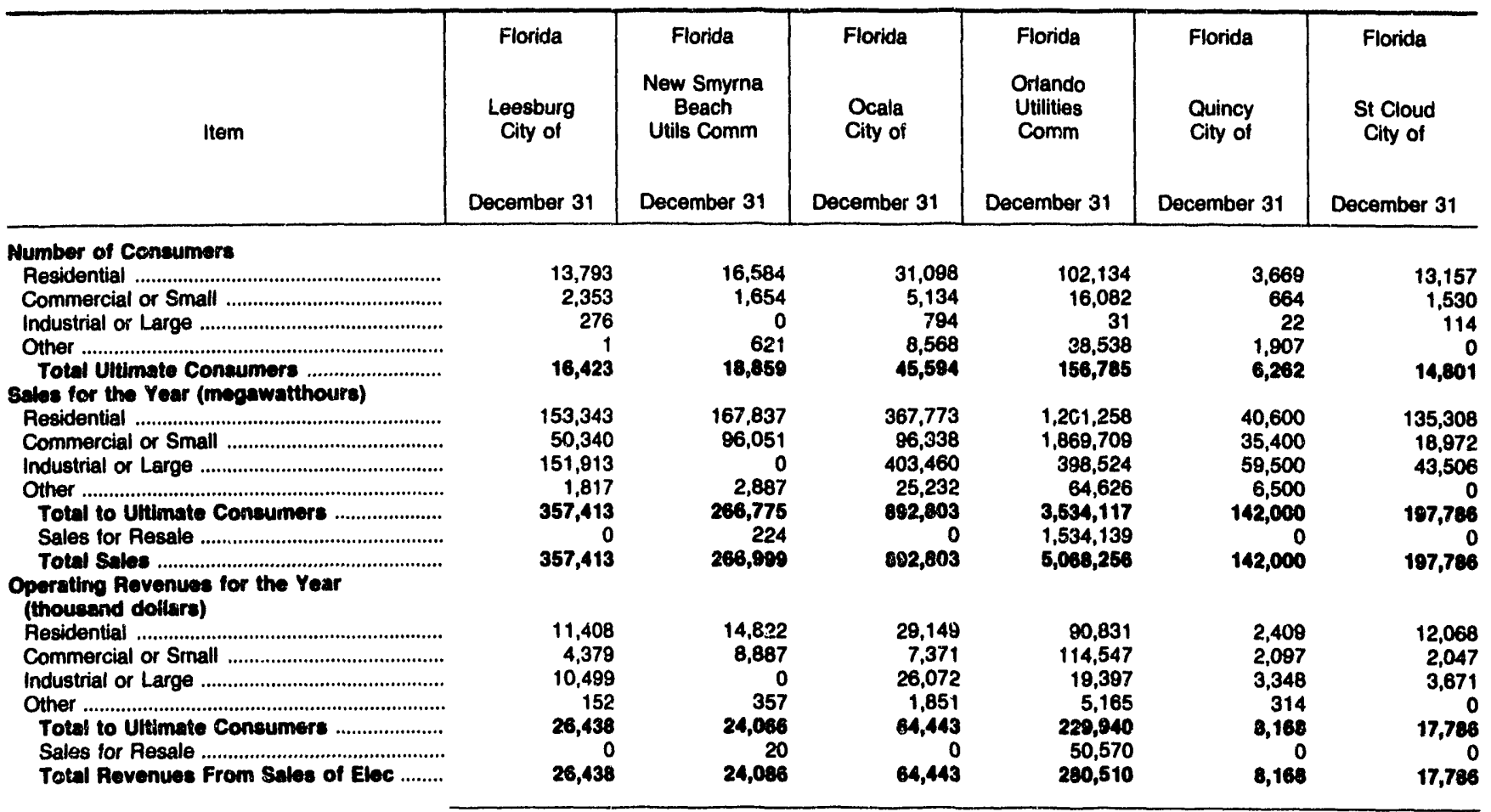

Note: Totals may not equal sum of components because of independent rounding.

Source: Energy Information Administration, Form ElA-861, "Annual Electric Utility Report." Data are submitted on a calendar year. 
Table 40. Number of Consumers, Sales, and Operating Revenue by Major Publicly Owned Electric Utility Within State, 1991 (Continued)

\begin{tabular}{|c|c|c|c|c|c|c|}
\hline ltem & $\begin{array}{c}\text { Florida } \\
\text { Tallahassee } \\
\text { City of } \\
\text { December } 31\end{array}$ & $\begin{array}{c}\text { Florida } \\
\text { Vero } \\
\text { Beach } \\
\text { City of } \\
\text { December } 31\end{array}$ & $\begin{array}{l}\text { Georgia } \\
\text { Albany Water } \\
\text { Gas \& Light } \\
\text { Comm } \\
\text { December } 31\end{array}$ & $\begin{array}{c}\text { Georgia } \\
\text { Calhoun } \\
\text { City of } \\
\text { December } 31\end{array}$ & $\begin{array}{c}\text { Georgia } \\
\text { Cartersville } \\
\text { City of } \\
\text { December } 31\end{array}$ & $\begin{array}{c}\text { Georgia } \\
\text { College } \\
\text { Park City of } \\
\text { December } 31\end{array}$ \\
\hline 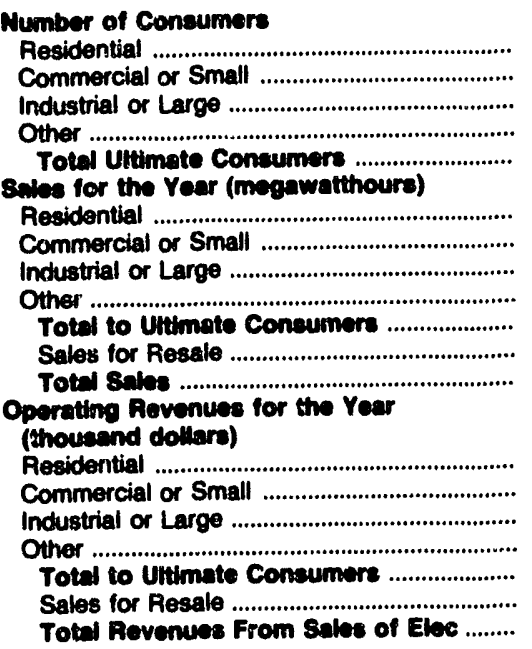 & $\begin{array}{r}64,997 \\
9,224 \\
0 \\
3,885 \\
70,206 \\
759,436 \\
888,760 \\
0 \\
82,134 \\
1,830,330 \\
188,562 \\
2,018,082\end{array}$ & $\begin{array}{r}266,361 \\
212,615 \\
8,222 \\
3,086 \\
490,284 \\
3,248 \\
493,532\end{array}$ & $\begin{array}{r}370,523 \\
451,611 \\
11,580 \\
9,684 \\
843,388 \\
0 \\
843,388\end{array}$ & $\begin{array}{r}24,368 \\
43,151 \\
186,094 \\
17,673 \\
271,286 \\
0 \\
271,286\end{array}$ & $\begin{array}{r}43,324 \\
59,737 \\
222,962 \\
14,586 \\
340,600 \\
0 \\
340,600\end{array}$ & $\begin{array}{r}85,273 \\
158,840 \\
0 \\
0 \\
244,113 \\
0 \\
244,113\end{array}$ \\
\hline
\end{tabular}

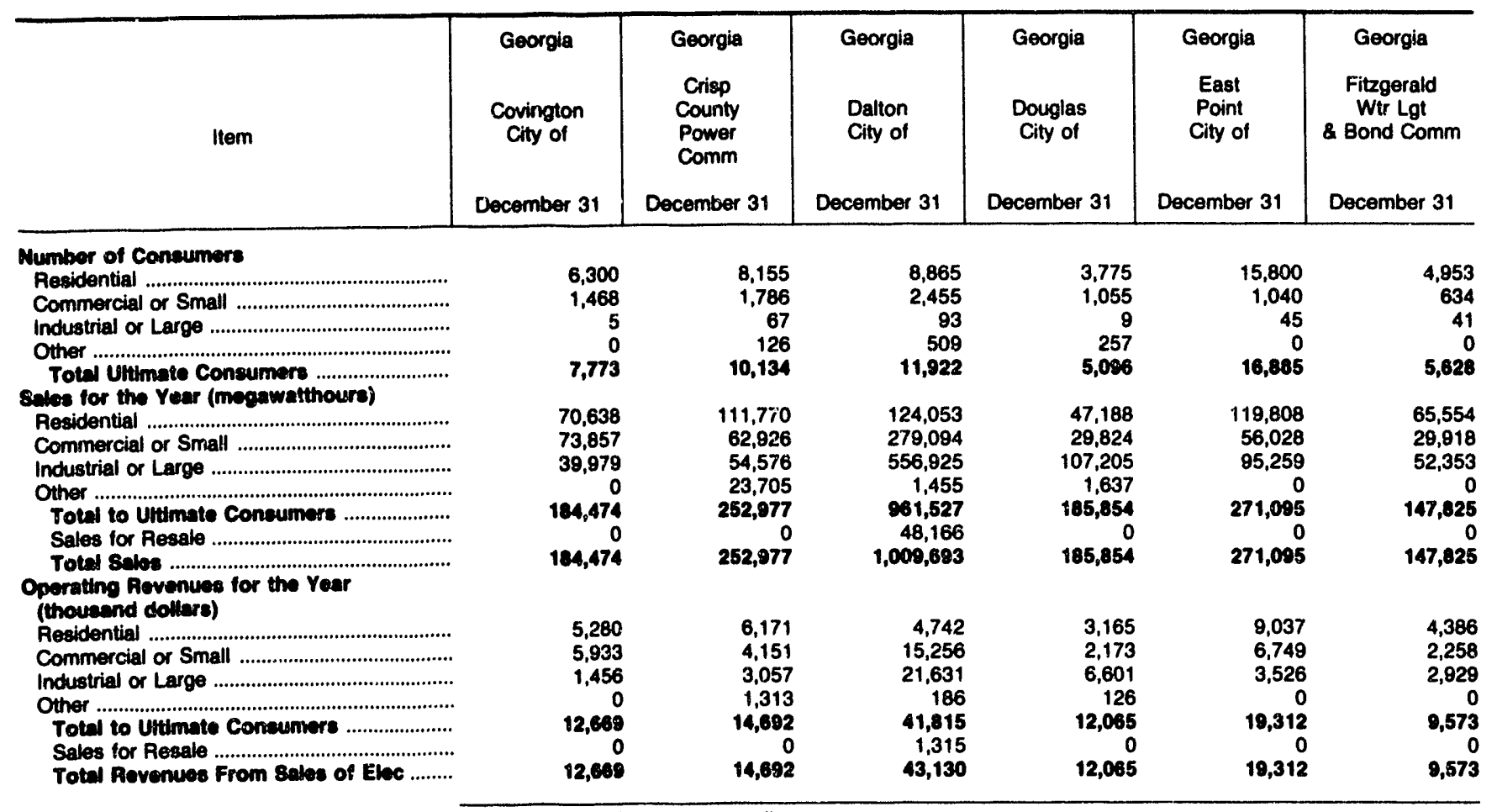

Note: Totals may not equal sum of components because of independent rounding.

Source: Energy Information Administration, Form ElA-861, "Annual Electric Utility Report." Data are submitted on a calendar year. 
Table 40. Number of Consumers, Sales, and Operating Revenue by Major Publicly Owned Electric Utility Within State, 1991 (Continued)

\begin{tabular}{|c|c|c|c|c|c|c|}
\hline Item & $\begin{array}{c}\text { Georgia } \\
\text { Griffin } \\
\text { City of } \\
\text { December } 31\end{array}$ & $\begin{array}{c}\text { Georgia } \\
\text { La Grange } \\
\text { City of } \\
\text { December } 31\end{array}$ & $\begin{array}{c}\text { Georgia } \\
\text { Lawrenceville } \\
\text { City of }\end{array}$ & $\begin{array}{l}\text { Georgia } \\
\text { Marietta } \\
\text { City of } \\
\text { December } 31\end{array}$ & $\begin{array}{l}\text { Georgia } \\
\text { Moultrie } \\
\text { City of } \\
\text { December } 31\end{array}$ & $\begin{array}{l}\text { Georgia } \\
\text { Municipal } \\
\text { Electric } \\
\text { Authority } \\
\text { December } 31\end{array}$ \\
\hline 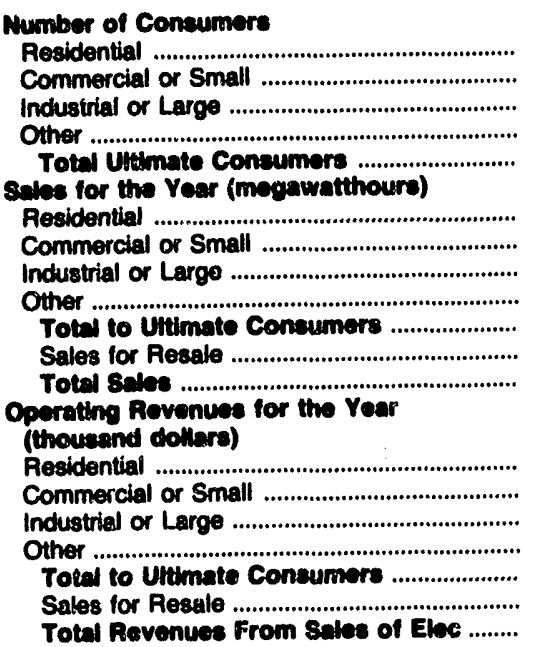 & $\begin{array}{r}11,616 \\
1,825 \\
12 \\
0 \\
13,453 \\
\\
101,822 \\
148,557 \\
35,095 \\
0 \\
285,474 \\
0 \\
285,474\end{array}$ & $\begin{array}{r}9,892 \\
1,564 \\
34 \\
0 \\
11,480 \\
93,189 \\
113,727 \\
287,681 \\
0 \\
494,597 \\
0 \\
494,597\end{array}$ & $\begin{array}{r}6,383 \\
1,007 \\
0 \\
0 \\
7,390 \\
\\
75,862 \\
89,596 \\
0 \\
0 \\
165,458 \\
0 \\
165,458\end{array}$ & $\begin{array}{r}30,996 \\
3,547 \\
0 \\
4,921 \\
38,484 \\
\\
282,554 \\
483,711 \\
0 \\
11,829 \\
778,094 \\
0 \\
778,094\end{array}$ & $\begin{array}{r}5,601 \\
901 \\
114 \\
7 \\
6,628 \\
\\
67,201 \\
21,448 \\
54,007 \\
648 \\
143,304 \\
0 \\
143,304\end{array}$ & $\begin{array}{r}0 \\
0 \\
0 \\
0 \\
0 \\
0 \\
9,310,838 \\
9,310,838\end{array}$ \\
\hline
\end{tabular}

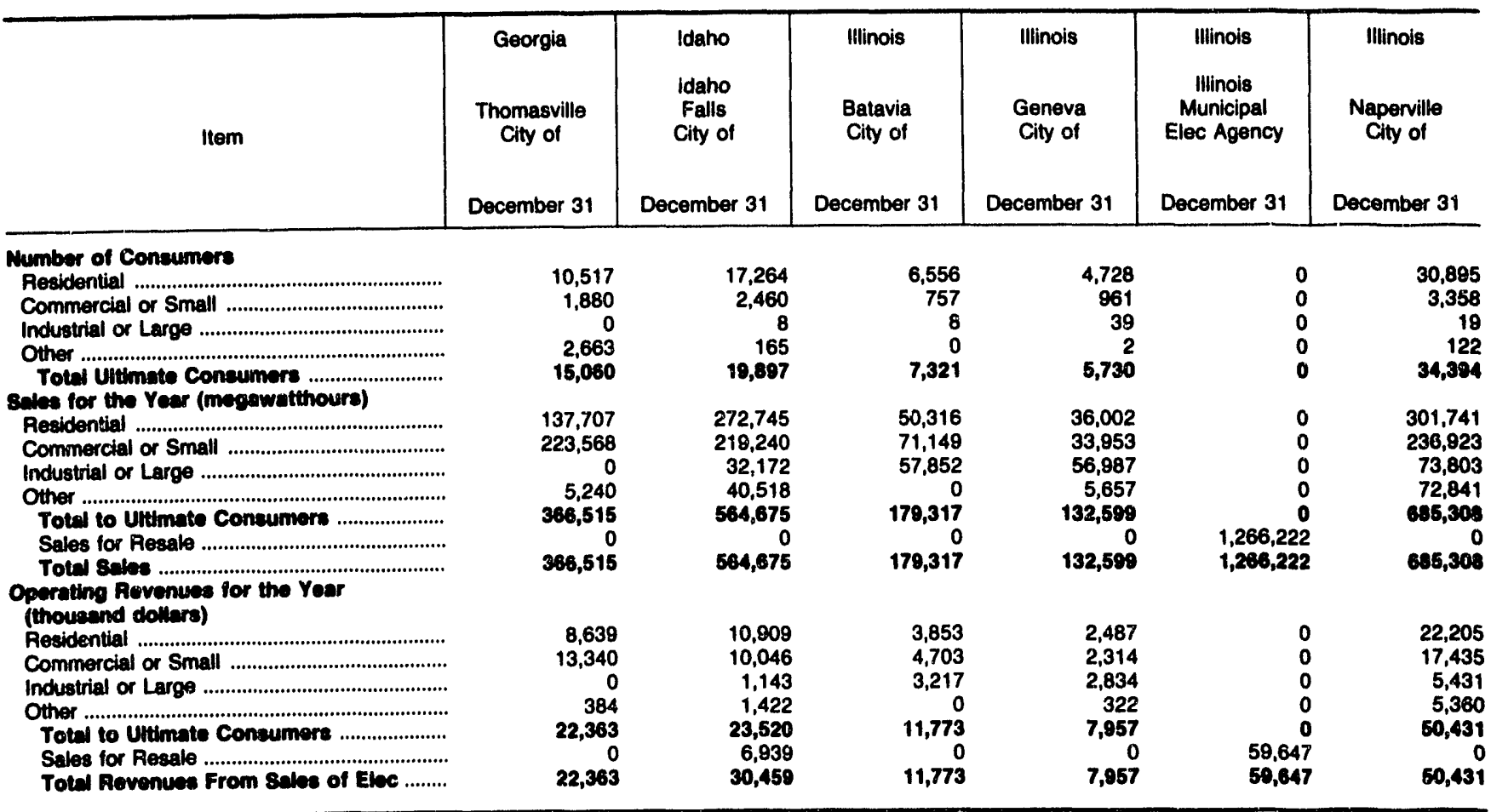

Note: Totals may not equal sum of components because of independentrounding.

Source: Energy Information Administration, Form ElA-861. "Annual Electric Utility Report." Data are submitted on a calendar year. 
Table 40. Number of Consumers, Sales, and Operating Revenue by Major Publicly Owned Electric Utility Within State, 1991 (Continued)

\begin{tabular}{|c|c|c|c|c|c|c|}
\hline Item & $\begin{array}{l}\text { Mllinois } \\
\text { Rochelle } \\
\text { Municipal } \\
\text { Utilities } \\
\text { December } 31\end{array}$ & $\begin{array}{c}\text { Illinois } \\
\text { Springfield } \\
\text { City of } \\
\text { December } 31\end{array}$ & $\begin{array}{c}\text { Illinois } \\
\text { St Charles } \\
\text { City of } \\
\text { December } 31\end{array}$ & $\begin{array}{c}\text { Indiana } \\
\text { Anderson } \\
\text { City of } \\
\text { December } 31\end{array}$ & $\begin{array}{l}\text { Indiana } \\
\text { Auburn } \\
\text { City of } \\
\text { December } 31\end{array}$ & $\begin{array}{l}\text { Indiana } \\
\text { Bluffton } \\
\text { City of } \\
\text { December } 31\end{array}$ \\
\hline 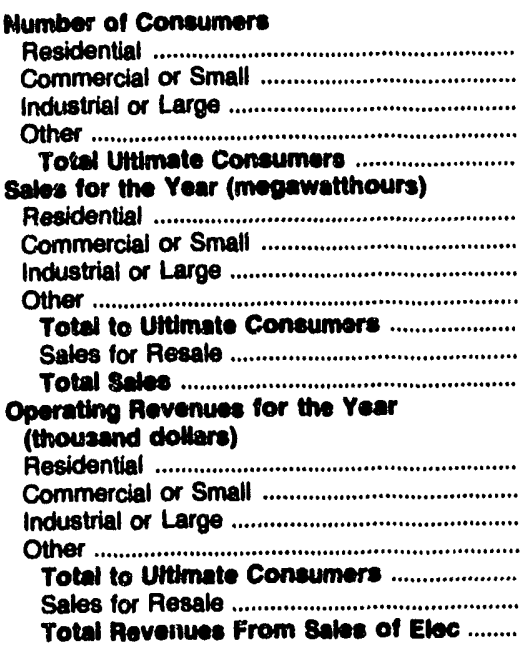 & $\begin{array}{r}37,930 \\
41,668 \\
58,767 \\
6,440 \\
144,805 \\
0 \\
144,005\end{array}$ & $\begin{array}{r}586,184 \\
835,526 \\
24,828 \\
98,010 \\
1,544,548 \\
136,454 \\
1,681,002\end{array}$ & $\begin{array}{r}66,120 \\
224,983 \\
0 \\
7,529 \\
288,632 \\
0 \\
288,632\end{array}$ & $\begin{array}{r}284,797 \\
250,351 \\
73,821 \\
11,114 \\
620,083 \\
0 \\
620,083\end{array}$ & $\begin{array}{r}4,235 \\
606 \\
74 \\
3 \\
4,918 \\
\\
38,402 \\
15,374 \\
210,789 \\
938 \\
285,503 \\
0 \\
265,503\end{array}$ & $\begin{array}{r}36,751 \\
23,328 \\
79,870 \\
4,270 \\
144,219 \\
0 \\
144,219\end{array}$ \\
\hline
\end{tabular}

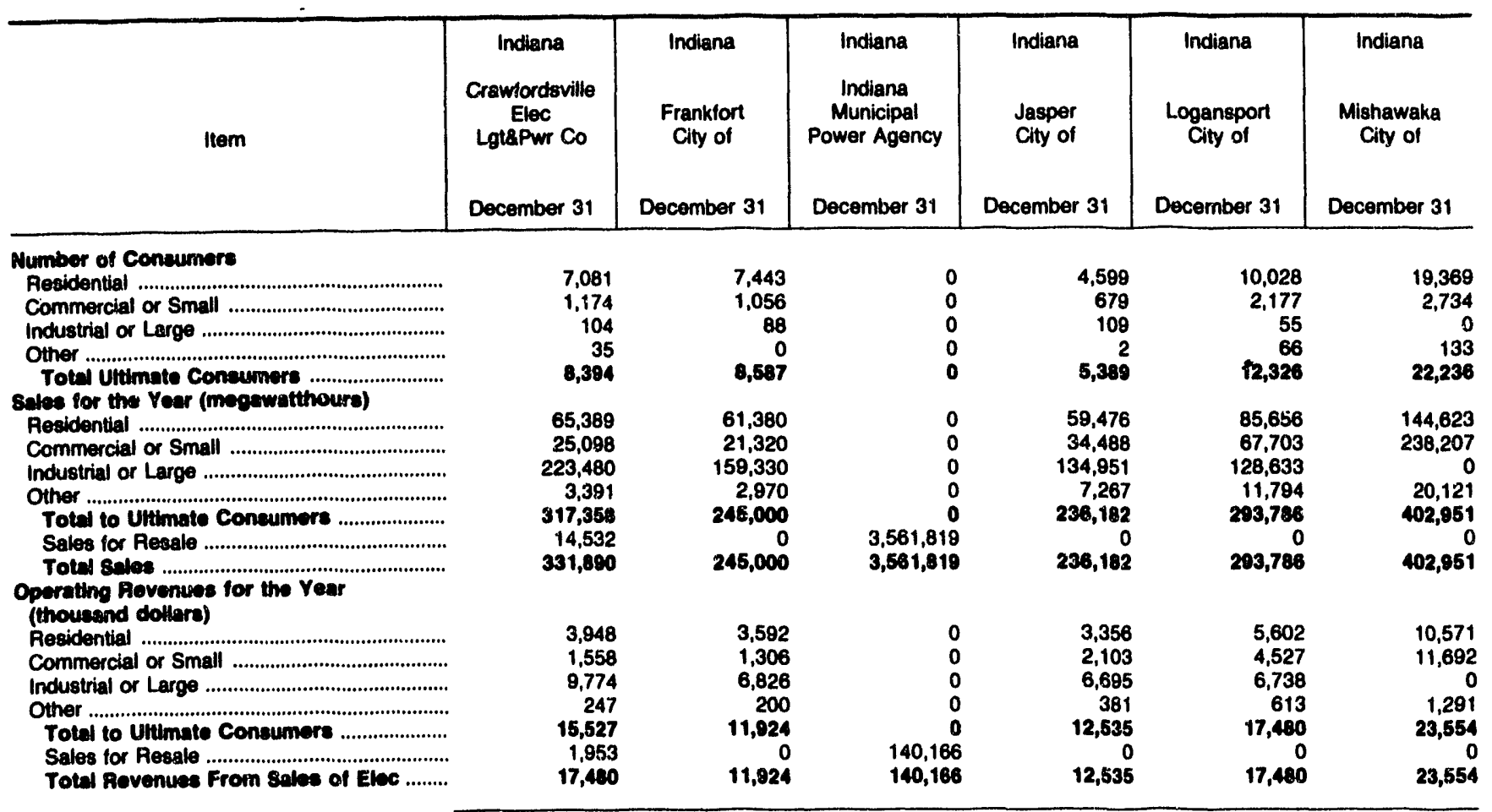

Note: Totals may not equal sum of components because of independent rounding.

Source: Energy Information Administration. Form ElA-861, "Annual Electric Utility Report." Data are submitted on a calendar year. 
Table 40. Number of Consumers, Sales, and Operating Revenue by Major Publicly Owned Electric Utility Within State, 1991 (Continued)

\begin{tabular}{|c|c|c|c|c|c|c|}
\hline Item & $\begin{array}{c}\text { Indiana } \\
\text { Peru } \\
\text { City of } \\
\text { December } 31\end{array}$ & $\begin{array}{l}\text { Indiana } \\
\text { Richmond } \\
\text { City of } \\
\text { December } 31\end{array}$ & $\begin{array}{c}\text { Indiana } \\
\text { Washington } \\
\text { City of } \\
\text { December } 31\end{array}$ & $\begin{array}{c}\text { lowa } \\
\text { Ames } \\
\text { City of } \\
\text { December } 31\end{array}$ & $\begin{array}{c}\text { lowa } \\
\text { Cedar } \\
\text { Falls } \\
\text { City of } \\
\text { December } 31\end{array}$ & $\begin{array}{c}\text { lowa } \\
\text { Muscatine } \\
\text { City of } \\
\text { December } 31\end{array}$ \\
\hline 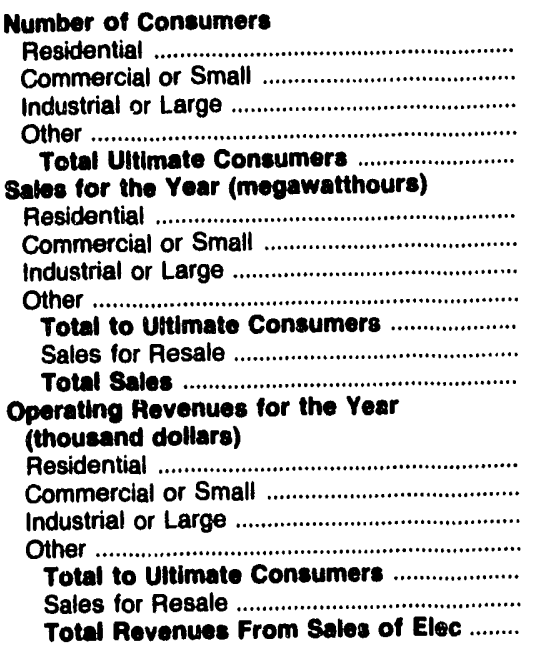 & $\begin{array}{r}79,806 \\
26,148 \\
66,122 \\
2,387 \\
174,463 \\
0 \\
174,463\end{array}$ & $\begin{array}{r}179,839 \\
87,199 \\
398,337 \\
13,400 \\
678,775 \\
0 \\
678,775\end{array}$ & $\begin{array}{r}61,158 \\
52,519 \\
28,299 \\
7,791 \\
149,767 \\
0 \\
149,767\end{array}$ & $\begin{array}{r}103,667 \\
38,696 \\
137,927 \\
60,804 \\
341,094 \\
0 \\
341,084\end{array}$ & $\begin{array}{r}122,151 \\
84,816 \\
44,709 \\
47,585 \\
298,261 \\
30,999 \\
330,260\end{array}$ & $\begin{array}{r}92,963 \\
41,234 \\
598,505 \\
14,817 \\
747,519 \\
479,071 \\
1,228,580\end{array}$ \\
\hline
\end{tabular}

\begin{tabular}{|c|c|c|c|c|c|c|}
\hline Item & $\begin{array}{c}\text { Kansas } \\
\text { Coffeyville } \\
\text { City of }\end{array}$ & $\begin{array}{c}\text { Kansas } \\
\text { Garden } \\
\text { City City of } \\
\text { December } 31\end{array}$ & $\begin{array}{c}\text { Kansas } \\
\text { Kansas } \\
\text { City City of } \\
\text { December } 31\end{array}$ & $\begin{array}{c}\text { Kansas } \\
\text { Kansas } \\
\text { Municipal } \\
\text { Energy } \\
\text { Agency } \\
\text { December } 31\end{array}$ & $\begin{array}{c}\text { Kansas } \\
\text { McPherson } \\
\text { City of } \\
\text { December } 31\end{array}$ & $\begin{array}{c}\text { Kansas } \\
\text { Winfield } \\
\text { City of } \\
\text { December } 31\end{array}$ \\
\hline 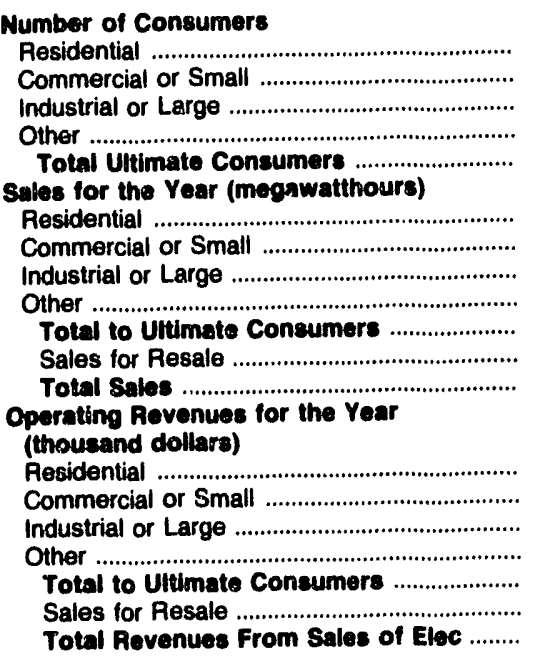 & $\begin{array}{r}53,417 \\
109,335 \\
0 \\
0 \\
162,752 \\
0 \\
162,752\end{array}$ & $\begin{array}{r}61,341 \\
15,223 \\
65,073 \\
0 \\
141,637 \\
0 \\
141,637\end{array}$ & $\begin{array}{r}519,379 \\
775,355 \\
712,696 \\
82,304 \\
2,089,734 \\
407,681 \\
2,497,415\end{array}$ & $\begin{array}{r}0 \\
0 \\
0 \\
0 \\
0 \\
394,759 \\
394,759\end{array}$ & $\begin{array}{r}66,438 \\
87,566 \\
253,727 \\
4,296 \\
412,027 \\
39,024 \\
451,051\end{array}$ & $\begin{array}{r}49,920 \\
16,466 \\
133,633 \\
5,622 \\
205,641 \\
4,682 \\
210,323\end{array}$ \\
\hline
\end{tabular}

Note: Totals may not equal sum of components because of independent rounding.

Source: Energy Information Administration, Form EIA-861, "Annual Electric Utility Report." Data are submitted on a calendar year. 
Table 40. Number of Consumers, Sales, and Operating Revenue by Major Publicly Owned Electric Utility Within State, 1991 (Continued)

\begin{tabular}{|c|c|c|c|c|c|c|}
\hline Item & $\begin{array}{c}\text { Kentucky } \\
\text { Bowling } \\
\text { Green } \\
\text { City of } \\
\text { December } 31\end{array}$ & $\begin{array}{c}\text { Kentucky } \\
\text { Franklort } \\
\text { City of } \\
\text { December } 31\end{array}$ & $\begin{array}{c}\text { Kentucky } \\
\text { Franklin } \\
\text { City of } \\
\text { December } 31\end{array}$ & $\begin{array}{c}\text { Kentucky } \\
\text { Glasgow } \\
\text { City of } \\
\text { December } 31\end{array}$ & $\begin{array}{l}\text { Kentucky } \\
\text { Henderson } \\
\text { City } \\
\text { Utility Comm } \\
\\
\text { December } 31\end{array}$ & $\begin{array}{c}\text { Kentucky } \\
\text { Hopkinsville } \\
\text { City of } \\
\text { December } 31\end{array}$ \\
\hline \multicolumn{7}{|l|}{ Number of Consumers } \\
\hline 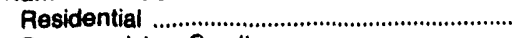 & 16,694 & 14,344 & 3,479 & 5,059 & 9,138 & 11,076 \\
\hline Commercial or Small ............................................. & 2,772 & 2,240 & 589 & 851 & 1,507 & 1,724 \\
\hline Industrial or Large & 352 & 275 & 49 & 99 & 8 & 161 \\
\hline 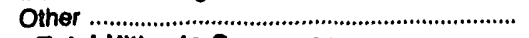 & 21 & 525 & 22 & 54 & 103 & 11 \\
\hline $\begin{array}{l}\text { Total Ultimate Consumers } \\
\text { Sales for the Year (megawathours) }\end{array}$ & 19,839 & 17,384 & 4,139 & 6,063 & 10,756 & 12,972 \\
\hline 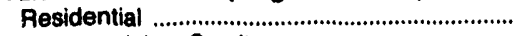 & 174,665 & 169,756 & 40,840 & 56,370 & 102,676 & 130,966 \\
\hline 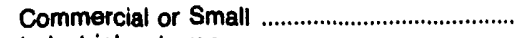 & 79,545 & 61,032 & 13,231 & 23,313 & 142,955 & 47,245 \\
\hline 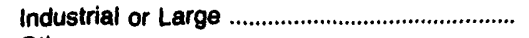 & 347,909 & 291,195 & 121,696 & 171,872 & 94,268 & 185,740 \\
\hline 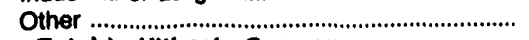 & 7,833 & 27,035 & 1,660 & 2,745 & 8,808 & 5,614 \\
\hline Total to Uitimate Consumers ......................... & 609,852 & 549,018 & 177,427 & 254,300 & 348,707 & 369,565 \\
\hline 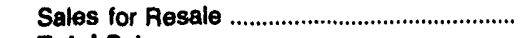 & & & & & $1,602,646$ & \\
\hline \multirow{2}{*}{\multicolumn{7}{|c|}{$\begin{array}{l}\text { Operating Revenues for the Year } \\
\text { (thoueand dollars) }\end{array}$}} \\
\hline & & & & & & \\
\hline 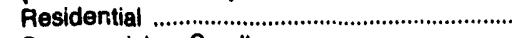 & 10,395 & 7,365 & 2,275 & 3,218 & 3,814 & 7,013 \\
\hline Commercial or Small .......................................... & 5,278 & 2,806 & 842 & 1,489 & 4,676 & 2,936 \\
\hline Industrial or Large & 19,464 & 10,782 & 6,045 & 9,006 & 2,543 & 8,863 \\
\hline 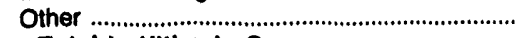 & 598 & 1,296 & 118 & 197 & 702 & 415 \\
\hline Total to Ultimate Consumers ........................ & 35,735 & 22,259 & 8,280 & 13,910 & 11,735 & 19,227 \\
\hline 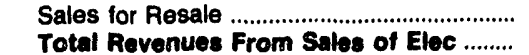 & $\begin{array}{r}0 \\
35,735\end{array}$ & $\begin{array}{r}0 \\
22,259\end{array}$ & $\begin{array}{r}0 \\
9,280\end{array}$ & $\begin{array}{r}0 \\
13,910\end{array}$ & $\begin{array}{l}13,061 \\
24,796\end{array}$ & $\begin{array}{r}0 \\
19.227\end{array}$ \\
\hline & & & & & & \\
\hline
\end{tabular}

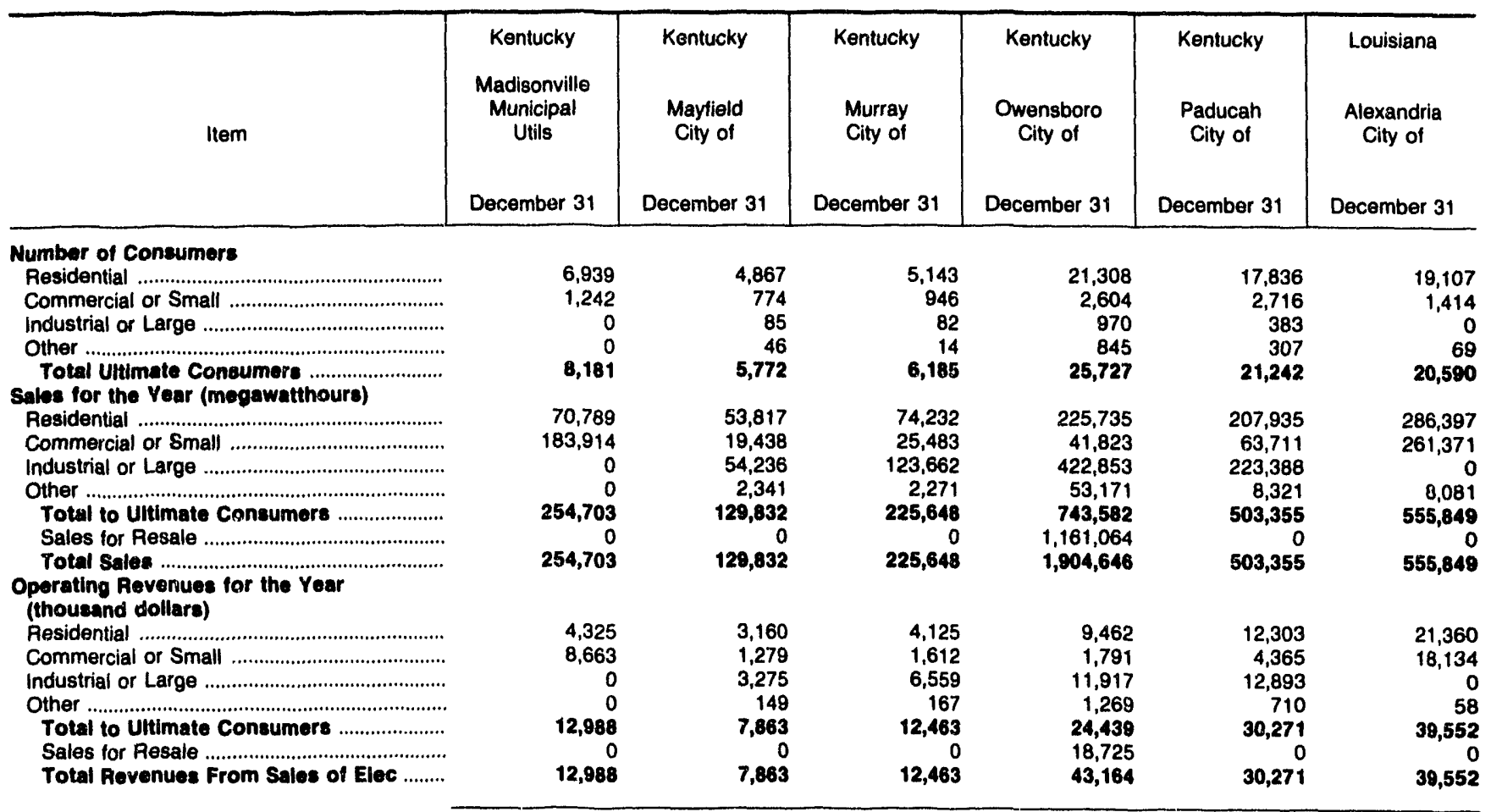

Note: Totals may not equal sum of components because of independent rounding.

Source: Energy Information Administration, Form ElA-661, "Annual Electric Utility Report." Data are submitted on a calendar year. 
Table 40. Number of Consumers, Sales, and Operating Revenue by Major Publicly Owned Electric Utility Within State, 1991 (Continued)

\begin{tabular}{|c|c|c|c|c|c|c|}
\hline Item & $\begin{array}{c}\text { Louisiana } \\
\begin{array}{c}\text { Lafayette } \\
\text { City of }\end{array} \\
\text { December } 31\end{array}$ & $\begin{array}{c}\text { Louisiana } \\
\text { Louisiana } \\
\text { Energy } \\
\& \\
\text { Power Auth } \\
\text { December } 31\end{array}$ & $\begin{array}{l}\text { Louisiana } \\
\text { Morgan } \\
\text { City City of } \\
\text { December } 31\end{array}$ & $\begin{array}{c}\text { Louisiana } \\
\begin{array}{c}\text { Natchitoches } \\
\text { City of }\end{array} \\
\text { December } 31\end{array}$ & $\begin{array}{l}\text { Louisiana } \\
\text { Ruston } \\
\text { City of } \\
\text { December } 31\end{array}$ & $\begin{array}{c}\text { ! nuisiana } \\
\text { Terrebonne } \\
\text { Parish } \\
\text { Consol Govt } \\
\text { December } 31\end{array}$ \\
\hline 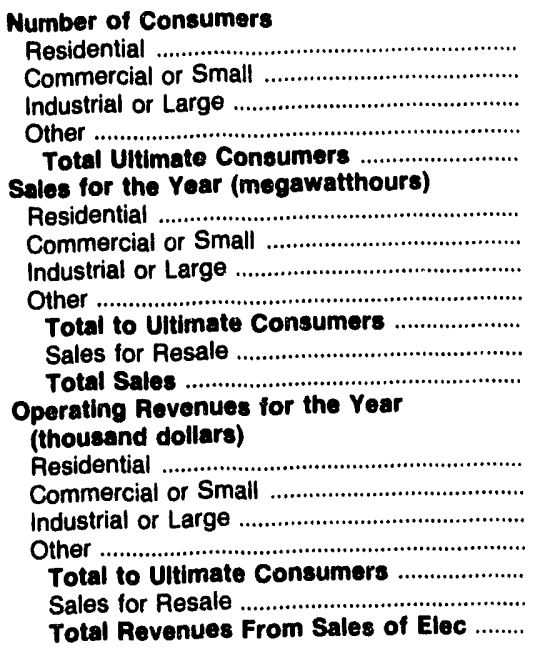 & $\begin{array}{r}542,978 \\
692,094 \\
0 \\
40,955 \\
1,276,027 \\
564,978 \\
1,841,005\end{array}$ & $\begin{array}{r}0 \\
0 \\
0 \\
0 \\
0 \\
0 \\
1,456,075 \\
1,456,075\end{array}$ & $\begin{array}{r}84,870 \\
65,767 \\
0 \\
0 \\
150,637 \\
0 \\
0 \\
150,637\end{array}$ & $\begin{array}{r}56,533 \\
45,627 \\
60,421 \\
5,211 \\
167,792 \\
0 \\
167,792\end{array}$ & $\begin{array}{r}75,112 \\
44,372 \\
66,317 \\
13,293 \\
199,094 \\
0 \\
199,094\end{array}$ & $\begin{array}{r}107,079 \\
103,364 \\
0 \\
0 \\
210,443 \\
142,669 \\
353,112\end{array}$ \\
\hline
\end{tabular}

\begin{tabular}{|c|c|c|c|c|c|c|}
\hline Item & $\begin{array}{l}\text { Maryland } \\
\text { Easton } \\
\text { Utilities } \\
\text { Comm } \\
\text { December } 31\end{array}$ & $\begin{array}{l}\text { Maryland } \\
\text { Hagerstown } \\
\text { City of } \\
\text { December } 31\end{array}$ & $\begin{array}{l}\text { Massachusetts } \\
\text { Braintree } \\
\text { Town of } \\
\text { December } 31\end{array}$ & $\begin{array}{l}\text { Massachusetts } \\
\text { Chicopee } \\
\text { City of } \\
\text { December } 31\end{array}$ & $\begin{array}{l}\text { Massachusetts } \\
\text { Concord } \\
\text { Town of } \\
\text { December } 31\end{array}$ & $\begin{array}{l}\text { Massachusetts } \\
\text { Danvers } \\
\text { Town of } \\
\text { December } 31\end{array}$ \\
\hline 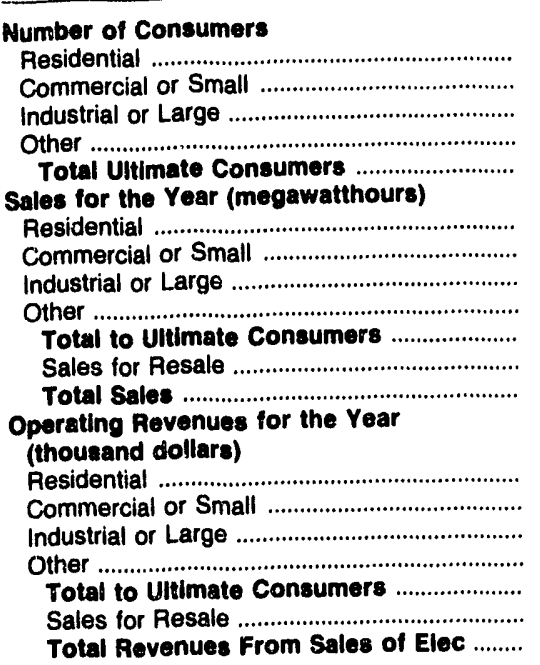 & $\begin{array}{r}63,885 \\
112,805 \\
0 \\
10,366 \\
187,056 \\
4,429 \\
191,485\end{array}$ & $\begin{array}{r}114,918 \\
58,996 \\
115,796 \\
8,641 \\
298,351 \\
0 \\
298,351\end{array}$ & $\begin{array}{r}87,986 \\
195,522 \\
51,551 \\
12,177 \\
347,236 \\
94,152 \\
441,388\end{array}$ & $\begin{array}{r}154,185 \\
167,727 \\
0 \\
49,864 \\
371,778 \\
12,573 \\
384,349\end{array}$ & $\begin{array}{r}51,535 \\
35,208 \\
52,956 \\
8,806 \\
148,505 \\
0 \\
148,505\end{array}$ & $\begin{array}{r}71,909 \\
34,913 \\
165,492 \\
15,067 \\
287,381 \\
6,392 \\
293,773\end{array}$ \\
\hline
\end{tabular}

Note: Totals may not equal sum of components because of independent rounding.

Source: Energy Information Administration, Form EIA-861, "Annual Electric Utility Report." Data are submitted on a calendar year. 
Table 40. Number of Consumers, Sales, and Operating Revenue by Major Publicly Owned Electric Utility Within State, 1991 (Continued)

\begin{tabular}{|c|c|c|c|c|c|c|}
\hline Item & $\begin{array}{l}\text { Massachusetts } \\
\text { Hingham } \\
\text { City of } \\
\text { December } 31\end{array}$ & $\begin{array}{c}\text { Massachusetts } \\
\text { Holyoke } \\
\text { City of } \\
\text { December } 31\end{array}$ & $\begin{array}{c}\text { Massachusetts } \\
\text { Hudson } \\
\text { Town of } \\
\text { December } 31\end{array}$ & $\begin{array}{l}\text { Massachusetts } \\
\text { Littleton } \\
\text { Town of } \\
\text { December } 31\end{array}$ & $\begin{array}{l}\text { Massachusetts } \\
\text { Mansfield } \\
\text { Town of } \\
\text { December } 31\end{array}$ & $\begin{array}{l}\text { Massachusetts } \\
\text { Massachusetts } \\
\text { Mun } \\
\text { Whis } \\
\text { Elec Co } \\
\text { December } 31\end{array}$ \\
\hline \multicolumn{7}{|l|}{ Number of Consumers } \\
\hline 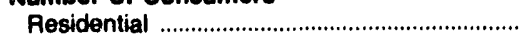 & 7,618 & 15,510 & 8,290 & 4,500 & 6,668 & 0 \\
\hline 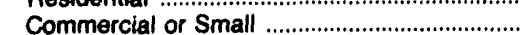 & 912 & 2,232 & 1,063 & 409 & 535 & 0 \\
\hline Industrial or Large & 36 & 10 & 198 & 60 & 195 & 0 \\
\hline Other & 46 & 535 & 247 & 89 & 224 & 0 \\
\hline $\begin{array}{l}\text { Total Uitimate Consumers ........................ } \\
\text { Sales for the Year (megawatthours) }\end{array}$ & 8,612 & 18,287 & 9,788 & 5,058 & 7,622 & 0 \\
\hline 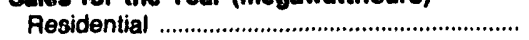 & 60,548 & 90,618 & 62,000 & 39,233 & 46,902 & 0 \\
\hline Commercial or Small & 24,309 & 135,958 & 12,400 & 7,414 & 5,948 & 0 \\
\hline Industrial or Large & 37,586 & 9,488 & 155,100 & 130,306 & 107,875 & 0 \\
\hline 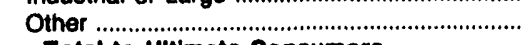 & 5,133 & 23,010 & 13,300 & 5,493 & 5,152 & 0 \\
\hline Total to Uitimate Consumers ....................... & 427,576 & 258,075 & 242,800 & 182,446 & 165,977 & 0 \\
\hline Sales for Resale & $\begin{array}{r}147 \\
127,723\end{array}$ & $\begin{array}{r}2,447 \\
261,522\end{array}$ & 242,800 & $\begin{array}{r}33,614 \\
216,060\end{array}$ & $\begin{array}{r}2,056 \\
168,033\end{array}$ & $\begin{array}{l}3,266,902 \\
3,266,902\end{array}$ \\
\hline \multicolumn{7}{|l|}{$\begin{array}{l}\text { Operating Revenues for the Year } \\
\text { (thousand dollars) }\end{array}$} \\
\hline 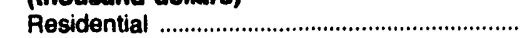 & 6,297 & 8,896 & 7,932 & 2,870 & 5,502 & 0 \\
\hline Commercial or Small & 3,403 & 14,273 & 1,749 & 661 & 843 & 0 \\
\hline Industrial or Large & 4,104 & 844 & 18,166 & 11,370 & 12,158 & 0 \\
\hline Other & 667 & 2,308 & 2,324 & 429 & 686 & 0 \\
\hline Totel to Uitimate Consumers & 14,471 & 26,321 & 30,171 & 15,330 & 19,189 & $\mathbf{0}$ \\
\hline 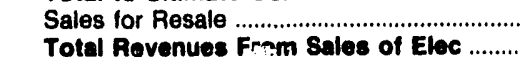 & $\begin{array}{r}18 \\
14,489\end{array}$ & $\begin{array}{r}67 \\
26,388\end{array}$ & $\begin{array}{r}0 \\
30,171\end{array}$ & $\begin{array}{r}2,078 \\
17,408\end{array}$ & $\begin{array}{r}158 \\
19,347\end{array}$ & 276,487 \\
\hline
\end{tabular}

\begin{tabular}{|c|c|c|c|c|c|c|}
\hline Item & $\begin{array}{l}\text { Massachusetts } \\
\text { Middleborough } \\
\text { Town of } \\
\text { December } 31\end{array}$ & $\begin{array}{l}\text { Massachusetts } \\
\text { North } \\
\text { Attleborough } \\
\text { Town of } \\
\text { December } 31\end{array}$ & $\begin{array}{l}\text { Massachusetts } \\
\text { Norwood } \\
\text { City of } \\
\text { December } 31\end{array}$ & $\begin{array}{l}\text { Massachusetts } \\
\text { Peabody } \\
\text { City of } \\
\text { December } 31\end{array}$ & $\begin{array}{c}\text { Massachusetts } \\
\text { Reading } \\
\text { Town of } \\
\text { December } 31\end{array}$ & $\begin{array}{l}\text { Massachusetts } \\
\text { Shrewsbury } \\
\text { Town of } \\
\text { December } 31\end{array}$ \\
\hline \multicolumn{7}{|l|}{ Number of Consumers } \\
\hline 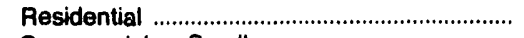 & 9,249 & 9,458 & 12,237 & 18,660 & 21,151 & 10,526 \\
\hline Commercial or Small ............................................. & 1,213 & 819 & 2,052 & 1,714 & 0 & 758 \\
\hline 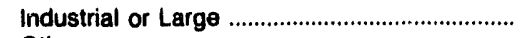 & 28 & 97 & 73 & 1,142 & 2,086 & 46 \\
\hline Other & 517 & 526 & 5 & 114 & 356 & 370 \\
\hline $\begin{array}{l}\text { Total Uitimate Consumere } \\
\text { Sales for the Year (megawathours) }\end{array}$ & 11,007 & 10,900 & 14,367 & 21,630 & 23,593 & 11,700 \\
\hline 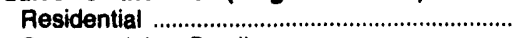 & 65,900 & 74,636 & 68,563 & 138,115 & 169,015 & 82,228 \\
\hline 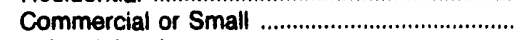 & 45,853 & if 301 & 80,784 & 17,729 & 0 & 28,670 \\
\hline 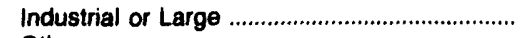 & 36,472 & 74,523 & 159,101 & 202,178 & 368,537 & 106,533 \\
\hline 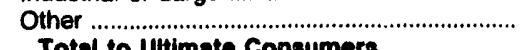 & 6,223 & $\begin{array}{r}11,482 \\
177,519\end{array}$ & $\begin{array}{r}6,954 \\
015,909\end{array}$ & 19,250 & 20,253 & 15,479 \\
\hline Total to Uttimate Consumers ...................... & 154,448 & 177,542 & 315,402 & 377,272 & 557,805 & 232,910 \\
\hline Sales for Resale & $\begin{array}{r}220 \\
154998\end{array}$ & $\begin{array}{r}699 \\
179241\end{array}$ & $\begin{array}{r}0 \\
315.192\end{array}$ & $\begin{array}{r}0 \\
377272\end{array}$ & 149 & 1,236 \\
\hline \multicolumn{7}{|l|}{$\begin{array}{l}\text { Operating Revenues for the Year } \\
\text { (thousend dollars) }\end{array}$} \\
\hline 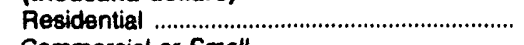 & 6,678 & 6,990 & 5,366 & 13,627 & 14,133 & 7,088 \\
\hline 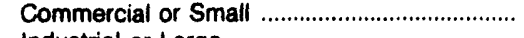 & 5,548 & 1,856 & 8,956 & 2,087 & 0 & 3,130 \\
\hline 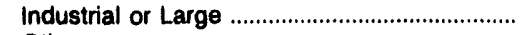 & 3,737 & 6,758 & 11,931 & 22,456 & 25,905 & 9,480 \\
\hline 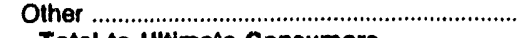 & 713 & 1,045 & 456 & 2,182 & 1,805 & 1,457 \\
\hline Total to Ultimate Consumers ....................... & 16,678 & 16,649 & 26,709 & 40,352 & 41,843 & 21,165 \\
\hline 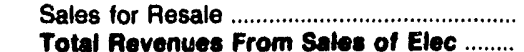 & $\begin{array}{r}47 \\
16,723\end{array}$ & $\begin{array}{r}115 \\
16,764\end{array}$ & $\begin{array}{r}0 \\
26.709\end{array}$ & $\begin{array}{r}0 \\
40.352\end{array}$ & $\begin{array}{r}52 \\
41,895\end{array}$ & 107 \\
\hline 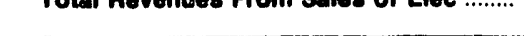 & & & & & 41,895 & 21,272 \\
\hline
\end{tabular}

Note: Totals may not equal sum of components because of independentrounding.

Source: Energy Information Administration, Form ElA-861, "Annual Electric Utility Report." Data are submitted on a calendar year. 
Table 40. Number of Consumers, Sales, and Operating Revenue by Major Publicly Owned Electric Utility Within State, 1991 (Continued)

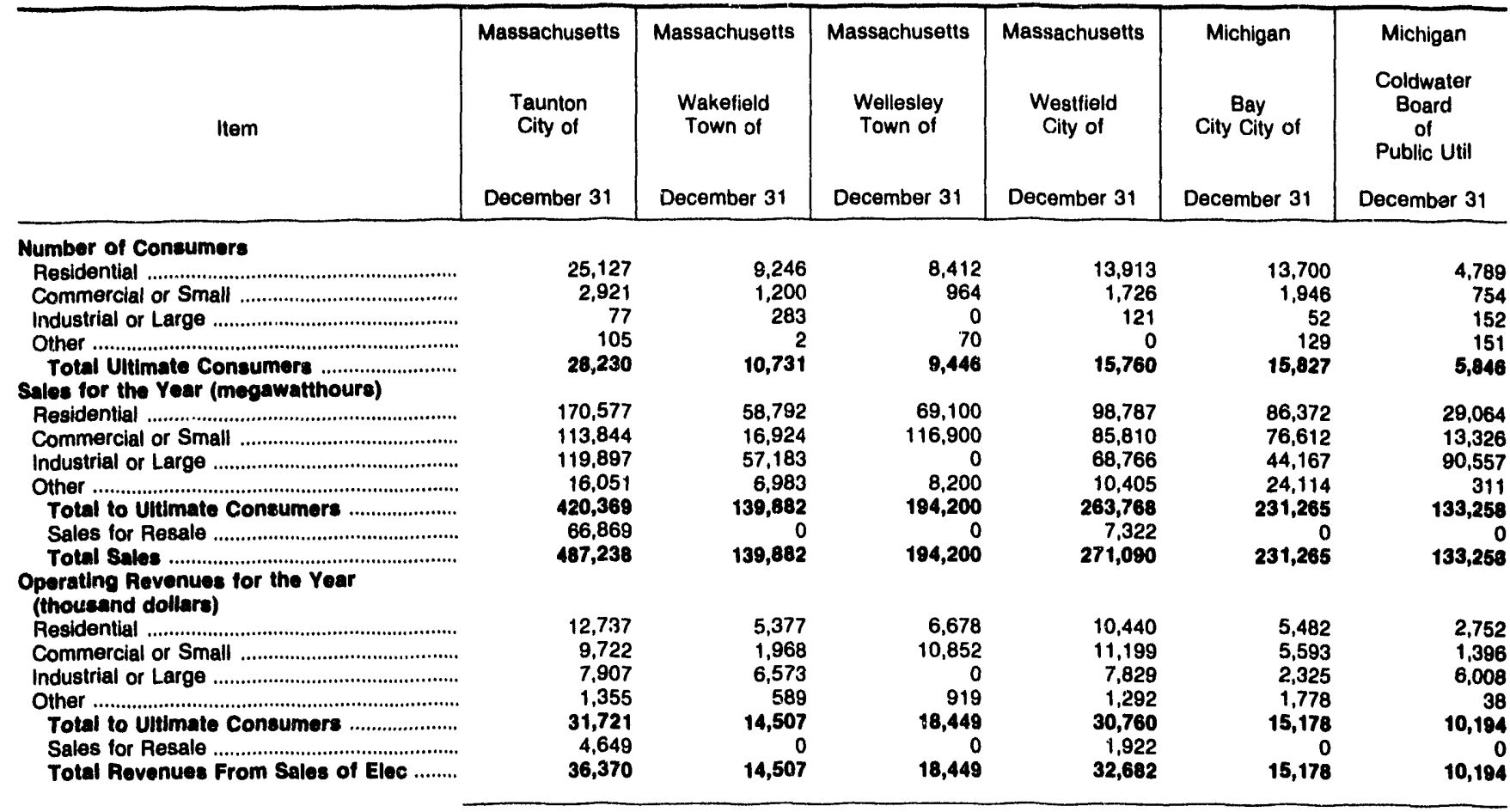

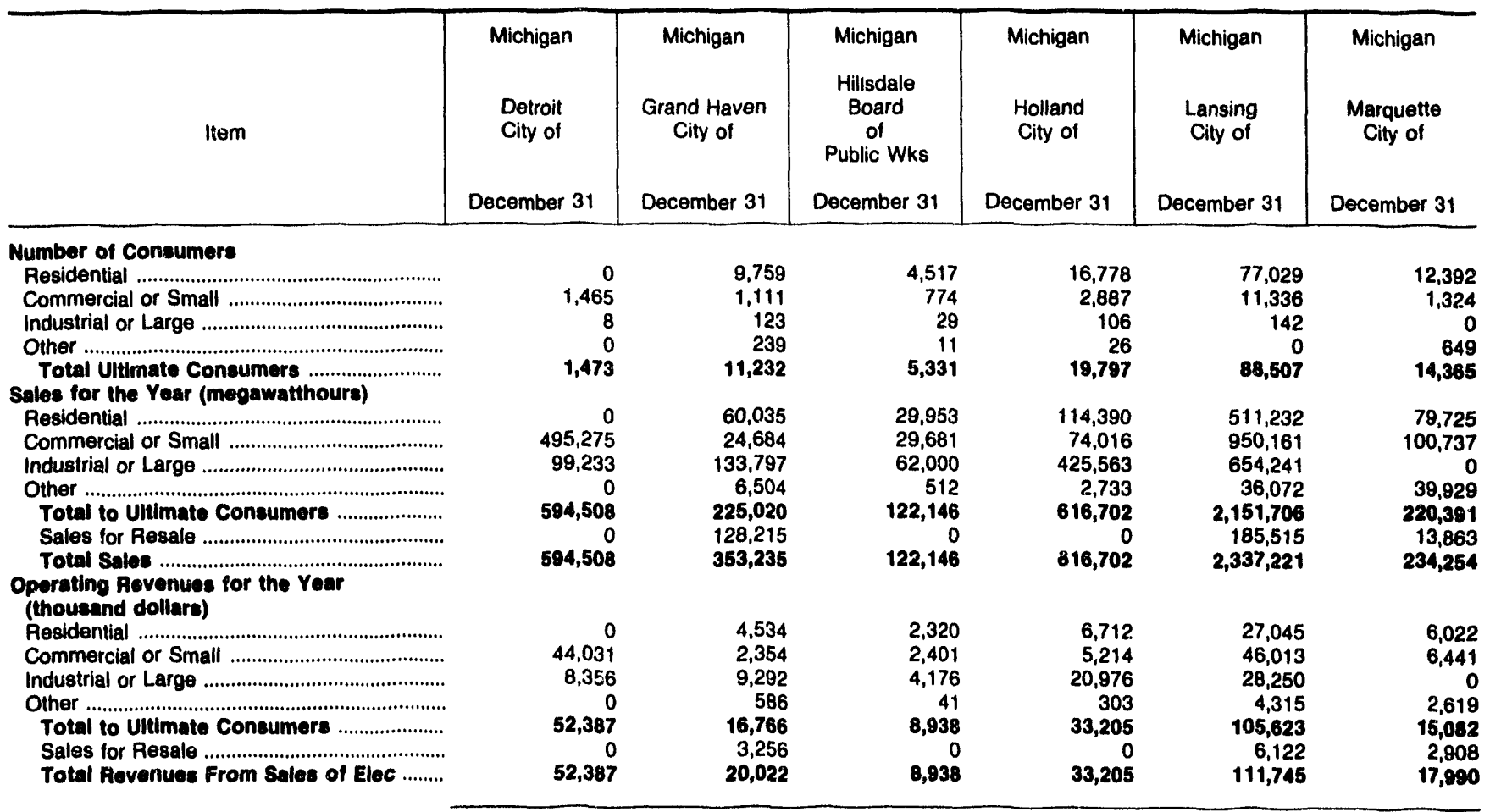

Note: Totals may not equal sum of components because of independent rounding.

Source: Energy information Administration, Form EIA-861, "Annual Electric Utility Report." Data are submitted on a calendar year. 
Table 40. Number of Consumers, Sales, and Operating Revenue by Major
Publicly Owned Electric Utility Within State, 1991 (Continued)

\begin{tabular}{|c|c|c|c|c|c|c|}
\hline Item & $\begin{array}{l}\text { Michigan } \\
\text { Michigan } \\
\text { Public } \\
\text { Power Agency } \\
\text { December } 31\end{array}$ & $\begin{array}{l}\text { Michigan } \\
\text { Michigan } \\
\text { South } \\
\text { Central } \\
\text { Pwr Agy } \\
\text { December } 31\end{array}$ & $\begin{array}{l}\text { Michigan } \\
\text { Sturgis } \\
\text { City of } \\
\text { December } 31\end{array}$ & $\begin{array}{l}\text { Michigan } \\
\text { Traverse } \\
\text { City City of } \\
\text { December } 31\end{array}$ & $\begin{array}{l}\text { Michigan } \\
\text { Wyandotte } \\
\text { Municipal } \\
\text { Serv Comm } \\
\text { December } 31\end{array}$ & $\begin{array}{l}\text { Minnesota } \\
\text { Alexandria } \\
\text { City of } \\
\text { December } 31\end{array}$ \\
\hline 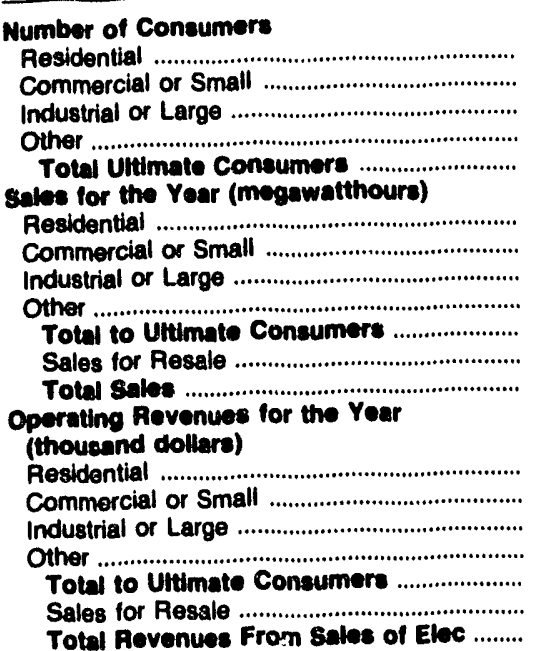 & $\begin{array}{r}0 \\
0 \\
0 \\
0 \\
0 \\
2,035,593 \\
2,035,593\end{array}$ & $\begin{array}{r}0 \\
0 \\
0 \\
0 \\
0 \\
409,731 \\
409,731\end{array}$ & $\begin{array}{r}5,459 \\
788 \\
76 \\
228 \\
6,551 \\
42,330 \\
46,060 \\
92,595 \\
1,447 \\
182,432 \\
0 \\
182,432\end{array}$ & $\begin{array}{r}36,127 \\
104,554 \\
66,486 \\
843 \\
208,010 \\
0 \\
208,010\end{array}$ & $\begin{array}{r}71,615 \\
21,698 \\
146,870 \\
4,595 \\
244,878 \\
0 \\
244,878\end{array}$ & $\begin{array}{r}50,446 \\
43,044 \\
65,059 \\
2,542 \\
161,001 \\
0 \\
161,001\end{array}$ \\
\hline
\end{tabular}

\begin{tabular}{|c|c|c|c|c|c|c|}
\hline Item & $\begin{array}{l}\text { Minnesota } \\
\text { Anoka } \\
\text { City of } \\
\text { December } 31\end{array}$ & $\begin{array}{l}\text { Minnesota } \\
\text { Austin } \\
\text { City of } \\
\text { December } 31\end{array}$ & $\begin{array}{l}\text { Minnesota } \\
\text { Fairmont } \\
\text { Public } \\
\text { Utilities } \\
\text { Comm } \\
\text { December } 31\end{array}$ & $\begin{array}{l}\text { Minnesota } \\
\text { Hutchinson } \\
\text { Utilities } \\
\text { Comm } \\
\text { December } 31\end{array}$ & $\begin{array}{l}\text { Minnesota } \\
\text { Marshall } \\
\text { City of } \\
\text { December } 31\end{array}$ & $\begin{array}{l}\text { Minnesota } \\
\text { Moorhead } \\
\text { City of } \\
\text { December } 31\end{array}$ \\
\hline 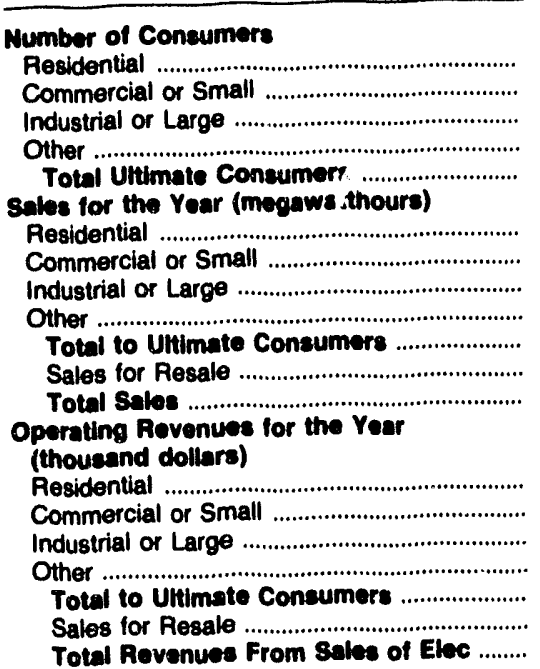 & $\begin{array}{r}61,631 \\
56,788 \\
69,219 \\
275 \\
187,813 \\
0 \\
187,913\end{array}$ & $\begin{array}{r}68,458 \\
107,167 \\
49,492 \\
4,862 \\
229,979 \\
37,349 \\
267,328\end{array}$ & $\begin{array}{r}5,039 \\
752 \\
18 \\
8 \\
5,817 \\
\\
36,968 \\
36,676 \\
66,923 \\
5,473 \\
146,040 \\
0 \\
146,040\end{array}$ & $\begin{array}{r}4,674 \\
653 \\
1 \\
1 \\
5,329 \\
\\
38,510 \\
78,776 \\
115,707 \\
1,139 \\
234,132 \\
137 \\
234,369\end{array}$ & $\begin{array}{r}4,924 \\
582 \\
193 \\
0 \\
5,600 \\
\\
46,581 \\
13,112 \\
203,347 \\
1,202 \\
264,242 \\
0 \\
264,242\end{array}$ & $\begin{array}{r}10,867 \\
1,618 \\
5 \\
3 \\
12,503 \\
126,994 \\
107,081 \\
80,776 \\
8,018 \\
322,869 \\
0 \\
322,869\end{array}$ \\
\hline
\end{tabular}

Note: Totals may not equal sum of components because of independent rounding.

Source: Energy Information Administration, Form EIA-861. "Annual Electric Utility Report." Data are submitted on a calendar year. 
Table 40. Number of Consumers, Sales, and Operating Revenue by Major Publicly Owned Electric Utility Within State, 1991 (Continued)

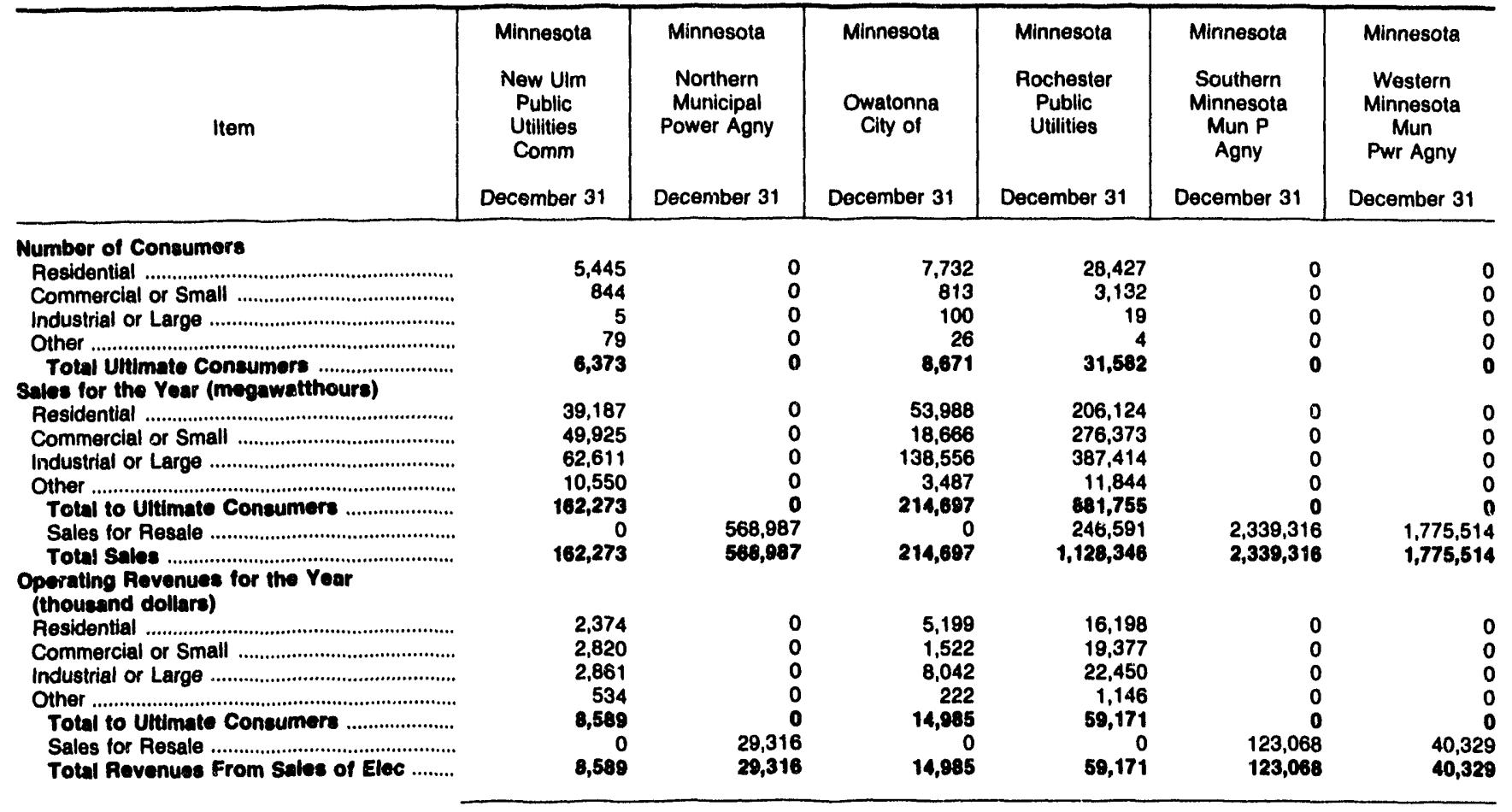

\begin{tabular}{|c|c|c|c|c|c|c|}
\hline Item & $\begin{array}{c}\text { Minnesota } \\
\text { Willmar } \\
\text { Municipal } \\
\text { Utils Comm } \\
\text { December } 31\end{array}$ & $\begin{array}{l}\text { Mississippi } \\
\text { Aberdeen } \\
\text { City of } \\
\text { December } 31\end{array}$ & $\begin{array}{l}\text { Mississippi } \\
\text { Clarksdale } \\
\text { City of }\end{array}$ & $\begin{array}{l}\text { Mississippi } \\
\text { Columbus } \\
\text { City of } \\
\text { December } 31\end{array}$ & $\begin{array}{l}\text { Mississippi } \\
\text { Greenwood } \\
\text { Utilities } \\
\text { Comm } \\
\text { December } 31\end{array}$ & $\begin{array}{c}\text { Mississippi } \\
\text { Holly } \\
\text { Springs } \\
\text { City of } \\
\text { December } 31\end{array}$ \\
\hline \multicolumn{7}{|l|}{ Number of Concumers } \\
\hline 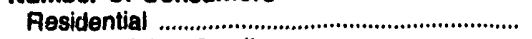 & 6,857 & 2,875 & 6,387 & 9,332 & 8,627 & 7,827 \\
\hline Commercial or Small ............................................ & 1,203 & 564 & 1,274 & 2,031 & 1,311 & 1,484 \\
\hline 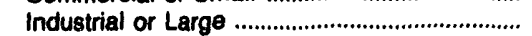 & 0 & 42 & 17 & 227 & 3 & 56 \\
\hline Other & 0 & 18 & 80 & 21 & 135 & 3,098 \\
\hline $\begin{array}{l}\text { Total Ultimate Consumers .............................. } \\
\text { Seles for the Year (meogwatthours) }\end{array}$ & 8,060 & 3,499 & 7,758 & 11,811 & 10,076 & 12,465 \\
\hline 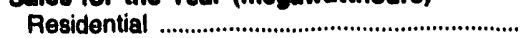 & 53,177 & 37,170 & 65,663 & 118,169 & 91,581 & 105,084 \\
\hline Commercial or Small ........................................ & 135,164 & 13,368 & 58,642 & 51,710 & 120,009 & 24,251 \\
\hline 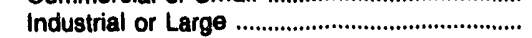 & 0 & 99,534 & 25,402 & 256,619 & 25,225 & 54,163 \\
\hline Other & 0 & 2,613 & 4,074 & 4,282 & 7,455 & 4,752 \\
\hline 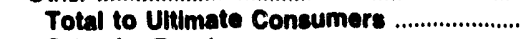 & 188,341 & 152,685 & 153,781 & 430,780 & 244,270 & 188,250 \\
\hline 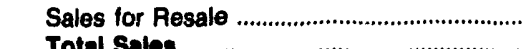 & & & 74,541 & $\begin{array}{r}0 \\
190700\end{array}$ & 0 & \\
\hline \multicolumn{7}{|l|}{$\begin{array}{l}\text { Operating Ravenues for the Year } \\
\text { (thousand dollars) }\end{array}$} \\
\hline 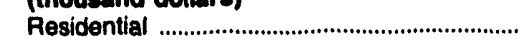 & 3,144 & 2,090 & 3,984 & 6,251 & 5,265 & 5,822 \\
\hline Commercial or Small & 7,158 & 852 & 3,422 & 3,144 & 7,230 & 1,566 \\
\hline Industrial or Large & 0 & 4,814 & 1,226 & 13,174 & 1,304 & 3,080 \\
\hline Other & 0 & 188 & 296 & 329 & 653 & 416 \\
\hline Total to Ultimate Consumers ...................... & 10,302 & 7,944 & $\mathbf{8 , 9 2 8}$ & 22,898 & 14,452 & 10,884 \\
\hline $\begin{array}{l}\text { Sales for Resale ............................................ } \\
\text { Total Rovenues From Sales of Elec ....... }\end{array}$ & $\begin{array}{r}0 \\
10,302\end{array}$ & $\begin{array}{r}0 \\
7,944\end{array}$ & $\begin{array}{r}1,853 \\
10,781\end{array}$ & $\begin{array}{r}0 \\
22,688\end{array}$ & $\begin{array}{r}0 \\
14,452\end{array}$ & $\begin{array}{r}0 \\
10,884\end{array}$ \\
\hline
\end{tabular}

Note: Totals may not equal sum of components because of independent rounding.

Source: Energy information Administration, Form ElA-861, "Annual Electric Utility Report." Data are submitted on a calendar year. 
Table 40. Number of Consumers, Sales, and Operating Revenue by Major Publicly Owned Electric Utility Within State, 1991 (Continued)

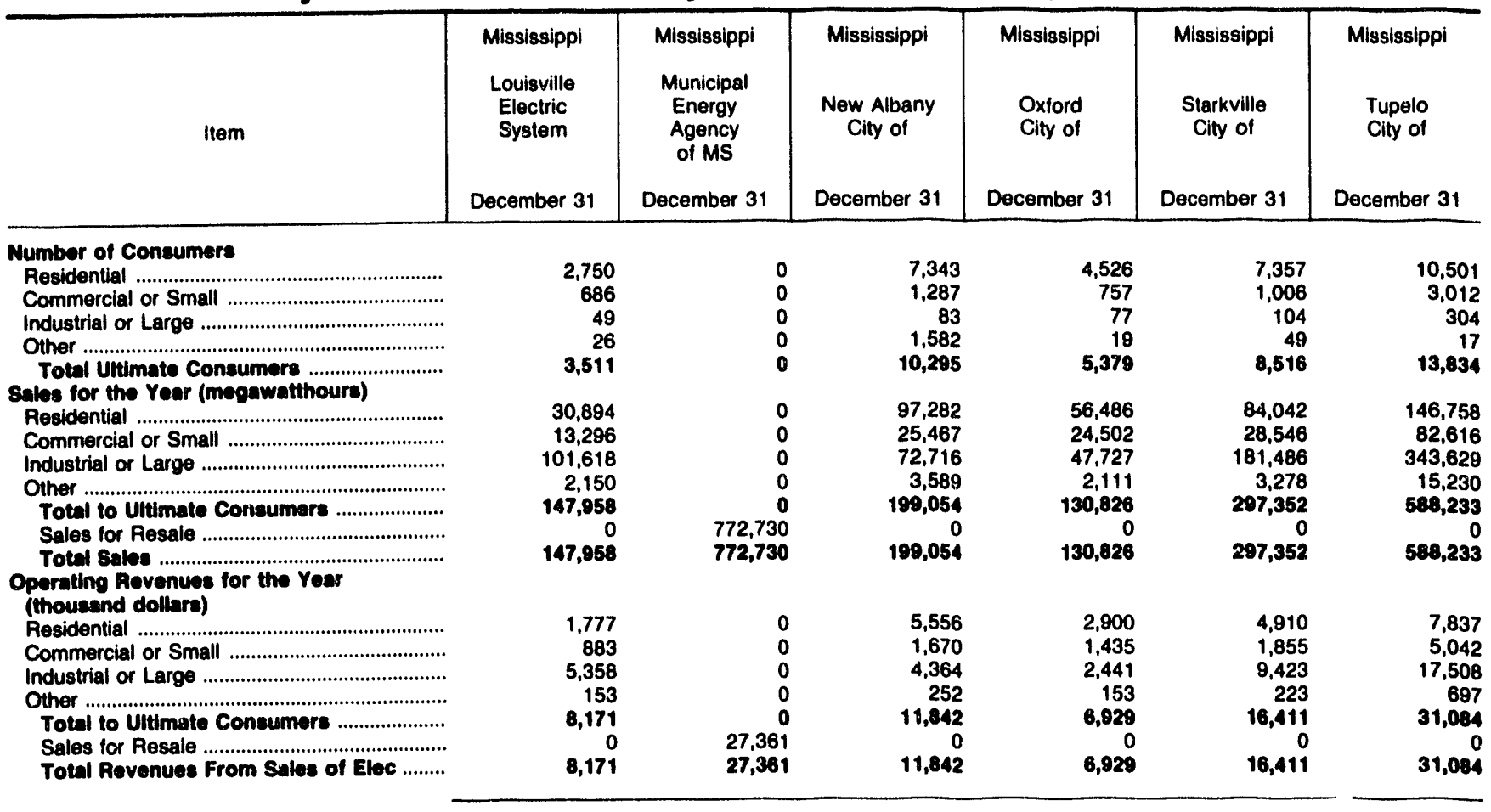

\begin{tabular}{|c|c|c|c|c|c|c|}
\hline Item & $\begin{array}{c}\text { Mississippi } \\
\text { West } \\
\text { Point } \\
\text { City of } \\
\text { December } 31\end{array}$ & $\begin{array}{l}\text { Missouri } \\
\text { Carthage } \\
\text { City of } \\
\text { December } 31\end{array}$ & $\begin{array}{l}\text { Missouri } \\
\text { Columbia } \\
\text { City of } \\
\text { December } 31\end{array}$ & $\begin{array}{c}\text { Missouri } \\
\text { Hannibal } \\
\text { City of } \\
\text { December } 31\end{array}$ & $\begin{array}{c}\text { Missouri } \\
\text { Independence } \\
\text { City of } \\
\text { December } 31\end{array}$ & $\begin{array}{l}\text { Missouri } \\
\text { Kennett } \\
\text { City of } \\
\text { December } 31\end{array}$ \\
\hline 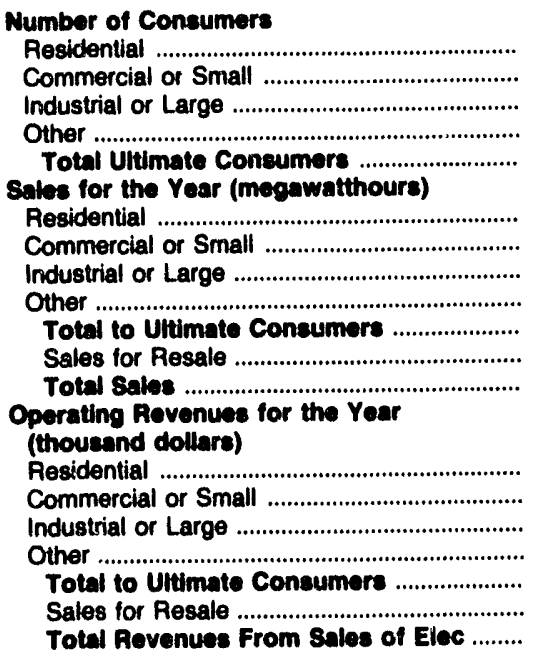 & $\begin{array}{r}34,228 \\
15,179 \\
119,426 \\
2,691 \\
171,524 \\
0 \\
171,524\end{array}$ & $\begin{array}{r}5,554 \\
941 \\
19 \\
0 \\
6,514 \\
\\
44,345 \\
35,865 \\
73,294 \\
6,623 \\
160,127 \\
1,532 \\
161,659\end{array}$ & $\begin{array}{r}23,426 \\
3,644 \\
222 \\
1 \\
27,283 \\
\\
240,465 \\
143,312 \\
304,072 \\
6,511 \\
694,360 \\
0 \\
694,360\end{array}$ & $\begin{array}{r}7,351 \\
1,072 \\
116 \\
19 \\
8,558 \\
\\
61,603 \\
20,240 \\
74,130 \\
6,443 \\
162,416 \\
0 \\
162,416\end{array}$ & $\begin{array}{r}44,204 \\
4,257 \\
16 \\
1 \\
48,478 \\
397,210 \\
355,105 \\
39,072 \\
9,012 \\
800,390 \\
12,062 \\
812,461\end{array}$ & $\begin{array}{r}4,644 \\
822 \\
117 \\
1 \\
5,584 \\
58,300 \\
13,236 \\
62,629 \\
128 \\
134,293 \\
0 \\
134,293\end{array}$ \\
\hline
\end{tabular}

Note: Totals may nol equal sum of components because of independent rounding.

Source: Energy information Administration, Form ElA-861, "Annual Electric Utility Report." Data are submitted on a calendar year. 
Table 40. Number of Consumers, Sales, and Operating Revenue by Major Publicly Owned Electric Utility Within State, 1991 (Continued)

\begin{tabular}{|c|c|c|c|c|c|c|}
\hline Item & $\begin{array}{l}\text { Missouri } \\
\text { Kirkwood } \\
\text { City of } \\
\text { December } 31\end{array}$ & $\begin{array}{c}\text { Missouri } \\
\text { Lebanon } \\
\text { City of } \\
\text { December } 31\end{array}$ & $\begin{array}{c}\text { Missouri } \\
\text { Marshall } \\
\text { City of } \\
\text { December } 31\end{array}$ & $\begin{array}{l}\text { Missouri } \\
\text { Monett } \\
\text { City of } \\
\text { December } 31\end{array}$ & $\begin{array}{c}\text { Missouri } \\
\text { Poplar } \\
\text { Bluff } \\
\text { City of } \\
\text { December } 31\end{array}$ & $\begin{array}{c}\text { Missouri } \\
\text { Rolla } \\
\text { City of } \\
\text { December } 31\end{array}$ \\
\hline \multicolumn{7}{|l|}{ Number of Consumers } \\
\hline 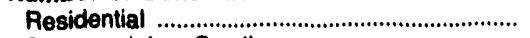 & 8,282 & 3,575 & 4,760 & 3,870 & 6,937 & 5,241 \\
\hline 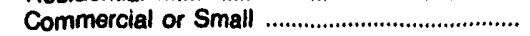 & 963 & 954 & 793 & 0 & 1,366 & 1,148 \\
\hline 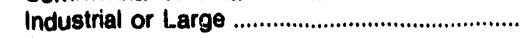 & 35 & 41 & 3 & 17 & 24 & 110 \\
\hline Other & 1 & 0 & 1 & 3 & 3 & 0 \\
\hline \multicolumn{5}{|l|}{ Sales for the Year (megawatthours) } & 8,330 & 6,490 \\
\hline 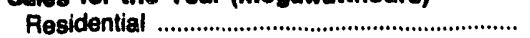 & 81,854 & 39,238 & 40,760 & 53,620 & 88,930 & 65,631 \\
\hline 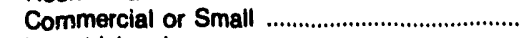 & 32,092 & 33,094 & 57,270 & & 102,028 & 32,034 \\
\hline 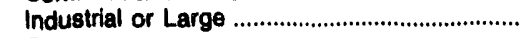 & 56,878 & 57,319 & 39,124 & 83,423 & 33,420 & 100,091 \\
\hline Other & 1,781 & & 1,591 & 7,663 & 231 & \\
\hline Total to Ultimate Consumers ....................... & 172,605 & 129,651 & 138,745 & 144,706 & 224,609 & 197,756 \\
\hline 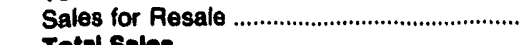 & & & & & & \\
\hline 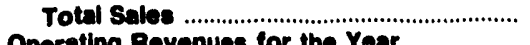 & 172,605 & 129,651 & 138,745 & 144,706 & 224,609 & 197,758 \\
\hline \multicolumn{7}{|l|}{$\begin{array}{l}\text { Operating Revenues for the Year } \\
\text { (thousand dollars) }\end{array}$} \\
\hline 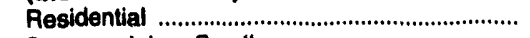 & 6,377 & 2,305 & 3,018 & 2,800 & 3,696 & 3,558 \\
\hline 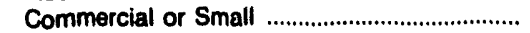 & 2,329 & 2,034 & 3,689 & & 4,608 & 1,680 \\
\hline 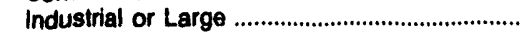 & 3,283 & 3,054 & 2,120 & 4,132 & 1,226 & 5,196 \\
\hline Other & & & 117 & 283 & 10 & \\
\hline Total to Uitimate Consumers ......................... & 12,046 & 7,393 & 8,945 & 7,215 & 9,540 & 10,434 \\
\hline 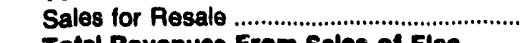 & & & & & & 0 \\
\hline Total Revenues From Sales of Elec ......... & 12,046 & 7,393 & 8,945 & 7,215 & 9,540 & 10,434 \\
\hline
\end{tabular}

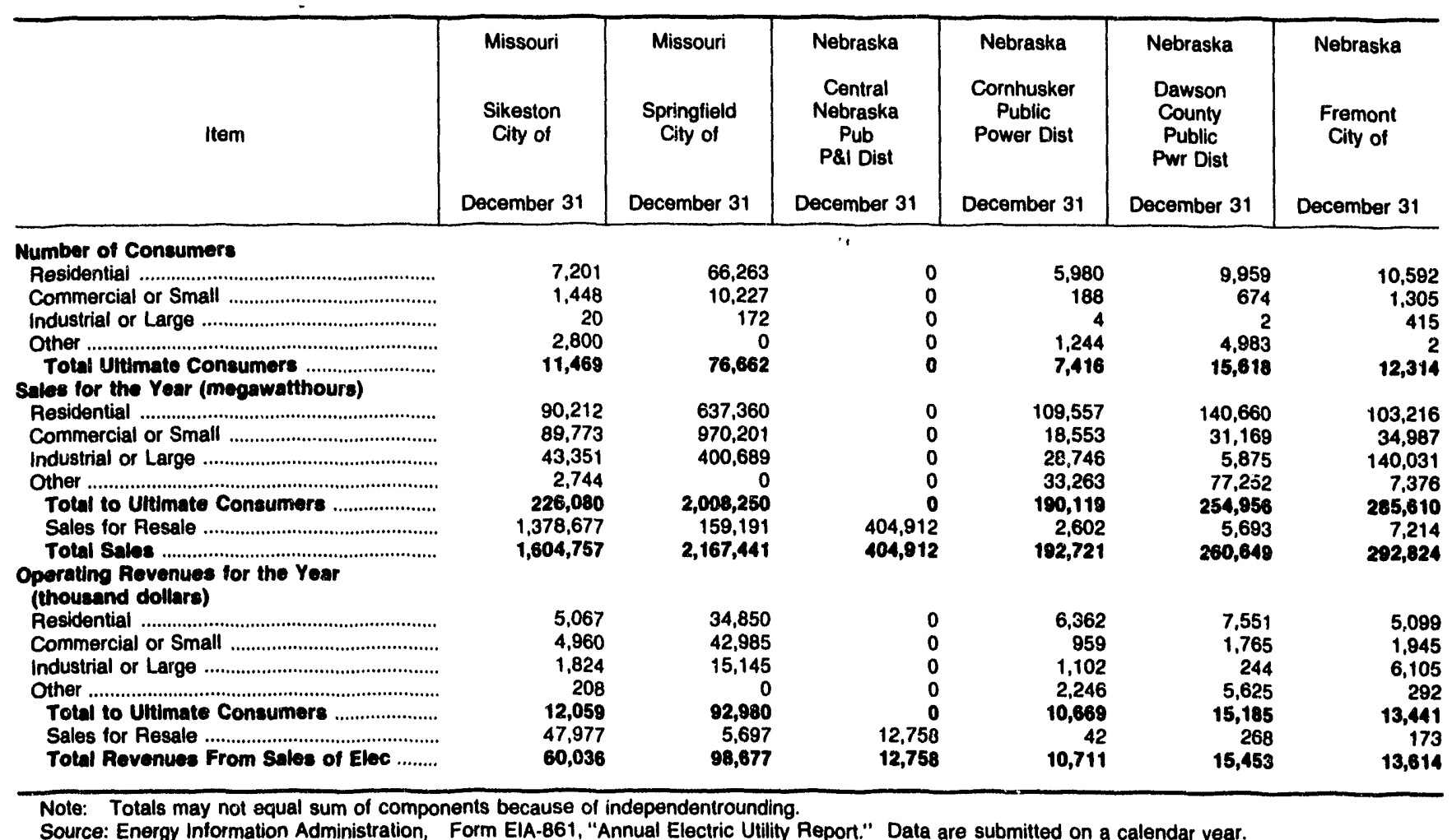


Table 40. Number of Consumers, Sales, and Operating Revenue by Major Publicly Owned Electric Utility Within State, 1991 (Continued)

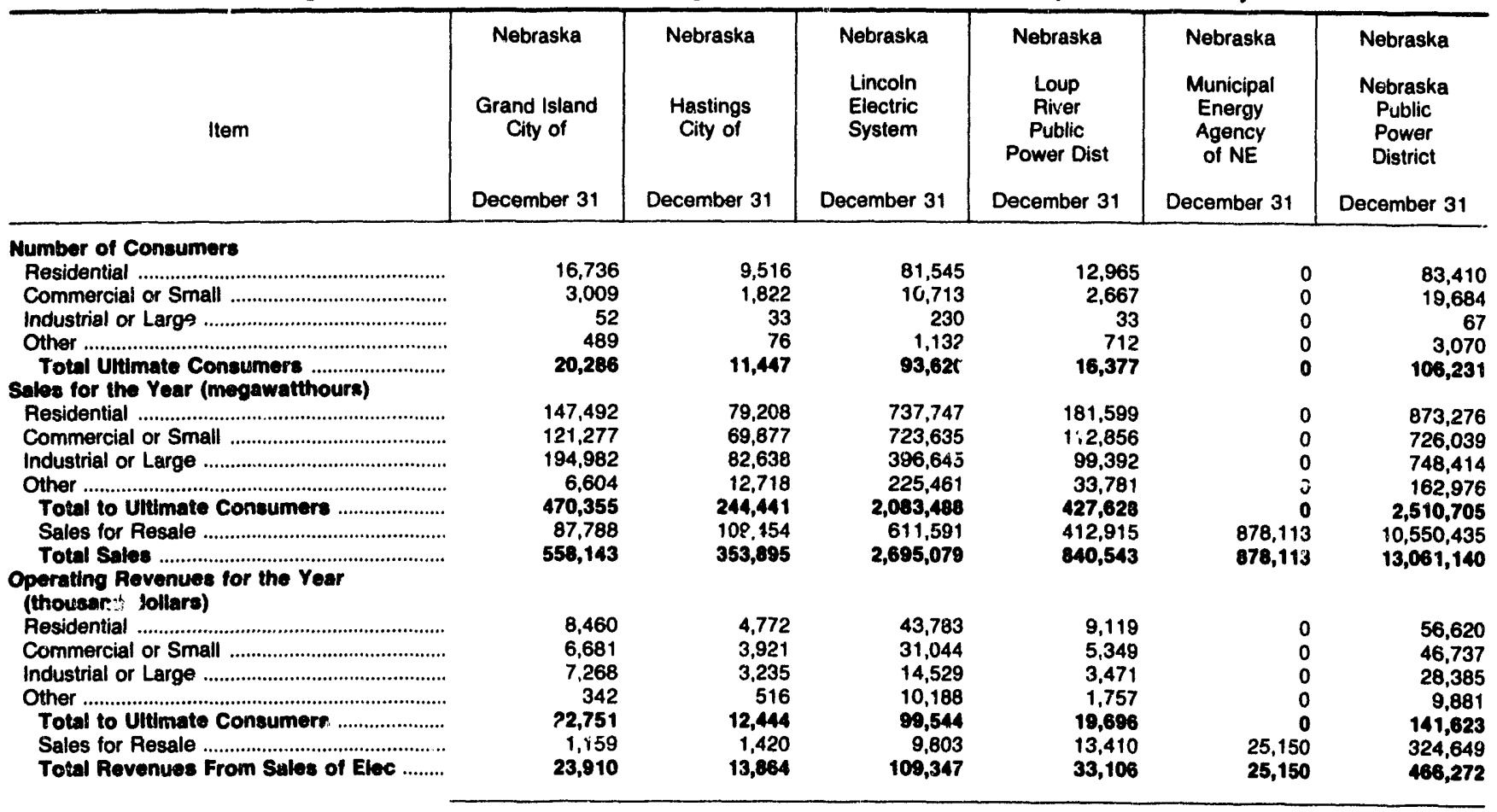

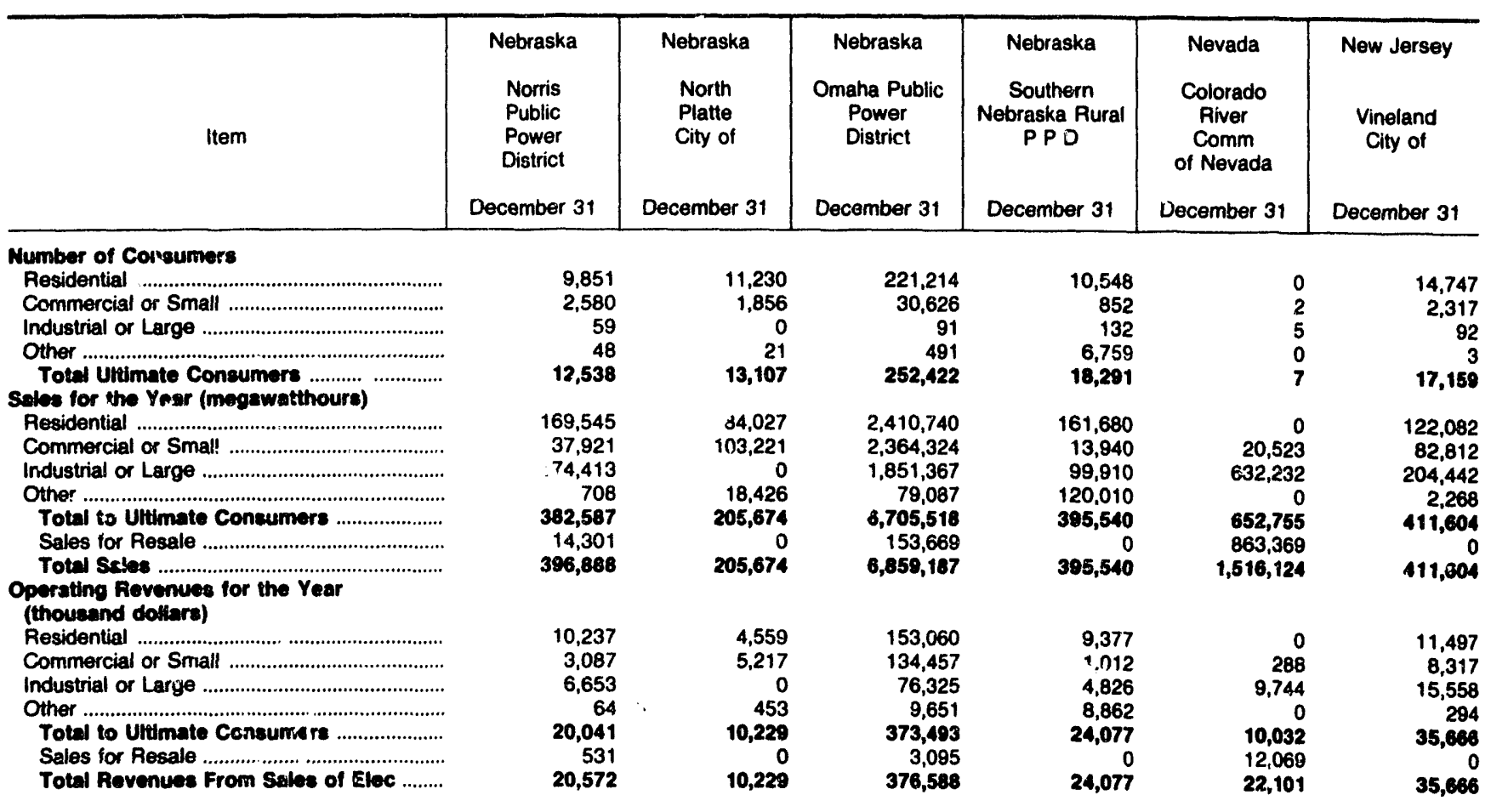

Note: Totals may not equal s m of components because of independent rounding

Sourse: Energy Information Administration, Form EIA-861. "Annual Electric Utility Peport." Data are submifted on a calendar year. 

Table 40. Number of Consumers, Sales, and Operating Revenue by Major
Publicly Owned Electric Utility Within State, 1991 (Continued)

\begin{tabular}{|c|c|c|c|c|c|c|}
\hline Item & $\begin{array}{c}\text { New Mexico } \\
\text { Farmington } \\
\text { City of } \\
\text { December } 31\end{array}$ & $\begin{array}{c}\text { New Mexico } \\
\text { Gallup } \\
\text { City of } \\
\text { December } 31\end{array}$ & $\begin{array}{l}\text { New Mexico } \\
\text { Los Alamos } \\
\text { County } \\
\text { December } 31\end{array}$ & $\begin{array}{c}\text { New York } \\
\text { Fairport } \\
\text { Village of } \\
\text { December } 31\end{array}$ & $\begin{array}{c}\text { New York } \\
\text { Freeport } \\
\begin{array}{c}\text { Village of } \\
\text { Ine }\end{array} \\
\text { December } 31\end{array}$ & $\begin{array}{l}\text { New York } \\
\text { Jamestown } \\
\text { City of } \\
\text { December } 31\end{array}$ \\
\hline 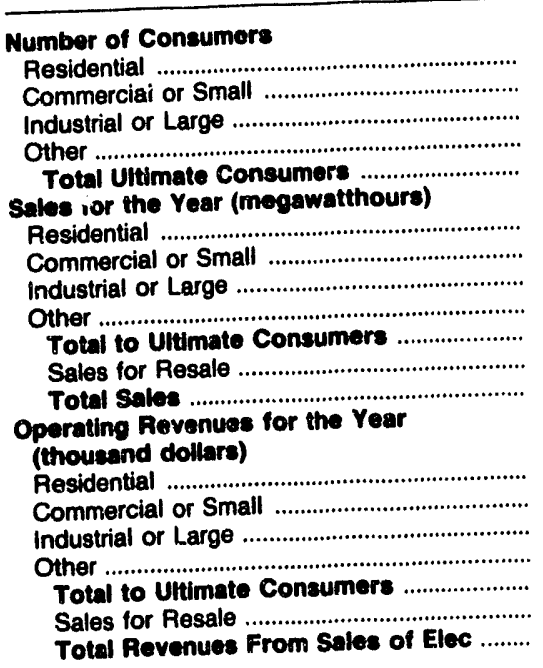 & $\begin{array}{r}145,219 \\
237,782 \\
101,822 \\
8,741 \\
493,564 \\
29,340 \\
522,904\end{array}$ & $\begin{array}{r}37,923 \\
99,318 \\
14,854 \\
20,226 \\
172,321 \\
0 \\
172,321\end{array}$ & $\begin{array}{r}43,788 \\
27,900 \\
0 \\
364,762 \\
436,450 \\
16,141 \\
452,591\end{array}$ & $\begin{array}{r}12,580 \\
1,046 \\
35 \\
184 \\
13,845 \\
\\
185,667 \\
50,195 \\
70,514 \\
2,547 \\
308,923 \\
0 \\
308,923\end{array}$ & $\begin{array}{r}12,830 \\
1,749 \\
0 \\
124 \\
14,703 \\
\\
97,396 \\
111,714 \\
0 \\
14,005 \\
223,115 \\
0 \\
223,115\end{array}$ & $\begin{array}{r}17,016 \\
2,733 \\
125 \\
191 \\
20,065 \\
128,943 \\
123,770 \\
126,651 \\
33,868 \\
413,232 \\
165,005 \\
578,237\end{array}$ \\
\hline
\end{tabular}

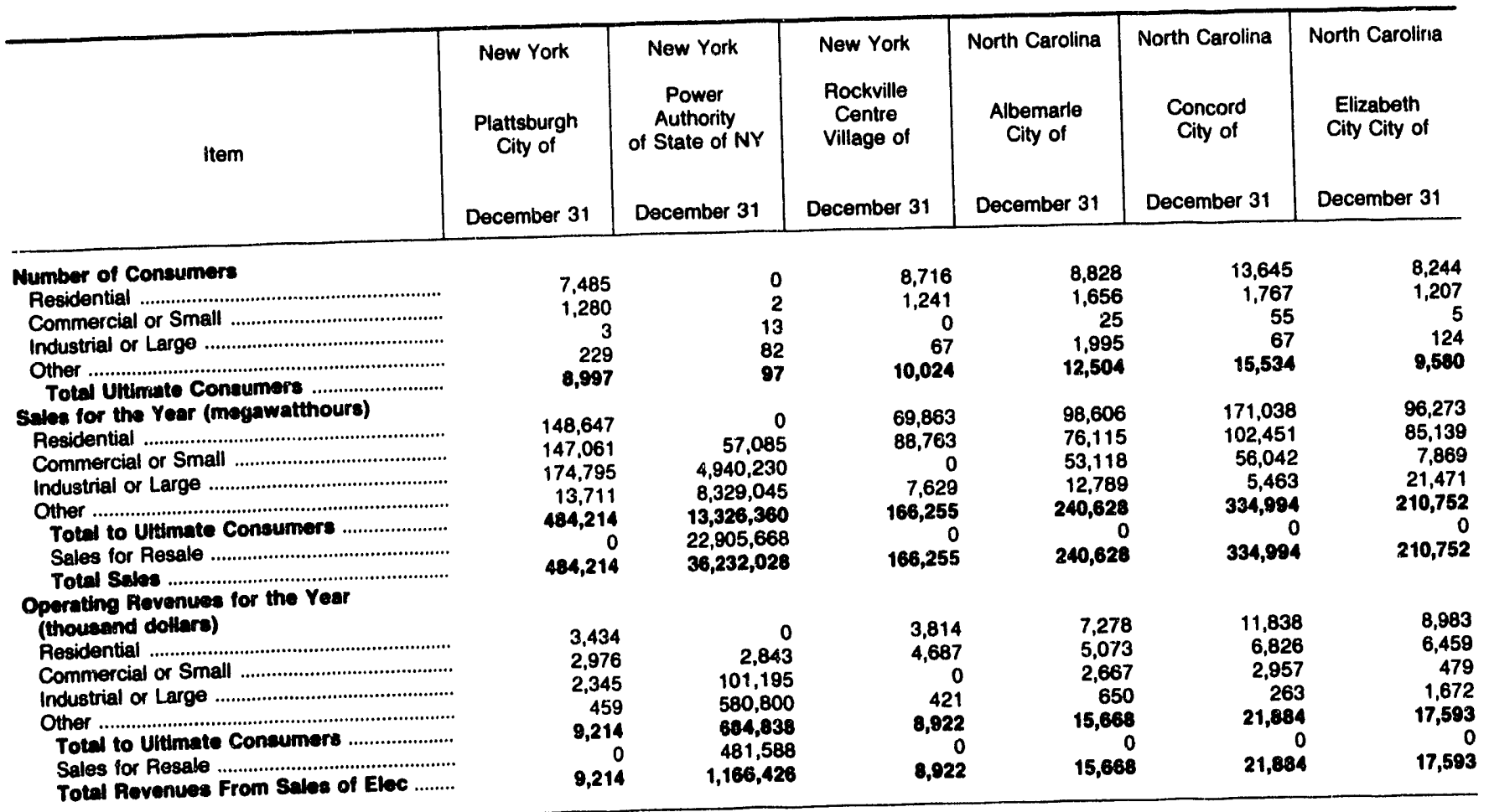

Tote. Tols may not equal sum of components because of independent rounding.

Note: Totals may not equal sum of components because of independent rounding. 
Table 40. Number of Consumers, Sales, and Operating Revenue by Major Publicly Owned Electric Utility Within State, 1991 (Continued)

\begin{tabular}{|c|c|c|c|c|c|c|}
\hline Item & $\begin{array}{l}\text { North Carolina } \\
\text { Fayetteville } \\
\text { Public } \\
\text { Works Comm } \\
\text { December } 31\end{array}$ & $\begin{array}{l}\text { North Carolina } \\
\text { Gastonia } \\
\text { City of } \\
\text { December } 31\end{array}$ & $\begin{array}{l}\text { North Carolina } \\
\text { Greenville } \\
\text { Utilities } \\
\text { Comm } \\
\text { December } 31\end{array}$ & $\begin{array}{c}\text { North Carolina } \\
\text { High } \\
\text { Point } \\
\text { Town } \\
\text { of } \\
\text { December } 31\end{array}$ & $\begin{array}{l}\text { North Carolina } \\
\text { Kinston } \\
\text { City of }\end{array}$ & $\begin{array}{l}\text { North Carolina } \\
\text { Lexington } \\
\text { City of } \\
\text { December } 31\end{array}$ \\
\hline \multicolumn{7}{|l|}{ Number of Consumers } \\
\hline 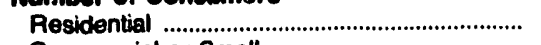 & 51,537 & 20,201 & 31,992 & 26,133 & 10,658 & 14,250 \\
\hline Commercial or Small ............................................ & 5,853 & 2,682 & 4,301 & 4,244 & 1,822 & 2,039 \\
\hline 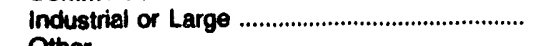 & 11 & 72 & 14 & 316 & 8 & 59 \\
\hline Other Total Uitimate Consumers & $\begin{array}{r}3,470 \\
60,871\end{array}$ & $\begin{array}{r}2 \\
22,957\end{array}$ & 36,309 & $\begin{array}{r}3 \\
30,686\end{array}$ & $\begin{array}{r}1,676 \\
14,164\end{array}$ & $\begin{array}{r}0 \\
16,348\end{array}$ \\
\hline \multirow{7}{*}{ 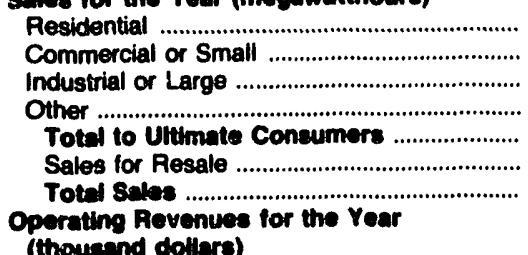 } & & & & & & \\
\hline & 670,347 & 201,878 & 392,961 & 270,537 & 128,449 & 167,468 \\
\hline & 458,117 & 237,208 & 283,664 & 353,914 & 144,621 & 114,285 \\
\hline & $\begin{array}{r}377,606 \\
24,185\end{array}$ & $\begin{array}{r}102,665 \\
28,242\end{array}$ & $\begin{array}{r}292,316 \\
30,561\end{array}$ & $\begin{array}{r}116,366 \\
13544\end{array}$ & $\begin{array}{l}95,485 \\
17597\end{array}$ & $\begin{array}{r}109,626 \\
6,944\end{array}$ \\
\hline & $1,530,255$ & 569,903 & 990,502 & 754,361 & 386,152 & 398,323 \\
\hline & $\begin{array}{r}420 \\
1,530,675\end{array}$ & & $\begin{array}{r}0 \\
999,502\end{array}$ & $\begin{array}{r}0 \\
754,361\end{array}$ & $\begin{array}{r}0 \\
386,152\end{array}$ & $\begin{array}{r}0 \\
398,323\end{array}$ \\
\hline & & & & & & \\
\hline \multirow{3}{*}{ 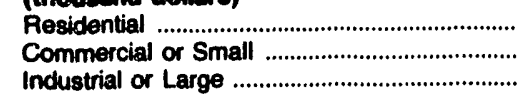 } & 52,882 & 16,344 & 37,290 & 20,754 & 12,378 & 12,982 \\
\hline & 32,407 & 15,947 & 24,570 & 22,870 & 12,008 & 8,345 \\
\hline & 21,133 & 5,912 & 19,332 & 7,073 & $6,25: 2$ & 6,365 \\
\hline \multirow{2}{*}{ 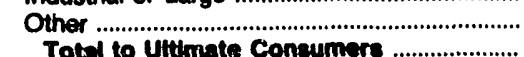 } & 2,469 & 1.456 & 2,803 & 1,925 & 1,673 & 471 \\
\hline & 108,891 & 39,659 & 83,995 & 52,622 & 32,311 & 28,163 \\
\hline 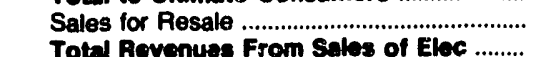 & $\begin{array}{r}14 \\
108,805\end{array}$ & $\begin{array}{r}0 \\
39,659\end{array}$ & $\begin{array}{r}0 \\
83,995\end{array}$ & $\begin{array}{r}0 \\
52,622\end{array}$ & $\begin{array}{r}0 \\
32,311\end{array}$ & $\begin{array}{r}0 \\
28,163\end{array}$ \\
\hline & & & & & & \\
\hline
\end{tabular}

\begin{tabular}{|c|c|c|c|c|c|c|}
\hline Item & $\begin{array}{l}\text { North Carolina } \\
\text { Lumberton } \\
\text { City of } \\
\text { December } 31\end{array}$ & $\begin{array}{c}\text { North Carolina } \\
\text { Monroe } \\
\text { City of } \\
\text { December } 31\end{array}$ & $\begin{array}{l}\text { North Carolina } \\
\text { Morganton } \\
\text { City of } \\
\text { December } 31\end{array}$ & $\begin{array}{c}\text { North Carolina } \\
\text { Murphy } \\
\text { City of } \\
\text { December } 31\end{array}$ & $\begin{array}{l}\text { North Carolina } \\
\text { New Bern } \\
\text { City of } \\
\text { December } 31\end{array}$ & $\begin{array}{c}\text { North Carolina } \\
\text { Now River } \\
\text { Light } \\
8 \\
\text { Power Co } \\
\text { December } 31\end{array}$ \\
\hline \multicolumn{7}{|l|}{ Number of Consumers } \\
\hline 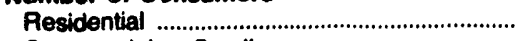 & 7,276 & 5,960 & 6,100 & 2,218 & 12,263 & 4,841 \\
\hline 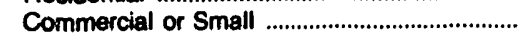 & 1,829 & 1,326 & 1,120 & 972 & 1,834 & 1,254 \\
\hline 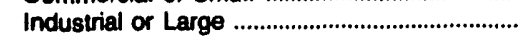 & 0 & 927 & 51 & 52 & 7 & 4 \\
\hline Other & & 1,039 & 57 & 5 & $\begin{array}{r}1 \\
1105\end{array}$ & 241 \\
\hline $\begin{array}{l}\text { Total Uitimate Consumers .......................... } \\
\text { Seles for the Year (megawatthours) }\end{array}$ & 9,105 & 9,252 & 7,328 & 3,247 & 14,105 & 6,340 \\
\hline 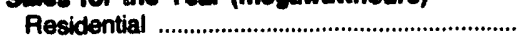 & 82,791 & 70,928 & 59,650 & 27,374 & 85,711 & 38,872 \\
\hline Commercial or Small .................................... & 157,818 & 19,205 & 44,341 & 15,798 & 193,700 & 71,438 \\
\hline 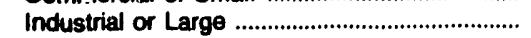 & 0 & 293,415 & 123,273 & 91,934 & 35,707 & 9,366 \\
\hline Other & 0 & 1,670 & 17,786 & 1,651 & & 38,887 \\
\hline Totel to UiH, wate Consumere ..................... & 240,609 & 385,218 & 245,050 & 138,757 & 315,155 & 158,563 \\
\hline $\begin{array}{l}\text { Sales for Resale } \\
\text { Totel Setee }\end{array}$ & 240,609 & 385,218 & 245,050 & 136,757 & $\begin{array}{r}0 \\
315,155\end{array}$ & $\begin{array}{r}0 \\
158,583\end{array}$ \\
\hline \multicolumn{7}{|l|}{$\begin{array}{l}\text { Operating Revenues for the Year } \\
\text { (thousand dollars) }\end{array}$} \\
\hline 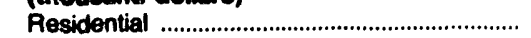 & 7,619 & 5,166 & 4,540 & 1,663 & 10,620 & 3,054 \\
\hline Commercial or Small ............................................ & 13,150 & 1,582 & 3,277 & 1,152 & 16,543 & 4,714 \\
\hline 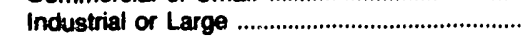 & 0 & 16,719 & 6,753 & 4,947 & 2,587 & 591 \\
\hline Other & 0 & 175 & 803 & 95 & 3 & 2,714 \\
\hline 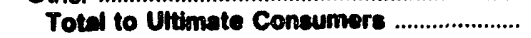 & 20,769 & 23,642 & 15,373 & 7,857 & 29,753 & 11,073 \\
\hline Sales for Resale .................................... & & & & & & \\
\hline Totel Revenues From Sales of Elec ......... & 20,769 & 23,642 & 15,373 & 7,857 & 29,753 & 11,073 \\
\hline
\end{tabular}

Note: Totals may not equal sum of components because of independent rounding.

Source: Energy Informgtion Administration, Form E!A-861, "Ann!ula! Electric Utility Report." Deta are gubmitted on a calendar year. 
Table 40. Number of Consumers, Sales, and Operating Revenue by Major Publicly Owned Electric Utility Within State, 1991 (Continued)

\begin{tabular}{|c|c|c|c|c|c|c|}
\hline Item & $\begin{array}{l}\text { North Carolina } \\
\text { North } \\
\text { Carolina } \\
\text { Eastern M P A } \\
\text { December } 31\end{array}$ & $\begin{array}{l}\text { North Carolina } \\
\text { North } \\
\text { Carolina } \\
\text { Mun } \\
\text { Power Agny } \\
\text { December } 31\end{array}$ & $\begin{array}{l}\text { North Carolina } \\
\text { Rocky Mount } \\
\text { City of }\end{array}$ & $\begin{array}{l}\text { North Carolina } \\
\text { Shelby } \\
\text { City of } \\
\text { December } 31\end{array}$ & $\begin{array}{l}\text { North Carolina } \\
\text { Statesville } \\
\text { City of } \\
\text { December } 31\end{array}$ & $\begin{array}{l}\text { North Carolina } \\
\text { Tarboro } \\
\text { Town of } \\
\text { December } 31\end{array}$ \\
\hline 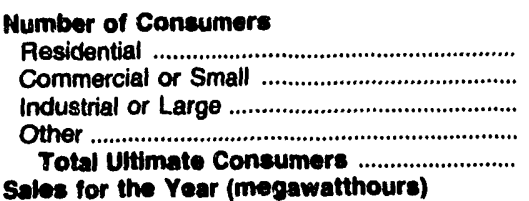 & $\begin{array}{l}0 \\
0 \\
0 \\
0 \\
0\end{array}$ & $\begin{array}{l}0 \\
0 \\
0 \\
0 \\
0\end{array}$ & $\begin{array}{r}22,365 \\
3,103 \\
11 \\
128 \\
25,807\end{array}$ & $\begin{array}{r}6,323 \\
1,242 \\
13 \\
2 \\
7,580\end{array}$ & $\begin{array}{r}9,246 \\
1,780 \\
126 \\
2 \\
11,154\end{array}$ & $\begin{array}{r}4,908 \\
668 \\
33 \\
1,286 \\
6,895\end{array}$ \\
\hline 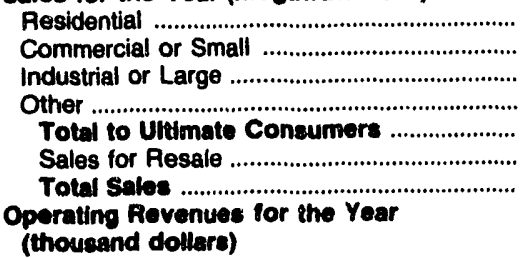 & $\begin{array}{r}0 \\
0 \\
0 \\
0 \\
0 \\
5,962,319 \\
5,862,319\end{array}$ & $\begin{array}{r}0 \\
0 \\
0 \\
0 \\
0 \\
8,022,722 \\
8,022,722\end{array}$ & $\begin{array}{r}261,146 \\
299,816 \\
152,105 \\
9,888 \\
722,955 \\
15,845 \\
738,800\end{array}$ & $\begin{array}{r}70,483 \\
79,305 \\
5,838 \\
1,637 \\
157,283 \\
0 \\
157,263\end{array}$ & $\begin{array}{r}81,380 \\
129,754 \\
109,893 \\
15,112 \\
336,139 \\
0 \\
336,139\end{array}$ & $\begin{array}{r}53,870 \\
36,665 \\
129,804 \\
7,135 \\
227,474 \\
0 \\
227,474\end{array}$ \\
\hline 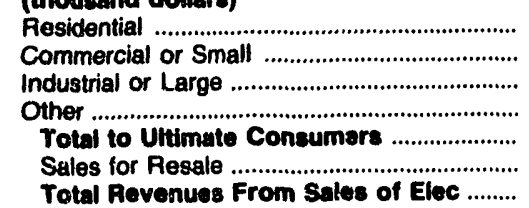 & $\begin{array}{r}0 \\
0 \\
0 \\
0 \\
0 \\
370,749 \\
370,749\end{array}$ & $\begin{array}{r}0 \\
0 \\
0 \\
0 \\
0 \\
438,810 \\
438,810\end{array}$ & $\begin{array}{r}22,257 \\
22,727 \\
9,373 \\
984 \\
55,341 \\
1,034 \\
56,375\end{array}$ & $\begin{array}{r}5,324 \\
5,250 \\
362 \\
20 \\
10,956 \\
0 \\
10,956\end{array}$ & $\begin{array}{r}6,610 \\
8,741 \\
6,742 \\
876 \\
22,989 \\
0 \\
22,869\end{array}$ & $\begin{array}{r}5,305 \\
3,124 \\
8,881 \\
614 \\
17,924 \\
0 \\
17,924\end{array}$ \\
\hline
\end{tabular}

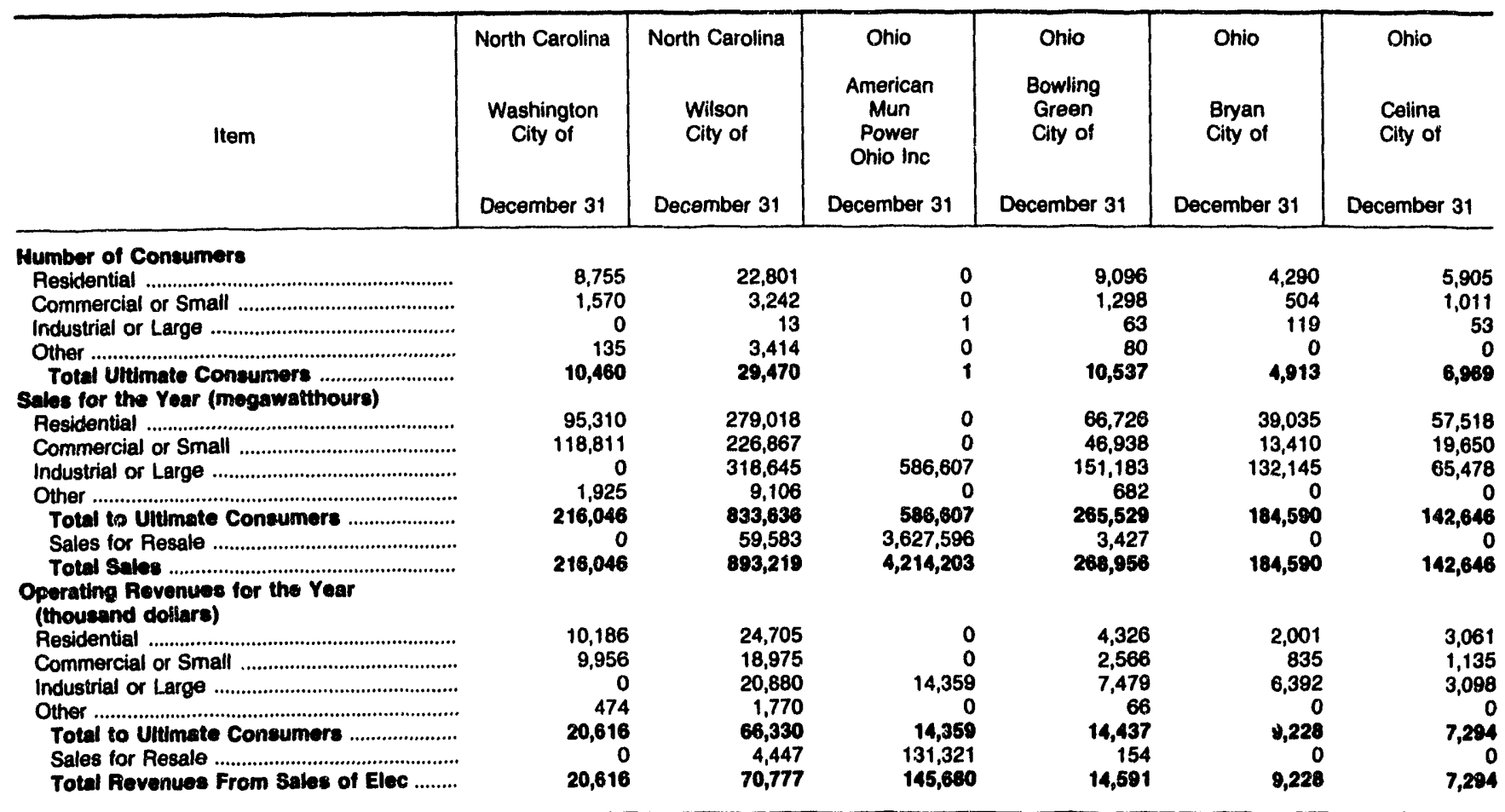

Note: Totals may not equal sum of components because of independent rounding.

Source: Energy Information Administration, Form EIA-861, "Annual Electric Utility Feport." Data are submitted on a calendar year. 
Table 40. Number of Consumers, Sales, and Operating Revenue by Major Publicly Owned Electric Utility Within State, 1991 (Continued)

\begin{tabular}{|c|c|c|c|c|c|c|}
\hline Item & $\begin{array}{c}\text { Ohio } \\
\text { Cleveland } \\
\text { City of } \\
\text { December } 31\end{array}$ & $\begin{array}{c}\text { Ohio } \\
\text { Columbus } \\
\text { City of } \\
\text { December } 31\end{array}$ & $\begin{array}{c}\text { Ohio } \\
\text { Cuyahoga } \\
\text { Falls } \\
\text { City of } \\
\text { December } 31\end{array}$ & $\begin{array}{c}\text { Onio } \\
\text { Dover } \\
\text { City of } \\
\text { December } 31\end{array}$ & $\begin{array}{c}\text { Ohio } \\
\begin{array}{c}\text { Hamilton } \\
\text { City of }\end{array} \\
\text { December } 31\end{array}$ & $\begin{array}{c}\text { Ohio } \\
\text { Niles } \\
\text { City of } \\
\text { December } 31\end{array}$ \\
\hline \multicolumn{7}{|l|}{ Number of Consumers } \\
\hline 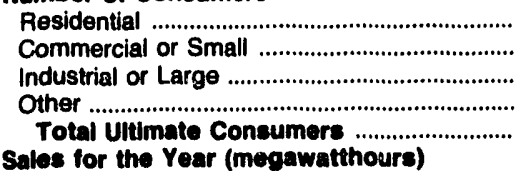 & $\begin{array}{r}47,328 \\
5,932 \\
10 \\
3 \\
53,273\end{array}$ & $\begin{array}{r}6,764 \\
2,240 \\
312 \\
728 \\
10,044\end{array}$ & $\begin{array}{r}18,474 \\
1,285 \\
113 \\
96 \\
19,968\end{array}$ & $\begin{array}{r}5,150 \\
700 \\
60 \\
0 \\
5,910\end{array}$ & $\begin{array}{r}23,592 \\
2,765 \\
92 \\
0 \\
26,449\end{array}$ & $\begin{array}{r}10,157 \\
1,100 \\
4 \\
232 \\
11,493\end{array}$ \\
\hline 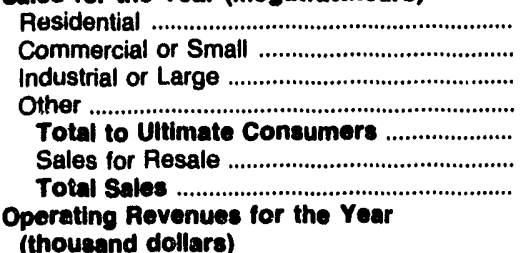 & $\begin{array}{r}235,811 \\
255,105 \\
154,125 \\
47,265 \\
692,306 \\
0 \\
692,306\end{array}$ & $\begin{array}{r}41,024 \\
56,685 \\
399,535 \\
79,680 \\
576,924 \\
1,254 \\
578,178\end{array}$ & $\begin{array}{r}122,446 \\
39,337 \\
100,042 \\
8,497 \\
270,322 \\
C \\
270,322\end{array}$ & $\begin{array}{r}49,210 \\
32,830 \\
69,283 \\
0 \\
151,423 \\
0 \\
151,423\end{array}$ & $\begin{array}{r}207,127 \\
182,112 \\
105,400 \\
0 \\
494,639 \\
89,396 \\
584,035\end{array}$ & $\begin{array}{r}76,584 \\
109,401 \\
37,242 \\
1,224 \\
224,451 \\
0 \\
224,451\end{array}$ \\
\hline 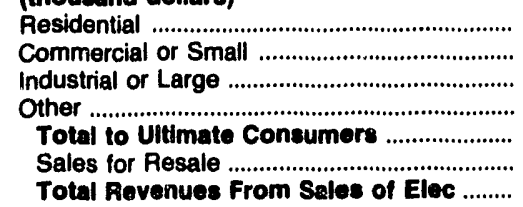 & $\begin{array}{r}19,499 \\
20,523 \\
8,862 \\
4,514 \\
53,398 \\
0 \\
53,398\end{array}$ & $\begin{array}{r}2,716 \\
3,978 \\
18,508 \\
4,672 \\
29,874 \\
0 \\
29,874\end{array}$ & $\begin{array}{r}9,176 \\
3,110 \\
6,006 \\
556 \\
18,848 \\
0 \\
18,848\end{array}$ & $\begin{array}{r}2,801 \\
1,880 \\
3,937 \\
0 \\
8,618 \\
0 \\
8,618\end{array}$ & $\begin{array}{r}14,806 \\
14,046 \\
6,162 \\
0 \\
35,014 \\
1,854 \\
36,868\end{array}$ & $\begin{array}{r}5,931 \\
6,993 \\
1,652 \\
126 \\
14,702 \\
0 \\
14,702\end{array}$ \\
\hline
\end{tabular}

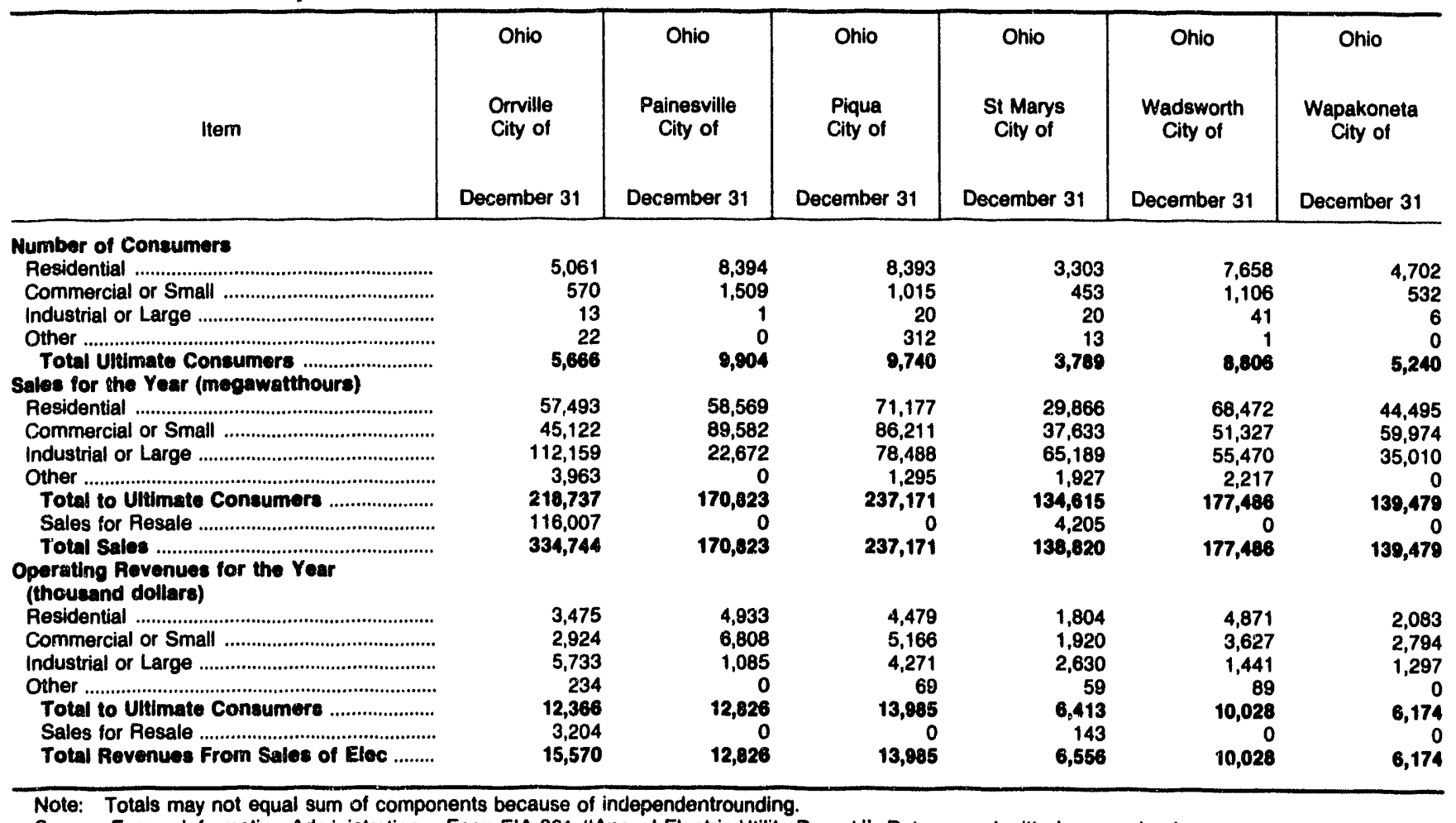

Source: Energy Information Administration, Form EIA-861, "Annual Electric Utility Report." Data are submitted on a calendar year. 
Table 40. Number of Consumers, Sales, and Operating Revenue by Major Publicly Owned Electric Utility Within State, 1991 (Continued)

\begin{tabular}{|c|c|c|c|c|c|c|}
\hline Item & $\begin{array}{c}\text { Ohio } \\
\text { Westerville } \\
\text { City of } \\
\text { December } 31\end{array}$ & $\begin{array}{c}\text { Oklahoma } \\
\text { Altus } \\
\text { City of } \\
\text { December } 31\end{array}$ & $\begin{array}{c}\text { Oklahoma } \\
\begin{array}{c}\text { Claremore } \\
\text { City of }\end{array} \\
\text { December } 31\end{array}$ & $\begin{array}{l}\text { Oklahoma } \\
\text { Edmond } \\
\text { City of } \\
\text { December } 31\end{array}$ & $\begin{array}{c}\text { Oklahoma } \\
\text { Grand Fiver } \\
\text { Dam } \\
\text { Authority } \\
\text { December } 31\end{array}$ & $\begin{array}{c}\text { Oklahoma } \\
\text { Oklahoma } \\
\text { Municipal } \\
\text { Power Auth } \\
\text { December } 31\end{array}$ \\
\hline 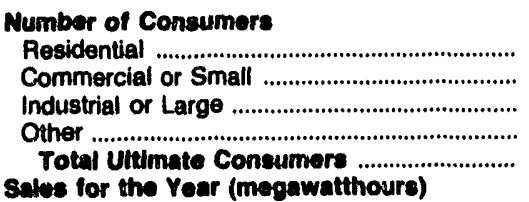 & $\begin{array}{r}10,404 \\
1,269 \\
12 \\
0 \\
11,685\end{array}$ & $\begin{array}{r}7,654 \\
1,016 \\
84 \\
0 \\
8,754\end{array}$ & $\begin{array}{r}6,903 \\
838 \\
83 \\
0 \\
7,824\end{array}$ & $\begin{array}{r}18,421 \\
1,976 \\
0 \\
0 \\
20,397\end{array}$ & $\begin{array}{r}0 \\
39 \\
17 \\
13 \\
69\end{array}$ & $\begin{array}{l}0 \\
0 \\
0 \\
0 \\
0\end{array}$ \\
\hline 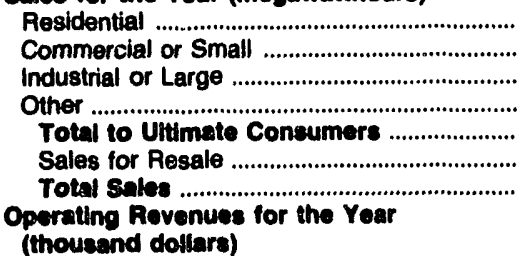 & $\begin{array}{r}146,107 \\
116,887 \\
38,795 \\
0 \\
301,789 \\
0 \\
301,789\end{array}$ & $\begin{array}{r}66,495 \\
21,520 \\
38,623 \\
0 \\
126,638 \\
0 \\
126,638\end{array}$ & $\begin{array}{r}78,322 \\
20,226 \\
94,590 \\
0 \\
193,138 \\
0 \\
193,138\end{array}$ & $\begin{array}{r}233,992 \\
174,679 \\
0 \\
0 \\
408,671 \\
0 \\
408,671\end{array}$ & $\begin{array}{r}0 \\
16,138 \\
638,258 \\
10,356 \\
864,752 \\
4,062,452 \\
4,727,204\end{array}$ & $\begin{array}{r}0 \\
0 \\
0 \\
0 \\
0 \\
1,412,134 \\
1,412,134\end{array}$ \\
\hline 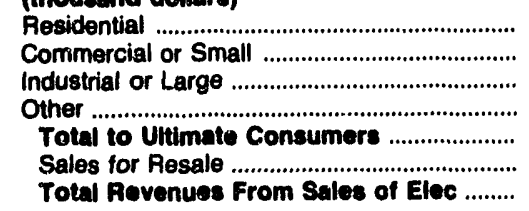 & $\begin{array}{r}8,691 \\
6,723 \\
1,683 \\
0 \\
17,097 \\
0 \\
17,097\end{array}$ & $\begin{array}{r}4,686 \\
1,586 \\
1,928 \\
0 \\
8,200 \\
0 \\
0 \\
8,200\end{array}$ & $\begin{array}{r}5,508 \\
1,600 \\
4,680 \\
0 \\
11,788 \\
0 \\
11,788\end{array}$ & $\begin{array}{r}15,612 \\
9,849 \\
0 \\
0 \\
25,461 \\
0 \\
25,461\end{array}$ & $\begin{array}{r}0 \\
786 \\
18,735 \\
361 \\
18,882 \\
121,734 \\
141,616\end{array}$ & $\begin{array}{r}0 \\
0 \\
0 \\
0 \\
0 \\
61,575 \\
61,575\end{array}$ \\
\hline
\end{tabular}

\begin{tabular}{|c|c|c|c|c|c|c|}
\hline Item & $\begin{array}{c}\text { Oklahoma } \\
\text { Ponca } \\
\text { City City of } \\
\text { December } 31\end{array}$ & $\begin{array}{c}\text { Oklahoma } \\
\text { Stillwater } \\
\text { Utilitios } \\
\text { Authority } \\
\text { December } 31\end{array}$ & $\begin{array}{l}\text { Oregon } \\
\text { Ashland } \\
\text { City of } \\
\text { December } 31\end{array}$ & $\begin{array}{l}\text { Oregon } \\
\text { Central } \\
\text { Lincoln } \\
\text { Peoples } \\
\text { UtI Dt } \\
\text { December } 31\end{array}$ & $\begin{array}{l}\text { Oregon } \\
\text { Clatskanie } \\
\text { Peoples } \\
\text { Util Dist } \\
\text { December } 31\end{array}$ & $\begin{array}{l}\text { Oregon } \\
\text { Columbia } \\
\text { Piver } \\
\text { Peoples } \\
\text { Ut Dist } \\
\text { December } 31\end{array}$ \\
\hline 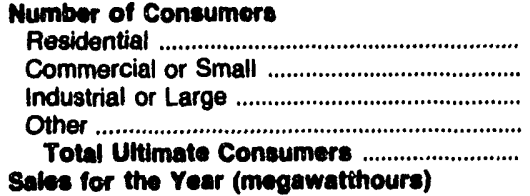 & $\begin{array}{r}13,816 \\
1,629 \\
41 \\
90 \\
15,576\end{array}$ & $\begin{array}{r}13,458 \\
1,339 \\
5 \\
0 \\
14,802\end{array}$ & $\begin{array}{r}6,805 \\
1,033 \\
0 \\
106 \\
8,044\end{array}$ & $\begin{array}{r}24,441 \\
3,936 \\
88 \\
20 \\
28,485\end{array}$ & $\begin{array}{r}2,845 \\
386 \\
2 \\
1 \\
3,234\end{array}$ & $\begin{array}{r}6,404 \\
584 \\
8 \\
576 \\
7,572\end{array}$ \\
\hline 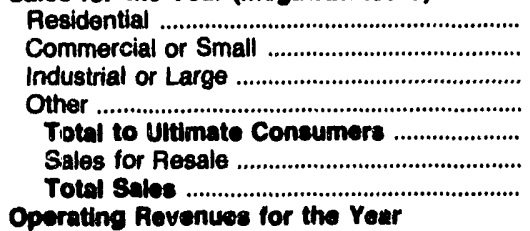 & $\begin{array}{r}131,780 \\
92,882 \\
37,261 \\
17,429 \\
278,352 \\
0 \\
279,352\end{array}$ & $\begin{array}{r}130,361 \\
114,811 \\
125,173 \\
0 \\
370,345 \\
0 \\
370,345\end{array}$ & $\begin{array}{r}82,976 \\
51,853 \\
0 \\
14,775 \\
149,604 \\
0 \\
149,604\end{array}$ & $\begin{array}{r}363,850 \\
192,062 \\
809,036 \\
2,924 \\
1,387,872 \\
0 \\
1,367,872\end{array}$ & $\begin{array}{r}53,282 \\
22,744 \\
804,564 \\
612 \\
881,202 \\
0 \\
881,202\end{array}$ & $\begin{array}{r}97,152 \\
19,691 \\
157,688 \\
1,156 \\
275,697 \\
0 \\
275,697\end{array}$ \\
\hline 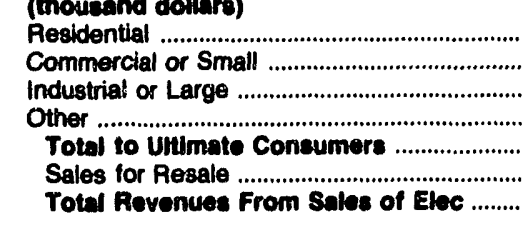 & $\begin{array}{r}9,877 \\
6,937 \\
2,029 \\
859 \\
19,702 \\
0 \\
19,702\end{array}$ & $\begin{array}{r}8,619 \\
6,665 \\
5,354 \\
0 \\
20,638 \\
0 \\
20,638\end{array}$ & $\begin{array}{r}3,203 \\
2,396 \\
0 \\
906 \\
6,505 \\
0 \\
6,505\end{array}$ & $\begin{array}{r}16,758 \\
8,037 \\
21,678 \\
525 \\
46,900 \\
0 \\
46,000\end{array}$ & $\begin{array}{r}1,643 \\
915 \\
16,561 \\
3,135 \\
22,254 \\
0 \\
22,254\end{array}$ & $\begin{array}{r}4,229 \\
1,047 \\
5,968 \\
96 \\
11,340 \\
0 \\
11,340\end{array}$ \\
\hline
\end{tabular}

Note: Totals may not equal sum of components because of independent rounding.

Source: Energy Information Administration, Form EIA-861, "Annual Electric Utility Report." Data are submitted on a calendar year. 
Table 40. Number of Consumers, Sales, and Operating Revenue by Major Publicly Owned Electric Utility Within State, 1991 (Continued)

\begin{tabular}{|c|c|c|c|c|c|c|}
\hline Item & $\begin{array}{l}\text { Oregon } \\
\text { Emerald } \\
\text { Peoples } \\
\text { Utility Dist } \\
\text { December } 31\end{array}$ & $\begin{array}{l}\text { Oregon } \\
\text { Eugene } \\
\text { City of } \\
\text { December } 31\end{array}$ & $\begin{array}{c}\text { Forest Grove } \\
\text { City of } \\
\text { December } 31\end{array}$ & $\begin{array}{c}\text { McMinnville } \\
\text { City of }\end{array}$ & $\begin{array}{l}\text { Oregon } \\
\text { Northern } \\
\text { Wasco County } \\
\text { P U D } \\
\text { December } 31\end{array}$ & $\begin{array}{c}\text { Oregon } \\
\text { Springfield } \\
\text { City of }\end{array}$ \\
\hline 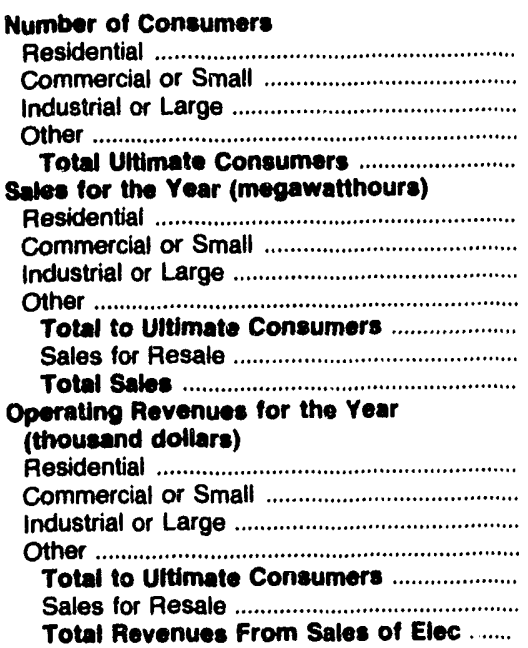 & $\begin{array}{r}195,638 \\
62,315 \\
91,617 \\
10,814 \\
360,384 \\
123 \\
360,507\end{array}$ & $\begin{array}{r}968,937 \\
930,530 \\
292,358 \\
24,438 \\
2,216,263 \\
178,951 \\
2,395,214\end{array}$ & $\begin{array}{r}98,044 \\
48,700 \\
55,622 \\
1,399 \\
203,765 \\
0 \\
203,765\end{array}$ & $\begin{array}{r}155,182 \\
123,267 \\
175,392 \\
1,254 \\
455,095 \\
0 \\
455,005\end{array}$ & $\begin{array}{r}116,462 \\
27,205 \\
75,143 \\
2,265 \\
221,075 \\
23,076 \\
244,151\end{array}$ & $\begin{array}{r}319,489 \\
136,962 \\
283,645 \\
25,088 \\
765,184 \\
0 \\
765,184\end{array}$ \\
\hline
\end{tabular}

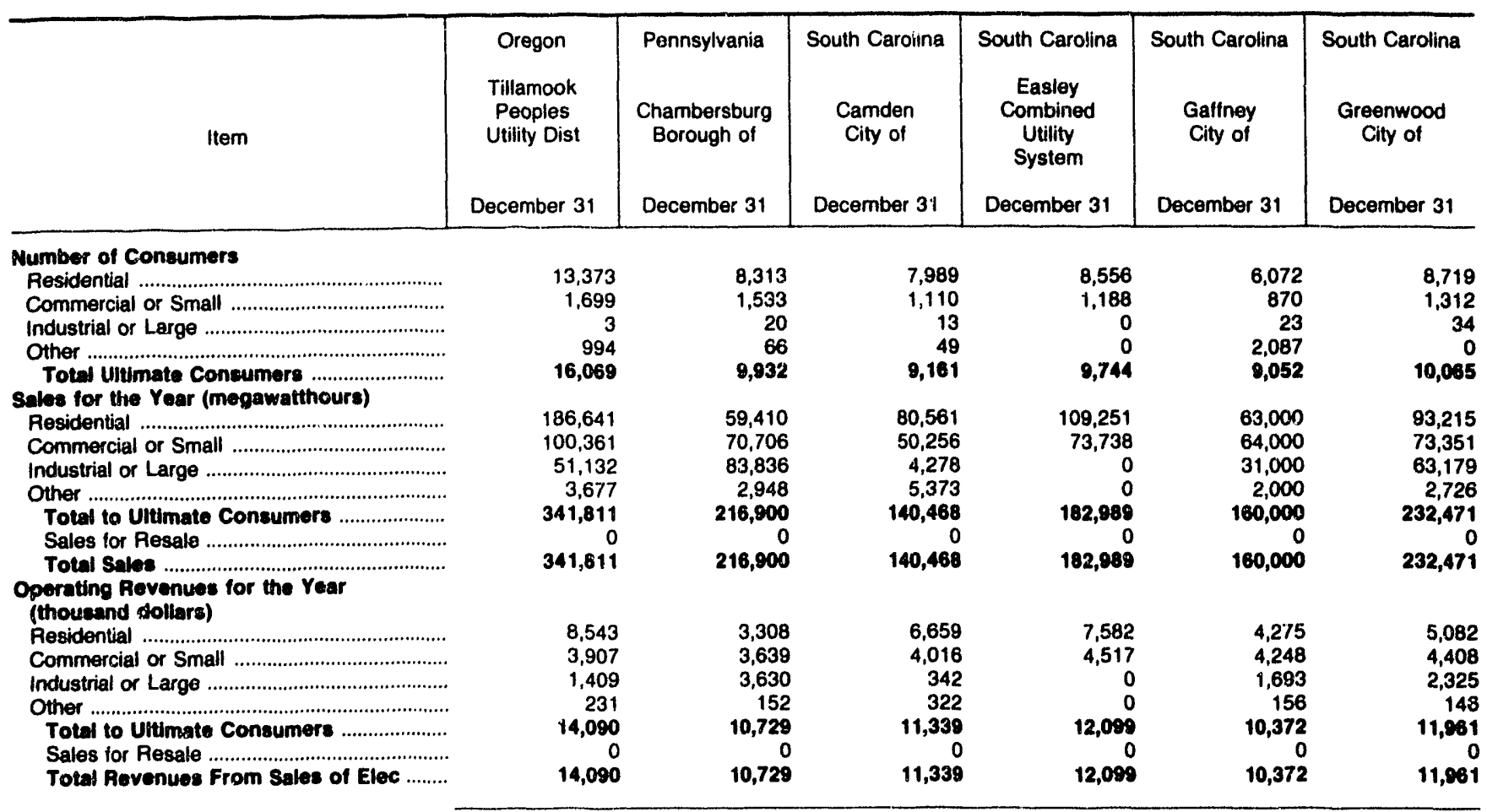

Note: Totals may not equal sum of components because of independent rounding.

Source: Energy Information Administration, Form EIA-861, "Annual Electric Utility Report." Data are submitted on a calendar year. 
Table 40. Number of Consumers, Sales, and Operating Revenue by Major Publicly Owned Electric Utility Within State, 1991 (Continued)

\begin{tabular}{|c|c|c|c|c|c|c|}
\hline item & $\begin{array}{c}\text { South Carolina } \\
\text { Greer } \\
\text { Comm } \\
\text { of } \\
\text { Public Works } \\
\text { December } 31\end{array}$ & $\begin{array}{l}\text { South Carolina } \\
\begin{array}{c}\text { Newberry } \\
\text { City of }\end{array} \\
\text { December } 31\end{array}$ & $\begin{array}{l}\text { South Carolina } \\
\begin{array}{c}\text { Orangeburg } \\
\text { City of }\end{array} \\
\text { December } 31\end{array}$ & $\begin{array}{l}\text { South Carolina } \\
\text { Piedmont } \\
\text { Municipal } \\
\text { Power Agny } \\
\text { December } 31\end{array}$ & $\begin{array}{l}\text { South Carolina } \\
\text { Rock Hill } \\
\text { City of } \\
\text { December } 31\end{array}$ & $\begin{array}{c}\text { South Carolina } \\
\text { South } \\
\text { Carolina } \\
\text { Pub } \\
\text { Serv Auth } \\
\text { December } 31\end{array}$ \\
\hline \multicolumn{7}{|l|}{ Number of Consumers } \\
\hline 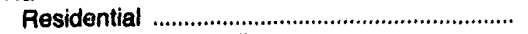 & 6,544 & 3,869 & 17,815 & 0 & 18,118 & 76,527 \\
\hline 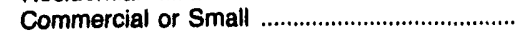 & 878 & 770 & 2,646 & 0 & 2,492 & 15,107 \\
\hline Industrial or Large & 174 & 11 & 64 & 0 & 3 & 32 \\
\hline Other & 1,762 & & 4,256 & 0 & 1 & 296 \\
\hline $\begin{array}{l}\text { Total Ultimate Consumers } \\
\text { Sales for the Year (megawa................... }\end{array}$ & 9,358 & 4,650 & 24,781 & $\mathbf{0}$ & 20,614 & 91,962 \\
\hline 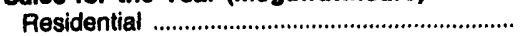 & 78,153 & 39,996 & 220,605 & 0 & 198,706 & 935,650 \\
\hline 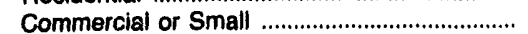 & 15,793 & 49,214 & 126,606 & 0 & 235,084 & $1,062,371$ \\
\hline Industrial or Large & 42,848 & 41,626 & 281,184 & 0 & 34,524 & $5,474,394$ \\
\hline Other & 5,242 & 0 & 7,056 & 0 & 3,893 & 36,304 \\
\hline 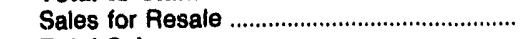 & & & & $2,814,950$ & & $6,088,552$ \\
\hline Total Sales & 142,036 & 130,838 & 635,451 & $2,814,950$ & 472,207 & $13,587,271$ \\
\hline \multicolumn{7}{|l|}{$\begin{array}{l}\text { Operating Revenues for the Year } \\
\text { (thousand dollars) }\end{array}$} \\
\hline 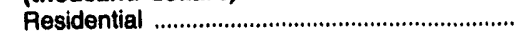 & 5,402 & 2,835 & 12,408 & 0 & 16,267 & 56,884 \\
\hline 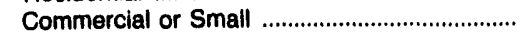 & 1,154 & 3,149 & 7,693 & 0 & 18,359 & 58,064 \\
\hline Industrial or Large & 2,525 & 2,265 & 12,168 & 0 & 2,052 & 184,707 \\
\hline Other & 171 & & 605 & 0 & 305 & 2,010 \\
\hline Total to Uitimate Consumers .......................... & 9,252 & 8,249 & 32,874 & $\mathbf{0}$ & 36,983 & 301,665 \\
\hline Sales for Resale & & & & 153,325 & & 256,071 \\
\hline Total Revenues From Sales of Elec ......... & 9,252 & 8,249 & 32,874 & 153,325 & 36,983 & 557,736 \\
\hline
\end{tabular}

\begin{tabular}{|c|c|c|c|c|c|c|}
\hline Item & $\begin{array}{l}\text { South Dakota } \\
\text { Brookings } \\
\text { City of } \\
\text { December } 31\end{array}$ & $\begin{array}{l}\text { South Dakota } \\
\text { Heartland } \\
\text { Consumers } \\
\text { Power Dist } \\
\text { December } 31\end{array}$ & $\begin{array}{l}\text { South Dakota } \\
\text { Missouri } \\
\text { Basin } \\
\text { Mun } \\
\text { Power Agny } \\
\text { December } 31\end{array}$ & $\begin{array}{c}\text { South Dakota } \\
\text { Pierre } \\
\text { City of } \\
\text { December } 31\end{array}$ & $\begin{array}{c}\text { South Dakota } \\
\text { Watertown } \\
\text { Municipal } \\
\text { Utilities } \\
\text { December } 31\end{array}$ & $\begin{array}{c}\text { Tennessee } \\
\text { Alcoa } \\
\text { Utilities } \\
\text { December } 31\end{array}$ \\
\hline \multicolumn{7}{|l|}{ Number of Consumers } \\
\hline Residential ..................................................... & 5,655 & 0 & 0 & 5,330 & 7,758 & 16,166 \\
\hline Commercial or Small ................................................. & 838 & 0 & 0 & 615 & 1,222 & 2,500 \\
\hline Industrial or Large ..................................................... & 33 & 0 & 0 & 63 & 233 & 146 \\
\hline Other & 1,946 & 0 & 0 & 71 & 874 & 38 \\
\hline Total Uitimate Consumers & 8,472 & 0 & 0 & 6,079 & 10,087 & 18,850 \\
\hline \multicolumn{7}{|l|}{ Sales for the Year (megawatthours) } \\
\hline 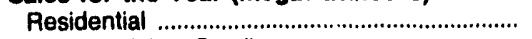 & 59,748 & 0 & 0 & 73,446 & 79,014 & 232,000 \\
\hline Commercial or Small .......................................... & 34,265 & 0 & 0 & 20,159 & 25,342 & 40,500 \\
\hline Industrial or Large ........................................... & 63,172 & 0 & 0 & 32,992 & 89,463 & 104,900 \\
\hline Other ................................................... & 12,479 & 0 & 0 & 9,651 & 3,005 & 5,900 \\
\hline Total to Uitimate Consumers .......................... & 169,664 & 0 & $\mathbf{0}$ & 138,248 & 196,824 & 383,300 \\
\hline 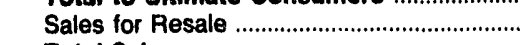 & & 358,804 & $1,873,259$ & 9,438 & & \\
\hline Total Sales ………………………………........... & 169,664 & 358,804 & $1,873,259$ & 145,686 & 196,824 & 383,300 \\
\hline \multicolumn{7}{|l|}{$\begin{array}{l}\text { Operating Revenues for the Year } \\
\text { (thousand dollars) }\end{array}$} \\
\hline 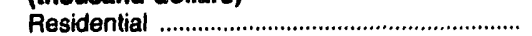 & 2,252 & 0 & 0 & 2,778 & 2,987 & 12,965 \\
\hline Commercial or Small ....................................... & 1,549 & 0 & 0 & 839 & 1,230 & 2,740 \\
\hline industrial or Large ............................................ & 2.425 & 0 & 0 & 1,332 & 3,374 & 5,842 \\
\hline 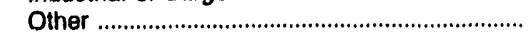 & 649 & 0 & 0 & 349 & 181 & 424 \\
\hline Total to Uitimate Consumers ..................... & 6,875 & 0 & o & 5,298 & 7,772 & 21,971 \\
\hline 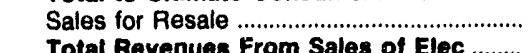 & & $\begin{array}{l}10,040 \\
10,040\end{array}$ & $\begin{array}{l}50,674 \\
50,674\end{array}$ & $\begin{array}{r}160 \\
5.458\end{array}$ & $\begin{aligned} 0 \\
7770\end{aligned}$ & \\
\hline enues From Sales of $\mathrm{E}$ & 6,875 & 10,040 & 50,674 & $\mathbf{5 , 4 5 8}$ & 7,772 & 21,971 \\
\hline
\end{tabular}

Note: Totals may not equal sum of components because of independent rounding.

Source: Energy Information Administration, Form EIA-861, "Annual Electric Utility Report." Data are submitted on a calendar year. 
Table 40. Number of Consumers, Sales, and Operating Revenue by Major Publicly Owned Electric Utility Within State, 1991 (Continued)

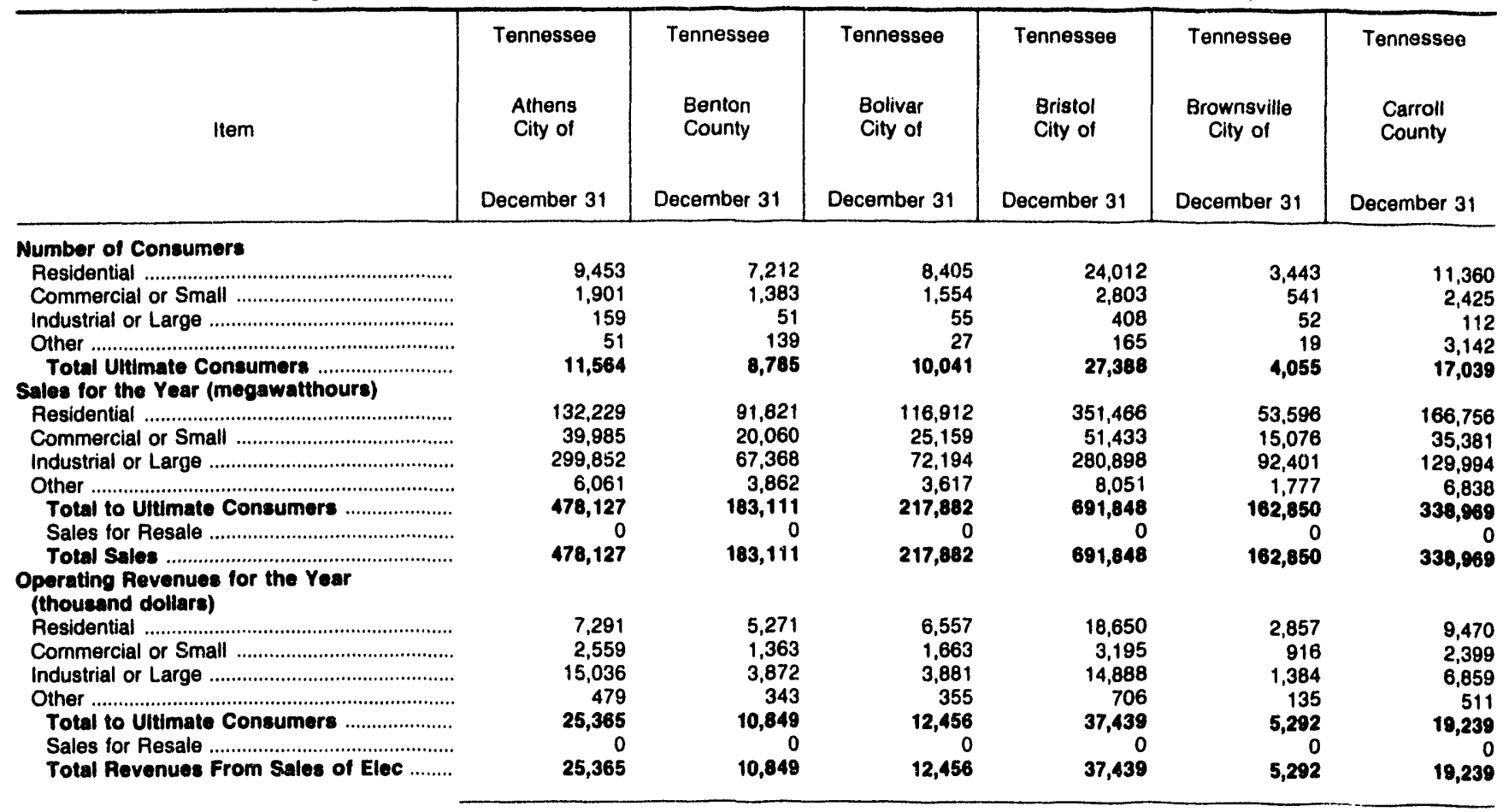

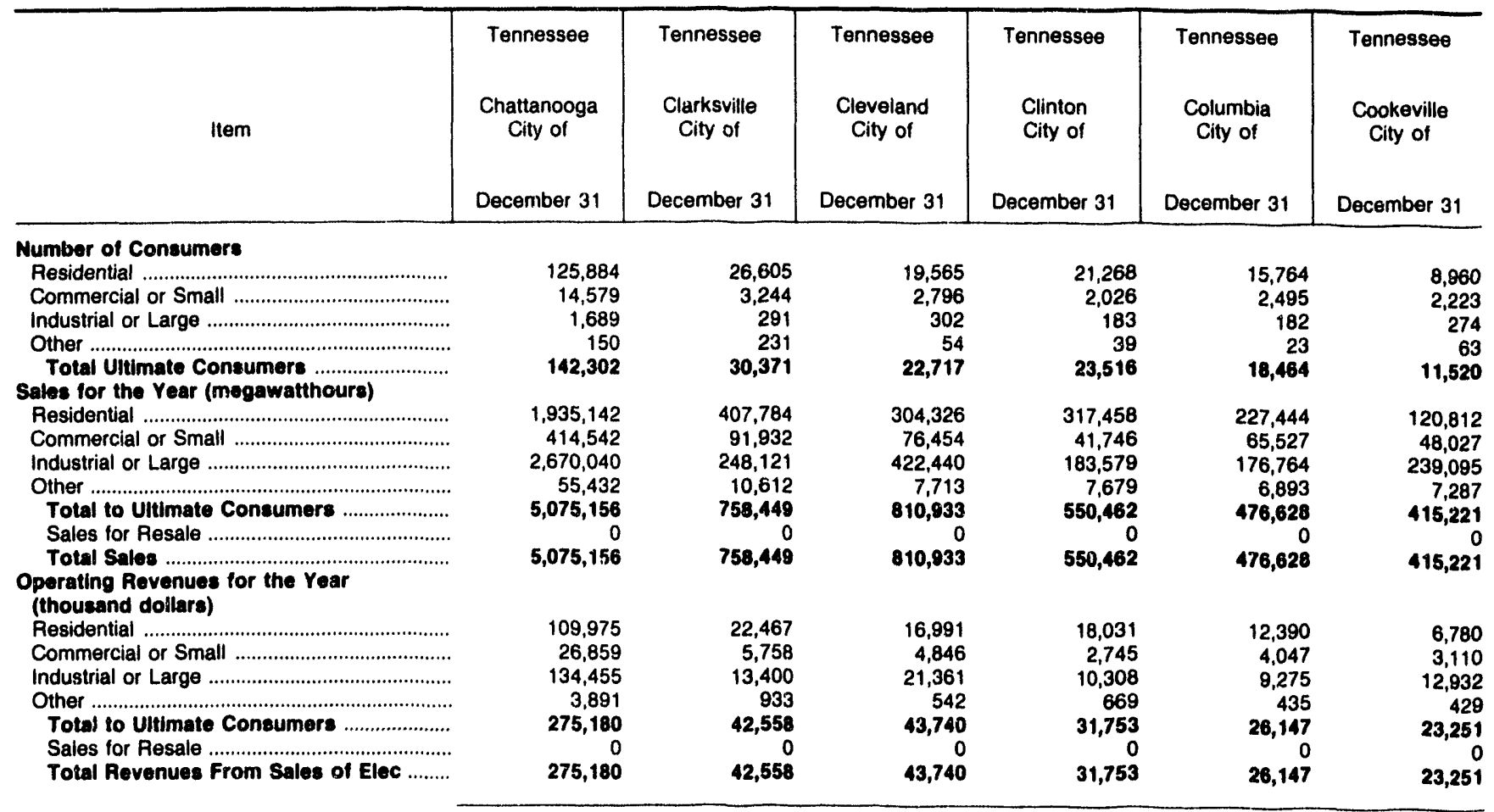

Note: Totals may not equal sum of components because of independent rounding.

Source: Energy Information Administration, Form EIA-861, "Annual Electric Utility Report." Data are submitted on a calendar year. 

Table 40. Number of Consumers, Sales, and Operating Revenue by Major
Publicly Owned Electric Utillty Within State, 1991 (Continued)

\begin{tabular}{|c|c|c|c|c|c|c|}
\hline Item & $\begin{array}{c}\text { Tennessee } \\
\text { Covington } \\
\text { City of } \\
\text { December } 31\end{array}$ & $\begin{array}{c}\text { Tennessee } \\
\text { Dayton } \\
\text { City of } \\
\text { December } 31\end{array}$ & $\begin{array}{c}\text { Tennessee } \\
\text { Dickson } \\
\text { City of } \\
\text { December } 31\end{array}$ & $\begin{array}{c}\text { Tennessee } \\
\text { Dyersburg } \\
\text { Electric } \\
\text { System } \\
\text { December } 31\end{array}$ & $\begin{array}{c}\text { Tennessee } \\
\text { Elizabethton } \\
\text { City of } \\
\text { December } 31\end{array}$ & $\begin{array}{c}\text { Tennessee } \\
\text { Erwin } \\
\text { Town of } \\
\text { December } 31\end{array}$ \\
\hline 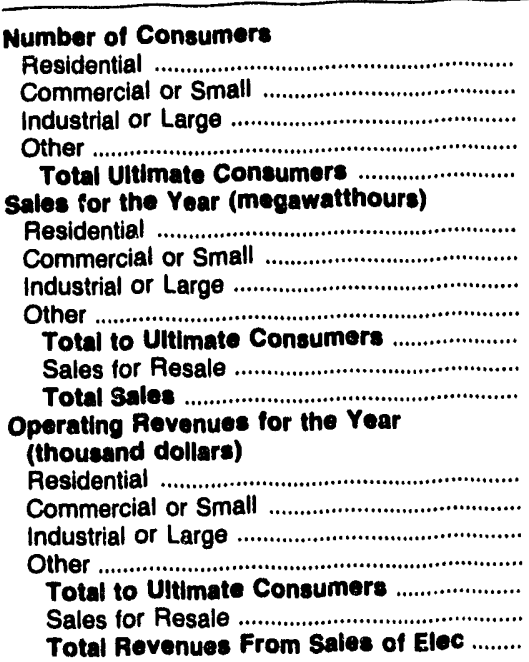 & $\begin{array}{r}35,618 \\
15,625 \\
125,955 \\
2,079 \\
179,277 \\
0 \\
179,277\end{array}$ & $\begin{array}{r}71,863 \\
19,190 \\
77,118 \\
2,472 \\
170,643 \\
0 \\
170,643\end{array}$ & $\begin{array}{r}292,947 \\
142,655 \\
71,114 \\
3,942 \\
510,658 \\
0 \\
510,658\end{array}$ & $\begin{array}{r}117,825 \\
39,301 \\
361,967 \\
4,909 \\
524,002 \\
0 \\
524,002\end{array}$ & $\begin{array}{r}18,793 \\
2,402 \\
153 \\
96 \\
21,444 \\
\\
251,000 \\
42,000 \\
146,000 \\
6,000 \\
445,000 \\
0 \\
445,000\end{array}$ & $\begin{array}{r}81,396 \\
16,110 \\
90,772 \\
1,939 \\
190,217 \\
0 \\
190,217\end{array}$ \\
\hline
\end{tabular}

\begin{tabular}{|c|c|c|c|c|c|c|}
\hline Item & $\begin{array}{c}\text { Tennessee } \\
\text { Etowah } \\
\text { City of } \\
\text { December } 31\end{array}$ & $\begin{array}{c}\text { Tennessee } \\
\text { Fayetteville } \\
\text { City of } \\
\text { December } 31\end{array}$ & $\begin{array}{c}\text { Tennessee } \\
\text { Gallatin } \\
\text { City of } \\
\text { December } 31\end{array}$ & $\begin{array}{c}\text { Tennessee } \\
\text { Greeneville } \\
\text { City of }\end{array}$ & $\begin{array}{c}\text { Tennessee } \\
\text { Harriman } \\
\text { City of }\end{array}$ & $\begin{array}{c}\text { Humboldt } \\
\text { City of } \\
\text { December } 31\end{array}$ \\
\hline 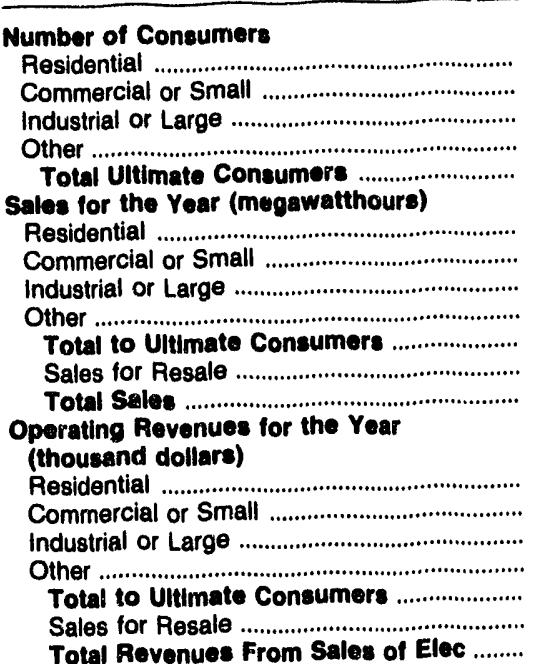 & $\begin{array}{r}3,955 \\
497 \\
25 \\
21 \\
4,498 \\
\\
52,400 \\
9,200 \\
68,000 \\
1,800 \\
131,400 \\
0 \\
131,400\end{array}$ & $\begin{array}{r}170,926 \\
82,346 \\
70,915 \\
1,306 \\
325,493 \\
0 \\
325,498\end{array}$ & $\begin{array}{r}122,084 \\
30,869 \\
238,826 \\
4,520 \\
394,299 \\
0 \\
394,299\end{array}$ & $\begin{array}{r}329,700 \\
66,800 \\
390,100 \\
8,300 \\
794,900 \\
0 \\
794,900\end{array}$ & $\begin{array}{r}114,453 \\
20,372 \\
125,048 \\
3,785 \\
263,658 \\
0 \\
263,658\end{array}$ & $\begin{array}{r}50,600 \\
13,600 \\
125,100 \\
1,900 \\
191,200 \\
0 \\
191,200\end{array}$ \\
\hline
\end{tabular}

Note: Totals may not equal sum of components because of independentrounding.

Source: Energy information Administration, Form ElA-861, "Annual Electric Utility Report." Data are submitted on a calendar year. 
Table 40. Number of Consumers, Sales, and Operating Revenue by Major Publicly Owned Electric Utility Within State, 1991 (Continued)

\begin{tabular}{|c|c|c|c|c|c|c|}
\hline Item & $\begin{array}{c}\text { Tennessee } \\
\text { Jackson } \\
\text { City of } \\
\text { December } 31\end{array}$ & $\begin{array}{l}\text { Tennessee } \\
\text { Johnson } \\
\text { City City of } \\
\text { December } 31\end{array}$ & $\begin{array}{c}\text { Tennessee } \\
\text { Knoxville } \\
\text { Utilities } \\
\text { Board } \\
\text { December } 31\end{array}$ & $\begin{array}{l}\text { Tennessee } \\
\text { Lawrenceburg } \\
\text { City of } \\
\text { December } 31\end{array}$ & $\begin{array}{c}\text { Tennessee } \\
\text { Lafollette } \\
\text { City of } \\
\text { December } 31\end{array}$ & $\begin{array}{c}\text { Tennessee } \\
\text { Lebanon } \\
\text { City of } \\
\text { December } 31\end{array}$ \\
\hline \multicolumn{7}{|l|}{ Number of Consumere } \\
\hline 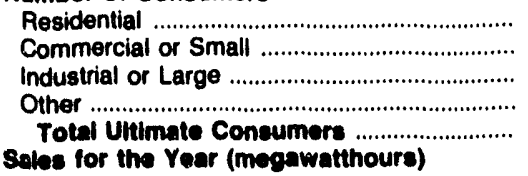 & $\begin{array}{r}22,173 \\
3,517 \\
489 \\
2,766 \\
28,945\end{array}$ & $\begin{array}{r}45,064 \\
6,081 \\
428 \\
414 \\
51,987\end{array}$ & $\begin{array}{r}132,554 \\
15,422 \\
1,497 \\
1,075 \\
150,548\end{array}$ & $\begin{array}{r}13,742 \\
2,126 \\
168 \\
66 \\
16,102\end{array}$ & $\begin{array}{r}14,242 \\
2,129 \\
7 \\
20 \\
16,398\end{array}$ & $\begin{array}{r}6,041 \\
1,467 \\
156 \\
9 \\
7,673\end{array}$ \\
\hline 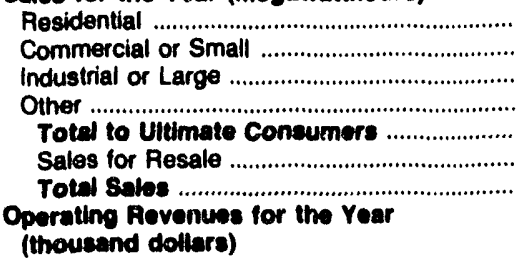 & $\begin{array}{r}288,269 \\
101,209 \\
666,269 \\
12,480 \\
1,068,227 \\
0 \\
1,068,227\end{array}$ & $\begin{array}{r}652,617 \\
138,140 \\
519,502 \\
14,163 \\
1,324,422 \\
0 \\
1,324,422\end{array}$ & $\begin{array}{r}2,015,554 \\
430,599 \\
1,914,040 \\
52,415 \\
4,412,608 \\
0 \\
4,412,608\end{array}$ & $\begin{array}{r}195,163 \\
37,531 \\
174,387 \\
5,283 \\
412,384 \\
0 \\
412,364\end{array}$ & $\begin{array}{r}180,998 \\
88,909 \\
29,753 \\
1,618 \\
301,278 \\
0 \\
301,278\end{array}$ & $\begin{array}{r}91,712 \\
40,529 \\
161,850 \\
5,906 \\
290,997 \\
0 \\
299,997\end{array}$ \\
\hline 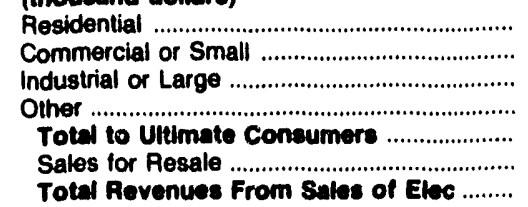 & $\begin{array}{r}15,775 \\
6,226 \\
32,893 \\
1,194 \\
56,088 \\
0 \\
56,088\end{array}$ & $\begin{array}{r}34,398 \\
8,365 \\
26,347 \\
1,187 \\
70,297 \\
0 \\
70,297\end{array}$ & $\begin{array}{r}115,485 \\
28,031 \\
98,620 \\
4,341 \\
246,477 \\
0 \\
246,477\end{array}$ & $\begin{array}{r}10,497 \\
2,403 \\
9,178 \\
387 \\
22,465 \\
0 \\
22,465\end{array}$ & $\begin{array}{r}10,256 \\
5,613 \\
2,003 \\
99 \\
17,971 \\
0 \\
17,971\end{array}$ & $\begin{array}{r}5,060 \\
2,525 \\
8,362 \\
366 \\
16,313 \\
0 \\
16,313\end{array}$ \\
\hline
\end{tabular}

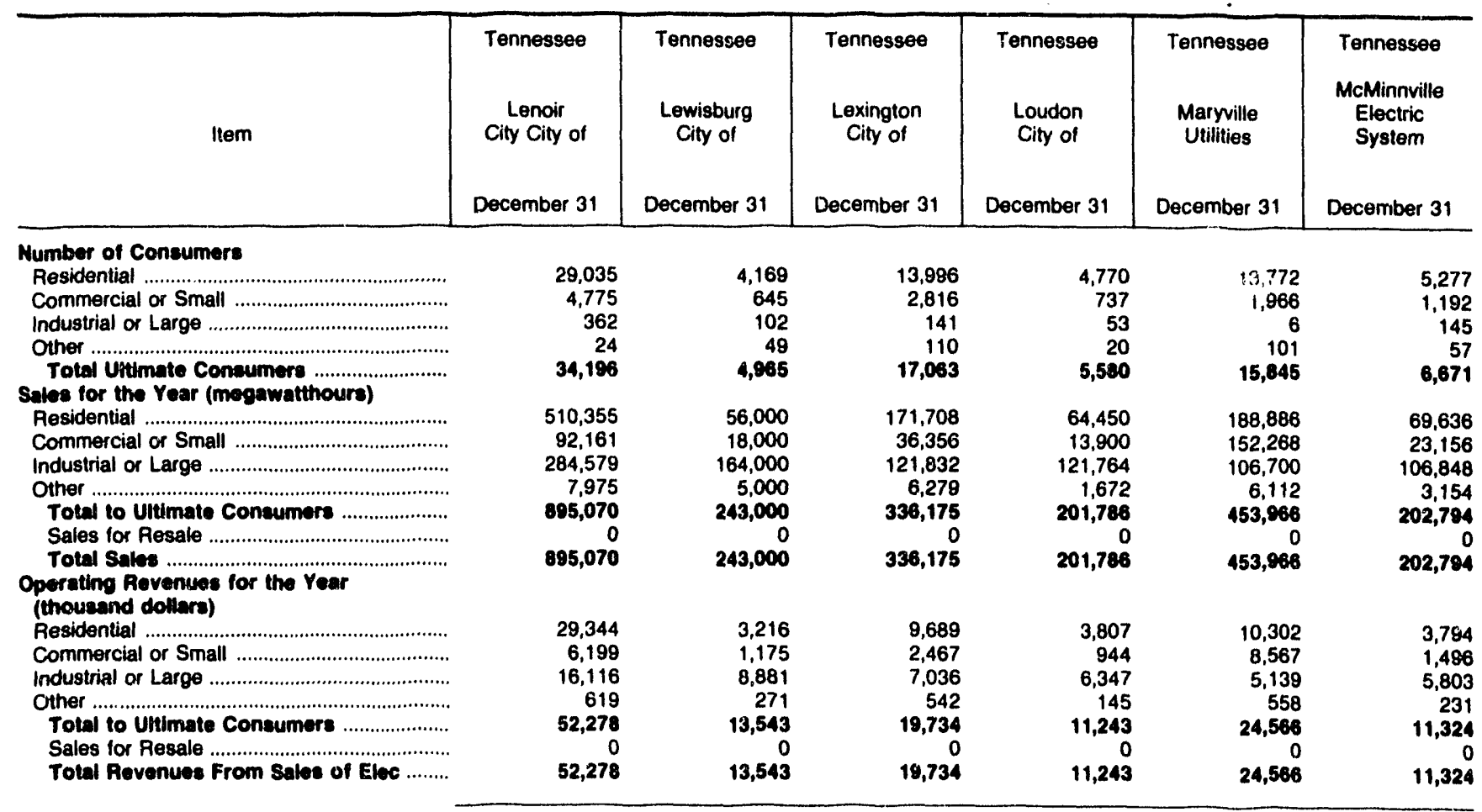

Note: Totals may not equal sum of components because of independent rounding.

Source: Energy Information Administration, Form EIA-861, "Annual Eleciric Utility Report." Data are submitted on a calendar year. 
Table 40. Number of Consumers, Sales, and Operating Revenue by Major Publicly Owned Electric Utility Within State, 1991 (Continued)

\begin{tabular}{|c|c|c|c|c|c|c|}
\hline Item & $\begin{array}{l}\text { Tennessee } \\
\text { Memphis } \\
\text { City of } \\
\text { December } 31\end{array}$ & $\begin{array}{l}\text { Tennessee } \\
\text { Milan } \\
\text { City of } \\
\text { December } 31\end{array}$ & $\begin{array}{l}\text { Tennessee } \\
\text { Morristown } \\
\text { City of } \\
\text { December } 31\end{array}$ & $\begin{array}{l}\text { Tennessee } \\
\text { Murfreesboro } \\
\text { City of } \\
\text { December } 31\end{array}$ & $\begin{array}{l}\text { Tennessee } \\
\text { Nashville } \\
\text { Electric } \\
\text { Service } \\
\text { December } 31\end{array}$ & $\begin{array}{l}\text { Tennessee } \\
\text { Newport } \\
\text { City of } \\
\text { December } 31\end{array}$ \\
\hline 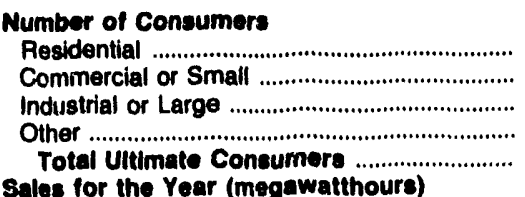 & $\begin{array}{r}308,657 \\
34,064 \\
186 \\
13,887 \\
356,794\end{array}$ & $\begin{array}{r}6,000 \\
1,000 \\
55 \\
23 \\
7,078\end{array}$ & $\begin{array}{r}9,737 \\
1,747 \\
234 \\
52 \\
11,770\end{array}$ & $\begin{array}{r}19,346 \\
2,734 \\
14 \\
53 \\
22,147\end{array}$ & $\begin{array}{r}244,499 \\
27,809 \\
3,210 \\
293 \\
275,811\end{array}$ & $\begin{array}{r}12,975 \\
2,436 \\
120 \\
150 \\
15,681\end{array}$ \\
\hline 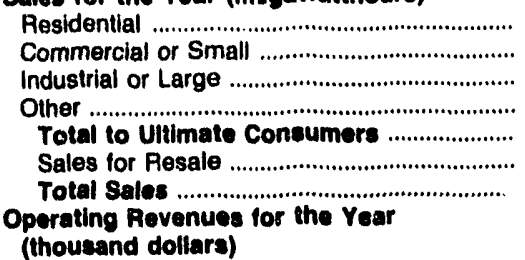 & $\begin{array}{r}4,498,811 \\
4,958,536 \\
1,743,036 \\
251,444 \\
11,451,827 \\
0 \\
11,451,827\end{array}$ & $\begin{array}{r}47,942 \\
9,418 \\
46,012 \\
1,399 \\
104,771 \\
0 \\
104,771\end{array}$ & $\begin{array}{r}125,134 \\
51,602 \\
368,581 \\
8,055 \\
553,372 \\
0 \\
553,372\end{array}$ & $\begin{array}{r}277,156 \\
283,789 \\
205,243 \\
9,563 \\
775,751 \\
0 \\
775,751\end{array}$ & $\begin{array}{r}3,839,837 \\
1,007,217 \\
4,961,055 \\
104,856 \\
9,912,965 \\
0 \\
9,912,965\end{array}$ & $\begin{array}{r}158,796 \\
38,360 \\
165,472 \\
5,352 \\
367,980 \\
0 \\
367,980\end{array}$ \\
\hline 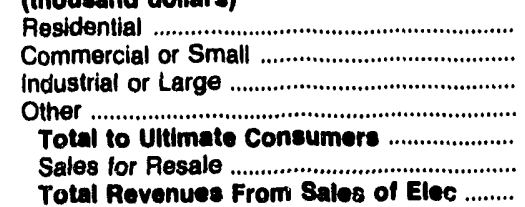 & $\begin{array}{r}258,727 \\
281,731 \\
69,314 \\
14,850 \\
624,622 \\
0 \\
624,622\end{array}$ & $\begin{array}{r}2,544 \\
583 \\
2,410 \\
115 \\
5,652 \\
0 \\
5,652\end{array}$ & $\begin{array}{r}7,030 \\
3,261 \\
19,679 \\
480 \\
30,460 \\
0 \\
30,480\end{array}$ & $\begin{array}{r}14,932 \\
15,589 \\
10,011 \\
696 \\
41,228 \\
0 \\
41,228\end{array}$ & $\begin{array}{r}211,198 \\
63,898 \\
247,255 \\
8,644 \\
530,906 \\
0 \\
530,996\end{array}$ & $\begin{array}{r}9,246 \\
2,651 \\
8,878 \\
425 \\
21,200 \\
0 \\
21,200\end{array}$ \\
\hline
\end{tabular}

\begin{tabular}{|c|c|c|c|c|c|c|}
\hline Item & $\begin{array}{l}\text { Tennessee } \\
\text { Oak Ridge } \\
\text { City of } \\
\text { December } 31\end{array}$ & $\begin{array}{l}\text { Tennessee } \\
\text { Paris } \\
\text { City of } \\
\text { December } 31\end{array}$ & $\begin{array}{l}\text { Tennessos } \\
\text { Pulaski } \\
\text { City of } \\
\text { December } 31\end{array}$ & $\begin{array}{l}\text { Tennessee } \\
\text { Pipley } \\
\text { City of } \\
\text { December } 31\end{array}$ & $\begin{array}{l}\text { Tennessee } \\
\text { Rockwood } \\
\text { City of } \\
\text { December } 31\end{array}$ & $\begin{array}{l}\text { Tennessee } \\
\text { Sevier } \\
\text { County } \\
\text { Electric } \\
\text { System } \\
\text { December } 31\end{array}$ \\
\hline \multicolumn{7}{|l|}{ Number of Consumers } \\
\hline 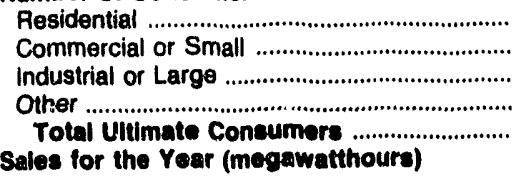 & $\begin{array}{r}12,370 \\
1,621 \\
0 \\
42 \\
14,033\end{array}$ & $\begin{array}{r}13,618 \\
2,909 \\
134 \\
36 \\
16,697\end{array}$ & $\begin{array}{r}9,749 \\
1,816 \\
117 \\
35 \\
11,717\end{array}$ & $\begin{array}{r}4,980 \\
1,002 \\
75 \\
1,180 \\
7,237\end{array}$ & $\begin{array}{r}9,536 \\
1,414 \\
82 \\
38 \\
11,070\end{array}$ & $\begin{array}{r}19,943 \\
7,235 \\
476 \\
215 \\
27,871\end{array}$ \\
\hline 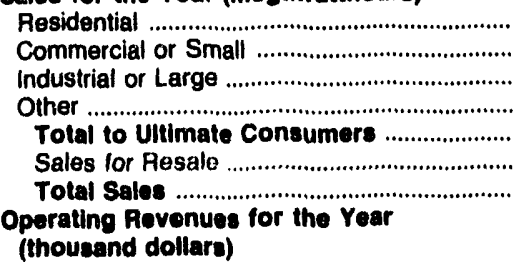 & $\begin{array}{r}163,367 \\
231,581 \\
0 \\
5,577 \\
400,525 \\
0 \\
400,525\end{array}$ & $\begin{array}{r}195,048 \\
42,624 \\
137,638 \\
6,507 \\
381,817 \\
0 \\
381,817\end{array}$ & $\begin{array}{r}134,331 \\
31,273 \\
165,809 \\
5,038 \\
336,451 \\
0 \\
336,451\end{array}$ & $\begin{array}{r}63,257 \\
20,682 \\
150,798 \\
3,280 \\
238,017 \\
0 \\
238,017\end{array}$ & $\begin{array}{r}139,322 \\
24,642 \\
67,841 \\
3,582 \\
235,387 \\
0 \\
235,387\end{array}$ & $\begin{array}{r}282,214 \\
154,281 \\
318,888 \\
7,174 \\
782,557 \\
0 \\
762,657\end{array}$ \\
\hline 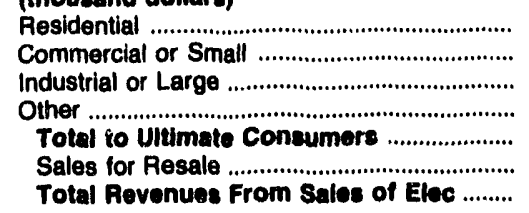 & $\begin{array}{r}8,923 \\
12,485 \\
0 \\
518 \\
21,926 \\
0 \\
21,926\end{array}$ & $\begin{array}{r}10,444 \\
2,695 \\
7,394 \\
567 \\
21,100 \\
0 \\
21,100\end{array}$ & $\begin{array}{r}7,315 \\
2,026 \\
8,271 \\
351 \\
17,883 \\
0 \\
17,963\end{array}$ & $\begin{array}{r}3,378 \\
1,274 \\
7,534 \\
248 \\
12,434 \\
0 \\
12,434\end{array}$ & $\begin{array}{r}8,013 \\
1,666 \\
3,739 \\
313 \\
13,731 \\
0 \\
13,731\end{array}$ & $\begin{array}{r}16,401 \\
10,373 \\
17,540 \\
493 \\
44,807 \\
0 \\
44,807\end{array}$ \\
\hline
\end{tabular}

Note: Totals may not equal sum of components because of independent rounding.

Source: Energy Information Administration, Form ElA-861, "Annual Electric Utility Report." Data are submitted on a calendar year. 
Table 40. Number of Consumers, Sales, and Operating Revenue by Major Publicly Owned Electric Utility Within State, 1991 (Continued)

\begin{tabular}{|c|c|c|c|c|c|c|}
\hline Item & $\begin{array}{c}\text { Tennessee } \\
\text { Shelbyville } \\
\text { City of }\end{array}$ & $\begin{array}{c}\text { Tennessee } \\
\text { Springtield } \\
\text { City of }\end{array}$ & $\begin{array}{c}\text { Tennessee } \\
\text { Swestwater } \\
\text { City of } \\
\text { December } 31\end{array}$ & $\begin{array}{c}\text { Tennessee } \\
\text { Tullahoma } \\
\text { Board } \\
\text { of } \\
\text { Pub Utils } \\
\text { December } 31\end{array}$ & $\begin{array}{l}\text { Tennessee } \\
\text { Union } \\
\text { City City of } \\
\text { December } 31\end{array}$ & $\begin{array}{c}\text { Tennesseo } \\
\text { Weakley } \\
\text { County } \\
\text { Mun } \\
\text { Elec Sys } \\
\text { December } 31\end{array}$ \\
\hline 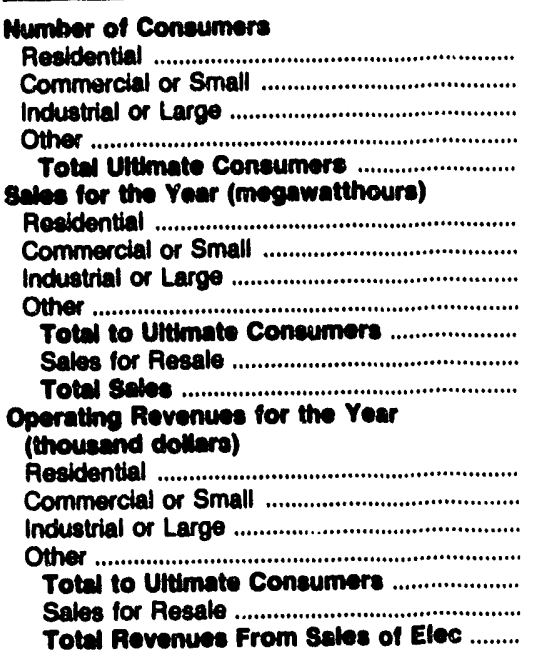 & $\begin{array}{r}6,160 \\
909 \\
126 \\
27 \\
7,222 \\
\\
78,644 \\
26,715 \\
179,987 \\
3,596 \\
288,942 \\
0 \\
288,942\end{array}$ & $\begin{array}{r}4,614 \\
686 \\
86 \\
13 \\
5,389 \\
\\
61,436 \\
22,359 \\
80,813 \\
4,205 \\
168,813 \\
0 \\
168,813\end{array}$ & $\begin{array}{r}5,038 \\
1,154 \\
67 \\
5 \\
6,284 \\
\\
70,306 \\
19,393 \\
68,362 \\
3,724 \\
161,785 \\
0 \\
161,785\end{array}$ & $\begin{array}{r}103,303 \\
30,520 \\
110,166 \\
4,235 \\
248,224 \\
0 \\
248,224\end{array}$ & $\begin{array}{r}4,806 \\
786 \\
104 \\
9 \\
5,705 \\
57,949 \\
21,683 \\
239,975 \\
2,772 \\
322,379 \\
0 \\
322,379\end{array}$ & $\begin{array}{r}14,581 \\
2,660 \\
177 \\
81 \\
17,500 \\
235,035 \\
45,375 \\
149,378 \\
6,601 \\
438,390 \\
0 \\
438,390\end{array}$ \\
\hline
\end{tabular}

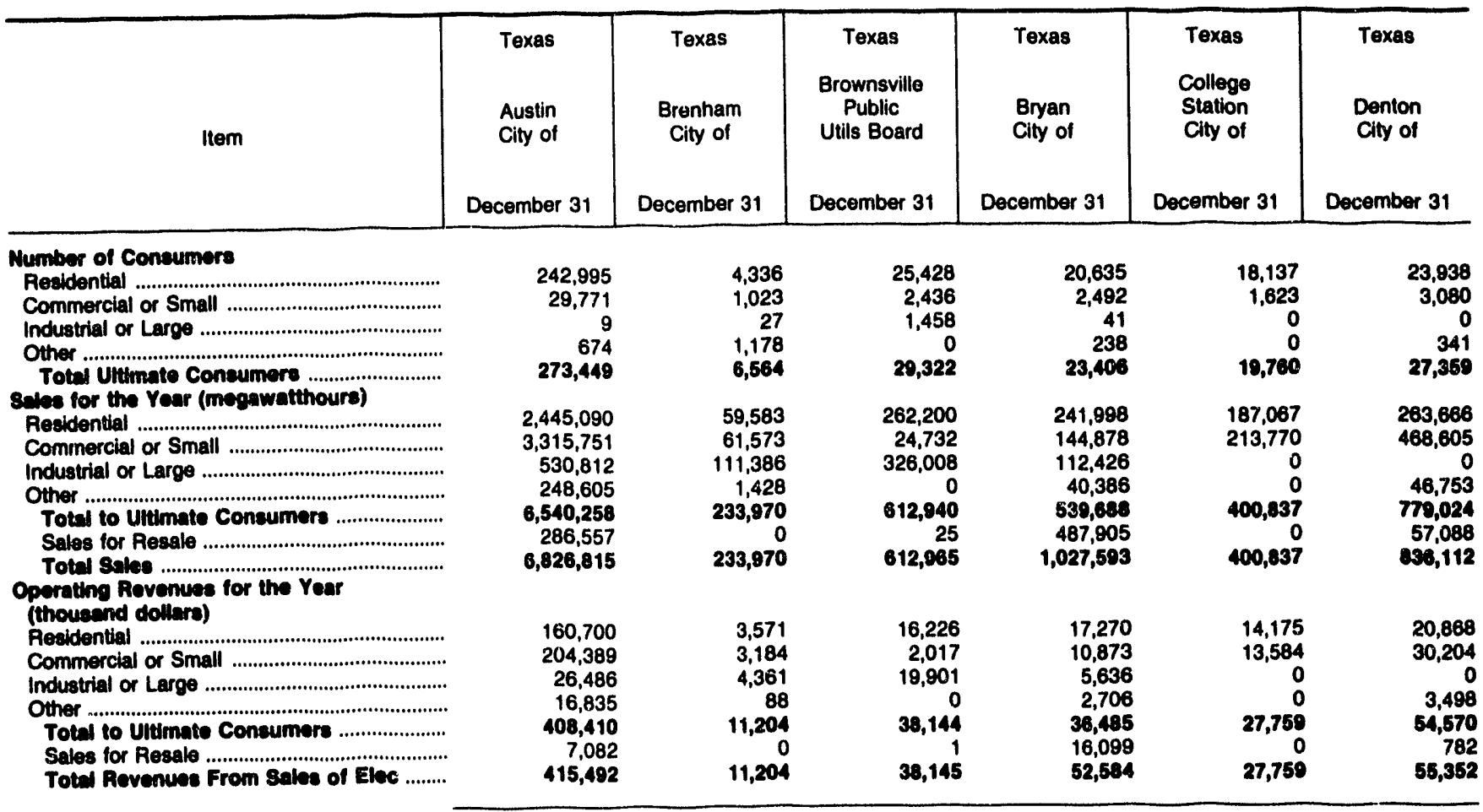

Note: Totals may not equal sum of components because of independent rounding.

Source: Energy Information Administration, Form ElA-861, "Annual Electric Utility Report." Data are submitted on a calendar year. 
Table 40. Number of Consumers, Sales, and Operating Revenue by Major
Publicly Owned Electric Utilly Within State, 1991 (Continued)

\begin{tabular}{|c|c|c|c|c|c|c|}
\hline Item & $\begin{array}{l}\text { Texas } \\
\text { Garland } \\
\text { City of } \\
\text { December } 31\end{array}$ & $\begin{array}{l}\text { Texas } \\
\text { Georgetown } \\
\text { City of } \\
\text { December } 31\end{array}$ & $\begin{array}{c}\text { Texas } \\
\text { Greenville } \\
\text { City of } \\
\text { December } 31\end{array}$ & $\begin{array}{c}\text { Texas } \\
\text { Kerrville } \\
\text { Public } \\
\text { Utility } \\
\text { Board } \\
\text { December } 31\end{array}$ & $\begin{array}{l}\text { Texas } \\
\text { Lower } \\
\text { Colorado } \\
\text { River } \\
\text { Authority } \\
\text { December } 31\end{array}$ & $\begin{array}{l}\text { Texas } \\
\text { Lubbock } \\
\text { City of } \\
\text { December } 31\end{array}$ \\
\hline 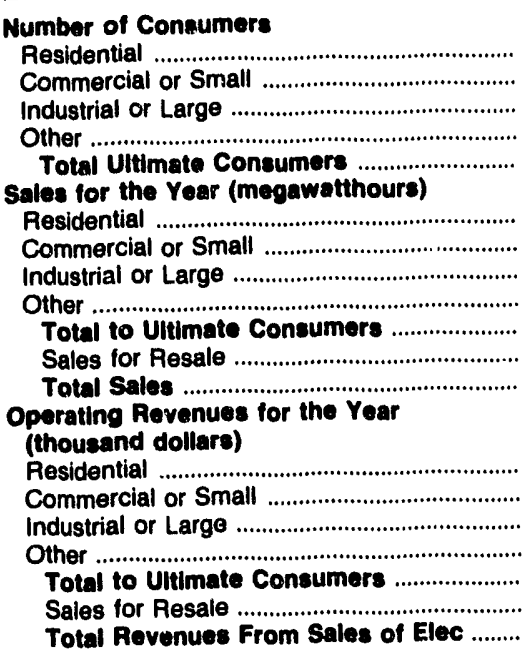 & $\begin{array}{r}831,737 \\
70,013 \\
710,420 \\
98,625 \\
1,710,795 \\
467,342 \\
2,178,137\end{array}$ & $\begin{array}{r}68,626 \\
96,223 \\
0 \\
278 \\
165,127 \\
0 \\
165,127\end{array}$ & $\begin{array}{r}102,755 \\
255,833 \\
40,537 \\
1,990 \\
401,115 \\
61,005 \\
462,120\end{array}$ & $\begin{array}{r}167,478 \\
150,454 \\
0 \\
4,877 \\
322,809 \\
0 \\
322,809\end{array}$ & $\begin{array}{r}204 \\
896 \\
135,110 \\
0 \\
136,210 \\
7,869,101 \\
8,005,311\end{array}$ & $\begin{array}{r}334,219 \\
196,308 \\
266,310 \\
110,894 \\
907,731 \\
0 \\
907,731\end{array}$ \\
\hline
\end{tabular}

\begin{tabular}{|c|c|c|c|c|c|c|}
\hline Item & $\begin{array}{c}\text { Texas } \\
\text { New Braunfels } \\
\text { City of } \\
\text { December } 31\end{array}$ & $\begin{array}{c}\text { Texas } \\
\text { Sam Rayburn } \\
\text { Municipal } \\
\text { Pwr } \\
\text { Agny } \\
\text { December } 31\end{array}$ & $\begin{array}{c}\text { Texas } \\
\text { San Antonio } \\
\text { City of } \\
\text { December } 31\end{array}$ & $\begin{array}{c}\text { Texas } \\
\text { San Marcos } \\
\text { City of } \\
\text { December } 31\end{array}$ & $\begin{array}{l}\text { Texas } \\
\text { Seguin } \\
\text { City of } \\
\text { December } 31\end{array}$ & $\begin{array}{c}\text { Texas } \\
\text { Texas } \\
\text { Municipal } \\
\text { Power Agency } \\
\text { December } 31\end{array}$ \\
\hline 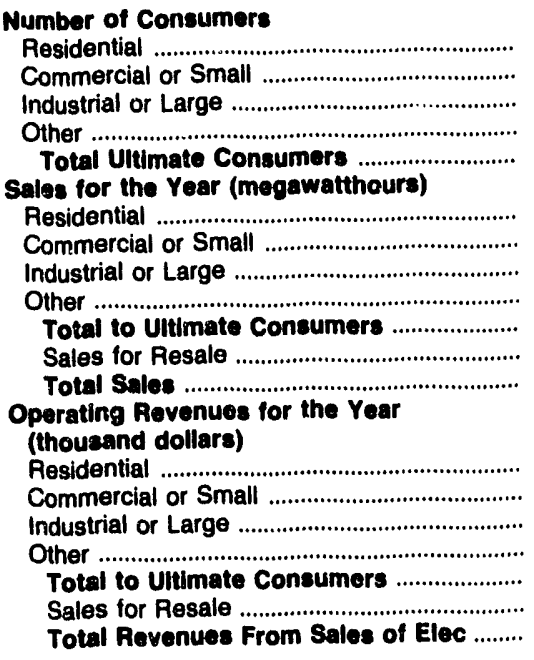 & $\begin{array}{r}13,528 \\
2,001 \\
10 \\
918 \\
16,457 \\
\\
193,756 \\
132,072 \\
352,733 \\
24,312 \\
702,873 \\
0 \\
702,873\end{array}$ & $\begin{array}{r}0 \\
0 \\
0 \\
0 \\
0 \\
590,177 \\
590,177\end{array}$ & $\begin{array}{r}4,818,717 \\
2,209,002 \\
3,060,020 \\
1,709,472 \\
11,797,211 \\
223,942 \\
12,021,163\end{array}$ & $\begin{array}{r}118,215 \\
116,751 \\
53,277 \\
7,239 \\
295,482 \\
0 \\
295,482\end{array}$ & $\begin{array}{r}66,648 \\
60,081 \\
48,073 \\
6,507 \\
181,309 \\
0 \\
181,309\end{array}$ & $\begin{array}{r}0 \\
0 \\
0 \\
0 \\
0 \\
0 \\
2,686,155 \\
2,686,155\end{array}$ \\
\hline
\end{tabular}

Note: Totals may not equal sum of components because of independent rounding.

Source: Energy Information Administration, Form ElA-861, "Annual Electric Utility Report." Data are submitted on a calendar year. 
Table 40. Numt ar of Consumers, Sales, and Operating Revenue by Major Publicl. Owned Electric Utility Within State, 1991 (Continued)

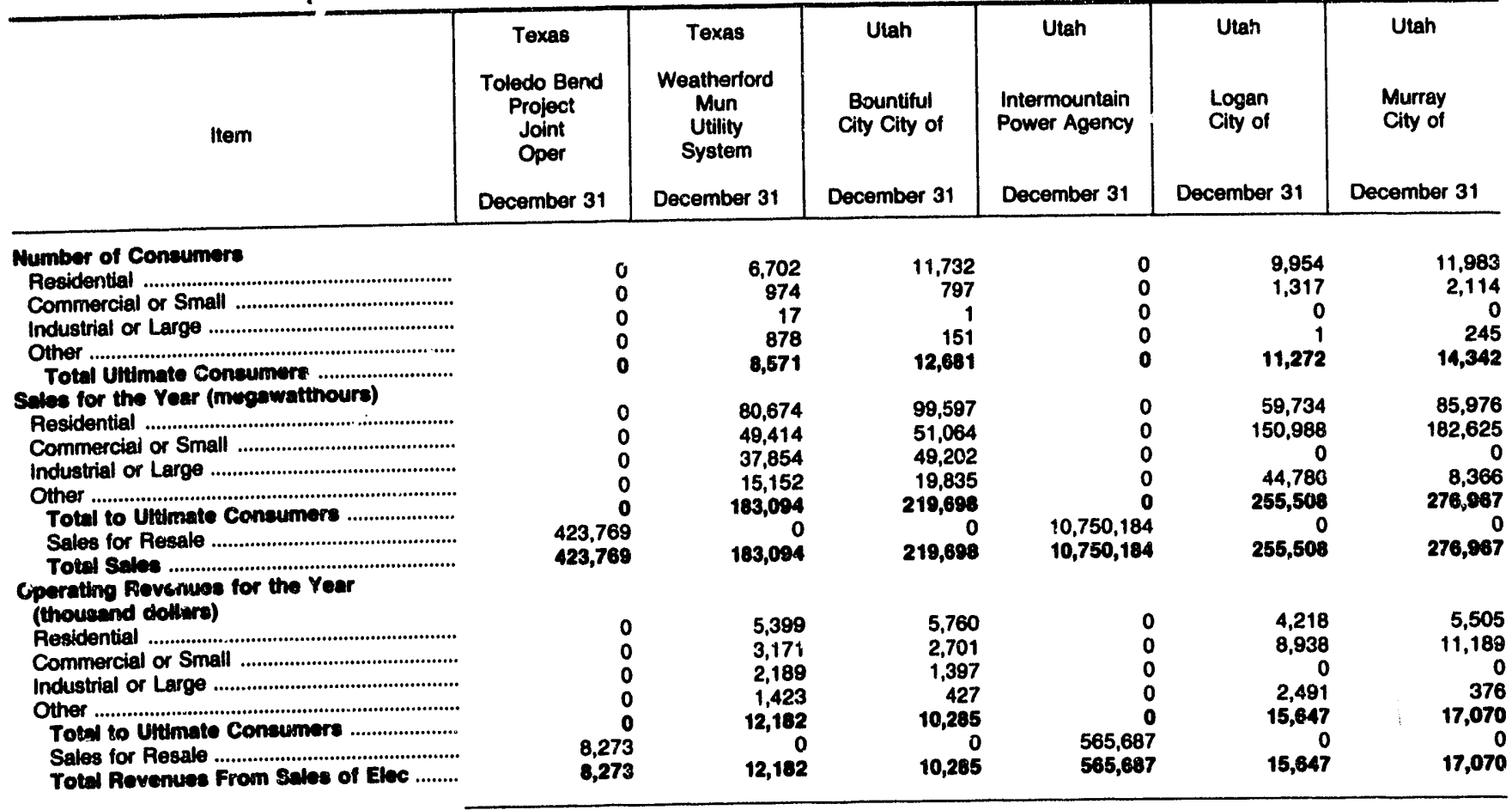

\begin{tabular}{|c|c|c|c|c|c|c|}
\hline Item & $\begin{array}{c}\text { Utah } \\
\text { Provo } \\
\text { City Corp } \\
\text { December } 31\end{array}$ & $\begin{array}{c}\text { Utah } \\
\text { St George } \\
\text { City of } \\
\text { December } 31\end{array}$ & $\begin{array}{c}\text { Utah } \\
\text { Utah } \\
\text { Associated } \\
\text { Mun } \\
\text { Power Sys } \\
\text { December } 31\end{array}$ & $\begin{array}{c}\text { Utah } \\
\text { Utah } \\
\text { Municipal } \\
\text { Power Agency } \\
\text { December } 31\end{array}$ & $\begin{array}{c}\text { Vermont } \\
\begin{array}{c}\text { Burlington } \\
\text { City of }\end{array} \\
\text { December } 31\end{array}$ & $\begin{array}{l}\text { Vermont } \\
\text { Vermont } \\
\text { Public } \\
\text { Pur } \\
\text { Supply Auth } \\
\text { December } 31\end{array}$ \\
\hline 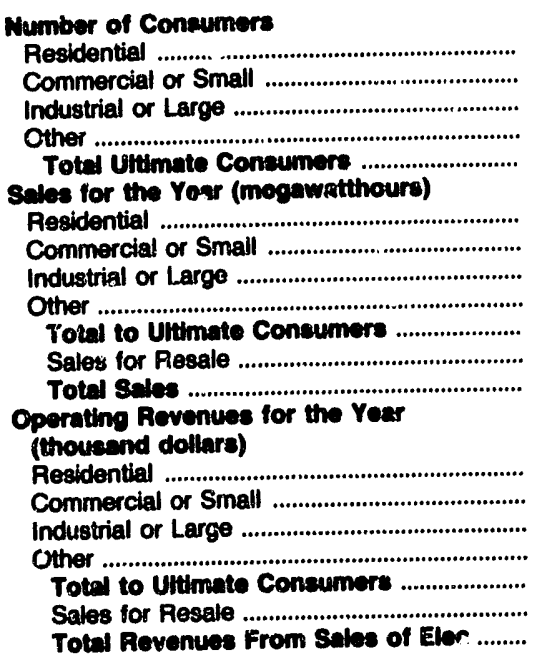 & $\begin{array}{r}21,292 \\
2,848 \\
1 \\
0 \\
24,141 \\
\\
150,781 \\
247,854 \\
98,410 \\
0 \\
497,045 \\
0 \\
497,045\end{array}$ & $\begin{array}{r}131,488 \\
137,540 \\
0 \\
12,423 \\
281,451 \\
0 \\
281,451\end{array}$ & $\begin{array}{r}0 \\
0 \\
0 \\
0 \\
0 \\
0 \\
79.950 \\
7,950\end{array}$ & $\begin{array}{r}0 \\
0 \\
0 \\
0 \\
0 \\
771,802 \\
771,002\end{array}$ & $\begin{array}{r}14,603 \\
2,845 \\
662 \\
1 \\
18,115 \\
82,423 \\
20,145 \\
212,120 \\
2,609 \\
317,297 \\
110,611 \\
427,008\end{array}$ & $\begin{array}{r}0 \\
0 \\
0 \\
0 \\
0 \\
0 \\
135,797 \\
135,797\end{array}$ \\
\hline
\end{tabular}

Note: Totals may not equal sum of components because of independentrounding.

Source: Energy Iniormation Administration, Form EIA-861. "Ann, 2j Elestric Utility Report." Data are submitted on a calendar year. 
Table 40. Number of Consumers, Sales, and Operating Revenue by Major Publicly Owned Electric Utility Within State, 1991 (Continued)

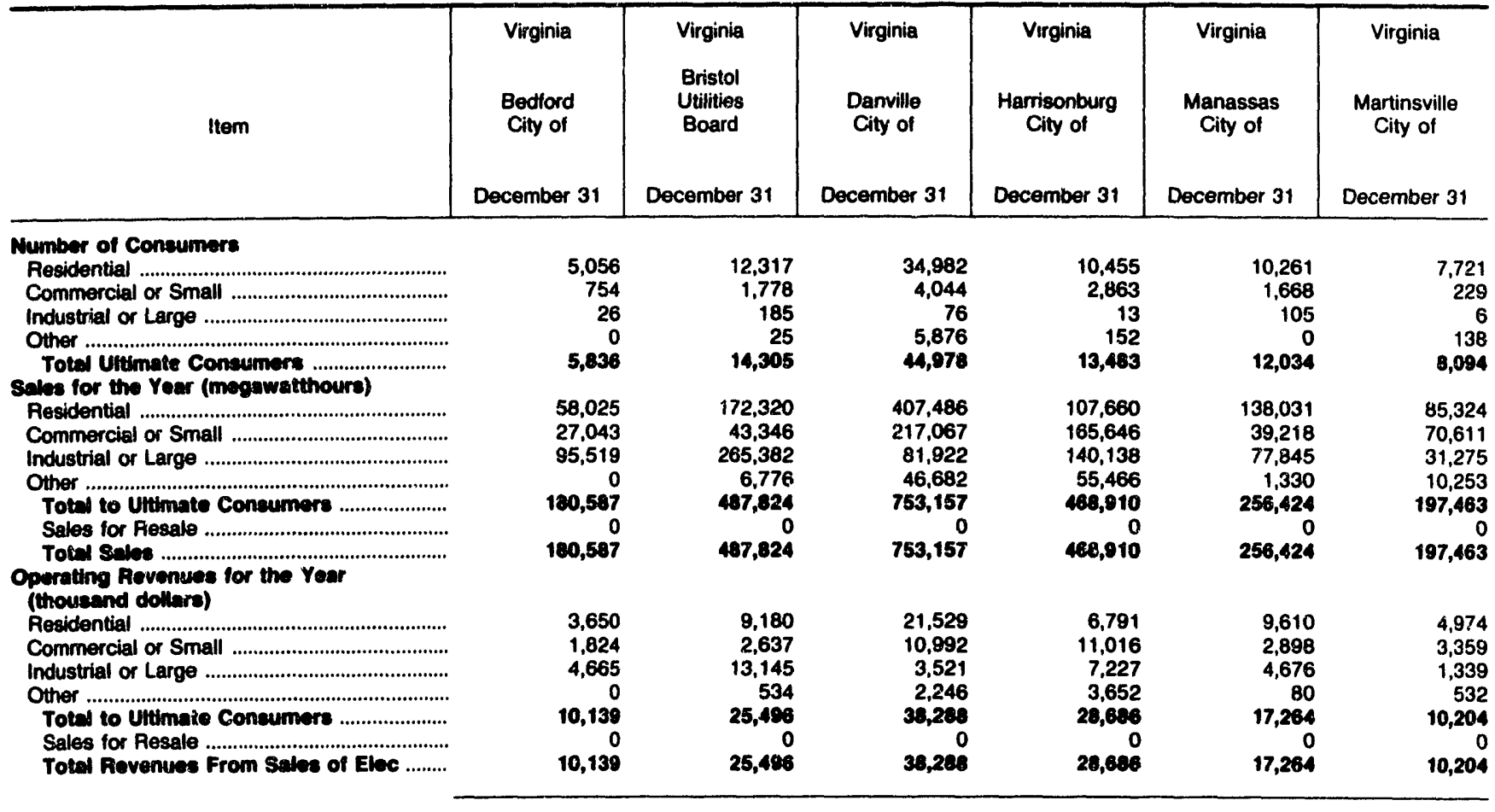

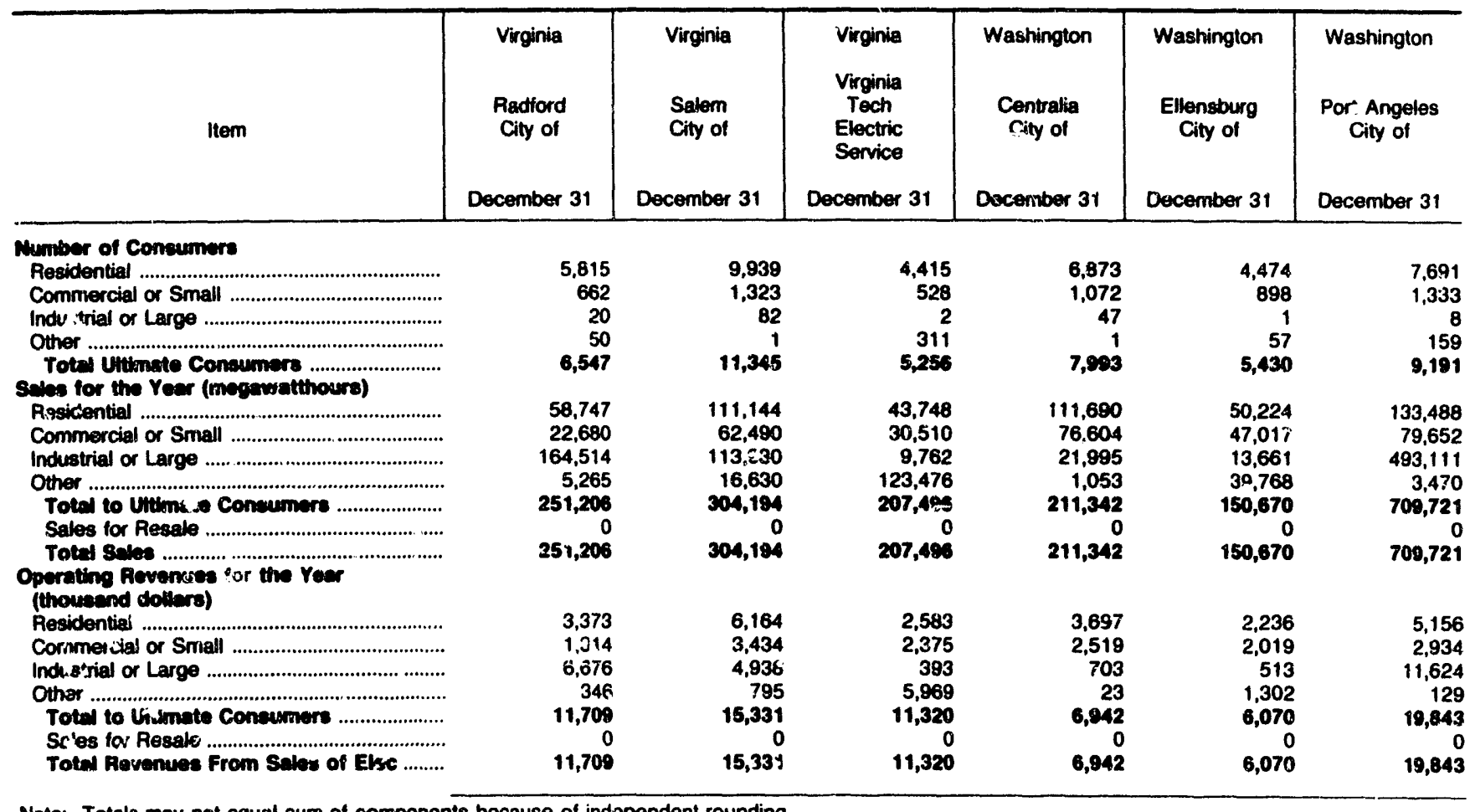

Note: Totals may not equal sum of components because of independent rounding.

Source: Energy Information Administration, Form ElA-861, "Annual Electric Utility Report." Data are submitted on a calendar year. 
Table 40. Number of Consumers, Sales, and Operating Revenue by Major Publicly Owned Electric Utility Within State, 1991 (Continued)

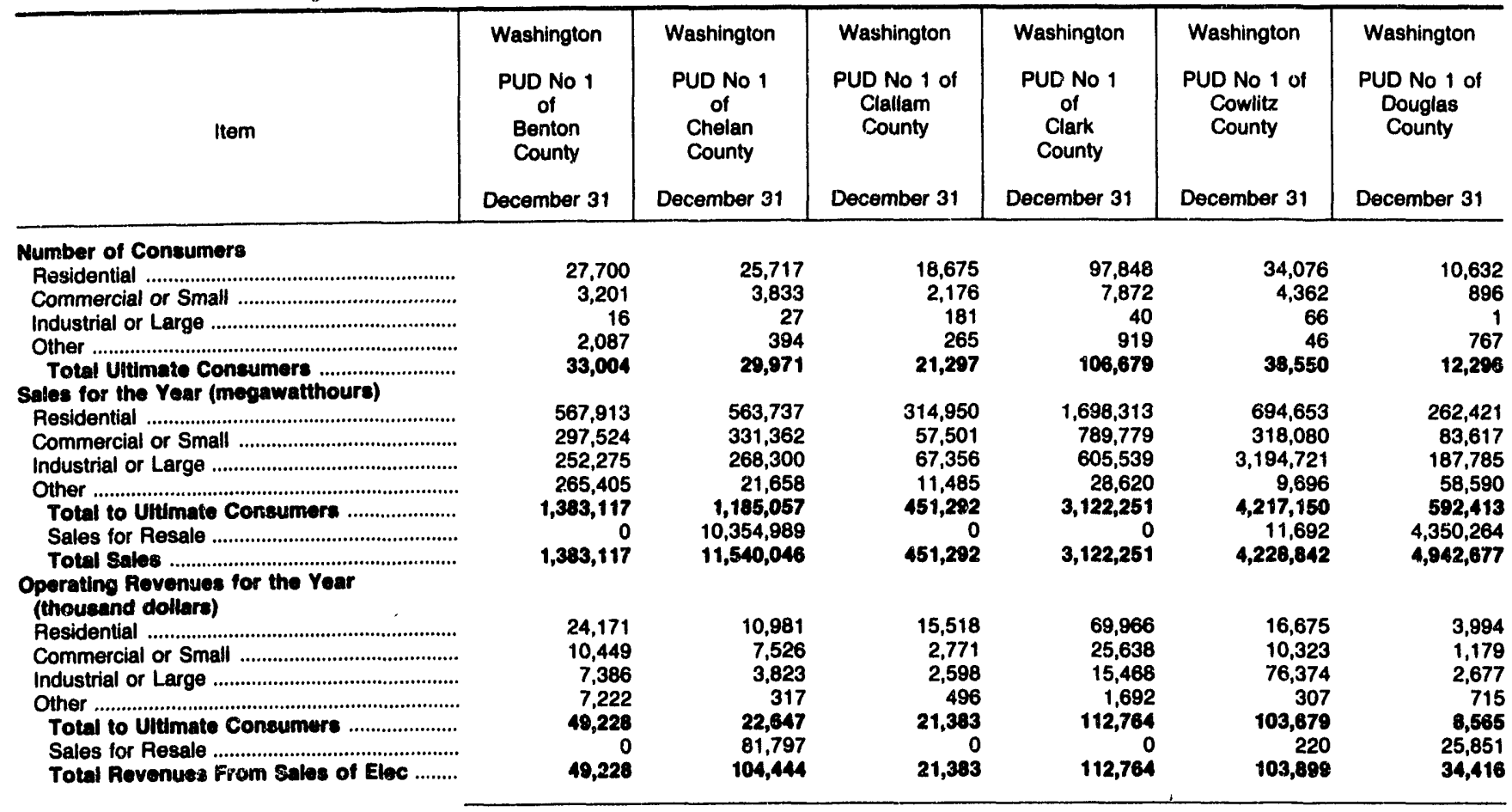

\begin{tabular}{|c|c|c|c|c|c|c|}
\hline Item & $\begin{array}{l}\text { Washington } \\
\text { PUD No } 1 \text { of } \\
\text { Franklin } \\
\text { County } \\
\text { December } 31\end{array}$ & $\begin{array}{c}\text { W: ington } \\
\text { PUD No } 1 \\
\text { of } \\
\text { Grays } \\
\text { Harbor Cnty } \\
\text { Decemuer } 31\end{array}$ & $\begin{array}{l}\text { Washington } \\
\text { PUD No } 1 \text { of } \\
\text { Klickitat } \\
\text { County } \\
\text { December } 3 \text { ! }\end{array}$ & $\begin{array}{c}\text { Washington } \\
\text { PUD No } 1 \\
\text { of } \\
\text { Lewis } \\
\text { County } \\
\text { December } 31\end{array}$ & $\begin{array}{l}\text { Washington } \\
\text { PUD No } 1 \text { of } \\
\text { Okanogan } \\
\text { County } \\
\text { December } 31\end{array}$ & $\begin{array}{l}\text { Washington } \\
\text { PUD No } 1 \text { of } \\
\text { Pend Oreille } \\
\text { Cnty } \\
\text { December } 31\end{array}$ \\
\hline \multicolumn{7}{|l|}{ Number of Consumers } \\
\hline 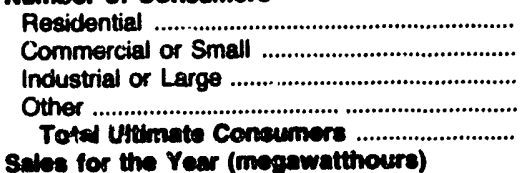 & $\begin{array}{r}11,774 \\
2,326 \\
0 \\
1,270 \\
15,370\end{array}$ & $\begin{array}{r}30,640 \\
3,089 \\
41 \\
947 \\
34,717\end{array}$ & $\begin{array}{r}6,973 \\
1,181 \\
116 \\
223 \\
8,493\end{array}$ & $\begin{array}{r}19,069 \\
2,566 \\
76 \\
769 \\
22,490\end{array}$ & $\begin{array}{r}13,555 \\
2,026 \\
5 \\
1,910 \\
17,408\end{array}$ & $\begin{array}{r}4,562 \\
541 \\
9 \\
8 \\
5,120\end{array}$ \\
\hline 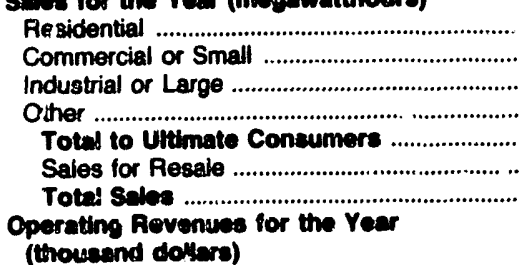 & $\begin{array}{r}218,535 \\
261,921 \\
0 \\
114,781 \\
595,237 \\
0 \\
505,287\end{array}$ & $\begin{array}{r}513,411 \\
60,187 \\
395,688 \\
167,179 \\
1,136,465 \\
310,384 \\
1,446,849\end{array}$ & $\begin{array}{r}101,150 \\
24,150 \\
117,390 \\
20,690 \\
263,380 \\
0 \\
283,390\end{array}$ & $\begin{array}{r}319,600 \\
105,200 \\
160,700 \\
59,500 \\
645,000 \\
0 \\
645,000\end{array}$ & $\begin{array}{r}249,314 \\
169,415 \\
51,804 \\
59,876 \\
530,409 \\
0 \\
530,409\end{array}$ & $\begin{array}{r}65,492 \\
31,952 \\
704,440 \\
315 \\
802,190 \\
139,149 \\
941,398\end{array}$ \\
\hline 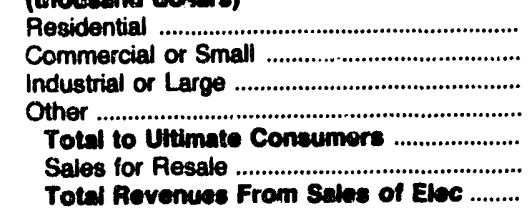 & $\begin{array}{r}9,277 \\
8,831 \\
0 \\
3,270 \\
21,378 \\
0 \\
21,378\end{array}$ & $\begin{array}{r}20,340 \\
2,880 \\
11,369 \\
7,407 \\
41,996 \\
8,004 \\
50,000\end{array}$ & $\begin{array}{r}5,154 \\
1,235 \\
3,783 \\
758 \\
10,980 \\
0 \\
10,930\end{array}$ & $\begin{array}{r}12,392 \\
4,275 \\
5,488 \\
2,348 \\
24,503 \\
0 \\
24,503\end{array}$ & $\begin{array}{r}6,616 \\
5,091 \\
1,127 \\
1,258 \\
14,092 \\
0 \\
14,092\end{array}$ & $\begin{array}{r}2,206 \\
790 \\
12,904 \\
26 \\
15,928 \\
1,024 \\
16,950\end{array}$ \\
\hline
\end{tabular}

Note: Totals may not equal sum of components because of independent rounding.

Source: Energy information Administration, Form ElA-861, "Annual Electric Utility Report." Data are submitted on a calendar year. 
Table 40. Number of Consumers, Sales, and Operating Revenue by Major Publicly Owned Electric Utility Within State, 1991 (Continued)

\begin{tabular}{|c|c|c|c|c|c|c|}
\hline Item & $\begin{array}{l}\text { Washington } \\
\text { PUD No } 1 \text { of } \\
\text { Snohomish } \\
\text { County } \\
\text { December } 31\end{array}$ & $\begin{array}{l}\text { Washington } \\
\text { PUD No } 1 \text { of } \\
\text { Whatcom } \\
\text { County } \\
\text { December } 31\end{array}$ & $\begin{array}{c}\text { Washington } \\
\text { PUD No } 2 \\
\text { of } \\
\text { Grant } \\
\text { County } \\
\text { December } 31\end{array}$ & $\begin{array}{l}\text { Washington } \\
\text { PUD No } 2 \text { of } \\
\text { Pacific } \\
\text { County } \\
\text { December } 31\end{array}$ & $\begin{array}{c}\text { Washington } \\
\text { PUD No } 3 \\
\text { of } \\
\text { Mason } \\
\text { County } \\
\text { December } 31\end{array}$ & $\begin{array}{c}\text { Washington } \\
\text { Richland } \\
\text { City of } \\
\text { December } 31\end{array}$ \\
\hline 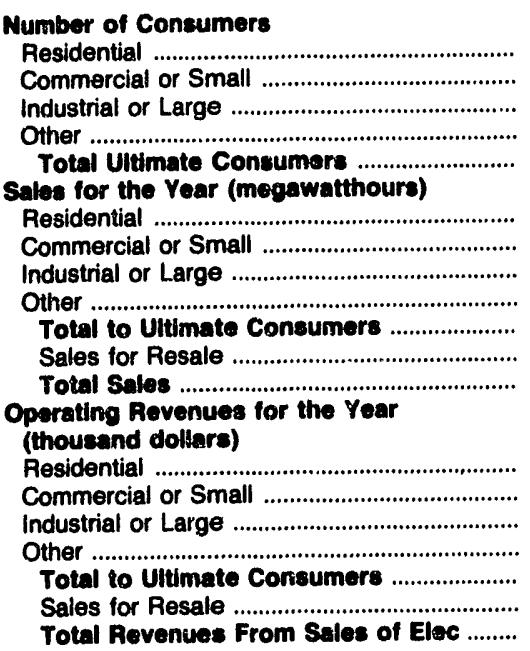 & $\begin{array}{r}3,111,799 \\
1,547,317 \\
956,050 \\
16,832 \\
5,631,998 \\
122,220 \\
5,754,218\end{array}$ & $\begin{array}{r}0 \\
0 \\
149,043 \\
0 \\
149,043 \\
0 \\
149,043\end{array}$ & $\begin{array}{r}567,322 \\
717,743 \\
1,287,928 \\
4,024 \\
2,577,017 \\
7,326,020 \\
8,903,037\end{array}$ & $\begin{array}{r}156,398 \\
52,912 \\
25,168 \\
20,218 \\
254,696 \\
0 \\
254,696\end{array}$ & $\begin{array}{r}280,077 \\
125,173 \\
52,911 \\
1,633 \\
459,794 \\
567 \\
460,361\end{array}$ & $\begin{array}{r}272,694 \\
41,273 \\
278,648 \\
3,498 \\
596,113 \\
0 \\
596,113\end{array}$ \\
\hline
\end{tabular}

\begin{tabular}{|c|c|c|c|c|c|c|}
\hline Item & $\begin{array}{c}\text { Washington } \\
\text { Seattle } \\
\text { City of } \\
\text { December } 31\end{array}$ & $\begin{array}{c}\text { Washington } \\
\text { Tacoma } \\
\text { Gity of } \\
\text { December } 31\end{array}$ & $\begin{array}{c}\text { Washington } \\
\text { Vera } \\
\text { Irrigation } \\
\text { District } \# 15 \\
\text { December } 31\end{array}$ & $\begin{array}{c}\text { Washington } \\
\text { Washington } \\
\text { Pub } \\
\text { Pwr } \\
\text { Supply Sys } \\
\text { December } 31\end{array}$ & $\begin{array}{c}\text { Wisconsin } \\
\text { Jefferson } \\
\text { City of } \\
\text { December } 31\end{array}$ & $\begin{array}{c}\text { Wisconsin } \\
\text { Kaukauna } \\
\text { City of } \\
\text { December } 31\end{array}$ \\
\hline 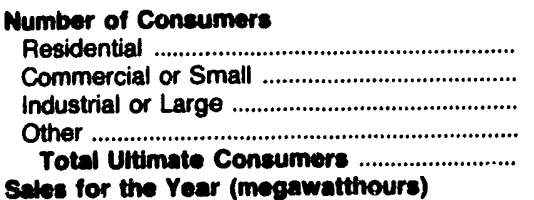 & $\begin{array}{r}295,816 \\
33,166 \\
301 \\
2,168 \\
331,451\end{array}$ & $\begin{array}{r}118,748 \\
9,695 \\
1,511 \\
271 \\
130,225\end{array}$ & $\begin{array}{r}5,700 \\
449 \\
0 \\
40 \\
6,180\end{array}$ & $\begin{array}{l}0 \\
0 \\
0 \\
0 \\
0\end{array}$ & $\begin{array}{r}2,623 \\
368 \\
35 \\
2 \\
3,028\end{array}$ & $\begin{array}{r}8,494 \\
933 \\
2 \\
30 \\
9,459\end{array}$ \\
\hline 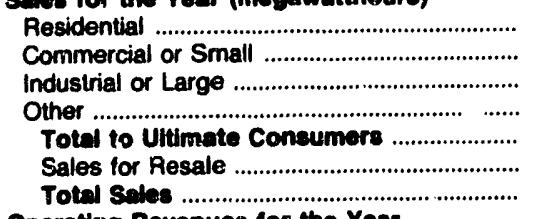 & $\begin{array}{r}3,349,065 \\
3,301,670 \\
1,396,395 \\
785,508 \\
8,832,638 \\
0 \\
8,832,638\end{array}$ & $\begin{array}{r}1,836,227 \\
313,288 \\
2,878,122 \\
541,024 \\
5,588,661 \\
984,354 \\
6,553,015\end{array}$ & $\begin{array}{r}118,999 \\
40,213 \\
0 \\
5,866 \\
165,078 \\
0 \\
165,078\end{array}$ & $\begin{array}{r}0 \\
0 \\
0 \\
0 \\
0 \\
4,322,982 \\
4,322,982\end{array}$ & $\begin{array}{r}24,929 \\
9,665 \\
89,571 \\
1,477 \\
125,642 \\
0 \\
125,642\end{array}$ & $\begin{array}{r}95,417 \\
103,499 \\
346,799 \\
3,602 \\
549,317 \\
0 \\
549,317\end{array}$ \\
\hline 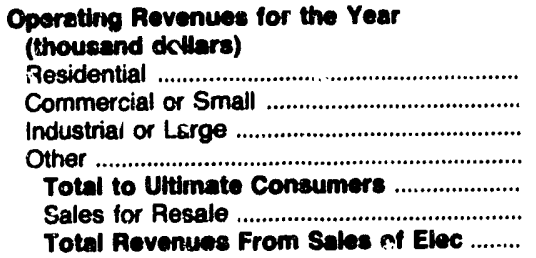 & $\begin{array}{r}112,243 \\
104,130 \\
38,023 \\
26,549 \\
280,945 \\
0 \\
280,945\end{array}$ & $\begin{array}{r}68,423 \\
14,847 \\
69,004 \\
13,512 \\
162,788 \\
23,788 \\
186,584\end{array}$ & $\begin{array}{r}4,203 \\
1,497 \\
0 \\
224 \\
5,924 \\
0 \\
5,924\end{array}$ & $\begin{array}{r}0 \\
0 \\
0 \\
0 \\
0 \\
440,905 \\
440,905\end{array}$ & $\begin{array}{r}1,237 \\
563 \\
3,601 \\
94 \\
5,495 \\
0 \\
5,495\end{array}$ & $\begin{array}{r}3,949 \\
3,743 \\
11,936 \\
234 \\
19,862 \\
0 \\
19,862\end{array}$ \\
\hline
\end{tabular}

Note: Totals may not equal sum of components because of independent rounding.

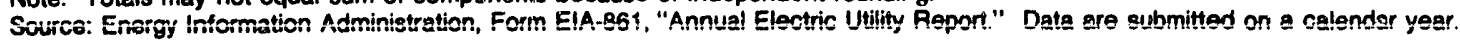


Table 40. Number of Consumers, Sales, and Operating Revenue by Major Publicly Owned Electric Utility Within State, 1991 (Continued)

\begin{tabular}{|c|c|c|c|c|c|c|}
\hline Item & $\begin{array}{c}\text { Wisconsin } \\
\text { Manitowoc } \\
\text { Public } \\
\text { Utilities } \\
\text { December } 31\end{array}$ & $\begin{array}{l}\text { Wisconsin } \\
\begin{array}{c}\text { Marshifield } \\
\text { City of }\end{array} \\
\text { December } 31\end{array}$ & $\begin{array}{c}\text { Wisconsin } \\
\text { Menasha } \\
\text { City of } \\
\text { December } 31\end{array}$ & $\begin{array}{l}\text { Wisconsin } \\
\begin{array}{c}\text { New London } \\
\text { City of }\end{array} \\
\text { December } 31\end{array}$ & $\begin{array}{c}\text { Wisconsin } \\
\begin{array}{c}\text { Oconomowoc } \\
\text { City of }\end{array} \\
\text { December } 31\end{array}$ & $\begin{array}{l}\text { Wisconsin } \\
\text { Plymouth } \\
\text { City of } \\
\text { December } 31\end{array}$ \\
\hline 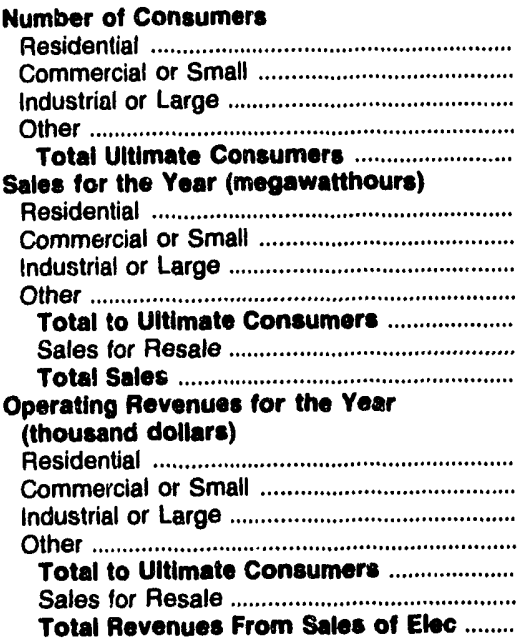 & $\begin{array}{r}87,974 \\
52,019 \\
285,761 \\
10,116 \\
435,870 \\
0 \\
435,870\end{array}$ & $\begin{array}{r}82,131 \\
70,210 \\
134,559 \\
8,988 \\
295,888 \\
0 \\
295,888\end{array}$ & $\begin{array}{r}45,200 \\
9,000 \\
438,200 \\
3,000 \\
495,400 \\
25,512 \\
520,912\end{array}$ & $\begin{array}{r}24,741 \\
12,063 \\
114,804 \\
2,918 \\
164,526 \\
0 \\
154,526\end{array}$ & $\begin{array}{r}46,922 \\
17,711 \\
77,514 \\
2,620 \\
144,767 \\
0 \\
144,767\end{array}$ & $\begin{array}{r}5,098 \\
592 \\
66 \\
10 \\
5,766 \\
\\
50,791 \\
14,100 \\
78,280 \\
4,042 \\
147,213 \\
0 \\
147,213\end{array}$ \\
\hline
\end{tabular}

\begin{tabular}{|c|c|c|c|c|c|c|}
\hline Item & $\begin{array}{l}\text { Wisconsin } \\
\text { Reedsburg } \\
\text { Utility Comm } \\
\text { December } 31\end{array}$ & $\begin{array}{l}\text { Wisconsin } \\
\text { Shawano } \\
\text { Municipal } \\
\text { Utilities } \\
\text { December } 31\end{array}$ & $\begin{array}{l}\text { Wisconsin } \\
\text { Sheboygan } \\
\text { Falis } \\
\text { City of } \\
\text { December } 31\end{array}$ & $\begin{array}{l}\text { Wisconsin } \\
\text { Sturgeon Bay } \\
\text { Combined } \\
\text { Utils }\end{array}$ & $\begin{array}{l}\text { Wisconsin } \\
\text { Wisconsin } \\
\text { Public } \\
\text { Power } \\
\text { Inc Sys } \\
\text { December } 31\end{array}$ & $\begin{array}{l}\text { Wisconsin } \\
\text { Wisconsin } \\
\text { Rapids W W } \\
\& L \\
\text { Comm } \\
\text { December } 31\end{array}$ \\
\hline 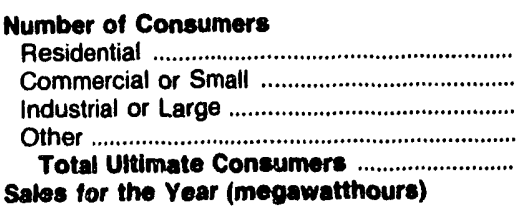 & $\begin{array}{r}2,575 \\
464 \\
23 \\
44 \\
3,106\end{array}$ & $\begin{array}{r}3,767 \\
681 \\
90 \\
103 \\
4,641\end{array}$ & $\begin{array}{r}2,486 \\
310 \\
34 \\
183 \\
3,013\end{array}$ & $\begin{array}{r}6,333 \\
717 \\
44 \\
48 \\
7,142\end{array}$ & $\begin{array}{l}0 \\
0 \\
0 \\
0 \\
0\end{array}$ & $\begin{array}{r}9,810 \\
1,140 \\
132 \\
12 \\
11,004\end{array}$ \\
\hline 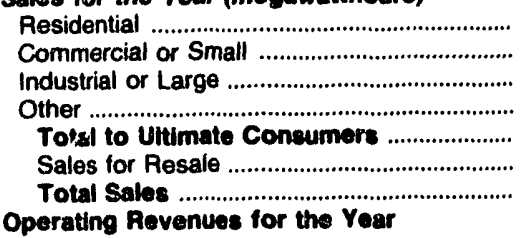 & $\begin{array}{r}23,500 \\
16,100 \\
92,000 \\
1,300 \\
132,900 \\
0 \\
132,900\end{array}$ & $\begin{array}{r}29,681 \\
13,407 \\
120,794 \\
1,800 \\
165,682 \\
0 \\
165,682\end{array}$ & $\begin{array}{r}18,391 \\
7,357 \\
134,487 \\
3,313 \\
163,546 \\
0 \\
163,546\end{array}$ & $\begin{array}{r}47,763 \\
26,184 \\
49,650 \\
3,021 \\
126,618 \\
0 \\
126,618\end{array}$ & $\begin{array}{r}0 \\
0 \\
0 \\
0 \\
0 \\
3,164,342 \\
3,164,342\end{array}$ & $\begin{array}{r}82,972 \\
24,864 \\
78,837 \\
5,153 \\
181,026 \\
0 \\
101,826\end{array}$ \\
\hline 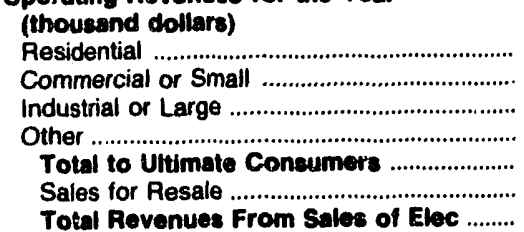 & $\begin{array}{r}1,095 \\
864 \\
3,926 \\
79 \\
5,964 \\
0 \\
5,964\end{array}$ & $\begin{array}{r}1,667 \\
842 \\
5,128 \\
138 \\
7,775 \\
0 \\
7,775\end{array}$ & $\begin{array}{r}858 \\
350 \\
5,280 \\
190 \\
6,678 \\
0 \\
6,678\end{array}$ & $\begin{array}{r}2,867 \\
1,550 \\
2,682 \\
235 \\
7,334 \\
0 \\
7,334\end{array}$ & $\begin{array}{r}0 \\
0 \\
0 \\
0 \\
0 \\
115,277 \\
115,277\end{array}$ & $\begin{array}{r}4,477 \\
1,549 \\
3,909 \\
404 \\
10,330 \\
0 \\
10,339\end{array}$ \\
\hline
\end{tabular}

Note: Totals may not equal sum of components because of independent rounding.

Source: Energy Information Administration, Form EIA-861, "Annual Electric Utility Report." Data are submitted on a calendar year. 
Table 40. Number of Consumers, Sales, and Operating Revenue by Major Publicly Owned Electric Utillty Within State, 1991 (Continued)

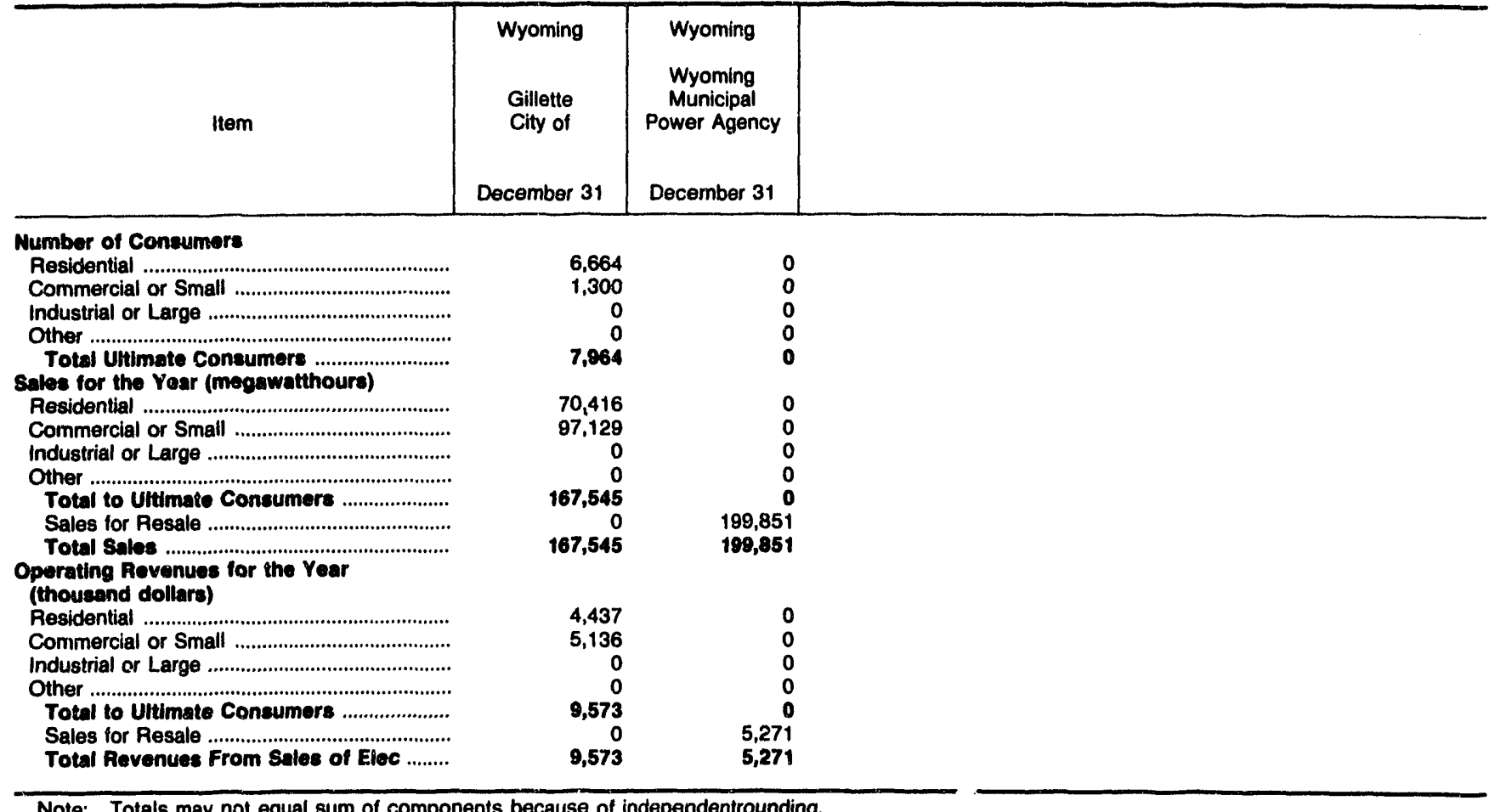

Note: Totals may not equal sum of components because of independentrounding.

Source: Energy Information Administration, Form ElA-861, "Annual Electric Utility Report." Data are submitted on a calendar year. 
Table 41. Electric Energy Account by Major Publicly Owned Electric Utility Within State, 1991

(Megawatthours)

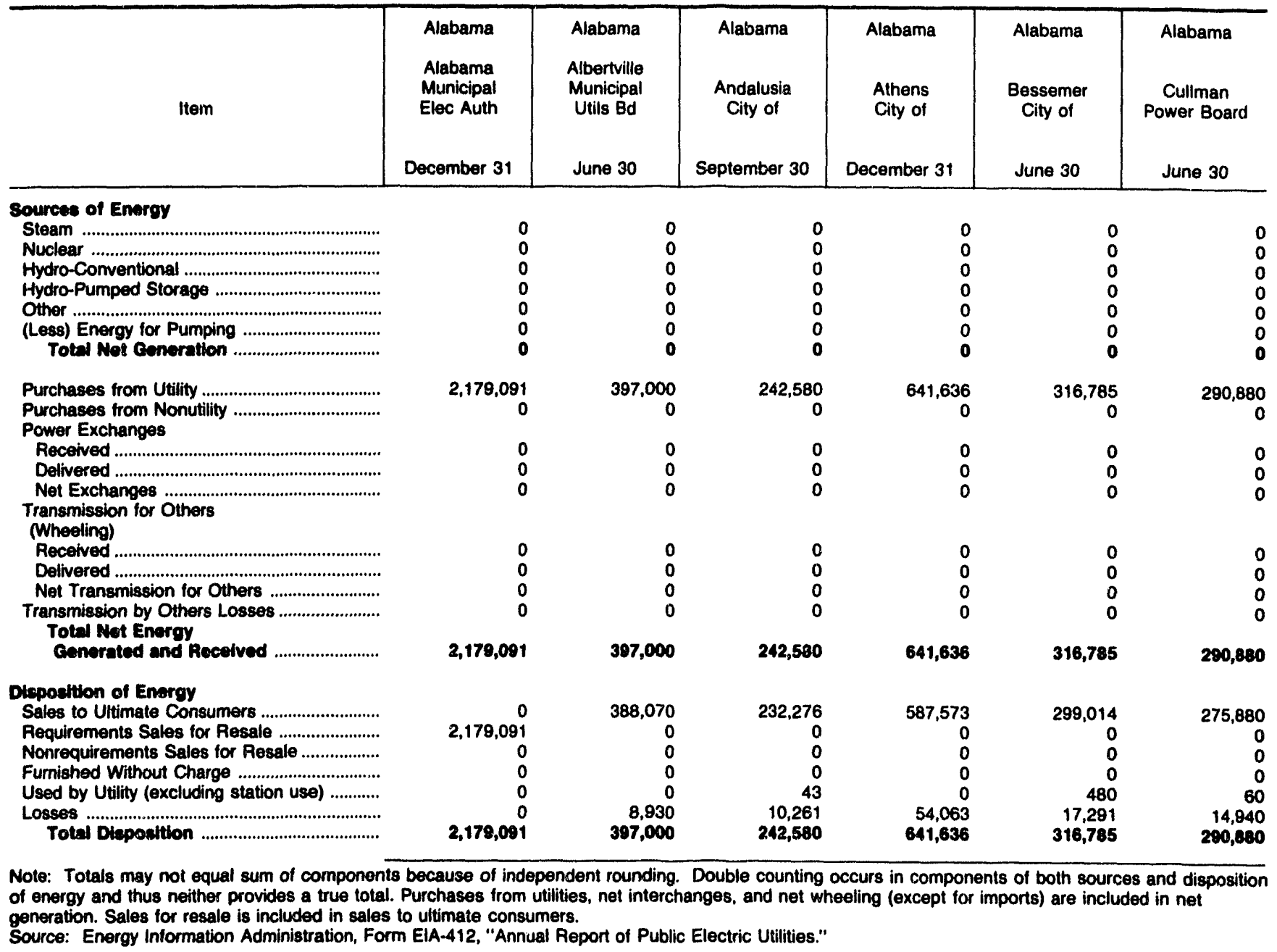


Table 41. Electric Energy Account by Major Publicly Owned Electric Utility Within State, 1991 (Continued) (Megawatthours)

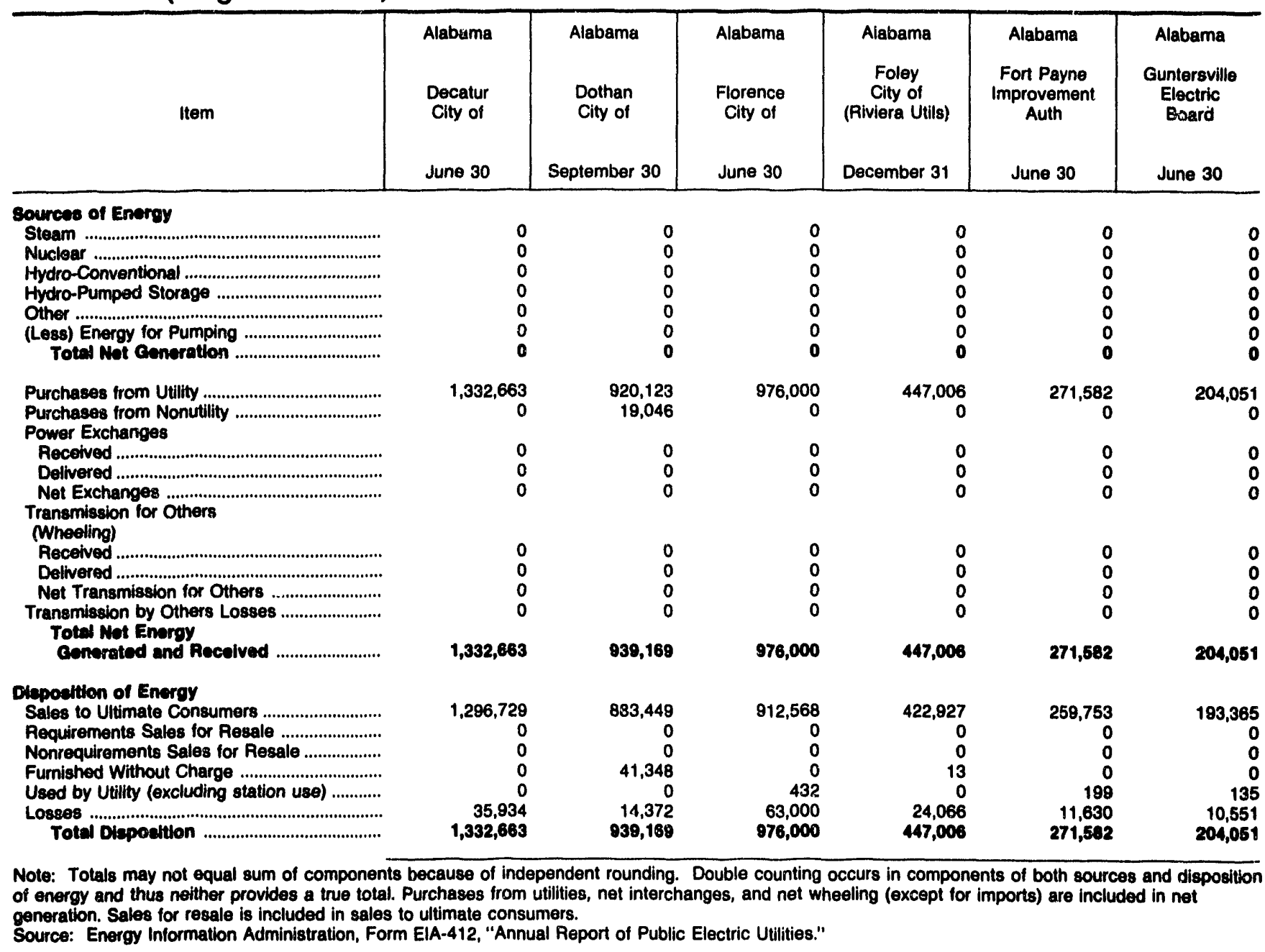



Table 41. Electric Energy Account by Major Publicly Owned Electric
Utility Within State, 1991 (Continued) (Megawatthours)

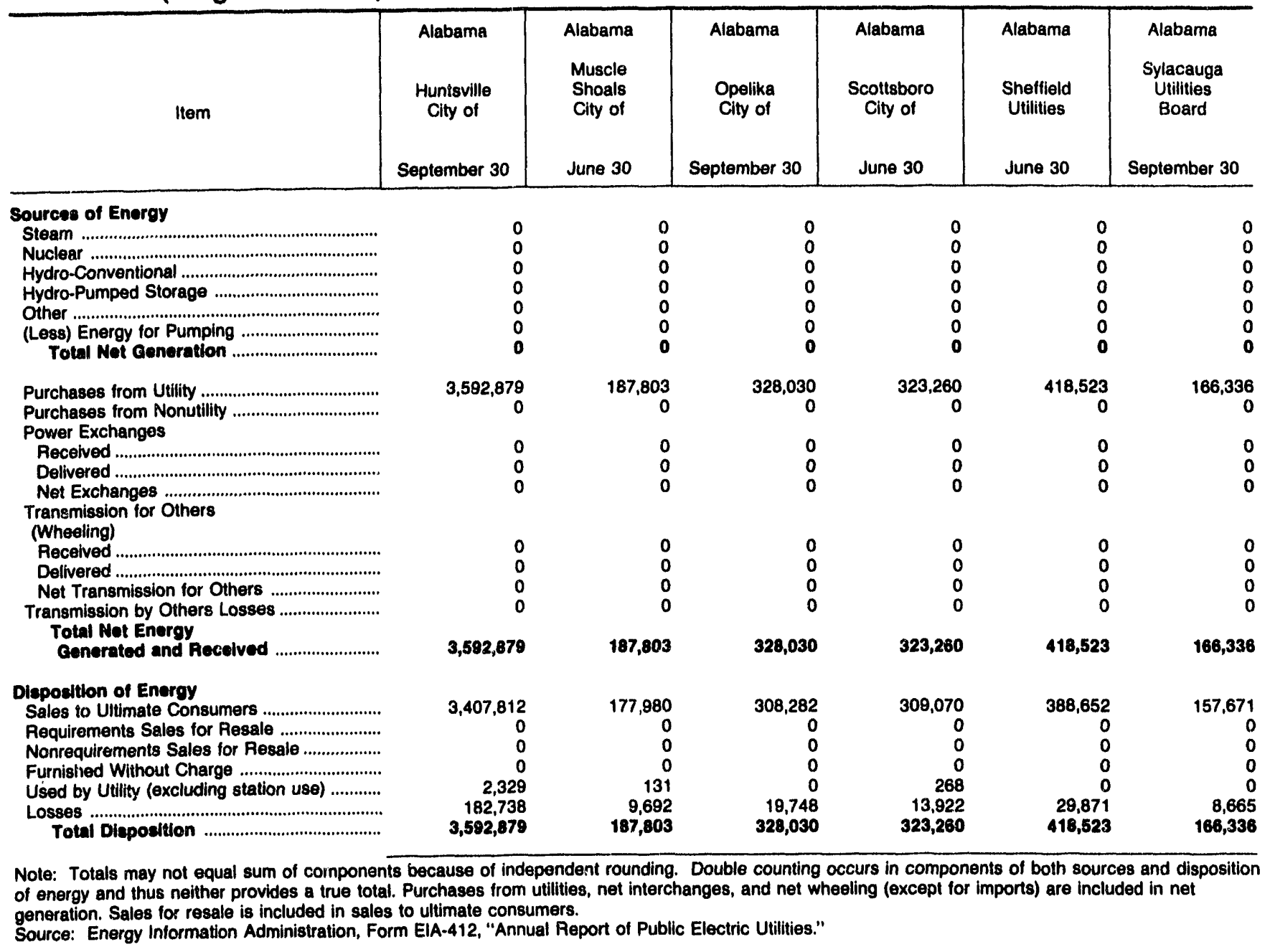


Table 41. Electric Energy Account by Major Publicly Owned Electric Utility Within State, 1991 (Continued)

(Megawatthours)

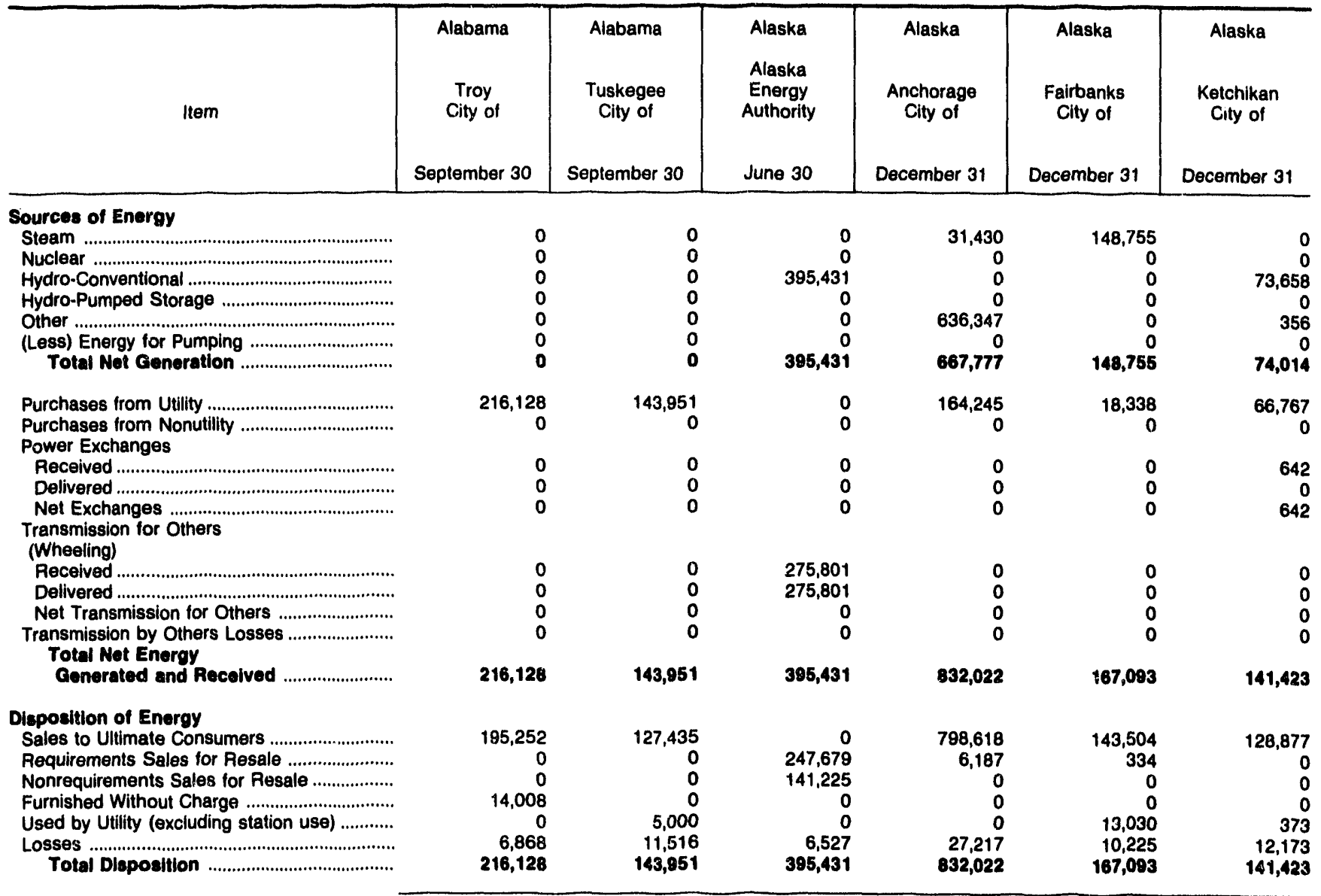

Note: Totals may not equal sum of components because of independent rounding. Double counting occurs in components of both sources and disposition of energy and thus neither provides a true total. Purchases from utilities, net interchanges, and net wheeling (except for imports) are included in net generation. Sales for resale is included in sales to uitimate consumers.

Source: Energy Information Administration, Form ElA-412, "Annual Report of Public Electric Utilities." 
Table 41. Electric Energy Account by Major Publicly Owned Electric Utillty Within State, 1991 (Continued) (Megawatthours)

\begin{tabular}{|c|c|c|c|c|c|c|}
\hline Item & $\begin{array}{l}\text { Arizona } \\
\text { Arizona } \\
\text { Power } \\
\text { Authority } \\
\text { June } 30\end{array}$ & $\begin{array}{l}\text { Arizona } \\
\text { Mesa } \\
\text { City of } \\
\text { June } 30\end{array}$ & $\begin{array}{l}\text { Arizona } \\
\text { Navajo } \\
\text { Tribal } \\
\text { Utility } \\
\text { Auth } \\
\text { December } 31\end{array}$ & $\begin{array}{l}\text { Arizona } \\
\text { Salt Piver } \\
\text { Prol Ag } \\
\text { I \& P Dist } \\
\text { April } 30\end{array}$ & $\begin{array}{l}\text { Arkansas } \\
\text { Benton } \\
\text { City of } \\
\text { December } 31\end{array}$ & $\begin{array}{c}\text { Arkansas } \\
\begin{array}{c}\text { Bentonville } \\
\text { City of }\end{array} \\
\text { December } 31\end{array}$ \\
\hline 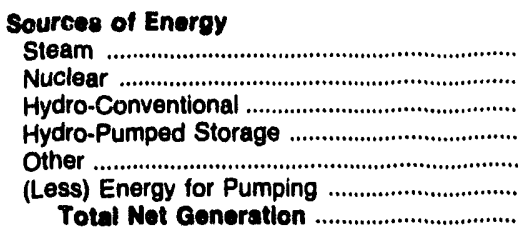 & $\begin{array}{l}0 \\
0 \\
0 \\
0 \\
0 \\
0 \\
0\end{array}$ & $\begin{array}{l}0 \\
0 \\
0 \\
0 \\
0 \\
0 \\
0\end{array}$ & $\begin{array}{l}0 \\
0 \\
0 \\
0 \\
0 \\
0 \\
0\end{array}$ & $\begin{array}{r}11,920,255 \\
4,319,603 \\
216,841 \\
177,622 \\
470,833 \\
241,165 \\
16,863,989\end{array}$ & $\begin{array}{r}0 \\
0 \\
0 \\
0 \\
44 \\
0 \\
44\end{array}$ & $\begin{array}{l}0 \\
0 \\
0 \\
0 \\
0 \\
0 \\
0\end{array}$ \\
\hline 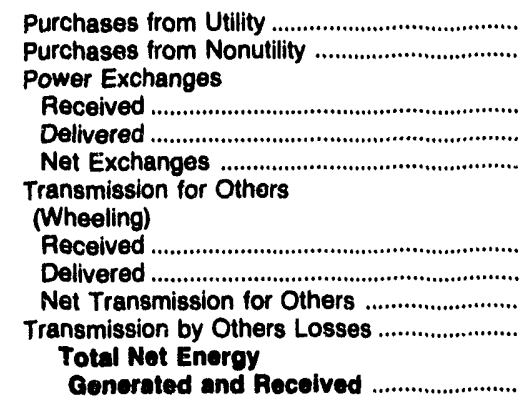 & $\begin{array}{r}863,722 \\
0\end{array}$ & $\begin{array}{r}312,907 \\
0 \\
0 \\
0 \\
0\end{array}$ & $\begin{array}{r}564,255 \\
0\end{array}$ & $\begin{array}{r}3,245,099 \\
3,245,099 \\
0 \\
0\end{array}$ & $\begin{array}{r}0 \\
0 \\
0 \\
0 \\
148,506\end{array}$ & $\begin{array}{r}0 \\
0 \\
0 \\
0 \\
193,956\end{array}$ \\
\hline 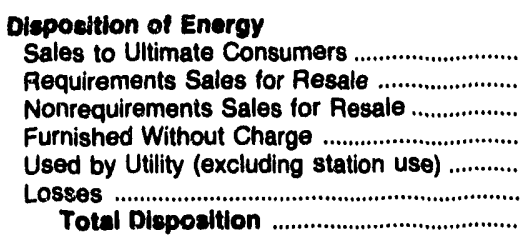 & $\begin{array}{r}0 \\
833,232 \\
0 \\
0 \\
0 \\
30,490 \\
863,722\end{array}$ & $\begin{array}{r}300,097 \\
1,551 \\
0 \\
0 \\
0 \\
11,259 \\
312,907\end{array}$ & $\begin{array}{r}520,661 \\
0 \\
0 \\
0 \\
0 \\
43,594 \\
564,255\end{array}$ & $\begin{array}{r}14,591,965 \\
2,835,354 \\
0 \\
0 \\
0 \\
1,056,586 \\
18,483,805\end{array}$ & $\begin{array}{r}128,488 \\
0 \\
0 \\
7,382 \\
91 \\
12,545 \\
148,506\end{array}$ & $\begin{array}{r}185,016 \\
0 \\
0 \\
0,499 \\
0 \\
6,441 \\
193,956\end{array}$ \\
\hline
\end{tabular}

Note: Totals may not equal sum of components because of independent rounding. Double counting occurs in components of both sources and disposition of energy and thus neither provides a true total. Purchases from utilities, net interchanges, and net wheeling (except for imports) are included in net generation. Sales for resale is included in sales to ultimate consumers.

Source: Energy Information Administration, Form EIA-412, "Annual Report of Public Electric Utilities." 
Table 41. Electric Energy Account by Major Publicly Owned Electric Utility Within State, 1991 (Continued)

(Megawatthours)

\begin{tabular}{|c|c|c|c|c|c|c|}
\hline ltom & $\begin{array}{l}\text { Arkansas } \\
\text { Conway } \\
\text { Corp } \\
\text { December } 31\end{array}$ & $\begin{array}{c}\text { Arkansas } \\
\text { Hope } \\
\text { City of } \\
\text { December } 31\end{array}$ & $\begin{array}{c}\text { Arkansas } \\
\text { Jonesboro } \\
\text { City of }\end{array}$ & $\begin{array}{c}\text { Arkansas } \\
\text { North } \\
\text { Little } \\
\text { Rock } \\
\text { City of } \\
\text { December } 31\end{array}$ & $\begin{array}{c}\text { Arkansas } \\
\text { Osceola } \\
\text { City of } \\
\text { December } 31\end{array}$ & $\begin{array}{l}\text { Arkansas } \\
\text { Paragould } \\
\text { Light } \\
\&\end{array}$ \\
\hline 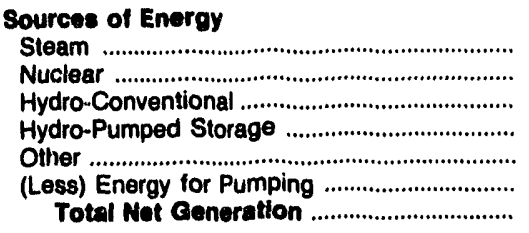 & $\begin{array}{r}350,785 \\
0 \\
0 \\
0 \\
0 \\
0 \\
350,785\end{array}$ & $\begin{array}{l}0 \\
0 \\
0 \\
0 \\
0 \\
0 \\
0\end{array}$ & $\begin{array}{r}315,300 \\
0 \\
0 \\
0 \\
0 \\
0 \\
315,300\end{array}$ & $\begin{array}{r}0 \\
0 \\
140,908 \\
0 \\
0 \\
0 \\
140,808\end{array}$ & $\begin{array}{l}0 \\
0 \\
0 \\
0 \\
0 \\
0 \\
0\end{array}$ & $\begin{array}{r}0 \\
0 \\
0 \\
0 \\
147 \\
0 \\
147\end{array}$ \\
\hline 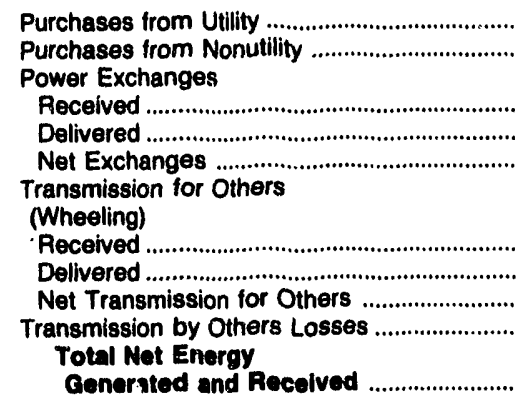 & $\begin{array}{r}91,241 \\
0\end{array}$ & $\begin{array}{r}172,795 \\
0\end{array}$ & $\begin{array}{r}742,472 \\
0\end{array}$ & $\begin{array}{r}667,194 \\
0\end{array}$ & $\begin{array}{r}165,338 \\
0\end{array}$ & $\begin{array}{r}314,924 \\
0\end{array}$ \\
\hline 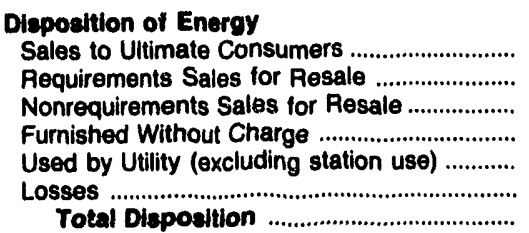 & $\begin{array}{r}404,251 \\
0 \\
0 \\
0 \\
0 \\
37,775 \\
442,026\end{array}$ & $\begin{array}{r}161,012 \\
0 \\
0 \\
3,736 \\
0 \\
8,047 \\
172,795\end{array}$ & $\begin{array}{r}680,048 \\
0 \\
328,450 \\
6,683 \\
11,156 \\
31,435 \\
1,057,772\end{array}$ & $\begin{array}{r}772,833 \\
0 \\
0 \\
0 \\
0 \\
35,269 \\
808,102\end{array}$ & $\begin{array}{r}158,663 \\
0 \\
0 \\
2,340 \\
4,335 \\
0 \\
165,338\end{array}$ & $\begin{array}{r}308,152 \\
0 \\
0 \\
0 \\
0 \\
6,919 \\
315,071\end{array}$ \\
\hline
\end{tabular}

Note: Totals may not equal sum of components because of independent rounding. Double counting occurs in components of both sources and disposition of energy and thus neither provides a true total. Purchases from utilities, net interchanges, and net wheeling (except for imports) are included in net generation. Sales for resale is included in sales to ultimate consumers.

Source: Energy Information Administration, Form EIA-412, "Annual Report of Public Electric Utilities." 

Table 41. Electric Energy Account by Major Publicly Owned Electric
Utility Within State, 1991 (Continued)

(Megawatthours)

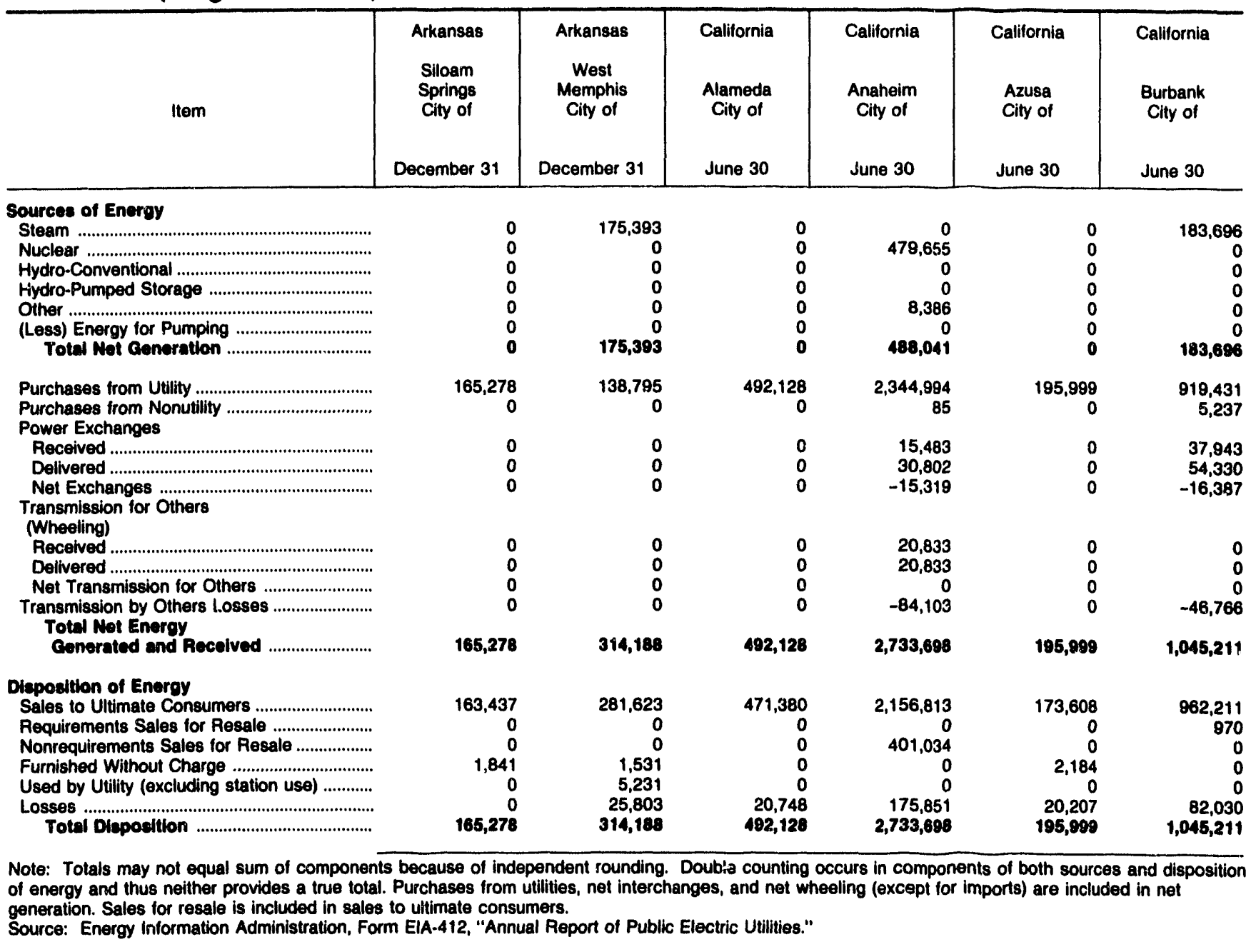


Table 41. Electric Energy Account by Major Publicly Owned Electric Utility Within State, 1991 (Continued) (Megawatthours)

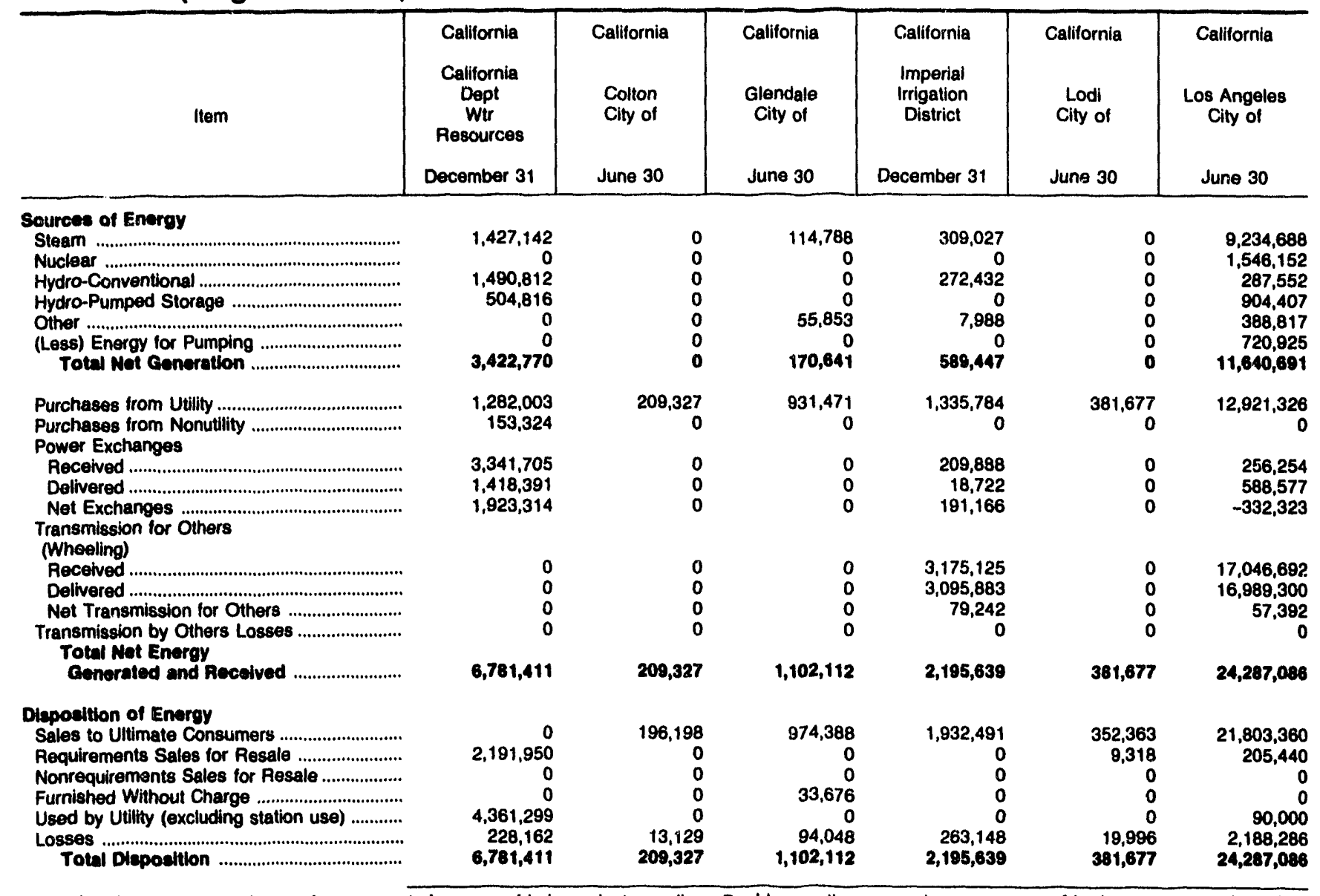

Note: Totals may not equal sum of components because of independent rounding. Double counting occurs in components of both sources and disposition of energy and thus neither provides a true total. Purchases from utilities, net interchanges, and net wheeling (except for imports) are included in net generation. Sales for resale is included in sales to ultimate consumers.

Source: Energy Information Administration, Form ElA-412, "Annual Report of Public Electric Utilities." 
Table 41. Electric Energy Account by Major Publicly Owned Electric Utility Within State, 1991 (Continued)

(Megawatthours)

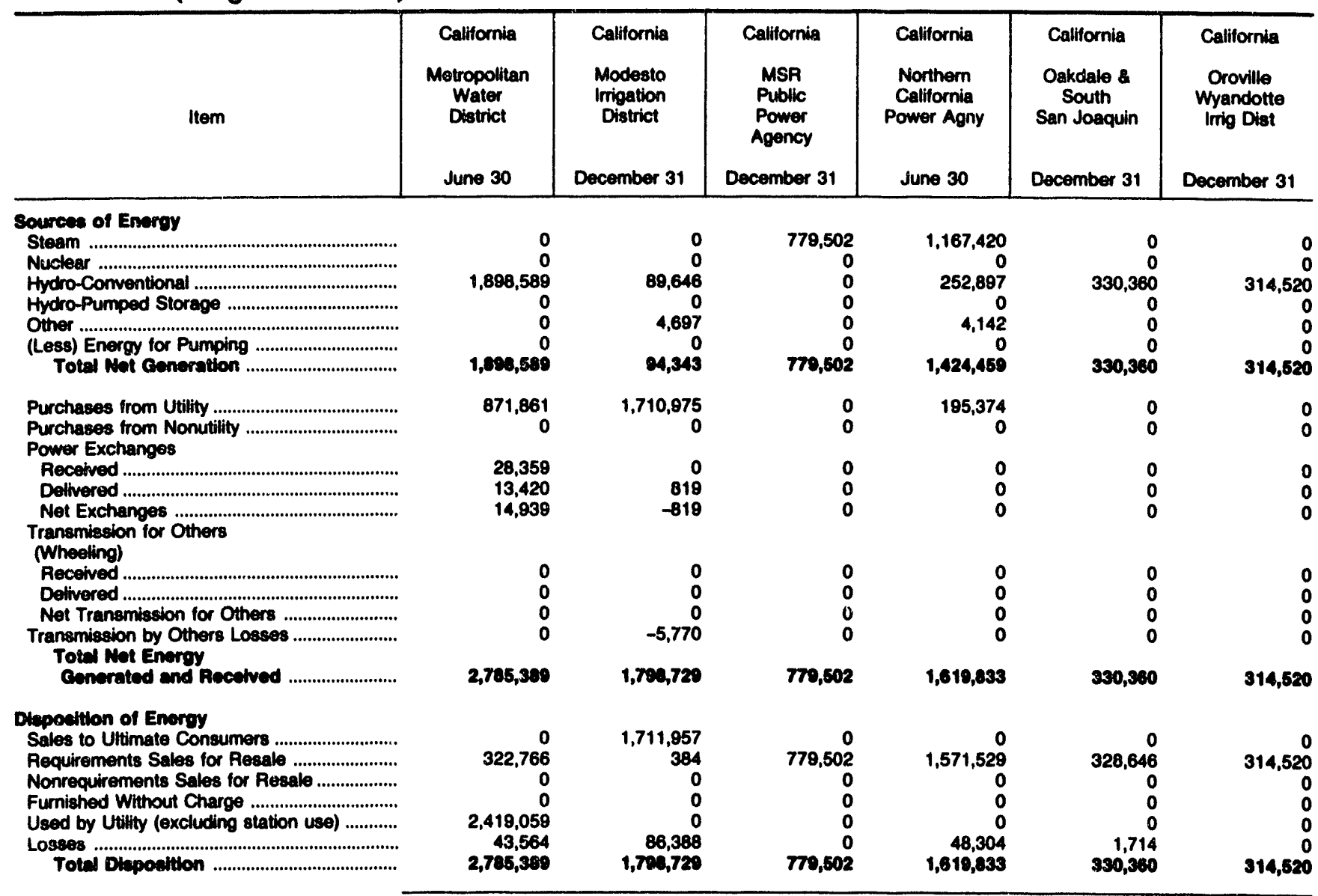

Note: Totals may not equal sum of components because of independent rounding. Double counting occurs in components of both sources and disposition of energy and thus neither provides a true total. Purchases irom utilities, net interchanges, and not wheeling (except for imports) are included in net generation. Seles for resale is inchuded in sales to ultimate consumers.

Source: Energy Information Administration, Form ElA-412, "Annual Report of Public Electric Utilities." 

Table 41. Electric Energy Account by Major Publicly Owned Electric
Utility Within State, 1991 (Continued)

(Megawatthours)

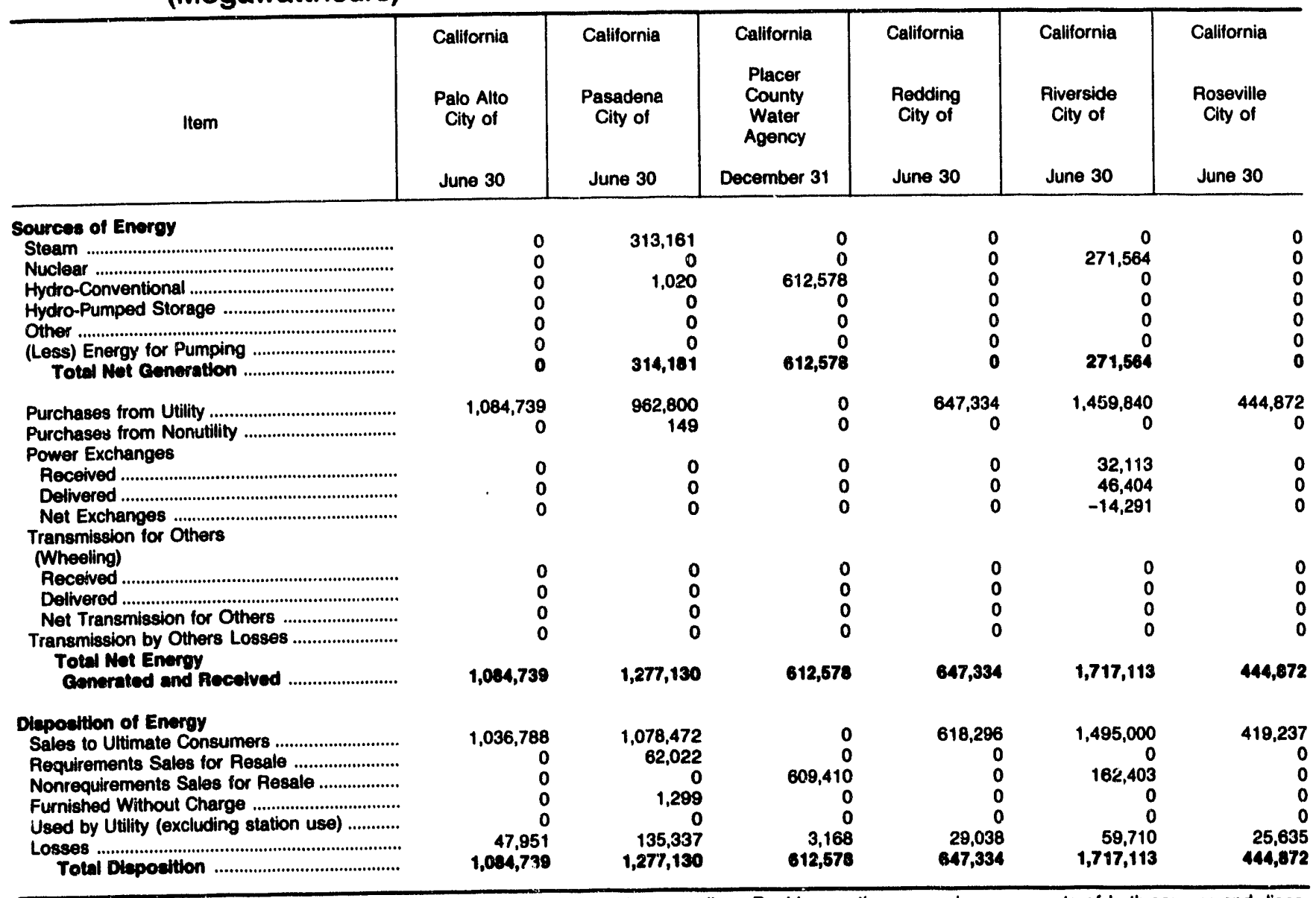

Note: Totals may not equal sum of components because of independent rounding. Double counting occurs in components of both sources and disposition of energy and thus neither provides a true total. Purchases from utilities, net interchanges, and net wheeling (except for imports) are included in net generation. Sales for resale is included in sales to ultimate consumers.

Source: Energy Information Administration, Form EIA-412, "Annual Report of Public Electric Utilities." 
Table 41. Electric Energy Account by Major Publicly Owned Electric Utility Within State, 1991 (Continued) (Megawatthours)

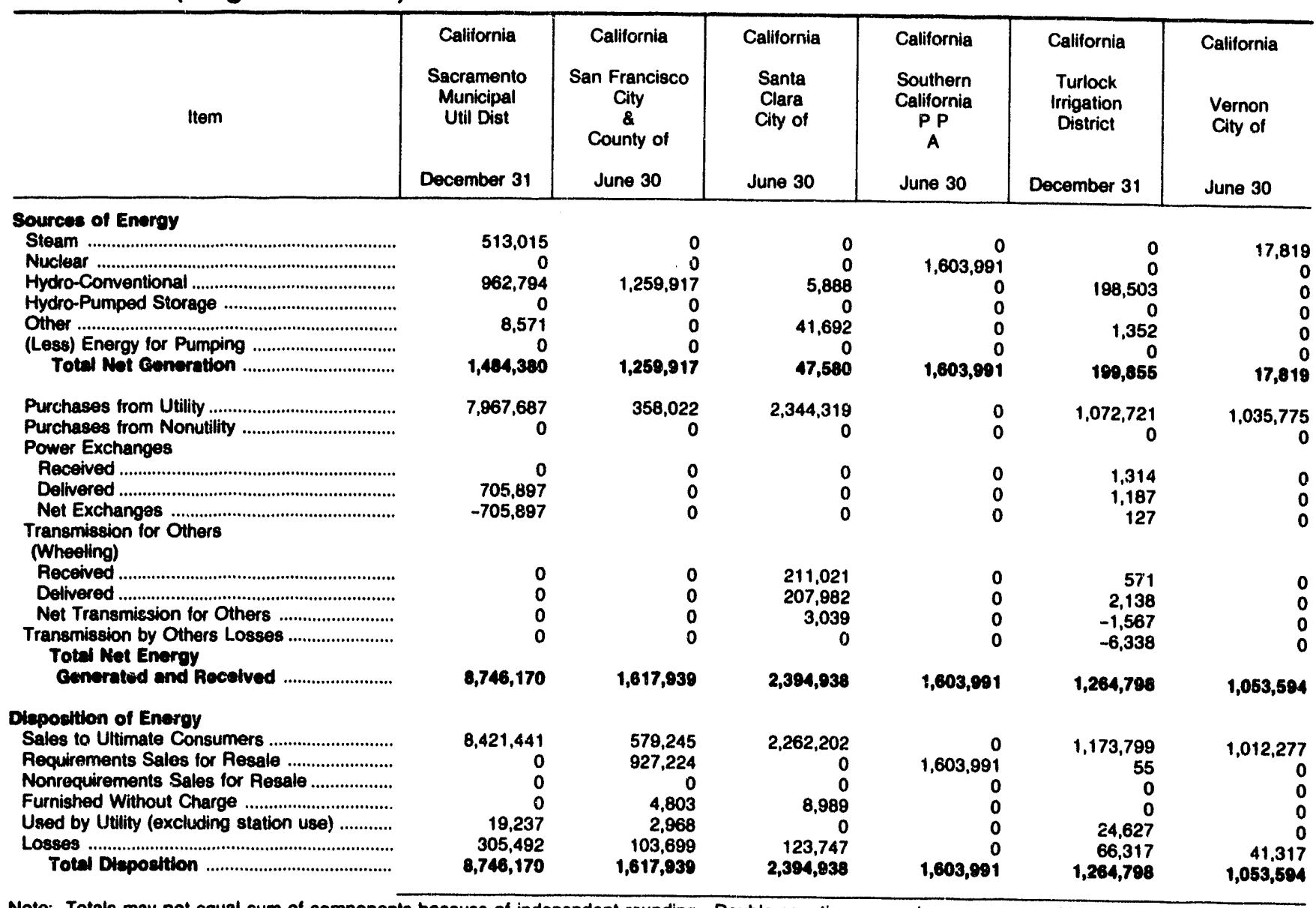

Note: Totals may not equal sum of components because of independent rounding. Double counting occurs in components of both sources and disposition of energy and thus neither provides a true total. Purchases from utilities, net interctianges, and net wheeling (except for imports) are included in net generation. Sales for resale is included in sales to ultimate consumers.

Source: Energy Information Administration, Form ElA-412, "Annual Report of Public Electric Utilities." 

Table 41. Electric Energy Account by Major Publicly Owned Electric
Utility Within State, 1991 (Continued) (Megawatthours)

\begin{tabular}{|c|c|c|c|c|c|c|}
\hline Item & $\begin{array}{l}\text { California } \\
\text { Yuba } \\
\text { County } \\
\text { Water } \\
\text { Agency } \\
\text { June } 30\end{array}$ & $\begin{array}{l}\text { Colorado } \\
\text { Arkansas } \\
\text { Piver } \\
\text { Power } \\
\text { Authority } \\
\text { December } 31\end{array}$ & $\begin{array}{c}\text { Colorado } \\
\text { Colorado } \\
\text { Springs } \\
\text { City of } \\
\text { December } 31\end{array}$ & $\begin{array}{l}\text { Colorado } \\
\text { Fort Collins } \\
\text { City of } \\
\text { December } 31\end{array}$ & $\begin{array}{l}\text { Colorado } \\
\text { Longmont } \\
\text { City of } \\
\text { December } 31\end{array}$ & $\begin{array}{l}\text { Colorado } \\
\text { Loveland } \\
\text { City of } \\
\text { December } 31\end{array}$ \\
\hline 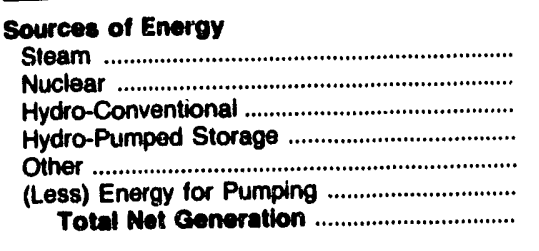 & $\begin{array}{r}0 \\
0 \\
698,261 \\
0 \\
0 \\
0 \\
698,261\end{array}$ & $\begin{array}{l}0 \\
0 \\
0 \\
0 \\
0 \\
0 \\
0\end{array}$ & $\begin{array}{r}2,644,992 \\
0 \\
23,396 \\
0 \\
0 \\
0 \\
2,668,388\end{array}$ & $\begin{array}{l}0 \\
0 \\
0 \\
0 \\
0 \\
0 \\
0\end{array}$ & $\begin{array}{r}0 \\
0 \\
3,920 \\
0 \\
0 \\
0 \\
3,920\end{array}$ & $\begin{array}{r}0 \\
0 \\
1,294 \\
0 \\
0 \\
0 \\
1,294\end{array}$ \\
\hline 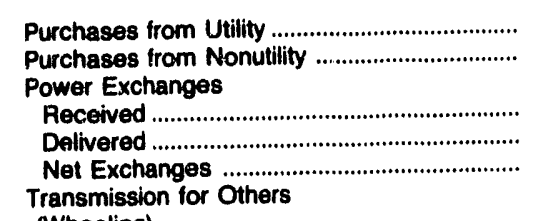 & $\begin{array}{l}0 \\
0 \\
0\end{array}$ & $\begin{array}{r}274,012 \\
0 \\
0 \\
0 \\
0\end{array}$ & $\begin{array}{r}476,112 \\
0 \\
5,671 \\
28,280 \\
-22,609\end{array}$ & $\begin{array}{r}834,696 \\
0\end{array}$ & $\begin{array}{r}412,857 \\
0\end{array}$ & $\begin{array}{r}374,906 \\
0 \\
0 \\
0 \\
0\end{array}$ \\
\hline 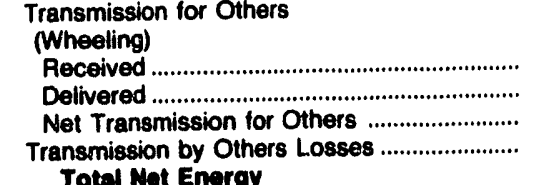 & $\begin{array}{l}0 \\
0 \\
0 \\
0\end{array}$ & $\begin{array}{l}0 \\
0 \\
0 \\
0\end{array}$ & $\begin{array}{r}28,411 \\
28,411 \\
0 \\
0\end{array}$ & $\begin{array}{l}0 \\
0 \\
0 \\
0\end{array}$ & $\begin{array}{l}0 \\
0 \\
0 \\
0\end{array}$ & $\begin{array}{l}0 \\
0 \\
0 \\
0\end{array}$ \\
\hline 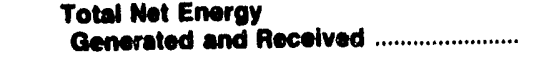 & 698,261 & 274,012 & $3,121,891$ & 834,696 & 416,777 & 376,200 \\
\hline 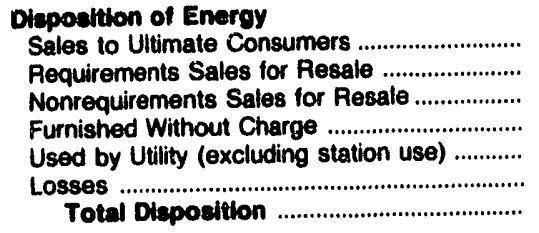 & $\begin{array}{r}0 \\
694,481 \\
0 \\
0 \\
0 \\
3,780 \\
688,261\end{array}$ & $\begin{array}{r}0 \\
263,863 \\
0 \\
0 \\
0 \\
10,149 \\
274,012\end{array}$ & $\begin{array}{r}2,899,022 \\
108,649 \\
0 \\
0 \\
0 \\
114,220 \\
3,121,891\end{array}$ & $\begin{array}{r}815,311 \\
0 \\
0 \\
6,025 \\
0 \\
13,360 \\
834,686\end{array}$ & $\begin{array}{r}399,478 \\
0 \\
0 \\
5,548 \\
0 \\
11,751 \\
416,777\end{array}$ & $\begin{array}{r}369,369 \\
0 \\
0 \\
5,000 \\
0 \\
1,831 \\
378,200\end{array}$ \\
\hline
\end{tabular}

Note: Totals may not equal sum of components because of independent rounding. Double counting occurs in components of both sources and disposition of energy and thus neither provides a true total. Purchases from utilities, net interchanges, and net wheeling (except for imports) are included in net generation. Sales for resale is included in sales to ultimate consumers.

Source: Energy Information Administration, Form EIA-412, "Annual Report of Public Electric Utilities." 
Table 41. Electric Energy Account by Major Publicly Owned Electric
Utility Within State, 1991 (Continued) (Megawatthours)

\begin{tabular}{|c|c|c|c|c|c|c|}
\hline Item & $\begin{array}{l}\text { Colorado } \\
\text { Platte River } \\
\text { Power } \\
\text { Authority } \\
\text { December } 31\end{array}$ & $\begin{array}{l}\text { Connecticut } \\
\text { Connecticut } \\
\text { Mun } \\
\text { Elec } \\
\text { Engy Coop } \\
\text { December } 31\end{array}$ & $\begin{array}{l}\text { Connecticut } \\
\text { Groton } \\
\text { City of } \\
\text { June } 30\end{array}$ & $\begin{array}{l}\text { Connecticut } \\
\text { Nonwich } \\
\text { City of } \\
\text { June } 30\end{array}$ & $\begin{array}{l}\text { Connecticut } \\
\text { Wallingford } \\
\text { Town of } \\
\text { June } 30\end{array}$ & $\begin{array}{l}\text { Delaware } \\
\text { Dover } \\
\text { City of } \\
\text { June } 30\end{array}$ \\
\hline 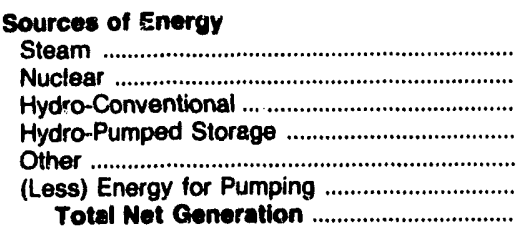 & $\begin{array}{r}2,578,696 \\
0 \\
0 \\
0 \\
0 \\
0 \\
2,578,696\end{array}$ & $\begin{array}{r}0 \\
31,597 \\
0 \\
0 \\
0 \\
0 \\
31,597\end{array}$ & $\begin{array}{l}0 \\
0 \\
0 \\
0 \\
0 \\
0 \\
0\end{array}$ & $\begin{array}{r}0 \\
0 \\
14,570 \\
0 \\
0 \\
0 \\
14,570\end{array}$ & $\begin{array}{r}455 \\
0 \\
0 \\
0 \\
0 \\
0 \\
455\end{array}$ & $\begin{array}{r}394,371 \\
0 \\
0 \\
0 \\
0 \\
0 \\
394,371\end{array}$ \\
\hline 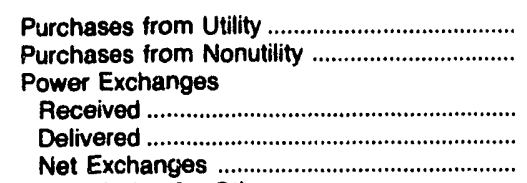 & $\begin{array}{r}3,840 \\
39,496 \\
-35,656\end{array}$ & $\begin{array}{r}771,046 \\
0 \\
304,116 \\
27,985 \\
276,131\end{array}$ & $\begin{array}{r}655,707 \\
0\end{array}$ & $\begin{array}{r}269,363 \\
0\end{array}$ & $\begin{array}{r}534,894 \\
0\end{array}$ & $\begin{array}{r}154,935 \\
80,270 \\
74,665\end{array}$ \\
\hline 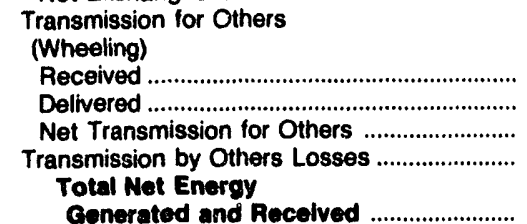 & $\begin{array}{l}0 \\
0 \\
0 \\
0\end{array}$ & $\begin{array}{l}0 \\
0 \\
0 \\
0\end{array}$ & $\begin{array}{l}0 \\
0 \\
0 \\
0\end{array}$ & $\begin{array}{l}0 \\
0 \\
0 \\
0\end{array}$ & $\begin{array}{l}0 \\
0 \\
0 \\
0\end{array}$ & $\begin{array}{r}0 \\
0 \\
0 \\
0 \\
523,836\end{array}$ \\
\hline 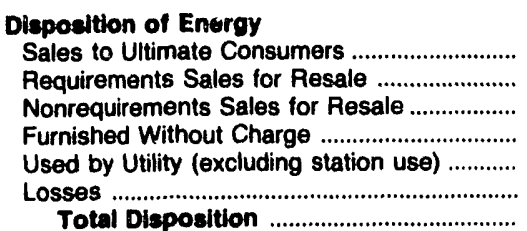 & $\begin{array}{r}0 \\
2,954,701 \\
339,273 \\
0 \\
4,335 \\
34,150 \\
3,332,459\end{array}$ & $\begin{array}{r}0 \\
1,074,828 \\
0 \\
0 \\
0 \\
3,946 \\
1,078,774\end{array}$ & $\begin{array}{r}635,883 \\
3,851 \\
0 \\
1,015 \\
668 \\
14,290 \\
655,707\end{array}$ & $\begin{array}{r}267,204 \\
0 \\
0 \\
0 \\
0 \\
16,724 \\
283,933\end{array}$ & $\begin{array}{r}514,960 \\
0 \\
0 \\
0 \\
0 \\
20,389 \\
535,349\end{array}$ & $\begin{array}{r}443,666 \\
80,270 \\
0 \\
0 \\
0 \\
0 \\
523,936\end{array}$ \\
\hline
\end{tabular}

Note: Totals may not equal sum of components because of independent rounding. Double counting occurs in components of both sources and disposition of energy and thus neither provides a true total. Purchases from utilities, net interchanges, and net wheeling (except for imports) are included in net generation. Sales for resale is included in sales to ultimate consumers.

Source: Energy Information Administration, Form EIA-412, "Annual Report of Public Electric Utilities." 


\section{Table 41. Electric Energy Account by Major Publicly Owned Electric}

Utility Within State, 1991 (Continued)

(Megawatthours)

\begin{tabular}{|c|c|c|c|c|c|c|}
\hline Item & $\begin{array}{l}\text { Delaware } \\
\text { Newark } \\
\text { City of } \\
\text { December } 31\end{array}$ & $\begin{array}{l}\text { Florida } \\
\text { Bartow } \\
\text { City of } \\
\text { September } 30\end{array}$ & $\begin{array}{c}\text { Florida } \\
\text { Florida } \\
\text { Municipal } \\
\text { Power Agency } \\
\text { September } 30\end{array}$ & $\begin{array}{l}\text { Florida } \\
\text { Fort Pierce } \\
\text { Utilities } \\
\text { Auth } \\
\text { September } 30\end{array}$ & $\begin{array}{l}\text { Florida } \\
\text { Gainesville } \\
\text { Regional } \\
\text { Utilities } \\
\text { September } 30\end{array}$ & $\begin{array}{c}\text { Florida } \\
\text { Homestead } \\
\text { City of } \\
\text { September } 30\end{array}$ \\
\hline 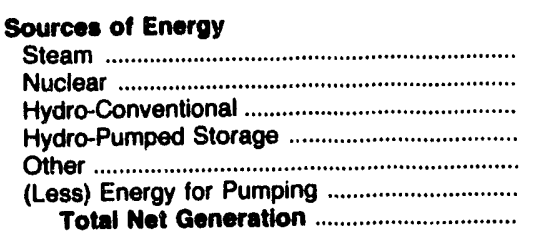 & $\begin{array}{l}0 \\
0 \\
0 \\
0 \\
0 \\
0 \\
0\end{array}$ & $\begin{array}{l}0 \\
0 \\
0 \\
0 \\
0 \\
0 \\
0\end{array}$ & $\begin{array}{r}749,655 \\
530,028 \\
0 \\
0 \\
22,127 \\
0 \\
1,301,810\end{array}$ & $\begin{array}{r}279,825 \\
0 \\
0 \\
0 \\
615 \\
0 \\
280,440\end{array}$ & $\begin{array}{r}1,797,634 \\
86,752 \\
0 \\
0 \\
31,119 \\
0 \\
1,915,505\end{array}$ & $\begin{array}{r}0 \\
0 \\
0 \\
0 \\
98,679 \\
0 \\
98,679\end{array}$ \\
\hline $\begin{array}{l}\text { Purchases from Utility } \\
\text { Purchases from Nonutility } \\
\text { Power Exchanges } \\
\text { Received } \\
\text { Delivered } \\
\text { Net Exchanges }\end{array}$ & $\begin{array}{r}278,087 \\
0\end{array}$ & $\begin{array}{r}250,440 \\
0\end{array}$ & $\begin{array}{r}1,941,125 \\
0\end{array}$ & $\begin{array}{r}291,708 \\
0\end{array}$ & $\begin{array}{r}76,290 \\
0\end{array}$ & $\begin{array}{r}205,572 \\
0\end{array}$ \\
\hline 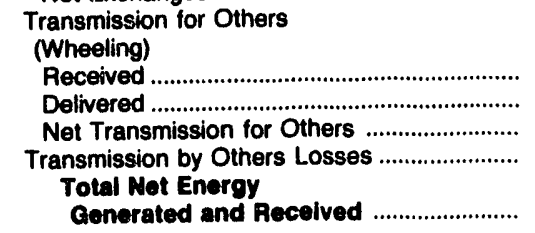 & $\begin{array}{l}0 \\
0 \\
0 \\
0\end{array}$ & 250,440 & $3,242,935$ & 572,148 & $1,991,795$ & 304,251 \\
\hline 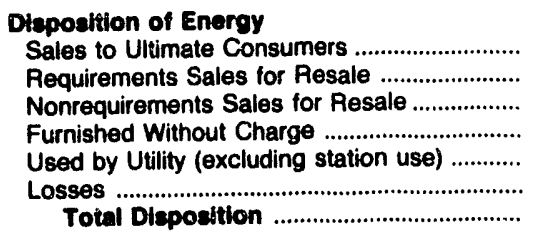 & $\begin{array}{r}257,575 \\
0 \\
0 \\
5,872 \\
0 \\
14,640 \\
278,087\end{array}$ & $\begin{array}{r}227,963 \\
0 \\
0 \\
0 \\
0 \\
22,477 \\
250,440\end{array}$ & $\begin{array}{r}0 \\
3,048,672 \\
0 \\
0 \\
0 \\
194,263 \\
3,242,935\end{array}$ & $\begin{array}{r}496,475 \\
0 \\
58,756 \\
0 \\
907 \\
16,010 \\
572,148\end{array}$ & $\begin{array}{r}1,240,708 \\
89,748 \\
582,206 \\
0 \\
0 \\
79,133 \\
1,991,795\end{array}$ & $\begin{array}{r}233,945 \\
38,183 \\
0 \\
6,204 \\
0 \\
25,919 \\
304,251\end{array}$ \\
\hline
\end{tabular}

Note: Totals may not equal sum of components because of independent rounding. Double counting occurs in components of both sources and disposition of energy and thus neither provides a true total. Purchases from utilities, net interchanges, and net wheeling (except for imports) are included in net generation. Sales for resale is included in sales to ultimate consumers.

Source: Energy Information Administration, Form ElA-412, "Annual Report of Public Electric Utilities." 

Table 41. Electric Energy Account by Major Publicly Owned Electric
Utility Within State, 1991 (Continued)

(Megawatthours)

\begin{tabular}{|c|c|c|c|c|c|c|}
\hline Item & $\begin{array}{c}\text { Florida } \\
\text { Jacksonville } \\
\text { Beach } \\
\text { City of } \\
\text { September } 30\end{array}$ & $\begin{array}{c}\text { Florida } \\
\text { Jacksonville } \\
\text { Electric } \\
\text { Auth } \\
\text { September } 30\end{array}$ & $\begin{array}{c}\text { Florida } \\
\text { Key West } \\
\text { City of } \\
\text { Seplember } 30\end{array}$ & $\begin{array}{c}\text { Florida } \\
\text { Kissimmee } \\
\text { Utility } \\
\text { Authority } \\
\text { September } 30\end{array}$ & $\begin{array}{c}\text { Florida } \\
\text { Lake Worth } \\
\text { City of } \\
\text { September } 30\end{array}$ & $\begin{array}{l}\text { Florida } \\
\text { Lakeland } \\
\text { City of } \\
\text { September } 30\end{array}$ \\
\hline \multicolumn{7}{|l|}{ Sources of Energy } \\
\hline 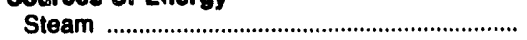 & 0 & $7,181,860$ & 125,128 & 129,503 & 158,290 & $1,638,367$ \\
\hline Nuclear & 0 & 0 & 0 & 40,222 & 0 & 0 \\
\hline 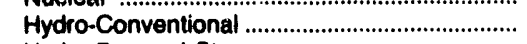 & 0 & 0 & 0 & $\begin{array}{r}70.626 \\
0\end{array}$ & 0 & 0 \\
\hline 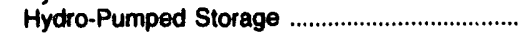 & 0 & 0 & $\mathbf{0}$ & 0 & 0 & 0 \\
\hline Other & $\mathbf{0}$ & 7,370 & 22,430 & 105,706 & 1,493 & 50,671 \\
\hline 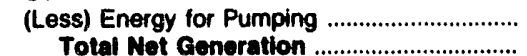 & $\begin{array}{l}\mathbf{0} \\
\mathbf{0}\end{array}$ & $\begin{array}{r}0 \\
7,189,230\end{array}$ & $\begin{array}{r}0 \\
147,558\end{array}$ & $\begin{array}{r}0 \\
275,431\end{array}$ & $\begin{array}{r}0 \\
159783\end{array}$ & 0 \\
\hline 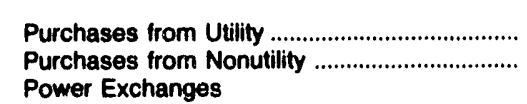 & $\begin{array}{r}487,965 \\
0\end{array}$ & $\begin{array}{r}1,592,573 \\
9,053\end{array}$ & $\begin{array}{r}371,102 \\
6,455\end{array}$ & $\begin{array}{r}443,781 \\
0\end{array}$ & $\begin{array}{r}200,738 \\
0\end{array}$ & $\begin{array}{r}349,340 \\
0\end{array}$ \\
\hline 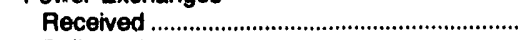 & 0 & $\mathbf{0}$ & 0 & 0 & 0 & 0 \\
\hline 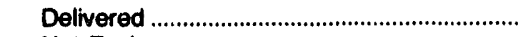 & 0 & $\mathbf{0}$ & 0 & 0 & 0 & 0 \\
\hline 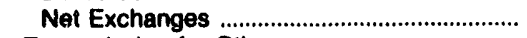 & $\mathbf{0}$ & $\mathbf{0}$ & $\mathbf{0}$ & 0 & 0 & 0 \\
\hline \multicolumn{7}{|l|}{$\begin{array}{l}\text { Transmission for Others } \\
\text { (Wheeling) }\end{array}$} \\
\hline Received & 0 & 0 & 0 & 0 & 0 & 0 \\
\hline 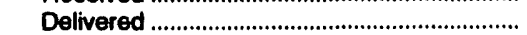 & 0 & 0 & 0 & 0 & 0 & 0 \\
\hline 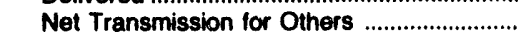 & 0 & 0 & 0 & 0 & 0 & 0 \\
\hline $\begin{array}{l}\text { Transmission by Others Losses ........................ } \\
\text { Total Net Energy }\end{array}$ & 0 & 0 & 0 & 0 & -5 & 0 \\
\hline Generated and Recelved ........................ & 487,965 & $8,790,856$ & 525,115 & 719,212 & 360,516 & $2,038,378$ \\
\hline \multicolumn{7}{|l|}{ Disposition of Energy } \\
\hline 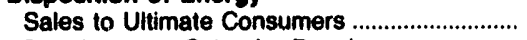 & 455,057 & $7,751,649$ & 492,847 & 678,602 & 312,720 & $1,891,258$ \\
\hline 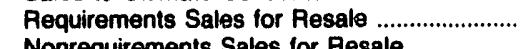 & 0 & 228,013 & 0 & 0 & 26,863 & \\
\hline Nonrequirements Sales for Resale ................... & 0 & 359,173 & 28 & 231 & 0 & 16,404 \\
\hline 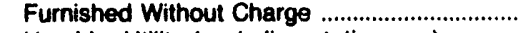 & 0 & 0 & 0 & 0 & 0 & 0 \\
\hline Used by Utility (excluding station use) ............ & $\mathbf{0}$ & 12,921 & 1,037 & 0 & 0 & $\mathbf{0}$ \\
\hline $\begin{array}{l}\text { Losses } \\
\text { Totel Diaposition }\end{array}$ & $\begin{array}{r}32,908 \\
487,965\end{array}$ & $\begin{array}{r}439,100 \\
8,790,856\end{array}$ & $\begin{array}{r}31,203 \\
525,115\end{array}$ & $\begin{array}{r}40,379 \\
719,212\end{array}$ & $\begin{array}{r}20,933 \\
390,516\end{array}$ & $\begin{array}{r}130,716 \\
2,038,378\end{array}$ \\
\hline
\end{tabular}


Table 41. Electric Energy Account by Major Publicly Owned Electric Utility Within State, 1991 (Continued)

(Megawatthours)

\begin{tabular}{|c|c|c|c|c|c|c|}
\hline Item & $\begin{array}{c}\text { Florida } \\
\text { Leesburg } \\
\text { City of } \\
\text { September } 30\end{array}$ & $\begin{array}{c}\text { Florida } \\
\text { New Smyına } \\
\text { Beach } \\
\text { Utils Comm } \\
\text { September } 30\end{array}$ & $\begin{array}{l}\text { Florida } \\
\text { Ocala } \\
\text { City of } \\
\text { September } 30\end{array}$ & $\begin{array}{l}\text { Florida } \\
\text { Orlando } \\
\text { Utilities } \\
\text { Comm } \\
\text { September } 30\end{array}$ & $\begin{array}{l}\text { Florida } \\
\text { Quincy } \\
\text { City of } \\
\text { September } 30\end{array}$ & $\begin{array}{l}\text { Florida } \\
\text { St Cloud } \\
\text { City of } \\
\text { September } 30\end{array}$ \\
\hline 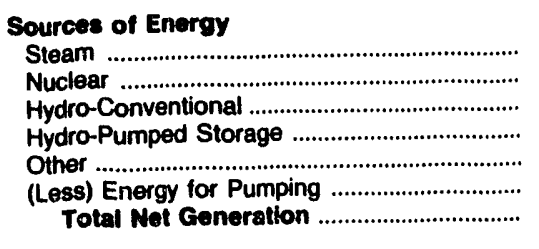 & $\begin{array}{r}0 \\
71,081 \\
0 \\
0 \\
0 \\
0 \\
71,081\end{array}$ & $\begin{array}{r}0 \\
32,079 \\
0 \\
0 \\
10,938 \\
0 \\
43,017\end{array}$ & $\begin{array}{r}0 \\
94,768 \\
0 \\
0 \\
0 \\
0 \\
94,768\end{array}$ & $\begin{array}{r}4,490,539 \\
480,297 \\
0 \\
0 \\
24,761 \\
0 \\
4,995,597\end{array}$ & $\begin{array}{l}0 \\
0 \\
0 \\
0 \\
0 \\
0 \\
0\end{array}$ & $\begin{array}{r}0 \\
0 \\
0 \\
0 \\
42,957 \\
0 \\
42,957\end{array}$ \\
\hline 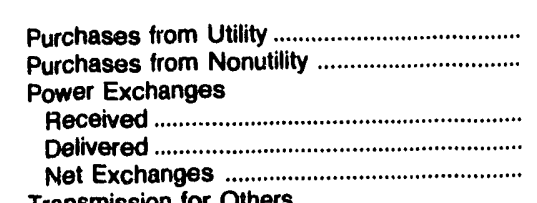 & $\begin{array}{r}298,213 \\
0\end{array}$ & $\begin{array}{r}251,452 \\
0 \\
0 \\
0 \\
0\end{array}$ & $\begin{array}{r}845,033 \\
0\end{array}$ & $\begin{array}{r}203,403 \\
0\end{array}$ & $\begin{array}{r}142,000 \\
0\end{array}$ & $\begin{array}{r}167,979 \\
0\end{array}$ \\
\hline 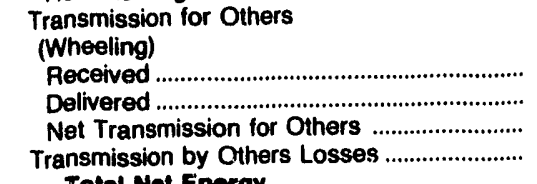 & $\begin{array}{l}0 \\
0 \\
0 \\
0\end{array}$ & $\begin{array}{r}0 \\
0 \\
0 \\
-8,128\end{array}$ & $\begin{array}{l}0 \\
0 \\
0 \\
0\end{array}$ & $\begin{array}{r}350,451 \\
342,460 \\
7,991 \\
-7,991\end{array}$ & $\begin{array}{l}0 \\
0 \\
0 \\
0\end{array}$ & $\begin{array}{r}0 \\
0 \\
0 \\
-1,618\end{array}$ \\
\hline 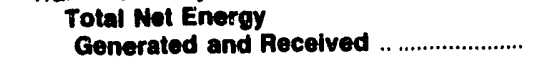 & 369,294 & 286,341 & 939,801 & $5,199,000$ & 142,000 & 209,318 \\
\hline 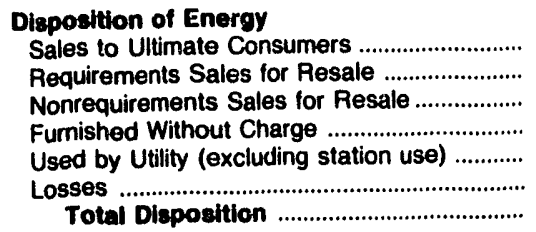 & $\begin{array}{r}360,940 \\
0 \\
0 \\
0 \\
0 \\
8,354 \\
369,294\end{array}$ & $\begin{array}{r}266,774 \\
224 \\
0 \\
0 \\
0 \\
19,343 \\
286,341\end{array}$ & $\begin{array}{r}886,348 \\
0 \\
0 \\
0 \\
0 \\
53,453 \\
939,801\end{array}$ & $\begin{array}{r}3,546,436 \\
73,308 \\
1,495,813 \\
0 \\
0 \\
83,443 \\
5,199,000\end{array}$ & $\begin{array}{r}142,000 \\
0 \\
0 \\
0 \\
0 \\
0 \\
142,000\end{array}$ & $\begin{array}{r}197,638 \\
0 \\
66 \\
0 \\
0 \\
11,614 \\
209,318\end{array}$ \\
\hline
\end{tabular}

Note: Totals may not equal sum of components because of independent rounding. Double counting occurs in components of both sources and disposition of energy and thus neither provides a true total. Purchases from utiities, net interchanges, and net wheeling (except for imports) are included in net generation. Sales for resale is included in sales to ultimate consumers.

Source: Energy Information Administration, Form EIA-412, "Annual Report of Public Electric Utilities." 
Table 41. Electric Energy Account by Major Publicly Owned Electric Utility Within State, 1991 (Continued) (Megawatthours)

\begin{tabular}{|c|c|c|c|c|c|c|}
\hline Item & $\begin{array}{l}\text { Florida } \\
\text { Tallahassee } \\
\text { City of } \\
\text { September } 30\end{array}$ & $\begin{array}{l}\text { Florida } \\
\text { Vero } \\
\text { Beach } \\
\text { City of } \\
\text { September } 30\end{array}$ & $\begin{array}{l}\text { Georgia } \\
\text { Albany Water } \\
\text { Gas \& Light } \\
\text { Comm } \\
\text { June } 30\end{array}$ & $\begin{array}{l}\text { Georgia } \\
\text { Calhoun } \\
\text { City of } \\
\text { June } 30\end{array}$ & $\begin{array}{l}\text { Georgia } \\
\text { Cartersville } \\
\text { City of } \\
\text { June } 30\end{array}$ & $\begin{array}{l}\text { Georgia } \\
\text { College } \\
\text { Park City of } \\
\text { June } 30\end{array}$ \\
\hline 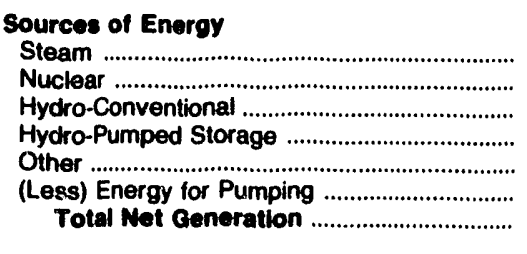 & $\begin{array}{r}1,485,697 \\
82,844 \\
29,716 \\
0 \\
0 \\
0 \\
1,598,257\end{array}$ & $\begin{array}{r}172,883 \\
0 \\
0 \\
0 \\
0 \\
0 \\
172,883\end{array}$ & $\begin{array}{l}0 \\
0 \\
0 \\
0 \\
0 \\
0 \\
0\end{array}$ & $\begin{array}{l}0 \\
0 \\
0 \\
0 \\
0 \\
0 \\
0\end{array}$ & $\begin{array}{l}0 \\
0 \\
0 \\
0 \\
0 \\
0 \\
0\end{array}$ & \\
\hline 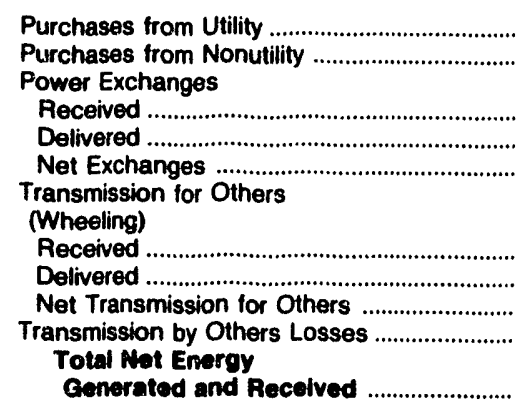 & $\begin{array}{r}570,721 \\
0\end{array}$ & $\begin{array}{r}354,372 \\
0\end{array}$ & $\begin{array}{r}883,554 \\
0\end{array}$ & $\begin{array}{r}277,833 \\
0\end{array}$ & $\begin{array}{r}350,283 \\
0\end{array}$ & $\begin{array}{r}272,413 \\
0\end{array}$ \\
\hline 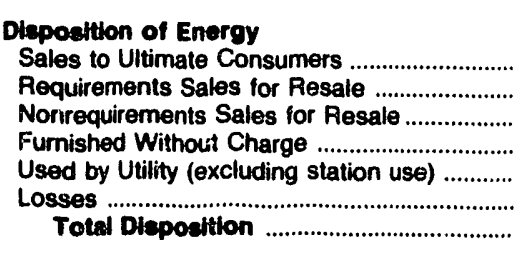 & $\begin{array}{r}1,828,287 \\
220,955 \\
0 \\
0 \\
0 \\
119,736 \\
2,168,978\end{array}$ & $\begin{array}{r}489,923 \\
0 \\
7,044 \\
0 \\
0 \\
30,288 \\
\mathbf{5 2 7 , 2 5 5}\end{array}$ & $\begin{array}{r}851,484 \\
0 \\
0 \\
0 \\
0 \\
32,070 \\
883,554\end{array}$ & $\begin{array}{r}271,286 \\
0 \\
0 \\
0 \\
0 \\
6,547 \\
277,833\end{array}$ & $\begin{array}{r}340,609 \\
0 \\
0 \\
0 \\
0 \\
9,674 \\
350,283\end{array}$ & $\begin{array}{r}248,849 \\
0 \\
0 \\
0 \\
17,049 \\
6,515 \\
272,413\end{array}$ \\
\hline
\end{tabular}

Note: Totals may not equal sum of components because of independent rounding. Double counting occurs in components of both sources and disposition of energy and thus neither provides a true total. Purchases from utilities, net interchanges, and net wheeling (except for imports) are included in net

Source: Energy Information Administration, Form EIA-412, "Annual Report of Public Electric Utilities." 
Table 41. Electric Energy Account by Major Publicly Owned Electric Utility Within State, 1991 (Continued)

(Megawatthours)

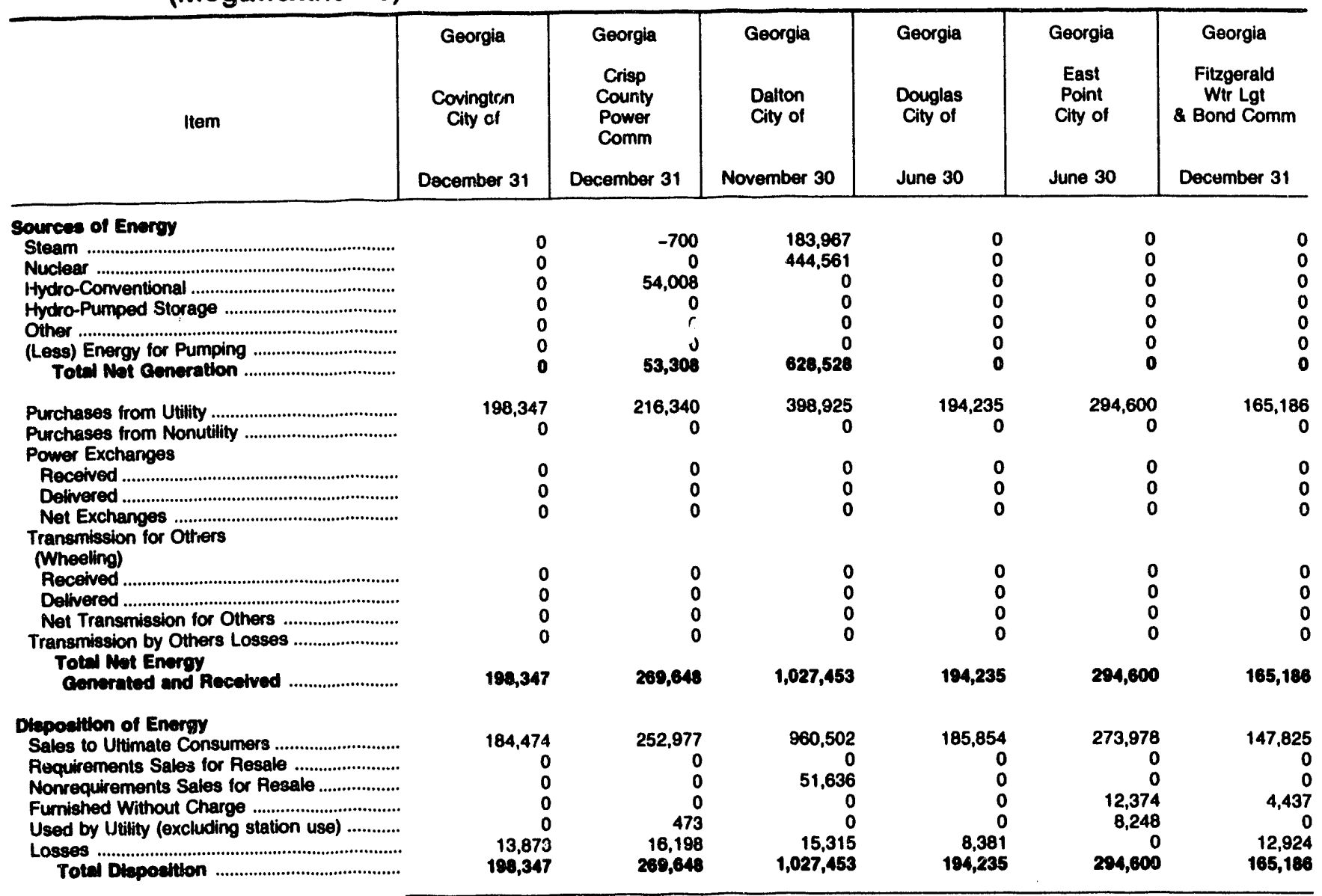

Note: Totals may not equal sum of cornponents because of independent rounding. Double counting occurs in components of both sources and disposition of energy und thus neither provides a true total. Purchases from utilities, net interchanges, and net wheeling (except for imports) are included in net generation. Sales for resale is included in sales to ultimate consumers.

Source: Energy Information Administration, Form EIA-412, "Annual Report of Public Electric Utilities." 
Table 41. Electric Energy Account by Major Publicly Owned Electric Utility Within State, 1991 (Continued)

(Megawatthours)

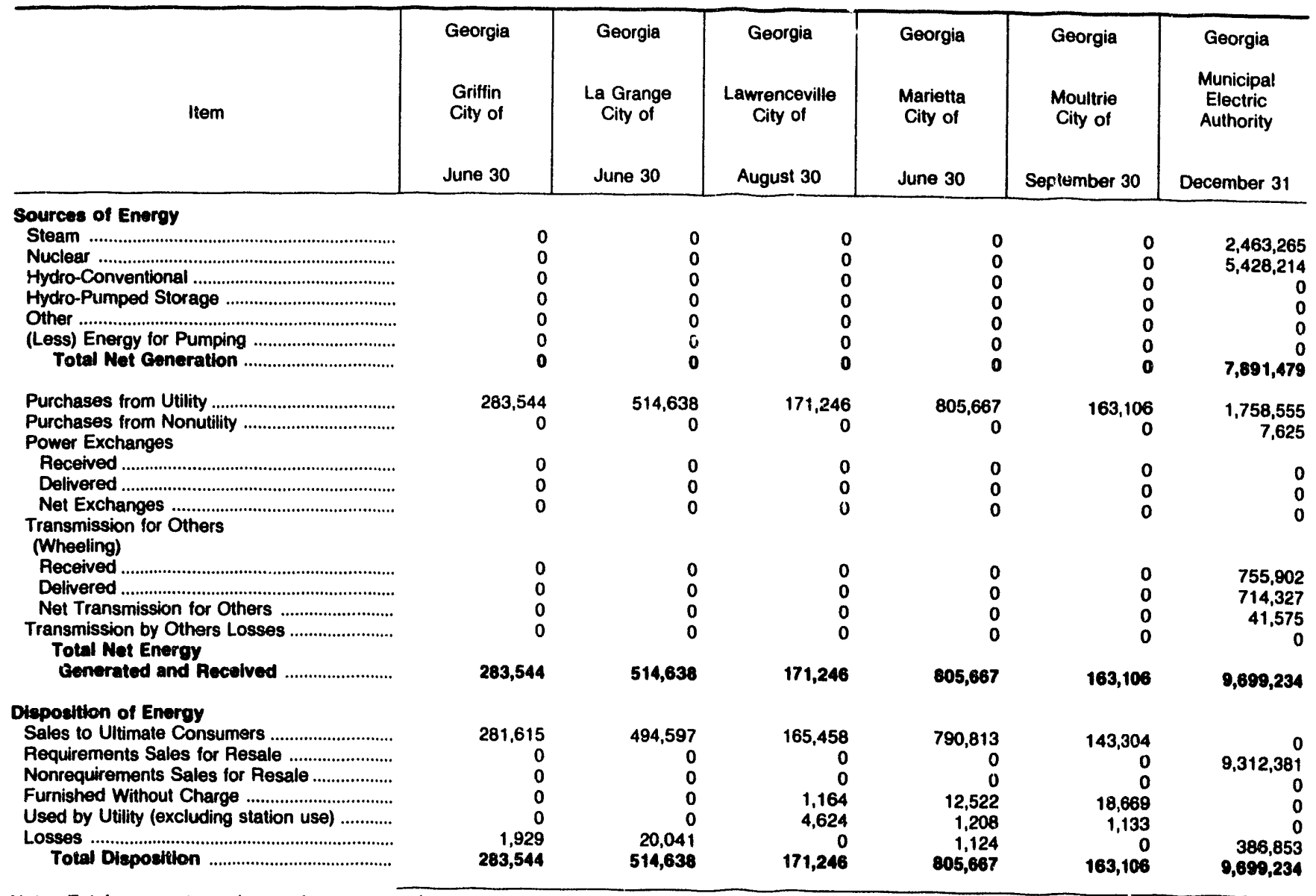

Note: Totals may not equal sum of components because of independent rounding. Double counting occurs in components of both sources and disposition of energy and thus neither provides a true total. Purchases from utilities, net interchanges, and net wheeling (except for imports) are included in net generation. Sales for resale is included in sales to ultimate consumers.

Source: Energy Information Administration, Form EIA-412, "Annual Report of Public Electric Utilities." 
Table 41. Electric Energy Account by Major Publicly Owned Electric Utility Within State, 1991 (Continued)

(Megawatthours)

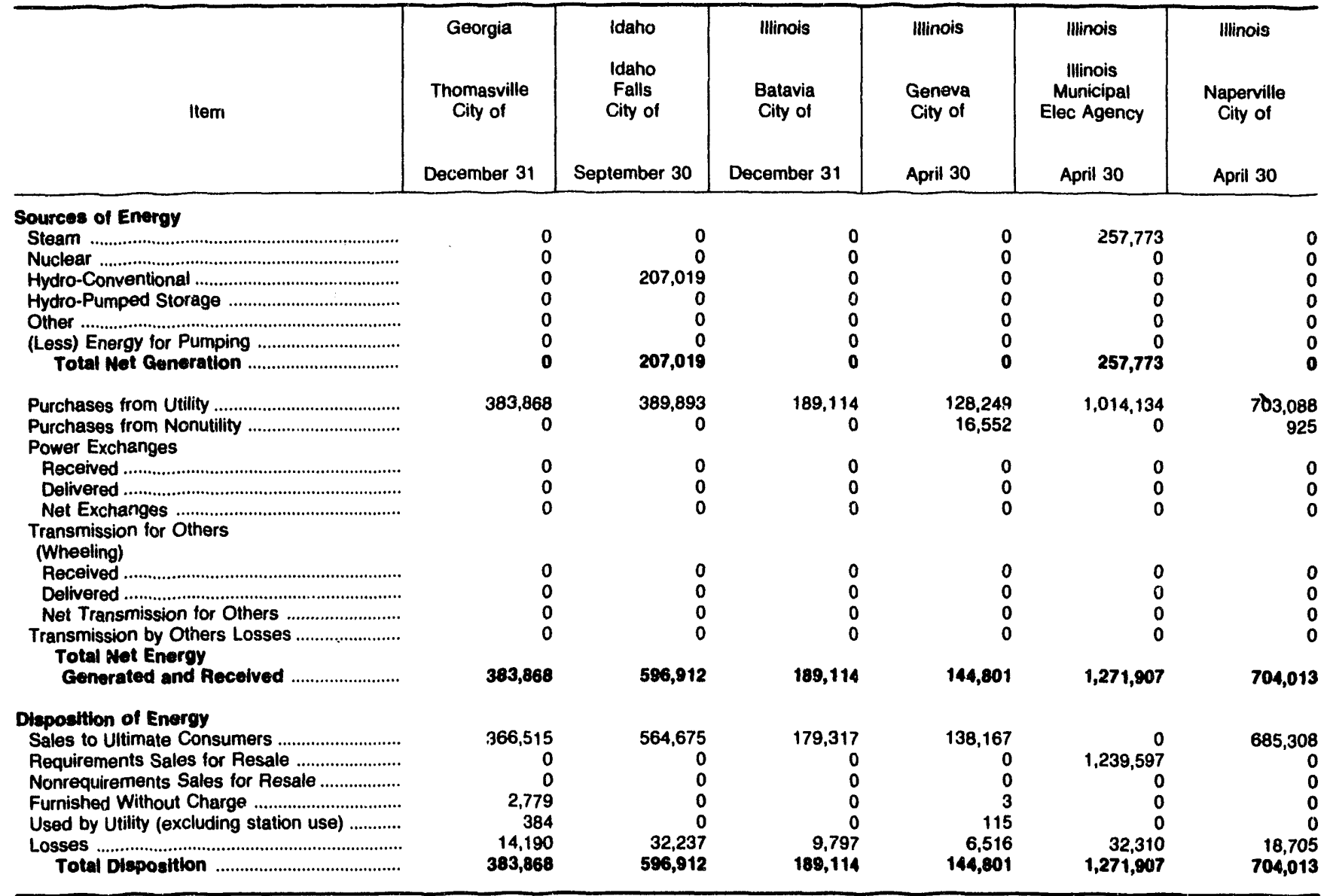

Note: Totals may not equal sum of components because of independent rounding. Double counting occurs in components of both sources and disposition of energy and thus neither provides a true total. Purchases from utilities, net interchanges, and net wheeling (except for imports) are included in net generation. Sales for resale is included in sales to ultimate consumers.

Source: Energy Information Administration, Form EIA-412, "Annual Report of Public Electric Utilities." 
Table 41. Electric Energy Account by Major Publicly Owned Electric Utility Within State, 1991 (Continued)

(Megawatthours)

\begin{tabular}{|c|c|c|c|c|c|c|}
\hline Item & $\begin{array}{l}\text { Illinois } \\
\text { Rocinelle } \\
\text { Municipal } \\
\text { Utilities }\end{array}$ & $\begin{array}{l}\text { Illinois } \\
\text { Springfield } \\
\text { City of }\end{array}$ & $\begin{array}{l}\text { Illinois } \\
\text { St Chartes } \\
\text { City of }\end{array}$ & $\begin{array}{l}\text { Indiana } \\
\text { Anderson } \\
\text { City of }\end{array}$ & $\begin{array}{l}\text { Indiana } \\
\text { Auburn } \\
\text { City of }\end{array}$ & $\begin{array}{l}\text { Indiane } \\
\text { Bluffton } \\
\text { City of }\end{array}$ \\
\hline & April 30 & February 28 & April 30 & December 31 & December 31 & December 31 \\
\hline
\end{tabular}

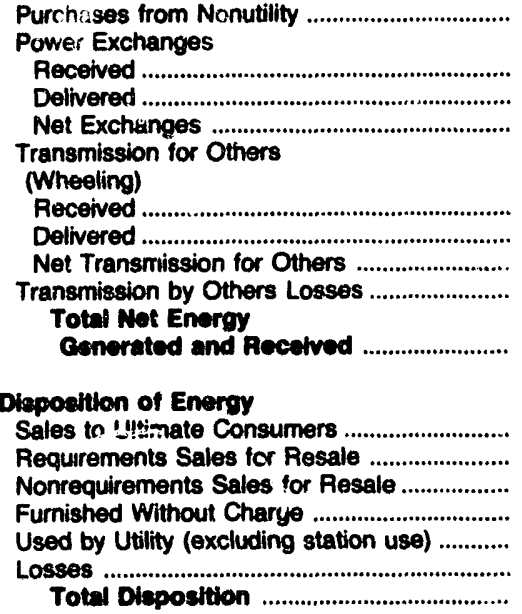

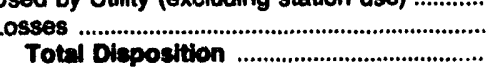

Sapostion of Enerey

Requirements Sales for Resale

Furnished without Charyo

45,320
0
0
0
5,720
0
51,038

$1,698,193$
0
0
0
1,234
0
$1,699,427$

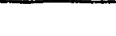

cember 31

December 31

$\begin{array}{ll}0 & 0 \\ 0 & 0 \\ 0 & 0 \\ 0 & 0 \\ 0 & 0 \\ 0 & 0 \\ 0 & 0\end{array}$

0
0
0
0
0
0
0

$\begin{array}{lr}0 & 0 \\ 0 & 0 \\ 0 & 0 \\ 0 & 0 \\ 0 & 3,545 \\ 0 & 0 \\ 0 & 3,545\end{array}$

105.683

10,027

0

\section{8,256}

0

650,226

272,784

147,427

$0 \quad 0$

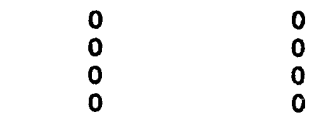

156,723

$1,700,454$

318,256

650,226

150,072

Note: Total: may not equal sum of components because of independent rounding. Double counting occurs in components of both sources and disposition of energy and thus neither provides a true total. Purchases from utilities, net interchanges, and net wheeling (except for imports) are included in net generation. Salss for resale is included in sales to ultimate consumers.

Source: Energy Information Administration, Form EIA-412, "Annual Report of Public Electric Utilities." 
Table 41. Electric Energy Account by Major Publicly Owned Electric Utility Within State, 1991 (Continued) (Megawatthours)

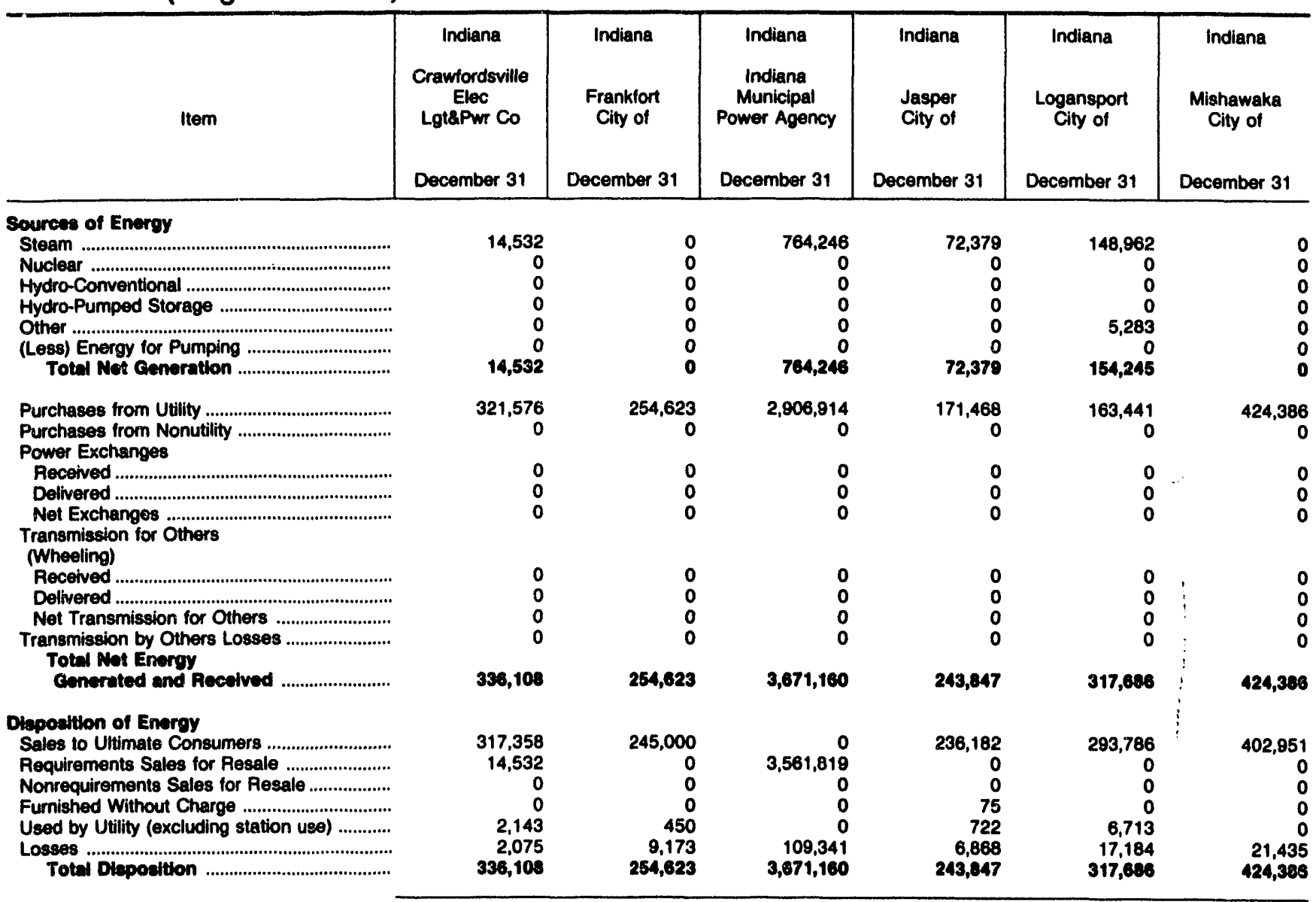

Note: Totals may not equal sum of components because of independent rounding. Doubls counting occurs in components of both sources and disposition of energy and thus neither provides a true total. Purchases from utilities, net interchanges, and net wheeling (except for imports) are included in net generation. Sales for resale is included in sales to ultimate consumers.

Source: Energy Information Administration, Form EIA-412, "Annual Report of Public Electric Utilities." 
Table 41. Electric Energy Account by Major Publicly Owned Electric Utility Within State, 1991 (Continued)

(Megawatthours)

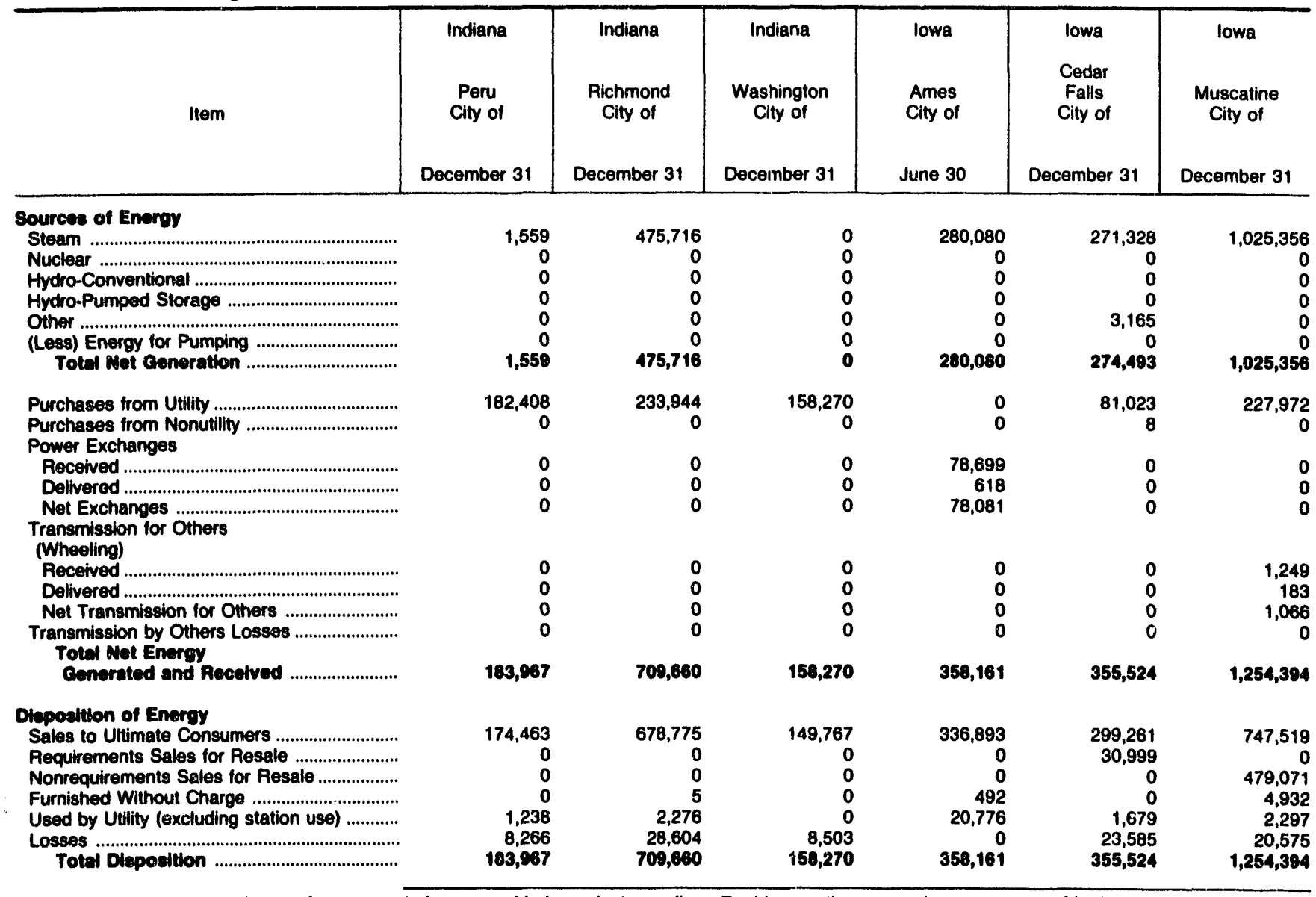

Note: Totals may not equal sum of components because of independent rounding. Double counting occurs in components of both sources and disposition of energy and thus neither provides a true total. Purchases from utilities, net interchanges, and net wheeling (except for imports) are included in net generation. Sales for resale is included in sales to ultimate consumers.

Source: Energy Information Administration, Form EIA-412, "Annual Report of Public Electric Utilities." 
Table 41. Electric Energy Account by Major Publicly Owned Electric Utillty Within State, 1991 (Continued) (Megawatthours)

\begin{tabular}{|c|c|c|c|c|c|c|}
\hline Item & $\begin{array}{l}\text { Kansas } \\
\text { Cofieyville } \\
\text { City of } \\
\text { December } 31\end{array}$ & $\begin{array}{l}\text { Kansas } \\
\text { Garden } \\
\text { City City of } \\
\text { Docember } 31\end{array}$ & $\begin{array}{l}\text { Kansas } \\
\text { Kansas } \\
\text { City City of } \\
\text { December } 31\end{array}$ & $\begin{array}{l}\text { Kansas } \\
\text { Kansas } \\
\text { Municipal } \\
\text { Energy } \\
\text { Agency } \\
\text { December } 31\end{array}$ & $\begin{array}{l}\text { Kansas } \\
\text { McPherson } \\
\text { City of } \\
\text { December } 31\end{array}$ & $\begin{array}{l}\text { Kansas } \\
\text { Winfield } \\
\text { City of } \\
\text { December } 31\end{array}$ \\
\hline 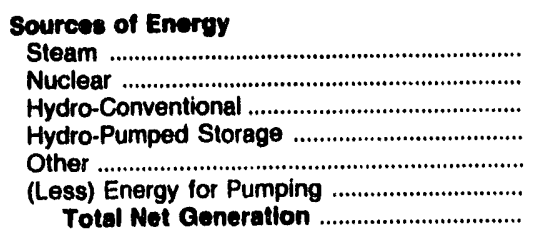 & $\begin{array}{r}64,703 \\
0 \\
0 \\
0 \\
0 \\
0 \\
64,703\end{array}$ & $\begin{array}{l}0 \\
0 \\
0 \\
0 \\
0 \\
0 \\
0\end{array}$ & $\begin{array}{r}2,301,787 \\
0 \\
0 \\
0 \\
1,674 \\
0 \\
2,303,441\end{array}$ & $\begin{array}{l}0 \\
0 \\
0 \\
0 \\
0 \\
0 \\
0\end{array}$ & $\begin{array}{r}4,203 \\
0 \\
0 \\
0 \\
14,949 \\
0 \\
19,152\end{array}$ & $\begin{array}{r}65,098 \\
0 \\
0 \\
0 \\
0 \\
0 \\
65,098\end{array}$ \\
\hline 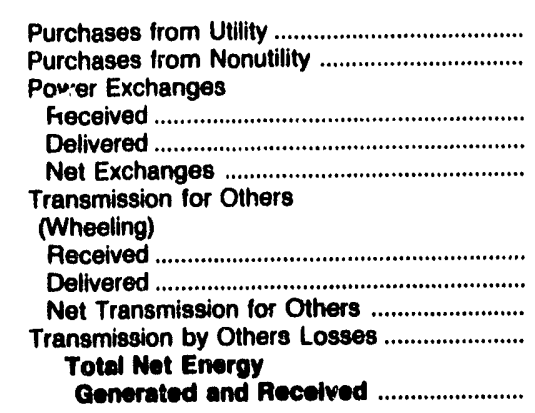 & $\begin{array}{r}109,075 \\
0\end{array}$ & $\begin{array}{r}161,092 \\
0\end{array}$ & $\begin{array}{r}352,999 \\
0 \\
1 \\
16,244 \\
-16,243\end{array}$ & $\begin{array}{r}394,759 \\
0\end{array}$ & $\begin{array}{r}445,742 \\
0\end{array}$ & $\begin{array}{r}162,819 \\
0\end{array}$ \\
\hline 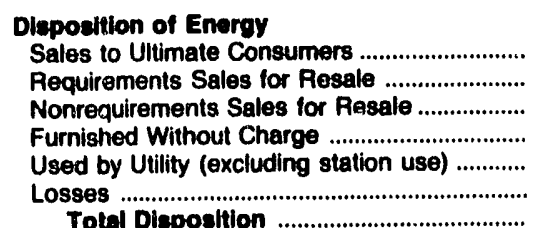 & $\begin{array}{r}162,752 \\
0 \\
0 \\
3,802 \\
3,199 \\
4,025 \\
173,778\end{array}$ & $\begin{array}{r}141,637 \\
0 \\
0 \\
5,478 \\
5,638 \\
8,339 \\
161,092\end{array}$ & $\begin{array}{r}2,089,734 \\
407,681 \\
0 \\
70,768 \\
0 \\
0 \\
72,014 \\
2,640,197\end{array}$ & $\begin{array}{r}0 \\
394,759 \\
0 \\
0 \\
0 \\
0 \\
394,759\end{array}$ & $\begin{array}{r}411,919 \\
39,024 \\
0 \\
109 \\
0 \\
13,842 \\
484,894\end{array}$ & $\begin{array}{r}205,641 \\
4,682 \\
0 \\
0 \\
7,103 \\
10,491 \\
227,917\end{array}$ \\
\hline
\end{tabular}

Note: Totals may not equal sum of components because of independent rounding. Double counting occurs in components of both sources and disposition of energy and thus neither provides a true total. Purchases from utilities, net interchanges, and net wheeling (except for imports) are included in net generation. Sales for resale is included in sales to ultimate consumers.

Source: Energy Information Administration, Form EIA-412, "Annual Report of Public Electric Utilities." 
Table 41. Electric Energy Account by Major Publicly Owned Electric Utility Within State, 1991 (Continued)

(Megawatthours)

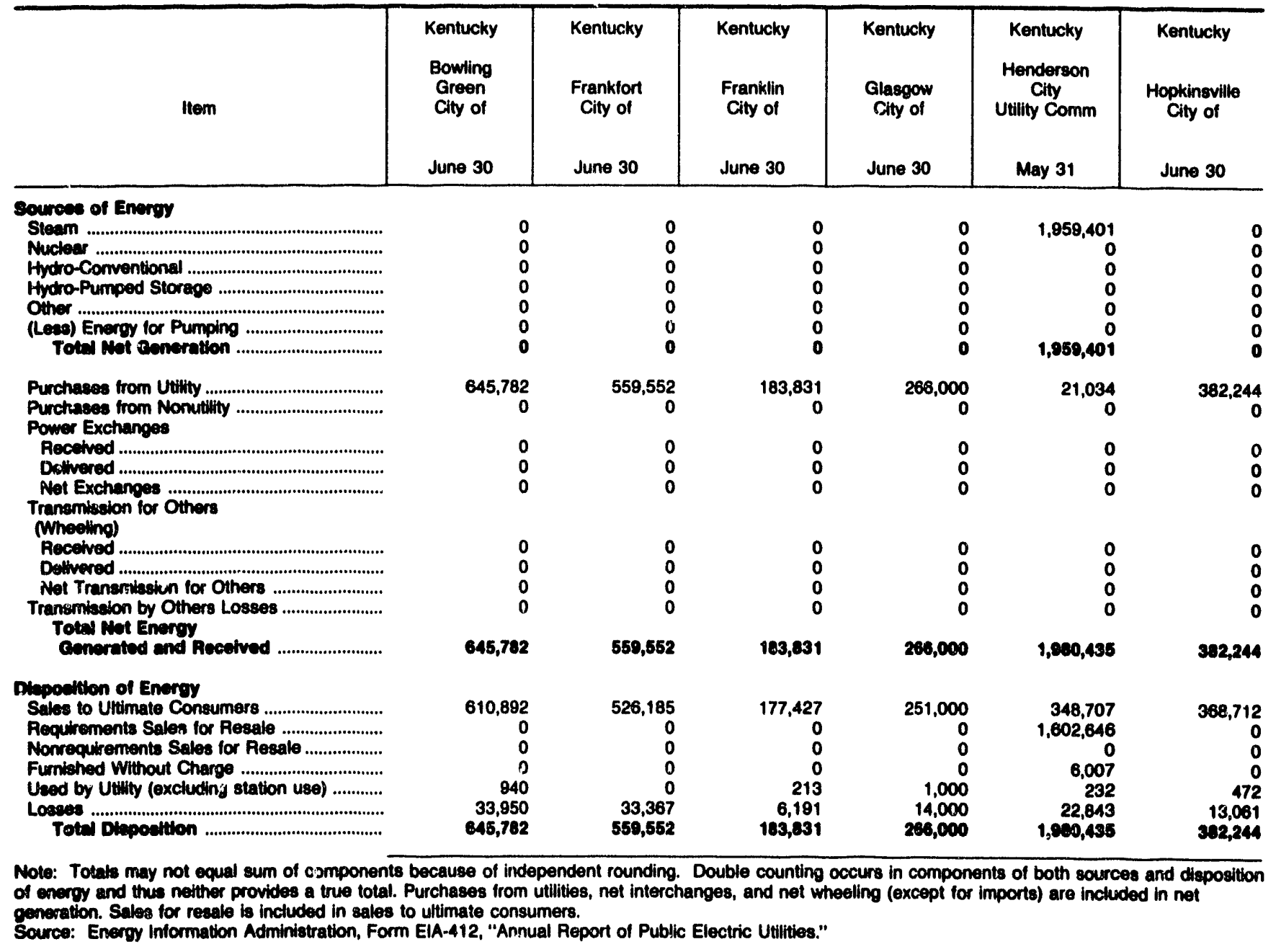


Table 41. Electric Energy Account by Major Publicly Owned Electric Utility Within State, 1991 (Continued) (Megawatthours)

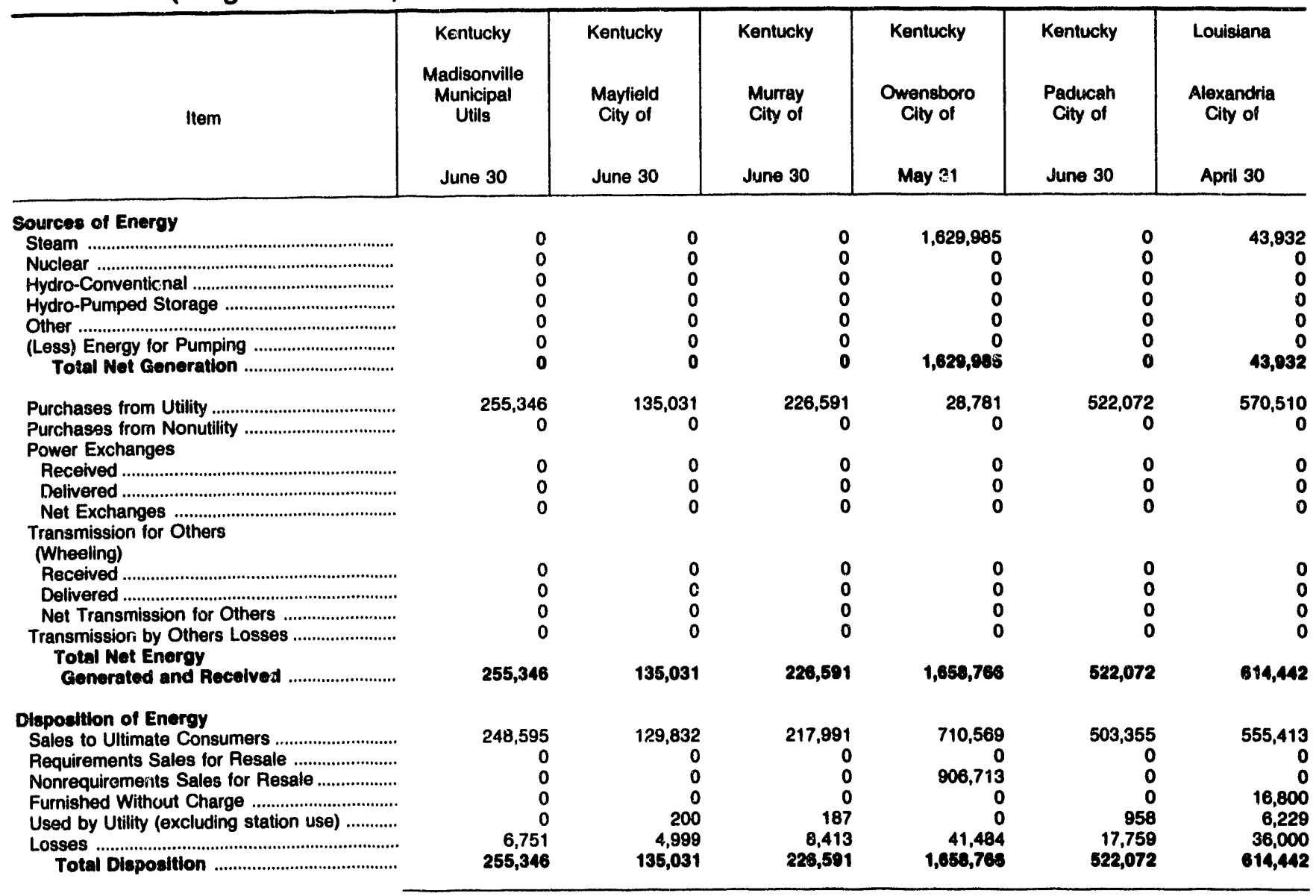

Note: Totals may not equal sum of components because of independent rounding. Double counting occurs in components of both sources and disposition of energy and thus neither provides a true total. Purchases from utilities, net interchanges, and net wheeling (except for imports) are included in net generation. Sales for resale is included in sales to ultimate consumers.

Source: Energy Information Administration, Form EIA-412, "Annual Peport of Public Electric Utilities." 


\section{Table 41. Electric Energy Account by Major Publicly Owned Electric Utility Within State, 1991 (Continued)}

(Megawatthours)

\begin{tabular}{|c|c|c|c|c|c|c|}
\hline Item & $\begin{array}{l}\text { Louisiana } \\
\text { Lafayette } \\
\text { City of } \\
\text { October } 31\end{array}$ & $\begin{array}{l}\text { Louisiana } \\
\text { Louisiana } \\
\text { Energy } \\
8 \\
\text { Power Auth } \\
\text { December } 31\end{array}$ & $\begin{array}{l}\text { Louisiana } \\
\text { Morgan } \\
\text { City City of } \\
\text { December } 31\end{array}$ & $\begin{array}{l}\text { Louisiana } \\
\text { Natchitoches } \\
\text { City of } \\
\text { May } 31\end{array}$ & $\begin{array}{l}\text { Louisiana } \\
\text { Ruston } \\
\text { City of } \\
\text { September } 30\end{array}$ & $\begin{array}{c}\text { Louisiana } \\
\text { Terrebonne } \\
\text { Parish } \\
\text { Consol Govt } \\
\text { December } 31\end{array}$ \\
\hline 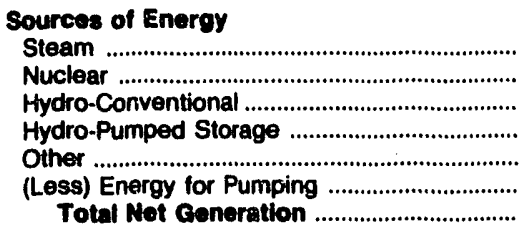 & $\begin{array}{r}281,456 \\
0 \\
0 \\
0 \\
0 \\
0 \\
281,456\end{array}$ & $\begin{array}{r}738,318 \\
0 \\
0 \\
0 \\
0 \\
0 \\
738,318\end{array}$ & $\begin{array}{r}22,664 \\
0 \\
0 \\
0 \\
0 \\
0 \\
22,684\end{array}$ & $\begin{array}{l}0 \\
0 \\
0 \\
0 \\
0 \\
0 \\
0\end{array}$ & $\begin{array}{r}161,600 \\
0 \\
0 \\
0 \\
0 \\
0 \\
161,600\end{array}$ & $\begin{array}{r}142,669 \\
0 \\
0 \\
0 \\
0 \\
0 \\
142,689\end{array}$ \\
\hline 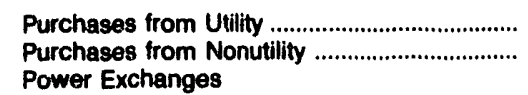 & $\begin{array}{r}1,658,518 \\
0\end{array}$ & $\begin{array}{r}758,838 \\
0\end{array}$ & $\begin{array}{r}163,552 \\
0\end{array}$ & $\begin{array}{r}197,063 \\
0\end{array}$ & $\begin{array}{l}34,368 \\
16,365\end{array}$ & $\begin{array}{r}228,875 \\
0\end{array}$ \\
\hline 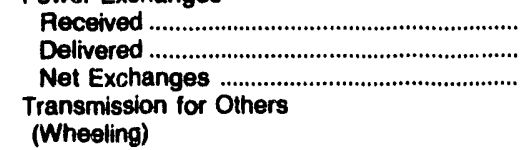 & $\begin{array}{r}32,192 \\
32,127 \\
65\end{array}$ & $\begin{array}{l}0 \\
0 \\
0\end{array}$ & $\begin{array}{l}0 \\
0 \\
0\end{array}$ & $\begin{array}{l}0 \\
0 \\
0\end{array}$ & $\begin{array}{l}0 \\
0 \\
0\end{array}$ & $\begin{array}{l}0 \\
0 \\
0\end{array}$ \\
\hline 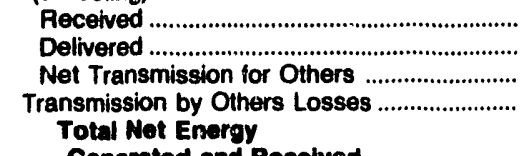 & $\begin{array}{l}0 \\
0 \\
0 \\
0\end{array}$ & $\begin{array}{l}0 \\
0 \\
0 \\
0\end{array}$ & $\begin{array}{l}0 \\
0 \\
0 \\
0\end{array}$ & $\begin{array}{r}0 \\
0 \\
0 \\
-7,488\end{array}$ & $\begin{array}{l}0 \\
0 \\
0 \\
0\end{array}$ & $\begin{array}{l}0 \\
0 \\
0 \\
0\end{array}$ \\
\hline Generated and Pecelved ............................. & $1,940,039$ & $1,497,156$ & 186,216 & 189,574 & 212,333 & 371,544 \\
\hline 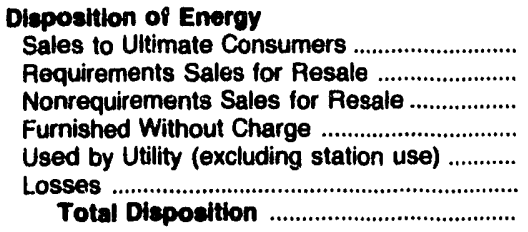 & $\begin{array}{r}1,276,156 \\
555,843 \\
0 \\
0 \\
0 \\
108,040 \\
1,940,039\end{array}$ & $\begin{array}{r}0 \\
1,456,075 \\
0 \\
0 \\
0 \\
41,081 \\
1,497,156\end{array}$ & $\begin{array}{r}173,301 \\
0 \\
0 \\
0 \\
0 \\
12,915 \\
186,216\end{array}$ & $\begin{array}{r}170,624 \\
0 \\
0 \\
0 \\
0 \\
18,950 \\
189,574\end{array}$ & $\begin{array}{r}189,814 \\
0 \\
0 \\
0 \\
9,300 \\
13,219 \\
212,333\end{array}$ & $\begin{array}{r}211,888 \\
142,669 \\
0 \\
0 \\
15,945 \\
1,042 \\
371,544\end{array}$ \\
\hline
\end{tabular}

Note: Totals may not equal sum of components because of independent rounding. Double counting occurs in components of both sources and disposition of energy and thus neither provides a true total. Purchases from utilities, net interchanges, and net wheeling (except for imports) are included in net generation. Sales for resale is included in sales to ultimate consumers.

Source: Energy Information Administration, Form EIA-412, "Annual Report of Public Electric Utilities." 
Table 41. Electric Energy Account by Major Publicly Owned Electric Utility Within State, 1991 (Continued) (Megawatthours)

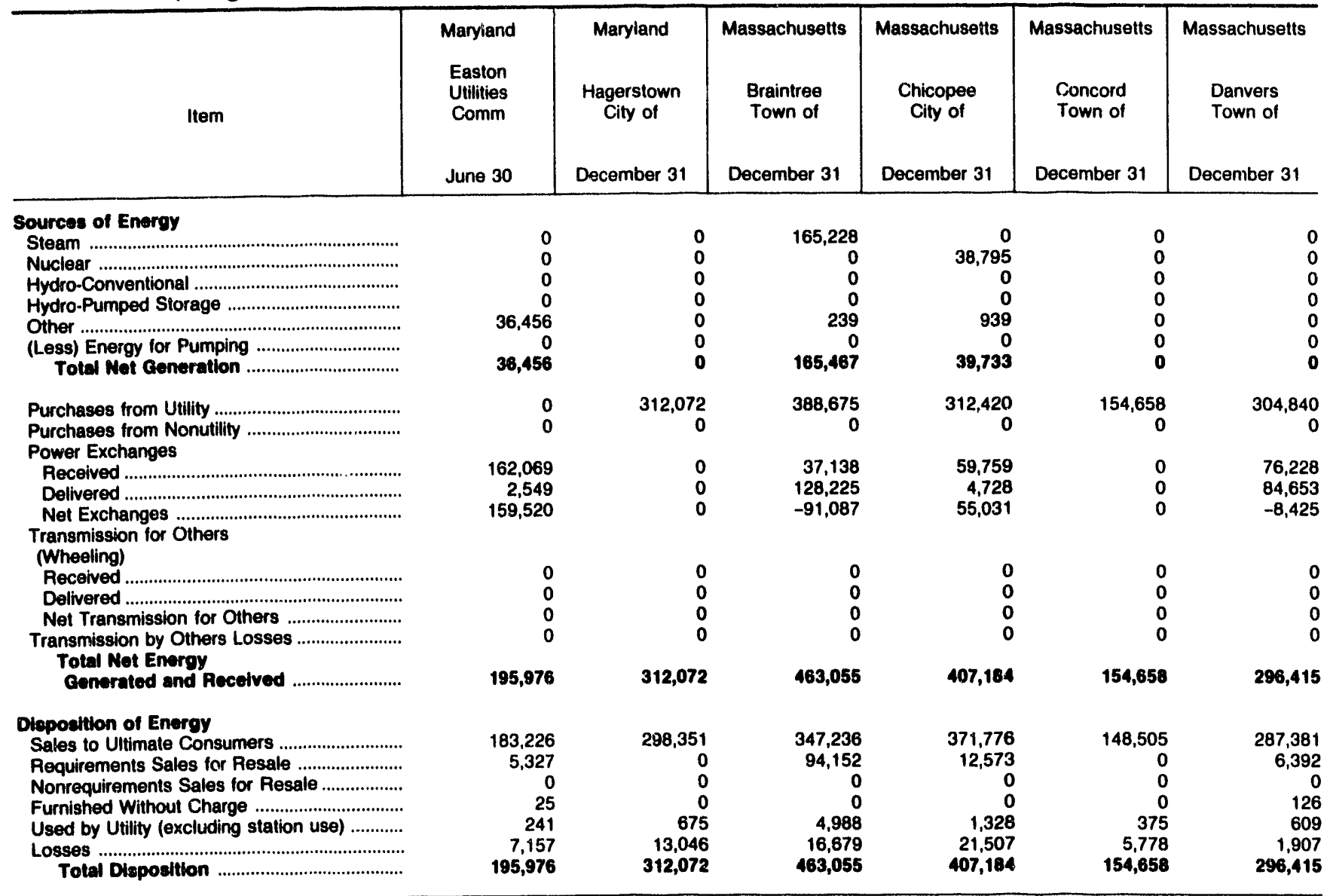

Note: Totals may not equal sum of components because of independent rounding. Double counting occurs in components of both sources and disposition of energy and thus neither provides a true total. Purchases from utilities, net interchanges, and net wheeling (except for imports) are included in net generation. Sales for resale is included in sales to ultimate consumers.

Source: Energy Information Administration, Form ElA-412, "Annual Report of Public Electric Utilities." 
Table 41. Electric Energy Account by Major Publicly Owned Electric Utility Within State, 1991 (Continued)

(Megawatthours)

\begin{tabular}{|c|c|c|c|c|c|c|}
\hline Item & $\begin{array}{l}\text { Massachusetts } \\
\text { Hingham } \\
\text { City of } \\
\text { December } 31\end{array}$ & $\begin{array}{c}\text { Massachusetts } \\
\text { Holyoke } \\
\text { City of } \\
\text { December } 31\end{array}$ & $\begin{array}{l}\text { Massachusetts } \\
\text { Hudson } \\
\text { Town of } \\
\text { December } 31\end{array}$ & $\begin{array}{l}\text { Massachusetts } \\
\text { Littleton } \\
\text { Town of } \\
\text { December } 31\end{array}$ & $\begin{array}{l}\text { Massachusetts } \\
\text { Mansfield } \\
\text { Town of } \\
\text { December } 31\end{array}$ & $\begin{array}{l}\text { Massachusetts } \\
\text { Massachuselts } \\
\text { Mun } \\
\text { Whls } \\
\text { Elec Co } \\
\text { December } 31\end{array}$ \\
\hline \multicolumn{7}{|l|}{ Sources of Energy } \\
\hline Steam & 0 & -69 & 0 & 4,892 & 0 & 575,292 \\
\hline 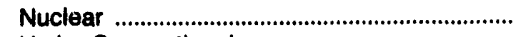 & 0 & 0 & 5,289 & 0 & 0 & 929,518 \\
\hline Hydro-Conventional ............................................... & 0 & 10,408 & 0 & $\mathbf{0}$ & 0 & \\
\hline 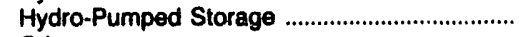 & 0 & 0 & 0 & $\mathbf{0}$ & 0 & 0 \\
\hline Other & 0 & 0 & 9,400 & 0 & 0 & 143,824 \\
\hline (Less) Energy for Pumping & $\begin{array}{l}0 \\
0\end{array}$ & & $\begin{array}{r}0 \\
14,689\end{array}$ & & $\begin{array}{l}\mathbf{0} \\
\mathbf{0}\end{array}$ & \\
\hline 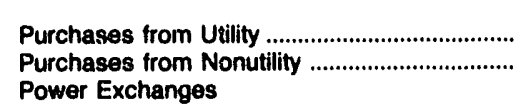 & $\begin{array}{r}134,603 \\
0\end{array}$ & $\begin{array}{r}308,556 \\
0\end{array}$ & $\begin{array}{r}238,866 \\
4,155\end{array}$ & $\begin{array}{r}167,611 \\
0\end{array}$ & $\begin{array}{r}184,952 \\
0\end{array}$ & $\begin{array}{r}1,317,190 \\
51,300\end{array}$ \\
\hline 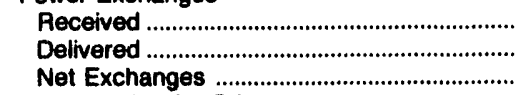 & $\begin{array}{r}12,468 \\
7,214 \\
5,254\end{array}$ & $\begin{array}{r}16,861 \\
51,727 \\
-34,766\end{array}$ & $\begin{array}{r}44,147 \\
35,046 \\
9,101\end{array}$ & $\begin{array}{l}81,538 \\
24,745 \\
56,793\end{array}$ & $\begin{array}{l}0 \\
0 \\
0\end{array}$ & $\begin{array}{l}817,509 \\
567,731 \\
249,778\end{array}$ \\
\hline \multicolumn{7}{|l|}{ Transmission for Others } \\
\hline 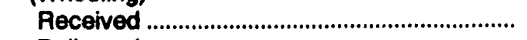 & 0 & 0 & 0 & $\mathbf{0}$ & 0 & 0 \\
\hline 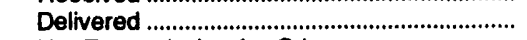 & 0 & 0 & 0 & $\mathbf{0}$ & 0 & 0 \\
\hline 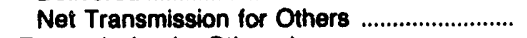 & 0 & 0 & 0 & 0 & 0 & 0 \\
\hline $\begin{array}{l}\text { Transmission by Others Losses ............................. } \\
\text { Totw Net Energy }\end{array}$ & 0 & 0 & 0 & 0 & $\mathbf{0}$ & 0 \\
\hline Generated and Received ........................... & 139,857 & 284,129 & 266,911 & 229,296 & 184,952 & $3,266,902$ \\
\hline \multicolumn{7}{|l|}{ Disposition of Energy } \\
\hline $\begin{array}{l}\text { Sales to Ultimate Consumers } \\
\text { Requirements Sales for Resale }\end{array}$ & $\begin{array}{r}127,577 \\
147\end{array}$ & $\begin{array}{r}259,075 \\
2,447\end{array}$ & $\begin{array}{r}242,790 \\
0\end{array}$ & $\begin{array}{r}182,446 \\
33,614\end{array}$ & $\begin{array}{r}165,977 \\
2,055\end{array}$ & $\begin{array}{r}0 \\
3,266.902\end{array}$ \\
\hline Nonrequirements Sales for Resale .................. & 0 & 0 & 0 & 0 & 0 & 0 \\
\hline 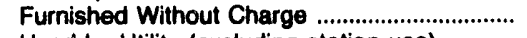 & 0 & 0 & 0 & 0 & 0 & 0 \\
\hline Used by Utility (excluding station use) ............ & 300 & 537 & 288 & 176 & 30 & $\mathbf{0}$ \\
\hline Losses Total Dieposition & $\begin{array}{r}11,833 \\
139,857\end{array}$ & $\begin{array}{r}22,070 \\
284,129\end{array}$ & $\begin{array}{r}23,833 \\
268,911\end{array}$ & $\begin{array}{r}13,060 \\
228,296\end{array}$ & $\begin{array}{r}16,888 \\
184,052\end{array}$ & $\begin{array}{r}0 \\
3,266,902\end{array}$ \\
\hline
\end{tabular}

Note: Totals may not equal sum of components because of independent rounding. Double counting occurs in components of both sources and disposition of energy and thus neither provides a true total. Purchases from utilities, net interchanges, and net wheeling (except for imports) are included in net generation. Sales for resale is included in sales to ultimate consumers.

Source: Energy Information Administration, Form EIA-412, "Annual Report of Public Electric Utilities." 


\section{Table 41. Electric Energy Account by Major Publicly Owned Electric Utility Within State, 1991 (Continued) (Megawatthours)}

\begin{tabular}{|c|c|c|c|c|c|c|}
\hline Item & $\begin{array}{l}\text { Massachusetts } \\
\text { Middleborough } \\
\text { Town of } \\
\text { December } 31\end{array}$ & $\begin{array}{c}\text { Massachusetts } \\
\text { North } \\
\text { Attleborough } \\
\text { Town of } \\
\text { December } 31\end{array}$ & $\begin{array}{l}\text { Massachusetts } \\
\text { Norwood } \\
\text { City of } \\
\text { June } 30\end{array}$ & $\begin{array}{l}\text { Massachusetts } \\
\text { Peabody } \\
\text { City of } \\
\text { December } 31\end{array}$ & $\begin{array}{l}\text { Massachusetts } \\
\text { Reading } \\
\text { Town of } \\
\text { December } 31\end{array}$ & $\begin{array}{c}\text { Massachusetts } \\
\text { Shrewsbury } \\
\text { Town of }\end{array}$ \\
\hline \multicolumn{7}{|l|}{ Sources of Energy } \\
\hline Steam & 0 & 9,790 & 0 & 0 & 0 & 0 \\
\hline Nuclear & 0 & 0 & 0 & 0 & 0 & 0 \\
\hline 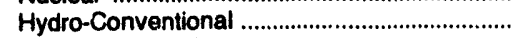 & 0 & 0 & 0 & 0 & 0 & 0 \\
\hline 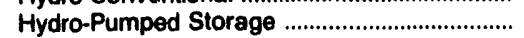 & 0 & 0 & 0 & 0 & 0 & 0 \\
\hline Other & 0 & 0 & 0 & 13,296 & 0 & 1,286 \\
\hline 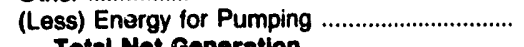 & 0 & & 0 & 0 & 0 & 0 \\
\hline 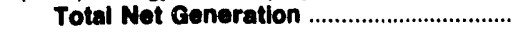 & $\mathbf{0}$ & 9,790 & $\mathbf{0}$ & 13,286 & $\mathbf{0}$ & 1,286 \\
\hline 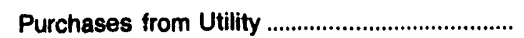 & 164,794 & 125,425 & 329,043 & 368,403 & 567,847 & 253,672 \\
\hline $\begin{array}{l}\text { Purchases from Nonutility ................................... } \\
\text { Power Exchanges }\end{array}$ & 0 & 0 & 0 & 876 & 0 & 0 \\
\hline 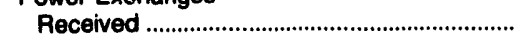 & 0 & 80,683 & 0 & 127,786 & 143,007 & 0 \\
\hline 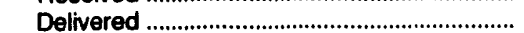 & 0 & 30,447 & 0 & 108,765 & 110,002 & 0 \\
\hline 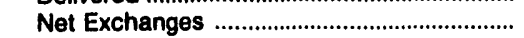 & 0 & 50,236 & 0 & 19,021 & 33,005 & 0 \\
\hline \multicolumn{7}{|l|}{$\begin{array}{l}\text { Transmission for Others } \\
\text { (Wheeling) }\end{array}$} \\
\hline 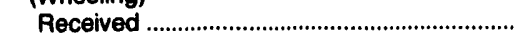 & 0 & 0 & 0 & 0 & 0 & 0 \\
\hline 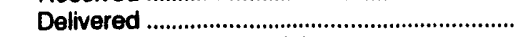 & 0 & 0 & 0 & 0 & 0 & 0 \\
\hline 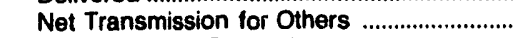 & 0 & 0 & 0 & 0 & 0 & 0 \\
\hline Transmission by Others L.osses ........................ & 0 & $\mathbf{0}$ & 0 & 0 & 0 & 0 \\
\hline Generated and Recelved ........................... & 164,784 & 185,451 & 329,043 & 401,586 & 600,852 & 254,958 \\
\hline \multicolumn{7}{|l|}{ Diaposition of Energy } \\
\hline Sales to Ultimate Consumers ............................... & 154,448 & 177,542 & 310,498 & 377,272 & 557,805 & 232,911 \\
\hline 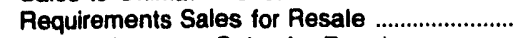 & 220 & 698 & 0 & 0 & 149 & 1,236 \\
\hline Nonrequirements Sales for Resale .................. & 0 & 0 & 0 & 0 & 0 & 0 \\
\hline Furnished Without Charge ................................... & 0 & 0 & 0 & 11 & 0 & 0 \\
\hline Used by Utility (excluding station use) ............ & 0 & 39 & 0 & 2,154 & 803 & 1,181 \\
\hline $\begin{array}{l}\text { Losses } \\
\text { Total Dieposition }\end{array}$ & $\begin{array}{r}10,126 \\
164,794\end{array}$ & $\begin{array}{r}7,172 \\
185,451\end{array}$ & $\begin{array}{r}18,545 \\
329,043\end{array}$ & $\begin{array}{r}22,159 \\
401,586\end{array}$ & $\begin{array}{r}42,095 \\
600,852\end{array}$ & $\begin{array}{r}19,630 \\
254,958\end{array}$ \\
\hline
\end{tabular}

Note: Totals may not equal sum of components because of independent rounding. Double counting occurs in components of both sources and disposition of energy and thus neither provides a true total. Purchases from utilities, net interchanges, and net wheeling (except for imports) are included in net generation. Sales for resale is included in sales to ultimate consumers.

Source: Energy Information Administration, Form EIA-412, "Annual Report of Public Electric Utilities." 
Table 41. Electric Energy Account by Major Publicly Owned Electric Utility Within State, 1991 (Continued) (Megawatthours)

\begin{tabular}{|c|c|c|c|c|c|c|}
\hline litem & $\begin{array}{l}\text { Massachusetts } \\
\text { Taunton } \\
\text { City of } \\
\text { December } 31\end{array}$ & $\begin{array}{l}\text { Massachusetts } \\
\text { Wakefield } \\
\text { Town of } \\
\text { December } 31\end{array}$ & $\begin{array}{l}\text { Massachusetts } \\
\text { Wellesley } \\
\text { Town of } \\
\text { December } 31\end{array}$ & $\begin{array}{l}\text { Massachusetts } \\
\text { Westfield } \\
\text { City of } \\
\text { December } 31\end{array}$ & $\begin{array}{l}\text { Michigan } \\
\text { Bay } \\
\text { City City of } \\
\text { June } 30\end{array}$ & $\begin{array}{l}\text { Michigan } \\
\text { Coldwater } \\
\text { Board } \\
\text { of } \\
\text { Public Util } \\
\text { June } 30\end{array}$ \\
\hline 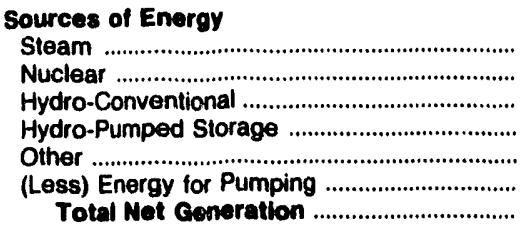 & $\begin{array}{r}145,913 \\
0 \\
0 \\
0 \\
38,218 \\
0 \\
184,131\end{array}$ & $\begin{array}{l}0 \\
0 \\
0 \\
0 \\
0 \\
0 \\
0\end{array}$ & $\begin{array}{l}0 \\
0 \\
0 \\
0 \\
0 \\
0 \\
0\end{array}$ & $\begin{array}{l}0 \\
0 \\
0 \\
0 \\
0 \\
0 \\
0\end{array}$ & $\begin{array}{r}0 \\
0 \\
0 \\
0 \\
1,092 \\
0 \\
1,002\end{array}$ & $\begin{array}{r}0 \\
0 \\
0 \\
0 \\
4,016 \\
0 \\
4,016\end{array}$ \\
\hline 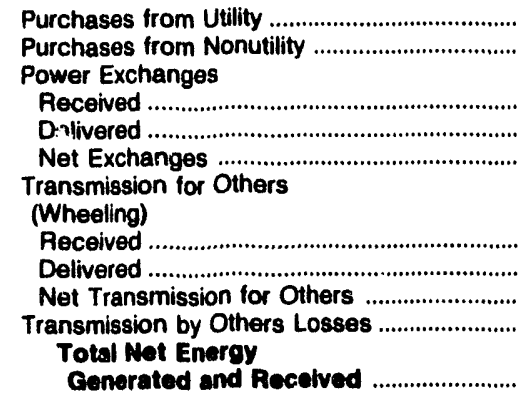 & $\begin{array}{r}167,241 \\
0 \\
205,742 \\
38,413 \\
167,329\end{array}$ & $\begin{array}{r}154,571 \\
0\end{array}$ & $\begin{array}{r}0 \\
0 \\
0 \\
0 \\
206,300\end{array}$ & $\begin{array}{r}0 \\
0 \\
0 \\
0 \\
285,922\end{array}$ & $\begin{array}{r}0 \\
0 \\
0 \\
0 \\
238,611\end{array}$ & $\begin{array}{r}0 \\
0 \\
0 \\
0 \\
139,062\end{array}$ \\
\hline 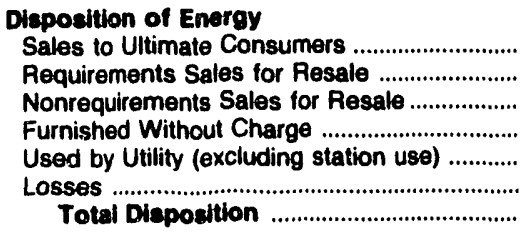 & $\begin{array}{r}420,369 \\
38,486 \\
28,383 \\
0 \\
6,174 \\
25,289 \\
518,701\end{array}$ & $\begin{array}{r}139,881 \\
0 \\
0 \\
0 \\
285 \\
14,405 \\
154,571\end{array}$ & $\begin{array}{r}194,200 \\
0 \\
0 \\
200 \\
500 \\
11,400 \\
206,300\end{array}$ & $\begin{array}{r}263,768 \\
7,322 \\
0 \\
0 \\
614 \\
14,218 \\
285,922\end{array}$ & $\begin{array}{r}231,266 \\
0 \\
0 \\
0 \\
0 \\
7,345 \\
238,611\end{array}$ & $\begin{array}{r}128,820 \\
0 \\
0 \\
0 \\
1,596 \\
8,646 \\
139,082\end{array}$ \\
\hline
\end{tabular}


Table 41. Electric Energy Account by Major Publicly Owned Electric Utility Within State, 1991 (Continued)

(Megawatthours)

\begin{tabular}{|c|c|c|c|c|c|c|}
\hline Item & $\begin{array}{l}\text { Michigan } \\
\text { Detroit } \\
\text { City of } \\
\text { June } 30\end{array}$ & $\begin{array}{l}\text { Michigan } \\
\text { Grand Haven } \\
\text { City of } \\
\text { June } 30\end{array}$ & $\begin{array}{l}\text { Michigan } \\
\text { Hillsdale } \\
\text { Board } \\
\text { of } \\
\text { Public Wks } \\
\text { June } 30\end{array}$ & $\begin{array}{l}\text { Michigan } \\
\text { Holland } \\
\text { City of } \\
\text { June } 30\end{array}$ & $\begin{array}{l}\text { Michigan } \\
\text { Lansing } \\
\text { City of } \\
\text { June } 30\end{array}$ & $\begin{array}{l}\text { Michigan } \\
\text { Marquette } \\
\text { City of } \\
\text { June } 30\end{array}$ \\
\hline 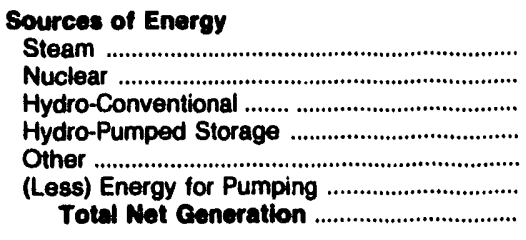 & $\begin{array}{r}332,887 \\
0 \\
0 \\
0 \\
0 \\
0 \\
332,887\end{array}$ & $\begin{array}{r}383,972 \\
0 \\
0 \\
0 \\
207 \\
0 \\
384,179\end{array}$ & $\begin{array}{r}0 \\
0 \\
0 \\
0 \\
4,316 \\
0 \\
4,316\end{array}$ & $\begin{array}{r}333,742 \\
0 \\
0 \\
0 \\
553 \\
0 \\
334,295\end{array}$ & $\begin{array}{r}2,367,836 \\
0 \\
2,818 \\
0 \\
0 \\
0 \\
2,370,654\end{array}$ & $\begin{array}{r}218,178 \\
0 \\
15,817 \\
0 \\
-19 \\
0 \\
233,976\end{array}$ \\
\hline 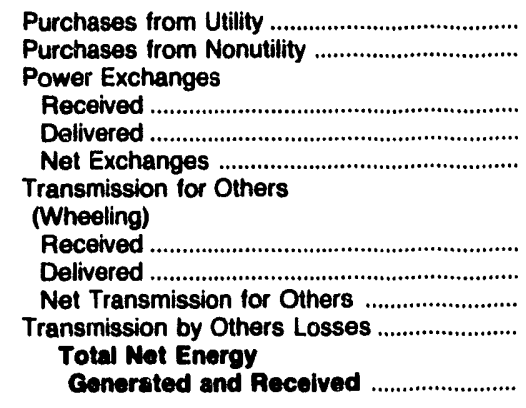 & $\begin{array}{r}434,706 \\
0\end{array}$ & $\begin{array}{r}7,740 \\
0\end{array}$ & $\begin{array}{r}127,193 \\
0\end{array}$ & $\begin{array}{r}0 \\
0 \\
0 \\
0 \\
636,023\end{array}$ & $\begin{array}{r}67,496 \\
0 \\
35,072 \\
35,425 \\
-353\end{array}$ & $\begin{array}{r}0 \\
0 \\
0 \\
0 \\
245,467\end{array}$ \\
\hline 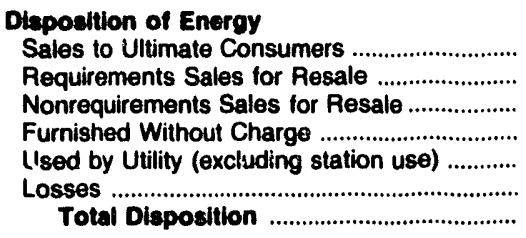 & $\begin{array}{r}594,508 \\
0 \\
0 \\
117,330 \\
4,376 \\
51,379 \\
767,593\end{array}$ & $\begin{array}{r}225,386 \\
157,266 \\
0 \\
0 \\
371 \\
8,896 \\
391,919\end{array}$ & $\begin{array}{r}122,820 \\
0 \\
0 \\
0 \\
0 \\
8,389 \\
131,509\end{array}$ & $\begin{array}{r}600,457 \\
0 \\
0 \\
0 \\
0 \\
35,566 \\
636,023\end{array}$ & $\begin{array}{r}2,151,707 \\
185,515 \\
0 \\
0 \\
0 \\
100,575 \\
2,437,797\end{array}$ & $\begin{array}{r}220,391 \\
13,863 \\
0 \\
0 \\
626 \\
60,587 \\
245,467\end{array}$ \\
\hline
\end{tabular}

Note: Totals may not equal sum of components because of independent rounding. Double counting occurs in components of both sources and disposition of energy and thus neither provides a true total. Purchases from utilities, net interchanges, and net wheeling (except for imports) are included in net generation. Sales for resale is included in sales to ultimate consumers.

Source: Energy Information Administration, Form EIA-412, "Annual Report of Public Electric Utilities." 
Table 41. Electric Energy Account by Major Publicly Owned Electric Utilisy Within State, 1991 (Continued) (Megawatthours)

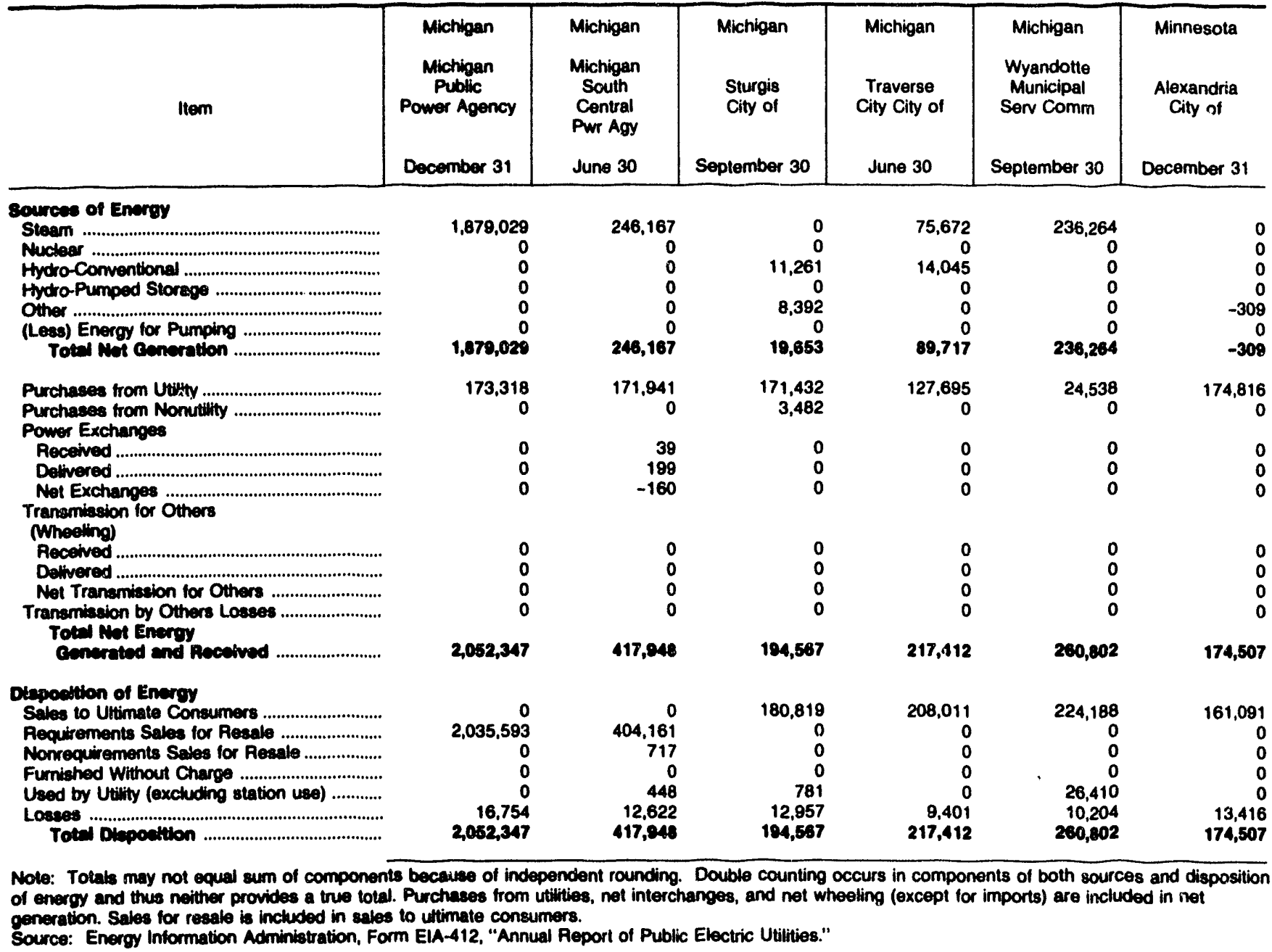


Table 41. Electric Energy Account by Major Publicly Owned Electric Utility Within State, 1991 (Continued) (Megawatthours)

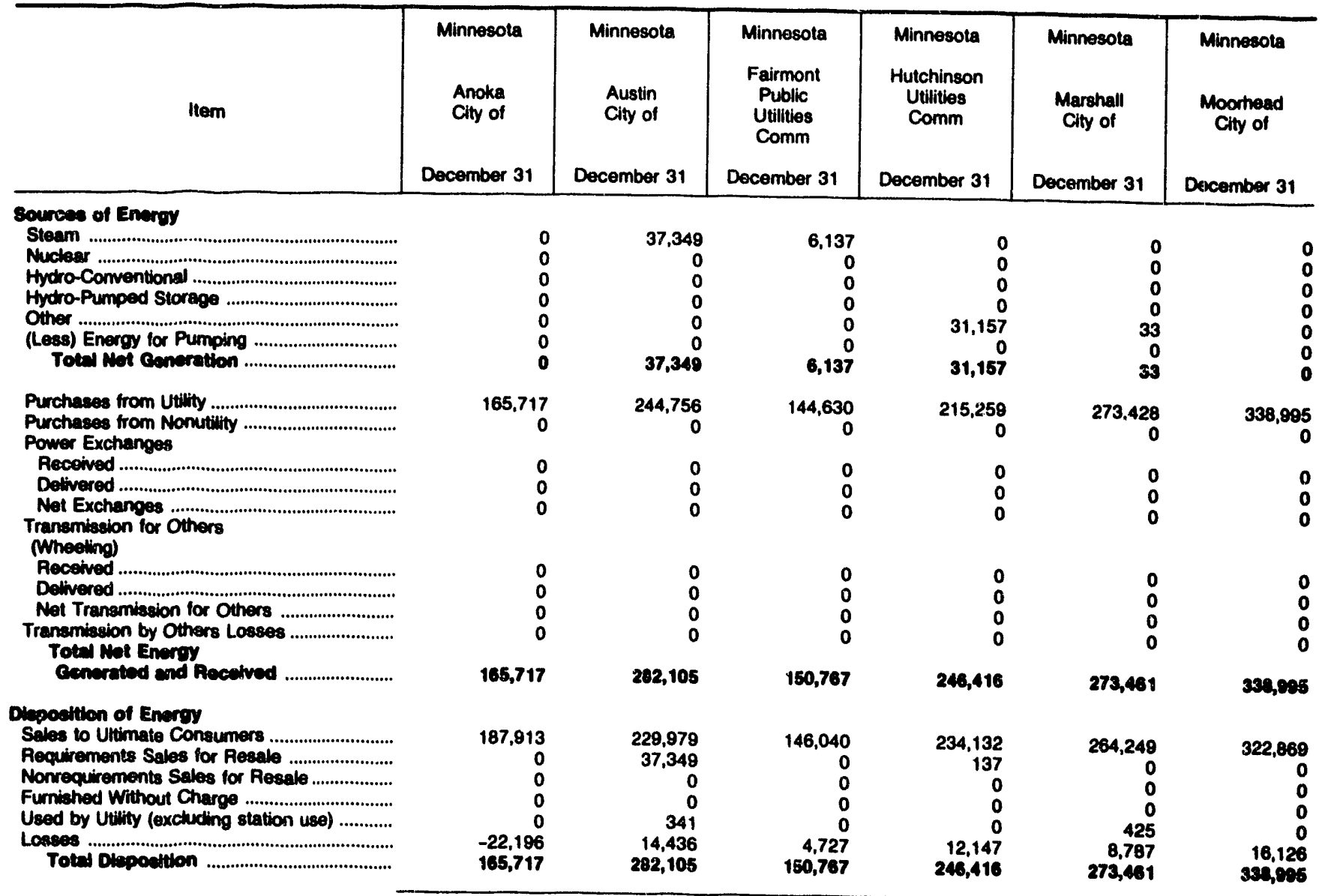

Note: Totals may not equal sum of components because of independent rounding. Double counting occurs in components of both sources and cieposition generation. Sales for resale is inchuded in sales to ultimate consumers.

Source: Energy Information Administration, Form ElA-412, "Annual Report of Public Electric Utilities." 

Table 41. Electric Energy Account by Major Publicly Owned Electric
Utility Withir State, 1991 (Continued) (Megawatthours)

\begin{tabular}{|c|c|c|c|c|c|c|}
\hline Item & $\begin{array}{l}\text { Minnesotc } \\
\text { New Uim } \\
\text { Publt: } \\
\text { Utilitior } \\
\text { Comm } \\
\text { Desemiver } 31\end{array}$ & $\begin{array}{l}\text { Minnesuis } \\
\text { Northern } \\
\text { Municipal } \\
\text { Power Agny } \\
\text { Cecembers } 31\end{array}$ & $\begin{array}{c}\text { Minnesota } \\
\text { Owatonna } \\
\text { City of } \\
\text { December } 31\end{array}$ & $\begin{array}{l}\text { Minnesota } \\
\text { Rochester } \\
\text { Public } \\
\text { Utilitias } \\
\text { December } 31\end{array}$ & $\begin{array}{c}\text { Minnesota } \\
\text { Southern } \\
\text { Minnesota } \\
\text { Mun P } \\
\text { Agny } \\
\text { December } 31\end{array}$ & $\begin{array}{l}\text { Minnesota } \\
\text { Western } \\
\text { Ninnesota } \\
\text { Mun } \\
\text { Pwr Agny } \\
\text { December } 31\end{array}$ \\
\hline 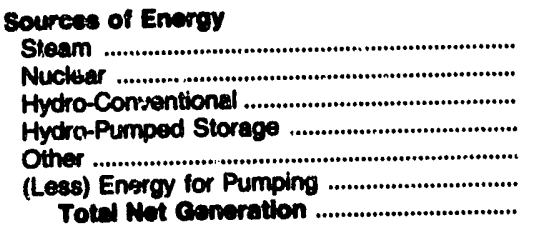 & $\begin{array}{r}62,124 \\
0 \\
0 \\
0 \\
0 \\
0 \\
62,124\end{array}$ & $\begin{array}{r}568,987 \\
0 \\
0 \\
0 \\
0 \\
0 \\
598,997\end{array}$ & $\begin{array}{l}0 \\
0 \\
0 \\
0 \\
0 \\
0 \\
0\end{array}$ & $\begin{array}{r}245,459 \\
0 \\
14,896 \\
0 \\
1,132 \\
0 \\
0 \\
281,497\end{array}$ & $\begin{array}{r}1,826,276 \\
0 \\
0 \\
0 \\
0 \\
0 \\
0 \\
1,826,276\end{array}$ & $\begin{array}{r}1,775,009 \\
0 \\
0 \\
0 \\
0 \\
0 \\
1,775,000\end{array}$ \\
\hline 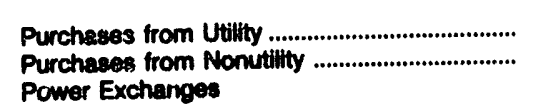 & $\begin{array}{r}109,307 \\
0\end{array}$ & $\begin{array}{l}0 \\
0\end{array}$ & $\begin{array}{r}228,847 \\
0\end{array}$ & $\begin{array}{r}896,721 \\
0\end{array}$ & $\begin{array}{r}574,644 \\
5,728\end{array}$ & $\begin{array}{r}505 \\
0\end{array}$ \\
\hline 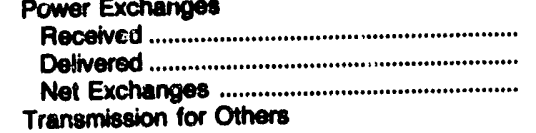 & $\begin{array}{l}0 \\
0 \\
0\end{array}$ & $\begin{array}{l}0 \\
0 \\
0\end{array}$ & $\begin{array}{l}\mathbf{0} \\
\mathbf{0} \\
\mathbf{0}\end{array}$ & $\begin{array}{l}0 \\
0 \\
0\end{array}$ & $\begin{array}{l}0 \\
0 \\
0\end{array}$ & $\begin{array}{l}\mathbf{0} \\
\mathbf{0} \\
\mathbf{0}\end{array}$ \\
\hline 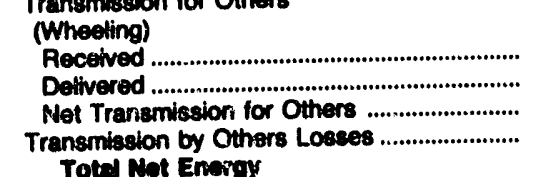 & $\begin{array}{l}0 \\
0 \\
0 \\
0\end{array}$ & $\begin{array}{l}0 \\
0 \\
0 \\
0\end{array}$ & $\begin{array}{l}0 \\
0 \\
0 \\
0\end{array}$ & $\begin{array}{l}0 \\
0 \\
0 \\
0\end{array}$ & $\begin{array}{l}0 \\
0 \\
0 \\
0\end{array}$ & $\begin{array}{l}0 \\
0 \\
0 \\
0\end{array}$ \\
\hline $\begin{array}{l}\text { Toted Rot Enorgy } \\
\text { Cenorated and hecetved ............................ }\end{array}$ & 171,431 & $58,, 907$ & 228,047 & $1,168,208$ & $2,406,648$ & $1,776,514$ \\
\hline 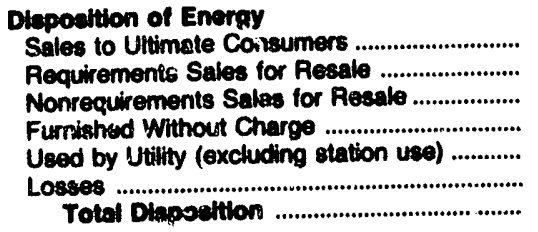 & $\begin{array}{r}162,273 \\
0 \\
0 \\
0 \\
0 \\
9,158 \\
171,431\end{array}$ & $\begin{array}{r}0 \\
568,887 \\
0 \\
0 \\
0 \\
0 \\
598,997\end{array}$ & $\begin{array}{r}214,697 \\
0 \\
0 \\
6,769 \\
0 \\
7,381 \\
228,847\end{array}$ & $\begin{array}{r}881,756 \\
246,591 \\
0 \\
0 \\
2,042 \\
27,819 \\
1,150,208\end{array}$ & $\begin{array}{r}0 \\
2,339,316 \\
0 \\
0 \\
0 \\
67,332 \\
2,408,648\end{array}$ & $\begin{array}{r}0 \\
1,775,514 \\
0 \\
0 \\
0 \\
0 \\
1,776,514\end{array}$ \\
\hline
\end{tabular}

Note: Totels msy not equal sum of components beceuse of indejsondent rounding. Double counting occurs in components of both sources and disposition of eneroy and thus netthes provide, a true total. Purchases from utitites, net inferchanges, and net wheeling (except for imports) are included in net generation. Sales for resale is included in seles to utimate coneumers.

generation. Sales Ior restion Administration, Form ElA-412, "Annual Peport of Public Electric Utilities." 
Table 41. Electric Energy Account by Major Publicly Owned Electric Utility Within State, 1991 (Continued) (Megawatthours)

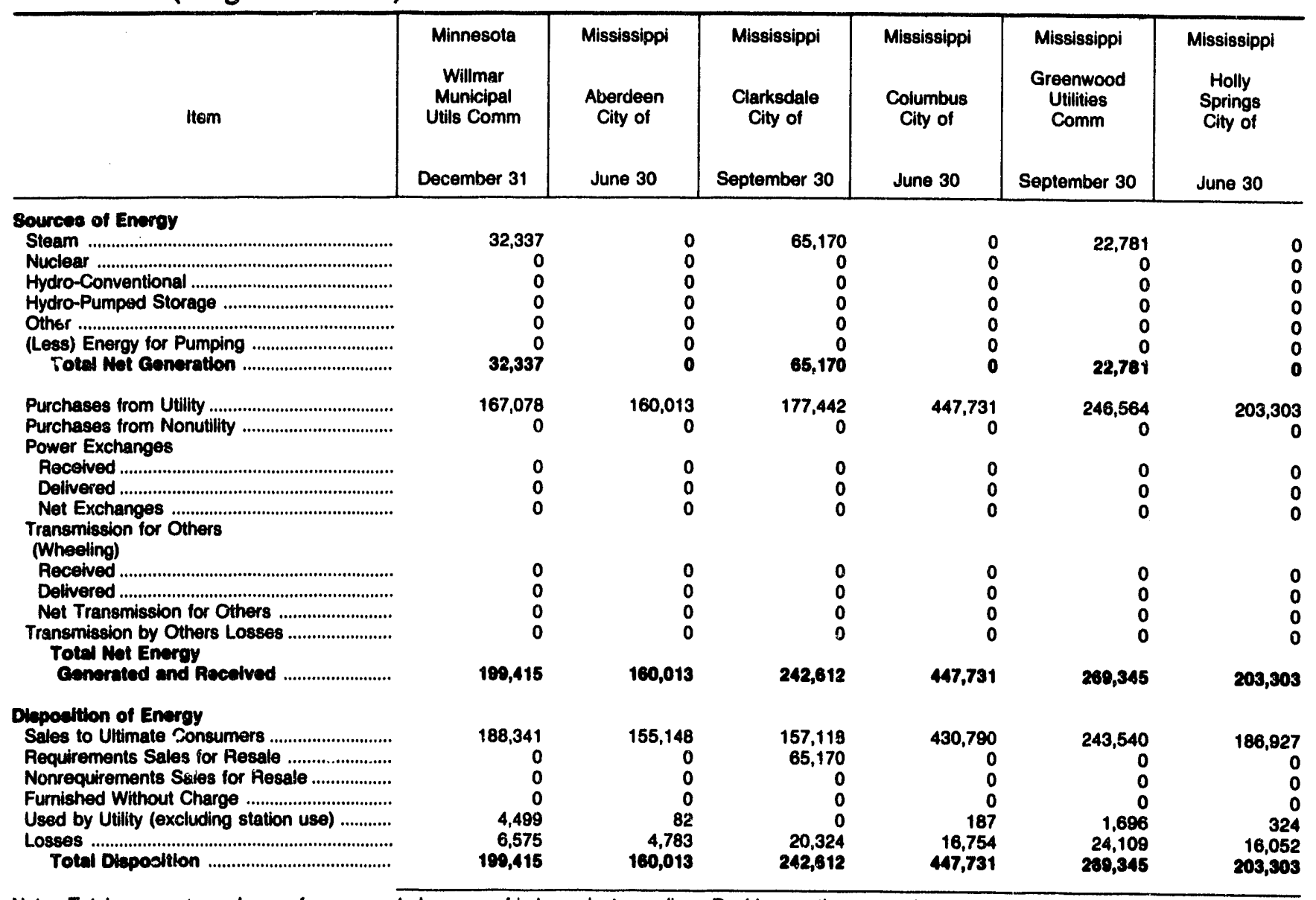

Note: Totals may not equal sum of components because of independent rounding. Double counting occurs in components of both sources and disposition of energy and thus neither provides a true total. Purchases from utilities, net interchanges, and net wheeling (except for imports) are included in net generation. Sales for resale is included in sales to ultimate consumers.

Source: Energy Information Administration, Form EIA-412, "Annual Report of Public Electric Utilities." 
Table 41. Electric Energy Account by Major Publicly Owned Electric Utility Within State, 1991 (Continued) (Megawatthours)

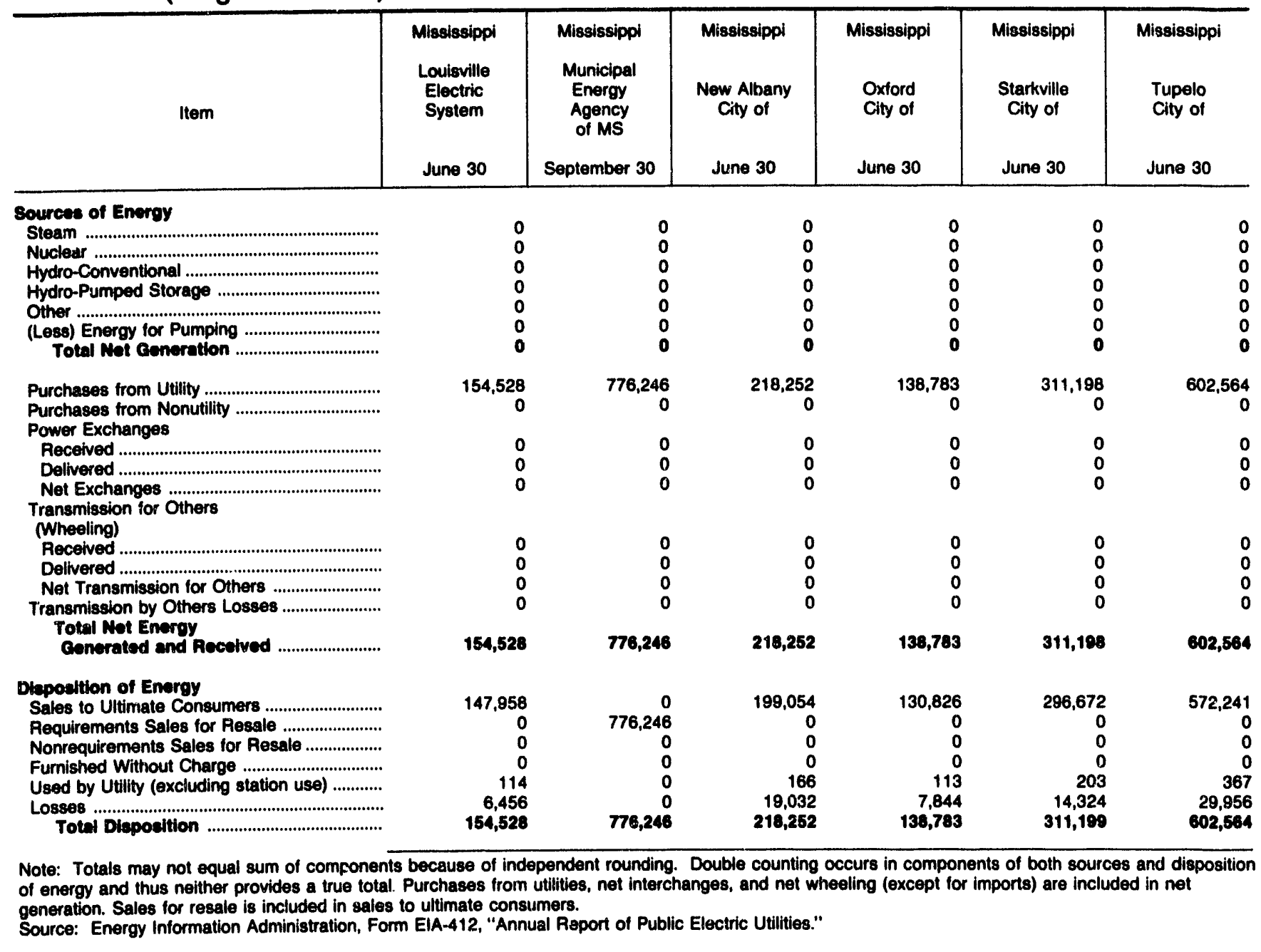


Table 41. Electric Energy Account by Major Publicly Owned Electric Utility Within State, 1991 (Continued)

(Megawatthours)

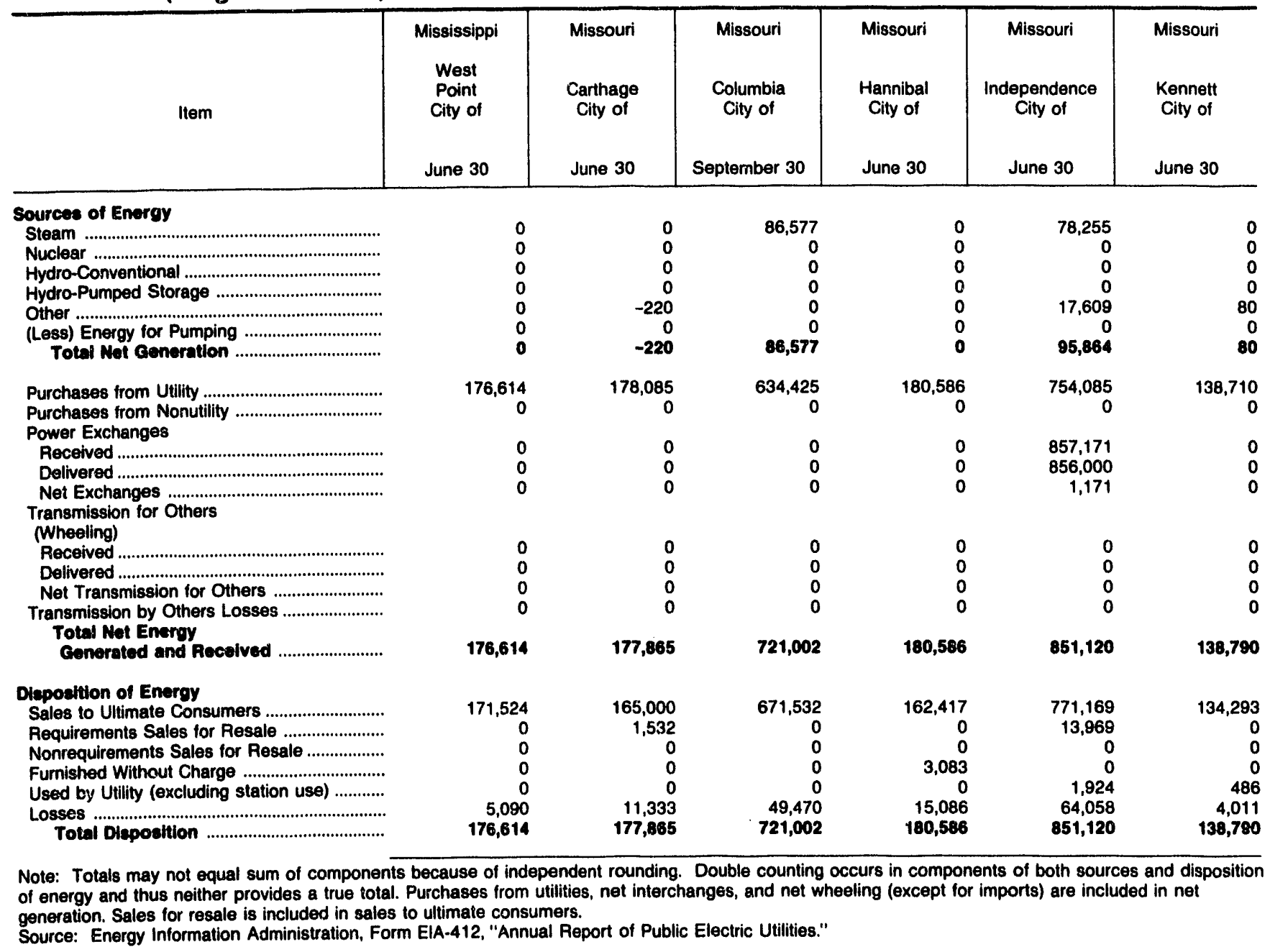




\section{Table 41. Electric Energy Account by Major Publicly Owned Electric Utility Within State, 1091 (Continued)}

(Megawatthours)

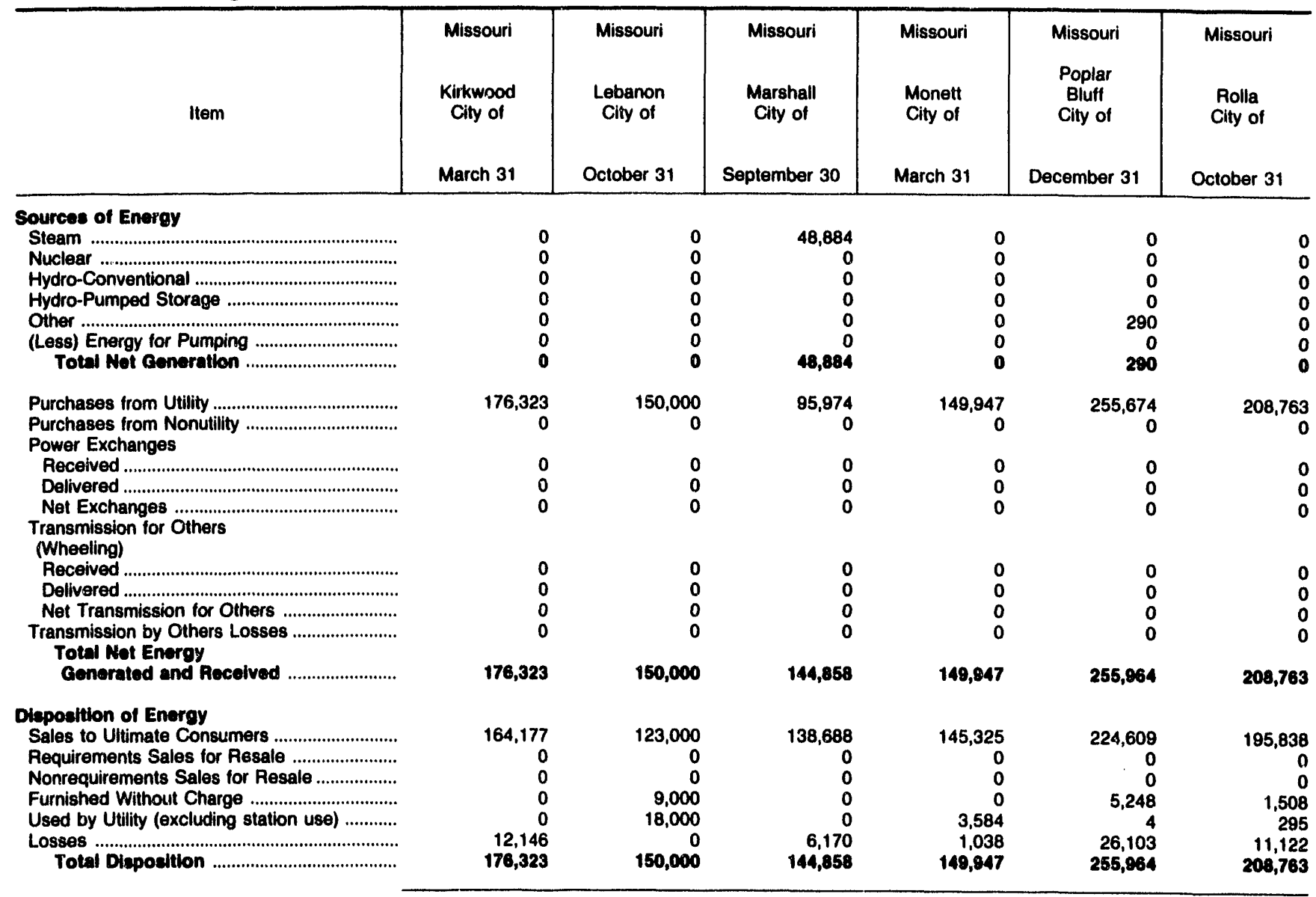

Note: Totals may not equal sum of components because of independent rounding. Double counting occurs in components of both sources and disposition of energy and thus neither provides a true total. Purchases from utilities, net interchanges, and net wheeling (except for imports) are included in net generation. Sales for resale is included in sales to ultimate consumers.

Source: Energy Information Administration, Form ElA-412, "Annual Report of Public Electric Utilities." 
Table 41. Electric Energy Account by Major Publicly Owned Electric Utility Within State, 1991 (Continued) (Megawatthours)

\begin{tabular}{|c|c|c|c|c|c|c|}
\hline Item & $\begin{array}{l}\text { Missouri } \\
\text { Sikeston } \\
\text { City of } \\
\text { May } 31\end{array}$ & $\begin{array}{c}\text { Missouri } \\
\text { Springfield } \\
\text { City of }\end{array}$ & $\begin{array}{c}\text { Nebraska } \\
\text { Central } \\
\text { Nebrzska } \\
\text { Pub } \\
\text { P\&I Dist } \\
\text { December } 31\end{array}$ & $\begin{array}{c}\text { Nobraska } \\
\text { Cornhusker } \\
\text { Public } \\
\text { Power Dist } \\
\text { December } 31\end{array}$ & $\begin{array}{c}\text { Nebraska } \\
\text { Dawson } \\
\text { County } \\
\text { Public } \\
\text { Pwr Dist } \\
\text { December } 31\end{array}$ & $\begin{array}{l}\text { Nebraska } \\
\text { Fremont } \\
\text { City of } \\
\text { July } 31\end{array}$ \\
\hline 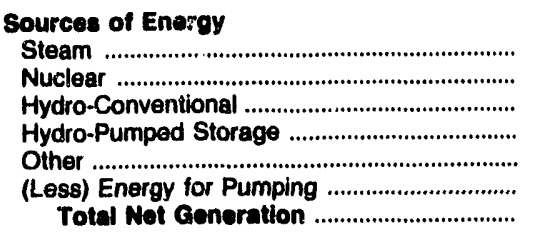 & $\begin{array}{r}1,525,715 \\
0 \\
0 \\
0 \\
0 \\
0 \\
1,525,715\end{array}$ & $\begin{array}{r}2,079,164 \\
0 \\
0 \\
0 \\
52,835 \\
0 \\
2,131,999\end{array}$ & $\begin{array}{r}181,864 \\
0 \\
223,048 \\
0 \\
0 \\
0 \\
404,912\end{array}$ & $\begin{array}{l}0 \\
0 \\
0 \\
0 \\
0 \\
0 \\
0\end{array}$ & $\begin{array}{l}0 \\
0 \\
0 \\
0 \\
0 \\
0 \\
0\end{array}$ & $\begin{array}{r}264,934 \\
0 \\
0 \\
0 \\
0 \\
0 \\
264,934\end{array}$ \\
\hline 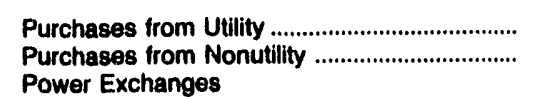 & $\begin{array}{r}128,912 \\
0\end{array}$ & $\begin{array}{r}239,567 \\
0\end{array}$ & $\begin{array}{l}0 \\
0\end{array}$ & $\begin{array}{r}211,195 \\
0\end{array}$ & $\begin{array}{r}283,782 \\
0\end{array}$ & $\begin{array}{r}51,814 \\
0\end{array}$ \\
\hline 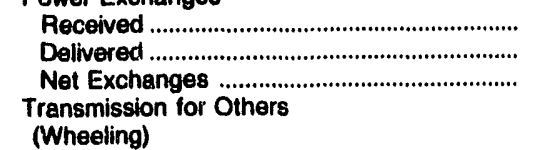 & $\begin{array}{r}74,376 \\
110,303 \\
-35,927\end{array}$ & $\begin{array}{r}100,098 \\
73,528 \\
26,570\end{array}$ & $\begin{array}{l}0 \\
0 \\
0\end{array}$ & $\begin{array}{l}0 \\
0 \\
0\end{array}$ & $\begin{array}{l}0 \\
0 \\
0\end{array}$ & $\begin{array}{l}0 \\
0 \\
0\end{array}$ \\
\hline 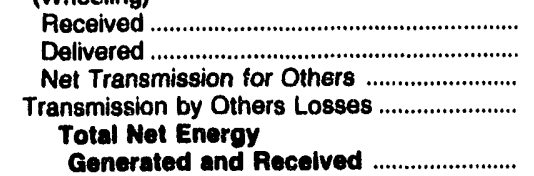 & $\begin{array}{l}0 \\
0 \\
0 \\
0\end{array}$ & $\begin{array}{r}0 \\
0 \\
0 \\
-1,526 \\
2,396,610\end{array}$ & 404,812 & $\begin{array}{r}7,164 \\
7,164 \\
0 \\
0\end{array}$ & 283,782 & 316,748 \\
\hline 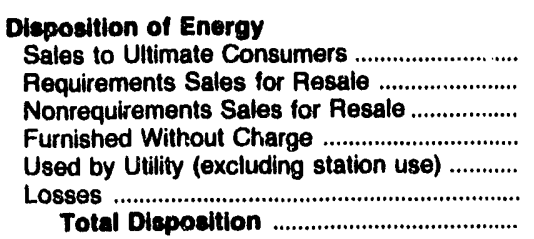 & $\begin{array}{r}222,782 \\
1,378,677 \\
0 \\
3,298 \\
0 \\
13,943 \\
1,618,700\end{array}$ & $\begin{array}{r}2,008,250 \\
230,155 \\
11,847 \\
30,997 \\
31,110 \\
84,251 \\
2,386,610\end{array}$ & $\begin{array}{r}0 \\
404,912 \\
0 \\
0 \\
0 \\
0 \\
404,912\end{array}$ & $\begin{array}{r}190,119 \\
2,602 \\
0 \\
0 \\
596 \\
17,878 \\
211,195\end{array}$ & $\begin{array}{r}254,957 \\
5,682 \\
0 \\
0 \\
121 \\
23,012 \\
283,782\end{array}$ & $\begin{array}{r}285,608 \\
8,709 \\
0 \\
5,048 \\
1,553 \\
15,830 \\
316,748\end{array}$ \\
\hline
\end{tabular}

Note: Totals may not equal sum of components because of independent rounding. Double counting occurs in components of both sources and disposition of energy and thus neither provides a true total. Purchases from utitities, net interchanges, and net wheeling (except for imports) are included in net generation. Sales for resale is included in sales to ultimate consumers.

Source: Energy Information Administration, Form EIA-412, "Annual Report of Public Electric Utilities." 
Table 41. Electric Energy Account by Major Publicly Owned Electric Utility Within State, 1991 (Continued)

(Megawatthours)

\begin{tabular}{|c|c|c|c|c|c|c|}
\hline Item & $\begin{array}{l}\text { Nebraska } \\
\text { Grand Island } \\
\text { City of } \\
\text { July } 31\end{array}$ & $\begin{array}{l}\text { Nebraska } \\
\text { Hastings } \\
\text { City of } \\
\text { December } 31\end{array}$ & $\begin{array}{l}\text { Nebraska } \\
\text { Lincoln } \\
\text { Electric } \\
\text { System } \\
\text { December } 31\end{array}$ & $\begin{array}{c}\text { Nebraska } \\
\text { Loup } \\
\text { River } \\
\text { Public } \\
\text { Power Dist } \\
\text { December } 31\end{array}$ & $\begin{array}{l}\text { Nebraska } \\
\text { Municipal } \\
\text { Energy } \\
\text { Agency } \\
\text { of NE } \\
\text { March } 31\end{array}$ & $\begin{array}{l}\text { Nebraska } \\
\text { Nebraska } \\
\text { Public } \\
\text { Power } \\
\text { District } \\
\text { December } 31\end{array}$ \\
\hline 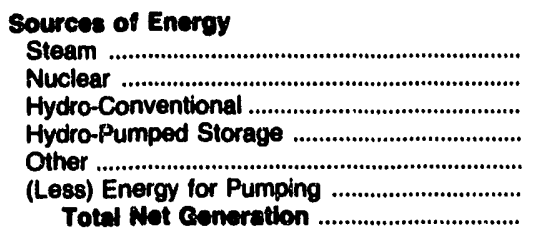 & $\begin{array}{r}517,179 \\
0 \\
0 \\
0 \\
0 \\
0 \\
517,170\end{array}$ & $\begin{array}{r}309,232 \\
0 \\
0 \\
0 \\
-83 \\
0 \\
300,149\end{array}$ & $\begin{array}{r}1,232,888 \\
0 \\
0 \\
0 \\
4,618 \\
0 \\
1,237,508\end{array}$ & $\begin{array}{r}0 \\
0 \\
124,494 \\
0 \\
0 \\
0 \\
124,404\end{array}$ & $\begin{array}{r}182,448 \\
0 \\
0 \\
0 \\
0 \\
0 \\
192,448\end{array}$ & $\begin{array}{r}6,719,722 \\
4,803,807 \\
75,728 \\
0 \\
1,255 \\
0 \\
0 \\
11,600,512\end{array}$ \\
\hline 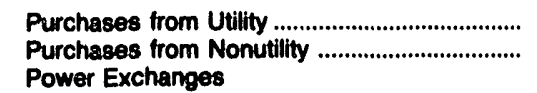 & $\begin{array}{r}64,321 \\
0\end{array}$ & $\begin{array}{r}56,107 \\
0\end{array}$ & $\begin{array}{r}1,625,685 \\
6\end{array}$ & $\begin{array}{r}737,153 \\
0\end{array}$ & $\begin{array}{r}723,953 \\
0\end{array}$ & $\begin{array}{r}1,954,185 \\
0\end{array}$ \\
\hline $\begin{array}{l}\text { Received } \\
\text { Delivered } \\
\text { Net Exchanges } \\
\text { Transmission for Others } \\
\text { (Wheling) }\end{array}$ & $\begin{array}{l}952 \\
614 \\
238\end{array}$ & $\begin{array}{l}0 \\
0 \\
0\end{array}$ & $\begin{array}{r}165 \\
2,819 \\
-2,654\end{array}$ & $\begin{array}{l}0 \\
0 \\
0\end{array}$ & $\begin{array}{l}0 \\
0 \\
0\end{array}$ & $\begin{array}{r}72,374 \\
66,062 \\
6,312\end{array}$ \\
\hline 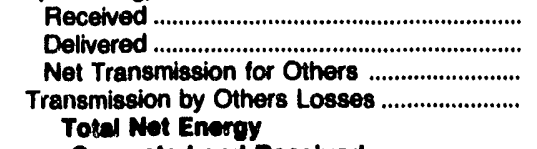 & $\begin{array}{l}0 \\
0 \\
0 \\
0\end{array}$ & $\begin{array}{r}5,470 \\
5,470 \\
0 \\
0\end{array}$ & $\begin{array}{r}111,335 \\
111,335 \\
0 \\
0\end{array}$ & $\begin{array}{l}0 \\
0 \\
0 \\
0\end{array}$ & $\begin{array}{l}0 \\
0 \\
0 \\
0\end{array}$ & $\begin{array}{l}0 \\
0 \\
0 \\
0\end{array}$ \\
\hline Gonerated and Recelved ............................ & 581,738 & 365,256 & $2,840,543$ & 861,647 & 916,401 & $13,581,000$ \\
\hline 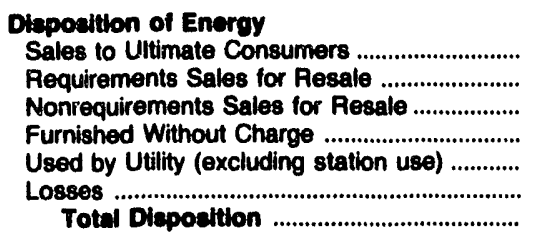 & $\begin{array}{r}462,262 \\
94,438 \\
0 \\
0 \\
0 \\
25,038 \\
\mathbf{5 8 1 , 7 3 8}\end{array}$ & $\begin{array}{r}244,441 \\
109,454 \\
0 \\
0 \\
0 \\
11,361 \\
365,256\end{array}$ & $\begin{array}{r}2,083,488 \\
78,786 \\
531,795 \\
0 \\
4,644 \\
160,820 \\
2,860,543\end{array}$ & $\begin{array}{r}552,122 \\
288,421 \\
0 \\
0 \\
1,875 \\
19,229 \\
881,647\end{array}$ & $\begin{array}{r}0 \\
675,786 \\
197,445 \\
0 \\
0 \\
43,170 \\
916,401\end{array}$ & $\begin{array}{r}2,510,705 \\
10,550,435 \\
0 \\
0 \\
18,231 \\
481,638 \\
13,681,000\end{array}$ \\
\hline
\end{tabular}

Note: Totals may not equal sum of components because of independent rounding. Double counting occurs in components of both sources and disposition of energy and thus neither provides a true total. Purchases from utilities, net interchanges, and net wheeling (except for imports) are included in net generation. Sales for resale is included in sales to ultimate consumers.

Source: Energy Information Administration, Form EIA-412, "Annual Report of Public Electric Utilities." 
Table 41. Electric Energy Account by Major Publicly Owned Electric Utility Within State, 1991 (Continued)

(Megawatthours)

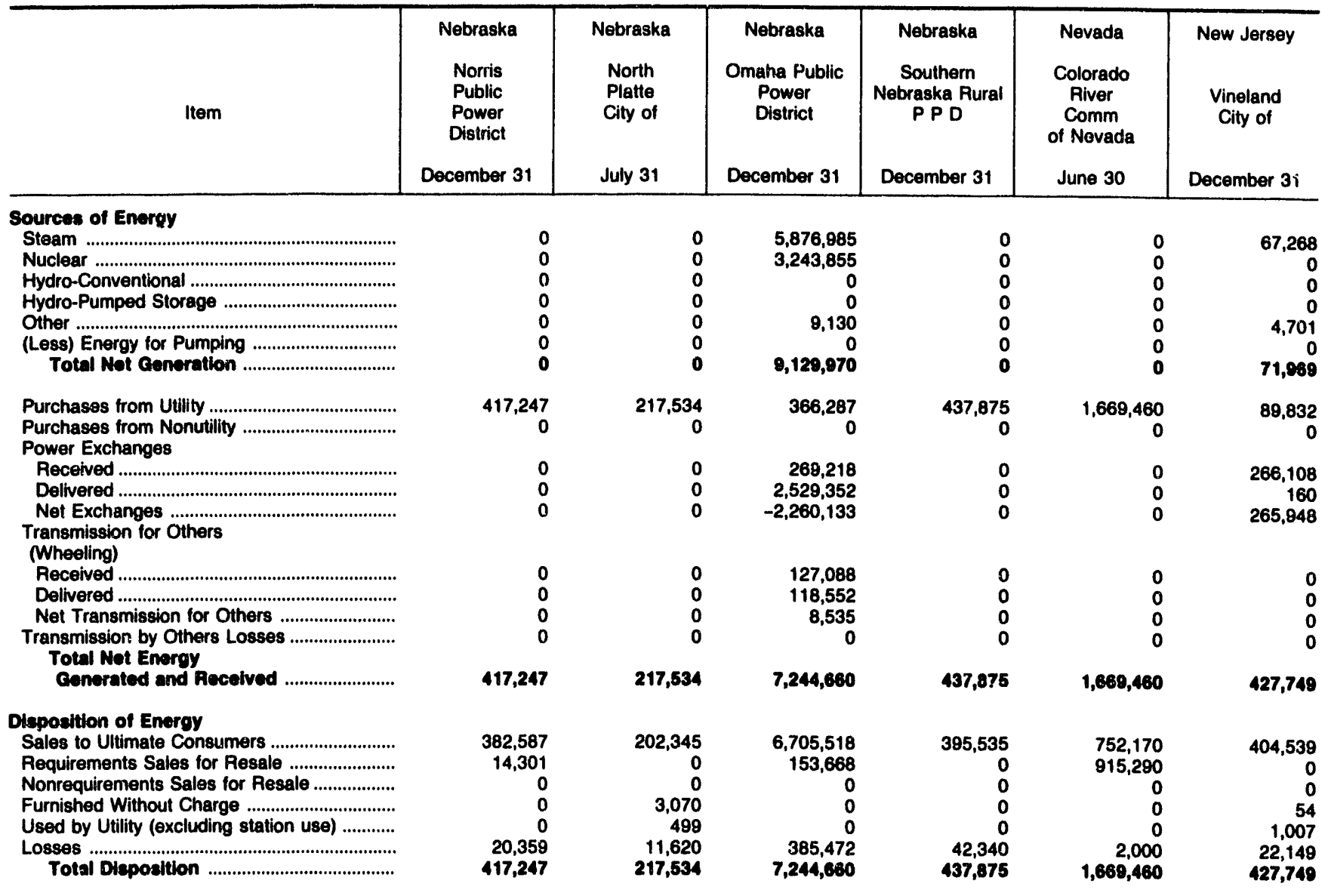

Note: Totals may not equal sum of components because of independent rounding. Double counting occurs in components of both sources and disposition of energy and thus neither provides a true total. Purchases from utilities, net interchanges, and net wheeling (except for imports) are included in net generation. Sales for resale is included in sales to ultimate consumers.

Source: Energy Information Administration, Form EIA-412, "Annual Report of Public Electric Utilities." 
Table 41. Electric Energy Account by Major Publicly Owned Electric Utility Within State, 1991 (Continued) (Megawatthours)

\begin{tabular}{|c|c|c|c|c|c|c|}
\hline Item & $\begin{array}{l}\text { New Mexico } \\
\text { Farmington } \\
\text { City of } \\
\text { June } 30\end{array}$ & $\begin{array}{l}\text { New Mexico } \\
\text { Gallup } \\
\text { City of } \\
\text { June } 30\end{array}$ & $\begin{array}{l}\text { New Mexico } \\
\text { Los Alamos } \\
\text { County } \\
\text { June } 30\end{array}$ & $\begin{array}{l}\text { New York } \\
\text { Fairport } \\
\text { Village of } \\
\text { May } 31\end{array}$ & $\begin{array}{l}\text { New York } \\
\text { Freeport } \\
\text { Village of } \\
\text { Inc } \\
\text { February } 28\end{array}$ & $\begin{array}{l}\text { New York } \\
\text { Jamestown } \\
\text { City of } \\
\text { December } 31\end{array}$ \\
\hline 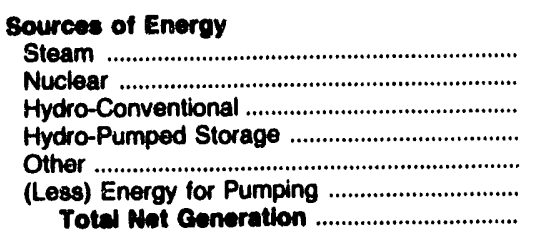 & $\begin{array}{r}277,061 \\
0 \\
141,557 \\
0 \\
0 \\
0 \\
418,618\end{array}$ & $\begin{array}{l}0 \\
0 \\
0 \\
0 \\
0 \\
0 \\
0\end{array}$ & $\begin{array}{r}157,467 \\
0 \\
62,846 \\
0 \\
0 \\
0 \\
220,313\end{array}$ & $\begin{array}{l}0 \\
0 \\
0 \\
0 \\
0 \\
0 \\
0\end{array}$ & $\begin{array}{r}0 \\
0 \\
0 \\
0 \\
5,335 \\
0 \\
5,335\end{array}$ & $\begin{array}{r}193,401 \\
0 \\
0 \\
0 \\
0 \\
0 \\
193,401\end{array}$ \\
\hline 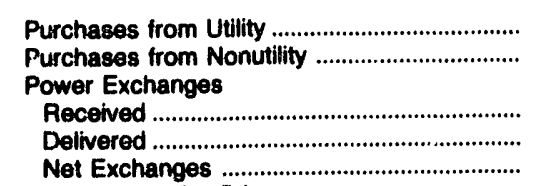 & $\begin{array}{r}125,919 \\
0 \\
2,685 \\
34,730 \\
-32,045\end{array}$ & $\begin{array}{r}182,051 \\
0 \\
0 \\
0 \\
0\end{array}$ & $\begin{array}{r}51,733 \\
63,837 \\
-12,104\end{array}$ & $\begin{array}{r}329,185 \\
0\end{array}$ & $\begin{array}{r}217,517 \\
0\end{array}$ & $\begin{array}{r}406,208 \\
0\end{array}$ \\
\hline 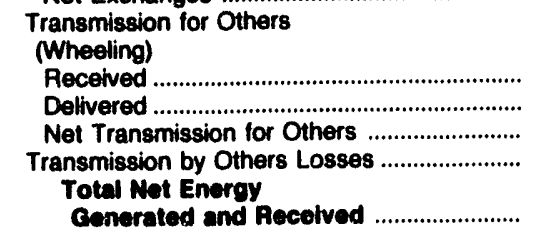 & $\begin{array}{r}9,921 \\
9,921 \\
0 \\
0\end{array}$ & $\begin{array}{l}0 \\
0 \\
0 \\
0\end{array}$ & 490,593 & $\begin{array}{l}0 \\
0 \\
0 \\
0\end{array}$ & $\begin{array}{l}0 \\
0 \\
0 \\
0\end{array}$ & 599,609 \\
\hline 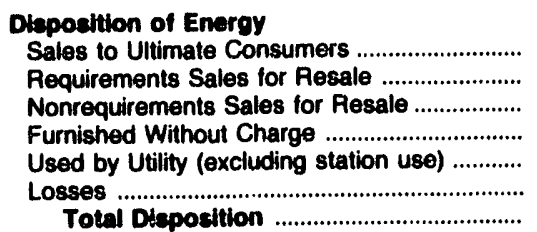 & $\begin{array}{r}452,744 \\
16,051 \\
21,586 \\
0 \\
0 \\
22,111 \\
512,492\end{array}$ & $\begin{array}{r}172,321 \\
0 \\
0 \\
0 \\
0 \\
9,730 \\
182,051\end{array}$ & $\begin{array}{r}458,914 \\
16,141 \\
0 \\
0 \\
0 \\
15,538 \\
480,593\end{array}$ & $\begin{array}{r}308,923 \\
0 \\
0 \\
0 \\
322 \\
19,940 \\
329,185\end{array}$ & $\begin{array}{r}209,078 \\
171 \\
0 \\
0 \\
3,874 \\
9,729 \\
222,852\end{array}$ & $\begin{array}{r}413,232 \\
165,005 \\
0 \\
0 \\
1,153 \\
20,219 \\
590,609\end{array}$ \\
\hline
\end{tabular}

Note: Totals may not equal sum of components because of independent rounding. Double counting occurs in components of both sources and disposition of energy and thus neither provides a true total. Purchases from utilities, net interchanges, and net wheeling (except for imports) are included in net generation. Sales for resale is included in sales to ultimate consumers.

Source: Energy Information Administration, Form ElA-412, "Annual Report of Public Electric Utilities." 
Table 41. Electric Energy Account by Major Publicly Owned Electric Utility Within State, 1991 (Continued) (Megawatthours)

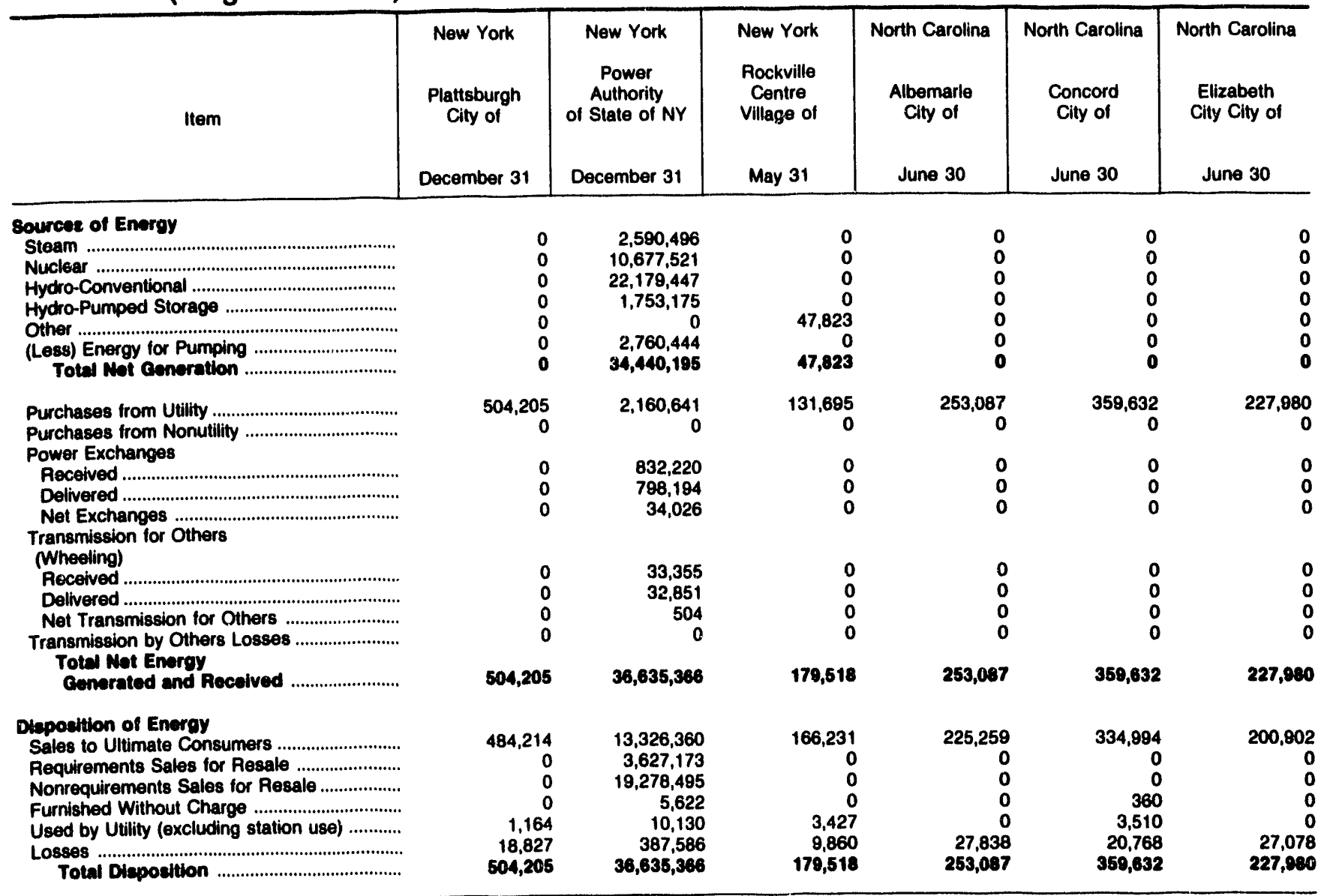

Note: Totals may not equal sum of components because of independent rounding. Double counting occurs in components of both sources and disposition of energy and thus neither provides a true total. Purchases from utilities, net interchanges, and net wheeling (except for imports) are included in net generation. Sales for resale is included in sales to ultimate consumers.

Source: Energy Information Administration, Form ElA-412, "Annual Report of Public Electric Utilities." 
Table 41. Electric Energy Account by Major Publicly Owned Electric Utility Within State, 1991 (Continued)

(Megawatthours)

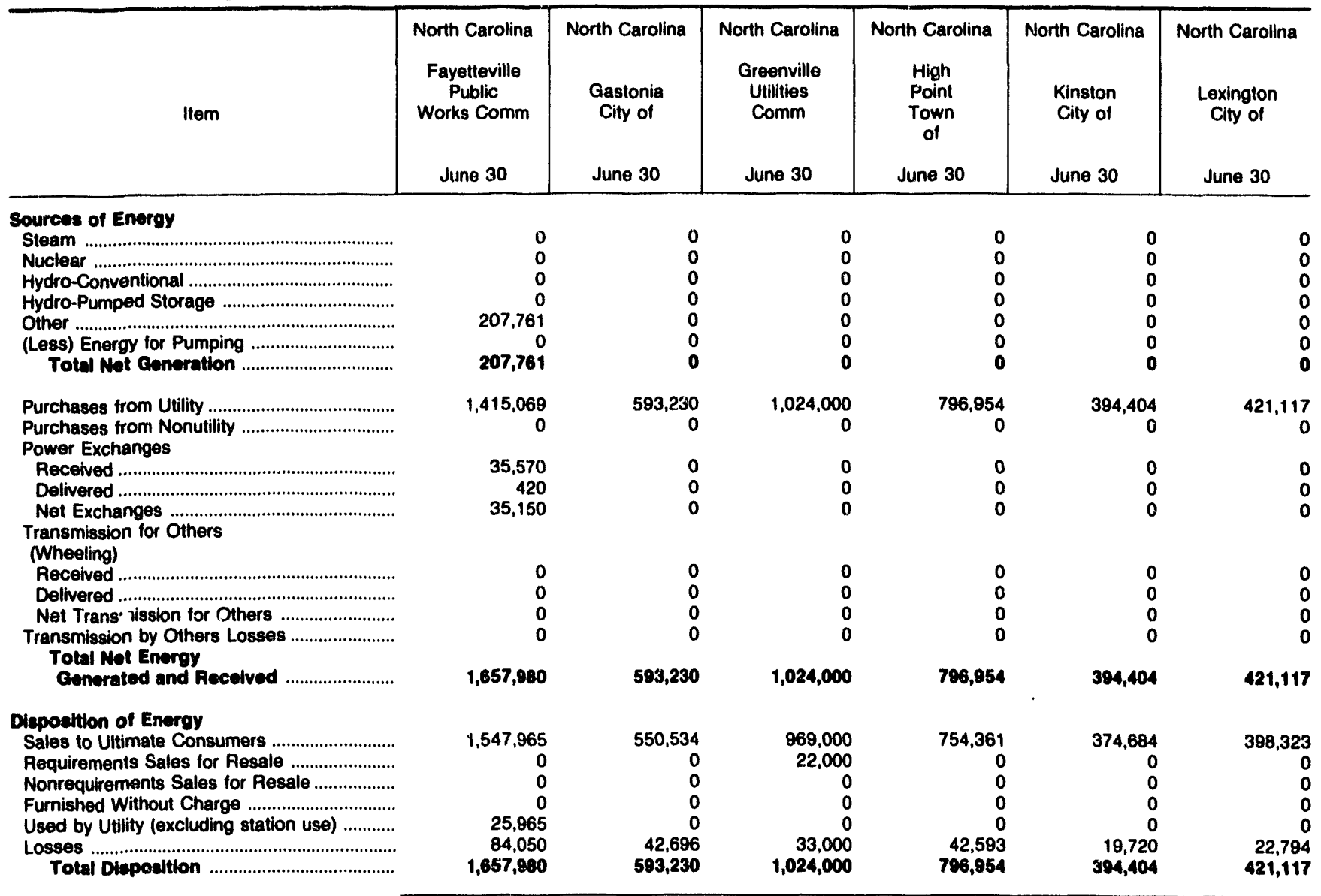

Note: Totals may not equal sum of components because of independent rounding. Double counting occurs in components of both sources and disposition of energy and thus neither provides a true total. Purchases from utilities, net interchanges, and net wheeling (except for imports) are included in net generation. Sales for resale is included in sales to ultimate consumers.

Source: Energy Information Administration, Form EIA-412, "Annual Report of Public Electric Utilities." 
Table 41. Electric Energy Account by Major Publicly Owned Electric Utility Within State, 1991 (Continued)

(Megawatthours)

\begin{tabular}{|c|c|c|c|c|c|c|}
\hline Item & $\begin{array}{l}\text { North Carolina } \\
\text { Lumberton } \\
\text { City of } \\
\text { June } 30\end{array}$ & $\begin{array}{l}\text { North Carolina } \\
\text { Monroe } \\
\text { City of } \\
\text { June } 30\end{array}$ & $\begin{array}{l}\text { North Carolina } \\
\text { Morganton } \\
\text { City of } \\
\text { June } 30\end{array}$ & $\begin{array}{l}\text { North Carolina } \\
\text { Murphy } \\
\text { City of } \\
\text { June } 30\end{array}$ & $\begin{array}{l}\text { North Carolina } \\
\text { New Bern } \\
\text { City of } \\
\text { June } 30\end{array}$ & $\begin{array}{c}\text { North Carolina } \\
\text { New River } \\
\text { Light } \\
\& \\
\text { Power Co } \\
\text { December } 31\end{array}$ \\
\hline 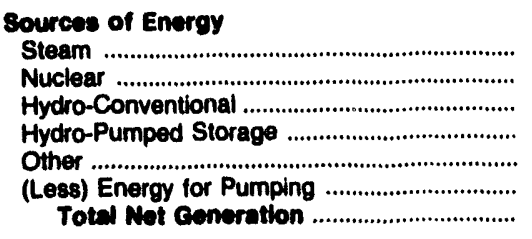 & $\begin{array}{l}0 \\
0 \\
0 \\
0 \\
0 \\
0 \\
0\end{array}$ & $\begin{array}{l}0 \\
0 \\
0 \\
0 \\
0 \\
0 \\
0\end{array}$ & $\begin{array}{l}0 \\
0 \\
0 \\
0 \\
0 \\
0 \\
0\end{array}$ & $\begin{array}{l}0 \\
0 \\
0 \\
0 \\
0 \\
0 \\
0\end{array}$ & $\begin{array}{l}0 \\
0 \\
0 \\
0 \\
0 \\
0 \\
0\end{array}$ & $\begin{array}{l}0 \\
0 \\
0 \\
0 \\
0 \\
0 \\
0\end{array}$ \\
\hline 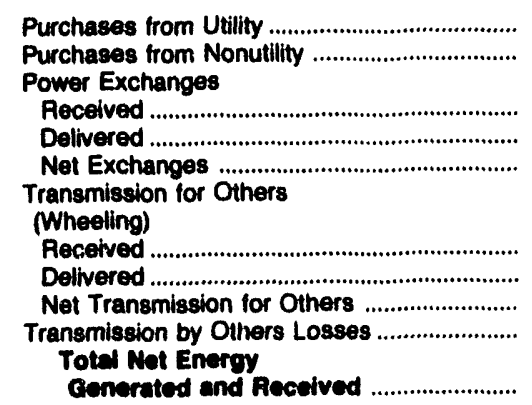 & $\begin{array}{r}262,486 \\
0\end{array}$ & $\begin{array}{r}403,715 \\
0\end{array}$ & $\begin{array}{r}261,682 \\
0 \\
0 \\
0 \\
0\end{array}$ & $\begin{array}{r}138,393 \\
0\end{array}$ & $\begin{array}{r}347,544 \\
0\end{array}$ & $\begin{array}{r}165,383 \\
0\end{array}$ \\
\hline 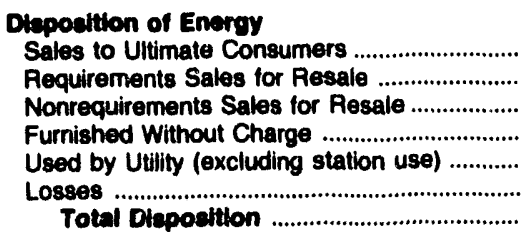 & $\begin{array}{r}235,945 \\
0 \\
0 \\
4,189 \\
114 \\
22,238 \\
282,486\end{array}$ & $\begin{array}{r}380,443 \\
0 \\
0 \\
0 \\
0 \\
23,272 \\
403,715\end{array}$ & $\begin{array}{r}254,544 \\
0 \\
0 \\
0 \\
0 \\
7,138 \\
281,892\end{array}$ & $\begin{array}{r}133,920 \\
0 \\
0 \\
0 \\
145 \\
4,328 \\
138,393\end{array}$ & $\begin{array}{r}312,391 \\
0 \\
0 \\
0 \\
3,092 \\
32,061 \\
347,544\end{array}$ & $\begin{array}{r}158,563 \\
0 \\
0 \\
0 \\
0 \\
6,820 \\
185,393\end{array}$ \\
\hline
\end{tabular}

Note: Totals may not equal sum of components because of independent rounding. Double counting occurs in components of both sources and disposition of energy and thus neither provides a true total. Purchases from utilities, net interchanges, and net wheeling (except for imports) are included in net generation. Sales for resale is included in sales to ultimate consumers.

Source: Energy Information Administration, Form EIA-412, "Annual Report of Public Electric Utilities." 
Table 41. Electric Energy Account by Major Publicly Owned Electric Utility Within State, 1991 (Continued)

(Megawatthours)

\begin{tabular}{|c|c|c|c|c|c|c|}
\hline Item & $\begin{array}{l}\text { North Carolina } \\
\text { North } \\
\text { Carolina } \\
\text { Eastern M P A } \\
\text { December } 31\end{array}$ & $\begin{array}{l}\text { North Carolina } \\
\text { North } \\
\text { Carolina } \\
\text { Mun } \\
\text { Power Agny } \\
\text { December } 31\end{array}$ & $\begin{array}{l}\text { North Carolina } \\
\text { Rocky Mount } \\
\text { City of } \\
\text { June } 30\end{array}$ & $\begin{array}{l}\text { North Carolina } \\
\text { Shelby } \\
\text { City of } \\
\text { June } 30\end{array}$ & $\begin{array}{l}\text { North Carolina } \\
\text { Statesville } \\
\text { City of } \\
\text { June } 30\end{array}$ & $\begin{array}{l}\text { North Carolina } \\
\text { Tarboro } \\
\text { Town of } \\
\text { June } 30\end{array}$ \\
\hline 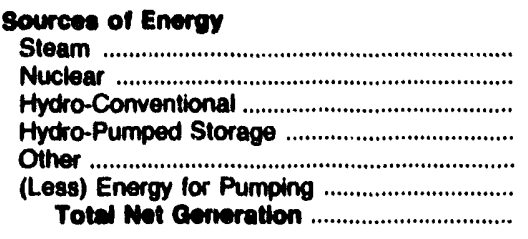 & $\begin{array}{r}1,576,233 \\
2,444,683 \\
0 \\
0 \\
0 \\
0 \\
4,020,916\end{array}$ & $\begin{array}{r}0 \\
5,328,120 \\
0 \\
0 \\
0 \\
0 \\
5,328,120\end{array}$ & $\begin{array}{l}0 \\
0 \\
0 \\
0 \\
0 \\
0 \\
0\end{array}$ & $\begin{array}{l}0 \\
0 \\
0 \\
0 \\
0 \\
0 \\
0\end{array}$ & $\begin{array}{l}0 \\
0 \\
0 \\
0 \\
0 \\
0 \\
0\end{array}$ & $\begin{array}{l}0 \\
0 \\
0 \\
0 \\
0 \\
0 \\
0\end{array}$ \\
\hline 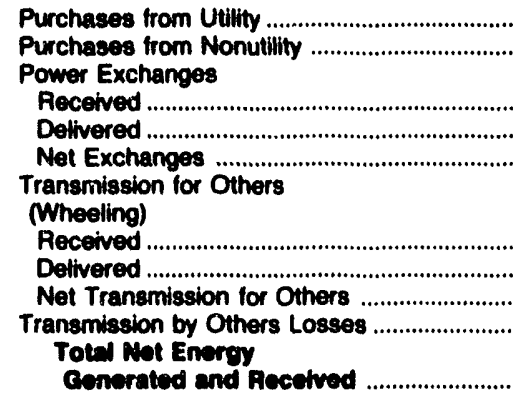 & $\begin{array}{r}2,066,898 \\
0\end{array}$ & $\begin{array}{r}3,055,703 \\
0\end{array}$ & $\begin{array}{r}772,453 \\
0\end{array}$ & $\begin{array}{r}168,061 \\
0\end{array}$ & $\begin{array}{r}359,937 \\
0\end{array}$ & $\begin{array}{r}232,861 \\
0\end{array}$ \\
\hline 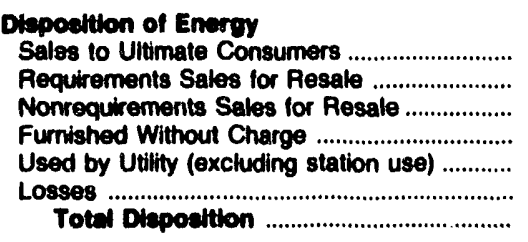 & $\begin{array}{r}0 \\
5,962,319 \\
0 \\
0 \\
0 \\
125,495 \\
6,087,814\end{array}$ & $\begin{array}{r}0 \\
8,022,722 \\
0 \\
0 \\
0 \\
361,101 \\
8,383,823\end{array}$ & $\begin{array}{r}722,955 \\
15,845 \\
0 \\
0 \\
0 \\
0 \\
33,653 \\
772,453\end{array}$ & $\begin{array}{r}155,673 \\
0 \\
0 \\
0 \\
0 \\
12,388 \\
168,081\end{array}$ & $\begin{array}{r}339,203 \\
0 \\
0 \\
0 \\
0 \\
20,734 \\
350,937\end{array}$ & $\begin{array}{r}223,342 \\
0 \\
0 \\
0 \\
0 \\
9,519 \\
232,061\end{array}$ \\
\hline
\end{tabular}

Nole: Totals may not equal sum of components because of independent rounding. Double counting occurs in components of both sources and disposition of energy and thus neither provides a true total. Purchases from utilities, net interchanges, and net wheeling (except for imports) are included in net generation. Sales for resale is included in sales to ultimate consumers.

Source: Energy Information Administration, Form EIA-412. "Annual Report of Public Electric Utilities." 


\section{Table 41. Electric Energy Account by Major Publicly Owned Electric Utility Within State, 1991 (Continued)}

(Megawatthours)

\begin{tabular}{|c|c|c|c|c|c|c|}
\hline Item & $\begin{array}{l}\text { North Carolina } \\
\text { Washington } \\
\text { City of } \\
\text { June } 30\end{array}$ & $\begin{array}{c}\text { North Carolina } \\
\text { Wilson } \\
\text { City of } \\
\text { June } 30\end{array}$ & $\begin{array}{c}\text { Ohio } \\
\text { American } \\
\text { Mun } \\
\text { Power } \\
\text { Ohio Inc } \\
\text { December } 31\end{array}$ & $\begin{array}{c}\text { Ohio } \\
\text { Bowling } \\
\text { Green } \\
\text { City of } \\
\text { December } 31\end{array}$ & $\begin{array}{c}\text { Ohio } \\
\text { Bryan } \\
\text { City of } \\
\text { December } 31\end{array}$ & $\begin{array}{l}\text { Ohio } \\
\text { Celina } \\
\text { City of } \\
\text { December } 31\end{array}$ \\
\hline 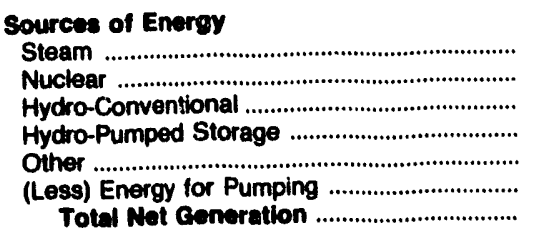 & $\begin{array}{l}0 \\
0 \\
0 \\
0 \\
0 \\
0 \\
0\end{array}$ & $\begin{array}{l}0 \\
0 \\
0 \\
0 \\
0 \\
0 \\
0\end{array}$ & $\begin{array}{r}1,316,128 \\
0 \\
0 \\
0 \\
616 \\
0 \\
1,316,744\end{array}$ & $\begin{array}{l}0 \\
0 \\
0 \\
0 \\
0 \\
0 \\
0\end{array}$ & $\begin{array}{l}0 \\
0 \\
0 \\
0 \\
0 \\
0 \\
0\end{array}$ & $\begin{array}{l}0 \\
0 \\
0 \\
0 \\
0 \\
0 \\
0\end{array}$ \\
\hline 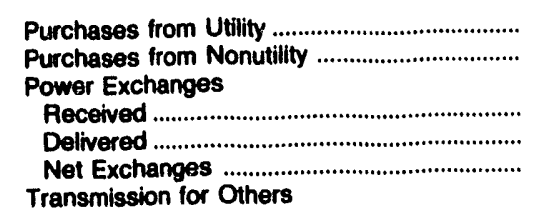 & $\begin{array}{r}231,249 \\
0 \\
0 \\
0 \\
0\end{array}$ & $\begin{array}{r}931,328 \\
0\end{array}$ & $\begin{array}{r}2,890,885 \\
0\end{array}$ & $\begin{array}{r}285,328 \\
0 \\
0 \\
0 \\
0\end{array}$ & $\begin{array}{r}192,860 \\
0\end{array}$ & $\begin{array}{r}156,306 \\
0 \\
0\end{array}$ \\
\hline 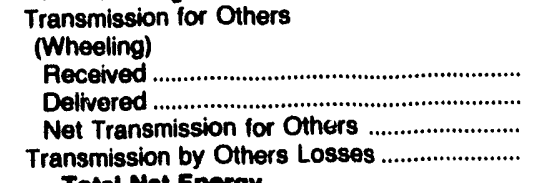 & $\begin{array}{l}0 \\
0 \\
0 \\
0\end{array}$ & $\begin{array}{l}0 \\
0 \\
0 \\
0\end{array}$ & $\begin{array}{r}210,000 \\
210,000 \\
0 \\
0\end{array}$ & $\begin{array}{l}0 \\
0 \\
0 \\
0\end{array}$ & $\begin{array}{l}0 \\
0 \\
0 \\
0\end{array}$ & $\begin{array}{l}0 \\
0 \\
0 \\
0\end{array}$ \\
\hline $\begin{array}{l}\text { Total Not Energy } \\
\text { Generated and Received ......................... }\end{array}$ & 231,249 & 931,328 & $4,207,629$ & 285,328 & 182,060 & 156,306 \\
\hline 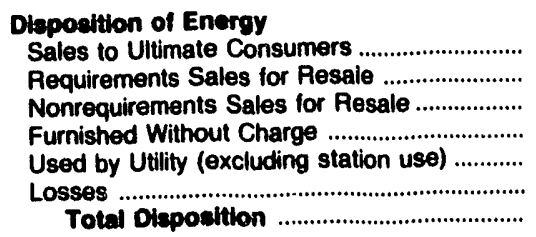 & $\begin{array}{r}211,883 \\
0 \\
0 \\
0 \\
0 \\
19,366 \\
231,249\end{array}$ & $\begin{array}{r}812,224 \\
59,098 \\
0 \\
0 \\
9,057 \\
50,949 \\
931,328\end{array}$ & $\begin{array}{r}580,033 \\
3,627,596 \\
0 \\
0 \\
0 \\
0 \\
4,207,629\end{array}$ & $\begin{array}{r}265,529 \\
3,427 \\
0 \\
3,695 \\
152 \\
12,525 \\
285,328\end{array}$ & $\begin{array}{r}184,510 \\
0 \\
0 \\
8,348 \\
0 \\
2 \\
192,880\end{array}$ & $\begin{array}{r}142,646 \\
0 \\
0 \\
2,234 \\
359 \\
11,067 \\
156,306\end{array}$ \\
\hline
\end{tabular}

Note: Totals may not equal sum of components because of independent rounding. Double counting occurs in components of both sources and disposition of energy and thus neither provides a true total. Purchases from utilities, net interchanges, and net wheeling (except for imports) are included in net generation. Sales for resale is included in sales to ultimate consumers.

Source: Energy Information Administration, Form E|A-412, "Annual Report of Public Electric Utilities." 
Table 41. Electric Energy Account by Majc: Publlcly Owned Electric Utility Within State, 1991 (Continued) (Megawatthours)

\begin{tabular}{|c|c|c|c|c|c|c|}
\hline llem & $\begin{array}{c}\text { Ohio } \\
\text { Cleverund } \\
\text { City of } \\
\text { December } 31\end{array}$ & $\begin{array}{l}\text { Ohio } \\
\text { Columbus } \\
\text { City of } \\
\text { December } 31\end{array}$ & $\begin{array}{c}\text { Ohio } \\
\text { Cuyahoga } \\
\text { Falls } \\
\text { City of } \\
\text { December } 31\end{array}$ & $\begin{array}{l}\text { Ohio } \\
\text { Dover } \\
\text { City of } \\
\text { December } 31\end{array}$ & $\begin{array}{c}\text { Ohio } \\
\text { Hamition } \\
\text { City of } \\
\text { December } 31\end{array}$ & $\begin{array}{c}\text { Onio } \\
\text { Niles } \\
\text { City of } \\
\text { December } 31\end{array}$ \\
\hline 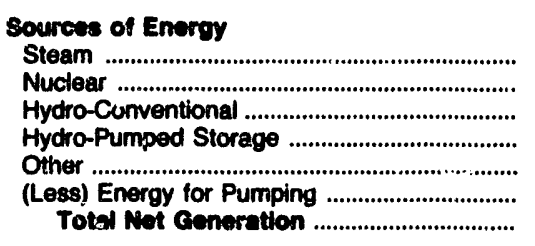 & $\begin{array}{r}0 \\
0 \\
0 \\
0 \\
3,247 \\
0 \\
3,247\end{array}$ & $\begin{array}{r}27,292 \\
0 \\
6,591 \\
0 \\
342,500 \\
0 \\
376,393\end{array}$ & $\begin{array}{l}0 \\
0 \\
0 \\
0 \\
0 \\
0 \\
0\end{array}$ & $\begin{array}{r}77,841 \\
0 \\
0 \\
0 \\
0 \\
0 \\
77,841\end{array}$ & $\begin{array}{r}311,842 \\
0 \\
207,890 \\
0 \\
2,968 \\
0 \\
522,700\end{array}$ & $\begin{array}{l}0 \\
0 \\
0 \\
0 \\
0 \\
0 \\
0\end{array}$ \\
\hline 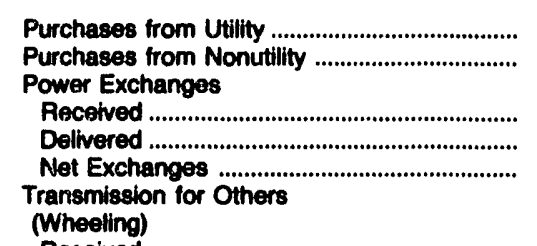 & $\begin{array}{r}764,031 \\
0 \\
0 \\
0 \\
0\end{array}$ & $\begin{array}{r}288,742 \\
0 \\
0 \\
0 \\
0\end{array}$ & $\begin{array}{r}298,001 \\
0\end{array}$ & $\begin{array}{r}92,004 \\
0\end{array}$ & $\begin{array}{r}85,112 \\
0 \\
9,270 \\
0 \\
9,270\end{array}$ & $\begin{array}{r}250,848 \\
0\end{array}$ \\
\hline 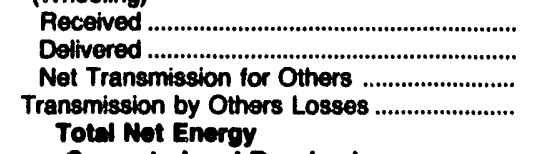 & $\begin{array}{l}0 \\
0 \\
0 \\
0\end{array}$ & $\begin{array}{r}295,333 \\
295,333 \\
0 \\
0\end{array}$ & $\begin{array}{l}0 \\
0 \\
0 \\
0\end{array}$ & $\begin{array}{l}0 \\
0 \\
0 \\
0\end{array}$ & $\begin{array}{l}0 \\
0 \\
0 \\
0\end{array}$ & $\begin{array}{l}0 \\
0 \\
0 \\
0\end{array}$ \\
\hline Cenerated and Recelved ........................... & 767,278 & 665,125 & 298,001 & 180,245 & 617,082 & 250,840 \\
\hline 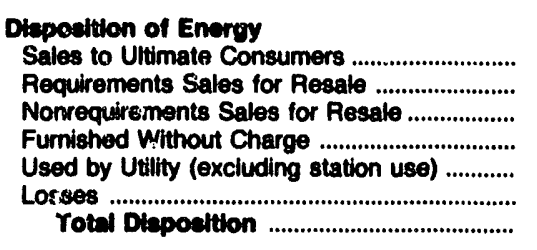 & $\begin{array}{r}692,306 \\
0 \\
0 \\
1,824 \\
73,148 \\
0 \\
787,278\end{array}$ & $\begin{array}{r}576,924 \\
1,254 \\
0 \\
0 \\
55,127 \\
31,820 \\
685,125\end{array}$ & $\begin{array}{r}270,322 \\
0 \\
0 \\
7,371 \\
485 \\
19,823 \\
298,001\end{array}$ & $\begin{array}{r}151,423 \\
0 \\
0 \\
9,422 \\
0 \\
9,000 \\
169,845\end{array}$ & $\begin{array}{r}494,639 \\
38,782 \\
50,614 \\
11,411 \\
0 \\
21,636 \\
617,082\end{array}$ & $\begin{array}{r}224,723 \\
0 \\
0 \\
7,165 \\
43 \\
18,917 \\
250,848\end{array}$ \\
\hline
\end{tabular}

Note: Totals may not equal sum of components because of indepandent rounding. Double counting occurs in components of both sources and disposition of energy and thus neither provides a true total. Purchases from utilities, net interchanges, and net whaeling (except for imports) are included in net generation. Sales for resale is included in sales to uttimate consumors.

Source: Energy Information Administration, Form EIA-412, "Annual Aeport of Public Electric Litilities." 
Table 41. Electric Energy Account by Major Publicly Owned Electric
Utillty Within State, 1991 (Continued) (Megawatthours)

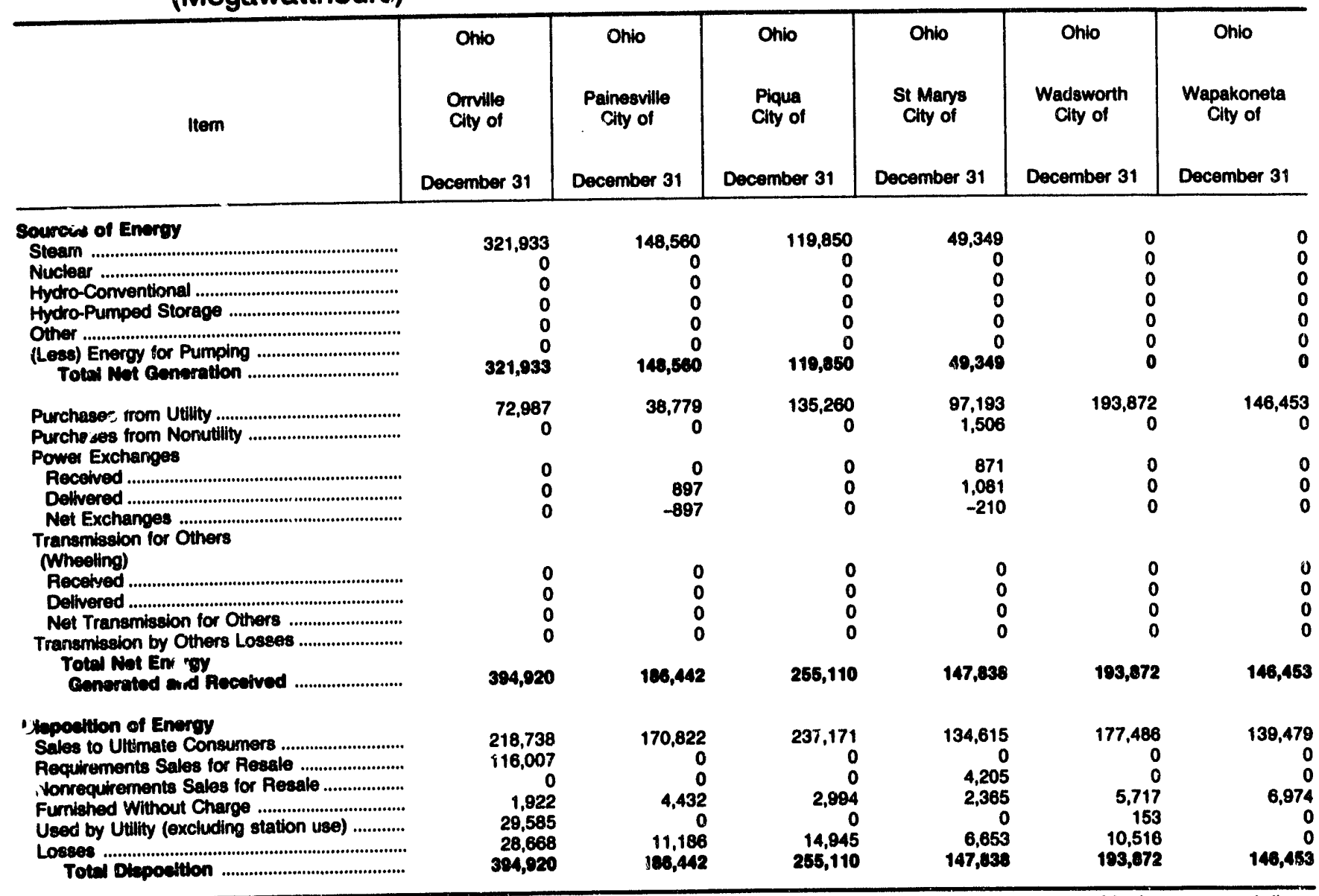

Note: Totals may not equal sum of components because of independent rounding. Double counting occurs in components of both sources and dispostion of energy and thus neither provides a tus total. Purchases from uthities, net interchanges, and net wheeling (except for imports) are inciuded in net ceneration. Sales for resale is included in sales to ultimate consumers.

Source: Energy information Administration, Form EIA-412, "Annual Report of Public Electric Utilities." 

Table 41. Electric Energy Account by Major Publicly Owned Electric
Utility Within State, 1991 (Continued)

(Megawatthours)

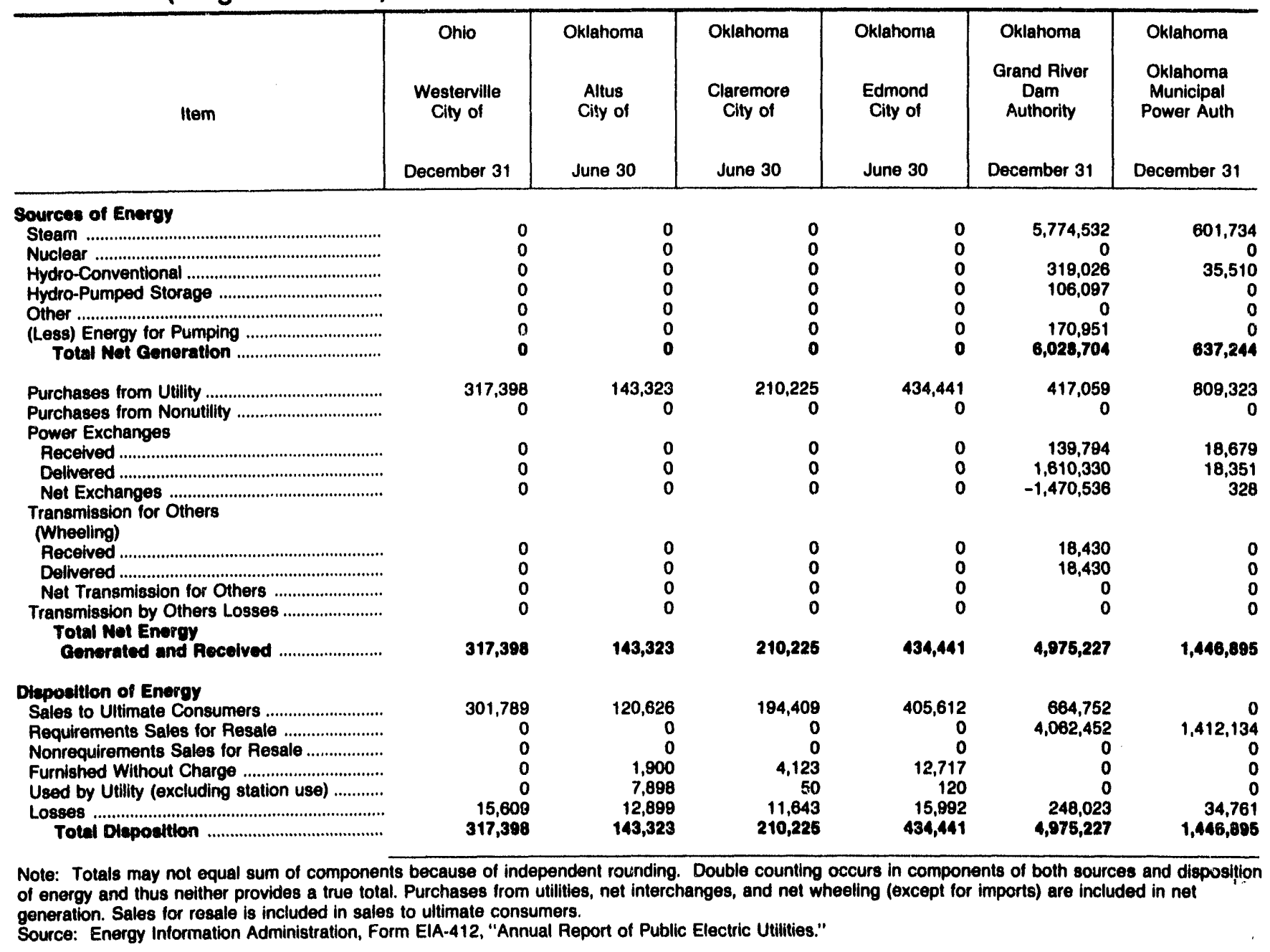




\section{Table 41. Electric Energy Account by Major Publicly Owned Electric Utility Within State, 1991 (Continued) (Megawatthours)}

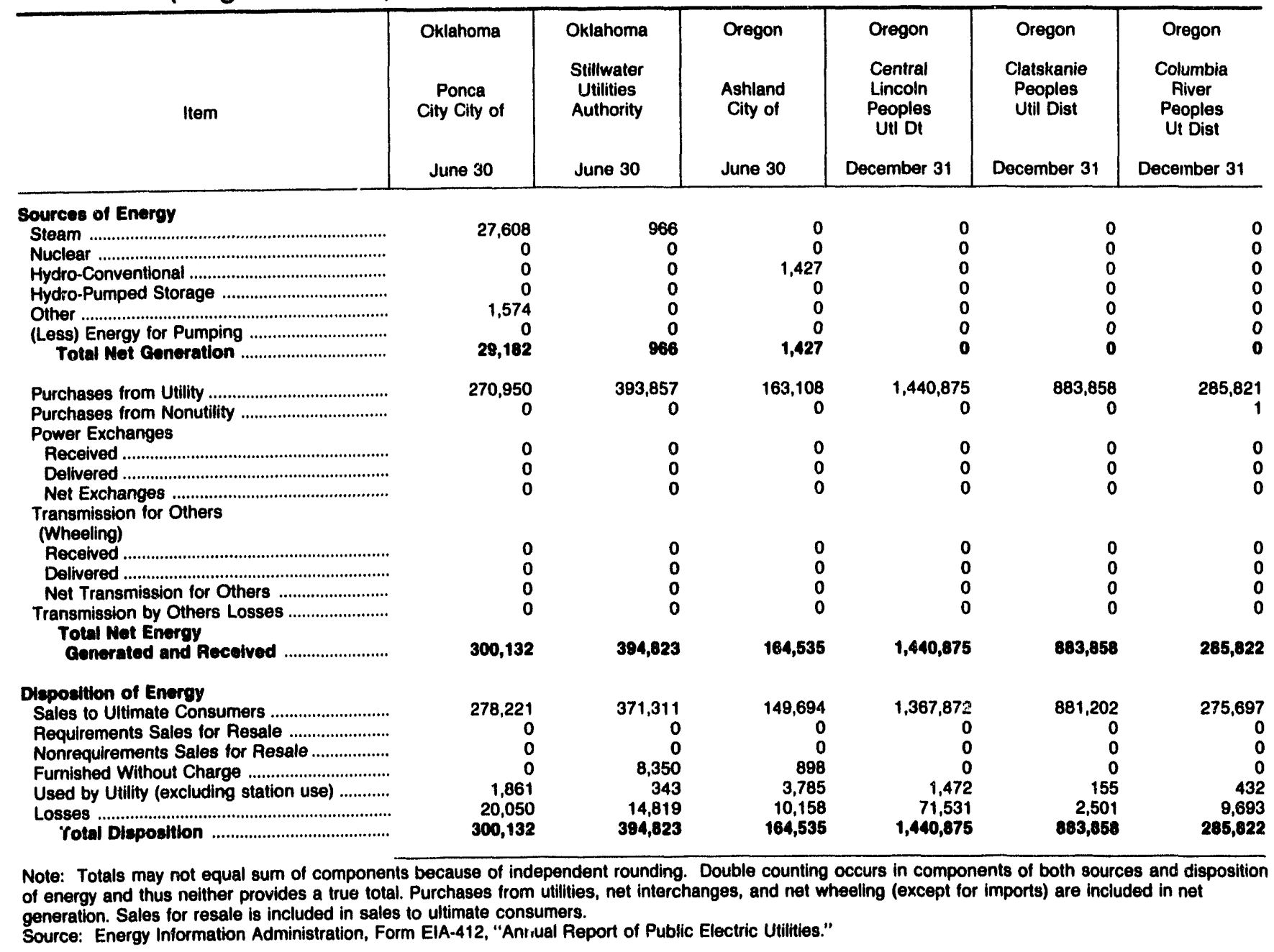


Table 41. Electric Energy Account by Major Publicly Owned Electric Utility Within State, 1991 (Continued) (Megawatthours)

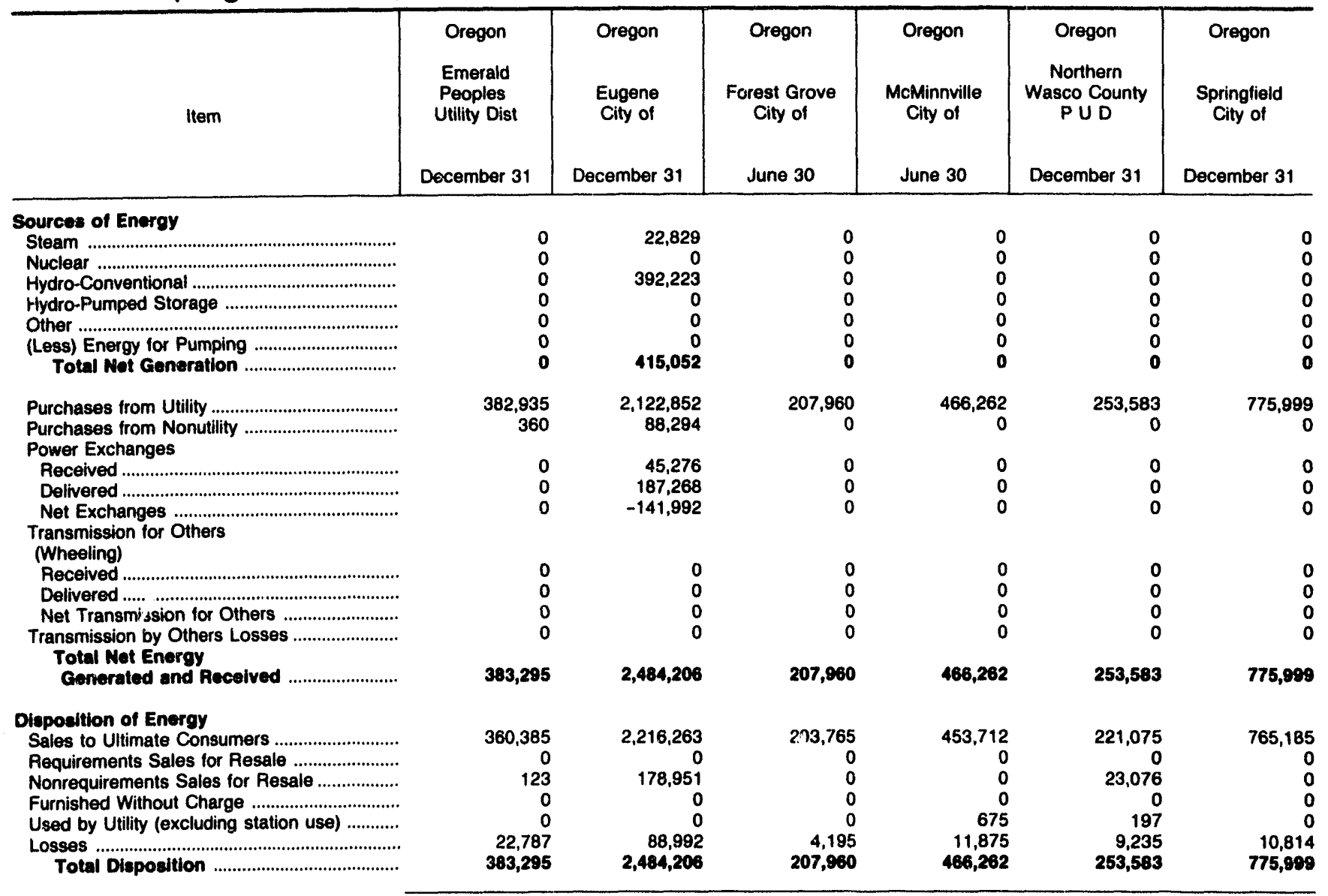

Note: Totals may not equal sum of components because of independent rounding. Double counting occurs in components of both sources and disposition of energy and thus neither provides a true total. Purchases from utilities, net interchanges, and net wheeling (except for imports) are included in net generation. Sales for resale is included in sales to ultimate consumers.

Source: Energy Information Administration, Form EIA-412, "Annual Report of Public Electric Utilities." 
Table 41. Electric Energy Account by Major Publicly Owned Electric Utility Within State, 1991 (Continued) (Megawatthours)

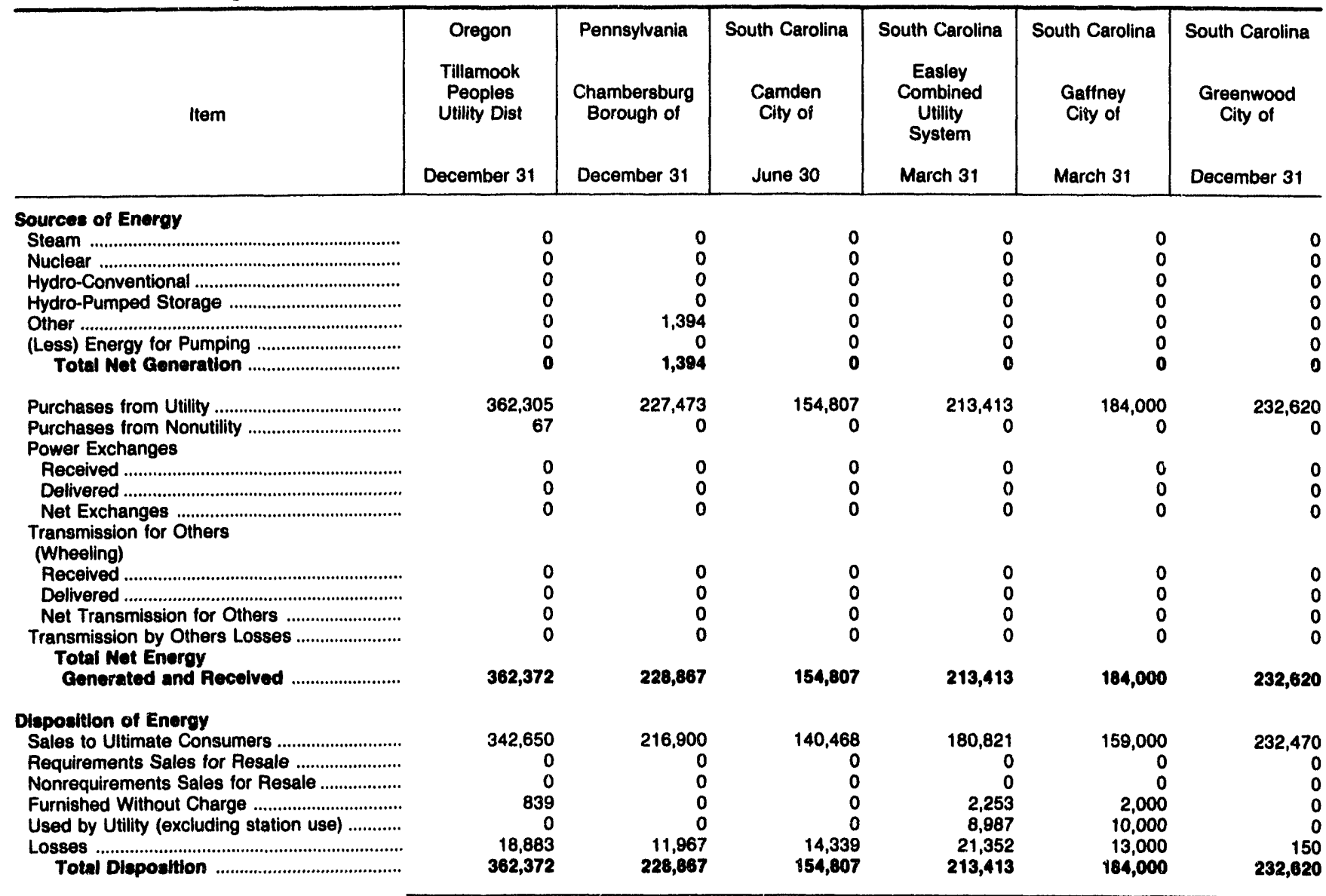

Note: Totals may not equal sum of components because of independent rounding. Double counting occurs in components of both sources and disposition of energy and thus neither provides a true total. Purchases from utilities, net interchanges, and net wheeling (except for imports) are included in net generation. Sales for resale is included in sales to ultimate consumers.

Source: Energy Information Administration, Form EIA-412, "Annual Report of Public Electric Utilities." 
Table 41. Electric Energy Account by Major Publicly Owned Electric Utility Within State, 1991 (Continued)

(Megawatthours)

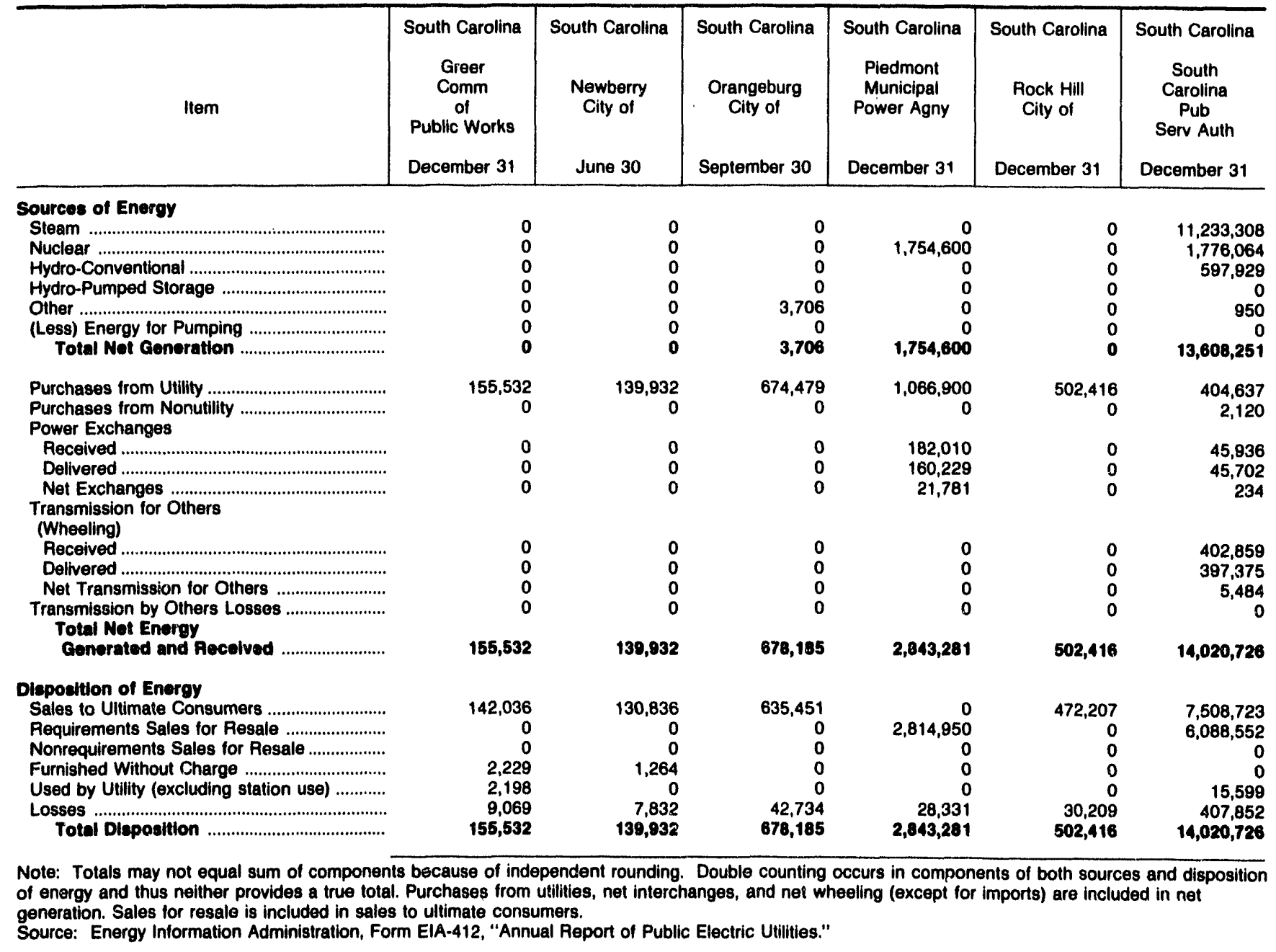


Table 41. Electric Energy Account by Major Publicly Owned Electric Utility Within State, 1991 (Continued)

(Megawatthours)

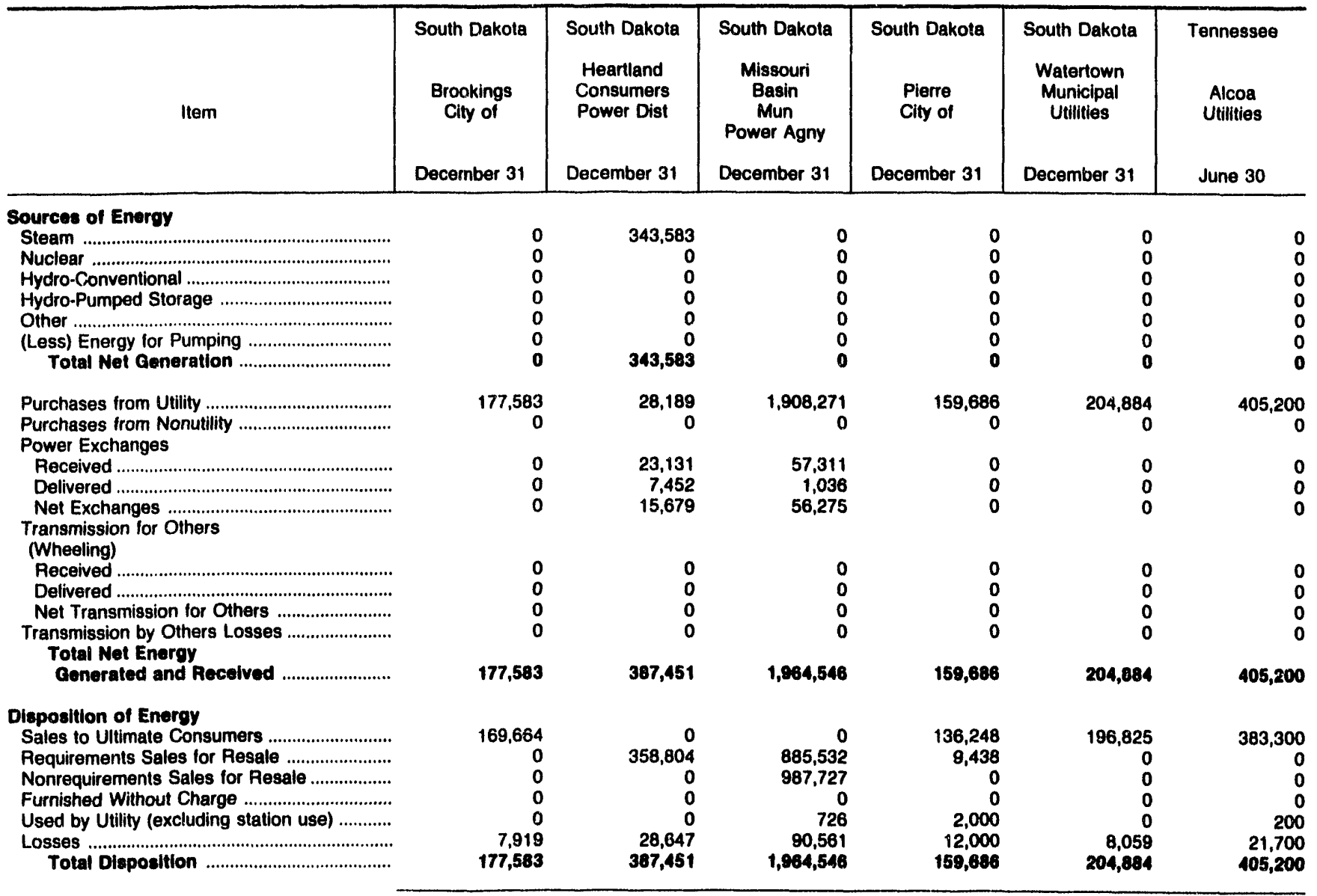

Note: Totals may not equal sum of components because of independent rounding. Double counting occurs in components of both sources and disposition of energy and thus neither provides a true total. Purchases from utilities, net interchanges, and net wheeling (except for imports) are included in net generation. Sales for resale is included in sales to ultimate consumers.

Source: Energy Information Administration, Form ElA-412, "Annual Report of Public Electric Utilities." 
Table 41. Electric Energy Account by Major Publicly Owned Electric Utillty Within State, 1991 (Continued)

(Megawatthours)

\begin{tabular}{|c|c|c|c|c|c|c|}
\hline Itom & $\begin{array}{l}\text { Tennessee } \\
\text { Athens } \\
\text { City of } \\
\text { June } 30\end{array}$ & $\begin{array}{l}\text { Tennessee } \\
\text { Benton } \\
\text { County } \\
\text { June } 30\end{array}$ & $\begin{array}{l}\text { Tennessee } \\
\text { Bolvar } \\
\text { City of } \\
\text { June } 30\end{array}$ & $\begin{array}{l}\text { Tennessee } \\
\text { Briatol } \\
\text { City of } \\
\text { June } 30\end{array}$ & $\begin{array}{l}\text { Tennessee } \\
\text { Brownsville } \\
\text { City of } \\
\text { June } 30\end{array}$ & $\begin{array}{l}\text { Tenreasee } \\
\text { Carroll } \\
\text { County } \\
\text { June } 30\end{array}$ \\
\hline 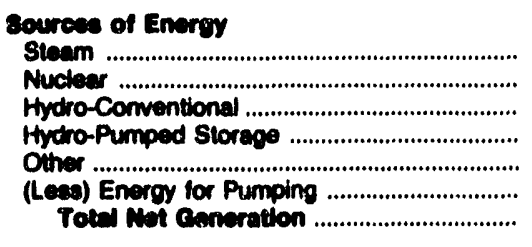 & $\begin{array}{l}0 \\
0 \\
0 \\
0 \\
0 \\
0 \\
0\end{array}$ & $\begin{array}{l}0 \\
0 \\
0 \\
0 \\
0 \\
0 \\
0\end{array}$ & $\begin{array}{l}0 \\
0 \\
0 \\
0 \\
0 \\
0 \\
0\end{array}$ & $\begin{array}{l}0 \\
0 \\
0 \\
0 \\
0 \\
0 \\
0\end{array}$ & $\begin{array}{l}0 \\
0 \\
0 \\
0 \\
0 \\
0 \\
0\end{array}$ & $\begin{array}{l}0 \\
0 \\
0 \\
0 \\
0 \\
0 \\
0\end{array}$ \\
\hline 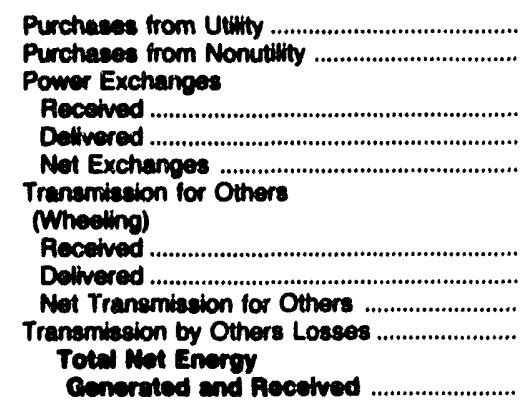 & $\begin{array}{r}0 \\
0 \\
0 \\
0 \\
492,800\end{array}$ & $\begin{array}{r}0 \\
0 \\
0 \\
0 \\
186,000\end{array}$ & $\begin{array}{r}0 \\
0 \\
0 \\
0 \\
220,451\end{array}$ & $\begin{array}{r}0 \\
0 \\
0 \\
0 \\
728,143\end{array}$ & $\begin{array}{r}0 \\
0 \\
0 \\
0 \\
175,941\end{array}$ & $\begin{array}{r}0 \\
0 \\
0 \\
0 \\
351,703\end{array}$ \\
\hline 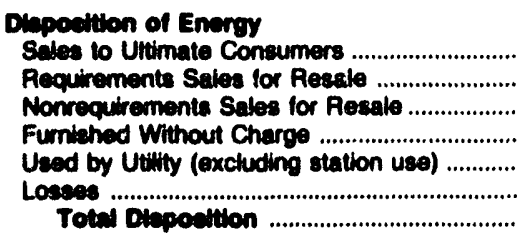 & $\begin{array}{r}471,692 \\
0 \\
0 \\
0 \\
808 \\
20,100 \\
492,600\end{array}$ & $\begin{array}{r}183,000 \\
0 \\
0 \\
0 \\
219 \\
12,781 \\
196,000\end{array}$ & $\begin{array}{r}213,761 \\
0 \\
0 \\
0 \\
281 \\
15,409 \\
229,451\end{array}$ & $\begin{array}{r}691,848 \\
0 \\
0 \\
0 \\
789 \\
35,606 \\
723,143\end{array}$ & $\begin{array}{r}155,103 \\
0 \\
0 \\
0 \\
272 \\
20,566 \\
175,041\end{array}$ & $\begin{array}{r}331,075 \\
0 \\
0 \\
0 \\
181 \\
20,537 \\
381,793\end{array}$ \\
\hline
\end{tabular}



Utility Within State, 1991 (Continued) (Megawatthours)

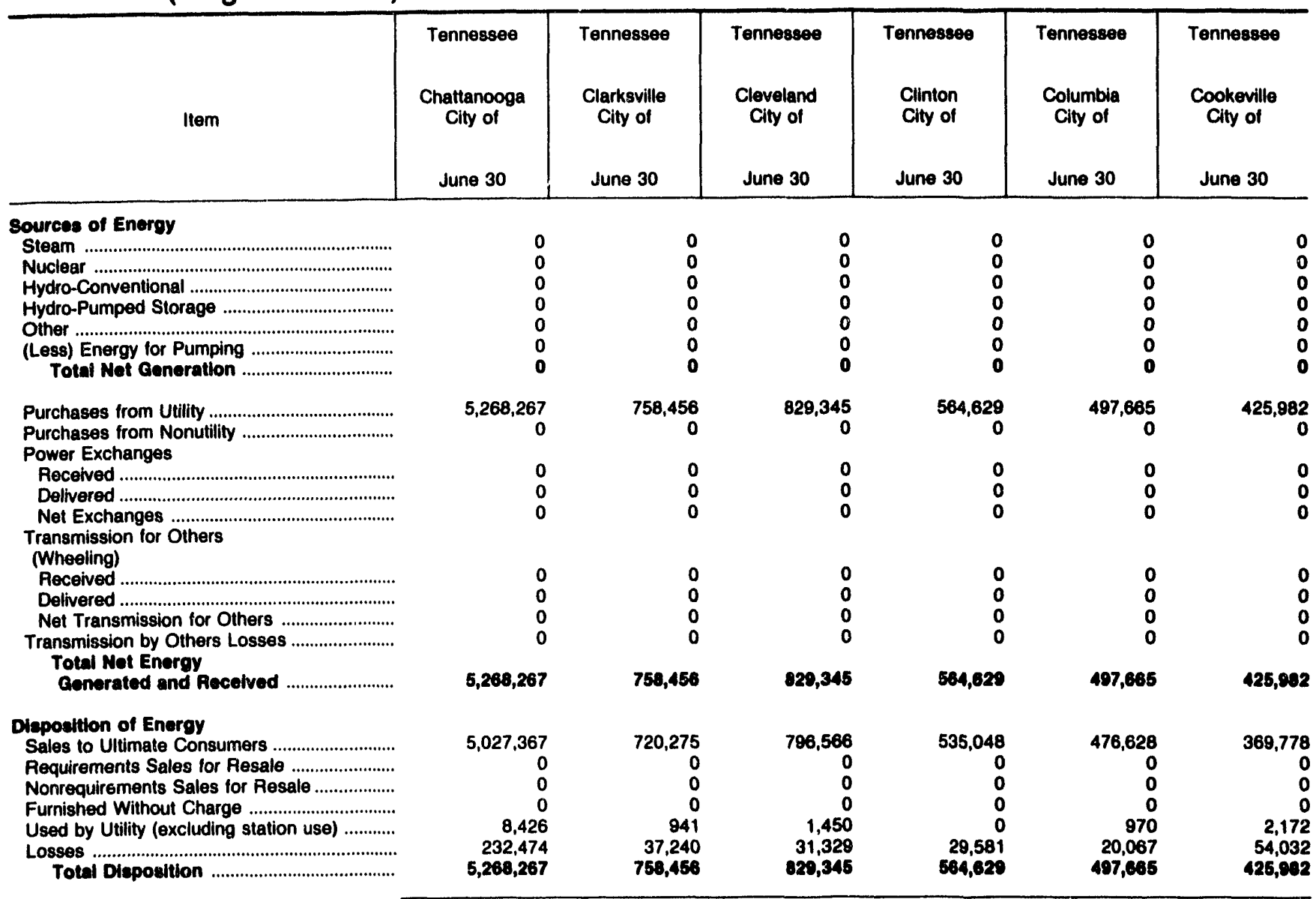

Note: Totals may not equal sum of components because of independent rounding. Double counting occurs in components of both sources and disposition of energy and thus neither provides a true total. Purchases from utilities, net interchanges, and net wheeling (except for imports) are included in net generation. Sales for resale is included in sales to ultimate consumers.

Source: Energy Information Administration, Form EIA-412, "Annual Report of Public Electric Utilities." 
Table 41. Electric Energy Account by Major Publicly Owned Electric Utility Within State, 1991 (Continued) (Megawatthours)

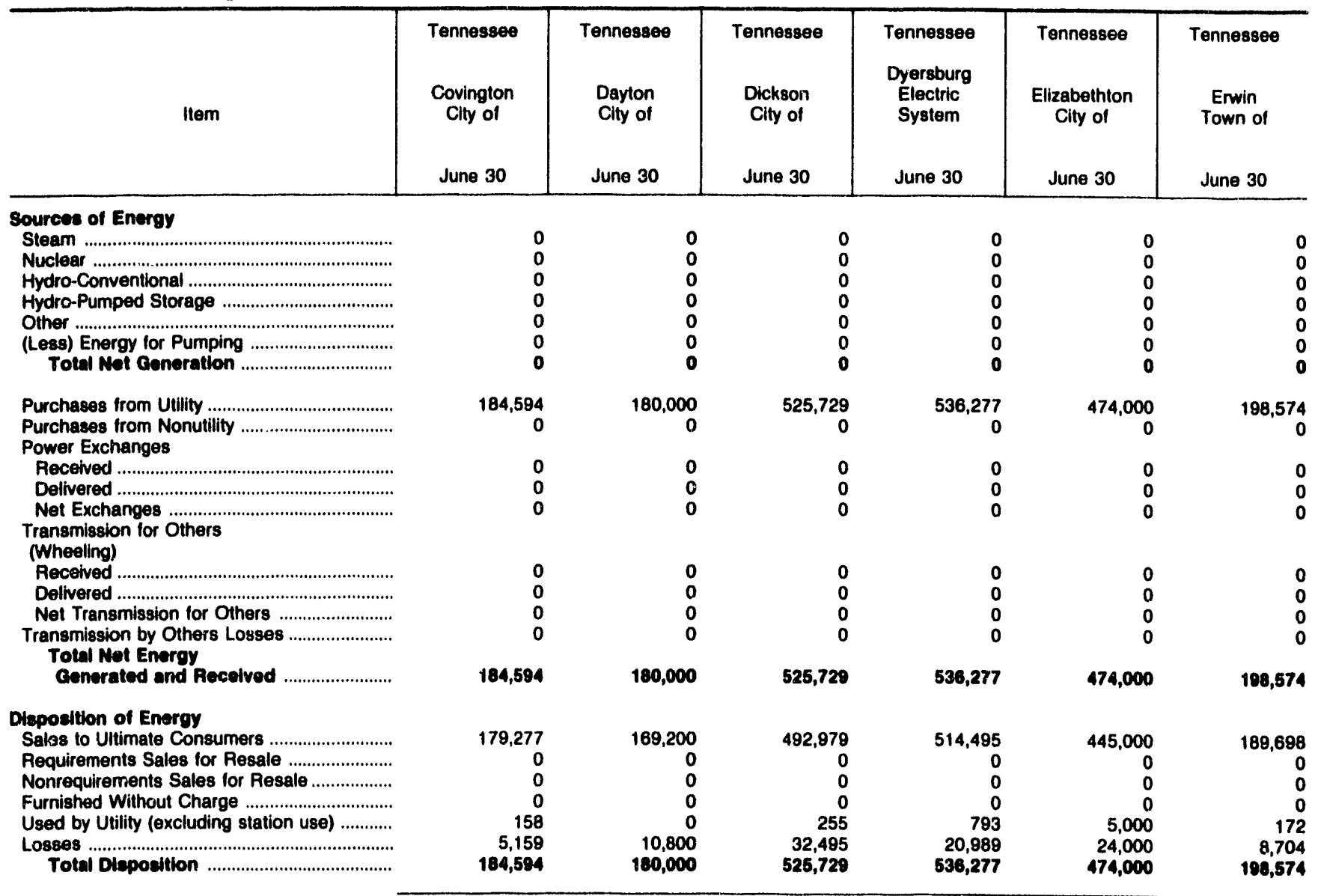

Note: Totals may not equal sum of components because of independent rounding. Double counting occurs in components of both sources and disposition of energy and thus neither provides a true total. Purchases from utilities, net interchanges, and net wheeling (except for imports) are included in net generation. Sales for resale is included in sales to ultimate consumers.

Source: Energy Information Administration, Form ElA-412, "Annual Report of Public Electric Utilities." 
Table 41. Electric Energy Account by Major Publicly Owned Electric Utility Within State, 1991 (Continued) (Megawatthours)

\begin{tabular}{|c|c|c|c|c|c|c|}
\hline Item & $\begin{array}{l}\text { Tennessne } \\
\text { Etowah } \\
\text { Cily of } \\
\text { June } 30\end{array}$ & $\begin{array}{c}\text { Tennessee } \\
\text { Fayetteville } \\
\text { City of } \\
\text { June } 30\end{array}$ & $\begin{array}{l}\text { Tennessee } \\
\text { Gallatin } \\
\text { City of } \\
\text { June } 30\end{array}$ & $\begin{array}{l}\text { Tennessee } \\
\text { Greeneville } \\
\text { City of } \\
\text { June } 30\end{array}$ & $\begin{array}{l}\text { Tennessee } \\
\text { Harriman } \\
\text { City of } \\
\text { June } 30\end{array}$ & $\begin{array}{l}\text { Tennessee } \\
\text { Humboldt } \\
\text { City of } \\
\text { June } 30\end{array}$ \\
\hline 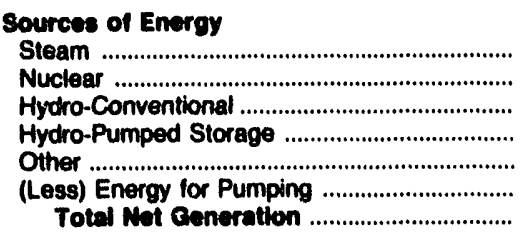 & $\begin{array}{l}0 \\
0 \\
0 \\
0 \\
0 \\
0 \\
0\end{array}$ & $\begin{array}{l}0 \\
0 \\
0 \\
0 \\
0 \\
0 \\
0\end{array}$ & $\begin{array}{l}0 \\
0 \\
0 \\
0 \\
0 \\
0 \\
0\end{array}$ & $\begin{array}{l}0 \\
0 \\
0 \\
0 \\
0 \\
0 \\
0\end{array}$ & $\begin{array}{l}0 \\
0 \\
0 \\
0 \\
0 \\
0 \\
0\end{array}$ & $\begin{array}{l}0 \\
0 \\
0 \\
0 \\
0 \\
0 \\
0\end{array}$ \\
\hline 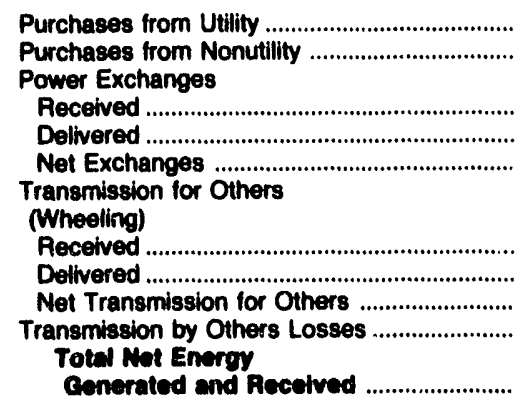 & $\begin{array}{r}136,508 \\
0 \\
0 \\
0 \\
0\end{array}$ & $\begin{array}{r}342,879 \\
0 \\
0 \\
0 \\
0\end{array}$ & $\begin{array}{r}0 \\
0 \\
0 \\
0 \\
402,001\end{array}$ & $\begin{array}{r}0 \\
0 \\
0 \\
0 \\
834,200\end{array}$ & $\begin{array}{r}0 \\
0 \\
0 \\
0 \\
277,364\end{array}$ & $\begin{array}{r}0 \\
0 \\
0 \\
0 \\
200,289\end{array}$ \\
\hline 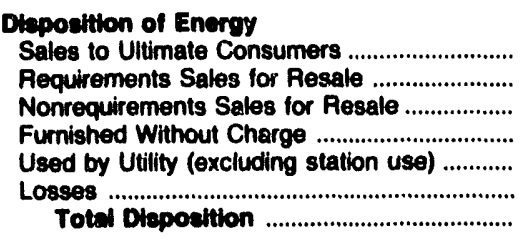 & $\begin{array}{r}131,408 \\
0 \\
0 \\
0 \\
0 \\
5,100 \\
136,508\end{array}$ & $\begin{array}{r}320,329 \\
0 \\
0 \\
0 \\
536 \\
22,014 \\
342,870\end{array}$ & $\begin{array}{r}388,926 \\
0 \\
0 \\
0 \\
287 \\
13,588 \\
402,001\end{array}$ & $\begin{array}{r}794,900 \\
0 \\
0 \\
0 \\
800 \\
38,500 \\
834,200\end{array}$ & $\begin{array}{r}264,076 \\
0 \\
0 \\
0 \\
418 \\
12,870 \\
277,384\end{array}$ & $\begin{array}{r}191,998 \\
0 \\
0 \\
0 \\
0 \\
8,291 \\
200,289\end{array}$ \\
\hline
\end{tabular}

Note: Totals may not equal sum of components because of independent rounding. Double counting occurs in components of both sources and disposition of energy and thus neither provides a true total. Purchases from utilities, net interchanges, and net wheeling (except for imports) are included in net generation. Sales for resale is included in sales to ultimate consumers.

Source: Energy Information Administration, Form EIA-412, "Annual Report of Public Electric Utilities." 
Table 41. Electric Energy Account by Major Publicly Owned Electric Utility Within State, 1991 (Continued)

(Megawatthours)

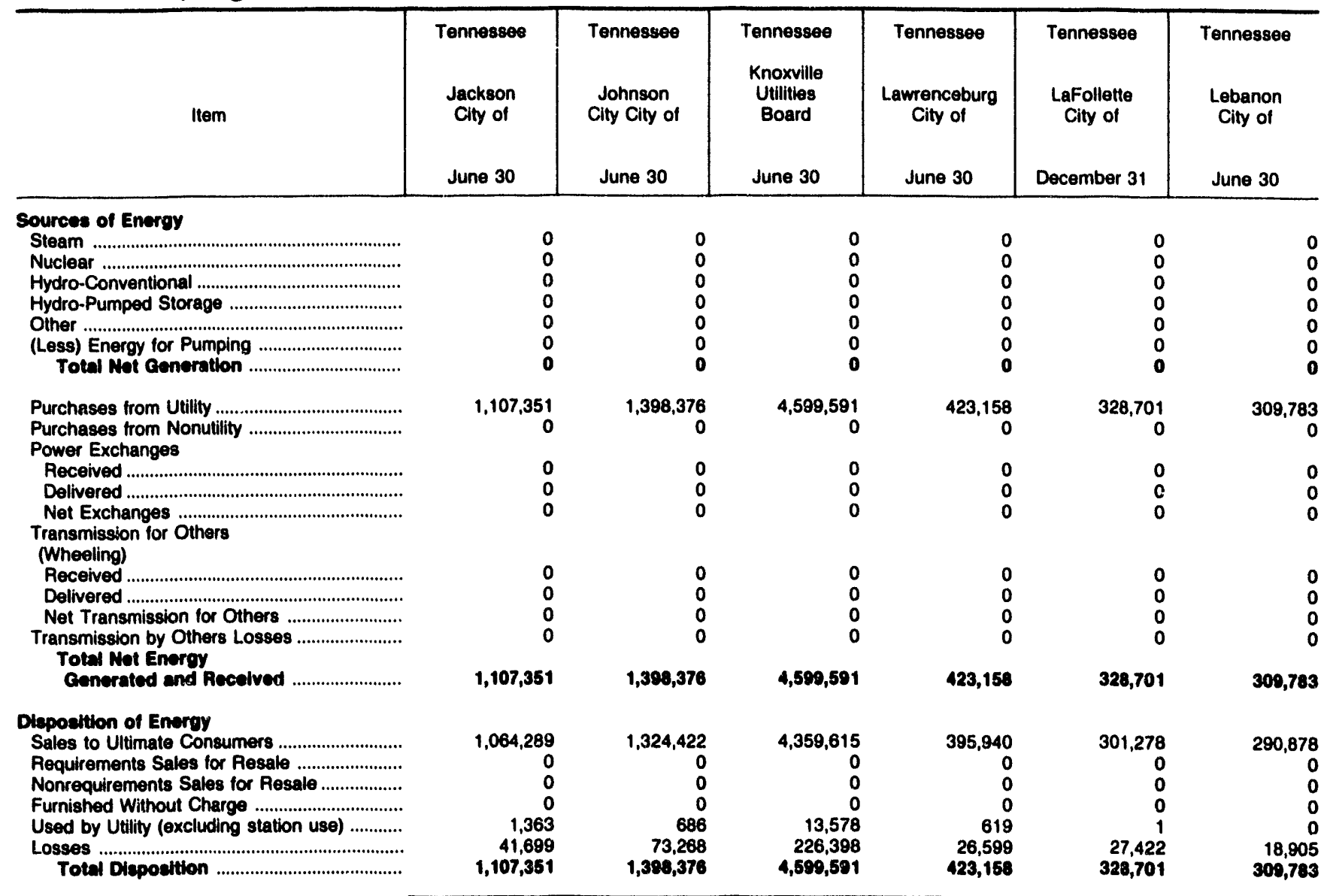

Note: Totals may not equal sum of components because of independent rounding. Double counting occurs in components of both sources and disposition of energy and thus neither provides a true total. Purchases from utilities, net interchanges, and net wheeling (except for imports) are included in net generation. Sales for ressile is included in sales to ultimate consumers.

Source: Energy Information Administration, Form ElA-412, "Annual Peport of Public Electric Utilities." 
Table 41. Electric Energy Account by Major Publiciy Owned Electric Utility Within State, 1991 (Continued) (Megawatthours)

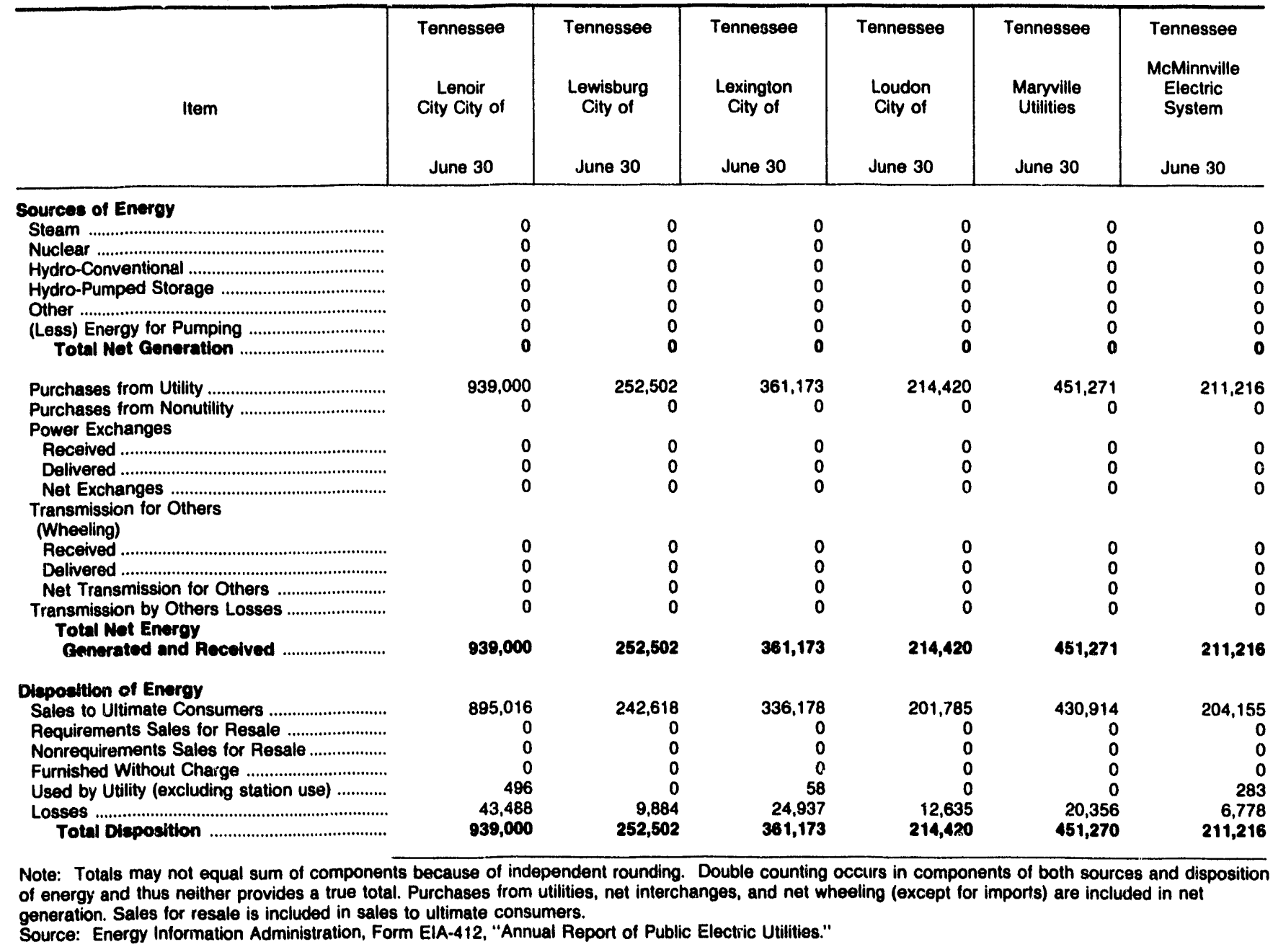


Table 41. Electric Energy Account by Major Publicly Owned Electrir Utility Within State, 1991 (Continued) (Megawatthours)

\begin{tabular}{|c|c|c|c|c|c|c|}
\hline Item & $\begin{array}{c}\text { Tennessee } \\
\text { Memphis } \\
\text { City of } \\
\text { December } 31\end{array}$ & $\begin{array}{l}\text { Tennessee } \\
\text { Millan } \\
\text { City of } \\
\text { June } 30\end{array}$ & $\begin{array}{l}\text { Tennessee } \\
\text { Morriutown } \\
\text { City of } \\
\text { June } 30\end{array}$ & $\begin{array}{l}\text { Tennessee } \\
\text { Murfreesboro } \\
\text { City of } \\
\text { June } 30\end{array}$ & $\begin{array}{l}\text { Tennessee } \\
\text { Nashville } \\
\text { Electric } \\
\text { Service } \\
\text { June } 30\end{array}$ & $\begin{array}{l}\text { Tennessee } \\
\text { Newport } \\
\text { City of } \\
\text { June } 30\end{array}$ \\
\hline 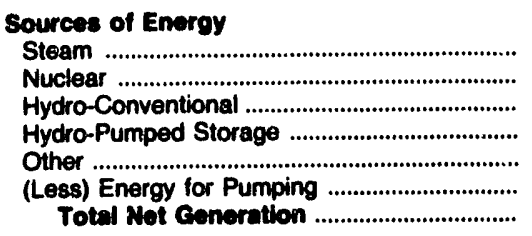 & $\begin{array}{l}0 \\
0 \\
0 \\
0 \\
0 \\
0 \\
0\end{array}$ & $\begin{array}{l}0 \\
0 \\
0 \\
0 \\
0 \\
0 \\
0\end{array}$ & $\begin{array}{l}0 \\
0 \\
0 \\
0 \\
0 \\
0 \\
0\end{array}$ & $\begin{array}{l}0 \\
0 \\
0 \\
0 \\
0 \\
0 \\
0\end{array}$ & $\begin{array}{l}0 \\
0 \\
0 \\
0 \\
0 \\
0 \\
0\end{array}$ & $\begin{array}{l}0 \\
0 \\
0 \\
0 \\
0 \\
0 \\
0\end{array}$ \\
\hline 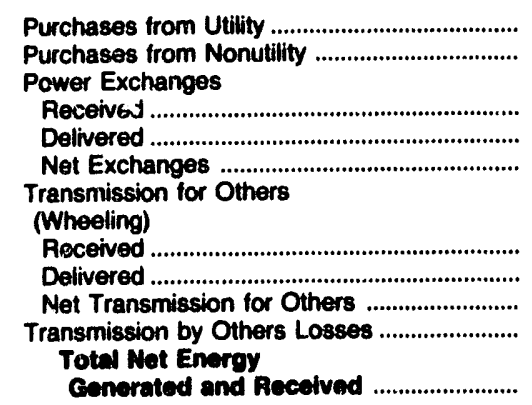 & $\begin{array}{r}11,778,182 \\
0\end{array}$ & $\begin{array}{r}210,955 \\
0\end{array}$ & $\begin{array}{r}0 \\
0 \\
0 \\
0\end{array}$ & $\begin{array}{r}772,149 \\
0\end{array}$ & $\begin{array}{r}10,107,228 \\
0\end{array}$ & $\begin{array}{r}393,695 \\
0\end{array}$ \\
\hline 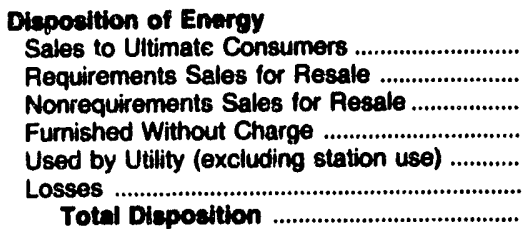 & $\begin{array}{r}11,451,824 \\
0 \\
0 \\
0 \\
7,308 \\
319,050 \\
11,778,182\end{array}$ & $\begin{array}{r}205,043 \\
0 \\
0 \\
0 \\
85 \\
5,827 \\
210,055\end{array}$ & $\begin{array}{r}546,745 \\
0 \\
0 \\
0 \\
1,033 \\
17,685 \\
565,443\end{array}$ & $\begin{array}{r}752,150 \\
0 \\
0 \\
0 \\
1,025 \\
18,974 \\
772,140\end{array}$ & $\begin{array}{r}9,742,817 \\
0 \\
0 \\
0 \\
21,574 \\
342,837 \\
10,107,228\end{array}$ & $\begin{array}{r}368,598 \\
0 \\
0 \\
0 \\
618 \\
24,479 \\
303,695\end{array}$ \\
\hline
\end{tabular}

Note: Totels may not equal sum of components because 3 independent rounding. Double counting occurs in components of both sources and disposition of energy and thus neither provides a true total. Purchases irom utilities, net interchanges, and net wheeling (except for imports) are included in net generation. Sales for resale is inctuded in sales to ultimate consumers.

Source: Energy Information Administration, Form ElA-412, "Annual Report of Public Electric Utilities." 
Table 41. Electric Energy Account by Major Publicly Owned Electric Utility Within State, 1991 (Continued)

(Megawatthours)

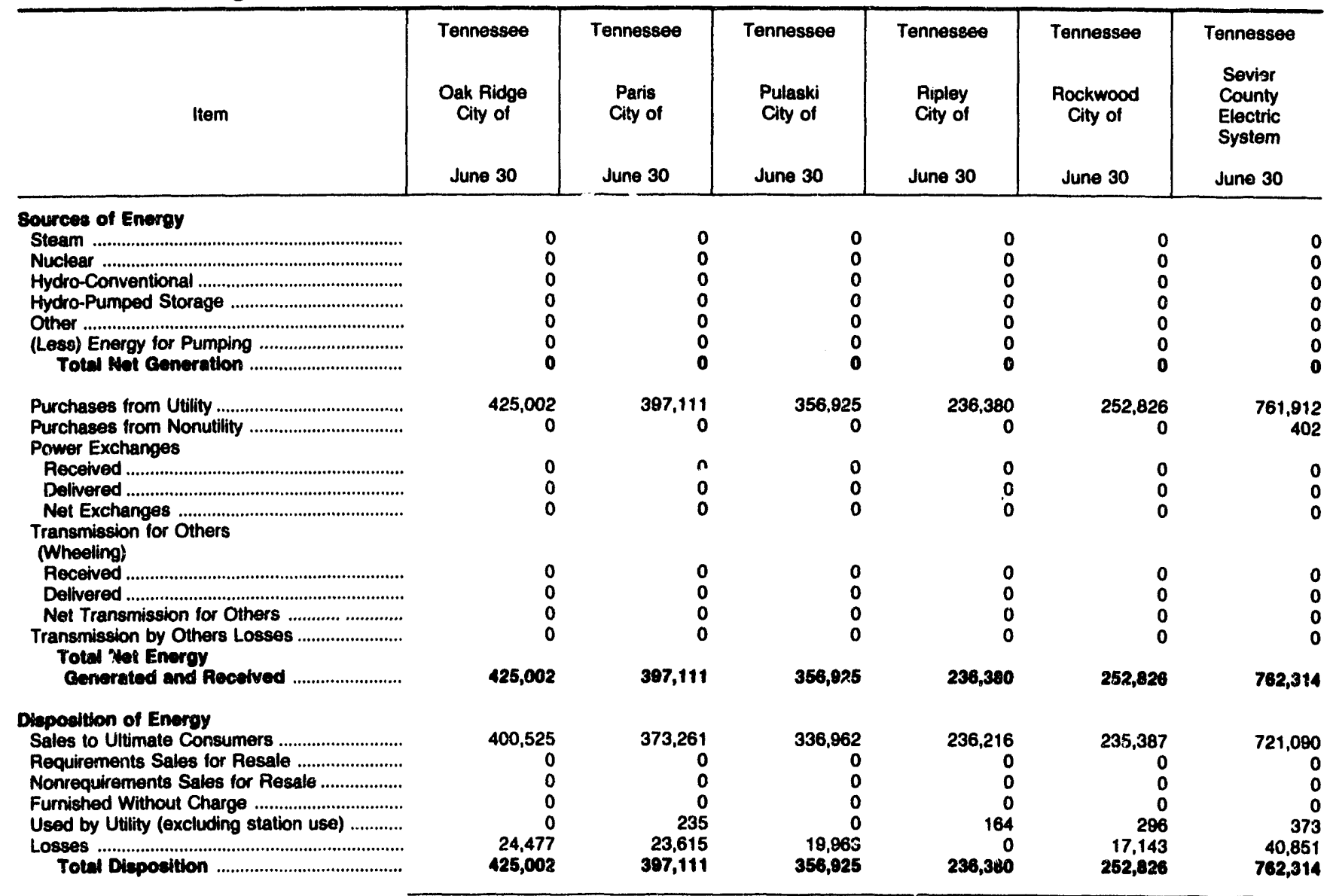

Note: Totals may not equal sum of components because of independent rounding. Double counting occurs in components of both sources and disposition of energy and thus neither provides a true total. Purchases from utilities, net interchanges, and net whesling (except for imports) are included in net generation. Sales for resale is included in sales to ultimate consumers.

Source: Energy Information Administration, Form EIA-412, "Annual Report of Public Electric Utilities." 
Table 41. Electric Energy Account by Major Publicly Owned Electric Utility Within State, 1991 (Continued)

(Megawatthours)

\begin{tabular}{|c|c|c|c|c|c|c|}
\hline Item & $\begin{array}{l}\text { Tennessee } \\
\text { Shelbyille } \\
\text { City of } \\
\text { June } 30\end{array}$ & $\begin{array}{l}\text { Tennessee } \\
\text { Springfield } \\
\text { City of } \\
\text { June } 30\end{array}$ & $\begin{array}{l}\text { Tennessee } \\
\text { Sweetwater } \\
\text { City of } \\
\text { June } 30\end{array}$ & $\begin{array}{l}\text { Tennessee } \\
\text { Tullahoma } \\
\text { Board } \\
\text { of } \\
\text { Pub Utils } \\
\text { June } 30\end{array}$ & $\begin{array}{l}\text { Tennessee } \\
\text { Union } \\
\text { City City of } \\
\text { June } 30\end{array}$ & $\begin{array}{l}\text { Tennessere } \\
\text { Weakley } \\
\text { County } \\
\text { Mun } \\
\text { Elec Sys } \\
\text { June } 30\end{array}$ \\
\hline 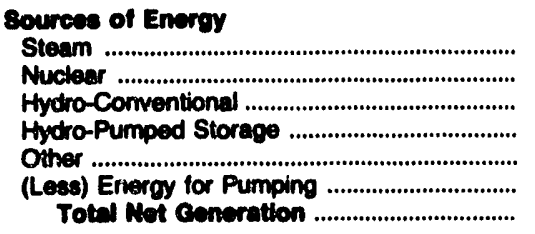 & $\begin{array}{l}0 \\
0 \\
0 \\
0 \\
0 \\
0 \\
0\end{array}$ & $\begin{array}{l}0 \\
0 \\
0 \\
0 \\
0 \\
0 \\
0\end{array}$ & $\begin{array}{l}0 \\
0 \\
0 \\
0 \\
0 \\
0 \\
0\end{array}$ & $\begin{array}{l}0 \\
0 \\
0 \\
0 \\
0 \\
0 \\
0\end{array}$ & $\begin{array}{l}0 \\
0 \\
0 \\
0 \\
0 \\
0 \\
0\end{array}$ & $\begin{array}{l}0 \\
0 \\
0 \\
0 \\
0 \\
0 \\
0\end{array}$ \\
\hline 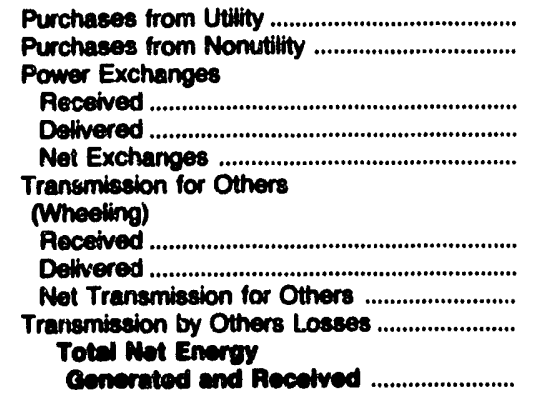 & $\begin{array}{r}0 \\
0 \\
0 \\
0 \\
294,275\end{array}$ & $\begin{array}{r}0 \\
0 \\
0 \\
0 \\
176,244\end{array}$ & $\begin{array}{r}0 \\
0 \\
0 \\
0 \\
164,513\end{array}$ & $\begin{array}{r}0 \\
0 \\
0 \\
0 \\
285,650\end{array}$ & $\begin{array}{r}333,681 \\
0 \\
0 \\
0 \\
0\end{array}$ & $\begin{array}{r}0 \\
0 \\
0 \\
0 \\
461,763\end{array}$ \\
\hline 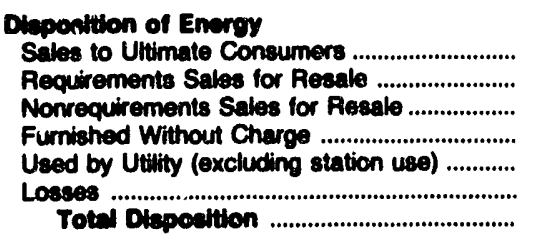 & $\begin{array}{r}282,101 \\
0 \\
0 \\
0 \\
301 \\
11,873 \\
284,275\end{array}$ & $\begin{array}{r}168,813 \\
0 \\
0 \\
0 \\
0 \\
7,431 \\
176,244\end{array}$ & $\begin{array}{r}157,837 \\
0 \\
0 \\
0 \\
0 \\
6,676 \\
164,513\end{array}$ & $\begin{array}{r}264,778 \\
0 \\
0 \\
0 \\
873 \\
0 \\
265,650\end{array}$ & $\begin{array}{r}322,378 \\
0 \\
0 \\
0 \\
155 \\
11,148 \\
333,681\end{array}$ & $\begin{array}{r}432,601 \\
0 \\
0 \\
0 \\
441 \\
28,721 \\
261,763\end{array}$ \\
\hline
\end{tabular}


Table 41. Electric Energy Account by Major Publicly Owned Electric Utility Within State, 1991 (Continued) (Megawatthours)

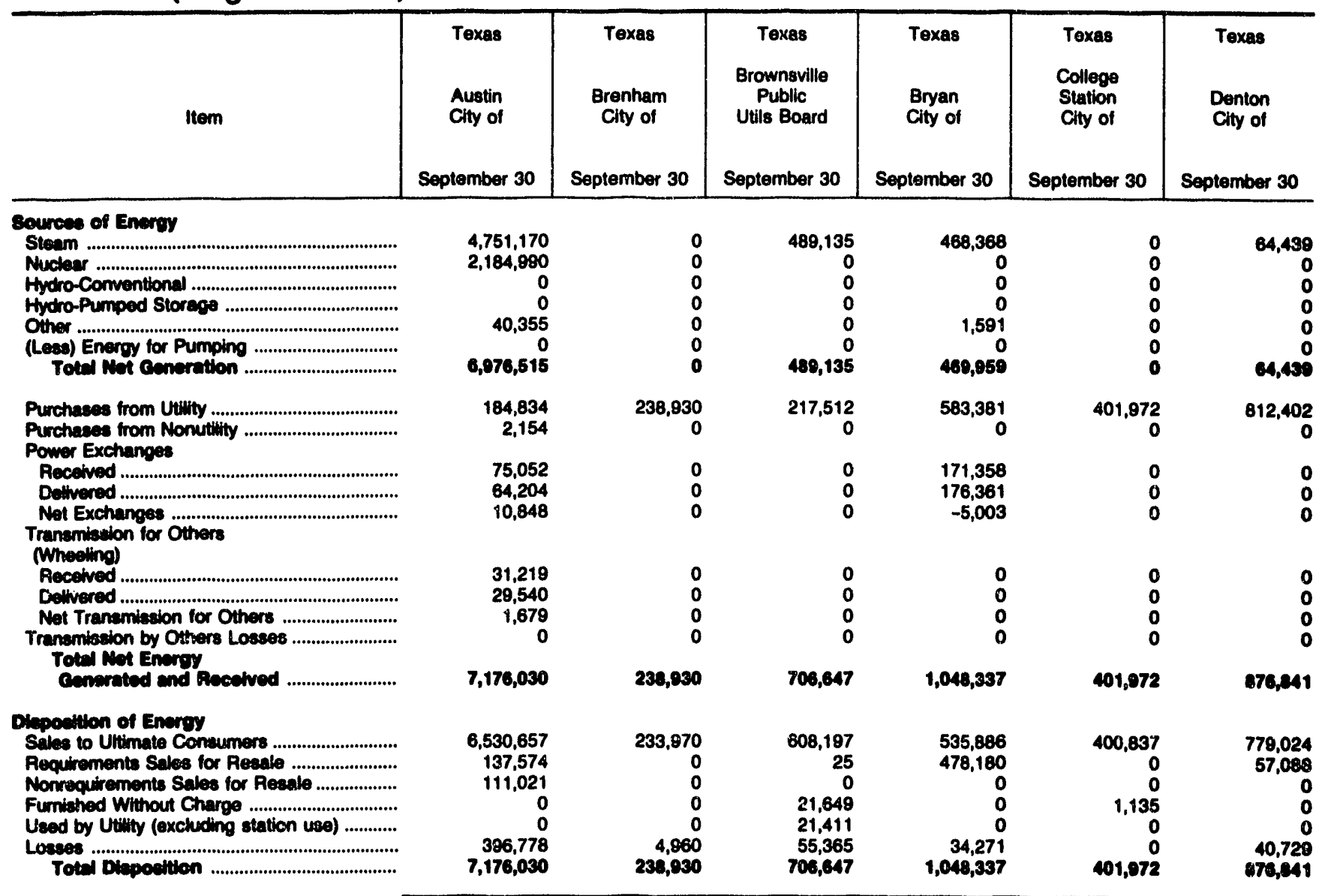

Nole: Totals may not equal sum of components because of independent rounding. Double counting occurs in components of both sources and disposition of energy and thus neither provides a true total. Purchases from utilities, net interchanges, and net wheeling (except for imports) are included in net ceneration. Sales for resale is included in sales to uhimate consumers.

Source: Energy Information Administration, Form EIA-412, "Annual Peport of Public Electric Utilities." 
Table 41. Electric Energy Account by Major Publicly Owned Electric Utillty Within State, 1991 (Continued) (Megawatthours)

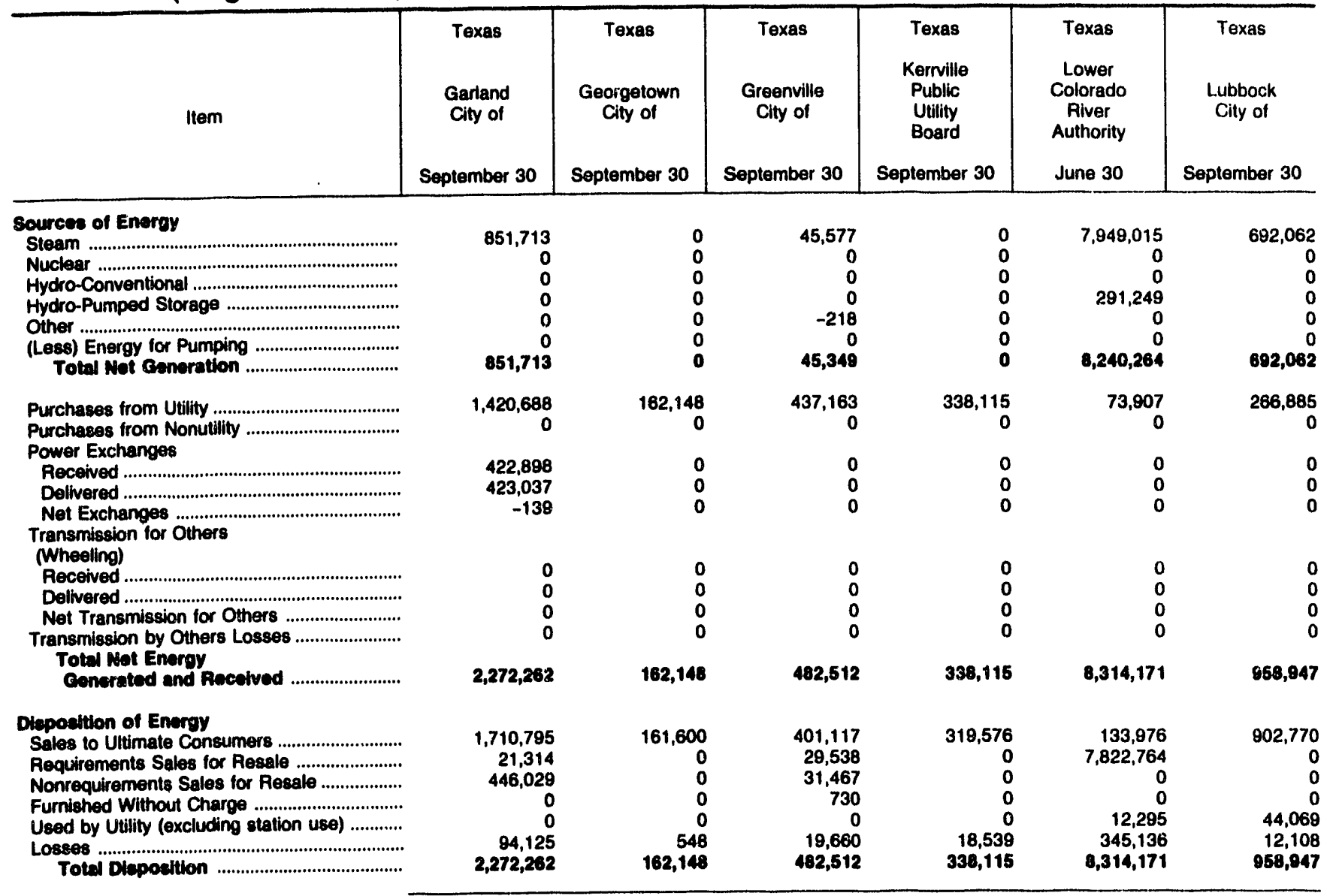

Note: Totals may not equal sum of components because of independent rounding. Double counting occurs in components of both sources and disposition of energy and thus neither provides a true total. Purchases from utilities, net interchanges, and net wheeling (except for imports) are included in net generation. Sales for resale is included in sales to ultimate consumers.

Source: Energy Information Administration, Form ElA-412, "Annual Report of Public Electric Utilities." 
Table 41. Electric Energy Account by Major Publicly Owned Electric Utility Within State, 1991 (Continued) (Megawatthours)

\begin{tabular}{|c|c|c|c|c|c|c|}
\hline Item & $\begin{array}{l}\text { Texas } \\
\text { New Braunfels } \\
\text { City of } \\
\text { July } 31\end{array}$ & $\begin{array}{l}\text { Texas } \\
\text { Sam Rayburn } \\
\text { Municipal } \\
\text { Pwr } \\
\text { Agny } \\
\text { September } 30\end{array}$ & $\begin{array}{l}\text { San Antonio } \\
\text { City of } \\
\text { January } 31\end{array}$ & $\begin{array}{l}\text { San Marcos } \\
\text { City of } \\
\text { September } 30\end{array}$ & $\begin{array}{l}\text { Texas } \\
\text { Seguin } \\
\text { City of } \\
\text { September } 30\end{array}$ & $\begin{array}{c}\text { Texas } \\
\text { Texas } \\
\text { Municipal } \\
\text { Power Agency } \\
\text { September } 30\end{array}$ \\
\hline 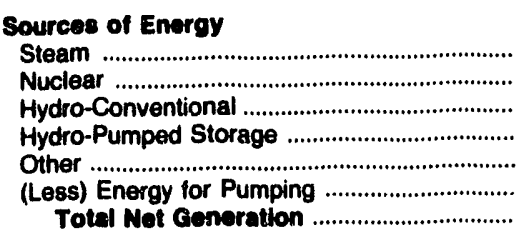 & $\begin{array}{l}0 \\
0 \\
0 \\
0 \\
0 \\
0 \\
0\end{array}$ & $\begin{array}{r}506,198 \\
0 \\
0 \\
0 \\
0 \\
0 \\
506,198\end{array}$ & $\begin{array}{r}9,153,620 \\
3,356,162 \\
0 \\
0 \\
0 \\
0 \\
12,608,782\end{array}$ & $\begin{array}{l}0 \\
0 \\
0 \\
0 \\
0 \\
0 \\
0\end{array}$ & $\begin{array}{r}0 \\
0 \\
1,209 \\
0 \\
0 \\
0 \\
1,200\end{array}$ & $\begin{array}{r}2,967,388 \\
0 \\
0 \\
0 \\
0 \\
0 \\
2,987,388\end{array}$ \\
\hline 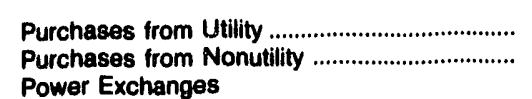 & $\begin{array}{r}725,419 \\
0\end{array}$ & $\begin{array}{r}91,322 \\
0\end{array}$ & $\begin{array}{r}68,990 \\
0\end{array}$ & $\begin{array}{r}306,526 \\
0\end{array}$ & $\begin{array}{r}188,680 \\
0\end{array}$ & $\begin{array}{l}0 \\
0\end{array}$ \\
\hline 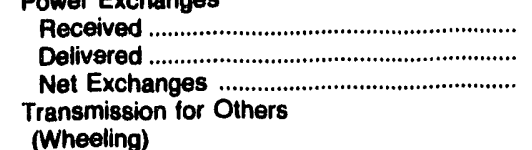 & $\begin{array}{l}0 \\
0 \\
0\end{array}$ & $\begin{array}{l}\mathbf{0} \\
\mathbf{0} \\
0\end{array}$ & $\begin{array}{r}1,063,874 \\
1,061,940 \\
1,934\end{array}$ & $\begin{array}{l}0 \\
0 \\
0\end{array}$ & $\begin{array}{l}\mathbf{0} \\
\mathbf{0} \\
\mathbf{0}\end{array}$ & $\begin{array}{l}\mathbf{0} \\
\mathbf{0} \\
\mathbf{0}\end{array}$ \\
\hline 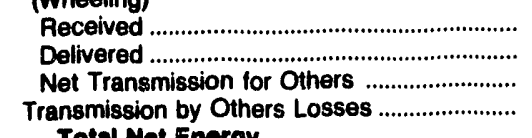 & $\begin{array}{l}0 \\
0 \\
0 \\
0\end{array}$ & $\begin{array}{l}0 \\
0 \\
0 \\
0\end{array}$ & $\begin{array}{l}0 \\
0 \\
0 \\
0\end{array}$ & $\begin{array}{l}0 \\
0 \\
0 \\
0\end{array}$ & $\begin{array}{l}\mathbf{0} \\
0 \\
0 \\
0\end{array}$ & $\begin{array}{l}0 \\
0 \\
0 \\
0\end{array}$ \\
\hline 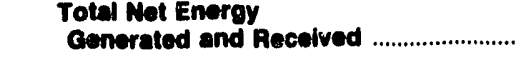 & 725,418 & 597,620 & $12,580,706$ & 306,526 & 189,889 & $2,967,388$ \\
\hline 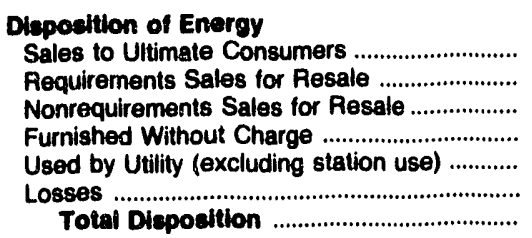 & $\begin{array}{r}700,224 \\
0 \\
0 \\
1,918 \\
0 \\
23,277 \\
725,419\end{array}$ & $\begin{array}{r}0 \\
590,177 \\
0 \\
0 \\
0 \\
7,343 \\
597,520\end{array}$ & $\begin{array}{r}11,634,855 \\
296,500 \\
0 \\
0 \\
65,000 \\
584,351 \\
12,580,708\end{array}$ & $\begin{array}{r}294,910 \\
0 \\
0 \\
0 \\
0 \\
11,616 \\
306,526\end{array}$ & $\begin{array}{r}180,532 \\
0 \\
0 \\
9,357 \\
0 \\
0 \\
189,889\end{array}$ & $\begin{array}{r}0 \\
2,869,616 \\
0 \\
41,436 \\
0 \\
56,336 \\
2,987,388\end{array}$ \\
\hline
\end{tabular}

Note: Totals may not equal sum of components because of independent rounding. Double counting occurs in components of both sources and disposition of energy and thus neither provides a true total. Purchases from utilities, net interchanges, and net wheeling (except for imports) are included in net generation. Sales for resale is included in sales to ultimate consumers.

Source: Energy Information Administration, Form EIA-412. "Annual Report of Public Electric Utilities." 
Table 41. Electric Energy Account by Major Publicly Owned Electric Utility Within State, 1991 (Continued) (Megawatthours)

\begin{tabular}{|c|c|c|c|c|c|c|}
\hline Item & $\begin{array}{l}\text { Texas } \\
\text { Toledo Bend } \\
\text { Project } \\
\text { Joint } \\
\text { Oper } \\
\text { August } 30\end{array}$ & $\begin{array}{l}\text { Texas } \\
\text { Weatherford } \\
\text { Mun } \\
\text { Utility } \\
\text { System } \\
\text { September } 30\end{array}$ & $\begin{array}{l}\text { Utah } \\
\text { Bountiful } \\
\text { City City of } \\
\text { June } 30\end{array}$ & $\begin{array}{c}\text { Intermountain } \\
\text { Power Agency } \\
\text { June } 30\end{array}$ & $\begin{array}{l}\text { Utah } \\
\text { Logan } \\
\text { City of } \\
\text { June } 30\end{array}$ & $\begin{array}{l}\text { Uiah } \\
\text { Murray } \\
\text { City of } \\
\text { June } 30\end{array}$ \\
\hline 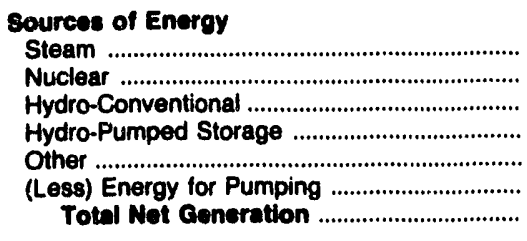 & $\begin{array}{r}0 \\
0 \\
336,812 \\
0 \\
0 \\
0 \\
338,812\end{array}$ & $\begin{array}{r}0 \\
0 \\
0 \\
0 \\
232 \\
0 \\
232\end{array}$ & $\begin{array}{r}0 \\
0 \\
8,961 \\
0 \\
745 \\
0 \\
0 \\
9,706\end{array}$ & $\begin{array}{r}10,749,061 \\
0 \\
0 \\
0 \\
0 \\
0 \\
10,749,061\end{array}$ & $\begin{array}{r}0 \\
0 \\
17,542 \\
0 \\
-158 \\
0 \\
17,384\end{array}$ & $\begin{array}{r}0 \\
0 \\
9,555 \\
0 \\
197 \\
0 \\
9,752\end{array}$ \\
\hline 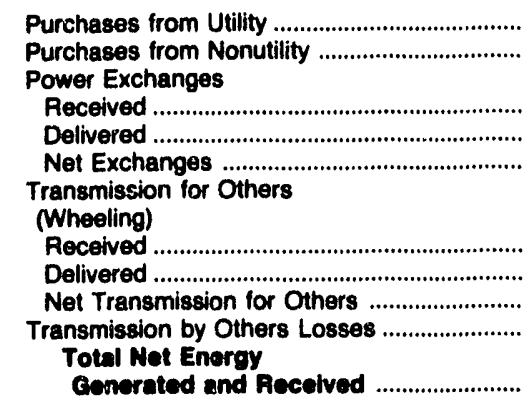 & $\begin{array}{r}413 \\
413 \\
0\end{array}$ & $\begin{array}{r}193,120 \\
0\end{array}$ & $\begin{array}{r}0 \\
0 \\
0 \\
0 \\
232,301\end{array}$ & $10,750,184$ & $\begin{array}{r}5,601 \\
5,579 \\
22 \\
0 \\
272,898\end{array}$ & $\begin{array}{r}288,990 \\
0\end{array}$ \\
\hline 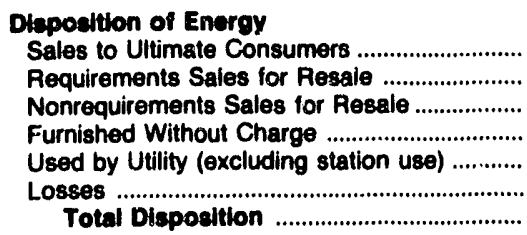 & $\begin{array}{r}0 \\
336,399 \\
0 \\
0 \\
229 \\
184 \\
338,812\end{array}$ & $\begin{array}{r}189,382 \\
0 \\
0 \\
0 \\
0 \\
3,970 \\
183,352\end{array}$ & $\begin{array}{r}219,268 \\
0 \\
0 \\
0 \\
1,491 \\
11,542 \\
232,301\end{array}$ & $\begin{array}{r}0 \\
10,750,184 \\
0 \\
0 \\
0 \\
0 \\
10,750,184\end{array}$ & $\begin{array}{r}253,140 \\
0 \\
0 \\
2,368 \\
1,206 \\
15,982 \\
272,696\end{array}$ & $\begin{array}{r}276,967 \\
0 \\
0 \\
1,911 \\
0 \\
19,864 \\
298,742\end{array}$ \\
\hline
\end{tabular}

Note: Totals may not equal sum of components because of independent rounding. Double counting occurs in components of both sources and disposition of energy and thus neither provides a true total. Purchases from utilities, net interchanges, and net wheeling (except for imports) are included in net generation. Sales for resale is included in sales to ultimate consumers.

Source: Energy Information Administration, Form ElA-412, "Annual Report of Public Electric Utilities." 
Table 41. Electric Energy Account by Major Publicly Owned Electric Utility Within State, 1991 (Continued) (Megawatthours)

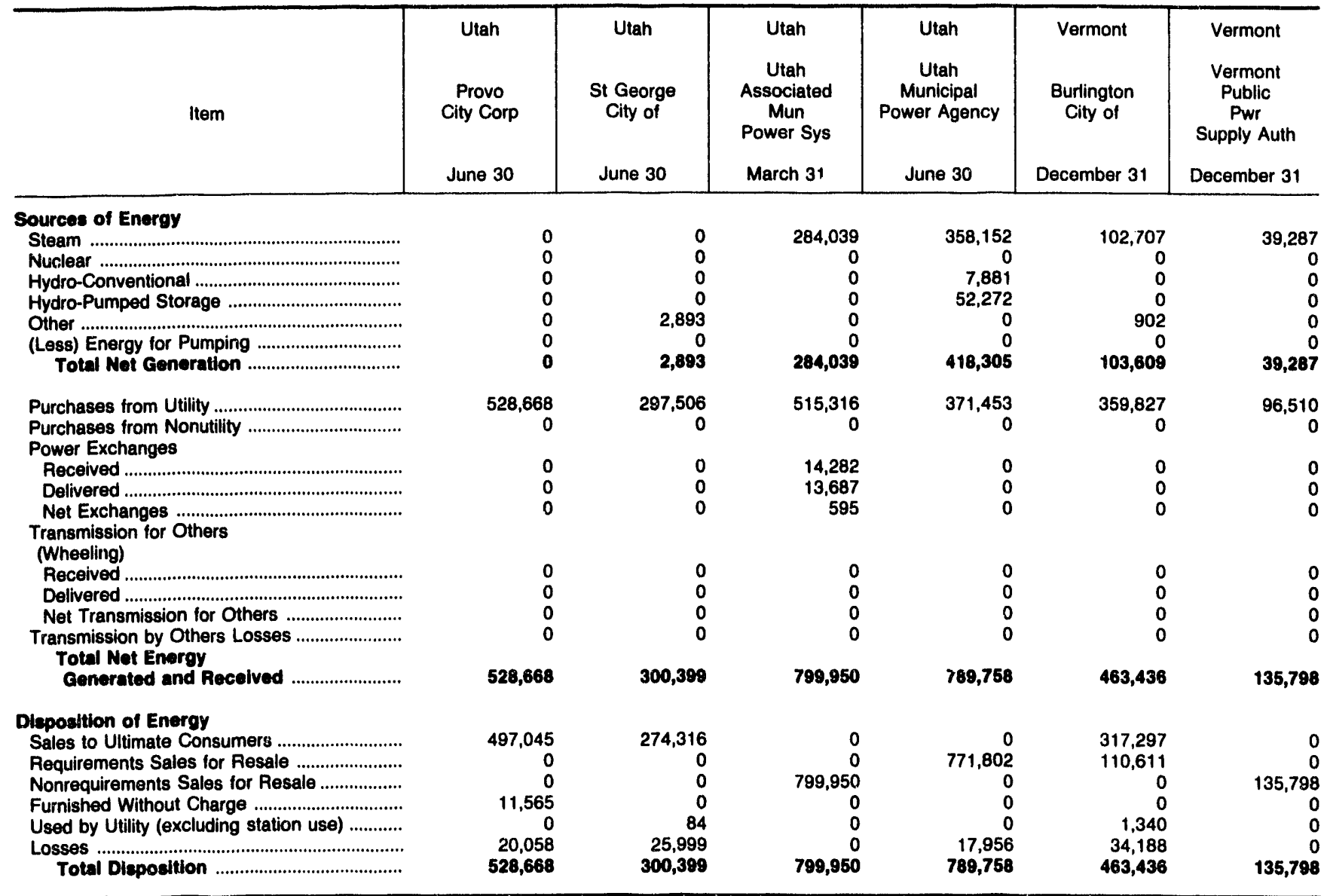

Note: Totals may not equal sum of components because of independent rounding. Double counting occurs in components of both sources and disposition of energy and thus neither provides a true total. Purchases from utilities, net interchanges, and net wheeling (except for imports) are included in net generation. Sales for resale is included in sales to ultimate consumers.

Source: Energy Information Administration, Form ElA-412, "Annual Report of Public Electric Utilities." 

Table 41. Electric Energy Account by Major Publicly Owned Electric
Utility Within State, 1991 (Continued)

(Megawatthours)

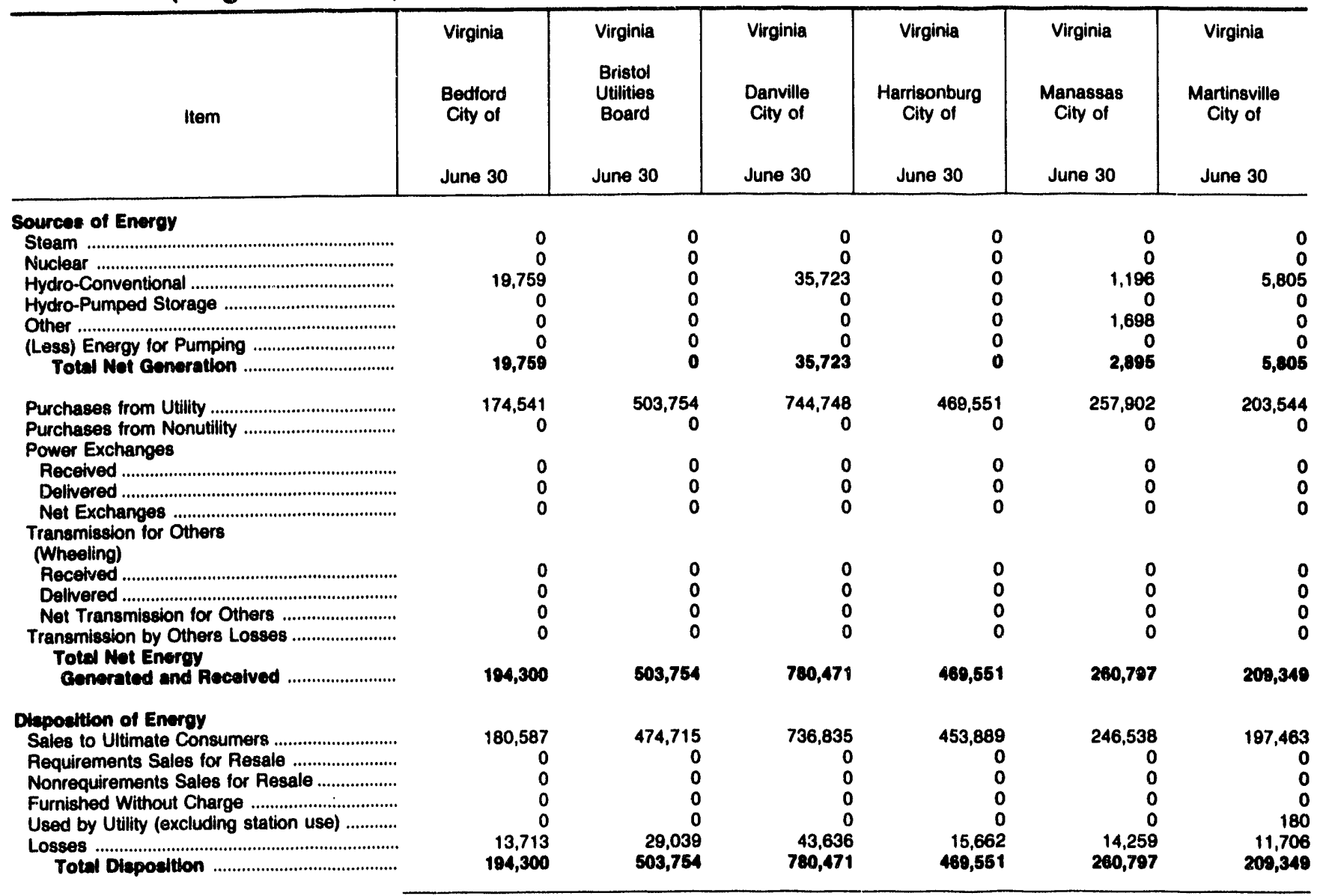

Note: Totals may not equal sum of components because of independent rounding. Double counting occurs in components of both sources and disposition of energy and thus neither provides a true total. Purchases from utilities, net interchanges, and net wheeling (except for imports) are included in net generation. Sales for resale is included in sales to ultimate consumers.

Source: Energy Information Administration, Form EIA-412, "Annual Report of Public Electric Utilities." 
Table 41. Electric Energy Account by Major Publicly Owned Electric Utility Within State, 1991 (Continued)

(Megawatthours)

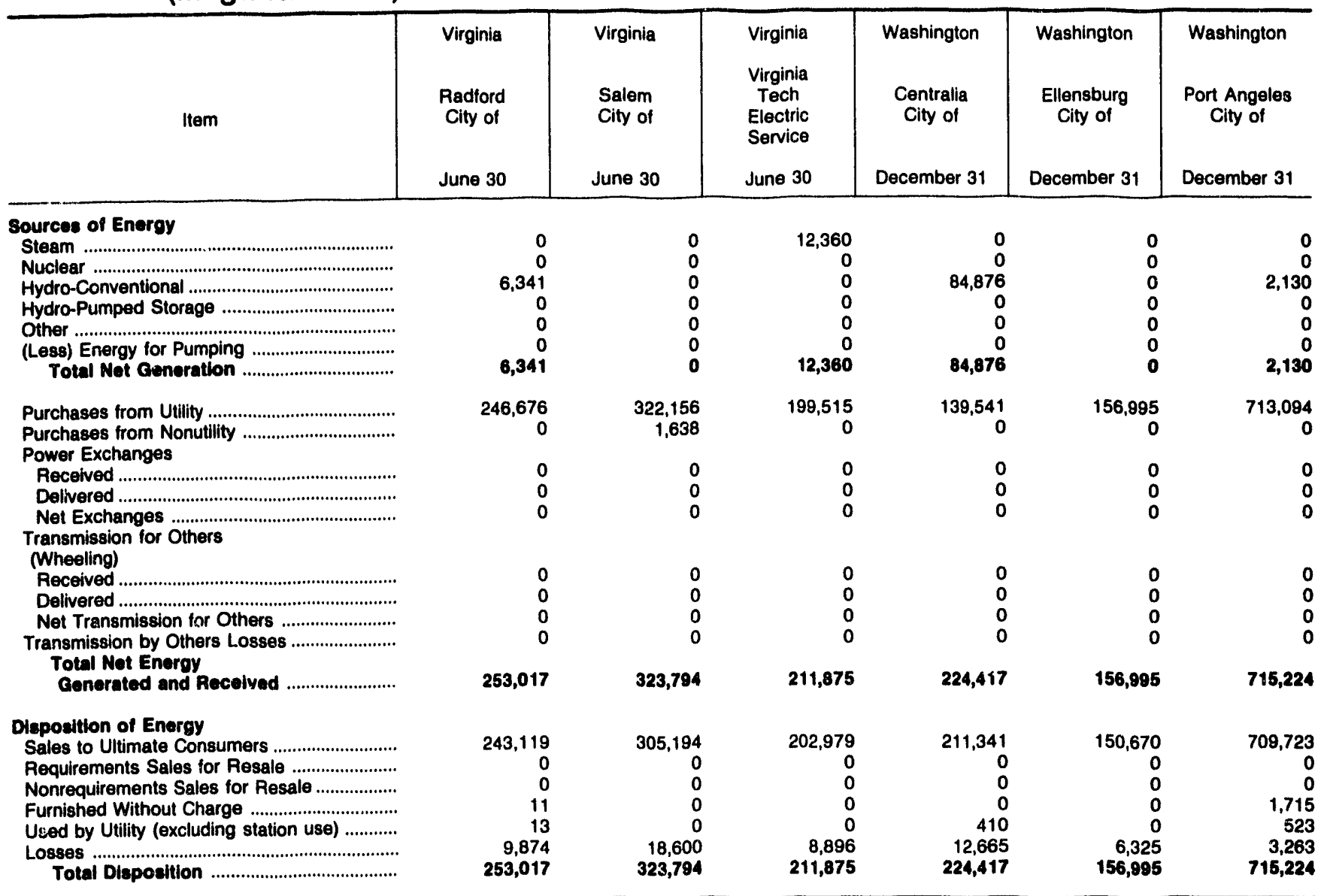

Note: Totals may not equal sum of components because of independent rounding. Double counting occurs in components of both sources and disposition of energy and thus neither provides a true total. Purchases from utitities, net interchanges, and net wheeling (except for imports) are included in net generation. Sales for resale is included in sales to ultimate consumers.

Source: Energy information Administration, Form ElA-412, "Annual Report of Public Electric Utilities." 
Table 41. Electric Energy Account by Major Publicly Owned Electric Utility Within State, 1991 (Continued) (Megawatthours)

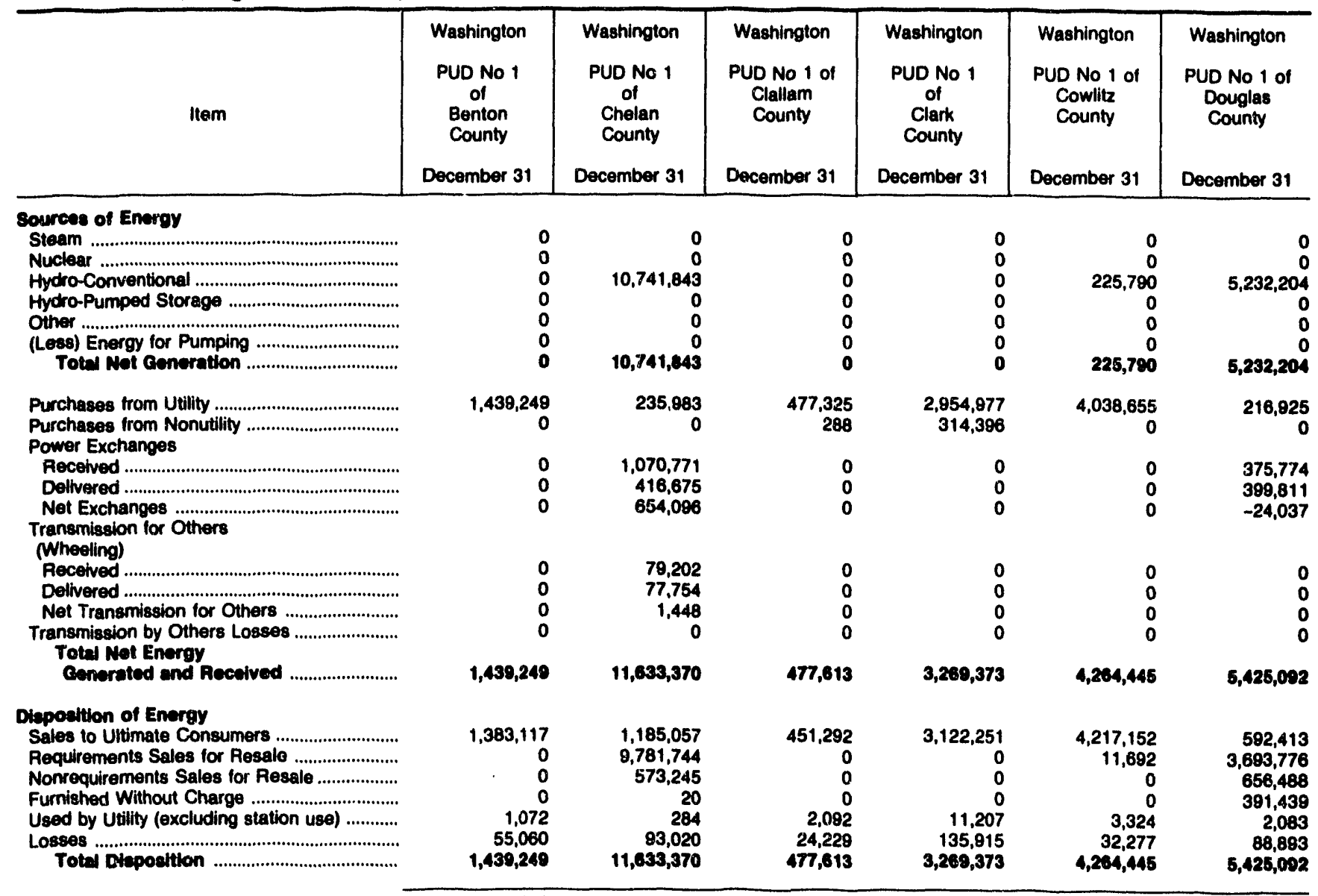

Note: Totals may not equal sum of components because of independent rounding. Double counting occurs in components of both sources and disposition of energy and thus neither provides a true total. Purchases from utilities, net interchanges, and net wheeling (except for imports) are included in net generation. Sales for resale is included in sales to ultimate consumers.

Source: Energy Information Administration, Form EIA-412, "Annual Report of Public Electric Utilities." 
Table 41. Electric Energy Account by Major Publicly Owned Electric Utility Within State, 1991 (Continued) (Megawatthours)

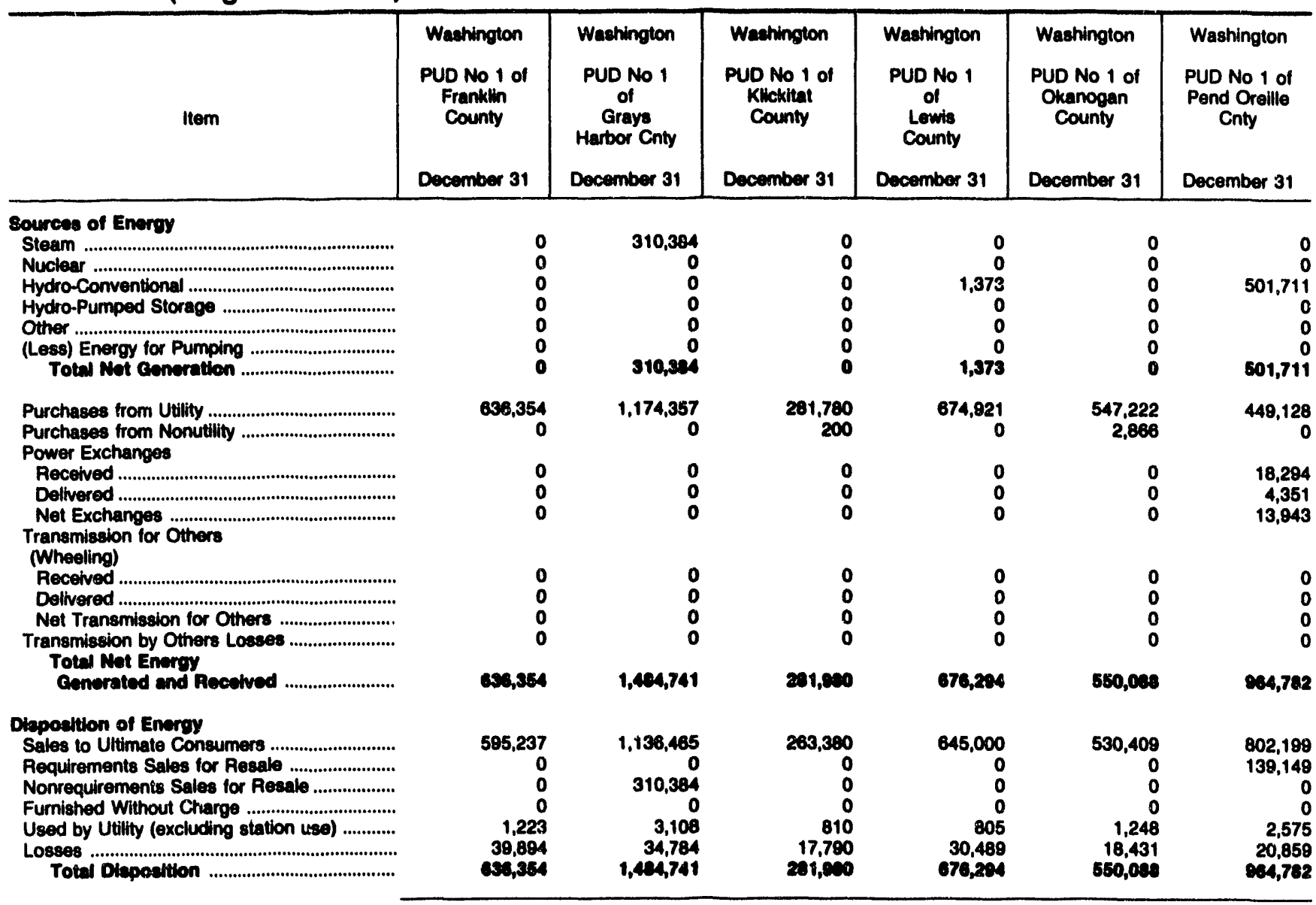

Note: Totals may not equal sum of components because of independent rounding. Double counting occurs in components of both sources and disposition of energy and thus neither provides a thie total. Purchases from utilities, net interchanges, and net wheeling (except for imports) are included in net generation. Sales for resale is included in sales to ultimate consumers.

Source: Energy Information Administration, Form EIA-412, "Annual Report of Public Electric Utilities." 


\section{Table 41. Electric Energy Account by Major Publicly Owned Electric Utility Within State, 1991 (Continued) (Megawatthours)}

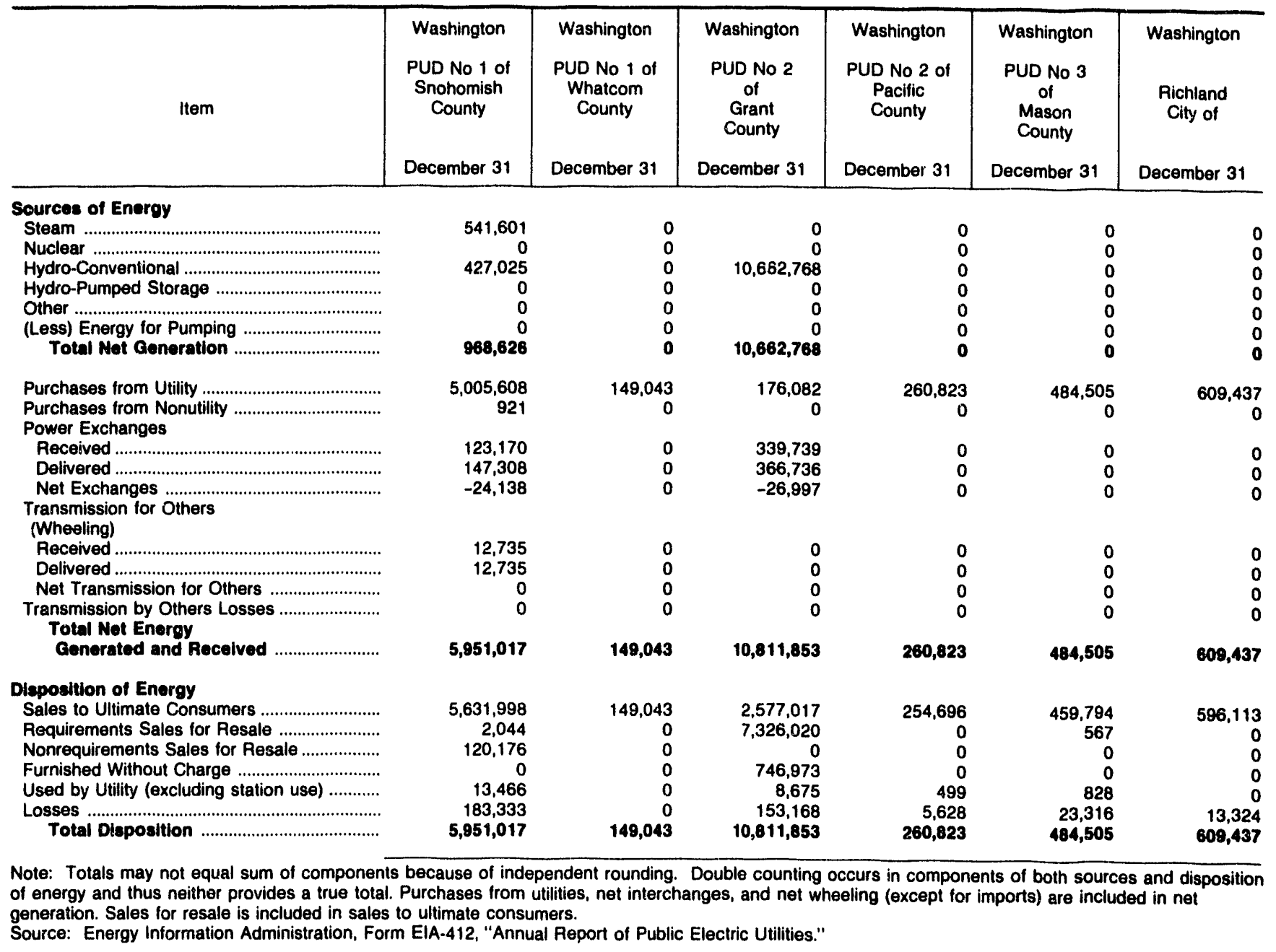


Table 41. Electric Energy Account by Major Publicly Owned Electric
Utility Within State, 1991 (Continued) (Megawatthours)

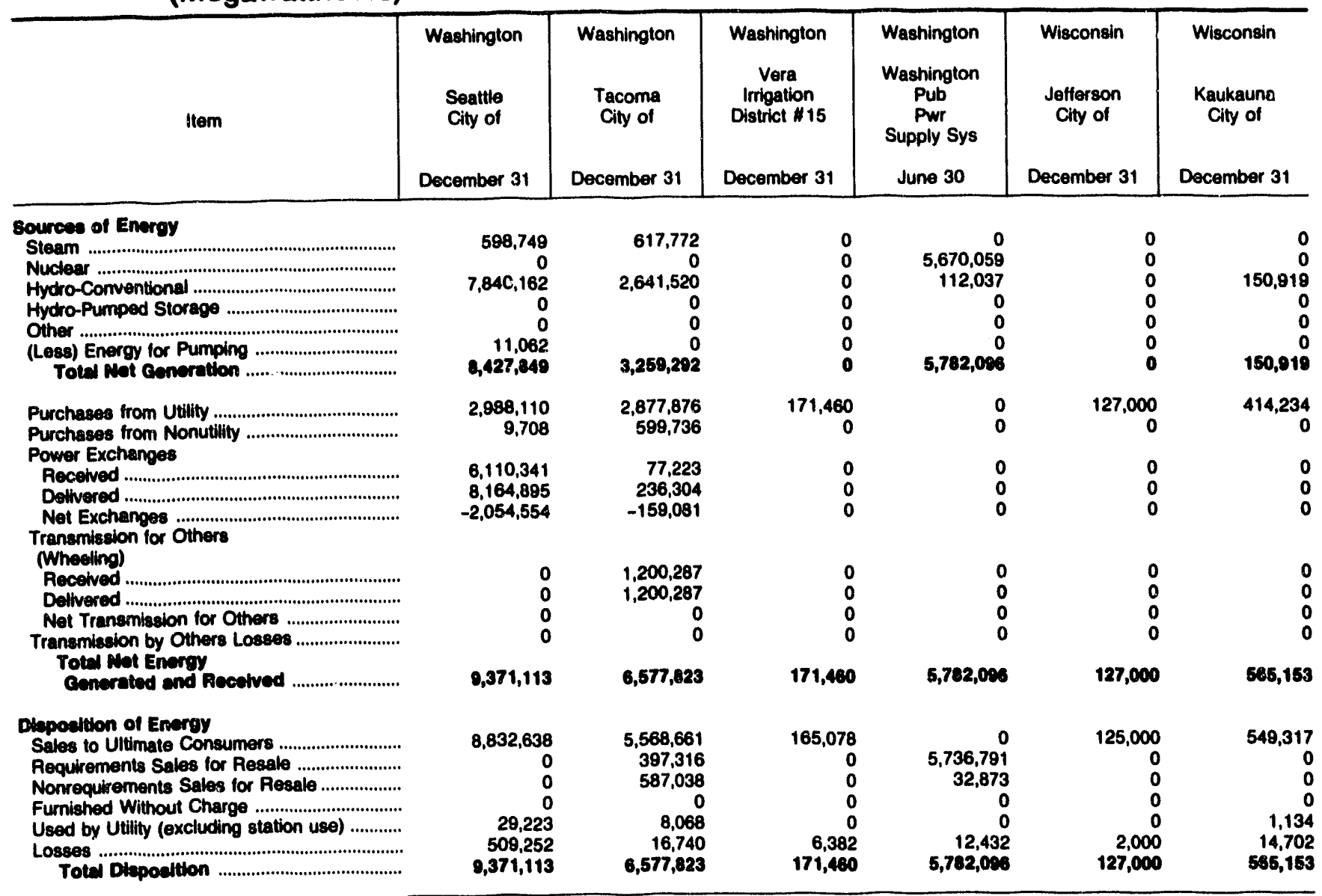

Note: Totals may not equal sum of components because of independent rounding. Double counting occurs in components of both sources and disposition of energy and thus neither provides a true total. Purchases from utilities, net interchanges, and net wheeling (except for imports) are included in net jeneration. Sales for resale is included in sales to ultimate consumers.

Source: Energy Information Administration, Form EIA-412, "Annual Report of Public Electric Utilities." 
Table 41. Elsctric Energy Account by Major Publicly Owned Electric Utility Within State, 1991 (Continued)

(Megawatthours)

\begin{tabular}{c|c|c|c|c|c|c}
\hline & $\begin{array}{c}\text { Visconsin } \\
\text { Manitowoc } \\
\text { Public } \\
\text { Utilities }\end{array}$ & $\begin{array}{c}\text { Marshfield } \\
\text { City of }\end{array}$ & $\begin{array}{c}\text { Menasha } \\
\text { City of }\end{array}$ & $\begin{array}{c}\text { Nein London } \\
\text { City of }\end{array}$ & $\begin{array}{c}\text { Oconomowoc } \\
\text { City of }\end{array}$ & $\begin{array}{c}\text { Plymouth } \\
\text { City of }\end{array}$ \\
& December 31 & December 31 & December 31 & December 31 & December 31 & December 31 \\
\hline
\end{tabular}

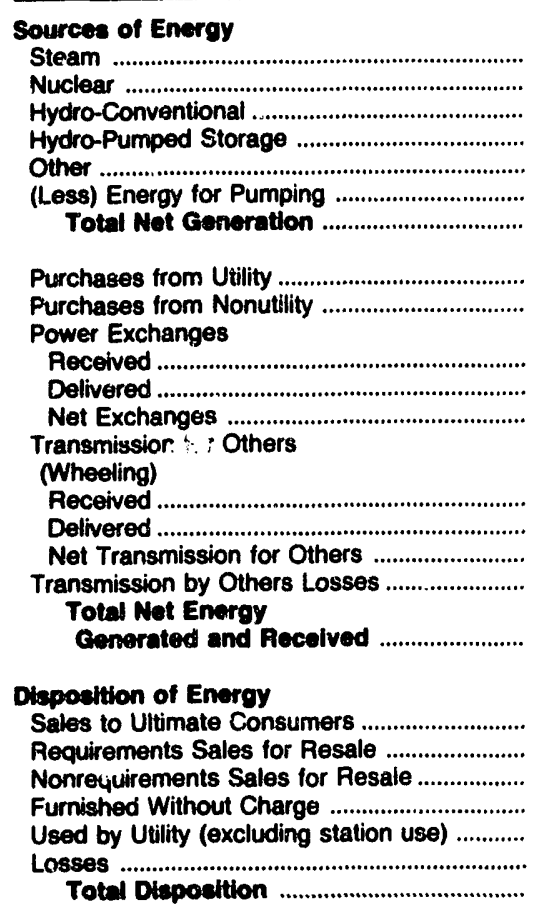

216,122
0
0
0
3,129
0
219,251

231,488

488
0

0

0
0

0
0
0
0

450,739

435,867
3
0
0
594
14,275
450,739

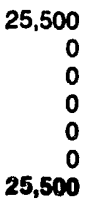

501,800

307,154
0

$$
\begin{aligned}
& u \\
& 0 \\
& 0
\end{aligned}
$$

0
0
0
0

0

0
0
0

307,154

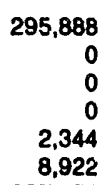

307,154

$\begin{array}{rr}295,888 & 495,400 \\ 0 & 25,500 \\ 0 & 0 \\ 0 & 0 \\ 2,344 & 100 \\ 8,922 & 6,300 \\ 307,154 & 527,300\end{array}$

0
0
0
0
0
0
0

158,348

0

150,840
0

0

0
0
0

0
0
0
0
0
0
0

0
0
0
0
0
0
0

157,032

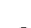

0

0
0
0

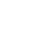

0
0
0
0

150,840

157,032

158,340

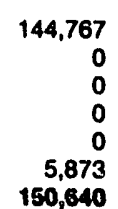

147,213

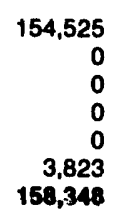

150,840

0

0

140

9,679 157,032

Note: Totals may not equal sum of components because of independent rounding. Double counting occurs in components of both sources and disposition f energy and thus neither provides a true total. Purchases from utilities, net interchanges, and net wheeling (except for imports) are included in net generation. Sales for resale is included in sales to ulitimate consumers.

Source: Energy Information Administration, Form Eli:-412, "Annual Report of Public Electric Utilities." 
Table 41. Electric Energy Account by Major Publicly Owned Electric Utility Within State, 1991 (Continued) (Megawatthours)

\begin{tabular}{|c|c|c|c|c|c|c|}
\hline Item & $\begin{array}{l}\text { Wisconsin } \\
\text { Reedsburg } \\
\text { Utility Comm } \\
\text { December } 31\end{array}$ & $\begin{array}{l}\text { Wisconsin } \\
\text { Shawano } \\
\text { Municipal } \\
\text { Utilities } \\
\text { December } 31\end{array}$ & $\begin{array}{c}\text { Wisconsin } \\
\text { Sheboygan } \\
\text { Falls } \\
\text { City of } \\
\text { December } 31\end{array}$ & $\begin{array}{l}\text { Wisconsin } \\
\text { Sturgeon Bay } \\
\text { Combined } \\
\text { Utils } \\
\text { December } 31\end{array}$ & $\begin{array}{l}\text { Wisconsin } \\
\text { Wisconsin } \\
\text { Public } \\
\text { Power } \\
\text { Inc Sys } \\
\text { June } 30\end{array}$ & $\begin{array}{l}\text { Wisconsin } \\
\text { Wisconsin } \\
\text { Rapids } W W \\
\& L \\
\text { Comm } \\
\text { December } 31\end{array}$ \\
\hline 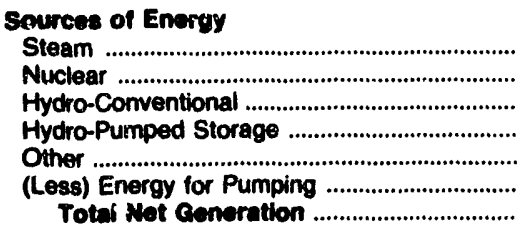 & $\begin{array}{l}0 \\
0 \\
0 \\
0 \\
0 \\
0 \\
0\end{array}$ & $\begin{array}{l}0 \\
0 \\
0 \\
0 \\
0 \\
0 \\
0\end{array}$ & $\begin{array}{l}0 \\
0 \\
0 \\
0 \\
0 \\
0 \\
0\end{array}$ & $\begin{array}{l}0 \\
0 \\
0 \\
0 \\
0 \\
0 \\
0\end{array}$ & $\begin{array}{r}531,095 \\
0 \\
0 \\
0 \\
0 \\
0 \\
531,095\end{array}$ & $\begin{array}{l}0 \\
0 \\
0 \\
0 \\
0 \\
0 \\
0\end{array}$ \\
\hline 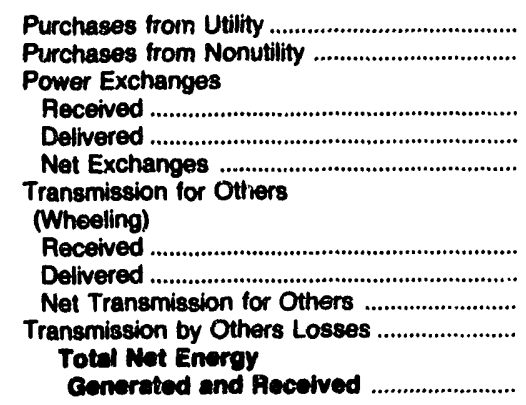 & $\begin{array}{r}139,000 \\
0\end{array}$ & $\begin{array}{r}170,334 \\
20\end{array}$ & $\begin{array}{r}170,931 \\
84\end{array}$ & $\begin{array}{r}131,390 \\
0\end{array}$ & $\begin{array}{r}2,633,247 \\
0\end{array}$ & $\begin{array}{r}199,719 \\
0\end{array}$ \\
\hline 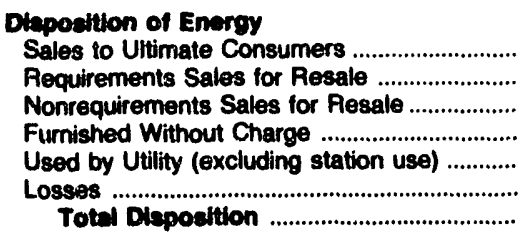 & $\begin{array}{r}133,000 \\
0 \\
0 \\
0 \\
0 \\
6,000 \\
139,000\end{array}$ & $\begin{array}{r}165,682 \\
0 \\
0 \\
0 \\
0 \\
4,672 \\
170,354\end{array}$ & $\begin{array}{r}163,595 \\
0 \\
0 \\
0 \\
91 \\
7,329 \\
171,015\end{array}$ & $\begin{array}{r}126,618 \\
0 \\
0 \\
0 \\
0 \\
4,772 \\
131,390\end{array}$ & $\begin{array}{r}0 \\
3,164,342 \\
0 \\
0 \\
0 \\
0 \\
3,164,342\end{array}$ & $\begin{array}{r}191,826 \\
0 \\
0 \\
0 \\
0 \\
7,893 \\
199,719\end{array}$ \\
\hline
\end{tabular}

Note: Totals may not equal sum of components because of independent rourding. Double counting occurs in components of both sources and disposition of energy and thus neither provides a true total. Purchases from utilities, net interchanges, and net wheeling (except for imports) are included in net generation. Sales for resale is included in sales to ultimate consumers.

Source: Energy Information Administration, Form ElA-412, "Annual Report of Public Electric Utilities." 
Table 41. Electric Energy Account by Major Publicly Owned Electric Utility Within State, 1991 (Continued)

(Megawatthours)

\begin{tabular}{|c|c|c|c|}
\hline liem & $\begin{array}{l}\text { Wyoming } \\
\text { Gillette } \\
\text { City of } \\
\text { June } 30\end{array}$ & $\begin{array}{l}\text { Wyoming } \\
\text { Wyoming } \\
\text { Municipal } \\
\text { Power Agency } \\
\text { December } 31\end{array}$ & \\
\hline 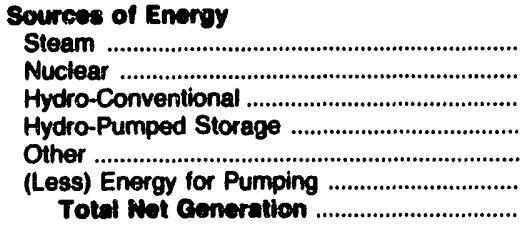 & $\begin{array}{l}0 \\
0 \\
0 \\
0 \\
0 \\
0 \\
0\end{array}$ & $\begin{array}{r}158,832 \\
0 \\
0 \\
0 \\
0 \\
0 \\
158,832\end{array}$ & $\begin{array}{l}2 \\
b \\
0 \\
0 \\
0 \\
0 \\
?\end{array}$ \\
\hline 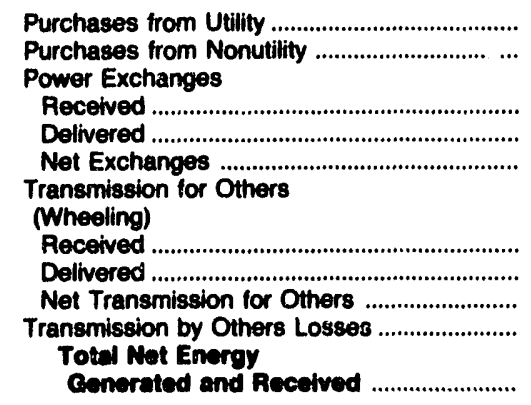 & $\begin{array}{r}181,525 \\
0 \\
0 \\
0 \\
0 \\
\\
0 \\
0 \\
0 \\
0 \\
181,525\end{array}$ & $\begin{array}{r}56,472 \\
0 \\
5,241 \\
7,689 \\
-2,448 \\
\\
0 \\
0 \\
0 \\
0 \\
212,856\end{array}$ & b \\
\hline 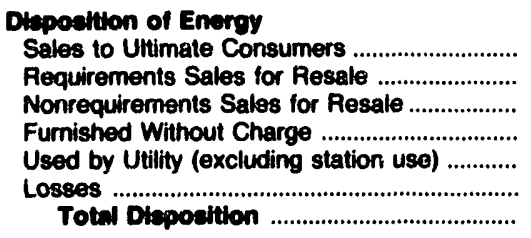 & $\begin{array}{r}164,551 \\
0 \\
0 \\
0 \\
0 \\
16,974 \\
181,525\end{array}$ & $\begin{array}{r}0 \\
170,608 \\
29,243 \\
0 \\
0 \\
13,005 \\
212,856\end{array}$ & \\
\hline
\end{tabular}




\section{Summary Statistics of Federal Electric Utilities}

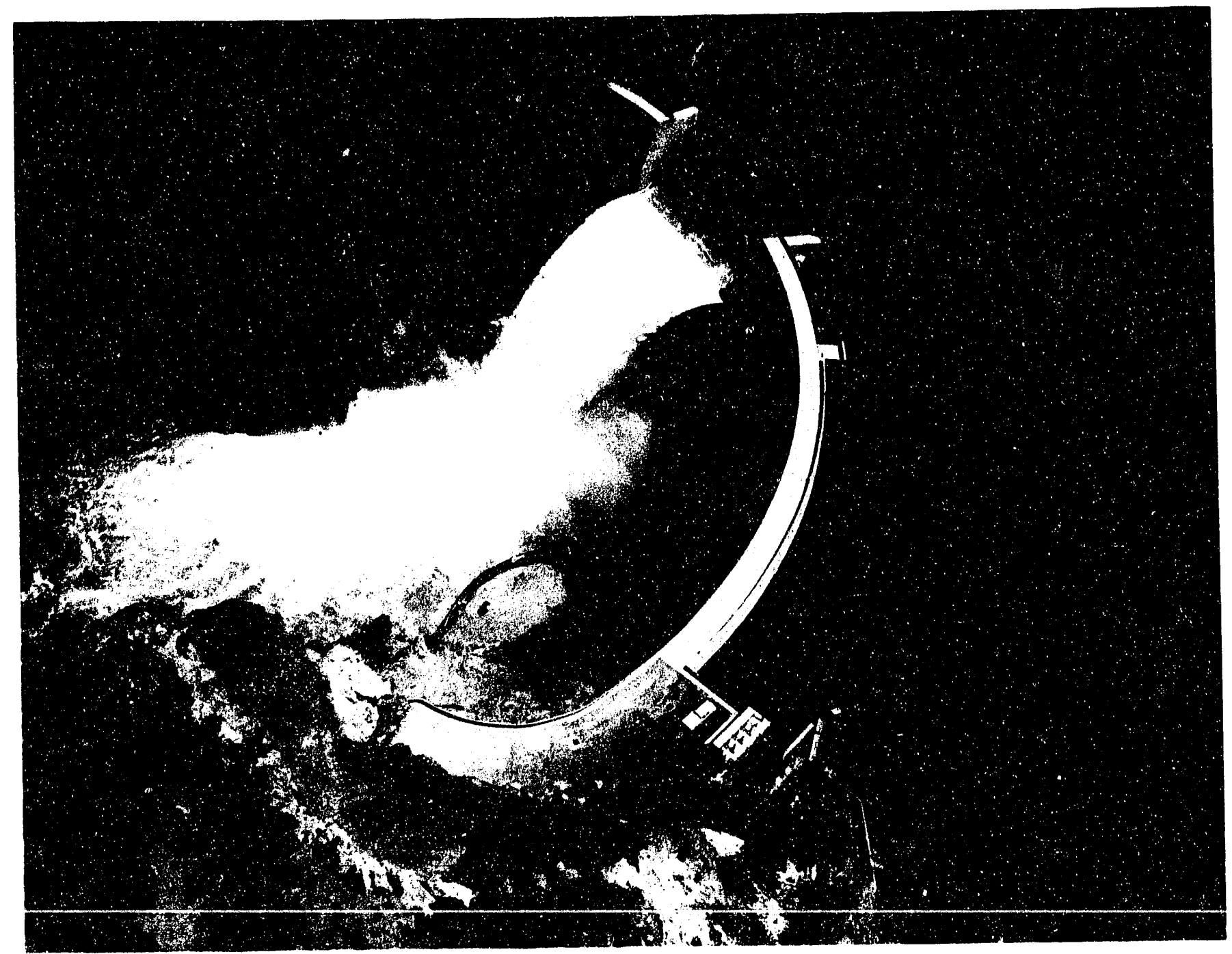

The Crystal Dam and Powerplant, built on the Gunnison River, is located in Montrose County, Colorado, and operated by the Bureau of Reclamation, U.S. Department of Interior. 


\section{Financial Performance}

\section{Background}

There are 10 Federal electric utilities in the United States. They are the Department of Defense-U.S. Army Corps of Engineers; the Department of Energy-the Alaska, Bonneville, Southeastern, Southwestern, and Western Area Power Administrations; the Department of Interior-U.S. Bureau of Indian Affairs and the U.S. Bureau of Reclamation; the Department of StateInternational Water and Boundary Commission; and, the Tennessee Valley Authority. The Federal electric utilities are primarily generators and wholesalers of electricity rather than distributors to ultimate consumers. Federal electric utilities operate over 150 power plants and produce approximately 8 percent of the electricity generated in the United States. Most of the power plants are Federal hydroelectric projects initially designed for flood control and irrigation purposes. Federal power is not sold for profit, but to recover the cost of operations. Most Federal generation is sold for resale to municipals, cooperative electric utilities, and other nonprofit preference customers, as required by law. There are three major producers of electricity: the Tennessee Valley Authority (TVA), the largest Federal producer, the U.S. Army Corps of Engineers (USCE), and the U.S. Bureau of Reclamation (USBR). The TVA markets its own power while the generation by the USCE, except for the North Central Division (Saint Mary's Falls at Sault St. Marie, Michigan), and the USBR is marketed by four of the Federal power marketing administrations - Bonneville, Southeastern, Southwestern, and Western Area. These four power marketing administrations also purchase energy for resale from other electric utilities in the United States and Canada. Alaska, the fifth power marketing administration, operates its own power plants and distributes power to ultimate consumers.

The Tennessee Valley Authority (TVA) was the first of the wholesale marketing organizations to be formed. It was authorized under the Tennessee Valley Authority Act in 1933 "for the purposes of maintaining and operating the properties now owned by the United States in the vicinity of Muscle Shoals, Alabama, in the interest of national defense and for agricultural and industrial development, and to improve navigation in the Tennessee River and to control the destructive flood waters in the Tennessee River and Mississippi River Basins." It was given the authority to both own and operate dams, transmission lines, and power plants along the Tennessee River and its tributaries. By World War II, the TVA had developed most of its water resources, but growing war demands and domestic needs required new capacity. In 1949, Congress approved construction of a steam plant, opening the way for construction of other non-hydroelectric facilities. Today, the TVA's fossil-fueled capacity $(17,647$ megawatts) and nuclear capacity (5,897 megawatts) each exceed its hydroelectric capacity $(4,876$ megawatts of river run and pumped storage). In 1991, the TVA sold 98.2 million megawatthours to its wholesale customers.

During the depression in the early 1930's, New Deal legislation was passed that authorized construction of a number of Federal dams, including Grand Coulee and Bonneville dams in the Pacific Northwest. In 1937, the Government decided that the U.S. Bureau of Reclamation would be responsible for building and operating the dams in the Northwest, and a new marketing administration, the Bonneville Power Administration (BPA), was created by the Bonneville Project Act of 1937 to build and operate transmission facilities and to market the power. The BPA grew, but in the late 1960 's, like the TVA, the BPA faced a potential shortage of hydroelectric capacity to meet their load. In 1980, the Pacific Northwest Electric Power Planning and Conservation Act gave the BPA the authority to plan for and acquire additional power to meet its growing load requirements. The BPA's responsibilities were also extended from only marketing Federal power to supplying the power. Its authority to supply power, however, was restricted to obtaining it from plants built by others. The BPA cannot build its own power plants. Only the BPA and the TVA are responsible for meeting their customers loads. Under the 1980 Act, the BPA also must protect and enhance the fish and wildlife of the Columbia River and its tributaries. In 1991, the BPA sold 59.2 million megawatthours of energy to its wholesale customers from over 30 Federally owned dams operated by either the U.S. Bureau of Reclamation or the U.S. Army Corps of Engineers and from non-Federal system generators.

In 1943, the Southwestern Power Administration (SWPA) was created using the Executive Branch's emergency war powers authority to meet the growing power demands from weapons development and domestic needs. Later, the SWPA's authority to continue to operate after World War II came from the Flood Control Act of 1944. Initially, the SWPA was assigned to market power from dams in Arkansas, Oklahoma, and Texas that were operated by the U.S. Department of Army to serve munitions plants. In 1945, the SWPA was designated as the agent for marketing power generated by the U.S. Army Corps of Engineers in the States of Arkansas, Kansas, Louisiana, Missouri, Oklahoma, and Texas. Today, the SWPA sells power from 24 hydroelectric facilities in these States that total 2,158 megawatts of installed capacity. In 1991, the SWPA sold 6.0 million megawatthours to its wholesale customers.

The third power marketing administration, Southeastern Power Administration (SEPA), was established in 1950 under the authority of the Flood Control Act of 1944 to sell power produced by the U.S. Army Corps of Engineers in the Southeast. The SEPA currently markets power in West Virginia, Virginia, North Carolina, South Carolina, Georgia, Florida, Alabama, Mississippi, Tennessee, and Kentucky. The SEPA is unique from the other marketing authorities in that it owns no 
transmission lines. It must rely on private firms to transmit the power it sells. In its role to market the energy generated by the Southeastern Federal reservoir projects, it participated in the establishment of the Southeastern Federal Power Alliance last July, which consists of SEPA, the South Atlantic Division of the U.S. Army Corps of Engineers, and SEPA's preference customers. The purpose of this organization is to improve communication and establish a strategy by which the three groups can better implement the Federal power program in the Southeast. In 1991, the SEPA sold over 7.8 million megawatthours to its wholesale customers.

The Alaska Power Marketing Administration (APA) was formed in 1967 under the Flood Control Act of 1944 to both operate and market the power from two hydroelectric plants in Alaska: the Eklutna Project ( 30 megawatts) and the Snettisham Project ( 78 megawatts). The TVA and the APA are the only two Federal marketing organizations to operate their own plants. Currently, the Federal government is investigating the potential sale of this marketing administration.

The last Federal marketing administration to be created was the Western Area Power Administration (WAPA), which was formed in 1977 when the Congress created the U.S. Department of Energy and assigned the other Federal marketing administrations to be a part of the new energy department. The territory that the WAPA serves covers the 15 Central and Western States of Arizona, California, Colorado, Iowa, Kansas, Minnesota, Montana, Nebraska, Nevada, New Mexico, North Dakota, South Dakota, Texas, Utah, and Wyoming. Its mission is to market Federally-owned hydroelectric resources "...in such a manner as to encourage the most widespread use thereof at the lowest possible rates to consumers consistent with sound business principles ..." The WAPA's authority was extended through the Hoover Power Plant Act of 1984 to require customer utilities to undertake certain conservation activities and to withhold a part of customer's power allocation if they did not comply. In 1991, the WAPA marketed hydroelectric power from 51 plants operated by the U.S. Bureau of Reclamation, the U.S. Army Corps of Engineers, and the International Boundary and Water Commission. In addition, the WAPA markets the Federal government's 547 megawatt entitlement from the coal-fired Navajo Generating Station in Arizona. The WAPA was responsible for selling 28.9 million megawatthours to its wholesale customers in 1991.

\section{The Largest Federal Producer}

The Tennessee Valley Authority provides power to approximately 110 municipal and 50 cooperative electric systems for distribution to over 3.3 million customers. The four largest municipalities are the Tennessee cities of Chattanooga, Knoxville, Memphis, and Nash- ville. Of the 116,435.8 million megawatthours of electricity generated in 1991 by TVA, the four largest municipals distributed 30.6 million megawatthours or 26.3 percent of TVA's total generation to their customers. The 160 locally owned distributors serve an 80,000square-mile area in parts of seven States. In 1991, the TVA accounted for approximately half of the total net generation by the Federal electric utilities.

\section{Composite Income Statement}

As of the end of the fiscal year (September 31, 1991), operating revenues for the Federal electric utilities totaled $\$ 8,193.9$ million. Total electric utility operating expenses were $\$ 5,288.1$ million in 1991 . A major portion of these total electric utility operating expenses include production expenses that totaled $\$ 3,650.5$ million. Production expenses for the Federal electric utilities were 69.0 percent of total electric utility operating expenses. Total electric operation and maintenance expenses were $\$ 4,473.2$ million, 84.5 percent of total electric utility operating expenses for the Federal electric utilities.

Total electric utility income for the Federal electric utilities was $\$ 2,997.8$ million. Income deductions totaled $\$ 2,000.1$ million. Of the income deductions, $\$ 1,746.8$ million came from interest on long-term debt, which represented 87.3 percent of total income deductions. Net income for the Federal electric utilities as of the end of September 1991 was $\$ 759.5$ million.

\section{Balance Sheet}

As of September 30, 1991, net investment in electric utility plant for the Federal electric utilities was $\$ 31,294.4$ million, including construction work in progress that totaled $\$ 7,097.2$ million.

Total investment and surplus accounts of the Federal electric utilities were $\$ 11,251.7$ million at the end of the fiscal year 1991, 25.1 percent of total liabilities and other credits. The amount of long-term debt and current and accrued liabilities was $\$ 33,476.6$ million, 74.7 percent of total liabilities and other credits of the Federal electric utilities.

\section{Sales of Electric Power}

For the fiscal year ending September 30, 1991, sales of electric energy to ultimate consumers by the Federal electric utilities were 49.4 million megawatthours. Electricity sold for resale amounted to 204.4 million megawatthours. Total disposition of energy was 264.1 million megawatthours of which the Federal electric utilities had a net generation of 254.7 million megawatthours (Table 47). 
Table 42. Statement of Income by Federal Electric Utility, 1991 (Thousand Dollars)

\begin{tabular}{|c|c|c|c|c|c|}
\hline Item & $\begin{array}{c}\text { Alaska } \\
\text { Power } \\
\text { Admin }\end{array}$ & $\begin{array}{l}\text { Bonneville } \\
\text { Power } \\
\text { Admin }\end{array}$ & $\begin{array}{l}\text { Southeastern } \\
\text { Power } \\
\text { Admin }\end{array}$ & $\begin{array}{c}\text { Southwestern } \\
\text { Power } \\
\text { Admin }\end{array}$ & $\begin{array}{c}\text { Western Area } \\
\text { Power } \\
\text { Admin }\end{array}$ \\
\hline 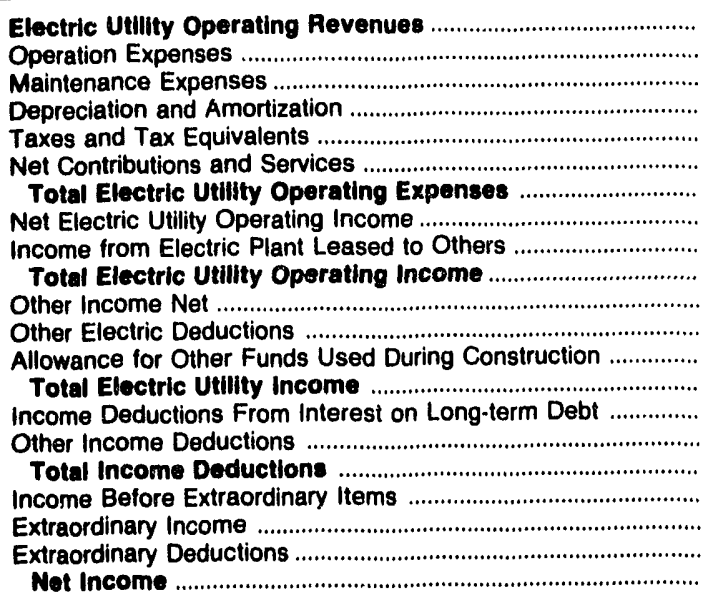 & $\begin{array}{r}9,368 \\
2,914 \\
971 \\
2,017 \\
0 \\
0 \\
5,902 \\
3,466 \\
0 \\
3,466 \\
0 \\
0 \\
0 \\
3,466 \\
2,904 \\
0 \\
2,904 \\
562 \\
0 \\
15,968 \\
-15,408\end{array}$ & $\begin{array}{r}2,211,203 \\
1,393,044 \\
94,122 \\
144,274 \\
0 \\
0 \\
1,631,440 \\
579,763 \\
196 \\
579,959 \\
2,890 \\
0 \\
0 \\
582,849 \\
157,490 \\
-10,667 \\
146,823 \\
436,026 \\
0 \\
0 \\
436,026\end{array}$ & $\begin{array}{r}145,861 \\
27,699 \\
69 \\
9 \\
0 \\
0 \\
27,776 \\
118,085 \\
0 \\
118,085 \\
15 \\
0 \\
0 \\
118,100 \\
48 \\
118,052 \\
118,100 \\
0 \\
0 \\
0\end{array}$ & $\begin{array}{r}94,797 \\
74,892 \\
8,907 \\
2,482 \\
0 \\
0 \\
86,281 \\
8,516 \\
0 \\
8,516 \\
0 \\
0 \\
0 \\
8,516 \\
838 \\
0 \\
838 \\
7,679 \\
0 \\
0 \\
7,679\end{array}$ & $\begin{array}{r}564,054 \\
490,401 \\
0 \\
08,553 \\
0 \\
0 \\
518,954 \\
45,100 \\
0 \\
45,100 \\
76,950 \\
89,025 \\
0 \\
33,025 \\
0 \\
55,002 \\
55,002 \\
-21,977 \\
0 \\
0 \\
-21,077\end{array}$ \\
\hline
\end{tabular}

'Includes data only for Saint Mary's Falls at Sault St. Marie, Michigan. The rest of the generation produced by the U.S. Army Corps of Engineers (USCE) is sold by the Department of Energy-Bonneville, Southeastern, Southwestern, and Western Area Power Administrations.

Note: Totals may not equal sum of components because of independent rounding.

Source: Energy Information Administration, Form EIA-412, "Annual Report of Public Electric Utilities."

Table 42. Statement of Income by Federal Electric Utility, 1991 (Continued) (Thousand Dollars)

\begin{tabular}{|c|c|c|c|c|c|}
\hline \multirow[b]{2}{*}{ Item } & \multirow[b]{2}{*}{$\begin{array}{c}\text { Tennessee } \\
\text { Valley } \\
\text { Authority } \\
\text { September } 30\end{array}$} & \multicolumn{2}{|c|}{ U.S. Bureau of Iridian Affairs } & \multirow[b]{2}{*}{$\begin{array}{l}\text { USCE- } \\
\text { North Central } \\
\text { Division' } \\
\text { September } 30\end{array}$} & \multirow[b]{2}{*}{$\begin{array}{c}\text { Total } \\
\text { September } 30\end{array}$} \\
\hline & & $\begin{array}{c}\text { Mission } \\
\text { Valley Power } \\
\text { September } 30\end{array}$ & $\begin{array}{l}\text { San Carlos } \\
\text { September } 30\end{array}$ & & \\
\hline 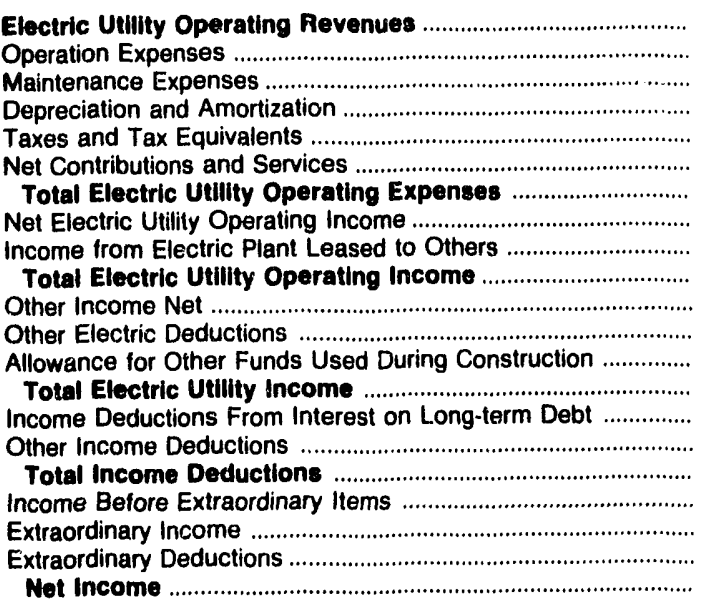 & $\begin{array}{r}5,136,690 \\
2,101,390 \\
252,062 \\
393,571 \\
242,897 \\
0 \\
2,989,919 \\
2,146,772 \\
4,554 \\
2,151,326 \\
0 \\
0 \\
95,965 \\
2,247,290 \\
1,585,499 \\
90,978 \\
1,676,477 \\
570,813 \\
0 \\
223,400 \\
347,413\end{array}$ & $\begin{array}{r}12,942 \\
8,281 \\
1,058 \\
16 \\
175 \\
0 \\
9,530 \\
3,412 \\
0 \\
3,412 \\
0 \\
0 \\
0 \\
3,412 \\
0 \\
0 \\
0 \\
3,412 \\
0 \\
0 \\
3,412\end{array}$ & $\begin{array}{r}17,940 \\
15,405 \\
803 \\
782 \\
0 \\
0 \\
16,990 \\
950 \\
0 \\
950 \\
505 \\
0 \\
0 \\
1,455 \\
0 \\
0 \\
0 \\
1,455 \\
1,211 \\
0 \\
2,666\end{array}$ & $\begin{array}{r}1,005 \\
984 \\
215 \\
147 \\
0 \\
0 \\
1,347 \\
-342 \\
0 \\
-342 \\
0 \\
0 \\
0 \\
-342 \\
0 \\
0 \\
0 \\
-342 \\
0 \\
0 \\
-342\end{array}$ & $\begin{array}{r}8,193,860 \\
4,115,009 \\
358,208 \\
571,850 \\
243,072 \\
0 \\
5,288,139 \\
2,905,721 \\
4,750 \\
2,910,471 \\
80,360 \\
89,025 \\
95,965 \\
2,997,771 \\
1,746,779 \\
253,365 \\
2,000,144 \\
997,627 \\
1,211 \\
239,368 \\
759,470\end{array}$ \\
\hline
\end{tabular}

'Includes data only for Saint Mary's Falls at Sault St. Marie, Michigan. The rest of the generation produced by the U.S. Army Corps of Engineers (USCE) is sold by the Department of Energy-Bonneville, Southeastern, Southwestern, and Western Area Power Administrations.

Note: Totals may not equal sum of components because of independent rounding.

Source: Energy Information Administration, Form EIA-412, "Annual Report of Public Electric Utilities." 
Table 43. Balance Sheet by Federal Electric Utility

on September 30, 1991

(Thousand Dollars)

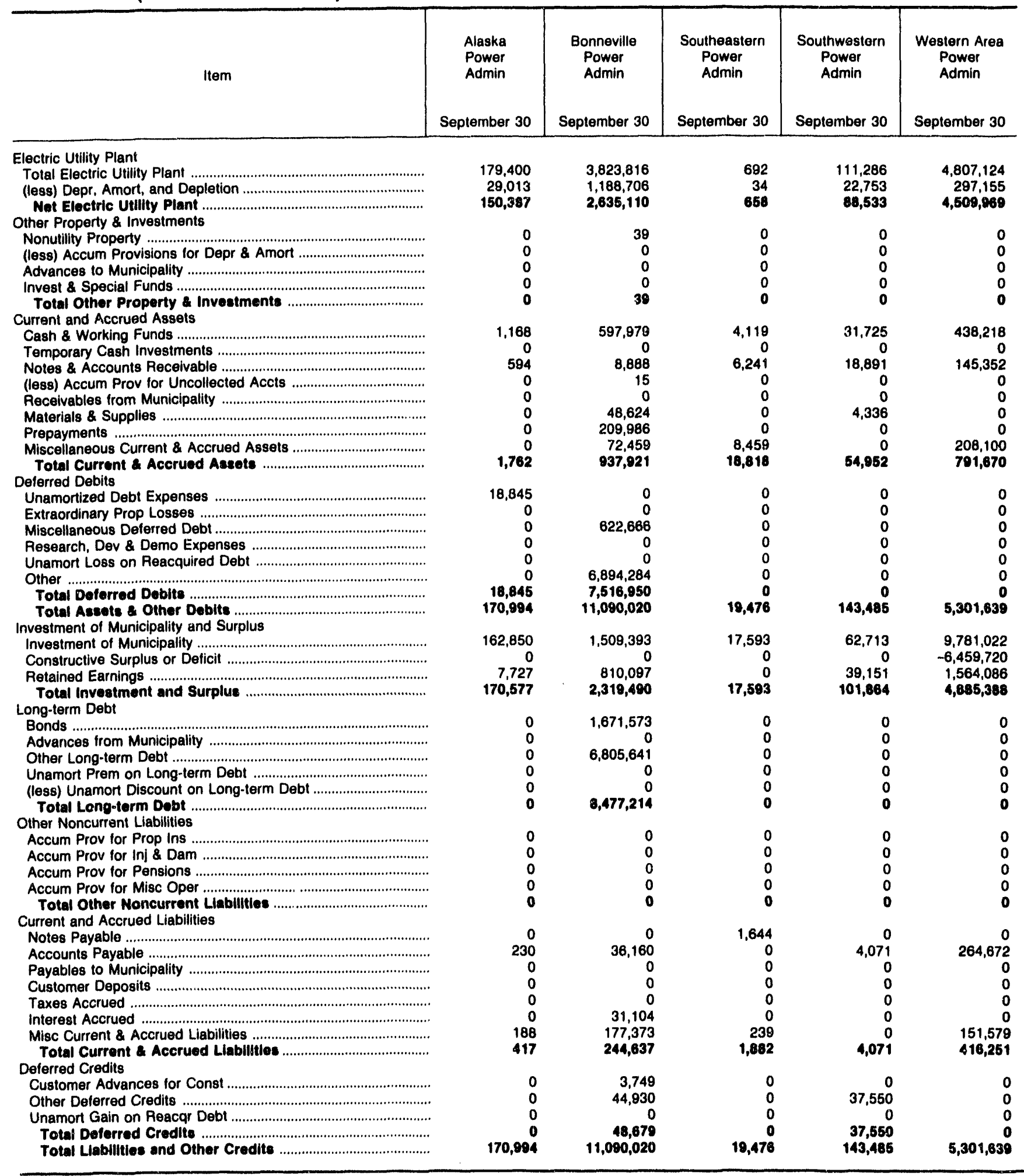

See endnotes at end of this table. 
Table 43. Balance Sheet by Federal Electric Utility on September 30, 1991 (Continued) (Thousand Dollars)

\begin{tabular}{|c|c|c|c|c|c|}
\hline \multirow[b]{2}{*}{ Item } & \multirow[b]{2}{*}{$\begin{array}{c}\text { Tennessee } \\
\text { Valley } \\
\text { Authority } \\
\text { September } 30\end{array}$} & \multicolumn{2}{|c|}{ U.S. Bureau of Indian Affairs } & \multirow[b]{2}{*}{$\begin{array}{l}\text { USCE- } \\
\text { North Central } \\
\text { Division' } \\
\text { September } 30\end{array}$} & \multirow[b]{2}{*}{$\begin{array}{c}\text { Total } \\
\text { September } 30\end{array}$} \\
\hline & & $\begin{array}{c}\begin{array}{c}\text { Mission } \\
\text { Valley Power }\end{array} \\
\text { September } 30\end{array}$ & September 30 & & \\
\hline \multicolumn{6}{|l|}{ Electric Utility Plant } \\
\hline 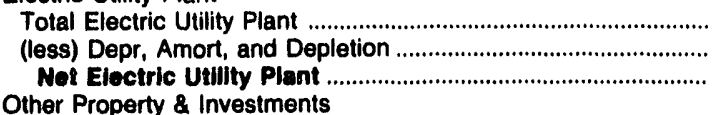 & $\begin{array}{r}29,334,107 \\
5,461,298 \\
23,872,809\end{array}$ & $\begin{array}{r}15,096 \\
16 \\
15,081\end{array}$ & $\begin{array}{r}21,691 \\
9,064 \\
12,627\end{array}$ & $\begin{array}{r}12,343 \\
3,145 \\
9,198\end{array}$ & $\begin{array}{r}38,305,555 \\
7,011,183 \\
31,294,372\end{array}$ \\
\hline Nonutility Property . . & 4,155 & 0 & 0 & 0 & 4.194 \\
\hline (less) Accum Provisions for Depr \& Amort .............................. & 3,067 & 0 & 0 & 0 & 3,067 \\
\hline 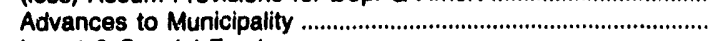 & & 0 & 0 & 0 & \\
\hline 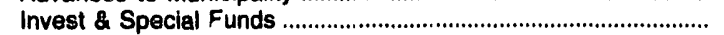 & 170,436 & 0 & 0 & 0 & 170,436 \\
\hline \multicolumn{6}{|l|}{ Current and Accrued Assets } \\
\hline 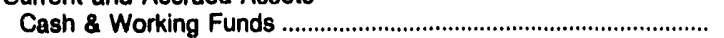 & 185,446 & 4,389 & 15,834 & 74 & $1,278,951$ \\
\hline 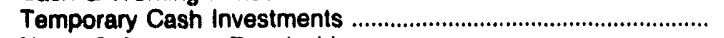 & 459,228 & & & 0 & 459,228 \\
\hline 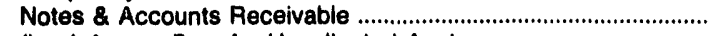 & 697,276 & 715 & 5,384 & 0 & 883,341 \\
\hline 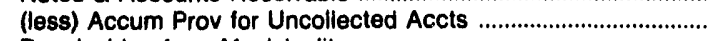 & & 20 & 216 & 0 & 251 \\
\hline 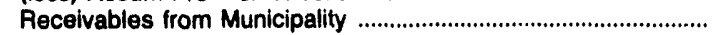 & 0 & 0 & 0 & 0 & 0 \\
\hline Materials \& Supplies & 470,997 & 921 & 4,516 & 0 & 529,394 \\
\hline 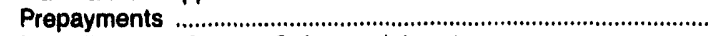 & 0 & 14 & 0 & 0 & 210,000 \\
\hline 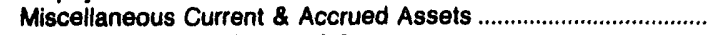 & 0 & 0 & 824 & 0 & 289,842 \\
\hline \multicolumn{6}{|l|}{ Deferred Debits } \\
\hline 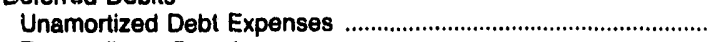 & 862,622 & 0 & 0 & 0 & 881,467 \\
\hline 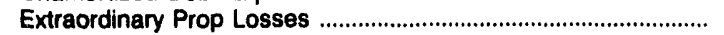 & & 0 & 0 & 0 & \\
\hline Miscellaneous Deferred Debt .................................................... & $1,005,442$ & 153 & 0 & 0 & $1,628,261$ \\
\hline 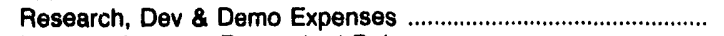 & & 0 & 0 & 0 & \\
\hline Unamort Loss on Reacquired Debt ............................................... & 0 & 0 & 0 & 0 & 0 \\
\hline Other & 295,265 & 0 & 0 & 0 & $7,189,549$ \\
\hline 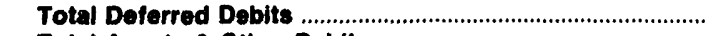 & $2,163,328$ & 153 & 0 & o & $9,699,277$ \\
\hline \multicolumn{6}{|l|}{ Investment of Municipality and Surplus } \\
\hline 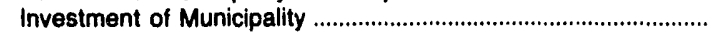 & 708,315 & 0 & 0 & 0 & $12,241,887$ \\
\hline 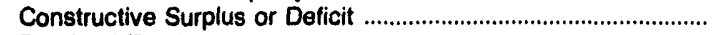 & & & 0 & 0 & $-6,459,720$ \\
\hline 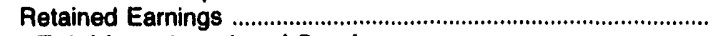 & $2,998,717$ & 15,139 & 25,364 & 9,272 & $5,469,553$ \\
\hline \multicolumn{6}{|l|}{ Long-term Debt } \\
\hline 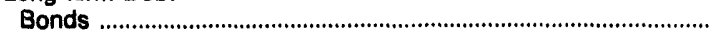 & $18,585,000$ & 0 & $\mathbf{0}$ & 0 & $20,256,573$ \\
\hline 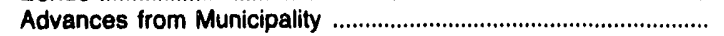 & & 0 & 0 & 0 & $20,20,0$ \\
\hline 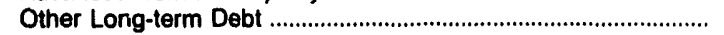 & 0 & 5,540 & 8,562 & 0 & $6,819,743$ \\
\hline 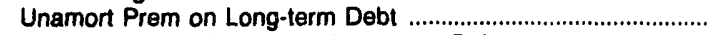 & & & & 0 & \\
\hline 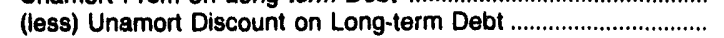 & 211,171 & & & 0 & 211,171 \\
\hline 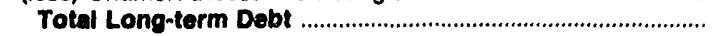 & $18,373,829$ & 5,540 & 8,562 & 0 & $26,885,145$ \\
\hline \multicolumn{6}{|l|}{ Other Noncurrent Liabilities } \\
\hline 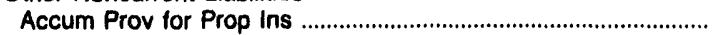 & 0 & 0 & 0 & 0 & \\
\hline 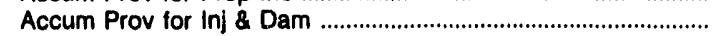 & 0 & 0 & 0 & 0 & 0 \\
\hline 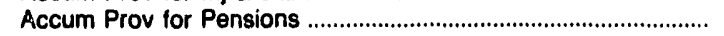 & 0 & 0 & 321 & 0 & 321 \\
\hline 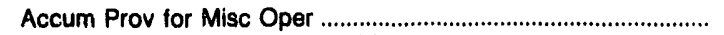 & 0 & 0 & 0 & 0 & 0 \\
\hline Total Other Noncurrent Liabilities ................................................. & $\mathbf{0}$ & $\mathbf{0}$ & 321 & 0 & 321 \\
\hline \multicolumn{6}{|l|}{ Current and Accrued Liabilities } \\
\hline 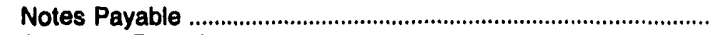 & $1,264,059$ & 0 & 479 & 0 & $1,266,181$ \\
\hline Accounts Payable & 645,365 & 0 & 2,776 & 0 & 953,273 \\
\hline Payables to Municipality & 0 & 0 & 0 & 0 & 0 \\
\hline 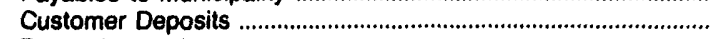 & 0 & 286 & 1,161 & 0 & 1,447 \\
\hline 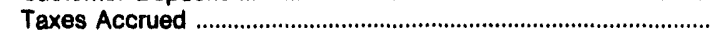 & 0 & 9 & 0 & 0 & 9 \\
\hline 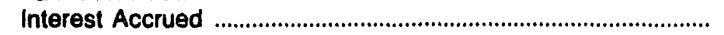 & 516,588 & 0 & 0 & 0 & 547,692 \\
\hline 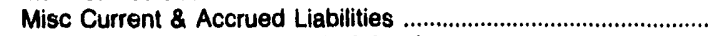 & $3,513,737$ & -220 & & 0 & $3,842,895$ \\
\hline 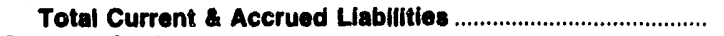 & $5,939,748$ & 76 & 4,415 & 0 & $8,611,498$ \\
\hline \multicolumn{6}{|l|}{ Deferred Credits } \\
\hline 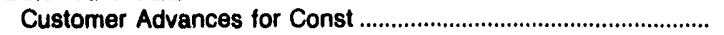 & 0 & 498 & 307 & 0 & 4,554 \\
\hline 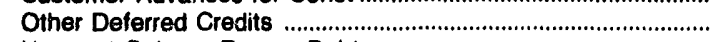 & 0 & 0 & 0 & 0 & 82,480 \\
\hline 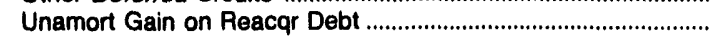 & 0 & 0 & 0 & 0 & 0 \\
\hline Total Deferred Crodits & 20 & 488 & 307 & 0 & 87,034 \\
\hline 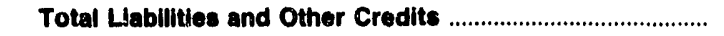 & $28,020,609$ & 1,253 & 38,970 & 9,272 & $44,815,718$ \\
\hline
\end{tabular}

' Includes data only for Saint Mary's Falls at Sault St. Marie, Michigan. The rest of the generation produced by the U.S. Army Corps of Engineers (USCE) is sold by the Department of Energy-Bonneville, Southeastern, Southwestern, and Western Area Power Administrations.

Note: Totals may not equal sum of components because of independent rounding.

Source: Energy Information Administration, Form EIA-412, "Annual Report of Public Electric Utilities." 
Table 44. Electric Operation and Maintenance Expenses by

Federal Electric Utillty, 1991

(Thousand Dollars)

\begin{tabular}{|c|c|c|c|c|c|}
\hline Item & $\begin{array}{l}\text { Alaska } \\
\text { Power } \\
\text { Admin } \\
\text { September } 30\end{array}$ & $\begin{array}{l}\text { Bonneville } \\
\text { Power } \\
\text { Admin } \\
\text { September } 30\end{array}$ & $\begin{array}{l}\text { Southeastern } \\
\text { Power } \\
\text { Admin } \\
\text { September } 30\end{array}$ & $\begin{array}{l}\text { Southwestern } \\
\text { Power } \\
\text { Admin } \\
\text { Seplember } 30\end{array}$ & $\begin{array}{l}\text { Western Area } \\
\text { Power } \\
\text { Admin } \\
\text { September } 30\end{array}$ \\
\hline 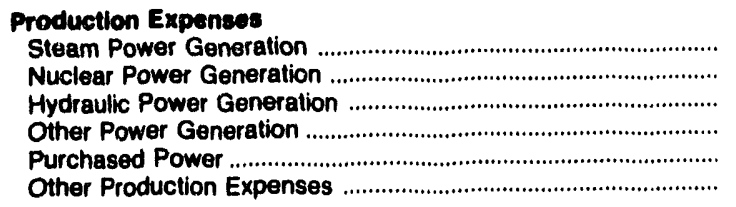 & $\begin{array}{r}0 \\
0 \\
775 \\
0 \\
0 \\
0\end{array}$ & $\begin{array}{r}0 \\
0 \\
1,322 \\
0 \\
17,548 \\
1,246,809\end{array}$ & $\begin{array}{r}0 \\
0 \\
2,336 \\
0 \\
870 \\
0\end{array}$ & $\begin{array}{r}0 \\
0 \\
60,696 \\
0 \\
6,665 \\
11,366\end{array}$ & $\begin{array}{r}0 \\
0 \\
186,499 \\
0 \\
232,907 \\
0\end{array}$ \\
\hline $\begin{array}{l}\text { Total Production } \\
\text { Expenses }\end{array}$ & 775 & $1,265,679$ & 3,207 & 78,728 & 419,406 \\
\hline $\begin{array}{l}\text { Transmission Expenses } \\
\text { Distribution Expenses } \\
\text { Customer Accounts Expenses } \\
\text { Customer Services and } \\
\text { Information Expenses } \\
\text { Sales Expenses } \\
\text { Administrative and General } \\
\text { Expenses } \\
\text { Total Electric Operation } \\
\text { and Maintenence Expenses }\end{array}$ & $\begin{array}{r}1,085 \\
0 \\
0 \\
0 \\
0 \\
2,025\end{array}$ & $\begin{array}{r}141,823 \\
0 \\
1,741\end{array}$ & $\begin{array}{r}24,482 \\
0 \\
39\end{array}$ & $\begin{array}{r}0 \\
4,460\end{array}$ & $\begin{array}{r}23,195 \\
0 \\
0\end{array}$ \\
\hline
\end{tabular}

See endnotes at end of this table.

Table 44. Electric Operation and Maintenance Expenses by Federal Electric Utility, 1991 (Continued) (Thousand Dollars)

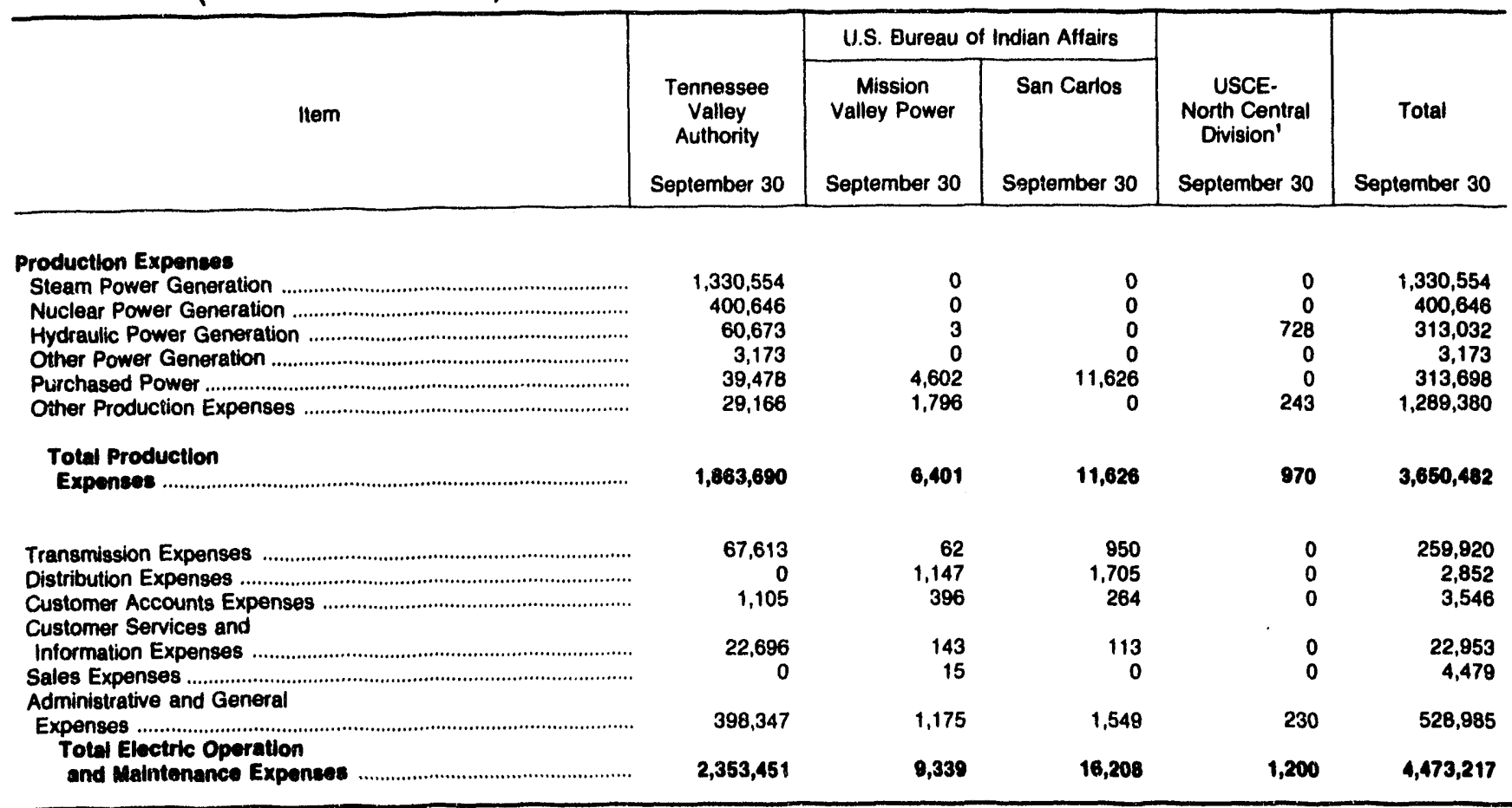

TIncludes data only for Saint Mary's Falls at Sault St. Marie, Michigan. The rest of the generation produced by the U.S. Army Corps of Engineers (USCE) is sold by the Department of Energy-Bonneville, Southeastern, Southwestern, and Western Area Power Administrations.

Note: Totals may not equal sum of components because of independent rounding.

Source: Energy Information Administration, Form EIA-412, "Annual Report of Public Electric Utilities." 
Table 45. Electric Utility Plant by Federal Electric Utility on September 30, 1991

(Thousand Dollars)

\begin{tabular}{|c|c|c|c|c|c|}
\hline Item & $\begin{array}{l}\text { Alaska } \\
\text { Power } \\
\text { Admin } \\
\text { Seplember } 30\end{array}$ & $\begin{array}{l}\text { Bonneville } \\
\text { Power } \\
\text { Admin } \\
\text { September } 30\end{array}$ & $\begin{array}{l}\text { Southeastern } \\
\text { Power } \\
\text { Admin } \\
\text { September } 30\end{array}$ & $\begin{array}{l}\text { Southwestern } \\
\text { Power } \\
\text { Admin } \\
\text { September } 30\end{array}$ & $\begin{array}{l}\text { Western Area } \\
\text { Power } \\
\text { Admin } \\
\text { September } 30\end{array}$ \\
\hline Electric Plant in Servlce & 331 & 0 & 0 & 0 & 0 \\
\hline 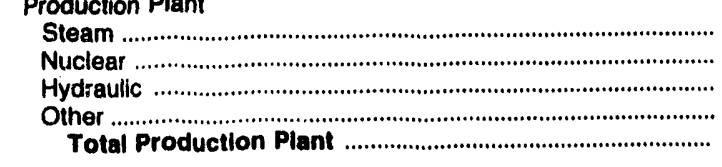 & $\begin{array}{r}0 \\
0 \\
142,880 \\
0 \\
142,880\end{array}$ & $\begin{array}{l}\mathbf{0} \\
\mathbf{0} \\
\mathbf{0} \\
\mathbf{0} \\
\mathbf{0}\end{array}$ & $\begin{array}{r}0 \\
0 \\
682 \\
0 \\
692\end{array}$ & $\begin{array}{l}0 \\
0 \\
0 \\
0 \\
0\end{array}$ & $\begin{array}{r}0 \\
0 \\
2,588,659 \\
0 \\
2,588,680\end{array}$ \\
\hline 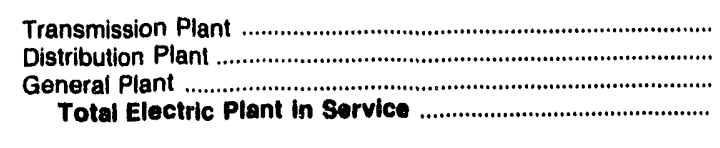 & $\begin{array}{r}32,505 \\
0 \\
3,684 \\
179,400\end{array}$ & $\begin{array}{r}3,186,175 \\
0 \\
401,122 \\
3,687,297\end{array}$ & $\begin{array}{r}0 \\
0 \\
0 \\
692\end{array}$ & $\begin{array}{r}80,875 \\
0 \\
19,833 \\
100,800\end{array}$ & $\begin{array}{r}1,457,840 \\
0 \\
0 \\
4,048,400\end{array}$ \\
\hline $\begin{array}{l}\text { Electric Plant Leased to Others } \\
\text { Construction Work in Progress - Electric } \\
\text { Electric Plant Held for Future Use .......................... } \\
\text { Electric Plant Acquisition Adjustments } \\
\text { Total Electric Utility Plant }\end{array}$ & $\begin{array}{r}0 \\
0 \\
0 \\
0 \\
179,400\end{array}$ & $\begin{array}{r}188 \\
234,758 \\
1,573 \\
0 \\
0,828,218\end{array}$ & $\begin{array}{r}0 \\
0 \\
0 \\
0 \\
692\end{array}$ & $\begin{array}{r}0 \\
10,478 \\
0 \\
0 \\
111,288\end{array}$ & $\begin{array}{r}0 \\
760,625 \\
0 \\
0 \\
4,807,124\end{array}$ \\
\hline $\begin{array}{l}\text { Accumulated Provision for } \\
\text { Depreciation and Amortization } \\
\text { Net Electric Utility Plant }\end{array}$ & $\begin{array}{r}29,013 \\
150,387\end{array}$ & $\begin{array}{l}1,188,706 \\
2,635,110\end{array}$ & $\begin{array}{r}34 \\
658\end{array}$ & $\begin{array}{l}22,753 \\
02,533\end{array}$ & $\begin{array}{r}297,155 \\
4,500,960\end{array}$ \\
\hline
\end{tabular}

See endnotes at end of this table.

Table 45. Electric Utility Plant by Federal Electric Utility on September 30, 1991 (Continued) (Thousand Dollars)

\begin{tabular}{|c|c|c|c|c|c|}
\hline \multirow[b]{2}{*}{ Item } & \multirow[b]{2}{*}{$\begin{array}{l}\text { Tennessee } \\
\text { Valley } \\
\text { Authority } \\
\text { September } 30\end{array}$} & \multicolumn{2}{|c|}{ U.S. Bureau of Indian Afiairs } & \multirow[b]{2}{*}{$\begin{array}{l}\text { USCE. } \\
\text { North Central } \\
\text { Division' } \\
\text { September } 30\end{array}$} & \multirow[b]{2}{*}{ Total } \\
\hline & & $\begin{array}{c}\text { Mission } \\
\text { Valley Power } \\
\text { September } 30\end{array}$ & $\begin{array}{l}\text { San Carlos } \\
\text { September } 30\end{array}$ & & \\
\hline $\begin{array}{l}\text { Electric Plant in Service } \\
\text { Intangible Plant . } \\
\text { Production Plant }\end{array}$ & 0 & 164 & $\mathbf{0}$ & 0 & 496 \\
\hline 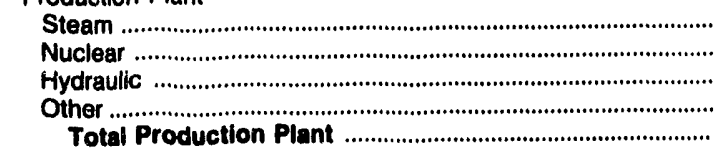 & $\begin{array}{r}4,651,093 \\
7,586,098 \\
1,073,516 \\
257,187 \\
13,567,095\end{array}$ & $\begin{array}{r}0 \\
0 \\
66 \\
0 \\
66\end{array}$ & $\begin{array}{l}0 \\
0 \\
0 \\
0 \\
0\end{array}$ & $\begin{array}{r}0 \\
0 \\
12,343 \\
0 \\
12,343\end{array}$ & $\begin{array}{r}4,651,093 \\
7,586,098 \\
3,818,156 \\
257,187 \\
16,312,535\end{array}$ \\
\hline 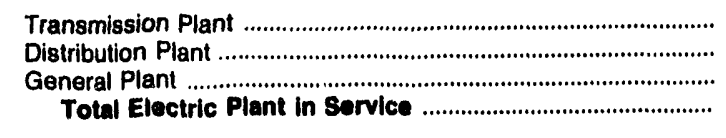 & $\begin{array}{r}2,081,604 \\
0 \\
1,087,637 \\
16,737,136\end{array}$ & $\begin{array}{r}2,481 \\
9,518 \\
2,867 \\
15,006\end{array}$ & $\begin{array}{r}917 \\
20,774 \\
0 \\
21,601\end{array}$ & $\begin{array}{r}0 \\
0 \\
0 \\
12,343\end{array}$ & $\begin{array}{r}6,842,488 \\
30,292 \\
1,515,143 \\
24,700,933\end{array}$ \\
\hline 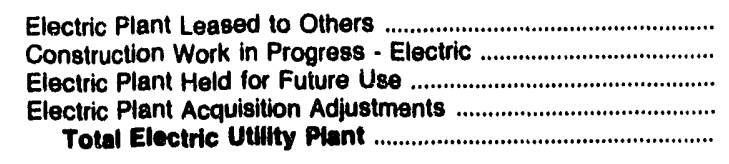 & $\begin{array}{r}144,556 \\
6,091,318 \\
6,361,086 \\
0 \\
29,334,107\end{array}$ & $\begin{array}{r}0 \\
0 \\
0 \\
0 \\
15,006\end{array}$ & $\begin{array}{r}0 \\
0 \\
0 \\
0 \\
21,691\end{array}$ & $\begin{array}{r}0 \\
0 \\
0 \\
0 \\
12,343\end{array}$ & $\begin{array}{r}144,744 \\
7,097,179 \\
6,362,669 \\
0 \\
30,305,656\end{array}$ \\
\hline 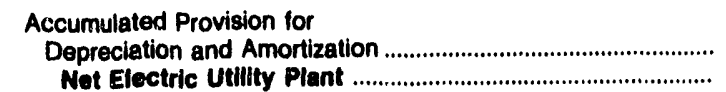 & $\begin{array}{r}5,461,298 \\
23,872,809\end{array}$ & $\begin{array}{r}16 \\
15,081\end{array}$ & $\begin{array}{r}9,064 \\
12,627\end{array}$ & $\begin{array}{l}3,145 \\
0,108\end{array}$ & $\begin{array}{r}7,011,183 \\
31,204,372\end{array}$ \\
\hline
\end{tabular}

' Includes data only for Saint Mary's Falls at Sault St. Marie. Michigan. The rest of the generation produced by the U.S. Army Corps of Engineers (USCE) is sold by the Department of Energy-Bonneville, Southeastern, Southwestern, and Western Area Power Administrations.

Note: Totals may not equal sum of components because of independent rounding.

Source: Energy Information Administration, Form EIA-412, "Annual Report of Public Electric Utillties." 
Table 46. Number of Consumers, Sales, and Operating Revenue by Federal Electric Utility, 1991

\begin{tabular}{|c|c|c|c|c|c|}
\hline Item & $\begin{array}{c}\text { Alaska } \\
\text { Power } \\
\text { Admin }\end{array}$ & $\begin{array}{c}\text { Bonneville } \\
\text { Power } \\
\text { Admin }\end{array}$ & $\begin{array}{l}\text { Southeastern } \\
\text { Power } \\
\text { Admin }\end{array}$ & $\begin{array}{l}\text { Southwestern } \\
\text { Power } \\
\text { Admin } \\
\text { December } 31\end{array}$ & $\begin{array}{l}\text { Western Area } \\
\text { Power } \\
\text { Admin }\end{array}$ \\
\hline 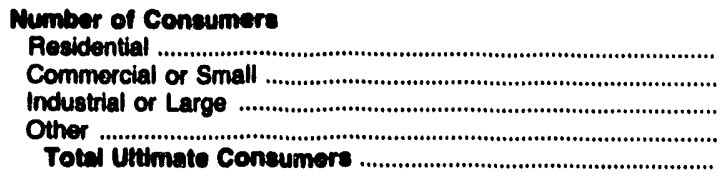 & $\begin{array}{l}0 \\
0 \\
0 \\
2 \\
2\end{array}$ & $\begin{array}{r}0 \\
0 \\
17 \\
9 \\
28\end{array}$ & $\begin{array}{l}0 \\
0 \\
0 \\
0 \\
0\end{array}$ & $\begin{array}{l}0 \\
0 \\
0 \\
0 \\
0\end{array}$ & $\begin{array}{r}0 \\
0 \\
0 \\
210 \\
210\end{array}$ \\
\hline 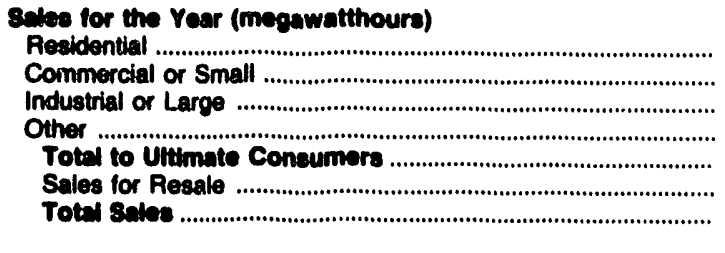 & $\begin{array}{r}0 \\
0 \\
0 \\
3,840 \\
\mathbf{3 , 8 4 0} \\
\mathbf{3 7 4 , 2 2 7} \\
\mathbf{3 7 8 , 0 6 7}\end{array}$ & $\begin{array}{r}0 \\
0 \\
27,114,151 \\
1,058,707 \\
28,172,858 \\
59,188,152 \\
87,361,010\end{array}$ & $\begin{array}{r}0 \\
0 \\
0 \\
0 \\
0 \\
7,841,235 \\
7,941,235\end{array}$ & $\begin{array}{r}0 \\
0 \\
0 \\
0 \\
0 \\
5,959,022 \\
5,059,022\end{array}$ & $\begin{array}{r}0 \\
0 \\
0 \\
4,925,186 \\
4,025,186 \\
28,933,157 \\
33,083,343\end{array}$ \\
\hline 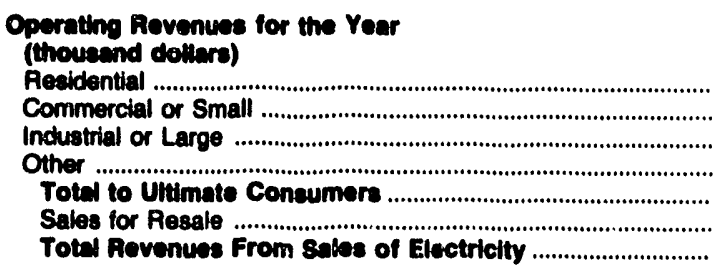 & $\begin{array}{r}0 \\
0 \\
0 \\
57 \\
57 \\
9,016 \\
9,073\end{array}$ & $\begin{array}{r}0 \\
0 \\
561,608 \\
24,646 \\
586,254 \\
1,288,126 \\
1,874,380\end{array}$ & $\begin{array}{r}0 \\
0 \\
0 \\
0 \\
0 \\
145,861 \\
145,881\end{array}$ & $\begin{array}{r}0 \\
0 \\
0 \\
0 \\
0 \\
85,197 \\
85,197\end{array}$ & $\begin{array}{r}0 \\
0 \\
0 \\
83,073 \\
83,073 \\
480,881 \\
884,054\end{array}$ \\
\hline
\end{tabular}

Table 46. Number of Consumers, Sales, and Operating Revenue by Federal Electric Utility, 1991 (Continued)

\begin{tabular}{|c|c|c|c|c|c|}
\hline \multirow[b]{2}{*}{ ltem } & \multirow[b]{2}{*}{$\begin{array}{l}\text { Tennessee } \\
\text { Velley } \\
\text { Authority } \\
\text { December } 31\end{array}$} & \multicolumn{2}{|c|}{ U.S. Bureau of Indian Affairs } & \multirow[b]{2}{*}{$\begin{array}{l}\text { USCE. } \\
\text { North Central } \\
\text { Division' } \\
\text { December } 31\end{array}$} & \multirow[b]{2}{*}{$\begin{array}{c}\text { Total } \\
\text { December } 31\end{array}$} \\
\hline & & $\begin{array}{l}\text { Mission } \\
\text { Valley Power } \\
\text { December } 31\end{array}$ & December 31 & & \\
\hline \multicolumn{6}{|l|}{ Nunber of Consumers } \\
\hline 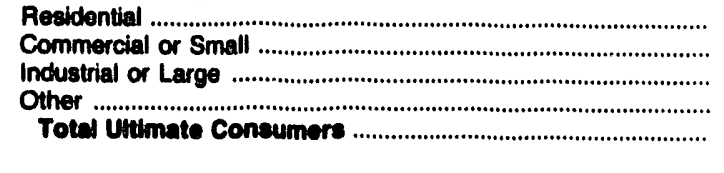 & $\begin{array}{r}0 \\
0 \\
65 \\
39 \\
104\end{array}$ & $\begin{array}{r}10,100 \\
2,013 \\
2 \\
2,133 \\
14,248\end{array}$ & $\begin{array}{r}12,637 \\
1,512 \\
86 \\
875 \\
15,110\end{array}$ & $\begin{array}{l}0 \\
0 \\
0 \\
0 \\
0\end{array}$ & $\begin{array}{r}22,737 \\
3,525 \\
170 \\
3,268 \\
20,700\end{array}$ \\
\hline \multicolumn{6}{|l|}{ 8ales for the Year (megawatthours) } \\
\hline 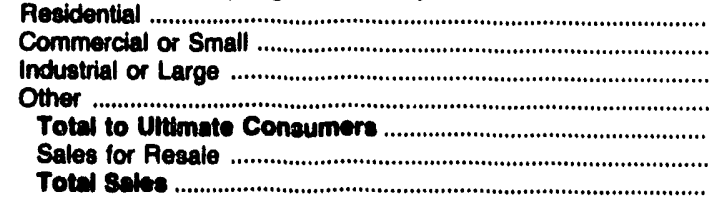 & $\begin{array}{r}0 \\
0 \\
19,068,011 \\
222,673 \\
19,290,884 \\
98,226,908 \\
117,517,593\end{array}$ & $\begin{array}{r}145,641 \\
67,918 \\
18,656 \\
18,099 \\
250,314 \\
0 \\
250,314\end{array}$ & $\begin{array}{r}89,731 \\
108,414 \\
53,277 \\
49,412 \\
300,834 \\
0 \\
300,084\end{array}$ & $\begin{array}{r}0 \\
0 \\
0 \\
0 \\
0 \\
143,983 \\
143,983\end{array}$ & $\begin{array}{r}235,372 \\
176,332 \\
46,254,095 \\
6,277,917 \\
62,049,718 \\
200,666,685 \\
263,610,401\end{array}$ \\
\hline \multicolumn{6}{|l|}{$\begin{array}{l}\text { Operating Rovenues for the Year } \\
\text { (thousend dollare) }\end{array}$} \\
\hline 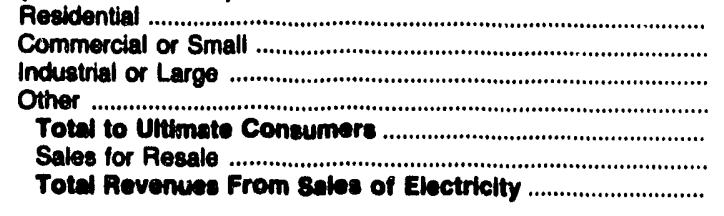 & $\begin{array}{r}0 \\
0 \\
765,982 \\
9,878 \\
775,860 \\
4,331,252 \\
6,107,112\end{array}$ & $\begin{array}{r}6,373 \\
3,373 \\
689 \\
646 \\
11,091 \\
0 \\
11,091\end{array}$ & $\begin{array}{r}7,825 \\
9,207 \\
2,354 \\
3,358 \\
22,744 \\
0 \\
22,744\end{array}$ & $\begin{array}{r}0 \\
0 \\
0 \\
0 \\
0 \\
1,086 \\
1,006\end{array}$ & $\begin{array}{r}14,188 \\
12,580 \\
1,330,643 \\
121,658 \\
1,479,070 \\
6,341,529 \\
7,020,00\end{array}$ \\
\hline
\end{tabular}

'Includes data only for Saint Mary's Falls at Sault St. Marie, Michigan. The rest of the generation produced by the U.S. Army Corps of Engineers (USCE) is sold by the Department of Energy-Bonneville, Southeastern, Southwestern, and Western Area Power Administrations.

Note: Totals may not equal sum of components because of independent rounding. Data are submitted on a calendar year.

Source: Energy Information Administration, Form EIA-861, "Annual Electric Utility Report." Data are submitted on a calendar year. 
Table 47. Electric Energy Account by Federal Electric Utility, 1991 (Megawatthours)

\begin{tabular}{|c|c|c|c|c|c|}
\hline Item & $\begin{array}{l}\text { Alaska } \\
\text { Power } \\
\text { Admin } \\
\text { September } 30\end{array}$ & $\begin{array}{l}\text { Bonneville } \\
\text { Power } \\
\text { Admin } \\
\text { September } 30\end{array}$ & $\begin{array}{l}\text { Southeastern } \\
\text { Power } \\
\text { Admin } \\
\text { September } 30\end{array}$ & $\begin{array}{l}\text { Southwestern } \\
\text { Power } \\
\text { Admin } \\
\text { September } 30\end{array}$ & $\begin{array}{l}\text { Western Area } \\
\text { Power } \\
\text { Admin } \\
\text { September } 30\end{array}$ \\
\hline 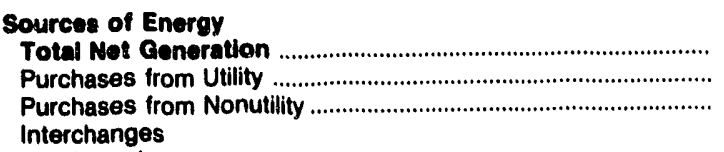 & $\begin{array}{r}395,755 \\
0 \\
0\end{array}$ & $\begin{array}{r}98,348,502 \\
790,458 \\
0\end{array}$ & $\begin{array}{r}8,261,739 \\
17,027 \\
0\end{array}$ & $\begin{array}{r}5,155,000 \\
72,000 \\
0\end{array}$ & $\begin{array}{r}25,983,586 \\
9,994,000 \\
0\end{array}$ \\
\hline 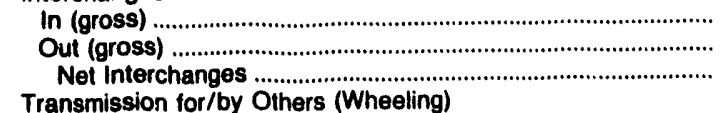 & $\begin{array}{l}0 \\
0 \\
0\end{array}$ & $\begin{array}{l}12,870,397 \\
20,118,492 \\
-7,248,095\end{array}$ & $\begin{array}{r}46 \\
0 \\
46\end{array}$ & $\begin{array}{l}542,000 \\
406,000 \\
136,000\end{array}$ & $\begin{array}{r}4,907,000 \\
4,924,000 \\
-17,000\end{array}$ \\
\hline 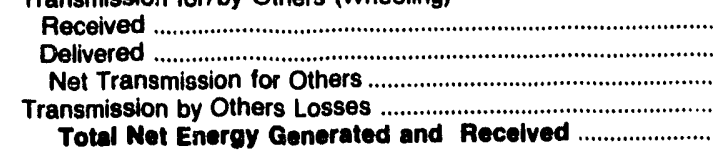 & $\begin{array}{r}312,996 \\
312,996 \\
0 \\
0 \\
395,755\end{array}$ & $\begin{array}{r}45,756,459 \\
44,718,582 \\
1,037,877 \\
0 \\
92,928,742\end{array}$ & $\begin{array}{r}4,447,590 \\
4,447,590 \\
0 \\
0 \\
8,278,812\end{array}$ & $\begin{array}{r}0 \\
0 \\
0 \\
0 \\
5,363,000\end{array}$ & $\begin{array}{r}4,690,661 \\
4,690,661 \\
0 \\
0 \\
35,960,586\end{array}$ \\
\hline 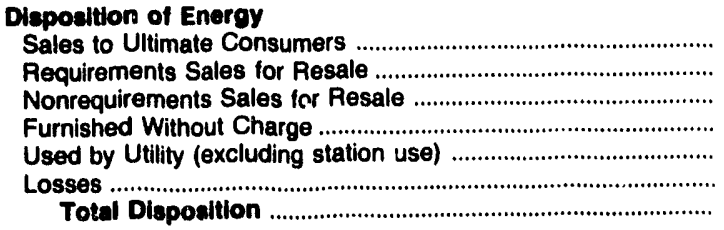 & $\begin{array}{r}3,840 \\
365,572 \\
17,078 \\
425 \\
0 \\
8,840 \\
395,755\end{array}$ & $\begin{array}{r}24,544,817 \\
64,627,861 \\
0 \\
0 \\
68,986 \\
3,687,078 \\
92,928,742\end{array}$ & $\begin{array}{r}0 \\
7,841,235 \\
0 \\
180,443 \\
5,107 \\
252,027 \\
8,278,812\end{array}$ & $\begin{array}{r}0 \\
5,166,000 \\
0 \\
141,000 \\
0 \\
56,000 \\
5,363,000\end{array}$ & $\begin{array}{r}4,925,186 \\
28,933,157 \\
0 \\
0 \\
0 \\
2,102,243 \\
35,960,586\end{array}$ \\
\hline
\end{tabular}

See endnotes at end of this table.

Table 47. Electric Energy Account by Federal Electric Utility, 1991 (Continued) (Megawatthours)

\begin{tabular}{|c|c|c|c|c|c|}
\hline \multirow[b]{2}{*}{ Item } & \multirow[b]{2}{*}{$\begin{array}{l}\text { Tennessee } \\
\text { Valley } \\
\text { Authority } \\
\text { September } 30\end{array}$} & \multicolumn{2}{|c|}{ U.S. Bureau of Indian Affairs } & \multirow[b]{2}{*}{$\begin{array}{l}\text { USCE- } \\
\text { North Central } \\
\text { Division' } \\
\text { September } 30\end{array}$} & \multirow[b]{2}{*}{ September 30} \\
\hline & & $\begin{array}{l}\text { Mission } \\
\text { Valley Power } \\
\text { September } 30\end{array}$ & $\begin{array}{l}\text { San Carlos } \\
\text { September } 30\end{array}$ & & \\
\hline 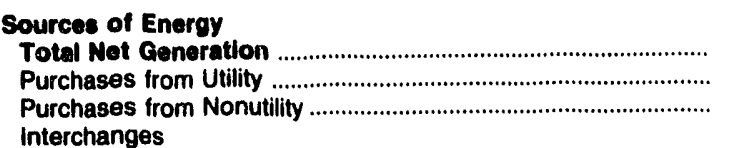 & $\begin{array}{r}116,435,858 \\
0 \\
1,077,178\end{array}$ & $\begin{array}{r}1,893 \\
283,778 \\
1,219\end{array}$ & $\begin{array}{r}0 \\
309,127 \\
0\end{array}$ & $\begin{array}{r}139,294 \\
0 \\
0\end{array}$ & $\begin{array}{r}254,721,627 \\
11,466,390 \\
1,078,397\end{array}$ \\
\hline 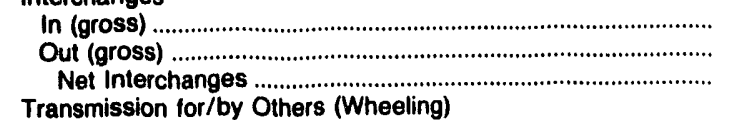 & $\begin{array}{r}23,254,262 \\
20,444,111 \\
2,810,151\end{array}$ & $\begin{array}{l}0 \\
0 \\
0\end{array}$ & $\begin{array}{l}0 \\
0 \\
0\end{array}$ & $\begin{array}{l}0 \\
0 \\
0\end{array}$ & $\begin{array}{l}41,573,705 \\
45,892,603 \\
-4,318,898\end{array}$ \\
\hline 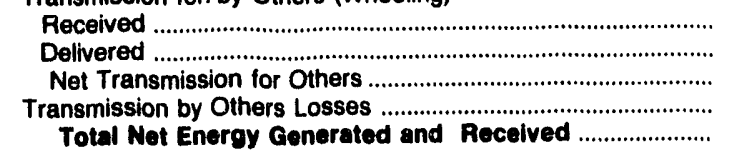 & $\begin{array}{r}2,382,294 \\
2,299,963 \\
82,331 \\
0 \\
120,405,518\end{array}$ & $\begin{array}{r}0 \\
0 \\
0 \\
0 \\
286,880\end{array}$ & $\begin{array}{r}0 \\
0 \\
0 \\
0 \\
309,127\end{array}$ & $\begin{array}{r}0 \\
0 \\
0 \\
0 \\
139,294\end{array}$ & $\begin{array}{r}57,590,000 \\
56,469,792 \\
1,120,208 \\
0 \\
264,067,724\end{array}$ \\
\hline 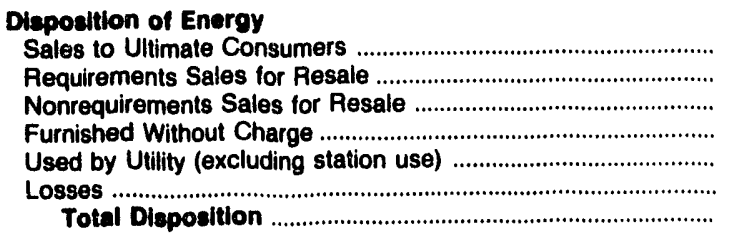 & $\begin{array}{r}19,344,623 \\
97,347,446 \\
0 \\
0 \\
8,175 \\
3,705,274 \\
120,405,518\end{array}$ & $\begin{array}{r}250,314 \\
0 \\
0 \\
0 \\
560 \\
36,016 \\
286,890\end{array}$ & $\begin{array}{r}300,834 \\
0 \\
0 \\
0 \\
0 \\
8,293 \\
309,127\end{array}$ & $\begin{array}{r}0 \\
133,784 \\
0 \\
4,334 \\
685 \\
491 \\
139,294\end{array}$ & $\begin{array}{r}49,369,614 \\
204,415,055 \\
17,078 \\
326,202 \\
83,513 \\
9,856,262 \\
264,067,724\end{array}$ \\
\hline
\end{tabular}

1 Includes data only for Saint Mary's Falls at Sault St. Marie, Michigan. The rest of the generation produced by the U.S. Army Corps of Engineers (USCE) is sold by the Department of Energy-Bonneville, Southeastern, Southwestern, and Western Area Power Administrations.

Note: Totals may not equal sum of components because of independent rounding.

Source: Energy Information Administration, Form EIA-412. "Annual Report of Public Electric Utilities." 


\section{Appendix A}

Summary

Statistics of Rura

Electric

Cooperative

Borrowers 


\section{Summary Statistics of Rural Electric Cooperative Borrowers}

\section{Background}

The Rural Electrification Administration (REA), U.S. Department of Agriculture, was established under the Rural Electrification Act of 1936. The purpose was to extend electric service to small rural communities (usually ur ter 1,500 customers) and farms where it was more exprnsive to provide service. Through the REA, electric cooperatives (customer-owned, nonprofit entities) 'vere formed and provided with low interest rate government-guaranteed loans to allow them to build power lines to transmit and distribute wholesale electricity purchased from other electric utilities. By the early 1960 's, the REA began to make large loans to cooperatives for the construction of generating plants and transmission facilities to "protect the security and effectiveness of REA-financed systems."

The latest statistics taken from the 1991 Statistical Report, Rural Electric Borrowers' publication show that 832 of the 887 cooperative borrowers were distribution borrowers. The remaining 28 were power supply borrowers. By the end of 1991, the REA-financed electric it tilities were serving more than 10 million consumers in 46 States. When the REA was formed, less than 10 percent of the rural areas in the United States had electric service. Today, about 99 percent of U.S. farmers have electric power.

\section{Composite Income Account}

Operating revenues for the cooperative borrowers were $\$ 22.8$ billion in 1991 , compared with $\$ 22.0$ billion in 1990, and \$20.9 billion in 1989.

Total electric utility operating expenses for the cooperative borrowers were $\$ 19.9$ billion in 1991 . Operation and maintenance expenses represented $\$ 1 \% .7$ billion or 88.8 percent of the total operating expenses. Purchased power, a major portion of operation and maintenance expenses, was $\$ 11.9$ billion. Taxes were $\$ 0.6$ billion or 3.0 percent of total electric operating expenses.

Utility operating income for the cooperative borrowers was $\$ 2.9$ billion in 1991 . Utility operating income, as a proportion of net utility plant, was 6.1 percent. Net income was $\$ 0.7$ billion.

Interest expense on long-term debt increased to \$2.9 billion. In 1989, interest on long-term debt totaled \$2.9 billion, which decreased to less than $\$ 2.8$ billion in 1990. Interest expressed as a percentage of long-term debt was 6.8 percent in 1991, compared with 6.9 percent in 1990.

\section{Balance Sheet}

The net investment in electric utility plant for the cooperative borrowers was $\$ 43.2$ billion at the end of 1991 , which includes $\$ 1.5$ billion for construction work in progress (CWIP). The CWIP was \$2.1 billion in 1989. As a percentage of net investment in electric utility plant, CWIP was about 38.5 percent lower in 1991, compared with 1989. The investment and funds accounts were $\$ 5.0$ billion and the long-term debt was $\$ 42.3$ billion at the end of 1991 .

\section{Electric Utility Operating Revenues}

The number of residential consumers served by the cooperative borrowers was 9.9 million in 1991, up slightly from $\$ .6$ million in 1990 . Revenues from residential consumers w ere $\$ 8.8$ billion or 66.6 percent of the total revenue from all ultimate consumers. In 1991, consumption of electricity by each residential customer averaged 11.8 thousand kilowathours at an average annual cost of \$892.59, an increase over 1990 and 1989 of 3.5 percent and 5.6 percent, respectively.

'U.S. Department of Agriculture, Kural Electrification Administration, Bulletin No. 1-1. 
Table A1. Composite Statement of Income for the Cooperative Borrowers, 1989-1991 (Thousand Dollars)

\begin{tabular}{|c|c|c|c|}
\hline Item & 1991 & 1990 & 1889 \\
\hline $\begin{array}{l}\text { Electric Utility } \\
\text { Operating Revenues .................................... } \\
\text { Utility Operating Expenses }\end{array}$ & $22,784,208$ & $21,996,6: 0$ & $20,804,318$ \\
\hline 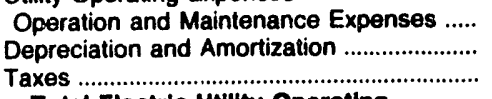 & $\begin{array}{r}17,654,756 \\
1,639,148 \\
592,850\end{array}$ & $\begin{array}{r}16,800,017 \\
1,549,685 \\
555,146\end{array}$ & $\begin{array}{r}15,863,365 \\
1,435,593 \\
518,931\end{array}$ \\
\hline $\begin{array}{l}\text { Total Electric Utility Operating } \\
\text { Expenses }\end{array}$ & $18,886,754$ & $18,804,840$ & $17,817,898$ \\
\hline 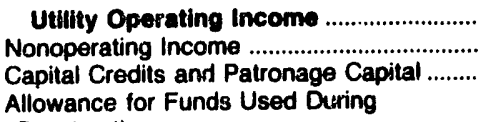 & $\begin{array}{r}2,097,454 \\
506,859 \\
234,137\end{array}$ & $\begin{array}{r}3,001,842 \\
526,654 \\
157,501\end{array}$ & $\begin{array}{r}3,038,427 \\
334,624 \\
185,057\end{array}$ \\
\hline 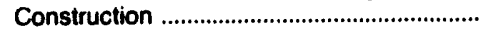 & 52,481 & 103,476 & 156,607 \\
\hline 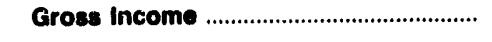 & $3,690,931$ & $3,669,473$ & $3,744,815$ \\
\hline 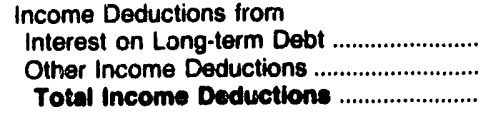 & $\begin{array}{r}2,883,852 \\
67,847 \\
2,951,690\end{array}$ & $\begin{array}{r}2,771,605 \\
358,795 \\
3,730,400\end{array}$ & $\begin{array}{r}2,891,078 \\
115,608 \\
3,009,025\end{array}$ \\
\hline Not Income and Patronace Capital .... & 739,232 & 790,073 & 739,280 \\
\hline
\end{tabular}

Notes: -Totals may nol equal sum of components because of independent rounding. -Data for 1981 represent 832 Distribution Borrowers and 55 Power Supply Borrowers; data for 1990 represent 838 Distribution Borrowers and 56 Power Supply Borrowers; data for 1889 represent 839 Distribution Borrowers and 58 Power Supply Borrowers.

Source: U.S. Department of Agriculture, Rural Electrification Administration, statibticel Report, Rural Electric Borrowers publications for the years 1989,1990 , and 1891 .

\section{Table A2. Composite Balance Sheet for the Cooperative Borrowers on December 31, 1989-1991 (Thousand Dollars)}

\begin{tabular}{|c|c|c|c|}
\hline llem & 1971 & 1990 & 1899 \\
\hline \multicolumn{4}{|l|}{ Assets and Other Debits } \\
\hline Construction Work in Progress ................ & $\begin{array}{r}56,752,533 \\
1,511,459\end{array}$ & $\begin{array}{r}55,102,550 \\
1,534,253\end{array}$ & $\begin{array}{r}51,326,336 \\
2,083,100\end{array}$ \\
\hline 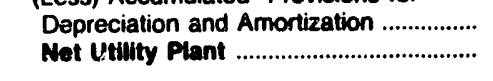 & $\begin{array}{r}15,093,304 \\
43,170,898\end{array}$ & $\begin{array}{l}12,867,844 \\
48,792,964\end{array}$ & $\begin{array}{l}11,275,176 \\
42,144,260\end{array}$ \\
\hline 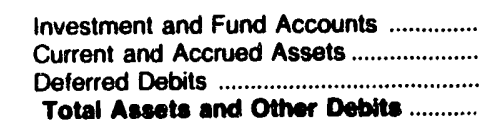 & $\begin{array}{r}5,017,772 \\
8,002,973 \\
1,811,064 \\
58,002,497\end{array}$ & $\begin{array}{r}4,204,565 \\
8,13 i, 379 \\
2,604,551 \\
58,710,754\end{array}$ & $\begin{array}{r}3,839,048 \\
7,154,734 \\
1,037,742 \\
55,075,792\end{array}$ \\
\hline \multicolumn{4}{|l|}{ Labillthes and Other Credits } \\
\hline 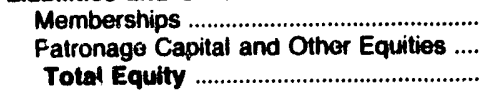 & $\begin{array}{r}91,664 \\
10,470,168 \\
10,561,032\end{array}$ & $\begin{array}{r}88,373 \\
9,391,401 \\
9,479,774\end{array}$ & $\begin{array}{r}85,355 \\
9,381,842 \\
9,467,297\end{array}$ \\
\hline $\begin{array}{l}\text { Long-term Debt ................................. } \\
\text { Current and Accrued Liabilities ............... } \\
\text { Deferred Credits ....................................... } \\
\text { Operating Reserves ............................. } \\
\text { Total Liabillties and Other Credite .... }\end{array}$ & $\begin{array}{r}42,273,768 \\
3,194,377 \\
1,442,849 \\
529,673 \\
68,002,487\end{array}$ & $\begin{array}{r}40,220,703 \\
6,555,326 \\
1,662,396 \\
392,555 \\
59,710,754\end{array}$ & $\begin{array}{r}40,228,411 \\
3,548,637 \\
1,512,523 \\
320,818 \\
55,075,702\end{array}$ \\
\hline
\end{tabular}

Notes: - Totals may not equal sum of components because of independent rounding. - Data for 1981 represent 832 Distribution Borrowers and 55 Power Supply Borrowers; deta for 1390 represent 838 Distribution Borrowers and 56 Power Supply Borrowers; dats for 1889 reprezent 839 Distribution Borrowers and 58 Power Supply Borrowers.

Sourcs: U.S. Department of Agriculture, Rural Electrification Administration, Statiatical Report, Rural Electric Borrowere publications for the years 1989, r890, and 1991. 
Table A3. Electric Operation and Maintenance Expenses for the Cooperative Borrowers, 1989-1991 (Thousand Dollars)

\begin{tabular}{|c|c|c|c|}
\hline Item & 1991 & 1990 & 1989 \\
\hline $\begin{array}{l}\text { Production Expenses } \\
\text { Power Production Expenses ........................... } \\
\text { Purchased Power .................................... } \\
\text { Total Production Expenses .................. }\end{array}$ & $\begin{array}{r}2,978,362 \\
11,857,765 \\
14,836,127\end{array}$ & $\begin{array}{r}3,020,715 \\
11,250,727 \\
14,271,442\end{array}$ & $\begin{array}{r}2,832,442 \\
10,661,938 \\
13,494,380\end{array}$ \\
\hline 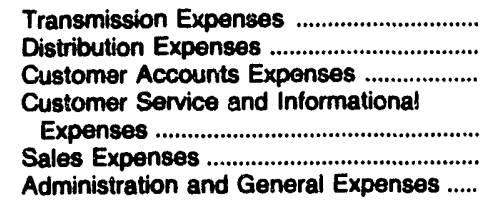 & $\begin{array}{r}89,029 \\
47,153 \\
1,104,291\end{array}$ & $\begin{array}{r}294,591 \\
821,151 \\
321,013 \\
75,569 \\
35,144 \\
981,109\end{array}$ & $\begin{array}{r}280,777 \\
764,536 \\
314,429 \\
62,740 \\
27,006 \\
919,498\end{array}$ \\
\hline $\begin{array}{l}\text { Total Electric Operation and } \\
\text { Maintenance Expenses ........................ }\end{array}$ & $17,654,756$ & $16,800,017$ & $15,863,367$ \\
\hline
\end{tabular}

Notes: - Totals may not equal sum of components because of independent rounding. -Data for 1991 represent 832 Distribution Borrowers and 55 Power Supply Borrowers; data for 1990 represent 838 Distribution Borrowers and 56 Power Supply Borrowers; data for 1989 represent 839 Distribution Borrowers and 58 Power Supply Borrowers.

Source: U.S. Department of Agriculture, Rural Electrification Adrrinistration, Statibtical Report, Rural Electric Borrowere publications for the years 1989, 1990, and 1991

Table A4. Number of Consumers, Sales, and Operating Revenue for the Cooperative Distributor Borrowers, 1989-1991

\begin{tabular}{|c|c|c|c|}
\hline Item & 1991 & 1990 & 1989 \\
\hline \multirow{2}{*}{ 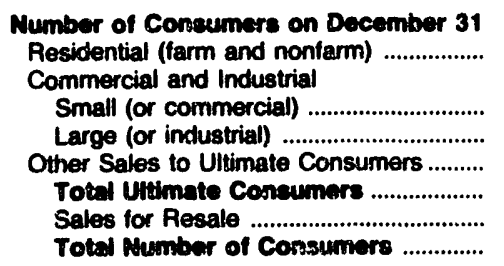 } & $9,865,739$ & $9,555,287$ & $9,284,923$ \\
\hline & $\begin{array}{r}928,085 \\
6,238 \\
157,506 \\
10,857,568 \\
197 \\
10,957,765\end{array}$ & $\begin{array}{r}862,804 \\
6,009 \\
148,764 \\
10,572,964 \\
208 \\
10,573,172\end{array}$ & $\begin{array}{r}806,136 \\
7,066 \\
143,878 \\
10,242,008 \\
211 \\
10,242,214\end{array}$ \\
\hline $\begin{array}{l}\text { Salea for the Year (Mogawatthours) } \\
\text { Residential (farm and nonfarm) ............... } \\
\text { Commercial and Industrial }\end{array}$ & $115,975,516$ & $108,715,899$ & $105,478,210$ \\
\hline 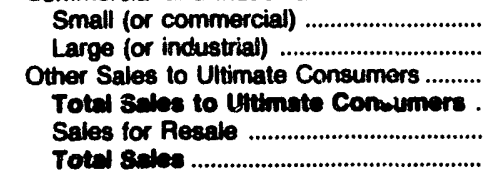 & $\begin{array}{r}34,862,307 \\
33,619,491 \\
5,603,651 \\
180,060,965 \\
1,934,117 \\
191,905,092\end{array}$ & $\begin{array}{r}32,750,344 \\
29,297,743 \\
4,615,639 \\
175,374,125 \\
3,107,445 \\
178,497,170\end{array}$ & $\begin{array}{r}31,385,951 \\
27,507,965 \\
5,234,475 \\
168,606,601 \\
3,110,218 \\
172,718,810\end{array}$ \\
\hline \multicolumn{4}{|l|}{$\begin{array}{l}\text { Operating Povimues for the Yoar } \\
\text { (thougend dollers) }\end{array}$} \\
\hline $\begin{array}{l}\text { Residential (farm and nontarm) ................. } \\
\text { Commercial and Industrial }\end{array}$ & $8,806,061$ & $8,077,510$ & $7,764,086$ \\
\hline 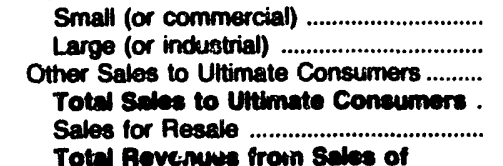 & $\begin{array}{r}2,543,472 \\
1,502,148 \\
365,037 \\
13,216,738 \\
84,548\end{array}$ & $\begin{array}{r}2,355,380 \\
1,437,407 \\
351,157 \\
12,221,454 \\
116,255\end{array}$ & $\begin{array}{r}2,243,740 \\
1,376,141 \\
333,348 \\
11,717,315 \\
116,680\end{array}$ \\
\hline 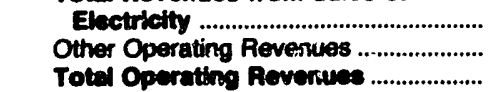 & $\begin{array}{r}12,301,298 \\
198,843 \\
13,500,220\end{array}$ & $\begin{array}{r}12,337,709 \\
160,293 \\
12,498,002\end{array}$ & $\begin{array}{r}11,033,005 \\
142,044 \\
11,978,030\end{array}$ \\
\hline
\end{tabular}

Notes: -Totals may not equal sum of components because of independent rounding. -This table does not include in 1991 the 55 Power Supply Borrowers, in 1990 the 56 Power Supply Borrowers, and in 1989 the 58 Power Supphy BorrowerB included in Tables A1, A2, and A3. -Data for 1991 represent 832 Distribution Borrowers; 1980 represent 838 Distribution Borrowers; and data for 1889 represent 639 Distribution Borrowers.

Source: U.S. Department of Agriculture, Rural Electrification Administrotion, Statiotloul Report, Rural Electric Borrowers publications for the years 1989,1990 , and 1991. 
Appendix B

\author{
Publicly Owned \\ Electric Utility \\ Respondents
}




\section{Publicly Owned Electric Utility Respondents}

\section{Table B1. Publicly Owned Electric Utilities Added to and Deleted from the} Form EIA-412, 1989-1991

\begin{tabular}{|c|c|c|c|c|c|}
\hline \multirow{2}{*}{ Year } & \multicolumn{2}{|r|}{ Added } & \multicolumn{2}{|r|}{ Deleted } & \multirow{2}{*}{$\begin{array}{l}\text { Total Number } \\
\text { Available' }\end{array}$} \\
\hline & No. & Name & No. & Name & \\
\hline $1989^{2} \ldots . .$. & 4 & $\begin{array}{l}\text { Illinois Muni Elec Agency (Illinois) } \\
\text { Kerville Public Utility Board (Texas) } \\
\text { Southern Calif Pub Serv Auth (Calif) } \\
\text { Terrebone Paris Consol Govt (Louisiana) }\end{array}$ & 40 & $\begin{array}{l}\text { Amory City of (Mississippi) } \\
\text { Arcade Village of (New York) } \\
\text { Benton City of (Arkansas) } \\
\text { Brainerd City of (Minnesota) } \\
\text { Denison City of (lowa) } \\
\text { Duncan City of (Oklahoma) } \\
\text { Electrical Dist No 4 Pinal Cnty (Ariz) } \\
\text { Elkhorn Rural Public Pwr Dist (Neb) } \\
\text { Geneva City of (Illinois) } \\
\text { Georgetown City of (South Carolina) } \\
\text { Hartselle City of (Alabama) } \\
\text { Hillsdale City of (Michigan) } \\
\text { Houma City of (Louisiana) } \\
\text { Jasper City of (Texas) } \\
\text { Kennett City of (Missouri) } \\
\text { Lansdale Borough of (Pennsylvania) } \\
\text { Lawrenceville City of (Georgia) } \\
\text { Lebanon City of (Indiana) } \\
\text { Lebanon City of (Missouri) } \\
\text { McCook Public Power District (Nebraska) } \\
\text { Miami City of (Oklahoma) } \\
\text { Milton-Freewater City of (Oregon) } \\
\text { Minden City of (Louisiana) } \\
\text { Monett City of (Missouri) } \\
\text { Napoleon City of (Ohio) } \\
\text { Niles City of (Michigan) } \\
\text { Oxford City of (Mississippi) } \\
\text { Paris City of (Tennesse) } \\
\text { Piedmont City of (Alabama) } \\
\text { Pierre City of (South Dakota) } \\
\text { Plymouth City of (Wisconsin) } \\
\text { PUD No } 1 \text { of Skamania County (Washington) } \\
\text { Rochelle Municipal Utilities (Illinois) } \\
\text { Russellville City of (Alabama) } \\
\text { Seneca City of (South Carolina) } \\
\text { South Hadley Town of (Massachusetts) } \\
\text { St Marys City of (Ohio) } \\
\text { Sturgeon Bay City of (Wisconsin) } \\
\text { Vanceburg City of (Kentucky) } \\
\text { Wapakoneta City of (Ohio) }\end{array}$ & 454 \\
\hline
\end{tabular}

- Excluded are the Federal electric utilities.

2 The threshold for reporting requirements changed from 100,000 megawatthours to 120,000 megawatthours.

Source: Energy Information Administration, Form EIA-412, "Annual Report of Public Electric Utilities." 
Table B1. Publicly Owned Electric Utilities Added to and Deleted from the Form ElA-412, 1989-1991(Continued)

\begin{tabular}{|c|c|c|c|c|c|}
\hline \multirow{2}{*}{ Year } & \multicolumn{2}{|r|}{ Added } & \multicolumn{2}{|r|}{ Deleted } & \multirow{2}{*}{$\begin{array}{l}\text { Total Number } \\
\text { Available' }\end{array}$} \\
\hline & No. & Name & No. & Name & \\
\hline $1990 \ldots . . . .$. & (1) & $\begin{array}{l}\text { Alabama Municipal Elec Auth (Alabama) } \\
\text { Geneva City of (lllinois) } \\
\text { Jefferson City of (Wisconsin) } \\
\text { Ketchikan City of (Alaska) } \\
\text { Lawrenceville City of (Georgia) } \\
\text { McCook Public Power Dist (Nebraska) } \\
\text { Oxford City of (Mississippi) } \\
\text { Paris City of (Tennessee) } \\
\text { Pierre City of (South Dakota) } \\
\text { Plymouth City of (Wisconsin) } \\
\text { Rochelle Municipal Utilities (lllinois) } \\
\text { San Marcos City of (Texas) } \\
\text { Wapakoneta City of (Ohio) }\end{array}$ & & & 467 \\
\hline $1991 \ldots . . . .$. & 08 & $\begin{array}{l}\text { Benton City of (Arkansas) } \\
\text { Hillsdale Board of Pub Works (Michigan) } \\
\text { Kennett City of (Missouri) } \\
\text { Lebanon City of (Missouri) } \\
\text { Monett City of (Missouri) } \\
\text { Reedsburg Util Commission (Wisconsin) } \\
\text { St Marys City of (Ohio) } \\
\text { Sturgeon Bay Combined Utils(Wisconsin) }\end{array}$ & 05 & $\begin{array}{l}\text { Kings River Conserv Dist (California } \\
\text { McCook Public Power Dist (Nebraska) } \\
\text { Merced Irrigation District (California) } \\
\text { Sebring Utilities Commission (Florida) } \\
\text { Village of Solvay (New York) }\end{array}$ & 470 \\
\hline
\end{tabular}

1 Excluded are the Federal electric utilities.

2 The threshold for reporting requirements changed from 100,000 megawatthours to 120,000 megawatthours. Source: Energy Information Administration, Form ElA-412, "Annual Report of Public Electric Utilities."

Figure B1. Principal Business Office of the Major Publicly Owned Electric Utilities, 1991

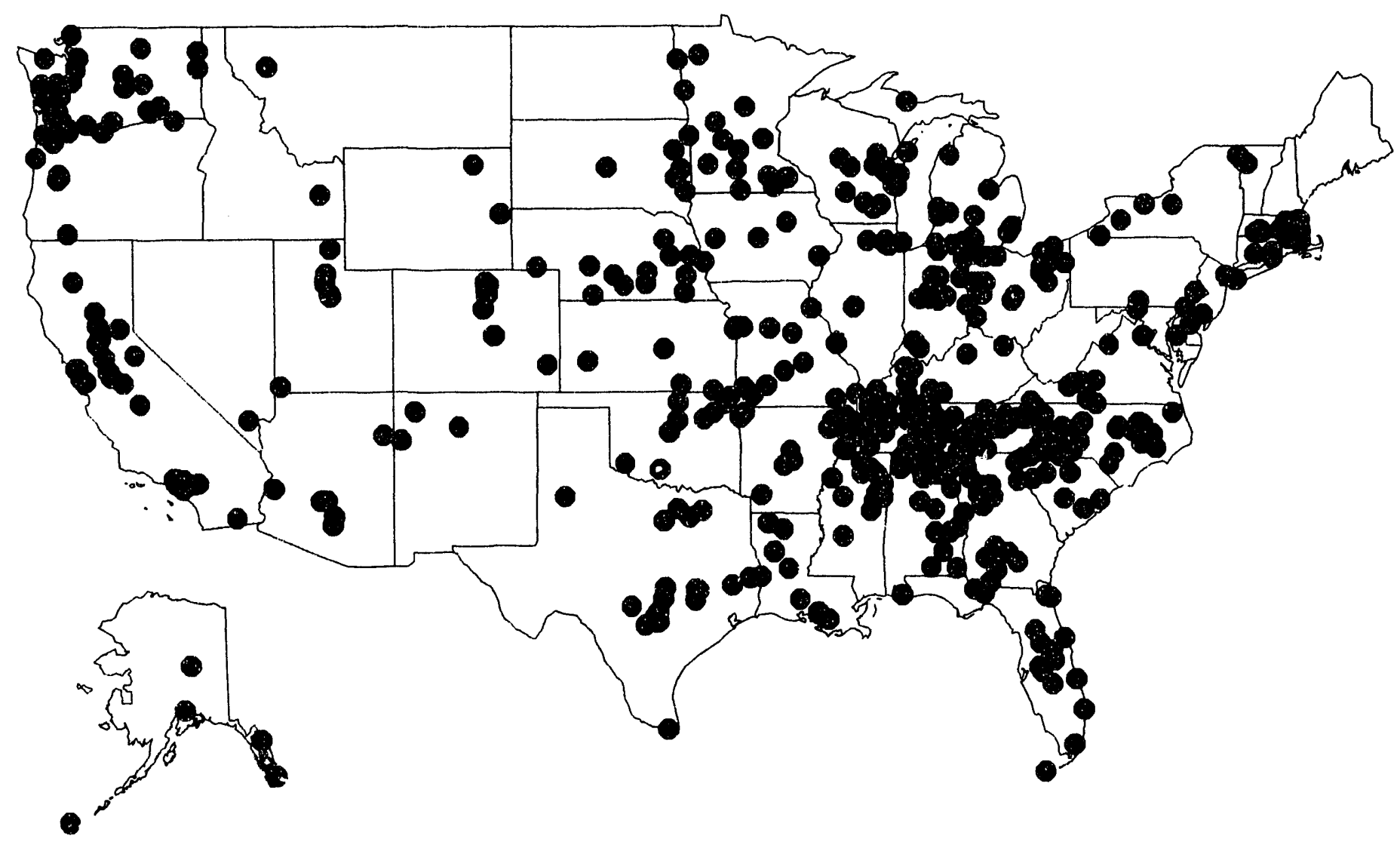

Source: Energy Information Administration, Form EIA-412. "Annual Report of Public Electric Utilities." 
Table B2. Publicly Owned Electric Utilities That Submitted the Form ElA-412, 1991

\begin{tabular}{|c|c|c|}
\hline Publicly Owned Electric Utilities & State & Reporting Date \\
\hline 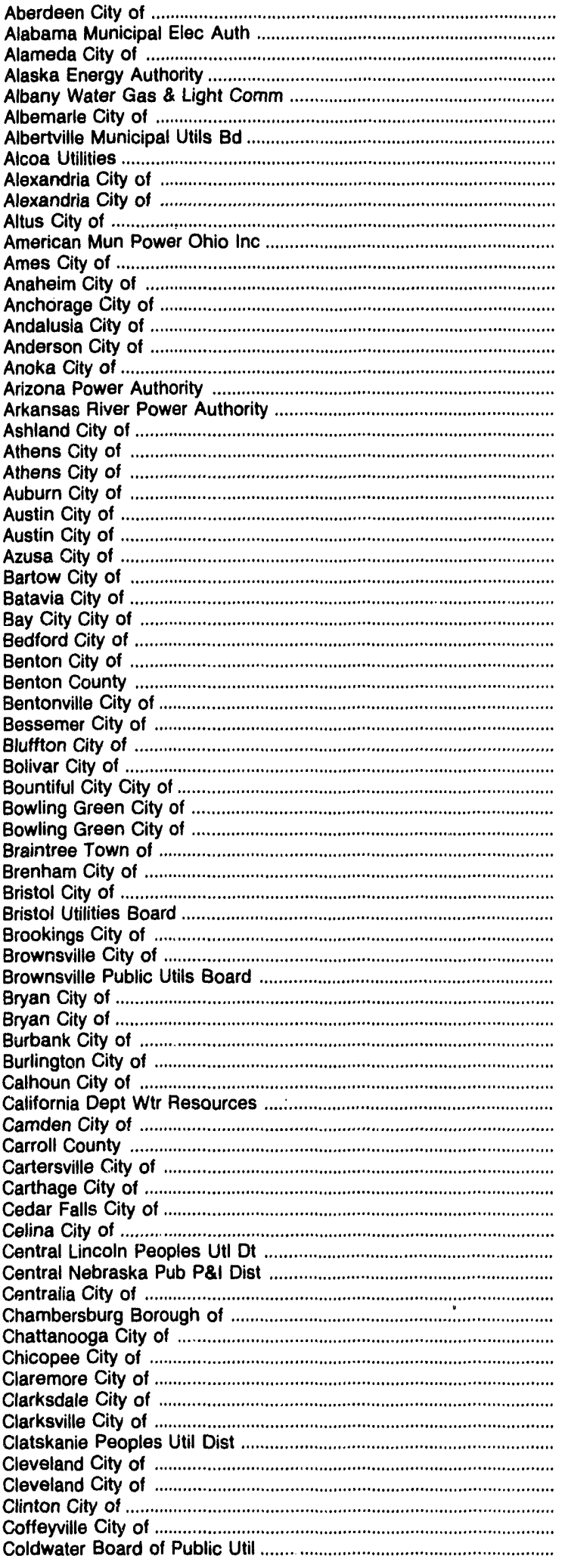 & 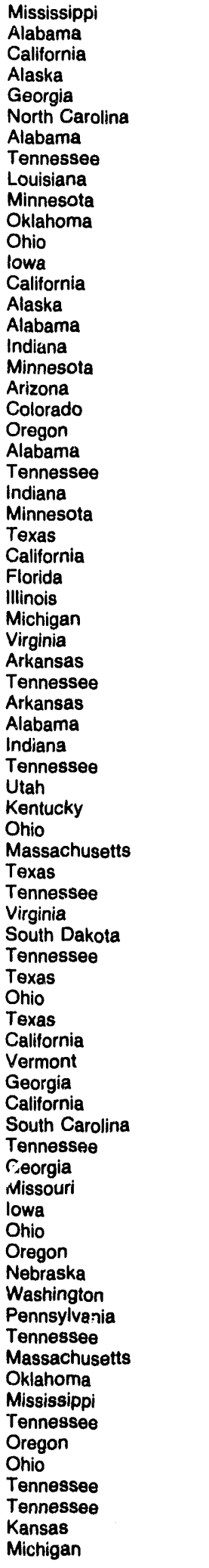 & 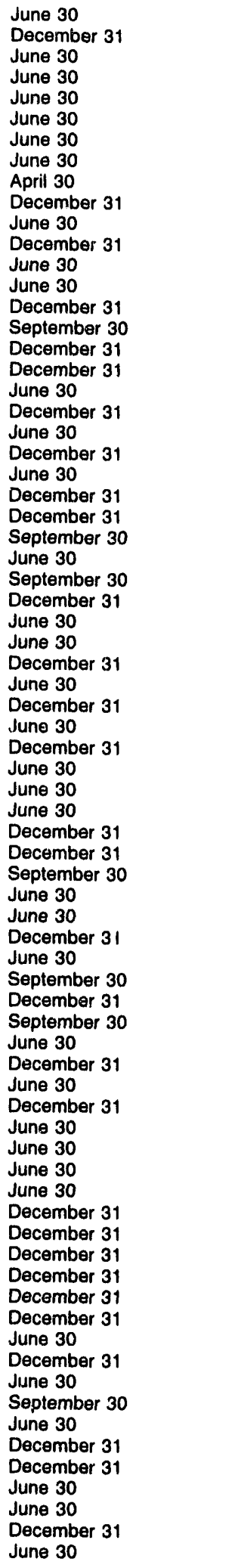 \\
\hline
\end{tabular}

See endnotes at end of this table. 
Table B2. Publicly Owned Electric Utilities That Submitted the Form ElA-412, 1991 (Continued)

\begin{tabular}{|c|c|c|}
\hline Publicly Owned Electric Utilities & State & Reporting Date \\
\hline College Park City of & Georgia & June 30 \\
\hline College Station City of & Texas & September 30 \\
\hline 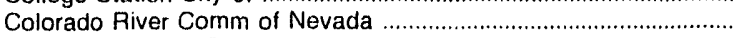 & Nevada & June 30 \\
\hline 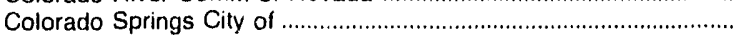 & Colorado & December 31 \\
\hline Colton City of & California & June 30 \\
\hline Columbia City of & Missouri & September 30 \\
\hline 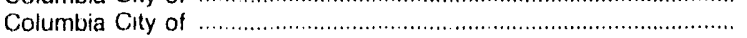 & Tennessee & June 30 \\
\hline 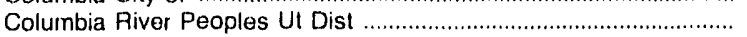 & Oregon & December 31 \\
\hline Columbus City of & Mississippi & June 30 \\
\hline Columbus City of & Ohio & December 31 \\
\hline Concord City of & North Carolina & June 30 \\
\hline 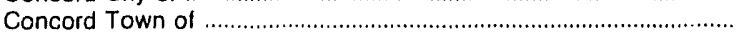 & Massachusetts & December 31 \\
\hline 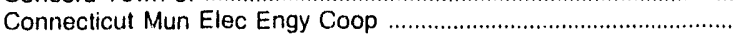 & Connecticut & December 31 \\
\hline Conway Corp & Arkansas & December 31 \\
\hline 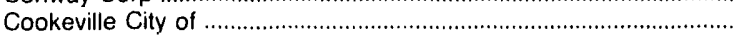 & Tennessee & June 30 \\
\hline 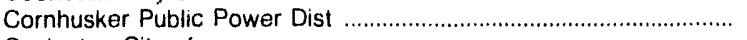 & Nebraska & December 31 \\
\hline Covington City of & Georgia & December 31 \\
\hline 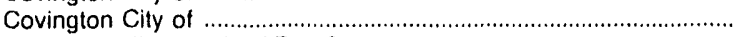 & Tennessee & June 30 \\
\hline 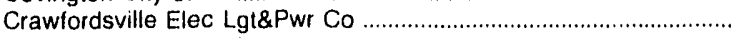 & Indiana & December 31 \\
\hline 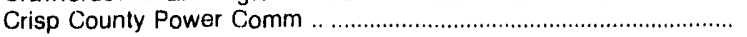 & Georgia & December 31 \\
\hline 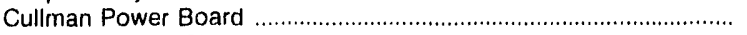 & Alabama & June 30 \\
\hline 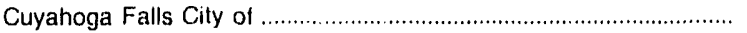 & Ohio & December 31 \\
\hline Dalton City of & Georgia & November 30 \\
\hline Danvers Town of & Massachusetts & December 31 \\
\hline 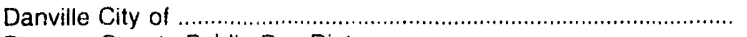 & Virginia & June 30 \\
\hline 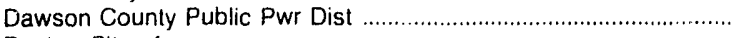 & Nebraska & December 31 \\
\hline 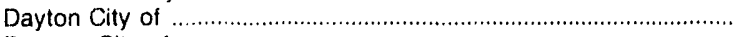 & Tennessee & June 30 \\
\hline 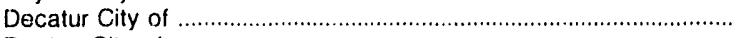 & Alabama & June 30 \\
\hline 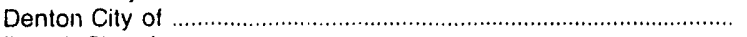 & Texas & Septernber 30 \\
\hline Detroit City of & Michigan & June 30 \\
\hline 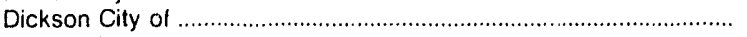 & Tennessee & June 30 \\
\hline Dothan City of & Alabama & September 30 \\
\hline Douglas City of & Georgia & June 30 \\
\hline Dover City of . & Delaware & June 30 \\
\hline Dover City of & Ohio & December 31 \\
\hline Dyersburg Electric System & Tennessee & June 30 \\
\hline 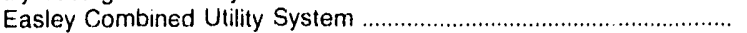 & South Carolina & March 31 \\
\hline 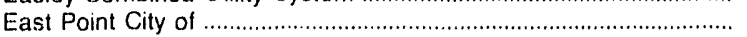 & Georgia & June 30 \\
\hline 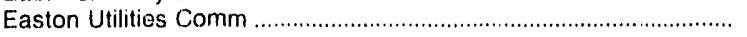 & Maryland & June 30 \\
\hline Edmond City of & Oklahoma & June 30 \\
\hline Elizabeth City City of & North Carolina & June 30 \\
\hline Elizabethton City of & Tennessee & June 30 \\
\hline Ellensburg City of & Washington & December 31 \\
\hline 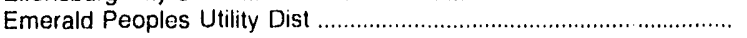 & Oregon & December 31 \\
\hline 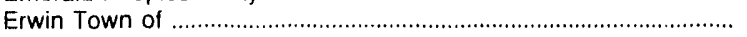 & Tennessee & June 30 \\
\hline Etowah City of & Tennessee & June 30 \\
\hline 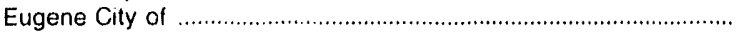 & Oregon & December 31 \\
\hline Fairbanks City of & Alaska & December 31 \\
\hline 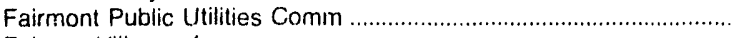 & Minnesota & December 31 \\
\hline Fairport Village of & Now York & May 31 \\
\hline 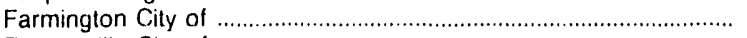 & New Mexico & June 30 \\
\hline 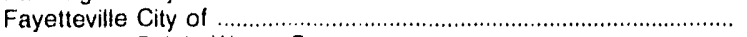 & Tennessee & June 30 \\
\hline 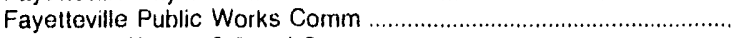 & North Carolina & June 30 \\
\hline 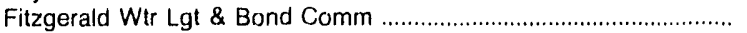 & Georgia & December 31 \\
\hline Florence City of & Alabama & June 30 \\
\hline Florida Municipal Power Agency & Florida & September 30 \\
\hline 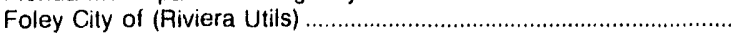 & Alabama & December 31 \\
\hline Forest Grove City of & Oregon & June 30 \\
\hline Fort Collins City of & Colorado & December 31 \\
\hline 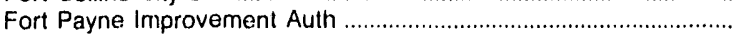 & Alabama & June 30 \\
\hline 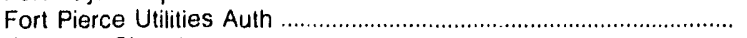 & Florida & September 30 \\
\hline Frankfort City of & Indiana & December 31 \\
\hline 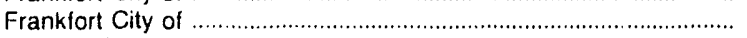 & Kentucky & June 30 \\
\hline Franklin City of & Kentucky & June 30 \\
\hline 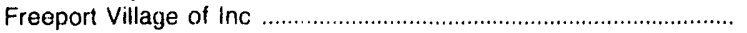 & New York & February 28 \\
\hline Fremont City of & Nebraska & July 31 \\
\hline 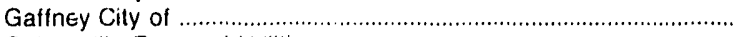 & South Carolina & March 31 \\
\hline 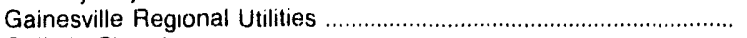 & Florida & September 30 \\
\hline 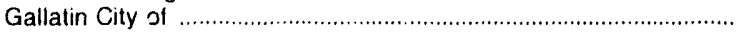 & Tennessee & June 30 \\
\hline Gallup City of & New Mexico & June 30 \\
\hline 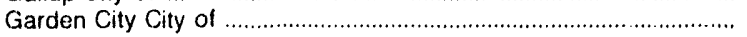 & Kansas & December 31 \\
\hline 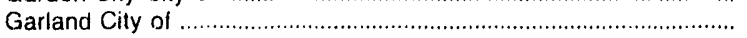 & Texas & September 30 \\
\hline Gastonia City of & North Carolina & Jline 30 \\
\hline Geneva City of & Illinois & April 30 \\
\hline
\end{tabular}

See endnotes at end of this table. 
Table B2. Publicly Owned Electric Utilities That Submitted the Form EIA-412, 1991 (Continued)

\begin{tabular}{|c|c|c|}
\hline Publicly Owned Electric Utilities & State & Reporting Date \\
\hline 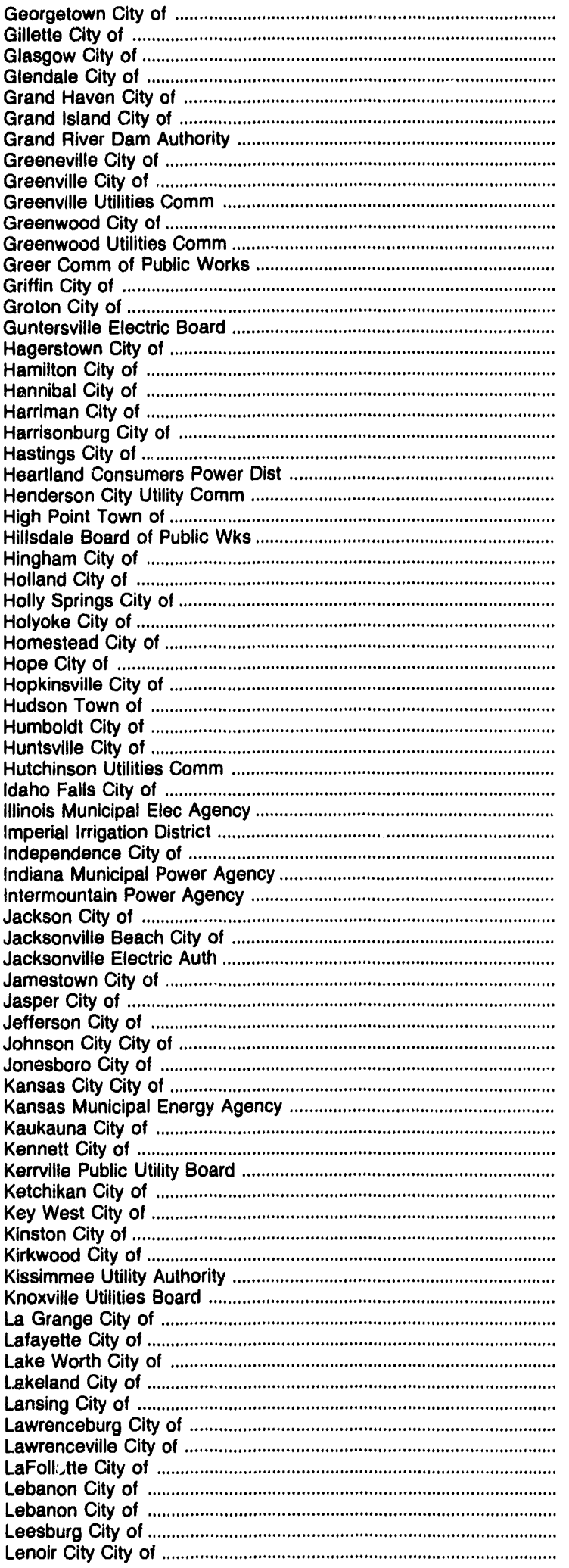 & 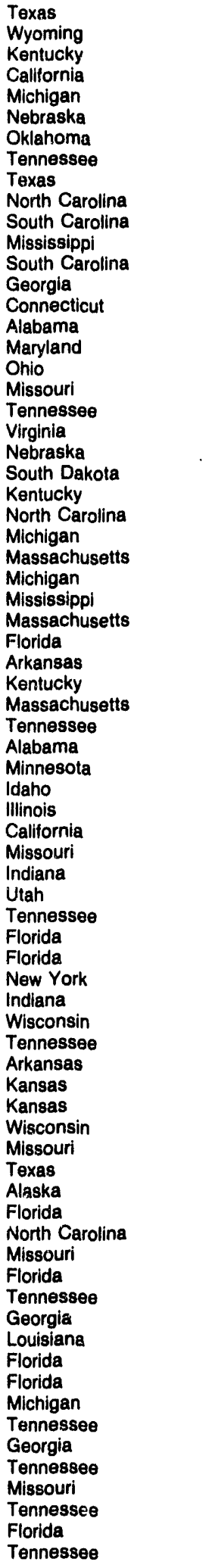 & 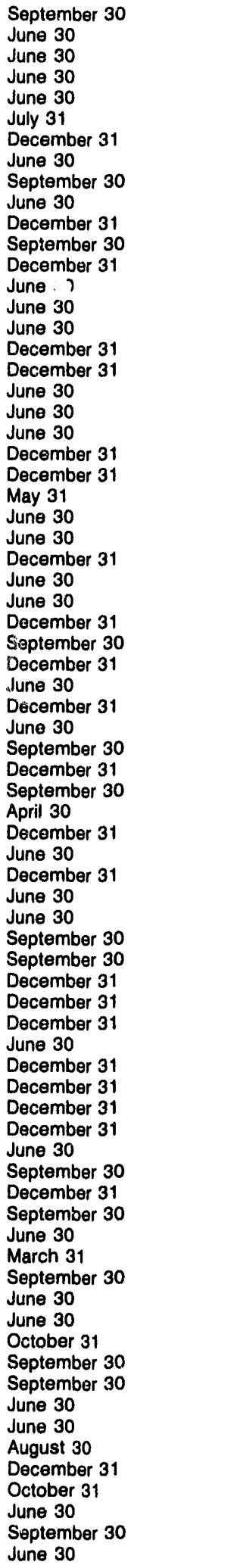 \\
\hline
\end{tabular}

See endnotes at end of this table. 
Table B2. Publicly Owned Electric Utilities That Submitted the Form ElA-412, 1991 (Continued)

\begin{tabular}{|c|c|c|}
\hline Publicly Owned Electric Utilities & State & Reporting Date \\
\hline 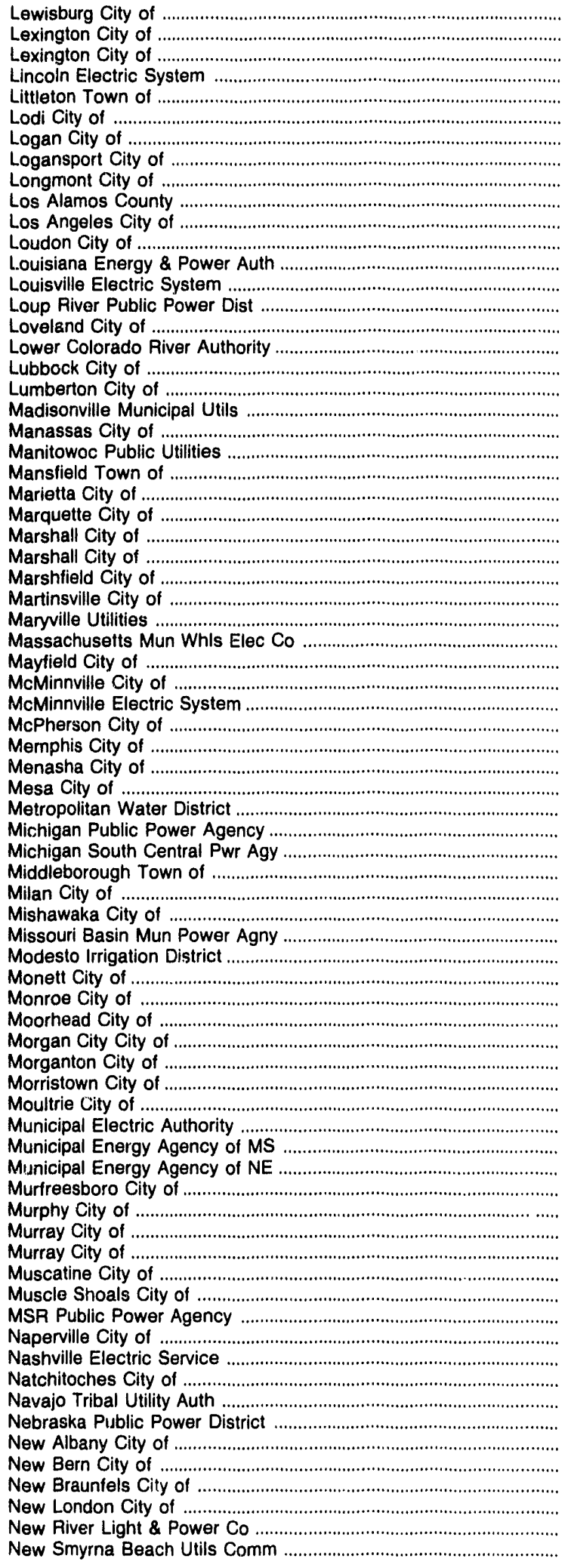 & 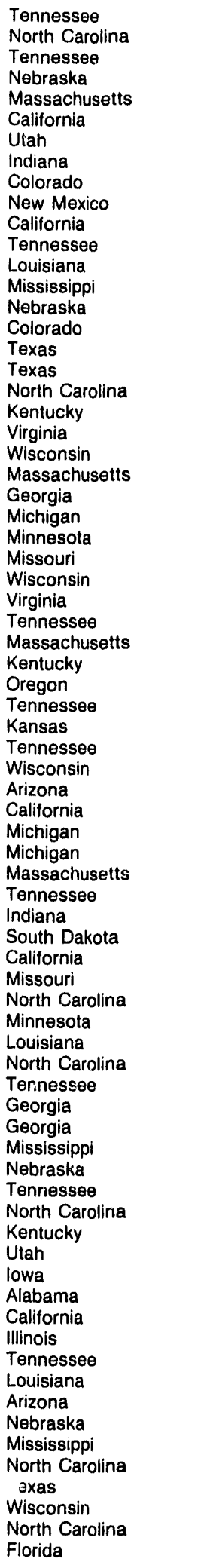 & 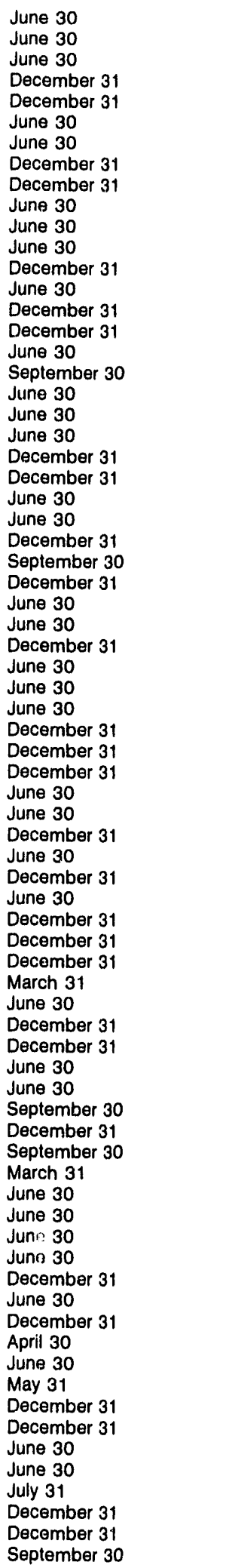 \\
\hline
\end{tabular}

See endnotes at end of this table. 
Table B2. Publicly Owned Electric Utilities That Submitted the Form ElA-412, 1991 (Continued)

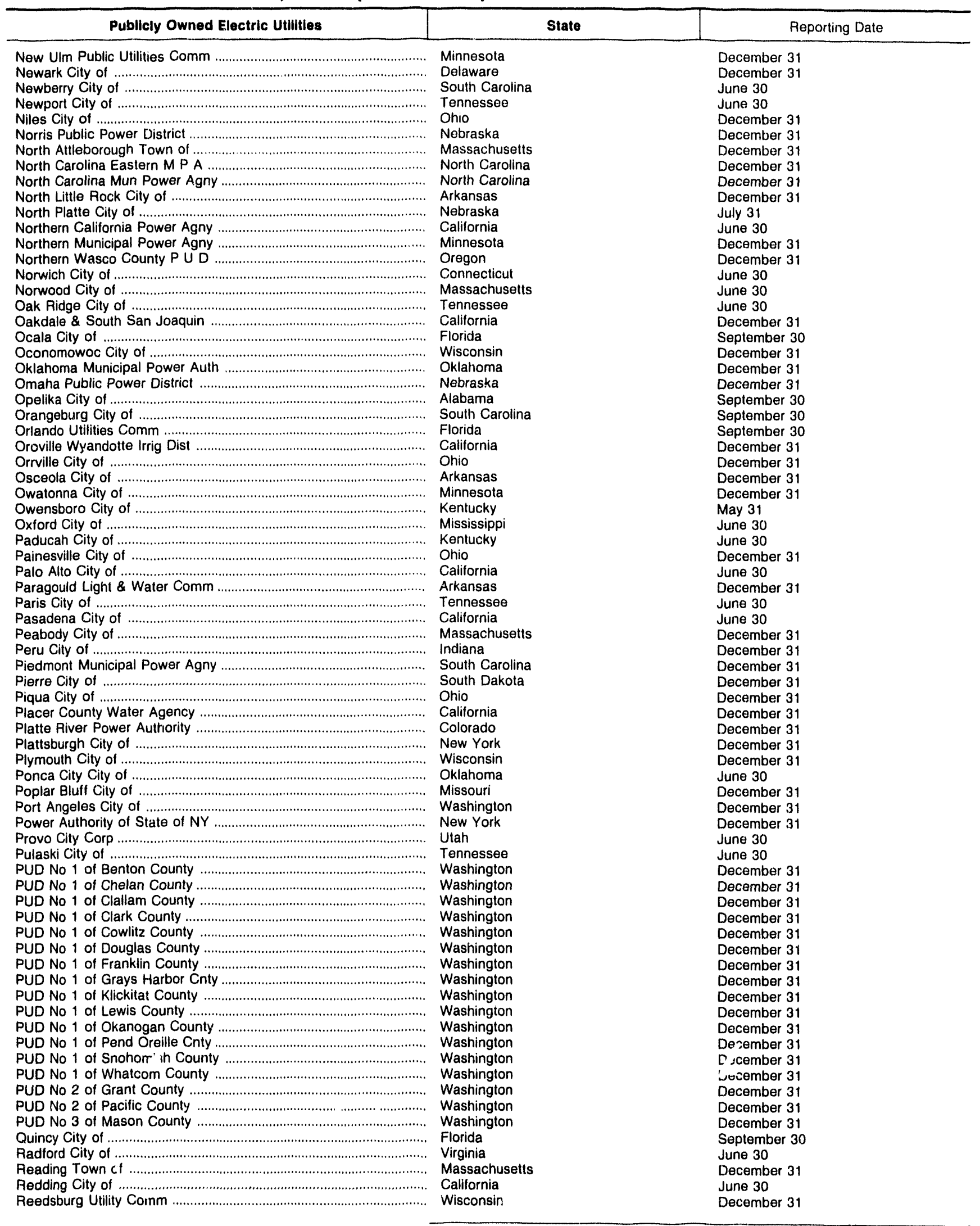

See endnotes at end of this table. 
Table B2. Publicly Owned Electric Utilities That Submitted the Form ElA-412, 1991 (Continued)

\begin{tabular}{|c|c|c|}
\hline Publicly Ownad Electric Utilities & State & Reporting Date \\
\hline 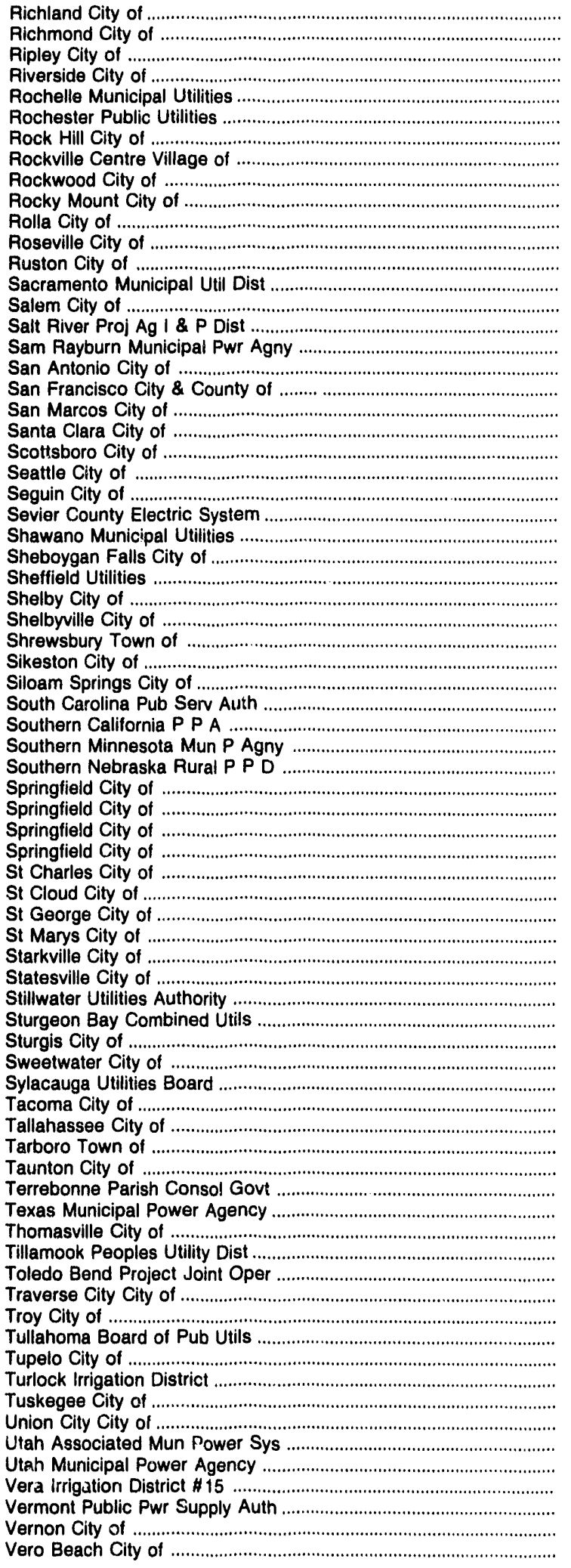 & 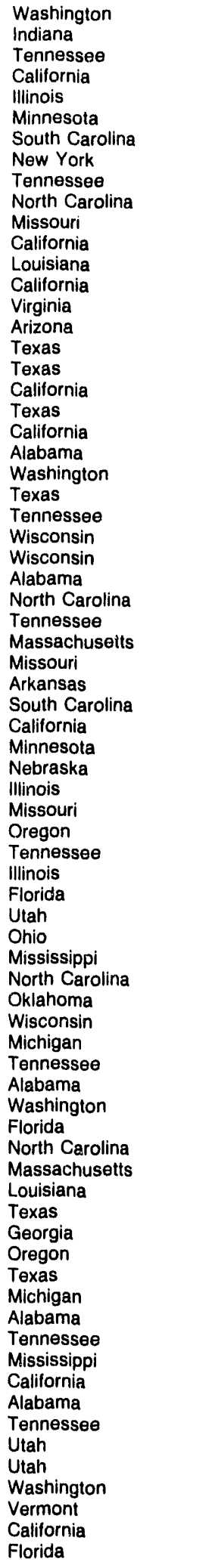 & 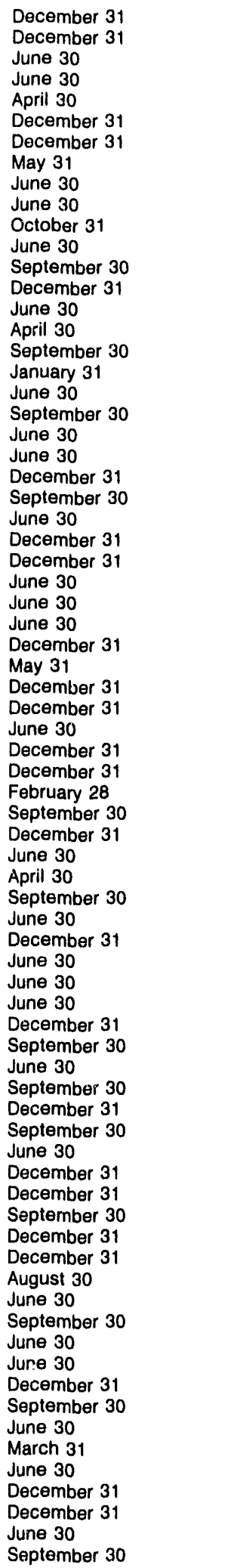 \\
\hline
\end{tabular}

See endnotes at end of this table. 
Table B2. Publicly Owned Electric Utilities That Submitted the Form ElA-412, 1991 (Continued)

\begin{tabular}{|c|c|c|}
\hline Publicly Owned Electric Utilities & State & Reporting Date \\
\hline 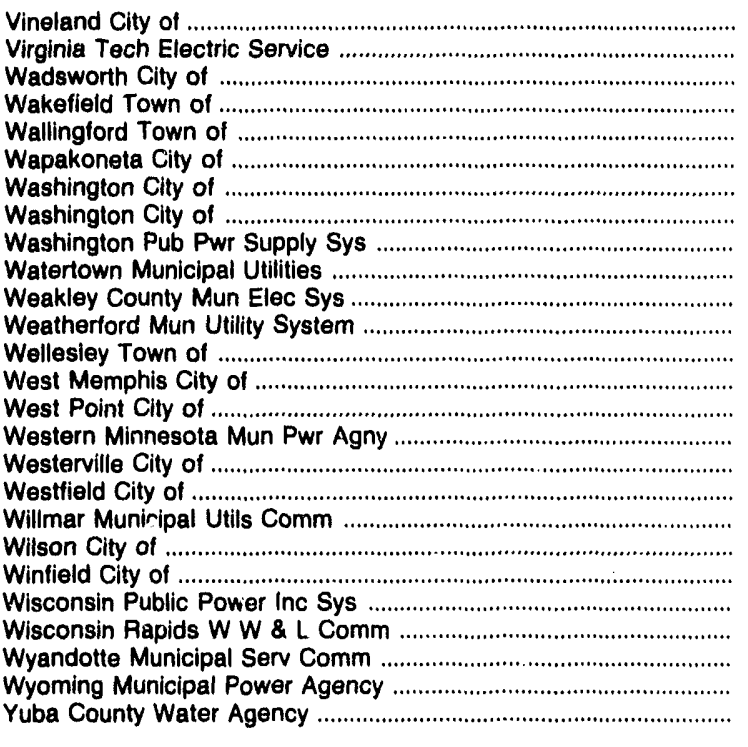 & $\begin{array}{l}\text { New Jersey } \\
\text { Virginia } \\
\text { Ohio } \\
\text { Massachusetts } \\
\text { Connecticut } \\
\text { Ohio } \\
\text { Indiana } \\
\text { North Carolina } \\
\text { Washington } \\
\text { South Dakota } \\
\text { Tennessee } \\
\text { Texas } \\
\text { Massachusetts } \\
\text { Arkansas } \\
\text { Mississippi } \\
\text { Minnesota } \\
\text { Ohio } \\
\text { Massachusetts } \\
\text { Minnesota } \\
\text { North Carolina } \\
\text { Kansas } \\
\text { Wisconsin } \\
\text { Wisconsin } \\
\text { Michigan } \\
\text { Wyoming } \\
\text { California }\end{array}$ & $\begin{array}{l}\text { December } 31 \\
\text { June } 30 \\
\text { December } 31 \\
\text { December } 31 \\
\text { June 30 } \\
\text { December } 31 \\
\text { December } 31 \\
\text { June } 30 \\
\text { June } 30 \\
\text { December } 31 \\
\text { June } 30 \\
\text { Seplember } 30 \\
\text { December } 31 \\
\text { December } 31 \\
\text { June } 30 \\
\text { December } 31 \\
\text { December } 31 \\
\text { December } 31 \\
\text { December } 31 \\
\text { June } 30 \\
\text { December } 31 \\
\text { June } 30 \\
\text { December } 31 \\
\text { September } 30 \\
\text { December } 31 \\
\text { June } 30\end{array}$ \\
\hline
\end{tabular}

Source: Energy Information Administration, Form EIA-412, "Annual Report of Public Electric Utilities." 


\section{Appendix C}

Respondents by

June 30 and

December 31

Fiscal Years and

by All

Respondents, 1989-1991 


\section{Appendix C}

\section{Respondents by June 30 and December 31 Fiscal Years and by All Respondents, 1989-1991}




\section{Financial Performance for June 30 Respondents}

Summary financial statistics are provided for the major publicly owned electric utilities with a fiscal year ending on June 30. These statistics include 188 electric utilities for each of the years 1989 through 1991. In 1990, the City of Foley (AL) and the South Carolina Public Service Authority (SC) changed fiscal year from June 30 to December 31. New respondents for June 30, 1990, are the City of Oxford (MS) and the City of Paris (TN). In 1991, new respondents were the Hillsdale Board of Public Works (MI) and the City of Kennett (MO). The Utah Associated Municipal Power System (UT) changed fiscal year from June 30 to March 31 in 1991. Deleted 1991 respondent was the Kings River Conservation District (CA).

For the major publicly owned electric utilities with a June 30 fiscal year (40.0 percent of the respondents), $\$ 2.60$ of investment is required to obtain $\$ 1$ in revenue. Compared with December 31 fiscal year respondents, a greater proportion of June 30 respondents are nongenerators. Electric operation and maintenance expenses averaged 76.5 percent of electric utility operating revenues from 1989 through 1991. Interest on longterm debt as a percent of electric utility operating revenues averaged 12.5 over the same 3 years (Table C7).

\section{Income Statement}

Electric utility operating revenues increased during 1991 by 0.9 percent, to $\$ 9,751.5$ million, identical to the increase experienced in 1990. Total electric utility operating expenses increased 2.1 percent, to $\$ 8,587.7$ million, compared with just 0.1 percent in 1990. Operation and maintenance expenses of $\$ 7,492.3$ million were up 1.2 percent over the prior year, represented 87.2 percent of total electric utility operating expenses.

With increases in expenses exceeding revenue gains, total electric utility operating income of $\$ 1,165.6$ million in 1991 decreased 7.2 percent from the prior year. Although total long-term debt increased \$272.0 million in 1991, interest expense on long-term debt increased only 0.7 percent over 1990 . The small increase in debt servicing was due to an increase in the average cost of debt (using end-of-fiscal-year balances), from 6.13 percent in 1990 to 6.25 percent in 1991. Both of these factors combined to push total net income down to $\$ 311.9$ million, a 8.2 percent decrease from $\$ 339.6$ million in 1990 and from $\$ 443.5$ million in 1989 (Table C5).

\section{Balance Sheet}

While still below the 1989 level, total assets and other debits of $\$ 35,409.3$ million increased 1.9 percent in 1991 over 1990 . Within this category, deferred debits showed the largest increase between 1990 and 1991, up $\$ 276.2$ million or 8.4 percent. Net electric utility plant increased 1.7 percent to $\$ 18,409.7$ million. Other property and investments increased 2.3 percent to $\$ 7,963.7$ million.

On the capital and liabilities side of the balance sheet, total capitalization (invesiment and surplus plus longterm debt) increased $\$ 655.5$ million or 2.2 percent. Long-term debt increased 1.4 percent or $\$ 272.0$ million, to $\$ 19,758.8$ million in 1991 . Debt to total assets in 1991 decreased marginally to 56.0 percunt from 56.1 percent in 1990, as did its proportion of total capitalization, which decreased from 65.5 percent in 1990 to 65.2 percent in 1991 (Table C6).

\section{Sales of Electric Power}

In 1991, total electric power sales declined for the third straight year. This was due largely to sharp declines in sales for resale, which dropped from 45.0 million megawatthours in 1989 to 40.1 million in 1990 , to 35.6 million megawatthours in 1991. Ultimate consumers sales increased in 1991 for all sectors except commercial. In 1991, residential and industrial sales both showed modest growth of 1.4 percent and 2.2 percent, respectively, while commercial sales were down by 0.8 percent. Average revenue per kilowatthour across the classes showed changes with residential and industrial average revenues increasing 1.6 percent and 3.0 percent, respectively. Commercial average revenues were off 2.4 percent in 1991 . The decrease in average revenue per kilowatthour and sales volume in the commercial class, produced a reduction in the overall average revenue from sales to ultimate consumers from 65.5 mills per kilowatthour in 1990 to 65.1 mills per kilowatthour in 1991 (Table C10).

\section{Generation and Purchased Power}

The 1991 decrease in total power disposition resulted in a corresponding decrease in generating requirements. Total net energy generated and received decreased 0.7 percent to 163.8 million megawatthours. The major shifts in the sources of generation were:

- A 7.7 percent decrease in steam generation to 35.8 million megawatthours

- A 17.4 percent increase in nuclear generaticn to 9.6 million megawatthours

- A 20.9 percent decrease in hydro-conventional generation to 5.3 million megawatthours.

Total purchased power from electric utilities and nonutilities increased 1.7 percent in 1991 and represented 68.4 percent of total net energy generated and received. Purchases represented 66.7 percent of all sources in 1990 (Table C11). 
Table C1. Ten Largest Publicly Owned Electric Utilities Ranked by Megawatthour Sales to Ultimate Consumers, June 30, 1991

\begin{tabular}{|c|c|c|c|}
\hline Publicly Owned Electric Utilities & State & Amount & Percent \\
\hline 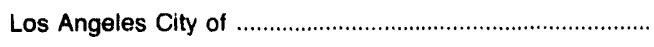 & $\mathrm{CA}$ & $21,803,360$ & 18.82 \\
\hline 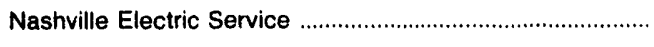 & TN & $9,742,817$ & 8.41 \\
\hline Chattanooga City of & TN & $5,027,367$ & 4.34 \\
\hline Knoxville Utilities Board & TN & $4,359,615$ & 3.76 \\
\hline Santa Clara City of & $C A$ & $2,262,202$ & 1.95 \\
\hline 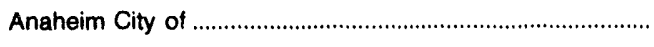 & $\mathrm{CA}$ & $2,156,813$ & 1.86 \\
\hline 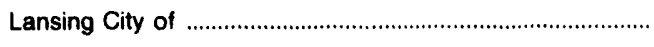 & MI & $2,151,707$ & 1.86 \\
\hline 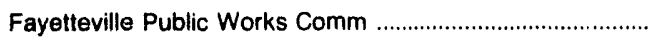 & NC & $1,547,965$ & 1.34 \\
\hline Riverside City of & CA & $1,495,000$ & 1.29 \\
\hline Johnson City City of & TN & $1,324,422$ & 1.14 \\
\hline Subtotal & & $51,871,268$ & 44.76 \\
\hline
\end{tabular}

Note: Percentage calculations are based on total Form EIA-412 respondents.

Source: Energy Information Administration, Form EIA-412, "Annual Report of Public Electric Utilities."

Table C2. Ten Largest Publicly-Owned Electric Utilities Ranked by Megawatthour Sales for Resale, June 30, 1991

\begin{tabular}{|c|c|c|c|}
\hline Publicly Owned Electric Utilities & State & Amount & Percent \\
\hline 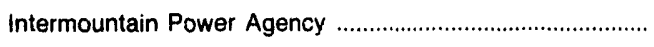 & UT & $10,750,184$ & 28.75 \\
\hline 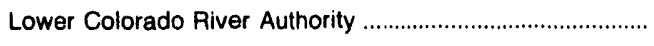 & $T X$ & $7,822,764$ & 20.92 \\
\hline 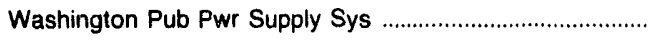 & WA & $5,769,664$ & 15.43 \\
\hline 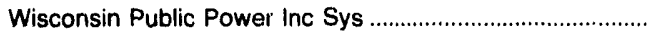 & WI & $3,164,342$ & 8.46 \\
\hline 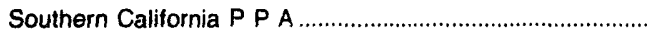 & CA & $1,603,991$ & 4.29 \\
\hline 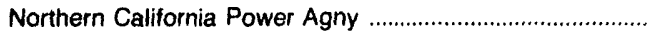 & CA & $1,571,529$ & 4.20 \\
\hline 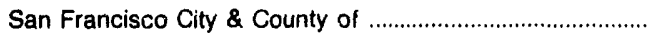 & $\mathrm{CA}$ & 927,224 & 2.48 \\
\hline 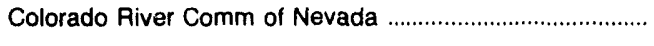 & NV & 915,290 & 2.45 \\
\hline 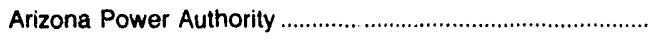 & $A Z$ & 833,232 & 2.23 \\
\hline 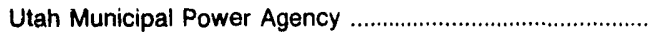 & UT & 771,802 & 2.06 \\
\hline Subtotal & & $34,130,022$ & 91.27 \\
\hline
\end{tabular}

Note: Percentage calculations are based on total Form EIA-412 respondents.

Source: Energy Information Administration, Form EIA.412, "Annual Report of Public Electric Utilities." 


\section{Financial Performance for December 31 Respondents}

Summary financial statistics are provided for the major publicly owned electric utilities with a fiscal year ending on December 31. These statistics include 196 electric utilities for December 31, 1991; 194 electric utilities for December 31, 1990; and 185 electric utilities for December 31, 1989. In 1990, the City of Foley (AL) and the South Carolina Public Service Authority (SC) changed to a December 31 fiscal year. New respondents in 1990 were the Alabama Municipal Electric Authority (AL), the City of Jefferson (WI), the City of Ketchikan (AK), the McCuok Public Power District (NE), the City of Pierre (SD), the City of Plymouth (WI) and the City of Wapakoneta (OH). In 1991, new respondents were the City of Benton (AR), the Reedsburg Utility Commission (WI), the City of St. Marys $(\mathrm{OH})$, and the Sturgeon Bay Combined Utilities (WI), but deleted were the McCook Public Power District (NE) and the Merced Irrigation District (CA).

For the major publicly owned electric utilities with a December 31 fiscal year (41.7 percent of the respondents), $\$ 3.30$ of investment is required to obtain $\$ 1$ in revenue. Electric operation and maintenance expenses averaged 71.4 percent of electric utility operating revenues from 1989 through 1991. Interest on long-term debt as a percent of electric utility operating revenues was 20.6 over the same 3 years (Table C7).

\section{Income Statement}

Electric utility operating revenues increased 4.3 percent to $\$ 12,196.9$ million in 1991 , compared with a 12.5 percent increase in 1990 . Total electric utility operating expenses increased 2.6 percent to $\$ 10,033.0$ million, compared with 10.1 percent in 1990 . Operation and maintenance expenses of $\$ 8,483.7$ million were up 1.4 percent over the prior year, represented 84.6 percent of total electric operating expenses.

With gains in revenue exceeding increased expenses, total electric utility operating income increased a substantial 12.9 percent in 1991 , to $\$ 2,166.6$ million, up from $\$ 1,918.6$ million in 1990 . Interest expenses on long-term debt were up 4.6 percent despite a 5.7 percent increase in debt outstanding. This occurred because the average cost of debt (using end-of-fiscal-year balances) decreased from 7.32 percent in 1990 to 7.21 percent in 1991. Total net income rose to $\$ 616.7$ million, up 82.8 percent from 1990 (Table C5).

\section{Balance Sheet}

Total assets and other debits grew a substantial 6.0 percent to $\$ 50,537.7$ million in 1991 . Net electric utility plant increased $\$ 800.1$ million to $\$ 29,220.6$ million or
2.8 percent, accounted for 28.1 percent of the increase in total assets and other debits. Other property and investments increased 19.2 percent, to $\$ 7,286.6$ million, represented 41.2 percent of the increase in total assets and other debits between 1990 and 1991 .

Total capitalization increased $\$ 2,206.8$ million or 5.2 percent, to $\$ 44,688.8$ million in 1991 . Virtually all the increase was the result of adding $\$ 1,905.0$ million in long-term debt, making debt's share of total capitalization to 78.6 percent in 1991 versus 78.2 percent in 1990, and 78.9 percent in 1989. The ratio of long-term debt to total assets decreased marginally from 69.5 percent in 1991 to 69.7 percent in 1990 (Table C6).

\section{Sales of Electric Power}

Total revenues from sales of electricity were up only 1.6 percent over the prior year. Increases in both average revenues per kilowatthour and megawatthour sales contributed to the 3.2 percent increase in revenues from sales to ultimate consumers. Megawatthour sales to ultimate consumers increased 2.7 percent over the prior year while average revenues per kilowatthour increased a more modest 0.6 percent. Sales for resale decreased in both megawatthour sales $(0.8$ percent $)$ and average revenues $(0.1$ percent $)$, produced revenues which were down 1.0 percent from 1990. All three primary consumer classes showed good signs of growth during 1991. In 1991, residential, commercial and industrial sales grew 4.5 percent, 2.9 percent, and 1.1 percent, respectively. Average revenue per kilowatthour also increased for each of the e consumer classes, propelling the overall average revenue from sales to ultimate consumers from 49.0 mills per kilowatthour in 1990 to 49.3 mills per kilowatthour in 1991 (Table C10).

\section{Generation and Purchased Power}

Total net energy generated and received decreased slightly, to 292.2 million megawatthours in 1991, down 0.6 percent. The biggest change in the source of generation was in nuclear generation, which was up 5.5 percent over the prior year and represented 21.3 percent of total net generation. Steam generation was down 1.8 percent from 1990 and represented 39.0 percent of total net generation in 1991. Pumped storage hydroelectric power was down 33.2 percent while conventional hydroelectric power remained essentially unchanged (down 0.3 percent). Conventional hydroelectric power generation represented 39.3 percent of total net generation. In 1991, purchased power continued to play a major role in meeting the power requirements of these electric utilities, contributed 42.3 percent of the total net generated and received megawatthours (Table C11). 


\section{Table C3. Ten Largest Publicly Owned Electric Utilities Ranked by Megawatthour Sales to Ultimate Consumers, December 31, 1991}

\begin{tabular}{|c|c|c|c|}
\hline Publicly Owned Electric Utilities & State & Amount & Percent \\
\hline Power Authority of State of NY & NY & $13,326,360$ & 9.14 \\
\hline Memphis City of & TN & $11,451,824$ & 7.86 \\
\hline Seattle City of & WA & $8,832,638$ & 6.06 \\
\hline 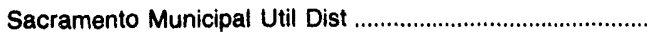 & $\mathrm{CA}$ & $8,421,441$ & 5.78 \\
\hline South Carolina Pub Serv Auth & SC & $7,508,723$ & 5.15 \\
\hline 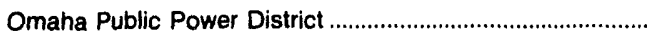 & NE & $6,705,518$ & 4.60 \\
\hline 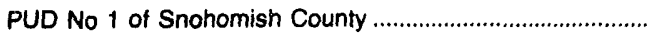 & WA & $5,631,998$ & 3.86 \\
\hline 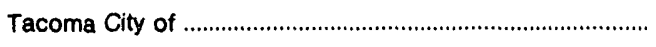 & WA & $5,568,661$ & 3.82 \\
\hline 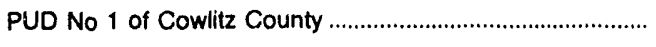 & WA & $4,217,152$ & 2.89 \\
\hline 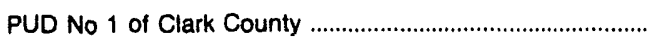 & WA & $3,122,251$ & 2.14 \\
\hline Subtotal & & $74,786,566$ & 51.31 \\
\hline
\end{tabular}

Note: Percentage calculations are based on total Form EIA-412 respondents.

Source: Energy Information Administration, Form EIA-412, "Annual Report of Public Electric Utilities."

Table C4. Ten Largest Publicly Owned Electric Utilities Ranked by Megawatthour Sales for Resale, December 31, 1991

\begin{tabular}{|c|c|c|c|}
\hline Publicly Owned Electric Utilities & State & Amount & Percent \\
\hline Power Authority of State of NY & NY & $22,905,668$ & 17.39 \\
\hline 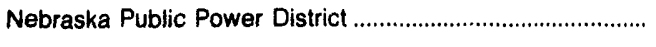 & NE & $10,550,435$ & 8.01 \\
\hline 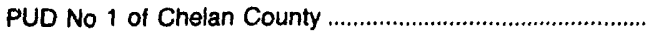 & WA & $10,354,989$ & 7.86 \\
\hline 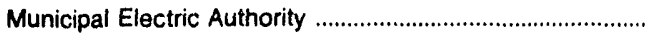 & GA & $9,312,381$ & 7.07 \\
\hline 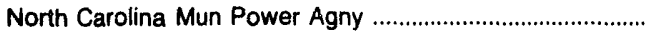 & NC & $8,022,722$ & 6.09 \\
\hline PUD No 2 of Grant County & WA & $7,326,020$ & 5.56 \\
\hline 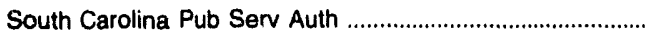 & SC & $6,088,552$ & 4.62 \\
\hline 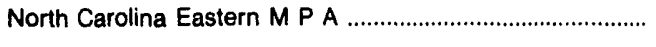 & NC & $5,962,319$ & 4.53 \\
\hline 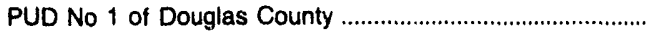 & WA & $4,350,264$ & 3.30 \\
\hline 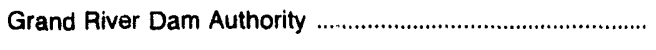 & OK & $4,062,452$ & 3.08 \\
\hline Subtotal & & $88,935,802$ & 67.50 \\
\hline
\end{tabular}

Note: Percentage calculations are based on total Form ElA-412 respondents.

Source: Energy Information Administration, Form EIA-412, "Annual Report of Public Electric Utilities." 
Table C5. Composite Statement of Income for Major
Publicly Owned Electric Utilities, 1989-1991

(Thousand Dollars)

\begin{tabular}{|c|c|c|c|c|c|c|}
\hline & 1991 & 1990 & 1989 & 1991 & 1990 & 1989 \\
\hline Item & \multicolumn{3}{|c|}{$\begin{array}{l}\text { Utilities with Financial Year } \\
\text { Ending on June } 30\end{array}$} & \multicolumn{3}{|c|}{$\begin{array}{l}\text { Utilities with Financial Year } \\
\text { Ending on December } 31\end{array}$} \\
\hline Electric Utility Operating Revenues ............ & $9,751,452$ & $9,665,561$ & $9,582,378$ & $12,196,916$ & $11,692,371$ & $10,389,832$ \\
\hline 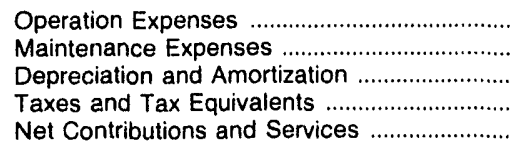 & $\begin{array}{r}7,036,463 \\
455,817 \\
745,143 \\
177,506 \\
172,813\end{array}$ & $\begin{array}{r}6,889,146 \\
516,075 \\
678,508 \\
166,155 \\
160,303\end{array}$ & $\begin{array}{r}6,681,855 \\
627,818 \\
749,056 \\
152,282 \\
194,548\end{array}$ & $\begin{array}{r}7,729,382 \\
754,348 \\
1,190,142 \\
291,157 \\
67,951\end{array}$ & $\begin{array}{r}7,655,061 \\
713,837 \\
1,053,567 \\
283,009 \\
70,314\end{array}$ & $\begin{array}{r}6,928,383 \\
670,012 \\
964,623 \\
261,476 \\
55,886\end{array}$ \\
\hline $\begin{array}{l}\text { Total Electric Utility Operating } \\
\text { Expenses }\end{array}$ & \multicolumn{5}{|c|}{ Total Electric Utility Operating } & $8,880,380$ \\
\hline $\begin{array}{l}\text { Net Electric Utility Operating Income } \\
\text { Income from Electric Plant Leased } \\
\text { to Others }\end{array}$ & $\begin{array}{r}1,163,710 \\
1,879\end{array}$ & $1,255,374$ & $1,176,819$ & $2,163,936$ & $1,916,582$ & $\begin{array}{r}1,509,451 \\
2,033\end{array}$ \\
\hline Total Electric Utility Operating Income. & $1,165,589$ & $1,256,517$ & $1,177,670$ & $2,166,568$ & $1,918,612$ & $1,511,484$ \\
\hline 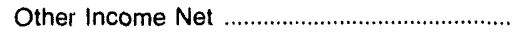 & 429,449 & 424,619 & 471,092 & 998,777 & 984,252 & $1,078,157$ \\
\hline $\begin{array}{l}\text { Other Electric Deductions ................................. } \\
\text { Allowance for Other Funds Used }\end{array}$ & 10,044 & - & - & 29,108 & - & - \\
\hline 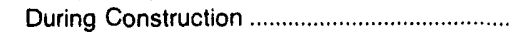 & 7,371 & 3,318 & 9,624 & 16,202 & 54,866 & 133,414 \\
\hline Total Electric Utility Income ......................... & $1,592,366$ & $1,684,454$ & $1,658,386$ & $3,152,440$ & $2,957,729$ & $2,723,055$ \\
\hline 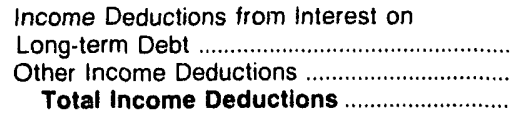 & $\begin{array}{r}1,225,965 \\
-70,665 \\
1,155,300\end{array}$ & $\begin{array}{r}1,217,497 \\
72,514 \\
1,290,012\end{array}$ & $\begin{array}{r}1,176,449 \\
9.247 \\
1,185,696\end{array}$ & $\begin{array}{r}2,466,487 \\
123,776 \\
2,590,263\end{array}$ & $\begin{array}{r}2,357,158 \\
190,369 \\
2,547,528\end{array}$ & $\begin{array}{r}2,230,716 \\
206,267 \\
2,436,983\end{array}$ \\
\hline Income Before Extraordinary Items ................. & 437,066 & 394,442 & 472,690 & 562,177 & 410,202 & 286,072 \\
\hline 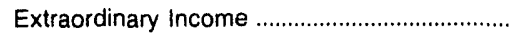 & 27,093 & 84,674 & 5,421 & 86,072 & 34,235 & 46,171 \\
\hline Extraordinary Deductions ................................... & 152,318 & 139,541 & 34,594 & 31,539 & 107,054 & 649,008 \\
\hline 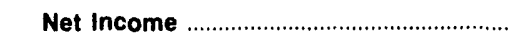 & 311,841 & 339,575 & 443,517 & 616,710 & 337,382 & $1-316,766$ \\
\hline $\begin{array}{l}\text { - Data not available. } \\
\text { Net income reflects } \$ 584 \text { million of extrao } \\
\text { ramento Municipal Utility District. } \\
\text { Note: Totals may not equal sum of compc } \\
\text { of publicly owned electric utilities for end of pe } \\
\text { cember } 31,1991 \text {; and } 194 \text { for December } 31,1 \\
\text { ity changed fiscal year from June } 30 \text { to Decen } \\
\text { March } 31 \text { in 1991. } \\
\text { Source: Energy information Administration }\end{array}$ & $\begin{array}{l}\text { ry deductior } \\
\text { s because o } \\
188 \text { for Ju } \\
\text { and } 185 \text { for } \\
31 \text { in } 1990 \text {. } \\
\text { m EIA-412, }\end{array}$ & $\begin{array}{l}\text { ciated with } t \\
\text { pendent ind } \\
1991 ; \text { and } \\
\text { nber } 31,19 \\
\text { Utah Assoc } \\
\text { al Report of }\end{array}$ & $\begin{array}{l}\text { andonment } \\
\text { ent rounding } \\
\text { June } 30,1 \\
\text { he City of F } \\
\text { Municpal Po } \\
\text { Electric }\end{array}$ & $\begin{array}{l}\text { Rancho Se } \\
\text { tailed data a } \\
\text { and } 188 \text { for } \\
\text { AL) and the } \\
\text { System (UT) }\end{array}$ & $\begin{array}{l}\text { lear Plant r } \\
\text { ided in Tab } \\
\text { e } 30,1989 \\
\text { Carolina Pu } \\
\text { ed fiscal ye }\end{array}$ & $\begin{array}{l}\text { d by the Sac } \\
\text { The numbe } \\
\text { s } 196 \text { for De } \\
\text { arvice Author } \\
\text { n June } 30 \text { te }\end{array}$ \\
\hline
\end{tabular}



Table C6. Composite Balance Sheet for Major Publicly Owned
Electric Utilities at End of Period, 1989-1991 (Thousand Dollars)

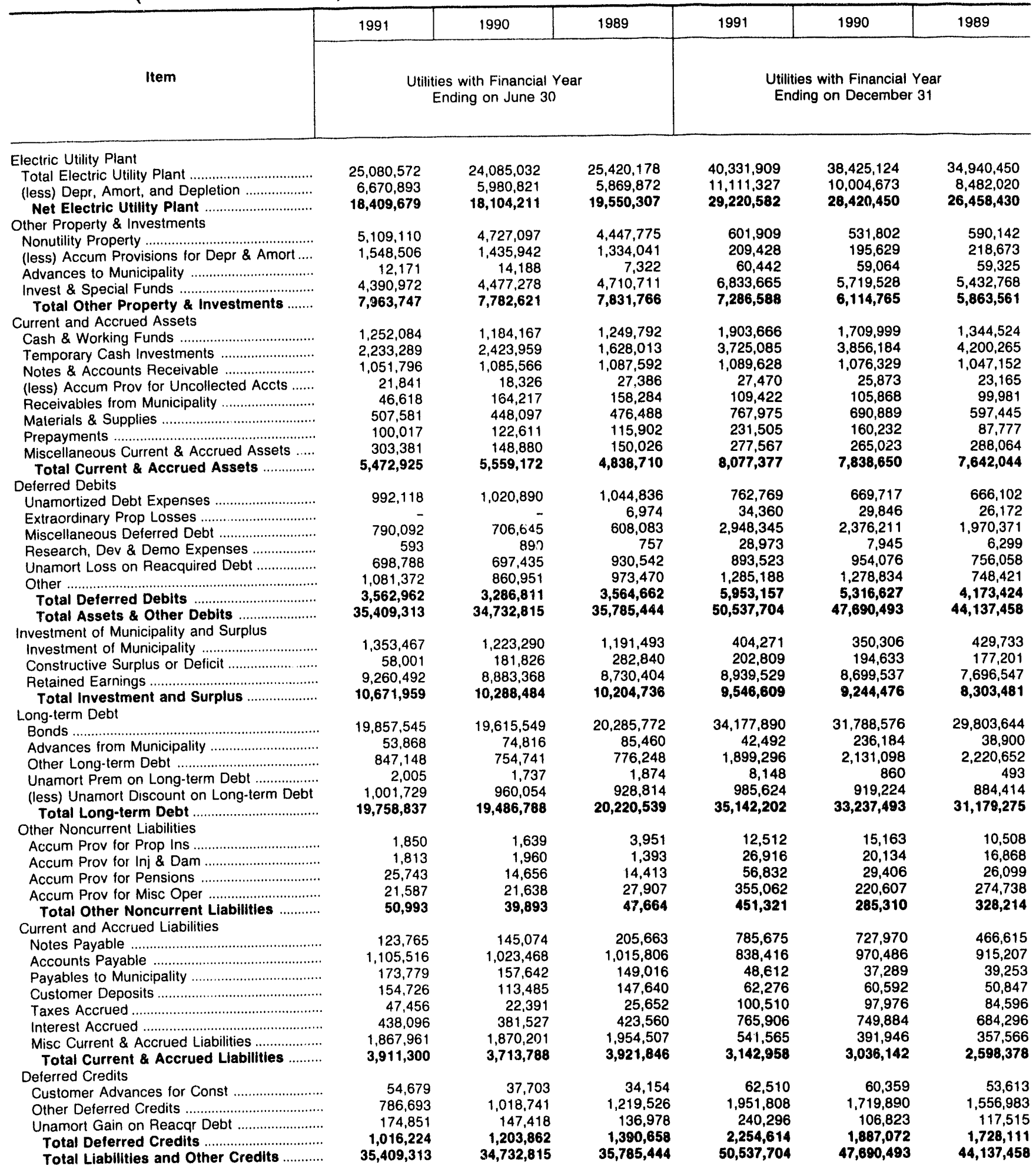

Note: Totals may not equal sum of components because of independent rounding. Detailed data are provided in Table 39 . The number of publicly owned electric utilities for end of period is 188 for June 30, 1991; and 188 for June 30, 1990; and 188 for June 30, 1989, and is 196 for December 31, 1991; and 194 for December 31, 1990, and 185 for December 31, 1989. The City of Foley (AL) and the South Carolina Public Service Authority changed fiscal year from. June 30 to December 31 in 1990 . The Utah Associated Municpal Power System (UT) changed fiscal year from June 30 to March 31 in 1991.

Source: Energy Information Administration, Form ElA-412. "Annual Report of Public Electric Utilities." 
Table C7. Composite Financial Indicators for Major Publicly Owned Electric Utilities, 1989-1991

\begin{tabular}{|c|c|c|c|c|c|c|}
\hline & 1991 & 1990 & 1989 & 1991 & 1990 & 1989 \\
\hline Item & \multicolumn{3}{|c|}{$\begin{array}{l}\text { Utilities with Financial Year } \\
\text { Ending on June } 30\end{array}$} & \multicolumn{3}{|c|}{$\begin{array}{l}\text { Utilities with Financial Year } \\
\text { Ending on December } 31\end{array}$} \\
\hline $\begin{array}{l}\text { Total Electric Utility Plant per Dollar of } \\
\text { Revenue }\end{array}$ & 2.6 & 2.5 & 2.7 & 3.3 & 3.3 & 3.4 \\
\hline Current Assets to Current Liabilities .................. & 1.4 & 1.5 & 1.2 & 2.6 & 2.6 & 2.9 \\
\hline $\begin{array}{l}\text { Total Electric Utility Plant as a Percent of } \\
\text { Total Assets }\end{array}$ & 70.8 & 69.3 & 71.0 & 79.8 & 80.6 & 79.2 \\
\hline $\begin{array}{l}\text { Net Electric Utility Plant as a Percent of } \\
\text { Total Assets }\end{array}$ & 52.0 & 52.1 & 54.6 & 57.8 & 59.6 & 59.9 \\
\hline $\begin{array}{l}\text { Depreciation, Amortization and Depletion } \\
\text { as a Percent of Total Electric Utility Plant .... }\end{array}$ & 26.6 & 24.8 & 23.1 & 27.5 & 26.0 & 24.3 \\
\hline $\begin{array}{l}\text { Electric Operation and Maintenance } \\
\text { Expenses } \\
\text { as a Percent of } \\
\text { Electric Utility Operating Revenues ................. }\end{array}$ & 76.8 & 76.6 & 76.3 & 69.6 & 71.6 & 73.1 \\
\hline $\begin{array}{l}\text { Electric Depreciation and Amortization } \\
\text { as a Percent of } \\
\text { Electric Utility Operating Revenues ................. }\end{array}$ & 7.6 & 7.0 & 7.8 & 9.8 & 9.0 & 9.3 \\
\hline $\begin{array}{l}\text { Taxes and Tax Equivalents } \\
\text { as a Percent of } \\
\text { Electric Utility Operating Revenues ................ }\end{array}$ & 1.8 & 1.7 & 1.6 & 2.4 & 2.4 & 2.5 \\
\hline $\begin{array}{l}\text { Net Contributions and Services } \\
\text { as a Percent of } \\
\text { of Electric Utility Operating Revenues ........... }\end{array}$ & 1.8 & 1.7 & 2.0 & .6 & .6 & .5 \\
\hline $\begin{array}{l}\text { Interest on Long-term Debt } \\
\text { as a Percent of } \\
\text { Electric Utility Operating Revenues .................. }\end{array}$ & 12.6 & 12.6 & 12.3 & 20.2 & 20.2 & 21.5 \\
\hline
\end{tabular}

Note: Totals may not equal sum of components because of independent rounding. The number of publicly owned electric utilities for end of period is 188 for June 30,1991; and 188 for June 30, 1990; and 188 for June 30, 1989, and is 196 for December 31, 1991; and 194 for December 31, 1990, and 185 for December 31, 1989. The City of Foley (AL) and the South Carolina Public Service Authority changed fiscal year from June 30 to December 31 in 1990. The Utah Associated Municpal Power System (UT) changed fiscal year from June 30 to March 31 in 1991.

Source: Energy Information Administration, Form ElA-412, "Annual Report of Public Electric Utilities." 
Table C8. Electric Operation and Maintenance Expenses for Major Publicly Owned Electric Utilities, 1989-1991 (Thousand Dollars)

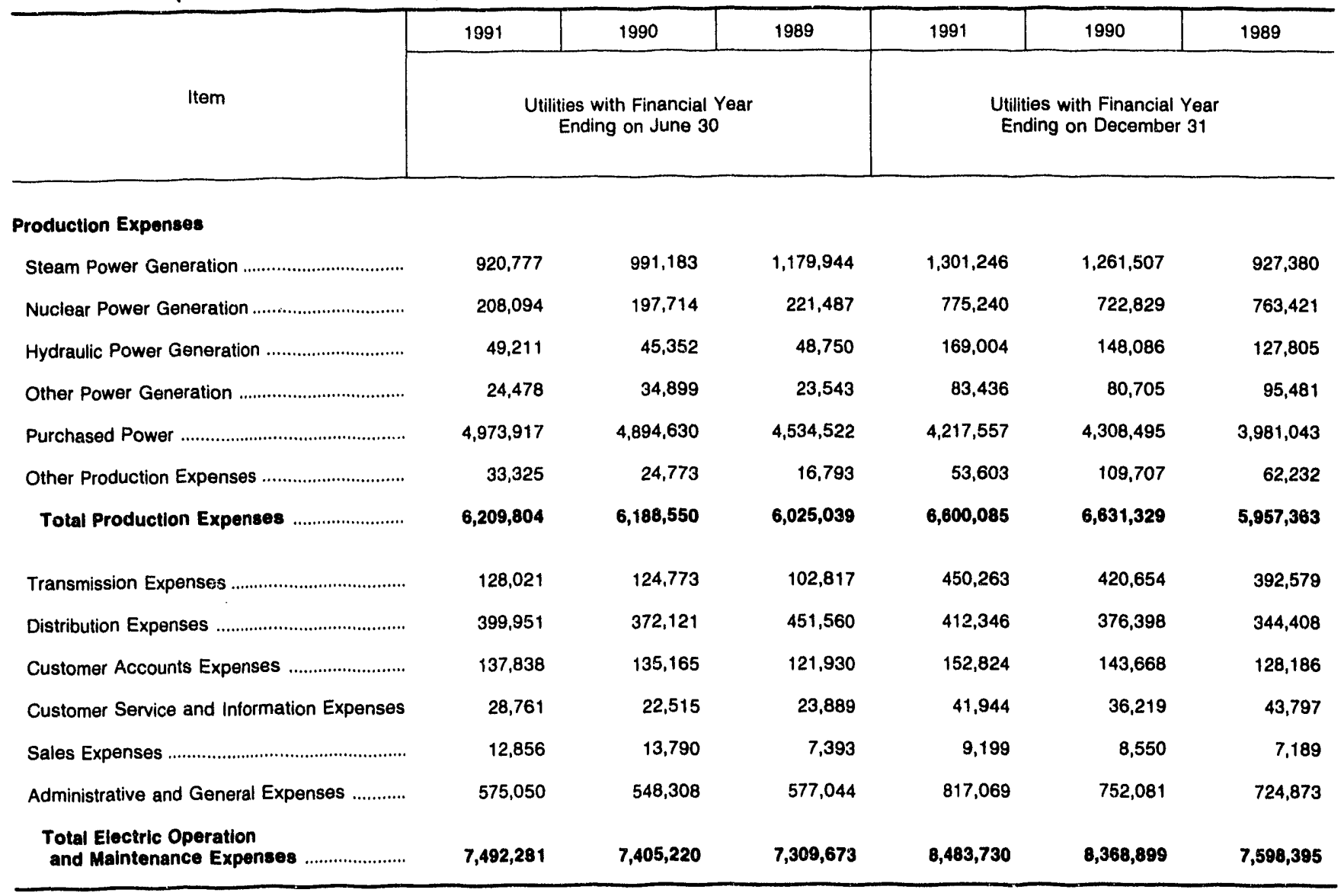

Note: Totals may not equal sum of components because of independent rounding. Detailed data are provided in Table 40 . The number of publicly owned electric utilities for end of period is 188 for June 30,1991; and 188 for June 30, 1990; and 188 for June 30, 1989, and is 196 for December 31,1991; and 194 for December 31, 1990, and 185 for December 31, 1989. The City of Foley (AL) and the South Carolina Public Service Authority changed fiscal year from June 30 to December 31 in 1990 . The Utah Associated Municpal Power System (UT) changed fiscal year from June 30 to March 31 in 1991.

Source: Energy Information Administration, Form EIA-412, "Annual Report of Public Electric Utilities." 
Table C9. Electric Utility Plant for Major Publicly Owned Generating Electric Utilities at End of Period, 1989-1991 (Thousand Dollars)

\begin{tabular}{|c|c|c|c|c|c|c|}
\hline \multirow[b]{2}{*}{ Item } & 1991 & 1990 & 1989 & 1991 & 1990 & 1989 \\
\hline & \multicolumn{3}{|c|}{$\begin{array}{l}\text { Generating Utilities with Financial Year } \\
\text { Ending on June } 30\end{array}$} & \multicolumn{3}{|c|}{$\begin{array}{c}\text { Generating Utilities with Financial Year } \\
\text { Ending on December } 31\end{array}$} \\
\hline \multicolumn{7}{|l|}{ Electric Plant in Service } \\
\hline 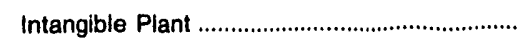 & 141,438 & 83,135 & 172,037 & 174,390 & 200,738 & 164,453 \\
\hline \multicolumn{7}{|l|}{ Production Plant } \\
\hline Steam & $5,889,946$ & $5,789,325$ & $6,525,633$ & $8,854,453$ & $7,992,646$ & $6,654,141$ \\
\hline Nuclear & $4,859,875$ & $4,857,227$ & $5,274,101$ & $9,494,275$ & $8,966,077$ & $8,028,487$ \\
\hline 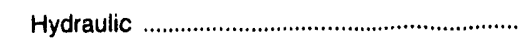 & $1,794,146$ & $1,793,520$ & $1,457,555$ & $4,941,250$ & $4,800,100$ & $4,643,680$ \\
\hline Other & 261,264 & 263,957 & 249,603 & 902,775 & 923,812 & 806,452 \\
\hline Total Production Plant ................................. & $12,805,230$ & $12,704,030$ & $13,506,892$ & $24,192,754$ & $22,682,636$ & $20,132,759$ \\
\hline 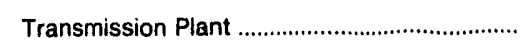 & $2,561,406$ & $2,437,376$ & $2,664,072$ & $4,583,799$ & $4,102,471$ & $3,529,316$ \\
\hline 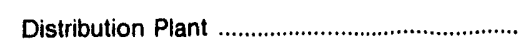 & $6,423,309$ & $5,978,200$ & $5,880,605$ & $6,969,488$ & $6,492,296$ & $5,907,695$ \\
\hline 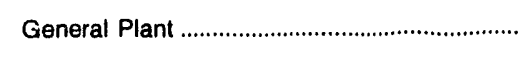 & $1,781,342$ & $1,662,292$ & $1,678,946$ & $2,275,453$ & $2,133,625$ & $1,789,815$ \\
\hline Total Electric Plant in Service .................... & $23,712,725$ & $22,865,034$ & $23,902,551$ & $38,1<5,884$ & $35,611,766$ & $31,524,039$ \\
\hline Electric Plant Leased to Others ....................... & 655 & 1,920 & 1 & 19,219 & 20,240 & 17,189 \\
\hline Construction Work in Progress - Electric ....... & $1,094,383$ & 947,949 & $1,465,319$ & $1,628,089$ & $2,073,987$ & $2,685,112$ \\
\hline Electric Plant Held for Future Use ................... & 267,502 & 269,473 & 53,115 & 106,816 & 95,266 & 245,526 \\
\hline Electric Plant Acquisition Adjustments ............ & 5,308 & 656 & -807 & 381,901 & 623,865 & 468,584 \\
\hline Total Electric Utility Plant ............................. & $25,080,572$ & $24,085,032$ & $25,420,178$ & $40,331,909$ & $38,425,124$ & $34,940,450$ \\
\hline 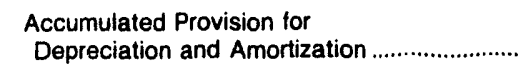 & $6,670,893$ & $5,980,821$ & $5,869,872$ & $11,111,327$ & $10,004,673$ & $8,482,020$ \\
\hline Net Electric Utility Plant ................................. & $18,409,679$ & $18,104,211$ & $19,550,307$ & $29,220,582$ & $28,420,450$ & $26,458,430$ \\
\hline
\end{tabular}

Note: Totals may not equal sum of components because of independent rounding. Detailed data are provided in Table 41 . The number of generating publicly owned electric utilities for end of period is 53 for June 30, 1991; 52 for June 30, 1990; and 50 for June 30, 1989; and is 110 for December 31 , 1991; 110 for December 31, 1990; and 108 for December 31, 1989. The South Carolina Public Service Authority (SC) changed fiscal year from June 30 to December 31 in 1990. The Utah Associated Municipal Power System (UT) changed fiscal year from June 30 to March 31 in 1991 . The City of Marshfield (WI) was a generator in 1989 and 1990, but became a nongenerator in 1991. The Wisconsin Public Power Incorporated System (WI) was a nongenerator in 1989 and 1990, but became a generator in 1991.

Source: Energy Information Administration, Form EIA-412, "Annual Report of Public Electric Utilities." 

Table C10. Number of Consumers, Sales, and Operating Revenue
for Major Publicly Owned Electric Utilities, 1989-1991

\begin{tabular}{|c|c|c|c|c|c|c|}
\hline \multirow[b]{2}{*}{ Item } & 1991 & 1990 & 1989 & 1991 & 1990 & 1989 \\
\hline & \multicolumn{3}{|c|}{$\begin{array}{l}\text { Utilities with Financial Year } \\
\text { Ending on June } 30\end{array}$} & \multicolumn{3}{|c|}{$\begin{array}{l}\text { Utilities with Financial Year } \\
\text { Ending on December } 31\end{array}$} \\
\hline \multicolumn{7}{|l|}{ Number of Consumers } \\
\hline 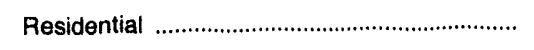 & $4,143,120$ & $4,019,151$ & $4,039,849$ & $3,980,695$ & $3,902,724$ & $3,714,300$ \\
\hline Commercial or Small & 539,016 & 537,243 & 578,509 & 510,434 & 503,394 & 468,112 \\
\hline Industrial or Large & 41,537 & 46,412 & 50,866 & 23,943 & 25,450 & 23,030 \\
\hline Other & 57,392 & 63,780 & 57,136 & 97,167 & 90,445 & 82,853 \\
\hline Total Ultimate Consumers .............................. & $4,781,065$ & $4,666,586$ & $4,726,360$ & $4,612,239$ & $4,522,013$ & $4,288,295$ \\
\hline \multicolumn{7}{|l|}{ Sales for the Year (megawatthours) } \\
\hline 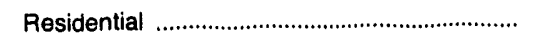 & $38,699,913$ & $38,158,293$ & $38,510,238$ & $45,914,785$ & $43,957,657$ & $41,765,488$ \\
\hline 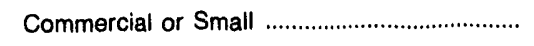 & $31,570,059$ & $31,820,834$ & $30,475,236$ & $33,726,108$ & $32,762,856$ & $30,458,758$ \\
\hline Industrial or Large & $42,461,700$ & $41,546,616$ & $46,959,775$ & $52,891,701$ & $52,339,725$ & $43,019,111$ \\
\hline Other & $3,634,325$ & $3,554,156$ & $3,622,356$ & $13,106,858$ & $12,759,535$ & $12,392,351$ \\
\hline Total Sales to Uitimate Consumers ......... & $116,365,997$ & $115,079,899$ & $119,567,605$ & $145,639,452$ & $141,819,773$ & $127,635,708$ \\
\hline 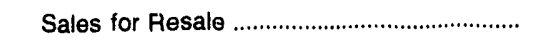 & $35,560,920$ & $40,125,038$ & $45,018,825$ & $131,876,573$ & $132,970,378$ & $120,725,129$ \\
\hline Total Sales & $151,926,917$ & $155,204,937$ & $164,586,430$ & $277,516,025$ & $274,790,151$ & $248,360,837$ \\
\hline \multicolumn{7}{|l|}{$\begin{array}{l}\text { Operating Revenues for the Year } \\
\text { (thousand dollars) }\end{array}$} \\
\hline 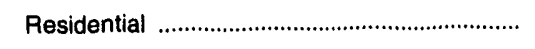 & $2,609,524$ & $2,567,484$ & $2,533,064$ & $2,521,534$ & $2,409,695$ & $2,238,366$ \\
\hline 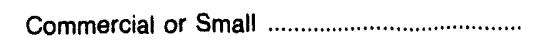 & $2,344,198$ & $2,401,626$ & $2,219,067$ & $1,807,735$ & $1,733,078$ & $1,604,619$ \\
\hline Industrial or Large & $2,377,871$ & $2,308,794$ & $2,503,899$ & $2,035,885$ & $1,995,184$ & $1,651,243$ \\
\hline Other & 246,975 & 261,068 & 245,384 & 819,094 & 821,272 & 782,335 \\
\hline $\begin{array}{l}\text { Total Revenues from Sales to } \\
\text { Ultimate Consumers }\end{array}$ & $7,578,568$ & $7,538,972$ & $7,501,414$ & $7,184,248$ & $6,959,229$ & $6,276,563$ \\
\hline Sales for Resale & $1,893,263$ & $2,074,118$ & $2,099,053$ & $4,482,693$ & $4,525,868$ & $4,085,046$ \\
\hline $\begin{array}{l}\text { Total Revenues From Sales of } \\
\text { Electricity }\end{array}$ & $9,471,831$ & $9,613,090$ & $9,600,467$ & $11,666,941$ & $11,485,097$ & $10,361,609$ \\
\hline
\end{tabular}

Note: Totals may' not equal sum of components because of independent rounding. Detailed data are provided in Table 42 . The number of publicly owned electric utilities for end of period is 188 for June 30, 1991; and 188 for June 30, 1990; and 188 for June 30 , 1989, and is 196 for December 31 , 1991; and 194 for December 31, 1990, and 185 for December 31, 1989. The City of Foley (AL) and the South Carolina Public Service Authority changed fiscal year trom June 30 to December 31 in 1990 . The Utah Associated Municpal Power System (UT) changed fiscal year from June 30 to March 31 in 1991.

Source: Energy Information Administration, Form ElA-861, "Annual Electric Utility Report." Data are based on calender year submissions. 
Table C11. Electric Energy Account for Major Publicly Owned Electric Utilities, 1989-1991 (Megawatthours)

\begin{tabular}{|c|c|c|c|c|c|c|}
\hline \multirow[b]{2}{*}{ Item } & 1991 & 1990 & 1989 & 1991 & 1990 & 1989 \\
\hline & \multicolumn{3}{|c|}{$\begin{array}{l}\text { Utilities with Financial Year } \\
\text { Ending on June } 30\end{array}$} & \multicolumn{3}{|c|}{$\begin{array}{l}\text { Utilities with Financial Year } \\
\text { Ending on December } 31\end{array}$} \\
\hline \multicolumn{7}{|l|}{ Sources of Energy } \\
\hline 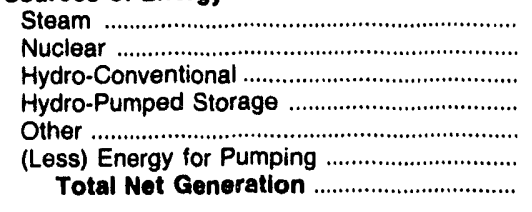 & $\begin{array}{r}35,805,972 \\
9,571,421 \\
5,277,435 \\
1,247,928 \\
777,690 \\
720,925 \\
\mathbf{5 1 , 9 5 9 , 5 2 2}\end{array}$ & $\begin{array}{r}38,852,538 \\
8,156,114 \\
6,663,865 \\
1,158,727 \\
819,236 \\
494,296 \\
55,156,184\end{array}$ & $\begin{array}{r}56,925,918 \\
10,739,246 \\
7,572,745 \\
1,010,187 \\
609,282 \\
608,410 \\
76,248,968\end{array}$ & $\begin{array}{r}66,891,679 \\
36,462,063 \\
67,268,340 \\
2,364,088 \\
1,302,950 \\
2,942,457 \\
171,346,662\end{array}$ & $\begin{array}{r}68,121,001 \\
34,561,351 \\
67,433,345 \\
3,537,783 \\
\text { R } 1,316,570 \\
2,983,818 \\
171,986,234\end{array}$ & $\begin{array}{r}53,992,803 \\
36,125,796 \\
60,581,382 \\
3,048,854 \\
1,374,343 \\
2,995,236 \\
152,127,942\end{array}$ \\
\hline 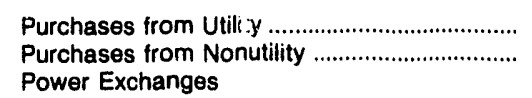 & $\begin{array}{r}111,902,547 \\
62,411\end{array}$ & $\begin{array}{r}109,978,279 \\
56,689\end{array}$ & $\begin{array}{r}98,381,426 \\
4,188\end{array}$ & $\begin{array}{r}122,415,592 \\
1,243,589\end{array}$ & $\begin{array}{r}122,675,530 \\
870,205\end{array}$ & $\begin{array}{r}113,779,308 \\
781,338\end{array}$ \\
\hline 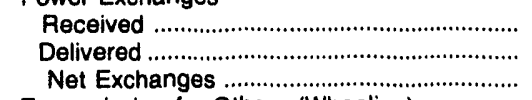 & $\begin{array}{r}1,748,125 \\
1,807,581 \\
-59,456\end{array}$ & $\begin{array}{r}18,533,936 \\
18,905,883 \\
-371,947\end{array}$ & $\begin{array}{r}2,518,919 \\
2,103,502 \\
415,417\end{array}$ & $\begin{array}{l}15,653,059 \\
18,621,419 \\
-2,968,359\end{array}$ & $\begin{array}{r}14,690,002 \\
16,432,066 \\
-1,742,065\end{array}$ & $\begin{array}{r}16,324,258 \\
16,968,847 \\
-644,591\end{array}$ \\
\hline \multicolumn{7}{|l|}{ Transmission for Others (Wheeling) } \\
\hline 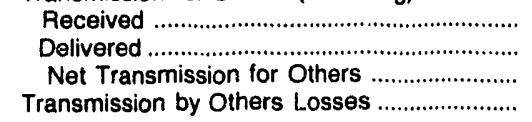 & $\begin{array}{r}17,569,869 \\
17,509,416 \\
60,453 \\
-130,869\end{array}$ & $\begin{array}{r}16,146,595 \\
16,005,354 \\
141,241 \\
-49,401\end{array}$ & $\begin{array}{r}22,123,228 \\
21,842,800 \\
280,428 \\
-\end{array}$ & $\begin{array}{r}6,464,516 \\
6,328,228 \\
136,287 \\
-12,108\end{array}$ & $\begin{array}{r}12,330,712 \\
12,212,372 \\
118,339 \\
8-16,107\end{array}$ & $\begin{array}{r}5,175,148 \\
5,081,377 \\
93,771 \\
\end{array}$ \\
\hline 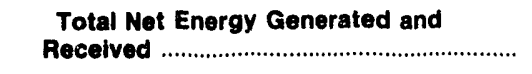 & $163,794,608$ & ' $164,911,045$ & $175,330,426$ & $292,161,665$ & ค $293,892,135$ & $266,138,373$ \\
\hline 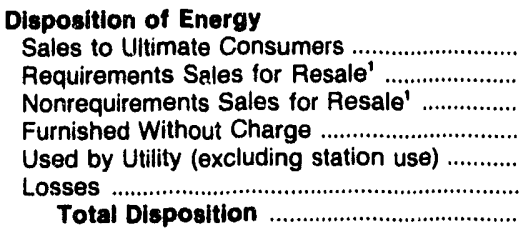 & $\begin{array}{r}115,880,574 \\
36,636,265 \\
759,838 \\
247,448 \\
2,718,543 \\
7,551,947 \\
163,794,608\end{array}$ & $\begin{array}{r}114,266,097 \\
38,498,373 \\
1,695,756 \\
110,391 \\
2,684,302 \\
7,656,116 \\
\text { A } 164,911,045\end{array}$ & $\begin{array}{r}119,199,785 \\
44,301,096 \\
- \\
257,945 \\
3,220,333 \\
8,351,275 \\
175,330,426\end{array}$ & $\begin{array}{r}145,765,861 \\
106,501,669 \\
25,251,945 \\
1,378,601 \\
4,847,668 \\
8,415,911 \\
292,161,665\end{array}$ & $\begin{array}{r}\text { A } 141,841,280 \\
\text { A } 105,486,542 \\
27,484,047 \\
1,560,974 \\
8,934,448 \\
8,584,831 \\
\text { R } 293,892,135\end{array}$ & $\begin{array}{r}127,577,808 \\
120,733,706 \\
- \\
1,478,778 \\
8,021,995 \\
8,326,068 \\
266,138,373\end{array}$ \\
\hline
\end{tabular}

1 The 1989 data were reported as Sales for Resale (one entry) which is shown as Requirements Sales for Resale. $R=$ Revised data.

Note: Totals may not equal sum of components because of independent rounding. Detailed data are provided in Table 43 . The number of publicly owned electric utilities for end of period is 188 for June 30, 1991; and 188 for June 30, 1990; and 188 for June 30,1989 , and is 196 for December 31 , 1991; and 194 for December 31, 1990, and 185 for December 31, 1989. The City of Foley (AL) and the South Carolina Public Service Authority changed fiscal year from June 30 to December 31 in 1990 . The Utah Associated Municpal Power System (UT) changed fiscal year from June 30 to March 31 in 1991. Double counting occurs in components of both sources and disposition of energy and thus neither provides a true total. Purchases from utilities, net exchanges, and net wheeling (except for imports) are included in net generation. Sales for resale is included in sales to ultimate consumers.

Source: Energy Information Administration, Form ElA-412, "Annual Report of Public Electric Utilities." 


\section{Financial Performance for All Respondents}

Summary financial statistics are provid d for the publicly owned electric utilities for all respondents. These statistics include 470 electric utilities for 1991; 467 electric utilities for 1990; and 454 electric utilities for 1989. The publicly owned electric utilities added to and deleted from the survey are contained in Appendix B.

Major publicly owned electric utilities require over $\$ 3$ of investment to obtain $\$ 1$ in revenue. Electric operation and maintenance expenses averaged 71.5 percent of electric utility operating revenues during the years 1989 through 1991. Interest on long-term debt as a percent of electric utility operating revenues averaged 17.3 percent over the same 3 years (Table C20).

\section{Income Statement}

Total publicly owned electric utility operating revenues increased 2.7 percent, to $\$ 28,202.7$ million in 1991 , compared with a 6.3 percent increase 1990 . Total electric utility operating expenses increased 2.3 percent, to $\$ 23,746.5$ million, compared with 5.1 percent in 1990 . Operation and maintenance expenses of $\$ 19,907.0 \mathrm{mil}$ lion, up 1.4 percent over the prior year, represented 83.8 percent of total electric utility operating expenses.

Because revenue gains outstripped expense increases, total electric utility operating income increased 4.8 percent in 1991 , to $\$ 4,465.4$ million, up from $\$ 4,260.9$ million in 1990. Interest expenses on long-term debt were up 2.4 percent despite a 4.1 percent increase in debt outstanding. This occurred because the average cost of debt (using end-of-fiscal-year balances) decreased from 7.11 percent in 1990 to 6.97 percent in 1991. Total net income iuse to $\$ 1,017.6$ million, up from $\$ 950.8$ million in 1990 , and $\$ 385.8$ million in 1989 (Table C18).

\section{Balance Sheet}

Total assets and other debits grew 4.0 percent in 1991, to $\$ 112,043.4$ millic 1 , compared with 4.5 percent in 1990. The leading cause was a 9.2 percent increase in other property and investments, represented 37.1 percent of the increase in total assets and other debits between 1990 and 1991 . Net electric utility plant increased $\$ 1,395.8$ million, to $\$ 65,399.8$ million or 2.2 percent, accounted for 32.2 percent of the increase in total assets and other debits.
Total capitalization (investment and surplus plus longterm debt) increased $\$ 3,346.8$ million or 3.5 percent, reaching $\$ 98,880.9$ million in 1991. A large part of the increase was the result of adding $\$ 2,551.1$ million in long-term debt, raising debt's share of total capitalization to 72.2 percent in 1991, versus 72.1 percent in 1990 and 71.7 percent in 1989. The ratio of long-term debt to total assets and other debits decreased slightly from 63.9 for 1990 to 63.7 for 1991 (Table C19).

\section{Sales of Electric Power}

In 1991, total sales to ultimate consumers grew 6.5 million megawatthours or 1.9 percent over 1990 . However, this growth was less than the 13.5 million megawatthours or 4.2 percent increase that occurred in 1990 over 1989. Much of the increase between 1989 and 1990 can be attributed to the increase in the number of respondents. Revenues collected from the sales to ultimate consumers grew $\$ 320.2$ million or 1.6 percent over 1990 , compared with the $\$ 1,005.5$ million or 5.4 percent increase in revenues from 1990 over 1989. Despite the smaller increases in both energy sales and revenues in 1991 over 1990 as compared with the increases in 1940 over 1989, the average revenue per kilowatthour for 1991, 1990 and 1989 remained a constant 5.8 cents per kilowatthour.

Sales for resale decreased by 2.5 percent in 1991 from the prior year. Average revenue per kilowatthour was essentially unchanged and produced revenues that were down 2.4 percent from 1990 (Table C23).

\section{Generation and Purchased Power}

Total net energy generated and received decreased 0.1 percent to 566.6 million megawatthours in 1991. The biggest change in the source of generation was nuclear generation, which was up 13.8 percent from 1990 and approached the level achieved in 1989. Steam generation continued to represent the highest rercentage of total net generation, 55.1 percent in 1991 and 56.3 percent in 1990. Conventional hydroelectric power generation represented 24.6 percent of total net generation for these electric utilities, substantially more than the 13.0 percent contribution industry-wide.

In 1991, total purchased power continued to play a major role in meeting the power requirements of publicly owned electric utilities, contributed 47.8 percent of the total net generated and received megawatthours. Total purchased power from utilities and nonutilities in 1991 was 271.0 million megawatthours (Table C24). 


\section{Table C12. Ten Largest Publicly Owned Electric Utilities Ranked by Megawatthour Sales to Ultimate Consumers for All Respondents, 1991}

\begin{tabular}{|c|c|c|c|}
\hline Publicly Owned Electric Utilities & State & Amount & Percent \\
\hline 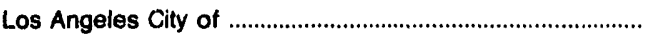 & CA & $21,803,360$ & 6.35 \\
\hline Salt River Proj Ag I \& P Dist & $A Z$ & $14,591,965$ & 4.25 \\
\hline Power Authority of State of NY & NY & $13,326,360$ & 3.88 \\
\hline San Antonio City of & $T X$ & $11,634,855$ & 3.39 \\
\hline Memphis City of & TN & $11,451,824$ & 3.33 \\
\hline 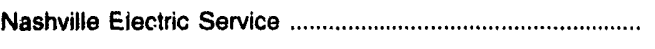 & TN & $9,742,817$ & 2.84 \\
\hline 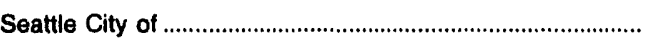 & WA & $8,832,638$ & 2.57 \\
\hline 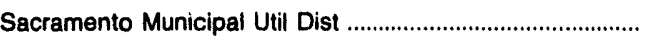 & CA & $8,421,441$ & 2.45 \\
\hline 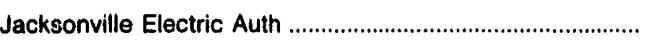 & FL & $7,751,649$ & 2.26 \\
\hline 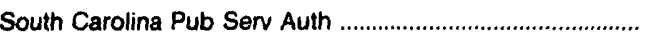 & SC & $7,508,723$ & 2.19 \\
\hline Subtotal & & $115,065,632$ & 33.49 \\
\hline
\end{tabular}

Note: Percentage calculations are based on total Form EIA-412 respondents.

Source: Energy Information Administration, Form EIA-412, "Annual Report of Public Electric Utilities." Individual electric utilities report fiscal year data. Appendix $B$ shows the tiscal year for each electric utility.

\section{Table C13. Ten Largest Publicly Owned Electric Utilities Ranked by} Megawatthour Sales for Resale for All Respondents, 1991

\begin{tabular}{|c|c|c|c|}
\hline Publicly Owned Electric Utilities & State & Amount & Percent \\
\hline Power Authority of State of NY & NY & $22,905,668$ & 11.91 \\
\hline 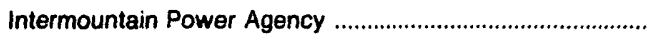 & UT & $10,750,184$ & 5.59 \\
\hline 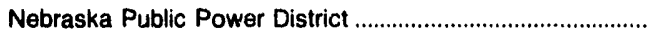 & NE & $10,550,435$ & 5.48 \\
\hline 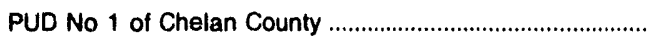 & WA & $10,354,989$ & 5.38 \\
\hline 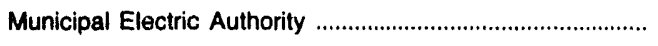 & GA & $9,312,381$ & 4.84 \\
\hline 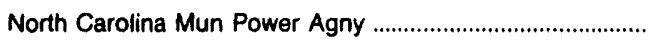 & NC & $8,022,722$ & 4.17 \\
\hline 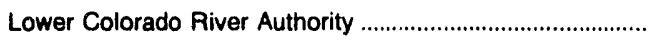 & $T X$ & $7,822,764$ & 4.07 \\
\hline PUD No 2 of Grant County & WA & $7,326,020$ & 3.81 \\
\hline South Carolina Pub Serv Auth & SC & $6,088,552$ & 3.16 \\
\hline North Carolina Eastern M P A & NC & $5,962,319$ & 3.10 \\
\hline Subtotal & & $99,096,034$ & 51.51 \\
\hline
\end{tabular}

Note: Percentage calculations are based on total Form ElA-412 respondents

Source: Energy Information Administration, Form EIA-412, "Annual Report of Public Electric Utilities." Individual electric utilities report fiscal year data. Appendix $B$ shows the fiscal year for each electric utility. 


\section{Table C14. Twenty Largest Publicly Owned Electric Utilities Ranked by Electric Utility Revenues, 1991 (Thousand Dollars)}

\begin{tabular}{|c|c|c|c|}
\hline Publicly Owned Electric Utilities & State & Amount & Reporting Date \\
\hline $\begin{array}{l}\text { Los Angeles City of } \\
\text { Power Authority of State of NY } \\
\text { Salt Piver Proj Ag I \& P Dist } \\
\text { San Antonio City of } \\
\text { Nebraska Public Power District }\end{array}$ & $\begin{array}{l}\text { CA } \\
N Y \\
A Z \\
T X \\
N E\end{array}$ & $\begin{array}{r}1,811,955 \\
1,194,226 \\
1,149,503 \\
675,180 \\
674,527\end{array}$ & $\begin{array}{c}\text { June } 30 \\
\text { December } 31 \\
\text { April } 30 \\
\text { January } 31 \\
\text { December } 31\end{array}$ \\
\hline 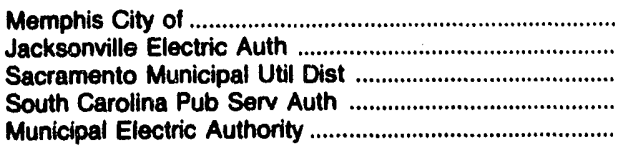 & $\begin{array}{l}\text { TN } \\
\text { FL } \\
\text { CA } \\
\text { SC } \\
\text { GA }\end{array}$ & $\begin{array}{l}657,033 \\
651,219 \\
644,393 \\
562,578 \\
550,841\end{array}$ & $\begin{array}{l}\text { December } 31 \\
\text { September } 30 \\
\text { December } 31 \\
\text { December } 31 \\
\text { December } 31\end{array}$ \\
\hline $\begin{array}{l}\text { Intermountain Power Agency } \\
\text { Neshville Electric Service } \\
\text { Washington Pub Pwr Supply Sys } \\
\text { North Carolina Mun Power Agny } \\
\text { Austin City of }\end{array}$ & $\begin{array}{l}\text { UT } \\
\text { TN } \\
\text { WA } \\
\text { NC } \\
\text { TX }\end{array}$ & $\begin{array}{l}534,254 \\
533,702 \\
533,027 \\
438,810 \\
422,466\end{array}$ & $\begin{array}{c}\text { June } 30 \\
\text { June } 30 \\
\text { June } 30 \\
\text { December } 31 \\
\text { September } 30\end{array}$ \\
\hline $\begin{array}{l}\text { North Carolina Eastern M P A } \\
\text { Omaha Public Power District } \\
\text { Lower Colorado River Authority . } \\
\text { Ortando Utilities Comm } \\
\text { Seattle City of }\end{array}$ & $\begin{array}{l}\text { NC } \\
\text { NE } \\
\text { TX } \\
\text { FL } \\
\text { WA }\end{array}$ & $\begin{array}{l}398,000 \\
381,959 \\
321,567 \\
289,962 \\
283,386\end{array}$ & $\begin{array}{c}\text { December } 31 \\
\text { December } 31 \\
\text { June } 30 \\
\text { September } 30 \\
\text { December } 31\end{array}$ \\
\hline
\end{tabular}

Source: Energy Information Administration, Form ElA-412, "Annual Report of Public Electric Utilities." Individual electric utilities report fiscal year data. Appendix B shows the fiscal year for each electric utility.

\section{Table C15. Twenty Largest Publicly Owned Electric Utilities Ranked by Purchase Power Expenses, 1991 (Thousand Dollars)}

\begin{tabular}{|c|c|c|c|}
\hline Publlcly Owned Electric Utillities & State & Amount & Reporting Date \\
\hline 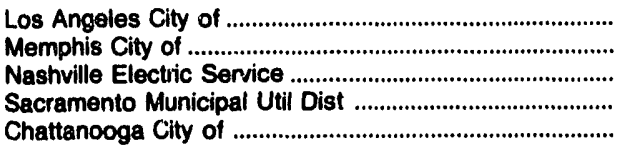 & $\begin{array}{l}\text { CA } \\
\text { TN } \\
\text { TN } \\
\text { CA } \\
\text { TN }\end{array}$ & $\begin{array}{l}664,389 \\
511,167 \\
441,119 \\
316,915 \\
230,583\end{array}$ & $\begin{array}{l}\text { June } 30 \\
\text { December } 31 \\
\text { June } 30 \\
\text { December } 31 \\
\text { June } 30\end{array}$ \\
\hline 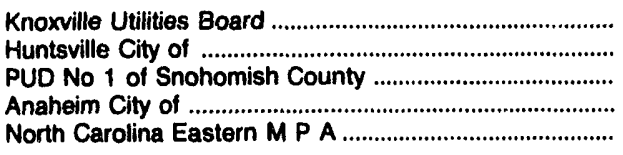 & $\begin{array}{l}\text { TN } \\
\text { AL } \\
\text { WA } \\
\text { CA } \\
\text { NC }\end{array}$ & $\begin{array}{l}204,054 \\
160,607 \\
133,371 \\
127,730 \\
122,018\end{array}$ & $\begin{array}{c}\text { June } 30 \\
\text { September } 30 \\
\text { December } 31 \\
\text { June } 30 \\
\text { December } 31\end{array}$ \\
\hline 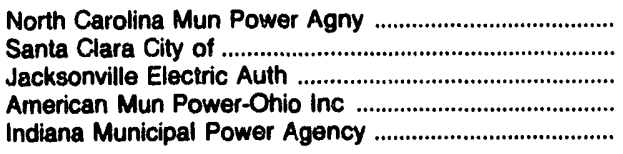 & $\begin{array}{l}\text { NC } \\
\text { CA } \\
\text { FL } \\
\text { OH } \\
\text { IN }\end{array}$ & $\begin{array}{r}121,469 \\
114,037 \\
102,791 \\
99,832 \\
99,254\end{array}$ & $\begin{array}{l}\text { December } 31 \\
\text { June } 30 \\
\text { September } 30 \\
\text { December } 31 \\
\text { December } 31\end{array}$ \\
\hline 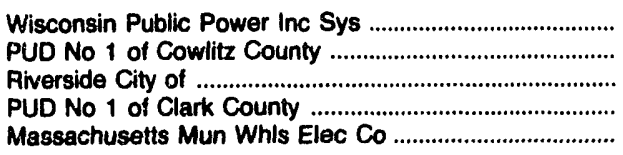 & $\begin{array}{l}\text { WI } \\
\text { WA } \\
\text { CA } \\
\text { WA } \\
\text { MA }\end{array}$ & $\begin{array}{l}92,468 \\
87,951 \\
78,483 \\
76,373 \\
76,351\end{array}$ & $\begin{array}{c}\text { June } 30 \\
\text { December } 31 \\
\text { June } 30 \\
\text { December } 31 \\
\text { December } 31\end{array}$ \\
\hline
\end{tabular}

Source: Energy Information Administration, Form EIA-412, "Annual Report of Public Electric Utilities." Individual electric utilities report fiscal year data. Appendix B shows the fiscal year for each electric utility. 
Table C16. Twenty Largest Publicly Owned Electric Utilities Ranked by Electric Utility Plant, 1991

(Thousand Dollars)

\begin{tabular}{|c|c|c|c|}
\hline Publicly Owned Electric Utillties & State & Amount & Reporting Date \\
\hline $\begin{array}{l}\text { Los Angeles City of } \ldots . . . . . . \\
\text { Salt River Proj Ag I \& Dist . } \\
\text { Power Authority of State of NY } \\
\text { San Antonio City of } \\
\text { Washington Pub Pwr Supply Sys }\end{array}$ & $\begin{array}{l}\text { CA } \\
\text { AZ } \\
\text { NY } \\
\text { TX } \\
\text { WA }\end{array}$ & $\begin{array}{l}5,676,169 \\
5,439,779 \\
5,144,414 \\
4,537,196 \\
3,624,781\end{array}$ & $\begin{array}{c}\text { June } 30 \\
\text { April } 30 \\
\text { December } 31 \\
\text { January } 31 \\
\text { June } 30\end{array}$ \\
\hline 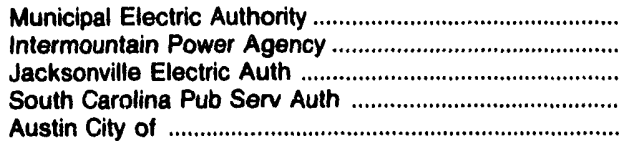 & $\begin{array}{l}\text { GA } \\
\text { UT } \\
\text { FL } \\
\text { SC } \\
\text { TX }\end{array}$ & $\begin{array}{l}3,160,373 \\
2,805,914 \\
2,716,243 \\
2,542,281 \\
2,101,600\end{array}$ & $\begin{array}{l}\text { December } 31 \\
\text { June } 30 \\
\text { September } 30 \\
\text { December } 31 \\
\text { September } 30\end{array}$ \\
\hline 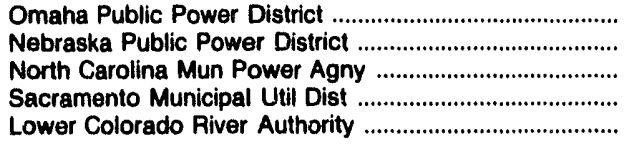 & $\begin{array}{l}\text { NE } \\
\text { NE } \\
\text { NC } \\
\text { CA } \\
\text { TX }\end{array}$ & $\begin{array}{l}2,062,520 \\
1,896,023 \\
1,646,112 \\
1,497,699 \\
1,419,409\end{array}$ & $\begin{array}{c}\text { December } 31 \\
\text { December } 31 \\
\text { December } 31 \\
\text { December } 31 \\
\text { June } 30\end{array}$ \\
\hline 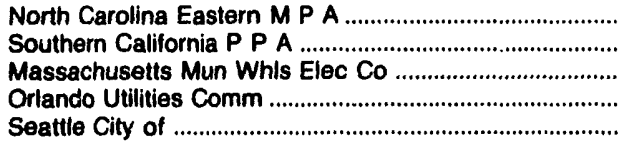 & $\begin{array}{l}\text { NC } \\
\text { CA } \\
\text { MA } \\
\text { FL } \\
\text { WA }\end{array}$ & $\begin{array}{l}1,392,020 \\
1,343,667 \\
1,291,556 \\
1,182,267 \\
1,175,644\end{array}$ & $\begin{array}{l}\text { December } 31 \\
\text { June } 30 \\
\text { December } 31 \\
\text { September } 30 \\
\text { December } 31\end{array}$ \\
\hline
\end{tabular}

Source: Energy Information Administration, Form ElA-412, "Annual Report of Public Electric Utilities." Individual electric utilities report fiscal year data. Appendix $B$ shows the fiscal year for each electric utility.

\section{Table C17. Twenty Largest Publicly Owned Electric Utilities Ranked by Construction Work in Progress, 1991 (Thousand Dollars)}

\begin{tabular}{|c|c|c|c|}
\hline Publicly Owned Electric Utilities & State & Amount & Reporting Date \\
\hline 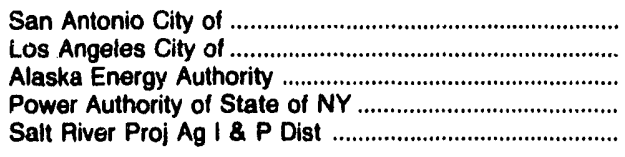 & $\begin{array}{l}\text { TX } \\
\text { CA } \\
\text { AK } \\
\text { NY } \\
\text { AZ }\end{array}$ & $\begin{array}{l}455,905 \\
278,947 \\
271,490 \\
231,176 \\
206,819\end{array}$ & $\begin{array}{c}\text { January } 31 \\
\text { June } 30 \\
\text { June } 30 \\
\text { December } 31 \\
\text { April } 30\end{array}$ \\
\hline 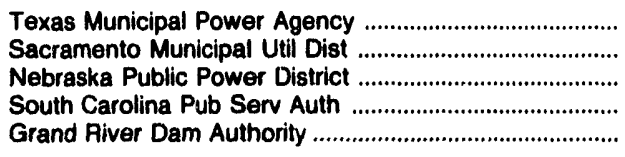 & $\begin{array}{l}\text { TX } \\
\text { CA } \\
\text { NE } \\
\text { SC } \\
\text { OK }\end{array}$ & $\begin{array}{l}202,648 \\
162,347 \\
154,475 \\
150,649 \\
130,748\end{array}$ & $\begin{array}{l}\text { September } 30 \\
\text { December } 31 \\
\text { December } 31 \\
\text { December } 31 \\
\text { December } 31\end{array}$ \\
\hline 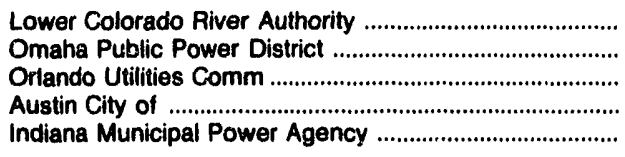 & $\begin{array}{l}\text { TX } \\
\text { NE } \\
\text { FL } \\
\text { TX } \\
\text { IN }\end{array}$ & $\begin{array}{r}107,201 \\
95,583 \\
76,013 \\
67,445 \\
65,500\end{array}$ & $\begin{array}{l}\text { June } 30 \\
\text { December } 31 \\
\text { September } 30 \\
\text { September } 30 \\
\text { December } 31\end{array}$ \\
\hline 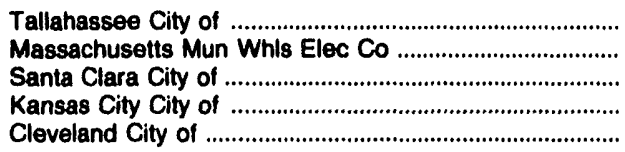 & $\begin{array}{l}\text { FL } \\
\text { MA } \\
\text { KA } \\
\text { OH }\end{array}$ & $\begin{array}{l}61,218 \\
61,207 \\
59,599 \\
56,688 \\
54,350\end{array}$ & $\begin{array}{l}\text { Septemiber } 30 \\
\text { December } 31 \\
\text { June } 30 \\
\text { December } 31 \\
\text { December } 31\end{array}$ \\
\hline
\end{tabular}

Source: Energy Information Administration, Form EIA-412, "Annual Report of Public Electric Utilities." Individual electric utilities report fiscal year data. Appendix B shows the fiscal year for each electric utility. 
Table C18. Composite Statement of Income for Major Publicly Owned Electric Utilities for All Respondents, 1989-1991 (Thousand Dollars)

\begin{tabular}{|c|c|c|c|}
\hline Item & 1991 & 1990 & 1989 \\
\hline Electric Utifity Operating Revenues ....................... & $28,202,745$ & $27,449,123$ & $25,814,644$ \\
\hline 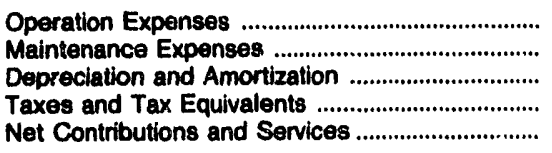 & $\begin{array}{r}18,274,460 \\
1,632,563 \\
2,547,126 \\
734,209 \\
558,182\end{array}$ & $\begin{array}{r}17,978,112 \\
1,647,407 \\
2,306,792 \\
683,167 \\
586,148\end{array}$ & $\begin{array}{r}17,003,962 \\
1,668,932 \\
2,251,638 \\
624,584 \\
526,596\end{array}$ \\
\hline Total Electric Utility Operating Expenses .... & $.23,746,541$ & $23,201,628$ & $22,075,712$ \\
\hline 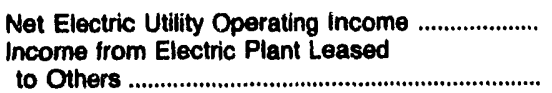 & $\begin{array}{r}4,456,204 \\
9,207\end{array}$ & $\begin{array}{r}4,247,497 \\
13,452\end{array}$ & $\begin{array}{r}3,738,832 \\
7,052\end{array}$ \\
\hline Total Electric Utility Operating Income ........ & $4,465,411$ & $4,260,949$ & $3,745,884$ \\
\hline Other Income Net & $2,037,255$ & $1,889,347$ & $1,909,736$ \\
\hline 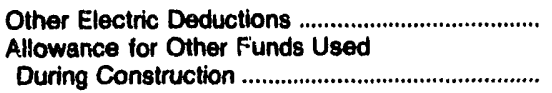 & 137,294 & 123,069 & 231,694 \\
\hline 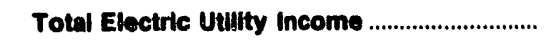 & $6,438,004$ & $6,273,365$ & $5,887,314$ \\
\hline 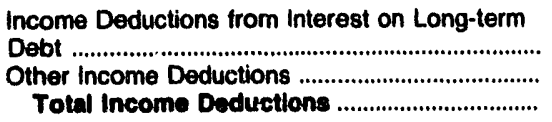 & $\begin{array}{r}4,887,034 \\
458,570 \\
5,345,605\end{array}$ & $\begin{array}{r}4,773,086 \\
429,161 \\
5,202,247\end{array}$ & $\begin{array}{r}4,439,431 \\
423,163 \\
4,862,594\end{array}$ \\
\hline 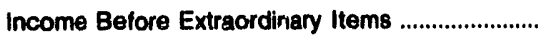 & $1,092,399$ & $1,071,118$ & $1,024,721$ \\
\hline 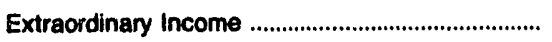 & 123.504 & 141,966 & 87,059 \\
\hline 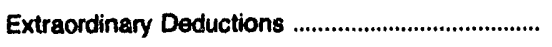 & 198,300 & 262,239 & 725,970 \\
\hline Not Income & $1,017,603$ & 950,845 & ' 385,809 \\
\hline
\end{tabular}

- Data not available.

1 Net income reflects $\$ 584$ million of extraordinary deduction associated with the abandonment of the Rancho Seco Nuclear Plant reported by the Sacramento Municipal Utility District.

Note: Totals may not equal sum of components because of independent rounding. Detailed data are provided in Table 38 . The number of publicly owned electric utilities for end of period is 470 for 1991, 467 for 1990, and 454 for 1989.

Source: Energy Information Administration, Form EIA-412, "Annual Report of Public Electric Utilities." Individual electric utilities report fiscal year data. Appendix B shows the fiscal year for each electric utility. 


\section{Table C19. Composite Balance Sheet for Major Publicly Owned Electric Utilities for All Respondents at End of Period, 1989-1991 (Thousand Dollars)}

\begin{tabular}{|c|c|c|c|}
\hline Item & 1991 & 1990 & 1989 \\
\hline \multicolumn{4}{|l|}{ Electric Utility Plant } \\
\hline 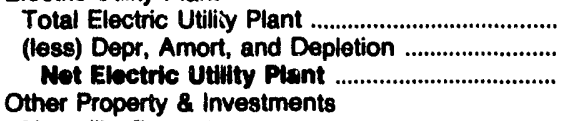 & $\begin{array}{l}88,854,231 \\
23,454,394 \\
65,399,837\end{array}$ & $\begin{array}{l}85,106,027 \\
21,101,985 \\
\mathbf{6 4 , 0 0 4 , 0 3 2}\end{array}$ & $\begin{array}{l}81,009,708 \\
18,572,145 \\
62,437,683\end{array}$ \\
\hline 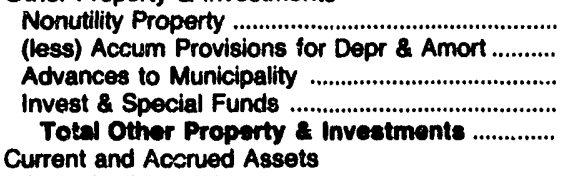 & $\begin{array}{r}6,069,837 \\
1,840,621 \\
87,717 \\
14,865,256 \\
19,182,188\end{array}$ & $\begin{array}{r}5,578,256 \\
1,712,103 \\
81,471 \\
13,624,271 \\
17,571,804\end{array}$ & $\begin{array}{r}5,335,765 \\
1,624,556 \\
70,790 \\
12,965,817 \\
16,747,815\end{array}$ \\
\hline 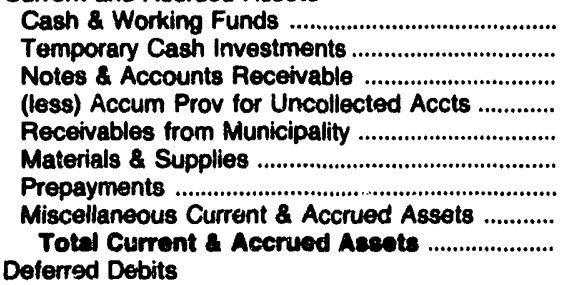 & $\begin{array}{r}3,706,127 \\
6,722,416 \\
2,878,917 \\
114,245 \\
186,491 \\
1,796,964 \\
377,684 \\
692,469 \\
16,246,822\end{array}$ & $\begin{array}{r}3,390,549 \\
6,925,082 \\
2,922,393 \\
104,326 \\
331,679 \\
1,620,700 \\
321,876 \\
523,141 \\
15,831,093\end{array}$ & $\begin{array}{r}2,974,509 \\
6,504,345 \\
2,808,066 \\
100,219 \\
305,657 \\
1,555,731 \\
240,698 \\
610,942 \\
14,899,730\end{array}$ \\
\hline 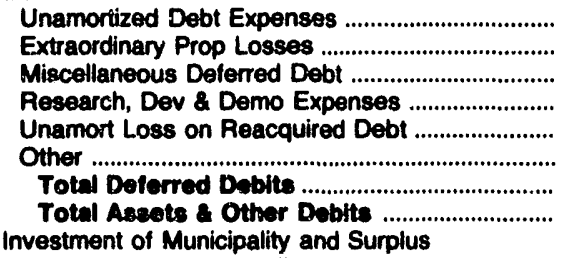 & $\begin{array}{r}1,809,159 \\
34,360 \\
4,394,314 \\
30,860 \\
2,251,996 \\
2,593,812 \\
11,214,601 \\
112,043,449\end{array}$ & $\begin{array}{r}1,830,959 \\
31,911 \\
3,695,866 \\
11,631 \\
2,306,990 \\
2,320,789 \\
10,189,147 \\
107,705,188\end{array}$ & $\begin{array}{r}1,857,147 \\
33,146 \\
3,121,891 \\
8,666 \\
2,087,777 \\
1,870,212 \\
8,878,840 \\
103,083,940\end{array}$ \\
\hline 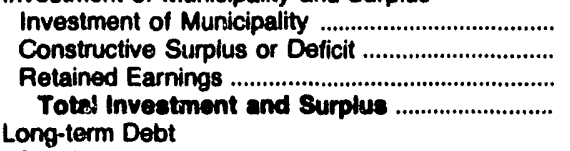 & $\begin{array}{r}2,089,179 \\
452,305 \\
24,925,509 \\
27,466,993\end{array}$ & $\begin{array}{r}1,801,842 \\
445,306 \\
24,328,102 \\
26,675,251\end{array}$ & $\begin{array}{r}1,946,296 \\
657,259 \\
23,121,259 \\
25,724,815\end{array}$ \\
\hline 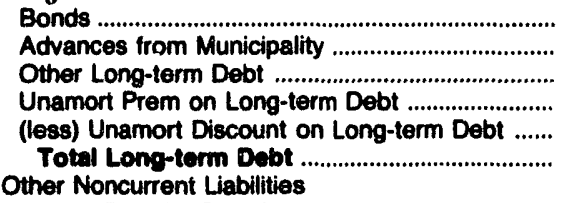 & $\begin{array}{r}70,415,936 \\
107,952 \\
3,473,671 \\
15,850 \\
2,599,459 \\
\mathbf{7 1 , 4 1 3 , 9 5 1}\end{array}$ & $\begin{array}{r}67,432,594 \\
313,989 \\
3,565,979 \\
1,468 \\
2,455,142 \\
68,858,890\end{array}$ & $\begin{array}{r}63,852,226 \\
127,769 \\
3,572,974 \\
3,134 \\
2,237,748 \\
65,318,358\end{array}$ \\
\hline 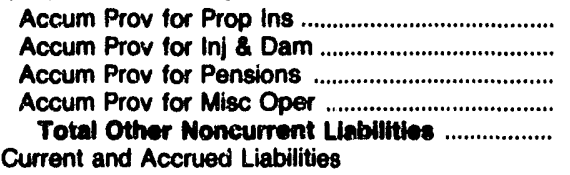 & $\begin{array}{r}21,678 \\
40,301 \\
91,267 \\
524,749 \\
677,995\end{array}$ & $\begin{array}{r}24,115 \\
30,877 \\
51,984 \\
366,751 \\
473,827\end{array}$ & $\begin{array}{r}17,035 \\
26,749 \\
50,604 \\
347,852 \\
442,239\end{array}$ \\
\hline 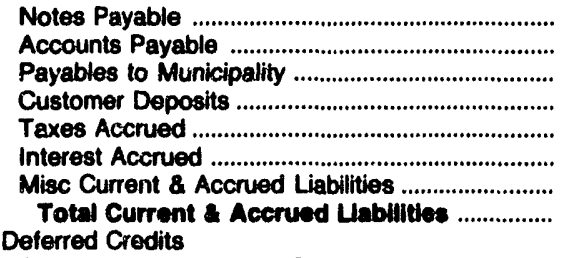 & $\begin{array}{r}1,234,282 \\
2,437,591 \\
269,323 \\
384,587 \\
285,651 \\
1,549,877 \\
2,642,284 \\
\mathbf{8 , 8 1 3 , 5 9 4}\end{array}$ & $\begin{array}{r}1,041,608 \\
2,505,401 \\
252,383 \\
326,546 \\
249,297 \\
1,472,067 \\
2,385,522 \\
8,232,424\end{array}$ & $\begin{array}{r}1,132,035 \\
2,329,922 \\
224,494 \\
342,498 \\
227,780 \\
1,353,716 \\
2,489,779 \\
8,100,225\end{array}$ \\
\hline 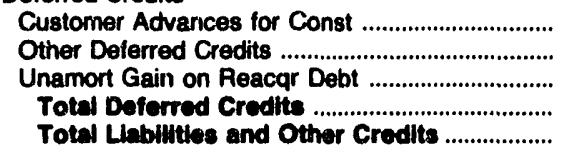 & $\begin{array}{r}189,349 \\
2,912,524 \\
569,043 \\
3,670,916 \\
112,043,449\end{array}$ & $\begin{array}{r}171,257 \\
2,868,551 \\
424,557 \\
3,494,385 \\
107,705,168\end{array}$ & $\begin{array}{r}132,018 \\
2,895,655 \\
450,641 \\
3,478,312 \\
103,033,948\end{array}$ \\
\hline
\end{tabular}

Note: Totals may not equal sum of components because of independent rounding. Detailed data are provided in Table 39 . The number of publicly owned electric utilities for end of period is 470 for 1991,467 for 1990 , and 454 for 1989 .

Source: Energy Information Administration, Form ElA-412, "Annual Report of Public Electric Utilities." Individual electric utilities report fiscal year data. Appendix B shows the fiscal year for each electric utility. 
Table C20. Composite Financial Indicators for Major Publlcly Owned Electric Utilities for All Respondents, 1989-199

\begin{tabular}{|c|c|c|c|}
\hline Item & 1991 & 1990 & 1988 \\
\hline Total Electric Utility Plant per Dollar of Revenue & 3.2 & 3.1 & 3.1 \\
\hline 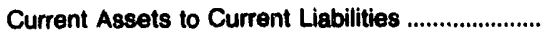 & 1.8 & 1.9 & 1.6 \\
\hline $\begin{array}{l}\text { Total Electric Utility Plant as a Percent of Total } \\
\text { Assels }\end{array}$ & 79.3 & 79.0 & 78.6 \\
\hline $\begin{array}{l}\text { Net Electric Utility Piant as a Percent of Total } \\
\text { Assets }\end{array}$ & 58.4 & 58.4 & 60.6 \\
\hline $\begin{array}{l}\text { Depreciation, Amortization and Depletion } \\
\text { as a Percent of Total Electric Utility Plant ........... }\end{array}$ & 26.4 & 24.8 & 22.9 \\
\hline $\begin{array}{l}\text { Electric Operation and Maintenance Expenses } \\
\text { as a Percent of } \\
\text { Electric Utility Operating Revenues ........................... }\end{array}$ & 70.6 & 71.5 & 72.3 \\
\hline $\begin{array}{l}\text { Electric Depreciation and Amortization } \\
\text { as a Percent of } \\
\text { Electric Utility Operating Revenues ........................ }\end{array}$ & 9.0 & 8.4 & 8.7 \\
\hline $\begin{array}{l}\text { Taxes and Tax Equivalents } \\
\text { as a Percent of } \\
\text { Electric Utility Operating Revenues ....................... }\end{array}$ & 2.6 & 2.5 & 2.4 \\
\hline $\begin{array}{l}\text { Net Contributions and Services } \\
\text { as a Percent of } \\
\text { Electric Utility Operating Revenues ....................... }\end{array}$ & 2.0 & 2.1 & 2.0 \\
\hline $\begin{array}{l}\text { Interest on Long-term Debt } \\
\text { as a Percent of } \\
\text { Electric Utility Operating Revenues .......................... }\end{array}$ & 17.3 & 17.4 & 17.2 \\
\hline
\end{tabular}

Note: Totals may not equal sum of components because of independent rounding. The number of publicly owned electric utilities for end of period is 470 for 1991, 467 for 1990, and 454 for 1989.

Source: Energy Information Administration, Form EIA-412. "Annual Report of Public Electric Utilities." Individual electric utilities report fiscal year data. Appendix B shows the fiscal year for each electric utility. 
Table C21. Electric Operation and Maintenance Expenses for

Major Publicly Owned Electric Utilities for

All Respondents, 1989-1991

(Thousand Dollars)

\begin{tabular}{|c|c|c|c|}
\hline Item & 1991 & 1990 & 1989 \\
\hline \multicolumn{4}{|l|}{ Production Expenses } \\
\hline 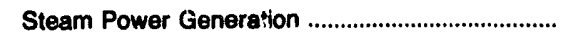 & $3,688,872$ & $3,741,569$ & $3,437,966$ \\
\hline 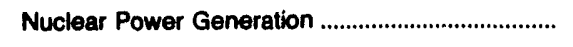 & $1,217,567$ & $1,133,495$ & $1,179,125$ \\
\hline 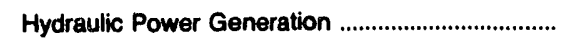 & 225,699 & 204,512 & 187,182 \\
\hline 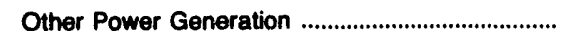 & 167.230 & 196.419 & 171,971 \\
\hline 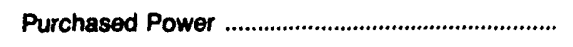 & $10,571,167$ & $10,541,975$ & $10,000,080$ \\
\hline 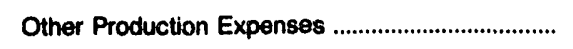 & 102,572 & 154,970 & 99,149 \\
\hline 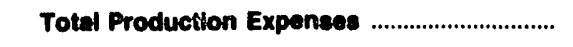 & $15,973,107$ & $15,972,941$ & $15,075,473$ \\
\hline 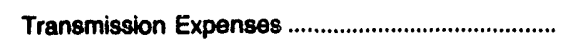 & 645,169 & 604,017 & 552,316 \\
\hline 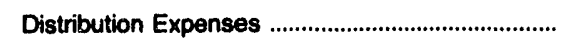 & $1,027,679$ & 950,271 & 988,374 \\
\hline 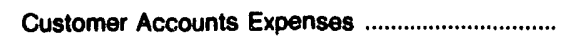 & 393,462 & 374,729 & 344,197 \\
\hline Customer Service and Information Expenses ..... & 89,656 & 74,710 & 77,971 \\
\hline Sales Expenses & 29,665 & 29,350 & 17,615 \\
\hline Administrative and General Expenses ..................... & $1,748,285$ & $1,619,500$ & $1,616,947$ \\
\hline $\begin{array}{l}\text { Total Electric Operation } \\
\text { and Maintenance Expences }\end{array}$ & $19,907,023$ & $19,625,519$ & $18,672,894$ \\
\hline
\end{tabular}

Note: Totals may not equal sum of components because of independent rounding. Detailed data are provided in Table 40. The number of publicly owned electric utilities for end of period is 470 for 1991,467 for 1990 , and 454 for 1989.

Source: Energy Information Administration, Form EIA-412, "Annual Report of Public Electric Utilities." Individual electric utilities report fiscal year data. Appendix B shows the fiscal year for each electric utility. 
Table C22. Electric Utility Plant for Major Publicly Owned Electric Utilities for All Respondents at End of Period, 1989-1991 (Thousand Dollars)

\begin{tabular}{|c|c|c|c|}
\hline Item & 1991 & 1990 & 1989 \\
\hline \multicolumn{4}{|l|}{ Electric Plant in Sarvice } \\
\hline Intangible Plant & 373,212 & 325,985 & 390,809 \\
\hline \multicolumn{4}{|l|}{ Production Plant } \\
\hline Steam & $22,556,413$ & $21,246,646$ & $19,191,316$ \\
\hline 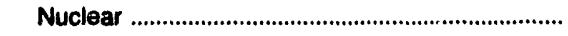 & $19,440,482$ & $18,992,687$ & $18,313,109$ \\
\hline 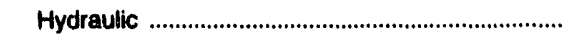 & $6,991,010$ & $6,852,874$ & $6,348,174$ \\
\hline Other & $1,576,299$ & $1,639,697$ & $1,485,027$ \\
\hline Total Production Plant ......................................... & $50,564,203$ & $48,731,905$ & $45,337,626$ \\
\hline Transmission Plant & $9,079,912$ & $8,348,613$ & $7,936,162$ \\
\hline 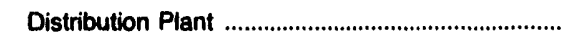 & $17,779,290$ & $16,579,615$ & $15,686,298$ \\
\hline 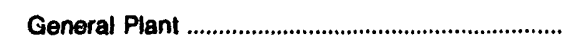 & $5,221,061$ & $4,867,426$ & $4,227,270$ \\
\hline Total Electric Plant In Sorvice ........................... & $83,017,677$ & $78,053,544$ & $73,578,165$ \\
\hline 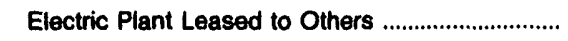 & 566,610 & 483,654 & 478,683 \\
\hline Construction Work in Progress - Electric ............... & $4,119,184$ & $4,151,170$ & $5,559,795$ \\
\hline Electric Plant Held for Future Use .............................. & 640,637 & 830,399 & 754,445 \\
\hline Electric Plant Acquisition Adjustments ...................... & 510,123 & 787,260 & 638,620 \\
\hline 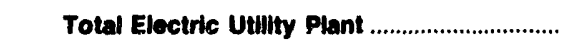 & $88,854,231$ & $85,106,027$ & $81,009,708$ \\
\hline $\begin{array}{l}\text { Accumulated Provision for } \\
\text { Depreciation and Amortization ................................ }\end{array}$ & $23,454,394$ & $21,101,995$ & $18,572,145$ \\
\hline Not Eloctric Utility Plant .......................................... & $65,399,837$ & $64,004,032$ & $62,437,563$ \\
\hline
\end{tabular}

Note: Totals may not equal sum of components because of independent rounding. Detailed data are provided in Table 41. The number of publicly owned electric utilities for end of period is 470 for 1991, 467 for 1990, and 454 for 1989.

Source: Energy Information Administration, Form EIA-412, "Annual Report of Public Electric Utilities." Individual electric utilities report fiscal year data. Appendix B shows the fiscal year for each electric utility. 


\section{Table C23. Number of Consumers, Sales, and Operating Revenue for Major Publicly Owned Electric Utilities for All Respondents, 1989-1991}

\begin{tabular}{|c|c|c|c|}
\hline Item & 1991 & 1990 & 1889 \\
\hline \multicolumn{4}{|l|}{ Number of Consuiners } \\
\hline 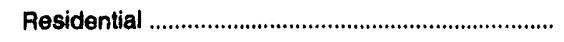 & $10,944,056$ & $10,712,154$ & $10,481,242$ \\
\hline Commercial or Small & $1,398,521$ & $1,386,959$ & $1,381,860$ \\
\hline Industrial or Large & 75,831 & 82,683 & 85,539 \\
\hline Other & 266,248 & 264,000 & 232,393 \\
\hline Total ultimate Coneumers ................................. & $12,684,656$ & $12,445,796$ & $12,181,034$ \\
\hline
\end{tabular}

Sales for the Year (megawatthours)

\begin{tabular}{|c|c|c|c|}
\hline 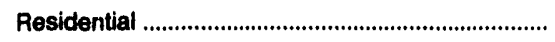 & $118,476,942$ & $115,426,617$ & $112,306,344$ \\
\hline 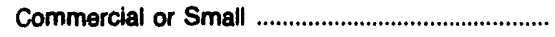 & $92,271,342$ & $91,071,107$ & $86,439,072$ \\
\hline Industrial or Large & $113,244,276$ & $111,325,058$ & $107,626,843$ \\
\hline Other & $20,790,016$ & $20,433,764$ & $18,405,984$ \\
\hline Total Sales to Uitimate Conaumers .................. & $344,782,576$ & $338,256,546$ & $324,778,243$ \\
\hline 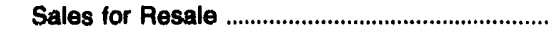 & $190,797,303$ & $195,603,526$ & $189,673,716$ \\
\hline Total Sales & $535,579,879$ & $533,860,072$ & $514,451,959$ \\
\hline \multicolumn{4}{|l|}{$\begin{array}{l}\text { Operating Revenues for the Year } \\
\text { (thousand dollars) }\end{array}$} \\
\hline 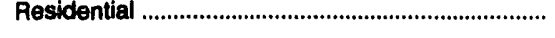 & $7,512,382$ & $7,333,324$ & $7,014,301$ \\
\hline 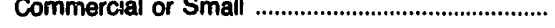 & $5,924,545$ & $5,893,278$ & $5,469,714$ \\
\hline Industrial or Large & $5,305,256$ & $5,165,253$ & $5,044,231$ \\
\hline Other & $1,303,801$ & $1,333,963$ & $1,192,077$ \\
\hline $\begin{array}{l}\text { Total Revenues from Sales to } \\
\text { Ultimate Consumers .......................................... }\end{array}$ & $20,045,984$ & $19,725,818$ & $18,720,323$ \\
\hline 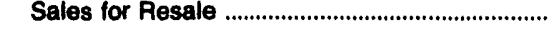 & $7,221,545$ & $7,397,548$ & $7,075,131$ \\
\hline 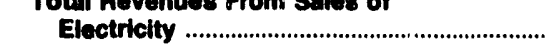 & $\mathbf{2 7 , 2 6 7 , 5 2 9}$ & $27,123,366$ & $25,795,454$ \\
\hline
\end{tabular}

Note: Totals may not equal sum of components because of independent rounding. Detailed data are provided in Table 42 . The num ber of publicly owned electric utilities for end of period is 470 for 1991, 467 for 1990, and 454 for 1989. sions.

Source: Energy Information Administration, Form ElA-861, "Annual Electric Utility Report." Data are based on calender year submis. 


\section{Table C24. Electric Energy Account for Major Publicly Owned Electric Utilities for All Respondents, \\ 1989-1991 \\ (Megawatthours)}

\begin{tabular}{|c|c|c|c|}
\hline Item & 1991 & 1990 & 1989 \\
\hline 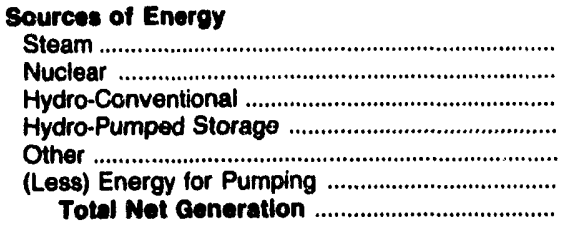 & $\begin{array}{r}164,401,739 \\
57,756,871 \\
73,348,633 \\
3,789,638 \\
3,137,344 \\
3,904,547 \\
288,529,666\end{array}$ & $\begin{array}{r}168,806,546 \\
50,740,159 \\
75,007,682 \\
4,741,854 \\
3,990,503 \\
3,551,799 \\
299,734,947\end{array}$ & $\begin{array}{r}177,940,856 \\
53,149,705 \\
68,743,015 \\
4,059,041 \\
2,371,953 \\
3,603,646 \\
302,660,924\end{array}$ \\
\hline 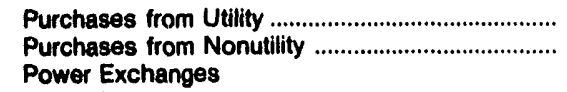 & $\begin{array}{r}269,663,812 \\
1,380,739\end{array}$ & $\begin{array}{r}268,249,437 \\
1,006,129\end{array}$ & $\begin{array}{r}244,431,395 \\
1,026,297\end{array}$ \\
\hline 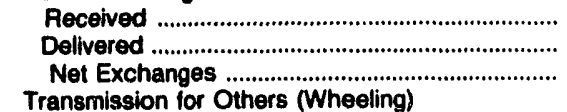 & $\begin{array}{r}19,788,332 \\
22,835,269 \\
-3,046,936\end{array}$ & $\begin{array}{l}35,464,128 \\
37,525,397 \\
-2,061,270\end{array}$ & $\begin{array}{r}21,257,570 \\
21,995,791 \\
-738,223\end{array}$ \\
\hline 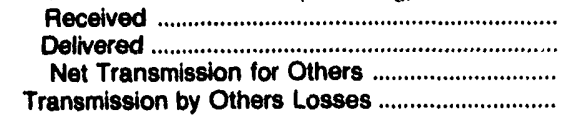 & $\begin{array}{r}27,661,154 \\
27,454,743 \\
206,410 \\
-169,733\end{array}$ & $\begin{array}{r}30,857,303 \\
30,584,606 \\
272,696 \\
-81,436\end{array}$ & $\begin{array}{r}30,259,971 \\
29,732,194 \\
527,777 \\
-\end{array}$ \\
\hline $\begin{array}{l}\text { Total Net Energy Cenerated and } \\
\text { Received }\end{array}$ & $566,563,961$ & $567,120,501$ & $547,908,177$ \\
\hline 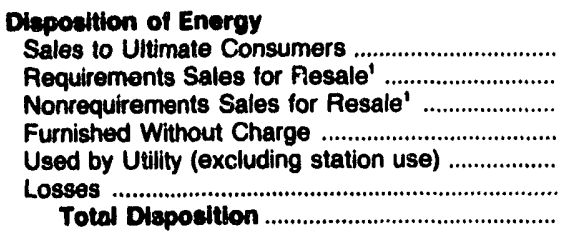 & $\begin{array}{r}343,531,980 \\
161,294,421 \\
31,087,612 \\
1,881,389 \\
7,865,267 \\
20,903,280 \\
568,563,961\end{array}$ & $\begin{array}{r}336,588,347 \\
160,452,347 \\
34,819,786 \\
1,957,491 \\
11,843,735 \\
21,458,772 \\
567,120,501\end{array}$ & $\begin{array}{r}324,252,064 \\
188,376,475 \\
- \\
2,006,568 \\
11,633,694 \\
21,639,359 \\
547,908,177\end{array}$ \\
\hline
\end{tabular}

- The 1989 data were reported as Sales for Resale (one entry) which is shown as Requirements Sales for Resale.

Note: Totals may not equal sum of components because of independent rounding. Detailed data are provided in Table 43. The number of publicly owned electric utilities for end of period is 470 for 1991, 467 for 1990, and 454 for 1989. Double counting occurs in components of both sources and disposition of energy and thus neither provides a true total. Purchases from utilities, net exchanges, and net vineeling (except for imports) are included in net generation. Sales for resale is included in sales to ultimate consumers.

Source: Energy Information Administration, Form EIA-412, "Annual Report of Public Electric Utilities." Individual electric utilities report fiscal year data. Appendix B shows the fiscal year for each electric utility. 
Appendix D

Regulation of

Publicly Owned

Electric Utilities 


\section{Regulation of Publicly Owned Electric Utilities}

\section{Table D1. State Agency Authority to Regulate Rates of Public Owned Electric Utilities, 1991}

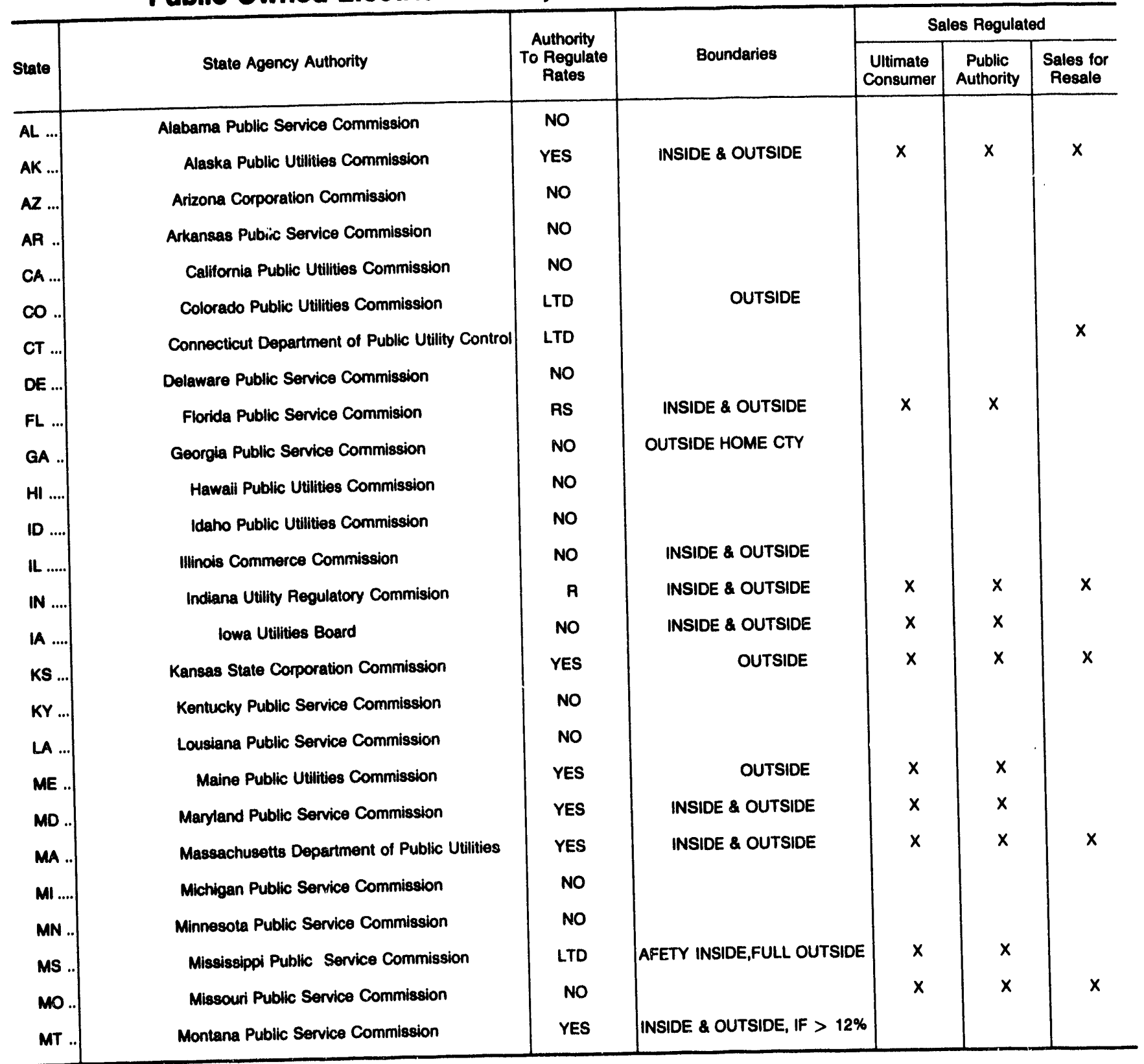

See footnotes at end of table 
Table D1. State Agency Authority to Regulate Rates of Public Owned Electric Utilities, 1991

\begin{tabular}{|c|c|c|c|c|c|c|}
\hline \multirow[b]{2}{*}{ State } & \multirow[b]{2}{*}{ State Agency Authority } & \multirow{2}{*}{$\begin{array}{c}\text { Authority } \\
\text { To Regulate } \\
\text { Rates }\end{array}$} & \multirow[b]{2}{*}{ Boundaries } & \multicolumn{3}{|c|}{ Sales Regulated } \\
\hline & & & & $\begin{array}{l}\text { Ultimate } \\
\text { Consumer }\end{array}$ & $\begin{array}{l}\text { Public } \\
\text { Authority }\end{array}$ & $\begin{array}{c}\text { Sales for } \\
\text { Resale }\end{array}$ \\
\hline NE .. & Nebraska Fublic Service Commission & NO & INSIDE \& OUTSIDE & & & \\
\hline NV ... & Nevada Public Senvice Commission & NO & & & & \\
\hline NH .. & New Hampshire Public Utilities Commission & YES & OUTSIDE & $x$ & $x$ & $x$ \\
\hline NJ ... & New Jersey Board of Public Utilities & YES & OUTSIDE & $x$ & & \\
\hline NM .. & New Mexico Public Service Commission & NO & & & & \\
\hline NY .. & New York Public Service Commission & YES & OUTSIDE & $x$ & $x$ & $x$ \\
\hline NC .. & North Carolina Utilities Commission & NO & & & & \\
\hline ND ... & North Dakota Public Service Commission & NO & & & & \\
\hline $\mathrm{OH} .$. & Onio Public Utilities Commission & No & & & & \\
\hline OK .. & Oklahoma Corporation Commission & NO & & & & \\
\hline OR .. & Oregon Public Utility Commission & LTD & & & & \\
\hline PA ... & PennsysIvania Public Utility Commission & YES & OUTSIDE & $x$ & & \\
\hline RI .... & Rhode Island Public Utilities Commission & NO & INSIDE \& OUTSIDE & $x$ & $x$ & \\
\hline SC ... & South Carolina Public Service Commission & LTD & INSIDE \& OUTSIDE & & & \\
\hline SD ... & South Dakota Public Utilities Commission & LTD & & & & \\
\hline TN ... & Tennessee Public Service Commission & NO & OUTSIDE & & & \\
\hline $\mathrm{TX} \ldots$ & Texas Public Utility Commission & YES & OUTSIDE & $x$ & $x$ & $x$ \\
\hline UT ... & Utah Public Service Commission & NO & & & & \\
\hline VT $\ldots$ & Vermont Public Service Board & YES & INSIDE \& OUTSIDE & $x$ & $x$ & $x$ \\
\hline VA ... & Virginia State Corporation Commission & NO & & & & \\
\hline WA.. & Washington Utilities \& Transportation Commission & NO & INSIDE \& OUTSIDE & & & \\
\hline WV .. & West Virginia Public Service Commission & LTD & & & & \\
\hline WI ... & Wisconsin Public Service Commission & YES & INSIDE \& OUTSIDE & $x$ & $x$ & $x$ \\
\hline Wr.. & Wyoming Public Service Commission & YES & OUTSIDE & $x$ & & \\
\hline
\end{tabular}

Note: There are no publicly owned electric utilities in the District of Columbia. The District of Columbia Public Service Commission does regulate invester-owned electric utilities.

Source: National Association of Regulatory Utility Commissioners, 1990 Annual Report on Utilty and Carrier Regulation, publication. 
Appendix E

Technical Notes 


\section{Technical Notes}

\section{Sources of Data}

The Financial Statistics of Major Publicly Owned Electric Utilities (FSMPO) publication is prepared by the Management Survey Division; Office of Coal, Nuclear, Electric and Alternate Fuels; Energy Information Administration (EIA); U.S. Department of Energy (DOE). Detailed financial data published in this publication are from the Form EIA-412, "Annual Report of Public Electric Utilities." Other summary data are provided from the Form EIA-861, "Annual Electric Utility Report," and the Rural Electrification Administration statistics taken from the Statistical Report, $R u$ ral Electric Borrowers publication for the years 1987, 1988 , and 1990. A brief summary of surveys in this publication is presented below.

\section{Form EIA-412}

The Form EIA-412 is used annually to collect accounting, financial, and operating data from major publicly owned electric utilities in the United States. For the fiscal or calendar year that ended December 31, 1991, the criteria used to select the respondents for this survey resulted in submissions by 470 publicly owned and 8 Federal electric utilities. Those publicly owned electric utilities engaged in the generation, transmission, or distribution of electricity which had 120,000 megawatthours of sales to ultimate consumers and/or 120,000 megawatthours of sales for resale for the 2 previous years, as reported on the Form EIA-861, "Annual Electric Utility Report," must submit the Form EIA-412. Summary data are published in the Electric Power Annual.

Federally owned electric utilities are required to file the Form EIA-412. The financial data for the U.S. Army Corps of Engineers (except for Saint Mary's Falls at Sault St. Marie, Michigan), the U.S. International Boundary and Water Commission, and the U.S. Department of Interior Bureau of Reclamation were collected on the Form EIA-412 from the Federal power marketing administrations.

Data on piant construction cost, production expenses, generating equipment characteristics, and other rele- vant operating data are in tabular form for publication. These data are published in Electric Plant Cost and Power Production Expenses.

Instrument and Design History. The FPC created the Form $1 M$ in 1961 as a mandatory survey. It became the responsibility of the EIA in October 1977 when the FPC was merged with DOE. Since 1979, the FPC Form $1 \mathrm{M}$ has been superseded by the Economic Regulatory Administration (ERA) Form ERA-412, and in January 1980 by the Form EIA-412.

Data Processing. The processing of data reported on this survey is the responsibility of the Management Survey Division, Office of Coal, Nuclear, Electric and Alternate Fuels. The completed surveys are due on or before the last day of the third month following the close of the fiscal year. Nonresponse follow-up procedures are used to attain 100 percent response. Automated systems are used to edit data from the surveys using deterministic and statistical checks. When all data have passed the edit process, the data are aggregated into a master file used as input to the publication.

\section{Form EIA-861}

The Form EIA-861 is a mandatory census of electric utilities in the United States, its territories, and Puerto Rico. The survey is used to collect information on power production and sales data from 3,241 electric utilities in the United States. (3,245 electric utilities if U.S. territories are included.) These data collected are used to maintain and update the electric utility frame data base for the EIA. This data base supports queries from the Executive Branch, Congress, other public agencies, and the general public. Summary data from the Form EIA-861 are also contained in the Electric Power Monthly, the Electric Power Annual, the Electric Sales and Revenue, the Annual Outlook for U.S. Electric Power, the Financial Statistics of Major Investor-Owned Electric Utilities and the Financial Statistics of Major Publicly Owned Electric Utilities. These reports present aggregate totals for electric utilities on a national level by State and by ownership type.

Instrument and Design Fiistory. The Form EỉA -86́i was implemented in January 1985 to collect data as of year-end 1984. The Federal Administration Act of 
1974 (Public Law 93-275) defines the legislative authority to collect these data.

Data Processing. The Form EIA-861 is mailed to the respondents in February to collect data for the preceding calendar year. The completed surveys are returned to the EIA by May 1. These data are manually edited before being entered into the interactive on-line system. Internal edit checks are performed to verify that current data total across and between schedules, and are comparable to data reported the previous year. Edit checks are also performed to compare data reported on the Form EIA-861 and similar data reported on the Form EIA-826, "Monthly Electric Utility Sales and Revenue Report with State Distributions," the FERC Form 1, "Annual Report of Major Electric Utilities, Licensees and Others," and the Form EIA-412, "Annual Report of Public Electric Utilities." These are utility-level checks. Respondents are called to clarify reported data and to obtain missing data.

\section{Rural Electrification Administration}

The Rural Electrification Administration (REA) in the U.S. Department of Agriculture is authorized to provide long-term financing and guarantee long-term loans for utilities supplying power to rural America. Borrowing electric utilities file the REA Form 7, "Financial and Statistical Report" and the REA Form 12a through 12i, "Electric Power Supply Borrowers" or the REA Form 12c through 12g, "Electric Distribution Borrowers with Generating Facilities." Data are provided on a yearly basis. Other revenue and expense statistics show the year's financial operations. For 1991, borrowers' operations data are based on the financial and operating statements of 894 active borrowers, of which 838 were distribution borrowers and 56 were power supply borrowers. Operations of cooperative borrowers systems are based on reports submitted by borrowers. The reports are subject to possible revisions from audits and adjustments. No attempt has been made to consolidate (in the technical accounting sense) the borrowers' accounts in the summary statement appearing in this publication. The combined totals represent the sum of all accounts as reported by the individual borrowers.

\section{Quality of Data}

The Office of Coal, Nuclear, Electric, and Alternate Fuels (CNEAF) is responsible for routine data improvement and quality assurance. All operations at CNEAF are done in accordance with formal standards established by EIA. Data improvement efforts include verification of data-keyed input by automatic computerized methods, editing by subject matter specialists, and follow-up on nonrespondents. CNEAF reviews the structure of information requirements and proposed designs for new and revised data collection surveys and systems. Once started, the performance of working data collection systems is also validated. Computerized respondent data files are checked to identify those respondents which fail to respond to the survey. EIA tries to obtain required information by encouraging the cooperation of nonrespondents. By law, nonrespondents may be fined or penalized for not filing a mandatory EIA data survey.

CNEAF screens submitted surveys for completeness, and keys the data onto computer tapes for storage. These data are transferred to random access databases for computer processing. The information coded on the computer tapes is manually spot-checked against the surveys to certify accuracy of the tapes. To ensure EIA quality standards, formulas using the past history of data values in the data base have been designed and implemented to automatically check data input for errors. Data values falling outside the ranges prescribed in the formulas are verified by telephoning respondents to resolve any discrepancies.

Conceptual problems affecting the quality of data are discussed in the report, An Assessment of the Quality of Selected EIA Data Series: Electric Power Data. This report is published by the Office of Statistical Standards in EIA.

\section{Data Editing System}

Data from the surveys are edited using automated systems. The edit includes deterministic and statistical checks. The deterministic part of the edit checks for the presence of required fields and their validity. Statistical checks use estimation techniques to validate data according to their behavior in the past and in comparison to other current fields.

\section{Confidentiality of the Data}

Data collected on the surveys for this publication are not confidential.

\section{Rounding Rules for Data}

Given a number with $r$ digits to the left of the decimal and $d+t$ digits in the fraction part, with $d$ being the place to which the number is to be rounded and $t$ being the remaining digits which will be truncated. This number is then rounded to $r+d$ digits by adding five to the $(r+d+1)$ th digit when the number is positive or by subtracting five when the number is negative. The $t$ digits are then truncated at the $(r+d+1)$ th digit. The symbol for a rounded number truncated to zero is $(*)$. 


\section{Data Correction and Revision Procedures}

CNEAF has adopted the following policy for the revision and correction of data published in energy data reports and made available in a machine format:

1. All data collected by this office (excluding secondary source data) will be published as preliminary data when it first appears in an energy data report.

2. The next publication of these data will be in final form and the data base will be closed.

3. Revisions or corrections will be made only in the event a substantial (greater than 1 percent) reporting change is received or a substantial error is discovered.

4. Revisions or corrections to published secondary source data will be made if the organization from which these data were received submits changes.

5. No revisions will be made without the approval of the Director, Survey Management Division.

\section{Formulas and Calculations}

\section{Composite Financial Indicators for Selected Publicly Owned Electric Utilities}

Total Electric Utility Plant per Dollar of Revenue =

$$
\frac{\sum_{i}\left(T E U P_{i}\right)}{\sum_{i}\left(E U O R_{i}\right)}
$$

where TEUP is the Total Electric Utility Plant for the $i^{\text {th }}$ public utility; and, EUOR is the Electric Utility Operating Revenue for the $i^{t h}$ public utility.

Current Assets to Current Liabilities =

$$
\frac{\sum_{i}\left(C A_{i}\right)}{\sum_{i}\left(C L_{i}\right)}
$$

where $C A_{i}$ are the Current and Accrued Assets for the $i^{t h}$ public utility; and, $C L_{i}$ are the Current and Accrued Liabilities for the $i^{\text {th }}$ public utility.

Total Electric Utility Plant as a Percent of Total Assets $=$

$$
\frac{\sum_{i}\left(T E U P_{i}\right)}{\sum_{i}\left(T A_{i}\right)} \times 100
$$

where $T E U P_{i}$ is the Total Electric Utility Plant for the $i^{\text {th }}$ public utility; and, $T A_{i}$ are the Total Assets for the $i^{\text {th }}$ public utility.

Net Electric Utility Plant as a Percent of

Total Assets =

$$
\frac{\sum_{i}\left(N E U P_{i}\right)}{\sum_{i}\left(T A_{i}\right)} \times 100,
$$

where $N E U P_{i}$ is the Net Electric Utility Plant for the $i^{\text {th }}$ public utility; and, $T A_{i}$ is the Total Assets for the $i^{\text {th }}$ public utility.

Depreciation, Amortization and Depletion as a Percent of Total Electric Utility Plant =

$$
\frac{\sum_{i}\left(D A D_{i}\right)}{\sum_{i}\left(T E U P_{i}\right)} \times 100,
$$

where $D A D_{i}$ is the Depreciation, Amortization and Depletion for the $i^{\text {th }}$ public utility; and, TEUP $P_{i}$ is the Total Electric Plant for the $i^{\text {th }}$ public utility.

Electric Operation and Maintenance Expenses as a Percent of Electric Utility Operating Revenues =

$$
\frac{\sum_{i}\left(E O M E_{i}\right)}{\sum_{i}\left(E U O R_{i}\right)} \times 100
$$

where $E O M E_{i}$ is the Electric Operation and Maintenance Expenses for the $i^{\text {th }}$ public utility; and, EUOR is the Electric Utility Operating Revenues for the $i^{t h}$ public utility.

Electric Depreciation and Amortization as a Percent of Electric Utility Operating Revenues =

$$
\frac{\sum_{i}\left(E D A_{i}\right)}{\sum_{i}\left(E U O R_{i}\right)} \times 100
$$

where $E D A_{i}$ is Electric Depreciation and Amortization for the $i^{\text {th }}$ public utility; and, $E U O R_{i}$ is the Electric Utility Operating Revenues for the $i^{t h}$ public utility.

Taxes and Tax Equivalents as a Percent of Electric Utility Operating Revenues = 


$$
\frac{\sum_{i}\left(T T E_{i}\right)}{\sum_{i}\left(E U O R_{i}\right)} \times 100
$$

where $T T E_{i}$ are the Taxes and Tax Equivalents for the $i^{\text {th }}$ public utility; and, $E U O R_{i}$ is the Electric Utility Operating Revenues for the $i^{\text {th }}$ public utility.

Net Contributions and Services as a Percent of Electric Utility Operating Revenues =

$$
\frac{\sum_{i}\left(C S_{i}\right)}{\sum_{i}\left(E U O R_{i}\right)} \times 100
$$

where $C_{i}$ are the Net Contributions and Services for the $i^{t h}$ public utility; and $E U O R_{i}$ is the Electric Utility Operating Revenues for the $i^{\text {th }}$ public utility.

Interest on Long-term Debt as a Percent of Electric Utility Operating Revenues =

$$
\frac{\sum_{i}\left(I L T D_{i}\right)}{\sum_{i}\left(E U O R_{i}\right)} \times 100
$$

where $I L T D_{i}$ is the Interest on Long-term Debt for the $i^{\text {th }}$ public utility; and, $E U O R_{i}$ is the Electric Utility Operating Revenues for the $i^{\text {th }}$ public utility.

\section{General Information}

\section{Use of the Glossary}

The terms in the glossary have been defined for general use. Restrictions on the definitions, as used in these data collection systems, are included in each definition when necessary to define the terms as they are used in this report.

\section{Obtaining Coples of Data}

Upon EIA approval of the Financial Statistics of Major Publicly Owned Electric Utilities, these data are available for public use on a cost-recovery basis.

Computer listings and diskettes are obtained for a charge by submitting a written request to:

$$
\begin{aligned}
& \text { Energy Information Administration } \\
& \text { Survey Management Division, EI-523 } \\
& 1000 \text { Independence Ave., S.W. } \\
& \text { Washington, DC } 20585
\end{aligned}
$$

These data are also available monthly on machinereadable tapes. Tapes may be purchased by using Visa, Master Card, or American Express cards, as well as money orders or checks, payable to the National Technical Information Service (NTIS). Purchasers may also use NTIS and Government Printing Office depository accounts. To place an order, contact:

National Technical Information Service (NTIS) Office of Data Base Services

U.S. Department of Commerce 5285 Port Royal Road

Springfield, Virginia 22161

(703) $487-4650$ 


\section{Glossary}

Accounting System: A method of recording accounting data for a utility or company or a method of supplying accounting information for controlling, evaluating, planning and decision-making.

Administrative and General Expenses: Expenses of an electric utility relating to the overall directions of its corporate offices and administrative affairs, as contrasted with expenses incurred for specialized functions. Examples include office salaries, office supplies, advertising, and other general expenses.

\begin{abstract}
Allowance for Funds Used During Construction (AFUDC): A noncash item representing the estimated composite interest costs of debt and a return on equity funds used to finance construction. The allowance is capitalized in the property accounts and included in income.
\end{abstract}

Amortization: The gradual write-off of an amount in an account by distributing such amount over a fixed period, over the life of the asset or liability to which it applies, or over the period during which it is anticipated the benefit will be realized.

Asset: An economic resource, tangible or intangible, which is expected to provide benefits to a business.

Average Stream Flow: The rate, usually expressed in cubic feet per second, at which water passes a given point in a stream over a set period of time.

Capacity: The amount of electric power delivered or required for which a generator, turbine, transformer, transmission circuit, station, or system is rated by the manufacturer.

Capacity (Purchased): The amount of energy and capacity available for purchase from outside the system.
Capital: The equity interest of the owners consisting of common stock, preferred stock, and retained earnings in the entity, that is the difference between assets and liabilities.

Capital (Financial): The line items on the right side of a balance sheet, that include debt, preferred stock, and common equity. A net increase in assets must be financed by an increase in one or more forms of capital.

Capital Intensive: $\mathbf{A}$ condition in which investment in plant and equipment is relatively large compared to labor and to operation and maintenance expenses.

Capitalization: The long-term sources of funds comprising an entity's total capitalization; that is, the longterm debt, preferred stock, and common equity. The short-term sources of capital are not included.

Capitalization Ratio: The percentage of debt, or preferred stock, or common stock, or other equity to the total capital structure of an entity.

Circuit: A conductor or a system of conductors through which electric current flows.

Circuit-Miles: The total length in miles of separate circuits regardless of the number of conductors used per circuit.

Classes of Service: Consumers grouped by similar characteristics in order to be identified for the purpose of setting a common rate for electric service. Usually classified into groups identified as residential, commercial, industrial and other.

Commercial: The commercial sector is generally defined as nonmanufacturing business establishments, including hotels, motels, restaurants, wholesale businesses, retail stores, and health, social, and educational 
institutions. The utility may classify commercial service as all consumers whose demand or annual use exceeds some specified limit. The limit may be set by the utility based on the rate schedule of the utility.

Commercial and Industrial: Classes of service supplied to a similar grouping of consumers. These customer groupings are usually subdivided into smaller segments by classifying such consumers as commercial or industrial using the Federal Government's Office Of Management and Budget's Standard Industrial Classification Guide and/or a scale of energy usage as yardsticks; other consumers are reclassified as commercial or industrial when their demands or annual use exceeds some specified limit. These limits are generally based on a utility's rate schedules, except for those consumers who ars supplied under special contracts or agreements calling for particular services.

Common Equity, Book Value: The retained earnings and common stock earnings plus the balances in common equity reserves and all other common stock accounts. This also includes the capital surplus, the paidin surplus, the premium on common stocks, except those balances specifically related to preferred or preference stocks; less any common stocks held in the treasury.

Common Stock Equity Ratio: The net income after interest taxes and the preferred dividends divided by the average common stock equity.

Condenser Cooling Water: A source of water external to a boiler's feed system is passed through the steam leaving the turbine in order to cool and condense the steam. This reduces the steam's exit pressure and recaptures its heat, which is then used to preheat fluid entering the boiler, thereby increasing the plant's thermodynamic efficiency.

Conditionally Effective Rates: An electric rate scheaule that has been put into effect by the FERC subject to refund pending final disposition or refiling.

Construction Costs (of the electric power industry): All direct and indirect costs incurred in acquiring and constructing electric utility plant and equipment and proportionate shares of common utility plant. Included are the cost of land and improvements, nuclear fuel and spare parts, allowance for funds used during construction, general overheads capitalized, less the cost of acquiring plant and equipment previously operated in utility service.

Construction Expenditures (of the electric power industry): The gross expenditures for construction costs, including the cost of replacing worn-out plants, and electric construction costs and land held for future use.

Construction Work In Progress (CWIP): The balance shown on a utility's balance sheet for construction work not yet completed but in process. This balance line item may or may not be included in the rate base.

Conventional Hydroelectric Plant: A plant in which all of the power is produced from natural streamflow as regulated by available storage.

Cooperative Electric Utility: An electric utility legally established to be owned by and operated for the benefit of those using its service. The utility company will generate, transmit, and/or distribute supplies of electric energy to a specified area not being serviced by another utility. Such ventures are generally exempt from Federal income tax laws. Most electric cooperatives have been initially financed by the Rural Electrification Administration, U.S. Department of Agriculture.

Cost: The amount paid to acquire resources, such as plant and equipment, fuel, or labor services.

Cost of Capital: The rate of return an entity must offer to obtain additional funds. The cost of capital varies with the leverage ratio, the effective income tax rate, conditions in the bond and stock markets, growth rate of the firm, its dividend strategy, stability of net income, the amount of new capital required, and other factors dealing with business and financial risks. It is a composite of the cost for debt interest, preferred stock dividends, and common stockholders' earnings that provide the facilities used in supplying utility service.

Cost of Debt: The interest rate paid on new increments of debt capital multiplied by 1 minus the tax rate.

Cost of Preferred Stock: Equals the preferred dividend divided by the net price of preferred stock. 
Cost of Retained Earnings: The residual of an entity's earnings over expenditures, including taxes and dividencis, that are reinvested in its business. The cost of these funds is always lower than the cost of new equity capital, due to taxes and transactions costs. Therefore, the cost of retained earnings is the yield that retained earnings accrue upon reinvestment.

Cost of Service: A ratemaking concept used for the design and development of rate schedules to ensure that the filed rate schedules recover only the cost of providing the electric service at issue. These costs include operating and maintenance expenses, depreciation and amortization expenses, and income and other taxes found just and reasonable by the regulatory agency for ratemaking purposes plus, in the case of privately owned electric utilities, an allowance for a return on capital (usually computed by applying a rate of return to the rate base). This concept attempts to equate the cost incurred by the utility to the revenue received for the service provided to each of the consumer classes.

Current Assets: Cash and other assets that are expected to be turned into cash, sold, or exchanged within the normal operating cycle of the firm, usually one year. Current assets include cash, marketable securities, receivables, inventory and current prepayments.

Current Liabilities: A debt or other obligation that must be discharged within a short time, usually the earnings cycle or one year, normally by expending current assets.

Current Ratio: The ratio (current assets divided by current liabilities) that shows the ability of an entity to pay its current obligations from its current assets.

Debt: Money or services owed through a legal obligation to an outside party. Debt may be classified short-term which is 1 year or less or long-term which is more than 1 year.

Deferred Cost: An expenditure not recognized as a cost of operation of the period in which incurred, but carried forward to be written off in future periods.

Deferred Fuel Costs: An expenditure for fuel that is not recognized for bookkeeping practices as a cost in the operating period incurred, but carried forward to be written off in future periods.
Deferred Income Tax: Usually, a liability in the balance sheet representing the additional Federal income taxes that would have been due if a company had not been allowed to compute tax expenses differently for income tax reporting purposes than for ratemaking reporting purposes.

Depreciation: Charges made against income for distributing the cost of a tangible asset, so as to allocate it systematically across the period in which the asset is used.

Design Head: The achieved river, pondage, or reservoir surface height (forebay elevation) that provides the water level to produce the full flow at the gate of the turbine in order to attain the manufacturer's installed nameplate rating for generation capacity.

Diesel-Electric Plant: A generating station that uses diesel engines to drive its electric generators.

Distribution System: The portion of an electric system that is dedicated to delivering electric energy to an end user.

Docket: A formal record of a Federal Energy Regulatory Commission proceeding. These records are available for inspection and copying by the public. Each individual case proceeding is identified by an assigned number.

Economy of Scale: The principle that larger production facilities have lower unit costs than smaller facilities.

Electric Expenses: The cost of labor, material, and expenses incurred in operating a facility's prime movers, generators, auxiliary apparatus, switching gear, and other electric equipment for each of the points where electricity enters the transmission or distribution grid.

Electric Operating Expenses: Summation of electric operation-related expenses, such as operation expenses, maintenance expenses, depreciation expenses, amortization, taxes other than income taxes, Federal income taxes, other income taxes, provision for deferred income taxes, provision for deferred income-credit, and investment tax credit adjustment. 
Electric Plant (Financial): Assets comprising land, building, and equipment permanently employed.

Electric Power Industry: The privately, publicly, federally and cooperatively owned electric utilities of the United States taken as a whole. This includes all electric systems serving the public: regulated investorowned electric utility companies; Federal power projects; State, municipal, and other governmentowned systems, including electric public utility districts; electric cooperatives, including generation and transmission entities. Excluded from this definition are the special purpose electric facilities or systems that do not offer service to the public.

Electric Power System: An individual electric power entity -- a company, an electric cooperative, a public electric supply corporation as the Tennessee Valley Authority, a similar Federal department or agency as the Bonneville Power Administration, the Bureau of Reclamation or the Corps of Engineers, a municipally owned, electric department offering service to the public, or an electric public utility district (a "PUD"); also a jointly owned electric supply project such as the Keystone.

Electric Rate Schedule: A statement of the electric rate and the terms and conditions governing its application, including attendant contract terms and conditions that have been accepted by a regulatory body with appropriate oversite authority.

Electric Utility: A corporation, person, agency, authority, or other legal entity or instrumentality that owns and/or operates facilities within the United States, its territories, or Puerto Rico for the generation, transmission, distribution, or sale of electric energy primarily for use by the public and files forms listed in the Code of Federal Regulations, Title 18, Part 141. Facilities that qualify as cogenerators or small power producers under the Public Utility Regulatory Policies Act (PURPA) are not considered electric utilities.

Electrical System Energy Losses: The amount of energy lost during generation, transmission, and distribution of electricity, including plant and unaccounted for use.

End User: The final consumer of electricity.
Energy: The capacity for doing work as measured by the capability of doing work (potential energy) or the conversion of this capability to motion (kinetic energy). Energy has several forms, some of which are easily convertible and can be changed to another form useful for work. Most of the world's convertible energy comes from fossil fuels that are burned to produce heat that is then used as a transfer medium to mechanical or other means in order to accomplish tasks. Electrical energy is usually measured in kilowatthours, while heat energy is usually measured in British thermal units.

Energy Deliveries: Energy generated by one electric utility system and delivered to another system through one or more transmission lines.

Energy Information Administration (EIA): An independent agency within the U.S. Department of Energy that develops surveys, collects energy data, and does analytical and modeling analyses of energy issues. The Agency must satisfy the requests of Congress, other elements within the Department of Energy, Federal Energy Regulatory Commission, the Executive Branch, its own independent needs, and assist the general public, or other interest groups, without taking a policy position.

Energy Loss: The difference between energy input and output as a result of transfer of energy between two points.

Energy Receipts: Energy generated by one electric utility system and received by another system through one or more transmission lines.

Equity (Financial): Ownership interest of shareholders in a corporation represented by stock.

Equity Capital: The sum of capital from retained earnings and the issuance of stocks.

Expenditure: The incurrence of a liability to obtain an asset or service.

Federal Electric Utility: A utility that is either owned or financed by the Federal Government. 
Federal Energy Regulatory Commission (FERC): A quasi-independent regulatory agency within the Department of Energy having jurisdiction over interstate electricity sales, wholesale electric rates, hydroelectric licensing, natural gas pricing, oil pipeline rates, and gas pipeline certification.

Federal Power Act: Enacted in 1920, and amended in 1935, the Act consists of three parts. The first part incorporated the Federal Water Power Act administered by the former Federal Power Commission, whose activities were confined almost entirely to licensing non-Federal hydroelectric projects. Parts II and III were added with the passage of the Public Utility Act. These parts extended the Act's jurisdiction to include regulating the interstate transmission of electrical energy and rates for its sale as wholesale in interstate commerce. The Federal Energy Regulatory Commission is now charged with the administration of this law.

Federal Power Commission: The predecessor agency of the Federal Energy Regulatory Commission. The Federal Power Commission (FPC) was created by an Act of Congress under the Federal Water Power Act on June 10, 1920. It was charged originally with regulating the electric power and natural gas industries. The FPC was abolished on September 20,1977, when the Department of Energy was created. The functions of the FPC were divided between the Department of Energy and the Federal Energy Regulatory Commission.

FERC: The Federal Energy Regulatory Commission.

FERC Guidelines: A compilation of the Federal Energy Regulatory Commission's enabling statutes, procedural and program regulations, and orders, opinions and decisions.

Financial Accounting Standards Board (FASB): An independent board responsible, since 1973, for establishing generally accepted accounting principles. Its official pronouncement are called "Statements of Financial Accounting Standards" and "Interpretations of Financial Accounting Standards."

Fiscal Year: A financial year based on a predetermined starting date. The Federal Government's financial year runs from October 1 through September 30.
Fixed Asset Turnover: A ratio of revenue to fixed assets which is a measure of the productivity and efficiency of property, plant, and equipment in generating revenue.

Fixed Assets: Tangible property used in the operations of an entity, but not expected to be consumed or converted into cash in the ordinary course of events.

Fixed Charge Coverage: The ratio of earnings available to pay so-called fixed charges to such fixed charges. Fixed charges include interest on funded debt, including leases, plus the related amortization of debt discount, premium and expense. Earnings available for fixed charges may be computed before or after deducting income taxes. Occasionally credits for the "allowance for fund used during construction " are excluded from the earnings figures. The precise procedures followed in calculating fixed charge or interest coverages vary widely.

Fixed Cost (expense): An expenditure or expense that does not vary with volume of activity.

Fixed Operating Costs: Costs other than those associated with capital investment that do not vary with the operation, such as maintenance and payroll.

Fossil Fuel: Any naturally occurring organic fuel, such as petroleum, coal, and natural gas.

Fossil-Fuel Plant: A plant using coal, petroleum, or gas as its source of energy.

Fuel Expenses: These costs include the fuel used in the production of steam or driving another prime mover for the generation of electricity. Other associated expenses include unloading the shipped fuel and all handling of the fuel up to the point where it enters the first bunker, hopper, bucket, tank, or holder in the boiler-house structure.

Gas Turbine Plant: A plant in which the prime mover is a gas turbine. A gas turbine consists typically of an axial-flow air compressor, one or more combustinn chambers, where liquid or gaseous fuel is burned and the hot gases are passed to the turbine and where the hot gases expand to drive the generator and are then used to run the compressor. 
Generally Accepted Accounting Principles (GAAP): Defined by the FASB as the conventions, rules, and procedures necessary to define accepted accounting practice at a particular time; includes both broad guidelines and relatively detailed practices and procedures.

Generating Unit: Any combination of physically connected generator(s), reactor(s), boiler(s), combustion turbine(s), or other prime mover(s) operated together to produce electric power.

Generator Nameplate Capacity: The full-load continuous rating of a generator, prime mover, or other electric power production equipment under specific conditions as designated by the manufacturer. Installed generator nameplate rating is usually indicated on a nameplate physically attached to the generator.

Geothermal Plant: A plant in which the prime mover is a steam turbine. The turbine is driven either by steam produced from hot water or by natural steam that derives its energy from heat found in rocks or fluids at various depths beneath the surface of the earth. The energy is extracted by drilling and/or pumping.

Grid: The layout of an electrical distribution system.

Gross Generation: The total amount of electric energy produced by a generating facility, as measured at the generator terminals.

Head: The product of the water's weight and a usable difference in elevation gives a measurement of the potential energy possessed by water.

Historical Plant Cost of Equipment: The charges for equipment assigned to power production include: the net purchased price thereof; sales taxes; investigation and inspection expenses necessary for such purchases, any expenses of transportation when borne by the utility; labor employed charges; materials and supplies consumed; and expenses incurred by the utility in unloading and placing the equipment in readiness to operate.

Historical Plant Cost of Land and Land Rights: The cost of land purchased or the fees paid by the utility for rights, interests, and privileges to be held by the utility in land owned by others. The types of rights acquired include leaseholds, easements, water and water power rights, rights-of-way, and other like interests.

Historical Plant Cost of Structures and Improvements (Expenses): The cost of all buildings and facilities to house, support, or safeguard property or persons, including all fixtures permanently attached to and made a part of building. Also includes the cost incurred in connection with the first clearing and grading of land and rights-of-ways.

Holding Company: A company that confines its activities to owning stock in, and supervising management of, other companies. The Securities and Exchange Commission, as administrator of the Public Utility Holding Company Act of 1935, defines a holding company as "a company which directly or indirectly owns, controls or holds 10 percent or more of the outstanding voting securities of a holding company" (15 USC 79b, par. a (7)).

Hydroelectric Energy: The production of electricity from kinetic energy in flowing water.

Hydroelectric Plant: A plant in which the turbine generators are driven by falling water.

Hydroelectric Plant Capacity: This capacity figure is a function of fluid flow losses, hydraulic turbines, head, and water flow. The minimum net head limits the firm capacity of the plant.

Hydroelectric Power: The harnessing of flowing water to produce mechanical or electrical energy.

Independent Power Producer: A corporation, person, agency, authority, or other legal entity or instrumentality that owns electric generating capacity and is a wholesale electric producer without a designated franchised service a.ta. The entity is not a qualifying facility as defined in the Public Utility Regulatory Policies Act of 1978.

Industrial: The industrial sector is generally defined as manufacturing, construction, mining, agriculture, fishing and forestry establishments Standard Industrial Classification (SIC) codes 01-39. The utility may classify industrial service using the SIC codes, or based on demand or annual usage exceeding some specified 
limit. The limit may be set by the utility based $0:$ the rate schedule of the utility.

Instantaneous Peak Demand: The maximum demand at the instant of greatest load.

Interchange Energy: Kilowatthours delivered to or received by one electric utility or pooling system from another. Settlement may be by payment, returned in kind at a later time or accumulated as energy balances until the end of the stated period.

Interconnection: Two or more electric systems having a common transmission line that permits a flow of energy between them. The physical connection of the electric power transmission facilities allows for the sale or exchange of energy.

Interdepartmental Service (Electric): Interdepartmental service includes amounts charged by the electric department at tariff or other specified rates for electricity supplied by it to other utility departments.

Interest Coverage Ratio: The number of times that fixed interest charges were earned indicates the margin of safety of interest on fixed debt. The timesinterest-earned ratio is calculated using net income before and after income taxes; and the credits of interest charged to construction being treated as other incomes. The interest charges include interest on longterm debt, interest on debt of associated companies, and other interest expense.

Interlocking Directorates: The holding of a significant position in management or a position on the corporate board of a utility, while simultaneously holding a comparable position with another utility, or with a firm doing business with the utility.

Internal Cash Flow: Composed of funds available for common stockholders after adjustments for common stock equivalents, depreciation and depletion, amortization, deferred income taxes (net), investment tax credit (net), and other internal sources (net); less common dividends and AFUDC (total).

Internal Combustion Plant: A plant in which the prime mover is an internal combustion engine. An internal combustion engine has one or more cylinders in which the process of combustion takes place, con- verting energy released from the rapid burning of a fuel-air mixture into mechanical energy. Diesel or gasfired engines are the principal types used in electric plants. The plant is usually operated during periods of high demand for electricity.

Investor-Owned Electric Utility: A class of utility that is investor owned and organized as a tax paying business, usually financed by the sales of securities in the capital market.

Kilowatt (kW): One thousand watts.

Kilowatthour (kWh): One thousand watthours.

Leverage Ratio: A measure that indicates the financial ability to meet debt service requirements and increase the value of the investment to the stockholders. (i.e. the ratio of total debt to total assets).

Liability: An amount payable in dollars or by future services to be rendered.

Licensees: Entity that has been granted permission to engage in an activity otherwise unlawful (i.e. hydropower project).

Line Loss: Energy kilowatthours lost in transmission and distribution lines.

Load (Electric): The amount of electric power delivered or required at any specific point or points on a system. The requirement originates at the energyconsuming equipment of the consumers.

Long-term Debt: Debt securities or borrowings having a maturity of more than a year.

Maintenance Expenses: That portion of operating expenses consisting of labor, materials, and other direct and indirect expenses incurred for preserving the operating efficiency and/or physical condition of utility plants used for power production, transmission, and distribution of energy. 
Maximum Demand: The greatest of all demands of the load that has occurred within a specified period of time.

Mcf: One thousand cubic feet.

Megawatt (MW): One million watts.

. Megawatthour (MWh): One million watthours.

Mill: A monetary cost and billing unit used by utilities; it is equal to $1 / 1000$ of the U.S. dollar (equivalent to $1 / 10$ of 1 cent).

Multiple Purpose Reservoir: Stored water and its usage governed by advanced water rescurce conservation practices to achieve more than one water control objective. Some of the objectives include flood control, hydro- electric power development, irrigation, recreation usage, and wilderness protection.

Municipality: (As defined in section 3, paragraph (7) of the Federal Power Act, P.L. 66-280 as amended) A city, county, irrigation district, drainage district, or other political subdivision or agency of a State competent under the laws thereof to carry on the business of developing, transmitting, utilizing, or distributing power (41 Stat. 1064; 49 Stat. 838; 16 U.S.C. 796(7)).

Net Generation: Gross generation minus plant use from all electric utility owned plants. The energy required for pumping at a pumped-storage plant is regarded as plant use and must be deducted from the gross generation.

Net Income: The excess of all revenues and gains for a period over all expenses and losses of the period.

Nonutility Power Producer: A corporation, person, agency, authority, or other legal entity or instrumentality that owns electric generating capacity and is not an electric utility. Nonutility power producers include qualifying cogenerators, qualifying small power producers, and other nonutility generators (including independent power producers) without a designated franchised service area, and which do not file forms listed in the Code of Federal Regulations, Title 18, Part 141.
Nuclear Fuel: Fissionable materials that have been enriched to such a composition that, when placed in a nuclear reactor, will support a self-sustaining fission chain reaction, producing heat in a controlled manner for process use.

Nuclear Power Plant: A facility in which heat produced in a reactor by the fissioning of nuclear fuel is used to drive a steam turbine.

Nuclear Reactor: An apparatus in which the nuclear fission chain can be initiated, maintained, and controlled so that energy is released at a specific rate. The reactor includes fissionable material (fuel), such as uranium or plutonium; fertile material; moderating material (unless it is a fast reactor); a heavy-walled pressure vessel; shielding to protect personnel; provision for heat removal; and control elements and instrumentation.

Ohm: The unit of measurement of electrical resistance. The resistance of a circuit in which a potential difference of 1 volt produces a current of 1 ampere.

Operating Expenses: Expenses related to utility operations, which include operation and maintenance expenses, provisions for depreciation and amortization, taxes other than income taxes, income taxes, provision for deferred income taxes, income taxes deferred in prior years-- credit and investment tax credit adjustments--net.

Operating Income: Operating revenues less operating expenses.

Operation Expenses: The components of power production expenses that incur cost for operations that are directly related to producing electricity. The major item is almost always fuel that has to be burned to generate the electricity.

Operation Supervision and Engineering (Expenses): These expenses include the cost of labor and expenses incurred in the general supervision and direction of the operation of power generation stations. The supervision and engineering costs consist of the pay and expenses of staff and consultants engaged in supervising and directing the operation of each utility function. Direct supervision and engineering of activities, such as fuel handling, boiler room operations, and generator operations, are charged to the appropriate accounts. 
Original Cost: The initial amount of money spent to acquire an asset.

Other Generation: Electricity originating from these sources: biomass, fuel cells, geothermal heat, solar power, waste, wind, and wood.

Owmers Equity: Interest of the owners in the assets of the business represented by capital contributions and retained earnings.

Parent Company: Company owning more than 50 percent of the voting shares of another company, called the subsidiary.

Plant: A facility at which are located prime movers, electric generators, and auxiliary equipment for converting mechanical, chemical, and/or nuclear energy into electric energy. A plant may contain more than one type of prime mover. Electric utility plants exclude facilities that satisfy the definition of a qualifying facility under the Public Utility Regulatory Policies Act of 1978.

Plant-Use Electricity: The electric energy used in the operation of a plant. This energy total is subtracted from the gross energy production of the plant; for reporting purposes the plant energy production is then reported as a net figure. The energy required for pumping at pumped-storage plants is, by definition, subtracted, and the energy production for these plants is then reported as a net figure.

Pole-Mile: A unit of measuring the simple length of a transmission line carrying electric conductors, without regard to the number of conductors carried.

Power: The rate at which energy is transferred. Electrical energy is usually measured in watts. Also used for a measurement of capacity.

Power (Electrical): An electric measurement unit of power called a voltampere is equal to the product of 1 volt and 1 ampere. This is equivalent to $1 \mathrm{Watt}$ for a direct current system and a unit of apparent power is separated into real and reactive power. Real power is the work-producing part of apparent power that measures the rate of supply of energy and is denoted as Kilowatts (KW). Reactive power is the portion of apparent power that does no work and is referred to as kilovars; this type of power must be supplied to most types of magnetic equipment, such as motors, and is supplied by generator or by electrostatic equipment. Voltamperes are usually divided by 1,000 and called kilovoltamperes ( $\mathrm{kVA}$ ). Energy is denoted by the product of real power and the length of time utilized; this product is expressed as kilowatthours.

Power Production Plant: All the land and land rights, structures and improvements, boiler or reactor vessel equipment, engines and engine-driven generator, turbogenerator units, accessory electric equipment, and miscellaneous power plant equipment are grouped together for each individual facility.

Preferred Stock: Ownership interests in a corporation which have been granted a preference, usually in the distribution of dividends before payment of dividends to common stockholders and assets in dissolution. It is usually nonvoting.

Price: The amount of money or consideration-in-kind for which a service is bought, sold, or offered for sale.

Prime Mover: The motive force that drives an electric generator (e.g., steam engine, turbine, or water wheel).

Production (Electric): Act or process of producing electric energy from other forms of energy; also, the amount of electric energy expressed in watthours (Wh).

Production Expenses: Costs incurred in the production of electric power that conform to the accounting requirements of the Operation and Maintenance Expense Accounts of the FERC Uniform System of Accounts.

Profit: The income remaining after all business expenses are paid.

Public Authority Service to Public Authorities: Public authority service includes electricity supplied and services rendered to municipalities or divisions or agencies of State or Federal governments, under special contracts or agreements or service classifications applicable only to public authorities.

Public Street and Highway Lighting: Public street and highway lighting includes electricity supplied and ser- 
vices rendered for the purposes of lighting streets, highways, parks, and other public places; or for traffic or other signal system service, for municipalities, or other divisinns or agencies of State or Federal governments.

Public Utility District: Municipal corporations organized to provide electric service to both incorporated cities and towns and unincorporated rural areas. Public utility districts, sometimes called "People's Utility Districts" or "Public Power Districts," operate in six States.

Pumped arage Hydroelectric Plant: A plant that usually generates electric energy ciuring peak-load periods by using water previously pumped into an elevated storage reservoir during off-peak periods when excess generating capacity is available to do so. When additionai generating capacity is needed, the water can be released from the reservoir through a conduit to turbine generators located in a power plant at a lower level.

Purchased Power: Power purchased or available for purchase from a source outside the system.

Railroad and Railway Services: Railroad and railway services include electricity supplied and services rendered to railroads and interurban and street railways, for general railroad use, including the propulsion of cars or locomotives, where such electricity is supplied under separate and distinct rate schedules.

Rate Base: The value of property upon which a utility is permitted to earn a specified rate of return as established by a regulatory authority. The rate base generally represents the value of property used by the utility in providing service and may be calculated by any one or a combination of the following accounting methods: fair value, prudent investment, reproduction cost, or original cost. Depending on which method is used, the rate base includes cash, working capital, materials and supplies, and deductions for accumulated provisions for aepreciation, contributions in aid of construction, customer advances for construction, accumulated deferred income taxes, and accumulated deferred investment tax credits.

Ratemaking Authority: A utility commission's legal authority to fix, modify, approve, or disapprove rates, as determined by the powers given the commission by a State or Federal legislature.
Rate of Return: The ratio of net operating income earned by a utility is calculated as a percentage of its rate base.

Rate of Return on Rate Base: The ratio of net operating income to a specified rate base, expressed as a percentage.

Rate of Return on Common Equity: Net income less preferred stock dividends divided by common stock equity.

Refunding: Retirement of one security issue with proceeds received from selling another. Refunding provides for retiring maturing debt by taking advantage of favorable money market conditions.

Regulation: The governmental function of controliing or directing economic entities through the process of rulemaking and adjudication.

Residentia: The residential sector is defined as private household establishments which consume energy primarily for space heating, water heating, air conditioning, lighting, refrigeration, cooking and clothes diying. The classification of an individual consumer's acciunt, where the use is both residential and commercial, is based on principal use. For the residential class, do not duplicate consumer accounts due to inultiple metering for special services (water, ho ating, etc.). Apartment houses are also included.

Retail: Sales covering electrical energy supplied for residential, commercial, and industrial end-use purposes. Other small classes, such as agriculture and street lighting, also are included in this category.

Retail Wheeling: An arrangement in which a utility transmits electricity from outside its service territory to a retail customer within its customer service 'erritory.

Retained Earnings: The balance, either debit or credit, of appropriated or unappropriated earnings of an entity that are retained in the business.

Return on Common Equity: An entity's earnings available for common stockholders calculated as a percentage of its common equity capital. 
Revenue: The total amount of money received by a firm from sales of its products and/or services, gains from the sales or exchange of assets, interest and dividends earned on investments, and other increases in the owner's equity except those arising from capital adjustments.

Revenue Requirement: The total revenue that the utility is authorized an opportunity to recover, which includes operating expenses and a reasonable return on rate base.

Rural Electrification Administration (REA): A lending agency of the U.S. Department of Agriculture, the REA makes self-liqui-lation loans to qualified borrowers to finance electric and telephone service to rural areas. The REA also finances the construction and operation of generating plants, electric transmission and distribution lines, or systems for the furnishing of initial and continued adequate electric services to persons in rural areas not receiving central station service.

Sales: The amount of kilowatthours sold in a given period of time; usually grouped by classes of service, such as residential, commercial, industrial, and other. Other sales include public street and highway lighting, other sales to public authorities and railways, and interdepartmental sales.

Sales for Resale: Energy supplied to other electric utilities, cooperatives, municipalities, and Federal and State electric agencies for resale to ultimate consumers.

Short-term Debt or Borrowings: Debt securities or borrowings having a maturity of less than 1 year.

Solar Energy: Energy produced from the sun's radiation.

Steam-Electric Plant (Conventional): A plant in which the prime mover is a steam turbine. The steam used to drive the turbine is produced in a boiler where fossil fuels are burned.

Steam Expenses: The cost of labor, materials, fuel, and other expenses incurred in production of steam for electric generation.
Steam from other Sources: Steam purchased, transferred from another department of the utility, or acquired from others under a joint-facility operating agreement.

Steam Transferred-Credit: The expenses of producing steam charged to others or to other utility departments under a joint operating arrangement.

Substation: Facility equipment that switches, changes, or regulates electric voltage.

Switching Station: Facility equipment used to tie together two or more electric circuits through switches. The switches are selectively arranged to permit a circuit to be disconnected, or to change the electric connection between the circuits.

System (Electric): Physically connected generation, transmission, and distribution facilities operated as an integrated unit under one central management, or operating supervision.

Transformer: An electrical device for changing the voltage of alternating current.

Transmission: The movement or transfer of electric energy over an interconnected group of lines and associated equipment between points of supply and points at which it is transformed for delivery to consumers, or is delivered to other electric systems. Transmission is considered to end when the energy is transformed for distribution to the consumer.

Transmission System (Electric): An interconnected group of electric transmission lines and associated equipment for moving or transferring electric energy in bulk between points of supply and points at which it is transformed for delivery over the distribution system lines to consumers, or is delivered to other electric systems.

Turbine: A machine for generating rotary mechanical power from the energy of a stream of fluid (such as water, steam, or hot gas). Turbines convert the kinetic energy of fluids to mechanical energy through the principles of impulse and reaction, or a mixture of the two. 
Ultimate Consumer: A consumer that purchases electricity for its own use and not for resale.

Uniform System of Accounts: Prescribed financial rules and ragulations established by the Federal Energy Regulatory Commission for utilities subject to its jurisdiction under the authority granted by the Federal Power Act.

Utility Generation: Generation by electric systems engaged in selling electric energy to the public.
Watt: The electrical unit of power. The rate of energy transfer equivalent to 1 ampere flowing under a pressure of 1 volt at unity power factor.

Watthour (Wh): An electrical energy unit of measure equal to 1 watt of power supplied to, or taken from, an electric circuit steadily for 1 hour.

Wheeling Service: The movement of electricity from one system to another over transmission facilities of intervening systems. Wheeling service contracts can be established between two or more systems. 

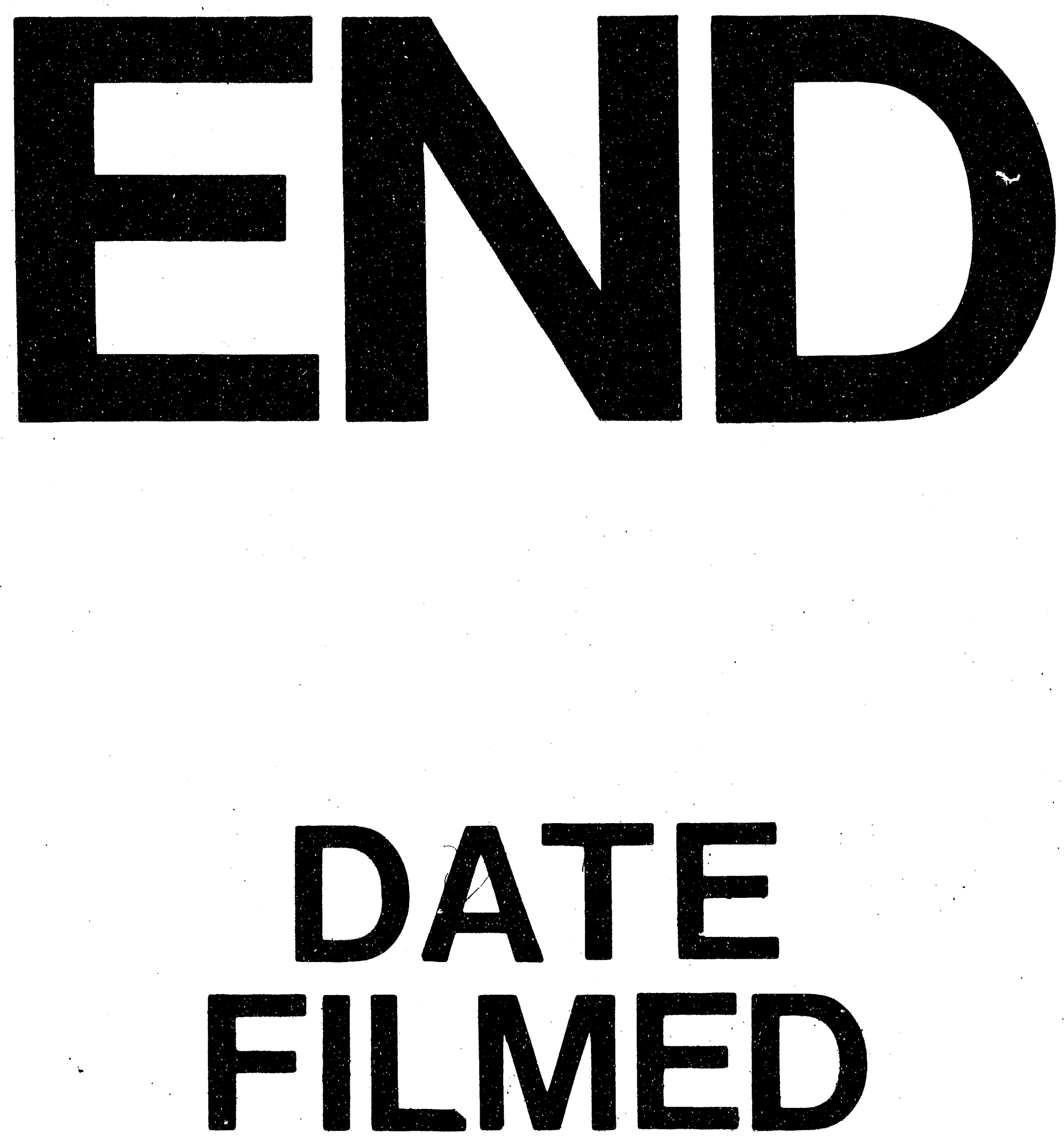

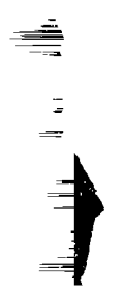

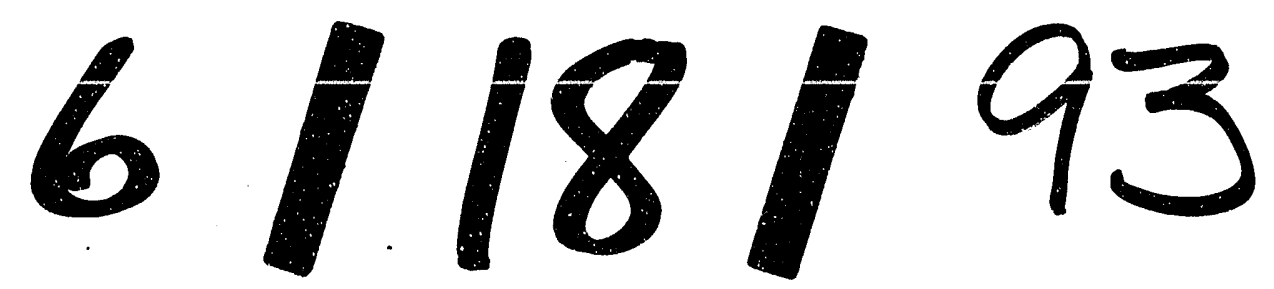


